\title{
MORFOLOGÍA DEL APARATO MÚSCULO-ESQUELETARIO DEL POSTCRÁNEO DE LOS MUSTÉLIDOS (CARNIVORA, MAMMALIA) FÓSILES Y VIVIENTES DE AMÉRICA DEL SUR: IMPLICANCIAS FUNCIONALES EN UN CONTEXTO FILOGENÉTICO
}

Tesis Doctoral

Lic. Marcos Darío Ercoli

Director: Dr. Francisco Juan Prevosti

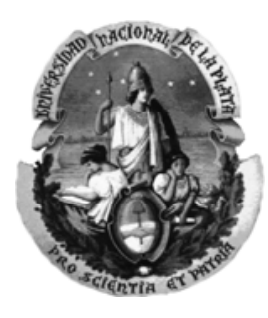

Facultad de Ciencias Naturales y Museo, Universidad Nacional de La Plata 2015 



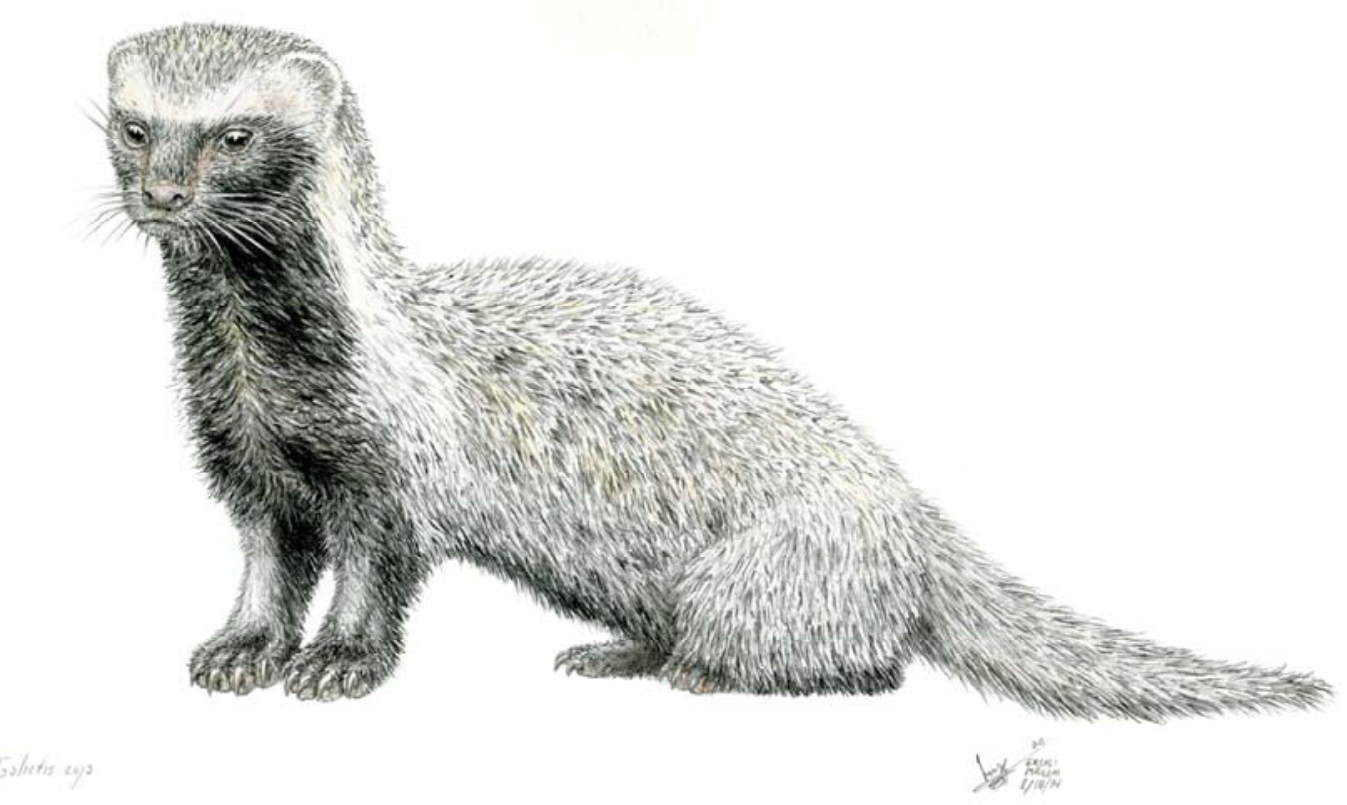





\section{RESUMEN}

La familia Mustelidae es la más diversa del Orden Carnivora, representada por 22 géneros vivientes, que presentan una gran variación eco-morfológica. Los mustélidos de América del Sur están representados por 11 especies vivientes: el gulonino Eira barbara; los hurones ictoniquinos lincodontininos Lyncodon patagonicus, Galictis cuja y Ga. vittata; los lutrinos Lontra felina, Lo. longicaudis, Lo. provocax y Pteronura brasiliensis; y los hurones mustelinos Mustela frenata, Mu. felipei y Mu. africana. Los ictoniquinos son la subfamilia más antigua dentro del subcontinente (Plioceno Tardío-actualidad), representados por múltiples especies extintas de los dos géneros actuales y por Stipanicicia pettorutii, representante del único género extinto; otros linajes de mustélidos de América del Sur se registran a partir del Pleistoceno. La musculatura postcraneal de los mustélidos fue estudiada intensamente en el siglo XIX, aunque las especies de América del Sur permanecen prácticamente inexploradas. Estudios de la osteología postcraneal han demostrado correspondencias entre la morfología, los tipos locomotores y otras variables (e.g., tamaño corporal, filogenia, estrategia de caza). Sin embargo, varios tópicos permanecen pobremente explorados, especialmente en lo que respecta a las especies de América del Sur. Por otro lado, el postcráneo prácticamente no ha sido evaluado como fuente potencial de caracteres filogenéticos. El objetivo de esta Tesis fue analizar la diversidad morfológica postcraneal de los mustélidos extintos y vivientes de América del Sur, explorando su relación con distintos factores (e.g., locomoción, hábitos alimentarios, tamaño corporal, estructura filogenética), en un marco comparativo.

Los materiales miológicos estudiados incluyen a tres especímenes de Galictis cuja. Se estudió exhaustivamente la musculatura craneal y postcraneal. Se describieron variantes intraespecíficas y se realizaron mapas musculares y pesado de cada músculo. Se realizó un estudio osteológico descriptivo detallado de siete especies de mustélidos de América del Sur. Se realizaron análisis morfo-funcionales cualitativos y cuantitativos en un marco comparativo a nivel Musteloidea. Se describieron en detalle siete especímenes fósiles con elementos postcraneales preservados, así como también materiales craneales de lincodontininos fósiles, incluyendo a $S$. pettorutii. Se construyeron 8 índices sintetizando las longitudes relativas de las

principales regiones axiales y apendiculares. Se tomaron fotografías orientadas de cuatro elementos postcraneales (axis, penúltima vértebra lumbar, extremo distal del húmero y proximal del fémur), realizándose análisis de morfometría geométrica y análisis de componentes principales por grupos. Para evaluar el efecto de la locomoción y la dieta sobre las variables lineales y de forma se realizaron análisis de la varianza considerándose la estructura filogenética de los datos y la influencia del tamaño. Para evaluar el valor filogenético y obtener reconstrucciones de estados ancestrales de los principales rasgos miológicos y osteológicos, se 
diseñaron, codificaron y optimizaron caracteres osteológicos (83 caracteres x 31 taxones; cinco caracteres continuos y 78 discretos) y musculares ( 47 caracteres x 32 taxones).

La descripción miológica de Ga. cuja reveló rasgos de importancia. La musculatura cervical es voluminosa y está muy subdividida (e.g., sternocephalicus, cleidocephalicus), incluyendo múltiples paquetes profundos de inserciones "lateralizadas" (mm. obliquus capitis, rectus capitis, multifidi cervicis). La región torácica presenta numerosos y amplios músculos rotadores. La musculatura epiaxial lumbar está dominada por el $\mathrm{m}$. iliocostalis, mientras que la hipoaxial está compuesta de metámeros breves. Los extensores fuertes del miembro posterior (e.g., isquiotibiales, extensores del tobillo), son voluminosos y de inserciones relativamente distales. Los flexores rápidos (e.g., m. infraspinatus, m. gluteus) y estabilizadores articulares (e.g., m. anconeus, m. articularis coxae) de ambas extremidades están reducidos o ausentes. El $\mathrm{m}$. brachioradialis presenta variantes intraespecíficas con un origen extendido proximalmente. Los protractores y extensores del miembro anterior (contrariamente a sus antagonistas), están marcadamente desarrollados y subdivididos, con un $\mathrm{m}$. rhomboideus profundus y capitis separados. Existen múltiples fascículos biarticulares y aductores en ambos miembros. Los flexores del hombro (e.g., m. infraspinatus) y codo (e.g., m. biceps brachii, m. brachialis) y aductores de ambas extremidades están reducidos, mientras que el $\mathrm{m}$. coracobrachialis se encuentra ausente. El análisis de la miología de Ga. cuja permitió reconocer rasgos relacionados con las estrategias de caza y locomoción en galerías y half-bound. A partir de las optimizaciones y análisis comparativo se determinaron rasgos miológicos potencialmente informativos respecto a la estructura filogenética.

En las descripciones y análisis osteológicos se reconoce la presencia un cuello largo, con regiones de agarre muscular bien desarrolladas para todos los mustélidos de América del Sur. La región tóraco-lumbar es alargada en lutrinos y lincodontininos. Se registra una gran diversidad de variantes en la región lumbar y caudal (forma, fórmula vertebral, proporciones). En la región lumbar, los cuerpos y procesos son elongados en los hurones y Ei. barbara. En la región caudal, Ly. patagonicus y Galictis spp. presentan arcos neurales reducidos. Eira barbara presenta una cola elongada, móvil y de elementos distales delgados, mientras que Galictis spp. y lutrinos presentan colas amplias con numerosos procesos espinosos caudales, y en las nutrias, con procesos transversos en forma de "H". Los elementos apendiculares son relativamente largos y delgados en Ei. barbara, mientras que en las nutrias son robustos y con amplias áreas de agarres musculares. El plano isquio-púbico, la cabeza y la tróclea femoral de los lutrinos presentan una configuración particular. El ilion y los trocánteres del fémur se encuentran reducidos en los hurones. Las regiones articulares del hombro, codo, cadera y rodilla favorecen movimientos mayormente dentro del plano sagital en los hurones, mientras que las restricciones son menores en Ei. barbara y lutrinos. En la muñeca, carpo y tarso de Ei. barbara se registra el 
mayor grado de movilidad, mientras que en lutrinos existen mayores restricciones. En hurones y lutrinos, el zeugopodio es ancho. Los autopodios de Ly. patagonicus son gráciles y elongados, mientras que en Ei. barbara y especialmente en lutrinos son más robustos y amplios. Para el caso de los siete especímenes fósiles, se confirmaron las asignaciones previas o propusieron por primera vez asignaciones taxonómicas, todas a ellas correspondiendo a especies actuales.

El estudio comparativo de la morfología postcraneal de los mustélidos mediante los diversos enfoques considerados, permitió relacionar un gran número de rasgos anatómicos a los diversos hábitos de vida y tamaños corporales, siendo también informativos de la historia evolutiva y afinidades filogenéticas. En los half-bounders, la musculatura epiaxial, extensora de la cadera y del tobillo, encargada de la propulsión en marchas a saltos, músculos que cuentan con importantes superficies de agarre muscular (e.g., plano isquio-púbico y zeugopodio posterior). El gran desarrollo de la musculatura extensora y protractora del miembro anterior y sus áreas de orígenes (e.g., fosa supraespinosa, proceso subhamatus) concuerdan con la especialización del miembro anterior en la amortiguación de los saltos. Los nadadores presentan un gran número de rasgos postcraneales únicos vinculados al nado. Desde la región cervical a caudal son capaces de realizar movimientos amplios y poderosos de flexo-extensión. La morfología de los miembros (e.g., húmero de curvatura sigmoidea, amplitud y posición "dorsalizada" del plano isquio-púbico, fémur breve) y gran desarrollo de áreas de agarre muscular (e.g., ala de la escápula, crestas del húmero, ilion) se relacionan a una posición caudal habitual de los miembros y a la generación de poderosos movimientos de propulsión. Los trepadores presentan regiones postdiafragmáticas largas, miembros largos y articulaciones con amplias libertades de movimientos. Los músculos estabilizadores, aductores y abductores, así como sus áreas de agarre (e.g., acromion, cresta pectoral, cresta epicondilar, ala del ilion) están bien desarrollados. En los trepadores ágiles como los guloninos, las colas largas y livianas son útiles durante el balance, pero sin permitir prensión. Las falanges ungueales, recurvadas y agudas, son el principal medio de sujeción sin existir grandes capacidades de manipulación (si presentes en muchos prociónidos y Ailurus). Los cavadores presentan músculos retractores, aductores y abductores del miembro anterior y flexores del hombro y muñeca voluminosos, con amplias áreas de agarre (e.g., crestas, tubérculos y epicóndilos del húmero, olécranon, tubérculo del carpal accesorio), similar a trepadores y nadadores. La musculatura extensora del codo desarrollada, miembro anterior relativamente elongado, restricciones articulares en el codo y carpo, y modificaciones en las proporciones del autopodio anterior, les permiten la penetración y remoción del sustrato. La características de la región lumbar (e.g., reducida en longitud y rígida), articulación sacro-ilíaca reforzada y miembros posteriores robustos permiten transmitir y resistir las fuerzas generadas en la región anterior del cuerpo. Se reconocen también características en la región axial y pelvis vinculadas al comportamiento aposemático de tipo 
battle-flag de ictoniquinos y mefítidos, así como características cervicales informativas del grado de carnivoría y estrategias de caza de distintos linajes.

El plan corporal de los grisones puede considerarse generalizado, permitiéndoles depredar sobre un espectro variado de presas y moverse con facilidad sobre la superficie y en túneles subterráneos, lo que posiblemente permitió al linaje establecerse en variados ambientes de América del Sur. Las evidencias recabadas apoyan la posibilidad de una antigua vinculación a hábitos acuáticos para el linaje. Lyncodon patagonicus se encontraría altamente especializado en la caza de roedores fosoriales. Este taxón converge con los linajes de mustelinos más especializados en un tamaño corporal pequeño, cuello de movimientos amplios y poderosos, miembros y cola reducidos, una región axial muy larga y móvil. La anatomía mastoidea de $S$. pettorutii sugiere que habría poseído una musculatura mastoidea más marcadamente desarrollada y subdividida que otros lincodontininos, indicando poderosos y complejos movimientos cervicales lo que, junto con otros rasgos craneales, indicaría que fue capaz de depredar sobre presas de gran tamaño relativo. Eira barbara es posiblemente es el mustélido más especializado al sustrato arbóreo; presenta un gran número de rasgo intermedios entre musteloideos galopantes y mustélidos weasel-like aunque muchos rasgos (zeugopodios relativamente breves, zona axial flexible, y cuello elongado y musculoso) la vinculan a un plan ancestral weasel-like. Los representantes sudamericanos de Lontra difieren de la especie norteamericana Lo. canadensis en poseer los miembros anteriores y dígitos más largos, evidenciando una mayor capacidad de manipulación y/o propulsión braquial. Por otro lado, las nutrias de América del Sur, y especialmente Pt. brasiliensis, poseen regiones axiales, y específicamente colas, altamente especializadas al nado.

Se sugiere un plan weasel-like ancestral para Mustelidae-Taxidea. Un gran número de rasgos postcraneales son propuestos como filogenéticamente informativos a diferentes niveles jerárquicos, e.g., osteológicos: presencia de foramen alar del atlas, abertura de foramen transverso de C7, morfología de arcos neurales de vértebras caudales, tipo de contactos entre carpales; miológicos: configuración de los mm. rhomboideus, sistemas epiaxial es y del m. semitendinosus, posición de origen del m. brachioradialis. Esta fuente de caracteres prácticamente inexplorada podría ser utilizada en futuros estudios filogenéticos. 


\begin{abstract}
The Family Mustelidae is the most diverse one within the Order Canivora. Compound by 22 extant genera, it shows a wide ecomorphological variation. There are 11 extant South American mustelids species: the scansorial gulonine Eira barbara; the ictonychine lyncodontinine weasels Lyncodon patagonicus, Galictis cuja y Ga. vittata; the lutrines Lontra felina, Lo. longicaudis, Lo. Provocax, and Pteronura brasiliensis; and the musteline weasels Mustela frenata, Mu. felipei, and Mu. africana. The ictonychines are the oldest subfamily in the subcontinent (Late Pliocene-Recent), represented by numerous extinct species belonging to the extant genera and by the only extinct genus Stipanicicia, represented by S. pettorutii; other mustelid lineages of South America were recorded since the Pleistocene. Mustelid postcranial musculature was intensively studied during the XIX century, although South American species remained almost unexplored. Previous studies of postcranial osteology reported a close association between morphology and locomotor modes and other variables (e.g., body size, phylogeny, hunting behavior). Nevertheless, many topics remain scarcely explored, especially among South American species. Furthermore, postcranium has almost not been studied as a potential source of phylogenetic characters. The goal of this thesis was to study the postcranial morphological diversity of South American extinct and extant mustelids, exploring its relationship with different factors (e.g., locomotion, food habits, body size, phylogenetic structure), within a comparative framework.

In this thesis, three myological specimens of Galictis cuja were studied by dissections; cranial and postcranial musculature was exhaustively described. Individual variation was described and each muscle was weighted. Muscular maps were constructed. Also, a detailed osteological description of seven South American mustelids was achieved. Morphofuctional qualitative and quantitative analyses were performed within a comparative framework at the Musteloidea level. Seven fossil specimens with preserved postcranial elements were described in detail, as well as cranial specimens of fossil lyncodontinines, including S. pettorutti. Eight indexes summarizing the relative length of axial and appendicular regions were constructed. Four postcranial elements (axis, penultimate lumbar vertebra, distal end of the humerus and proximal end of the femur) were analyzed using geometric morphometric approaches; betweengroups principal component analysis were performed in order to capture, summarize, and assess the diversity of shapes for each studied element. To evaluate the effect of the locomotion and diet on the linear and shape variables, variance analyses were performed considering the phylogenetic structure of the data and body size influence. Osteologic and myologic characters were designed, codified, and optimized (osteologic: 83 characters x 31 taxa; five continuous and 78 discrete characters; muscular: 47 characters x 32 taxa) in order to evaluate the phylogenetic value and to obtain reconstructions of ancestral states of those characters.
\end{abstract}


The myological description of Ga. cuja revealed remarkable features. The cervical musculature is bulky and notably subdivided (e.g., sternocephalicus, cleidocephalicus), including numerous deep bundles with "lateralized" insertions (mm. obliquus capitis, rectus capitis, multifidi cervicis) associated to strong and complex movements. The thoracic region is elongated and narrow, with wide spinous processes and numerous and wide rotator muscles. The epaxial lumbar musculature is dominated by the $\mathrm{m}$. iliocostalis, while the hipoaxial one is made of short metameres, evidence of a high intervertebral mobility. Strong extensors of the hind limb (e.g., hamstrings, ankle extensors) which dominate the propulsion forwards during half-bound, were massive and have relatively distal insertions. The fast flexors (e.g., mm. infraspinatus, m. gluteus) and joint stabilizers (e.g., m. anconeus, m. articularis coxae) of both limbs are reduced or absent. The $\mathrm{m}$. brachioradialis has intraspecific variants with a proximally extended origin. Protractors and extensors of the forelimb (on the contrary to its antagonists) are markedly developed and subdivided, with separated m. rhomboideus profundus and capitis. Also, there are many biarticular fascicules and adductors in both limbs. The shoulder (e.g., m. infraspinatus) and elbow (e.g., m. biceps brachii, m. brachialis) flexors and adductors of both limbs are reduced, while the $\mathrm{m}$. coracobrachialis is absent. The myological analysis of Ga. cuja allowed recognizing features related to hunting behavior, subterranean locomotion and halfbound gait employed by the species. From the optimizations and comparative analyses, many myological features were determined as potentially informative regarding to the phylogenetic structure.

Osteologic descriptions and analyses documented a long neck, with very well developed muscular attachment surfaces in all South American mustelids. The thoraco-lumbar region is elongated in lutrines and lyncodontinines. There is a great diversity in the lumbar and caudal regions (shape, vertebral formula, proportions). In the former region, the vertebral body and processes are elongated in weasels and Ei. barbara. In the caudal region, Ly. patagonicus and Galictis spp. display reduced neural arches. Eira barbara has an elongated mobile tail, with thin distal elements, while Galictis spp. and lutrines have wide tails with numerous caudal spinous processes and, in otters, with H-shaped transverse processes. Appendicular elements are relatively long in Ei. barbara, while in otters are robust, with wide surfaces for muscular attachments. The ischio-pubic plane, the femoral head and the trochlea in lutrines have a particular configuration. The ilion and both femoral trochanters are reduced in weasels. The articular regions of the shoulder, elbow, hip and knee mostly favor parasagital movements in weasels, while restrictions are smaller in Ei. barbara and lutrines. The largest degree of mobility was found in the wrist, carpus and tarsus of Ei. barbara, while in lutrines there are more restrictions. In weasels and lutrines, the zeugopods are laterally expanded. The autopodium of Ly. patagonicus is slender and elongated, while in Ei. barbara and especially in 
lutrines is robust and wide. For the seven fossil specimens, previous taxonomic assignations were confirmed, or new ones were here suggested for the first time, all of them agreeing with extant species.

The comparative study of the osteological morphology of the postcranium of mustelids, analyzed by diverse and complementary approaches, allowed relating a great number of anatomical features to different habits and body size, but was also found informative for the evolutionary history and phylogenetic affinities. In half-bounders, epaxial musculature, hip extensors and ankle extensors which are the main responsible of propulsion in jumping gaits, have large attachment surfaces (e.g., ischio-pubic plane and zeugopod of the hind limb). The great development of the extensor and protractor muscles of the forelimb and their origin surfaces (e.g., supraspinous fossa, subhamatus process) coincide with the specialization of the forelimb as a shock-absorber when jumping. Swimmers have a large number of unique postcranial features associated to their swimming capabilities. From the cervical to the caudal region, they are able to perform wide and powerful flexion-extension movements. Their limb morphology (e.g., sigmoid humerus, amplitude and "dorsalized" position of the ischio-pubic plane, short femur) and the great development of the muscular attachment areas (e.g., wing of the scapula, crest of the humerus, ilium) are related to a usual caudal position of the limbs, and to strong propulsive movements. Scansorial species have long postdiaphragmatic regions, long limbs and articulations with a wide freedom of movements. Stabilizers, adductors and abductors muscles, together with their attachment surfaces (e.g., acromion, pectoral crest, epicondylar crest and wing of the ilium respectively), are well developed. In agile scansorial species such as many gulonines, long and light tails are useful during balance, but do not allow prehension. The ungueal phalanges, that are curved and acute, are the primary means of clamping, given that these species do not present manipulation abilities (that are present in many procyonids and Ailurus). Fossorial species has bulky retractor, adductors and abductor muscles of the forelimb and flexors of the shoulder and wrist, with large attachment areas (e.g., crests, tubercles and epicondyles of the humerus, olecranon process, tubercle of the accessory carpal bone), similar to scansorial and swimmer species. A developed extensor musculature of the elbow joint, a relatively elongated forelimb, articular restrictions in the elbow and carpus, and some modifications of the anterior autopodium ratios facilitate penetration and removal of the substrate. The characteristics of the lumbar region (e.g., short and rigid), the reinforced sacroiliac articulation and the short and robust hind limbs allow transmitting and resisting the forces generated in the anterior region of the body. There are also axial and pelvic features associated to the aposematic battle-flag behavior of ictonychines and mephitids, as well as cervical characteristics informative about carnivore degree and hunting behavior in different lineages. 
The body plan of grisons can be considered generalized, allowing predating on a wide spectrum of prey and moving easily on surface and tunnels, which permitted this lineage to establish in a variety of habitats in South America. Gathered evidence support the possibility of an ancient association with aquatic environments for this lineage. Lyncodon patagonicus would be highly specialized to hunt on fossorial rodents. This taxon converge with the most specialized musteline lineages in a small body size, strong and wide movements of the neck, reduced limbs and tail, and a very long and mobile axial region. Mastoid anatomy of $S$. pettorutti suggest that it would have possessed a mastoid musculature markedly more developed and subdivided than other lyncodontinines, indicating strong and complex cervical movements, which together with other cranial features, would indicate the ability to hunt on prey with a relative large size. Eira barbara is possibly the most specialized mustelid for the arboreal substrate; it has a great number of intermediate characters between galloping and weasel-like mustelids, although many features such as relatively short limbs, flexible axial region and elongated and muscular neck, associate it to an ancestral weasel-like body plan. South American representatives of Lontra differ of the North American species Lo. canadensis in having longer forelimbs and digits, revealing a wider manipulation capability and/or brachial propulsion. On the other hand, South American otters, and specially Pt. brasiliensis, have axial regions and specifically tails, highly specialized for swimming.

A weasel-like plan is suggested as ancestral for Mustelidae-Taxidea clade. A great number of postcranial features are suggested as phylogenetically informative at different hierarchical levels, e.g., osteologic: presence of the alar foramen of the atlas, opening of the transverse foramen of the $\mathrm{C} 7$, morphology of the neural arches of the caudal vertebrae, contact configuration among carpal bones; myological: configuration of the $\mathrm{mm}$. rhomboideus, epaxial systems and the $\mathrm{m}$. semitendinosus, position of the origin of the $\mathrm{m}$. brachioradialis. This mostly unexplored source of characters could be useful in future phylogenetic analyses. 


\section{AGRADECIMIENTOS}

Quiero agradecer a mi director de Tesis y beca, el Dr. Francisco J. Prevosti por haberme guiado durante el desarrollo de mi Tesis, y a la Dra. Adriana M. Candela, por haber aceptado ser mi codirectora de beca; y a ambos por compartir su lugar de trabajo conmigo.

Agradezco a los Dres. Alfredo Carlini, David Flores y Néstor Toledo asignados como jurados de esta Tesis, cuyos comentarios y correcciones mejoraron grandemente la forma final de la misma.

Agradezco al Jefe de la División Mastozoología del Museo Argentino de Ciencias Naturales "Bernardino Rivadavia", Dr. David Flores, y al Director de la institución, Dr. Pablo Tubaro, por el lugar de trabajo dentro del Museo.

Agradezco a los curadores y técnicos de las distintas colecciones que visité durante el transcurso de mi Tesis: Dr. Diego Verzi y Dra. Itatí Olivares, curador y encargada de la Sección Mastozoología del Museo de La Plata; Dr. Marcelo Reguero, curador de la División Paleontología Vertebrados del MLP (La Plata); Dr. David Flores y Sr. Sergio Lucero, curador y técnico de la División Mastozoología del Museo Argentino de Ciencias Naturales; Dr. Alejandro Kramarz y Sra. Stella Álvarez, curador y técnica de la División Paleontológica de Vertebrados del MACN (Ciudad Autónoma de Buenos Aires), Dr. Rubén Barquez y Dra. Mónica Díaz, curador y encargada del Instituto Miguel Lillo (Tucumán), Dr. Jorge Noriega y Sra. Griselda Gottardi, curador y técnica del Laboratorio del Paleontología de Vertebrados del Centro de Investigaciones Científicas y Transferencia de Tecnología a la Producción de Diamante (CICYTTP-CONICET, Entre Ríos), Dr. Jhoann Canto Hernández, curador del Área Vertebrados del Museo Nacional de Historia Natural (Santiago de Chile).

Agradezco a David Flores, Sergio Lucero, el personal de la Estación Hidrobiológica de Puerto Quequén, Marcela Deborah Huerta de la Rocha, Mariano Ramírez, Maximiliano Álvarez, Yolanda Davies, Santiago Nenda (todos ellos del MACN), Sergio Bogan (Universidad de Maimónides) y Mariela Superina (CCT-Mendoza) por brindarme amable y desinteresadamente su ayuda, así como acceso a materiales y/o lugares de trabajo para las disecciones realizadas en el marco de mi Tesis. Especialmente agradezco a los miembros del "equipo diseccionador", incluyendo en distintos momentos a Sebastián Echarri, M. Ignacio

Stefanini, Guillermo F. Turazzini, Miriam M. Morales, Alicia Álvarez, y a Felipe Busker, que estuvo presente en todas las temporadas. Sin el enorme trabajo aportado por ellos, coautores 
implícitos de los capítulos de miología de esta Tesis, habrían sido irrealizables los aportes más valiosos de esta Tesis.

Estoy especialmente agradecido con distintas personas de diversos lugares que me brindaron una enorme ayuda en muchos aspectos, y que sin ellos la realización de esta Tesis hubiese sido mucho más difícil o incluso imposible. Entre ellos: A Jhoann Canto Hernández, quien no sólo me facilitó a mí y otro colega el acceso a materiales del MNHN de Santiago de Chile, sino que también nos trató como en casa. A Atilio Francisco J. Zangrando (CADIC, Tierra del Fuego) y Alejandro Valenzuela (Administración de PN, Tierra del Fuego) por brindarme información inédita sobre Lontra provocax, Aldo Vassallo (Universidad Nacional de Mar del Plata) y Juan Manuel Moreno por contarme sus invaluables observaciones sobre el comportamiento de un ejemplar de Galictis cuja silvestre y cautivo ("Lola"), respectivamente. A Dionisios Youlatos (Aristotle University of Thessaloniki, Grecia) por brindarme acceso a información inédita y verdaderamente única sobre el comportamiento y la morfología de Eira barbara. A Alberto Valenciano Vaquero (Facultad de Ciencias Geológicas UCM, España), Juan Abella (Universidad Estatal de la Península de Santa Elena, Ecuador), por tantos fructíferos intercambios de ideas y trabajos a lo largo de estos últimos años.

A Analía M. Forasiepi, Constanza B. Gómez Álvarez, Daniel Martineau, Juan Fernicola, Néstor Toledo, Nahuel A. Muñoz, Miriam M. Morales, Daria Wingreen-Mason, Thor Holmes, Danny Walker, Emily Julik, Rebecca Fisher, Valenciano Vaquero, César GarcíaEsponda, Robert Scapino, Cecilia Morgan, Susanne Whitaker, Steven Presley, Thomas Burkholder, Evelyne Picco, Sergio F. Vizcaíno, Anna Perepelova, L. Donald Quaife, Anthony P. Russell y Eric Yensen, a la biblioteca virtual Biodiversity Heritage Library, la Universitäts bibliothek Gießen, la bibliothèque de l'École Nationale Vétérinaire de Toulouse, y la FlowerSprecher Veterinary Library of Cornell University, y nuevamente a mis directores (Francisco J. Prevosti y Adriana M. Candela), por información y ayuda en la búsqueda de bibliografía importantísima y muy difícil de conseguir.

Agradezco al equipo de colegas y amigos del Museo, con quienes he compartido tantos buenos momentos y anécdotas, incluyendo a Sergio Lucero, Valentina Segura, David Flores, Daniela del Castillo, Alicia Álvarez, Mariano Ramírez, Sebastián Echarri, Damián Pérez, Maximiliano Álvarez, M. Belén Santelli, Ignacio Legari, Mariana Viglino, Bárbara Tarnawski, Laura Barone, Liu Idarraga, Francisco J. Prevosti, Amelia Chemisquy y Guillermo Cassini. En muchos de los lugares en donde estuve (especialmente en las provincias de Tucumán y Jujuy) fui muy bien recibido y acompañado por gente muy amable y amigos, entre los cuales se 
encuentran Miriam M. Morales, Rocío Moyano, Juliana Rajmil, Luz Carrizo, Mariano Sánchez, Leticia Moyers.

Estoy especialmente agradecido con el Dr. Federico A. Gianechini (Área de Zoología, UNSL, San Luis), el Dr. Francisco J. Prevosti, el Lic. Mariano Ramírez (MACN), la Lic. Hannah Selvey (Hartstone-Rose Lab, University of South Carolina, EEUU), la Lic. Rocío Moyano (CETAS, UNJU, Jujuy), y la Dra. Heidi Schutz (Pacific Lutheran University, EEUU) y miembros de su equipo (Kjesten Braaten-Fierros, Christopher Higginbotham), colegas que tomaron y cedieron gentilmente fotos orientadas de elementos postcraneales analizados en esta Tesis, y agradezco también al Dr. John Ososky por contactarme con Hannah Selvey. Su aporte fue crucial para incluir especies claves en varios de los análisis realizados.

Estoy especialmente en deuda con Mariano Ramírez, un gran compañero durante todos estos años, por múltiples motivos, desde comprarme parte del almuerzo el complicado día lunes 16 de junio de 2014, aportar tantas ideas y ayudas durante la realización de esta Tesis, evitar la eliminación de parte de mis archivos de Tesis, hasta incluso ayudarme a despellejar un zorrino fresco. Se podría decir sin duda que su ayuda fue significativamente distinta al azar.

Estoy muy agradecido con el Dr. Sergio Vizcaíno y mi director, Dr. Francisco J. Prevosti, responsables de subsidios que permitieron solventar parcialmente los gastos de esta Tesis, incluyendo parte del equipamiento utilizado, un viaje de visita de colección y la totalidad de los viajes de campaña. Agradezco enormemente a las instituciones/sociedades SAREM, APA, MACN, ASM, NSF, FCNyM-UNLP, así como a los comités de organización de la RCAPA 2013 y JAM 2014, quienes me han asignado subsidios y premios que me permitieron comprar equipamiento, materiales y solventar viajes de visitas de colección y asistencias a reuniones científicas. Agradezco especialmente a CONICET por otorgarme una beca doctoral durante los cinco años del desarrollo de esta Tesis. Agradezco también a la Dra. Andrea Concheyro (FCEN-UBA), al Ing. Eduardo Taboada (ET28, DE10) y al Dr. Sergio Vizcaíno (MLP) por sus invaluables aportes y ayuda en etapas tempranas y previas a la Tesis. También quiero agradecerle a Cecilia Morgan, Néstor Toledo (MLP), Guillermo Cassini y especialmente a Alicia Álvarez (MACN) por ayudarme a resolver problemas metodológicos y de anatomía funcional. También agradezco a Valentina Segura Gago (Lillo) por su ayuda en cuestiones administrativas y consejos.

Estoy muy especialmente agradecido con Miriam M. Morales una gran amiga jujeña e increíble persona que ofrece desinteresadamente su tiempo y conocimientos a quien lo necesite. Con ella compartimos y compartiremos muchísimas charlas, ideas y proyectos. Fue quien me 
ayudó con gran paciencia tantas veces, me enseñó los métodos de disección y hospedó en su casa más de una vez.

Agradezco también a mi familia, mis papás Lionel y María Ester, a mis hermanos Trinidad, Anahí y David, a Shinji, a la abuela Keka, a los tíos, primos y demás parientes que siempre me acompañan. A los amigos de la vida, Hernán, Pipy, Luis, Emiliano, Claudio, Matías, Carli y Carla, y al resto del grupo de la facu, Diego, Guille, Romi, Mateo, Virginia.

Por último, dedico esta Tesis y agradezco infinitamente a Alicia Álvarez, mi amada compañera de vida, que todos los días me hace sentir el hombre más afortunado. Ella es un angelito-genio que un día apareció y desde entonces siempre estuvo allí para ayudarme en todo, y la Tesis no fue una excepción, realizando funciones tan diversas como ser opinóloga crítica de ideas, revisora de manuscritos, coautora de trabajos, buscadora de bibliografía, coequiper de disecciones, profesora particular... muchas gracias linda. 


\section{ÍNDICE}

\section{Tomo I}

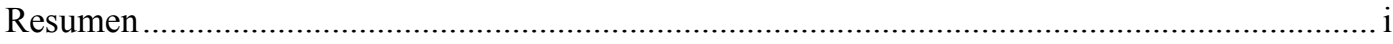

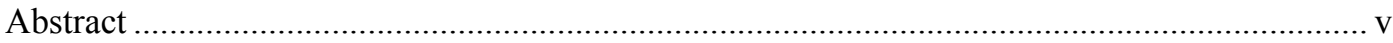

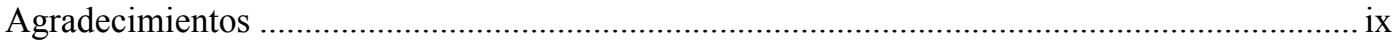

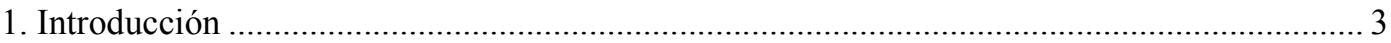

1.1. Diversidad ecológica y funcional de los mustélidos ............................................................. 3

1.1.1. Tejones (Subfamilias Melinae, Mellivorinae, Taxidiinae) .......................................... 3

1.1.2. Martas y sus parientes (Subfamilia Guloninae) ....................................................... 5

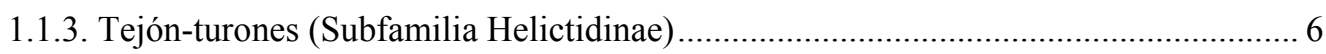

1.1.4. Hurones mustelinos (Subfamilia Mustelinae) …………...................................... 7

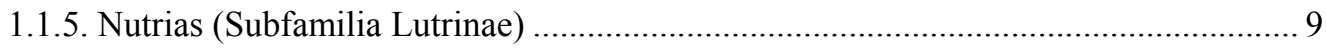

1.1.6. Zorrillas y hurones ictoniquinos (Subfamilia Ictonychinae) .................................... 11

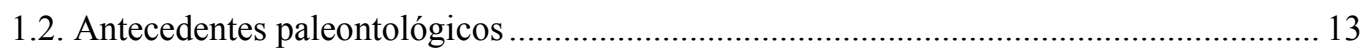

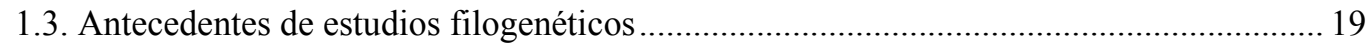

1.4. Principales antecedentes de estudios músculo-esqueletarios de mustélidos ..................... 21

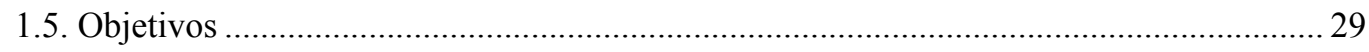

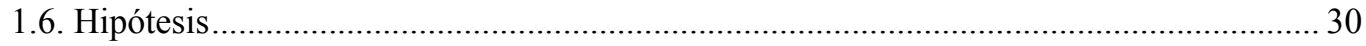

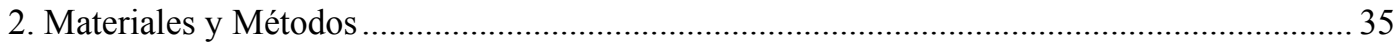

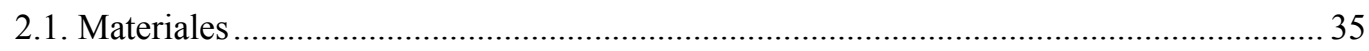

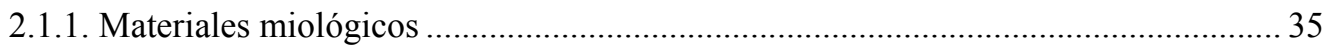

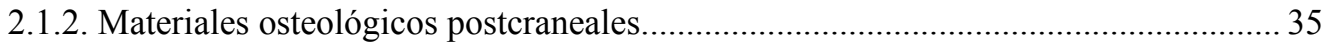

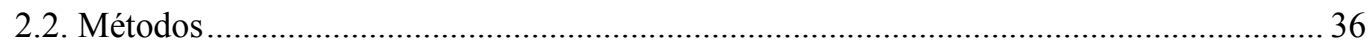

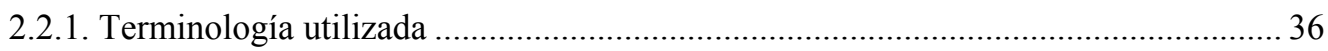

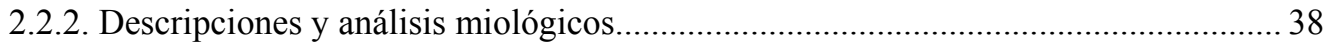

2.2.3. Descripciones y análisis osteológicos postcraneales................................................ 39

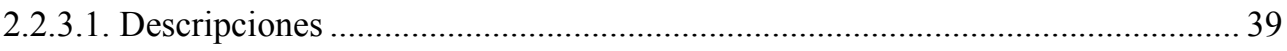

2.2.3.2. Análisis cuantitativo de medidas lineales.......................................................... 40 
2.2.3.3. Análisis cuantitativo de morfometría geométrica.

2.2.4. Optimizaciones de caracteres miológicos y osteológicos ......................................... 45

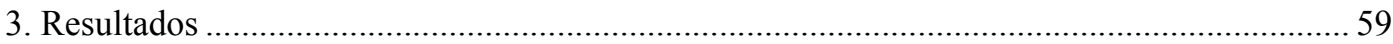

3.1. Descripción de la miología de Galictis cuja ...................................................................... 59

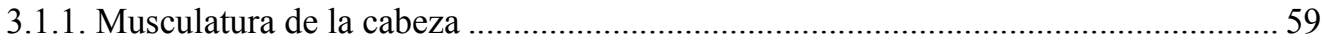

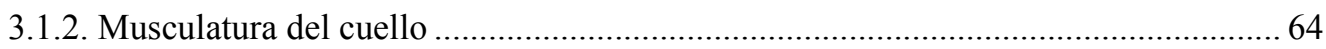

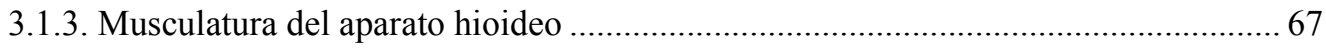

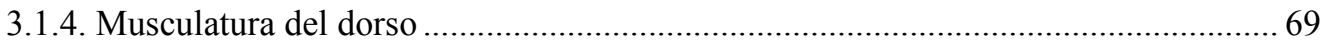

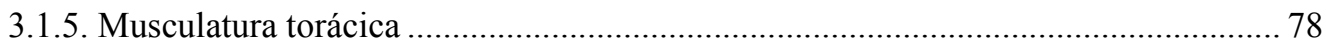

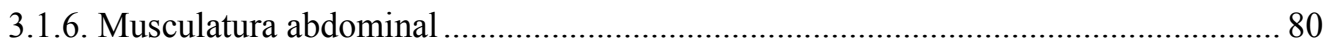

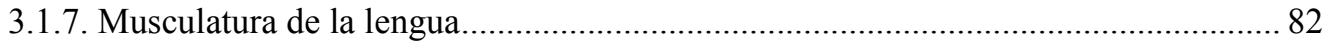

3.1.8. Musculatura extrínseca e intrínseca del miembro anterior....................................... 82

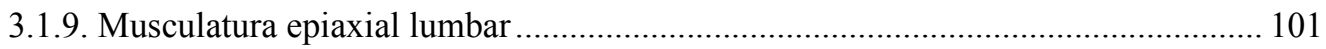

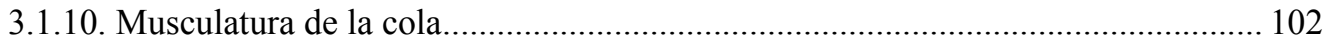

3.1.11. Algunos músculos del sistema urogenital y recto .............................................. 105

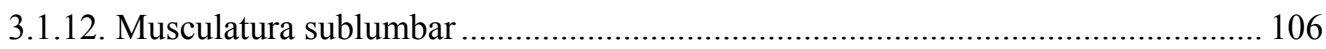

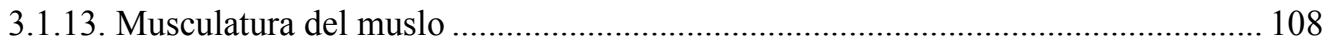

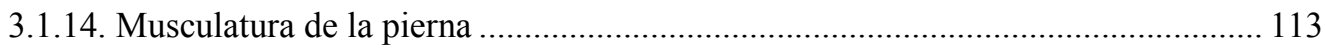

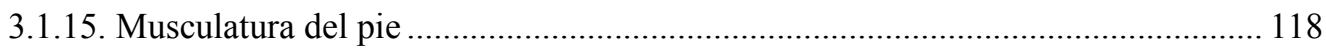

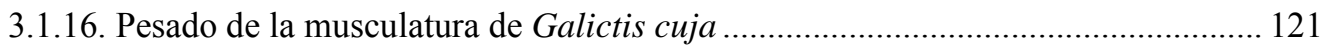

3.2. Descripciones osteológicas del postcráneo de mustélidos de América del Sur .............. 126

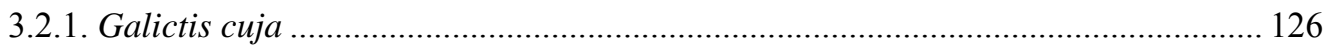

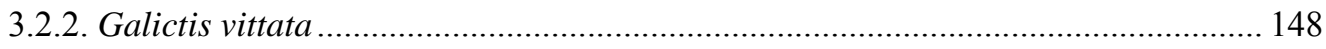

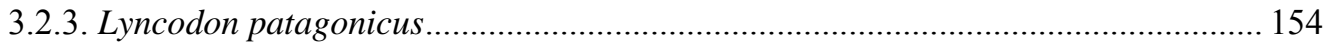

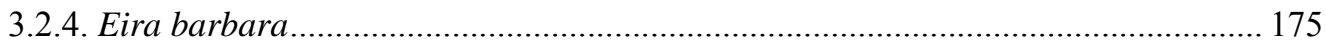

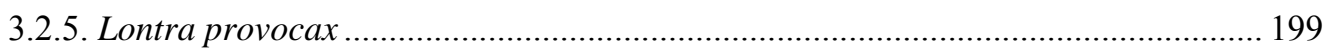

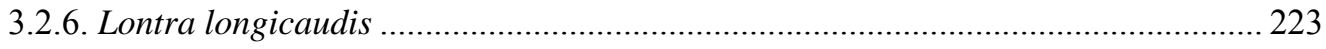

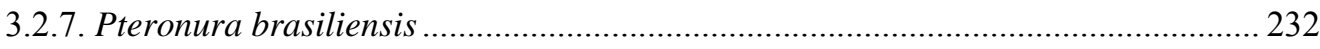




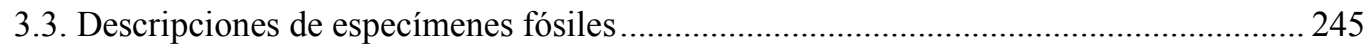

3.3.1. Lyncodon patagonicus MLP 96-V-1-1 y MLP 96-V-2-2/3 _.................................... 245

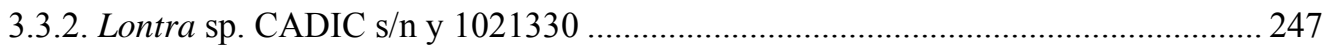

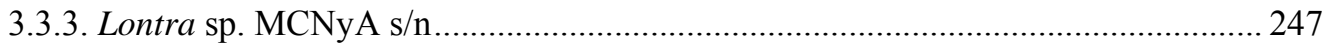

3.3.4. Pteronura brasiliensis CICyTTP-Pv-1-21 ……………………………............. 247

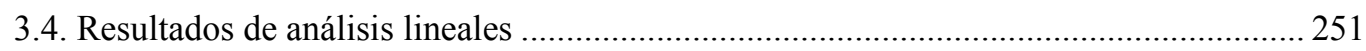

3.4.1. Largo de la región tóraco-lumbar sobre largo promedio de los miembros

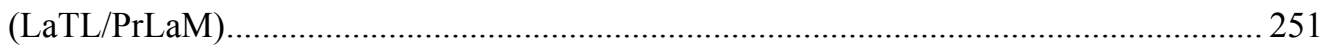

3.4.2. Largo de región cervical sobre largo de región tóraco-lumbar (LaCe-LaTL)........ 252

3.4.3. Largo de región lumbar sobre largo de región tóraco-lumbar (LaLu/LaTL) ........... 253

3.4.4. Largo de la región sacro-caudal sobre largo de región tóraco-lumbar (LaSC/LaTL)

3.4.5. Largo de miembro anterior sobre largo de miembro posterior (LaMA/LaMP) ...... 255

3.4.6. Largo del radio sobre largo del húmero (LaRa/LaHu) .......................................... 256

3.4.7. Largo del metacarpal III sobre largo de la falange proximal de dígito III

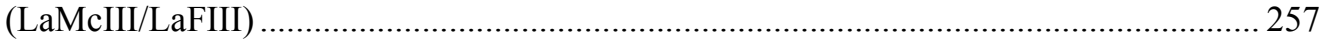

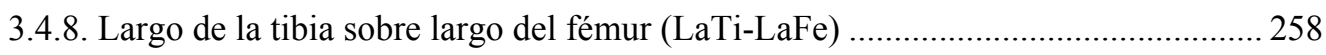

3.5. Resultados de análisis de morfometría geométrica ........................................................ 268

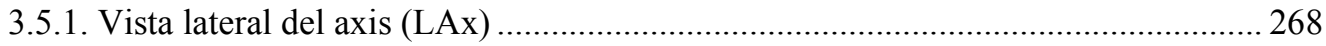

3.5.2. Vista dorsal de penúltima vértebra lumbar (DPLu) ................................................ 270

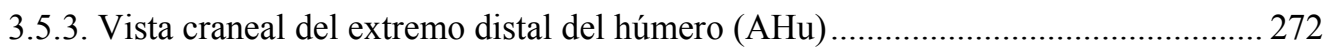

3.5.4. Vista caudal del extremo proximal del fémur $(\mathrm{PFe})$............................................... 275

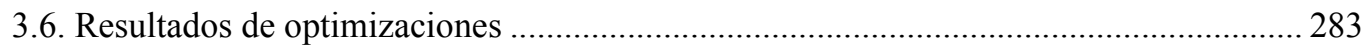

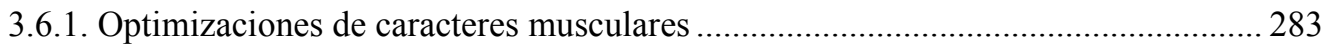

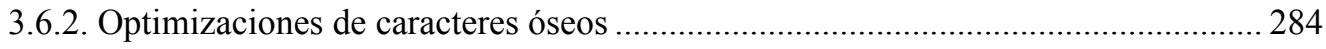

3.6.3. Optimizaciones de caracteres ecológicos y tamaño corporal .................................... 291

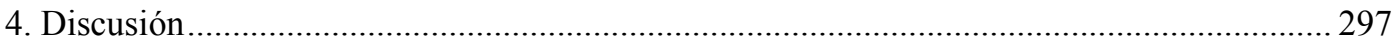

4.1. Análisis morfo-funcional comparativo con consideraciones filogenéticas de la miología

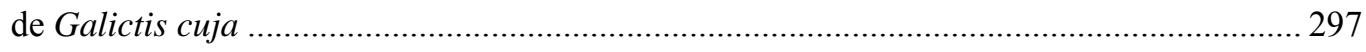

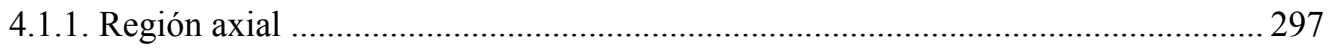


4.1.2. Miembro anterior 306

4.1.3. Miembro posterior ............................................................................... 325

4.1.4. Cooperación y correspondencias entre miembro anterior y posterior. 333

4.2. Comentarios sobre la morfología de Lyncodon patagonicus y el espécimen CML 0655

4.3. Análisis morfo-funcional comparativo de la osteología de los mustélidos .................. 336

4.3.1. Proporciones generales............................................................................... 336

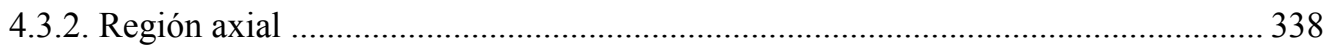

4.3.2.2. Región tóraco-lumbar...................................................................... 349

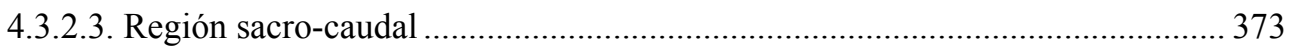

4.3.3. Proporciones intermembrales ..................................................................... 387

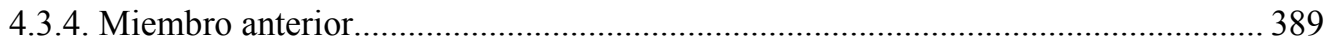

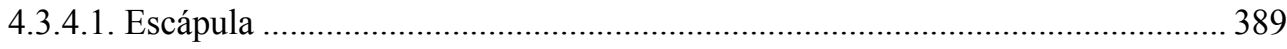

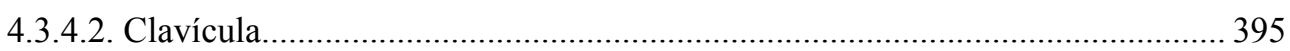

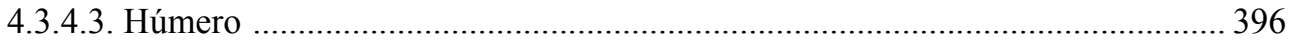

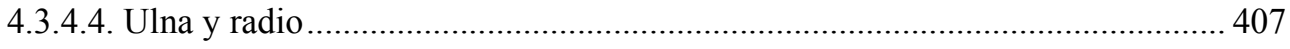

4.3.4.5. Autopodio anterior ........................................................................... 416

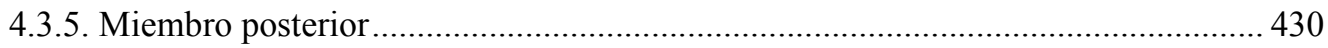

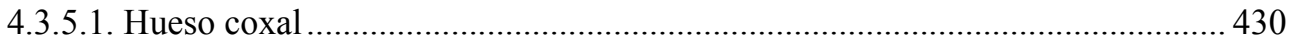

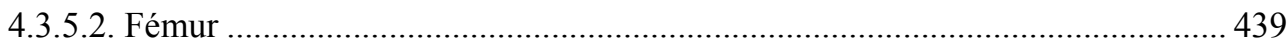

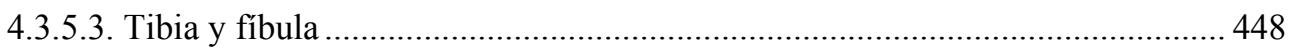

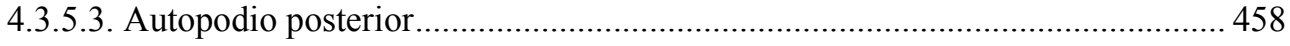

4.4. Comentarios sobre los elementos postcraneales de especímenes de mustélidos fósiles 472

4.4.1. Lyncodon patagonicus MLP 96-V-1-1 y MLP 96-V-2-2/3 ................................ 472

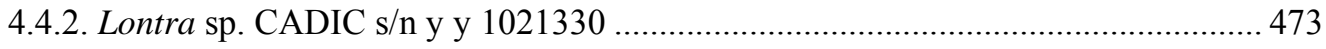

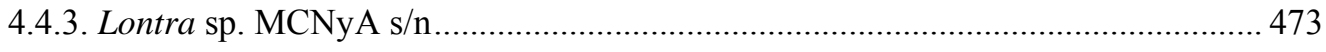

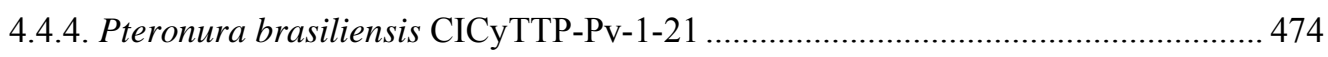

4.5. Comentarios generales sobre los análisis lineales y de morfometría geométrica.......... 476 
5. Comentarios finales y conclusiones

6. Anexo: Análisis morfo-funcional de la anatomía mastoidea de Stipanicicia pettorutii....... 519

6.1. Introducción 519

6.1.1. Introducción a Stipanicicia pettorutii, Reig 1956 519

6.1.2. Introducción a las estrategias de caza en mustélidos. 519

6.2. Materiales y Métodos 523

6.2.1. Materiales osteológicos craneales 523

6.2.2. Análisis morfo-funcional de la región mastoidea de Stipanicicia pettorutii 524

6.3. Resultados 525

6.3.1. Análisis comparativo de la región mastoidea de Stipanicicia pettorutii 525

6.3.2. Reconstrucción muscular de Stipanicicia pettorutii 526

6.4. Discusión 528

6.4.1. Análisis morfo-funcional de la anatomía mastoidea de Stipanicicia pettorutii...... 528

6.4.2. Comentarios sobre la influencia del tamaño y el dimorfismo. 533

6.4.3. Estrategias de caza en hurones 534

6.4.4. Estrategia de caza de Stipanicicia pettorutii 536

Bibliografía 547

\section{Tomo II}

Láminas 1

Láminas de terminología utilizada en elementos postcraneales ................................... 3

Láminas miológicas de Galictis cuja.................................................................. 15

Láminas osteológicas de elementos postcraneales de mustélidos de América del Sur ....... 43

Láminas osteológicas de elementos postcraneales de mustélidos fósiles ......................... 85

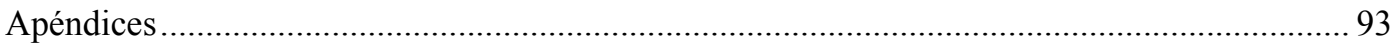

Apéndices de Materiales y Métodos............................................................................. 95

Apéndices de Resultados ............................................................................... 127

Apéndices de Discusión ..................................................................................... 190 

Capítulo 1

INTRODUCCIÓN

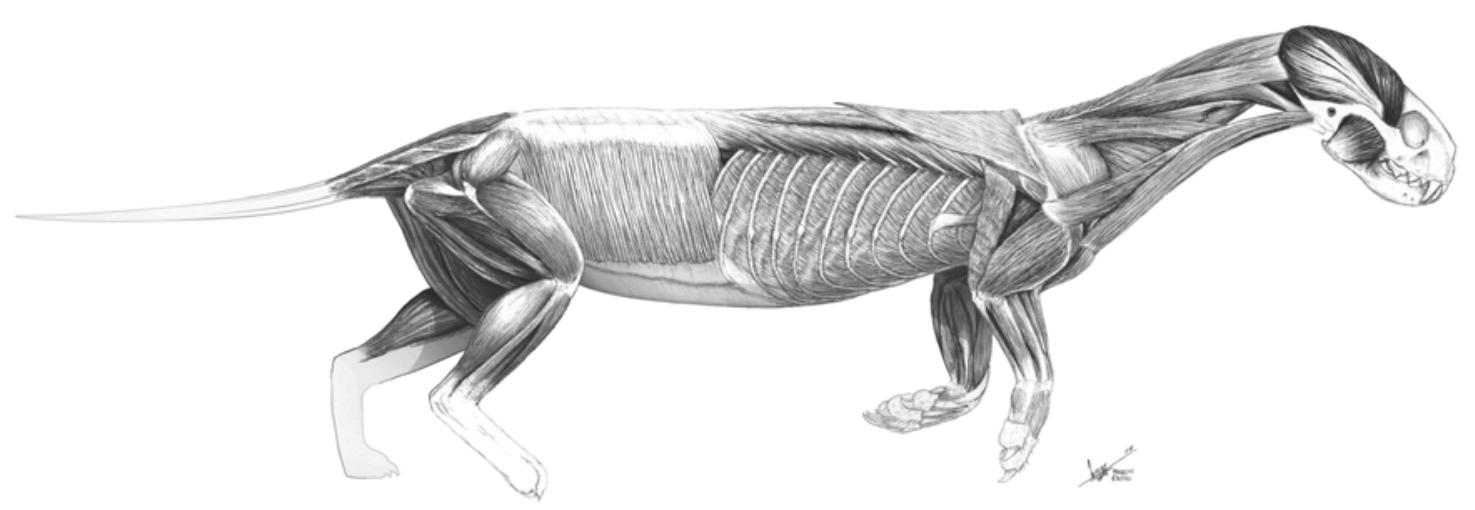





\section{Introducción}

Mustelidae es la familia más diversa del Orden Carnivora, representada actualmente por 22 géneros y aproximadamente 57 especies (Nowak 2005, Wilson y Reeder 2005, Wilson y Mittermeier 2009). Agrupa a los hurones, martas, tejones y a las nutrias (Baskin 1998, Wilson y Reeder 2005, Koepfli et al. 2008, Sato et al. 2012; Fig. 1.1). Presentan una amplia distribución geográfica, encontrándose especies nativas en todos los continentes exceptuando Antártida y gran parte de Oceanía (Ewer 1973, Van Valkenburgh 1987, Hutchins 2003, Wilson y Reeder 2005).

Muchos mustélidos poseen cuerpos alargados y patas cortas, mientras que otros poseen formas más generalizadas (Hutchins 2003, Nowak 2005). Los mustélidos son un grupo que ocupa una gran variedad de hábitats (e.g., terrestre, semiacuático, subterráneo), y diverso respecto a los hábitos alimentarios (e.g., hipercarnivoría, omnivoría, insectivoría). En lo que respecta al tamaño corporal, son un grupo también diverso, desde 11 a $150 \mathrm{~cm}$ de longitud (Mustela nivalis y Pteronura brasiliensis respectivamente; Hutchins 2003, Jones et al. 2009) y desde menos de 100 gr. a $45 \mathrm{~kg}$. (Mustela nivalis y Enhydra lutris respectivamente; Peigné et al. 2008, Jones et al. 2009), incluyendo a los carnívoros más pequeños del mundo. Dependiendo de la especie, existe dimorfismo en tamaño corporal en donde los machos son entre 10 y $100 \%$ mayores que las hembras, repercutiendo esto también en el tamaño de presa capturada típico o máximo y en las variantes de estrategias de caza (Hall 1951, Rowe-rowe 1978, Sheffield y King 1994, Hutchins 2003, Wilson y Mittermeier 2009). El dimorfismo sexual se ha comprobado en

algunas especies fósiles (e.g. ${ }^{\dagger}$ Trigonictis; Björk 1970, Baskin 1998). Son animales en general nocturnos y solitarios, aunque muchas nutrias y el tejón europeo se destacan por formar importantes grupos (Hutchins 2003, Kruuk 2006).

Teniendo en cuenta esto, se considera a ésta como la familia de Carnivora más rica en número de especies, diversa en ecomorfología y de más amplia distribución (Wilson y Mittermeier 2009, Sato et al. 2012)

Siguiendo el arreglo subfamiliar planteado por Sato et al. (2012; Fig. 1.2), la Familia Mustelidae incluye ocho Subfamilias: Taxidiinae, Melinae, Mellivorinae, Guloninae, Helictidinae, Mustelinae, Lutrinae e Ictonychinae, cuatro de las cuales con representantes sudamericanos (i.e., Guloninae, Mustelinae, Lutrinae e Ictonychinae).

A continuación se describen las principales características ecológicas y funcionales relacionadas a estas para cada subfamilia.

\subsection{Diversidad ecológica y funcional de los mustélidos}

\subsubsection{Tejones (Subfamilias Melinae, Mellivorinae, Taxidiinae)}


La Subfamilia Melinae incluye a los tejones del Viejo Mundo, mientras que la Subfamilia Taxidiinae al tejón del Nuevo Mundo. Son animales medianos a grandes (3,5 a 14 kg.; Jones et al. 2009, Wilson y Mittermeier 2009, Myers et al. 2014). Los tejones son terrestres y se encuentran especializados en la excavación, construyen galerías complejas, y pasan gran parte del tiempo bajo tierra (Heptner y Naumov 1967, Goodrich y Burskirk 1998, Helgen et al. 2008, Wilson y Mittermeier 2009, Myers et al. 2014). Sus miembros anteriores se encuentran adaptados a la excavación, con gran desarrollo de la musculatura extensora del codo, y aductora/abductora y flexora del hombro, permitiendo que sus garras penetren y remuevan sustratos duros (Quaife 1978, Schutz y Guralnick 2007, Moore et al. 2013, Rose et al. 2014). Suelen desplazarse con movimientos lentos, pero pueden correr utilizando trote o galope, sin flexionar significativamente la espalda durante estas marchas (inferido por descripción de Taxidea en Coues 1877, registrado para Meles en Heptner y Naumov 1967, Dagg 1973).

Los tejones del Viejo Mundo son mayormente vermívoros e insectívoros, aunque pueden variar ampliamente los ítems incluidos en su dieta (pequeños mamíferos, anfibios, materia vegetal; Heptner y Naumov 1967, Johnson et al. 2000, McDonald 2002, Zabala y Zuberogoitia 2003, Wilson y Mittermeier 2009, Myers et al. 2014).

Arctonyx recientemente ha sido dividido en tres especies (Ar. collaris, Ar. hoevenii y Ar. albogularis; Helgen et al. 2008). Es un género muy poco conocido, pero parece ser menos especializado en la excavación que Meles y Taxidea (Gao y Sun 2005, Wilson y Mittermeier 2009). Al igual que los cerdos, utiliza su nariz móvil para obtener sus alimentos (que incluyen además raíces y tubérculos) y sus patas como eventual ayuda; así como también para cavar túneles de descanso (Gao y Sun 2005, Wilson y Mittermeier 2009). Vive en bosques y pastizales de altitud, y tierras cultivadas aledañas (Wilson y Mittermeier 2009, Myers et al. 2014).

Meles comprende tres especies (Mel. anakuma, Mel. leucurus y Mel. meles) que viven en una gran variedad hábitats, incluyendo bosques, semi-desiertos, estepas y pastizales (Heptner y Naumov 1967, Wilson y Mittermeier 2009) Al menos para la especie Mel. meles, se ha descripto la capacidad eventual de trepar (Dagg 1973).

Taxidea está representado actualmente por T. taxus, al contrario de otros tejones es principalmente carnívoro y predador, cazando principalmente roedores terrestres fosoriales con su boca (Long 1973, Goodrich y Burskirk 1998, Michener y Iwaniuk 2001). Se ha descripto como un eventual buen nadador (Long 1973).

La Subfamilia Mellivorinae incluye exclusivamente al tejón melero o ratel, Mellivora capensis, un mustélido africano y asiático de gran tamaño (entre 7,5 y $9 \mathrm{~kg}$.; Johnson et al. 2000, Vanderhaar y Hwang 2003, Jones et al. 2009), y que se encuentra desde desiertos y arbustales, a bosques cerrados (Heptner y Naumov 1967, Vanderhaar y Hwang 2003). Es un 
animal terrestre relativamente lento y robusto que puede trepar o nadar. Cuando se desplaza caminando mantiene la espalda recta (Heptner y Naumov 1967, Dagg 1973), mientras que cuando trota o galopa lo hace con un estilo similar a los úrsidos y Gulo (seguramente haciendo referencia a galope transverso; Heptner y Naumov 1967, Dagg 1973, Vanderhaar y Hwang 2003, Wilson y Mittermeier 2009). Es un fuerte y persistente cavador, posee garras y miembros anteriores robustos, y cava sus propios túneles incluso en terrenos duros (Heptner y Naumov 1967, Vanderhaar y Hwang 2003, Rose et al. 2014). Tanto cavando, como inspeccionando los arbustos obtiene la mayor parte de su alimento, que sostiene entre sus miembros anteriores y el suelo (Vanderhaar y Hwang 2003, Wilson y Mittermeier 2009). Principalmente carnívoro, consume también miel de colmenas y algunos ítems vegetales (Wilson y Mittermeier 2009).

\subsubsection{Martas y sus parientes (Subfamilia Guloninae)}

La Subfamilia Guloninae está integrada por las martas (Martes, o incluyendo a $M$. pennanti en el género Pekania; Sato et al. 2012), la tayra (Eira) y el glotón (Gulo), todos ellos animales trepadores en mayor o menor grado, y malos cavadores (Presley 2000, Wilson y Mittermeier 2009). Los representantes de esta Subfamilia son en general oportunistas; pequeños y medianos mamíferos y aves son una porción mayoritaria de su dieta, pero suelen incluir un gran número de otros ítems (insectos, frutos, semillas; Heptner y Naumov 1967, Johnson et. al. 2000, Presley 2000, McDonald 2002, Wilson y Mittermeier 2009). Bajo ciertas condiciones, muchos guloninos pueden depredar sobre carcasas o presas mucho más grandes que ellos mismos: se ha registrado a martas, como $M$. flavigula, cazando pequeños cérvidos como el almizclero (Moschus sp.) o incluso el wapití (Cervus canadensis; Heptner y Naumov, 1967), a Eira cazando corzuelas (Cabrera y Yepes 1940), y a Gulo cazando ungulados de todo tipo, incluso matando caribúes atorados en nevadas (Heptner y Naumov 1967, Pasitschniak-Arts y Larivière 1995). Aunque los guloninos se diferencian de los hurones por la mayor diversidad de ítems en la dieta y su menor grado de especialización a la hipercarnivoría, este linaje, así como otros linajes mustélidos, recurre una misma estrategia de caza, que puede ser considerada común a todos los mustélidos (más allá de variantes propias de cada linaje), en donde el depredador se ubica sobre la presa y sujeta a la misma con sus miembros anteriores, mordiendo la región occipital (Ewer 1973, Rowe-rowe 1978 y citas allí; ver también sección 6.1.2). Los guloninos son típicos de ambientes arbolados (Cabrera y Yepes 1940, Emmons, 1990). Tanto la tayra como la mayoría de las martas son excelentes trepadores, puede correr por las ramas y bajar por los troncos cabeza abajo, y usar su larga cola como balancín (Kaufmann y Kaufmann 1965, Heptner y Naumov 1967, Emmons 1990, Presley 2000).

Las martas (desde 500 gr. a hasta 6 kg.; Johnson et. al. 2000, Powell et al. 2003, Jones et al. 2009) incluyen a las especies Ma. americana, Ma. flavigula, Ma. foina, Ma. gwatkinsii, 
Ma. martes, Ma. melampus, Ma. pennanti y Ma. zibellina. Se desplazan ágilmente y algunas pueden realizar saltos importantes de rama a rama y en tierra (Heptner y Naumov 1967, Powell et al. 2003). Bajando de los árboles, o sujetándose de ramas, pueden rotar los miembros posteriores orientando la palma medialmente, movimiento denominado inversión, mediante el cual los miembros de éste y otros grupos trepadores y arborícolas aseguran un contacto adecuado con el sustrato (Trapp 1972, Taylor 1976, Jenkins y McClearn 1984, Taylor 1989, Heinrich y Rose 1997, Sargis 2002, Heinrich y Houde 2006). Algunas martas (e.g., Ma. martes, Ma. pennanti y Ma. zibellina), no son tan frecuentes trepadoras, prefiriendo el sustrato terrestre (e.g., Heptner y Naumov 1967). Son relativamente buenas nadadoras (Wilson y Mittermeier, 2009). En tierra generalmente no trotan (Dagg 1973, pero ver Flaherty et al. 2014), se desplazan con la espalda arqueada, y mediante galopes o bounding/half-bounding estrictos en algunas especies, utilizando la espalda como propulsor en velocidad (Heptner y Naumov 1967, Dagg 1973, Gambaryan 1974, Leach 1977a, b, Griffin y Gilbert 1993, ver más adelante).

El glotón, Gulo gulo, es un animal de gran tamaño corporal (típicamente de unos $12 \mathrm{~kg}$., registrándose casos de $30 \mathrm{~kg}$.; Johnson et. al. 2000, Jones et al. 2009). Se encuentra adaptado a la caminata sobre nieve (incluso blanda; observado también en algunas martas) y también puede trepar (Heptner y Naumov 1967, Pasitschniak-Arts y Larivière 1995). Se lo considera un viajero terrestre de grandes distancias, y puede nadar (Ondrias 1961). Al contrario de otros guloninos, suele desplazarse también en ambientes abiertos (Heptner y Naumov 1967, Pasitschniak-Arts y Larivière 1995)

La tayra, Eira barbara (de aproximadamente 5 kg.; Johnson et. al. 2000, Presley 2000, Jones et al. 2009), es el único gulonino centro- y sudamericano. Es un animal trepador frecuente, pasando gran parte del tiempo en los árboles, donde se mueve con gran soltura, y realiza acrobacias (Cabrera y Yepes, 1940, Kaufmann y Kaufmann 1965, Kavanau 1971, Emmons 1990, Presley 2000, Dionisios Youlatos comunicación personal). Evita nadar y eventualmente cava (Kaufmann y Kaufmann 1965, Presley 2000); también se desplaza con destreza en tierra, en donde corre trotando y usando un galope que tiende o es similar al bounding, arqueando su espalda en estos pasos (Kaufmann y Kaufmann 1965, Dagg 1973, Presley 2000). Suele pararse en sus patas posteriores para explorar (Kaufmann y Kaufmann 1965). Eira barbara, en vez de emboscar, persigue activamente a sus presas por tierra y árboles, pudiendo ayudarse a retener con sus patas, pero sin manipular mucho, a sus presas, y puede desplazarse grandes distancias (Kaufmann y Kaufmann 1965, Presley 2000).

\subsubsection{Tejón-turones (Subfamilia Helictidinae)}

La Subfamilia Helictidinae, incluye a los tejón-hurones del género Melogale (Melo. everetti, Melo. moschata, Melo. orientalis y Melo. personata), animales de entre 0,8 y $3 \mathrm{~kg}$., que 
habitan los bosques tropicales, pastizales y áreas cultivadas del sudeste asiático (Johnson et al. 2000, Wilson y Mittermeier 2009). Son animales principalmente terrestres, pero pueden trepar, a veces ágilmente (Storz y Wozencraft 1999, Wilson y Mittermeier 2009). Ha sido descripto, para varias de sus especies, que cavan con sus miembros anteriores y se ayudan con el hocico para construir sus madrigueras, en general modificando otras preexistentes, así como para buscar su alimento (Storz y Wozencraft 1999, Egi 2001, Wilson y Mittermeier 2009). Consumen insectos, raíces y gusanos, así como también pequeños vertebrados y frutos (Storz y Wozencraft 1999, Wilson y Mittermeier 2009).

\subsubsection{Hurones mustelinos (Subfamilia Mustelinae)}

La Subfamilia Mustelinae es la Subfamilia más rica y cosmopolita a nivel especie dentro de Mustelidae (King y Powell 2007), que incluye a los hurones, compuesta por los géneros Mustela y Neovison (este último integrado únicamente por $N$. vison, a veces incluido dentro de Mustela; Harding y Smith 2009). Mustela incluye a las especies Mu. africana, Mu. altaica, Mu. erminea, Mu. eversmanni, Mu. felipei, Mu. frenata, Mu. itatsi, Mu. kathiah, Mu. lutreola, Mu. lutreolina, Mu. nigripes, $M u$. nivalis, $M u$. nudipes, $M u$. putorius, $M u$. sibirica, $M u$. strigidorsa y Mu. subpalmata, variando en peso desde menos de 100 gr. (e.g., Mu. nivalis) a aproximadamente $3 \mathrm{~kg}$ (e.g., Mu. frenata). Son animales marcadamente dimórficos en lo que respecta a tamaño corporal, especialmente en las especies de menor tamaño (Sheffield y King, 1994, Johnson et. al. 2000, Jones et al. 2009, Wilson y Mittermeier 2009). Muchos hurones suelen trepar, aunque no se encuentran especializados en la locomoción en este sustrato (Coues 1877, Heptner y Naumov 1967, Shieffield y King 1994, Wilson y Mittermeier 2009).

Los hurones se encuentran especializados en cazar a roedores y lagomorfos en sus madrigueras, por lo cual frecuentan sus galerías, aunque no son buenos cavadores, rara vez lo hacen y en general sólo modificando túneles preexistentes (Ondrias 1961, Heptner y Naumov 1967, King 1989, Emmons 1990, Zielinski 2000, Wilson y Mittermeier 2009, Horner y Biknevicius 2010). Mustela nigripes es el hurón más especializado en este sentido (Holmes 1980, Vargas y Anderson 1998, Zielinski 2000). Muchos hurones del género Mustela (así como también ocurre en algunos ictoniquinos como Galictis), depredan frecuentemente sobre presas mayores que ellos mismas (Hall 1951, King y Powell 2007). Tanto los hurones mustelinos como los hurones ictoniquinos comparten un gran número de rasgos ecológicos, comportamentales y morfológicos relacionados a especializaciones a la caza de roedores (así como lagomorfos y topos) mediante la persecución en las galerías de sus presas (Ewer 1973, King y Powell 2007, Schutz y Guralnick 2007, Wilson y Mittermeier 2009). A la técnica de caza típica de los mustélidos, se suman variantes comportamentales y del modo de killing bite no presentes en otros linajes, en relación a la aproximación, dominación y muerte de presas de 
gran tamaño o agresivas (Rowe-rowe 1978, Ben-David et al. 1991, Ewer 1973, King 1989, Vargas and Anderson 1998, King y Powell 2007; ver una explicación más detallada en sección 6.1.2). Algunas especies de hurones de ambas subfamilias se encuentran especializadas en dominar a sus presas enrollándose y desestabilizando a las mismas mediante giros, propiciando mordidas en la zona del cuello y frecuentemente más precisas en la zona de la tráquea; mientras que otras utilizan estrategias más similares a las descriptas para otros mustélidos, sujetando o presionando a las presas contra el suelo mientras son mordidas desde arriba en forma menos precisa, generalmente en la región occipital o cuello (Goethe 1964, Ewer 1973, Rowe-rowe 1978, Ben-David et al. 1991, Wilson y Mittermeier 2009).

Los hurones poseen patas muy cortas y cuerpos alargados, y pueden mantenerse parados sobre las patas posteriores (Dagg 1973, Emmons 1990, King y Powell 2007). Al desplazarse en túneles, los hurones poner recto y estiran su tronco para minimizar la altura del cuerpo, mientras que llevan la espalda curvada al desplazarse sobre tierra para minimizar el torque sobre las cinturas (Dagg 1973, Horner y Biknevicius 2010, Fig. 1.3). No suelen trotar (aunque fue descripto para $\mathrm{Mu}$. putorius; Horner y Biknevicius 2010), prefiriendo el galope (aunque no todas las especies; Heptner y Naumov 1967, Dagg 1973), pero cuando se desplazan a mayor velocidad, utilizan un paso denominado half-bounding, un galope sinuoso en el que los miembros posteriores se encuentran sincronizados, o eventualmente bounding, cuando lo mismo ocurre además para los miembros anteriores (Hall 1951, Heptner y Naumov 1967, Dagg 1973, Gambaryan 1974, Hildebrand 1977, Williams 1983a, b, Lodé 1999, Williams et al. 2002, Schutz y Guralnick 2007). La espalda, y secundariamente los miembros posteriores, participa activamente en la propulsión en la carrera; mientras que los miembros anteriores son amortiguadores del impacto luego de la fase flotante más que propulsores (Schutz y Guralnick 2007, Gambaryan 1974, Hildebrand 1977, Ercoli y Schutz 2012); pueden realizar rápidos cambios de dirección (Heptner y Naumov 1967, Gambaryan 1974).

Muchos hurones pueden nadar bien, y algunos presentan hábitos íntimamente asociados al agua, como el visón europeo ( $M u$. lutreola) y el americano ( $M u$. vison), nadando frecuentemente en la superficie. Mustela vison es el más especializado de los dos, aunque ambos bucean para capturar presas, aunque sin utilizar la cola como propulsor (Heptner y Naumov 1967, Williams 1983a, Fish 1994, 2000, Lodé 1999, Wilson y Mittermeier 2009). Estas especies nunca se alejan a muchos metros del curso de agua (Heptner y Naumov 1967, Wilson y Mittermeier 2009), y es más frecuente el cavado de túneles y madrigueras ribereñas en comparación con otros hurones (Heptner y Naumov 1967, Wilson y Mittermeier 2009), al punto que se ha descripto a Mu. vison entrando a túneles de roedores semi-acuáticos (Hutchins 2003).

Las especies presentes en América del Sur son: Mu. frenata, desde el norte de América del Norte hasta Bolivia y otras dos especies restringidas al norte de América del Sur: Mu. felipei 
у Mu. africana. Mustela africana, de aproximadamente 500 gr. (Jones et al. 2009), es una especie que habita selvas lluviosas de tierras bajas (Emmons 1990), vive en zonas ribereñas, nada bien y frecuentemente, $\mathrm{y}$ en función de que posee pies con plantas peladas y con membranas interdigitales extensas, se infiere que probablemente posea hábitos similares a los del visón, aunque también sería un predador de galería de roedores (Cabrera y Yepes 1940, Izor y de la Torre 1978). Mustela felipei, de aproximadamente 200 gr. (Jones et al. 2009), al igual que la anterior es una especie muy poco estudiada. Se han inferido hábitos similares a la anterior, pero algunos autores dicen que prefiere zonas selváticas de alta montaña, y que las membranas pueden explicarse por la anegación del terreno donde viven (Ramírez-Chaves y Mantilla-Meluk, 2009, Ramírez-Chaves y Patterson 2014).

Mustela frenata, distribuida en el continente americano, posee un tamaño similar a la anterior (Johnson et al. 2000), y tanto en sus hábitos como en sus estilos locomotores, es muy similar a otros hurones (Hall 1951, Emmons 1990, Vargas y Anderson 1998).

\subsubsection{Nutrias (Subfamilia Lutrinae)}

La subfamilia Lutrinae incluye a las nutrias de río y marina. Todos los representantes de este grupo se encuentran especializados, en menor o mayor grado, a vivir en el agua y moverse en este medio; son animales sociales, gregarios, y en algunos casos cazan en grupo (Kruuk 2006, Wilson y Mittermeier 2009). En general, aunque muchas especies suelen consumir a las presas grandes en la costa, las nutrias cazan a la mayoría de sus presas dentro de cursos de agua (Kruuk 2006, Wilson y Mittermeier 2009), por lo cual la dinámica de caza es diferente a la de los mustélidos terrestres, existiendo casos de caza cooperativa. En todos los casos puede destacarse una importante participación de los miembros anteriores en la caza y alimentación (Howard 1973, Kruuk 2006, Wilson y Mittermeier 2009).

El género Aonyx (Ao. capensis, Ao. cinerea y Ao. congicus) incluye especies de 2 a 25 kg., que viven en terrenos inundados, ríos y arroyos, poco especializados al nado, moviéndose frecuentemente y descansando sobre tierra (Fish, 2000, Larivière 2001a, Wilson y Mittermeier 2009). Consiguen su alimento (cangrejos, insectos, gusanos, anuros y peces entre otros) tanteando en el fango, en la vegetación o entre las rocas, y lo retienen con sus miembros anteriores, teniendo dígitos sensitivos y reducción de membrana interdigital en relación a estos hábitos (Willemsen 1980a, b, Kruuk 2006, Wilson y Mittermeier 2009).

Los géneros Hydrictis (H. maculicollis), Lontra (Lo. canadensis, Lo. felina, Lo. longicaudis y Lo. provocax), Lutrogale (Lutro. perspicillata) y Lutra (Lu. lutra, Lu. nippon y Lu. sumatrana), incluyen especies de entre 3,5 y 8,5 kg., son acuáticos relativamente más especializados, y realizan nado tipo padding (pataleo) o buceo, extendiendo hacia atrás ambos pares de miembros, coordinando miembros posteriores, ondulaciones de cuerpo y cola; sin 
embargo, pasan la mayor parte del tiempo sobre la línea costera (Fish, 1994, 1996, Williams et al. 2002, Peigné et al. 2008, Jones et al. 2009). Lutra nippon se considera actualmente extinta (Sato et al. 2012). En general, son cazadores activos que suelen perseguir o embestir a los peces en nado (Cabrera y Yepes 1940, Fish 1994, Larivière 1998, 1999). Las especies de Lontra prefieren peces pequeños y lentos, y suelen ayudarse con las manos, mientras que Lutra e Hydrictis suelen depredar también sobre peces grandes, tomándolos directamente con sus bocas (Larivière 2002b, Heptner y Naumov 1967, Larivière y Walton 1998, Kruuk 2006).

Enhydra lutris, de entre 15 y $45 \mathrm{~kg}$. (Estes 1980) es el mayor de los mustélidos, y la nutria más especializada en vivir en el agua, específicamente marina, rara vez se encuentra en tierra, dónde sólo puede desplazarse con un paso torpe (Kirkpatrick et al. 1955, Heptner y Naumov 1967, Williams 1989, Peigné et al. 2008). Al contrario de otras nutrias, no utiliza ni los miembros anteriores ni la cola como principales propulsores en el nado, usando los miembros posteriores o simplemente movimientos ondulatorios corporales (Holmes 1980, Williams 1989, Lewis 2008, Peigné et al. 2008, pero ver Tarasoff 1972). Caza bivalvos y erizos por tacto, y tomándolos con sus miembros anteriores, a veces directamente con la boca; también puede depredar sobre peces (Heptner y Naumov 1967, Estes 1980, Kruuk 2006), Se alimenta flotando de espaldas en la superficie del mar, utilizando sus miembros anteriores para sujetar sus presas, y frecuentemente utilizando herramientas para procesarlos (Heptner y Naumov 1967, Howard 1973, Williams 1989). Durante este comportamiento, las nutrias marinas suelen ayudarse para el procesamiento de sus presas ubicando un objeto duro (e.g., roca) en su pecho, y golpeándolas repetidas veces sobre este objeto con el fin de romper las partes duras (Heptner y Naumov 1967, Wilson y Mittermeier 2009).

Según los datos publicados, los pasos utilizados por los lutrinos en tierra cuando se desplazan a alta velocidad suelen ser de tipo bound (e.g., Enhydra, Pteronura, Lutra, Lontra, Lutrogale; Heptner y Naumov 1967, Dagg 1973, Willemsen 1980b, Williams et al. 2002), o de tipo half-bound, (e.g., Lontra, Lutrogale; Hildebrand 1977, Willemsen 1980b, Williams et al. 2002, Larivière y Walton 1998), más que un galope estricto (pero ver también Kirkpatrick 1955, Dagg 1973); con una fase aérea reducida o incluso ausente (e.g., Williams et al. 2002).

En lo que respecta a las especies sudamericanas, Lo. felina (el chungungo), al contrario de otras nutrias (exceptuando Enhydra lutris), prefiere costas marinas rocosas, desplazándose frecuentemente y trepando entre rocas y grietas en búsqueda de comida, y pueden nadar de espalda (Larivière 1998). Suelen depredar sobre peces y en gran medida sobre crustáceos que captura al nado, pero los lleva a la costa para comerlos (Cabrera y Yepes 1940, Wilson y Mittermeier 2009). Lontra sp. se distribuye desde el norte de Canadá hasta el sur de Chile y Argentina y cuenta con tres especies en América del Sur: Lo. felina (desde la costa de Perú hasta Tierra del Fuego), Lo. longicaudis (desde el sur de México hasta Uruguay y Buenos Aires), y 
Lo. provocax (sur de Chile y Argentina). El género monotípico de nutrias Pteronura (Pt. brasiliensis) se encuentra en América del Sur desde Colombia hasta el noreste de Argentina (Wilson y Reeder 2005, Prevosti y Ferrero 2008).

El lobito de río, Lo. longicaudis, prefiere ríos y arroyos rápidos y claros, con vegetación ribereña (Larivière, 1999). Suele cazar los peces en la vegetación costera, prefiere peces pequeños y lentos, y otros ítems que obtiene de forma oportunista (e.g., mamíferos, aves, insectos; Pardini 1998, Larivière 1999, Kruuk, 2006, Wilson y Mittermeier 2009).

Lontra provocax (el huillín) habita principalmente ambientes de agua dulce como ríos, lagos y esteros, y cuando se encuentra en zona de aguas oceánicas y playas rocosas, siempre lo es cerca de una fuente de agua dulce (Cabrera y Yepes 1940, Kruuk 2006, Wilson y Mittermeier 2009).

Pteronura brasiliensis, llamada nutria gigante por su tamaño corporal (aproximadamente $25 \mathrm{~kg}$.), presenta hábitos similares a las otras especies sudamericanas, aunque se diferencia de ellas porque utiliza en mayor medida la cola como principal propulsor (Fish 1994, Peigné et al. 2008), y por cazar peces de mayor tamaño, frecuentemente rápidos, a los que persiguen y atrapan con sus manos, así como también a veces grandes reptiles (i.e., caimanes; Cabrera y Yepes 1940, Emmons 1990, Kruuk 2006).

\subsubsection{Zorrillas y hurones ictoniquinos (Subfamilia Ictonychinae)}

La Subfamilia Ictonychinae está integrada por especies terrestres, muchas cavadoras, y algunas de ellas especialistas en depredar sobre roedores en galerías (similar a Mustelinae), presentan coloración aposemática combinada con comportamientos defensivos que incluyen exhibiciones y secreciones penetrantes de glándulas anales agrandas (Cabrera y Yepes 1940, Larivière 2001b, 2002a, Gorsuch y Larivière 2005, Koepfli et al. 2008, Caro 2009, Wilson y Mittermeier 2009). Las especies dentro de esta subfamilia utilizan en gran medida el olfato para ubicar a sus presas, y varían desde omnívoros (e.g., Ictonyx striatus) a hipercarnívoros (Lyncodon patagonicus) (Johnson et. al. 2000, Wilson y Mittermeier 2009).

El género Ictonyx se encuentra representado por las especies I. libyca (de 200 a 600 gr.; Wilson y Mittermeier 2009), e I. striatus (1,3 a 1,8 kg.; Johnson et al. 2000), aunque estudios recientes (e.g., Sato et al. 2012) ha sugerido reservar este género exclusivamente para I. striatus, y utilizar el género Poecilictis para la zorrilla líbica. Otros taxones del grupo son Poecilogale albinucha, de pequeño tamaño (200 a 500 gr.; Johnson et. al. 2000, Wilson y Mittermeier 2009) y Vormela peregusna, (300 a 700 gr.; Johnson et. al. 2000, Gorsuch y Larivière 2005), ambos son predadores voraces, y únicos representantes de sus géneros. Todos son activos cavadores de zonas abiertas, arbustivas o sabanas (Larivière 2001b, 2002a, Gorsuch y Larivière 2005, Wilson y Mittermeier 2009), frecuentes cazadores de roedores pero no estrictos. Ictonyx (al menos para 
el caso de I. striatus), es el menos hipercarnívoro, suele cazar roedores en superficie o escarbando sus guaridas, y sólo persigue mamíferos grandes dentro de sus madrigueras (Michener y Iwaniuk 2001, Larivière 2002a, Wilson y Mittermeier 2009); en su apariencia, hábitos y comportamientos puede considerarse en muchos aspectos convergente con los zorrinos. Además del típico comportamiento aposemático, se ha registrado un andar rápido similar al trote de los zorrinos, y son capaces de nadar y trepar eventualmente (Larivière 2002a, Caro 2009). Por otro lado, Poecilogale albinucha y V. peregusna, de proporciones corporales más similares a los hurones mustelinos, son especialistas en cazar roedores en túneles, incluso a aquellos de tamaño corporal mayor que el suyo, aunque suelen incluir otros ítems en su dieta (Rowe-rowe 1978, Johnson et. al. 2000, Larivière 2001b, 2002a, Wilson y Mittermeier 2009). Estas especies suelen pararse sobre las patas posteriores para vigilar y pueden caminar con el cuerpo estirado o arqueado, mientras que la carrera la realizan moviendo y arqueando la espalda en un estilo de galope de tipo bounding (Heptner y Naumov 1967, Larivière 2001b).

Existen dos géneros y tres especies en América del sur de esta subfamilia: Lyncodon patagonicus (el huroncito patagónico), Galictis cuja (el hurón menor) y Galictis vittata (el hurón mayor), estos últimos dos también denominados frecuentemente como grisones. Todos ellos poseen patas cortas y se especializan en mayor o menor grado en la depredación sobre roedores, siendo mayormente terrestres. Galictis presenta una distribución que abarca desde el sur de México hasta el sur de Argentina (Bornholdt et al. 2013; y en el sur de esta distribución se encuentran todos los registros fósiles del género, ver Soibelzon y Prevosti 2012; ver más adelante). Lyncodon presenta una distribución que incluye el oeste y sur de Argentina y sur de Chile.

Galictis spp. (grisones) suelen cavar pero no se encuentran marcadamente especializados en esta actividad. Aunque hay cierto desacuerdo en la bibliografía disponible en lo que respecta al grado de especialización al cavado de la especie, pueden cavar sus propias madrigueras (lo cual es más frecuente en Ga. cuja que en Ga. vittata), aunque otras veces modifican o utilizan otras preexistentes (Kaufmann y Kaufmann 1965, Yensen y Tarifa 2003a, Wilson y Mittermeier 2009). Parecen no utilizar tanto este recurso para conseguir a sus presas, las que persiguen tanto dentro de sus madrigueras como sobre tierra. Pueden desplazarse muy bien en el agua (y suele encontrarse cerca de ella), y pocas veces trepan (Azara 1802, Cabrera y Yepes 1940, Yensen y Tarifa 2003a, b). Existen registros en cautiverio y vida silvestre que revelan gran afinidad y destreza de los grisones en el agua, nadando en superficie, realizando inmersiones (Ga. cuja: Aldo Vassallo comunicación personal, observaciones personales), e incluso realizando giros cerrados y buceando en distintas posiciones manteniendo la respiración durante al menos 30 segundos (Ga. vittata: Dalquest y Harvey 1951). Las especies de Galictis se desplazan mediante caminatas o trotes con la espalda en general estirada (Dücker 1968, 
Kaufmann y Kaufmann 1965, Kavanau 1971, Yensen y Tarifa 2003a, b), pero en velocidad se han descripto carreras asimétricas (para Ga. cuja; Dücker 1968), o carreras con pequeños saltos y espalda arqueada (para Ga. vittata; Yensen y Tarifa, 2003b), se pueden referir estas descripciones a galopes similares al half-bounding o al bounding (respaldado por observaciones personales). Utilizan su musculoso y elongado cuello para inspeccionar grietas y túneles, así como para elevar la cabeza por sobre la línea de vegetación pudiendo, al menos en el caso de Ga. cuja, pararse en los miembros posteriores para esto (Azara 1802, Cabrera y Yepes 1940, Kaufmann y Kaufmann 1965). Roedores y lagomorfos conforman la mayor parte de su dieta (Yensen y Tarifa 2003a, 2003b, Wilson y Mittermeier 2009). Ambas especies habitan una gran diversidad de ambientes, pero Ga. cuja puede encontrarse en ambientes áridos en los cuales Ga. vittata no habita (Wilson y Mittermeier 2009).

Galictis cuja pesa entre 1 y 2,5 kg. (Yensen y Tarifa 2003a, Wilson y Mittermeier 2009), y explora frecuentemente cuevas de roedores pequeños, incluyendo cuises (Yensen y Tarifa 2003a, Wilson y Mittermeier 2009). Galictis vittata, pesa entre 1,8 y 3,4 kg. (Emmons, 1990, Johnson et al. 2000), y explora cuevas de roedores relativamente grandes, como los agutíes y cuises de las rocas (Kaufmann y Kaufmann 1965, Yensen y Tarifa 2003b).

Lyncodon patagonicus, de entre 200 y 250 gr., es una de las especies de mustélidos menos conocidas (Wilson y Mittermeier 2009). Habita en lugares áridos o semi-áridos (Prevosti y Pardiñas 2001, Wilson y Mittermeier 2009, Schiaffini et al. 2013). Su comportamiento no ha sido estudiado, y sólo se sabe que frecuenta cuevas y es un feroz cazador de roedores fosoriales como los tuco-tucos (Cabrera y Yepes 1940, Cicchino y Castro 1998, Teta et al. 2008, Wilson y Mittermeier 2009). Doering (1881) y Koslowsky (1904) son unos de los pocos investigadores que han aportado datos sobre el comportamiento de la especie, y de estos autores provienen los únicos comentarios relacionados a las estrategias locomotoras y de defensa, indicando marchas ágiles y gran agresividad. Se han inferido hábitos dietarios carnívoros, probablemente hipercarnívoros (Cabrera y Yepes 1940). En función del mayor desarrollo de las membranas interdigitales de los miembros anteriores y de sus garras alargadas y estrechas, Pocock (1921) y Cabrera y Yepes (1940) infirieron probables habilidades de excavación para la especie.

\subsection{Antecedentes paleontológicos}

Los registros fósiles de mustélidos son relativamente escasos, y especialmente los restos postcraneales. Entre los factores que pueden relacionarse a este hecho, se encuentra que son usualmente pequeños, presentan poblaciones con baja densidad, y suelen preferir ambientes forestados (Baskin 1998), en los cuales las características tafonómicas de los mismos dificultan la preservación de los restos. 
Los primeros restos fósiles de mustélidos provienen del Eoceno-Oligoceno, de Asia y América del Norte (Koepfli et al. 2008, Sato et al. 2012). Entre los miembros más primitivos reconocidos para la Familia se encuentran ${ }^{\dagger}$ Mustelavus y ${ }^{\dagger}$ Mustelictis, representantes de la extinta Subfamilia Mustelavinae del Nuevo y Viejo Mundo respectivamente (Baskin 1998).

La historia biogeográfica del grupo es compleja, miembros de la Familia Mustelidae participaron de repetidos de intercambios entre el viejo continente y América del Norte, en donde se registraron un gran número de Subfamilias extintas (e.g., Oligobuninae, Leptarctinae; Baskin, 1998). Recién en el Mioceno Temprano se diversificaron marcadamente e invaden África, y se estima a éste como el periodo de origen del crown group (Hunt 1996, Sato et al. 2012). Los ancestros de los linajes sudamericanos arribaron a América del Sur desde América del Norte a partir del Plioceno Tardío, durante el Gran Intercambio Biótico Americano (Reig 1957, Hunt 1996, Soibelzon y Prevosti 2007, Prevosti y Soibelzon 2012, Soibelzon y Prevosti 2012), en donde representantes de las Subfamilias Ictonychinae, Guloninae y Lutrinae invadieron América del Sur en al menos cinco oleadas independientes (representados por Lontra spp., Pt. brasiliensis, los hurones ictoniquinos, los hurones mustelinos y un único gulonino; Hunt 1996, Soibelzon y Prevosti 2007, Prevosti y Ferrero 2008, Eizirik 2012, Soibelzon y Prevosti 2012).

Los mustélidos sudamericanos se registran a partir del Vorohuense (Marplatense; Reig 1957; Cione y Tonni 2005; Soibelzon y Prevosti 2007) hasta la actualidad, y comprenden los géneros: Galictis, Lyncodon y ${ }^{\dagger}$ Stipanicicia, pertenecientes a la Subfamilia Ictonychinae (tribu Lyncodontini); Mustela, de la Subfamilia Mustelinae, Eira de la Subfamilia Guloninae, y Lontra y Pteronura de la Subfamilia Lutrinae (Reig 1956, Sato et al. 2012, Prevosti y Soibelzon 2012, Soibelzon y Prevosti 2012).

Según los estudios filogenéticos y paleobiogeográficos de Koepfli et al. (2008) y Sato et al. (2012), los primeros Ictonychinae se habrían originado probablemente en Asia durante el Mioceno Tardío temprano (9,5-8,9 Ma.), conclusión similar a la arribada previamente por paleontólogos sobre la base del análisis morfológico de especies del Viejo Mundo (e.g., ${ }^{\dagger}$ Trochictis, ${ }^{\dagger}$ Enhydrictis; Pilgrim 1932, Reig 1956, 1957, Björk 1970). Uno de los primeros fósiles de Ictonychinae conocidos es ‘“Baranogale” adroveri, del Mioceno Tardío de Eurasia (Petter 1964). Los mismos habrían ingresado tempranamente a América del Norte (durante el Mioceno Tardío, e.g., ${ }^{\dagger}$ Cernictis hesperus, Baskin 1998), y a África (durante la crisis del Messiniense, en la transición Mioceno-Plioceno). Entre los 2,9 y 2,6 Ma. (Plioceno), inmediatamente después de la formación del estrecho de Panamá, se habrían diferenciado dentro de América del Sur los Ictonychinae sudamericanos (Tribu Lyncodontini; Sato et al. 2012), periodo en el cual se registran también los primeros representantes del clado presentes en América del Sur (i.e., 'Ga. sorgentinii, Subedad Vorohuense, 3,0-2,4 Ma.; Cione y Tonni 2005, 
Woodburne et al. 2006, Sato et al. 2012, Soibelzon y Prevosti 2012), y formas afines del sur de América del Norte $\left(^{\dagger}\right.$ Trigonictis cookii, ${ }^{\dagger}$ Trigonictis macrodon y ${ }^{\dagger}$ Sminthosinis bowleri; Björk 1970). Reig (1957) propuso un origen del linaje Trigonictis-Galictis (lo que comprendería actualmente a Tribu Lyncodontini) en América del Norte, y una posterior circunscripción de su distribución al sur de América del Norte, América Central y del Sur, en relación a cambios climáticos y a la formación del puente terrestre entre las Américas.

En América del Norte, existe en el registro paleontológico del Plioceno (principalmente durante el Blanquense) varios grison-like (i.e., con morfologías similares a los grisones actuales): ${ }^{\dagger}$ Trigonictis macrodon (idahoensis) de mayor tamaño (similar a una marta) habría depredado sobre ardillas terrestres y lagomorfos (Björk 1970, Kurtén y Anderson 1980) y ${ }^{\dagger}$ Trigonictis cookii, un tercio menor que la especie cogenérica, y similar en tamaño aunque con huesos largos más gráciles que Ga. vittata (especie con la cual se ha relacionado estrechamente). Se ha demostrado para ambas especies la presencia de dimorfismo sexual por tamaño (Björk 1970, Baskin 1998). Las proporciones y robustez de los huesos largos, desarrollo del olécranon y trocánteres, entre otros procesos, llevaron a Björk (1970) a concluir capacidades locomotoras trepadoras y nadadoras en ${ }^{\dagger}$ Trigonictis, siendo ${ }^{\dagger} T r$. cookii destacada en este último tipo locomotor, siendo mejor nadador que Galictis. En función de la morfología cráneodentaria, tamaño y fauna asociada, habría depredado sobre roedores microtinos, presas más pequeñas que ${ }^{\dagger}$ Trigonictis macrodon (Björk 1970, Kurtén y Anderson 1980). Según Schutz y Guralnick (2007), tanto la forma como el tamaño de los elementos postcraneales de estas especies son coincidentes con un estilo locomotor generalizado, half-bound y trepado (pero no fuertemente relacionado a la natación o fosorialidad). Björk (1970) describió otro galictino, ${ }^{\dagger}$ Sminthosinus bowleri, relacionado a los géneros anteriores, y más estrechamente con Ga. cuja, el cual al parecer reemplazó ecológicamente a ${ }^{\dagger}$ Trigonictis cookii; y habría vivido en cercanías de cursos de agua y pantanos. En función de su morfología cráneodentaria, fauna asociada y tamaño, habría sido un cazador especializado de roedores microtinos. Por último, ${ }^{\dagger}$ Canimartes cumminsi fue un ictoniquino, también de América del Norte, pero poco conocido y de afinidades inciertas (Kurtén y Anderson 1980).

${ }^{\dagger}$ Galictis sorgentinii del Vorohuense (Marplatense, Plioceno Tardío; Berman 1994, Cione y Tonni 2005), descripto por Reig (1957), corresponde a un fragmento de mandíbula incompleto. Este fósil proviene de la costa atlántica del partido de General Pueyrredón, sudeste de la provincia de Buenos Aires, Formación Vorohué, en ese entonces considerada como Pleistoceno Temprano, y representa el registro más temprano de los Ictonychinae sudamericanos (Cione y Tonni 2005, Cione et al. 2007, Soibelzon y Prevosti 2007, Soibelzon y Prevosti 2012, pero ver también Verzi y Montalvo 2008, Prevosti y Pardiñas 2009). Dentro de la diagnosis de la especie, Reig (1957) destaca la rama horizontal baja, un p2 biradiculado, 
premolares de disposición oblicua, y un margen anterior de la fosa masetérica alcanzando la altura del talónido del $\mathrm{m} 1$, muchas de estas características compartidas con ictoniquinos norteamericanos y del Viejo Mundo pero no presentes en los representantes sudamericanos pleistocénicos (Gazin 1934, Reig 1957, Björk 1970, Berman 1994). La presencia del metacónido en el molar carnicero lo relaciona más estrechamente a Ga. vittata que con Ga. cuja (Reig 1957, Bornholdt et al. 2013).

Otro registro asignable al Plioceno Tardío es el de un Galictis sp. (†Ga. "sanandresensis"; Berman 1994; material perdido, Francisco J. Prevosti comunicación personal), proveniente del partido General Pueyrredón, provincia de Buenos Aires, Formación San Andrés, Subedad Sanandrense (Berman 1994 Soibelzon y Prevosti 2007, 2012). El material, ¿ una mandíbula descripta en la tesis de Berman (1994), es destacado en su diagnosis como marcadamente grácil, recta y alta, talónido expandido, p2 oblicuo y biradiculado (estos últimos rasgos similares a los de ${ }^{\dagger} G a$. sorgentinii) y un reborde inferior (presente en otros lincodontininos) delgado (contrario a ${ }^{\dagger} G a$. sorgentinii), que sugieren una dieta carnívora menos estricta (Berman 1994).

${ }^{\dagger}$ Galictis hennigi del Ensenadense (Pleistoceno; Berman 1994, Cione y Tonni 2005, material perdido, Francisco J. Prevosti comunicación personal), descripto por Rusconi (1932), corresponde a un fragmento de mandíbula incompleto, proveniente de la localidad de Olivos de la provincia de Buenos Aires, Edad Ensenadense. Este resto, que incluye sólo el m1 y el alvéolo del $\mathrm{m} 2$, es lo único conocido para la especie; y en su diagnosis se destaca un proceso "aliforme" en el borde inferior de la mandíbula y una fosa masetérica profunda. Esta especie se encontraría más estrechamente relacionada a Ga. cuja que a Ga. vittata (Reig 1957).

Registros más modernos de Argentina, Chile, Bolivia y Brasil (e.g., Pleistoceno de Brasil, Holoceno), incluyen restos de Ga. cuja y Ga. vittata tanto en marcos paleontológicos como arqueológicos (Lund 1842, Berman 1994, Berta y Marshall 1978, Quintana 2001, Prevosti y Pardiñas 2001, Yensen y Tarifa 2003a, b, Cartelle y Hirooka 2005, Soibelzon y Prevosti 2007, 2012, Prevosti y Soibelzon 2012).

${ }^{\dagger}$ Lyncodon bosei, especie descripta por Pascual (1958), corresponde a una mandíbula y cráneo casi completo colectado sobre el margen costero entre las localidades Olivos y Anchorena, Buenos Aires, de depósitos correspondientes a la Edad Ensenadense (Pleistoceno, Pascual 1958, Cione y Tonni 2005). Dentro de la diagnosis de la especie, Pascual (1958) destaca, más allá de un gran número de similitudes con Ly. patagonicus, diferencias importantes, como la presencia de p2, P2 y m2 vestigial, y algunos cambios en las proporciones del P4. Pascual propone en este trabajo a ${ }^{\dagger} L y$. bosei como cercano al linaje que dio origen a $L y$. patagonicus, y a Lyncodon más estrechamente relacionado a Galictis que a mustelinos. 
Respecto a Ly. patagonicus, los restos craneanos y mandibulares descriptos por Ameghino (1888) como pertenecientes a Ly. "lujanensis", colectados en el partido de San Cayetano, Buenos Aires, corresponderían en realidad a la especie viviente según lo descripto por Cabrera (1929; ver también Pascual 1958, Berman 1994). Estos restos representarían el registro más antiguo del taxón, junto con un fragmento de mandíbula proveniente de Córdoba, también descripto por Ameghino (1888). Pese a que estos materiales fueron asignados en trabajos previos al Bonaerense (Pleistoceno Tardío, Cione y Tonni 2005), otros trabajos indican que no hay registros certeros de la especie en depósitos anteriores al Lujanense (Prevosti y Pardiñas 2001, Soibelzon y Prevosti 2012, Prevosti y Soibelzon 2012, Schiaffini et al. 2013). Prevosti y Pardiñas (2001) también comentan a estos y otros dos registros para el Lujanense, y varios para sitios más del Holoceno de Argentina y Chile, todos ellos piezas mandibulares o craneales (e.g., Politis et al. 1983). Los autores relacionan a las variaciones de la paleodistribución de la especie con los principales cambios climáticos, favoreciéndose una mayor distribución en pulsos áridos.

†Stipanicicia, el único género de mustélidos sudamericanos sin representantes actuales, es monoespecífico (†S. pettorutii; Reig 1956, Berman 1994). Esta especie se encuentra exclusivamente registrada en la Edad Ensenadense de la provincia de Buenos Aires (Argentina) (Prevosti y Pardiñas 2001, Wilson y Reeder 2005, Soibelzon y Prevosti 2007; Prevosti y Soibelzon 2012). Los materiales conocidos provienen de localidades costeras de los partidos de Miramar y Necochea, provincia de Buenos Aires (Reig 1956, Berman 1994). Este mustélido es destacable por la robustez del cráneo y el gran desarrollo de los procesos de inserción muscular (cresta sagital, arcada zigomática, proceso mastoideo), y lo breve y ancho de su hocico y paladar (Reig 1956). Berman (1994), discute estos restos y describe un tercer espécimen, que corresponde a una hemimandíbula incompleta, en principio asignable al género, proveniente de Necochea, y que presenta un metacónido en el m1, similar a la especie viviente Ga. vittata, y las fósiles ${ }^{\dagger} G a$. sorgentini y ${ }^{\dagger} G a$. “sanandresensis”. Según Berman (1994) `Stipanicicia sería un mustélido especializado en hábitos predadores en mayor medida que los grisones actuales.

Mustela, el género de mayor riqueza específica dentro de Mustelidae, posee representantes en todos los continentes habitados por mustélidos (Kurtén y Anderson 1980, Wilson y Mittermeier 2009). Según Hall (1951) y Koepfli et al. (2008), el linaje de Mustela frenata se diferenció probablemente en el Plioceno de América del Norte.

El género Mustela tiene un amplio registro en ese subcontinente, incluyendo tres especies fósiles y seis vivientes (Kurtén y Anderson 1980). Mustela frenata registrada a partir de la Edad Blanquense (Plioceno), en depósitos del Pleistoceno y Holoceno (Kurtén y Anderson 1980, Sheffield y Thomas 1997). La especie ha sido mencionada como posiblemente originada a partir de formas afines norteamericanas (e.g., ${ }^{\dagger} M u$. rexroadensis; Hall 1951, Björk 1970, 
Kurtén y Anderson 1980, Sheffield y Thomas 1997). Hall (1951) propuso que Mu. africana habría sido el resultado de una primera invasión a América del Sur antes de que el estrecho de Panamá se consolidara, mientras que Izor y de la Torre (1978) y Eizirik (2012) consideraron más factible que las especies endémicas de América del Sur habrían divergido posteriormente (probablemente durante el Pleistoceno Temprano), relacionado esto a cambios orográficos y ambientes acuáticos disponibles en el norte de este continente. En lo que respecta al contexto fósil, sólo un único registro de Mustela (probablemente $M$. frenata) es conocido para el Holoceno Medio del Ecuador (Soibelzon y Prevosti 2007). La ausencia de fósiles de esta especie en América del Sur y Central impide algo más que estas aproximaciones.

Eira, con una única especie sudamericana de la Subfamilia Guloninae registrada (E. barbara), se distribuye desde el centro de México hasta el norte de Argentina. Esta especie también presenta algunos restos craneanos y postcraneanos (incluyendo una ulna bien preservada, Lessa et al. 1998) en el registro fósil del Pleistoceno o específicamente del Lujanense de Brasil (Gruta dos Brejões, Municipio Morro do Chapéu, Bahia, Lessa et al. 1998; Lagoa Santa, Cartelle 1999) y restos dudosos del "Ensenadense" de Bolivia (Tarija, Hoffstetter 1963; ver Soilbelzon y Prevosti 2007, 2012). Los registros que alguna vez fueron asignados a este género en América del Norte fueron posteriormente reasignados como pertenecientes a otros musteloideos, y el lugar (cuál subcontinente americano) y momento de origen de la especie está en discusión (ver Presley 2000), aunque Eizirik (2012) opinó que es probable que Eira represente un linaje antiguo, que se habría diferenciado de los restantes representantes de la subfamilia tan tempranamente como en el Mioceno Tardío.

El registro de las nutrias en América del Sur es muy escaso y comienza en el Pleistoceno (Cartelle e Hirooka 2005, Prevosti y Ferrero 2008), aunque los análisis paleobiogeográficos indican que la llegada del linaje de Pt. brasiliensis a América del Sur podría ser mucho más antiguo, y que habría divergido de otros lutrinos vivientes en el Mioceno Tardío (ver Eizirik 2012 contra Willemsen 1992).

El registro más antiguo de lutrinos de América del Sur fue registrado por Rusconi (1932), con la descripción de un fragmento de mandíbula sin dientes perteneciente a la especie Lontra longicaudis, aunque descripta originalmente como una subespecie de "Lo. paranaense", proveniente de sedimentos del Ensenadense, Localidad de Anchorena, provincia de Buenos Aires (Pleistoceno Temprano-Medio, Berman 1994, Soibelzon y Prevosti 2007, Prevosti y Ferrero 2008). Existen también otros registros de esta especie para el Lujanense (Pleistoceno Tardío-Holoceno Temprano) para Argentina y Uruguay, sin destacarse la presencia de restos postcraneales (Ameghino 1889, Berman 1994, Ubilla et al. 2004, Prevosti y Ferrero 2008; Martín Ubilla, comunicación personal). Lessa et al. (1998) y Cartelle e Hirooka (2005, y citas dentro) mencionan el registro de Lo. longicaudis para Bahia y Minas Gerais, Brasil, en 
depósitos pleistocenos; en el registro de Bahia, se recuperaron restos postcraneanos (esqueleto parcial de L. longicaudis; Castor Cartelle, comunicación personal).

Por otro lado, Lund (1842) identificó la presencia de lutrinos, denominándolos "Lutra brasiliensis", en la región de Lagoa Santa (Minas Gerais, Brasil), asignados por Paula Couto (1950) a Pteronura brasiliensis, aunque Winge (1895), revisor que tuvo acceso a los materiales, no concordó con la asignación, indicando que Lund (1842) se refería a Lo. longicaudis y no a Pt. brasiliensis (ver Cartelle e Hirooka 2005).

Existen algunos restos craneanos y postcraneanos de Lo. longicaudis para sitios arqueológicos argentinos, incluyendo los descriptos por Bonomo et al. $(2009,2010)$ y Politis et al. (2011) en varios asentamientos de Entre Ríos (Bonomo et al. 2010; menciona un resto que corresponde a un calcáneo, Mariano Bonomo, comunicación personal y observaciones personales, ver más adelante).

Cartelle e Hirooka (2005) describieron el primer registro seguro de Pteronura brasiliensis para el Pleistoceno Tardío de Brasil, los cuales fueron encontrados en una caverna (Gruta do Curupira, Municipio de Rosário do Oeste). Este registro incluye dientes y un húmero izquierdo, sin mayores diferencias respecto a los materiales comparativos actuales, y dañado en su sector proximal. Cartelle (comunicación personal) comentó el hallazgo de una epífisis distal de húmero en las cuevas mencionadas de Bahia. Prevosti y Ferrero (2008, basándose en materiales mencionados por Carlini et al. 2002) describieron el primer registro fósil de la especie para Argentina (Localidad de Diamante, provincia de Entre Ríos), de sedimentos del Pleistoceno Tardío. Este material, además de presentar cráneo y mandíbula, presenta un gran número de elementos postcraneales, incluyendo vértebras y huesos largos, fragmentos de costillas y elementos del autopodio, siendo el registro fósil con postcráneo preservado más completo de América del Sur. En consecuencia, no existen restos fósiles de lutrinos de América del Sur asignables a una especie extinguida.

Como resumen de esta síntesis de los materiales fósiles de mustélidos de América del Sur, existe un único género extinto ('Stipanicicia), tres especies extintas válidas: ${ }^{\dagger} G a$. hennigi, ${ }^{\dagger}$ Ga. sorgentinii y ${ }^{\dagger} L y$. bosei (pero ver Berman 1994, que describe en su tesis otra especie fósil del género Galictis), todos ellos pertenecientes a la Subfamilia Ictonychinae. Todos los restos fósiles de los ictoniquinos de América del Sur se encuentran representados exclusivamente por elementos craneales y mandibulares. Para el caso de las Subfamilias Guloninae y Lutrinae, no existe ningún representante exclusivamente extinto, pero en este caso sí se preservan algunos restos postcraneales de especímenes fósiles de especies actuales (Eira barbara, Lontra longicaudis y Pteronura brasiliensis) del Pleistoceno y Holoceno de Argentina y Brasil.

\subsection{Antecedentes de estudios filogenéticos}


Mustelidae ha sido reconocida desde principios del siglo XIX (Fischer 1817, Swainson 1835) sobre la base de caracteres de anatomía externa y blanda, dentición y hábitos locomotores. Actualmente, dentro de los caracteres más importantes que definen a la Familia Mustelidae se destacan: la caja craneana baja, el adelantamiento del molar carnicero, el occipucio amplio, los procesos paraoccipital y mastoideo ampliamente separados, reducciones en el número de molares, la presencia de cinco dígitos en cada miembro, cuerpos alargados y miembros relativamente cortos (Radinsky 1981a, Baskin 1998). Pocock (1921) separó a los mustélidos vivientes en 15 subfamilias, la mayoría de ellas monogenéricas. Muchas de las clasificaciones más recientes (Stains 1984, Wozencraft 1989) siguieron, en su mayor parte, el arreglo de subfamilias planteado por Simpson (1945), quien reconoció cinco subfamilias denominadas posteriormente "simpsonianas": Mustelinae (hurones, martas, glotón), Melinae (tejones), Mellivorinae (ratel), Mephitinae (zorrinos) y Lutrinae (nutrias). Revisiones recientes basadas en análisis cladísticos mostraron que la mayoría de ellas eran parafiléticas (Bryant et al. 1993, Sato et al. 2004, 2012, Flynn et al. 2005, Koepfli et al. 2008). Baskin (1998) destacó que un gran número de investigadores incluyen a especies fósiles dentro de Subfamilias vivientes, generando un gran número de grupos polifiléticos, y sugirió un rearreglo sistemático de dos Subfamilias actuales (Mustelinae y Melinae) y tres fósiles ('Mustelavinae, 'Oligobuninae y ${ }^{\dagger}$ Leptarctinae).

La posición filogenética de Mustelidae dentro de Carnivora ha sufrido importantes modificaciones en las últimas décadas (ver Tedford 1976, Wozencraft 1989, Wyss y Flynn 1993, Flynn et al. 2005). Recientes análisis filogenéticos basados en genes nucleares y mitocondriales mostraron que los mustélidos son el grupo hermano de los prociónidos (Dragoo y Honeycutt 1997, Flynn et al. 2005, Sato et al. 2012). En estos estudios, los mustélidos fueron interpretados como un grupo monofilético, pero los Mephitinae ("zorrinos") fueron excluidos ya que resultaron ser grupo hermano de Mustelidae + Procyonidae. Estas filogenias soportan en parte la división de los mustélidos en dos subfamilias: Mustelinae y Lutrinae (e.g., Flynn et al. 2005), clasificación que siguen distintos autores recientes (e.g., Wilson y Reeder 2005). Sin embargo, la Subfamilia Mustelinae sería parafilética (véase Koepfli et al. 2008, Harding y Smith 2009, Sato et al. 2012). Recientes estudios filogenéticos de "evidencia total" (i.e., con caracteres obtenidos a partir de secuencias génicas, cráneo y dentición, ver Flynn y WesleyHunt 2005, Finarelli 2008) han coincidido en la exclusión de los zorrinos de la Familia Mustelidae y la parafilia de Mustelinae planteada por los estudios cladísticos moleculares. Otros autores (e.g., Sato et al. 2004) prefieren subdividir a la tradicional Subfamilia Mustelinae en múltiples subfamilias monofiléticas, muchas de ellas monogenéricas, con un planteamiento similar al propuesto por Pocock (1921) casi un siglo atrás. En esta Tesis se seguirá principalmente el arreglo de relaciones filogenéticas planteado por Sato et al. (2012), dada la 
robustez de su análisis, y la inclusión en este estudio de especies de particular interés para esta Tesis, como es el caso de Ly. patagonicus, no incluidas en otros estudios filogenéticos.

\subsection{Principales antecedentes de estudios músculo-esqueletarios de mustélidos}

Los carnívoros, como depredadores, necesitan realizar una amplia gama de movimientos para encontrar, perseguir, capturar y matar a sus presas (Ewer 1973, Taylor 1989). De esta manera, cada especie, incluso las más especializadas, son capaces de realizar una relativamente amplia variedad de movimientos en comparación con otros linajes de mamíferos (e.g., ungulados; Maynard Smith y Savage 1956, Ewer 1973).

Los estudios miológicos y osteológicos son relevantes, tanto para comprender funciones y capacidades motoras específicas desempeñadas por las especies en su ambiente natural (Gambaryan 1974, Leach 1977a, b, Hildebrand 1988), así como también como un potencial recurso de información filogenética (e.g., Windle and Parsons 1897, 1898, Parsons 1898, Fisher et al. 2008, 2009, Julik et al. 2012).

Mediante disecciones en mayor o menor grado detalladas, la musculatura postcraneal de numerosos mustélidos fue estudiada intensamente entre 1875 y 1898 (ver Fisher et al. 2008, 2009, Ercoli et al. 2013, 2014), proporcionando información relevante sobre las zonas de origen e inserción y morfología de cada músculo.

Meckel (1828) escribió un trabajo pionero en esta área, describiendo la musculatura de un gran número de mamíferos de todas partes del mundo en su tratado general de anatomía comparada. En este incluyó a Lutra lutra, Martes foina y Meles meles, realizando descripciones con un enfoque comparativo y destacando algunos rasgos sugerente de afinidad entre los representantes de los grandes grupos.

Cuvier y Laurillard (1849) realizaron el trabajo más importante existente en relación a la diversidad de la anatomía muscular de los mamíferos, compilados en cuatro volúmenes profusamente ilustrados. Incluyendo a tres mustélidos (Lutra lutra, Martes foina y Meles meles), cada especie es descripta en unos pocos párrafos, haciendo hincapié en aspectos comparativos (con mínimas referencias funcionales o de afinidad), y con un gran número de ilustraciones representando la totalidad del arreglo muscular de ellas.

Lucae (1875) describió e ilustró el total de la musculatura de Lutra lutra, en comparación con cetáceos y pinnípedos, siendo estos últimos grupos el verdadero eje de su trabajo. Por otro lado, además de presentar dibujos y tablas de peso de este y otros carnívoros (incluyendo comparaciones con Meles meles), realizó algunas inferencias funcionales y filogenéticas.

Alix (1876) describió e ilustró el total de la musculatura de Mustela putorius, y realizó consideraciones funcionales; entre ellas, relacionó el gran número de fascículos breves de la 
musculatura axial con la gran movilidad necesaria para desplazarse en galerías de roedores; el desarrollo de la musculatura abdominal, sublumbar y m. latissimus dorsi con la flexión activa previa al salto, y la participación del m. triceps brachii caput angulare en la sobre-extensión del miembro anterior, compensando su breve extensión. Por otro lado, utilizó caracteres musculares como evidencia de afinidad con otros linajes carnívoros.

Windle y Parsons $(1897,1898)$ realizaron la revisión bibliográfica más exhaustiva para su época, e incluyeron un gran número de datos y algunas ilustraciones de disecciones propias y previas no publicadas, siendo sus trabajos un punto de partida básico en estudios miológicos comparativos de carnívoros. En lo que respecta a mustélidos, presentaron nuevos datos (aunque aislados) de Galictis vittata, Poecilictis libyca, Ictonyx striatus, Lutra lutra y Meles meles. Los autores compilaron toda la información disponible bajo un enfoque comparativo. Con el objetivo de esclarecer las relaciones filogenéticas entre las familias de carnívoros, plantearon las principales similitudes y diferencias en el sistema muscular de estos grupos. Dentro de algunas de las características destacadas para Mustelidae se encuentra la presencia para todas las especies del $\mathrm{m}$. rhomboideus capitis, $\mathrm{m}$. rhomboideus profundus, una cabeza extra del $\mathrm{m}$. triceps brachii (caput angulare), m. sartorius simple, y presencia del vientre caudal del $\mathrm{m}$. semitendinosus variable.

Hall $(1926,1927)$ realizó descripciones más exhaustivas, aunque pobremente ilustradas, de la musculatura de Martes americana y Taxidea taxus, además de los mefítidos Mephitis mephitis y Spilogale putorius. Destacó, entre otras, la ausencia de m. rhomboideus capitis en los mefítidos (considerados en ese entonces mustélidos, y por ende contradiciendo a Windle y Parsons 1897,1898$)$, y la presencia casi exclusiva de m. rhomboideus profundus y exclusiva del m. triceps brachii caput angulare en mefítidos y mustélidos (confirmando y extendiendo lo observado por Windle y Parsons 1897, 1898).

Williams (1955), realizó la descripción de la totalidad de la musculatura y osteología de Mustela vison. En su trabajo, extendió y confirmó las generalizaciones realizadas por Hall (1926, 1927). Destacó el gran desarrollo de la musculatura caudal (sólo superada dentro de mustélidos por las nutrias) y su rol en el nado, así como otras peculiaridades, como la ausencia del m. omohyoideus y m. stylohyoideus (registrado también en otros mustélidos; ver, Alix 1876).

Gambaryan y Karapetyan (1961) realizaron un estudio de desarrollo muscular relativo (proporcionando datos de pesado) y adaptaciones postcraneanas al medio acuático en carnívoros, incluyendo en este estudio a Lutra lutra, Enhydra lutris, y a modo comparativo a Vormela peregusna, Mustela nivalis, Martes foina y Meles meles. Los autores destacaron variantes en el desarrollo de diferentes grupos musculares de los miembros y zona axial, en relación a su utilización diferencial en diferentes estrategias de nado. Tarasoff (1972), realizó 
estudios similares, incorporando otros tejidos blandos y duros, realizando inferencias sobre la vida acuática de Lontra canadensis, Lutra lutra y Enhydra lutris, así como en la foca Pagophilus groenlandicus, utilizando también los datos previamente publicados por otros autores (e.g., Fisher 1942, Gambaryan y Karapetyan 1961). En lo que respecta a musculatura, estos autores identificaron una reducción progresiva de los principales extensores de la cadera (e.g., mm. psoas), y un aumento relativo de los músculos que rotan, retraen a los miembros posteriores (e.g., mm. gluteus, $\mathrm{m}$. biceps femoris, m. semimembranosus, m. semitendinosus) en relación a la posición de nado. Específicamente para Enhydra lutris, y secundariamente en otras nutrias, destacaron la importancia de los movimientos axiales dorsoventrales por sobre los lateromediales (i.e., contrarios a otras formas de nado, como el caso de las focas).

Piérard (1965) y Souteyrand-Boulenger (1969) proporcionaron datos sobre músculos específicos ( $\mathrm{m}$. fibularis longus y $\mathrm{m}$. articularis coxae, respectivamente) de un gran número de carnívoros, incluyendo mustélidos.

Gambaryan (1974) realizó un importante estudio de locomoción en mamíferos, en donde incluye un gran número de datos de disecciones de mustélidos, mayormente de desarrollo relativo de grupos musculares (brindando datos de pesado). En ese trabajo incluyó a las especies Enhydra lutris, Gulo gulo, Lutra lutra, Martes foina, Mellivora capensis, Mustela eversmanni, Mu. nivalis, Mu. putorius y Vormela peregusna, revisándose e incluyéndose los aportes ya comentados proporcionados por Gambaryan y Karapetyan (1961), y de otros estudios morfofuncionales realizados por autores rusos previos (Sokolov y Sokolov 1970, 1971). Gambaryan (1974) relacionó muchas de las características presentes en mustélidos con la caza en galerías, incluyendo la alta flexibilidad de la espina. Por otro lado, el autor relacionó el gran desarrollo de la musculatura epiaxial con la poderosa extensión de la columna justo antes del despegue de los miembros posteriores en cada salto de la marcha bound (fase de vuelo extendido), y el moderado o breve desarrollo de la musculatura sublumbar con el breve o nulo periodo de vuelo, justo después del despegue de los miembros posteriores (fase de vuelo cruzado; conclusiones que en parte contradicen lo mencionado por Alix 1876, y Alexander y Jayes 1981).

Bisaillon (1976), presenta una descripción detallada e ilustrada del miembro posterior de Mustela nigripes, haciendo algunos comentarios comparativos finales sobre caracteres compartidos por mustélidos (e.g., ausencia de m. articularis coxae; ver también SouteyrandBoulenger 1969), variantes de interés (e.g., cantidad y posición de vientres del m. semimembranosus), y características de relevancia funcional, destacando la interacción compleja entre el $\mathrm{m}$. fibularis brevis y el $\mathrm{m}$. extensor digitorum lateralis y su posible influencia en la restricción de movimientos de rotación lateral del tobillo.

Leach (1977b) estudió en forma detallada la musculatura del miembro anterior de Martes martes y Martes pennanti. En su estudio no encontró diferencias significativas entre 
ambas especies, ni dimorfismo en la estructura muscular, más allá del mayor desarrollo muscular relativo en machos que en hembras, asignando esto último a cuestiones alométricas. También vinculó el gran desarrollo de la musculatura extensora de hombro, codo y flexora del carpo con la absorción del impacto durante la locomoción de tipo bound, o half-bound. Por otro lado, relacionó el gran desarrollo de la musculatura de control de movimientos de los hombros con la capacidad de trepar.

Alexander y Jayes (1981) estudiaron e hicieron estimaciones de momento de fuerza de la musculatura abdominal y lumbar de Mustela putorius en comparación con otros animales, determinando las contribuciones de los principales grupos musculares a la flexión y extensión de la columna.

Scherling (1989) estudió detalladamente la osteología y miología de Meles meles mediante radiografías y disecciones. Realizó una gran cantidad de dibujos, algunas inferencias de tipo funcional, mayormente relacionadas a funciones musculares durante la excavación (e.g., gran capacidad de pronación y supinación de los principales flexores del codo, gran ventaja mecánica de los principales extensores del codo), y un gran número de notas sobre nomenclatura muscular.

Moritz et al. (2007) describieron la musculatura lumbar de Mustela putorius, mediante disecciones, tomografías y tipo de fibras de los músculos, y realizaron filmaciones de la locomoción de esta especie tanto en túneles como epigea. Entre sus conclusiones principales se destaca que, durante la locomoción subterránea, el turón mantenía la espalda en una posición extendida gracias a la acción conjunta y estabilizadora de los $\mathrm{mm}$. psoas y la musculatura epiaxial, aumentando el torque sobre las cinturas, pero reduciendo significativamente su altura. Por otro lado, sobre tierra, la espalda es mantenida en una posición semi-flexionada, reduciendo el torque y permitiendo una locomoción energéticamente menos costosa.

Moore et al. (2013, continuando la tesis doctoral de Quaife 1978) describieron la musculatura de Taxidea taxus haciendo hincapié en brazos de palanca, momentos de fuerza, y aspectos funcionales durante la excavación. Destacaron la hipertrofia de los flexores del hombro y dígitos, y extensores del codo como rasgos relacionados a los torques ejercidos durante la excavación. Por otro lado, destacaron la gran capacidad de contracción y fuerza de las cabezas biarticulares del $\mathrm{m}$. triceps brachii durante la excavación, aunque nominaron erróneamente las cabezas de este músculo, y también asignando incorrectamente la presencia de una cabeza angular del m. triceps brachii como una característica única de tejones (ver más arriba). Además, Quaife (1978) proporcionó descripciones, ilustraciones y mapas musculares de algunos músculos del cuello de ejemplares de la especie.

Por último, una serie de publicaciones anatómicas exclusivamente descriptivas (o centradas en otros objetivos anatómicos, y utilizando a mustélidos como material comparativo) 
han proporcionado datos sobre la musculatura de varios mustélidos: miembro anterior de Gulo gulo (datos aislados, English 1975, 1976, 1977), Martes americana (datos aislados, English 1975, 1976, 1977), Martes pennanti (Feeney, 1999), Taxidea taxus (datos aislados, Wagner 1976); miembro anterior y posterior de Enhydra lutris (incluyendo datos de pesado, Howard 1973, 1975), Lutra lutra (exclusivamente datos de pesado, Haughton 1867a), Meles meles (exclusivamente datos de pesado, Haughton 1867b), Mustela putorius (Barone y Deustch 1953); musculatura axial de Mustela putorius, Lutra lutra (datos aislados, Slijper 1946), y musculatura axial, y miembro anterior y posterior de Aonyx cinerea (Macalister 1873a), Eira barbara (Macalister 1873b), Lontra canadensis (Fisher 1942), Martes foina (Mackintosh, 1875), y Melogale personata (sólo algunas características; Beddard 1905).

Sobre la base de estos antecedentes, previo al aporte que se desprende de esta Tesis, no existen descripciones de la miología de mustélidos sudamericanos más allá de cuatro estudios puntuales de finales del siglo XIX, que incluyen la descripción parcial de especímenes de Eira barbara (Macalister 1873b) y comentarios menores sobre Galictis vittata (Windle 1889, Windle and Parsons 1897, 1898). Por otro lado, hasta el presente sólo existen mapas musculares de cuatro géneros de mustélidos (Enhydra, Martes, Mustela y Taxidea; Howard 1973, 1975, Bisaillon 1976, Quaife 1978) y no existen mapas musculares axiales de ningún mustélido, útiles para estudios osteológicos tanto para neontólogos como paleontólogos. Los aportes que se desprenden de esta Tesis (Ercoli et al. 2013, 2014, en preparación), ayudan a salvar en parte estos hiatos del conocimiento, presentando la primera descripción exhaustiva e ilustrada de Galictis cuja.

La morfología osteológica postcraneal de mustélidos fósiles y vivientes ha sido estudiada con el objeto de evaluar su correlación con los estilos locomotores presentes en la familia, a través de distintos métodos. Estos trabajos (e.g., Heráň 1962, Ewer 1973, Gambaryan 1974, Quaife 1978, Holmes 1980, Van Valkenburgh 1987, Heinrich y Houde 2006, Schutz y Guralnick 2007, Lewis 2008, Ercoli y Schutz 2012, Fabre et al. 2013a) han demostrado claras correspondencias entre las formas o proporciones del esqueleto postcraneal y los tipos locomotores. Asimismo, autores como Simpson (1945), Gambaryan (1974), Holmes (1980) y Schutz y Guralnick (2007) sugirieron que los diversos tipos locomotores registrados en la Familia Mustelidae muestran una alta correspondencia con las relaciones filogenéticas de sus especies.

Un gran número de trabajos abordaron el tema de la adaptación al medio acuático en mustélidos (e.g., Savage 1957, Gambaryan y Karapetyan 1961, Tarasoff 1972, Tarasoff et al. 1972, Gambaryan 1974, Bisaillon et al. 1976, Malatesta 1977, Willemsen 1980a, b, 1992, Fish y Stein 1991, Fish 1994, 2001). En estos se detallan un gran número de características posturales y osteológicas progresivamente relacionadas a adaptaciones al medio acuático en 
nutrias, o en comparación con otros mamíferos terrestres o marinos, a veces incluyendo fósiles (e.g., 'ं"Isolalutra", 'Paralutra, †'Potamotherium; Savage 1957, Malatesta 1977, Willemsen 1980a, b). Entre las conclusiones morfofuncionales más relevantes de estos trabajos, se destaca: la reducción del cuello en los linajes más especializados al buceo y la caza de presas bentónicas (Savage 1957, Bisaillon et al. 1976), la progresiva importancia de los movimientos dorsoventrales axiales respecto a los lateromediales en nutrias (evidenciado en los procesos vertebrales y proporción de sistemas musculares epiaxiales; Savage 1957, Gambaryan y Karapetyan 1961, Tarasoff 1972, Tarasoff et al. 1972, Gambaryan 1974, Willemsen 1980b), la utilización diferencial de los miembros anteriores, posteriores, y cola en diferentes estrategias de nado (Savage 1957, Gambaryan y Karapetyan 1961, Tarasoff et al. 1972, Taylor 1989, Fish 1994, 2001), la mayor curvatura del húmero y largo del olécranon (en relación a esfuerzos de propulsión, resistencia a la flexión y cambios posturales del miembro anterior; Savage 1957, Gambaryan y Karapetyan 1961, Willemsen 1980b), la reducción progresiva del soporte del peso en los miembros posteriores y la reorganización de la articulación pélvica (e.g., mayor superficie isquio-púbica para aductores, posición lateralizada y posterior del fémur en vez de vertical, reducción del trocánter menor, ausencia del ligamento femoral en Enhydra; Savage 1957, Tarasoff 1972, Malatesta 1977, Willemsen 1980a, b), el aumento de la superficie de los autopodios relacionados a la propulsión (Savage 1957, Gambaryan y Karapetyan 1961, Tarasoff 1972, Tarasoff et al. 1972), y el incremento de la densidad ósea (relacionado al control del nado; Fish y Stein 1991), entre otros.

Gambaryan (1974) describió los modos y adaptaciones locomotoras principales en varios linajes de mamíferos terrestres, incluyendo a los carnívoros, y específicamente a los mustélidos. Destacó como tendencia principal en el linaje la adaptación a depredar roedores en galerías, y un gran número de adaptaciones relacionadas a esto, algunas de ellas rastreables hasta linajes oligocénicos. Entre estas, se destaca la gran flexibilidad de la zona axial (observada tanto en morfología y desarrollo de procesos vertebrales, hipertrofia de sistemas musculares epiaxiales, y reducción de ligamentos intervertebrales), y los miembros proporcionalmente reducidos respecto al tronco. El autor realizó inferencias evolutivas y propuso que las variantes epigeas de mayor tamaño (Mellivora, Gulo), cavadoras (tejones), trepadoras (martas) y acuáticas (nutrias) dentro del linaje, surgieron a partir de un plan corporal tipo Mustela, y aún en ellas pueden reconocerse rasgos de movilidad axial típicos de predadores de galerías. En lo que respecta a la locomoción epigea, relacionó la marcha rápida bound típica de mustélidos como una solución para alcanzar velocidades elevadas pese a lo breve de los miembros locomotores, en donde la zona axial participa mediante extensión activa en la propulsión, y flexión pasiva en el aterrizaje. Hildebrand $(1977,1988)$ abordó la cuestión, aunque más superficialmente, en trabajos más generales. 
Moritz et al. (2007), y Horner y Biknevicius (2010) han hecho importantes aportes al conocimiento de las diferencias en la locomoción epigea y subterránea tomando como modelo a Mustela putorius (Fig. 1.3). Ambos trabajos destacaron los cambios posturales, motrices y musculares necesarios para desplazarse y cazar en galerías. Los hurones, al desplazarse sobre tierra lo hacen con la espalda curvada, reduciendo el torque sobre las cinturas y desplazándose en velocidad mediante galopes o half-bound. Al introducirse en túneles, adquieren y mantienen en forma prolongada en el tiempo, una posición elongada de la columna, y flexionan los miembros (postura crouched), reduciendo la altura de las cinturas entre un 20 y $30 \%$ y en un $60 \%$ la altura total; al parecer sólo desplazándose mediante pasos simétricos (caminatas rápidas en secuencia lateral de pasos o trote), similares en secuencia y velocidad a los pasos simétricos epigeos.

Un gran número de trabajos hicieron hincapié e incluyeron distintas formas de cuantificar los usos de sustrato, habilidades fosoriales y estilos de marchas. Vale la pena destacar que estos autores (así como también ocurre en esta Tesis, ver más adelante) hacen referencia al conjunto de estas variables, o a las clases que se construyen a partir de las mismas, como variables del estilo locomotor y clases locomotoras, respectivamente, pese a que en sentido estricto implican un universo más amplio de factores resumidos (estilo de locomoción, sustrato de locomoción, habilidades fosoriales; ver Miljutin 2009). Holmes (1980) describió a los mustélidos como carnívoros de estilos locomotores generalizados, con gran dificultad a la hora de asignarlos a las categorías tradicionales (e.g., cursorial, arborícola). Van Valkenburgh (1987) analizó la morfología postcraneal de los carnívoros vivientes a partir de medidas lineales (e.g., largo del olécranon, profundidad de la tróclea astragalar), incluyendo ocho especies de mustélidos, y clasificándolos en las categorías "trepador", "terrestre" y "cavador". Recientemente, Schutz y Guralnick (2007) revisaron y replantearon las categorías locomotoras de los Mustelidae, realizándose las siguientes asignaciones: "half-bound" para el género Mustela, "cavadores" para taxones como Meles y Taxidea, "trepador" para Martes y Eira, "acuático" para los lutrinos, y "ambulatorio" para Galictis y Gulo. En su trabajo utilizaron análisis de morfometría geométrica y funciones discriminantes a partir de varios elementos postcraneales, incluyendo un gran número de especies sudamericanas. Los autores demostraron que la morfología de elementos apendiculares permiten reconocer significativamente los diferentes estilos locomotores, realizaron inferencias funcionales, y utilizaron estas funciones para clasificar a ${ }^{\dagger}$ Trigonictis cookii y ${ }^{\dagger} T$. macrodon, dos Ictonychinae norteamericanos afines a Galictis, como especies con hábitos intermedios a half-bound y trepador. Ercoli y Schutz (2012) extendieron este análisis con un mayor número de especies fósiles y vivientes (incluyendo lutrinos fósiles previamente no analizados), concluyendo en una asignación a hábitos saltadores para ambas especies de ${ }^{\dagger}$ Trigonictis, aunque un mayor grado de especialización a esta marcha 
para el caso de ${ }^{\dagger} T r$. cookii, y variantes secundarias en el tipo de marchas terrestres de los lutrinos. Otros análisis morfo-funcionales importantes, en donde se incluyeron muchos mustélidos fueron realizados por MacLeod y Rose (1993), Heinrich y Houde (2006), y Moore et al. (2013).

También han sido estudiadas las relaciones alométricas entre el tamaño corporal y las proporciones de los huesos de los miembros en mustélidos. Heinrich y Biknevicius (1998) observaron una fuerte relación alométrica positiva con la robustez, y una relación alométrica negativa con la longitud, tanto para el húmero como para el fémur, y cambios posturales (desde una posición agazapada a extendida) para el caso de los miembros posteriores.

Andersson (2004) realizó un estudio de la morfología de la articulación distal del húmero en carnívoros mediante la técnica de morfometría geométrica; en sus resultados planteó que los carnívoros pequeños (i.e. menor de $10 \mathrm{~kg}$, incluyendo a la mayoría de los mustélidos) poseen un alto grado de habilidades de manipulación con sus miembros anteriores, permitiendo una escasa variación morfológica y un amplio rango de actividades (e.g., nadar, trepar). En cambio, en los carnívoros grandes (i.e. mayores de $10 \mathrm{~kg}$, incluyendo a Enhydra, Gulo y Taxidea), la disparidad morfológica es amplia, distinguiéndose con mayor facilidad los hábitos locomotores a partir de la morfología del codo. Otros autores (e.g., Iwaniuk et al. 2000) evaluaron el grado de influencia del hábito locomotor, filogenia y dieta, en la capacidad de manipulación del miembro anterior de Carnivora, incluyendo seis taxones de mustélidos en el análisis.

Polly (2010) estudió mediante índices morfométricos los cambios intra- e interespecíficos en la morfología del miembro posterior (centrándose en el calcáneo), a lo largo de diversos clados de Carnivora, incluyendo como variables explicativas a regiones geográficas (incluyendo variables ambientales y ecológicas), taxonomía y hábitos locomotores y posturales, encontrando una relación significativa entre la morfología del calcáneo y muchas de estas variables, indicando que los cambios posturales en el tobillo pueden ser utilizados como un proxy (i.e., indicador) de provincias ecológicas, paleotemperatura y cobertura vegetal.

Fabre et al. (2013a) estudiaron la morfología del codo de musteloideos en relación con adaptaciones a hábitos arborícolas y capacidad de agarre, y la evolución de estos rasgos en el grupo. Los mismos autores (Fabre et al. 2013b, 2014) realizaron nuevos análisis sobre la muestra original, evaluando la influencia de la masa corporal y el grado de integración entre los elementos del miembro anterior, respectivamente. Fabre et al. (2013a) estimaron que el ancestro hipotético de Mustelidae habría tenido hábitos terrestres o trepadores, y pobres capacidades de prensión, características comunes a los representantes vivientes. En relación a esto, y mediante análisis de morfometría geométrica, concluyeron que los mustélidos, especialmente los terrestres (e.g., Ictonyx, Mustela, Vormela), presentan carillas articulares del codo que impiden 
amplios movimientos de pronación y supinación, $\mathrm{y}$ una porción relativamente amplia del soporte de la masa corporal es brindada por el radio. En el estudio de los efectos alométricos sobre la morfología de los elementos del miembro anterior (Fabre et al. 2013b) confirmaron la tendencia al robustecimiento del húmero y radio, y la menor importancia relativa de la ulna en el transporte del peso corporal, así como un incremento progresivo de restricciones a algunos movimientos (como fue previamente descripto para éste y otros grupos de mamíferos; ver Gambaryan 1974, Hildebrand 1988, Heinrich y Biknevicius 1998, Andersson 2003). Por último, en el análisis de la articulación del codo, Fabre et al. (2014) reconocieron un mayor grado de covariación entre el húmero y la ulna, que entre el húmero y el radio, en relación a una coevolución más estrecha entre las dos primeras estructuras en relación a la mayor importancia de este contacto articular en asegurar la estabilidad requerida para la articulación, mientras que las libertades de movimientos requeridas durante la pronación y supinación del radio explicarían la relación menos estrecha entre su forma y el húmero.

Rose et al. (2014) estudiaron, mediante índices clásicos, la diversidad morfológica del miembro anterior de los tejones, y la relacionaron con éxito con los diferentes grados de especialización al cavado. Los cavadores más especializados presentaron mayores áreas de anclaje de la musculatura braquial, mayor ventaja mecánica de los extensores del codo, y capacidad de aplicar importantes fuerzas sobre el sustrato. Los autores propusieron que una porción de los cambios morfológicos particulares de cada linaje se relacionaría con otras variables, como lo son los estilos locomotores y la filogenia.

A pesar de que existen varios trabajos en el tema, en general centrados en especies no sudamericanas, o de una visión más bien abarcadora pero muchas veces superficial, el aparato músculo-esqueletario de los representantes sudamericanos vivientes es poco conocido, y no hay estudios que incluyan representantes fósiles. Asimismo, sólo unas pocas especies vivientes sudamericanas han sido incluidas en los estudios morfo-funcionales publicados. Por último, el postcráneo prácticamente no ha sido evaluado como fuente potencial de caracteres filogenéticos.

\subsection{Objetivos}

El objetivo general de esta Tesis es analizar la diversidad morfológica postcraneal de los mustélidos fósiles y vivientes de América del Sur, explorando su relación con distintos factores (e.g., locomoción, hábitos alimentarios, tamaño corporal, estructura filogenética), en un marco comparativo.

Los objetivos particulares son:

-Realizar una descripción anatómica detallada de la musculatura postcraneal de Galictis cuja, y compilar la información bibliográfica disponible sobre la miología de mustélidos y familias cercanas. 
-Realizar descripciones anatómicas detalladas del esqueleto postcraneal de los mustélidos vivientes y extintos de América del Sur.

-Establecer posibles vinculaciones entre la forma del esqueleto postcraneal de los mustélidos sudamericanos vivientes, su musculatura y los distintos tipos de locomoción (e.g., semiacuático, trepador, half-bounder) y hábitos alimentarios (e.g., omnivoría, carnivoría).

-Realizar inferencias sobre los hábitos de vida de especies de mustélidos extintos de América del Sur.

-Codificar la información anatómica postcraneal obtenida y evaluar mediante optimizaciones y cualitativamente su potencial como fuente de información para análisis filogenéticos.

\subsection{Hipótesis}

H1. Los distintos sustratos utilizados y tipos locomotores, así como los hábitos alimentarios en menor medida, condicionan la morfología del esqueleto y la musculatura postcraneal, por lo que su estudio es útil para inferir hábitos en especies extintas o en las especies vivientes para las cuales no se cuentan con datos sobre sus hábitos.

H1a. Los hurones ictoniquinos presentan modificaciones en la anatomía músculoesqueletaria relacionadas al desplazamiento a saltos similares a las propuestas para hurones mustelinos.

H1b. Lyncodon patagonicus está especializada morfológicamente a la depredación de roedores en galerías subterráneas.

H1c. Eira barbara presenta modificaciones músculo-esqueletarias que le permiten moverse sobre el sustrato arbóreo.

H1d. Las nutrias de América del Sur presentan especializaciones músculo-esqueletarias vinculadas a la locomoción acuática similares a las presentes en lutrinos de otros continentes.

H1e. La morfología mastoidea de †Stipanicicia pettorutii indica una importante musculatura cervical en relación a un alto grado de especialización en su estrategia de caza.

H2. El tamaño corporal impone restricciones en la forma del postcráneo.

H3. La morfología del postcráneo de los mustélidos posee una fuerte señal filogenética.

H4. El ancestro común de los mustélidos poseyó hábitos locomotores y alimentarios similares a los presentes en los hurones vivientes (Gambaryan 1974). 

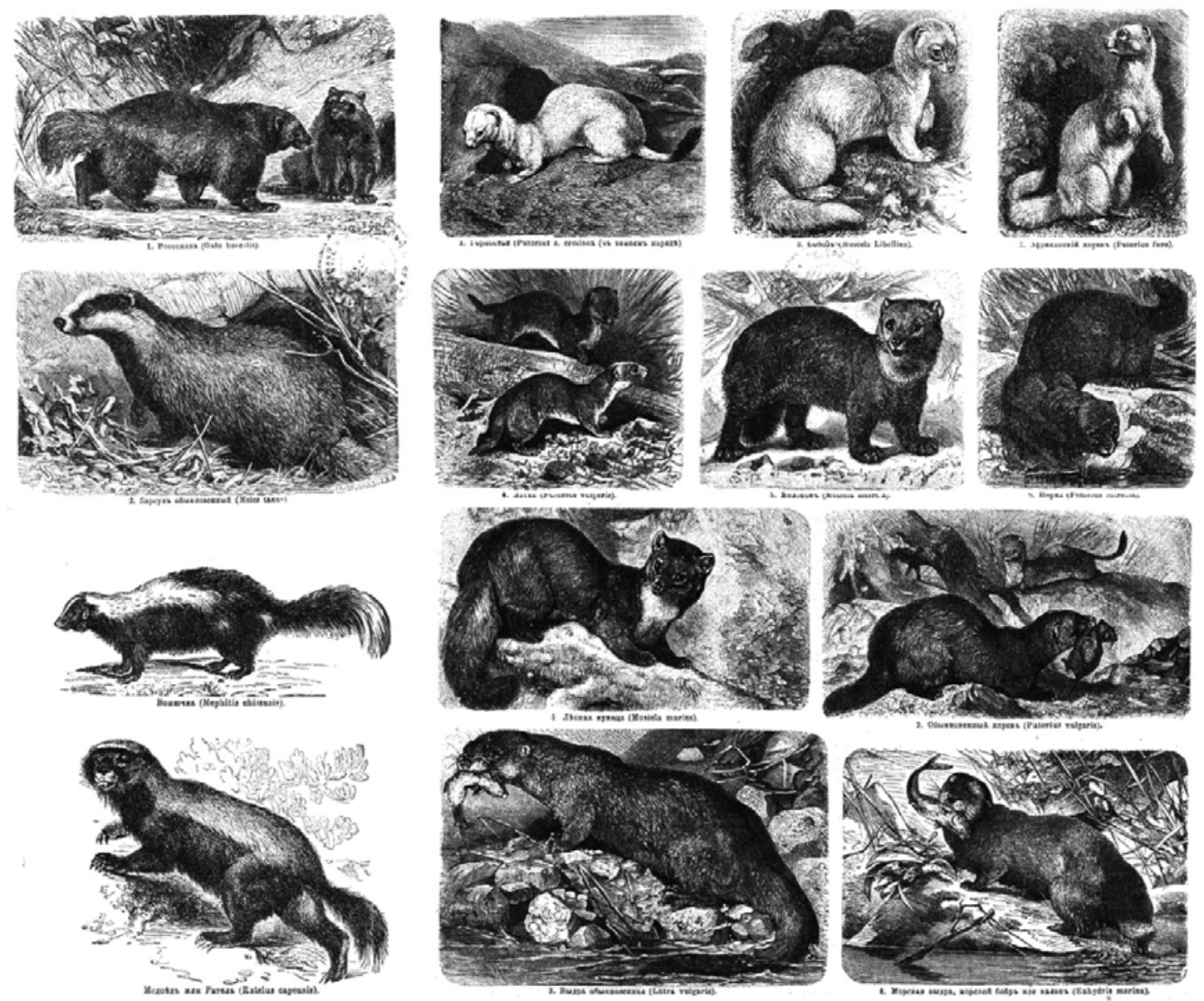

Figura 1.1. Diversidad de formas y hábitos de los mustélidos vivientes. Imágenes tomadas de "Brockhaus and Efron Encyclopedic Dictionary" de F. A. Brockhaus e I. A. Efron (1890; texto original en ruso). De izquierda a derecha y arriba hacia abajo: Gulo gulo, Mustela erminea, Mu. zibellina, Mu. putorius (variedad doméstica), Meles meles, Mu. nivalis, Mu. sibirica, Mu. lutreola, Conepatus chinga (actualmente considerado miembro de Mephitidae), Martes martes, Mu. putorius (variedad salvaje), Mellivora capensis, Lutra lutra y Enhydra lutris. 
Introducción

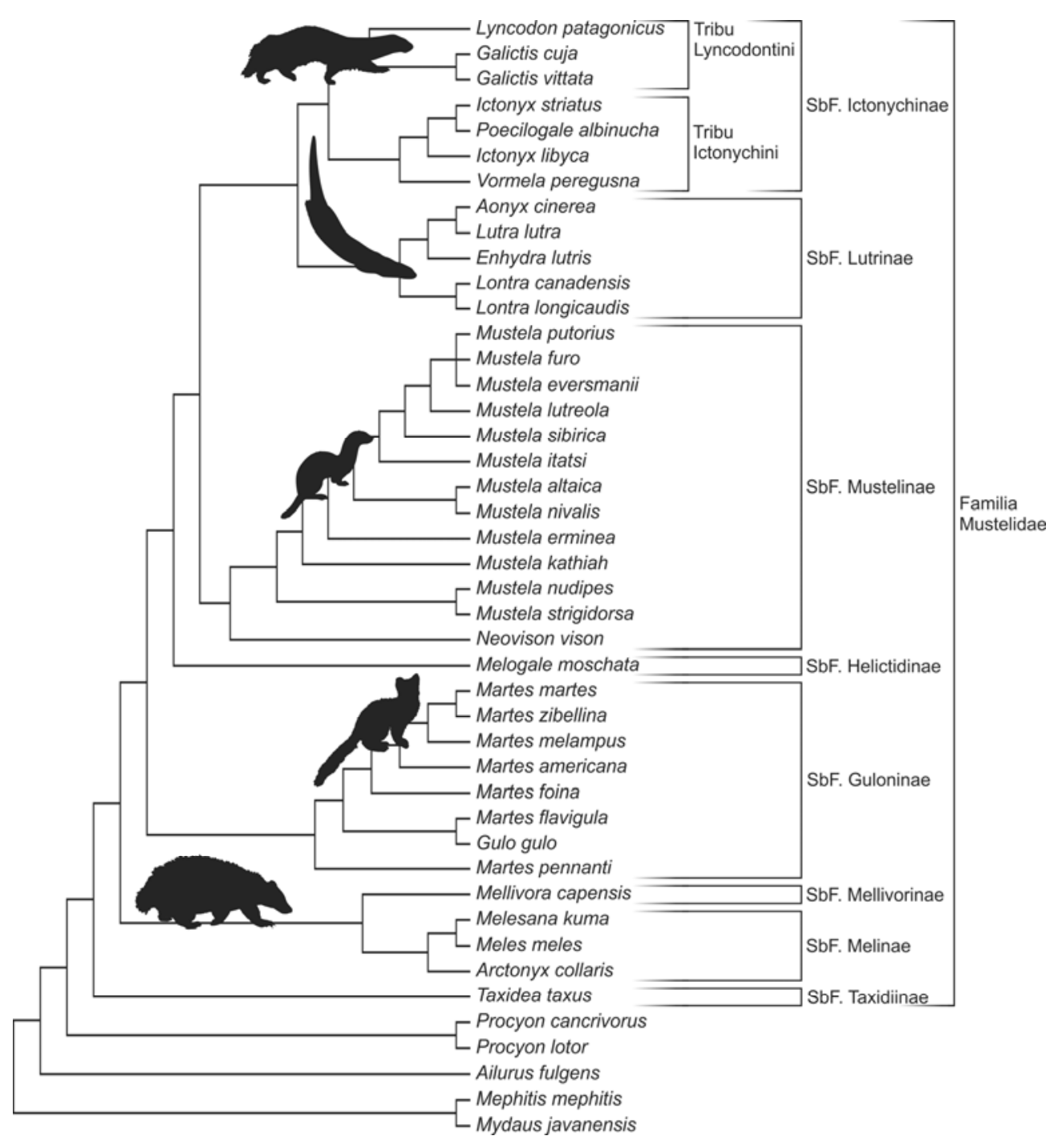

Figura 1.2. Filogenia y arreglo subfamiliar propuesto por Sato et al. (2012) y seguido en esta Tesis . Modificado a partir de Sato et al. (2012, Fig. 1). SbF.: Subfamilia.

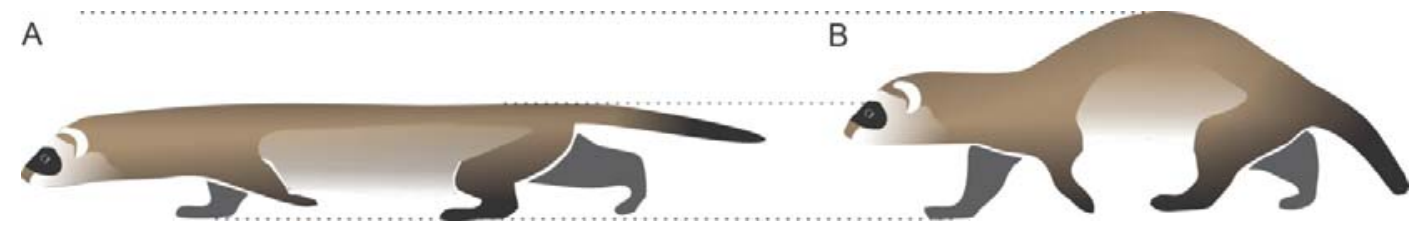

Figura 1.3. Cambio postural de un mustélido especializado para moverse en galerías (Mustela putorius) registrado al moverse dentro de túneles subterráneos $(\mathrm{A})$, respecto a la locomoción lenta epigea (B); en ambas se presenta el comienzo de la fase de apoyo del miembro posterior (izquierdo) y un estilo locomotor de tipo trote. Modificado a partir de Horner y Biknevicius (2010, Fig. 1). 

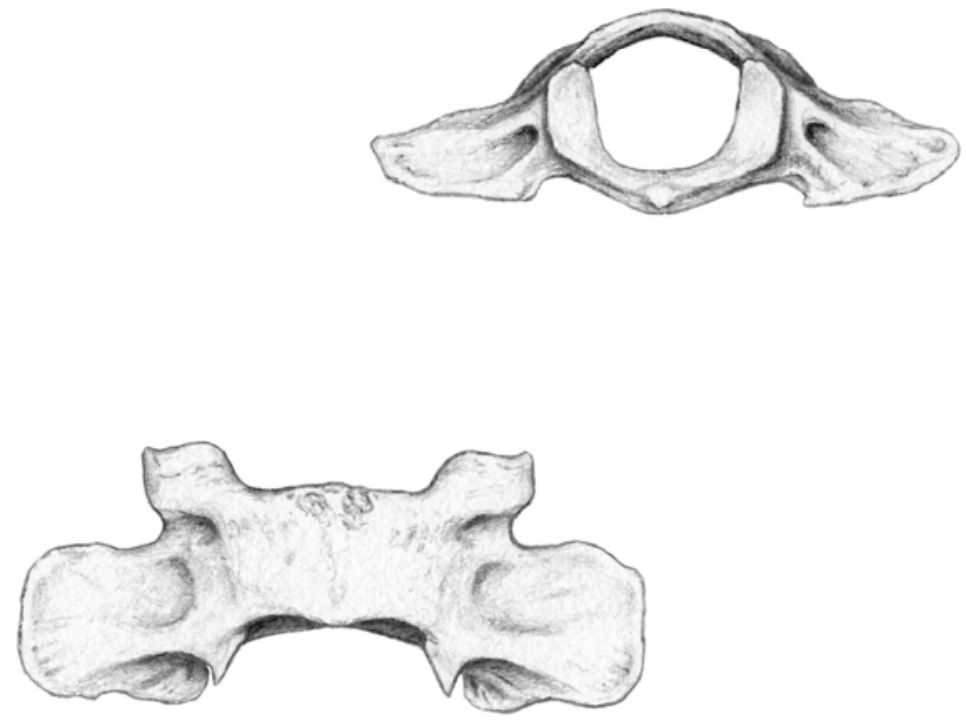

Capítulo 2

MATERIALES Y MÉTODOS
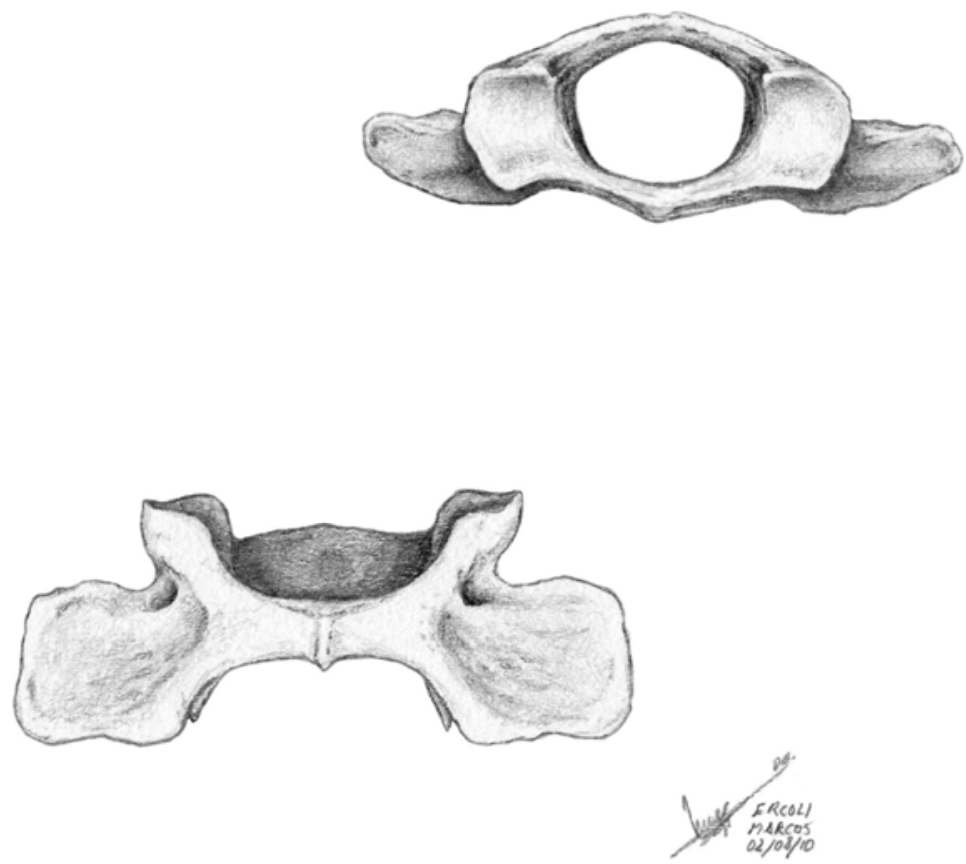



\section{Materiales y Métodos}

\subsection{Materiales}

\subsubsection{Materiales miológicos}

Se utilizaron tres especímenes miológicos de Galictis cuja preservados en la colección de especímenes en fluido de la división de Mastozoología del Museo Argentino de Ciencias Naturales, de los cuales fue estudiada en forma exhaustiva su musculatura craneal, hioidea, axial postcraneal (desde región cervical a caudal), apendicular, y parte de los sistemas faríngeo, lingual y urogenital.

El primer espécimen (MACN-Ma 25483) es un macho adulto, preservado con piel, colectado en el Km 96 de la Ruta Provincial 2, cerca al Río Samborombón, Buenos Aires, Argentina. Su largo total es $720 \mathrm{~mm}$. El segundo espécimen (MACN-Ma 28.163) es una hembra adulta preservada sin piel y sin algunas de las falanges distales de los miembros, posiblemente proveniente de Jujuy, Argentina. Su largo total es $450 \mathrm{~mm}$. El tercer espécimen (MACN-Ma 39.207) es un macho adulto preservado con parte de la musculatura tóraco-lumbar dañada, proveniente de la localidad de Bialet Massé, Departamento de Punilla, Córdoba, Argentina. Su largo total es de $750 \mathrm{~mm}$.

\subsubsection{Materiales osteológicos postcraneales}

Se revisaron en detalle materiales osteológicos postcraneales actuales de 32 ejemplares de cinco especies de mustélidos de América del Sur, y 32 ejemplares de nueve especies de musteloideos de América del Sur y otros continentes (tres especies de mustélidos de otros continentes, cuatro especies de prociónidos, y dos especies de mefítidos; Apéndice 2.1). Estos ejemplares se encuentran depositados en las colecciones argentinas: Colección Mamíferos Lillo, Tucumán (CML); Museo Argentino de Ciencias Naturales "Bernardino Rivadavia", Buenos Aires (MACN-Ma y MACN-Pv); Museo de La Plata, La Plata (MLP); y Museo Municipal de Ciencias Naturales "Lorenzo Scaglia”, Mar del Plata (MMPMa).

Además de estos materiales revisados, se contó con una gran cantidad de material fotográfico de 101 especímenes de 40 especies de musteloideos, tomadas para esta Tesis y cedidas gentilmente por varios colegas (ver Agradecimientos), los cuales fueron utilizados tanto para las descripciones como para los análisis de morfometría geométrica (ver sección 2.2.6 más adelante y los apéndices correspondientes). Estas fotografías fueron obtenidas en las siguientes colecciones: American Museum of Natural History, Nueva York, Estados Unidos (AMNH);

British Natural History Museum, Londres, Inglaterra (BNHM), Centro Austral de Investigaciones Científicas, Ushuaia, Argentina (CADIC); Denver Museum of Nature and Science, Colorado, Estados Unidos (DMNS); Field Museum of Natural History, Chicago, 
Estados Unidos (FMNH); Instituto de la Patagonia, Universidad de Magallanes, Punta Arenas, Chile (IPUM); Museo Municipal de Ciencias Naturales "Lorenzo Scaglia”, Mar del Plata, Argentina (MMPMa); Natural History Museum of Los Angeles County, Los Ángeles, Estados Unidos (LACM), Museo Nacional, Río de Janeiro, Brasil (MN); Museum of Southwestern Biology, Nuevo México, Estados Unidos (MSB), National Museum of Scotland (NMS); Osteological comparative collection of the Institute of Prehistory, University of Tübingen (MU); Naturhistorisches Museum, Vienna, Austria (NMV); National Science Museum, Tokyo, Japón (NSM); Staatliches Museum für Naturkunde in Stuttgart, Stuttgart, Alemania (SMNS); University of Tokyo, Tokyo, Japón (UMUT); National Museum of Natural History, Smithsonian Institution, Washington D.C., Estados Unidos (USNM); University of Washington Burke Museum, Estados Unidos (UWBM); Yale Peabody Museum, New Haven, Connecticut, Estados Unidos (YPM).

Por otro lado, se incluyeron en la muestra y revisaron en detalle siete especímenes fósiles con elementos postcraneales preservados de especies de mustélidos de América del Sur (tres Lontra sp., tres Lyncodon patagonicus, y un Pteronura brasiliensis; cuyos datos y elementos preservados son detallados en el Apéndice 2.2); así como materiales craneales de lincodontininos fósiles (ver sección 6, Anexo). Estos materiales se encuentran depositados en las siguientes colecciones argentinas: Centro Austral de Investigaciones Científicas, Ushuaia (CADIC), Centro de Investigaciones Científicas y Transferencia de Tecnología a la Producción de Diamante, Diamante (CICYTTP-PV-M); Museo Argentino de Ciencias Naturales "Bernardino Rivadavia", Ciudad Autónoma de Buenos Aires (MACN-Pv); Museo de Ciencias Naturales y Antropológicas "Prof. Antonio Serrano", Paraná (MCNyA); y Museo de La Plata, La Plata (MLP). Estos especímenes fósiles representan el total de los materiales postcraneales de mustélidos fósiles de América del Sur preservados en colecciones paleontológicas, y algunos restos aislados de especímenes colectados en sitios arqueológicos.

\subsection{Métodos}

\subsubsection{Terminología utilizada}

Para las descripciones y comparaciones osteológicas y musculares se utilizaron términos provenientes de distintas nóminas y otros trabajos específicos. Siguiendo la Nómina Anatómica Veterinaria (NAV; Waibl et al. 2005), los términos topológicos utilizados fueron craneal, caudal, dorsal, ventral, proximal, distal, lateral, medial, plano sagital, longitudinal, transversal; evitándose los términos superior, inferior, anterior y posterior, no recomendados en muchas estructuras postcraneales por la NAV (Waibl et al. 2005) y otras fuentes bibliográficas utilizadas como guías (e.g., Evans y De Lahunta 2013). Durante la descripción de posiciones relativas de estructuras, se consideró a los miembros en posición extendida (utilizándose en 
forma indistinta "palmar", "ventral" y "caudal" para referirse a la palma de los autopodios, y "dorsal" o "craneal" para referirse al dorso de los autopodios). Sin embargo, se utilizaron eventualmente los términos anterior y posterior en nombres compuestos de rasgos o estructuras (e.g., miembro anterior), y para indicar posiciones relativas de vértebras, evitándose confusiones que puedan surgir de una posición caudal respecto a la región anatómica caudal. Las descripciones anatómicas fueron acompañadas por láminas ilustrando, en forma general, los principales elementos, y lo mismo se hizo para detalles de interés particular.

Los términos utilizados para describir las estructuras osteológicas postcraneales provienen de varias fuentes, siendo las principales Evans y De Lahunta (2013) y Barone (1976), aunque algunos términos provienen de otras fuentes (esqueleto axial: Willemsen 1980a, Argot 2003a, Youlatos 2003; esqueleto apendicular: Kraglievich 1917, Davis 1964, Leach 1977a, Evans 1993, Heinrich y Rose 1997, Argot 2001, Sooriakumaran y Sivananthan 2005, Salesa et al. 2006). Todos se encuentran ilustrados en las figuras, aclarándose la fuente de la cual fue tomado o brindándose una breve definición para cada uno (ver Láminas 1 y aclaraciones en epígrafes).

Para las descripciones musculares, la terminología utilizada fue la propuesta en la NAV (Waibl et al. 2005), aunque excepcionalmente se utilizaron términos informales (i.e., m. abductor digiti II, IV, algunas divisiones del $\mathrm{mm}$. pectorales y $\mathrm{m}$. triceps brachii) o de otras fuentes (i.e., Spoor y Badoux 1986a, Fisher et al. 2008, 2009) para músculos o subdivisiones musculares no descriptas en la NAV.

Las letras C, T, L, S y Ca se utilizaron para referirse a las principales regiones del esqueleto axial: cervical, torácica, lumbar, sacra y caudal, respectivamente.

En casos específicos, se utilizaron términos no nativos para referirse sintéticamente a hábitos o grupos de especies. Se utilizó el término padding en referencia a estilos de nado en donde movimientos de patada generan presión de arrastre durante la fase de propulsión, seguida de una fase de recuperación (ver Fish 1994, 2000); bound o half-bound para referirse a marchas ágiles, sinuosas y asimétricas, similares al o considerados variante del galope, en donde la propulsión es generada por la extensión coordinada de la región axial sumado a los miembros posteriores extendidos en forma sincronizada al final de la fase de soporte, pudiendo o no (half-) ocurrir lo mismo en los miembros anteriores (ver Gambaryan 1974, Taylor 1989, Schutz y Guralnick 2007); scratch-dig para referirse a estilos de cavado en donde los miembros son los utilizados para penetrar y remover el sustrato (típico de carnívoros) en vez de los dientes y hocico (ver Hildebrand 1988, Taylor 1989). Por último, se utilizaron los términos informales skunk-like para referirse a especies con hábitos de vida similares a los zorrinos, principalmente Ictonyx striatus, y secundariamente otros ictoniquinos; otter-like para referirse a linajes carnívoros fósiles similares a nutrias, principalmente ${ }^{\dagger}$ Potamotherium valletoni (ver Savage 
1957); grison-like para referirse a las formas ictoniquinas fósiles similares a los grisones actuales; y weasel-like para referirse a especies con morfologías similares a los hurones incluyendo, además de los mustelinos, a ictoniquinos como los lincodontininos, Poecilogale albinucha y Vormela peregusna, y a los guloninos más pequeños como Martes americana.

\subsubsection{Descripciones y análisis miológicos}

El primer espécimen estudiado (MACN-Ma 25483), originalmente conservado congelado, fue tratado con una solución de formalin en 18 partes de agua saturada con $\mathrm{NaCl}$ (Woods 1972; ver también García-Esponda y Candela 2010) por una semana, y luego conservado en alcohol al 70\%. Los otros dos especímenes (MACN-Ma 28.163 y MACN-Ma 39.207), cuyo tratamiento químico de fijado es desconocido, fueron lavados y luego conservados en alcohol al 70\%.

Los especímenes fueron analizados mediante disecciones meticulosas. Utilizando como referencia descripciones e imágenes de disecciones de otros carnívoros (Hall 1926, 1927, Leach 1977b, Fisher et al. 2008, 2009; Evans y De Lahunta 2013; entre otras fuentes), cada músculo fue identificado, fotografiado y señalado mediante costuras de colores durante el procedimiento de extracción. Se describió la morfología, posiciones relativas, tipo de fibra y superficies de origen e inserción de cada músculo, variantes intraespecíficas, realizándose esquemas de mapas musculares e ilustraciones con el material en mano. Las ilustraciones y descripciones fueron revisadas y mejoradas posteriormente con el material fotográfico, y se construyeron tablas resumiendo la variables intraespecíficas. Este procedimiento se realizó para ambos lados de los tres especímenes.

Una vez extraídos, los músculos fueron guardados en bolsas independientes con cierre, con rótulos indicando el espécimen, lado y músculo. Los músculos fueron secados en horno eléctrico a aproximadamente $70^{\circ}$ durante al menos 1 hora, cerciorándose de la pérdida total del líquido alojado en los de mayor volumen mediante pesados y tratamientos de secado sucesivos. La masa seca de cada músculo fue pesada individualmente en una balanza digital OHAUS, precisión 0,0001 gr, informándose para cada lado de cada espécimen analizado. Debido a los daños puntuales de algunos especímenes comentados en la sección de materiales miológicos (ver Ercoli et al. 2013, 2014), algunas características del segundo espécimen (parte de la musculatura digital) y del tercer espécimen (parte de la musculatura axial), no fueron incluidas en la tablas de variantes intraespecíficas, ni pesado.

La masa relativa de los distintos grupos musculares de Ga. cuja fueron comparadas posteriormente con aquellas de otras especies mustélidas disponibles en bibliografía (Aonyx, Enhydra, Gulo, Lutra, Martes, Mellivora, Mustela, Vormela y Taxidea; Macalister 1873a, Gambaryan 1974, Moore et al. 2013), y otros cuatro carnívoros (Acinonyx, Canis, Leopardus y 
Ursus; Gambaryan 1974, Hudson et al. 2011, Julik et al. 2012). La discusión morfo-funcional de la miología de Galictis cuja se realizó en un contexto comparativo, incluyendo toda la información disponible sobre la miología postcraneal de otros mustélidos (Tabla 2.1), y de otros carnívoros (citas mencionadas a lo largo del texto).

\subsubsection{Descripciones y análisis osteológicos postcraneales}

2.2.3.1. Descripciones: con el fin de evitar reiteraciones a lo largo de la sección, las descripciones osteológicas de las especies de mustélidos sudamericanos siguieron el siguiente esquema: En una primera instancia se realizaron descripciones exhaustivas de cada elemento postcraneal de Galictis cuja, Lyncodon patagonicus, Eira barbara y Lontra provocax. En una segunda etapa, las otras especies del mismo género o familia (y en mayor o menor grado similares) fueron descriptas también en detalle, pero sólo mencionando aquellos rasgos en que se diferenciaron de las anteriores i.e.,: Ga. vittata en comparación con Ga. cuja, Lo. longicaudis y Pteronura brasiliensis en comparación con Lo. provocax. Las especies de Mustela de América del Sur y Lo. felina, no fueron incluidas en las descripciones detalladas de esta Tesis debido a la falta de acceso a materiales osteológicos adecuados y fotográficos en calidad y cantidad suficiente. Por otro lado, ya existen descripciones y análisis de un gran número de especies del género Mustela (e.g., Hall 1951, Williams 1955, Herán̆ 1962, Anderson et al. 1974, Evans y Quoc An 1980, Fish y Stein 1991, Schmidt y Fisher 2009) y algunas incluyen específicamente a especies presentes en América del Sur (Mu. frenata: Hall 1951, Izor y de la Torre 1978, Holmes 1980, Heinrich y Houde 2006; ver también comentarios sobre Mu. felipei en Izor y de la Torre 1978, Izor y Peterson 1985). Sin embargo, estas y otras especies sí fueron contempladas en las comparaciones más generales y en la discusión (ver sección 4.3). Se incluyeron también descripciones de los especímenes fósiles de Argentina con postcráneo preservado mencionados en el apartado de Materiales, haciendo mención de sus principales rasgos relevantes, similitudes y diferencias respecto a los representantes actuales, y una breve discusión sobre la implicancia de los restos y sus características morfológicas. Para esto, se utilizaron principalmente los materiales alojados en las colecciones mastozoológicas y paleontológicas de Argentina mencionadas y, secundariamente, se utilizó también el material fotográfico de colecciones extranjeras (ver sección 2.1.2).

Las descripciones osteológicas se realizaron en el siguiente orden: región cervical, región torácica, región lumbar, sacro, región caudal, escápula, húmero, ulna y radio, autopodio anterior, pelvis, fémur, tibia y fíbula, autopodio posterior. No se describió el aparato hioideo ni el baculum debido a la ausencia casi total de ellos en los especímenes de colección estudiados. Dentro de cada apartado sobre las regiones axiales las estructuras fueron descriptas 
principalmente en sentido cráneocaudal, mientras que en los miembros las estructuras fueron descriptas principalmente en sentido próximodistal.

La discusión de la morfología de los mustélidos sudamericanos se realizó bajo un enfoque comparativo y amplio a nivel Musteloidea, incorporando además de los datos propios comentados, observaciones adicionales y descripciones previas tomadas de la bibliografía (fuentes mencionadas oportunamente).

2.2.3.2. Análisis cuantitativo de medidas lineales: Se tomaron un total de 13 medidas postcraneales con calibre digital (precisión de 0,01 mm) (Tabla 2.2). Estas incluyeron a las longitudes totales de las principales regiones axiales, así como las longitudes máximas de los principales huesos largos y algunos elementos autopodiales. En el caso de las longitudes de regiones axiales se tomaron valores preferentemente de especímenes articulados. En el caso de especímenes de regiones axiales completas pero desarticuladas, se sumaron las longitudes de los cuerpos de los elementos vertebrales independientes, y estos valores sólo se utilizaron en los índices netamente axiales (en donde tanto en el denominador como numerador eran longitudes de regiones axiales), con el fin de evitar desvíos mayores relativos a la pérdida de discos intervertebrales (aproximadamente un octavo de la longitud de cada sector axial medido, Savage 1957). El largo del miembro anterior fue calculado a partir de la suma de los largos parciales del húmero, radio y metacarpal III, mientras que el largo del miembro posterior a partir de la suma del fémur, tibia y metatarsal III.

A partir de estas medidas (ver Tabla 2.2) se construyeron 8 índices: Largo tóracolumbar relativo a largo promedio de los miembros (LaTL/PrLaM), largo cervical relativo al largo tóraco-lumbar (LaCe/LaTL), largo lumbar relativo al largo tóraco-lumbar (LaLu/LaTL), largo sacro-caudal relativo al largo tóraco-lumbar (LaSC/LaTL), largo del miembro anterior relativo al largo del miembro posterior (LaMA/LaMP = índice intermembral), largo del radio relativo al largo del húmero $(\mathrm{LaRa} / \mathrm{LaHu}=$ índice braquial), largo del metacarpal III relativo al largo de la falange proximal del dígito III (LaMcIII/LaFIII), largo de la tibia relativo al largo del fémur $(\mathrm{LaTi} / \mathrm{LaFe}=$ índice crural). Estos índices, típicamente utilizados en otros estudios (e.g., Slijper 1946, Davis 1964, Holmes 1980, Van Valkenburgh 1987, Iwaniuk et al. 1999; ver también aclaraciones en epígrafe de Tabla 2.2), se encuentran principalmente diseñados para sintetizar las proporciones entre elementos, o sectores postcraneales, y son complementarios con los análisis de morfometría geométrica (que se focalizan en sectores más específicos, ver más adelante).

Los valores de estos índices fueron calculados a partir de las medidas tomadas para cada espécimen analizado (Apéndices 2.3, 2.4). Los valores promedios de cada especie fueron analizados en un contexto morfo-funcional y comparativo, incluyendo un gran número de 
especies de musteloideos de todo el mundo (Tabla 2.3). Para esto último se incluyeron, además de los ejemplares medidos para esta Tesis (47 especímenes de 13 especies de musteloideos de colecciones argentinas, ver Apéndices 2.3, 2.4), datos de varias fuentes bibliográficas clásicas (Mivart 1885, Slijper 1946, Davis 1964, Holmes 1980, Van Valkenburgh 1987, Iwaniuk 1999). Mivart (1885) y Davis (1964) proveyeron medidas lineales crudas y relativizadas de las longitudes de las principales regiones de la columna, principales huesos largos, metacarpal III, metatarsal III y falange III de la mano para 18 especies de musteloideos. Slijper (1946) presentó medidas lineales crudas y relativizadas del sector axial. Holmes (1980), Van Valkenburgh (1987), e Iwaniuk (1999) publicaron medidas relativizadas de los miembros.

Las especies fueron categorizadas en clases dietarias y locomotoras (Tabla 2.4). La definición de las clases dietarias, y la pertenencia de cada especie a cada una de ellas, fueron definidas siguiendo principalmente a Prevosti et al. (2012), y secundariamente otras fuentes bibliográficas para la asignación de algunas especies (Bassariscus astutus, Eira barbara y Taxidea taxus; Poglayen-Neuwall y Toweill 1988, Goodrich y Burskirk 1998, Johnson et al. 2000, Meloro y O'Higgins 2011). Sin embargo, las categorías planteadas por estos autores fueron simplificadas, fusionadas en categorías más abarcadoras por conveniencias inherentes a los análisis aquí presentados y la escasa representación de algunas de las categorías originales. La categoría "Carnívoro" (coincidente con "hipercarnívoro" y "mesocarnívoro" de Prevosti et al. 2012), incluyó carnívoros que consumen preferentemente carne; y la categoría "Omnívoro" ("omnívoro", "insectívoro" y "herbívoro" de Prevosti et al. 2012) incluyó a especies en los que plantas o invertebrados fueron una porción mayoritaria de la dieta, o lo único consumido por la especie. Las clases locomotoras son propias de este trabajo, pero inspiradas principalmente en Álvarez et al. (2013) y secundariamente otras fuentes (e.g., Schutz y Guralnick 2007). Se utilizaron las clases: "half-bounder" para animales que realizan carreras asimétricas, en quienes los movimientos de flexo-extensión de la columna son un propulsor activo y ambos miembros posteriores se encuentran en fase durante la propulsión; "trepador" para especies que utilizan frecuentemente el sustrato arbóreo (incluyendo a arborícolas estrictos); "cavador" para especies que frecuentemente cavan en búsqueda de alimento o refugio; y "nadador" para el caso de especies que frecuentemente nadan y realizan buceo (exclusivamente nutrias). La pertenencia de cada especie a cada categoría siguió estas fuentes, y la bibliografía mencionada en el apartado de Diversidad ecológica y funcional de los mustélidos de la introducción (ver Tabla 2.4). Para el caso de algunas especies (e.g., Lyncodon patagonicus), la asignación a una u otra categoría puede ser discutible por falta de datos ecológicos, o por la naturaleza de los hábitos diversos de una especie en particular. Por ello en algunos casos y análisis puntuales, se ensayaron diferentes clasificaciones (ver aclaraciones en Tabla 2.4, sección 3.4), con el fin de evaluar potenciales modificaciones en los resultados estadísticos. Lyncodon patagonicus, en función de lo poco que 
se conoce de la especie (e.g., Doering 1881, Koslowsky 1904, Cabrera y Yepes 1940, Prevosti y Pardiñas 2001, Teta et al. 2008, Wilson y Mittermeier 2009), fue tentativamente asignado a dietas carnívoras y hábitos locomotores half-bound, aunque el comportamiento del taxón en los análisis fue analizado con cautela y se ensayó la eliminación del taxón en algunos análisis particulares. El mismo esquema de clasificaciones y procedimiento de asignación fue aplicado a los análisis de morfometría geométrica.

Vale la pena destacar que, aunque estas categorías sean denominadas en forma simplificada como locomotoras, existe una amplia discusión metodológica y específicamente terminológica al respecto. Miljutin (2009) sugiere que no deben ser confundidos los medios o sustratos de locomoción (e.g., acuático, subterráneo, terrestre, arbóreo, aéreo) con las principales especializaciones al uso de estos sustratos (e.g., nadador, cavador, cursorial, trepador, volador). También plantea contemplar la diferencia en el sustrato utilizado tanto durante el forrajeo como en el descanso. Siguiendo a este autor, la definición de categorías locomotoras planteadas en esta Tesis no responden exclusivamente a estilos locomotores, sino a una combinación sintética de estilos locomotores y usos de sustratos (ver Miljutin 2009). Por otro lado, en el caso del grupo de estudio analizado y diseño de categorías planteadas, la diferenciación entre el concepto "acuático" y "nadador" es teórico, dado que todas las especies de carnívoros musteloideos que se desplazan principalmente en el medio acuático lo hacen mediante el nado, y algo similar puede plantearse para el caso del sustrato arbóreo y el trepado. Vale la pena también destacar que, en función de la definición brindada en este trabajo, las categorías "cavador" y "half-bounder" corresponden a dos estrategias ecológicas diferentes enmarcadas dentro de la categoría de uso de sustrato terrestre, dado que los carnívoros cavadores no utilizan el cavado como medio principal de locomoción, sino como una forma de búsqueda de refugio o presas. De esta manera, la categoría "cavador" no responde específicamente a un estilo locomotor o uso de sustrato específico, aunque en el caso específico de los carnívoros, las especies aquí denominadas como cavadoras se asemejen tanto en estilo locomotor (marchas lentas, galope) como sustrato de locomoción (principalmente terrestres).

A partir de estos datos se realizaron análisis de la varianza (ANOVA) de uno y dos factores, utilizando como variables categóricas independientes a los hábitos dietarios y locomotores. Para el caso de los índices que incluyeron la región cervical o elementos del miembro anterior (i.e., LaTL/PrLaM, LaCe/LaTL, LaMA/LaMP, LaRa/LaHu, LaMcIII/LaFIII), regiones influenciadas marcadamente por el factor dieta según estudios previos (ver Bisaillon et al. 1976, Iwaniuk et al. 1999, 2000, Samuels et al. 2013), la variable dieta fue incluida dentro de las variables explicativas y se construyeron funciones de dos factores. Para los restantes índices (i.e., LaLu/LaTL, LaSC/LaTL LaTi/LaFe) se consideró sólo a la variable locomoción como potencial factor explicativo, y se realizaron análisis de dos factores. Se evaluaron los 
supuestos de la homocedasticidad (test de Levene) y normalidad de los residuos (test de Shapiro-Wilk). Mediante ANOVAs de dos factores, se evaluó la significancia del efecto de cada factor y su interacción (i.e., $\mathrm{A}+\mathrm{B}+\mathrm{A} * \mathrm{~B}$ ). Los factores significativos se utilizaron para construir ANOVAs menos inclusivos (e.g., A o A+A*B). En el caso de que ninguno de los efectos fuese significativo en la función más incluyente, se evaluó también la significancia eliminando el efecto interacción (i.e., $\mathrm{A}+\mathrm{B}$ ), y finalmente a cada factor por separado (i.e., $\mathrm{A}$ o B). En resultados significativos para la variable "hábitos locomotores", se realizaron test a posteriori de Bonferroni para chequear diferencias entre pares de grupos. En casos puntuales de análisis no significativos con presencia de taxones outliers, los análisis fueron realizados nuevamente eliminando/modificando de grupo al taxón problemático dependiendo el caso (ver sección 3.4). Los valores de los índices obtenidos para cada grupo fueron analizados también mediante estadística descriptiva básica (e.g., media, cuartiles, rango, desvío estándar) y graficados mediante esquemas de cajas (box-plots).

Con el fin de tener en cuenta la estructura filogenética de los datos y la influencia del tamaño en la relación entre hábitos locomotores y dietarios en cada índice, se realizaron ANCOVAs filogenéticos de 1 y 2 factores utilizando GEE (Generalized Estimating Equations; Paradis y Claude 2002; ver también Morgan 2009, Cassini 2013), método derivado de regresiones de tipo Phylogenetic Generalized Least Squares regression model (PGLS; Martins y Hansen 1997, Paradis y Claude 2002); coneste método se re-analizaron las relaciones entre los factores y los índices.

Se utilizó al logaritmo natural de la masa corporal de cada especie como covariable. Los valores de masa corporal de cada especie fueron obtenidos de varias fuentes (ver Tabla 2.4), siguiendo principalmente la recopilación de Johnson et al. (2000). La estructura filogenética se obtuvo a partir de un árbol de relaciones filogenéticas combinado a partir de filogenias moleculares recientes, siendo la fuente principal Sato et al. (2012) (relaciones intra-familiares de Mustelidae; ver Fig. 1.1), y secundariamente: Koepfli et al. (2007) (intra-familiares de Procyonidae), Harding y Smith (2009) (relaciones intra-subfamiliares de Mustelinae no presentes en Sato et al. 2012), Eizirik et al. (2010) (relaciones inter-familiares, relaciones intrafamiliares de Mephitidae), Koepfli et al. (2008) (relaciones intra-subfamiliares de Guloninae no presentes en Sato et al. 2012), y Agnarsson et al. (2010) (posicionamiento de lutrinos no presentes en Sato et al. 2012, e.g., Lontra provocax). Se estandarizó el largo de rama en 1.

El procedimiento de análisis para los ANCOVAs filogenéticos fue similar al realizado para los ANOVAs. En una primera instancia, se construyeron funciones con el total de los factores y la covariable $($ Covariable $+A+B)$. En caso de no encontrarse una relación significativa entre la covariable y la variable explicada, se eliminó a la primera y se continuó con ANOVAs filogenéticos. En caso de que un factor no sea significativo, se eliminó también de las variables 
explicativas, presentándose finalmente la función ANCOVA o ANOVA filogenética menos inclusiva que incluya el total de los factores significativos. Debido a limitantes de los grados de libertad de las funciones, no fueron analizadas las interacciones entre factores en este procedimiento (casi universalmente insignificantes, ver sección 3.4).

Los análisis fueron realizados en R (versión 3.0.3; R Development Core Team 2013), y los paquetes "car" (Fox y Weisberg 2011), "mvnormtest" (Jarek 2009) y "ape" (Paradis et al. 2004).

2.2.3.3. Análisis cuantitativo de morfometría geométrica: La técnica morfometría geométrica permite, a partir de imágenes, e independizándose del efecto geométrico del tamaño, la rotación y la traslación, el estudio de los cambios de forma entre los objetos en estudio (mediante el análisis generalizado de Procrustes; Goodall 1991, Rohlf 1999).

Para cada análisis de morfometría geométrica de dos dimensiones, son necesarias fotografías orientadas y con escala. Sobre ellas se indican puntos anatómicos de referencia (landmarks), que son definidos con criterios de homología biológica, o geométrica (Barcinová 2009, Mitteroecker y Gunz 2009). Los semi-landmarks son un tipo de landmarks definidos con un criterio de homología más flexible. Estos poseen una mayor libertad de posicionamiento, y permiten trabajar con márgenes o superficies homólogas, cuando no es posible ubicar landmarks. Al conjunto de las coordenadas espaciales de los landmarks utilizados para representar la forma de un objeto se los denomina configuración de landmarks (Barcinová 2009, Mitteroecker y Gunz 2009).

Para el análisis de forma, las configuraciones de landmarks de todos los especímenes son superpuestas utilizando un análisis generalizado de Procrustes (GPA o Generalized Procrustes Analysis; Goodall 1991, Rohlf 1999), procedimiento que permite eliminar los efectos de traslación, rotación y escala, quedando el cambio de forma como único causante de las diferencias entre coordenadas de landmarks homólogos entre los distintos especímenes. Estos datos son volcados a las matrices de coordenadas de especímenes alineados. El espacio de especímenes alineados es no lineal (i.e., es curvo) y debe ser proyectado a un espacio lineal para luego poder realizar Análisis de Componentes Principales, que permitan resumir en ejes independientes los principales cambios de forma de la muestra (ver Barcinová 2009, Mitteroecker y Gunz 2009, y sus citas para un resumen del método). Para este estudio se utilizaron materiales de las colecciones nacionales y extranjeras mencionadas (ver Apéndice 2.5). La digitalización de landmarks fue llevada a cabo en el tpsDig 2.10 (Rohlf 2013a), y la edición de archivos en el tpsUtil 1.56 (Rohlf 2013b); se utilizaron tanto landmarks como semilandmarks (Fig. 2.1, Apéndice 2.6). Las vistas analizadas fueron: lateral del axis, dorsal de penúltima vértebra lumbar, craneal del extremo distal del húmero, y caudal del extremo 
proximal del fémur (Fig. 2.1). Se seleccionó la penúltima vértebra lumbar dado que las últimas vértebras lumbares presentan los rasgos de interés funcional (e.g., desarrollo de procesos de inserción muscular) más desarrollados, y se evitó el último elemento debido a que la morfología del mismo suele estar afectado por el escaso espacio entre iliones, alejándose de la morfología lumbar típica para la especie.

A partir de las coordenadas alineadas por espécimen, se construyeron coordenadas alineadas consenso por especie. Desde estas últimas se construyeron coordenadas consenso por cada grupo locomotor y dietario. A partir de estas matrices, se realizaron Análisis de Componentes Principales por grupos (between-groups PCA; Mitteroecker y Bookstein 2011). Para cada una de estas matrices (i.e., coordenadas consenso de los grupos locomotores y coordenadas consenso de los grupos dietarios), se obtuvieron las matrices de autovectores correspondientes, calculadas a partir de las matrices de varianza-covarianza entre grupos (locomotores o dietarios). Posteriormente a esto, los datos de forma promedio por especie son proyectados sobre estos autovectores, obteniéndose la maximización de separación de los grupos predefinidos en los primeros ejes sin modificarse las posiciones relativas de las especies en el morfo-espacio. Este procedimiento implica una ventaja sobre el Análisis de Componentes Principales tradicional cuando el objetivo es diferenciar grupos conocidos a priori, dado que en este último tipo de análisis los primeros ejes sintetizan la máxima separación entre muestras (e.g., especies), en vez de maximizar las diferencias entre los grupos de interés. Las coordenadas resultantes de la proyección fueron utilizadas como variables explicativas en regresiones contra las coordenadas alineadas promedio por especie, con el fin de reconstruir las grillas de deformación del morfoespacio y obtener el porcentaje de variación de forma explicada por cada eje del between-group PCA mediante el programa tpsRegr 1.38 (Rohlf 2011). Las coordenadas proyectadas fueron a su vez utilizadas como variables dependientes en análisis de varianza univariados contemplando o no la estructura filogenética y el efecto alométrico (i.e., ANOVAs sin control filogenético y ANCOVAs filogenéticos, en el caso de los análisis de la variable dieta), y multivariados (i.e., MANOVAs sin control filogenético y MANCOVAs filogenéticos, en el caso de los análisis de la variable locomoción), con el fin de evaluar la significancia del efecto de la locomoción y la dieta sobre estas variables de forma, en un procedimiento análogo al aplicado en los índices lineales, utilizando las mismas variables independientes y covariable ya comentadas (ver Tabla 2.4), y utilizando el mismo software (i.e., $\mathrm{R}$ versión 3.0.3; $\mathrm{R}$ development core team 2013; ver sección 2.2.5).

\subsubsection{Optimizaciones de caracteres miológicos y osteológicos}

Con el fin de evaluar la evolución, importancia filogenética y obtener la reconstrucción de estados ancestrales de los principales rasgos miológicos y osteológicos, y variables de interés 
ecológico, se realizaron optimizaciones de caracteres osteológicos y musculares, así como de los hábitos dietarios, locomotores y del tamaño corporal. Para esto, se utilizó la misma filogenia combinada utilizada para los análisis comparativos filogenéticos (ver más arriba). Este análisis fue realizado en TNT (Goloboff et al. 2008).

La codificación de los caracteres miológicos incluyó 32 taxones (1 félido, 1 cánido, 3 úrsidos, 2 mefítidos, 1 ailúrido, 6 prociónidos y 18 mustélidos) y 47 caracteres musculares (Apéndices 2.7, 2.8). La definición de caracteres y sus estados, incluyéndose comentarios y la forma en que fueron considerados en los análisis (aditivos vs. no aditivos) se encuentra en el Apéndice 2.7, mientras que la codificación figura en el Apéndice 2.8. Esta matriz se construyó, exceptuando el caso de la especie Galictis cuja, íntegramente sobre la base de descripciones miológicas publicadas en trabajos científicos, y presente en tesis inéditas. Estas fuentes se encuentran ya explicitadas en trabajos de Ercoli et al. (2013, 2014), y también tabuladas (para el caso de Mustelidae; Tabla 2.1) y comentadas en esta Tesis (ver sección 4.1).

La codificación de los caracteres osteológicos incluyó 31 taxones (1 félido, 2 cánidos, 1 úrsidos, 3 mefítidos, 4 prociónidos y 20 mustélidos) y 83 caracteres osteológicos: 5 continuos y 78 discretos (Apéndice 2.9, 2.10). La definición de caracteres y sus estados, indicándose comentarios y la forma en que fueron considerados en los análisis (aditivos vs. no aditivos) se encuentra en el Apéndice 2.9, mientras que la codificación figura en el Apéndice 2.10. Esta matriz se construyó, mayormente con especímenes en mano (Tabla 2.1) y material fotográfico propio, utilizándose también secundariamente información bibliográfica (Fisher 1942, Davis 1964). Algunos de los caracteres utilizados fueron modificados o tomados de propuestas previas, principalmente los trabajos de Flores (2009) y Spaulding y Flynn (2012) (ver comentarios en apéndices).

La codificación de los caracteres ecológicos incluyó 52 taxones (1 félido, 1 cánido, 1 úrsido, 5 mefítidos, 1 ailúrido, 7 prociónidos y 36 mustélidos). Sobre esta matriz se incluyeron dos carácteres discretos no aditivos, resumiendo los hábitos dietarios (c. 0 , omnívoro $=0$; carnívoro $=1)$, y los hábitos locomotores $($ c. 1 , cavador $=0$; nadador $=1$; trepador $=2$; halfbounder $=3$ ). Por otro lado, se incluyó un caracter continuo codificando la media de los tamaños coporales (unidad: Kgs./10). La información utilizada para la construcción de esta matriz, así como las fuentes bibliográficas utilizadas, se encuentra resumida en la Tabla 2.4 (ver también Ercoli et al. 2012). 


\section{Tablas de Materiales y Métodos}

Tabla 2.1 Trabajos sobre la musculatura postcraneal de la Familia Mustelidae. Los números entre paréntesis indican el número de especímenes estudiados en trabajos originales (si es conocido). Se indica con letras si los datos corresponden a la musculatura del miembro anterior, región axial o miembro posterior, en minúsculas cuando son datos aislados o exclusivamente de masa ("a", "b" o "c", respectivamente), y en mayúsculas cuando son descripciones detalladas o amplias (“A”, "B” o "C"). Asteriscos indican que corresponde a una revisión de trabajos previos, sin incluirse nuevos especímenes.

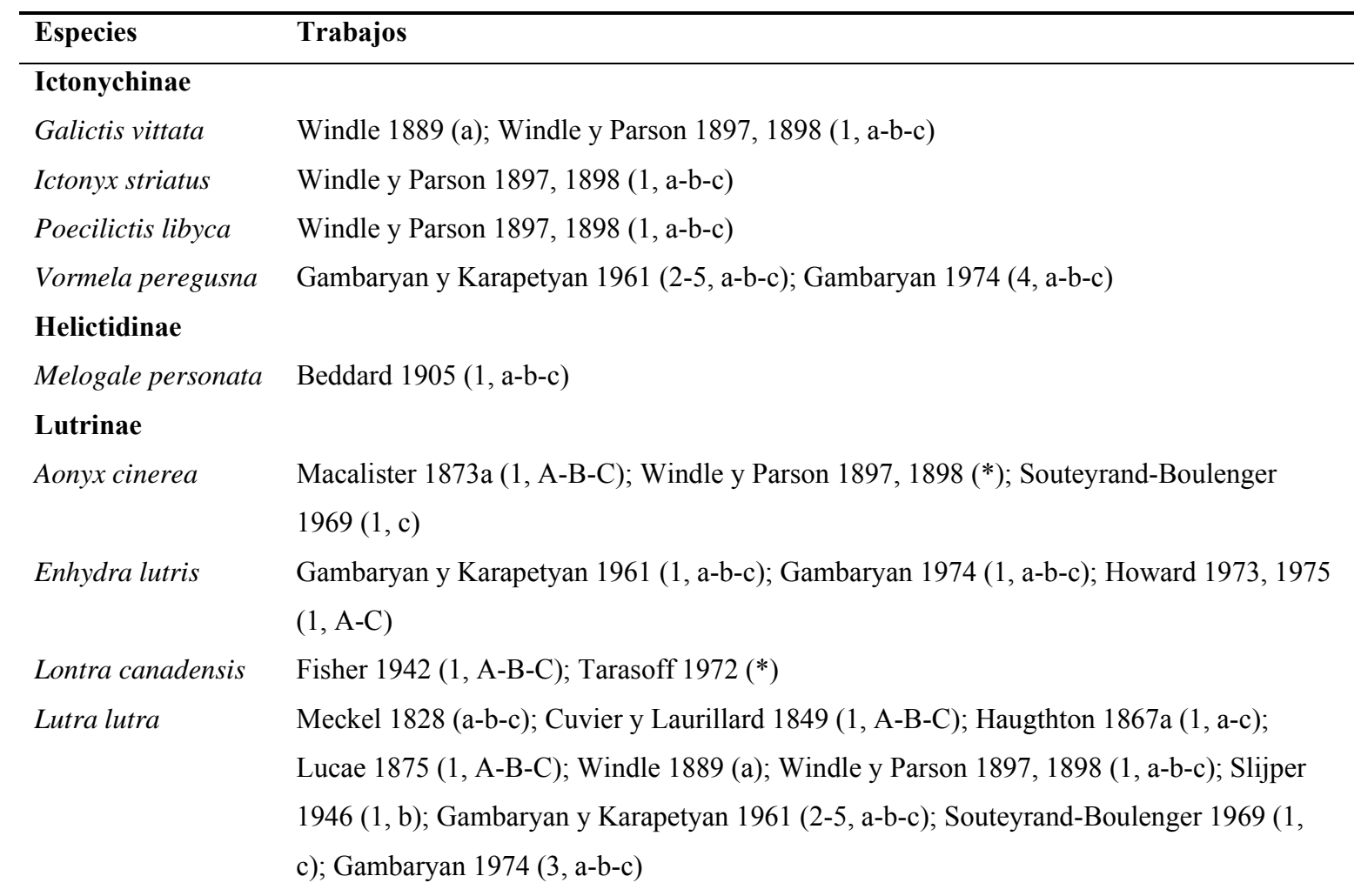

\section{Gulolinae}

Eira barbara

Macallister 1873b (1, A-B-C); Windle y Parson 1897, 1898 (*); Souteyrand-Boulenger $1969(1, \mathrm{c})$

Gulo gulo

Souteyrand-Boulenger 1969 (2, c); Gambaryan 1974 (1, a-b-c); English (1, a)

Martes americana

Hall 1926 (1, A-B-C); Piérard 1965 (*); Leach 1976 (25, A); English 1977 (1, a)

Martes foina

Meckel 1828 (a-b-c); Cuvier y Laurillard 1849 (1, A-B-C); Mackintosh 1875 (1, A-B-C);

Windle y Parson 1897, 1898 (*); Gambaryan y Karapetyan 1961 (2-5, a-b-c); Gambaryan

$1974(2, a-b-c)$

Martes pennanti $\quad$ Leach $1976(25$, A); Feeney 1999 (4, A-C)

\section{Melinae}

Meles meles
Meckel 1828 (a-b-c); Cuvier y Laurillard 1849 (1, A-B-C); Haughton 1867b (1, a-c); Windle 1889 (a); Windle y Parson 1897, 1898 (1, a-b-c); Gambaryan y Karapetyan 1961 
(2-5, a-b-c); Souteyrand-Boulenger 1969 (1, c); Gambaryan 1974 (6, a-b-c); Scherling $1989(6, \mathrm{~A}-\mathrm{C})$

\section{Mellivorinae}

Mellivora capensis

Mustelinae

Mustela eversmann

Mustela nigripes

Mustela nivalis

Mustela putorius

Taxidiinae

Taxidea taxus
Gambaryan 1974 (1, a-b-c)

Gambaryan 1974 (1, a-b-c)

Bisaillon $1976(2, \mathrm{C})$

Gambaryan y Karapetyan 1961 (2-5, a-b-c); Gambaryan 1974 (2, a-b-c)

Alix 1876 (A-B-C); Windle 1889 (a); Windle y Parson 1897, 1898 (*); Slijper 1946 (1, b);

Barone y Deustch 1953 (15, A-C); Piérard 1965 (*); Gambaryan 1974 (1, a-b-c); Evans y

Quoc An 1980 (a-b-c); Moritz et al. 2007 (1, B)

Williams 1955 (A-B-C); Piérard 1965 (*)

Hall 1927 (1, A-B-C); Piérard 1965 (*); Wagner 1976 (a); Quaife 1978 (7, A-B); Moore et al. $2013(6, \mathrm{~A})$ 
Tabla 2.2. Listado de definición y comentarios de cada una de las medidas postcraneales tomadas en los especímenes analizados (Apéndice 2.3), y utilizadas para construir los índices postcraneales (Apéndice 2.4). En comentarios, entre paréntesis, se aclara el nombre de las medidas analizadas y descriptas por Holmes (1980); y con asteriscos se indican las medidas coincidentes con la muestra de Mivart (1885). En el caso de la región torácica, fue medida por Mivart (1885) como un total, coincidente con la suma de la región post- y preanticlinal de este trabajo.

\begin{tabular}{|c|c|c|c|}
\hline Sigla & & Medida & Comentarios \\
\hline $\mathrm{LaCe}$ & & Largo de la región cervical & $\begin{array}{l}\text { Desde la articulación occipital a la } \\
\text { articulación cervico-torácica }(*)\end{array}$ \\
\hline \multirow[t]{3}{*}{ LaTL } & LaTo & Largo postanticlinal torácico & $\begin{array}{l}\text { Desde la vértebra anticlinal, } \\
\text { incluyéndola, a la articulación } \\
\text { tóraco-lumbar }\end{array}$ \\
\hline & & Largo preanticlinal torácico & $\begin{array}{l}\text { Desde la articulación cervico- } \\
\text { torácica a lavértebra anticlinal, } \\
\text { excluyéndola }\end{array}$ \\
\hline & $\mathrm{LaLu}$ & Largo de la región lumbar & $\begin{array}{l}\text { Desde la articulación tóraco- } \\
\text { lumbar a la lumbo-sacral }(*)\end{array}$ \\
\hline \multirow[t]{2}{*}{$\mathrm{LaSC}$} & $\mathrm{LaSa}$ & Largo de la región sacra & $\begin{array}{l}\text { Incluyendo exclusivamente } \\
\text { vértebras fusionadas total o } \\
\text { parcialmente }(*)\end{array}$ \\
\hline & $\mathrm{LaCa}$ & Largo de la región caudal & $\begin{array}{l}\text { Desde la articulación sacro-caudal } \\
\text { al extremo caudal }(*)\end{array}$ \\
\hline $\mathrm{LaHu}$ & & Largo del húmero & $\begin{array}{l}\text { Desde la cabeza articular al } \\
\text { cóndilo. Cuando el epicóndilo } \\
\text { medial superó distalmente a la } \\
\text { tróclea (e.g., Meles), éste no fue } \\
\text { incluido (i) }\left(^{*}\right)\end{array}$ \\
\hline LaRa & & Largo del radio & $\begin{array}{l}\text { Desde la carilla articular proximal } \\
\text { al proceso estiloides }(\mathrm{q})\left(^{*}\right)\end{array}$ \\
\hline LaMcIII & & Largo del tercer metacarpal & $\begin{array}{l}\text { Desde la articulación proximal a la } \\
\text { distal (s) }\end{array}$ \\
\hline LaFIII & & $\begin{array}{l}\text { Largo de la falange proximal del } \\
\text { tercer digito del carpo }\end{array}$ & $\begin{array}{l}\text { Desde la articulación proximal a la } \\
\text { distal }(*)\end{array}$ \\
\hline $\mathrm{LaFe}$ & & Largo máximo del fémur & $\begin{array}{l}\text { Desdela cabeza articular a los } \\
\text { cóndilos articulares }(\mathrm{x})(*)\end{array}$ \\
\hline LaTi & & Largo máximo de la tibia & $\begin{array}{l}\text { Desde los cóndilos articulares al } \\
\text { maléolo medial (D) }(*)\end{array}$ \\
\hline LaMtIII & & Largo máximo del metatarsal III & $\begin{array}{l}\text { Desde la articulación proximal a la } \\
\text { distal }(*)\end{array}$ \\
\hline
\end{tabular}


Tabla 2.3. Valores promedio por especie para cada índice de medidas lineales. Los valores fueron obtenidos a partir de valores tomados en esta Tesis ("Esta Tesis") y otros compilados de diversas fuentes: "M" = Mivart (1885); "S" = Slijper (1946); "D" = Davis (1964); "H" = Holmes (1980); "V" = Van Valkenburgh (1987); "I" = Iwaniuk et al. (1999).

(Ver a continuación, tres páginas siguientes) 


\begin{tabular}{|c|c|c|c|c|c|c|}
\hline \multirow{2}{*}{$\begin{array}{l}\text { Especie } \\
\text { Ailurus fulgens }\end{array}$} & \multicolumn{2}{|c|}{ LaTL/PrLaM } & \multicolumn{2}{|r|}{ LaCe/LaTL } & \multicolumn{2}{|r|}{ LaLu/LaTL } \\
\hline & 1,1947 & $\mathrm{M}$ & 0,2739 & M; D & 0,3966 & M; D \\
\hline Aonyx sp. & 1,6035 & M & 0,2363 & M & 0,3791 & M \\
\hline Arctonyx collaris & 1,6440 & M & 0,3052 & M & 0,2674 & M \\
\hline \multicolumn{7}{|l|}{ Bassaricyon sp. } \\
\hline Bassariscus astutus & 1,3729 & M & 0,3090 & M; D & 0,4400 & M; D \\
\hline \multicolumn{7}{|l|}{ Conepatus chinga } \\
\hline \multicolumn{7}{|l|}{ Conepatus leuconotus } \\
\hline Conepatus sp. & 1,2509 & M; Esta Tesis & 0,2439 & M; S; Esta Tesis & 0,2926 & M; D; Esta Tesis \\
\hline Eira barbara & 1,5300 & M; Esta Tesis & 0,2937 & M; Esta Tesis & 0,3666 & M; Esta Tesis \\
\hline Enhydra lutris & 1,9764 & M & 0,1808 & $\mathrm{M} ; \mathrm{S}$ & 0,3817 & $\mathrm{M} ; \mathrm{S}$ \\
\hline Galictis cuja & 1,8500 & Esta Tesis & 0,3298 & Esta Tesis & 0,3106 & Esta Tesis \\
\hline \multicolumn{7}{|l|}{ Galictis vittata } \\
\hline Gulo gulo & 1,2953 & M & 0,2951 & M & 0,3203 & M \\
\hline Ictonyx sp. & 1,4966 & M & 0,2549 & M & 0,3114 & M \\
\hline \multicolumn{7}{|l|}{ Lontra canadensis } \\
\hline Lontra longicaudis & 1,8471 & Esta Tesis & 0,3076 & Esta Tesis & 0,3093 & Esta Tesis \\
\hline Lontra provocax & & & 0,2846 & Esta Tesis & 0,2981 & Esta Tesis \\
\hline Lutra lutra & & & 0,3600 & S & 0,3200 & $\mathrm{~S}$ \\
\hline Lyncodon patagonicus & 2,1168 & Esta Tesis & 0,3108 & Esta Tesis & 0,2311 & Esta Tesis \\
\hline \multicolumn{7}{|l|}{ Martes americana } \\
\hline \multicolumn{7}{|l|}{ Martes pennanti } \\
\hline \multicolumn{7}{|l|}{ Meles meles } \\
\hline Meles sp. & 1,5312 & M; Esta Tesis & 0,3129 & M; S; D; Esta Tesis & 0,2964 & M; S; D; Esta Tesis \\
\hline Mellivora capensis & 1,2488 & M & 0,3508 & M; D & 0,2733 & M; D \\
\hline Melogale sp. & 1,5553 & M & 0,2640 & M & 0,3817 & M \\
\hline Mephitis sp. & 1,5138 & M & 0,2629 & M & 0,3415 & M \\
\hline \multicolumn{7}{|l|}{ Mustela erminea } \\
\hline \multicolumn{7}{|l|}{ Mustela frenata } \\
\hline Mustela putorius & 1,9724 & M & 0,3067 & M & 0,4314 & M \\
\hline \multicolumn{7}{|l|}{ Mustela nivalis } \\
\hline Mustela vison & 1,8728 & Esta Tesis & 0,3136 & Esta Tesis & 0,3750 & Esta Tesis \\
\hline Mydaus sp. & 1,3047 & M & 0,2271 & M & 0,3398 & $\mathrm{M} ; \mathrm{S}$ \\
\hline \multicolumn{7}{|l|}{ Nasua narica } \\
\hline \multicolumn{7}{|l|}{ Nasua nasua } \\
\hline Nasua sp. & 1,1521 & M; Esta Tesis & 0,2748 & M; S; D; Esta Tesis & 0,4308 & M; S; Esta Tesis \\
\hline Potos flavus & 1,5277 & M & 0,1815 & M & 0,4704 & M \\
\hline \multicolumn{7}{|l|}{ Procyon cancrivorus } \\
\hline \multicolumn{7}{|l|}{ Procyon lotor } \\
\hline Procyon sp. & 1,0098 & M; Esta Tesis & 0,2614 & M; D; Esta Tesis & 0,3874 & D; Esta Tesis \\
\hline Spilogale gracilis & & & 0,2695 & Esta Tesis & 0,3791 & Esta Tesis \\
\hline \multicolumn{7}{|l|}{ Spilogale sp. } \\
\hline Taxidea taxus & 1,4918 & M & 0,2813 & M; D & 0,3314 & M; D \\
\hline
\end{tabular}




\begin{tabular}{|c|c|c|c|c|c|c|}
\hline \multirow{2}{*}{$\begin{array}{l}\text { Especie } \\
\text { Ailurus fulgens }\end{array}$} & \multicolumn{2}{|c|}{ LaSC/LaTL } & \multicolumn{2}{|c|}{ LaMA/LaMP } & \multicolumn{2}{|r|}{ LaRa/LaHu } \\
\hline & 1,6098 & M & 0,8940 & M & 0,7451 & M; D \\
\hline Aonyx sp. & 1,3201 & M & 0,8306 & M & 0,8396 & M \\
\hline Arctonyx collaris & 0,8169 & M & 0,8725 & M & 0,8207 & M \\
\hline Bassaricyon sp. & & & & & 0,7480 & $\mathrm{D}$ \\
\hline Bassariscus astutus & & & 0,8242 & M & 0,8000 & $\mathrm{M} ; \mathrm{D}$ \\
\hline Conepatus chinga & & & 0,7852 & Esta Tesis & 0,8954 & Esta Tesis \\
\hline Conepatus leuconotus & & & & & 0,8320 & $\mathrm{H}$ \\
\hline Conepatus sp. & 1,3233 & M; Esta Tesis & & & & \\
\hline Eira barbara & 1,2406 & M; Esta Tesis & 0,8366 & M; Esta Tesis & 0,7741 & M; H; Esta Tesis \\
\hline Enhydra lutris & 0,8607 & M & 0,6984 & $\mathrm{M} ; \mathrm{H}$ & 0,7677 & $\mathrm{M} ; \mathrm{D} ; \mathrm{H}$ \\
\hline Galictis cuja & 0,8826 & Esta Tesis & 0,7967 & Esta Tesis & 0,6934 & Esta Tesis \\
\hline \multicolumn{7}{|l|}{ Galictis vittata } \\
\hline Gulo gulo & 0,7287 & M & 0,8744 & M & 0,8453 & $\mathrm{M} ; \mathrm{D} ; \mathrm{H}$ \\
\hline Ictonyx sp. & 1,4980 & M & 0,8000 & M & 0,7963 & M \\
\hline Lontra canadensis & & & 0,6873 & $\mathrm{H}$ & 0,7270 & $\mathrm{D} ; \mathrm{H}$ \\
\hline Lontra longicaudis & 1,4811 & Esta Tesis & 0,8053 & Esta Tesis & 0,7045 & Esta Tesis \\
\hline Lontra provocax & 1,3980 & Esta Tesis & 0,8122 & Esta Tesis & 0,7078 & Esta Tesis \\
\hline \multicolumn{7}{|l|}{ Lutra lutra } \\
\hline Lyncodon patagonicus & & & 0,8303 & Esta Tesis & 0,6650 & Esta Tesis \\
\hline Martes americana & & & 0,7915 & $\mathrm{H}$ & 0,7930 & $\mathrm{H}$ \\
\hline Martes pennanti & & & 0,7728 & $\mathrm{H}$ & 0,7890 & $\mathrm{D} ; \mathrm{H}$ \\
\hline \multicolumn{7}{|l|}{ Meles meles } \\
\hline Meles sp. & 0,6113 & M; Esta Tesis & 0,8688 & M; Esta Tesis & 0,8460 & M; Esta Tesis \\
\hline Mellivora capensis & 0,7478 & M & 0,9025 & M & 0,8117 & M; D \\
\hline Melogale sp. & 1,1026 & M & 0,7736 & M & 0,8325 & M \\
\hline Mephitis sp. & 1,2168 & M & 0,7808 & M & 0,8132 & $\mathrm{M} ; \mathrm{H}$ \\
\hline \multicolumn{7}{|l|}{ Mustela erminea } \\
\hline Mustela frenata & & & 0,7694 & $\mathrm{H}$ & 0,7090 & $\mathrm{H}$ \\
\hline Mustela putorius & 0,5910 & M & 0,7877 & M & 0,7469 & $\mathrm{M}$ \\
\hline Mustela nivalis & & & & & 0,7440 & $\mathrm{H}$ \\
\hline Mustela vison & 0,9745 & Esta Tesis & 0,7506 & M; Esta Tesis & 0,6917 & H; Esta Tesis \\
\hline Mydaus sp. & & & 1,0231 & M & 0,5179 & M \\
\hline \multicolumn{7}{|l|}{ Nasua narica } \\
\hline \multicolumn{7}{|l|}{ Nasua nasua } \\
\hline Nasua sp. & 1,7611 & M; Esta Tesis & 0,8108 & M; Esta Tesis & 0,8656 & M; D; Esta Tesis \\
\hline Potos flavus & 1,7110 & M & 0,8377 & M & 0,7901 & D; Esta Tesis \\
\hline Procyon cancrivorus & & & 0,8121 & Esta Tesis & 0,9505 & Esta Tesis \\
\hline Procyon lotor & & & 0,8321 & Esta Tesis & 1,0091 & D; Esta Tesis \\
\hline Procyon sp. & 1,0980 & M; Esta Tesis & & & & \\
\hline Spilogale gracilis & 1,1666 & Esta Tesis & & & & \\
\hline Spilogale sp. & & & 0,7982 & $\mathrm{H}$ & 0,7976 & H; Esta Tesis \\
\hline Taxidea taxus & 0,7551 & $\mathrm{M}$ & 0,9528 & $\mathrm{M} ; \mathrm{H}$ & 0,8124 & $\mathrm{M} ; \mathrm{D} ; \mathrm{H}$ \\
\hline
\end{tabular}




\begin{tabular}{|c|c|c|c|c|}
\hline \multirow{2}{*}{$\begin{array}{l}\text { Especie } \\
\text { Ailurus fulgens }\end{array}$} & \multicolumn{2}{|c|}{ LaMcIII/LaFIII } & \multicolumn{2}{|r|}{ LaTi/LaFe } \\
\hline & & & 0,9495 & M; D \\
\hline Aonyx sp. & & & 1,0452 & $\mathrm{M}$ \\
\hline Arctonyx collaris & 2,008 & $\mathrm{~V}$ & 0,8263 & M \\
\hline Bassaricyon sp. & & & 1,0170 & $\mathrm{D}$ \\
\hline Bassariscus astutus & 1,551 & $\mathrm{~V}$ & 0,9641 & M; D \\
\hline Conepatus chinga & 2,33888 & Esta Tesis & 1,0625 & Esta Tesis \\
\hline Conepatus leuconotus & & & 1,0200 & $\mathrm{H}$ \\
\hline \multicolumn{5}{|l|}{ Conepatus sp. } \\
\hline Eira barbara & 1,51264 & $\mathrm{~V}$; Esta Tesis & 0,9204 & M; H; Esta Tesis \\
\hline Enhydra lutris & & & 1,1719 & $\mathrm{M} ; \mathrm{D} ; \mathrm{H}$ \\
\hline Galictis cuja & 1,59763 & Esta Tesis & 0,9706 & Esta Tesis \\
\hline Galictis vittata & 1,67 & $\mathrm{~V}$ & & \\
\hline Gulo gulo & 2,00914 & $\mathrm{~V} ; \mathrm{I}$ & 0,9434 & $\mathrm{M} ; \mathrm{D} ; \mathrm{H}$ \\
\hline Ictonyx sp. & & & 1,0000 & $\mathrm{M}$ \\
\hline Lontra canadensis & 1,79188 & $\mathrm{I}$ & 1,1770 & $\mathrm{D} ; \mathrm{H}$ \\
\hline Lontra longicaudis & 1,39344 & Esta Tesis & 1,1588 & Esta Tesis \\
\hline Lontra provocax & & & 1,1023 & Esta Tesis \\
\hline \multicolumn{5}{|l|}{ Lutra lutra } \\
\hline Lyncodon patagonicus & 1,2541 & Esta Tesis & 1,0696 & Esta Tesis \\
\hline Martes americana & 2,01224 & I & 1,0890 & $\mathrm{H}$ \\
\hline Martes pennanti & 1,88346 & $\mathrm{~V} ; \mathrm{I}$ & 1,0275 & $\mathrm{D} ; \mathrm{H}$ \\
\hline Meles meles & 2,05681 & $\mathrm{~V}$; Esta Tesis & & \\
\hline Meles sp. & & & 0,8564 & M; Esta Tesis \\
\hline Mellivora capensis & 1,575 & $\mathrm{~V}$ & 0,7866 & $\mathrm{M} ; \mathrm{D}$ \\
\hline Melogale sp. & & & 0,9487 & $\mathrm{M}$ \\
\hline Mephitis sp. & 2,42815 & $\mathrm{~V} ; \mathrm{I}$ & 1,0161 & $\mathrm{M} ; \mathrm{H}$ \\
\hline Mustela erminea & 1,61808 & $\mathrm{I}$ & & \\
\hline Mustela frenata & 1,44547 & I & 1,0920 & $\mathrm{H}$ \\
\hline Mustela putorius & & & 1,0000 & M \\
\hline Mustela nivalis & 1,57036 & I & 1,0270 & $\mathrm{H}$ \\
\hline Mustela vison & 1,30208 & I; Esta Tesis & 1,0981 & $\mathrm{H}$; Esta Tesis \\
\hline Mydaus sp. & & & 0,9802 & $\mathrm{M}$ \\
\hline Nasua narica & 1,887 & $\mathrm{~V}$ & & \\
\hline Nasua nasua & 1,83508 & Esta Tesis & & \\
\hline Nasua sp. & & & 0,9486 & M; Esta Tesis \\
\hline Potos flavus & 1,409 & $\mathrm{~V}$ & 0,9502 & M; D; Esta Tesis \\
\hline Procyon cancrivorus & & V; I; Esta & 1,0329 & Esta Tesis \\
\hline Procyon lotor & 1,95926 & Tesis & 1,0267 & D; Esta Tesis \\
\hline \multicolumn{5}{|l|}{ Procyon sp. } \\
\hline Spilogale gracilis & 1,74214 & Esta Tesis & 1,0059 & Esta Tesis \\
\hline \multicolumn{5}{|l|}{ Spilogale sp. } \\
\hline Taxidea taxus & 1,40929 & $\mathrm{~V} ; \mathrm{I}$ & 0,7941 & $\mathrm{M} ; \mathrm{D} ; \mathrm{H}$ \\
\hline
\end{tabular}


Tabla 2.4. Variables independientes (locomoción, dieta) y covariable (masa) utilizadas en los análisis cuantitativos. Las categorías y asignaciones de la variable dieta corresponden principalmente a una simplificación de la propuesta por Prevosti et al. (2012). Las categorías y asignaciones de la variable de locomoción fueron construidas para esta tesis, inspiradas principalmente en las propuestas en los trabajos Schutz y Guralnick (2007) y Álvarez et al. (2013; ver Materiales y Métodos). Con "*" se indican especies que fueron trasladadas de categoría locomotora o eliminadas en análisis de índices específicos (en general outliers que presentaron dificultades en la asignación a una categoría específica; ver sección 3.4). La variable masa se encuentra expresada en gramos, indicándose la bibliografía de referencia en la última columna.

\begin{tabular}{|c|c|c|c|c|}
\hline Especie & Locomoción & Dieta & Masa & \\
\hline Ailurus fulgens & trepador & omnívoro & 3740 & Fabre et al. (2013b) \\
\hline Aonyx cinerea & nadador & carnívoro & 3100 & Wilson y Mittermeier (2009) \\
\hline Aonyx congicus & nadador & carnívoro & 25000 & Kruuk (2006) \\
\hline Aonyx sp. & nadador & carnívoro & 18990 & Johnson et al. (2000) \\
\hline Arctonyx collaris & cavador & omnívoro & 10500 & Wilson y Mittermeier (2009) \\
\hline Bassaricyon sp. & trepador & omnívoro & 1242 & Fabre et al. (2013b) \\
\hline Bassariscus astutus & half-bounder* & carnívoro & 1020 & Silva y Downing 1995 \\
\hline Conepatus chinga & cavador & omnívoro & 1917 & Johnson et al. (2000) \\
\hline Conepatus leuconotus & cavador & omnívoro & 2103 & Johnson et al. (2000) \\
\hline Conepatus sp. & cavador & Omnívoro & 2010 & Johnson et al. (2000) \\
\hline Eira barbara & trepador & carnívoro & 4620 & Johnson et al. (2000) \\
\hline Enhydra lutris & nadador & omnívoro & 23780 & Johnson et al. (2000) \\
\hline Galictis cuja & half-bounder* & carnívoro & 1000 & Johnson et al. (2000) \\
\hline Galictis vittata & half-bounder & carnívoro & 2590 & Johnson et al. (2000) \\
\hline Gulo gulo & trepador* & carnívoro & 12700 & Johnson et al. (2000) \\
\hline Hydrictis maculicollis & nadador & carnívoro & 3940 & Johnson et al. (2000) \\
\hline Ictonyx striatus & cavador & omnívoro & 1590 & Johnson et al. (2000) \\
\hline Ictonyx sp. & cavador & omnívoro & 1590 & Johnson et al. (2000) \\
\hline Lontra canadensis & nadador & carnívoro & 8190 & Johnson et al. (2000) \\
\hline Lontra longicaudis & nadador & carnívoro & 6560 & Johnson et al. (2000) \\
\hline Lontra provocax & nadador & carnívoro & 7500 & Jones et al. (2009) \\
\hline Lontra felina & nadador & carnívoro & 4000 & Johnson et al. (2000) \\
\hline Lutra lutra & nadador & carnívoro & 7100 & Johnson et al. (2000) \\
\hline Lutrogale perspicillata & nadador & carnívoro & 8795 & Johnson et al. (2000) \\
\hline Lyncodon patagonicus & half-bounder* & carnívoro & 250 & Wilson y Mittermeier (2009) \\
\hline Martes americana & half-bounder & carnívoro & 870 & Johnson et al. (2000) \\
\hline Martes martes & half-bounder & carnívoro & 1200 & Johnson et al. (2000) \\
\hline Martes pennanti & half-bounder & carnívoro & 3380 & Johnson et al. (2000) \\
\hline Meles anakuma & cavador & omnívoro & 11500 & Wilson y Mittermeier (2009) \\
\hline Meles meles & cavador & omnívoro & 11610 & Johnson et al. (2000) \\
\hline Meles sp. & cavador & omnívoro & 7780 & Johnson et al. (2000), Wilson y M. (2000) \\
\hline Mellivora capensis & cavador & omnívoro & 8080 & Johnson et al. (2000) \\
\hline Melogale moschata & cavador & omnívoro & 2000 & Johnson et al. (2000) \\
\hline Melogale orientalis & cavador & omnívoro & 2000 & Johnson et al. (2000) \\
\hline Melogale sp. & cavador & omnívoro & 1650 & Wilson y Mittermeier (2009) \\
\hline Mephitis mephitis & cavador & omnívoro & 2400 & Johnson et al. (2000) \\
\hline Mephitis sp. & cavador & omnívoro & 2400 & Johnson et al. (2000) \\
\hline Mustela erminea & half-bounder & carnívoro & 180 & Johnson et al. (2000) \\
\hline Mustela frenata & half-bounder & carnívoro & 240 & Johnson et al. (2000) \\
\hline Mustela itatsi & half-bounder & carnívoro & 300 & Abramov y Wozencraft (2012) \\
\hline Mustela putorius & half-bounder & carnívoro & 1030 & Johnson et al. (2000) \\
\hline Mustela nigripes & half-bounder & carnívoro & 915 & Johnson et al. (2000) \\
\hline Mustela nivalis & half-bounder & carnívoro & 80 & Johnson et al. (2000) \\
\hline Mustela vison & half-bounder & carnívoro & 910 & Johnson et al. (2000) \\
\hline Mydaus sp. & cavador* & omnívoro & 2510 & Fabre et al. (2013b) \\
\hline
\end{tabular}




\begin{tabular}{|c|c|c|c|c|}
\hline Nasua narica & trepador & omnívoro & 4000 & Fabre et al. (2013b) \\
\hline Nasua nasua & trepador & omnívoro & 4500 & Fabre et al. (2013b) \\
\hline Nasua sp. & trepador & omnívoro & 3600 & Silva y Downing 1995 \\
\hline Poecilictis libyca & cavador & omnívoro & 400 & Wilson y Mittermeier (2009) \\
\hline Potos flavus & trepador & omnívoro & 2500 & Silva y Downing 1995 \\
\hline Procyon cancrivorus & trepador & omnívoro & 5000 & Fabre et al. (2013b) \\
\hline Procyon lotor & trepador & omnívoro & 6170 & Fabre et al. (2013b) \\
\hline Procyon sp. & trepador & omnívoro & 7300 & Silva y Downing 1995 \\
\hline Pteronura brasiliensis & nadador & carnívoro & 25000 & Johnson et al. (2000) \\
\hline Spilogale gracilis & cavador & omnívoro & 340 & Johnson et al. (2000) \\
\hline Spilogale sp. & cavador & omnívoro & 355 & Johnson et al. (2000) \\
\hline Taxidea taxus & cavador & carnívoro & 6300 & Johnson et al. (2000) \\
\hline Vormela peregusna & half-bounder & carnívoro & 600 & Johnson et al. (2000) \\
\hline
\end{tabular}


Figuras de Materiales y Métodos

A

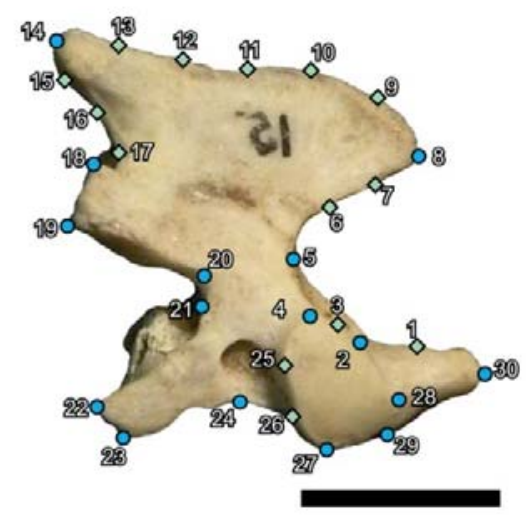

C

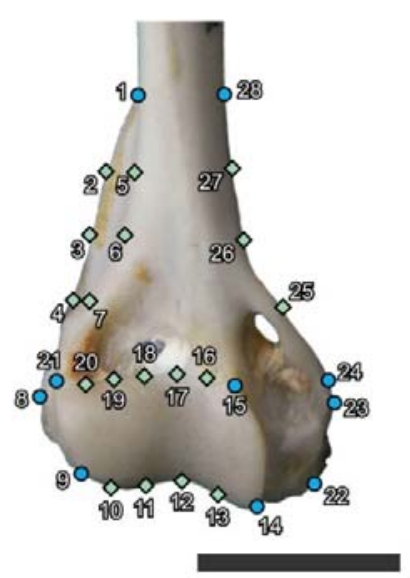

B

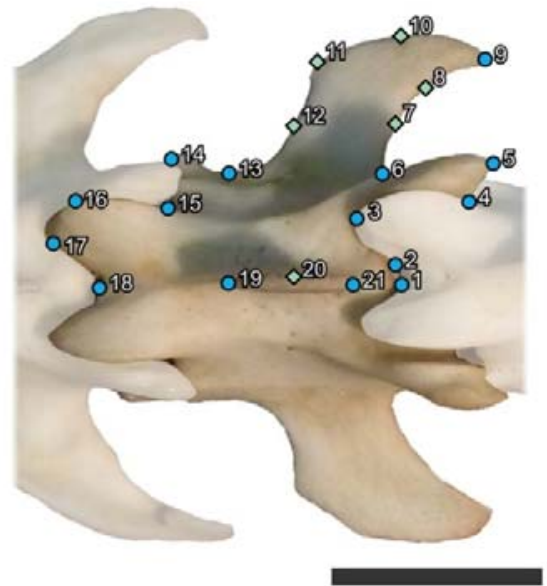

D

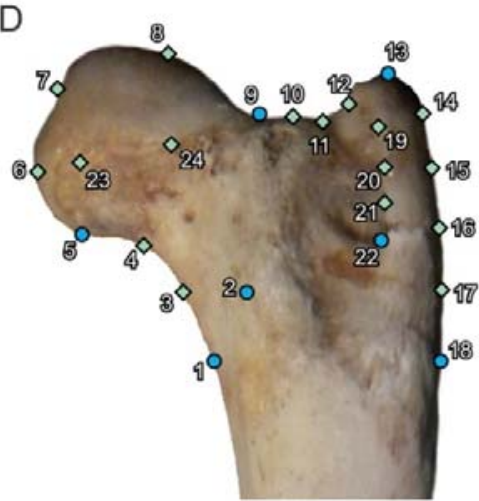

Figura 2.1. Configuraciones de landmarks diseñadas para sintetizar los cambios de formas en cada una de las vistas analizadas: lateral del axis (A), dorsal de la penúltima vértebra lumbar (B), craneal del extremo distal del húmero (C) y caudal del extremo proximal del fémur (D). Ver Apéndice 2.6, para la definición de cada landmark (círculos celestes) y grupo de semi-landmark (rombos verdes) indicados. Escala $=10 \mathrm{~mm}$. 
Capítulo 3

RESULTADOS
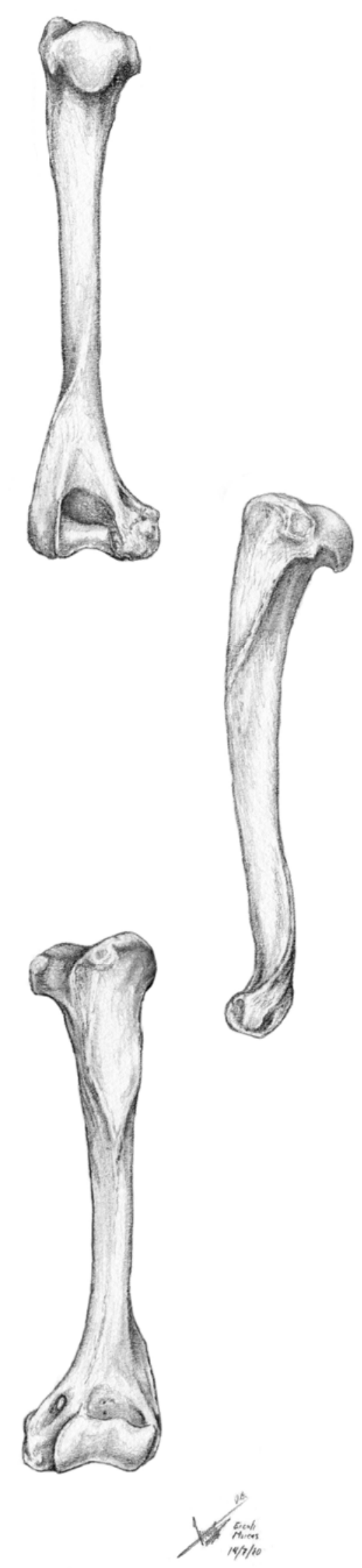

57 



\section{Resultados}

\subsection{Descripción de la miología de Galictis cuja}

Se presenta la descripción exhaustiva de la musculatura de Galictis cuja en el siguiente orden: cefálica, cervical, hioides, dorsal y torácica, abdominal, lingual, extrínseca e intrínseca del miembro anterior, epiaxial lumbar, caudal, urogenital y rectal, sublumbar, del muslo, de la pierna y del pie. Este orden, así como el orden de los músculos descriptos dentro de cada región, es el presentado en la Nómina Anatómica Veterinaria (Waibl et al. 2005). En el Tomo II (Láminas 2), se ilustra, con mapas musculares y dibujos, cada una de las regiones y músculos descriptos. Las variantes intraespecíficas que presentan los diferentes especímenes diseccionados se presentan en el Apéndice 3.1.

\subsubsection{Musculatura de la cabeza}

M. rectus capitis ventralis (= rectus capitis anterior) (Láminas 2.1, 2.5)

Pequeño y cilíndrico. Se ubica medial al $\mathrm{m}$. rectus capitis lateralis y profundo con respecto al $\mathrm{m}$. longus capitis. Corre desde el atlas hasta la región basioccipital.

Origen: Mediante fibras carnosas en la región ventral de la base del ala del atlas y la cápsula atlanto-occipital contigua.

Inserción: Mediante fibras carnosas sobre el hueso basioccipital, inmediatamente caudal a la inserción del $\mathrm{m}$. longus capitis y la cápsula atlanto-occipital contigua.

M. rectus capitis dorsalis major $(=\mathbf{m}$. rectus capitis posterior/dorsalis major) (Láminas 2.1, 2.5)

Ubicado en el sector cráneodorsal del cuello, por debajo del $\mathrm{m}$. biventer cervicis y $\mathrm{m}$. complexus, y superficial al $\mathrm{m}$. rectus capitis dorsalis minor. En vista general es delgado, carnoso y alargado. Está compuesto por dos vientres: uno superficial extenso, y otro profundo pequeño y delgado. En un caso subdividido, el vientre profundo se encontró compuesto a su vez por dos capas musculares. Este músculo alcanza la línea media a lo largo de todo su recorrido vía fascia, y en su sector profundo, ambos vientres alcanza vía aponeurosis la región dorsal al atlas.

Origen: El vientre superficial se origina mediante fibras carnosas sobre el extremo caudodorsal del proceso espinoso del axis. El vientre profundo se origina del margen cráneodorsal del proceso espinoso del axis.

Inserción: El vientre superficial se inserta mediante fibras carnosas, y algunas tendinosas, sobre un área delgada sobre el cuarto medial y profundo de la cresta lambdoidea. El vientre profundo se inserta inmediatamente ventral (interno) a éste, sobre la base de la cresta.

M. rectus capitis dorsalis intermedius $(=\mathrm{m}$. rectus capitis posterior/dorsalis major) (Láminas 2.1, 2.5) 
Dde forma alargada, se ubica profundo al $\mathrm{m}$. rectus capitis dorsalis major, por delante del m. obliquus capitis caudalis (con el cual comparte algunas fibras en cercanías a su origen) y lateral al $\mathrm{m}$. rectus capitis dorsalis minor.

Origen: Mediante fibras carnosas sobre el aspecto craneal del extremo del proceso espinoso del axis.

Inserción: Mediante fibras carnosas sobre el hueso occipital, inmediatamente lateral al $\mathrm{m}$. rectus capitis dorsalis major y profundo al $\mathrm{m}$. obliquus capitis cranialis.

\section{M. rectus capitis dorsalis minor (= rectus capitis posterior minor) (Láminas 2.1, 2.4-5)}

Se ubica por debajo del $\mathrm{m}$. rectus capitis dorsalis major y $\mathrm{m}$. rectus capitis dorsalis intermedius. Este músculo se encuentra compuesto por dos vientres diferenciados en mayor o menor medida. El medial posee forma triangular y breve, mientras que el lateral tiene forma elongada.

Origen: El vientre medial se origina mediante fibras carnosas sobre la región craneal y medial del arco neural del atlas. Un gran número de fibras se originan desde la cápsula articular atlascráneo. El vientre lateral se origina sobre todo el margen craneal del arco neural del atlas no ocupado por el anterior.

Inserción: El vientre medial se inserta mediante fibras carnosas sobre el sector mediodorsal del hueso occipital, inmediatamente lateroventral a la protuberancia occipital externa. El vientre lateral se inserta mediante fibras carnosas sobre el sector dorsal del hueso occipital, inmediatamente lateral al anterior.

M. rectus capitis lateralis (Láminas 2.1, 2.4-5)

Aplanado y triangular. Se ubica en el aspecto lateroventral y profundo del sector atlanto-occipital. En cercanías a su inserción (en dos lados) o la mayor parte de su recorrido (en dos lados), comparte fibras con el vientre ventral del $\mathrm{m}$. obliquus capitis cranialis.

Origen: Mediante fibras carnosas sobre el aspecto ventral del ala del atlas y sobre el margen lateroventral del proceso articular craneal.

Inserción: Mediante fibras carnosas sobre el proceso paraoccipital y sobre el hueso occipital inmediatamente dorsal a este proceso.

M. obliquus capitis cranialis (=obliquus capitis superior) (Láminas 2.1, 2.3, 2.5)

Compuesto por dos vientres, uno dorsal y otro ventral, superficiales al m. rectus capitis dorsalis intermedius y $\mathrm{m}$. rectus capitis lateralis respectivamente. El vientre dorsal se encuentra engrosado en su zona media, mientras que el ventral es aplanado a lo largo de todo su recorrido. El grado de fusión con el $\mathrm{m}$. rectus capitis lateralis es variable (ver arriba).

Origen: El vientre dorsal se origina mediante fibras carnosas sobre el margen craneal y el lateral del ala del atlas. Las fibras más dorsales del paquete dorsal se originan vía fascia sobre el 
m. obliquus capitis caudalis. El vientre ventral se origina mediante fibras carnosas sobre el sector craneal y lateral de la superficie ventral del atlas.

Inserción: El vientre dorsal se inserta mediante una fascia tendinosa breve, sobre el hueso occipital, sobre una cresta ósea breve y profunda a la cresta lambdoidea principal e inmediaciones, inmediatamente lateral al $\mathrm{m}$. rectus capitis dorsalis major, y superficial al $\mathrm{m}$. rectus capitis dorsalis intermedius. El vientre ventral se inserta principalmente mediante fibras carnosas y una fascia tendinosa superficial, sobre el hueso mastoideo, inmediatamente ventral a la cresta lambdoidea y en continuación con la inserción del vientre anterior.

\section{M. obliquus capitis caudalis (=obliquus capitis posterior, obliquus inferior, obliquus} inferior capitis) (Láminas 2.1,2.5)

Voluminoso, ventral a los mm. rectus capitis dorsalis, y cuyas fibras transcurren desde caudodorsal a cráneoventral, desde el axis al atlas, en contacto con la mayor parte del aspecto lateral del axis. En el sector más craneal del mismo comparte algunas fibras con el m. rectus capitis dorsalis intermedius.

Origen: Mediante fibras carnosas sobre el proceso espinoso de axis, incluyendo su margen caudal. Algunas fibras se originan desde la base de este proceso y del proceso articular caudal.

Inserción: Mediante fibras carnosas sobre el total de la cara dorsal del ala del atlas, inmediatamente medial y caudal al origen del m. obliquus capitis cranialis. Algunas fibras se insertan sobre la cápsula articular del axis-atlas. En tres de los cuatro lados se registraron además fibras insertadas sobre el margen lateral del proceso articular craneal del atlas.

M. longus capitis (Láminas 2.1-2, 2.5)

Compuesto de múltiples paquetes aplanados, se ubica medial al mm. intertransversarii ventrales cervicis y lateral al $\mathrm{m}$. longus colli. Los paquetes se dirigen, desde sus orígenes a inserciones, en dirección cráneomedial. En su sector caudal comparte algunas fibras con el m. longus colli.

Origen: Mediante fibras carnosas y tendinosas, sobre la región craneal de las láminas ventrales de los procesos transversos cervicales entre $\mathrm{C} 6$ y $\mathrm{C} 3$, y mediante fibras principalmente carnosas, sobre el margen ventral y central del proceso transverso del axis.

Inserción: Mediante fibras carnosas y un tendón aplanado caudolateral sobre el hueso basioccipital, medial a la bulla timpánica, sin sobrepasar su margen craneal.

\section{M. masseter (Láminas 2.2-5)}

Compuesto por tres porciones diferenciables: superficial, intermedia y profunda. El paquete superficial posee fibras que inclinan marcadamente en dirección caudal hacia la inserción y que se encuentran cubiertas totalmente por una fascia. El sector caudal de la zona de inserción se continúa por el margen caudal y la cara medial del proceso angular (porción reflexa; Scapino 1974). Caudal al proceso angular, la porción superficial del masetero se 
continua e inserta sobre el rafe que la une al m. pterygoideus medial, el cual se continua caudalmente como el ligamento meato-rafeal (ver Scapino 1974). Los paquetes superficial e intermedio se encuentran fusionados en cercanías al origen e inserción de ambos. El paquete intermedio presenta una fascia que lo cubre parcialmente; sus fibras corren en dirección caudoventral, con una inclinación intermedia entre las que presentan los paquetes superficial y profundo; compartiendo algunas fibras con este último. El paquete profundo presenta fibras con una dirección mayormente vertical, cubiertas en el sector caudal por una fascia. Se observa también una fascia que separa al $\mathrm{m}$. masseter y al m. digastricus.

Origen: La porción superficial se origina mediante fibras carnosas a lo largo de algo más que la mitad craneal del margen ventral del arco cigomático incluyendo la raíz craneal. El origen sobre la raíz es mediante un tendón fuerte. El paquete intermedio se origina mediante fibras carnosas a lo largo de todo el arco cigomático excluyendo la raíz craneal e incluyendo la cara lateroventral de la raíz caudal y el sector dorsal de la base del proceso preglenoideo. El origen del paquete profundo es mediante fibras carnosas sobre la superficie interna del arco cigomático, alcanzando cranealmente el nivel del borde caudal de la órbita; a su vez, su origen más caudal es, mediante fibras tendinosas, sobre la raíz caudal del arco, sobre la superficie craneal del proceso preglenoideo, profundo al origen de la parte intermedia.

Inserción: La inserción del paquete superficial es mediante fibras carnosas a lo largo del margen y la superficie ventral de la mandíbula, desde el extremo caudal del proceso angular hasta un punto justo caudal al margen craneal de la fosa masetérica. En el extremo caudal del proceso angular, se inserta mediante un tendón robusto. Una inserción adicional del paquete superficial se registra sobre un rafe que une a este músculo con el m. pterygoideus medialis. La porción intermedia se inserta mediante fibras carnosas, o tendinosas, a lo largo del margen ventral de la fosa masetérica, dorsal a la inserción del paquete superficial; la inserción sobre el extremo del proceso angular es vía fibras tendinosas. La inserción del paquete profundo es mediante fibras carnosas, y cranealmente tendinosas, sobre la fosa masetérica y la superficie lateral del proceso coronoides.

M. temporalis (Láminas 2.2-5)

Está dividido en cinco paquetes que no son totalmente separables. El paquete A es superficial a los paquetes $\mathrm{C}$ y $\mathrm{D}$, y presenta una menor extensión que la de estos dos. Este paquete está compuesto internamente por algunas fibras tendinosas. El paquete B es pequeño y de posición ventrocaudal, ubicándose sobre la raíz caudal del arco cigomático. El paquete $\mathrm{C}$ es el de mayor tamaño, y ocupa la mayor parte de la fosa temporal, cubierto por una fascia tendinosa propia. El paquete $\mathrm{D}$ es superficial, y de posición craneal respecto al paquete $\mathrm{C}$, con el que internamente comparte muchas fibras. El paquete $\mathrm{E}$ es interno, se ubica por debajo del 
paquete A y medial a B; y está cubierto por una fascia tendinosa sobre la que se insertan algunas fibras del paquete $\mathrm{B}$.

Origen: Mediante fibras carnosas sobre toda la fosa temporal y raíz caudal del arco cigomático. En el sector cráneodorsal, la fijación al hueso es débil. El paquete A se origina de la fascia que cubre los paquetes $\mathrm{B}, \mathrm{C}, \mathrm{D}$, y presenta algunas fibras de origen carnoso sobre la superficie de estos paquetes. La fascia de origen del paquete A alcanza los dos tercios craneales de la cresta sagital y el proceso postorbitario. El paquete B se origina mediante fibras carnosas sobre la superficie interna del sector caudal del arco cigomático, al nivel de la raíz caudal. El paquete $\mathrm{C}$ se origina desde todo el margen de la cresta lambdoidea y la mitad caudal del borde dorsal de la fosa temporal, así como de gran parte de esta fosa. El paquete D se origina sobre la mitad craneal del borde dorsal de la fosa temporal y el sector postorbital hasta inmediatamente por detrás del proceso postorbital y sobre la fascia que cubre al paquete C. El paquete E se origina, mediante fibras carnosas, sobre el aspecto dorsal de la raíz caudal del arco cigomático y la porción ventral de la fosa temporal.

Inserción: El paquete B se inserta sobre el sector caudal de la superficie lateral del proceso coronoides, alcanzando la región contigua al cóndilo. El paquete $\mathrm{C}$ se inserta mediante un tendón plano y corto sobre el extremo dorsal del proceso coronoides. El paquete D se inserta mediante fibras carnosas sobre la superficie medial y craneal de la base del proceso coronoides, y mediante un tendón definido en el sector más craneal de esta región. El paquete A se inserta mediante fibras carnosas y tendinosas sobre el mitad ventral del margen craneal del proceso coronoides. Algunas fibras principalmente carnosas y superficiales que se desprenden de la fascia superficial, se insertan en el ligamento postorbital y tejidos ventrales a éste, hasta la base de la arcada. El paquete $\mathrm{E}$ se inserta mediante fibras carnosas sobre el sector medio y dorsal de la superficie medial del proceso coronoides, inmediatamente dorsal al paquete $\mathrm{D}$. La fascia superficial del paquete E se inserta sobre el margen caudodorsal del proceso coronoides.

M. pterygoideus lateralis (Lámina 2.5)

Profundo al m. pterygoideus medialis, con fibras que discurren principalmente en dirección lateromedial.

Origen: Mediante fibras carnosas en la fosa contigua a la placa pterigoidea, dorsal al área de origen del m. pterygoideus medialis, entre el foramen óptico, y la región glenoidea.

Inserción: Mediante fibras carnosas (y una fascia tendinosa ventral) sobre el área inmediatamente dorsal al m. pterygoideus medialis, y craneal al cóndilo articular de la mandíbula, alcanzando a cubrir toda la superficie craneal e interna a su base.

\section{M. pterygoideus medialis (Lámina 2.5)}

Es más grande que el m. pterygoideus lateralis, y se encuentra parcialmente dividido en dos paquetes, uno superficial y ventral, y otro profundo y dorsal. Sus fibras corren 
caudolateralmente. El paquete superficial es más amplio y presenta forma redondeada o de abanico, mientras que el profundo es reducido, y podría ser considerado parte del $\mathrm{m}$. pterygoideus lateralis. En conjunto con el m. pterygoideus lateralis y con parte del aparato hioideo, se encuentran cubiertos por una aponeurosis. Una fascia une la superficie caudal del $\mathrm{m}$. pterygoideus medialis con el sector craneal de la bulla y el sector ventral del meato auditivo.

Origen: El paquete superficial del $\mathrm{m}$. pterygoideus medialis se origina mediante fibras cranealmente tendinosas y caudalmente carnosas sobre el margen lateral de la placa pterigoidea. El paquete profundo del $\mathrm{m}$. pterygoideus medialis se origina mediante fibras carnosas de la fosa pterigoidea, laterodorsal al área anterior del origen del paquete superficial.

Inserción: Los paquetes superficial y profundo del $\mathrm{m}$. pterygoideus medialis se insertan mediante fibras carnosas y tendinosas (respectivamente) sobre la repisa pterigoidea. El paquete superficial se inserta inmediatamente ventral al profundo, y alcanza, vía una fascia, al margen ventral del paquete superficial del $\mathrm{m}$. masseter y los tejidos que rodean ventralmente al meato auditivo, bajo el ligamento meato-rafeal.

M. digastricus (Láminas 2.2, 2.5, 2.9-10)

Es robusto con forma de huso y de sección aproximadamente elíptica, corre anteromedialmente. Se ubica en la parte ventral de la cabeza, entre el paquete superficial del $\mathrm{m}$. masseter y el m. mylohyoideus. Compuesto por dos vientres unidos ( $\mathrm{m}$. digastricus venter rostralis y venter caudalis) por un tejido tendinoso (intersección tendinosa).

Origen: Mediante fibras carnosas centralmente y una fascia periférica, sobre el proceso paraoccipital, extendiéndose el área de origen por el margen caudolateral de la bulla, alcanzando el sector medial de la base del proceso mastoideo, justo caudal al meato auditivo.

Inserción: Mediante fibras carnosas, y eventualmente fibras tendinosas craneales, sobre toda la superficie ventral de la rama horizontal de la mandíbula, alcanzando anteriormente típicamente el nivel del p4.

\subsubsection{Musculatura del cuello}

\section{M. splenius capitis (Láminas 2.1-2, 2.5, 2.10)}

Se encuentra eventualmente dividido en dos (uno dorsal y uno ventral) o incluso tres vientres, mientras que en otros casos la diferenciación sólo se registró en el tipo de fibras de origen (fascia tendinosa vs. principalmente carnosas). Es aplanado y especialmente delgado y tendinoso en su sector dorsal. En su origen está cubierto en conjunto con el m. longissimus thoracis por la fascia de inserción del m. serratus dorsalis cranialis. En la zona cervical craneal y media se fusiona superficialmente con el $\mathrm{m}$. longissimus capitis. Por otro lado, en su aspecto ventral, una fascia lo une con el margen craneal del m. longissimus cervicis. 
Origen: El vientre ventral se origina vía una fascia breve y delgada sobre la línea media a nivel de T2 y T3, sobre el m. spinalis et semispinalis. El vientre dorsal (y el intermedio, en caso de estar presente) se origina sobre el rafe medio cervical, hasta el nivel de T2. Este origen es carnoso en la zona torácica, y se vuelve progresivamente tendinoso hacia la zona cervical.

Inserción: El vientre ventral se inserta mediante fibras tendinosas que convergen abruptamente a la base del proceso mastoideo, inmediatamente dorsal y en parte craneal a la inserción del m. longissimus capitis. El vientre dorsal se inserta mediante fibras carnosas y secundariamente tendinosas sobre toda la cresta lambdoidea.

\section{M. sternocephalicus (= m. sternomastoideus) (Láminas 2.1, 2.5, 2.9)}

Compuesto de dos vientres principales aplanados y carnosos: el m. sternocephalicus pars mastoidea, y pars occipitalis. En su origen, se encuentra parcialmente fusionado al $\mathrm{m}$. cleidocephalicus pars cervicalis, ubicándose principalmente por debajo de este último y compuesto por seis grupos de fibras paralelos diferenciables. Este recibe un delgada banda desde el m. cleidocephalicus pars cervicalis. El m. sternocephalicus pars mastoideus se encuentra a su vez dividido en dos vientres, uno superficial y otro profundo, que comparten algunas fibras.

Origen: El m. sternocephalicus pars occipitalis se origina mediante fascia sobre las tres cuartas partes más ventrales de la cresta nucal, desde justo dorsal al proceso mastoideo hasta la región de origen del $\mathrm{m}$. cleidocephalicus pars cervicalis, fusionándose parcialmente con el mismo. M. sternocephalicus pars mastoidea toma origen generalmente mediante un tendón sobre el proceso mastoideo (vientre profundo) y mediante fibras tendinosas y carnosas (vientre superficial), justo ventral al músculo $\mathrm{m}$. sternocephalicus pars occipitalis y craneal al m. cleidocephalicus pars mastoidea, compartiendo algunas fibras carnosas con este último.

Inserción: El m. sternocephalicus pars occipitalis se inserta mediante fibras tendinosas sobre la superficie dorsal del manubrio, inmediatamente caudal al $\mathrm{m}$. sternocephalicus pars mastoidea, pero sin alcanzar la primer articulación esterno-costal. El m. sternocephalicus pars mastoidea se inserta mediante fibras carnosas sobre la parte dorsal (vientre profundo) y extremo craneal del manubrio (vientre superficial). Craneal a la inserción ósea, ambas contrapartes se fusionan a lo largo de la mitad caudal de la línea ventral cuello, formando un rafe tendinoso.

\section{M. longus colli (Lámina 2.1, 2.4)}

De posición ventral y profunda, se ubica entre el m. longus capitis y su contraparte. El sector caudal presenta metámeros originados en la región torácica, separados por un breve espacio de sus contrapartes, divergiendo en dirección cráneolateral y mayormente independientes en sus inserciones y continuados cranealmente por el m. longus capitis. En este sector se diferencian parcialmente dos metámeros principales, el más caudal puede entenderse como la confluencia de otros menores. El sector craneal del $\mathrm{m}$. longus colli se encuentra 
compuesto por metámeros originados mayormente en el sector cervical, en íntimo contacto con sus contrapartes, que corren en sentido cráneomedial y se fusionan en gran medida en sus inserciones.

Origen: Los dos paquetes torácicos principales presentan orígenes mediante fibras carnosas y tendones delicados desde T1 a T7. Los paquetes cervicales se originan mediante fibras principalmente carnosas, desde el aspecto ventral de los cuerpos vertebrales de $\mathrm{C} 2$ a $\mathrm{C} 7$, y la cara interna de sus procesos transversos, así como mediante tendones aplanados desde el sector anterior del proceso alar de estos últimos para el caso de las vértebras $\mathrm{C} 6$ a $\mathrm{C} 4$.

Inserción: Los paquetes torácicos principales, caudal y craneal, presentan inserciones mediante tendones aplanados e independientes, típicamente sobre los extremos caudales de las láminas ventrales de los procesos transversos de las vértebras C6 y C5 respectivamente (y en lado mayormente insertados sobre la $\mathrm{C} 6$ y secundariamente la $\mathrm{C} 7$ ), y mediante fibras carnosas sobre sus caras internas. Los paquetes cervicales se insertan en vértebras precedentes, en general saltando un elemento, y mediante tendones aplanados y fibras carnosas sobre los tubérculos ventrales e inmediaciones de los cuerpos vertebrales. Por otro lado, muchas fibras se fusionan (provenientes principalmente del axis y $\mathrm{C} 3$, y secundariamente de $\mathrm{C} 4$ ) y alcanzan directa o indirectamente a la inserción principal y más craneal, la cual se da por fibras carnosas sobre el tubérculo ventral del cuerpo del atlas.

M. scalenus ventralis (Láminas 2.1-2)

Presenta forma de huso. Se ubica entre el $\mathrm{m}$. scalenus medius y el $\mathrm{mm}$. intertransversarii ventrales cervicis, y fusionándose en gran medida con el primero.

Origen: Mediante fibras carnosas del sector medio de la primer costilla, justo sobre la unión condrocostal.

Inserción: Mediante tendones breves sobre el extremo caudal del la lámina ventral de los procesos transversos de la $\mathrm{C} 5$ y $\mathrm{C} 4$, compartiendo algunas fibras con los $\mathrm{mm}$. intertransversarii medii cervicis.

\section{M. scalenus medius (Láminas 2.1-2)}

Breve y en forma de cinta, ubicado dorsal y compartiendo un gran número de fibras con el m. scalenus ventralis. En el sector más craneal, comparte algunas fibras con los mm. intertransversarii medii cervicis.

Origen: Mediante fibras mayormente carnosas, y algunas fibras tendinosas dorsales, sobre el sector craneal y dorsal de la primer costilla, inmediatamente por encima del origen del $\mathrm{m}$. scalenus ventralis.

Inserción: Mediante fibras principalmente carnosas sobre el sector central de la superficie lateral de la lámina ventral de la C6, y la superficie y caudal y ventral del proceso transverso de la C7. 


\section{M. scalenus dorsalis (Láminas 2.1-2)}

Ubicado ventral al $\mathrm{m}$. serratus ventralis thoracis y $\mathrm{m}$. longissimus cervicis, compuesto de dos vientres en forma de bandas musculares delgadas contiguas: un vientre dorsal y un vientre ventral. En la región torácica, la porción ventral es la más larga y delgada, y se ubica inmediatamente dorsal al m. "supracostalis". En su sector más caudal, está cubierto parcialmente por el m. obliquus externus abdominis. En la región cervical ambos vientres comparten fibras con los mm. scalenus ventralis y medius; en cercanías a su inserción, comparten fibras con el mm. intertransversarii medii cervicis, y entre sí.

Origen: El vientre dorsal se origina mediante fibras principalmente carnosas sobre el sector distal del cuerpo de la tercera costilla, inmediatamente ventral al origen de los mm. serratus ventralis. El vientre ventral se origina en la mayoría de los casos mediante fibras tendinosas sobre la unión condrocostal de la sexta costilla, aunque en un lado se registraron orígenes múltiples sobre la quinta, y secundariamente. la sexta y séptima costillas.

Inserción: El tendón del vientre dorsal atraviesa y contacta al mm. intertransversarii medii cervicis, a la altura del sector caudal la lámina ventral del proceso transverso de la C5, insertándose finalmente sobre el extremo caudoventral de la lámina ventral del proceso transverso de la $\mathrm{C} 4$. El tendón del vientre ventral atraviesa y contacta al $\mathrm{m}$. scalenus ventralis a la altura del sector centrocraneal de la lámina ventral del proceso transverso de la C6, insertándose en el extremo caudoventral de la lámina ventral del proceso transverso de la C5.

\subsubsection{Musculatura del aparato hioideo}

\section{M. stylohyoideus}

Ausente en todos los especímenes.

M. mylohyoideus (Láminas 2.5, 2.7, 2.10)

Ubicado entre las dos hemimandíbulas, es el más externo de los músculos del piso de la boca, y sus fibras tienen dirección lateromedial, divergiendo hacia su inserción. Una fascia lo mantiene unido al margen ventromedial de la mandíbula. En su aspecto profundo, está fusionado al $\mathrm{m}$. geniohyoideus.

Origen: Mediante fibras carnosas sobre la cara medial de la mandíbula en cercanías del margen alveolar de la serie yugal, desde un punto al nivel del p3 hasta justo por delante del extremo craneal de la repisa pterigoidea.

Inserción: Mediante fibras carnosas contra su contraparte sobre la línea media del piso de la boca. Alcanza cranealmente la sínfisis mandibular, y caudalmente el margen craneal del hueso basihioides.

M. geniohyoideus (Láminas 2.5, 2.7) 
Delgado, corre sobre la línea media del piso de la boca. Es interno al m. mylohyoideus y medial al m. hyoglossus.

Origen: Mediante fibras carnosas sobre el sector central del hueso basihioides.

Inserción: Mediante fibras carnosas puntualmente en el sector caudal y ventral a la sínfisis mandibular.

M. sternohyoideus (Láminas 2.1-2, 2.7, 2.9-10)

Con forma de banda, totalmente fusionado con el m. sternothyroideus desde su origen y típicamente a lo largo de su tercio caudal, mientras que a partir de este punto, se diferencia y ubica ventral a éste, insertándose en estrecho contacto con el m. omohyoideus. En toda la línea media (primer espécimen), o sólo el sector medio del cuello (segundo espécimen), se encuentra inmediatamente contiguo a su contraparte, con la cual comparte una fascia tendinosa. Una aponeurosis laxa lo une a la tráquea y otros músculos hioides.

Origen: Mediante fibras carnosas sobre el sector dorsal de la primer esternebra, desde el sector próximo e interno a la primer unión esterno-costal.

Inserción: Mediante fibras carnosas sobre el basihioides y secundariamente el tirohioides.

M. sternothyroideus (Láminas 2.1-2, 2.7, 2.9-10)

Músculo con forma de banda, fusionado con el $\mathrm{m}$. sternohyoideus típicamente en su tercio caudal, divergiendo en sentido lateral hacia su inserción.

Origen: Al igual que el $\mathrm{m}$. sternohyoideus, mediante fibras carnosas sobre el sector dorsal de la primer esternebra, desde el sector próximo e interno a la primer unión esterno-costal.

Inserción: Mediante fibras carnosas sobre el margen caudolateral del cartílago tiroides.

\section{M. thyrohyoideus (Lámina 2.7)}

Se encuentra ubicado principalmente sobre el cartílago tiroides, profundo al $\mathrm{m}$. sternohyoideus y m. omohyoideus, y craneal al m. sternothyroideus. Es aplanado y de forma triangular, y sus fibras corren cráneomedialmente.

Origen: Mediante fibras carnosas sobre la superficie del cartílago tiroides, principalmente sobre su margen caudolateral, inmediatamente craneal a la inserción del m. sternothyroideus.

Inserción: Mediante fibras carnosas sobre el hueso basihioides y la mitad medial del tirohioides, inmediatamente caudal al $\mathrm{m}$. sternohyoideus.

\section{M. occipitohyoideus (=m. jugulohyoideus) (Láminas $2.5,2.7$ )}

Muy pequeño y compuesto por unas pocas fibras (en su mayor parte tendinosas), y solamente presenta algunas fibras musculares en la zona media.

Origen: Mediante fibras tendinosas, desde el sector craneal de la base del proceso paraoccipital. Inserción: Sobre el cartílago timpanohioides, inmediatamente caudal al hueso stilohioides.

M. ceratohyoideus (Lámina 2.7)

Carnoso, aplanado y breve, profundo al m. styloglossus. 
Origen: Mediante fibras carnosas sobre el margen caudal del hueso ceratohioides y el sector inmediatamente proximal del hueso epihioides.

Inserción: Se inserta sobre el sector ventrolateral del hueso tirohioides.

\subsubsection{Musculatura del dorso}

M. serratus dorsalis caudalis (= serratus posterior inferior) (Láminas 2.1-2)

En la descripción de este músculo se incluye también a los paquetes correspondientes al m. retractor costae. Grupo de paquetes metaméricos y aplanados, de posición cráneodorsal, que puede considerarse como una continuación caudal del $\mathrm{m}$. serratus dorsalis cranialis. Se encuentra parcialmente fusionado al $\mathrm{m}$. obliquus internus abdominis, y presenta similar orientación de sus fibras. En sus orígenes, los metámeros se encuentran parcialmente cubiertos por divisiones de los $\mathrm{mm}$. intercostales externi y las inserciones del $\mathrm{mm}$. obliquus externus e internus abdominis en su sector ventral.

Origen: Vía fascias tendinosas sobre un breve sector medio del cuerpo costal de las costillas de T11/T12 al último elemento (i.e., T15/16).

Inserción: Mediante una aponeurosis sobre la fascia tóraco-lumbar, en sectores precedentes a sus orígenes.

M. serratus dorsalis cranialis (= serratus posterior superior) (Láminas 2.1-2, 2.10)

Ubicado sobre la zona media del aspecto lateral de la caja torácica, profundo y caudal al $\mathrm{m}$. serratus ventralis thoracis y dorsal al $\mathrm{m}$. obliquus externus abdominis. Es aplanado y cuadrangular, y se compone por siete/ocho fascículos con fibras que corren cráneodorsalmente. Una aponeurosis marginal lo une ventralmente a los mm. intercostales externi.

Origen: Mediante fibras principalmente carnosas desde cercanías del ángulo costal de las costillas de T4 a T10/11. También se origina, mediante una aponeurosis, sobre los mm. intercostales externi.

Inserción: En continuación craneal con el m. serratus dorsalis caudalis, mediante una aponeurosis sobre la fascia tóraco-lumbar que cubre al sistema longissimus, marginalmente al sistema iliocostalis y al sector caudal del $\mathrm{m}$. splenius, continuándose vía esta fascia hasta los procesos espinosos desde T3 a T9, y cubriendo T2 sin alcanzar una inserción ósea sobre la misma.

\section{M. iliocostalis thoracis (Láminas 2.1-3)}

Ubicado sobre el sector proximal de las costillas, inmediatamente lateral y ventral respecto al $\mathrm{m}$. longissimus thoracis. Compuesto de una serie de metámeros, prácticamente indiferenciables en la zona media de su recorrido, donde a su vez alcanzan su máximo desarrollo. Los paquetes más craneales comparten algunas pocas fibras con el $\mathrm{m}$. longissimus thoracis y la fascia tóraco-lumbar, mientras que en el caso de los paquetes más caudales 
comparten un mayor número de fibras con el $\mathrm{m}$. longissimus thoracis y el $\mathrm{m}$. iliocostalis lumborum, existiendo paquetes transicionales entre el sector lumbar y el torácico del sistema iliocostal de características intermedias entre ambos sectores. Cada paquete abarca en general cuatro elementos desde sus orígenes a inserciones (aunque varían entre 3 y 5 las costillas cubiertas por algunas fibras).

Origen: Se origina mediante fibras carnosas sobre el sector dorsal y proximal al ángulo de las costillas de T3 a T14.

Inserción: Las inserciones sobre las primeras 6 o 7 inserciones más craneales se dan exclusivamente vía tendones sobre el sector inmediatamente dorsal al ángulo costal. Los paquetes caudales a estos presentan fibras carnosas con un tendón lateral hasta la costilla de T9/T10. Los restantes paquetes presentan una inserción más amplia y exclusivamente carnosas. Sobre las últimas tres o cuatro costillas se registran inserciones amplias netamente carnosas de paquetes iliocostales originados sobre el sector próximo de la fascia tóraco-lumbar, pudiendo estos paquetes transicionales ser considerados parte del $\mathrm{m}$. iliocostalis thoracis en función del tipo de inserción, o m. iliocostalis lumborum en función de su origen.

\section{M. longissimus thoracis (Láminas 2.1, 2.3)}

Aplanado y alargado, lateral al m. spinalis et semispinalis thoracis, mm. multifidi y m. longissimus cervicis (desde caudal hacia craneal), compuesto por metámeros aguzados y diferenciados hacia sus inserciones. En el sector caudal a la décima vértebra torácica, una fuerte aponeurosis lo une al sistema transversospinalis. Aunque el $\mathrm{m}$. longissimus thoracis es mayormente lateral al sistema iliocostal, en su sector más caudal, al nivel de la región lumbar se ubica por sobre este último sistema (ver Ercoli et al. 2013). Las inserciones del m. longissimus thoracis son en todos los casos mediales a los orígenes e inserciones del $\mathrm{m}$. iliocostalis thoracis excepto en la primer costilla, en donde la inserción es craneal. En el sector más craneal, comparte algunas fibras y una aponeurosis con el m. longissimus cervicis, aunque estos están claramente diferenciados.

Origen: Mediante la fascia tóraco-lumbar y fibras tendinosas definidas, desde los extremos dorsales de los procesos espinosos de las vértebras anticlinal y postanticlinales. Indirectamente, vía la fascia tóraco-lumbar, se origina también desde el sector dorsal y craneal del ala ilíaca y procesos espinosos lumbares.

Inserción: Mediante tendones definidos sobre los tubérculos de las costillas de T1/T2 a T6. En un caso, se registró un tendón de inserción cervical, sobre el tubérculo dorsal del proceso transverso de la C7. Típicamente a partir de la costilla de T4 (excepto un caso, en donde ocurre a partir de la costilla de T2) se registran fibras carnosas mediales acompañando las inserciones tendinosas, y posterior a este punto, el número de las fibras carnosas mediales es progresivamente mayor. A partir de la séptima los tendones definidos están ausentes. Desde T7 
hasta la vértebra anticlinal, se registran inserciones extras sobre los procesos transversos, progresivamente ubicadas más caudalmente. En la vértebra anticlinal y sector postanticlinal se registran inserciones mediante fibras carnosas en los procesos accesorios. En el sector postanticlinal (y en dos casos ya incluso desde la vértebra anticlinal), las inserciones costales se encuentran ausentes.

M. longissimus cervicis (= transversalis colli, longissimus cervicis et atlantis) (Láminas 2.13)

Carnoso y metamérico, compuesto por paquetes superpuestos que corren en dirección cráneolateral desde su origen a inserción, abarcando un número de vértebras progresivamente menor en dirección craneal, siendo nueve para el caso de los paquetes más caudales y tres para el caso del más craneal. El músculo alcanza su máximo desarrollo en la zona de transición cervical-torácica. En su sector profundo comparte numerosas fibras con los $\mathrm{mm}$. intertransversarii dorsales cervicis.

Origen: Mediante fibras carnosas sobre el sector craneal de los procesos transversos desde T8 a T2, y sobre los tubérculos de los procesos articulares craneales desde T2 a C3. En el sector torácico se origina también vía la fascia que cubre a los $\mathrm{mm}$. multifidi. Se registran orígenes secundarios sobre los procesos articulares caudales de C3-C6.

Inserción: Mediante tendones caudales y fibras carnosas craneales, sobre los procesos transversos de $\mathrm{T} 1$, y progresivamente más carnosos, sobre los tubérculos dorsales de los procesos transversos de $\mathrm{C} 7$ a $\mathrm{C} 3$, y sobre el sector caudal del proceso transverso del axis y ala del atlas. Algunas fibras a modo de fascia se insertan en la cápsula articular atlas-axis.

M. longissimus capitis (= transversalis capitis) (Láminas 2.1, 2.3)

Ubicado por debajo del $\mathrm{m}$. splenius, y superficial al $\mathrm{m}$. biventer cervicis $\mathrm{y} \mathrm{m}$. complexus. Es aplanado en su origen, donde se ubica medial al m. longissimus cervicis y comparte algunas fibras con este último; y se vuelve cilíndrico hacia la inserción, donde se fusiona con el m. splenius.

Origen: Mediante fibras carnosas sobre los tubérculos dorsales de los procesos articulares caudales e inmediatamente craneal a estos sobre $\mathrm{C} 5$ a $\mathrm{C} 7$, rudimentariamente sobre $\mathrm{C} 4$, sobre el sector intermedio entre facetas articulares en T1, y desde los tubérculos de los procesos articulares craneales de $\mathrm{T} 2$, y eventualmente $\mathrm{T} 3$.

Inserción: Mediante un tendón breve y robusto sobre el sector caudal y lateral del proceso mastoideo, justo ventral a la región de inserción del m. splenius, y dorsal a la inserción del m. cleidocephalicus pars mastoidea.

M. spinalis et semispinalis thoracis (Láminas 2.1, 2.3)

Se ubica superficial al $\mathrm{m}$. longissimus thoracis entre $\mathrm{T} 10 / 11$ a $\mathrm{T} 15$, mientras que cranealmente se ubica medial respecto a éste y comparte algunas fascias e intercalaciones de 
paquetes con el $\mathrm{m}$. biventer. Luego de su origen mediante fascia, la fibras musculares se diferencian al nivel de la región anticlinal. En este sector, los tendones de origen son profundos y divergentes del plano sagital en dirección cráneolateral, y se convierten en fibras carnosas que se ubican superficialmente y convergen al plano sagital, insertándose en la línea media. La separación superficial entre el $\mathrm{m}$. longissimus thoracis y este músculo ocurre cranealmente a la $\mathrm{T} 9$, pero el $\mathrm{m}$. spinalis et semispinalis presenta orígenes sobre la cara interna del $\mathrm{m}$. longissimus thoracis aún hasta a T6.

Origen: Mediante una fascia tendinosa que cubre al m. longissimus thoracis, el sector anterior de la región lumbar (y posteriormente a otros sistemas musculares más mediales) y, mediante fibras carnosas y tendinosas, sobre la cara interna del m. longissimus thoracis (especialmente en el sector anterior a T9). Además se registran orígenes tendinosos puntuales sobre las caras internas de los procesos mamilares de las vértebras T11 a T14.

Inserción: Mediante fibras carnosas posteriormente, y tendones definidos anteriormente, sobre los procesos espinosos de T1 a T9/10. En todos los elementos las inserciones se registran en el extremo dorsal de cada proceso espinoso excepto en $\mathrm{T} 1$ y $\mathrm{T} 2$, donde alcanzan directamente la región centrodorsal de estos procesos, ubicándose por debajo de los orígenes del $\mathrm{m}$. spinalis cervicis, y compartiendo algunas fibras con éste. Algunas fibras tendinosas alcanzan el margen caudal de los procesos espinosos y a los sistemas mediales. En algunos casos (dos lados), se registró un tendón robusto insertándose sobre el m. multifidus cervicis, a la altura del proceso espinoso de la C7.

M. spinalis cervicis (Láminas 2.1, 2.5)

Anterior, y en parte dorsal, a su correspondiente torácico (m. spinalis et semispinalis thoracis). Alargado en forma de banda que conecta los procesos espinosos de la zona cervical y torácica anterior, fuertemente fusionado con su contraparte en la línea media del cuello.

Origen: Mediante fibras carnosas, sobre el sector dorsal del proceso espinoso de T1, y secundariamente T2, y sobre los de las últimas cinco vértebras cervicales.

Inserción: Mediante fibras carnosas, sobre el margen caudal del proceso espinoso del axis, y sobre los de las últimas cinco vértebras cervicales.

M. biventer cervicis (Láminas 2.1, 2.3, 2.5)

Dorsal al m. complexus y profundo al $\mathrm{m}$. splenius y sistema longissimus. Compuesto por dos vientres con forma de cinta en general unidos vía aponeurosis entre sí, y al m. complexus, siendo variable el grado de unión entre estos paquetes.

Origen: El paquete caudal se origina vía una fascia tendinosa desde los sistemas mediales ( $\mathrm{mm}$. mutifidii) a la altura de T2/T3 a T4/T5. En dos lados se reconocieron orígenes tendinosos laminares más robustos sobre el sector craneal del proceso transverso de T5. El paquete craneal 
se origina vía una fascia tendinosa (y eventualmente fibras carnosas) y breve sobre el sector dorsal del proceso transverso de T3 y $\mathrm{T} 2$.

Inserción: El paquete caudal se inserta mediante fibras carnosas sobre el rafe cervical desde la zona media del cuello (a la altura de la C5) hasta el cráneo, y sobre el sector más medial de la cresta lambdoidea. El paquete craneal se inserta mediante un tendón elongado inmediatamente lateral a esta inserción.

M. complexus (Láminas 2.1, 2.3, 2.5)

Con forma de una banda aplanada compuesto de unidades que se ubican sobre la cara lateral del cuello.

Origen: Sobre el tubérculo de los procesos articulares caudales de C3 a C6/C7. Desde C4 a C6, el área de origen se extiende cranealmente sobre el arco neural, y las fibras de origen son carnosas (especialmente en el sector central) y tendinosas. En C3 el origen es exclusivamente tendinoso y reducido.

Inserción: Mediante una tendón breve, aplanado, inmediatamente lateral al m. biventer cervicis en un sector relativamente reducido de la cresta lambdoidea. En un caso se registró una inserción extra tendinosa sobre el contacto de los mm. obliquus capitis.

Mm. multifidi (Láminas 2.1, 2.4)

Complejo de músculos metaméricos presentes en la región cervical y torácica (además de la región lumbar), que corren, desde sus orígenes a sus inserciones, solapándose en dirección anterodorsal y medial. Los paquetes torácicos son mucho más breves y menos diferenciados que los cervicales.

\section{M. multifidus cervicis (Láminas 2.1, 2.4)}

Se ubica lateral y ventral al m. spinalis cervicis. Compuesto en general por cuatro paquetes laterales aplanados, ampliamente superpuestos, y cinco paquetes mediales, que comparten la región de inserción con los anteriores.

Origen: El primero de los paquetes laterales se origina mediante fascias breves sobre el $\mathrm{m}$. interspinalis T2-T3, en inmediaciones a la región articular craneal de T3, y sobre los tubérculos de los procesos articulares caudales de la $\mathrm{C} 7, \mathrm{~T} 1$ y T2, y arcos neurales de $\mathrm{T} 1$ y T2. El segundo y tercer paquete lateral se originan mediante fibras tendinosas sobre el tubérculo de los procesos articulares caudales de $\mathrm{C} 7$ a $\mathrm{C} 5$, originándose el tercer paquete indirectamente vía las fibras de origen del segundo. El cuarto paquete lateral es reducido y se origina mediante fibras carnosas del tubérculo del proceso articular caudal de C3. Los paquetes mediales se originan mediante fibras carnosas desde el margen craneal y base de los procesos espinosos desde la C7 a la C3. En un lado, se registraron fibras extras originadas en la cara más interna del tubérculo del proceso articular caudal de la $\mathrm{C} 4$, correspondientes al segundo paquete medial. En un lado, se registró un origen extra sobre el proceso espinoso de T1. 
Inserción: Los paquetes laterales se fusionan en cercanías a su inserción con sus respectivos mediales y se inserta mediante fibras principalmente carnosas. El primer paquete lateral se inserta sobre los tubérculos de los procesos articulares caudales de la $\mathrm{C} 4, \mathrm{C} 5$ y los procesos articulares craneales de la $\mathrm{C} 5$ a $\mathrm{C} 7$, incluyendo al arco neural de la C6 y C7; compartiendo algunas fibras con el m. spinalis cervicis. El segundo paquete lateral se inserta sobre el tubérculo del proceso articular caudal de la $\mathrm{C} 3, \mathrm{C} 4$ y procesos articulares craneales de $\mathrm{C} 4$ y C5, incluyendo al arco neural de C5. El tercer y cuarto paquete lateral se insertan mediante fibras exclusivamente carnosas sobre el tubérculo del proceso articular caudal del axis. El tercer paquete lateral posee además una inserción sobre el proceso articular craneal de la C3. Los paquetes mediales presentan una inserción secundaria y temprana sobre la mitad craneal de los arcos neurales de la vértebra precedente a la de origen. Las inserciones principales se registran en el tubérculo del proceso articular caudal de las vértebras C5 al axis, saltando estas fibras un elemento desde el origen a la inserción, excepto el quinto paquete.

\section{M. multifidus thoracis (Láminas 2.1, 2.4)}

Compuesto por múltiples metámeros breves fusiformes y aplanados, progresiva y transicionalmente diferenciados del $\mathrm{m}$. multifidus lumborum a partir de la T15. Cada metámero originado en una vértebra dada cubre al $\mathrm{m}$. rotator longus originado en ella, y se ubica caudalmente al $\mathrm{m}$. rotator longus de la vértebra anterior. Los paquetes más caudales son menos diferenciables y más alargados. El paquete más craneal comparte un gran número de fibras con el primer paquete lateral del m. multifidus cervicis, mientras que los paquetes más caudales comparten fibras con los $\mathrm{mm}$. interspinales y los paquetes anteriores del $\mathrm{m}$. multifidus lumborum. El paquete más craneal alcanza al sector cervical y une elementos contiguos (T1+T2 a C7). Para los restantes elementos, los paquetes de este músculo típicamente saltean dos elementos entre origen e inserción, y eventualmente, para los elementos torácicos medios (originados desde T9 a T6), los paquetes presentan algunas pocas fibras que saltean tres. En elementos torácicos medios y posteriores (posterior a T6) se registran inserciones extra que saltean sólo un elemento, originadas inmediatamente caudales a los mm. rotatores longi (en caso de estar diferenciados) y fusionados con estos últimos sólo en cercanías de la inserción. El paquete originado en T15 es reducido y saltea exclusivamente un único elemento. Sobre los últimos elementos torácicos, se registran inserciones de paquetes de origen lumbar, con un patrón similar de orígenes e inserciones, que pueden ser considerados como transicionales entre el m. multifidus lumborum (ver m. transversospinalis en Ercoli et al. 2013) y el m. multifidus thoracis.

Origen: Mediante fibras tendinosas sobre el sector craneal del proceso transverso (i.e., procesos mamilares en caso de estar diferenciados) desde T15 (aunque importantes sólo a partir de T12) hasta T4, existiendo fibras de origen carnoso en el caso de los paquetes de la región anticlinal y 
postanticlinal. Este último paquete también presenta fibras que se originan sobre el proceso articular caudal de T3, mientras que, anterior a este, el último paquete torácico toma origen en los procesos articulares caudales de $\mathrm{T} 1 \mathrm{y} \mathrm{T} 2$.

Inserción: Mediante fibras carnosas sobre el extremo caudodorsal del proceso espinoso desde T13 hasta C7. Las inserciones principales se vuelven progresivamente más ventrales y amplias en las dos primeras vértebras torácicas y la cervical. Sobre T15 y T14 se registran inserciones, sobre sus procesos espinosos, de paquetes originados en la región lumbar (en procesos mamilares de $\mathrm{L} 3+\mathrm{L} 2$, y $\mathrm{L} 1$ respectivamente; paquetes transicionales).

Mm. rotatores longi (Lámina 2.1)

Son 10 u 11 músculos triangulares, carnosos y aplanados, que se encuentran entre T12/T13 y T1, salteando un elemento entre origen e inserción, siendo el paquete originado en T13 vestigial en caso de estar presente. Estos se ubican mediales a los m. multifidus thoracis, con el cual comparten fibras especialmente en el caso de los metámeros anteriores.

Origen: Mediante fibras carnosas sobre el sector cráneomedial de los procesos transversos desde T12/T13 a T3.

Inserción: Mediante fibras carnosas sobre el sector caudal de los procesos espinosos desde T10

a T1. En el caso de los paquetes caudales (especialmente para los últimos cuatro), las inserciones principales se restringen al sector ventral del margen caudal de los procesos espinosos y son más robustas. A su vez, se registran, inserciones intermedias sobre el sector craneal de la base de la espina y arcos neurales de las vértebras intermedias.

Mm. rotatores breves (Lámina 2.1)

Compuesto de múltiples metámeros. Cada unidad tiene forma de un abanico estrecho que se ubica entre vértebras sucesivas y cuyas fibras poseen dirección principalmente vertical. Se encuentran presentes entre T11 y T2, siendo los posteriores progresivamente menores. Están recubiertos por una fascia tendinosa en cercanía a su origen.

Origen: Mediante fibras carnosas sobre la cara dorsomedial de los procesos transversos, inmediatamente lateral a las carillas articulares craneales, de la vértebra inmediatamente posterior a la de inserción, desde T11 a T3.

Inserción: Sobre los procesos espinosos desde T10 a T2. Los primeros paquetes se insertan mediante fibras carnosas y algunas fibras tendinosas sobre la mayor parte de la cara lateral de los procesos espinosos, e incluyen marginalmente a los arcos neurales. Los paquetes más caudales se insertan mediante fibras carnosas sobre un sector más reducido del proceso espinoso, en algunos casos también sobre los mm. interspinalis.

Mm. interspinales thoracis (Láminas 2.1)

Compuesto de múltiples metámeros que ocupan los espacios entre procesos espinosos contiguos y se encuentran diferenciados entre $\mathrm{T} 1$ y $\mathrm{T} 8$. Estos se continúan ventralmente 
mediante una fascia tendinosa que une la base de los procesos espinosos contiguos. Dorsalmente se continúan con el ligamento interespinal, el cual adquiere fibras carnosas y tendinosas caudalmente, volviéndose progresivamente más ancho, uniendo un gran número de vértebras torácicas, incluyendo fibras que rodean, se apoyan y se continúan, uniendo los extremos dorsales de los procesos espinosos de la región anticlinal.

Origen: Mediante fibras carnosas en el aspecto central y dorsal del margen caudal de los procesos espinosos

Inserción: Mediante fibras carnosas en el aspecto central y dorsal del margen craneal de los procesos espinosos subsiguientes

Mm. interspinales cervicis (Láminas 2.1)

Pequeños aplanados y carnosos, sólo parcialmente diferenciados de los paquetes mediales del $\mathrm{m}$. multifidus cervicis y el $\mathrm{m}$. spinalis cervicis entre $\mathrm{C} 7 \mathrm{y}$ axis.

Origen: Mediante fibras carnosas sobre margen craneal de los procesos espinosos de las vértebras cervicales $\mathrm{C} 7$ a $\mathrm{C} 3$.

Inserción: Mediante fibras carnosas sobre margen caudal de los procesos espinosos desde C6 al axis.

\section{Mm. intertransversarii thoracis (Lámina 2.1)}

Compuesto de múltiples metámeros, externos y parcialmente indiferenciables del $\mathrm{m}$. multifidus thoracis, que corren entre procesos mamilares de vértebras consecutivas y desde estos hasta procesos accesorios, sin saltear o saltando uno o dos elementos, en el sector postanticlinal y, en forma más rudimentaria, entre procesos transversos en el sector anticlinal. Se registran también paquetes transicionales de origen lumbar e inserción torácica.

Origen: Generalmente mediante fibras carnosas sobre los procesos mamilares. En el sector postanticlinal, las fibras que saltean dos elementos, se originan sobre el sector craneal y en este caso mediante fibras tendinosas; las que saltean un elemento, se origina sobre el sector lateral, mientras que las que van entre elementos contiguos se originan sobre la base del proceso mamilar correspondiente (similar a lo observado en el sector lumbar; Ercoli et al. 2013). A su vez, algunas fibras extra se originan sobre el sector medio y medial del proceso transverso de la vértebra precedente a la inserción. En el caso de los orígenes provenientes del sector lumbar (paquetes transicionales), el arreglo es similar pero no se registran aquellos paquetes que saltean dos elementos. Sobre el sector preanticlinal y la vértebra anticlinal, sólo se registran los paquetes breves, siendo unas pocas fibras las que toman origen sobre el sector craneal de los procesos transversos hasta tan cranealmente como $\mathrm{T} 8$.

Inserción: Para el caso de los paquetes posteriores, mediante fibras carnosas sobre los procesos mamilares de las vértebras precedentes, sobre la base y sector medio de los procesos accesorios de las vértebras precedentes, y sobre el extremo caudal del proceso accesorio de la segunda 
vértebra precedente al origen. Por otro lado, los paquetes preanticlinales alcanzan inserciones en los procesos transversos de las vértebras precedentes a los orígenes, distinguibles hasta tan cranealmente como T7.

Mm. intertransversarii dorsales cervicis (Láminas 2.1, 2.3-4)

Conformado por múltiples paquetes breves, divisibles, ubicados entre elementos contiguos desde $\mathrm{T} 1$ hasta el atlas; laterales y dorsales a los mm. intertransversarii ventrales cervicis y medii cervicis.

Origen: Mediante fibras carnosas. El primer paquete tiene un origen torácico sobre el sector craneal del cuello de la primera costilla y sobre el sector craneal del proceso transverso de T1. El segundo paquete se origina desde el margen craneal del proceso transverso hasta cercanías del sector craneal articular de C7. Los siguientes cuatro paquetes se originan sobre el sector medio y craneal de la base de los procesos transversos de C6 a C3. El último paquete está compuesto de unas pocas fibras que se originan en la cara externa de la región media del proceso transverso del axis.

Inserción: Mediante fibras carnosas. El primer y segundo paquete se insertan en el sector caudal del tubérculo y de la base del proceso transverso de C7 y C6 respectivamente. La inserción sobre C6 es particularmente amplia. Los siguientes cuatro paquetes se insertan sobre el sector caudomedial de los procesos transversos de la $\mathrm{C} 5$ al axis, alcanzando la base de estos procesos en las más caudales. El último paquete se inserta en el sector dorsal de la esquina caudomedial del proceso transverso del atlas.

Mm. intertransversarii medii cervicis (Láminas 2.1, 2.3)

Conformado por múltiples paquetes con forma de banda, en algunos sectores poco diferenciado de los mm. scalenus ventralis y medius. Se ubica dorsal a los $\mathrm{mm}$. scalenus y $\mathrm{mm}$. intertransversarii ventrales cervicis, y ventral a los $\mathrm{mm}$. intertransversarii dorsales cervicis y $\mathrm{m}$. longissimus cervicis.

Origen: Mediante fibras carnosas sobre el sector ventral y central de los procesos transversos de C6 a C2. En un lado, se registró un paquete extra originado en el mismo sector de la C7.

Inserción: Mediante grupos de fibras carnosas y tendinosas. Grupos de fibras breves, presentan inserciones en vértebras precedentes a sus orígenes, sobre la base y aspecto medial de los procesos transversos de $\mathrm{C} 5$ a $\mathrm{C} 3$, ventral a las inserciones de los $\mathrm{mm}$. intertransversarii dorsales cervicis. Una inserción similar pero reducida se registró para el axis. Los paquetes originados desde C5 al axis presentan a su vez una inserción conjunta sobre el extremo caudomedial del proceso transverso del atlas. El paquete extra se fusiona en su inserción a estos últimos.

Mm. intertransversarii ventrales cervicis (Láminas 2.1-4) 
Compuesto por metámeros aplanados, medioventrales a los mm. intertransversarii medii cervicis y laterales al m. longus capitis. Los dos paquetes más craneales son los mayores y mejor diferenciados.

Origen: Mediante fibras principalmente carnosas (fibras tendinosas craneales, y fascículos carnosos caudales) sobre todo el margen ventral de la lámina ventral de C6.

Inserción: Las inserciones principales se registran mediante tendones robustos sobre el sector caudal del margen ventral del proceso transverso desde C3 al axis. Se registran inserciones secundarias, principalmente vía fascias breves, sobre el sector medio del margen ventral de las láminas ventrales de $\mathrm{C} 5$ y C4.

\subsubsection{Musculatura torácica}

Mm. levatores costarum (Lámina 2.1)

Serie de paquetes ubicados entre vértebras torácicas y costillas, parcialmente fusionados con cada uno de los paquetes $\mathrm{mm}$. intercostales externi correspondientes. Poseen orígenes vertebral e inserciones costales. Son progresivamente mayores y más independientes desde la $\mathrm{T} 1$ a la T13, mientras que los ubicados posteriormente a T13 son progresivamente reducidos

Origen: Mediante fibras carnosas, sobre el sector posteroventral de los procesos transversos de cada elemento torácico (excepto el último), en cercanías a las fóveas costale craneales de los procesos transversos, y los procesos articulares craneales en el caso de los paquetes más anteriores. En las vértebras posteriores, que presentan procesos accesorios diferenciados, se originan desde la cara ventral y externa de sus bases.

Inserción: Mediante fibras carnosas sobre el sector craneal y proximal de los cuerpos costales, incluyendo al margen craneal del tubérculo costal. A la altura de la costilla de T11 y T12, alcanza en su inserción hasta la zona del ángulo costal.

Mm. intercostales externi (Láminas 2.1-2, 2.10)

Conformado por múltiples paquetes metaméricos ubicados entre costillas contiguas, superficiales a los mm. intercostales interni, con los cuales comparten unas pocas fibras. Los paquetes son aplanados (especialmente en el sector distal al ángulo costal), mayormente carnosos, y la dirección principal de las fibras es caudoventral. En el sector dorsal se continúan en gran medida fusionado a los $\mathrm{mm}$. levatores costarum. Los paquetes posteriores a la costilla de T4 presentan cada uno un subgrupo de fibras diferenciadas en su sector ventral (entre cartílagos costales), aunque continuas con las porciones principales.

Origen: Mediante fibras carnosas y secundariamente tendinosas sobre el aspecto caudal de los cuerpos costales de todas las costillas, excepto la última. Por otro lado, existen también orígenes más tendinosos sobre el sector dorsal de cada cartílago costal, excepto para la primer costilla, en donde el origen no alcanza el cartílago costal. 
Inserción: Mediante fibras carnosas sobre el sector craneal de los cuerpos costales y cartílagos costales de todas las costillas, excepto la primera. Alcanza en mayor o menor grado el sector lateral de la décima esternebra.

\section{Mm. intercostales interni (Láminas 2.1, 2.3)}

Músculos aplanados, metaméricos, ubicados entre todas las costillas en el aspecto interno de la caja torácica, profundos a los $\mathrm{mm}$. intercostales externi y superficiales al $\mathrm{m}$. transversus thoracis. Cada paquete es mucho más grueso que los correspondientes a los $\mathrm{mm}$. intercostales externi. A partir de la décima costilla se encuentran muy fusionados con estos últimos. Sus fibras corren en dirección caudodorsal. Cada uno de los mm. intercostales interni ocupa toda el área intercostal, a excepción de los paquetes ubicados entre las costillas de T10 a T13, donde no alcanzan a cubrir la región ventral. Los cinco o seis primeros paquetes presentan una subdivisión ventral (similar a lo descripto para algunos de los mm. intercostales externi).

Origen: Mediante fibras carnosas, sobre el margen caudal de la primer costilla a la penúltima, incluyendo el total de ellas, excepto desde las costillas de T10 a T12, donde éste no cubre el total del cartílago costal.

Inserción: Mediante fibras carnosas, sobre el margen anterior desde la segunda costilla a la última incluyendo el total de ellas, excepto desde la 11 a la 13, en donde este no alcanza a extenderse sobre el total del cartílago costal. A partir de la T7, y en forma menos definida en elementos craneales a esta posición, se registran zonas de inserción más dorsales que incluyen fibras carnosas y tendinosas de orientación más vertical que alcanzan la cara lateral de las vértebras torácicas.

\section{M. transversus thoracis (Láminas 2.1, 2.4)}

Aplanado, profundo a los $\mathrm{mm}$. intercostales interni y muy delgado, compuesto por múltiples metámeros indiferenciados (exceptuando los primeros) de fibras mayormente de dirección vertical. Se extiende mayormente entre las costillas 2 y 11, aunque de un lado se registró un origen reducido en el sector cartilaginoso de la 12.

Origen: Mediante fibras carnosas sobre los aspectos dorsal e interno de todas las esternebras, exceptuando las dos primeras, y desde el cartílago xifoides, exceptuando su extremo caudal. Algunas fibras se originan también sobre el aspecto interior de los cartílagos costales de las costillas de la T3 a la T11/T12.

Inserción: Se inserta mediante fibras carnosas sobre el sector dorsocaudal de los cartílagos costales precedentes a los orígenes, desde la costilla de la T2 a la T10/T11, y sobre la fascia que cubre los mm. intercostales interni, a la altura del límite entre la porción ósea y cartilaginosa de las costillas. Las inserciones costales son importantes solamente en el sector anterior de la caja torácica. 


\subsubsection{Musculatura abdominal}

\section{M. rectus abdominis (Láminas 2.1-2, 2.20)}

Músculo ubicado profundo a los $\mathrm{mm}$. pectorales (en su sector anterior) y la fascia ventral del $\mathrm{m}$. obliquus externus abdominis (en sus dos tercios posteriores). Posee una forma alargada y aplanada, se encuentra unido vía aponeurosis a la caja torácica. En su sector caudal se encuentra fuertemente unido y rodeado mediante una fascia al $\mathrm{m}$. obliquus internus abdominis. A la altura del sector más caudal del esternón, se ensancha abruptamente.

Origen: Se origina mediante una amplia fascia tendinosa, incluyendo o no fibras carnosas, sobre los cartílagos costales de las costillas T1 a T4 (dos lados analizados), o exclusivamente desde la primer costilla (dos lados analizados). Ventralmente, estos orígenes se continúan mediante una fascia que alcanza al margen del esternón comprendido entre estas costillas, agregándose algunos orígenes vía fascias aisladas, sobre los elementos cartilaginosos de las costillas posteriores.

Inserción: En su sector más anterior, mediante una fascia tendinosa sobre músculos adyacentes (intercostales y oblicuos abdominales). A partir de aquí, se inserta sobre la línea alba, participando progresivamente un mayor número de fibras carnosas, para finalmente insertarse junto al $\mathrm{m}$. obliquus internus abdominis y la fascia del $\mathrm{m}$. obliquus externus abdominis sobre el sector craneal de la sínfisis pélvica.

\section{M. obliquus externus abdominis (Láminas 2.1, 2.9)}

Extenso y mantiforme, cubre el sector caudal de la caja torácica y el abdomen, así como a los demás músculos abdominales. En su sector medio y dorsal está compuesto por fibras carnosas que discurren en dirección caudoventral, mientras que en su tercio ventral se continua como una fascia que cubre al $\mathrm{m}$. obliquus internus abdominis y al $\mathrm{m}$. rectus abdominis. En el sector dorsal de las últimas costillas, las inserciones son más fuertes y comparte fibras con los músculos intercostales.

Origen: Mediante fibras principalmente y progresivamente más carnosas sobre las costillas de T3/T4/T5 a la última, a modo de fascículos anchos. Caudal a la décimo segunda costilla, los orígenes son progresivamente más débiles, para continuarse caudal y dorsalmente como una fascia que cubre al $\mathrm{m}$. obliquus internus abdominis, y que a su vez alcanza a la lámina más superficial de la fascia tóraco-lumbar. En el sector craneal, las fibras se originan sobre el cuerpo costal, por debajo del ángulo costal, sin alcanzar la zona de la unión condrocostal, y se interdigita con los orígenes más caudales del $\mathrm{m}$. serratus ventralis thoracis. En el sector caudal de la caja torácica, las fibras se originan progresivamente más ventralmente, registrándose los últimos orígenes en los sectores más distales del cuerpo de las últimas costillas. En este sector, las fibras más dorsales también toman origen sobre los músculos intercostales. 
Inserción: Mediante una fascia sobre la línea alba, desde cercanías del esternón a la zona inguinal, superficial a la del m. rectus abdominis. En su sector ventrocaudal, mediante una fascia breve pero fuerte, este músculo alcanza una inserción sobre el margen craneal del pubis.

M. obliquus internus abdominis (Láminas 2.1-3, 2.20)

Músculo abdominal mantiforme, cuadrangular, extremadamente delgado y fuertemente unido al m. transversus abdominis, ubicándose superficial a éste. Las fibras de este músculo corren en dirección cráneoventral, y se convierten netamente en una fascia en el último tercio de su recorrido.

Origen: Sobre la fascia tóraco-lumbar y sobre el extremo craneal del ilion.

Inserción: Vía una fascia tendinosa que rodea al m. rectus abdominis, llegando a la línea alba. También se inserta, mediante fibras carnosas, sobre el margen caudal de la caja torácica (excepto en el sector más ventral, y tapado por el m. rectus abdominis), sobre las regiones caudales de los cartílagos de las últimas costillas.

M. transversus abdominis (Láminas 2.1, 2.4)

Mantiforme, extremadamente delgado y fuertemente unido al $\mathrm{m}$. obliquus internus abdominis. Se ubica en gran parte profundo a este último, y continuándose cranealmente con el $\mathrm{m}$. transversus thoracis. Las fibras del $\mathrm{m}$. transversus abdominis corren en dirección caudoventral, manteniéndose carnoso por debajo de la fascia del $\mathrm{m}$. obliquus internus abdominis y en cercanías a su inserción.

Origen: En su sector dorsal, se origina desde la fascia tóraco-lumbar y el extremo craneal del ilion. En su sector craneal, se origina desde la cara interna y caudal de los cartílagos de las últimas 6/7 costillas, interdigitado con los orígenes del diafragma, y siendo especialmente robustos los orígenes sobre las uniones condrocostales. En el caso de las últimas tres costillas, las fibras de origen alcanzan un breve sector óseo.

Inserción: Mediante una breve fascia sobre la línea alba, profundo al m. rectus abdominis, alcanzando la cara lateral de xifoides, inmediatamente lateral al origen xifoideo del diafragma.

M. rectus thoracis (= transversus costarum) (Láminas 2.1-2)

Breve, aplanado y superficial al sector craneal del m. rectus abdominis. Sus fibras discurren desde origen a inserción en dirección caudoventral.

Origen: Mediante fibras carnosas del margen caudal de la unión condrocostal y cartílago costal de la primer costilla, inmediatamente superficial al sector de origen del m. rectus abdominis.

Inserción: Mediante una fascia amplia y delgada, sobre el m. rectus abdominis y el esternón entre la primera y cuarta costilla.

M. supracostalis (= transversus costarum) (Láminas 2.1, 2.3)

Ubicado inmediatamente dorsal al $\mathrm{m}$. rectus abdominis y ventral al $\mathrm{m}$. scalenus dorsalis, ubicado sobre los cartílagos costales del sector craneal y medio de la caja torácica. Puede ser 
considerado como una subdivisión del $\mathrm{m}$. rectus thoracis de inserción ósea, pero aquí es descripto separadamente de este último por su total independencia en los especímenes analizados.

Origen: Mediante fibras principalmente carnosas sobre el margen caudal de la unión condrocostal de la primer costilla o inmediatamente dorsal a este punto, inmediatamente dorsal al origen del $\mathrm{m}$. rectus abdominis, con el cual comparte algunas pocas fibras, y caudal al origen del $\mathrm{m}$. scalenus ventralis.

Inserción: Mediante una fascia tendinosa breve. La posición de inserción fue muy variable, registrándose sobre las costillas de la T5 exclusivamente/T5 y T6/T6 exclusivamente/ T6 secundariamente $\mathrm{T} 4$ y $\mathrm{T} 5$.

\subsubsection{Musculatura de la lengua}

\section{M. genioglossus (Lámina 2.5)}

Ubicado profundo al $\mathrm{m}$. mylohyoideus y al $\mathrm{m}$. geniohyoideus, y parcialmente cubierto por el $\mathrm{m}$. hyoglossus lateralmente. Se fusiona con su contraparte en cercanías a su origen y se vuelve delgado hacia su inserción.

Origen: Sobre el margen ventromedial de la rama horizontal de la mandíbula, a la altura de la sínfisis y del sector caudal $\mathrm{p} 4$, inmediatamente caudodorsal al origen del $\mathrm{m}$. geniohyoideus.

Inserción: Sobre la línea media de la lengua hasta el nivel del hueso basihioides, profundo al $\mathrm{m}$. geniohyoideus y medial al m. hyoglossus.

M. hyoglossus (Láminas 2.5, 2.7)

Delgado y breve, lateral al m. genioglossus, medial al m. styloglossus, y profundo a este último.

Origen: Mediante fibras carnosas sobre el hueso basihioides, excepto en la porción media que está ocupada por el m. geniohyoideus, y sobre la porción proximal del hueso ceratohioides.

Inserción: En el sector medio de la base de la lengua.

M. styloglossus (Láminas 2.5, 2.7)

Músculo delgado, lateral a los demás músculos de la lengua. En un lado se detectó un paquete muscular extra, originado sobre el hueso ceratohioides y el sector próximo del epihioides, ubicado entre el $\mathrm{m}$. hyoglossus y el m. styloglossus, e insertándose en conjunto con estos, posiblemente correspondiente a un vientre accesorio de este último.

Origen: Mediante una fascia breve sobre el hueso stylohioides y sobre las inmediaciones en la bulla auditiva.

Inserción: Algunas fibras se insertan sobre el m. hyoglossus y el resto en la lengua.

\subsubsection{Musculatura extrínseca e intrínseca del miembro anterior}




\section{M. cutaneus trunci (=m. panniculus carnosus)}

Amplio, carnoso y rugoso que cubre el lateral y la región ventral del tórax, superficial al m. latissimus dorsi. Discurre en dirección craneal y ventral, hasta la región medial de brazo, convirtiéndose abruptamente en una fascia delgada antes de su inserción. En algunos casos una delgada banda se desprende y alcanza la superficie lateral y craneal del codo, ubicándose superficial al brazo.

Origen: Sobre el tejido cutáneo y fascias que cubren los músculos más superficiales a la altura del muslo y zona abdominal.

Inserción: Mediante una delgada pero amplia fascia, sobre la cara superficial del paquete ventral del $\mathrm{m}$. latissimus dorsi (el cual a su vez se inserta sobre el $\mathrm{m}$. pectoralis profundus), justo antes de la inserción de este último en cercanías al húmero proximal, aunque sin presentar una inserción ósea. Algunas fibras tendinosas alcanzan al vientre del m. biceps brachii.

M. brachiocephalicus (Láminas 2.5-6, 2.9, 2.11)

Ubicado en la zona craneal y ventral del cuello hasta el sector craneal del húmero. Compuesto por tres paquetes a modo de bandas: $\mathrm{m}$. cleidocephalicus pars cervicalis, $\mathrm{m}$. cleidocephalicus pars mastoidea y m. cleidobrachialis.

\section{M. cleidocephalicus pars mastoidea (=m. cleidomastoideus; Láminas 2.5, 2.9-10)}

Ubicado en el sector lateroventral del cuello, profundo al m. sternocephalicus, y ventral al $\mathrm{m}$. splenius y $\mathrm{m}$. omotransversarius.

Unido mediante aponeurosis al $\mathrm{m}$. omotransversarius y compuesto por dos vientres diferenciables cranealmente, siendo el más dorsal de ellos del doble de tamaño.

Origen: El paquete ventral se origina mediante fibras tendinosas sobre el sector ventral y craneal del proceso mastoideo. El paquete dorsal se origina caudal a éste, mediante fibras carnosas sobre el sector lateral de la base del proceso mastoideo.

Inserción: Mediante fibras carnosas sobre la intersección clavicular, uniéndose con la inserción del $\mathrm{m}$. cleidocephalicus pars cervicalis y el origen del m. cleidobrachialis.

\section{M. cleidocephalicus pars cervicalis (=m. cleidooccipitalis; Láminas $2.5-6,2.9)$}

Superficial, ubicado en el sector laterodorsal del cuello, craneal al m. trapezius pars cervicalis. En su sector caudodorsal, una aponeurosis lo une firmemente a este último. Comparte algunas fibras con el $\mathrm{m}$. sternocephalicus pars occipitalis.

Origen: Desde el rafe del cuello, al nivel del atlas y axis, o C3 (inmediatamente contiguo y craneal al m. trapezius pars cervicis), y mediante fibras carnosas sobre el primer cuarto dorsal de la cresta nucal. El sector más ventral de su origen se da mediante fibras tendinosas que se fusionan con el $\mathrm{m}$. sternocephalicus pars occipitalis.

Inserción: Mediante fibras carnosas sobre la intersección clavicular, uniéndose con la inserción del $\mathrm{m}$. cleidocephalicus pars mastoidea y el origen del m. cleidobrachialis. 


\section{M. cleidobrachialis (=m. deltoideus pars clavicularis) (Láminas 2.9-11)}

En forma de banda ancha, ubicado en el sector craneal del brazo, por sobre el m. biceps brachii y el sector distal del $\mathrm{m}$. deltoideus pars acromialis. El $\mathrm{m}$. cleidobrachialis se encuentra íntimamente unido, aunque sin fusionarse, al los mm. pectorales.

Origen: Mediante fibras mayormente carnosas sobre la intersección clavicular, uniéndose con la inserción del m. cleidocephalicus pars cervicalis y m. cleidocephalicus pars mastoidea.

Inserción: Mediante fascia sobre el sector proximal y craneal del $\mathrm{m}$. triceps lateralis, y en general mediante fibras carnosas sobre el sector distal del $\mathrm{m}$. deltoideus pars acromialis. Posee una inserción ósea amplia mediante fibras carnosas (excepto en los extremos proximal y distal en los que existe una componente tendinosa) sobre el aspecto craneal de la mitad distal del húmero, llegando hasta el nivel de la expansión de la diáfisis humeral.

M. omotransversarius (=m. acromio-trachelian, m. levator claviculae) (Láminas 2.6, 2.810)

Ubicado superficial al m. rhomboideus profundus. En cercanías a su origen, se encuentra por debajo del $\mathrm{m}$. brachiocephalicus, y en su sector medio unido mediante fascias al $\mathrm{m}$. cleidomastoideus, $\mathrm{m}$. omohyoideus y m. splenius. En cercanías a su inserción se posiciona dorsal al $\mathrm{m}$. cleidomastoideus y superficial al $\mathrm{m}$. trapezius pars cervicis, fusionándose en parte con este último.

Origen: Mediante fibras principalmente carnosas, sobre el aspecto caudomedial de la cara ventral del atlas, inmediatamente medial al $\mathrm{m}$. rectus capitis lateralis.

Inserción: Vía fibras musculares sobre el $\mathrm{m}$. deltoideus pars scapularis y mediante fibras carnosas y tendinosas sobre el sector caudal del metacromion.

M. omohyoideus (Láminas 2.8-10, 2.12)

Es delgado y en forma de banda. Se ubica por debajo del $\mathrm{m}$. cleidocephalicus pars mastoidea, y ventral al m. omotransversarius en la mayor parte de su recorrido. En la zona central del cuello, su margen dorsal comparte algunas fibras tendinosas con el sector ventral de éste último músculo. Inmediatamente antes de alcanzar su inserción, se ubica entre el $\mathrm{m}$. supraspinatus y el $\mathrm{m}$. subscapularis.

Origen: Mediante fibras carnosas, inmediatamente lateral al $\mathrm{m}$. sternohyoideus, sobre el hueso thirohioides y en general sobre el hueso basihioides.

Inserción: Mediante fibras carnosas, sobre un breve sector en la región craneal de la cara medial del cuello de la escápula.

M. trapezius (Láminas 2.6, 2.8-9)

Aplanado, compuesto de dos paquetes principales con forma de abanico invertido: $\mathrm{m}$. trapezius pars cervicalis y $\mathrm{m}$. trapezius pars thoracica. En el sector de unión de los paquetes se presenta una intersección tendinosa compleja, compuesta de dos fascias solapadas y que 
intercambian fibras: la capa superficial se continua cranealmente con el $\mathrm{m}$. trapezius pars cervicalis (y caudalmente con la zona de inserción del m. trapezius pars thoracica), y la profunda se continua caudalmente con el $\mathrm{m}$. trapezius pars thoracica. La posición de la intersección tendinosa se extiende entre la intersección tendinosa, a la altura de la primera torácica, el margen craneal del sector proximal de la espina escapular (ambas capas) y el margen proximal del $\mathrm{m}$. rhomboideus profundus (para el caso de la capa profunda). El m. trapezius pars thoracica se encuentra unido por una aponeurosis al sector proximal del $\mathrm{m}$. triceps caput angulare.

\section{M. trapezius pars cervicalis (Láminas 2.6, 2.8-9)}

Parte desde el sector medio y posterior del cuello y sus fibras convergen sobre la escápula.

Origen: A partir del rafe cervical desde la altura de la $\mathrm{C} 3-4$ a la $\mathrm{T} 1$, mediante fibras carnosas en el sector craneal, variable en el sector medio y netamente tendinosas en el sector caudal, algunas fibras originándose y otras continuándose caudalmente, con la capa superficial intersección tendinosa, hasta la altura de $\mathrm{T} 2$.

Inserción: Superficialmente vía fibras principalmente carnosas, sobre los dos tercios distales del margen craneal de la espina escapular, en muchos casos, alcanzando el metacromion.

\section{M. trapezius pars thoracica (Láminas 2.6, 2.8-9)}

Parte desde la línea media del sector anterior del tórax, y sus fibras convergen sobre la escápula, caudal al $\mathrm{m}$. trapezius pars cervicalis.

Origen: Mediante fibras carnosas desde el rafe torácico, desde la altura de la segunda y hasta la octava vértebra torácica. Algunas fibras tendinosas alcanzan el sector craneal de T9. Cranealmente algunas fibras se insertan y otras se continúan con la capa profunda de la intersección tendinosa, hasta la altura de T1.

Inserción: Superficialmente, mediante fibras carnosas distalmente y tendinosas proximalmente, sobre el margen caudal de la espina de la escápula, sin alcanzar la región del metacromion.

M. latissimus dorsi (Láminas 2.6, 2.9)

Amplio en forma de manto o abanico invertido que cubre la región dorsal y lateral de la caja torácica, ubicado entre el $\mathrm{m}$. trapezius pars thoracica y el $\mathrm{m}$. serratus ventralis thoracis en su sector craneal y medio, y por sobre la musculatura intercostal y abdominal en su sector medio y caudal. Una aponeurosis la cubre en conjunto con la musculatura abdominal próxima. En proximidades al miembro anterior y la zona de inserción, se subdivide en dos paquetes laminares (dorsal y ventral).

Origen: Toma origen a partir de fibras carnosas y tendinosas sobre las caras externas de los cuerpos costales, desde la T10/11 hasta la T12/13, siendo más amplias las áreas de orígenes en los últimos elementos. En el sector dorsal, el m. latissimus dorsi se origina mediante fibras carnosas desde el rafe a la altura de los extremos dorsales de los procesos espinales de la T3/T4, 
continuándose hasta el rafe ubicado sobre la zona de la vértebra anticlinal (T12) y finalmente sobre la fascia tóraco-lumbar superficial. Algunas fibras se originan sobre músculos abdominales.

Inserción: Cada paquete se inserta en dos sectores independientes. El dorsal se ubica profundo al m. teres major en vista lateral, y se inserta vía una fascia que se fusiona con las fibras de inserción más profundas del $\mathrm{m}$. teres major, formando netamente un tendón en el sector más ventral. El ventral presenta una inserción más amplia, vía fascia y sobre el sector superficial del vientre caudal del m. pectoralis profundus, en cercanías a la zona de inserción del mismo.

Mm. rhomboideus (Láminas 2.5-6, 2.8, 2.10)

Compuesto por cuatro paquetes independientes: $\mathrm{m}$. rhomboideus cervicis, $\mathrm{m}$. rhomboideus thoracis, $\mathrm{m}$. rhomboideus capitis y $\mathrm{m}$. rhomboideus profundus. Se ubica por debajo del $\mathrm{m}$. trapezius pars cervicalis y $\mathrm{m}$. brachiocephalicus. Los $\mathrm{m}$. rhomboideus cervicis, $\mathrm{m}$. rhomboideus capitis y $\mathrm{m}$. rhomboideus profundus son aplanados y en forma de banda. El $\mathrm{m}$. rhomboideus thoracis es una banda muy breve. Tanto los $\mathrm{mm}$. rhomboideus como el $\mathrm{m}$. sternocephalicus se encuentran unidos por una aponeurosis.

\section{M. rhomboideus cervicis (Láminas 2.6, 2.8, 2.10)}

En proximidades a su inserción, se ubica por sobre el m. rhomboideus capitis, y es dorsal a este en todo su recorrido. Músculo amplio y aplanado, siendo el mayor (en proximidades a su inserción) de los mm. rhomboideus. Sobre su inserción, comparte fibras carnosas con el $\mathrm{m}$. serratus ventralis.

Origen: Mediante fibras carnosas a lo largo del rafe entre la T1 y el atlas o el axis.

Inserción: Mediante fibras carnosas sobre el sector cráneomedial del margen dorsal de la escápula, incluyendo al ángulo dorsal.

\section{M. rhomboideus thoracis (Láminas 2.6, 2.8, 2.10)}

Pequeño carnoso y aguzado. Sus fibras discurren lateromedialmente. Separable del m. rhomboideus cervicis en mayor o menor grado, pero íntimamente relacionado a éste.

Origen: Mediante fibras carnosas sobre el rafe medio, a la altura de los procesos espinosos de las primeras dos vértebras torácicas.

Inserción: Mediante fibras carnosas sobre la mitad caudal del aspecto medial del margen dorsal de la escápula, inmediatamente caudal y por sobre el m. rhomboideus cervicis, y vía una fascia débil sobre inmediatamente lateral a este sector.

M. rhomboideus capitis (Láminas 2.5, 2.8, 2.10)

Sobre su inserción, comparte fibras carnosas con el m. serratus ventralis. Fuera de lo observado en la zona inserción, el m. rhomboideus capitis se encuentra totalmente separado del m. rhomboideus cervicis. 
Origen: Mediante fibras principalmente tendinosas a modo de una corta fascia sobre el tercio medio de la cara interna de la cresta nucal.

Inserción: Mediante fibras carnosas y tendinosas sobre la cara medial del ángulo dorsal de la escápula, inmediatamente medial al sector craneal de la inserción del m. rhomboideus cervicis.

M. rhomboideus profundus (Láminas 2.6, 2.8, 2.10)

Se ubica por debajo del m. omotransversarius, y se ensancha hacia su inserción. Es una banda un poco más delgada y ventral que el $\mathrm{m}$. rhomboideus capitis.

Origen: Mediante un tendón muy delgado y corto sobre el ángulo caudomedial del ala del atlas. Inserción: Vía fascia sobre la superficie dorsal del vientre del m. supraspinatus, inmediatamente craneal al sector más dorsal de la espina escapular, continuándose también con la aponeurosis que cubre el margen dorsal de la escápula.

Mm. pectorales superficiales (Láminas 2.6, 2.9, 2.11-12)

Compuestos por dos vientres: uno craneal y otro caudal. En conjunto poseen forma de abanico invertido y se encuentran unidos por una aponeurosis. El vientre caudal está compuesto por un vientre proximal y otro distal en relación a sus sitios de inserción, compartiendo un gran número de fibras en sus orígenes. En general, la diferenciación de estas porciones no es completa. En su sector caudal, los mm. pectorales superficiales son superficiales al m. pectoralis profundus.

Origen: El vientre craneal se origina mediante fibras carnosas sobre el sector craneal del manubrio. En sección, este sector es el más grueso de los pectorales. El vientre caudal proximal se origina mediante fibras carnosas, sobre el aspecto lateroventral del manubrio y bajo la región articular de la primera costilla. El vientre caudal distal se origina mediante fibras carnosas y tendinosas (exclusivamente en el sector caudal del área de origen) sobre el aspecto lateroventral de los cuerpos de las dos primeras esternebras, y el sector craneal de la tercera.

Inserción: El vientre craneal se inserta mediante fibras carnosas sobre el área medial y adyacente a la cresta deltoidea y sobre la base del tubérculo mayor del húmero, lateral a la inserción del vientre caudal del m. pectoralis profundus. El vientre caudal proximal se inserta mediante fibras carnosas sobre el aspecto craneal del segundo cuarto del húmero, desde el sector distal de la cresta pectoral (inmediatamente distal al vientre craneal), hasta el nivel de la mitad de la diáfisis humeral. El vientre caudal distal se inserta mediante fibras mayormente carnosas (aunque distalmente hay fibras tendinosas) en el tercer cuarto del húmero e inmediaciones, inmediatamente distal al anterior.

M. pectoralis profundus (Láminas 2.6, 2.9, 2.11-12)

Compuesto por dos vientres: uno craneal y otro caudal. En conjunto poseen forma de abanico invertido y se encuentran unidos por una aponeurosis. El vientre caudal es de gran tamaño y amplio en sección, mientras que el craneal es menor, o marcadamente menor, y se 
encuentra parcialmente cubierto por el vientre caudal del $\mathrm{m}$. pectorales superficialis. El margen dorsal del vientre caudal del $\mathrm{m}$. pectoralis profundus se encuentra unido a lo largo de parte de su recorrido al margen ventral del $\mathrm{m}$. latissimus dorsi. En cercanías a su inserción, recibe superficialmente la inserción ventral del m. latissimus dorsi e indirectamente vía este último la del $\mathrm{m}$. cutaneus trunci.

Origen: La extensión del origen del vientre craneal es variable, desde exclusivamente el aspecto lateral del sector craneal de la tercer esternebra hasta un origen incluyendo el total de la tercera y cuarta esternebras y el sector craneal de la quinta. El origen más craneal del vientre caudal también fue variable, alcanzando la mitad caudal de la tercer esternebra hasta el sector caudal de la cuarta esternebra. En todos los casos, el origen del vientre caudal se extiende hasta la novena esternebra y, mediante fibras mayormente carnosas, sobre el sector distal de los cartílagos costales de las costillas décima y décimo primera.

Inserción: El vientre craneal se inserta, vía fibras carnosas y una fascia profunda, sobre el extremo proximal de la cresta pectoral y la base del tubérculo mayor del húmero (en tres casos), y sobre el tubérculo menor (en una de estas tres, y como única zona en una cuarta). Algunas fibras se insertan sobre el vientre craneal del $\mathrm{m}$. supraspinatus y la cápsula articular del hombro. El vientre caudal se inserta, mediante fibras proximalmente carnosas y distalmente una fascia, sobre el aspecto medial de la cresta pectoral, inmediatamente medial al vientre craneal de los $\mathrm{mm}$. pectorales superficiales, a lo largo del primer tercio de la diáfisis.

\section{M. subclavius}

Ausente en todos los especímenes examinados.

Mm. serratus ventralis (Láminas 2.6, 2.8, 2.10-12)

Ubicado por debajo del $\mathrm{m}$. latissimus dorsi, m. rhomboideus y la escápula. Músculo amplio y con forma de abanico, conformado por múltiples fascículos que convergen en su inserción, por sobre las costillas y dorsal (y en parte profundo) a los mm. scalenus. Pueden subdividirse en función de la dirección de sus fibras y posición de fascículos en dos grupos principales, uno craneal y otro caudal ( $\mathrm{m}$. serratus ventralis cervicis y $\mathrm{m}$. serratus ventralis thoracis, respectivamente), unidos por una fuerte fascia interna, y diferenciables al nivel de la costilla de la T2 a T3, existiendo algunas veces solapamiento entre ambas partes sobre la T2. La porción craneal presenta en general siete fascículos, mientras que la caudal en general cinco (excepto en el lado izquierdo del tercer espécimen analizado). En el sector más posterior del origen el $\mathrm{m}$. serratus ventralis thoracis se interdigita con los orígenes del m. obliquus externus abdominis, y ambos son unidos por una aponeurosis. Otra aponeurosis cubre su sector de origen y los músculos próximos (e.g. escalenos).

Origen: Mediante fibras carnosas. La porción craneal se origina sobre los tubérculos dorsales de los procesos transversos de la tercera a la séptima cervical, sobre el margen dorsal de los m. 
scalenus medius (entre los tubérculos dorsales), y desde la cara lateral de las dos o tres primeras costillas. La porción caudal se origina desde las costillas de la T2/T3 a la T6/T7.

Inserción: Todos los fascículos confluyen y se insertan mediante fibras carnosas (exceptuando el sector extremo craneal) sobre la cara medial del margen dorsal y el ángulo caudal de la escápula, compartiendo algunas fibras con el $\mathrm{mm}$. rhomboideus.

\section{M. deltoideus (Láminas 2.8-11)}

Está compuesto de dos paquetes independientes: pars scapularis y pars acromialis. El primero es elongado y delgado, y se ubica caudal y proximal, y distalmente por debajo de la parte acromial, lugar en donde da paso a una fascia tendinosa. El $\mathrm{m}$. deltoideus pars acromialis es más breve y triangular. Una aponeurosis superficial une al $\mathrm{m}$. deltoideus con el $\mathrm{m}$. supraspinatus.

Origen: $\mathrm{El} \mathrm{m}$. deltoideus pars scapularis se origina directamente de la fascia que cubre el $\mathrm{m}$. infraspinatus y el sector proximal de la espina escapular, y mediante fibras carnosas y tendinosas sobre el metacromion. El m. deltoideus pars acromialis se origina mediante fibras carnosas y tendinosas sobre el acromion y, en general, sobre el sector más distal de la base del metacromion.

Inserción: El m. deltoideus pars scapularis se inserta mediante una fascia tendinosa amplia y plana, sobre la un sector medio de la cresta deltoidea, inmediatamente lateral al m. deltoideus pars acromialis. El m. deltoideus pars acromialis se inserta a lo largo de la cresta deltoidea, mediante fibras mayormente carnosas, exceptuando el sector más proximal, en donde se registran fibras tendinosas.

M. supraspinatus (Láminas 2.8, 2.10-13)

Amplio y compuesto por tres paquetes diferenciables: uno principal, alojado en la fosa supraespinal; uno superficial, laminar y fusionado profundamente con el principal, y uno craneal, con forma de huso y mayormente independiente ubicado por delante de los anteriores sobre el margen craneal de la escápula.

Origen: Mediante fibras carnosas. El paquete superficial se origina sobre la superficie proximal del vientre del paquete principal, el sector proximal de la fascia que lo cubre, y sobre el margen craneal de la espina escapular. El paquete principal se origina de toda la fosa supraespinal, la cara craneal de la espina y el margen craneal de la escápula. El paquete craneal se origina en un sector justo craneal al del paquete principal, a lo largo de la mitad ventral del margen craneal de la escápula, sobre el ángulo ventral, el margen ventral, incluyendo también la región craneal del cuello de la escápula. En algunos casos, el margen cráneomedial de este músculo comparte fibras con el m. subscapularis.

Inserción: El paquete superficial se inserta mediante fascia tendinosa y fibras musculares en el sector cráneodorsal del tubérculo mayor del húmero, mientras que algunas fibras se insertan 
tempranamente sobre la articulación del hombro. El paquete principal se inserta mayormente vía fibras tendinosas sobre la zona dorsal del tubérculo mayor. El paquete craneal del supraspinatus se inserta mediante fibras carnosas y algunas fibras tendinosas profundas sobre el aspecto medial del tubérculo mayor del húmero. En el caso de un miembro de un ejemplar, se observó que la inserción ocurrió sobre el sector craneal del tubérculo menor y mediante pocas fibras musculares sobre los otros paquetes del m. supraspinatus en inmediaciones del surco bicipital.

M. infraspinatus (Láminas 2.8, 2.11-13)

Cilíndrico, ubicado sobre la cara lateral de la escápula, caudal a la espina escapular, alcanzando el sector proximal del húmero.

Origen: Mediante fibras carnosas, desde toda la fosa infraespinal de la escápula, y la cara caudal de la espina, y la cara interna del metacromion y del ligamento que conecta el metacromion con el sector dorsal de la espina. A la altura del ángulo caudal, presenta algunas fibras de origen tendinosas.

Inserción: Vía un tendón corto y plano, sobre el sector caudal de la tubérculo mayor del húmero, sobre una fosa definida.

M. teres minor (Láminas 2.8, 2.10-11, 2.13)

Diminuto, en forma de abanico invertido. Ausente en ambos lados del espécimen 1.

Origen: Vía fibras carnosas sobre el margen caudal de la escápula y unas pocas fibras tendinosas dorsales. En algunos casos, incluyendo un origen vía fascia sobre el m. infraspinatus.

Inserción: Vía un tendón delgado inmediatamente distal a la inserción del m. infraspinatus, sobre el sector lateral de la base del tubérculo mayor.

M. teres major (Láminas 2.8, 2.11-12)

Carnoso y aplanado, ubicado profundo respecto a la escápula en la mayor parte de su recorrido. Corre distalmente y se vuelve tendinoso en cercanías a su inserción, por debajo del cuerpo del m. biceps brachii.

Origen: Mediante fibras carnosas y tendinosas sobre la aponeurosis que cubre al $\mathrm{m}$. subscapularis e inmediatamente por debajo del ángulo caudal de la escápula.

Inserción: Mediante una fascia tendinosa, amplia y delgada sobre el sector proximal de la cara medial de la diáfisis del húmero, frecuentemente continuándose con el origen del $\mathrm{m}$. triceps brachii caput mediale intermedio.

M. subscapularis (Láminas 2.8, 2.11-12)

Ubicado medial a la escápula. Compuesto por seis grupos de fibras que convergen hacia sus líneas centrales a modo de bipinnación, que están fusionados y que corren paralelos al eje mayor de la escápula. Este músculo está cubierto por una fuerte aponeurosis en su sector proximal. 
Origen: Vía fibras carnosas desde toda la cara medial de la escapula mediante seis paquetes de fibras. Los límites entre orígenes de paquetes se encuentran asociados a crestas óseas definidas y láminas tendinosas en mayor o menor medida. En el extremo proximal de la escápula, ventral a los mm. serratus ventralis, el $\mathrm{m}$. subscapularis se origina mediante una breve fascia.

Inserción: Vía fibras carnosas sobre el sector caudodorsal de la tubérculo menor del húmero.

M. articularis humeri (= m. coracobrachialis brevis) (Láminas 2.8, 2.11)

Músculo breve, compuesto en su mitad proximal por fibras exclusivamente tendinosas.

Origen: Vía un tendón delgado pobremente definido y aplanado sobre el proceso coracoides.

Inserción: Mediante fibras carnosas inmediatamente por debajo del sector caudal de la tubérculo menor.

\section{M. coracobrachialis (= m. coracobrachialis longus)}

Ausente en ambos lados de todos los especímenes examinados.

M. biceps brachii (Láminas 2.8, 2.12, 2.14)

Robusto, cilíndrico y compuesto por un único vientre. Se ubica craneal al húmero entre la escápula y el antebrazo. La aponeurosis que cubre al $\mathrm{m}$. biceps brachii se continúa con la fascia que cubre al antebrazo.

Origen: Mediante un tendón robusto desde el tubérculo supraglenoideo.

Inserción: Mediante un tendón aplanado sobre la tuberosidad bicipital del radio, alcanzando este sector desde la cara medial.

\section{M. brachialis (Láminas 2.11-14)}

En su sector proximal se ubica por debajo del m. triceps brachii caput laterale, y en su sector medio y distal, se ubica inmediatamente lateral al $\mathrm{m}$. biceps brachii y cubierto por el $\mathrm{m}$. brachioradialis. Este músculo posee forma cilíndrica levemente aplanada.

Origen: Mediante fibras generalmente carnosas, sobre gran parte de la cara lateral, y el sector craneodistal de la diáfisis humeral.

Inserción: Se inserta vía fibras carnosas en el sector medial de la ulna, inmediatamente distal a la articulación codo, y sobre la cápsula articular.

\section{M. triceps brachii (Láminas 2.8-14)}

Ubicado a lo largo del sector caudal y lateral del brazo. Compuesto por 6 cabezas bien diferenciadas en su origen: caput longum, caput laterale, caput angulare, caput accessorium, caput mediale accessorium y caput mediale; y esta última se encuentra a su vez claramente dividida en tres vientres: principal medial, principal lateral e intermedio.

M. triceps brachii caput laterale (Láminas 2.9-11, 2.13-14)

Ubicado sobre la cara lateral del brazo. Es voluminoso y posee forma de huso. 
Origen: Mediante fibras carnosas y tendinosas, sobre el sector caudolateral contiguo a la tubérculo mayor y cuello humeral, inmediatamente distal a la cabeza humeral. Algunas fibras tendinosas superficiales se originan sobre la cresta caudal a la tubérculo mayor.

Inserción: Mediante una fascia sobre el sector distal del m. triceps brachii caput longum, y sobre la superficie caudal de la cara lateral del olécranon.

M. triceps brachii caput longum (Láminas 2.8-10, 2.12, 2.14)

Ubicado en el sector caudal del brazo, es el músculo intrínseco más voluminoso, con forma de huso engrosado en su sector medio.

Origen: Mediante fibras carnosas y una fascia tendinosa medial sobre el sector caudal del cuello escapular y el sector próximo del margen caudal de la escápula.

Inserción: Mediante un tendón breve y robusto sobre el margen caudal del olécranon. Por otro lado, en el sector más medial se presentan algunas fibras carnosas, mientras que en el sector laterocaudal del olécranon se inserta mediante una fascia tendinosa breve.

M. triceps brachii caput angulare (Láminas 2.8-9, 2.14)

Aplanado, superficial y caudal a los demás vientres del m. triceps brachii. Algunas fibras aponeuróticas lo unen con las cabezas lateral y larga del $\mathrm{m}$. triceps brachii.

Origen: Mediante fibras carnosas y pequeños tendones sobre el sector proximal del $\mathrm{m}$. teres major y vía fibras carnosas justo lateral al sector del ángulo caudal de la escápula. Algunas fibras tendinosas toman origen sobre el sector proximal del $\mathrm{m}$. infraspinatus.

Inserción: Vía fascia sobre el sector proximoventral del olécranon. Por otro lado, se continua ampliamente con el sector medial de la fascia del brazo, cubriendo a los restantes vientres del $\mathrm{m}$. triceps brachii y al sector de inserción del los pectorales, y con el sector caudal y medial de la fascia del antebrazo, envolviendo a los músculos del sector.

\section{M. triceps brachii caput accessorium (Láminas 2.11, 2.13-14)}

Ubicado entre el caput laterale y el caput mediale, sobre el sector caudolateral del húmero. Cilíndrico y aplanado, es muscular en sus primeros cuatro quintos.

Origen: Mediante fibras carnosas, inmediatamente por detrás y por debajo del origen del $\mathrm{m}$. triceps brachii caput laterale, sobre un sector deprimido entre la cabeza humeral y el tubérculo mayor, sobre el sector caudal del cuello humeral.

Inserción: Tendinosa, sobre el sector laterodorsal del olécranon.

\section{M. triceps brachii caput mediale principal (Láminas 2.11-14)}

Se divide en dos vientres claramente diferenciados (excepto en un lado, y poco definido en otro), uno medial y otro lateral, diferenciados en la mayor parte de sus recorridos. El vientre lateral se convierte en un fino tendón más tempranamente que el vientre medial.

Origen: El paquete medial se origina mediante fibras carnosas y tendinosas en el sector distal a la tubérculo menor. El paquete lateral se origina mediante fibras carnosas y tendinosas 
inmediatamente dorsal al paquete medial, en el área deprimida ubicada sobre el sector caudomedial del cuello humeral.

Inserción: Ambos vientres se insertan sobre el mismo sector vía dos tendones delgados a modo de cintas contiguas sobre el extremo proximal del olécranon, en su sector cráneolateral.

M. triceps brachii mediale intermedio (Láminas 2.11-12, 2.14)

Ubicado inmediatamente medial respecto al $\mathrm{m}$. triceps brachii caput mediale principal.

Origen: Mediante fibras tendinosas sobre una línea proximodistal, en el sector medial del húmero, caudal a la inserción del $\mathrm{m}$. teres major y del m. latissimus dorsi, y distal y craneal al origen del $\mathrm{m}$. triceps brachii caput mediale principal.

Inserción: Mediante fibras carnosas sobre los tendones de inserción del m. triceps brachii caput mediale principal y sobre la cara dorsomedial del olécranon.

M. triceps brachii caput mediale accessorium (Láminas 2.11-12, 2.14)

Ubicado medial al m. anconeus, entre el entepicóndilo y el olécranon, breve y carnoso. Totalmente independiente a las otros mm. triceps brachii.

Origen: Mediante fibras carnosas, distal a la apertura caudal del foramen entepicondilar, sobre el entepicóndilo, alcanzando la base del puente del foramen entepicondilar (en el sp2 y sp3-li).

Inserción: Mediante fibras carnosas sobre la cara medial y caudal del olécranon. Distalmente comparte algunas fibras con el $\mathrm{m}$. flexor carpi ulnaris caput ulnare.

M. anconeus (Láminas 2.11, 2.13-14)

Músculo breve y carnoso, amplio en su región de origen.

Origen: Mediante fibras carnosas sobre el sector caudal del último tercio del húmero.

Inserción: Mediante fibras carnosas sobre la cápsula articular y superficie lateral del olécranon. Distalmente, algunas fibras carnosas y tendinosas alcanzan al sector caudal de la zona articular.

\section{M. tensor fasciae antebrachii}

Ausente o modificado. Ningún paquete de origen sobre el m. latissimus dorsi alcanza el olécranon. No puede descartarse una fusión al m. triceps brachii (ver discusión).

M. pronator teres (Láminas 2.11-12, 2.14)

En su sector proximal, se ubica sobre la cara medial del codo, para luego cruzar hacia lateral, ubicándose por debajo del $\mathrm{m}$. brachioradialis y otros extensores del carpo. Es elongado, de sección transversal cilíndrica en cercanías a su origen, y más bien aplanado hacia distal. En cercanías a su origen, se encuentra en mayor o menor grado dividido en dos vientres.

Origen: Sobre el sector medioproximal y craneal del entepicóndilo del húmero. El paquete de posición distal presenta un origen netamente tendinoso, mientras que el proximal es mayormente o netamente carnoso.

Inserción: Mediante fibras tendinosas sobre la cara craneal del sector mediodistal del radio.

M. flexor carpi radialis (Láminas 2.11-12, 2.16-17) 
En el sector cercano al origen, se ubica por debajo del m. pronator teres, volviéndose tendón abruptamente al principio de su último cuarto. Al transcurrir por la cara palmar del carpo es retenido por un retinaculum propio al carpal radial.

Origen: Inmediatamente ventral al $\mathrm{m}$. pronator teres, mediante fibras carnosas, sobre el sector medio del extremo medial en entepicóndilo.

Inserción: Tendinosa, mediante dos tendones poco definidos, sobre el sector proximal y palmar de los metacarpales II y III.

M. flexor carpi ulnaris (Láminas 2.9, 2.11-12, 2.14, 2.16)

Está compuesto de dos cabezas, la ulnar y la humeral. El m. flexor carpi ulnaris caput ulnare se ubica en la zona caudal del antebrazo, es amplio y posee forma de huso. El m. flexor carpi ulnaris caput humerale se ubica por debajo y medial al anterior, y es aplanado.

Origen: Mediante fibras carnosas. El m. flexor carpi ulnaris caput ulnare se origina sobre la cara caudal y medial del olécranon. El m. flexor carpi ulnaris caput humerale se origina en el extremo distal del entepicóndilo.

Inserción: El m. flexor carpi ulnaris caput ulnare se inserta mediante un tendón medial y mediante fibras carnosas, sobre la cara lateral del carpal accesorio, y mediante fibras carnosas y tendinosas sobre la fascia que cubre la muñeca. El ligamento distal al carpal accesorio, que alcanza la base del metacarpal $\mathrm{V}$, puede considerarse una continuación del tendón de inserción (ver McClearn 1985). El m. flexor carpi ulnaris caput humerale se inserta mediante fibras carnosas (excepto en el sector lateral, donde son tendinosas) sobre el sector medioproximal del carpal accesorio.

\section{M. palmaris brevis (Lámina 2.12)}

Breve y con fibras de dirección transversal, ubicado contiguo medialmente al $\mathrm{m}$. abductor digiti $\mathrm{V}$, superficial al $\mathrm{m}$. palmaris longus.

Origen: Vía fibras carnosas sobre la fascia que cubre los músculos y tendones del sector lateral de la muñeca, inmediatamente por debajo de la cabeza de carpal accesorio.

Inserción: Mediante fibras carnosas sobre dicha fascia a la altura del extremo ventral del sesamoideo radial.

M. palmaris longus (Láminas 2.11-12)

Aplanado, se ubica en la cara ventral del antebrazo. Se convierte en fibras tendinosas justo antes de la muñeca, en donde se ubica por sobre el retinaculum flexor.

Origen: Mediante tendón breve y plano, y en general fibras carnosas, sobre el margen caudomedial del extremo distal del entepicóndilo, por debajo del m. flexor carpi radialis.

Inserción: Mediante fibras tendinosas sobre la fascia palmar, conectándose indirectamente con el sesamoideo radial y el hueso accesorio. En la mayoría de los casos se definieron tendones 
para los dígitos II/III al IV/V, y en un caso un vientre muscular se diferenció tardíamente y dio origen a un tendón para el dedo I.

\section{M. flexor digitorum superficialis (Láminas 2.16-17)}

Breve y aplanado, superficial al sector distal $\mathrm{m}$. flexor digitorum profundus. Justo antes de ingresar al retinaculum flexor, se convierte en tres tendones muy finos que se dirigen superficialmente a los dígitos II, III y IV.

Origen: Vía fibras carnosas sobre la superficie del $\mathrm{m}$. flexor digitorum profundus. La porción que se dirige al dígito II parte de las fibras originadas sobre el $\mathrm{m}$. flexor digitorum profundus caput humerale mediale, mientras que las que se dirigen a los dígitos III y IV parten de las fibras originadas sobre el $\mathrm{m}$. flexor digitorum profundus caput humerale laterale.

Inserción: Mediante delgados tendones sobre los anillos anulares, a la altura de los sesamoideos metacarpales de los dígitos II, III y IV. Distal a esta zona, para cada dígito se diferencian dos pequeños tendones (excepto en cuatro casos para el dígito II) que se ubican en primera instancia externos a los del $\mathrm{m}$. flexor digitorum profundus, rodeando al mismo. En zona cercana al sector distal de cada falange proximal de cada dígito, cada par de tendones se fusionan por debajo del m. flexor digitorum profundus, para insertarse definitivamente sobre el sector proximal de la base de cada falange media.

\section{M. flexor digitorum profundus (Láminas 2.9, 2.11-12, 2.14, 2.17)}

Masivo y compuesto por cinco cabezas, tres de origen humeral (caput humerale laterale, caput humerale mediale y caput humerale profundus), una de origen ulnar (caput ulnare), y una de origen radial y ulnar (caput radiale). De estas cinco cabezas, la profunda y la medial son las menores. El caput humerale laterale se encuentra conformado por dos vientres parcialmente fusionados en su mitad distal. En su origen, caput humerale profundus es totalmente independiente de las otras dos cabezas humerales, las cuales se encuentran parcialmente fusionadas en este sector. En la zona media y proximal del antebrazo, las cabezas humerales comparten fibras. Las cinco cabezas se fusionan inmediatamente antes de ingresar al retinaculum flexor formando un tendón amplio y aplanado, ligeramente cóncavo: Las cabezas lateral y profunda se insertan mediante tendones al tendón común, la profunda se inserta entre la medial y la radial; la medial se inserta vía fascia y fibras carnosas; y la radial mediante fibras carnosas a la cara profunda del tendón común. La cabeza ulnar se convierte en un tendón breve y robusto antes de ingresar al retinaculum, ubicándose lateral y superficial a los restantes tendones, terminando de fusionarse a la altura de la serie carpal distal, presentando en este sector un sesamoideo en algunos casos.

Origen: Todas las cabezas humerales se originan sobre el entepicóndilo humeral. El caput humerale profundus se origina mediante un tendón inmediatamente dorsal al caput humerale laterale, y adyacente a la tróclea. El caput humerale mediale se origina principalmente vía fibras 
carnosas sobre el margen medial del entepicóndilo. El caput humerale laterale se origina del margen ventral del entepicóndilo humeral, mediante fibras carnosas (vientre distal o profundo) y una fascia tendinosa (vientre proximal o superficial). El caput ulnare se origina mediante fibras carnosas sobre la cara caudal y medial de la ulna, incluyendo parte del olécranon en la mayoría de los casos. El caput radiale se origina mediante fibras carnosas en la zona media de la cara medial del radio hasta inmediatamente caudal a la inserción del m. pronator teres, y sobre la cara medial del tercer cuarto de la ulna.

Inserción: El tendón común del $\mathrm{m}$. flexor digitorum profundus se subdivide en cinco tendones aplanados que se insertan en los tubérculos flexores de las falanges distales. Cada uno de estos tendones se diferencia dos bandas densas y una zona central más delgada, que se funden en una única zona densa al transcurrir por debajo de las articulaciones entre metacarpos y falanges, y entre falanges.

\section{M. flexor digitorum brevis manus}

Ausente en ambos lados de todos los especímenes analizados.

M. pronator quadratus (Láminas 2.14, 2.17)

Músculo aplanado, carnoso y cuadrangular, ubicado en el aspecto más profundo del sector distal y medial del antebrazo.

Origen: Mediante fibras carnosas sobre la cara medial del sector distal de la ulna.

Inserción: Mediante fibras carnosas sobre la cara cráneomedial y medial del sector distal del radio. Distalmente, la inserción se continúa con la fascia ligamentosa (ligamento radiocarpal palmar y ulnocarpal palmar) que cubre la cara ventral de los carpales.

M. brachioradialis (Láminas 2.9, 2.10-12, 2.14)

Se ubica sobre la cara craneal del antebrazo, para finalizar su recorrido en el sector cráneomedial del sector distal del antebrazo. Posee una forma relativamente aplanada y alargada.

Origen: Mediante fibras carnosas, inmediatamente caudodistal al origen del $\mathrm{m}$. brachialis. En tres casos, el área de origen fue breve, sobre el tercer cuarto de la cara caudal de la diáfisis humeral, hasta el sector proximal de la cara craneal de la cresta ectepicondilar. En otros tres casos, este origen fue más extenso, alcanzando la zona media o incluso la zona proximal de la diáfisis humeral (este último en cercanías al cuello humeral). En uno de estos últimos (lado derecho del tercer espécimen disecionado), algunas fibras se originaron desde el $\mathrm{m}$. brachialis.

Inserción: Mediante fibras tendinosas y carnosas en el sector medial del extremo distal del radio, inmediatamente distal al $\mathrm{m}$. pronator quadratus y caudoproximal al surco correspondiente al pasaje de los tendones de inserción del m. abductor digiti I longus.

M. extensor carpi radialis longus et brevis (Láminas 2.10, 2.11, 2.15-16) 
Músculo ubicado proximalmente entre el $\mathrm{m}$. brachioradialis y el $\mathrm{m}$. extensor digitorum communis. Distalmente, se ubica profundo respecto al abductor digiti I longus y los otros extensores digitales en la zona del carpo. El músculo da paso a dos tendones aplanados antes de entrar a la zona del carpo, contenidos ambos por un retinaculum propio sobre el sector deprimido de la cara craneal del extremo distal del radio (contiguo lateralmente al $\mathrm{m}$. abductor digiti I longus) y el retinaculum extensor principal. La diferenciación de los vientres que componen el m. extensor carpi radialis longus et brevis es variable: identificándose en algunos casos separados desde sus orígenes, o diferenciándose justo antes de la conformación de tendones.

Origen: Mediante fibras carnosas sobre el sector medio de la cara craneal de la cresta ectepicondilar. En el único caso en que se diferenciaron desde el origen ambos paquetes del $\mathrm{m}$. extensor carpi radialis longus et brevis, el primero posee un origen más proximal que el segundo.

Inserción: Sobre la base de los metacarpales II y III mediante tendones, correspondiendo al $\mathrm{m}$. extensor carpi radialis longus y brevis respectivamente.

\section{M. extensor digitorum communis (Láminas 2.11-12, 2.15-16)}

Se ubica lateral al m. extensor carpi radialis, y medial al m. extensor digitorum lateralis, y es contenido, en conjunto con estos y el m. abductor digiti I longus, el m. extensor digiti I et II y el m. extensor carpi ulnaris, por el retinaculum extensor principal. En tres casos se subdividió parcialmente en dos vientres, en su zona media; por debajo de la zona del retinaculum extensor principal, es contenido por un retinaculum propio extenso próximodistalmente, y se divide en 4 tendones principales, que se dirigen a los dígitos laterales. Los cuatro tendones principales de inserción son aplanados, amplios y se ubican por sobre y medial a los del m. extensor digitorum lateralis, observándose ambos grupos de tendones como independientes hasta la zona de inserción.

Origen: Vía fibras carnosas sobre el sector distal de la cresta ectepicondilar, y en cercanías del ectepicóndilo mediante fibras tendinosas. Algunas fibras alcanzan el extremo laterodorsal de la cápsula articular.

Inserción: Los cuatro tendones se insertan sobre los tubérculos extensores de las falanges distales de los dígitos II al V.

\section{M. extensor digitorum lateralis (Láminas 2.9, 2.11, 2.14-16)}

Se ubica ventrolateral al $\mathrm{m}$. extensor digitorum communis, y medial al m. extensor carpi ulnaris. Se fusiona parcialmente al m. extensor digitorum communis en su origen, y presenta dos vientres diferenciados, uno medial y uno lateral. En la zona de la muñeca es contenido por el retinaculum extensor principal y uno propio. El vientre lateral se inserta independientemente sobre el dígito $\mathrm{V}$, se vuelve carnoso inmediatamente después de su origen, para convertirse 
nuevamente en un tendón aplanado a la altura de la mitad, o último tercio, del antebrazo. El vientre medial da origen a los tendones que se dirigen a los dígitos III y IV, volviéndose netamente tendinoso al comienzo de la cara dorsal del carpo.

Origen: El vientre lateral se origina mediante un tendón corto sobre el epicóndilo lateral. El vientre medial se origina mediante fibras carnosas, o un tendón largo y plano, inmediatamente medial al anterior.

Inserción: El vientre lateral se inserta mediante un tendón sobre el dígito $\mathrm{V}$, mientras que el vientre medial da origen a dos tendones que se insertan en los dígitos III y IV, manteniéndose diferenciados y laterales respecto a los tendones del $\mathrm{m}$. extensor digitorum communis hasta las tuberosidades extensoras.

M. extensor carpi ulnaris (Láminas 2.9, 2.11, 2.15-16)

Aplanado y ubicado en el sector lateral del antebrazo.

Origen: Mediante fibras tendinosas, y algunas carnosas distales, sobre la cara laterodistal del ectepicóndilo. Algunas fibras se originan sobre la cápsula articular.

Inserción: Mediante fibras tendinosas sobre el sector lateral de la base del metacarpal V, y sobre la cara cráneolateral de la base del carpal accesorio.

M. supinator (Láminas 2.11, 2.13-14)

Aplanado y profundo, se ubica en la cara craneal del radio.

Origen: En la zona de la cápsula articular del codo, sobre los ligamentos laterales del codo, inmediatamente laterales al cóndilo humeral.

Inserción: Vía fibras carnosas, y distalmente fascia tendinosa, sobre la cara craneal de los dos tercios proximales del radio.

\section{M. abductor digiti I longus (Láminas 2.14-16),}

Se origina en el sector profundo y lateral del antebrazo, para luego ubicarse, en el extremo distal del antebrazo, en el sector medial y superficial, superficial respecto al $\mathrm{m}$. braquioradialis y los mm. extensor carpi radialis longus et brevis. En el extremo distal del radio, los tendones de inserción son contenidos en un surco de posición cráneomedial vía un retinaculum propio.

Origen: Mediante fibras carnosas sobre la cara lateral de la diáfisis ulnar y radial.

Inserción: Mediante un par de tendones íntimamente relacionados sobre el metacarpal I y secundariamente sobre el sesamoideo radial. En un lado pudo confirmarse que las fibras de origen ulnar se corresponden mayormente con el tendón que se inserta en el sesamoideo radial, pasando por debajo del tendón que proviene mayormente de la porción radial y se inserta en el metacarpal I.

M. extensor digiti I et II (Láminas 2.13-16) 
Alargado en forma de huso, se ubica lateral en el antebrazo y craneal al m. flexor digitorum profundus caput ulnare. Las fibras musculares se transforman en un tendón aplanado a nivel del carpo aunque fibras tendinosas se presentan internamente más proximalmente. A la altura del carpo transcurre en dirección medial, y es contenido, además de por el retinaculum extensor, por su propio retinaculum que se extiende entre el radio y la ulna, cubriendo al surco de pasaje propio de este músculo en el sector lateral del extremo distal del radio.

Origen: Vía fibras carnosas a lo largo del margen caudolateral de gran parte de la diáfisis ulnar. En el primer espécimen (sp1) alcanzó la región lateral del olécranon. Algunas fibras carnosas se originan sobre la cara lateral del $\mathrm{m}$. flexor digitorum profundus caput ulnare y sobre el margen caudal del $\mathrm{m}$. abductor digiti I longus.

Inserción: Mediante dos tendones pobremente definidos que se confunden con la fascia que cubre los metacarpales, y alcanzan la base de las falanges proximales de los dígitos I y II.

\section{M. opponens digiti V (Láminas 2.16-17)}

Carnoso y aplanado, ubicado profundo al $\mathrm{m}$. flexor digitorum profundus en su origen. El tendón de inserción se ubica durante todo su recorrido profundo al $\mathrm{m}$. flexor digitorum profundus del dígito $\mathrm{V}$ (excepto en un caso), pasando entre los sesamoideos metacarpales.

Origen: Mediante fibras carnosas y aponeurosis, desde ligamento distal al accesorio y sobre la cara medial del accesorio, y alcanzando un origen óseo sobre el metacarpal $\mathrm{V}$ y su sesamoideo (en la mayoría de los casos).

Inserción: Mediante un tendón delgado sobre el extremo lateroproximal de la falange media del dígito $\mathrm{V}$.

M. abductor digiti V (Láminas 2.9, 2.16-17)

Lateral a los mm. flexores breves profundi, amplio y aplanado, en general parcialmente dividido en dos vientres.

Origen: Mediante fibras carnosas sobre la cara distal del carpal accesorio.

Inserción: El vientre medial se inserta mediante fibras tendinosas sobre el sesamoideo lateral del dígito $\mathrm{V}$. El vientre lateral se inserta mediante fibras carnosas y tendinosas o exclusivamente tendinosas sobre el aspecto lateral del metacarpal V.

M. abductor et opponens digiti I (Láminas 2.16-17)

Cilíndrico, breve, y superficial al mm. flexores breves profundi.

Origen: Mediante fibras carnosas, sobre la mayor parte del margen distal del sesamoideo radial. Inserción: Mediante un tendón muy delgado y aplanado, sobre la cara medial del extremo proximal de la falange proximal del dígito I, registrándose una inserción extra vía fibras carnosas sobre el sector ventromedial del metacarpal I en algunos casos.

Mm. adductores digitorum (Láminas 2.16-17) 
Músculos palmares, ubicados superficiales a los mm. flexores breves profundi. Son tres vientres correspondientes a los dígitos I, II y V. Los vientres correspondientes a los dígitos II y $\mathrm{V}$ se encuentran parcialmente fusionados en las cercanías al origen, a la altura de los dedos III y $\mathrm{IV}$, mientras que el correspondiente al dígito I es independiente, originado a la altura del dígito II. El vientre correspondiente al dígito $\mathrm{V}$ es el mayor, mientras que el correspondiente al dígito II es el menor. En un caso no se registró el vientre correspondiente al dígito II.

Origen: Mediante fibras carnosas sobre el ligamento carpal transverso.

Inserción: La inserción de los tres vientres es mayormente carnosa. Los vientres correspondientes a los dígitos I y II se insertan en el aspecto lateral del extremo proximal de la falange proximal del dígito I y II respectivamente. El vientre correspondiente al dígito V se inserta en el aspecto medial del extremo proximal de la falange proximal del dígito $\mathrm{V}$.

Mm. lumbricales (Láminas 2.16-17)

Conformado por cuatro vientres independientes correspondientes a los dígitos II al V. Los vientres mayores son los correspondientes a los dígitos III y IV.

Origen: Mediante fibras carnosas sobre los tendones del $\mathrm{m}$. flexor digitorum profundus a la altura del sector proximal de los metacarpales.

Inserción: Mediante tendones delgados sobre la cara medial de la base de las falanges proximales o en algunos casos medias (Láminas 2.16-17).

Mm. flexores breves profundi ( $\mathrm{mm}$. interossei+m. flexor digiti I brevis $+\mathrm{m}$. flexor digiti $\mathrm{V}$ ) (Láminas 2.16-17)

Son los músculos más profundos del aspecto palmar del autopodio. Compuestos por diez paquetes mayormente carnosos, correspondiéndose dos (uno lateral y otro medial) a cada dígito. Cada paquete es aproximadamente cilíndrico o prismático e independiente en toda su extensión.

Origen: Los orígenes son carnosos, inmediatamente distales a los correspondientes a los $\mathrm{mm}$. adductores digitorum. En general, las zonas de origen de cada paquete se ubican en la zona proximal del metacarpal correspondiente. Los paquetes mediales del dígito III y lateral del dígito II, se originan en estrecho contacto sobre la zona correspondiente al proceso plantar del carpal III. En el caso del vientre medial. y secundariamente el lateral correspondiente al dígito I, se origina mediante fibras tendinosas y carnosas, además de desde el metacarpal I, y sobre el carpal I y marginalmente sobre el sesamoideo radial. En el caso de los vientres lateral y medial correspondientes al dígito $\mathrm{V}$, existe una zona de origen extra, mediante una fascia tendinosa sobre el ligamento distal al accesorio y la zona del sesamoideo proximal del dígito $\mathrm{V}$.

Inserción: Se insertan mediante fibras carnosas sobre los sesamoideos correspondientes a cada dígito y lado.

M. abductor digiti II (Lámina 2.16) 
Triangular, ubicado entre los $\mathrm{mm}$. flexores breves profundi correspondientes a los dígitos I y II.

Origen: Mediante fibras mayormente carnosas sobre la mitad proximal del margen lateral del metacarpal I.

Inserción: Mediante fibras tendinosas sobre el sector medial del sesamoideo metacarpal medial del metacarpal II.

\section{M. abductor digiti IV (Lámina 2.16)}

Triangular, ubicado entre los $\mathrm{mm}$. flexores breves profundi correspondientes a los dígitos IV y V.

Origen: Mediante fibras carnosas sobre el margen medial de la base del metacarpal $\mathrm{V}$ y su hueso sesamoideo.

Inserción: Mediante fibras tendinosas sobre el sector lateral del sesamoideo metacarpal lateral del metacarpal IV, y sobre el aspecto lateral del extremo distal de dicho metacarpal.

\subsubsection{Musculatura epiaxial lumbar}

\section{M. iliocostalis lumborum (Láminas 2.18-20)}

Se ubica dorsal a los procesos transversos lumbares, siendo el más lateral de los músculos epiaxiales lumbares. Es robusto, cilíndrico, con fibras que discurren superficialmente desde caudo-medial a cráneo-lateral. En la región anterior se continua como el m. iliocostalis thoracis, compartiéndose entre ambos un gran número de fibras, especialmente en la zona más superficial, en muchos casos ambos son apenas diferenciables y su separación necesariamente forzada. En la región antero-dorsal de la zona lumbar (a la altura de la primer y segunda vértebra lumbar), el $\mathrm{m}$. iliocostalis lumborum es cubierto parcialmente por un grupo de fibras carnosas, que se continúan como fascia superficial hacia la región posterior hasta el ilion. Este grupo de fibras se corresponden con el sector más posterior del $\mathrm{m}$. longissimus thoracis, pobremente diferenciado en esta región, sin identificarse propiamente el m. longissimus lumborum. En las regiones entre los procesos transversos algunas fibras se diferencian parcialmente en paquetes, correspondientes al mm. intertransversarii lumborum (ver más abajo).

Origen: Principalmente a través de fibras carnosas que parten de la región anterior de la cara medial del ala ossis ilii (ala del ilion) y la cresta del ilion, y mediante fibras tendinosas a partir de la zona medial de la fascia sacrolumbar. Algunas fibras toman origen desde el cuerpo de la última vértebra lumbar, justo posterior a sus procesos transversos.

Inserción: La inserción más anterior identificada se establece mediante una lámina tendinosa sobre el margen posterior de la últimas dos costillas, sobre el ángulo y la región dorsal. Algunas fibras alcanzan el sector lateroposterior de la última vértebra torácica. Este músculo se inserta también mediante un gran número de fibras carnosas y tendinosas sobre las superficies dorsales 
de los procesos transversos de la última vértebra lumbar, mientras que en las demás lumbares, las inserciones fuertes se registran exclusivamente en sus bases y extremos posterolaterales, y mediante algunas fibras tendinosas en la región ventral a los procesos accesorios.

Mm. transversospinalis, sector lumbar (Láminas 2.18-19)

Es la serie más medial de los músculos epiaxiales de la región tóraco-lumbar, ubicados entre los procesos espinales de las vértebras y el $\mathrm{m}$. sacrocaudalis dorsalis lateralis. Compuesto por metámeros mayormente fusionados entre sí, y con su continuación torácica. Es la continuación anterior del $\mathrm{m}$. sacrocaudalis dorsalis medialis.

Origen: Mediante fibras principalmente carnosas a lo largo de la cara lateral de los procesos espinales y la cara dorsal de los procesos articulares de todas las vértebras lumbares, excepto la última. Además, algunas fibras se originan de la fascia sacrolumbar.

Inserción: Mediante fibras principalmente carnosas sobre los procesos mamilares de las vértebras lumbares. El último paquete se inserta sobre la zona dorsal a los procesos articulares fusionados de la cresta sacra intermedia, entre la S1-2.

Mm. interspinales (Lámina 2.19)

Serie de paquetes laminares prácticamente indistinguibles del $\mathrm{mm}$. transversospinalis, aunque mejor definidos en el sector caudal de la región lumbar. Compuestos por fibras principalmente carnosas que se ubican a los lados de una fascia tendinosa que une a los procesos espinales de vértebras adyacentes.

Origen: Mediante fibras carnosas y tendinosas en el margen posterior de los procesos espinales.

Inserción: Mediante fibras carnosas y tendinosas en el margen anterior de los procesos espinales.

Mm. intertransversarii lumborum (Lámina 2.19)

Serie de paquetes aplanados laminares que se diferencian sólo parcialmente del $\mathrm{m}$. iliocostalis lumborum. Existen puntos de fusión con el m. quadratus lumborum entre los procesos transversos de las últimas lumbares.

Origen: Mediante fibras carnosas sobre el margen anterior de los procesos transversos de las vértebras lumbares.

Inserción: Mediante fibras carnosas sobre el margen posterior de los procesos transversos.

\subsubsection{Musculatura de la cola}

M. coccygeus (Láminas 2.18-22)

Se extiende desde la pelvis a las vértebras caudales, entre los $\mathrm{mm}$. intertransversarii dorsales caudae y el $\mathrm{m}$. sacrocaudalis ventralis lateralis, y posee forma de un abanico aplanado.

Origen: Mediante fibras carnosas, sobre la espina isquiática. 
Inserción: Principalmente mediante fibras carnosas, sobre la cara ventral de los procesos transversos de la $\mathrm{Ca} 2-4$, y algunas fibras alcanzan la zona posterior de la Ca1. En el sector más posterior de la inserción, comparte algunas fibras tendinosas o se fusiona a los $\mathrm{mm}$. intertransversarii dorsales caudae.

\section{M. sacrocaudalis ventralis medialis (Láminas 2.18-19)}

Alargado y delgado, compuesto de múltiples metámeros diferenciables, que corre paralelo y medial al m. sacrocaudalis ventralis lateralis, fusionándose parcialmente con este sobre la superficie ventral y especialmente en cercanías a las zonas de inserción. En la zona lumbar y sacra, las contrapartes derecha e izquierda no se contactan, manteniéndose un espacio libre de inserciones sobre la línea media.

Origen: Principalmente mediante fibras carnosas los primeros, y tendinosas los últimos, sobre la región media de la cara ventral de los cuerpos de las vértebras sacras y caudales. El primer paquete se origina en la cara ventral de S1. En los casos en que pudo ser determinado (dos lados), el segundo paquete se origina en la zona anterior de la Ca1, el tercero de Ca3-4, y Ca7.

Inserción: Mediante fibras tendinosas, sobre los paquetes más posteriores y a lo largo de toda la línea media de las vértebras caudales.

\section{M. sacrocaudalis ventralis lateralis (Láminas 2.18-19)}

Cilíndrico y robusto, está compuesto por múltiples metámeros, fuertemente fusionados. Las fibras de cada paquete se dirigen en sentido ventral y medial, conformando una serie de tendones aplanados. Un gran número de tendones agrupados circulan sobre la cara media del músculo, cubiertos por la cara lateral del $\mathrm{m}$. sacrocaudalis ventralis medialis, con el cual se encuentra parcialmente fusionado.

Origen: Mediante fibras carnosas, y en sectores puntuales vía fibras tendinosas, desde el extremo caudoventral de la última vértebra lumbar, desde la superficie ventral de los cuerpos y base de los procesos transversos del sacro, y de la cara ventral de los procesos transversos de las vértebras caudales. El último origen claramente diferenciable se observa en la décima vértebra caudal.

Inserción: Los paquetes musculares se continúan como tendones alargados que progresivamente se van acumulando, adelgazando y finalmente fusionando con los paquetes más posteriores en la zona medial.

\section{M. sacrocaudalis dorsalis medialis (Láminas 2.18-19)}

Alargado, compuesto por múltiples paquetes. Es la continuación posterior del sistema transversospinalis. Cada paquete posee fibras con dirección hacia caudal y lateral, cubriendo aproximadamente tres vértebras desde su origen hasta su inserción.

Origen: Principalmente mediante fibras tendinosas. El paquete más anterior se origina en el extremo posterior y dorsal del proceso espinoso de la última vértebra lumbar, y mediante 
algunas fibras carnosas del sector posterior de la base de dicho proceso. Los paquetes subsiguientes se originan del margen posterior de los procesos espinales de las vértebras sacras y caudales.

Inserción: Sobre los extremos anteriores de los procesos articulares anteriores de las vértebras caudales (y los procesos mamilares en caso de estar presentes). Los últimos paquetes diferenciables presentan fibras carnosas que se originan aproximadamente en la séptima vértebra caudal, mientras que los más posteriores se encuentran poco definidos y representados por fibras tendinosas.

\section{M. sacrocaudalis dorsalis lateralis (Láminas 2.18-19)}

Metamérico y aplanado, se ubica entre el $\mathrm{m}$. iliocostalis lumborum y el sistema transversospinalis. Puede ser entendido como la continuación posterior del sistema longissimus. Los paquetes poseen formas alargadas, fusiformes y se presentan entrelazados entre sí, cubriendo cada uno de ellos más de cinco vértebras. En algunos casos, algunas fibras tendieron a diferenciarse en paquetes menores (más mediales) abarcando uno o dos elementos vertebrales antes de fusionarse con los anteriormente descriptos. En la región sacra y lumbar posterior, se diferencian claramente los paquetes del $\mathrm{m}$. sacrocaudalis dorsalis lateralis de los músculos del sistema transversospinalis, separados por una fascia bien diferenciada poseyendo el primero un amplio desarrollo. Caudalmente, se agregan hasta formar un único ramillete de tendones. A medida que avanza caudalmente disminuye continuamente su sección, volviéndose netamente tendinoso luego del primer tercio de la cola, y ubicándose en una posición lateral y ventral respecto a los procesos articulares, y dorsal a los procesos transversos.

Origen: Mediante una fascia tendinosa sobre el sector posterior de la última vértebra torácica, y mediante fibras carnosas desde los procesos accesorios y el aspecto caudolateral de los cuerpos vertebrales lumbares y de la última vértebra torácica, desde la superficie dorsal de la cresta lateral sacra, y desde los procesos transversos y articulares craneales de las vértebras caudales. El último origen claramente diferenciado se registró en la Ca7.

Inserción: La gran mayoría de las fibras contribuyen a un tendón común que recorre la cola, siendo los procesos transversos de las vértebras caudales la superficie por la cual transcurre y algunas fibras toman inserción. Adicionalmente hay inserciones tendinosas sobre los procesos articulares craneanos y sector anterodorsal de las vértebras caudales.

Mm. intertransversarii ventrales caudae (Láminas 2.18-19)

Banda muscular alargada antero-posteriormente conformada por pocos paquetes fusionados, más breve y parcialmente fusionado con los $\mathrm{mm}$. intertransversarii dorsales caudae. Se puede interpretar como una continuación posterior del m. coccygeus. En la mayoría de los casos (cinco miembros), se compone específicamente de dos paquetes que se encuentran entre el 
m. coccygeus y la $\mathrm{Ca} 7$ o $\mathrm{Ca} 8$; mientras que un caso se muestra compuesto por múltiples paquetes que se continúan hasta las últimas caudales.

Origen: Mediante fibras tendinosas y carnosas, sobre los extremos lateroventrales de los procesos transversos de las vértebras caudales de Ca5-7. También se origina mediante una aponeurosis o fibras carnosas desde el extremo posterior del $\mathrm{m}$. coccygeus.

Inserción: Típicamente mediante fibras tendinosas y carnosas sobre el extremo lateroventral del proceso transverso de las vértebras Ca6-8.

Mm. intertransversarii dorsales caudae (Láminas 2.18-19)

Se ubica en el margen lateral al $\mathrm{m}$. sacrocaudalis dorsalis lateralis. Presenta una morfología tubular, y se vuelve progresivamente más tendinoso hacia la región caudal.

Origen: Mediante fibras carnosas y tendinosas en la espina ilíaca dorsal caudal, y del extremo caudal de la cresta lateral sacra y sobre el ligamento sacroilíaco dorsal. A partir de la Ca3, se observa un patrón metamérico de orígenes sobre los extremos laterales de los procesos transversos de las mismas.

Inserción: Mediante fibras principalmente tendinosas sobre la cara lateral de los procesos transversos caudales desde la Ca1 e identificables hasta la Ca13 o Ca14. En la región craneal de la cola algunas fibras se insertan sobre el $\mathrm{m}$. coccygeus, mientras que a partir de la $\mathrm{C} 4$, se observa un patrón metamérico de inserciones sobre los extremos laterales y anteriores de los procesos transversos.

\subsubsection{Algunos músculos del sistema urogenital y recto}

M. levator ani (Láminas 2.18, 2.20-22)

Compuesto por dos grupos musculares ( $\mathrm{m}$. pubocaudalis $\mathrm{y} \mathrm{m}$. iliocaudalis) con forma de abanico invertido. Estos están ubicados medialmente respecto al $\mathrm{m}$. coccygeus. Son descriptos a continuación independientemente.

M. pubocaudalis (Láminas 2.18-20)

Se ubica medial al m. iliocaudalis. Este posee forma de abanico y es aplanado; comparte fibras tendinosas con el m. iliocaudalis, en cercanías a su inserción. Al final de su recorrido se presenta como un tendón aplanado medial a los mm. sacrocaudalis ventralis.

Origen: Mediante fibras carnosas desde la superficie interna de la rama caudal y craneal del pubis, dorsal a la sínfisis pélvica.

Inserción: Tendinosa, sobre la parte craneal y lateral del cuerpo de la Ca4, en cercanías a la base del proceso transverso.

M. iliocaudalis (Láminas 2.18-20) 
Se ubica entre la pelvis y las vértebras caudales, medial al $\mathrm{m}$. coccygeus y posee forma de un abanico aplanado. En cercanías a su inserción se vuelve aplanado y netamente tendinoso y luego comparte fibras con el $\mathrm{m}$. pubocaudalis.

Origen: Mediante fibras carnosas. Sobre la superficie interna al acetábulo y sobre el margen ventral del ilion.

Inserción: Mediante fibras tendinosas y una fascia aplanada sobre el $\mathrm{mm}$. sacrocaudalis ventralis lateralis, a la altura de la Ca4. En algunos casos algunas fibras alcanzan también a la Ca3 o Ca5. Sólo unas pocas fibras mediales alcanzan una inserción ósea.

\section{M. ischiocavernosus (Lámina 2.20)}

Músculo breve y engrosado en su sector medio.

Origen: Mediante fibras carnosas en el margen posterior del isquion y pubis.

Inserción: Sobre la base de la protuberancia urogenital.

M. bulbospongiosus (Lámina 2.20)

Músculo pequeño. En el plano sagital del cuerpo, el paquete izquierdo y derecho se fusionan estrechamente.

Origen: En la superficie caudal e interna de la sínfisis pélvica, y de músculos y tejidos aledaños, mediante un gran número de fibras tendinosas, incluyendo algunas sobre la cara ventral de Ca1.

Inserción: Zona ventral y proximal del pene.

\section{M. retractor penis}

Este músculo está ausente en los especímenes analizados.

M. rectococcygeus (Láminas 2.18-19)

Alargado y de coloración clara, a modo de una banda impar que recorre la región media y ventral del sector caudal ubicado entre el ano y la zona caudal próxima, entre, y caudal a los $\mathrm{mm}$. pubocaudalis izquierdo y derecho.

Origen: Mediante fibras carnosas sobre el recto.

Inserción: Mediante fibras tendinosas débiles y dispersas sobre la zona media de la Ca4-Ca5, y mediante un breve tendón sobre la zona media de la Ca6.

\subsubsection{Musculatura sublumbar}

M. psoas minor (Láminas 2.19-20)

Se ubica ventral y superficial al m. iliopsoas. Músculo delgado, que se vuelve tendinoso y aplanado tempranamente, aproximadamente a la mitad de su recorrido.

Origen: Mediante fibras carnosas y tendinosas, sobre los tubérculos lateroventrales de los cuerpos vertebrales lumbares L2-3 (L1-2 en el espécimen 1) compartiendo fibras con el origen del diafragma. Algunas fibras se originan sobre paquetes del m. quadratus lumborum. 
Inserción: Tendinosa sobre el ilion, en un sector inmediatamente cráneoventral al acetábulo.

M. iliopsoas (Láminas 2.18-20, 2.23)

Su morfología general es de abanico o cono invertido. Compuesto por el $\mathrm{m}$. psoas major y el m. iliacus. En vista ventral, el m. psoas major izquierdo y derecho no llegan a contactarse en sus orígenes, se encuentran separados por una franja central descubierta de fibras carnosas donde los cuerpos vertebrales pueden observarse. En cercanías a la zona de inserción, el m. psoas major y $\mathrm{m}$. iliacus se fusionan y conforman el m. iliopsoas. A esta altura se ubica entre la masa de músculos abdominales y el ilion, para luego ubicarse por debajo de la articulación de la cadera.

Origen: El origen del $\mathrm{m}$. psoas major se da a través de fibras principalmente carnosas en las zonas ventro-laterales de los cuerpos vertebrales, tubérculos lateroventrales y de la base de los procesos transversos de las dos (o en algunos casos tres) últimas lumbares. Las zonas de origen son especialmente fuertes y tendinosas en los márgenes posteriores de la base de los procesos transversos, y el sector posterolateral de la cara ventral de cada vértebra. El m. iliacus se origina a través de fibras carnosas desde la línea arcuata y el margen ventral del ilion.

Inserción: A través de fibras principalmente carnosas, sobre el trocánter menor, y secundariamente en el cuello femoral y la cápsula articular femoral.

M. quadratus lumborum (Láminas 2.18-20)

Está compuesto por una serie de al menos seis o siete paquetes musculares o metámeros fusionados en mayor o menor medida, que se dirigen en dirección caudolateral. A lo largo de la serie de metámeros, estos se vuelven progresivamente más robustos, independientes, carnosos y cortos hacia caudal. Los primeros metámeros abarcan cuatro o cinco elementos, y poseen tanto un origen como inserción tendinosos; los intermedios abarcan cuatro elementos, siendo tendinosos exclusivamente en cercanías a su inserción; y el último abarca tres elementos (incluyendo al ilion) y es netamente carnoso.

Origen: En forma metamérica, desde las últimas cuatro vértebras torácicas y todas las lumbares. Los primeros paquetes poseen orígenes tendinosos puntuales sobre los tubérculos ventrolaterales, y mediante fibras accesorias desde al menos tres elementos tóraco-lumbares durante su recorrido. Los metámeros siguientes, presentan orígenes desde toda la superficie ventral de los cuerpos vertebrales. El primer paquete netamente lumbar se origina mediante fibras carnosas de los procesos transversos y cuerpos de las L1-3, mientras que cada uno de los dos paquetes más posteriores se originan exclusivamente de los procesos transversos de sólo dos elementos lumbares.

Inserción: Mediante fibras tendinosas y carnosas. Los paquetes más anteriores se insertan a los extremos cráneolaterales de los procesos transversos de las vértebras lumbares. El último paquete es el único que se inserta directamente sobre la espina ilíaca ventral caudal. 


\subsubsection{Musculatura del muslo}

\section{M. gluteus superficialis (Láminas 2.20-21, 2.23)}

Ubicado en la región craneoproximal del muslo. Presenta morfología de abanico invertido, bipinnado y con el sector posterior más desarrollado, cubriendo al m. gluteus medius, $\mathrm{m}$. gluteus profundus y a los orígenes del $\mathrm{m}$. abductor cruris caudae y $\mathrm{mm}$. intertransversarii dorsales caudae. En tres miembros, en el sector posterior del m. gluteus superficialis, tienden a diferenciarse, en mayor o menor medida, uno o más paquetes de fibras (ver m. gluteofemoralis).

Origen: Mediante una aponeurosis sobre la cresta ilíaca, a través de fibras carnosas y tendinosas sobre la aponeurosis que cubre la región sacra y caudal (cubriendo a Ca1 y Ca2) y mediante aponeurosis o pequeños tendones desde $\mathrm{Ca} 2$.

Inserción: Mayormente mediante fibras carnosas en el trocánter mayor y sobre la inserción del $\mathrm{m}$. gluteus medius y el $\mathrm{m}$. tensor fasciae latae.

\section{M. gluteofemoralis (=m. caudofemoralis)}

Este músculo está ausente. Un grupo de fibras parcialmente diferenciables en el sector caudal del m. gluteus superficialis observadas en tres miembros posteriores podría indicar un relicto del mismo.

M. gluteus medius (Láminas 2.20-21, 2.23)

Se ubica justo por debajo del $\mathrm{m}$. gluteus superficialis, presentando también una morfología de abanico invertido. En algunos casos, el $\mathrm{m}$. gluteus medius se encuentra subdividido en paquetes parcialmente diferenciables. El grado de fusión entre el m. gluteus medius y el m. piriformis (inmediatamente posterior a éste) es variable a nivel inter- e intraindividuo (Apéndice 3.1).

Origen: Mediante fibras carnosas en el sector laterodorsal del cuerpo y ala del ilion, incluyendo al tubérculo sacro. Cuando se encuentra fusionado, se origina también, al menos indirectamente, desde la cresta lateral sacra. Un grupo de fibras anteriores superficiales se vuelven tendinosas y alcanzan la fascia sacrolumbar a la altura de la articulación.

Inserción: Mediante fibras carnosas y tendinosas en el sector laterodorsal del trocánter mayor.

M. piriformis (Láminas 2.19, 2.21, 2.23)

Músculo a modo de banda, posterior al $\mathrm{m}$. gluteus medius; en muchos casos indiferenciable de este último.

Origen: Mediante fibras carnosas, sobre la región ventral y media de la cresta sacra lateral (S2, $\mathrm{y}$ a veces incluyendo a $\mathrm{S} 3$ ).

Inserción: Principalmente mediante fibras tendinosas en el sector lateroposterior del trocánter mayor.

M. gluteus profundus (Láminas 2.20, 2.22-23) 
Se ubica profundo al $\mathrm{m}$. gluteus medius y posee morfología de abanico invertido. Típicamente dividido en dos vientres, uno craneal y otro caudal, aunque a veces se registra un tercero.

Origen: Mediante fibras carnosas. El vientre craneal, sobre la cara lateral del ala y cuerpo del ilion, desde la espina ilíaca ventral caudal hasta el sector antero-dorsal al acetábulo. El origen del vientre caudal se restringe a una pequeña área dorsal al acetábulo. Algunas fibras provienen de la capsula articular del acetábulo.

Inserción: Principalmente mediante fibras tendinosas, sobre el extremo dorsal del cuello del fémur, y sector dorsomedial del trocánter mayor.

Mm. gemelli (Láminas 2.20-23)

Estos músculos son pequeños y se encuentran fusionados en su origen junto con el del m. obturatorius internus, apenas diferenciándose superficialmente en este sector.

Origen: Mediante fibras carnosas, sobre el margen craneal, lateral y dorsal de la base de la tuberosidad isquiática y el cuerpo del isquion.

Inserción: Tendinosa, en conjunto con el $\mathrm{m}$. obturatorius internus en la fosa trocantérica, proximal y parcialmente fusionado a la inserción del m. obturatorius externus.

\section{M. obturatorius internus (Láminas 2.20-23)}

Transcurre por sobre el isquion para alcanzar su zona de inserción. Posee forma de abanico invertido, y se encuentra imperfectamente dividido en dos paquetes de fibras.

Origen: Mediante fibras principalmente carnosas desde la cara medial del foramen obturador. Las fibras originadas en el margen dorsal del foramen obturador son tendinosas.

Inserción: Tendinosa, en conjunto con los $\mathrm{mm}$. gemelli y $\mathrm{m}$. obturatorius externus en la fosa trocantérica.

\section{M. quadratus femoris (Láminas 2.20-21, 2.23)}

Fusiforme, robusto y breve.

Origen: Mediante fibras carnosas, por debajo de los orígenes del $\mathrm{m}$. biceps femoris, $\mathrm{m}$. semitendinosus y m. semimembranosus, sobre el sector dorsal de la tabla isquiática y lateral de la tuberosidad isquiática.

Inserción: Mediante fibras carnosas y tendinosas, sobre las paredes posteriores y distales del trocánter mayor, el sector laterodistal de la fosa trocantérica. Algunas fibras alcanzan la cápsula articular de la cadera.

\section{M. biceps femoris (Láminas 2.20-21, 2-23-24)}

Uno de los músculos más grandes, cubre la región lateral del muslo y los tres primeros cuartos de la pierna. Posee dos vientres aplanados y fusionados, lo que le brinda aspecto de abanico bilobado. El vientre proximal se muestra mucho más amplio en sentido próximo-distal, mientras que el distal es más breve, pero más robusto y carnoso. Presenta fibras carnosas desde 
proximidades a su origen y hasta la cara cráneolateral de la tibia, dando paso luego a una aponeurosis que envuelve el sector anterior y anteromedial de la tibia. En la zona proximal del margen caudal de este músculo, se fusiona con el m. semitendinosus.

Origen: Mediante un tendón robusto y breve y fibras carnosas sobre un breve sector en la parte dorsal de la tuberosidad isquiática.

Inserción: El vientre proximal se inserta mediante una aponeurosis desde el epicóndilo lateral de fémur, hasta los dos primeros tercios de la cara antero-lateral y antero-medial de la tibia. En el sector más proximal, un grupo de fibras tendinosas alcanzan la zona de la tuberosidad tibial y se fusiona con el m. vastus lateralis. El vientre distal se inserta mediante aponeurosis en el sector cráneomedial de la sección distal de la tibia, fusionándose parcialmente con el $\mathrm{m}$. abductor cruris caudalis. De la fascia que recubre la superficie interna del bíceps surge un tendón aplanado y delgado que transcurre por debajo de la zona de inserción del $\mathrm{m}$. abductor cruris caudalis, sobre la superficie posterolateral de la pantorrilla y se inserta en la zona del calcáneo.

M. abductor cruris caudalis (=m. tenuissimus) (Láminas 2.19)

En forma de cinta, que transcurre por debajo del m. biceps femoris sobre el sector lateral y caudal del muslo. En cercanías de la inserción se fusiona parcialmente con el m. biceps femoris.

Origen: Mediante fibras tendinosas a modo de aponeurosis, por lo general directamente sobre el $\mathrm{mm}$. intertransversarii dorsales caudae, a la altura de Ca1, por debajo del m. gluteus maximus.

Inserción: Tendinosa, sobre la cara cráneomedial del sector distal de la tibia, sin alcanzar directamente la región del tobillo. Algunas fibras se unen, en conjunto con el m. biceps femoris, al tendón distal que se continúa hasta el calcáneo.

M. semitendinosus (Láminas 2.19-21, 2.24)

Compuesto por dos vientres independientes proximalmente, uno sacrocaudal, y el otro isquiático. Ambos tienen aspecto de cinta y se fusionan a mitad de su recorrido.

Origen: Mediante fibras principalmente carnosas. El vientre caudal se origina sobre el margen lateral del proceso transverso de $\mathrm{Ca} 2$, y mediante aponeurosis desde $\mathrm{Ca} 1$ y $\mathrm{Ca} 2$. El vientre isquiático se origina en la tuberosidad isquiática.

Inserción: Mediante aponeurosis sobre una línea próximodistal en la zona central y medial de la tibia, justo distal al $\mathrm{m}$. gracilis.

M. semimembranosus (Láminas 2.18, 2.20-21, 2.23-24)

Ubicado en la región medial del muslo, algo aplanado y de sección elíptica. Luego de un origen único, se dicotomiza inmediatamente en un vientre craneal y otro caudal. Cada vientre está compuesto a su vez de paquetes parcialmente fusionados. En tres miembros se detectó un pequeño tercer grupo de fibras que se desprende en una posición intermedia. 
Origen: Por debajo del m. semitendinosus, a lo largo de la rama caudal del isquion.

Inserción: El vientre craneal ( $\mathrm{y}$ el intermedio si está presente) se inserta mediante fibras carnosas en el epicóndilo femoral medial, cápsula articular de la rodilla y en la región de la diáfisis femoral adyacente. El caudal, mayormente vía fibras tendinosas, se inserta en la región posteromedial del sector proximal de la tibia, justo por debajo del cóndilo articular medial.

\section{M. articularis coxae}

Este músculo está ausente en ambos lados de todos los especímenes analizados.

\section{M. sartorius (Láminas 2.20-21, 2.23-24)}

Cubre la zona anterior y medial del m. quadriceps femoris. Conformado por un único vientre.

Origen: Mediante fibras carnosas y tendinosas en la zona anterior del ala ilíaca. Algunas fibras provienen de la aponeurosis que cubre el sector sacrocaudal, cranealmente a aquellas que dan origen al $\mathrm{m}$. gluteus superficialis.

Inserción: Mediante aponeurosis sobre la fasciae latae, el m. quadriceps femoris, la patela, cara medial de la cresta cnemial y fascia crural, continuándose y fusionándose parcialmente en su sector distal con la inserción del m. gracilis.

\section{M. tensor de la fasciae latae (Láminas 2.20-21)}

Masivo, cubre parte anterior del muslo y la rodilla. En su origen posee sección cilíndrica, y rápidamente se expande en abanico continuándose como la fascia latae.

Origen: Mediante fibras tendinosas y carnosas, en una región reducida del extremo anteroventral de la cara lateral del ilion, por sobre la espina ilíaca ventral craneal, sobre la zona anterior del $\mathrm{m}$. gluteus profundus.

Inserción: Mediante la fascia lata sobre el $\mathrm{m}$. gluteus superficialis, $\mathrm{m}$. biceps femoris, $\mathrm{m}$. sartorius, y la fascia cruris.

\section{M. quadriceps femoris (Láminas 2.18-23)}

Compuesto por el $\mathrm{m}$. rectus femoris, $\mathrm{m}$. vastus lateralis, $\mathrm{m}$. vastus medialis $\mathrm{y} \mathrm{m}$. vastus intermedius. Una lámina tendinosa une los orígenes del $\mathrm{m}$. vastus lateralis y $\mathrm{m}$. rectus femoris, y secundariamente el $\mathrm{m}$. vastus medialis.

M. rectus femoris (Láminas 2.18, 2.20-21, 2.23)

Ubicado anterior a los restantes vientres del $\mathrm{m}$. quadriceps femoris. Es voluminoso, posee forma de huso con sección circular.

Origen: Tendinoso, desde la tuberosidad del $\mathrm{m}$. quadriceps femoris y la parte anterior de la cápsula articular de la cadera.

Inserción: Tendinosa, al sector cráneodorsal de la patela.

M. vastus lateralis (Láminas 2.21, 2.23) 
De forma subcilíndrica, angostándose y aplanándose hacia su inserción. En el último cuarto de su longitud comienzan a predominar fibras tendinosas.

Origen: Principalmente mediante fibras carnosas. Proximalmente se origina en el sector craneal y craneoproximal del fémur, medial a la base del trocánter mayor, compartiendo fibras con el m. vastus intermedius.

Inserción: Tendinosa en la cara lateral de la patela y sobre la región próximolateral de la tibia, donde se fusiona con la inserción del $\mathrm{m}$. biceps femoris y la fascia cruris.

M. vastus medialis (Láminas 2.18, 2.22-23)

Elongado y subcilíndrico, angostándose hacia su inserción, y parcialmente fusionado al $\mathrm{m}$. vastus intermedius en algunos miembros.

Origen: Mediante fibras carnosas, sobre la cara cráneomedial del cuello femoral y de la diáfisis femoral, cubriendo el primer tercio de la misma.

Inserción: Tendinosa, sobre la cara medial y mediodistal de la patela.

M. vastus intermedius (Láminas 2.22-23)

Cubierto totalmente por los otros paquetes de m. quadriceps femoris, este músculo posee forma alargada y algo aplanada. Proximalmente, frecuentemente comparte fibras con el $\mathrm{m}$. vastus medialis, y distalmente al $\mathrm{m}$. vastus lateralis, a veces debiéndose forzar la separación entre estos.

Origen: Mediante fibras carnosas, sobre la cara craneal de la diáfisis del fémur.

Inserción: Tendinosa, en la región dorsal de la patela.

M. gracilis (Láminas 2.20, 2.24)

En forma de cinta, transcurre por la cara medial del muslo.

Origen: Principalmente mediante fibras tendinosas en la zona ventral de la sínfisis pélvica, fusionándose parcialmente a la inserción de los músculos abdominales en el sector anterior, y con su contraparte en el sector posterior.

Inserción: Mediante aponeurosis sobre la cara cráneomedial de la tibia. Su inserción es proximal a la del m. semitendinosus, cubriendo la porción más proximal de éste último.

M. pectineus (Láminas 2.18, 2.20, 2.23)

En la región proximomedial del muslo, medial al m. adductor longus. Presenta morfología de abanico.

Origen: Mediante fibras carnosas desde la zona craneal de la sínfisis pélvica, tuberosidad pectínea y en la eminencia iliopúbica.

Inserción: Mediante fibras carnosas y aponeurosis tendinosa, la cara caudomedial de la diáfisis femoral. Algunas fibras alcanzan al m. vastus medialis.

M. adductor longus (Láminas 2.18, 2.20, 2.23) 
Se encuentra en la región medial del muslo, lateral al $\mathrm{m}$. pectineus y medial al $\mathrm{m}$. adductor magnus, compartiendo algunas fibras con este último. Presenta forma de abanico y está compuesto por dos vientres diferenciables (excepto en un miembro), uno proximal y otro distal, que se diferencian sutílmente en cercanías a la zona de inserción.

Origen: Mediante fibras carnosas, dorsal al sector anterior y central de la sínfisis pélvica, sobre la rama caudal del pubis.

Inserción: El vientre proximal se inserta mediante aponeurosis sobre el sector caudoproximal del fémur. El vientre distal se inserta principalmente por fibras carnosas, inmediatamente distal al vientre proximal.

\section{M. adductor brevis (Láminas 2.20-21, 2.23)}

Se ubica profundo al $\mathrm{m}$. adductor longus y presenta una morfología cuadrangular, levemente expandido hacia su inserción.

Origen: Mediante fibras carnosas sobre un área reducida sobre la rama caudal del pubis y la rama del isquion.

Inserción: Mediante fibras carnosas sobre el tercio proximal de la cara lateral del fémur.

M. adductor magnus (Láminas 2.18, 2.20-21, 2.13)

Ubicado en el sector medial de la pierna, por debajo del m. adductor longus. Presenta una morfología cuadrangular y aplanada, levemente ensanchado distalmente. Cerca de su inserción se encuentra parcialmente dividido en dos fascículos, uno medial y otro lateral.

Origen: Mediante fibras carnosas desde un sector reducido sobre la región caudal de la rama caudal del pubis y la rama del isquion.

Inserción: Mediante fibras carnosas sobre el final distal de la superficie caudal de fémur, en dos áreas independientes, inmediatamente proximales a los cóndilos femorales.

M. obturatorius externus (Láminas 2.20, 2.23)

Posee forma de abanico invertido, muy delgado la mayor parte de su extensión.

Origen: Mediante fibras carnosas, sobre la cara lateral del isquion y pubis, a lo largo de los márgenes craneal, ventral y caudal del foramen obturador, y de la membrana que lo cubre.

Inserción: Tendinosa, en el sector central y más profundo de la fosa trocantérica, y fusionándose parcialmente con la inserción del m. obturatorius internus. Algunas fibras alcanzan la capsula articular de la cadera.

\subsubsection{Musculatura de la pierna}

M. gastrocnemius (Láminas 2.18, 2.21, 2.23, 2.25)

Es un músculo robusto y cada cabeza se encuentra comprimida lateromedialmente y separadas a lo largo de su recorrido por el $\mathrm{m}$. flexor digitorum superficialis. En tres miembros, la cabeza lateral del $\mathrm{m}$. gastrocnemius y el $\mathrm{m}$. flexor digitorum superficialis se encuentran 
fuertemente fusionados y comparten algunas fibras a lo largo de todo su recorrido, excepto en cercanías a su inserción donde se fusiona parcialmente con el $\mathrm{m}$. flexor digitorum superficialis y el m. soleus formando el tendón del calcáneo.

Origen: Mediante tendones robustos. La cabeza lateral se origina del epicóndilo lateral del fémur, de las fascias que cubren el lateral del fémur y la tibia, y del sesamoideo lateral. La cabeza medial, se origina del epicóndilo medial. Ambos paquetes se originan también de la zona posterior y adyacente de la diáfisis femoral y cápsula articular.

Inserción: Tendinosa, en el extremo posterodorsal del tubérculo del calcáneo, y mediante aponeurosis se inserta a los músculos periféricos.

M. soleus (Láminas 2.22, 2.24-25)

Ubicado por debajo del $\mathrm{m}$. gastrocnemius y del $\mathrm{m}$. flexor digitorum superficialis, es un músculo aplanado y con forma de huso.

Origen: Mediante un tendón fino y aplanado en un sector caudal del sector proximal de la fíbula.

Inserción: En la fascia que recubre la zona medial del calcáneo, extremo distal de fíbula y tobillo en general, y mediante tendón sobre la cara proximal del tubérculo del calcáneo.

\section{M. flexor digitorum superficialis (=m. plantaris) (Láminas 2.23, 2.25-26)}

Robusto comprimido lateromedialmente, intercalado entre las dos cabezas del $\mathrm{m}$. gastrocnemius. Luego de una primera inserción, rodea medialmente al calcáneo y al tendón del m. gastrocnemius, adquiere una posición caudal, y da origen el m. flexor digitorum brevis, continuándose y fusionándose con este.

Origen: Tendinoso. En la parte posterior del epicóndilo lateral y el sesamoideo correspondiente del fémur, medial respecto a la cabeza lateral del m. gastrocnemius, en estrecho contacto con él.

Inserción: Tendinosa. En la mayoría de los casos, el tendón de este músculo se fusiona a los de las cabezas del m. gastrocnemius, formando un único tendón que inserta en el calcáneo, y en la fascia que lo envuelve. Distal a esta primera inserción, este músculo se continúa como fibras tendinosas (observado en dos miembros) o como un tendón aplanado y definido (cuatro miembros) sobre la cara posteromedial del calcáneo, fusionándose con el origen al $\mathrm{m}$. flexor digitorum brevis. En varios casos (tres miembros) se observaron fibras tendinosas del $\mathrm{m}$. flexor digitorum superficialis continuándose distalmente por sobre el $\mathrm{m}$. flexor digitorum brevis.

\section{M. popliteus (Láminas 2.22-24)}

Se ubica sobre el sector proximal y caudal de la tibia, cubriendo el sector proximal del $\mathrm{m}$. flexor digitorum medialis. Posee forma de abanico o triangular, asimétrico y con fibras divergentes hacia la región distal. Desde el origen, y sobre las superficies proximal e interna del músculo, se presenta un gran número de fibras tendinosas. Tanto el m. popliteus, m. extensor 
digitorum medialis, como el $\mathrm{m}$. tibialis caudalis, se encuentran fuertemente unidos por aponeurosis. El tendón de origen no posee un sesamoideo.

Origen: Mediante un tendón robusto y breve, sobre el cóndilo lateral, y mediante la aponeurosis que cubre la cara lateral del sector distal del fémur.

Inserción: Mediante fibras carnosas y tendinosas en la cara medial y caudal del primer y segundo tercio de la tibia. La inserción se vuelve particularmente fuerte y tendinosa a la altura de las superficies articulares proximales de la tibia. Algunas fibras se insertan sobre el m. flexor digitorum medialis.

\section{Mm. flexores digitorum profundi (Láminas 2.24-26)}

Conformado por el $\mathrm{m}$. flexor digitorum lateralis y el $\mathrm{m}$. flexor digitorum medialis, ambos originados en la superficie posterior de la tibia y fíbula. Ambos se vuelven tendinosos antes de llegar a la zona del tobillo. Ambos son retenidos por retinaculum independientes en la cara ventromedial del calcáneo y ventral del astrágalo. A la altura de los carpales distales y zona proximal de los metatarsales, se fusionan en una única lámina tendinosa. Esta hace las veces de superficie de inserción del $\mathrm{m}$. quadratus plantae, para luego subdividirse en cinco tendones aplanados y moderadamente robustos. Algunas fibras se insertan sobre los sesamoideos distales de los metatarsales. Finalmente, los tendones pasan por los anillos formados por el m. flexor digitorum brevis para luego insertarse en las falanges distales.

\section{M. flexor digitorum lateralis (=m. flexor hallucis longus) (Láminas 2.24.26)}

Marcadamente bipinnado, cilíndrico y algo aplanado. En cercanías a su origen, comparte fibras junto con el $\mathrm{m}$. tibialis caudalis y el $\mathrm{m}$. fibularis brevis. A la altura del tobillo, las fibras carnosas dan paso en forma abrupta a un tendón aplanado y ancho, el cual se posiciona entre el calcáneo y la tibia, pasando por el surco de la superficie ventral del área sustentacular del calcáneo, antes de la fusión con el m. flexor digitorum medialis.

Origen: Mediante fibras carnosas, de toda la extensión de la membrana interósea, y de la cara caudal de las diáfisis de la tibia y la fíbula.

Inserción: Luego de la fusión al tendón del m. flexor digitorum medialis, se subdivide en tendones menores que se insertan en la superficie ventral de las falanges distales de los dígitos I al V.

\section{M. flexor digitorum medialis (=m. flexor digitorum longus) (Láminas 2.24-26)}

Alargado y bipinnado, volviéndose agudo hacia su inserción. Sólo su primer cuarto presenta fibras carnosas, volviéndose un tendón moderadamente robusto y aplanado que corre por el surco del maléolo medial, en conjunto y superficial al tendón del m. tibialis caudalis, y por la cara medial del tobillo hacia el tarso, siendo contenidos ambos por un retinaculum. 
Origen: Mediante fibras carnosas y tendinosas desde el aspecto caudal y caudomedial de la cabeza de la fíbula, del ligamento interóseo, y mediante fibras carnosas a lo largo de todo el borde lateral de la inserción de m. popliteus en la tibia.

Inserción: Tendinosa. Luego de la fusión al tendón del $\mathrm{m}$. flexor digitorum lateralis, sobre la superficie ventral de las falanges distales de los dígitos I al V.

M. tibialis caudalis (Láminas 2.24, 2.26)

Se ubica lateral y en estrecho contacto con el $\mathrm{m}$. flexor digitorum medialis, para luego transcurrir, internamente respecto a este último, por el surco del maléolo medial. Posee forma de abanico invertido, delgado, con pinnación poco definida y aplanado, volviéndose un fino tendón aproximadamente a mitad de su recorrido.

Origen: Vía fibras carnosas sobre el aspecto caudal de la diáfisis de la tibia, y del aspecto craneal, medial y caudal de la cabeza de la fíbula. Algunas fibras provienen de los músculos aledaños, como el $\mathrm{m}$. flexor digitorum lateralis y $\mathrm{m}$. flexor digitorum medialis.

Inserción: Tendinosa en la cara medial y ventral del central y carpal I, y sobre el sesamoideo que se encuentra entre estos.

\section{M. fibularis longus (=m. peroneus longus) (Láminas 2.21-22, 2.24-26)}

Morfología semiaplanada y alargada, craneal y superficial al m. extensor digitorum y el m. fibularis longus. Transcurre dentro del lateral del maléolo lateral, exclusivo para el mismo, cráneodorsal respecto al $\mathrm{m}$. fibularis brevis, y distalmente lateral al tarso y metatarsal $\mathrm{V}$, para luego cruzar lateromedialmente el sector distal del tarso, ubicándose internamente al ligamento plantar largo. El m. fibularis longus, el $\mathrm{m}$. extensor digitorum lateralis y el $\mathrm{m}$. fibularis brevis son contenidos por un retinaculum justo proximal y lateral al tobillo. Fibras que participan en la construcción del primer retinaculum anterior (ver arriba), se originan de la superficie medial de este retinaculum.

Origen: Tendinoso, sobre la zona anterior de la cabeza de la fíbula, cara lateral del cóndilo lateral de la tibia y la zona de la diáfisis de la tibia adyacente. Algunas fibras se originan de la fascia que cubre la cara lateral de la rodilla.

Inserción: Tendinosa. Algunas pocas fibras lo unen firmemente al extremo laterodistal del calcáneo y al margen proximal del tubérculo del metatarsal V. La inserción final (luego de cruzar el tarso por debajo al ligamento tarsal largo) se produce en la cara lateral del tubérculo plantar del metatarsal I.

\section{M. extensor digitorum lateralis (Láminas 2.22, 2.24-25)}

Músculo alargado, levemente bipinnado, que transcurre por la cara craneal y lateral de la fíbula. Se vuelve tendinoso a la altura del último quinto de la tibia, ubicándose justo caudal y paralelo al $\mathrm{m}$. fibularis longus. Su recorrido continúa, craneal y dorsal al $\mathrm{m}$. fibularis brevis, por la parte más profunda del surco del maléolo lateral, y por la cara lateral del tarso y el metatarsal 
V. En esta zona se encuentra estrechamente unido a m. fibularis brevis, compartiendo algunas fibras con éste.

Origen: Mediante fibras carnosas, sobre la primera mitad de la fíbula, y desde otros músculos periféricos (i.e., $\mathrm{m}$. flexor digitorum lateralis y $\mathrm{m}$. fibularis brevis).

Inserción: Tendinosa. La primera inserción es débil, sobre la superficie proximal del metatarsal $\mathrm{V}$, en donde comparte algunas fibras con el $\mathrm{m}$. fibularis brevis. Luego se continúa como un tendón aun definido y presenta una segunda inserción sobre la zona lateral de la articulación metatarso-falange, $\mathrm{y}$ en la superficie laterodorsal de la falange proximal del dígito $\mathrm{V}$, donde se fusiona con el tendón del m. extensor digitorum longus, la lámina tendinosa correspondiente de la fusión previa del $\mathrm{m}$. extensor digitorum brevis y del $\mathrm{m}$. fibularis brevis. Finalmente, pierde definición como una fascia amplia sobre las superficies laterodorsal de las falanges intermedia y distal del dígito $\mathrm{V}$.

\section{M. fibularis brevis (Láminas 2.24-25)}

Compuesto de un vientre craneal y otro caudal. El vientre craneal, es en general más pequeño, levemente bipinnado y más tendinoso. El vientre caudal es levemente bipinnado. Ambos vientres se vuelven netamente tendinosos justo antes o justo después del maléolo lateral, por el cual transcurren. En cuatro miembros, a esta altura ambos tendones se fusionan, y se encontró un sesamoideo dentro del tendón de inserción. En dos miembros, en vez de darse la fusión entre tendones del $\mathrm{m}$. fibularis brevis, el vientre caudal forma un anillo para el pasaje del tendón del vientre craneal.

Origen: El vientre craneal se origina mediante fibras carnosas, desde la cara cráneolateral del tercio medio de la fíbula. El vientre caudal se origina mediante fibras carnosas, desde la cara caudolateral de zona media de la fíbula.

Inserción: Tendinosa, principalmente sobre el extremo laterodorsal de la tuberosidad del metatarsal $\mathrm{V}$, compartiendo algunas fibras con el $\mathrm{m}$. extensor digitorum lateralis y abductor digiti V. Secundariamente, se continua vía un tendón aplanado, o, como algunas fibras, ubicado principalmente por debajo del tendón del $\mathrm{m}$. extensor digitorum lateralis (e íntimamente a él), para alcanzar a insertarse sobre la cara laterodorsal de todo el metatarsal $\mathrm{V}$ y la zona de la articulación tarso-metatarso del mismo dígito y tendones extensores: del m. extensor digitorum lateralis, m. extensor digitorum longus, y la aponeurosis del m. extensor digitorum brevis. En todos los casos en donde la fusión de ambos vientres no fue total, pudo determinarse que estas fibras distales correspondieron al vientre craneal.

M. tibialis cranialis (Láminas 2.21, 2.24-26)

Amplio y moderadamente aplanado en su origen. Atraviesa la zona del tobillo estrechamente unido (aunque sin fusionarse) con el $\mathrm{m}$. extensor digiti I longus. El m. tibialis cranialis, $\mathrm{m}$. extensor digiti I longus y el m. extensor digitorum longus, son contenidos por un 
retinaculum amplio en el sector proximocraneal de la articulación del tobillo, y por un segundo retinaculum a la altura del tarso proximal

Origen: Mediante fibras tendinosas y carnosas sobre la cara cráneolateral del cuarto proximal de la tibia, incluyendo la cresta cnemial, sector proximal de la membrana interósea y la fascia que cubre al $\mathrm{m}$. fibularis longus. Posee un segundo origen tendinoso reducido en el extremo craneal de la cabeza de la fíbula.

Inserción: Tendinosa, en el aspecto medial del tubérculo ventral de la base del metatarsal I.

M. extensor digiti I longus (Láminas 2.24-25)

Delgado y algo aplanado, transcurre por debajo del m. tibialis cranialis, uniéndose estrechamente a éste, para luego continuar su recorrido por la cara medial del dígito I, como un tendón extremadamente delgado. Como se comentó anteriormente (ver arriba), es contenido por dos retinacula en el sector anterior de la articulación del tobillo.

Origen: Mediante fibras carnosas sobre la cara medial y craneal del sector proximal de la diáfisis de la fíbula, y sobre la membrana interósea aledaña.

Inserción: Tendinosa, sobre el tubérculo extensor de la falange distal del digito I. En un miembro, la inserción se dio mediante un tendón moderadamente diferenciado sobre el tubérculo extensor de la falange distal del dígito II en lugar del dígito I.

M. extensor digitorum longus (Láminas 2.21-23, 2.25)

Dividido parcialmente en dos vientres en la zona media y distal. En conjunto poseen una forma de huso. Proximalmente transcurre por debajo del $\mathrm{m}$. tibialis cranialis y luego laterocaudal a éste. El vientre medial se vuelve tendinoso más tempranamente que el lateral. El m. extensor digitorum longus es contenido por dos retinaculum (ver más arriba). Luego del tobillo, se vuelve totalmente tendinoso y se divide a la altura del principio de los metatarsales en cuatro tendones. Una fascia muy fina y frágil cubre y une a los tendones de este con el $\mathrm{m}$. extensor digitorum brevis y el $\mathrm{m}$. extensor digiti I longus.

Origen: Tendinoso, sobre el cóndilo lateral del fémur, anterior al del $\mathrm{m}$. popliteus y sobre la aponeurosis que cubre al $\mathrm{m}$. tibialis cranialis.

Inserción: Tendinosa, mediante cuatro tendones aplanados que van hacia los dígitos II al V, fusionándose con los tendones provenientes del $\mathrm{m}$. extensor digitorum brevis y el $\mathrm{m}$. extensor digitorum lateralis (digito V), e insertándose sobre las falanges distales. En la mayoría de los casos, un pequeño grupo de fibras tendinosas se insertan tempranamente en la aponeurosis lateral de la primera hilera de carpales.

\subsubsection{Musculatura del pie}

M. extensor digitorum brevis (Lámina 2.25) 
Cubre la zona dorsal del tarso y proximal de los metatarsales; es aplanado y está imperfectamente subdividido en tres o cuatro vientres. A partir de los metatarsales se continúa por medio de fibras tendinosas y tendones.

Origen: Mediante aponeurosis en la cara laterodorsal del calcáneo y de la fascia que cubre los tarsales proximales.

Inserción: En general, mediante tendones definidos sobre los tendones extensores del $\mathrm{m}$. extensor digitorum longus, alcanzando indirectamente los tubérculos extensores de los dígitos II al IV. En cuatro miembros, este músculo se inserta también mediante aponeurosis al dígito $\mathrm{V}$, fusionándose con los demás tendones extensores. En 3 miembros, el m. extensor digitorum brevis no alcanza al dígito I; en 2 miembros existe una inserción sobre este digito mediante una aponeurosis al m. extensor digiti I longus, mientras que en un único miembro se registra un tendón diferenciado insertándose sobre este último. En resumen, en ningún caso existió un tendón diferenciado para el dígito $\mathrm{V}$, y sólo en un caso para el dígito $\mathrm{I}$.

\section{M. abductor digiti $V$ (Lámina 2.26)}

Pequeño, se ubica por sobre el $\mathrm{m}$. quadratus plantae y bajo el $\mathrm{m}$. flexor digitorum superficialis. Posee forma de banda, compuesto de unas pocas fibras carnosas.

Origen: Por medio de un tendón aplanado en la cara plantar de la tuberosidad del calcáneo.

Inserción: Mediante fibras tendinosas y carnosas sobre la cara lateral y plantar de la tuberosidad de la base del metatarsal $\mathrm{V}$, fusionándose con la inserción principal de $\mathrm{m}$. fibularis brevis.

\section{M. flexor digitorum brevis (Lámina 2.26)}

Continuación distal del m. flexor digitorum superficialis. Músculo aplanado conformado por cuatro o cinco vientres fuertemente fusionados. En cercanías a su origen, y hasta la altura de la articulación entre tarsales y metatarsales compuesto de fibras carnosas, mientras que a partir de aquí da paso a una aponeurosis y tendones superficiales al $\mathrm{m}$. flexor digitorum profundus. A partir de la zona de los metatarsos se diferencian cinco tendones que se dirigen a los dígitos. En el caso de los cuatro dígitos laterales, estos tendones se subdividen para insertarse a los lados de las falanges, formando un anillo para el pasaje de los tendones del $\mathrm{m}$. flexor digitorum profundus. Para el caso del dígito I, solo se observa un único tendón, definido en mayor o menor medida.

Origen: Mediante aponeurosis desde el tendón de la principal inserción del tendón del $\mathrm{m}$. flexor digitorum superficialis, a la altura de la cara plantar del tubérculo del calcáneo, y con un pequeño origen óseo sobre la cara medial del tubérculo del calcáneo.

Inserción: Mediante aponeurosis y cinco tendones principales sobre el aspecto plantar de las falanges intermedias de los dígitos II-V, y la proximal del dígito I.

Mm. interflexorii (Lámina 2.26) 
Situados entre el $\mathrm{m}$. flexor digitorum brevis y el $\mathrm{m}$. flexor digitorum profundus, compuesto por tres pequeños paquetes musculares de forma de gota, rematados en un tendón grácil. En la mayoría de los casos el paquete ubicado sobre el metatarsal V (el más lateral) es el más reducido y se encuentran parcialmente fusionados, o diferenciados pero parcialmente superpuestos al del metatarsal IV (vientre central). Los paquetes ubicados sobre el metatarsal III (el más medial) y los del IV son de una longitud de aproximadamente un tercio de la de los metatarsales que cubre.

Origen: Carnoso, en la zona distal y ventral de la plataforma tendinosa de el $\mathrm{m}$. flexor digitorum profundus.

Inserción: Tendinosa, sobre la cara dorsal de los tendones del $\mathrm{m}$. flexor digitorum brevis que se dirigen a los dígitos III-V, a la altura del sector distal de los metatarsos.

M. quadratus plantae (Lámina 2.26)

Aplanado, transcurre diagonalmente desde la cara lateral del pie, por debajo del $\mathrm{m}$. abductor digiti $\mathrm{V}$.

Origen: En general, exclusivamente tendinoso, sobre la cara lateral del calcáneo.

Inserción: Mediante fibras carnosas, sobre una línea diagonal (perpendicular a la trayectoria de las fibras) sobre la superficie de la lámina tendinosa del $\mathrm{m}$. flexor digitorum profundus.

Mm. lumbricales (Lámina 2.26)

Compuesto por tres bandas delgadas carnosas entre los tendones del $\mathrm{m}$. flexor digitorum profundus que se dirigen a los dígitos II-V. En uno de los miembros, se presenta un paquete extra entre los dígitos I y II, encontrándose a su vez el más lateral hipertrofiado.

Origen: Mediante fibras carnosas sobre las caras laterales y mediales de los tendones del $\mathrm{m}$. flexor digitorum profundus que se dirigen a los dígitos II-V, a la altura de los metatarsales.

Inserción: Sobre la cara plantomedial y proximal de las falanges proximales de los dígitos IIIV.

Mm. adductores digitorum (Lámina 2.26)

En posición plantar respecto a los mm. flexor brevis profundi centrales. Está compuesto de tres paquetes musculares parcialmente fusionados en su origen. El más lateral de los mm. adductores digitorum posee una morfología triangular, mientras que el central y el medial son bandas delgadas. En un miembro se registró un cuarto paquete muy reducido.

Origen: Mediante fibras carnosas sobre la superficie distal de los ligamentos plantares que cubren la serie distal de los tarsales y la base de los metatarsales.

Inserción: Mediante fibras carnosas sobre la cara lateral de los sesamoideos laterales de los dígitos I y II, de la cabeza de dichos metatarsales, y en la cara interna del sesamoideo medial del digito $\mathrm{V}$, y de la cabeza del metatarsal V.

Mm. flexor breves profundi (= interossei) (Lámina 2.26) 
Son los músculos plantares más profundos. Aplanados lateromedialmente, algo aguzado hacia ambos extremos, y mayoritariamente compuestos por fibras carnosas. Existe un par de $\mathrm{mm}$. flexor breves profundi (uno lateral y otro medial) por cada dígito. Las partes medial y lateral de los flexores breves profundi digiti I y $\mathrm{V}$ se muestran totalmente diferenciadas en todos los casos, mientras que los paquetes centrales se encuentran algunas veces fusionados. En algunos dígitos se observan excepcionalmente tres en vez de dos paquetes.

Origen: Todos los puntos de origen se dan principalmente mediante fibras carnosas en los procesos plantares de los tarsales, y áreas adyacentes de metatarsales y ligamentos. La parte medial de los mm. flexor breves profundi digiti I está más desarrollada que la lateral, y tiene su origen mediante fibras carnosas en desde el sector proximal del metatarsal I, tarsal I, y desde las superficies ligamentosas que cubre al calcáneo y el central (incluyendo al tubérculo plantar del central), así como sobre la superficie ventral del sesamoideo presente entre el central y el primer tarsal. La parte lateral del $\mathrm{m}$. flexor brevis profundi digiti I se origina mediante fibras carnosas y aponeurosis del sector plantar del sector proximal del metatarsal I. Los paquetes de fibras de los $\mathrm{mm}$. flexor breves profundi digiti II, III y IV se originan a partir de las bases ventrales y tubérculos plantares de los metacarpales correspondientes. Ambos paquetes de los mm. flexor brevis profundi digiti IV se originan a partir del sesamoideo del dígito $\mathrm{V}$, y el paquete más lateral también de la porción próximo-medial del metatarsal del dígito $\mathrm{V}$. Tanto la parte medial como lateral de los mm. flexor breves profundi digiti $\mathrm{V}$ (y marginalmente el $\mathrm{mm}$. flexor brevis profundi digiti IV) se originan desde el sesamoideo ubicado en la base del metatarsal V, y desde dicho metatarsal.

Inserción: Todos los puntos de inserción se dan mediante fibras carnosas sobre los huesos sesamoideos de la articulación metatarsal-falange de los dígitos y lados respectivos, así como en el extremo distal de los metatarsales correspondientes.

\subsubsection{Pesado de la musculatura de Galictis cuja}

La masa seca de cada músculo por lado y por espécimen de Galictis cuja es presentada en los Apéndices 3.2, 3.3, 3.4, y 3.5. En las Tablas 3.1 y 3.2, se presentan los pesos de los principales grupos musculares relativizados al peso total de la musculatura del miembro anterior y posterior, respectivamente. Estos datos son los utilizados en las Láminas 2.27 y 2.28, en conjunto con datos comparativos provenientes de bibliografía (ver epígrafes de esas láminas).

Tanto en los miembros anteriores como posteriores, el peso de cada músculo en el espécimen macho (primer espécimen; y tercero en el caso del miembro posterior, ver Ercoli et al. 2013) fue aproximadamente el triple que el del espécimen hembra (segundo espécimen). Sin embargo el desarrollo relativizado al total de la masa del miembro de cada músculo fue muy similar en ambos especímenes. 
En lo que respecta al miembro anterior, sin embargo, existen algunas diferencias menores en algunos músculos entre el espécimen macho y la hembra, como lo son las diferencias observadas entre el $\mathrm{m}$. rhomboideus thoracis y el cervicis. Respecto al $\mathrm{m}$. rhomboideus cervicis, el espécimen macho posee una masa seca relativa al peso del miembro de aproximadamente $2,5 \%$, cerca del doble de lo observado en el espécimen hembra. La relación opuesta ocurre comparando al $\mathrm{m}$. rhomboideus thoracis, el cual es el doble en el espécimen hembra. Otras diferencias destacables se encuentran en los valores de peso del $\mathrm{m}$. teres major del espécimen macho y los del $\mathrm{m}$. abductor digiti $\mathrm{V}$ del espécimen hembra (este último relacionado a la pérdida de un vientre en el lado izquierdo, ver más adelante). Algunas variantes en el peso muscular de diferentes miembros del mismo espécimen pueden atribuirse a una separación incorrecta de vientres relativamente poco diferenciados dentro de un mismo músculo, como lo son en el caso del m. supraspinatus, m. triceps brachii, m. flexor digitorum profundus y m. flexor brevis profundi (Apéndice 3.4).

También surgieron algunas diferencias marcadas en algunos músculos específicos del miembro posterior al comparar los especímenes macho contra la hembra. Por ejemplo el $\mathrm{m}$. iliocostalis lumborum, mm. gemelli, y el m. tibialis caudalis. Con respecto al m. iliocostalis lumborum, el espécimen 1 posee una masa relativa al miembro de aproximadamente $15 \%$, el doble de lo observado en el espécimen 2. La masa relativa del $\mathrm{mm}$. gemelli fue muy variable entre los miembros tanto entre como dentro de cada espécimen. En el caso del m. tibialis caudalis, el espécimen hembra poseyó una masa relativa del $0,77 \%$, aproximadamente el doble que los valores observados en los especímenes macho (Apéndice 3.5).

La distribución de la masa muscular del miembro anterior de Ga. cuja es muy similar a la observada en otros mustélidos terrestres weasel-like, como lo son los mustelinos y otros ictoniquinos (e.g., Mustela, Vormela), y algo diferente a lo observado en otros carnívoros, incluyendo cursoriales (e.g., Acinonyx, Canis), arctoideos generalizados (e.g., Martes, Gulo, Mellivora, Ursus), o mustélidos semiacuáticos (e.g., Aonyx, Lutra, Enhydra). Galictis cuja presenta un enorme desarrollo de la musculatura extrínseca del miembro anterior (tanto protractora como retractora, Láminas $2.27 \mathrm{~A}, \mathrm{~B}, \mathrm{C}$ ), un bajo desarrollo de la musculatura intrínseca, especialmente la musculatura del hombro, pero un alto desarrollo relativo de los extensores del hombro y codo en relación a otros grupos funcionales (Láminas 2.27E, G), y un moderado desarrollo de la musculatura antebraquial y autopodial (Láminas 2.27I, J, K).

La distribución de masas del miembro posterior de Ga. cuja fue muy similar a la de otros weasel-like mustélidos como Mustela, Martes y Vormela, géneros que usan pasos de tipo bounding, pero muy diferente a la de cursoriales (e.g., Acinonyx, Canis), semiacuáticos (e.g., Enhydra y en menor grado Lutra), y carnívoros ambulatorios (e.g. Gulo, Mellivora, Ursus). Galictis cuja presentó un débil desarrollo de la masa adductora y extensora rápida (i.e., grupo 
gluteus) de la cadera (Láminas 2.28A, B), un moderado a débil desarrollo de los extensores de la rodilla (Láminas 2.28D), y un fuerte desarrollo de los extensores fuertes de la cadera (Láminas 2.28C), el tobillo y flexores digitales (Láminas 2.28E, F, G). 


\section{Tablas de Resultados de descripción de la miología de Galictis cuja}

Tabla 3.1. Valores de masa seca porcentual de cada músculo del miembro anterior de Galictis cuja, relativizado a la masa total de la masa muscular del miembro anterior (excluyendo la musculatura intrínseca del autopodio). Los valores fueron calculados como el promedio del valor porcentual para cada uno de los dos especímenes analizados (espécimen 1 y 2). La nomenclatura sigue la Nómina Anatómica Veterinaria excepto cuando es indicado lo contrario (itálicas).

\begin{tabular}{|c|c|c|c|}
\hline Músculo & $\begin{array}{l}\text { Masa } \\
(\%)\end{array}$ & Músculo & $\begin{array}{l}\text { Masa } \\
(\%)\end{array}$ \\
\hline Cutaneus trunci & 58,59 & Anconeus & 0,79 \\
\hline Cleidobrachialis & 3,81 & Pronator teres & 1,92 \\
\hline Cleidocephalicus pars cervicalis & 12,46 & Flexor carpi radialis & 0,75 \\
\hline Cleidocephalicus pars mastoidea & 6,49 & Flexor carpi ulnaris caput humerale & 1,42 \\
\hline Omotransversarius & 6,11 & Flexor carpi ulnaris caput ulnare & 2,48 \\
\hline Omohyoideus & 0,98 & Palmaris longus & 2,60 \\
\hline Trapezius cervicalis & 6,09 & Palmaris brevis & 0,34 \\
\hline Trapezius thoracica & 7,05 & $\begin{array}{l}\text { Flexor digitorum profundus caput humerale, } \\
\text { lateral }\end{array}$ & 1,37 \\
\hline Latissimus dorsi & 26,06 & $\begin{array}{l}\text { Flexor digitorum profundus caput humerale, } \\
\text { medial }\end{array}$ & 1,70 \\
\hline Rhomboideus thoracis & 1,24 & $\begin{array}{l}\text { Flexor digitorum profundus caput humerale, } \\
\text { profundus }\end{array}$ & 0,59 \\
\hline Rhomboideus cervicis & 5,79 & Flexor digitorum profundus caput radiale & 0,83 \\
\hline Rhomboideus capitis & 3,87 & Flexor digitorum profundus caput ulnare & 1,49 \\
\hline Rhomboideus profundus & 3,07 & Flexor digitorum profundus, tendón común & 1,01 \\
\hline Pectoralis superficialis, cranialis & 2,85 & Flexor digitorum superficialis & 0,23 \\
\hline Pectorales superficiales, caudal & 9,39 & Pronator quadratus & 0,28 \\
\hline Pectoralis profundus, craneal & 4,08 & Brachioradialis & 1,68 \\
\hline Pectoralis profundus, caudal & 18,29 & Extensor carpi radialis & 3,13 \\
\hline Serratus ventralis cervicis & 12,70 & Extensor digitorum communis & 1,31 \\
\hline Serratus ventralis thoracis & 10,11 & Extensor digitorum lateralis & 0,93 \\
\hline Deltoideus pars acromialis & 1,88 & Extensor carpi ulnaris & 2,16 \\
\hline Deltoideus pars scapularis & 1,23 & Supinator & 0,72 \\
\hline Supraspinatus, superficialis & 2,10 & Abductor digiti I longus & 1,21 \\
\hline Supraspinatus, principal & 7,14 & Extensor digiti I et II & 0,31 \\
\hline Supraspinatus, craneal & 2,31 & Abductor et opponens digiti I & 0,09 \\
\hline Infraspinatus & 5,12 & Adductores digitorum & 0,14 \\
\hline Teres minor & 0,09 & Adductores digitorum, $I$ & 0,02 \\
\hline Teres major & 1,68 & Adductores digitorum, II & 0,02 \\
\hline Subscapularis & 7,26 & Adductores digitorum, $\mathrm{V}$ & 0,06 \\
\hline Articularis humeri & 0,08 & Abductor digiti II & 0,09 \\
\hline Biceps brachii & 3,59 & Abductor digiti IV & 0,10 \\
\hline Brachialis & 3,32 & Lumbricales & 0,13 \\
\hline Triceps brachii caput longum & 13,87 & Opponens digiti $\mathrm{V}$ & 0,18 \\
\hline Triceps brachii caput laterale & 8,60 & Abductor digiti $\mathrm{V}$ & 0,32 \\
\hline Triceps brachii caput mediale, principal & 1,75 & Flexores breves profundi I & 0,12 \\
\hline Triceps brachii caput mediale, intermedium & 2,16 & Flexores breves profundi III & 0,24 \\
\hline Triceps brachii caput accessorium & 1,57 & Flexores breves profundi IV (+abd en $\mathrm{sp} 1)$ & 0,22 \\
\hline Triceps brachii caput angulare & 4,86 & Flexores breves profundi $\mathrm{V}$ & 0,14 \\
\hline Triceps brachii caput mediale accessorium & 0,29 & & \\
\hline
\end{tabular}


Tabla 3.2. Valores de masa seca porcentual de cada músculo del miembro posterior, región lumbar y cola de Galictis cuja, relativizado al total de la masa muscular del miembro posterior (excluyendo musculatura intrínseca del autopodio). Los valores fueron calculados como el promedio del valor porcentual para cada uno de los especímenes analizados. La nomenclatura sigue la Nómina Anatómica Veterinaria excepto cuando es indicado lo contrario (itálicas).

\begin{tabular}{|c|c|c|c|}
\hline Músculo & $\begin{array}{l}\text { Masa } \\
(\%)\end{array}$ & Músculo & $\begin{array}{l}\text { Masa } \\
(\%)\end{array}$ \\
\hline Epiaxial & & Vastus intermedius & 0,79 \\
\hline Iliocostalis lumborum & 10,06 & Gracilis & 4,22 \\
\hline Transversospinalis (lumbar sector) & 3,33 & Pectineus & 0,68 \\
\hline Interspinales (L2-3) & 0,04 & Adductor longus, proximal & 0,29 \\
\hline Interspinales (L3-4) & 0,08 & Adductor longus, distal & 1,70 \\
\hline Intertransversarii lumborum (L4-5) & 0,02 & Adductor brevis & 1,30 \\
\hline Cola & & Adductor magnus & 2,64 \\
\hline Coccygeus & 0,55 & Obturatorius externus & 0,91 \\
\hline Sacrocaudalis ventralis medialis & 1,32 & Pierna & \\
\hline Sacrocaudalis ventralis lateralis & 1,92 & Gastrocnemius caput laterale & 2,85 \\
\hline Sacrocaudalis dorsalis medialis & 1,80 & Gastrocnemius caput mediale & 3,91 \\
\hline Sacrocaudalis dorsalis lateralis & 6,81 & Soleus & 0,95 \\
\hline Intertransversarii ventrales caudae & 0,78 & Flexor digitorum superficialis & 2,84 \\
\hline Intertransversarii dorsales caudae & 1,79 & Popliteus & 0,69 \\
\hline Recto y urogenital & & Flexor digitorum lateralis & 2,31 \\
\hline Levator ani & 0,59 & Flexor digitorum medialis & 0,61 \\
\hline Pubocaudalis & 0,48 & Tibialis caudalis & 0,55 \\
\hline Iliocaudalis & 0,62 & Fibularis longus & 0,58 \\
\hline Ischiocavernosus & 0,26 & Fibularis brevis & 0,70 \\
\hline Bulbospongiosus (par) & 0,76 & Extensor digitorum lateralis & 0,34 \\
\hline Rectococcygeus & 0,08 & Tibialis cranialis & 2,49 \\
\hline Sublumbar & & Extensor digiti I longus & 0,28 \\
\hline Psoas minor & 0,77 & Extensor digitorum longus & 1,53 \\
\hline Iliopsoas & 4,05 & Pie & \\
\hline Quadratus lumborum & 2,36 & Extensor digitorum brevis & 0,41 \\
\hline Muslo & & Abductor digiti $\mathrm{V}$ & 0,05 \\
\hline Gluteus superficialis & 2,29 & Flexor digitorum brevis & 0,59 \\
\hline Gluteus medius & 4,47 & Interflexores & 0,06 \\
\hline Piriformis & 0,63 & Quadratus plantae & 0,21 \\
\hline Gluteus profundus & 0,70 & Lumbricales & 0,13 \\
\hline Gemelli & 0,26 & Adductores digitorum & 0,10 \\
\hline Obturatorius internus & 0,46 & Flexor breves profundi (I) & 0,13 \\
\hline Biceps femoris & 12,42 & Flexor breves profundi (II) & 0,15 \\
\hline Abductor cruris caudalis & 0,72 & Flexor breves profundi (III) & 0,22 \\
\hline Semitendinosus & 3,66 & Flexor breves profundi (IV) & 0,22 \\
\hline Semimembranosus, femoral & 5,50 & Flexor breves profundi (V) & 0,27 \\
\hline Semimembranosus, tibial & 5,29 & & \\
\hline Sartorius & 5,50 & & \\
\hline Tensor fasciae latae & 1,81 & & \\
\hline Quadratus femoris & 0,61 & & \\
\hline Rectus femoris & 6,21 & & \\
\hline Vastus lateralis & 7,09 & & \\
\hline Vastus medialis & 1,87 & & \\
\hline
\end{tabular}




\subsection{Descripciones osteológicas del postcráneo de mustélidos de América del Sur}

Con el fin de acompañar las descripciones que siguen abajo, en el Tomo II (Láminas 3, ver también Láminas 4) muestran la diversidad de formas de los principales elementos del postcráneo de especies de mustélidos de América del Sur. Por otro lado, la Tabla 3.3, sintetiza los principales cambios de la región caudal, mientras que en el apartado de discusión pueden encontrarse otras tablas e imágenes también útiles para este objetivo.

\subsubsection{Galictis cuja}

Complejo atlas-axis (Láminas 3.1C, 3.2C)

El atlas (Lámina 3.1C) es un elemento moderadamente robusto y algo extendido en dirección cráneocaudal. El foramen vertebral es ovalado en vista craneal, con su eje principal de dirección mediolateral, mientras que en vista caudal posee una forma más bien circular.

Los forámenes vertebrales laterales están poco extendidos cráneocaudalmente en vista dorsal; internamente se ubican justo dorsal a las superficies articulares craneales. En vista dorsal, el arco neural posee un margen craneal recto a levemente convexo a bilobado. El tubérculo dorsal del arco neural es reemplazado por un sector rugoso en su superficie dorsal o se encuentra poco desarrollado. El tubérculo ventral se proyecta en forma de un extremo agudo en sentido ventral y caudal. En vista ventral, existe un quiebre de pendiente moderado entre el margen de las superficies articulares craneales y el del arco ventral. Las superficies articulares caudales inclinan moderadamente en sentido medial. Estas son de contornos angulosos y se proyectan en forma aguda en sentido caudal y dorsal.

El desarrollo de las alas del atlas varía mucho en los distintos especímenes analizados, pero en líneas generales son cuadrangulares, sobresaliendo moderadamente por detrás de los procesos articulares caudales. Las alas se ubican en un plano cráneodorsal-caudoventral, pero cercanas a una dirección cráneocaudal, siendo planas a levemente convexas en vista ventral. En líneas generales, el margen caudal es recto o cóncavo (e.g., MLP 674 y MLP 25.IV.01.1, respectivamente), mientras que el lateral es convexo (e.g., CML 7260, MACN 23519) o recto (MLP 25.IV.01.1). La incisura alar se encuentra claramente definida, como una depresión parcialmente encerrada. En ningún caso se encuentra totalmente obliterada por un puente lateral (como es típico de lincodontininos, ver más adelante). Los forámenes transversos se muestran desarrollados, abriendo caudalmente a los lados de las superficies articulares caudales.

El axis (Lámina 3.2C) posee un proceso espinoso moderadamente alto y amplio en dirección cráneocaudal, apenas superando la extensión del cuerpo vertebral en sentido caudal. Los extremos craneal y caudal del proceso se encuentran engrosados; el caudal posee forma de un tubérculo redondeado y ancho. En vista lateral, el margen dorsal es recto en su sector medio, $\mathrm{y}$ es levemente cóncavo hacia el sector caudal y convexo en el sector craneal. El proceso 
odontoides se proyecta marcadamente en sentido craneal y es poco robusto. El foramen vertebral es más alto que su base. En vista craneal, las carillas articulares craneales se encuentran posicionadas medialmente, continuándose con el proceso odontoides y ubicándose a nivel del foramen vertebral. Las carillas articulares caudales son elongadas cráneocaudalmente $\mathrm{y}$, sobre los procesos articulares, se presenta un tubérculo dorsal a modo de lámina engrosada. La incisura vertebral craneal es aguda. La incisura vertebral caudal es somera y breve.

La cresta ventral del cuerpo está definida y posee un tubérculo caudal bien definido. En vista ventral, justo entre los procesos articulares craneales y en la base del proceso odontoides, se encuentra diferenciado un margen semicircular, separado parcialmente de las carillas articulares craneales por escotaduras. Los procesos transversos están poco proyectados, diferenciados sólo de forma transicional de los márgenes laterales del cuerpo vertebral. Estos divergen del plano sagital y longitudinal aproximadamente a $30^{\circ}$. Estos procesos no alcanzan al extremo craneal del proceso transverso de la tercera vértebra cervical. Los forámenes transversos son elípticos y amplios. En vista lateral, su extremo más craneal está tapado por el límite caudal de las carillas articulares craneales. En vista caudal, poseen forma de triángulos escalenos, encontrándose sus bases a la altura de la mitad del cuerpo vertebral y sus ápices apenas lo superan dorsalmente.

\section{Tercera a séptima vértebra cervical (Lámina 3.3C)}

Los procesos espinosos desde la tercera hasta la séptima vértebra cervical crecen progresivamente. En vista lateral, la tercera vértebra cervical posee un proceso espinoso bajo y delgado; su margen craneal es recto a cóncavo y el caudal, cóncavo; su base es amplia y su extremo dorsal se ubica caudalmente. En el caso del espécimen MLP 2034, la tercera vértebra cervical posee un proceso espinoso bifurcado, con la proyección craneal de menor tamaño y apuntando hacia la base del proceso espinoso del axis. La cuarta, quinta y sexta vértebra poseen

procesos espinosos muy similares entre sí, engrosados en su extremo dorsal, especialmente en el caso de la cuarta y quinta. En vista lateral, estos procesos poseen una altura similar (o algo mayor en las más posteriores) respecto a sus bases. El proceso espinoso de la séptima vértebra cervical es claramente superior en altura al de la sexta vértebra cervical y a su propia base, y está engrosado en su extremo dorsal. En vista lateral, se inclina y recurva cranealmente. Su margen craneal es levemente cóncavo y el caudal recto. En vista dorsal, la relación entre ancho y largo de cada arco neural es aproximadamente de uno a uno, o levemente más anchos. Entre vértebras sucesivas se abre una luz de aproximadamente un sexto a un quinto del desarrollo cráneocaudal del arco neural. Las carillas articulares son alargadas cráneocaudalmente y angostas. Los procesos que portan las carillas articulares craneales están engrosados a modo de tubérculos ventrales; y progresivamente disminuyen en sentido caudal. Los procesos que portan 
las carillas articulares caudales están engrosados a modo de tubérculos dorsales amplios a lo largo de toda la serie, hipertrofiados desde el axis a la quinta vértebra cervical.

Los procesos transversos cervicales son amplios a partir de la cuarta vértebra cervical. En el caso de la tercera y cuarta vértebras cervicales, las láminas ventrales de los procesos transversos superan en extensión craneal y caudal al largo del cuerpo, solapándose con los procesos transversos adyacentes. Para el caso de la quinta y sexta vértebras cervicales, la lámina ventral se extiende tanto como el cuerpo vertebral. Los tubérculos dorsales de los procesos transversos están definidos a partir de la cuarta vértebra cervical. Hasta la sexta vértebra cervical se proyectan en sentido caudal a caudodorsal y se originan en el sector caudal y caudocentral en el caso del sexto elemento. El tubérculo dorsal del proceso transverso de la séptima vértebra cervical es similar en forma, posición y tamaño al de la sexta vértebra, aunque con sus extremos levemente inclinados en sentido ventral. En vista ventral, los tubérculos ventrales de los cuerpos vertebrales corresponden a un único tubérculo en el axis y la tercera vértebra cervical, y están representados como procesos delgados en la cuarta, y secundariamente, quinta vértebras.

\section{Vértebras torácicas y caja torácica (Lámina 3.4C)}

La serie torácica posee 15 vértebras. Sin embargo, en el espécimen MLP 2034, el decimoquinto elemento sólo tiene fóvea articular y la costilla correspondiente del lado izquierdo, mientras que del lado derecho tiene un proceso transverso expandido, triangular e inclinado caudalmente en el ápice y con una inclinación ventral similar a los posteriores. Otra excepción fue registrada en el espécimen MACN-Ma 25483 que presenta 16 vértebras torácicas (reducido en 1 el número de vértebras lumbares, ver más adelante). La vértebra diafragmática corresponde al décimo primer elemento, excepto en el único caso del espécimen MLP 2020, en donde coincidió con la anticlinal. Las crestas ventrales se insinúan en el sector lateroventral del décimo cuarto elemento y están claramente definidas y posicionadas en el décimo quinto elemento. Las escotaduras craneales y caudales son amplias al comienzo de la serie tóracolumbar, se reducen a partir de la zona de la sexta y séptima vértebra torácica, y están obliteradas en la región postanticlinal.

En vista lateral, los procesos espinosos disminuyen progresivamente en altura desde la primera vértebra torácica, con una altura del proceso claramente superior al resto de la vértebra, hasta su mínima expresión en la décima segunda, correspondiendo esta última con la vértebra anticlinal. En las primeras vértebras torácicas los procesos espinosos se ubican prácticamente perpendiculares y poseen márgenes craneales rectos (o convexos en su margen caudal; e.g. MLP 2020) y extremo distal engrosado; caudalmente (hasta la décimo primera vértebra torácica), se solapan progresivamente sobre los cuerpos de las vértebras adyacentes posteriores, presentando márgenes craneales convexos o sinuosos, y caudales sinuosos. El desarrollo en área de los 
procesos espinosos varía intraespecíficamente, aunque en todos los casos es relativamente importante en todos los elementos de la serie, especialmente entre el segundo y el décimo. En el caso del espécimen MLP 2020, el proceso espinoso de la décimo primera vértebra torácica contacta y envuelve ligeramente al de la vertebra anticlinal. En vista lateral, la décimo segunda vértebra posee un proceso espinoso simétrico, de margen dorsal recto, bajo en altura, con forma de meseta y una breve extensión cráneocaudal. A partir de éste, y hasta el último elemento de la serie, los procesos espinosos poseen forma de meseta, son sólo levemente más elevados y algo inclinados cranealmente, progresivamente más engrosados en su margen dorsal y desarrollados cráneocaudalmente.

Las fóveas costales de los procesos transversos son robustas, cóncavas y amplias en todos los elementos preanticlinales; se presentan como un rudimento o están ausentes en la vértebra anticlinal y elementos posteriores. En el caso de la primera vértebra torácica, se posicionan por detrás del nivel de los procesos articulares craneales y muy distantes a los mismos. A partir del tercer elemento de la serie, las fóveas costales se posicionan justo por debajo de las zonas articulares, mientras que en el segundo elemento se observa una posición y distancia intermedia. En las vértebras anticlinal y posteriores, las fóveas costales se ubican exclusivamente sobre el cuerpo vertebral correspondiente (sin incidir además en el precedente). Los procesos mamilares se presentan por primera vez en la vértebra anticlinal, bien definidos y tan altos y robustos como los procesos espinosos de las últimas vértebras de la serie; se mantienen desarrollados hasta los últimos elementos lumbares. Los procesos accesorios se presentan con claridad a partir de la vértebra anticlinal. En vista dorsal, los primeros procesos accesorios inclinan $45^{\circ}$ en sentido caudal, y progresivamente se hacen cada vez más paralelos al eje cráneocaudal.

Toda la caja torácica, y en especial el sector anterior y la abertura craneal del tórax son muy angostos. El esternón diverge respecto a la columna en bajo grado (aproximadamente $30^{\circ}$ ). La sección de la caja torácica se ensancha lateromedialmente, alcanzando un máximo desarrollo a la altura de la séptima u octava vértebra torácica, mientras su altura llega a un máximo al nivel de la décimo segunda torácica.

El esternón está compuesto de 9 esternebras entre las costillas 1 y 10, siendo el noveno elemento reducido. El primero de los elementos es algo menos que el doble de longitud que los caudales y presenta, al final del primer tercio de su extensión, una zona robusta donde articula el primer par de costillas. El manubrio es algo aplanado lateromedialmente, y redondeado en su extremo craneal, donde presenta tubérculos laterales; en la cara ventral se observa una quilla que se proyecta caudalmente en forma aguda hasta la mitad del cuerpo de la esternebra. Los metámeros restantes son subiguales (exceptuando el último que es claramente más corto) y 
moderadamente engrosados. El xifoides es principalmente cartilaginoso, aplanado, angosto y con el extremo caudal agudo.

Las costillas son 15 pares de elementos (ver excepciones más arriba) gráciles en su sector ventral. Los 10 primeros pares contactan con los elementos del esternón, mientras que al menos hasta la décimo tercera convergen en un reducido sector y contactan al esternón vía el décimo par de costillas. En el primer par de costillas, el cartílago costal se encuentra muy reducido, mientras que en las últimas costillas verdaderas, más de la mitad de la extensión total es cartílago costal. En el sector preanticlinal y anticlinal cada costilla presenta un tubérculo costal, que se pierde en la sección postanticlinal. El quiebre de dirección en la zona del ángulo costal se distingue a partir del segundo elemento, y es visible en todas las demás costillas exceptuando las más posteriores.

\section{Vértebras lumbares (Lámina 3.5C)}

La serie lumbar está compuesta típicamente por 5 vértebras, progresivamente más altas y elongadas en dirección posterior. En el caso del espécimen MLP 2034, la última vértebra torácica (considerando la fórmula típica) posee fisonomía de vértebra lumbar del lado derecho, sin fóveas articulares y con un proceso transverso triangular y reducido, perpendicular, e inclinado en sentido caudal. El espécimen MACN-Ma 25483 presenta sólo cuatro elementos lumbares. En vista dorsal, los cuerpos vertebrales son angostos y alargados, especialmente en el caso de la penúltima lumbar. En vista ventral, se observan en el último tercio del primer elemento lumbar dos crestas, que corresponden a orígenes de la musculatura sublumbar, paralelas y sobresalientes del margen caudal del cuerpo vertebral a modo de tubérculos ventrales. Estas crestas poseen un máximo desarrollo en el segundo elemento lumbar; mientras que en las vértebras posteriores poseen un desarrollo cada vez menos definido y desplazándose a una posición más lateral.

Los procesos espinosos lumbares poseen forma intermedia entre meseta y "onda baja", inclinados en sentido craneal y similares a los descriptos en los últimos elementos torácicos, aunque son progresivamente más altos y menos robustos. Los márgenes dorsal, craneal y caudal son redondeados. La última vértebra lumbar posee un proceso espinoso relativamente reducido cráneocaudalmente, y con una posición más perpendicular de su eje principal. El desarrollo lateromedial de las facetas articulares en la zona de la articulación entre el último y penúltimo elemento (y entre el penúltimo y antepenúltimo para el caso del espécimen MLP 2034) se encuentra reducido en comparación con lo observado en el resto de la serie lumbar, mientras que la articulación entre la última vértebra lumbar y el sacro posee el mayor desarrollo y separación de zonas articulares. Las escotaduras dorsales caudales están reducidas, o totalmente obliteradas, excepto en el último elemento lumbar. Al igual que en los elementos 
postdiafragmáticos torácicos, las facetas articulares inclinan y se apartan respecto al plano longitudinal (típico en las demás vértebras tóraco-lumbares) en sentido dorsal hasta $45^{\circ} \mathrm{o}$ incluso más. Los procesos mamilares muestran un mayor desarrollo que el observado en los elementos postanticlinales torácicos, proyectándose fuertemente en sentido craneal, más allá de las carillas articulares de las cuales parten. Por otro lado, los procesos accesorios se encuentran bien desarrollados aún en las tres primeras vértebras lumbares, y se muestran reducidos en las últimas dos. En el último elemento lumbar, están representados por una pequeña protuberancia caudal. Al comienzo de la serie lumbar, las escotaduras vertebrales craneales y caudales son amplias y están cruzadas y obliteradas en su sector medio por los procesos accesorios (excepto entre los últimos dos elementos).

Los procesos transversos inclinan por debajo del plano horizontal. En el primer elemento lumbar se encuentran moderadamente desarrollados, apenas alcanzan cranealmente el margen craneal del cuerpo vertebral y poseen márgenes redondeados, inclinandos cranealmente y con forma de "ola"; el margen craneal es cóncavo y breve, y el caudal es convexo y amplio. Los siguientes elementos poseen procesos transversos gradualmente mayores y proyectados lateroventralmente. Los procesos transversos de los últimos dos elementos lumbares son siempre los más desarrollados y poseen morfologías muy variantes intraespecíficamente, pero como tendencia general, tienden a terminar con un margen distal recto o aproximadamente recto, separado del margen caudal por un quiebre. Poseen un margen craneal cóncavo, y un margen caudal recto o levemente convexo, en general interrumpido por una saliencia aguda, o grupos de crenulaciones (en relación al origen de paquetes del $\mathrm{m}$. iliocostalis y $\mathrm{m}$. quadratus lumborum), a veces también presente en las vértebras lumbares más anteriores. El margen lateral de los procesos transversos, además de ser plano, se muestra en vista lateral como una superficie plana, expandida en sentido ventral y craneal, especialmente en el caso de los últimos dos elementos, alcanzando, y en la mayoría de los casos superando, el extremo cráneoventral del cuerpo vertebral correspondiente.

\section{Sacro (Lámina 3.6B)}

Está compuesto por tres elementos fusionados (aunque esto no ocurre en el ejemplar MLP 2020, en el que sólo dos elementos se encuentran totalmente fusionados). En vista dorsal posee una forma cuadrangular. Los procesos espinosos se fusionan sólo parcialmente en una única cresta sacra media, principalmente entre el segundo y tercer elemento, observándose separados el primero y segundo en lo que respecta a sus extremos distales en algunos casos. El primero de los procesos espinosos suele ser levemente mayor a los restantes. En el caso del espécimen MLP 2034, el proceso espinoso central es mayor que los otros dos. La superficie articular sacro-ilion tiene forma elíptica. La participación del segundo par de procesos 
transversos en la zona articular es breve (excepto en el lado derecho del espécimen MLP 2020, en donde abarca algo más que la mitad de su extremo lateral). Esta superficie se extiende levemente por debajo del margen ventral de los cuerpos vertebrales, especialmente a nivel del primer elemento. La cresta sacra lateral se proyecta en forma aguda en sentido caudal y lateral, tanto o más allá que la zona articular entre la zona sacra y caudal de los cuerpos vertebrales. La región caudal de esta cresta inclina dorsalmente. Los forámenes sacros son circulares. En el caso del segundo par, poseen un menor desarrollo, en algunos casos mostrándose parcialmente obliterados en vista ventral. Los procesos articulares craneales son amplios, orientados en un plano más cercano al sagital que al longitudinal (mayor a $45^{\circ}$ respecto al plano horizontal). Los procesos articulares caudales presentan una baja inclinación o son prácticamente horizontales. En vista craneal, el cuerpo vertebral posee forma semicircular, con el margen dorsal aplanado, y sobre éste la apertura del canal vertebral es moderada a pequeña y aplanada; en vista caudal, la apertura es semicircular, posee un tamaño aun menor.

Vértebras caudales (Lámina 3.7B)

Los especímenes MLP 2034 y MACN-Ma 25483 presentan la serie de vértebras caudales completa, compuesta por 21 elementos, mientras que el espécimen MLP 2020 posee la mayoría de los elementos a excepción del último y el fragmento distal del penúltimo. Otros especímenes permiten complementar la descripción del sector más proximal de la serie. Las primeras vértebras son robustas y aplanadas, y los procesos sobre ellas son amplios hasta el sexto o séptimo elemento. Los cuerpos vertebrales de los primeros elementos son muy similares al último elemento del sacro y gradualmente se vuelven cilíndricos. Los primeros cinco elementos caudales poseen un proceso espinoso diferenciable (a veces rudimentos en el sexto, e.g., MLP 25.IV.01.1). Los primeros presentan bases amplias, y morfología de meseta, mientras que los últimos están reducidos.

Los cuerpos de las vértebras caudales son breves, siendo en todos los casos menos largos que el cuádruple de su ancho. Los procesos y las carillas articulares craneales y caudales poseen moderado a poco desarrollo. En vista dorsal, la escotadura craneal y dorsal de las seis primeras vértebras caudales es importante, profundizándose en las primeras cuatro hasta la zona media del cuerpo vertebral. En vista lateral, la escotadura caudal de las vértebras caudales se encuentra en extremo reducida o ausente. La vértebra transicional (ver Youlatos 2003) corresponde al tercer elemento. Los procesos que portan las carillas articulares caudales se encuentran presentes hasta el tercer o cuarto elemento, mientras que a partir del quinto elemento, el arco neural y el cuerpo se fusionan, y las carillas articulares caudales no se distinguen, encontrándose en su lugar una cresta redondeada muy poco diferenciada que corona 
el extremo caudal del margen dorsal de cada elemento. Los procesos mamilares se diferencian bien hasta el elemento número 11 o 12.

Los procesos transversos de las tres primeras vértebras caudales parten de todo el margen lateral del cuerpo vertebral, y tienen un margen distal o lateral truncado. En el primer elemento, los procesos transversos inclinan en sentido dorsal y caudal. El segundo elemento caudal posee los procesos transversos más desarrollados lateromedialmente y con orientación más perpendicular que el primero, al igual que el tercer elemento. A partir del cuarto elemento, se proyectan y posicionan gradualmente en sentido caudal. En los siguientes tres elementos son menos conspicuos. A partir del séptimo u octavo elemento, y hasta el número 11, los procesos transversos se dividen en una protuberancia mayor en el sector caudal de cada vértebra que corresponde al proceso transverso caudal (que continúa la tendencia gradual mencionada anteriormente), y una pequeña proyección perpendicular ubicada cranealmente, que corresponde al proceso transverso craneal. Ambas proyecciones están ampliamente distanciadas, y a veces se conectan a través de una quilla en la cara lateral de cada vértebra; se observan incluso en los últimos elementos (dependiendo del espécimen). A partir de la quinta (e.g., MACN 21319) o sexta (e.g., MLP 25.IV.01.1) vértebra caudal, se desarrollan procesos hemales a modo de protuberancias cráneoventrales para arcos hemales pequeños e incompletos.

\section{Escápula (Lámina 3.8C)}

La escápula tiene forma subrectangular con ángulos marcados, con un ángulo caudal recto, un ángulo craneal recto a levemente abierto, y un ángulo de similar amplitud al anterior (aunque más abierto) sobre el final del margen craneal, el cual hace las veces de límite entre el margen craneal y la escotadura escapular profunda, cuyos márgenes forman un ángulo algo obtuso aunque cercano a los $90^{\circ}$. El margen craneal se muestra totalmente recto, solo evidenciándose en algunos especímenes una levemente convexidad o sinuosidad (e.g. MLP 671, MLP 2020). En vista medial, la escápula es aplana a levemente cóncava, y francamente deprimida en la contracara de la espina. La espina es robusta y elevada, recta a lo largo de toda su extensión, formando un área elevada, triangular y expandida en cercanías pero caudal al ángulo craneal, delimitando una fosa supraespinosa con un área dos veces mayor a la de la infraespinosa. En el sector del ángulo caudal, la zona de origen del m. teres major y m. triceps brachii caput angulare, está desarrollada dorsoventralmente y se flexiona medialmente; es de extensión variable y triangular, con un margen definido pero no engrosado que la separa de la fosa infraespinosa.

El acromion se desarrolla abruptamente a partir de la espina, observándose en vista craneal un ángulo de $90^{\circ}$ entre éste y el plano de la espina. Hay una escotadura profunda entre éste y la zona articular. El proceso hamatus es algo robusto y se proyecta en general paralelo a 
la espina en vista lateral y algo divergente al plano de la escápula en vista craneal, alcanzando o superando en proyección a la cavidad glenoidea. El proceso subhamatus alcanza el margen caudal de la escápula, con el margen ventral marcadamente cóncavo a recto, el caudal recto y paralelo a la espina, y el dorsal convexo o recto, en general escotado en su base, siendo aproximadamente rectangular en vista lateral. En la zona ventral de la base del acromion se presenta en algunos especímenes un foramen pequeño (escápula derecha e izquierda de MLP 23.X.98.3).

En vista distal, la cavidad glenoidea posee forma de gota u ovoide, con un tubérculo supraglenoideo algo robusto, y un proceso coracoides delgado y reducido. En vista medial, se observa que la zona articular se encuentra moderadamente proyectada hacia ventral en la zona craneal, y que el cuello de la escápula es similar en ancho cráneocaudalmente respecto a la zona articular. En la base del cuello, en posición caudomedial, el área de origen del m. triceps brachii caput longum y secundariamente $\mathrm{m}$. teres minor presenta estrías paralelas.

\section{Húmero (Lámina 3.9C)}

El húmero es un elemento moderadamente robusto a lo largo de toda su extensión y en forma más pronunciada en el sector proximal. La diáfisis del húmero es mayormente recta en vista lateral, aunque en el sector medio-proximal presenta una leve curvatura (convexo en vista craneal). En vista proximal, la superficie articular posee un mayor desarrollo en el eje cráneocaudal. A su vez, en vista craneal se eleva por sobre, o es igualado en altura, respecto al tubérculo mayor. Éste tubérculo es muy robusto y está separado de la zona articular y del tubérculo menor mediante un amplio y profundo surco intertubercular. Sobre la cara lateral y sobre el extremo caudal del tubérculo mayor, se desarrolla una zona deprimida muy desarrollada donde se inserta el m. infraspinatus. En algunos especímenes, el área de inserción del m. teres minor parece diferenciarse a modo de una rugosidad (e.g., MACN 21319). La línea tricipital, y en menor medida la tuberosidad deltoidea, poseen una gran diferenciación respecto a la diáfisis formando una cresta marcada, especialmente en la zona media y proximal, la cual se continúa proximalmente con similar desarrollo, continuándose luego en sentido caudal con la cresta que marca la zona proximal de origen del $\mathrm{m}$. triceps brachii caput laterale. La cresta del tubérculo mayor se diferencia sutílmente en la zona medial proximal de la diáfisis, aunque se presenta sólo como un leve cambio de pendiente distalmente sobre la diáfisis, al principio del segundo tercio del húmero. La zona delimitada por ambas crestas es amplia y aplanada, claramente diferenciable a lo largo del primer tercio del húmero y un poco más distalmente. Existe un margen craneal rugoso en lugar de una cresta deltopectoral, que se extiende hasta el principio del último cuarto del húmero. El tubérculo menor es robusto, desarrollado en dirección 
proximodistal, y orientado directamente en sentido medial, con un límite caudal con cóndilo algo difuso.

En la zona distal, ambos epicóndilos presentan un importante engrosamiento en sentido cráneocaudal. El epicóndilo lateral posee un desarrollo lateromedial moderado, mientras que el medial posee un gran desarrollo en dicha dirección. El epicóndilo medial se encuentra muy desarrollado en dirección proximodistal, alcanzando y superando el margen distal medial de la tróclea. El foramen supracondiloideo, de moderado desarrollo, posee forma oval. En vista caudal, su apertura es similar a la observada en vista craneal. Su margen medial es delgado, especialmente en su zona media, mientras que lateralmente existe en cambio abrupto de pendiente y la formación de una pequeña cresta a la altura del principio de la tróclea. La cresta epicondiloidea posee un desarrollo próximodistal elevado, alcanzando el tercio medio de la diáfisis, con un moderado desarrollo lateromedial, acentuado en la zona media de la cresta. La tróclea presenta un moderado desarrollo proximodistal, y bajo desarrollo lateromedial en relación al capítulo, con un margen medial desarrollado en dirección mediodistal, algo inclinado medialmente. La profundización de la tróclea es moderada. El capítulo posee una forma intermedia entre semiesférica y cilíndrica, con un margen lateral moderadamente engrosado. Las fosas coronoidea y radial se encuentran indiferenciadas entre sí, confundidas en una única fosa, adelgazada y típicamente parcialmente perforada (similar a G. vittata y distinto a los otros mustélidos descriptos), y moderadamente diferenciadas respecto a la diáfisis distal. En vista caudal, la zona articular posee un margen medial moderadamente marcado que la separa de una muy somera y poco definida fosa para el tendón del olécranon, mientras que el margen lateral posee un límite marcado y bien definido. La fosa olecraneana es amplia, de bajo desarrollo proximal, de profundidad importante sólo en cercanías a la zona articular, y los márgenes lateroproximal y medial definidos. La fosa para el tendón del olécranon es somera, cuadrangular, apenas diferenciable como un cambio de pendiente respecto a la superficie caudal del cóndilo medial, con márgenes lateral y medial suaves y redondeados, apenas incidiendo mínimamente en sentido laterodistal sobre la zona articular en su extremo medial. Entre la fosa olecraneana y la fosa para el tendón del olécranon existe un leve cambio de pendiente, siendo la primera más profunda que la segunda.

\section{Ulna (Lámina 3.10C)}

Es recta a levemente cóncava medialmente, aunque en su sector más distal posee un muy leve quiebre de dirección, desviándose dicho extremo en sentido lateral. En vista lateral, la ulna está moderadamente desarrollada cráneocaudalmente tanto en el olécranon como en cercanías a la zona incisura troclear, pero disminuye en forma continuada y gradual hasta justo antes del extremo distal. El olécranon se encuentra moderadamente desarrollado en dirección 
cráneocaudal y en dirección próximodistal en relación al resto del elemento. El extremo cráneomedial de la tuberosidad del olécranon (zona de inserción de la cabeza medial del m. triceps brachii) posee un bajo desarrollo medial y se encuentra algo robustecido. El sector caudal y medial de la tuberosidad del olécranon (donde se insertan otras cabezas del $\mathrm{m}$. triceps brachii, principalmente la larga y angular) se encuentran desarrollados y fuertemente proyectados en sentido medial, determinando en parte un importante desarrollo lateromedial del olécranon. Tanto el margen craneal como proximal son cóncavos, mientras que el caudal es más bien recto. En la cara medial del olécranon, se presenta una zona deprimida y somera en cercanías al margen craneal. La incisura troclear es profunda . El proceso ancóneo es levemente asimétrico; tiene un desarrollo similar o algo mayor que el coronoides. La incisura radial posee forma oval a cuadrangular, alargada lateromedialmente, con su eje mayor orientado a unos $45^{\circ}$ del plano definido por la diáfisis de la ulna, articulando el radio en una posición diagonal respecto de ésta. El margen extremo lateral de esta zona articular es aproximadamente recto. La tuberosidad ulnar está claramente marcada en el sector cráneolateral de la diáfisis.

En la zona proximomedial de la diáfisis se presenta con cierta claridad la concavidad correspondiente al pasaje y la inserción de los flexores digitales (e.g. flexor carpi ulnaris y $\mathrm{m}$. flexor digitorum profundus), aunque pierde definición en el sector distal a la zona articular. En la zona mediodistal, y en una posición cráneolateral, la cresta del ligamento interóseo está bien desarrollada (correspondiéndose a una similar en la cara caudolateral del radio). En la zona lateral de la diáfisis, se presenta con cierta claridad la concavidad próximodistal correspondiente al pasaje varios extensores digitales y el origen del $\mathrm{m}$. abductor digiti I longus. El desarrollo próximodistal del área de origen del $\mathrm{m}$. pronator quadratus es amplia, acercándose a la zona media de la diáfisis. En el extremo distal, el proceso estiloides se encuentra desarrollado cráneocaudalmente, aunque es delgado en sentido lateromedial. Su superficie articular posee una forma ovalada a cuadrangular y alargada. La superficie diartrodial para el radio se encuentra bien desarrollada, en una posición craneal, orientada cranealmente, sin elevarse respecto de la diáfisis ulnar.

\section{Radio (Lámina 3.11B)}

Es algo mayor a dos tercios del largo del húmero. En vista lateral y craneal es levemente convexo. En su sector proximal y medio es cilíndrico a algo aplanado cráneocaudalmente, mientras que es aplanado lateromedialmente en su mitad distal. La carilla articular proximal del radio posee una forma elíptica o arriñonada, con una leve escotadura en su sector cráneolateral (coincidiendo con la importante elevación del extremo lateral del capítulo húmero), más desarrollada en su sector medial respecto al lateral. En la zona lateral de la epífisis proximal se diferencia una moderada elevación a modo de un tubérculo que representa la inserción el 
ligamento colateral. La diáfisis proximal muestra un cambio abrupto en la dirección del eje principal, formando un ángulo de dirección caudal, distal a la articulación proximal con la ulna. En la cara caudomedial de la diáfisis; inmediatamente distal a esta epífisis, se observa la tuberosidad radial (inserción de ligamentos y m. biceps brachii), a modo de una zona rugosa y plana, levemente cóncava, limitada caudalmente por una cresta sutílmente definida y breve.

En la zona lateral y menos definidamente en el sector proximolateral de la diáfisis, se presenta una muesca pobremente definida en forma de cresta correspondiente al ligamento interóseo, la cual se presenta con un gran desarrollo proximodistal, aunque pierde definición luego de superar la mitad de la diáfisis. A lo largo de toda la cara caudal del sector medial y distal de la diáfisis se presenta una cresta moderadamente amplia correspondiente a la zona de inserción del m. abductor digiti I longus (en la cara lateral) y cabeza radial del flexor digitorum profundus (en la cara medial). A lo largo del tercer cuarto de la diáfisis radial, se observa una cresta craneal correspondiente al $\mathrm{m}$. pronator teres.

El extremo distal, en vista ventral, presenta una superficie articular carpal cóncava de forma triangular, cuyo eje principal posee dirección cráneomedial-caudolateral, y orientada principalmente en sentido distal. En vista medial, el surco para el pasaje del $\mathrm{m}$. abductor digiti I longus tiene una orientación principalmente lateroproximal-mediodistal, a unos $45^{\circ}$ del eje de la diáfisis radial. Aunque con un pobre desarrollo en este sentido, presenta ambos márgenes definidos. El tubérculo de inserción del $\mathrm{m}$. brachioradialis es agudo. El proceso estiloides se proyecta moderadamente en sentido distal. La escotadura ulnar, ubicada en el margen laterocaudal del extremo distal del radio, es circular a elíptica, a modo de una superficie cóncava de márgenes diferenciados. Justo craneal a la escotadura ulnar, el surco para el pasaje del m. extensor digiti I et II es muy profundo y su dirección principal es proximodistal, y está delimitado cranealmente por un tubérculo agudo cráneolateral proyectado lateralmente.

\section{Autopodio anterior (Lámina 3.12C)}

La serie carpal se encuentra fuertemente empaquetada; es convexa en vista dorsal y cóncava en vista plantar. El carpal radial y el ulnar son huesos más bien aplanados, con un desarrollo próximodistal breve, especialmente en vista craneal. En vista craneal, el radial presenta un desarrollo lateromedial cercano al doble del observado para el ulnar. La carilla articular para el radio del radial se extiende lateralmente tanto como a la altura de la mitad del metacarpal IV, y es sólo moderadamente convexa en sentido cráneocaudal. En vista craneal, la zona de articulación entre el radial y ulnar posee una mínima extensión próximodistal en relación al importante desarrollo del cuarto carpal, inmediatamente distal a dicho contacto (ver más adelante). En su extremo medial, el radial contacta al sesamoideo radial mediante una carilla articular convexa. En vista caudal, el sector medial se proyecta caudalmente a modo de 
un tubérculo radial ensanchado proximodistalmente a la altura del carpal I. Distalmente, el radial articula con los cuatro carpales distales por medio de una serie de bandas cóncavas y convexas. El sesamoideo radial es aplanado y alargado, desarrollado en dirección ventral. El carpal ulnar es un hueso cuadrangular y algo aplanado en sentido proximodistal. La mitad caudal de su cara proximal es una superficie articular aplanada y triangular, que contacta al carpal accesorio, mientras que la mitad craneal es convexa en el plano transverso y aplanada a levemente cóncava en el plano cráneocaudal. La separación entre ambas superficies se denota como un cambio de pendiente. La cara laterodistal del ulnar es alargada cráneocaudalmente y cóncava, a fuertemente cóncava, y contacta al quinto metacarpal. El carpal accesorio posee su extremo libre marcadamente robusto y redondeado, desarrollado proximodistalmente y dirigido caudalmente. La articulación con el ulnar es triangular a cuadrangular y principalmente plana, aguda en su sector dorsal. En vista dorsal, el carpal accesorio presenta en el sector craneal una región articular triangular y cóncava que, junto con la superficie correspondiente y adyacente del ulnar, recibe a la ulna. Entre esta superficie y el extremo caudal libre existe una zona constreñida.

Los carpales distales se contactan entre ellos por zonas de articulación aproximadamente planas, a excepción del segundo y el tercero, en donde dicho contacto es en alguna medida convexo-cóncavo, teniendo el tercero forma de "L", o triangular. En vista craneal, el carpal I se extiende marcadamente en dirección distal a modo de una cuña entre los metacarpales I y II, tanto como el tubérculo plantar del metatarsal I. En vista caudal existe un tubérculo rudimentario justo proximal y lateral al tubérculo plantar del metatacarpal I. El carpal II, en vista craneal, posee una superficie no articular cuadrangular a triangular, aplanada en sentido proximodistal. La arista más lateral se proyecta fuertemente en sentido lateral, resultando rodeada parcialmente por la cara medial del carpal III y el extremo laterodistal del radial. El carpal III es moderadamente alargado proximodistalmente y cráneocaudalmente. En vista craneal posee forma de "L": el sector medial se proyecta a modo de una superficie proximodistalmente aplanada que contacta en su margen cráneomedial al carpal II. El margen lateral del carpal III se eleva marcadamente (alcanzando aproximadamente de la altura del carpal IV), aumentando el área de contacto con el carpal IV, siendo este área semicircular y aplanada. En vista craneal, esta articulación es cubierta en su tercio proximal por el radial. En vista caudal, el tubérculo plantar del carpal III se encuentra bien desarrollado como un área plana y algo proyectada medialmente. En vista craneal, el carpal IV duplica en desarrollo en área a cualquiera de los demás cárpales distales; tiene una morfología similar a un triángulo de vértices romas, proyectado en sentido proximal y lateral. Es levemente más alto que el carpal III. El área de contacto con el carpal III ocupa toda la vista medial, exceptuando un breve sector proximal que corresponde al área de contacto con el radial, y un breve sector no articular 
incidente en el extremo caudodistal de dicho sector. En el carpal IV no se diferencia un tubérculo plantar. La cara lateral del carpal IV articula con el ulnar y es levemente convexa y triangular. En vista craneal, el contacto radial-carpal IV no se aparta en gran medida del plano horizontal (mucho menor a $45^{\circ}$ ), mientras que el contacto ulnar-carpal IV se aparta $45^{\circ}$.

Los dígitos periféricos (especialmente el I y el V) se encuentran reducidos respecto a los centrales, siendo los metacarpos de menor longitud, I y V, cercanos a la mitad del mayor y tres cuartos de la longitud del mayor (III) respectivamente; y siendo la longitud de las falanges proximales de los dígitos I y $\mathrm{V}$ aproximadamente dos tercios de la longitud observada en los restantes dígitos. Tanto metacarpales como falanges son moderadamente robustos.

Los metacarpales son rectos a levemente convexos en vista dorsal. El metacarpal V articula con un pequeño hueso sesamoideo metacarpal en el principio de su cara plantar. El metacarpal III es el más elongado, seguido cercanamente por el IV, y seguidos por el II, V y I. Proximalmente, todos los metacarpales poseen bases definidas y expandidas caudalmente, especialmente en el caso del metacarpal V (en relación a la inserción del m. fibularis brevis y m. extensor digitorum lateralis). Los sesamoideos metacarpales son elongados, aplanados para el caso de los metacarpales II, III, IV y V; mientras que en el metacarpal I, el hueso sesamoideo medial se muestra atrofiado y menos elongado. Las falanges proximales y mediales son de robustez similar a los metacarpales, con zonas articulares y de inserciones tendinosas robustas. Las falanges de los dígitos II al $\mathrm{V}$ son aproximadamente dos tercios de la longitud que sus metacarpales. En algunos especímenes la falange proximal del dígito I es más grácil y se curva levemente hacia lateral, siendo en general similar en longitud a las demás falanges proximales. Las falanges ungueales poseen crestas ungueales robustas y elongadas dorsoventralmente, y procesos ungueales bien desarrollados, robustos en sus bases y más bien aguzados hacia su extremo distal. El margen ventral de estos es levemente cóncavo en su sector proximal o a veces netamente recto, y el margen dorsal es levemente curvo en su sector distal. Las unguis son elongadas, agudas distalmente, levemente curvadas y moderadamente engrosadas, aumentando grandemente la extensión distal de las falanges ungueales.

\section{Hueso coxal (Lámina 3.13C)}

El ilion define un plano de unos $60^{\circ}$ o $70^{\circ}$ respecto del definido por isquion y pubis. El acetábulo, de tamaño moderado, posee una forma algo aplanada del sector dorsal del margen acetabular. La incisura acetabular es profunda y angosta en su sector caudal, aunque poco desarrollada en su sector ventral, continuándose con el margen acetabular en este último sector. $\mathrm{Su}$ extensión total es de un cuarto de la circunferencia. El foramen obturado es grande, de forma oval, pero algo irregular, con su margen dorsal algo aplanado. La superficie sinfisaria posee un gran desarrollo en sentido cráneocaudal; está engrosada en su sector más craneal y 
moderadamente dentada. El ala del ilion posee una forma rectangular, algo cóncava en vista lateral y robusta. El cuello es de sección rectangular y moderadamente ancho. Las espinas ilíacas ventro-craneal, dorso-craneal y dorso-caudal poseen un desarrollo y robustecimiento similar y moderado. La tuberosidad sacra y coxal, así como la cresta ilíaca ventro-caudal se muestran algo más engrosadas que el resto del ala ilíaca. La cresta ilíaca se muestra como un margen recto a levemente convexo, el cual inclina levemente en sentido cráneodorsal. La espina ventro-caudal posee un bajo desarrollo apenas diferencia del margen ventral del ilion como un engrosamiento y algunas rugosidades. La escotadura ciática mayor se encuentra moderadamente profundizada a marcadamente profundizada en su sector cráneomedial debido al desarrollo de la espina dorso-caudal; es amplia en sentido cráneocaudal. La superficie articular para el sacro se encuentra desarrollada y posee una forma angulosa y bastante bien definida. En la cara lateral del cuello del ilion, se diferencian sutílmente la línea glútea caudal y el tubérculo del m. rectus femoris.

El ángulo formado entre el cuerpo del isquion y pubis es de aproximadamente $70^{\circ}$. El cuerpo del isquion es moderadamente robusto y forma un ángulo de aproximadamente $130^{\circ}$ respecto a rama del isquion, la cual es aplanada y fuertemente adelgazada cráneocaudalmente en el sector ventral, en parte debido a la expansión caudoventral del foramen obturador. La espina isquiática se presenta como un pequeño tubérculo agudo, que se continúa cranealmente como una zona elevada a modo de cresta que llega a la zona dorsal al acetábulo. Caudalmente se continúa por la escotadura ciática menor, que se muestra como un margen mayormente recto y moderadamente engrosado. La arcada isquiática se diferencia del resto del margen caudal del isquion en parte debido al gran desarrollo caudal de la tabla del isquion; en su margen craneal se diferencia claramente del cuerpo del isquion debido a un margen engrosado y elevado entre ambas estructuras. La tuberosidad isquiática es muy engrosada a lo largo de todo su recorrido cráneocaudal, claramente diferenciada del resto del isquion, proyectada en sentido lateral y dorsal. El cuerpo del pubis es bastante alargado dorsoventralmente, aplanado y delgado lateromedialmente y expandido cráneocaudalmente en sus extremos, presentando una eminencia ilio-pubiana en general levemente diferenciada (al igual que su continuación por medio de la línea arqueada), en una posición cercana a la altura del margen craneal del acetábulo. En su margen dorsal una fina y amplia lámina se proyecta dentro del foramen obturado en el caso del ángulo con la rama caudal del pubis, aunque con una constricción en su zona central. El cuerpo del pubis no muestra una curvatura medial significativa, sino que es más bien recto en vista craneal. El pecten pubiano, en general se diferencia del resto del margen cráneoventral a modo de un tubérculo redondeado. La rama caudal del pubis posee un sector craneal de gran desarrollo superficial, que decrece en forma continua hasta su extremo caudal. 


\section{Fémur y patela (Lámina 3.14C)}

Elemento en alguna medida robusto, principalmente cilíndrico, levemente curvado en sentido lateral en la zona media de la diáfisis, y muy levemente curvado en sentido caudal en la zona mediodistal de la misma. La cabeza del fémur se muestra proyectada en sentido medial y se encuentra orientada fuertemente en sentido dorsal, y secundariamente, en sentido medial. En vista medial, la fóvea se encuentra desplazada hacia el margen caudal de la cabeza. El trocánter mayor se encuentra moderadamente desarrollado, con una proyección roma y algo robustecida que se eleva por sobre el cuello, pero sin sobrepasar en altura a la cabeza articular, inclinado cranealmente y algo medialmente. La fosa trocantérica es profunda, presenta un importante desarrollo proximodistal, superando el nivel de la base de la cabeza articular proximalmente y alcanzando el nivel de la base del cuello en sentido distal. En el margen dorsal del cuello femoral, la escotadura dorsal entre la cabeza femoral y el trocánter mayor es somera. El trocánter menor se muestra de moderadamente a bien diferenciado, sin sobresalir medialmente en vista caudal. Posee una marcada extensión próximodistal (como también ocurre en Ga. vittata, ver más adelante). La tuberosidad glútea se encuentra moderada a marcadamente desarrollada como un área aplanada amplia y cuadrangular que ocupa toda la cara lateral del trocánter mayor, y que supera distalmente a la altura del trocánter menor. El margen craneal de la tuberosidad se encuentra bien definido y es sobresaliente a modo de cresta en toda su extensión. Distalmente se continúa un breve tramo como una línea rugosa.

En el extremo distal, la tróclea femoral se encuentra bien delimitada por los labios medial y lateral, el primero de los cuales es algo más elevado que el segundo, terminando gradualmente en su sector craneoproximal, por sobre la altura de las carillas articulares para los huesos sesamoideos supracondiloideos (i.e. terminación proximal y caudal de los cóndilos articulares), dando, en vista lateral y medial, un aspecto asimétrico al extremo distal femoral (alcanzando, hacia proximal, los labios de la tróclea una mayor altura que los cóndilos articulares). En la región proximal a la tróclea, un área aplanada se continúa por la superficie craneal de la diáfisis, ocupando aproximadamente el último quinto de la misma, perdiéndose proximalmente tempranamente. En vista distal, ambos epicóndilos poseen similar desarrollo lateral, mientras que los cóndilos se proyectan moderadamente en sentido caudal, el medial algo más que el lateral. En esta vista, el desarrollo cráneocaudal de la tróclea es mayor al de los cóndilos. Debido a estas características, en vista distal el fémur posee un mayor desarrollo cráneocaudal que lateromedial. Sobre el epicóndilo lateral, la fosa del extensor (fossa extensoria) se encuentra poco definida. La fosa de origen del $\mathrm{m}$. popliteus es marcada y es profunda. La fosa intercondiloidea es algo angosta en sentido lateromedial. Sobre el epicóndilo medial, se presenta una zona deprimida a aplanada correspondiente a un importante desarrollo del ligamento colateral medial. Tanto ambos epicóndilos como la fosa intercondiloidea en vista 
caudal poseen un gran número de foramina nutricias. En vista caudal no se encuentran presente ni la tuberosidad supracondiloidea lateral, ni la medial. Ambas carillas para los sesamoideos supracondiloideos se encuentran desarrolladas. La patela es aplanada y de forma oblonga, algo más aguda en su ápice respecto a la base.

Tibia (Láminas 3.15C, 3.16B, 3.17B)

Es un hueso robusto, algo aplanado mediolateralmente en su sector medioproximal, y curvado lateralmente en su zona media, excepto su extremo distal que se vuelve más bien recto y robusto. En vista proximal (Lámina 3.16B), el cóndilo lateral (faceta condilar lateral) es aproximadamente circular, continuándose en su extremo caudolateral en forma transicional con un área expandida y sobresaliente (relacionada a la zona de articulación con la fíbula, ver más adelante), y posee un desarrollo mediolateral mayor que el medial. El cóndilo medial (faceta condilar medial) posee forma arriñonada, con su mayor eje en sentido cráneocaudal, superando caudalmente al cóndilo lateral. El cóndilo lateral es levemente convexo en vista lateral, mientras que el medial es más bien plano en vista medial; ambos se encuentran aproximadamente en el mismo plano, o el cóndilo lateral en un plano levemente superior al medial. En vista proximal, la zona intercondiloidea craneal tiene un desarrollo extenso en sentido cráneocaudal, terminando en una tuberosidad sobresaliente cranealmente y de moderado desarrollo lateralmente. La zona laterocraneal (craneal al cóndilo lateral) se muestra proyectada por sobre la zona deprimida y cóncava correspondiente al surco del extensor, formándose una región marginal también cóncava entre este sector y la tuberosidad tibial. La eminencia intercondiloidea se muestra moderada, a marcadamente, desarrollada. Tanto el área intercondiloidea craneal como caudal (áreas de inserción de los ligamentos crucianos craneales y caudales), como los márgenes laterales y mediales de la epífisis proximal de la tibia (áreas de inserción de los ligamentos colaterales) se muestran rugosos y socavados. En vista caudal, bajo el cóndilo medial, se observa un tubérculo aplanado en sentido próximodistal correspondiente a la superficie de inserción del ligamento cruciano caudal, mientras que en el sector caudolateral del cóndilo lateral se presenta un área plana que expande el contacto con la fíbula y posiblemente da origen al ligamento craneal de la cabeza fibular. Tanto en la zona craneal, como lateral y medial a los cóndilos, se presentan un gran número de foramina nutricias.

En vista lateral, la fosa tibial se muestra como una superficie cóncava en su sector proximal y aplanada distalmente, ocupando aproximadamente el primer tercio, o un poco más, de la diáfisis tibial. Está delimitada en su margen craneal por una cresta tibial recta y levemente reflecta en sentido lateral, robusta y rugosa, que se pierde distalmente en el margen craneal.

La superficie articular para la cabeza de la fíbula posee forma elíptica y se encuentra tanto o más desarrollada caudalmente como el cóndilo lateral; se ubica ventral al cóndilo lateral 
en vista caudal, pero no inmediatamente ventral a éste, sino separada por una amplia superficie, que en vista lateral posee una forma oval. En vista caudal, la diáfisis posee al menos dos crestas diferenciables, y otras rugosidades secundarias. La más lateral es la más marcada, nace en la zona caudal de la diáfisis, a media altura de la cresta tibial, surca todo la diáfisis algo interrumpida, divergiendo lateralmente, y terminando justo sobre la zona articular con la fíbula. Esta cresta es la zona de inserción del m. flexor digitorum lateralis. La segunda cresta es medial a la anterior y pierde definición antes de alcanzar la mitad de la diáfisis, posiblemente sea la zona de inserción del $\mathrm{m}$. popliteus o m. flexor digitorum medialis.

El extremo distal de la tibia es amplio lateromedialmente y cráneocaudalmente, con un gran número de forámenes nutricios en su sector craneal y medial. En vista distal, la superficie articular distal posee forma cuadrangular, con su superficie central incidida por los dos surcos de la cóclea tibial. La depresión correspondiente a la zona de articulación con la cresta medial y aguda de la tróclea del astrágalo es marcada (aunque en menor grado que en el caso de Ly. patagonicus). El segundo de los surcos, en el sector lateral de esta superficie articular (y medial de la superficie articular distal de la fíbula), corresponde a la zona de articulación con la cresta lateral de la tróclea del astrágalo, y se observa como una zona también incidida en similar magnitud a la anterior. En vista caudal, el margen caudal de la superficie articular distal es sinuoso: sobresaliente y agudo en la zona central, y abruptamente escindido en la región lateral. La faceta fibular distal es muy breve y su eje principal es caudomedial-cráneolateral. El maléolo medial es muy robusto y proyectado. En la zona medial y caudal del maléolo medial, medial al surco maleolar tibial, se observa el surco para el pasaje del tendón del m. tibialis caudalis. Este presenta una dirección próximodistal (aunque inclinando hacia craneal en su extremo distal), franqueado por dos crestas delgadas, y se pierde en cercanías de la superficie articular distal.

Fíbula (Lámina 3.17A)

Es un elemento aplanado en el plano cráneomedial-caudolateral y bastante amplio a lo largo de casi toda su extensión; los extremos articulares son moderadamente robustos a robustos. En vista proximal, la articulación de la cabeza de la fíbula tiene forma elíptica, ocupando aproximadamente la mitad del área observada en esta vista, en una posición central. En el sector proximal y laterocraneal, el tubérculo del $\mathrm{m}$. fibularis longus posee una base robusta y su extremo agudo. En el sector mediocaudal se diferencia una zona elevada, coronada por un tubérculo, correspondiente al origen del m. soleus. Justo medial a éste, se diferencia un segundo tubérculo comprimido lateromedialmente, correspondiendo principalmente al origen del m. tibialis caudalis. Bajo este último, se proyecta una cresta bien marcada que se extiende aproximadamente hasta el final del primer cuarto de la diáfisis, en donde converge con una 
segunda cresta de trayectoria más lateral (no muy definida en el espécimen MLP 674), circunscribiendo un área rugosa, que corresponde al origen del m. extensor digiti I longus.

El extremo distal de la fíbula posee su eje principal desarrollado en dirección cráneomedial-caudolateral. El sector más craneal del maléolo lateral posee un desarrollo distal similar al caudal, siendo robusto y proyectado en similar magnitud que el maléolo medial. En vista distal, el sector medial y craneal corresponde a la faceta astragalar de la fíbula, la cual es ovoide, con su extremo distal algo agudo, levemente cóncava, y se dispone casi verticalmente. La faceta tibial es convexa, de forma cuadrangular y su mayor eje se dispone en dirección cráneocaudal. En el extremo laterocaudal distal del maléolo lateral, un tubérculo alargado proximodistalmente de contorno semicircular y muy bien diferenciado separa dos surcos, a su vez son delimitados por dos crestas. El primer surco, zona de tránsito del tendón del m. fibularis longus, posee una posición lateral, es explayado y delimitado en su margen craneal por una pequeña cresta bien definida que finaliza antes de contactar el extremo distal de la fíbula. El segundo surco, el surco maleolar fibular (zona de pasaje de los tendones del m. extensor digitorum lateralis y $\mathrm{m}$. fibularis brevis), posee una posición caudolateral, es más amplio y mejor definido, con su margen caudal delimitado por una cresta moderadamente definida.

Autopodio posterior (Láminas 3.18B, 3.19B)

Los huesos del tarso poseen un fuerte empaquetamiento, con un gran desarrollo de las áreas de agarres musculares. El astrágalo (o talus; Lámina 3.18B) tiene un cuello y cabeza aplanados y ambas estructuras en conjunto poseen un similar desarrollo próximodistal al observado para la tróclea. La tróclea es moderadamente profunda, con un desarrollo cráneocaudal similar y algo mayor al lateromedial. Sus dos crestas están bien definidas a lo largo de toda su extensión, siendo la lateral algo más elevada que la medial. La separación entre las crestas es mínima en el extremo más caudal de la tróclea, para luego alcanzar una separación máxima en el sector medio y más elevado de la tróclea, lo que se mantiene hasta el extremo distal. En vista dorsal, en el sector lateral de la base del cuello se observa una depresión astrágalotibial moderadamente desarrollada. En vista lateral, la carilla maleolar lateral está fuertemente desarrollada, y es semicircular. En vista ventral, tanto la superficie articular proximal como el tubérculo del talus sobresalen caudalmente. La superficie articular proximal es amplia, alargada y delgada, fuertemente cóncava y en su extremo craneal se curva y sobresale lateralmente. La superficie articular medial inclina medialmente, es convexa, ocupando la mayor parte de la superficie central y medial del cuello. En vista distal, la superficie articular para el tarsal central es oval y alargada en sentido lateromedial, con una leve constricción, y angostándose en su extremo medial. Aunque en ningún espécimen se observó la abertura caudal del canal astragalar desarrollada, en MACN 23519 un pequeño foramen, al parecer 
ciego, parece indicar su posición. Entre las superficies articulares hay múltiples forámenes secundarios.

El tubérculo del calcáneo (Lámina 3.18B) es breve y presenta un importante desarrollo en altura. En vista dorsal, se observa que la base es angosta con ambos márgenes cóncavos. El surco del tubérculo del calcáneo (zona de inserción y de pasaje del $\mathrm{m}$. flexor digitorum superficialis) se presenta bien definido y simétrico. El área sustentaculum tali diverge abruptamente respecto a la cara medial del tubérculo, formándose, en vista dorsal, un ángulo mayor y cercano a los $90^{\circ}$ entre ambos. La articulación medial, es cuadrangular a triangular, levemente cóncava, y se encuentra fuertemente expandida en sentido medial en su sector proximal. En vista distal, la articulación medial forma un ángulo menor a $45^{\circ}$ respecto al eje mayor de la articulación para el tarsal IV. La superficie articular proximal para el talus es marcadamente alargada y convexa en dirección cráneocaudal. A lo largo del margen laterodistal de la superficie articular proximal, se extiende un área articular pequeña, convexa, de orientación laterodorsal y en forma de gota, que contacta a la fíbula cuando el tobillo se encuentra flexionado. El proceso troclear, zona de origen del $\mathrm{m}$. quadratus plantae, posee forma de plataforma extendida lateralmente y alcanza ligeramente menos que el margen distal del calcáneo. La superficie articular para el tarsal IV es cuadrangular y sutílmente cóncava.

El tarsal central (Lámina 3.19B) es aplanado en sentido proximodistal, apenas superando la altura del carpal II. En vista medial, la cara articular que contacta al astrágalo no se encuentra elevada en su margen craneal, sin presentarse un tope importante a los movimientos de flexión entre ambos elementos. En el extremo medial del central y tarsal I contactan a un sesamoideo tibial alargado proximodistalmente sobre el cual se inserta el $\mathrm{m}$. tibialis caudalis. Las carillas articulares distales son convexas, reniformes, con el sector que recibe al tarsal III claramente delimitado. Los sectores de articulación con el tarsal I y II son aproximadamente rectangulares. El proceso plantar es una protuberancia poco desarrollada. Los tarsales I, II y III se muestran fuertemente imbricados, con todas sus aristas angulosas. En el tarsal I, la carilla articular para el metatarsal I, que posee forma ovoide y superficie cóncava en vista distal, está fuera del plano transversal, inclinando marcadamente hacia medial. El tarsal II tiene forma de cubo. La zona de contacto con el metatarsal II es triangular a cuadrangular y levemente cóncava. En vista ventral el tarsal II se encuentra obliterado por los tarsales contiguos. El tarsal III posee un proceso plantar amplio y redondeado; posee una carilla articular para el metatarsal III con forma de "L" o "T", cóncava y con una leve constricción central. El tarsal IV posee un desarrollo próximodistal similar al del tarsal III y central juntos. La cara medial del tarsal IV contacta en su primer tercio al central, y en los dos tercios más distales con el tarsal III, ambas en un mismo plano, inclinándose levemente en sentido distal. Las facetas articulares para el tarsal III y central se encuentran separadas por un surco que presenta numerosas foramina. La 
zona centrodistal y el margen distal del tarsal IV se encuentra incidido. Esta zona deprimida se continua hacia dorsal como una pequeña luz entre el tarsal IV y III, y hacia distal como un canal entre el metatarsal III y IV. En vista ventral, el proceso plantar del tarsal IV es robusto. Este se proyecta hacia ventromedial formando una pared proximal al pasaje del tendón del m. fibularis longus. Entre el proceso plantar del central y el tarsal IV se delimita un canal ancho con algunas foramina en la superficie del segundo elemento. En vista lateral, el surco para el tendón del m. fibularis longus se observa como incisura profunda entre el proceso plantar del metatarsal $\mathrm{V}$ y el proceso plantar del tarsal IV, que se continua, en vista plantar, como un surco profundo y angosto, de trayectoria recta y diagonal. La cara distal del tarsal IV articula con el metatarsal IV y $\mathrm{V}$ exclusivamente, y se presenta como dos regiones cóncavas separadas por una cresta, recibiendo en el sector lateral una cresta elevada en el metatarsal $\mathrm{V}$, produciéndose un contacto que tiende a ser de tipo cóclea-tróclea.

Los cinco metatarsales son robustos en un grado moderado y levemente aplanados; los tres centrales poseen un moderado a fuerte empaquetamiento. Todos los metatarsales son levemente convexos en dirección próximodistal y expandidos lateromedialmente en su extremo distal. El metatarsal I se destaca por ser fuertemente plano en comparación con los otros. Los metatarsales III y IV son similares y son los elementos de mayor longitud total (siendo el IV sutílmente mayor que el III). Son seguidos en longitud por el II y V (siendo el V sutílmente mayor que el II). Finalmente, el metatarsal I es el de menor longitud, aproximadamente tres cuartas partes de la longitud del mayor metatarsal. En vista ventral, el proceso plantar del metatarsal I es amplio y robusto. Justo lateral a éste, la base del metatarsal se proyecta lateralmente a modo de una plataforma hasta alcanzar a obliterar la base del metatarsal II en casi todo su ancho; sin contactar al proceso plantar del metatarsal III. Esta plataforma supera, hacia distal, al tubérculo plantar (superando el primer cuarto de la longitud total del metatarsal I). Su margen lateral está engrosado y bien diferenciado. El proceso plantar del metatarsal II es grácil, en posición proximal respecto al del metatarsal I. Los procesos plantares del metatarsal III y IV poseen forma redondeada. El sector proximal del metatarsal IV contacta al V mediante una superficie circular y cóncava, y mediante una superficie convexa al metatarsal III. En la zona central de esta área articular se observa la continuación del surco o canal descripto entre el tarsal III y IV. En vista ventral, el metatarso $\mathrm{V}$ posee un proceso plantar desarrollado proximodistalmente, moderadamente proyectado lateralmente. El sector central del extremo proximal es una superficie cóncava a aplanada, con un margen proximal engrosado, que se encuentra separada del proceso plantar por una breve región deprimida, y hace las veces de pared distal del surco para el tendón del m. fibularis longus. Sobre esta superficie, el metatarsal $\mathrm{V}$ recibe al sesamoideo basal del metatarsal $\mathrm{V}$, que es de moderado desarrollo y circular. Los sesamoideos metatarsales para los dígitos II al $\mathrm{V}$ se encuentran bien desarrollados 
proximodistalmente. En el dígito I, los dos sesamoideos son más pequeños, se encuentran fuertemente empaquetados, y el medial es aproximadamente esférico o con forma de "gota", y más breve que el lateral.

Las falanges proximales presentan una robustez similar a la de los metatarsos correspondientes. Las falanges medias poseen aproximadamente la mitad de la longitud de las proximales, siendo similares a estas últimas en los demás aspectos. En la superficie ventral y distal poseen un par de tubérculos redondeados moderadamente desarrollados (en donde reciben a los flexores superficiales de los dígitos). Tanto la base como cresta ungueal de las falanges ungueales son robustos y prominentes. En vista lateral, el proceso ungueal posee una superficie dorsal convexa en todos los casos, mientras que la superficie ventral es levemente cóncava a plana, reduciéndose en altura de manera progresiva y terminando en un extremo moderadamente agudo. En vista dorsal los procesos ungueales son robustos. Las unguis son elongadas, finalizando en un extremo distal agudo, engrosadas y poco curvadas. 


\subsubsection{Galictis vittata}

Complejo atlas-axis (Láminas 3.1B, 3.2B)

El atlas (Lámina 3.1B) es un elemento alargado lateromedialmente. El foramen vertebral es ovalado a circular tanto en vista craneal como caudal, algo más alto que en Ga. cuja. El tubérculo dorsal y ventral, así como el largo cráneocaudal del arco ventral, se encuentran similar o menos desarrollados en comparación con Ga. cuja. En líneas generales, el margen caudal de las alas del atlas es mayormente recto, variando entre ligeramente convexo a ligeramente cóncavo (e.g., AMNH 35514 lado derecho y AMNH 267055 lado izquierdo, y AMNH 35514 lado izquierdo respectivamente). El margen craneal de las alas del atlas está marcadamente engrosado, delimitando un área deprimida posterior éste (zona de origen del $\mathrm{m}$. obliquus capitis cranialis y caudalis respectivamente).

El axis (Lámina 3.2B) posee un proceso espinoso marcadamente amplio en dirección cráneocaudal (en comparación con los otros lincodontininos analizados), superando ampliamente la extensión del cuerpo vertebral en sentido craneal y caudal; el proceso se acerca al ápice del proceso espinoso de la vértebra posterior. En el espécimen AMNH 35514, el desarrollo ventrodorsal del proceso espinoso en su sector caudal es marcado, dejando libre un espacio mínimo entre éste y el proceso espinoso subsiguiente. En vista lateral, margen dorsal es recto en su sector medio y caudal. El tubérculo caudal está hipertrofiado, al menos en el espécimen USNM 395077. Los procesos transversos divergen ventralmente del plano sagital en más de $40^{\circ}$. En vista lateral el extremo más craneal de los forámenes transversos termina justo a nivel (AMNH 35514) o está tapado (AMNH 267055) por el límite caudal de las carillas articulares craneales.

Tercera a séptima vértebra cervical (Láminas 3.3B)

El proceso espinoso de la tercera vértebra cervical es menor a los demás, con similar o menor tamaño al observado en varios especímenes de Ga. cuja. Los procesos que portan las carillas articulares caudales son similares en forma y posición a los observados en otros lincodontininos, aunque en algunos casos más desarrollados en las cervicales medias, sobresaliendo a modo de tubérculos diferenciados. Los procesos transversos son similares a los observados en Ga. cuja, y en algunos casos ligeramente menos expandidos en sentido caudal cráneocaudalmente. Los tubérculos dorsales de los procesos transversos son similares a Ga. cuja aunque más pedunculados y proyectados, mientras que el de la séptima vértebra cervical, es relativamente más amplio que lo observado en la especie cogenérica.

\section{Vértebras torácicas y caja torácica}


La serie torácica posee 15 elementos, y la vértebra diafragmática corresponde al décimo primer elemento, mientras que la vértebra anticlinal al décimo segundo elemento, como en $G a$. cuja. Los procesos espinosos, especialmente para los elementos postanticlinales, son algo más elevados que en Ga. cuja. Los procesos mamilares presentes en la vértebras anticlinal y posteriores, no alcanzan en ningún la altura de los procesos espinosos. En el espécimen USNM 395077 pudo constatarse que los procesos accesorios se diferencian tempranamente, presentándose con claridad a partir de la última vértebra preanticlinal. La caja torácica no es aquí descripta debido a la falta de materiales adecuados para esto.

\section{Vértebras lumbares (Lámina 3.5B)}

La serie lumbar está compuesta por 5 vértebras (como fue típicamente observado en $G a$. cuja). En el espécimen AMNH 35514, los procesos transversos de la primera vértebra lumbar son triangulares, son mayormente perpendiculares e inclinan levemente en sentido caudal (similar en algunos especímenes de Ga. cuja y ver más adelante Ei. barbara). El desarrollo de procesos transversos de las vértebras lumbares, especialmente en el caso de la tercera y cuarta es, en líneas generales, menor al observado en Ga. cuja. Los procesos transversos del espécimen AMNH 267055 presentan algunos rasgos anómalos (e.g., sobrecrecimientos y fisuras en los márgenes craneales). En vista lateral, la altura de los procesos espinosos es aproximadamente un cuarto mayor que lo observado en Ga. cuja, siendo similares en las demás características. En general, la forma y posición de los procesos mamilares es similar a lo observado en Ga. cuja, siendo la extensión de los procesos transversos de las vértebras lumbares de Ga. vittata, especialmente en el grado de proyección craneal, relativamente menor que lo típicamente observado en Ga. cuja.

\section{Sacro}

Los procesos espinosos del sacro son altos (en similar o menor medida que los lumbares), angostos, de contorno cuadrangular, expandidos cráneocaudalmente en sus ápices y no están fusionados (no se forma una cresta sacra media como generalmente ocurre en Ga. cuja). El segundo de los procesos espinosos es el mayor (AMNH 35514, AMNH 267055), contrario a lo observado en Ga. cuja, excepto MLP 2034 (espécimen que muestra la configuración de Ga. vittata). En vista craneal, el cuerpo vertebral posee forma semicircular, con el margen dorsal aplanado, y sobre éste la apertura del canal vertebral es moderada a pequeña y aplanada; en vista caudal, la apertura es semicircular, posee un tamaño aún menor, y es menos aplanada que lo observado en Ly. patagonicus.

\section{Vértebras caudales}


El espécimen AMNH 35514 presenta los seis primeros elementos de la serie de vértebras caudales, mientras que el espécimen USNM 395077 los 12 primeros de los menos de 19 elementos típicamente presentes para la especie (número menor que el observado en Ga. cuja; Yensen y Tarifa 2003b). Las primeras cuatro vértebras caudales poseen un proceso espinoso diferenciable; en la quinta es rudimentario (en Ga. cuja al menos los cinco primeros están bien desarrollados). La vértebra transicional corresponde al cuarto elemento (uno más que Ga. cuja). La morfología de los procesos transversos de los primeros tres elementos de la serie es muy similar a la de Ga. cuja, pero su reducción, así como la de otras estructuras es mayor. A partir del sexto, y sólo hasta el octavo elemento, los procesos transversos se dividen en una protuberancia mayor en el sector caudal de cada vértebra que corresponde al proceso transverso caudal y craneal, siendo estas reducidas respecto a Ga. cuja.

Escápula (Lámina 3.8B)

La escápula de $G a$. vittata posee características muy similares a las observadas en $G a$. cuja. El proceso subhamatus, menos desarrollado que en otros lincodontininos especialmente en dirección caudodorsal, posee un margen dorsal convexo o recto, no escotado o mínimamente escotado (espécimen USNM 395077) en su base. El proceso coracoides de Ga. vittata es algo más proyectado que el observado en Ga. cuja. En la base del cuello, en posición caudomedial, el área de origen del $\mathrm{m}$. triceps brachii caput longum y secundariamente $\mathrm{m}$. teres minor presenta estrías paralelas.

\section{Húmero (Lámina 3.9B)}

Presenta rasgos principales muy similares a Ga. cuja, aunque es más grácil en su sector medio y proximal. El tubérculo mayor es moderadamente robusto, en general algo menor que Ga. cuja. La línea tricipital y la tuberosidad deltoidea, poseen una diferenciación respecto a la diáfisis menor formando una cresta menos marcada que lo observado en Ga. cuja. La cresta del tubérculo mayor se diferencia sólo como un leve cambio de pendiente, restringida al cuarto proximal del húmero (AMNH 35514) o una cresta grácil algo más extensa (USNM 395077), en algunos casos (AMNH 35514) sin llegar a contactar distalmente la tuberosidad deltoidea. Ni la zona entre ambas crestas ni la cresta deltopectoral se muestran diferenciadas en el grado observado en Ga. cuja. La zona distal del húmero G. vittata no presenta mayores diferencias respecto a Ga. cuja.

La cresta epicondiloidea posee un desarrollo próximodistal elevado en relación a otras estructuras distales. En vista craneal, esta es en general sutílmente más breve que en Ga. cuja ( $s i n$ alcanzar el tercio medio de la diáfisis en esta vista). La tróclea presenta un margen medial pobremente o no inclinado medialmente. En USNM 395077, una fosa similar a la fosa del 
tendón del olécranon se presenta como una depresión relativamente profunda y con márgenes definidos, excepto el proximal, pero con una posición proximal y continuándose con la fosa olecraneana.

\section{Ulna (Lámina 3.10B)}

La morfología general es muy similar a la de Ga. cuja, aunque el elemento es proporcionalmente más elongado en el caso de Ga. vittata. El extremo cráneomedial de la tuberosidad del olécranon (zona de inserción de la cabeza medial del m. triceps brachii) posee un moderado desarrollo medial. El proceso ancóneo posee un desarrollo craneal mucho mayor que el coronoides (excepto en el lado izquierdo de USNM 395077). La cara lateral del proceso ancóneo se encuentra más desarrollada hacia proximal que la medial. El margen extremo lateral de esta zona articular proximal para el radio es aproximadamente recto (especímenes del AMNH), o sobresaliente en forma aguda (USNM 395077). La superficie diartrodial para el radio se eleva en baja medida respecto a la diáfisis ulnar.

\section{Radio}

Elemento muy similar al descripto para $G a$. cuja. La diáfisis proximal presenta un ángulo distal a la articulación con la ulna poco pronunciado.

\section{Autopodio anterior}

La morfología de los elementos del autopodio anterior es similar a la descripta para $G a$. cuja. El sesamoideo radial se encontró ausente en los especímenes revisados.

El carpal accesorio posee su extremo libre marcadamente robusto y elongado proximodistalmente y proyectado caudalmente. Los demás elementos cárpales, metatarsales, y falanges son similares a las descriptas para Ga. cuja.

\section{Hueso coxal (Lámina 3.13B)}

El foramen obturado presenta forma oval, es de tamaño moderado, aunque reducido respecto a $G a$. cuja en relación a la extensión de la tabla isquiática. La superficie sinfisaria posee un desarrollo cráneocaudal similar o algo menor a lo generalmente observado en $G a$. cuja. El ilion (tanto el cuello y el ala) es similar en morfología, aunque más elongado, respecto a Ga. cuja, y el total del complejo isquion-pubis se encuentra menos desarrollado que el ilion en Ga. vittata que en Ga. cuja. El ala del ilion del espécimen AMNH 35514 se muestra algo expandida en su base, debido al mayor desarrollo de la espina dorso-caudal (en relación a la articulación sacro-hueso coxal), pero esto no se observa en otros especímenes (e.g., USNM 395077). 
El cuerpo del isquion es moderadamente robusto y forma un ángulo agudo cercano a los $60^{\circ}$ respecto al cuerpo de pubis (algo menor que en el caso de Ga. cuja). La espina isquiática presenta un desarrollo similar o algo mayor que en Ga. cuja. La tuberosidad isquiática se muestra algo menos engrosada y poco proyectada, diferenciándose de lo observado en Ga. cuja. El cuerpo del pubis es expandido cráneocaudalmente a lo largo de toda su extensión. El margen dorsal presenta dos proyecciones agudas hacia el foramen obturado en dos de los especímenes (AMNH 267055, USNM 395077), pero no fueron observadas en un tercero (AMNH 35514). El pecten pubiano se encuentra mínimamente diferenciado (AMNH 35514) a indiferenciado (AMNH 35514).

Fémur y patela (Lámina 3.14B)

Elemento elongado y adelgazado en su zona media (en comparación con Ga. cuja), principalmente cilíndrico. La cabeza del fémur, proyectada en sentido dorsomedial, se ubica en una posición más dorsal respecto a la gran mayoría de los especímenes de Ga. cuja.

El trocánter mayor se encuentra moderadamente desarrollado en sentido dorsal, como una proyección relativamente aguda y delgada. La cabeza del fémur se encuentra en una posición relativamente elevada respecto al trocánter mayor en comparación con Ga. cuja. La fosa trocantérica es relativamente somera, angosta, y está poco encerrada dorsalmente. En el margen dorsal del cuello femoral, la escotadura dorsal entre la cabeza femoral y el trocánter mayor es variable, desde somera y similar a Ga. cuja, a moderadamente profunda (e.g., USNM 395077).

En la región proximal a la tróclea, un área aplanada se continúa por la superficie craneal de la diáfisis, ocupando el último cuarto.

Tibia (Lámina 3.15B)

Es un hueso que posee una robustez moderada a marcada (algo mayor que Ga. cuja). La curvatura de la diáfisis (concavidad en vista lateral) es baja, mucho menos importante que en Ga. cuja. En vista proximal, la zona laterocraneal (craneal al cóndilo lateral), se muestra proyectada por sobre la zona deprimida y cóncava correspondiente al surco del extensor, aunque en menor grado que Ga. cuja (especialmente en el espécimen AMNH 267055). Aunque sólo pudo ser constatado en USNM 395077, la depresión correspondiente a la zona de articulación con la cresta medial del astrágalo es más marcada que en Ga. cuja. La faceta fibular distal sobresale moderadamente respecto a la diáfisis.

\section{Fíbula}


Las crestas que delimitan el área de origen del $\mathrm{m}$. extensor digiti I longus se extienden distalmente hasta casi el final del primer tercio de la diáfisis. La faceta tibial es mayormente plana.

\section{Autopodio posterior}

La morfología de los elementos del autopodio posterior de $\mathrm{Ga}$. vittata es muy similar a lo descripto para Ga. cuja. El cuello y cabeza del astrágalo presentan en conjunto un desarrollo próximodistal similar o levemente mayor al desarrollo observado para la tróclea (siendo el cuello algo más elongado que en Ga. cuja). El sector lateral de la tróclea y su cresta lateral se encuentran truncados en su sector extremo caudal. El cuello del tubérculo del calcáneo es algo más robusto que en Ga. cuja. El área sustentaculum tali y la articulación medial, presentan una forma similar a la observada en Ga. cuja, aunque son relativamente más amplia. El proceso troclear, zona de origen del m. quadratus plantae, es algo más robusto y extenso que en $G a$. cuja. Debido a la falta de materiales apropiados, no pudo confirmarse la presencia de un canal astragalar, morfología del sesamoideo tibial, canal del $\mathrm{m}$. fibularis longus, y muchas de las articulaciones intratarsales distales e intrametatarsales y algunos rasgos de los metatarsales, todas estas estructuras, de todas formas, similares de a Ga. cuja. En la cara medial del tarsal IV, el área de contacto con el central ocupa algo más que el primer tercio de la vista medial del mismo. Los cinco metatarsales son en su conjunto levemente más breves y menos empaquetados que lo observado en Ga. cuja. El metatarsal I presenta una longitud menor a las tres cuartas partes de la longitud del mayor metatarsal. 


\subsubsection{Lyncodon patagonicus}

Complejo atlas-axis (Láminas 3.1D, 3.2D)

El atlas (Lámina 3.1D) es un elemento más bien grácil y poco extendido en dirección cráneocaudal. El foramen vertebral es ovalado en vista craneal, con su eje principal de dirección mediolateral, mientras que en vista caudal es levemente más desarrollado en sentido dorsoventral (en relación a la interposición de las facetas articulares caudales). Los forámenes vertebrales laterales están poco extendidos cráneocaudalmente en vista dorsal, mientras que internamente se ubican justo dorsal a las superficies articulares craneales. En vista dorsal, el arco neural posee un margen craneal recto a levemente convexo o bilobado. Tanto el tubérculo dorsal como el ventral se encuentran desarrollados (aunque en el espécimen MACN 21982 el tubérculo dorsal es vestigial); el ventral está claramente definido y proyectado ventralmente, o caudalmente sólo en el espécimen CML 0655. En vista ventral, el margen de las superficies articulares craneales y el arco ventral se continúa sin quiebres de pendientes destacables. Las superficies articulares caudales tienen contornos angulosos y se proyectan moderadamente en sentido caudal, sobresaliendo escasamente.

Las alas del atlas poseen morfologías muy variables, en general cuadrangulares, con un desarrollo acotado en sentido cráneocaudal, superando cranealmente al margen caudal del arco neural y sobresaliendo por detrás de los procesos articulares caudales. Para el caso de CML 0655, las alas del atlas son más redondeadas y poco desarrolladas en sentido lateromedial, en comparación con lo observado en los demás especímenes. En vista lateral, las alas del atlas se ubican principalmente en un plano cráneodorsal-caudoventral, inclinando caudalmente en su sector caudomedial, y con el extremo laterocaudal recurvado caudodorsalmente. Estas son marcadamente convexas en vista dorsal. En líneas generales, el margen caudal es levemente cóncavo o cóncavo (en espécimen MACN 21982 y MLP 29.XII.00.17 respectivamente), mientras que el lateral es convexo o recto (en espécimen MACN 21982 y MLP 29.XII.00.17 respectivamente). La morfología de la incisura alar es muy variable. En algunos especímenes (MACN 21852 y MLP 29.XII.00.17, ambos machos adultos), se encuentra claramente definida, como una depresión muy amplia y abierta. En el espécimen CML 0655 (no sexado), se encuentra cerrada en su margen lateral por un puente, convirtiéndose en un foramen alar que se comunica con los forámenes vertebrales mediante una zona deprimida a modo de surco. El margen lateral de puente es sutílmente cóncavo. Los forámenes transversos se muestran desarrollados, abriendo hacia los lados de las superficies articulares caudales.

El axis (Lámina 3.2D) posee un proceso espinoso moderadamente alto (excepto en el caso del espécimen CML 0655) y de escaso desarrollo cráneocaudal, similar al del cuerpo vertebral. El extremo craneal del proceso espinoso sólo se extiende hasta el nivel del margen craneal de las carillas articulares craneales, mientras que el extremo caudal se extiende hasta la 
altura de las carillas articulares caudales o incluso menos. El proceso espinoso se encuentra moderadamente engrosado en sus extremos (e.g. MACN 21982). En vista lateral, posee un margen dorsal recto a levemente cóncavo en su sector medio, y un extremo caudal redondeado y poco proyectado. El proceso odontoides es breve y robusto. El foramen vertebral es más alto que su base. En vista craneal, las carillas articulares craneales se encuentran posicionadas medialmente, continuándose con el proceso odontoides y ubicándose en parte la altura foramen vertebral. Los procesos articulares caudales, y secundariamente los craneales, son robustos (aunque algo menos que en $G a$. cuja). Los procesos articulares caudales son elongados cráneocaudalmente. La incisura vertebral craneal es amplia. La incisura vertebral caudal es aguda y breve. La cresta ventral del cuerpo está claramente definida y posee un tubérculo caudal definido y marcadamente robusto. Los procesos transversos son bastante delgados, incluso en sus bases, posicionados caudalmente diferenciándose en forma abrupta. Divergen del plano sagital y longitudinal algo menos que $45^{\circ}$. En vista lateral alcanzando y cubriendo al extremo craneal del proceso transverso de la tercera vértebra cervical. Los forámenes transversos son elípticos. En vista lateral, no alcanzan al margen caudal de las carillas articulares craneales, y en vista caudal, poseen forma de triángulos escalenos.

\section{Tercera a séptima vértebra cervical (Lámina 3.3D)}

Los procesos espinosos de las vértebras cervicales crecen progresivamente en sentido caudal desde la tercera hasta la séptima. La tercera vértebra cervical posee un proceso espinoso pequeño, delgado y triangular en vista lateral, con una altura menor que su base. La cuarta y quinta vértebra poseen procesos espinosos (y forma general) muy similares entre sí y a la descripta para la tercera vértebra cervical, pero de mayor tamaño. El proceso espinoso de la sexta vértebra cervical, posee una forma aproximada de triángulo equilátero (con su base ocupando toda la extensión cráneocaudal del cuerpo, al igual que en las vértebras anteriores), superando claramente en altura y superficie a las previas. El proceso espinoso de la séptima vértebra cervical supera por más del doble en altura al proceso espinoso de la anterior, y es claramente distinto en lo que respecta a su forma en vista lateral, siendo curvado caudalmente en su sector medio y mediodorsal, con un margen craneal convexo y uno caudal cóncavo, a modo de "ola". Su extremo dorsal es redondeado y engrosado. Con respecto a los arcos neurales, en vista dorsal, se encuentran comprimidos cráneocaudalmente y separados; siendo la relación entre ancho lateromedial y largo cráneocaudal de cada arco neural aproximadamente de tres a dos. Entre vértebras sucesivas (al ensamblarse la serie) abre una luz cráneocaudal de aproximadamente un quinto a un cuarto del desarrollo cráneocaudal del arco neural. Las carillas articulares son alargadas cráneocaudalmente y angostas. Los procesos articulares craneales están moderadamente engrosados a modo de tubérculos ventrales; y prácticamente ausentes en 
las vértebras sexta y séptima. Los procesos que portan las carillas articulares caudales están engrosados a modo de tubérculos dorsales muy desarrollados a lo largo de toda la serie, hipertrofiado desde el axis hasta la quinta vértebra cervical.

En comparación con lo observado en Ga. cuja, en Ly. patagonicus la extensión de los procesos transversos es similar o incluso menor hasta la quinta vértebra cervical, mientras que son amplios en el caso de la sexta. Las láminas ventrales poseen una morfología cuadrangular, de base ancha, levemente constreñidos dorsoventralmente en la zona media y proyectados ventrocranealmente. En el caso de la tercera y cuarta vértebra cervical la lámina ventral supera en extensión al cuerpo vertebral, solapándose con los procesos transversos adyacentes. Para el caso de la quinta vértebra cervical, la lámina ventral posee un similar desarrollo cráneocaudal que el cuerpo vertebral, mientras que en el caso de la sexta vértebra, la lámina ventral posee una morfología muy asimétrica en vista lateral, superando caudalmente, en gran medida, al cuerpo vertebral. Para el caso de la séptima vértebra cervical, se observa una superficie reducida proyectada caudalmente detrás de cada tubérculo dorsal de los procesos transversos, obstruyendo la visión del cuerpo vertebral de esta vértebra, y la articulación con la primera vértebra torácica en vista lateral. Los tubérculos dorsales de los procesos transversos se diferencian tempranamente, en la tercera (espécimen MLP 29.LVII.00.17) o cuarta vértebra (espécimen MACN 21982). Hasta la quinta vértebra cervical se proyectan en sentido caudal a caudodorsal, partiendo de la región caudocentral del proceso alar correspondiente, mientras que en la sexta vértebra, se diferencia en una posición central y son perpendiculares. El tubérculo dorsal de la séptima vértebra cervical es similar en forma, posición y tamaño al de la sexta, con su extremo más desviado en sentido dorsal. En vista ventral, la cresta ventral y el tubérculo ventral de los cuerpos vertebrales poseen un desarrollo moderado desde el axis hasta la cuarta vértebra cervical, y reducidas a ausentes desde la quinta a la séptima.

\section{Vértebras torácicas y caja torácica}

La serie torácica posee, en la mayoría de los casos, 16 elementos (e.g., MLP 29.XII.00.17, MNHN 1897.422, MNHN 1897.570, MACN 21982), aunque en un espécimen se estimaron únicamente 15 elementos (en CML 0655 en función del número de lumbares y considerando la fórmula tóraco-lumbar mamaliana típica de 20 elementos; ver también Koslowsly, 1904). Las crestas ventrales sólo se insinúan en las últimas vértebras torácicas (14 o 15). Las escotaduras craneal y caudal son amplias a lo largo de toda la serie torácica y lumbar (especialmente profundas en las vértebras preanticlinales), excepto en la zona de transición entre ambas regiones. En vista lateral, los procesos espinosos disminuyen progresivamente en altura desde la primera vértebra torácica, con una altura del proceso ligeramente superior a la del resto de la vértebra, hasta su mínima expresión en la décimo segunda, siendo esta última la 
vértebra anticlinal y a su vez la diafragmática. En las primeras vértebras torácicas los procesos espinosos se ubican perpendiculares y poseen márgenes craneales rectos y caudales sinuosos, siendo el extremo distal engrosado. En dirección caudal, los procesos espinosos se solapan progresivamente sobre los cuerpos de las vértebras adyacentes posteriores, presentando márgenes craneales convexos o rectos, y caudales sinuosos o cóncavos. En vista lateral, el desarrollo areal de los procesos espinosos es máximo desde la segunda a la quinta vértebra (aunque no en la magnitud que se observa en Ga. cuja, ver más arriba). La décimo segunda vértebra posee un proceso espinoso simétrico, de margen dorsal recto, bajo en altura, con forma de meseta y una breve extensión cráneocaudal. A partir de ésta, y hasta el último elemento de la serie torácica, los procesos espinosos son levemente más elevados y algo inclinados en sentido craneal, progresivamente más engrosados en su margen dorsal y amplios cráneocaudalmente. Para el ejemplar MACN 21982, los procesos espinosos del elemento 13 y 14 poseen un margen caudal más convexo y una extensión cráneocaudal más breve, respecto a lo observado en MLP 29.XII.00.17.

Las fóveas costales de los procesos transversos son robustas, cóncavas y amplias en las primeras vértebras torácicas, manteniéndose robustas y salientes en todos los elementos preanticlinales, para convertirse en rudimentos o no estar presentes en la vértebra anticlinal y posteriores. En el caso de la primera vértebra torácica, las fóveas se posicionan por detrás de la altura de los procesos articulares craneales, ampliamente separados de estos últimos. En los demás elementos tienden a posicionarse justo por debajo de esta última zona articular. A partir de la vértebra anticlinal, las fóveas costales se ubican exclusivamente sobre el cuerpo vertebral correspondiente (sin incidir además en el precedente). Los procesos mamilares se presentan por primera vez en la serie esbozados en la décimo segunda vértebra para el ejemplar MLP 29.XII.00.17, mientras que en MACN 21982 aparecen por primera vez y claramente definidos en el décimo tercer elemento. En las vértebras posteriores (e incluso hasta los últimos elementos lumbares) poseen un desarrollo similar y relativamente bajo. Los procesos accesorios se presentan con claridad a partir de la vértebra anticlinal en el caso del espécimen MLP 29.XII.00.17, y en la primera vértebra postanticlinal en el espécimen MACN 21982, aunque para el caso del ejemplar MLP 29.XII.00.17 se insinúan incluso en el lado izquierdo de la décimo primera vértebra. Los primeros procesos accesorios inclinan fuertemente en sentido lateral. En el caso del ejemplar MLP 29.XII.00.17, además de la proyección principal del proceso, existe una proyección secundaria apenas diferenciable y de posición más medial. Posteriormente se reducen y pierden.

Toda la caja torácica, y en especial el sector craneal y la abertura craneal, son muy angostas. El esternón diverge en un bajo ángulo respecto del eje de la columna, siendo en la parte media y craneal paralelo a ésta. La sección de la caja torácica se ensancha 
lateromedialmente, alcanzando un máximo desarrollo a la altura de la octava o novena vértebra torácica, mientras su altura llega a un máximo a nivel de la décimo segunda vértebra. El esternón está compuesto de 9 esternebras entre las costillas 1 y 10 . El noveno elemento está muy reducido. El primero de los elementos tiene el doble de longitud que los posteriores y presenta una zona central robusta donde articula el primer par de costillas. El manubrio es aplanado lateromedialmente, redondeado en su ápice craneal y algo inclinado en sentido ventral, con una quilla ventral grácil y poco desarrollada. Los elementos restantes son subiguales y relativamente gráciles, aunque el último de ellos es menor en extensión cráneocaudal. El xifoides es pequeño delgado, y se encuentra parcialmente obliterado por las últimas costillas falsas.

Las costillas son 16 pares (o 15, ver más arriba) de elementos gráciles. Los diez primeros pares de costillas contactan con las esternebras del esternón, mientras que al menos hasta la décimo tercera (en función de los fragmentos de los elementos cartilaginosos preservados en el espécimen MACN 21982 y MNHN 1897.422, y la caja torácica parcialmente preservada de MLP 29.XII.00.17) convergen en un reducido sector y contactan indirectamente vía el décimo par al resto del esternón. La costilla número 16 se encuentra conformada únicamente por un breve cuerpo costal. En el espécimen MACN 21982, el cuerpo de esta costilla es tan largo como el de la anterior, mientras que en el espécimen MLP 29.XII.00.17, se encuentra reducido a una vez y media la longitud cráneocaudal del cuerpo vertebral. En la primera costilla, el cartílago costal se encuentra muy reducido, predominando el cuerpo costal, mientras que en las últimas no flotantes, más de la mitad de la extensión total es cartílago costal. En el sector preanticlinal cada costilla presenta un tubérculo costal, que se pierde en el sector anticlinal y postanticlinal. El quiebre de dirección en la zona del ángulo costal es muy bajo y solo presente en algunas costillas de la zona media de la caja torácica.

\section{Vértebras lumbares (Lámina 3.5D)}

La serie lumbar está compuesta por 5, 4 o 3 vértebras (CML 0655, MACN 21982 y MLP 29.XII.00.17 respectivamente). Observaciones adicionales (MNHN 1897.422 y MNHN 1897.570) indican que cuatro es el número típico (pero ver también Koslowsky 1904, cinco elementos). Las vértebras lumbares son progresivamente más altas y elongadas. En vista dorsal, los cuerpos vertebrales son angostos y alargados, especialmente en el caso de la penúltima lumbar. El desarrollo de procesos espinosos, mamilares y transversos es menor que el observado en Ga. cuja (ver más arriba). En vista ventral se observan crestas ventrolaterales, relacionadas al origen de la musculatura sublumbar, marcadas en los primeros elementos lumbares, presentes pero reducidas y algo lateralizadas en el penúltimo elemento, sin poder ser reconocidas claramente en el último elemento lumbar. 
Los procesos espinosos lumbares poseen forma de meseta, inclinados cranealmente, similar a lo descripto para las últimas vértebras torácicas, y claramente más altos y delgados en las últimas lumbares. La última vértebra lumbar posee un proceso espinoso relativamente reducido cráneocaudalmente. En relación a las facetas articulares, en la zona de la articulación entre el último y penúltimo elemento, poseen un desarrollo lateromedial fuertemente reducido.

En el caso de los especímenes MACN 12982 y CML 0655, la articulación entre la última vértebra lumbar y la zona sacra posee el mayor desarrollo y separación de zonas articulares de la serie, mientras que en el espécimen MLP 29.XII.00.17, la separación es sutílmente mayor, pero el desarrollo lateromedial no es diferente al observado en el penúltimo elemento. Acompañando esta tendencia, entre los procesos articulares se observa una escotadura caudal y dorsal, presente en forma reducida en la mayoría de las vértebras postanticlinales, pero especialmente desarrollada en la última vértebra lumbar para el caso del espécimen MACN 21982 y CML 0655 (no observado para el espécimen MLP 29.XII.00.17). Al igual que en los elementos postdiafragmáticos torácicos, las facetas articulares craneales se apartan respecto al plano longitudinal (típico en las demás vértebras tóraco-lumbares) en sentido dorsal hasta aproximadamente unos $30^{\circ}$ (típico para MACN 21982) a 60 (típico para CML 0655 y MLP 29.XII.00.17), siendo muy variable en los distintos elementos y especímenes estudiados. Las articulaciones entre la primer y segunda lumbar y posteriores del espécimen MACN 21982, y la articulación entre la última lumbar y el sacro del espécimen CML 0655, son claramente más cercanas al plano longitudinal que las precedentes; mientras que en el espécimen MLP 29.XII.00.17, se mantiene hasta el sacro un ángulo cercano a los $45^{\circ}$.

Los procesos mamilares muestran similar desarrollo que el observado en la mayoría de los elementos postanticlinales como ya fue descripto. Por otro lado, los procesos accesorios están reducidos a una pequeña saliencia ya en el segundo elemento lumbar (MACN 21982 y CML 0655), o incluso en el primero (MLP 29.XII.00.17). Al comienzo de la serie lumbar, las escotaduras craneales y caudales se muestran obliteradas por los procesos accesorios, pero esto no ocurre entre la antepenúltima, penúltima y entre la penúltima y última vertebras lumbares, debido a la reducción de estos procesos.

En el caso del espécimen MACN 21982, los procesos transversos del primer elemento lumbar (décimo sexto o más frecuentemente el décimo séptimo elemento tóraco-lumbar) son rudimentarios, craneales, mayormente perpendiculares y terminando en una proyección roma. Los tres pares (eventualmente cuatro) de procesos transversos restantes se encuentran bien desarrollados, expandidos e inclinando por debajo del plano horizontal, con un margen caudal cóncavo o sinuoso, y un margen lateral recto y extendido, ambos separados por un cambio de pendiente abrupto (borde caudolateral anguloso), dándole un aspecto geniculado; el margen craneal es convexo. El margen lateral de los procesos transversos se muestra en vista lateral 
como una superficie plana, expandida ventral y cranealmente, especialmente en el caso de los últimos dos elementos, alcanzando y superando el extremo cráneoventral del cuerpo vertebral correspondiente. Los últimos dos elementos de la serie poseen los procesos transversos más desarrollados y proyectados lateralmente. En el margen caudal de la base de los procesos transversos, especialmente en el caso de los tres últimos elementos, se observan algunas crenulaciones, poco desarrolladas en algunos casos (zona de inserción origen del m. quadratus lumborum y $\mathrm{m}$. iliocostalis).

\section{Sacro}

Está compuesto por dos elementos. En el caso del espécimen MACN 21872 tiene tres, aunque los dos primeros están, en gran medida, fusionados entre sí, se distingue la zona de fusión de los cuerpos vertebrales de estos y los contactos articulares. El tercer elemento del sacro se encuentra parcialmente fusionado a los precedentes en MACN 21982, o no fusionado en lo absoluto en la mayoría de los especímenes, pudiendo considerarse a éste como un elemento caudal. Sin embargo, hecha esta salvedad, estos son descriptos aquí en conjunto a fines comparativos. Posee una forma cónica aplastada debido a que el primer elemento es notablemente más alto y ancho que el último.

Los procesos espinosos sacros no se fusionan en una única cresta sacra media. Estos se reducen en tamaño progresivamente, siendo el último apenas una saliencia. La superficie articular sacro-ilion tiene forma elíptica. En vista lateral, no se extiende en gran medida por debajo del margen ventral de los cuerpos vertebrales. Los procesos transversos de la segunda y última sacra/primer caudal, en general no fusionados a los de la precedente, poseen forma subrectangular y se proyectan inclinados por arriba del plano horizontal. Los primeros forámenes sacros son circulares, mientras que los segundos se encuentran sólo parcialmente delimitados en relación a la ausencia de fusión total de los últimos procesos transversos sacros. Los procesos articulares caudales son prácticamente horizontales. En vista craneal, el cuerpo vertebral posee forma semicircular y aplanada, y la apertura del canal sacro es moderada a pequeña y aplanada. En vista caudal, posee un tamaño aun menor.

\section{Vértebras caudales (Lámina 3.7C)}

Además del tercer elemento sacro-caudal (a veces fusionado al sacro y muchas otras veces no, y no considerado en los conteos de este apartado por haberse descripto en el sacro), en el espécimen MACN 21982 se conservan otras 7 primeras vértebras caudales, mientras que en el espécimen MLP 29.XII.00.17 al parecer se preserva la gran mayoría de los elementos (una 12 vértebras), quizás faltando el tercer elemento, y quizás también el cuarto, siendo la serie marcadamente reducida tanto en número de elementos como en la longitud de los mismos (17 
elementos sensu Koslowsky 1904). Las vértebras preservadas son relativamente pequeñas y gráciles, y los procesos sobre ellas se reducen rápidamente en los elementos más posteriores.

Los cuerpos vertebrales de los primeros elementos son muy similares al último elemento del sacro; gradualmente se vuelven cilíndricos. Ninguno de las vértebras caudales posee un proceso espinoso diferenciable, pero existe frecuentemente una rugosidad representándolo en el primer elemento. Los cuerpos de las vértebras caudales son breves, siendo en todos los casos menos largos que el triple o cuádruple de su ancho. Los procesos y las carillas articulares craneales y caudales son distinguibles sólo en los primeros dos elementos. En vista dorsal, las escotaduras craneales y dorsales de las primeras vértebras caudales están marcadas, profundizándose en las primeras tres hasta la zona media del cuerpo vertebral (similar a Galictis spp. pero distinto a otros mustélidos descriptos), y llegando a socavar totalmente el arco neural en algunas vértebras caudales: Ca2 en MNHN 1897.423 (considerando dos elementos sacros) y MACN 21982 (considerando 3 elementos sacros), Ca3 y aparentemente Ca2 en MLP 29.XII.00.17 (considerando 2 elementos sacros). Esta condición es un rasgo único de Ly. patagonicus. En vista lateral, la escotadura caudal de las vértebras caudales se encuentra presente en los tres primeros elementos. La vértebra transicional se encuentra presente en el segundo (MLP 29.XII.00.17) o tercer elemento caudal (restantes especímenes). Las carillas articulares caudales se encuentran presentes hasta el tercer o cuarto elemento, mientras que a partir del estos, el arco neural y el cuerpo se fusionan, y las carillas articulares caudales no se distinguen, ni ninguna estructura o prominencia en su lugar.

Los procesos mamilares se diferencian bien hasta el sexto elemento caudal. Los procesos transversos de los primeros tres elementos caudales nacen desde el sector medio y caudal del cuerpo, y tienen un margen distal o lateral truncado. Estos procesos transversos nacen perpendiculares a levemente inclinados en sentido dorsal. A partir del cuarto elemento los procesos transversos son más redondeados, y rápida y progresivamente reducidos en tamaño. A partir del sexto elemento, sólo se diferencian las porciones caudales de los procesos transversos (procesos transversos caudales). Se detectó la quilla en la cara lateral de algunas vértebras (en general en la quinta o sexta vértebra caudal). A partir de la cuarta vértebra caudal, se desarrollan protuberancias cráneoventrales para los procesos hemales, muy robustas en el quinto elemento.

\section{Escápula (Lámina 3.8D)}

La escápula posee una forma trapezoidal o irregular, con un ángulo caudal recto a levemente agudo y marcado, un ángulo craneal cercano a los $130^{\circ}$ y redondeado, y dos ángulos de similar amplitud sobre el margen craneal, el más dorsal produce un quiebre abrupto en el margen craneal, y el más ventral haciendo las veces de límite entre el margen craneal y una escotadura escapular expandida (de mayor desarrollo que el margen dorsal) y amplia 
(característica acentuada en el espécimen MLP 29.XII.00.17). En vista medial, la escápula es aplana, levemente cóncava en cercanías al margen dorsal y craneal. Todo el margen caudal de la escápula se muestra plegado, encerrando parcialmente la región infraespinosa. La espina es grácil, recta, bien definida y elevada a lo largo de toda su extensión, delimitando una fosa supraespinosa con un área que duplica a la infraespinosa. Justo bajo el ángulo caudal, se define un área triangular a cuadrangular, algo reflecta hacia medial donde se origina el $\mathrm{m}$. teres major y $\mathrm{m}$. triceps brachii caput laterale, sin un margen neto que la separe de la fosa infraespinosa.

El acromion se desarrolla abruptamente a partir de la espina, originándose a la altura del ángulo craneal. En dicha región, se observa en vista craneal un ángulo de aproximadamente $90^{\circ}$ entre éste y la espina, desarrollándose algunas crenulaciones en este margen. Distalmente existe una escotadura profunda entre el acromion y el cuello de la escapula y la zona articular. El proceso hamatus es muy agudo y se proyecta paralelo a la espina en vista lateral, y paralelo al plano de la escápula en vista caudal, alcanzando y sobrepasando brevemente el margen caudal de la cavidad glenoidea. El proceso subhamatus es amplio, sobrepasando el margen caudal de la escápula, con un margen ventral cóncavo, y uno caudodorsal convexo, teniendo la forma de un abanico en vista lateral, y marcadamente escotado en su base dorsal. En vista distal, la cavidad glenoidea posee forma de gota u ovoide, con un tubérculo supraglenoideo robusto, y un proceso coracoides grácil. En vista medial, se observa que la zona articular se encuentra muy proyectada en sentido ventral y craneal en la zona craneal, y el cuello de la escápula está algo menos desarrollado cráneocaudalmente que la zona articular. A lo largo de todo el cuello, en posición caudomedial, las áreas de origen del $\mathrm{m}$. triceps brachii caput longum y posiblemente el $\mathrm{m}$. teres minor se presentan como estrías paralelas.

\section{Húmero (Lámina 3.9D)}

El húmero es grácil, con la diáfisis recta en vista lateral. En vista caudal, ésta es mínimamente cóncava en la zona extrema proximal (observado en ejemplar MLP 29.XII.00.17) o claramente cóncava (observado en el ejemplar CML 0655). En vista proximal, la cabeza articular es redondeada y proporcionada, con similar desarrollo cráneocaudal y lateromedial, mientras que en vista craneal, es igualada en altura por el tubérculo mayor. Este último es delgado y elevado, separado del tubérculo menor mediante una surco intertubercular estrecho, el cual da paso a una zona deprimida también estrecha pero más profunda entre el cóndilo y el tubérculo mayor. En vista lateral, en el sector más caudal del tubérculo mayor, se destaca una zona deprimida equiproporcionada donde se inserta el $\mathrm{m}$. infraspinatus. El área de inserción del m. teres minor es mínima (aparentemente en el espécimen CML 0655) o indiferenciada.

La tuberosidad deltoidea se diferencia de la diáfisis en similar medida o algo más aun que la línea tricipital. La línea tricipital posee un desarrollo más sutil y continuo en la zona 
proximal de la diáfisis humeral y específicamente en la zona del cuello, terminado e interceptando proximalmente a la zona proximal de origen del $\mathrm{m}$. triceps brachii caput laterale. La cresta del tubérculo mayor se diferencia moderada a sutílmente en la zona proximomedial de la diáfisis, fusionándose con la cresta deltoidea en la zona del primer tercio del húmero, y a veces formando una levemente insinuada cresta deltopectoral (más claramente observado en ejemplar MLP 29.XII.00.17), pero que se pierde totalmente antes de alcanzar la segunda mitad del húmero. El tubérculo menor es delgado, desarrollado en dirección craneoproximalcaudodistal, y orientando en sentido medial. Está poco diferenciado del cóndilo.

En la zona distal, ambos epicóndilos poseen un desarrollo lateromedial moderado, y un escaso engrosamiento cráneocaudal. El epicóndilo medial posee a su vez un importante desarrollo distal, alcanzando la altura del margen distal medial de la tróclea y el proximal, debido al desarrollo de la zona de origen de músculos flexores carpales y digitales (e.g. m. flexor carpi radialis y m. flexor carpi ulnaris). El foramen supracondiloideo, de moderado desarrollo y forma oblonga, se encuentra en una posición netamente proximal respecto a la zona articular. En vista caudal, su apertura es similar a la observad en vista craneal. El puente o margen medial del mismo es extremadamente delgado, especialmente en su zona media. La cresta epicondiloidea posee un desarrollo próximodistal moderado a bajo, y un muy bajo desarrollo lateromedial a lo largo de toda su extensión. La tróclea muestra gran desarrollo próximodistal, pero escaso desarrollo lateromedial en relación al capítulo, con un margen medial principalmente desarrollado en dirección próximodistal, y con una profundización moderada. El capítulo posee forma cilíndrica, con un margen lateral mínimamente engrosado y redondeado distalmente. Las fosas coronoidea y radial se encuentran poco diferenciadas entre sí y respecto a la diáfisis distal; y en todos los casos no están perforada. En vista caudal, la zona articular posee un margen medial escasa a moderadamente marcado, mientras que el margen lateral posee un límite marcado y bien definido. La fosa olecraneana es amplia, de bajo desarrollo proximal, de profundidad importante y los márgenes lateral, proximal y medial definidos, con el margen proximal netamente definido. La fosa para el tendón del olécranon es muy somera, cuadrangular, apenas diferenciable como un cambio de pendiente respecto a la superficie caudal del cóndilo medial, con márgenes lateral y medial suaves y redondeados, apenas incidiendo mínimamente en sentido laterodistal sobre la zona articular en su extremo medial. Entre la fosa olecraneana y la fosa para el tendón del olécranon, existe un leve cambio de pendiente, siendo la primera más profunda que la segunda.

\section{Ulna (Lámina 3.10D)}

Es recta, a muy levemente curvada en sentido medial, aunque en su sector más distal posee un importante cambio de dirección, desviándose lateralmente. En vista lateral, está 
desarrollada cráneocaudalmente tanto en el olécranon como en cercanías a la zona de la incisura troclear, pero disminuye continuamente hasta hacerse muy delgada justo antes del extremo distal. El olécranon se encuentra muy desarrollado en sentido cráneocaudal y próximodistal, inclinando en sentido medial. La región cráneomedial de la tuberosidad del olécranon posee un desarrollo variable hacia medial en los distintos especímenes estudiados (bajo en el caso de MLP 29.XII.00.17 y pronunciado en el caso de MACN 21982), pero en todos los casos el sector es aplanado y no se encuentra robustecido. La zona caudal de la tuberosidad del olécranon posee un gran desarrollo medial. Tanto el margen craneal, caudal como proximal del olécranon son ligeramente cóncavos. En la cara medial de olécranon, un pequeño tubérculo o muesca sobresale en cercanías al margen craneal. La incisura troclear es moderadamente profunda (ejemplar MACN 21982) o muy profunda (ejemplar MLP 29.XII.00.17), encontrándose la diáfisis adelgazada en gran medida en sentido cráneocaudal en dicho sector para el segundo caso. El proceso ancóneo es más bien simétrico, y posee un similar desarrollo craneal que el coronoides. La incisura radial posee forma de medialuna o medio óvalo, y su eje mayor se orienta a unos $45^{\circ}$ del plano definido por la diáfisis de la ulna, articulando el radio en una posición diagonal respecto de ésta. Esta carilla articular se proyecta lateralmente como una arista aguda. La tuberosidad ulnar se presenta como una muesca o pequeña cresta de sentido próximodistal en el sector cráneomedial de la diáfisis.

En la zona proximomedial de la diáfisis, se presenta con cierta claridad la concavidad próximodistal correspondiente al pasaje de los flexores digitales (m. flexor carpi ulnaris y $\mathrm{m}$. digitorum profundus). En la zona distomedial (a la altura del límite entre el tercer y cuarto quinto de la diáfisis), y en una posición cráneolateral, se evidencia una cresta puntual correspondiente al ligamento interóseo (correspondiéndose a una similar en la cara caudolateral del radio). El área aplanada correspondiente al origen del $\mathrm{m}$. pronator quadratus, ocupa sólo el quinto distal de la diáfisis. En el extremo distal, el proceso estiloides se encuentra desarrollado cráneocaudalmente, aunque es delgado en sentido lateromedial. Su superficie articular posee forma cuadrangular a oval y alargada. La superficie diartrodial para el radio posee una posición cráneomedial y se encuentra poco desarrollada, moderadamente a pobremente elevada e inclinada en sentido craneal.

\section{Radio (Lámina 3.11C)}

Es corto en relación al húmero (aproximadamente dos tercios el largo del mismo), delgado y comprimido mediolateralmente, convexo en su extremo distal en vista craneal y lateral. La carilla articular proximal, posee una forma cuadrangular o arriñonada, con una leve escotadura en su sector cráneolateral (coincidiendo con la mayor elevación del extremo lateral del capítulo del húmero), más desarrollada en su sector medial respecto al lateral. En la zona 
lateral de la epífisis proximal se diferencia un tubérculo de moderada elevación que representa la inserción del ligamento colateral del codo).

La diáfisis proximal muestra un cambio abrupto en la dirección del eje principal, formando un ángulo de dirección caudal, distal a la articulación con la ulna. En la cara caudomedial de la diáfisis cercana a ésta epífisis se presenta la tuberosidad radial (zona de inserción de ligamentos y de inserción del $\mathrm{m}$. biceps brachii) como un área aplanada y rugosa, limitada caudalmente por una cresta prominente y breve. En la zona media de la diáfisis, en vista caudolateral, se presenta una muesca claramente definida en forma de cresta correspondiente al ligamento interóseo, que presenta poco desarrollo próximodistal. A lo largo de toda la cara caudal del sector medial y distal de la diáfisis, se presenta una cresta aguda amplia correspondiente a la zona de inserción del m. abductor digiti I longus (en la cara lateral) y cabeza radial del flexor digitorum profundus (en la cara medial). A lo largo del tercer cuarto de la diáfisis radial, se observa una cresta craneal correspondientes al m. pronator teres. En vista ventral, el extremo distal del radio presenta una superficie articular carpal cóncava y triangular, cuyo eje principal posee dirección cráneomedial-caudolateral, y orientada principalmente en sentido posterodistal, debido a la fuerte curvatura del extremo distal de la diáfisis radial. En vista medial, el surco para el pasaje del $\mathrm{m}$. abductor digiti I longus está bien marcado y se ubica inmediatamente proximal al proceso estiloides. Este surco posee una orientación principalmente lateroproximal-mediodistal, acercándose a la perpendicular de la diáfisis radial, aunque con un breve desarrollo en este sentido, poseyendo márgenes definidos, especialmente el proximal. El tubérculo de inserción del m. brachioradialis es agudo. El proceso estiloides está poco proyectado hacia distal. La escotadura ulnar, en el margen laterocaudal del extremo distal del radio, es aproximadamente triangular (con su base en una posición distal) y levemente cóncava, aunque se encuentra poco diferenciada, siendo difícil identificar los márgenes de la misma. Justo craneal a la escotadura ulnar, el surco para el pasaje del m. extensor digiti I et II tiene dirección próximodistal; está delimitado dorsalmente por un tubérculo cráneolateral agudo y proyectado lateralmente.

Autopodio anterior (Lámina 3.12B)

La serie carpal se encuentra fuertemente empaquetada; es convexa en vista dorsal y cóncava en vista plantar. El carpal radial y el ulnar son huesos más bien aplanados, con un desarrollo próximodistal breve, especialmente en vista craneal. En vista craneal, el radial presenta un desarrollo lateromedial cercano al doble del observado en el ulnar. La carilla articular para el radio del radial se extiende lateralmente tanto como a la altura de la mitad del cuarto metacarpo, y es sólo convexa en sentido cráneocaudal. En vista craneal, la zona de articulación entre el radial y ulnar posee una mínima extensión próximodistal, vinculado al 
importante desarrollo del cuarto carpal, inmediatamente distal a dicho contacto (ver más adelante). En su extremo medioventral, el radial contacta al sesamoideo radial mediante una carilla convexa. En vista caudal el sector medial del radial, se proyecta caudalmente a modo de un tubérculo de breve desarrollo próximodistal. Distalmente, el radial articula con los cuatro carpales distales por medio de una serie de bandas cóncavas y convexas. El sesamoideo radial es aplanado (e.g., MACN 21982) y desarrollado en sentido ventral (de un tamaño relativo algo mayor que Ga. cuja). El ulnar es un hueso cuadrangular y aplanado en sentido próximodistal. La mitad caudal de su cara proximal es una superficie articular aplanada y triangular, que contacta al carpal accesorio, mientras que la mitad craneal es aplanada en el plano transverso y levemente cóncava en el plano cráneocaudal, delimitada en el sector cráneolateral por un margen algo elevado. La separación entre ambas superficies se denota como un cambio de pendiente. La cara laterodistal del ulnar es alargada cráneocaudalmente (aunque en menor medida que lo observado en Ga. cuja), plana y contacta al quinto metacarpal. El carpal accesorio posee su extremo libre moderadamente robusto, desarrollado proximodistalmente y dirigido caudalmente. La articulación con el ulnar es triangular a cuadrangular y principalmente plana, aguda en su sector dorsal. En vista dorsal, en el sector craneal el carpal accesorio presenta una región articular triangular y cóncava, que junto con la superficie correspondiente y adyacente del ulnar, recibe a la ulna. Entre esta superficie y el extremo caudal libre el carpal accesorio se muestra fuertemente adelgazado tanto lateromedial como proximodistalmente.

Los carpales distales se contactan entre ellos por zonas de articulación aplanas, a excepción del segundo y el tercero, en donde dicho contacto es convexo-cóncavo, sin formarse superficialmente un contacto en forma "L", debido a que la porción más elevada del tercer carpal se encuentra cubierta por el radial (distinto a lo observado en Ga. cuja). El carpal I, en vista craneal, posee una importante extensión distal a modo de una cuña entre los metacarpales I y II que se extiende distalmente tanto como la base del metatarsal I. En vista caudal, existe un tubérculo rudimentario justo proximal y lateral al tubérculo plantar del metatacarpal I. El carpal II, en vista craneal, posee una superficie no articular cuadrangular a triangular, aplanado en sentido proximodistal. La arista más lateral se proyecta fuertemente, resultando rodeada por la cara medial del carpal III. El carpal III es un hueso con forma muy irregular alargado proximodistalmente y cráneocaudalmente. En vista craneal (luego de retirar al radial) posee forma de "L": el sector caudolateral de la superficie proximal se proyecta proximalmente, articulando con el surco central y caudal del radial, aunque esta superficie no se extiende en gran medida sobre el plano craneal del carpal. La cara lateral del carpal III se eleva alcanzando aproximadamente la altura del carpal IV, aumentando el área de contacto con este último, siendo este área de contacto semicircular y aplanada. En vista craneal, cubierta en su tercio proximal por el radial. En vista caudal, el tubérculo plantar del carpal III se encuentra bien 
desarrollado como un área plana y algo proyectada medialmente. En vista craneal, el carpal IV duplica en desarrollo areal de cualquiera de los demás cárpales distales; presenta una morfología similar a un triángulo de vértices romas, proyectado en sentido proximal y lateral. Es levemente más alto que el carpal III. El área de contacto con el carpal III ocupa toda la vista medial, exceptuando un breve sector proximal que corresponde al área de contacto con el radial. No se diferencia el tubérculo palmar. La cara lateral de carpal IV, articula con el ulnar y es levemente convexa y triangular. En vista craneal, el contacto radial-carpal IV es mucho menor a $45^{\circ}$, más bien cercano al plano horizontal, mientras que el contacto ulnar-carpal IV se aparta $45^{\circ}$ de este plano.

Los dígitos periféricos se encuentran reducidos respecto a los centrales. Tanto los metacarpales como las falanges se muestran robustas (en similar o menor grado que Ga. cuja). Los metacarpos de menor longitud, el I y el V, son cercanos a la mitad del de mayor longitud (III; el $\mathrm{V}$ es aproximadamente la mitad del III), mientras que la longitud de las falanges proximales de los dígitos I y $\mathrm{V}$, son de aproximadamente dos tercios de la longitud observada en las correspondientes a los restantes dígitos. Los metacarpales son rectos a levemente convexos en vista dorsal. El metacarpal V articula con un pequeño hueso sesamoideo metacarpal circular en el principio de su cara plantar. El metacarpal III es el más elongado, seguido por el IV, y seguidos por el II, V y I. Proximalmente, todos los metacarpales poseen bases definidas y expandidas caudalmente, especialmente en el caso del metacarpal V (en relación a la inserción del $\mathrm{m}$. fibularis brevis y $\mathrm{m}$. extensor digitorum lateralis). Los sesamoideos metacarpales son elongados para los metacarpales II, III, IV y V; mientras que en el metacarpal I, el hueso sesamoideo medial se muestra algo reducido. Las falanges proximales y medias son elongadas y gráciles, con zonas articulares y de inserciones tendinosas poco robustas. Las falanges de los dígitos II al $\mathrm{V}$ presentan aproximadamente una longitud equivalente a dos tercios de la longitud de sus metacarpales. Las falanges proximales de los dígitos I y $\mathrm{V}$ son mucho más grácil y rectas. En algunos especímenes la falange proximal del dígito I es más grácil y se curva lateralmente, siendo en general de similar longitud a las demás falanges proximales. Las falanges ungueales poseen cresta ungueales poco marcadas y procesos homónimos bien desarrollados, con márgenes ventrales levemente cóncavos en su sector proximal, o a veces netamente rectos: el margen dorsal es levemente curvo en su sector distal. Las unguis son muy elongadas y agudas, curvadas y engrosadas, aumentando grandemente la extensión distal de las falanges ungueales.

\section{Hueso coxal (Lámina 3.13D)}

El hueso coxal es un elemento bastante plano, dado que el ilion define un plano sólo unos $45^{\circ}$ respecto del definido por isquion y pubis (y menor que el resto de los mustélidos comparados, ver más adelante). El acetábulo, de tamaño moderado, posee el margen dorsal del 
borde acetabular algo aplanado y una prominencia en el margen craneal; abre en sentido lateral con una leve inclinación caudal. La incisura acetabular posee un desarrollo moderado en su sector caudal y bajo en su sector ventral, continuándose en este último sector con el margen acetabular. Su extensión total es de aproximadamente un cuarto de la circunferencia total. El foramen obturador es de forma oval, con una pequeña constricción en el extremo más craneal, cercano al acetábulo. La superficie sinfisaria posee un desarrollo moderado (abreviado en sentido cráneocaudal en comparación con Ga. cuja), y está engrosada en su sector medio.

El ala del ilion posee forma rectangular, aplanada y robusta; algunas veces superando las articulaciones craneales del sacro (e.g. CML 0655), aunque esto no ocurre en otros especímenes (e.g., MACN 21982). El cuello es angosto y de sección elíptica. La espina ilíaca ventro-craneal muestra un bajo desarrollo, mientras que la dorso-craneal está desarrollada. La espina dorso-caudal se encuentra muy desarrollada, mientras que la ventro-caudal posee un desarrollo variable (sólo se encuentra fuertemente desarrollada en el elemento izquierdo de MLP 29.XII.00.17). La cresta ilíaca es recta a levemente convexa. Tanto la tuberosidad sacra y coxal, así como la cresta ilíaca son delgadas o poco engrosadas. La escotadura ciática mayor se encuentra profundizada en su sector mediocraneal debido al desarrollo de la espina dorsocaudal, y es alargada en dirección cráneocaudal. La superficie articular del ilion se encuentra desarrollada y posee una forma angulosa y bien definida. En la cara lateral del cuello del ilion, apenas se diferencian la línea glútea caudal y el tubérculo del músculo m. rectus femoris.

$\mathrm{El}$ isquion posee un cuerpo moderadamente robusto, formando un ángulo cercano a los $70^{\circ}$ respecto al cuerpo del pubis y abierto (cercano a los $130^{\circ}$ ) respecto a la rama del isquion, la cual es aplanada y algo adelgazada cráneocaudalmente en su sector medioventral. La espina isquiática es un pequeño tubérculo agudo posicionado muy cranealmente, justo a la altura del sector más caudal del margen acetabular. Caudalmente se continúa por la escotadura ciática menor, que se muestra como un margen cóncavo, rugoso y moderadamente engrosado. La arcada isquiática se diferencia del resto del margen caudal del isquion en parte debido al moderado desarrollo caudal de la tabla del isquion. La tuberosidad isquiática se muestra como una zona engrosada, proyectada en sentido lateral y dorsal, aunque aguzándose en su sector caudal.

El cuerpo del pubis es alargado dorsoventralmente, recto, cuadrangular, y muy aplanado y delgado lateromedialmente; presenta una eminencia ilio-pubiana prácticamente indiferenciada a indiferenciada, al igual que su continuación por medio de la línea arqueada. La posición de la misma es ventral al margen craneal de la zona articular. El cuerpo se curva levemente hacia medial en su extremo distal. El pecten pubiano apenas se diferencia del resto del margen cráneoventral como un robustecimiento somero del mismo, sin proyectarse a modo de 
tubérculo. La rama caudal del pubis y es también rectangular y aplanada, manteniendo una altura similar a lo largo de toda la superficie sinfisaria.

Fémur y patela (Lámina 3.14D)

El fémur es delgado, principalmente cilíndrico, y más bien reducido en longitud; principalmente recto, aunque con una leve curvatura lateral en la zona media de la diáfisis. La cabeza del fémur se muestra muy proyectada en sentido medial, en relación a un gran desarrollo del cuello del fémur en este sentido y se encuentra orientada fuertemente en sentido dorsal y craneal. En vista medial, la fóvea se encuentra en el centro de la cabeza, levemente desplazada en sentido caudal y ventral. El trocánter mayor se encuentra desarrollado como una proyección aguda que se eleva por sobre el cuello, pero sin sobrepasar en altura a la cabeza articular e inclinado medial y cranealmente (inclinación acentuada en MACN 21982). La fosa trocantérica es profunda, pero posee un escaso desarrollo dorsoventral, alcanzando la base la altura de la base de la cabeza articular. En el margen dorsal del cuello femoral, entre el trocánter mayor y la cabeza femoral, la escotadura dorsal entre la cabeza femoral y el trocánter mayor es somera, en relación al robustecimiento del margen medial del trocánter menor. El trocánter menor se muestra bien desarrollado y en una posición más bien proximal y claramente orientado en sentido caudomedial (con una inclinación medial más marcada que en Galictis spp.). La tuberosidad glútea se encuentra moderada a marcadamente desarrollada como un área aplanada amplia y cuadrangular que ocupa toda la cara lateral del trocánter mayor, superando distalmente el nivel del trocánter menor. El margen craneal de la misma se encuentra bien definido y sobresaliente a modo de cresta en toda su extensión. Distalmente se continúa un breve tramo como una línea rugosa.

En el extremo distal, la tróclea femoral se encuentra bien delimitada por los labios medial y lateral, terminando abruptamente en su sector craneoproximal, justo a la altura de las carillas articulares para los huesos sesamoideos supracondiloideos (i.e., terminación proximal y caudal de los cóndilos articulares). En vista lateral y medial, los labios de la tróclea se continúan con el inicio de los cóndilos articulares, dando un aspecto semicircular al extremo distal femoral (i.e. poseyendo un similar desarrollo hacia proximal tanto los labios de la tróclea como los cóndilos articulares). En la región proximal a la tróclea, un área aplanada con forma de cuña se continúa por la superficie craneal de la diáfisis, ocupando el último cuarto. En vista distal, ambos epicóndilos poseen un similar desarrollo lateromedial, mientras que los cóndilos se proyectan moderadamente en sentido caudal, el medial en mayor medida que el lateral. Debido a estas características, en vista distal el fémur posee un similar desarrollo cráneocaudal que lateromedial, o levemente mayor lateromedialmente. En esta vista, el desarrollo cráneocaudal de la tróclea es claramente mayor al de los cóndilos. Sobre el epicóndilo lateral, la fosa del 
extensor es poco profunda y parcialmente diferenciable de la fosa de origen del $\mathrm{m}$. popliteus. La fosa de origen del m. popliteus se encuentra algo más profundizada. En la región caudal de ambos epicóndilos, las fosas correspondientes a las inserciones de los ligamentos colaterales se encuentran poco definidas. La fosa intercondiloidea es bastante amplia en sentido lateromedial. En vista caudal no se encuentran presente ni la tuberosidad supracondiloidea lateral ni la medial, pero en el lugar de la primera transcurre una suave y breve cresta en sentido próximodistal (esto último observado únicamente en el espécimen MACN 21982).La carilla lateral correspondiente al sesamoideo supracondiloideo lateral se encuentra moderadamente desarrollada y profundizada. La patela se encuentra bastante desarrollada, con su base robustecida, elevándose en gran medida por sobre la tróclea en vista lateral, siendo su ápice algo más agudo que la base.

Tibia (Láminas 3.15D, 3.16C, 3.17C)

En forma general, es un elemento relativamente menos robusto en comparación con $G a$. cuja, algo aplanado mediolateralmente en su sector medioproximal, y curvado en sentido lateral y caudal en su zona media, mientras que su extremo distal es más bien recto y robusto. En vista proximal (Lámina 3.15D), el cóndilo lateral es aproximadamente circular, con la zona caudolateral expandida y un desarrollo mediolateral mayor que el medial. El cóndilo medial posee forma arriñonada, con su mayor eje en sentido cráneocaudal, superando caudalmente al cóndilo lateral. Ambos cóndilos son levemente convexos; encontrándose el lateral en un plano más elevado que el medial. En vista proximal, la zona intercondiloidea craneal tiene un desarrollo acotado en sentido cráneocaudal, perforada por múltiples foramina, terminando en una tuberosidad poco sobresaliente cranealmente y de moderado desarrollo lateralmente. La zona laterocraneal (craneal al cóndilo lateral), se muestra como un margen convexo desarrollado en forma homogénea, sin delimitarse claramente la depresión correspondiente al surco del extensor. La eminencia intercondiloidea se muestra moderada a marcadamente desarrollada. Tanto el área intercondiloidea craneal como caudal, como los márgenes laterales y mediales de la epífisis proximal de la tibia, muestran rugosidades sutiles. En vista caudal, bajo el cóndilo medial, se observa un tubérculo correspondiente a la superficie de inserción del ligamento cruciano caudal.

En vista lateral, la fosa tibial se muestra como una superficie principalmente cóncava que ocupa la mayor parte de la primera mitad de la diáfisis tibial, delimitada en su margen craneal por una cresta tibial recta y levemente reflecta hacia lateral, robusta y rugosa (con dos tubérculos definidos, uno distal y uno a altura media). La superficie articular para la cabeza de la fíbula posee forma elíptica y se encuentra tanto o más desarrollada caudalmente como el cóndilo lateral. Se encuentra inmediatamente ventral al cóndilo lateral en su sector más caudal. Posee forma triangular a cuadrangular, siendo más amplia en su margen caudal. En las vistas 
caudal y lateral la superficie entre el cóndilo y la superficie articular para la cabeza de la fíbula posee una forma de cuña, agudizándose y perdiéndose caudalmente. La diáfisis es más bien lisa, sin crestas o tubérculos notables (exceptuando la cresta tibial).

El extremo distal de la tibia es amplio lateromedialmente y cráneocaudalmente. En vista distal, la superficie articular distal posee una forma arriñonada, con una superficie fuertemente incidida por los dos surcos de la cóclea tibial. Uno de ellos se ubica en posición central a la zona articular, y se corresponde a la zona de articulación con la cresta medial y aguda de la tróclea del astrágalo. En el surco más lateral (formado en conjunto con la superficie articular distal de la fíbula), es menos profundo y amplio que el anterior. En vista caudal, el margen caudal de la superficie articular distal es sinuoso, mayormente aplanado en el sector medial, sobresaliente y agudo en la zona central, y moderada a abruptamente escindido por el margen lateral de la tróclea del astrágalo en la región lateral. La faceta fibular distal es ovalada, aplanada proximodistalmente y poco definida. El maléolo medial es robusto y proyectado. En la zona medial y caudal del maléolo medial, medial al surco maleolar tibial, el surco correspondiente al pasaje del tendón del $\mathrm{m}$. tibialis caudalis se muestra delimitado por dos crestas delgadas, que se pierden en cercanías a la superficie articular distal.

Fíbula (Lámina 3.17C)

Es cilíndrica, recta y extremadamente delgada a lo largo de casi toda su extensión, siendo sólo los extremos articulares son moderadamente robustos. En vista proximal, la articulación de la cabeza de la fíbula es ovalada, ocupando más la mitad del área observada en la vista, en una posición central y caudal. En el sector proximal y laterocraneal se proyecta el tubérculo del $\mathrm{m}$. fibularis longus, agudo y poco desarrollado, mientras que en el sector mediocaudal, se diferencia sutílmente una zona elevada e irregular, posiblemente correspondiente al origen del $\mathrm{m}$. soleus. Bajo este último se proyecta una fina cresta que se extiende aproximadamente hasta el final del primer tercio de la diáfisis, en relación al origen del $\mathrm{m}$. extensor digiti I longus.

El extremo distal de la fíbula posee su eje principal desarrollado en dirección cráneomedial-caudolateral. El extremo más craneal del maléolo lateral tiene un menor desarrollo distal que caudal, siendo robusto y proyectado en similar o menor magnitud que el maléolo medial. En vista distal, el sector medial y craneal corresponde a la faceta astragalar de la fíbula, la cual es ovoide, con su extremo caudal algo agudo y distal redondeado, aplanada o levemente convexa, y está poco extendida hacia distal. La faceta tibial es convexa a aplanada, de forma cuadrangular y con su mayor eje en dirección proximodistal, poco diferenciada de la anterior. En el extremo laterocaudal del sector distal de la fíbula, un tubérculo delgado, romo y alargado proximodistalmente separa dos surcos de pasajes de tendones. El primero, es la zona 
de tránsito del tendón del m. fibularis longus. Esta posee una posición lateral, delimitada en su margen craneal por una pequeña cresta bien definida que finaliza antes de contactar el extremo distal de la fíbula. El segundo surco, el surco maleolar fibular, posee una posición caudolateral, es más amplio y en su margen caudal está delimitado por una cresta poco definida, siendo esta la zona de tránsito del $\mathrm{m}$. extensor digitorum lateralis y $\mathrm{m}$. fibularis brevis.

\section{Autopodio posterior (Lámina 3.18C, 3.19C)}

Los huesos del tarso poseen un fuerte empaquetamiento, con un bajo desarrollo de las áreas de agarres musculares. El astrágalo (o talus; Lámina 3.18C) presenta un cuello y cabeza aplanados dorsoventralmente y en conjunto poseen un menor desarrollo próximodistal al observado para la tróclea (aproximadamente dos tercios de la misma). La tróclea es moderadamente profunda y alargada cráneocaudalmente (en mayor medida que en Ga. cuja). Sus dos crestas se encuentran bien definidas a lo largo de toda su extensión, siendo la lateral más elevada que la medial. La separación entre ambas es mínima en el sector más caudal de la tróclea, para luego alcanzar, en el sector medio y más elevado de la tróclea, una máxima separación la cual se mantiene hasta finalizar la estructura en su extremo distal. En vista dorsal, en el sector lateral de la base del cuello se observa una depresión astrágalotibial poco desarrollada. En vista lateral, la carilla maleolar lateral es amplia y de forma semicircular. En vista ventral, tanto la superficie articular proximal como la media no sobresalen caudalmente. La superficie articular proximal es alargada, cuadrangular y fuertemente cóncava. Por último, la superficie articular medial es fuertemente convexa, inclinando en sentido medial y ocupando la mayor parte de la superficie central y medial del cuello. En vista distal, la superficie articular para el tarsal central es oval y alargada en sentido lateromedial, sin una constricción marcada pero angostándose dorsoventralmente en su extremo medial. Entre las superficies articulares hay múltiples foramina secundarias.

El tubérculo del calcáneo (Lámina 3.18C) es relativamente breve y presenta un moderado desarrollo en altura. En vista dorsal la base y la zona media son angostas. El margen lateral es mayormente recto, mientras que el margen medial se vuelve fuertemente cóncavo en cercanías al proceso medial del extremo proximal del tubérculo. El proceso medial del tubérculo se presenta como una lámina marcadamente proyectada en sentido medial. El surco entre ambos (zona de inserción y de pasaje del $\mathrm{m}$. flexor digitorum superficialis) se presenta poco definido y asimétrico. El área sustentaculum tali diverge abruptamente respecto a la cara medial del tubérculo, formándose entre ambos un ángulo netamente recto. La articulación medial para el talus posee forma cuadrangular a triangular y se encuentra fuertemente en sentido medial en su sector proximal y medio. En vista distal, la articulación medial forma un ángulo igual o mayor a $45^{\circ}$ respecto al eje mayor de la articulación para el tarsal IV. La superficie articular proximal 
para el talus es en extremo alargada en dirección cráneocaudal (en mayor medida aun que en Ga. cuja) y es convexa en dirección cráneocaudal. El proceso troclear, zona de origen del m. quadratus plantae, posee forma de una plataforma expandida lateralmente (en menor medida que Ga. cuja) y alcanza a extenderse tanto como el margen distal del calcáneo. La superficie articular para el tarsal IV es cuadrangular y ligeramente cóncava.

El tarsal central (Lámina 3.19C) es aplanado en sentido próximodistal y cráneocaudal, apenas superando la altura del carpal II. Es levemente más alto en su cara caudal que craneal. En vista medial, la cara articular que contacta al astrágalo no se encuentra particularmente elevada en su margen craneal. En el extremo medial, el central contacta al sesamoideo tibial, el cual es alargado proximodistalmente sobre el cual se inserta el m. tibialis caudalis. En vista distal, las carillas articulares que reciben a los tarsales I, II y III poseen forma reniforme, convexa; el sector que recibe al tarsal III está claramente delimitado. Los sectores de articulación con el tarsal I y II son una superficie aproximadamente rectangular. El proceso plantar es una protuberancia poco desarrollada. Los tarsales I, II y III se muestran fuertemente imbricados, con todas sus aristas angulosas. En el tarsal I, la carilla articular para el metatarsal I se encuentra principalmente en el plano transversal, aunque inclina ligeramente hacia ventromedial. En vista distal, la carilla articular para el metatarsal I es ovoide y cóncava a aplanada. El tarsal II posee forma de prisma o cubo, con su articulación distal (área de contacto con el metatarsal II) triangular a cuadrangular y levemente cóncava. En vista ventral, el tarsal II se encuentra fuertemente obliterado por el proceso plantar del tarsal I. En vista distal, el tarsal III posee una carilla articular para el metatarsal III con forma de "L" o "T", siendo cóncava y con una leve constricción central. Posee un proceso plantar pequeño y redondeado. El tarsal IV posee un desarrollo próximodistal similar al del tarsal III y central juntos. La cara medial del tarsal IV contacta, en su primer tercio al tarsal III, y en los dos tercios restantes al central, ambas en el mismo plano. Las facetas articulares para el tarsal III y central se encuentran separadas por un surco que presenta numerosas foramina. En vista medial, el margen distal del tarsal IV presenta su zona media incidida, depresión que luego se continua como un canal entre el metatarsal III y IV. La cara distal del tarsal IV articula con el metatarsal IV y V exclusivamente, con un contacto que tiende a ser de tipo cóclea-tróclea. En vista ventral, el proceso plantar del tarsal IV, se diferencia como un sutil engrosamiento con un eje principal lateromedial, dorsal a la zona del pasaje del tendón del $\mathrm{m}$. fibularis longus. Entre el proceso plantar del central y el tarsal IV se delimita una zona deprimida. En vista lateral, el surco para el tendón del m. fibularis longus se observa como una incisura profunda entre los procesos plantares del metatarsal $\mathrm{V}$ y tarsal IV, que se continúa, en vista plantar, como un surco profundo y angosto, el cual posee una trayectoria recta y lateromedial más que diagonal. 
Los cinco metatarsales son gráciles (especialmente para el caso del metatarsal I); los tres centrales presentan moderado a fuerte empaquetamiento. Los dos metatarsales periféricos son breves y se ubican en parte por detrás de los centrales. Todos los metatarsales son levemente aplanados, rectos (principalmente los tres centrales) a levemente convexos en dirección próximodistal y expandidos lateromedialmente en su extremo distal. Los metatarsales II, III y IV son similares y son los elementos de mayor longitud total (siendo el III y IV sutílmente mayores que el II, y el III algo mayor que el IV). Son seguidos en longitud por el V (siendo el V claramente menor que el II). Finalmente el primer dígito posee el metatarso de menor longitud, menor a tres cuartas partes de la longitud del mayor metatarsal. El proceso plantar moderadamente desarrollado y robusto (en menor medida que lo observado en $G a$. cuja). Justo lateral a éste, la base del metatarsal I se proyecta lateralmente a modo de una plataforma que termina abruptamente y contacta, pero sin obliterar, al sector proximal del metatarsal II. Esta plataforma supera mínimamente en sentido distal al tubérculo plantar (aproximadamente igual a un quinto de la longitud total del metatarsal I). El proceso plantar del metatarsal II es grácil, lateral al del metatarsal I. Los procesos plantares de los metatarsales III y IV poseen forma redondeada. El metatarso IV contacta al $\mathrm{V}$ mediante un área circular y cóncava, mientras que recibe al III mediante una zona aplanada a convexa, presentándose un surco en la zona central del área articular de este último. En vista ventral, el metatarso V posee un proceso plantar poco desarrollado proximodistalmente. El sector central del extremo proximal de éste, se observa una superficie cóncava a aplanada, con un margen proximal engrosado, que se encuentra separado del proceso plantar por una breve región deprimida, y hace las veces de pared distal del surco para el transcurso del tendón del $\mathrm{m}$. fibularis longus. Sobre este margen proximal, se ubica el sesamoideo de la base del metatarsal V, de moderado desarrollo y circular. Los sesamoideos metatarsales para los dígitos II al V se encuentran desarrollados proximodistalmente. En el caso del digito I, los dos sesamoideos poseen un menor desarrollo, se encuentran fuertemente empaquetados, y el medial es aproximadamente esférico y menos desarrollado proximodistalmente que el lateral. Las falanges proximales son de similar robustez a los metatarsos correspondientes. Las falanges medias poseen aproximadamente la mitad de la longitud observada en las proximales, siendo similares a estas últimas en los demás aspectos. Tanto la base como cresta ungueal de las falanges ungueales son moderada a poco robustas y prominentes. En vista lateral, el proceso ungueal posee un margen dorsal convexo en todos los casos, mientras que la superficie ventral es levemente cóncava a plana, reduciéndose en altura de manera progresiva y terminando en un extremo agudo. En vista dorsal, los procesos ungueales son delgados desde sus bases. Las unguis son moderadamente a poco elongadas, agudas en su extremo distal y curvadas (especialmente en el caso de los dígitos laterales). 


\subsubsection{Eira barbara}

Complejo atlas-axis (Lámina 3.1A, 3.2A)

El atlas (Lámina 3.1A) es un elemento fuertemente extendido en dirección cráneocaudal. El foramen vertebral es ovalado en vista craneal, con su eje principal de dirección mediolateral, mientras que en vista caudal posee una forma más bien circular, con el eje dorsoventral levemente mayor que el mediolateral. Los forámenes vertebrales laterales se ubican internamente en el extremo caudodorsal de las superficies articulares craneales, justo craneal a la base de cada proceso transverso (diferenciado más claramente en el lado derecho de espécimen MLP 1013). En vista dorsal, el arco neural posee un margen craneal levemente cóncavo. Un sector algo rugoso representa al tubérculo dorsal del arco neural. El tubérculo ventral se proyecta en forma de un extremo agudo en sentido ventral y caudal. Las superficies articulares craneales sobresalen marcadamente respecto al arco neural. Las superficies articulares caudales inclinan fuertemente en sentido medial, son de contorno anguloso y se proyectan en forma aguzada en sentido caudal y dorsal.

El desarrollo de las alas del atlas varía mucho en los distintos especímenes analizados, pero en líneas generales son más largas cráneocaudalmente que anchas, cuadrangulares (especímenes MLP 1013 y CML 062308) a semicirculares (SNMS 480), sobresaliendo fuertemente por detrás de los procesos articulares caudales. Las alas se ubican principalmente en el plano longitudinal, siendo planas a levemente cóncavas en vista ventral. En líneas generales, el margen caudal es levemente convexo, inclinando en sentido medial, mientras que el lateral es mayormente recto (MLP 1013, CML 062308) o convexo (SNMS 480). La incisura alar está típicamente encerrada por un puente delgado lateral a la misma, dando paso a un foramen alar lateral desarrollado en sentido cráneocaudal y a un margen lateral convexo y abierto; la incisura se comunica mediante un surco con el foramen vertebral lateral. En el lado izquierdo del espécimen MLP 1013 y derecho del espécimen SNMS 480, dicho puente no está completo. Los forámenes transversos se muestran desarrollados, abriendo caudalmente inmediatamente caudal y lateral a las superficies articulares caudales.

El axis (Lámina 3.2A) posee un proceso espinoso alto y amplio en dirección cráneocaudal (excepto quizás el espécimen SNMS 480), superando la extensión del cuerpo vertebral en sentido caudal. El proceso espinoso, engrosado en su sector medio, conforma en su extremo más craneal un tubérculo robusto, mientras que el extremo caudodistal se presenta a modo de una saliencia aplanada dorsoventralmente. Este engrosamiento caudodistal se continúa a modo de crestas que se dirigen en sentido craneal y ventral por ambas caras de la lámina (no observado en el espécimen SNMS 480). En vista lateral, el margen dorsal recto en su sector medio, siendo muy levemente convexo hacia el sector posterior y convexo en sentido craneal. El proceso odontoides se proyecta marcadamente en sentido craneal y es robusto. El foramen 
vertebral posee una altura similar a su base. Las carillas articulares caudales son moderadamente elongadas cráneocaudalmente. Los procesos articulares caudales presentan tubérculos robustos y proyectados en sentido dorsal a modo de lámina engrosada. En vista craneal, las carillas articulares craneales se encuentran posicionadas lateralmente, separadas del proceso odontoides y $\sin$ que sus márgenes mediales alcancen medialmente la altura foramen vertebral. El desarrollo relativo de las mismas es menor que el observado en otros mustélidos descriptos (ver más adelante). La incisura vertebral craneal es amplia. La incisura vertebral caudal es profunda y aguda, sin alcanzar el margen craneal de los procesos articulares caudales ni el margen caudal del cuerpo vertebral, y con un margen dorsal convexo. La cresta ventral del cuerpo está definida y posee un tubérculo caudal poco definido.

Los procesos transversos del axis están fuertemente proyectados en sentido lateral, caudal y ventral. Sus márgenes distales son redondeados a truncados. En vista ventral, se diferencian en forma abrupta de los márgenes laterales del cuerpo vertebral. En vista lateral, estos divergen tanto del plano sagital como longitudinal en más de $30^{\circ}$. Estos procesos superan ampliamente el extremo craneal del proceso transverso de la tercera vértebra cervical. Los forámenes transversos son elípticos y su abertura craneal está comprimida dorsoventralmente. En vista lateral, sus extremos más craneales no llega a ser tapados por el limite caudal de las carillas articulares craneales. En vista caudal, los forámenes transversos poseen forma triangular.

\section{Tercera a séptima vértebra cervical (Lámina 3.3A)}

El proceso espinoso de la tercera vértebra cervical es claramente menor a los demás. En el espécimen MLP 1013 los procesos de la cuarta hasta la séptima vértebra cervical son de similar tamaño y elevados, creciendo progresiva aunque mínimamente en sentido caudal; por otro lado, en el espécimen SNMS 480, la serie consta de elementos relativamente bajos excluyendo al séptimo, el cual duplica en altura al precedente. La morfología de los procesos espinosos es muy variable intraespecíficamente, en general son más altos que largos, redondeados en el sector dorsal y engrosados en el extremo dorsal, especialmente en el caso de la cuarta y quinta vértebra (en el caso del espécimen MLP 1013), y de márgenes craneal y caudal rectos. El proceso espinoso de la séptima vértebra cervical es superior en altura y algo más angosto cráneocaudalmente en su sector dorsal. Los procesos espinosos son principalmente perpendiculares, aunque los de la quinta o sexta vértebras cervicales se inclinan y posicionan levemente hacia craneal. Con respecto a los arcos neurales, en vista dorsal, la relación entre ancho y largo de cada uno de ellos es aproximadamente de uno a uno, a levemente más largos. Entre vértebras sucesivas se abre una luz que alcanza, hacia el final de la serie, aproximadamente un tercio del desarrollo cráneocaudal del arco neural, y menor a un cuarto en 
los primeros. Las carillas articulares son alargadas cráneocaudalmente y angostas. Los procesos que portan las carillas articulares craneales están engrosados a modo de tubérculos ventrales a partir de la cuarta vértebra cervical. Se encuentran reducidos en los elementos posteriores. Los procesos que portan las carillas articulares caudales están engrosados a modo de tubérculos desde el axis hasta la cuarta vértebra cervical.

Los procesos transversos cervicales son amplios. Las láminas ventrales poseen una morfología cuadrangular a bifurcada (especialmente en el caso del cuarto y quinto elemento) a netamente bifurcada (en el caso del tercero y sexto elemento), proyectándose fuertemente en sentido caudal y cráneoventral, encontrándose algo comprimidos dorsoventralmente en la zona media. En el caso de la tercera, cuarta, quinta y sexta vértebras cervicales, los tubérculos ventrales de los procesos transversos superan en extensión al cuerpo vertebral, solapándose con los procesos transversos adyacentes, siendo especialmente extensos en sentido caudal en el caso de la tercera y sexta vértebras cervicales. Los tubérculos dorsales de los procesos transversos se esbozan tempranamente en la tercera vértebra cervical como un tubérculo caudodorsal sobre la proyección caudal de la lámina ventral. En la cuarta y quinta vértebras cervicales estos tubérculos nacen en el sector caudal respecto a las láminas ventrales y se proyectan en sentido caudodorsal, mientras que en la sexta vértebra se diferencian en la zona central y son mayormente perpendiculares al eje vertebral. El tubérculo dorsal del proceso transverso de la séptima vértebra cervical es similar en forma, posición y tamaño al de la sexta, aunque con sus extremos levemente inclinados en sentido ventral, siendo estos procesos para ambos elementos robustos, alargados y truncados. En vista ventral, los tubérculos ventrales de los cuerpos vertebrales se observan especialmente desarrollados en la quinta vértebra cervical, a modo de dos procesos delgados.

\section{Vértebras torácicas y caja torácica (Lámina 3.4A)}

La serie torácica posee 14 elementos. Sin embargo, el décimo quinto elemento tóracolumbar (primer lumbar) del espécimen MLP 1013 posee procesos transversos anómalos, con dirección y morfología que emulan las de las costillas (esto no ocurre en otros especímenes de Ei. barbara como SMNS 480). Acompañando esta morfología de procesos transversos anómalos, en este espécimen MLP se registran 21 en vez de los típicos 20 elementos tóracolumbares, para la especie (ver también Mivart 1885, Filler 2007) y carnívoros en general (ver discusión osteológica tóraco-lumbar). La vértebra diafragmática corresponde al décimo primer elemento. Las crestas ventrales se presentan a partir del décimo segundo elemento, y están claramente definidas y posicionadas en el décimo tercero. Las escotaduras craneales son amplias al comienzo de la serie tóraco-lumbar, reducidas a partir de la zona de la décima vértebra torácica, y obliteradas en la región postanticlinal. Las escotaduras caudales de todos los 
elementos son menores que las craneales, y están prácticamente ausentes a partir del décimo segundo elemento.

En vista lateral, los procesos espinosos disminuyen progresivamente en altura desde la primera vértebra torácica, con una altura del proceso claramente superior a la del resto de la vértebra, hasta su mínima expresión en la décima tercera, correspondiendo esta última a la primera vértebra postanticlinal, aunque la altura de la misma es muy similar a la de la vértebra anticlinal (décimo segundo elemento). En las primeras vértebras torácicas los procesos espinosos se ubican perpendiculares y poseen márgenes mayormente rectos, levemente convexos con el extremo distal engrosado; en sentido caudal (hasta la décimo primera vértebra), los procesos espinosos se solapan progresivamente sobre los cuerpos de las vértebras adyacentes posteriores, presentando márgenes principalmente craneales rectos y los caudales sinuosos a convexos. El desarrollo areal de los procesos espinosos varía intra-específicamente, siendo relativamente homogéneo a lo largo de la serie preanticlinal. La décimo segunda vértebra (vértebra anticlinal) posee un proceso espinoso moderado a bajo en altura (aunque mucho más desarrollado que lo observado en Ga. cuja y Ly. patagonicus). A partir de éste, y hasta el último elemento de la serie, los procesos espinosos poseen forma de meseta, con similar elevación y algo inclinados en sentido craneal, progresivamente más engrosados en su margen dorsal y desarrollados cráneocaudalmente.

Las fóveas costales de los procesos transversos son robustas, cóncavas y amplias en todos los elementos preanticlinales, y están ausentes en la vértebra anticlinal y elementos posteriores. En el caso de la primera vértebra torácica, se posicionan por debajo de la altura de los procesos articulares craneales, aunque distantes a dicha zona articular. La distancia entre las fóveas costales y los procesos articulares craneales es breve en el cuarto elemento, mientras que el segundo y tercer elemento poseen una morfología intermedia. A partir de la vértebra anticlinal, las fóveas costales se ubican exclusivamente sobre el cuerpo vertebral correspondiente (sin incidir esta zona articular en el elemento torácico precedente). Los procesos mamilares se presentan parcialmente diferenciados en el último elemento preanticlinal, y bien desarrollados y definidos en la vértebra anticlinal, casi tan altos y robustos como los procesos espinosos de las últimas vértebras de la serie, manteniéndose desarrollados hasta casi los últimos elementos lumbares. Los procesos accesorios se presentan con claridad a partir de la última vértebra preanticlinal, aunque esbozos de los mismos aparecen en la décima vértebra torácica. En vista dorsal, los primeros procesos accesorios divergen en bajo grado respecto al eje cráneocaudal del esqueleto axial, quedando en gran parte ocultos por debajo de los procesos articulares craneales de la vértebra posterior.

Aunque la abertura craneal del tórax es estrecha, la caja torácica se expande rápidamente divergiendo fuertemente el esternón del eje de la columna (estimado en un ángulo 
mayor a $45^{\circ}$ ). La sección de la caja torácica se ensancha lateromedialmente, alcanzando un máximo desarrollo a la altura de la octava vértebra torácica, mientras que su altura llega a un máximo al nivel de la décimo segunda torácica. El esternón del espécimen MLP 1013, es el más completo de los analizados, y preserva las primeras 8 esternebras con las costillas $1 \mathrm{y} 9$. El primero de los elementos es aproximadamente el doble en longitud respecto a los posteriores y presenta, al final del segundo quinto de su extensión, una zona robusta donde articula el primer par de costillas. El manubrio es aplanado lateromedialmente y se inclina levemente en sentido ventral, siendo agudo en su extremo craneal. El margen ventral del mismo es rugoso y engrosado. Los metámeros restantes son subiguales (exceptuando el último) y engrosados. El xifoides es principalmente cartilaginoso, con el extremo caudal redondeado y aplanado en forma de "cuchara". Las costillas son 14 elementos gráciles. Al menos los nueve primeros pares contactan el esternón. Debido a la falta de preservación de la porción cartilaginosa de las costillas en los especímenes analizados, no es posible describir los restantes contactos. En el sector preanticlinal y anticlinal cada costilla presenta un tubérculo costal, que se pierde en el sector postanticlinal. El quiebre de dirección en la zona del ángulo costal es mínimo para todas las costillas.

\section{Vértebras lumbares (Lámina 3.5A)}

La serie lumbar está compuesta por 6 vértebras lumbares (e.g., SNMS 480, USNM 397071, ver también Mivart 1885, Filler 2007), y excepcionalmente 7 vértebras (espécimen MLP 1013). El desarrollo de procesos espinosos, mamilares y transversos es destacable (ver más abajo), mayor que el observado en los hurones descriptos. En vista dorsal, los cuerpos vertebrales son angostos y alargados, especialmente en los elementos posteriores. En MLP 1013, esta tendencia al alargamiento de los cuerpos vertebrales lumbares se interrumpe en el último elemento, el cual está comprimido cráneocaudalmente a aproximadamente dos tercios del desarrollo observado en el penúltimo elemento. En vista ventral, se observan crestas ventrales, que corresponden al origen de la musculatura sublumbar, las cuales sobresalen en los primeros cuatro elementos lumbares, siendo mayores que las crestas observadas en las vértebras torácicas. En todos los casos, estas crestas tienen una posición lateralizada en vista ventral. Estas crestas se vuelven prácticamente indiferenciables en los elementos posteriores.

Los procesos espinosos lumbares poseen formas variables: los tres o cuatro primeros (SNMS 480 y MLP 1013, respectivamente) poseen formas intermedias entre meseta y "onda baja", inclinados cranealmente, similares a los descriptos en sector torácico posterior, aunque son progresivamente más altos y robustos, especialmente en el caso del tercer y cuarto elemento. En vista lateral, los márgenes dorsales son rectos a levemente convexos; los craneales, cóncavos, y los caudales, sigmoides a convexos. Las últimas tres vértebras lumbares 
poseen procesos espinosos progresivamente más reducidos en altura, ancho y largo, de márgenes mas rectos y orientación perpendicular. El proceso espinoso de la séptima vértebra lumbar de MLP 1013 se encuentra marcadamente reducido, con una morfología más similar a la observada en los procesos espinosos del sacro que la presente en otros elementos de la serie lumbar. En relación a las facetas articulares, en la zona de la articulación entre el último elemento y el sacro, su desarrollo lateromedial es similar o levemente menor a lo observado en los elementos precedentes, mientras que la separación de las mismas es levemente superior a lo observado en los elementos precedentes. Las escotaduras dorsales caudales están presentes y bien desarrolladas en la mayoría de las vértebras postanticlinales, pero especialmente en la última vértebra lumbar. Al igual que en los elementos post-diafragmáticos torácicos, las facetas articulares se apartan respecto al plano longitudinal (típico en las demás vértebras tóracolumbares) en sentido dorsal típicamente entre $45^{\circ}$ y $60^{\circ}$, o aproximadamente $45^{\circ}$ (para el caso de articulación entre último elemento lumbar y sacro).

Los procesos mamilares muestran un importante desarrollo y robustecimiento ya desde el primer elemento en el que se presentan (vértebra anticlinal), y la importancia de estos se incrementa hasta el segundo elemento lumbar, proyectándose fuertemente en sentido craneal, más allá de las carillas articulares de las cuales parten. Por otro lado, los procesos accesorios se encuentran bien desarrollados aun en las cuatro primeras vértebras lumbares. En la quinta (SNMS 480) o quinta y sexta (MLP 1013) vértebras lumbares, se encuentran reducidos, sólo definiéndose sus márgenes caudales y dorsales, mientras que en el último elemento de la serie están ausentes. Al comienzo de la serie lumbar, las escotaduras craneales y caudales son moderadas a reducidas y se muestran cruzadas y obliteradas en su sector medio por los procesos accesorios. Las escotaduras se hacen progresivamente más amplias y menos obliteradas hacia los elementos posteriores.

Todos los procesos transversos se encuentran en una posición relativamente craneal con respecto al cuerpo vertebral, y poseen bases relativamente angostas. Los procesos transversos del primer elemento lumbar del espécimen MLP 1013 poseen una morfología atípica; se encuentran moderadamente desarrollados, con dirección perpendicular al eje axial, inclinándose levemente en sentido caudal y sobre el plano sagital, y poseen un margen posterior cóncavo y uno craneal convexo a geniculado, con un quiebre de pendiente abrupto en su sector medio. Los demás procesos transversos inclinan por debajo del plano horizontal. Los procesos transversos del segundo (MLP 1013) o primer elemento lumbar (SNMS 480) se encuentran moderadamente desarrollados, apenas alcanzando cranealmente el margen craneal del cuerpo vertebral y poseen márgenes redondeados, inclinando cranealmente; el margen craneal es cóncavo y breve, y el posterior es convexo y amplio, con un quiebre de pendiente marcado. Las siguientes vértebras poseen procesos transversos gradualmente más desarrollados y proyectados lateroventralmente 
a modo de prolongaciones delgadas. Los procesos transversos del quinto y sexto (MLP 1013) o quinto elemento lumbar (SNMS 480) son los más desarrollados y poseen un margen craneal cóncavo, un extremo craneodistal engrosado y un margen caudal levemente cóncavo a recto, antes y después del quiebre, respectivamente. El margen lateral es recto a convexo, expandido en sentido craneal, y se encuentra engrosado en sentido dorsoventral. Los procesos transversos del séptimo (MLP 1013) o sexto elemento lumbar (SNMS 480) se encuentran reducidos respecto a los anteriores, siendo sus extremos agudos.

\section{Sacro (Lámina 3.6A)}

Está compuesto por tres elementos, los dos primeros están parcialmente fusionados entre sí, mientras que el tercero es parcialmente independiente, aunque fusionado al anterior en la región de los procesos transversos en el caso del espécimen MLP 1013. En el caso del espécimen SNMS 480, el tercer elemento es independiente y el sacro está compuesto por dos elementos. El sacro posee una forma aguzada en sentido caudal, debido a que el último elemento es más angosto y alto que el primero.

Los procesos espinosos no se fusionan en una única cresta sacra media. Los primero y segundo procesos está reducidos y poseen similar desarrollo. El tercer elemento posee una espina de robustez y altura variable respecto a los precedentes e inclina en sentido craneal. La superficie articular sacro-ilion tiene forma elíptica y se extiende en gran medida por debajo del margen ventral de los cuerpos vertebrales especialmente en el sector del primer elemento. La cresta sacra lateral (o el proceso transverso del tercer elemento sacro-caudal de SNMS 480) se proyecta brevemente en sentido caudal, sin superar la zona articular entre la zona sacra y caudal de los cuerpos vertebrales. Toda la extensión de la cresta sacra lateral se encuentra en el plano horizontal. Los forámenes sacros son elípticos, alargados cráneodorsalmente. Los procesos articulares caudales poseen una orientación cercana a los $45^{\circ}$. En vista craneal, el cuerpo vertebral posee forma semicircular y aplanada, y la apertura del canal sacro es moderada a pequeña y aplanada; mientras que en vista caudal, posee un tamaño proporcionalmente mayor y es menos aplanada.

\section{Vértebras caudales (Lámina 3.7A)}

En el espécimen MLP 1013 se preservan los primeros 20 elementos de la serie, y en función de la reducción de los mismos se puede estimar que quizás falta al menos el último elemento, mientras que Mivart (1885) registró 23 elementos para la especie. Las primeras vértebras son relativamente robustas, desarrollados lateromedialmente, y los procesos sobre ellas se mantienen desarrollados hasta el sexto elemento. Los cuerpos vertebrales de los primeros elementos son muy similares al último elemento del sacro y gradualmente se vuelven 
cilíndricos. Ninguna de las vértebras caudales del espécimen MLP 1013 y SNMS 480 posee un proceso espinoso diferenciable (excepto el tercer elemento sacro-caudal, independiente del resto del sacro en SNMS 480; mientras que sólo se registra un pequeño proceso espinoso en la primera vértebra caudal en USNM 399071), y sólo en los primeros dos o tres elementos se presenta un relieve a modo de cresta en su lugar. Los cuerpos de las primeras vértebras caudales son breves, pero su longitud aumenta progresivamente en sentido caudal, siendo algunas del sector medio cinco veces más largas que anchas, y siendo más del doble de largas que las primeras. Los procesos y las carillas articulares craneales y caudales poseen moderado desarrollo hasta el tercer elemento inclusive. En vista dorsal, las escotaduras dorsales craneales se encuentran diferenciadas para las seis primeras vértebras caudales, profundizándose en las primeras tres tanto como un tercio o un cuarto de cada cuerpo vertebral. En vista lateral, la escotadura caudal de las vértebras caudales se encuentra presente en los seis primeros elementos. La vértebra transicional corresponde al cuarto elemento caudal. Las carillas articulares caudales se encuentran presentes hasta el quinto elemento. A partir del sexto o séptimo elemento, el arco neural se fusiona con el cuerpo vertebral. En lugar de estas estructuras se observa una cresta triangular que corona el extremo caudal del margen dorsal de cada vértebra. Los procesos mamilares se diferencian bien al menos hasta el décimo quinto elemento; y a modo de tubérculos poco diferenciados hasta el último elemento.

Los procesos transversos de las tres primeras vértebras caudales parten de todo el margen lateral del cuerpo vertebral. En el primer y segundo elemento, estos procesos se inclinan en sentido caudal, sin alejarse del plano horizontal. El extremo caudodistal de los procesos transversos del segundo elemento se encuentra bifurcado. El tercer elemento caudal de MLP 1013, o segundo en el caso del espécimen USNM 399071 posee los procesos transversos más desarrollados lateromedialmente y con una orientación más perpendicular. Luego de esta vértebra, los procesos transversos se proyectan y posicionan gradualmente más caudalmente. Los siguientes elementos, poseen procesos transversos menos conspicuos y de márgenes más redondeados. A partir del octavo, y de manera reducida hasta los últimos de los elementos preservados, los procesos transversos se dividen en una protuberancia mayor en el sector caudal de cada vértebra, que corresponde al proceso transverso caudal (que continúa la tendencia gradual mencionada anteriormente), y una pequeña proyección perpendicular ubicada cranealmente, que corresponde al proceso transverso craneal. Ambas proyecciones transversas se encuentran ampliamente distanciadas y a veces se conectan a través de una quilla en la cara lateral de cada vértebra. En vista lateral, el margen ventral de los cuerpos vertebrales es cóncavo para los primeros cuatro elementos, y mayormente recto en los restantes. En todas las vértebras caudales exceptuando la primera, se desarrollan procesos hemales a modo de protuberancias 
craneales, importantes a partir de la cuarta y quinta vértebra caudal, sin observarse crestas caudoventrales en ningún elemento.

\section{Escápula (Lámina 3.8A)}

La escápula tiene forma subrectangular con vértices redondeados, con el ángulo caudal agudo cercano (SNMS 480) o menor a los $90^{\circ}$ (MLP 1013), el ángulo craneal abierto (cercano a los $140^{\circ}$ ), y un ángulo de menor amplitud pero muy redondeado sobre el final ventral del margen craneal, el cual hace las veces de límite entre el margen craneal y una escotadura escapular profunda, cuyos márgenes forman un ángulo cercano y mayor a los $90^{\circ}$. En la zona media del margen craneal, se insinúa un quiebre, aunque no se define claramente un nuevo ángulo, dando un aspecto convexo a dicho borde. En vista medial, la escápula es aplanada a cóncava, con un área francamente cóncava presente a lo largo de la zona marginal craneal y dorsal; al mismo tiempo, en el sector posterior medio y ventral se desarrolla una región convexa. El margen caudal inclina levemente en sentido lateral. En cercanías al ángulo craneal, existe un cambio de textura, posiblemente correspondiente la cara serrata. La espina es robusta y elevada, cóncava en vista craneal en su porción más dorsal, perdiendo definición y formando un sector rugoso en cercanías al ángulo craneal. Entre ella quedan delimitadas la fosa supraespinosa que tiene un área algo mayor a la de la infraespinosa (aunque relativamente menor comparado con otros mustélidos analizados). En cercanías del ángulo caudal, la zona de origen del $\mathrm{m}$. teres major y $\mathrm{m}$. triceps brachii caput angulare se distingue del margen como un engrosamiento y leve inflexión del mismo en sentido medial, o incluso desarrollándose una pequeña área por debajo y detrás del ángulo caudal (más definida en el espécimen SNMS 480). El acromion se desarrolla transicionalmente a partir de la espina, observándose en vista craneal una suave pendiente entre ambos. Distalmente, se observa una escotadura profunda entre éste y la zona articular. El proceso hamatus es robusto y se proyecta paralelo al margen caudal (divergiendo hacia craneal respecto a la espina), sobrepasando la cavidad glenoidea y, en vista caudal, divergente del plano definido por la escápula. El proceso subhamatus apenas sobrepasa al borde caudal de la escápula, presenta el margen ventral recto, y el caudodorsal recto a levemente convexo, teniendo en vista lateral la forma de un triángulo rectángulo. Entre los procesos hamatus y subhamatus se observan dos foramina alineadas dorsoventralmente. En algunos casos se puede observar una foramina marcada sobre el sector ventral de la base del acromion (escápula izquierda de MLP 1013).

En vista distal, la cavidad glenoidea posee forma de gota u ovoide, con un tubérculo supraglenoideo diferenciado y desarrollado lateromedialmente, y un proceso coracoides robusto. En vista medial, se observa que la zona articular se encuentra algo proyectada en sentido ventral en la zona craneal, y que el cuello de la escápula es tan ancho cráneocaudalmente como la zona 
articular. En la base del cuello, en posición caudomedial, el área de origen del m. triceps brachii caput longum y secundariamente $\mathrm{m}$. teres minor presenta estrías paralelas.

\section{Húmero (Lámina 3.9A)}

El húmero es un elemento elongado, y presenta un gran desarrollo próximodistal de la diáfisis, la cual es recta en vista lateral y de sección aproximadamente circular. En vista proximal, la cabeza articular posee un mayor desarrollo del eje cráneocaudal. A su vez, en vista craneal supera claramente en altura al tubérculo mayor. Por otro lado, este último es poco robusto y está separado del tubérculo menor mediante un amplio y profundo surco intertubercular, el cual se proyecta en forma de una zona deprimida de similares características entre la zona articular y el tubérculo menor. Sobre la cara lateral y sobre el extremo caudal del tubérculo mayor se desarrolla una zona deprimida muy desarrollada y equiproporcionada donde se inserta el m. infraspinatus. Una segunda región deprimida de márgenes definidos, inmediatamente caudal a la anterior, parece corresponderse con el área de inserción del m. teres minor. La tuberosidad deltoidea y la línea tricipital distal no se encuentran desarrolladas (excepto en algún grado en el espécimen CML 2722 y NMV B5987), sino que en su lugar se encuentra una zona rugosa, que sólo en la zona del cuello articular proximal da paso a una línea tricipital breve, la cual da paso proximalmente a una cresta definida que marca la zona proximal de origen del $\mathrm{m}$. triceps brachii caput laterale. La cresta del tubérculo mayor no se diferencia de manera clara en ningún sector, aunque en la zona entre el primer y segundo cuarto del húmero, se desarrolla una superficie elevada o engrosada y rugosa, a modo de una brevísima cresta, la cual se pierde sin contacto con la tuberosidad deltoidea. La zona delimitada por ambas crestas sólo es diferenciable a lo largo del primer cuarto del húmero a partir de una textura rugosa. Existe un margen craneal rugoso en lugar de una cresta deltopectoral, que se extiende hasta el principio del último tercio del húmero. El tubérculo menor, diferenciado claramente del cóndilo, es robusto y desarrollado en gran medida en dirección proximodistal, y se orienta en sentido medial.

En el extremo distal, ambos epicóndilos presentan un importante engrosamiento en sentido cráneocaudal. El epicóndilo lateral posee un desarrollo lateromedial moderado, mientras que el medial posee un gran desarrollo en dicha dirección. El epicóndilo medial no alcanza el margen distal medial de la tróclea y en su sector proximal presenta una incisura, de posición marginal en vista craneal. El foramen supracondiloideo, de moderado desarrollo, posee forma oval. En vista caudal, su apertura es mucho mayor, elongada proximodistalmente, en comparación con lo que ocurre en vista craneal. Este foramen se encontró ausente en el húmero derecho del espécimen MNHN CG1985-157. El puente supracondiloideo es moderado a robusto. En vista craneal, en el centro del epicóndilo medial, en algunos especímenes se 
diferencia una zona deprimida o incluso un pequeño foramen ciego (e.g., MLP 1013), distal al foramen supracondiloideo. La cresta epicondiloidea posee gran desarrollo próximodistal y un bajo desarrollo lateromedial a lo largo de toda su extensión, excepto en la zona próximomedial, en donde se muestra moderadamente desarrollada. La tróclea está bien desarrollada proximodistalmente, y moderadamente desarrollada en sentido lateromedial en relación al capítulo, con un margen medial principalmente desarrollado en dirección lateromedialmediodistal, y con una profundización moderada. El capítulo posee forma intermedia entre cilíndrica y semiesférica, con un margen lateral engrosado, y con un reborde proximal marcado (“capitular tail"). La fosa coronoidea posee un breve desarrollo y se encuentra poco diferenciada, mientras que la fosa radial es profunda, transicionalmente diferenciada respecto a la diáfisis distal. En ningún caso existe perforación del sector.

En vista caudal, la zona articular posee un margen medial marcado, mientras que el margen lateral posee un límite marcado y bien definido. La fosa olecraneana es amplia, de gran desarrollo en sentido proximal, de profundidad importante y los márgenes lateral y medial definidos. La fosa para el tendón del olécranon es amplia, triangular a oval, muy profunda, con márgenes lateral y medial definidos y excavados, mientras que su margen distal se proyecta hacia distal a modo de una plataforma que interrumpe la zona articular en su extremo medial. Entre la fosa olecraneana y la fosa para el tendón del olécranon existe un tabique divisor sobresaliente.

\section{Ulna (Lámina 3.10A)}

Es recta en vista lateral y levemente curvada en sentido medial en vista craneal, siendo recta en su cuarto más distal. En vista lateral, el desarrollo cráneocaudal del olécranon es similar al de la diáfisis a nivel de la incisura troclear, y disminuye suavemente hasta justo antes del extremo distal. El olécranon se encuentra moderadamente desarrollado en dirección cráneocaudal y reducido en dirección próximodistal en comparación con el resto del elemento, inclinando en sentido medial. Los extremos craneal y especialmente caudal de la tuberosidad del olécranon poseen un importante desarrollo en sentido medial y se encuentran a su vez engrosados. Tanto el margen craneal como proximal son ligeramente cóncavos, mientras que el posterior es recto a convexo. En la cara medial del olécranon, se presentan pequeños forámenes. La incisura troclear es somera. El proceso ancóneo es más bien asimétrico, con un mayor desarrollo del margen lateral en sentido proximal, y con un desarrollo en sentido craneal similar a algo menor que el coronoides. La incisura radial posee forma aproximada de triangulo isósceles (más claramente definida en MLP 1013 y CML 062308 que en CML 2722), y se orienta en un sentido cercano al plano posterior definido por la diáfisis ulnar, articulando el radio en una posición más bien lateral a la ulna. La base del mismo hace las veces de margen 
lateral de la misma y sobresale marcadamente en su sector distal. En este margen existe una muesca marcada que le da un aspecto cóncavo (excepto en CML 2722). La tuberosidad ulnar está claramente marcada en el sector cráneolateral de la diáfisis.

En la zona media y lateral del sector proximal de la diáfisis se presenta con claridad la concavidad próximodistal correspondiente al pasaje de un gran número de flexores y extensores digitales (e.g., flexor carpi ulnaris, extensor carpi ulnaris, m. abductor digiti I longus). En la zona lateral del centro de la diáfisis, la cresta correspondiente al ligamento interóseo está poco desarrollada (e.g., CML 2722 y CML 062308) o prácticamente no es visible (e.g., MLP 1013). En la zona distal, el proceso estiloides es romo y grueso lateromedialmente. Su superficie articular posee forma ovalada. La superficie diartrodial para el radio es grande, oval y se encuentra en posición craneal y elevada.

\section{Radio (Lámina 3.11A)}

Es de un largo similar a aproximadamente tres cuartos del largo del húmero, delgado y comprimido mediolateralmente, principalmente recto y cilíndrico, con una leve convexidad y algo aplanado en su extremo distal en vista craneal. La carilla articular proximal del radio posee una forma ovoide, con una leve escotadura en su cara cráneolateral (coincidiendo con la moderada elevación del extremo lateral del capítulo del húmero). En la zona lateral de la epífisis proximal se diferencia un tubérculo robusto que representa la inserción del ligamento colateral del codo. El sector medial del cuello del radio se encuentra particularmente engrosado. El sector proximal de la diáfisis muestra un cambio muy leve en la dirección del eje principal. En la cara caudomedial de la diáfisis, inmediatamente distal a la epífisis proximal, se diferencia la tuberosidad radial (inserción de ligamentos y del m. biceps brachii) como una zona rugosa seguida distalmente de un área aplanada con un surco próximodistal central y sobresaliente en su margen caudal.

En la zona caudal del segundo quinto de la diáfisis, se observa una cresta moderada a pobremente definida, que se corresponde con el lugar de fijación del ligamento interóseo; la misma presenta una longitud cercana a la mitad del largo total de la diáfisis. A lo largo de toda la cara caudal del sector medio y distal de la diáfisis se presenta una cresta aguda, suave, y amplia correspondiente a la zona de inserción del m. abductor digiti I longus (en la cara lateral) y cabeza radial del flexor digitorum profundus (en la cara medial). La cresta del m. pronator teres se presenta sutílmente definida a lo largo del tercer cuarto de la diáfisis radial.

El extremo distal, en vista ventral presenta una superficie articular carpal cóncava en forma de gota, cuyo eje principal posee dirección lateromedial, abriendo principalmente en sentido distal. En vista medial, el surco para el pasaje del $\mathrm{m}$. abductor digiti I longus tiene márgenes definidos y engrosados y posee una orientación principalmente lateroproximal- 
mediodistal, a unos $45^{\circ}$ del eje de la diáfisis radial. El tubérculo de inserción del $\mathrm{m}$. brachioradialis es agudo. El proceso estiloides está poco proyectado en sentido distal. La escotadura ulnar, en el margen lateral del extremo distal del radio, se encuentra claramente definida, con una forma circular y de márgenes marcados, inclinando en sentido proximal. Justo craneal a la escotadura ulnar, el surco para el pasaje del $\mathrm{m}$. extensor digiti I et II tiene su dirección principal próximodistal; está delimitado dorsalmente por un tubérculo cráneolateral robusto.

\section{Autopodio anterior (Lámina 3.12A)}

La serie carpal se encuentra moderadamente empaquetada; es convexa en vista dorsal y cóncava en vista plantar, y más extendida lateromedialmente que lo observado en otros mustélidos descriptos (pero ver lutrinos más adelante). El carpal radial y el ulnar son huesos aplanados, con un desarrollo próximodistal breve, especialmente en vista craneal. La superficie que recibe al radio es marcadamente convexa en sentido cráneocaudal (en mayor grado que hurones pero ver lutrinos más adelante), y posee un margen medial mucho menos marcado a prácticamente ausente debido a la gran extensión medial de la carilla articular para el radio. En vista craneal y dorsal, el carpal radial presenta un desarrollo lateromedial mayor al doble del observado en el ulnar (aproximadamente tres cuartos del mismo). La carilla articular para el radio del radial se extiende lateralmente tanto como a la altura de la mitad del cuarto metacarpo (o incluso más). En vista craneal, la zona de articulación entre el radial y ulnar posee una mínima extensión próximodistal en relación al importante desarrollo del cuarto carpal, inmediatamente distal a dicho contacto (ver más adelante). En su extremo medial, el radial contacta al sesamoideo radial mediante una superficie levemente convexa. En vista caudal se observa un sector no articular reducido y poco proyectado. Esta región se proyecta en sentido caudomedial, formando, a la altura del primer carpal, una prominencia redondeada poco desarrollada, sin llegar a formar un tubérculo diferenciado. En vista craneal, se observa una extensión distal del radial a modo de cuña entre los carpales II y III. El contacto del radial y los cuatro carpales se da por medio de una serie de bandas cóncavas y convexas marcadamente delimitadas. El sector medial de esta superficie contacta al primer carpal (contrario a lo observado en los otros mustélidos descriptos) y se separa del sector medial por una cresta convexa. El sesamoideo radial es algo aplanado pero robusto y desarrollado en dirección ventral o lateroventral. El carpal ulnar es un hueso cuadrangular y desarrollado en sentido proximodistal. La mitad caudal de su cara proximal se corresponde con la superficie de contacto con el carpal accesorio, es aplanada a levemente cóncava, ovalada o cuadrangular, y expandida lateromedialmente; la mitad craneal es aplanada en el plano transverso y cóncava en el plano cráneocaudal. La separación entre ambas superficies se denota como un margen algo elevado. 
La cara laterodistal es alargada cráneocaudalmente y mayormente plana, y contacta al quinto metacarpal. El sector caudal se proyecta a modo de un tubérculo palmar. El carpal accesorio posee su extremo libre moderadamente robusto y redondeado y relativamente poco proyectado, desarrollado proximodistalmente, y divergiendo en sentido lateral. La articulación con el ulnar es rectangular y levemente convexa, algo aguzada en su sector medial. En vista dorsal, en el sector craneal, el carpal accesorio presenta una región articular triangular y plana a levemente cóncava que, junto con la superficie correspondiente y adyacente del ulnar, recibe a la ulna. Entre esta superficie y el extremo posterior libre, el carpal accesorio se encuentra comprimido lateromedialmente.

Los carpales distales se contactan entre ellos por zonas de articulación aplanadas, a excepción del segundo y el tercero, cuyo contacto es mínimo en vista craneal y levemente convexo-cóncavo, teniendo el tercero una forma peculiar de "L" al retirar el radial. El carpal I posee una importante extensión en sentido distal a modo de una cuña roma entre los metacarpales I y II, aunque se extiende distalmente menos que la base del metacarpal I. En vista caudal, existe un tubérculo plantar rudimentario justo proximal y lateral al tubérculo plantar del metatacarpal I. El carpal II, en vista craneal, posee una superficie no articular ovalada, aplanada en sentido proximodistal. La arista más lateral se proyecta escasamente en sentido lateral, apenas contactando y superponiéndose lateralmente con el margen medial del carpal III. El carpal III es un hueso de forma irregular, alargado proximodistalmente (más que Ga. cuja) y cráneocaudalmente. En vista craneal posee forma de "L" o triangular (sin definirse tan claramente la forma de "L" característica Ga. cuja): el sector medial contacta al carpal II principalmente en el plano sagital. El margen lateral se eleva marcadamente (apenas menor que la altura del carpal IV), aumentando el área de contacto con el carpal IV, siendo este área semicircular y convexa a irregular (parcialmente cóncava en algunos sectores). En vista craneal, la mitad proximal de este contacto es cubierto por el radial. En vista caudal, el tubérculo plantar del carpal III se encuentra desarrollado como un área plana y algo proyectada lateral y medialmente. El carpal IV prácticamente triplica en desarrollo areal a cualquiera de los demás carpales distales en vista craneal; tiene una morfología similar a un triangulo de vértices romas, marcadamente proyectado en sentido proximal y lateral. Es notablemente más alto que el carpal III. Su base es muy amplia en sentido lateral, aumentando el área de contacto con el metacarpal V. El área de contacto con el carpal III ocupa toda la vista medial, exceptuando un sector proximal que corresponde al área de contacto con el radial, un breve sector no articular incidente en el sector caudodistal, y otro similar en el sector craneoproximal (estos últimos poblados de foramina; y el último de estos no registrado en $G a$. cuja). El carpal IV no presenta un tubérculo palmar definido. La cara lateral de carpal IV, articula con el ulnar y es convexa y 
ovalada. En vista craneal, el contacto radial-carpal IV se aleja más de $45^{\circ}$ del plano horizontal, mientras algo similar ocurre en el contacto ulnar-carpal IV.

Todos los dígitos se encuentran bien desarrollados. El metacarpal I es el de menor longitud, con un valor cercano a los dos tercios del de mayor longitud (metacarpo III). Los metacarpales son rectos a muy levemente convexos en vista dorsal. El metacarpal V articula con un pequeño hueso sesamoideo metacarpal elíptico en el principio de su cara plantar. El metacarpal III y IV son los más elongados, llegando levemente más distal el IV por la posición de la articulación distal del carpo, seguidos por el II, V, con similar desarrollo, y finalmente el metacarpal I. Proximalmente, los metacarpales II, III, IV y V poseen bases definidas y expandidas posteriormente, especialmente en el caso de los más laterales, mientras que el metacarpal I está relativamente poco proyectado en sentido caudal. Los sesamoideos metacarpales son robustos, bien desarrollados y redondeados para los metacarpales II, III, IV y $\mathrm{V}$; mientras que el sesamoideo medial del dígito I se encuentra reducido. Las falanges proximales tienen similar desarrollo en todos los dígitos. Estas falanges son robustas en comparación con los metacarpos. Las falanges medias también son robustas (especialmente para los dígitos II al V). Las zonas articulares y de inserciones tendinosas son generalmente robustas. La falange proximal del dígito I es más grácil y se curva hacia lateral, siendo similar en longitud a las demás falanges proximales. Los márgenes ventrolateral y ventromedial de la diáfisis de esta falange presentan engrosamientos a modo de cresta que se proyectan desde proximal hasta la mitad de la longitud de la misma. Las falanges ungueales poseen crestas ungueales robustas y elongadas dorsoventralmente, y procesos homónimos marcadamente desarrollados, aplanados lateromedialmente y elongados dorsoventralmente. El margen ventral de estos es mayormente recto, y el margen dorsal es curvo en toda su extensión, contactando al margen ventral en un ángulo marcado en el extremo distal. Las unguis son elongadas, muy agudas en sentido distal y poco engrosadas lateromedialmente, pero aumentando en gran medida la extensión distal de las falanges ungueales (más allá del nivel alcanzado por el proceso ungueal).

\section{Hueso coxal (Lámina 3.13A)}

El ilion define un plano de unos $60^{\circ}$ o $70^{\circ}$ respecto del definido por isquion y pubis. El acetábulo, de tamaño grande en relación al desarrollo del total de la pelvis, posee una forma circular algo distorsionada debido a la prominencia del margen craneal del mismo. La incisura acetabular es profunda y de tamaño moderado, y en su margen caudal, en una zona deprimida se diferencian claramente una (e.g., lado derecho de MLP 1013) o dos forámenes pequeños (e.g., lado izquierdo de MLP 1013). Su extensión total es de un tercio o algo menos respecto a la circunferencia total. El foramen obturador es de forma oval. La superficie sinfisaria posee un gran desarrollo en sentido cráneocaudal; está engrosada en el sector medio y craneal, y está 
fuertemente dentada. El ala del ilion posee forma rectangular, es cóncava y robusta (excepto en su extremo cráneoventral, el cual es más bien delgado); supera ampliamente las articulaciones craneales del sacro. El cuello tiene sección rectangular y es dorsoventralmente ancho. La espina ilíaca ventro-craneal se proyecta en sentido craneal y es aplanada, mientras que la dorso-craneal, la dorso-caudal, así como toda la tuberosidad sacra, presentan un fuerte robustecimiento. La espina ilíaca ventro-caudal, así como toda la tuberosidad coxal, poseen un moderado a bajo desarrollo, diferenciándose la primera como un leve engrosamiento y algunas rugosidades. La cresta ilíaca, en su sector medio y dorsal, presenta un margen recto inclinando cráneodorsalmente. La escotadura ciática mayor se encuentra profundizada a lo largo de su breve extensión en dirección cráneocaudal. La superficie articular del ilion se encuentra poco desarrollada y posee márgenes más bien redondeados. En la cara lateral del cuello del ilion, apenas se diferencian la línea glútea caudal y el tubérculo del $\mathrm{m}$. rectus femoris, el cual es de forma elíptica y rugoso.

El ángulo formado entre el cuerpo del isquion y pubis es de aproximadamente $70^{\circ}$. El cuerpo del isquion es robusto y forma un ángulo abierto, cercano a los $120^{\circ} \mathrm{o}$ menor, respecto a la rama del isquion, la cual es amplia, excepto en el sector medioventral donde se adelgaza cráneocaudalmente. La espina isquiática se presenta como un fuerte tubérculo de gran desarrollo mediolateral, que se posiciona algo caudal a la altura del sector más caudal del margen acetabular, y que se continua en sentido craneal como una zona elevada a modo de cresta. Caudalmente se continúa por la escotadura ciática menor, que se muestra como un borde recto y engrosado. La arcada isquiática se diferencia escasamente del resto del margen caudal del isquion, continuándose con el margen caudal de la tabla del isquion, excepto en el espécimen SNMS 480, en donde es amplia y somera. La tabla del isquion se muestra como una superficie amplia, ganando superficie hacia la parte caudal de la zona del foramen obturado. La tuberosidad isquiática se muestra como una zona engrosada con márgenes transicionales al resto del isquion a brevemente definidos, proyectada en sentido dorsal, pero no lateralmente.

El cuerpo del pubis es cuadrangular, corto y robusto lateromedialmente; presenta una eminencia ilio-pubiana no diferenciada, con una línea arqueada prácticamente indiferenciable. El margen dorsal presenta rugosidades o con pequeñas proyecciones hacia el foramen obturador. El cuerpo del pubis es levemente curvo medialmente en su extremo distal. El pecten pubiano se diferencia del resto del margen cráneoventral como una proyección aguda (robusta en SNMS 480), ubicada a media altura de la zona articular. La rama caudal del pubis posee sectores craneal y caudal de gran desarrollo areal, mientras que en su zona media o mediocaudal posee una constricción pronunciada. Aunque la rama caudal del pubis es relativamente amplia cráneocaudalmente, la sínfisis sólo ocupa el sector craneal y medio de la misma. 
Fémur y patela (Lámina 3.14A)

El fémur es un elemento delgado, principalmente cilíndrico y elongado, muy levemente curvado en sentido caudal en su sector mediodistal. La cabeza del fémur se muestra pobremente proyectada en sentido medial y se encuentra orientada en sentido dorsal. En vista medial, la fóvea se encuentra en el centro de la cabeza, levemente desplazada en sentido caudal. El trocánter mayor se encuentra bien desarrollado, como una proyección recta, roma y robusta que se eleva por sobre el cuello, pero sin sobrepasar en altura a la cabeza articular y más bien paralelo a la diáfisis, con una leve inclinación medial. La escotadura dorsal entre la cabeza femoral y el trocánter mayor es somera. La fosa trocantérica es profunda, presenta un moderado desarrollo proximodistal, y se encuentra en parte cubierta por su margen lateral. El trocánter menor se muestra bien desarrollado, robusto y claramente definido (aunque no tanto en el caso de CML 2722). La tuberosidad glútea se encuentra reducida a un área subcircular, sobre la cara lateral del trocánter mayor, sin superar distalmente la extensión de la fosa trocantérica. Esta tuberosidad se continúa distalmente por un área rugosa en el margen caudolateral del fémur que supera distalmente la altura del trocánter menor. Sobre las caras lateral, medial y posterior de la diáfisis, en cercanías al extremo distal, la superficie se muestra rugosa. El margen dorsal del cuello femoral, sector entre el trocánter mayor y la cabeza femoral, es deprimido, siendo más profundo en cercanías al trocánter mayor.

En el extremo distal, la tróclea femoral es amplia lateromedialmente y se encuentra delimitada por los labios medial y lateral, el primero de los cuales se encuentra poco desarrollado, de menor altura que el segundo en vista distal. En vista craneal, la tróclea posee una terminación abrupta en su sector craneoproximal a la altura, o justo por sobre, de las carillas articulares para los huesos sesamoideos supracondiloideos (i.e., terminación proximal y posterior de los cóndilos articulares), dando, en vista lateral y medial, un aspecto bastante simétrico al extremo distal femoral. En la región proximal a la tróclea, un área aplanada, rugosa y con foramina nutricias se continúa con una muy breve extensión por la superficie craneal de la diáfisis, perdiéndose hacia proximal muy tempranamente. En vista distal, ambos epicóndilos poseen un importante desarrollo en sentido lateral y medial, especialmente el lateral, mientras que los cóndilos se proyectan escasamente en sentido caudal, el medial en mayor magnitud que el lateral. Debido a estas características, en vista distal el fémur posee un mayor desarrollo lateromedial que cráneocaudal. En esta vista, el desarrollo cráneocaudal de la tróclea es claramente menor al de los cóndilos. Sobre el epicóndilo lateral, la fosa del extensor se encuentra poco definida. La fosa de origen del $\mathrm{m}$. popliteus parece confluir con la zona de fijación del ligamento colateral lateral y se encuentra muy bien definida, amplia y profunda, especialmente en su sector craneal. La fosa intercondiloidea es profunda y amplia en sentido lateromedial, separando en gran medida a los cóndilos articulares e inclinando en sentido lateral 
en su zona más craneal. Tanto ambos epicóndilos como la fosa intercondiloidea en vista caudal poseen un gran número de foramina nutricias, y zonas deprimidas amplias correspondientes a zonas de agarre de varios grupos de ligamentos (e.g. ligamentos crucianos). En vista caudal no se encuentran presente la tuberosidad supracondiloidea lateral, pero sí existe una sobresaliencia medial, posiblemente correspondiente a la tuberosidad supracondiloidea medial. Ambas carillas para los sesamoideos supracondiloideos se encuentran muy marcadas y profundas. La patela es principalmente cuadrangular en vista craneal, aplanada y ancha en la mayor parte de su extensión, poseyendo una base robusta en su extremo proximal, con un ápice que rápidamente se vuelve agudo en una breve extensión.

Tibia (Láminas 3.15A, 3.16A)

Es un hueso en general grácil, pero robusto en su sector medioproximal, con una sección aproximadamente triangular, curvado lateralmente en su zona media, excepto su extremo distal que es cilíndrico y totalmente recto. En vista proximal (Lámina 3.15A), el cóndilo lateral es aproximadamente circular y posee un desarrollo mediolateral mayor que el del cóndilo medial (aunque ambos cóndilos muestran un mayor desarrollo lateromedial de lo observado en Ga. cuja y Ly. patagonicus). El cóndilo medial posee forma arriñonada a semicircular, con su mayor eje en sentido cráneocaudal, dirección en la cual iguala en extensión al cóndilo lateral. Ambos cóndilos, en vistas lateral y medial, se muestran aplanados a levemente convexos en dirección caudal y cóncavos en dirección lateromedial, encontrándose el cóndilo lateral en un plano algo elevado respecto al del cóndilo medial. En vista proximal, la zona intercondiloidea craneal (área de inserción de los ligamentos crucianos craneales) tiene un desarrollo breve en sentido cráneocaudal, terminando en una tuberosidad relativamente aplanada y de moderado desarrollo lateromedial. La zona laterocraneal (craneal al cóndilo lateral), se muestra robusta y proyectada cranealmente a la zona levemente deprimida correspondiente al surco del extensor, formándose una región marginal también cóncava entre este sector y la tuberosidad tibial. La eminencia intercondiloidea se muestra moderada a marcadamente desarrollada. Tanto el área intercondiloidea craneal como caudal, y los márgenes laterales y mediales de la epífisis proximal de la tibia, muestran áreas cóncavas marcadamente delimitadas y desarrolladas, indicando un gran desarrollo de los ligamentos de la rodilla. El cóndilo medial posee un margen medial plano o fuertemente escindido (en el caso de MLP 1013), seguramente en relación al gran desarrollo y zona de tránsito del ligamento colateral medial. En vista caudal, bajo el cóndilo medial, se observa un tubérculo aplanado en sentido proximodistal, aunque de márgenes no muy definidos, correspondiente a la superficie de inserción del ligamento cruciano caudal. Tanto en la zona craneal, como lateral y medial a los cóndilos, se presentan un gran número de foramina nutricias. 
En vista lateral, la fosa tibial se muestra como una superficie fuertemente cóncava en su sector proximal, con la presencia de múltiples foramina nutricias, y levemente cóncava a aplanada distalmente, ocupando algo más que el primer cuarto de la diáfisis tibial, delimitada en su margen craneal por una cresta tibial recta y levemente reflecta en sentido lateral, robusta y muy rugosa, que termina abruptamente hacia distal en una muesca de márgenes definidos. En vista medial, el sector proximal de la diáfisis se muestra muy rugoso y posee foramina nutricias en su sector más proximal, y en la zona caudomedial de esta región, hay una cresta de dirección proximodistal, breve pero muy robusta y rugosa, que indica la inserción del ligamento colateral medial. La superficie articular para la cabeza de la fíbula posee forma ovoide y se encuentra menos desarrollada en sentido caudal que el cóndilo lateral. Se encuentra ventral al cóndilo lateral en vista caudal, pero no inmediatamente continuado con éste, sino separada por una superficie, que en vista lateral posee una forma oval, agudizada caudalmente. En vista caudal, la diáfisis posee al menos dos crestas robustas, separadas por una zona amplia, triangular y cóncava. La más lateral es la más marcada, nace en la zona caudolateral de la diáfisis, definida hasta el primer tercio de la diáfisis, y luego de la cual continúa con menor diferenciación, perdiéndose luego del segundo tercio, divergiendo lateralmente a lo largo de toda su trayectoria. En el sector medio de esta cresta, su cara medial presenta una incisión delgada, localizada y profunda, correspondiente a un foramen nutricio que ingresa tangencialmente (variando la altura en la cual se presenta en ambos miembros). Esta cresta posiblemente corresponda al origen del $\mathrm{m}$. flexor digitorum lateralis y membrana interósea. La segunda cresta es medial a la anterior y pierde definición antes de alcanzar el primer tercio de la diáfisis, posiblemente sea la zona de inserción $\mathrm{m}$. popliteus o m. flexor digitorum medialis.

El extremo distal de la tibia es amplio lateromedialmente y cráneocaudalemente, con un gran número de forámenes nutricios en su sector craneal y medial. En vista distal, la superficie articular posee una forma cuadrangular a triangular (algo más angosta en su sector lateral), con una superficie central incidida por los dos surcos de la cóclea tibial. La depresión correspondiente a la zona de articulación con la cresta medial y aguda de la tróclea del astrágalo, se muestra como una depresión muy marcada y abrupta, delimitando una base angosta del maléolo medial en vista craneal. El segundo de los surcos, en el sector lateral de esta superficie articular (continuada por superficie articular distal de la fíbula), corresponde a la zona de articulación con la cresta lateral de la tróclea del astrágalo, y se observa como una zona también incidida, en similar magnitud respecto a la craneal. En vista caudal, el margen caudal de la superficie articular distal es poco sinuoso: cóncavo en el sector medial, levemente convexo en la zona central, y con una concavidad amplia pero suave, en la región lateral, poco escindido por el margen medial y lateral de la tróclea del astrágalo. La faceta fibular distal es una pequeña región ovalada y aplanada, con su eje principal en dirección proximodistal. El maléolo medial es 
muy delgado y proyectado. En la zona medial y caudal del maléolo medial, medial al surco maleolar tibial, se observa un segundo surco, correspondiente al pasaje del tendón del $\mathrm{m}$. tibialis caudalis. Este canal es muy amplio, flanqueado por dos crestas robustas, de dirección lateroproximal-mediodistal, que se pierde en cercanías a la superficie articular distal. La más medial de las crestas sirve de origen a la porción larga del ligamento colateral medial y se proyecta en su sector proximal a modo de un tubérculo robusto.

\section{Fíbula (Lámina 3.17A)}

Es aplanada en un plano cráneomedial-caudolateral; sólo los extremos articulares son robustos. En vista proximal, la articulación de la cabeza de la fíbula muestra una forma elíptica a irregular, ocupando menos de la mitad del área observada en dicha vista, en una posición desplazada en sentido craneal y medial. En el sector proximal y laterocraneal se presenta el tubérculo del $\mathrm{m}$. fibularis longus con una base y extremo robustos. En el sector mediocaudal se diferencia una zona elevada finalizada abruptamente en una superficie plana, cuyo principal eje posee una dirección proximodistal, y que se relaciona con la inserción del $\mathrm{m}$. soleus. Justo medial a éste, se diferencia un segundo tubérculo de menor magnitud que sobresale notablemente en sentido medial, posiblemente el origen del $\mathrm{m}$. flexor digitorum medialis o $\mathrm{m}$. tibialis caudalis. Bajo este último se proyecta una cresta que se vuelve delgada rápidamente, a modo de una sobresaliencia que supera el primer tercio de la diáfisis, correspondiéndose posiblemente a la región de origen del $\mathrm{m}$. extensor digiti I longus y quizás secundariamente del m. flexor digitorum lateralis.

El extremo distal de la fíbula posee su eje principal fuertemente desarrollado en dirección cráneomedial-caudolateral. El sector más craneal del maléolo lateral posee un desarrollo en sentido distal levemente mayor respecto al caudal, y es moderado a delgado y proyectado en similar magnitud que el maléolo medial. En vista distal, el sector medial y craneal corresponde a la faceta astragalar de la fíbula, la cual posee forma cuadrangular a oval, aplanada, y se encuentra verticalizada. La faceta tibial es cuadrangular, aplanada a levemente cóncava, y con su mayor eje en dirección proximodistal. En el extremo laterocaudal del maléolo lateral, un tubérculo alargado proximodistalmente, de contorno semicircular y muy bien diferenciado separa dos surcos, que a su vez son delimitados por dos crestas. El primer surco, es la zona de tránsito del tendón del $\mathrm{m}$. fibularis longus, la cual posee una posición lateral y superficie cóncava, y está delimitada en su margen craneal por una cresta muy bien definida, que alcanza extremo distal de la fíbula en el caso del espécimen MLP 1013. El segundo surco, el surco maleolar fibular, posee una posición caudolateral, es más amplio y también muy bien definido, con su margen caudal delimitado por una cresta muy robusta pero de breve extensión. 
Este surco es la zona de tránsito de los tendones del $\mathrm{m}$. extensor digitorum lateralis y $\mathrm{m}$. fibularis brevis.

Autopodio posterior (Láminas 3.18A, 3.19A)

Los huesos del tarso poseen un moderado a débil empaquetamiento, con algunas aristas poco angulosas entre tarsales. Amplios espacios sin contacto se desarrollan en el centro de la cara de contacto entre el tarsal III y IV, así como en las zonas de contacto entre el tarsal II y III y metatarsal II, tarsal II y I, y en la zona de contacto entre el tarsal I, II y el central. El astrágalo presenta un cuello y cabeza con un desarrollo proximodistal, en vista medial, algo mayor al observado para la tróclea. La tróclea (Lámina 3.18A) es moderadamente profunda. Sus dos crestas están definidas a lo largo de toda su extensión, similares en altura. La separación entre ambas es aproximadamente constante a lo largo de toda la tróclea, aunque en el sector caudal se acercan levemente. En vista dorsal, en el sector lateral de la base del cuello se observa una depresión astrágalotibial amplia y muy somera. En vista lateral, la carilla maleolar lateral presenta forma ovalada, poco extendida en sentido craneal. La superficie articular proximal y el tubérculo del talus sobresalen escasamente en vista ventral. La superficie articular proximal es ancha, cuadrangular y cóncava. La superficie articular medial inclina medialmente, y es fuertemente convexa, alargada y algo angosta, ocupando la mayor parte de la superficie ventromedial del cuello. El área ubicada entre esta zona articular y la cabeza presenta una zona deprimida marcada. En vista distal, la superficie articular para el tarsal central es ovalada a arriñonada y alargada en sentido lateromedial, sin estar constreñida e incluso ensanchada en su extremo medial. En vista ventral, entre las superficies articulares hay múltiples forámenes pequeños secundarios o una principal, relacionado a un canal astragalar obliterado.

El tubérculo del calcáneo (Lámina 3.18A) es relativamente largo (excepto en CML 062308) y disminuye gradualmente en altura su extremo caudal. En vista dorsal, el cuello posee márgenes aproximadamente rectos y una robustez similar en toda su extensión. El surco del tubérculo del calcáneo (zona de pasaje e inserción del tendón del m. flexor digitorum superficialis) se presenta bien definido y asimétrico. El área sustentaculum tali es relativamente breve; diverge respecto a la cara medial del tubérculo, formándose, en vista dorsal, un ángulo mayor a los $90^{\circ}$ entre ambos (MLP 1013, CML 062308), o algo menor (CML 2722). La superficie articular medial para el talus posee forma oval, con un ancho máximo en la zona media, y forma un ángulo menor a $45^{\circ}$ respecto al eje mayor de la articulación para el tarsal IV. La superficie articular proximal para el talus es marcadamente alargada y convexa en dirección proximodistal. El proceso troclear, zona de origen del $\mathrm{m}$. quadratus plantae, posee forma de una plataforma poco expandida lateralmente, sin alcanzar el margen distal del calcáneo, siendo 
menos desarrollada distalmente que lo observado en otros mustélidos descriptos. La superficie articular para el tarsal IV es oval a circular y ligeramente cóncava.

El tarsal central (Lámina 3.19A) es poco aplanado en sentido proximodistal, prácticamente duplicando la altura del carpal II. En vista medial, la cara articular que contacta al astrágalo se encuentra fuertemente elevada en su margen craneal, a modo de un "tope" (muy distinto a lo observado en otros mustélidos sudamericanos comparados, ver más adelante). El extremo mediodistal del central y el sector medial del tarsal I, contactan a un sesamoideo tibial, reducido a atrofiado y aplanado sobre el cual se inserta el $\mathrm{m}$. tibialis caudalis. En vista distal, la carilla articular que recibe a los tarsales I, II y III es convexa, reniforme, con el sector que recibe al tarsal III parcialmente delimitado. La superficie de los sectores de articulación con el tarsal I y II es aproximadamente rectangular a triangular. El proceso plantar es una protuberancia muy poco desarrollada, sin extenderse proximodistalmente. Los tarsales I, II y III están moderadamente imbricados, con todas sus aristas redondeadas. En el tarsal I, la carilla articular para el metatarsal I se encuentra principalmente en el plano transversal, aunque inclina moderadamente en sentido ventromedial. El tarsal II posee forma de cubo. En el sector distal de la zona de contacto entre éste y el tarsal I, se abre un amplio espacio, debido a que ambas superficies son cóncavas. En vista distal, presenta la articulación para el metatarsal II es triangular a cuadrangular, con vértices redondeados y plana a levemente cóncava. En vista ventral el tarsal II se encuentra fuertemente encerrado por el tarsal I. El tarsal III posee un proceso plantar hipertrofiado y cuadrangular; en vista distal, la carilla articular para el metatarsal III posee forma de "L" o "T", es cóncava y con una constricción media. El tarsal IV posee un desarrollo próximodistal menor al del tarsal III y central juntos, y similar al desarrollo en altura del tarsal II y el central (debido al gran desarrollo proximal de la pared craneal del central). Las áreas de contacto de este tarsal con el calcáneo (proximal) y el astrágalo (proximomedial) son más bien irregulares, inclinando sutílmente en sentido distal y aproximadamente paralelos. La cara medial del tarsal IV articula en su primer tercio con el central y distalmente con el tarsal III, ambos en un mismo plano. Las facetas articulares para el tarsal III y central se encuentran separadas por un surco que presenta numerosas foramina. En vista medial, el margen distal del tarsal IV y la zona central de articulación con el tarsal III se encuentran incididas formándose una amplia zona deprimida, que abre dorsalmente como un canal entre este tarsal y el tarsal III, y que se continua distalmente como un canal entre los metatarsales III y IV. La cara distal del tarsal IV es cóncava en sentido dorsoventral y articula con el metatarsal IV y V exclusivamente, sin formar un contacto de tipo cóclea-tróclea. En vista ventral, el proceso plantar del tarsal IV es robusto y se proyecta en sentido ventromedial, formando la pared proximal y elevada del canal de pasaje del tendón del m. fibularis longus. En vista ventral, entre el proceso plantar del central y el tarsal IV se delimita una zona deprimida en 
la superficie del segundo elemento. En vista lateral, el surco para el tendón del m. fibularis longus se observa como una incisura muy profunda entre el proceso plantar del metatarsal $\mathrm{V}$ y el proceso plantar del tarsal IV, que se continua, en vista ventral como un surco muy profundo y ancho de trayectoria recta.

Los cinco metatarsales son moderadamente robustos; encontrándose el primero menos estrechamente empaquetados a los restantes. Todos los metatarsales son levemente convexos en dirección próximodistal y expandidos lateromedialmente en su extremo distal. Los metatarsales III y IV son los elementos de mayor longitud total, siendo el IV sutílmente mayor que el III. Son seguidos en longitud por el II y V, siendo el V sutílmente mayor que el II. Finalmente, el metatarsal I es el de menor longitud, aproximadamente cuatro quintas partes de la longitud del mayor metatarsal. En vista ventral, en el sector proximal del metatarsal I se observa un proceso plantar breve y robusto. Justo lateral a éste, la base de este metatarsal se proyecta a modo de una plataforma, hasta alcanzar a obliterar (en conjunto con el proceso plantar del metatarsal III) el sector proximal del metatarsal II en todo su ancho, exceptuando un breve sector. Esta plataforma no supera distalmente al tubérculo plantar (menor a un sexto de la longitud total del metatarsal I). El margen lateral se muestra como un reborde redondeado y engrosado. El proceso plantar del metatarsal II es moderado a grácil, se ubica lateroproximal al proceso plantar del metatarsal I. Los procesos plantares del metatarsal III y IV poseen una forma elíptica, aplanada proximodistalmente, especialmente en el segundo caso. El metatarso IV contacta al $\mathrm{V}$ mediante un área ovalada y fuertemente cóncava y al III mediante una superficie fuertemente convexa. Por otro lado, la cara medial del sector proximal del metatarso IV (incluyendo el sector ventral de la zona articular descripta) se encuentra fuertemente incidida, continuándose el canal descripto entre el tarsal IV y tarsal III. El proceso plantar del metatarsal $\mathrm{V}$ está bien desarrollado y proyectado marcadamente en sentido lateral, aunque con un desarrollo próximodistal restringido (mucho menor que el observado para el caso de Ga. cuja, especialmente en el espécimen MLP 1013). El sector central del extremo proximal es una superficie cóncava a aplanada, con un margen proximal engrosado, que se continúa con el proceso plantar, y hace las veces de pared distal del surco del tendón del $\mathrm{m}$. fibularis longus. Sobre este margen proximal, el metatarsal V recibe al sesamoideo de la base del metatarsal V, que es de moderado desarrollo, circular, y levemente aplanado en sentido proximodistal. Los sesamoideos metatarsales para los dígitos II al $\mathrm{V}$ se encuentran desarrollados proximodistalmente. En el dígito I, son más breves, subiguales y claramente individualizables. Las falanges proximales son de similar robustez o más robustas a lo observado en los metatarsos correspondientes. Las falanges medias poseen aproximadamente la mitad de la longitud de las proximales, siendo similares a estas últimas en los demás aspectos. En la superficie ventral y distal, se encuentran marcadamente desarrollados los tubérculos o crestas en donde reciben a los 
flexores superficiales de los dígitos. Tanto la base como la cresta ungueal de las falanges ungueales son moderadamente robustas y prominentes, poco desarrolladas lateromedialmente. En vista lateral, el proceso ungueal posee una superficie dorsal convexa en todos los casos, mientras que la superficie ventral es levemente cóncava a plana, siendo alto en la mayor parte del su extensión y terminando de manera abrupta. En vista dorsal, los procesos ungueales son delgados en toda su extensión. Las unguis son moderadamente elongadas, agudas en sentido distal, curvadas y poco engrosadas. 


\subsubsection{Lontra provocax}

Complejo atlas-axis (Láminas 3.1G, 3.2F)

El atlas (Lámina 3.1G) es un elemento robusto y comprimido en dirección cráneocaudal. En vista craneal, el foramen vertebral es ovalado a cuadrangular, con su eje mediolateral y dorsoventral similares, mientras que en vista caudal posee una forma más bien circular y comprimida en su zona media, a modo de un "reloj de arena" ancho, en relación a la proyección medial de las carillas articulares (ver más adelante). Los forámenes vertebrales laterales, relativamente amplios, son poco extendidos cráneocaudalmente en vista dorsal, mientras que internamente se ubican justo dorsal a las superficies articulares craneales. En vista dorsal, el arco neural posee un margen craneal recto a levemente convexo y bilobado. El tubérculo dorsal tiene una forma compleja y sobresaliente (ampliamente desarrollado en MACN 20821 y MMPMa 141 y menos desarrollado en IPUM 052). El tubérculo ventral se proyecta en forma de un extremo agudo en dirección ventral y caudal. Las superficies articulares caudales inclinan moderadamente (unos $45^{\circ}$ ) en sentido medial. Éstas son de contornos redondeados y se proyectan en forma aguda en sentido caudal, sin sobresalir dorsalmente. Estas carillas articulares poseen una proyección o ampliación a modo de sobresaliencia redondeada y marcada en sentido medial, dando la particular forma constreñida descripta para el foramen vertebral en vista ventral. Las alas del atlas son comprimidas en dirección cráneocaudal y expandidas lateromedialmente, rectangulares, sobresaliendo brevemente por detrás de los procesos articulares caudales, con su extremo caudolateral expandido. En vista lateral, las alas del atlas se ubican principalmente en un plano cráneodorsal-caudoventral en cercanías a la base, pero con una dirección cráneocaudal en sus extremos, siendo levemente cóncavas en su sector basal en vista ventral y levemente convexa en su margen lateral. En líneas generales, su margen caudal es levemente cóncavo, mientras que el lateral es convexo. La zona de transición entre ambos, así como el extremo caudomedial de las alas se encuentran engrosadas. La incisura alar se encuentra definida, es amplia, abierta, y en ningún caso, obliterada por un puente lateral. Los forámenes transversos son amplios y redondeados, y abren en sentido caudal a los lados de las superficies articulares caudales.

El axis (Lámina 3.2F) posee un proceso espinoso alto y amplio en dirección cráneocaudal, superando la extensión del cuerpo vertebral, el cual es relativamente comprimido. En su extremo más craneal se encuentra fuertemente engrosado, delimitándose tres tubérculos (en el espécimen MACN 20821, y secundariamente MMPMa 141); mientras que el extremo caudal posee forma de un tubérculo redondeado y ancho. En vista lateral, el margen dorsal es convexo en su sector medio (MACN 20821) o mayormente recto (MMPMa 141). El proceso odontoides se proyecta marcadamente en sentido craneal y es robusto, equiparando tres cuartas partes la altura de las carillas articulares craneales en su base. El foramen vertebral posee una 
altura de aproximadamente el doble que la base. Las carillas articulares caudales son elongadas lateromedialmente y posicionadas lateralmente. Los procesos articulares caudales son robustos, a modo de lámina engrosada. En vista craneal, las carillas articulares craneales se posicionan lateralmente, sin continuarse con el proceso odontoides, separadas del mismo por surcos profundos y amplios y ubicándose sólo su tercio dorsal a la altura foramen vertebral. La incisura vertebral craneal es redondeada. La incisura vertebral caudal es breve y de profundidad moderada. La cresta ventral del cuerpo está claramente definida y posee un tubérculo menor en la zona media, y dos caudales particularmente robustos. En vista ventral, entre los procesos articulares craneales y la cresta ventral, se delimita claramente la base del proceso odontoides, a modo de un margen semicircular que se continua por los márgenes laterales. Los procesos transversos se proyectan marcadamente. Estos divergen del plano sagital y longitudinal aproximadamente a $45^{\circ}$ en vista lateral, sin alcanzar el extremo craneal del proceso transverso de la tercera vértebra cervical, aunque sí el cuerpo de la misma. Los forámenes transversos son muy amplios, ovalados y altos. En vista lateral sus extremos más craneales están tapados por el límite caudal de las carillas articulares craneales. En vista caudal, los forámenes transversos poseen forma circular o de triángulo equilátero de aristas romas, encontrándose sus bases a la altura de la mitad del cuerpo vertebral y sus ápices a la altura de su margen dorsal.

\section{Tercera a séptima vértebra cervical (Lámina $3.3 \mathrm{~F}$ )}

Los procesos espinosos desde la tercera hasta la séptima vértebra cervical crecen en forma escalonada en sentido caudal. La tercera vértebra cervical posee un proceso espinoso breve y delgado. En vista lateral, su margen craneal es cóncavo y el caudal es recto a convexo, con una base amplia y el extremo dorsal redondeado. La cuarta, quinta y sexta vértebras poseen procesos espinosos (y forma general) muy similares entre sí; engrosados en su extremo dorsal. En vista lateral, son triangulares y poseen una altura que duplica la de sus bases. El proceso espinoso de la séptima vértebra cervical es apenas superior en altura al de la sexta vértebra cervical, prácticamente triplicando en altura a su base, y en su extremo dorsal está engrosado. En vista lateral, es triangular, con márgenes rectos, es algo curvado en sentido caudal. En vista dorsal, los arcos neurales se encuentran comprimidos cráneocaudalmente, siendo la relación entre ancho y largo aproximadamente de dos a uno. Entre vértebras sucesivas se abre una luz de un tercio a un quinto del desarrollo cráneocaudal de los arcos neurales. Las carillas articulares son grandes, anchas y de márgenes externos circulares. Los procesos que portan las carillas articulares craneales están levemente engrosados a modo de tubérculos ventrales a partir de la cuarta cervical (sin engrosamientos en la tercera); y progresivamente reducido en las posteriores en sentido caudal. Los procesos que portan las carillas articulares caudales están engrosados a 
modo de tubérculos o quillas dorsales amplias a lo largo de toda la serie (exceptuando el séptimo elemento), especialmente entre el axis y la quinta vértebra cervical.

Los procesos transversos cervicales son amplios. Las láminas ventrales poseen una morfología cuadrangular y alargada cranealmente, y constreñidas dorsoventralmente en la zona media en los elementos posteriores. En el caso de la tercera vértebra cervical, las láminas ventrales alcanzan en extensión al margen craneal y superan ampliamente al margen caudal del cuerpo vertebral, mientras que en el caso de la cuarta vértebra cervical estos superan ampliamente en extensión craneal y caudal al cuerpo, solapándose con los procesos transversos adyacentes. Para el caso de la quinta y sexta vértebras cervicales, las láminas ventrales de cada proceso transverso se extienden en sentido craneal y caudal hasta alcanzar, o levemente superar, los márgenes de cada cuerpo vertebral correspondiente. Los tubérculos dorsales de los procesos transversos se ubican en el sector caudodorsal, progresivamente mayores desde la tercera hasta la quinta vértebra cervical. En la sexta vértebra cervical se diferencia netamente a partir del centro del proceso transverso. En las primeras vértebras cervicales estos tubérculos se proyectan en sentido caudodorsal, acercándose a una dirección perpendicular en la sexta. Los tubérculos dorsales de los procesos transversos de la séptima vértebra cervical son similares en forma, posición y tamaño a los de la sexta vértebra cervical, levemente aplanados cráneocaudalmente. Los tubérculos ventrales de los cuerpos se presentan a modo de dos o tres procesos compartiendo una base robusta desde el axis hasta la quinta vértebra cervical.

\section{Vértebras torácicas y caja torácica (Lámina 3.4D)}

La serie torácica posee 15 elementos, ubicándose a la vértebra diafragmática en el elemento décimo segundo. Las crestas ventrales se presentan separadas y poco definidas a partir del elemento número 13. Las escotaduras craneal y caudal son amplias al comienzo de la serie tóraco-lumbar, se reducen a partir de la zona de la sexta y séptima vértebra torácica y se muestran especialmente obliteradas entre la última preanticlinal y anticlinal, y en la región postanticlinal. En vista lateral, la altura de los procesos espinosos se mantienen elevados y prácticamente perpendiculares hasta el cuarto elemento, y luego decrecen (e inclinan) progresivamente de manera monotónica. Los primeros procesos poseen una altura claramente superior a la de los cuerpos respectivos (el triple), mientras que la altura mínima es en la décima tercera, correspondiendo esta última con la vértebra anticlinal. En las primeras vértebras torácicas los procesos espinosos se ubican prácticamente perpendiculares y poseen márgenes convexos (exceptuando al margen caudal del primer elemento), mientras que en sentido caudal (hasta la décimo primera vértebra torácica, y en menor medida hasta la décimo segunda), se solapan progresivamente sobre los cuerpos de las vértebras adyacentes posteriores, con márgenes craneales rectos, y caudales levemente convexos a rectos. Todos los procesos 
espinosos poseen un extremo distal robusto. El desarrollo areal de los procesos espinosos es importante en todos los elementos de la serie, especialmente entre el segundo y el sexto (observaciones sobre ejemplar MACN 20821). El sector caudal de la base de los procesos espinosos, especialmente entre el segundo y el décimo primer elemento, se encuentra fuertemente expandido en sentido caudal y engrosado. En vista lateral, la décimo tercera vértebra posee un proceso espinoso algo asimétrico, de margen dorsal recto, bajo en altura y con forma de "ola truncada" o "meseta", que presenta un margen craneal cóncavo, una breve extensión cráneocaudal, y es más ancho en su margen caudal que craneal. A partir de éste, y hasta el último elemento de la serie, los procesos espinosos poseen forma de meseta, son sólo levemente más elevados y algo inclinados en sentido craneal, engrosados en su margen dorsal y desarrollados cráneocaudalmente.

Las fóveas costales de los procesos transversos son robustas, cóncavas y amplias en los primeros elementos preanticlinales; posteriormente, en la zona media y caudal anticlinal (desde el sexto elemento hasta el decimo segundo), son algo menores y convexas cráneocaudalmente, mientras que se encuentran ausentes en la vértebra anticlinal y elementos posteriores. En el caso de la primera vértebra torácica, la fóvea se posiciona por detrás de la altura de los procesos articulares caudales y muy distante a los mismos. A partir del cuarto elemento de la serie, las fóveas costales se posicionan justo a la altura de las zonas articulares, mientras que en el segundo y tercer elemento se observa una posición y distancia intermedia. A partir de la vértebra anticlinal (y prácticamente sobre la penúltima vértebra preanticlinal), las fóveas costales se ubican exclusivamente sobre el cuerpo vertebral correspondiente (sin incidir además en el precedente). Los procesos mamilares se presentan por primera vez y bien definidos en la vértebra anticlinal, presentándose casi tan robustos como los procesos espinosos, y alcanzando la mitad de la altura de estos últimos en todos los elementos de la serie, y reducidos hasta su mínima expresión en los últimos elementos lumbares. Los procesos accesorios se presentan con claridad a partir de la vértebra anticlinal, aunque se evidencian esbozos en la última preanticlinal. Desde la quinta a la décimo primera vértebra anticlinal, se diferencian unos tubérculos dorsales, que pueden entenderse como una continuación craneal a los procesos accesorios descriptos. En vista dorsal, los primeros procesos accesorios inclinan 20 a $30^{\circ}$ en sentido caudal, y rápidamente se vuelven paralelos al eje cráneocaudal.

Debido a que ninguno de los especímenes analizados preservó la caja torácica completa, algunos rasgos generales de la misma no pudieron ser descriptos (e.g., forma general, xifoides). En el espécimen MACN 20821 se registraron 8 esternebras desarticuladas (de las nueve potencialmente presentes, ver descripción de Lo. longicaudis). El elemento reconocido como la novena esternebra está reducido. El primero de los elementos es al menos dos veces y media la longitud que los posteriores y presenta, al final del su segundo quinto de su extensión, una zona 
robusta donde articula el primer par de costillas. El manubrio es aplanado dorsoventralmente, y se proyecta cranealmente a modo de una lanza de ápice romo y laterales agudos. Es totalmente plano en su cara dorsal y a modo de quilla en su cara ventral (la cual se continúa e incluso resulta más marcada en el sector craneal del cuerpo de esta primera esternebra). Los metámeros restantes son subiguales (exceptuando el último), robustos en extremo, y de sección cuadrangular (los primeros) a triangular (los últimos). Las costillas son 15 pares de elementos robustos, aplanados proximalmente. En el sector preanticlinal y anticlinal cada costilla presenta tubérculo costal, que se pierde en la sección postanticlinal correspondiente a las últimas tres vértebras torácicas. El quiebre de dirección en la zona del ángulo costal es suave desde los primeros elementos, y se pierde gradualmente en las últimas.

\section{Vértebras lumbares (Lámina $3.5 \mathrm{G}$ )}

La serie lumbar está compuesta por cinco vértebras. Son progresivamente más altas y grandes posteriormente, aunque no se observa una elongación cráneocaudal de los mismos en este sentido. El desarrollo areal de los procesos espinosos y transversos es importante. En vista dorsal, las vértebras son robustas, siendo especialmente corto el último elemento. En el primer elemento lumbar se observan crestas ventrales apenas diferenciables sobre el tercio caudal, similar a lo observado en el último elemento torácico. Estas crestas poseen un máximo desarrollo en el primer y segundo elemento lumbar; mientras que en las vértebras posteriores poseen un desarrollo menor y se posicionan más lateralmente.

En vista lateral, los procesos espinosos lumbares poseen forma intermedia entre meseta y cuadrangulares (especialmente en la zona media y caudal), inclinados en sentido craneal, similares a los descriptos en el último sector torácico, aunque son progresivamente más altos y menos robustos. Los márgenes dorsal y caudal son más bien rectos, mientras que el craneal es marcadamente sigmoideo. Las facetas articulares, presentan su mayor desarrollo lateromedial en la articulación entre la última vértebra lumbar y la zona sacra (similar a otras vértebras lumbares posteriores) y la mayor separación de zonas articulares de la serie. Entre los procesos articulares se observa escotaduras caudales y dorsales progresivamente más amplias en sentido caudal, partiendo desde casi obliterada en el sector caudal de la serie torácica, a amplias en la zona media y caudal de la región lumbar. Al igual que en los elementos postdiafragmáticos torácicos, las facetas articulares inclinan y se apartan respecto al plano longitudinal (distinto a lo observado entre las vértebras anteriores) entre 80 y $90^{\circ}$ (paralelas al plano sagital). En todo el sector postanticlinal torácico, y hasta la articulación entre la segunda y tercera lumbar, los procesos articulares craneales son cóncavos dorsoventralmente, rodeando parcialmente a los procesos articulares caudales con los que articulan. Por otro lado, en las vértebras posteriores, los contactos son progresivamente más planos, y ubicados menos perpendicularmente (a unos 
$80^{\circ}$ o incluso menos respecto al plano longitudinal). Los procesos mamilares muestran un similar o menor desarrollo que el observado en los elementos postanticlinales torácicos, proyectándose fuertemente hacia dorsal. Por otro lado, los procesos accesorios se encuentran poco proyectados y delgados en las tres primeras vértebras lumbares, a modo de una rugosidad en la penúltima, y ausentes en las últimas vértebras lumbares. Las escotaduras craneales son breves al comienzo de la serie lumbar y las caudales son amplias y, encontrándose a las tres primeras parcialmente obliteradas por los procesos accesorios.

Los procesos transversos se inclinan por debajo del plano horizontal, aunque en el caso del primer elemento se encuentran cercanos al mismo. El proceso transverso de la primera vértebra se encuentra moderadamente desarrollado, apenas alcanzando cranealmente el margen craneal del cuerpo vertebral y poseen márgenes redondeados, inclinando cranealmente y con forma de "ola"; el margen craneal es cóncavo y breve, y el caudal es convexo y amplio. Los siguientes elementos poseen procesos transversos gradualmente desarrollados y proyectados lateroventralmente con todas sus aristas redondeadas, marcadamente ensanchados cráneocaudalmente, con márgenes caudales crenulados. Estos se encuentran fuertemente expandidos lateralmente, duplicando o triplicando la extensión lateral observada en los mustélidos no acuáticos descriptos $\mathrm{y}$, en vista lateral, apenas alcanzan el nivel del margen ventral del cuerpo vertebral. Los procesos transversos de los últimos dos elementos lumbares son los más desarrollados y poseen morfologías algo variables intraespecíficamente, pero, como tendencia general, tienden a presentar un margen lateral recto o levemente convexo, separado del margen caudal por un quiebre proyectado caudalmente y redondeado, márgenes craneal y caudal cóncavos, en general interrumpidos por grupos de crenulaciones y rematados en sus bases por una saliencia aguda (en relación al origen de paquetes del $\mathrm{m}$. iliocostalis y $\mathrm{m}$. quadratus lumborum). Esta saliencia a veces también se presenta en las vértebras lumbares más craneales. El margen lateral de los procesos transversos de las cuatro primeras vértebras se está reflecto en sentido dorsal. Los últimos elementos se expanden ventral y cranealmente, especialmente en el caso del último elemento, alcanzando y superando, el extremo cráneoventral del cuerpo vertebral correspondiente. El extremo laterocaudal del último par de procesos transversos inclina ventralmente respecto al plano principal de los procesos y se encuentra marcadamente engrosado, aunque poco sobresaliente.

\section{Sacro (Lámina 3.6D)}

El hueso sacro está compuesto por tres elementos fusionados entre sí. Este posee una forma cónica debido al gran desarrollo de los procesos transversos y articulación sacra. En vista lateral, el sacro es alto. Los procesos espinosos se fusionan formando una única cresta sacra media entre el segundo y tercer elemento. El primer proceso espinoso es independiente y mayor 
que los otros dos. La superficie articular sacro-ilion es elíptica y se extiende marcada y ampliamente por debajo del margen ventral de los cuerpos vertebrales especialmente en el sector del primer elemento. La cresta sacra lateral se proyecta en forma aguda (aunque trunca en su extremo) en sentido caudal y lateral, tanto o más allá que la zona articular entre la zona sacra y caudal de los cuerpos vertebrales. La región caudal de la cresta sacra lateral inclina ventralmente. Los forámenes sacros son aproximadamente circulares. Inmediatamente en una posición caudolateral al primer par de forámenes, se observa un par de tubérculos de origen del m. intertransversarii dorsalis caudae particularmente robustos. Los procesos articulares caudales poseen una inclinación mayor a $45^{\circ}$. El cuerpo de la primera vértebra sacra posee forma cuadrangular en vista craneal, con el margen dorsal levemente cóncavo, incidido centralmente, y sobre éste la apertura craneal del canal sacro es moderada a pequeña y aplanada. En vista caudal, el tamaño de la apertura es aún menor y similar forma respecto a lo observado en el anterior.

Vértebras caudales (Lámina 3.7E)

El espécimen MACN 20821 presenta la serie de vértebras caudales completa, compuesta por 23 elementos. Las primeras vértebras (en especial la segunda y tercera) son relativamente robustas, desarrolladas lateromedialmente. Los procesos sobre ellas son amplios hasta el sexto o séptimo elemento. Los cuerpos vertebrales de los primeros elementos son muy similares al último elemento del sacro; gradualmente se vuelven cilíndricos. Los primeros nueve elementos caudales, poseen un proceso espinoso diferenciable. Los tres primeros están bien definidos, inclinados cranealmente y con morfología de meseta. Por otro lado, en los elementos posteriores son progresivamente más delgados, menos definidos, para registrarse finalmente un pequeño proceso en forma de "ola" en el noveno elemento, con una base angosta y en una posición central, inclinando en sentido caudal. Los cuerpos de las vértebras caudales son breves y robustos, siendo en todos los casos menos largos que el cuádruple o triple de su ancho (excepto quizás en los más distales). Los procesos y las carillas articulares craneales y caudales poseen moderado a importante desarrollo hasta el sexto o séptimo elemento (superando a la altura de los procesos espinosos a partir del cuarto elemento), y rodeando las craneales (cóncavas) a sus correspondientes caudales (convexas; recordando lo descripto en el sector torácico). En vista dorsal, las escotaduras craneales y dorsales de las seis primeras vértebras caudales tienen desarrollo importante, aunque sin alcanzar la zona media del cuerpo vertebral.

En vista lateral, las escotaduras caudales de las vértebras caudales se encuentran bien diferenciadas hasta el sexto elemento y en extremo reducidas o ausentes a partir del siguiente. La vértebra transicional corresponde al séptimo elemento. Las carillas articulares caudales se encuentran presentes hasta el sexto elemento, mientras que en el séptimo y octavo elemento el 
arco neural se transforma en un pequeño puente que encierra un breve conducto, y a partir del séptimo elemento, las carillas articulares caudales no se distinguen, encontrándose en su lugar un par de crestas redondeadas poco diferenciadas que coronan el extremo caudal del margen dorsal de cada elemento; a partir del duodécimo elemento se fusionan en una única cresta.

Los procesos mamilares se diferencian hasta muy tardíamente en la serie, incluyendo al elemento número 17 o 18; y a modo de tubérculos mal definidos hasta prácticamente el último elemento.

Los procesos transversos de las tres primeras vértebras caudales parten de casi todo el margen lateral del cuerpo vertebral. En el primer elemento, los procesos transversos se dirigen perpendicularmente. El segundo elemento caudal posee, en general, los procesos transversos más desarrollados lateromedialmente, y al igual que el tercer elemento, suelen poseer una orientación perpendicular o levemente caudal. A partir del cuarto se proyectan y posicionan gradualmente en sentido caudal. A partir del séptimo elemento los procesos transversos se dividen en una protuberancia mayor en el sector caudal de cada vértebra: proceso transverso caudal (que continua la tendencia gradual mencionada anteriormente), y una pequeña proyección perpendicular ubicada cranealmente: proceso transverso craneal; distanciados en extremo, y a veces conectadas sus bases por quillas. A partir del noveno elemento, el proceso transverso craneal supera al caudal en su extensión, y manteniéndose esto hasta el final de la serie. A partir de la quinta vértebra caudal y vestigialmente en la cuarta, se desarrollan procesos hemales a modo de protuberancias cráneoventrales amplias y extendidas en sentido craneal.

\section{Escápula (Lámina 3.8G)}

La escápula presenta forma aproximadamente semicircular, con ángulos redondeados, excepto el caudal, en el cual se forma un ángulo de unos $130^{\circ}$ entre el margen dorsal y el margen caudal del área de origen del $\mathrm{m}$. teres major, y algo más de $100^{\circ}$ respecto a la espina caudal que separa el área del $\mathrm{m}$. infraspinatus de la del $\mathrm{m}$. teres major. El ángulo craneal es abierto $\left(130\right.$ a $\left.140^{\circ}\right)$ y se encuentra desplazado en sentido caudal respecto a la espina (i.e., cercano al ángulo caudal). Por otro lado, se forma un ángulo algo mayor a los $90^{\circ} \mathrm{y}$ muy redondeado sobre el final del margen craneal, el cual hace las veces de límite entre el margen craneal y una escotadura escapular profunda, cuyos márgenes forman a su vez un ángulo algo abierto pero cercano a los $90^{\circ}$ y son redondeados. El margen craneal se muestra totalmente quebrado en dos sectores, correspondiéndose con las muescas dejadas en la cara interna por el m. subscapularis (ver más adelante). La espina es robusta y elevada. Está inclinada en gran medida hacia la fosa infraespinal, es recta a lo largo de toda su extensión y, en su sector proximal, forma un área elevada y triangular extensa (justo craneal al ángulo craneal). La fosa supraespinosa presenta un área algo menor a dos veces que el área de la fosa infraespinosa, 
siendo ambas amplias. Inmediatamente por debajo y detrás del ángulo caudal, se observa un área amplia, reflecta hacia medial, donde se origina el $\mathrm{m}$. teres major y $\mathrm{m}$. triceps brachii caput angulare, la cual se encuentra engrosada en su extremo caudomedial a modo de un tubérculo; ésta superficie se continúa con la cara caudal de la espina caudal. El margen caudal de la escápula es elevado, y se inclina en sentido lateral, volviéndose paralelo al plano de la espina principal, y flanqueando entre ambos a la fosa infraespinal. El margen caudal se extiende dorsalmente hacia el ángulo caudal, formando una espina caudal crenulada, y en cercanías a este ángulo da paso a un área expandida, triangular y elevada (análoga a la observada en la espina principal). En vista medial, el ala de la escápula es cóncava en el sector craneal, especialmente a lo largo de la contracara de la espina. Sobre la superficie medial, justo craneal a la zona deprimida descripta, se observan tres grupos de estrías elongadas dorsoventralmente; inmediatamente caudal a este área se observa un cuarto grupo de estrías. A partir del tubérculo caudal del área de origen del m. teres major se proyecta una cresta que pierde definición rápidamente en la superficie ventral de la escápula, justo medial a la espina caudal.

El acromion se desarrolla gradualmente a partir de la espina, observándose un cambio de pendiente suave entre éste y la espina. Una escotadura profunda y cerrada se presenta entre éste y la zona articular en vista craneal. El proceso hamatus es robusto, quillado en su margen caudal y se proyecta en sentido craneal respecto a la espina en vista lateral, alcanzando la altura de la cavidad glenoidea, y convergiendo al plano de la escápula en vista craneal. El proceso subhamatus, es amplio, superando al margen caudal de la escápula en vista lateral, con un margen ventral cóncavo a recto, mientras que los márgenes caudal y dorsal conforman una curva convexa y engrosada, delimitando un área triangular a cuadrangular en vista lateral, la cual presenta foramina. En vista distal, la cavidad glenoidea posee forma de gota u ovoide, con un tubérculo supraglenoideo diferenciado y robusto, y un proceso coracoides robusto y redondeado. En vista medial, se observa que la zona articular se encuentra proyectada en sentido ventral en la zona craneal, y que el cuello de la escápula presenta un ancho cráneocaudal similar a la zona articular. En el sector caudal del cuello se observan foramina y crenulaciones, y en posición caudomedial, la zona de origen del $\mathrm{m}$. triceps brachii caput longum y posiblemente el $\mathrm{m}$. teres minor, quedan delimitadas mediante una estría marcada.

\section{Húmero (Lámina 3.9G)}

El húmero es robusto, aplanado lateromedialmente en su sector próximo y medio, y expandido lateromedialmente en su sector distal. La diáfisis presenta una curvatura sigmoidea a convexa en vista craneal, especialmente en su sector medio y proximal. En vista proximal, la superficie articular posee un fuerte desarrollo en el eje cráneocaudal, y es más angosta en el sector caudal. La cabeza se ubica marcadamente por detrás de los tubérculos y otras estructuras 
proximales del húmero. En la vista craneal, la cabeza humeral iguala en altura al tubérculo mayor, el cual es muy robusto y separado de la zona articular y el tubérculo menor mediante un amplio y profundo surco intertubercular. Sobre el área circunscripta entre el surco intertrabecular y la cara medial del tubérculo mayor, se presentan muchas foramina, destacándose una en la base de este tubérculo por su gran desarrollo. Sobre la cara lateral y el extremo caudal del tubérculo mayor, se desarrolla una zona deprimida mayor y otra área plana o cóncava inmediatamente caudal a ésta, menor y sobresaliente ventralmente, donde se insertan el $\mathrm{m}$. infraspinatus y $\mathrm{m}$. teres minor.

La tuberosidad deltoidea se diferencia claramente como una cresta engrosada y expandida lateralmente. Por otro lado, la línea tricipital, la cual se continúa en sentido proximal con mínimo desarrollo, conecta la tuberosidad deltoidea con la cresta que marca el límite dorsal de la zona de inserción del m. triceps brachii caput laterale. La cresta del tubérculo mayor se diferencia como una zona rugosa proximalmente, que se convierte distalmente en una cresta prominente, sobresaliendo medialmente, especialmente en el segundo quinto de la diáfisis humeral. La zona delimitada por ambas crestas es amplia y aplanada, alcanzando a cubrir la mayor parte de la primera mitad del húmero. Distalmente a la unión de estas crestas se presenta una cresta deltopectoral moderada a breve y marcada, la cual no alcanza el último tercio del húmero (MACN 20821) o lo hace marginalmente (MMPMa 141). El tubérculo menor se encuentra hipertrofiado, con un tamaño apenas menor que el tubérculo mayor, diferenciado en todos sus márgenes de la diáfisis y cóndilo proximal; es rugoso y cuadrangular, y se orienta en sentido proximomedial. Sobre la cara medial de la diáfisis humeral, al final del segundo tercio de la misma, suele presentarse un foramen nutricio marcado (no observado en Lo. longicaudis, sí distalmente en Pt. brasiliensis), mientras que medial y caudal a la cresta del tubérculo mayor, se observan algunas muescas a modo de crestas paralelas.

El epicóndilo lateral es robusto y posee un desarrollo lateromedial importante, mientras que el medial posee un gran desarrollo en dicha dirección, poseyendo ambas estructuras un importante engrosamiento en sentido cráneocaudal. El epicóndilo medial posee una base relativamente delgada en dirección próximodistal, y no supera el margen distal medial de la tróclea, siendo esta región origen de músculos flexores cárpales y digitales (e.g. m. flexor carpi radialis y $\mathrm{m}$. flexor carpi ulnaris). La presencia del foramen supracondiloideo es variable (ausente en el miembro izquierdo de MACN 20821 y derecho de IPUM 052; y presente en los complementarios y ambos lados de MMPMa 141). En caso de estar presente, posee forma oval, y es de moderado desarrollo a amplio. El margen medial del mismo es robusto y algo aplanado, mientras que en sentido lateral existe en cambio suave de pendiente debido a la elevación de la diáfisis sobre la altura del principio de la tróclea a modo de una cresta definida. La cresta epicondiloidea posee un gran desarrollo proximodistal, alcanzando, o casi, el segundo tercio, 
con una muy amplia extensión lateromedial, acentuado en la zona medioproximal de la cresta. En vista caudal, el margen lateral de la cresta epicondiloidea se continúa proximalmente como una cresta o rugosidad sobre la diáfisis, alcanzando y adentrándose en la mitad proximal del elemento, a partir de donde se continúa proximalmente por una cresta sinuosa que alcanza la base del tubérculo menor. Estas crestas demarcan el origen de los vientres laterales del $\mathrm{m}$. triceps brachii, $\mathrm{m}$. brachialis, $\mathrm{m}$. brachioradialis y $\mathrm{m}$. anconeus. El sector distal de la cresta epicondiloidea, correspondiente al $\mathrm{m}$. extensor digitorum communis, y se encuentra engrosado y sobresaliente. La tróclea posee moderado desarrollo próximodistal, moderado a bajo desarrollo lateromedial en relación al capítulo, con una profundización moderada. Su margen medial, poco inclinado, está desarrollado principalmente en dirección mediodistal a distal. El capítulo es amplio en vista craneal, posee forma intermedia entre semiesférica y cilíndrica, con márgenes proximal y distal levemente convexos, alto en la zona media, y con un margen lateral no engrosado. La fosa coronoidea y la radial se encuentran indiferenciadas entre sí, pobladas de foramina, y poco diferenciadas respecto a la diáfisis distal, y en ningún caso perforadas. En vista caudal, la zona articular posee un margen medial marcado, separándola de una muy somera y amplia fosa para el tendón del olécranon, apenas diferenciable por cambios de pendiente y rugosidad, mientras que el margen lateral posee un límite algo más marcado y bien definido. La fosa olecraneana es amplia, de bajo desarrollo en sentido proximal (especialmente en su sector medial), de profundidad importante sólo en cercanías a la zona central. Sus márgenes proximolateral y proximomedial se encuentran definidos y contactándose en ángulo. Entre la fosa olecraneana y la fosa para el tendón del olécranon, existe un leve cambio de pendiente abrupto, siendo la primera mucho más profunda que la segunda.

\section{Ulna (Lámina 3.10G)}

La ulna es principalmente recta, aunque se curva cranealmente en la zona media y fuertemente en sentido medial a la altura del olécranon. En vista lateral, la ulna es amplia cráneocaudalmente a lo largo de toda su extensión, y especialmente en su sector medio y proximal. El olécranon se encuentra moderadamente desarrollado en dirección cráneocaudal y marcadamente en dirección próximodistal en relación al resto del elemento. Tanto el margen craneal como el proximal son cóncavos, mientras que el caudal es más bien recto. El extremo cráneomedial de la tuberosidad del olécranon posee un importante desarrollo medial y es muy robusto. El sector caudal y medial de la tuberosidad del olécranon está fuertemente proyectado en sentido medial y engrosado, determinando en parte un importante desarrollo lateromedial del olécranon. La incisura troclear es moderadamente profunda. El proceso ancóneo es mayormente simétrico, y posee un desarrollo craneal algo menor que el coronoides. La incisura radial posee forma oval o triangular, alargada lateromedialmente y su eje mayor se orienta a algo menos que 
$45^{\circ}$ del plano definido por la diáfisis ulnar, articulando el radio en una posición diagonal respecto a la ulna. El margen lateral es recto a levemente convexo, rematado en un ángulo agudo proximal. La tuberosidad ulnar se presenta como una zona rugosa en el sector cráneomedial de la diáfisis.

En la zona proximomedial de la diáfisis, restringido a un área reducida inmediatamente distal al olécranon, se presenta una leve concavidad correspondiente al pasaje de los flexores digitales (e.g. flexor carpi ulnaris y $\mathrm{m}$. flexor digitorum profundus), que pierde definición antes de alcanzar la altura de la zona articular. La cara cráneomedial de la zona mediodistal de la ulna, en donde se origina el $\mathrm{m}$. pronator quadratus (y secundariamente la cabeza radial del $\mathrm{m}$. flexor digitorum profundus), es fuertemente aplanada y extendida, dándole a la diáfisis un aspecto de triangulo equilátero en sección. En la zona mediodistal, justo a la altura del límite entre el segundo y tercer tercio de la diáfisis, y en una posición cráneolateral a lateral, se evidencia claramente una cresta bien desarrollada y rugosa correspondiente al ligamento interóseo (correspondiéndose a una similar en la cara caudolateral del radio). En la zona lateral de la diáfisis, desde la altura de la incisura troclear hasta la marca del ligamento interóseo, se presenta expandida y con márgenes bien definidos la concavidad correspondiente al pasaje varios extensores digitales, y específicamente vinculado al origen del $\mathrm{m}$. abductor digiti I longus (mayor a lo observado en otros mustélidos no lutrinos descriptos). Justo craneal al margen proximal de esta muesca, se presentan un gran número de forámenes pequeños.

En el extremo distal, el proceso estiloides se encuentra desarrollado cráneocaudalmente, aunque es delgado en sentido lateromedial excepto en su extremo craneal. Su superficie articular posee forma de "C" y se extiende en sentido caudal y proximal. La superficie diartrodial para el radio es pequeña, de forma irregular a arriñonada, en una posición craneal, orientando craneodistalmente, y elevada respecto a la diáfisis ulnar.

\section{Radio (Lámina 3.11E)}

Es de un largo similar a dos tercios del largo del húmero y convexo cranealmente. En su tercio proximal es de sección aproximadamente circular, y a partir de allí es principalmente aplanado en el plano cráneolateral a caudomedial. La carilla articular proximal del radio posee una forma cuadrangular o arriñonada, con una fuerte escotadura en su sector cráneolateral. La zona de contacto con la ulna es recta. En el extremo lateral, justo lateral a la escotadura mencionada, se proyecta un tubérculo amplio, agudo y recurvado en sentido medial y distal; mientras que en el extremo cráneolateral, contiguo a la escotadura, se presenta una moderada elevación a modo de un tubérculo, posiblemente la región de origen la inserción el ligamento colateral. El sector proximal de la diáfisis muestra un cambio suave en la dirección del eje principal, distal a la articulación con la ulna. En la cara caudomedial, inmediatamente distal a la 
epífisis proximal, se observa una tuberosidad radial amplia, elevada, aplanada, rugosa y levemente cóncava, limitada cranealmente por una cresta suave y breve correspondiente a la zona de inserción de ligamentos involucrados en la unión con la ulna y la inserción del m. biceps brachii.

En la cara caudolateral y proximal se diferencia claramente la inserción del ligamento interóseo, más desarrollada que en la ulna, aunque pierde definición en mitad de la diáfisis. A lo largo de toda la cara caudal del sector medio y distal de la diáfisis, se presenta una cresta amplia correspondiente a la zona de origen del $\mathrm{m}$. abductor digiti I longus (en la cara lateral) y cabeza radial del flexor digitorum profundus (en la cara medial). Justo proximal al origen de ésta, se encuentra un foramen nutricio importante. En vista cráneolateral de la diáfisis media y distal se observan dos crestas marcadas (una craneal correspondiente al m. pronator teres y otra lateral correspondiente al margen de craneal del origen del $\mathrm{m}$. abductor digiti I longus) que se originan a los lados y convergen distalmente.

El extremo distal, presenta una superficie articular carpal cóncava en forma cuadrangular a romboidea (con tres ángulos rectos y uno agudo), cuyo eje principal posee dirección cráneomedial-caudolateral, y orientada principalmente en sentido distal. En vista medial, el pasaje del $\mathrm{m}$. abductor digiti I longus está representado por una muesca que no llega a ser un surco propiamente dicho. El mismo rodea caudalmente al tubérculo de inserción del $\mathrm{m}$. brachioradialis convirtiéndose en un surco amplio y breve. El sector más caudal seguramente se corresponde también con la zona de pasaje del m. flexor carpi radialis. El tubérculo de inserción del $\mathrm{m}$. brachioradialis es aplanado e irregular. El proceso estiloides está moderadamente proyectado distalmente. La escotadura ulnar, en el margen laterocaudal del extremo distal del radio, es triangular y breve, aplanada y sobre una zona elevada. Justo craneal a la escotadura ulnar, el surco para pasaje del $\mathrm{m}$. extensor digiti I et II es muy profundo y extremadamente amplio, cuya dirección principal es proximodistal, limitado cranealmente por un tubérculo cráneolateral proyectado lateralmente y robusto. Justo medial a esta la escotadura ulnar, se observa una superficie articular extra, circular, que contacta al accesorio en posiciones flexionadas.

\section{Autopodio anterior (Lámina 3.12E)}

La serie carpal se encuentra moderadamente empaquetada y es aplanada, aunque levemente convexa en vista dorsal y cóncava en vista plantar. El carpal radial está bien desarrollado en sentido proximodistal, con una superficie proximal convexa amplia (marcadamente en sentido cráneocaudal), con un límite moderadamente abrupto medial y lateral, y una sobreelevación caudomedial marcada (más similar a hurones, que otras nutrias descriptas, ver más adelante), implicando un área contigua levemente cóncava. En vista craneal, 
el radial presenta un desarrollo lateromedial algo menor al doble del observado para el ulnar. La carilla articular para el radio del radial se extiende lateralmente tanto como el nivel de la articulación entre el tercer y cuarto metacarpo, siendo progresivamente más elevada en su sector lateral. Inmediatamente por debajo del área articular proximal, se desarrolla un área no articular triangular amplia que articula con los carpales II y III. En vista craneal, la zona de articulación entre el radial y ulnar está interrumpida por el desarrollo proximal del carpal IV. En vista caudal, en su zona central se observa una foramina, quizás relacionada a aquéllas presentes inmediatamente distal sobre la cara distal del elemento. En su extremo medial, el radial contacta al sesamoideo radial mediante una carilla articular plana. En vista caudal, el tubérculo medial se proyecta en sentido caudal y ventral, ensanchado proximodistalmente pero no marcadamente robusto. Distalmente, el radial articula con los cuatro carpales por medio de una serie de bandas cóncavas y convexas. Inmediatamente lateral y craneal a este sector se observa una banda cráneocaudal fuertemente convexa a modo de una cresta aguda, que articula con la zona deprimida observada entre el carpal II y III en la superficie complementaria. Inmediatamente caudal a esta cresta, se presenta una pequeña zona no articular, con algunas foramina grandes. El sesamoideo radial está desarrollado en dirección ventral, es robusto proximalmente y agudo en su extremo ventral.

El carpal ulnar es un hueso cuadrangular y sólo moderadamente aplanado en sentido proximodistal. La mitad caudal de su cara proximal es una superficie articular aplanada a cóncava y triangular, que contacta al carpal accesorio, mientras que la mitad craneal es plana en el plano transverso y cóncava en el plano cráneocaudal, ambas carillas separadas por un margen agudo y elevado. La cara laterodistal del ulnar es alargada cráneocaudalmente y cóncava, a fuertemente cóncava, y contacta al quinto metacarpal. El carpal accesorio posee su extremo libre marcadamente robusto y anguloso, desarrollado proximodistalmente y dirigido caudalmente. La articulación con el ulnar es triangular, plana a cóncava, redondeada en su sector dorsal. En vista dorsal, en el sector craneal, el carpal accesorio presenta una región articular triangular y plana que, junto con la superficie correspondiente y adyacente del ulnar, recibe a la ulna. Entre esta superficie articular y el extremo caudal libre existe una zona marcadamente constreñida, en cuya superficie mediodorsal se evidencia una quilla marcada. Las zonas de inserción del músculo flexor (cabeza ulnar y humeral) y extensor carpi ulnaris se diferencian claramente.

Los carpales distales se contactan entre ellos por zonas de articulación casi planas y reducidas en sentido proximodistal, especialmente en el caso del contacto entre segundo y tercer carpal distal, el cual es más bien diagonal, sin formarse un contacto convexo-cóncavo en forma de "L" o triangular típico de los mustélidos no acuáticos descriptos). El carpal I, en vista craneal, posee una moderada extensión distal a modo de una cuña redondeada entre los 
metacarpales I y II que se extiende tanto como la base del metatarsal I. En vista caudal (casi planta), existe un tubérculo plantar rudimentario justo proximal y lateral al tubérculo plantar del metatacarpal I. El carpal II, en vista craneal, posee una superficie no articular cuadrangular, marcadamente aplanada en sentido proximodistal (al igual que lo observado para el carpal III, ver más adelante). La arista más lateral se proyecta en sentido lateral, apenas contactando la cara medial del carpal III, sin ser rodeada por esta última. El carpal III tiene forma muy irregular, es alargado proximodistalmente y cráneocaudalmente. En vista craneal posee forma de triangulo escaleno o "L": con su sector medial levemente cóncavo y proyectado a modo de una superficie proximodistalmente aplanada que contacta marginalmente al carpal II. El margen lateral de este elemento se eleva marcadamente (i.e., prácticamente alcanza la altura del carpal IV), aumentando el área de contacto con el carpal IV. Este de contacto es semicircular y aplanado, y su mitad proximal está cubierta por el radial. En vista caudal, el tubérculo plantar del carpal III se encuentra bien desarrollado como un área circular, levemente plana y algo proyectada medialmente. El área de contacto con el carpal III ocupa la mitad craneal de la vista medial del carpal IV, exceptuando un breve sector proximal que corresponde al radial, y un amplio sector no articular incidente en el extremo caudodistal de dicha vista. El carpal IV prácticamente triplica el desarrollo areal de cualquiera de los demás carpales distales; en vista craneal presenta una morfología similar a un trapezoide de aristas romas, proyectado en sentido proximal y laterodistal. En vista craneal, su margen lateral se muestra elongado proximodistalmente. En el carpal IV se diferencia un pobremente definido tubérculo plantar. La cara lateral de carpal IV, articula con el ulnar y es convexa y triangular a oval. En vista craneal, el ángulo de contacto radial-carpal IV es claramente menor a los $45^{\circ}$, mientras que el contacto ulnar-carpal IV se aparta de la horizontal por unos $40^{\circ}$. Los dígitos periféricos se encuentran poco reducidos respecto a los centrales. Tanto metacarpales como falanges se muestran robustas. La longitud de las falanges proximales de los dígitos I y V son aproximadamente dos tercios de la longitud observada en los restantes dígitos. Los metacarpos I y V son los de menor longitud, cercanos a tres cuartos del mayor y cuarto quintos de la longitud del mayor (IV), respectivamente. Los metacarpales son rectos a levemente convexos en vista dorsal. El metacarpal $\mathrm{V}$ articula con un pequeño hueso sesamoideo metacarpal en el principio de su cara plantar. El metacarpal IV es el más elongado, seguido cercanamente por el III, y seguidos por el V, II y I. Proximalmente, todos los metacarpales poseen bases definidas y expandidas caudalmente, especialmente en el caso del metacarpal IV y V. Los tubérculos laterodistales de los metacarpales son particularmente robustos. Los sesamoideos metacarpales son elongados, proximalmente agudos y aplanados para los metacarpales II, III, IV y V; mientras que en el metacarpal I, ambos son redondeados y reducidos, en especial el caso del hueso sesamoideo medial se muestra atrofiado y menos elongado. Las falanges proximales y medias son robustas 
(levemente mas robustas que los metacarpales) y relativamente aplanadas, con zonas articulares y de inserciones tendinosas amplias. La falange proximal del dígito I es robusta y mayormente recta, siendo similar en longitud a las demás falanges proximales. Las falanges ungueales poseen cresta ungueales robustas y elongadas dorsoventralmente, y procesos ungueales robustos y altos en sus bases y más bien aguzados hacia su extremo distal. El margen ventral de estos es principalmente recto, y el dorsal marcadamente convexo. Las unguis son breves, algo agudas en su extremo distal, curvadas y marcadamente engrosadas, aunque aumentando brevemente la extensión distal de las falanges ungueales.

\section{Hueso coxal (Lámina 3.13G)}

El ilion define un plano de unos $60^{\circ}$ o $70^{\circ}$ respecto del definido por isquion y pubis. El acetábulo, de tamaño moderado a pequeño respecto al total del hueso coxal, es semicircular y abierto. La incisura acetabular es profunda y amplia en su sector caudoventral, de aproximadamente un tercio de la circunferencia total. El foramen obturado es de forma oval aunque algo irregular, algo alargado cráneocaudalmente y, especialmente en el caso de MACN 20821, levemente somero y constreñido en su sector más dorsal. La superficie sinfisiaria posee un moderado desarrollo en sentido cráneocaudal (breve en relación a otros mustélidos comparados) y está engrosada en toda su longitud.

El ala del ilion posee forma rectangular, cóncava en vista lateral, marcadamente robusta en su sector dorsal, y supera en bajo grado la articulación craneal del sacro. El cuello es de sección semicircular y ancho. Las espinas ventro-craneal, dorso-craneal y dorso-caudal poseen un desarrollo y robustecimiento similar y marcado, redondeadas y sobresalientes; la tuberosidad sacra se muestra engrosada en toda su extensión, mientras que la tuberosidad coxal sólo lo está en su sector caudal. La espina ventro-caudal posee un bajo desarrollo y está apenas diferenciada del margen ventral del ilion como un leve engrosamiento y algunas rugosidades. La cresta ilíaca es delgada respecto al resto del ala ilíaca, la cual se presenta como un margen recto, muy amplio y perpendicular al resto del ilion. La escotadura ciática mayor se encuentra profundizada en su sector mediocraneal debido al desarrollo de la espina dorso-caudal. La superficie articular del ilion se encuentra desarrollada y posee una forma angulosa y definida. En la cara lateral del cuello del ilion, se diferencian marcadamente la línea glútea caudal y el tubérculo del $\mathrm{m}$. rectus femoris. El cuerpo del isquion es muy robusto, de sección semicircular y forma un ángulo abierto, cercano a los $100^{\circ}$, respecto a la rama del isquion, la cual es aplanada, amplia y cuadrangular, para adelgazarse cráneocaudalmente abruptamente en el sector extremo ventral, en la zona de contacto con el pubis. El ángulo formado entre el cuerpo del isquion y el pubis es bajo, de aproximadamente $50^{\circ}$. La espina isquiática se presenta como un pequeño tubérculo engrosado, que se continúa cranealmente como una zona elevada a modo de cresta que llega a la 
zona caudodorsal con respecto al acetábulo. Caudalmente se continúa por la escotadura ciática menor, a modo de un margen moderadamente engrosado, cranealmente recto y fuertemente cóncavo en su sector caudal. La arcada isquiática se diferencia en gran medida del resto del margen caudal del isquion en parte debido al gran desarrollo caudal de la tabla del isquion. El límite entre ambas estructuras se encuentra marcado por un tubérculo engrosado. Por otro lado, sobre la arcada isquiática, en cercanías a la zona de la sínfisis, se diferencia un tubérculo engrosado, agudo y proyectado caudalmente en el caso del espécimen MACN 20821 (posiblemente correspondiente al origen del $\mathrm{m}$. adductor magnus). La tuberosidad isquiática se muestra como una zona engrosada a lo largo de todo su recorrido cráneocaudal, claramente diferenciada del resto del isquion, proyectada dorsalmente y con una quilla sobre su cara lateral.

El pubis es marcadamente alargado dorsoventralmente, y aplanado y delgado lateromedialmente; presenta una eminencia ilio-pubiana marcadamente robusta, aguda, adelantada (ubicándose por delante de la altura de la zona articular), y bien diferenciada, al igual que su continuación por medio de la línea arqueada. La cara lateral, zona de orígenes de músculos aductores, está estriada; el margen dorsal es mayormente liso y presenta, en general, una proyección (o varias) hacia el foramen obturador. El cuerpo del pubis es plano, recto en vista craneal. El pecten pubiano se diferencia y proyecta en dirección craneal. El ángulo entre la rama caudal y el cuerpo es cercano a los $45^{\circ}$. La rama caudal del pubis es de moderado desarrollo cráneocaudal, delgada en su margen dorsal (como en el caso del cuerpo del pubis), pero engrosada ventralmente.

\section{Fémur y patela (Lámina 3.14G)}

El fémur es muy robusto, breve, de sección cilíndrica aunque aplanado en el sector lateral. Su diáfisis es recta a levemente curvada en sentido lateral en la zona mediodistal, y muy levemente en sentido caudal en la zona media de la misma. La cabeza del fémur se muestra moderadamente proyectada en sentido medial, amplia y orientada en sentido mediodorsal. En vista medial, la fóvea se encuentra desplazada del centro de la cabeza hacia el margen caudal. La cabeza femoral se proyecta, en su sector cráneoventral, por debajo del cuello femoral. El trocánter mayor se encuentra bien desarrollado, con una proyección roma y algo robustecida que se eleva por sobre el cuello, alcanzando la cabeza articular y bastante inclinado cranealmente. Al contrario de otros mustélidos descriptos, sobre el margen dorsal del cuello femoral se define una escotadura dorsal aguda y profunda entre la cabeza femoral y el trocánter mayor. La fosa trocantérica es profunda y ancha; posee un moderado a breve desarrollo proximodistal, superando la altura de la base de la cabeza articular en sentido proximal y sin alcanzar la altura de la base del cuello distalmente. El trocánter menor se muestra bien desarrollado, proyectado en sentido caudomedial pero sin sobresalir medialmente en vista caudal. Inmediatamente 
craneal a éste se observa un foramen nutricio marcado, mientras que craneal y distal a éste se presenta un área particularmente rugosa. La tuberosidad glútea se encuentra marcadamente desarrollada como un área aplanada, amplia y triangular, que ocupa toda la cara lateral, cráneolateral y craneal del trocánter mayor, y que supera distalmente a la altura del trocánter menor. La región craneal de la misma se encuentra hipertrofiada y sobresaliente a modo de un área plana y rugosa, incidida por un surco amplio y definido de dirección lateromedial. Distalmente, se continúa por una zona elevada y rugosa a lo largo de toda la cara laterocaudal de la diáfisis femoral. Sobre el cuello femoral, y justo medial al trocánter menor, se observan forámenes importantes.

En el extremo distal, la tróclea femoral se encuentra algo desplazada en sentido medial; está bien delimitada por los labios medial y lateral, ambos similares en robustez, mientras que el medial se continua en mayor medida hacia proximal a modo de una cresta rugosa que cubre el sector cráneomedial de último quinto de la diáfisis femoral, dando, en vista lateral y medial, un aspecto levemente asimétrico al extremo distal femoral (alcanzando, hacia proximal, los labios de la tróclea una mayor altura que los cóndilos articulares). En la región proximal a la tróclea, un área aplanada se continúa por la superficie craneal de la diáfisis, ocupando aproximadamente el último quinto o menos de la misma. En vista distal, ambos epicóndilos se desarrollan marcadamente hacia los lados, especialmente el lateral, mientras que los cóndilos se proyectan moderadamente en sentido caudal. Debido a estas características, en vista distal el fémur posee un similar desarrollo cráneocaudal que lateromedial. En esta vista, el desarrollo cráneocaudal de la tróclea es claramente mayor al de los cóndilos. Sobre el epicóndilo lateral, la fosa del extensor se encuentra presente, amplia, pero poco definida. La fosa de origen del $\mathrm{m}$. popliteus, es marcada y profunda. La fosa intercondiloidea es algo angosta en sentido lateromedial. Sobre la zona central del epicóndilo medial el área de origen del ligamento colateral medial se presenta una zona deprimida a aplanada y con un margen ventral engrosado. Los epicóndilos y la fosa intercondiloidea poseen un gran número de forámenes nutricios en su aspecto caudal. En vista caudal se encuentran presente la tuberosidad supracondiloidea lateral, a modo de una zona rugosa, expandida lateralmente, sobresaliendo sobre la diáfisis distal y epicóndilo lateral (especialmente desarrollada en el espécimen MACN 20821). Ambas carillas para los sesamoideos supracondiloideos se encuentran desarrolladas; la medial está hipertrofiada y sobresale marcadamente; la lateral está marcadamente lateralizada. La patela es gruesa y con forma de gota, aguda en su ápice respecto a su amplia base.

Tibia (Láminas 3.15G, 3.16E)

La tibia es relativamente grande y presenta robustez marcada, y se curva en sentido lateral en su zona media, mientras que su extremo distal se vuelve más bien recto y robusto. En 
vista proximal (Lámina 3.15G), el cóndilo lateral es oval a semicircular, redondeado en todo su margen caudal, laterocaudal y laterocraneal, y posee un desarrollo mediolateral mucho mayor que el del cóndilo medial. El cóndilo medial posee forma oval a semicircular, con su mayor eje en sentido cráneocaudal, sin superar caudalmente al cóndilo lateral. Los cóndilos son planos a levemente cóncavos en sus sectores centrales, encontrándose ambos aproximadamente en el mismo plano. En vista proximal, la zona intercondiloidea tiene un desarrollo breve en sentido cráneocaudal, terminando en una tuberosidad aplanada, sólo sobresaliente cranealmente en su zona central. La zona cráneolateral (craneal al cóndilo lateral) se muestra como un tubérculo amplio y aplanado, proyectado por sobre la zona deprimida y cóncava correspondiente al surco del extensor, formándose una región marginal también cóncava entre este sector y la tuberosidad tibial. Todo el sector cráneolateral al cóndilo lateral está marcadamente desarrollado en dirección próximodistal y poblado de foramina. La eminencia intercondiloidea es amplia. Tanto el área intercondiloidea craneal como caudal (áreas de inserción de los ligamentos crucianos craneales y caudales), como el margen lateral y, secundariamente, el medial de la epífisis proximal de la tibia se muestran rugosos y socavados. El área intercondiloidea posee foramina amplias. En vista caudal, bajo el cóndilo medial, se observa un tubérculo amplio, e inmediatamente distal a este una cresta aplanada en sentido próximodistal correspondientes a la superficie de inserción proximal del ligamento cruciano caudal. En vista lateral, la fosa tibial se muestra como una superficie cóncava en su sector proximal y aplanada hacia distal, que ocupa menos que el primer tercio de la diáfisis tibial. Cranealmente se encuentra delimitada por una cresta tibial recta, robusta, poco rugosa, pero escasamente definida, que da paso luego de los dos primeros quinto de la diáfisis a una cresta suave que se continua hasta el sector distal de la misma. En vista medial, el sector proximal de la diáfisis se muestra rugoso y con algunas foramina nutricias. En la zona caudomedial de la región proximal, una cresta o tubérculo de dirección proximodistal, breve pero bien definida y muy robusta y rugosa, indica la inserción del ligamento colateral medial. La superficie articular para la cabeza de la fíbula posee forma elíptica y se encuentra tanto o más desarrollada en sentido caudal como el cóndilo lateral. Esta articulación, se encuentra ventral al cóndilo lateral en vista caudal, pero no inmediatamente ventral a éste, sino separada por una amplia superficie, que en vista lateral posee una forma de banda, y principalmente aplanada y expandida proximodistalmente en el sector de inserción de parte del tibial craneal.

En vista caudal, la diáfisis posee al menos dos crestas diferenciables, y otras rugosidades secundarias. La más lateral se extiende por los dos tercios distales de la diáfisis tibial, y se encuentra interrumpida por un foramen nutricio en la zona media de la diáfisis, divergiendo lateralmente y finalizando justo sobre la zona articular con la fíbula. Esta cresta posiblemente sea la zona de origen del $\mathrm{m}$. flexor digitorum lateralis. La segunda cresta es 
medial a la anterior y pierde definición antes de alcanzar la mitad de la diáfisis; posiblemente delimite la zona de origen del $\mathrm{m}$. caudalis tibialis o el $\mathrm{m}$. flexor digitorum medialis.

El extremo distal de la tibia es amplio lateromedialmente y cráneocaudalmente, con un gran número de forámenes nutricios en su sector craneal y medial. En vista distal, la superficie articular distal posee una forma cuadrangular, con una superficie central incidida por los dos surcos de la cóclea tibial. La depresión correspondiente medial es marcada. El segundo de los surcos, en el sector lateral de esta superficie articular (y medial de la superficie articular distal de la fíbula), se observa como una zona también incidida en similar o levemente mayor magnitud a la anterior. En vista craneal, ambos surcos están separados por una proyección marcadamente aguda. En vista caudal, el margen caudal de la superficie articular distal es sinuoso, mayormente aplanado en el sector lateral, sobresaliente y agudo en la zona centromedial, e incidido por el margen lateral de la tróclea del astrágalo en la región lateral. La faceta fibular distal es muy breve y más bien alargada sobre su eje principal caudomedialcráneolateral. El maléolo medial es muy robusto y proyectado distalmente en su sector medio y craneal, y desarrollado cráneocaudalmente, pero más bien delgado en su sector caudal. En la zona medial y caudal del maléolo medial, medial al surco maleolar tibial, se observa el surco del tendón del $\mathrm{m}$. tibialis caudalis, el cual es amplio y de dirección próximodistal (aunque inclinando hacia craneal en su extremo distal), franqueado por dos crestas, que se pierden en la zona central del maléolo.

Fíbula (Lámina 3.17E)

Es un elemento aplanado en un plano cráneomedial-caudolateral y recto o levemente convexo en sentido caudal a lo largo de casi toda su extensión; en su cuarto proximal es aplanada cráneolateral-caudomedialmente. En vista craneal es cóncava. Sus extremos articulares son robustos. En vista proximal, la articulación de la cabeza de la fíbula muestra una forma circular, ocupando aproximadamente un cuarto del área observada en esta vista, en una posición centrocaudal. En el sector proximal y cráneolateral se proyecta el tubérculo del $\mathrm{m}$. fibularis longus, con una base angosta y extremo robusto y expandido. En el sector mediocaudal se diferencia una zona elevada, coronada por un tubérculo robusto, correspondiente al origen del m. soleus. Entre estos dos tubérculos, justo cráneolateral a la zona articular, se observa un promontorio elevado, posiblemente correspondiente a una segunda zona de origen del $\mathrm{m}$. fibularis longus. Justo medial al tubérculo para el $\mathrm{m}$. soleus, se diferencia una zona elevada comprimida lateromedialmente, correspondiente al origen del $\mathrm{m}$. tibialis caudalis. Bajo este último, se proyecta una cresta bien marcada y expandida que se extiende aproximadamente hasta el final del primer tercio de la diáfisis, en donde converge con una segunda cresta de trayectoria más lateral (sobresaliendo marcadamente del cuerpo de la diáfisis fibular), 
circunscribiendo un área estriada, posiblemente el origen del $\mathrm{m}$. extensor digiti I longus y secundariamente del $\mathrm{m}$. flexor digitorum lateralis.

El extremo distal de la fíbula es muy robusto; posee su eje principal desarrollado en dirección cráneomedial-caudolateral. El sector craneal del maléolo lateral posee un desarrollo en dirección distal mayor que el caudal. La faceta astragalar de la fíbula, es semicircular a arriñonada, de contorno irregular y su extremo distal agudo, aplanada, y mayormente vertical.

La faceta tibial es plana a convexa, de forma semicircular y con su mayor eje en dirección craneodistal-caudoproximal. Justo caudal a estas facetas articulares se observa una cresta delgada pero bien definida. En el extremo laterocaudal distal del maléolo lateral se proyecta un tubérculo alargado proximodistalmente, de contorno semicircular a cuadrangular y muy bien diferenciado que separa dos surcos amplios y profundos, que a su vez son delimitados por dos crestas. El primero, zona de tránsito del tendón del $\mathrm{m}$. fibularis longus, posee una posición lateral, es amplio y está delimitado en su margen craneal por una pequeña cresta amplia, y sobresaliente caudoproximalmente, que finaliza distalmente en la zona media del maléolo. El segundo surco, el surco maleolar fibular (zona de tránsito del $\mathrm{m}$. extensor digitorum lateralis y m. fibularis brevis), posee una posición caudolateral, es de similar amplitud y más profundo, siendo su margen caudal delimitado por una cresta robusta y definida.

\section{Autopodio posterior (Láminas 3.18E, 3.19E)}

Los huesos del tarso poseen un moderado empaquetamiento, con un gran desarrollo de las áreas de agarres musculares. El astrágalo (Lámina 3.18E) tiene un cuello y cabeza aplanados dorsoventralmente y con un desarrollo próximodistal marcadamente menor que el observado para la tróclea. La tróclea es moderadamente profunda y amplia en dirección cráneocaudal. Sus dos crestas están bien definidas a lo largo de toda su extensión, siendo la lateral algo más elevada que la medial. La separación entre ambas es aproximadamente constante, acercándose levemente en sector medio de la tróclea. En vista dorsal, en el sector lateral de la base del cuello se observa la depresión astrágalotibial moderadamente desarrollada. En vista lateral, la carilla maleolar lateral posee forma de "garfio" o "media luna" y está fuertemente desarrollada (especialmente en dirección cráneocaudal), extendiéndose en sentido caudal tanto como la tróclea misma (distinto a Ga. cuja). En vista ventral, tanto la superficie articular proximal para el calcáneo como el tubérculo del talus sobresalen caudalmente, ampliamente separados entre sí por una distancia similar a la de las crestas de la tróclea. La superficie articular proximal es alargada, cuadrangular y fuertemente cóncava; en su extremo craneal es curvada y sobresale lateralmente (distinto a lo observado en Ei. barbara, en donde es ancha). Por último, la superficie articular medial es convexa, algo aplanada en su sector central, dirigida netamente ventralmente y ocupando la mayor parte de la superficie central y basal del cuello. En vista 
distal, la superficie articular para el tarsal central es ovalada a irregular, alargada en sentido lateromedial, y con una leve constricción, y angostada en su extremo medial. Esta presente una gran proyección en sentido proximomedial, envolviendo la cara medial del cuello astragalar y sobresaliendo ampliamente respecto al mismo. Sobre la superficie laterodistal, la carilla articular para el tarsal IV es plana y bien definida. Inmediatamente ventral al sector caudal de la tróclea se observa el foramen o abertura caudal del canal astragalar. Éste abre en forma amplia, en la cara ventral, entre las zonas articulares para el calcáneo.

El tubérculo del calcáneo (Lámina 3.18E) es relativamente largo y posee importante desarrollo en altura. En vista dorsal, se observa que la base es angosta en sentido lateromedial, con el margen medial cóncavo y el lateral irregular. El surco del tubérculo del calcáneo (zona de inserción y de pasaje del $\mathrm{m}$. flexor digitorum superficialis) se presenta poco definido y asimétrico. El margen medial se mantiene robusto y definido hasta el margen ventral del tubérculo del calcáneo. La zona de origen del $\mathrm{m}$. abductor digiti $\mathrm{V}$ se encuentra definida por crestas. En vista dorsal, el área sustentaculum tali diverge respecto a la cara medial del tubérculo, en un ángulo mayor y cercano a $\operatorname{los} 100^{\circ}$. La articulación medial es cuadrangular a circular, y se encuentra fuertemente expandida en sentido medial en su sector central. Su margen proximomedial, está replegado ventralmente en un ángulo. En vista distal, la articulación medial forma un ángulo cercano a $0^{\circ}$ respecto al eje mayor de la articulación para el tarsal IV, encontrándose ambos ejes cercanos al plano transverso. La superficie articular proximal para el talus es alargada y convexa en dirección cráneocaudal. El proceso troclear, posee forma de una plataforma extendida lateral y proximodistalmente, alcanzando al margen distal del calcáneo. La superficie articular para el tarsal IV es oval y cóncava. Justo ventral a ésta, el sector ventrodistal se proyecta a modo de un tubérculo muy amplio (i.e., similar en desarrollo a la cara articular para el tarsal IV) aunque mal definido.

El tarsal central (Lámina 3.19E) es aplanado en sentido proximodistal, apenas superando en la altura del carpal II. En vista medial, la cara articular que contacta al astrágalo se encuentra levemente elevada en su margen craneal. En el extremo mediodistal, el central contacta a un proceso del tarsal I. El sesamoideo tibial no se encontró presente como tal en ningún espécimen, pero un proceso medial del tarsal I (ver más adelante) parece representar al sesamoideo fusionado a éste. Las carillas articulares distales que reciben a los tarsales I, II y III son convexas a irregulares, con forma conjunta de "L", siendo el sector que recibe al tarsal III poco delimitado. Los sectores de articulación con el tarsal I y II se muestran algo constreñidos en su sector medio. El proceso plantar está bien desarrollado y definido. Los tarsales I, II y III se muestran imbricados, con todas sus aristas algo redondeadas. En el tarsal I, la carilla articular para el metatarsal I se encuentra fuera del plano transversal, inclinando marcadamente en sentido medial. En vista distal posee forma ovoide, y una superficie elongada 
proximodistalmente y cóncava. En el sector proximomedial, se proyecta un tubérculo breve y constreñido en su base, al parecer en relación a la zona de contacto proximal con el sesamoideo tibial, o más seguramente, el mismo fusionado al tarsal I (distinto a otros mustélidos sudamericanos comparados, incluso Lo. longicaudis, ver más adelante). El tarsal II tiene forma de cubo y una articulación distal triangular y levemente cóncava, que contacta al metatarsal II en un plano oblicuo (inclinando hacia lateral). En vista ventral, el tarsal II se encuentra obliterado por los aledaños. En vista distal, el tarsal III posee forma de "T", siendo cóncava, con una constricción central, y ensanchado en su sector ventral. Este carpal posee un proceso plantar redondeado y amplio. El tarsal IV posee un desarrollo próximodistal menor al del tarsal III y central juntos. La cara medial del tarsal IV contacta en su primer cuarto al central, y en los dos cuartos medios al tarsal III, inclinando esta segunda superficie levemente hacia distal. En vista medial, las facetas articulares para el tarsal III y central se continúan dorsalmente, y solo se encuentran separadas por un surco que presenta numerosas foramina en el sector ventral. La zona central y dorsal del tercio distal de la articulación entre el tarsal III y IV se encuentra fuertemente incidida, y esta incisión se continua ampliamente en el sector central y dorsal de la articulación entre metatarsal III y el metatarsal IV. En vista dorsal, esta zona deprimida abre a modo de un foramen elongado proximodistalmente entre estos cuatro elementos. La cara distal del tarsal IV articular con el metatarsal IV y V exclusivamente, es una área cóncava, sino conformarse un contacto de tipo cóclea-tróclea. El proceso plantar del tarsal IV es robusto. Se proyecta ventralmente formando una pared proximal al pasaje del tendón del $\mathrm{m}$. fibularis longus. Entre el proceso plantar del central y el tarsal IV se delimita un canal ancho con algunas foramina en la superficie del segundo elemento. La cara articular distal se proyecta ventromedialmente en forma aguda.

En vista lateral, el surco para el tendón del $\mathrm{m}$. fibularis longus es una incisura profunda entre el proceso plantar del metatarsal $\mathrm{V}$ y el proceso plantar del mismo tarsal IV, que se continua, en vista plantar, como un surco profundo de trayectoria recta y diagonal.

Los cinco metatarsales son robustos y se disponen presentando un débil empaquetamiento, divergiendo distalmente (incluso los tres centrales). Todos los metatarsales son cilíndricos, siendo el I y V aplanados proximalmente, mayormente rectos y levemente expandidos lateromedialmente en sus extremos distales, mientras que el metatarsal I se destaca por ser fuertemente plano en comparación con los otros. El metatarsal IV es el mayor de los elementos, seguido por el III; seguidos en longitud por el II y V (siendo estos de similar magnitud, si se incluyen los procesos plantares en esta medida), y finalmente el metatarsal I, notablemente menor longitud, aproximadamente tres quintas partes de la longitud del mayor metatarsal. En vista ventral, el proceso plantar del metatarsal I es amplio y robusto. Justo lateral a éste, la base del metatarsal se proyecta lateralmente a modo de una plataforma hasta alcanzar a 
obliterar la mitad medial de la base del metatarsal II; sin contactar al proceso plantar del metatarsal III. Esta plataforma supera distalmente al tubérculo plantar (extendiéndose sobre el primer cuarto de la longitud total del metatarsal I). Su margen lateral está engrosado y bien diferenciado en su sector más proximal. El proceso plantar del metatarsal II es robusto y se ubica proximal al del metatarsal I. El proceso plantar del metatarsal III y IV poseen forma aplanada y expandida lateromedialmente. El metatarsal IV recibe al V mediante una superficie irregular y cóncava, y recibe al III mediante una superficie cóncava. En la zona central de este área articular se observa la continuación del surco o canal descripto entre el tarsal III y IV, separando a dicha zona articular en dos facetas claramente diferenciables: una proximoventral elongada próximo-distalmente, y otra distodorsal, oval, que se ubica sobre un tubérculo o promontorio en el metatarsal IV, abriendo finalmente entre ambos metatarsales, en el sector ventrodistal de la zona articular. Finalmente el surco descripto abre en vista ventral, entre ambas facetas articulares. En vista ventral, el metatarso V posee un proceso plantar desarrollado proximodistalmente y delgado. En vista lateral se proyecta en forma aguda hacia ventral en su sector medio. El sector central del extremo proximal es una superficie cóncava a aplanada, con un margen proximal engrosado y continuado con el proceso plantar, y hace las veces de pared distal del surco para el tendón del $m$. fibularis longus. El sesamoideo típicamente presente sobre esta superficie no se encontró en ninguno de los especímenes analizados. Los sesamoideos metatarsales para los dígitos II al V están bien desarrollados. En el caso del dígito I, los dos sesamoideos poseen un menor desarrollo, en especial el caso del medial, el cual posee forma de "gota", es agudo en su sector proximal, y poco breve en sentido proximodistal. Las falanges proximales son de similar robustez (quizás levemente menor) a lo observado en los metatarsos. Las falanges medias poseen aproximadamente la mitad de la longitud observada en las proximales, siendo similares a estas últimas en los demás aspectos. Tanto la base como cresta ungueal de las falanges ungueales son robustos y prominentes. En vista lateral, el proceso ungueal posee una superficie dorsal fuertemente convexa en todos los casos, mientras que la superficie ventral es levemente cóncava a plana, convergiendo abruptamente y terminando en un extremo moderadamente agudo y breve. En vista dorsal los procesos ungueales son robustos. Las unguis son engrosadas, de márgenes redondeados, curvadas y engrosadas. 


\subsubsection{Lontra longicaudis}

Complejo atlas-axis (Láminas 3.1F, 3.2E)

El atlas (Lámina 3.1F) presenta regiones de agarre muscular menos desarrolladas en Lo. longicaudis que en Lo. provocax. Tanto en vista craneal como caudal, el foramen vertebral es levemente más ancho que alto, y en vista caudal, posee una forma más bien circular y levemente comprimido en su zona media, a modo de un "reloj de arena" ancho, en relación a la proyección medial de las carillas articulares, aunque menos marcada que lo observado en Lo. provocax. Los forámenes vertebrales laterales son relativamente amplios y muy profundos. El tubérculo ventral se proyecta en forma de un extremo agudo dirigido caudalmente. Las superficies articulares caudales son de contornos redondeados, sobresaliendo en sus márgenes mediales (algo menor marcada que en Lo. provocax). El desarrollo de las alas del atlas varía mucho en los distintos especímenes analizados, pero en líneas generales son relativamente comprimidas en dirección cráneocaudal y expandidas lateromedialmente (aunque reducidas respecto a Lo. provocax), y con un ángulo caudomedial marcado. Los márgenes caudal y lateral son en general levemente cóncavos. La incisura alar es amplia y abierta (en menor grado que Lo. provocax). Como excepciones a incisuras abiertas, en el lado derecho del espécimen MLP 1959 y ambos lados de MLP 1964 y MACN 47.218 se encontraron obliterados por un puente lateral formando un foramen alar lateral. En MLP 4-X-94-1, ambos lados presentaron puentes laterales incompletos pero de bases evidentes. Los forámenes transversos abren caudalmente, inmediatamente lateroventrales a las superficies articulares caudales (una posición más ventral respecto a la observada en Lo. provocax).

El axis (Lámina 3.2E) posee un proceso espinoso moderadamente alto y amplio en dirección cráneocaudal, apenas superando la extensión del cuerpo vertebral. El cuerpo del axis se encuentra reducido en extensión cráneocaudal, aunque en un grado algo menos extremo que Lo. provocax, similar a lo observado en los demás elementos cervicales. El proceso espinoso en su extremo más craneal se encuentra fuertemente engrosado, y en su extremo caudal se presenta un tubérculo aplanado cráneocaudalmente. En vista lateral, el margen dorsal es recto en su sector medio. En vista craneal, las carillas articulares craneales se encuentran posicionadas lateralmente, continuándose con el proceso odontoides mediante una región angosta y ventral. Las carillas están separadas en su sector dorsal por surcos profundos y amplios. Los procesos que portan las carillas articulares caudales están engrosados a modo de tubérculos o quillas dorsales muy desarrollados a hipertrofiados en el axis. Sobre la cresta ventral del cuerpo, no se observa el tubérculo medio, pero si un levemente engrosamiento cráneomedial. En vista ventral, la base del proceso odontoides no se delimita con tanta claridad como en Lo. provocax, y no se continua con los márgenes laterales del mismo exceptuando un leve cambio de pendiente. En vista caudal, los forámenes transversos poseen forma elongada dorsoventralmente, 
encontrándose su margen dorsal muy por sobre la altura del margen dorsal del foramen vertebral, y por sobre la base del proceso transverso en sí mismo.

\section{Tercera a séptima vértebra cervical (Lámina 3.3E)}

En vista lateral, el proceso espinoso de la tercera vértebra cervical posee forma triangular, con los márgenes craneal y caudal rectos. Los procesos que portan las carillas articulares caudales están engrosados a modo de tubérculos o quillas dorsales muy desarrollados

a hipertrofiados en la tercera, cuarta y quinta vértebra cervical, y atrofiados sobre el sexto y séptimo elementos. Los procesos transversos desde la cuarta a séptima vértebras cervicales son similares a los de Lo. provocax, aunque, en vista lateral, sus márgenes craneales son convexos. El tubérculo dorsal de la séptima vértebra cervical presenta una plataforma extendida en dirección cráneoventral. En las últimas vértebras cervicales, los tubérculos dorsales se proyectan progresivamente en sentido laterodorsal, alejándose levemente de una posición perpendicular en sentido caudal (en mayor medida que Lo. provocax). Los tubérculos ventrales de los cuerpos vertebrales anteriores son menos robustos que los observados en Lo. provocax.

\section{Vértebras torácicas y caja torácica (Lámina 3.4C)}

La serie torácica posee, al igual que Lo. provocax, 15 elementos. La vértebra diafragmática corresponde al décimo segundo elemento en el espécimen MLP 1959, mientras que es el décimo tercero en MACN 47.218. Las escotaduras craneal y caudal de las vértebras son relativamente más amplias en el sector preanticlinal en relación con lo observado en Lo. provocax. En vista lateral, los márgenes craneales de los procesos transversos son más bien rectos, y sólo se mantienen elevados y prácticamente perpendiculares hasta el tercer elemento. La mayoría de los procesos espinosos poseen un extremo distal robusto en mayor o menor grado, aunque este engrosamiento es mínimo entre las últimas vertebras preanticlinales, desde el séptimo al décimo tercer elemento. El desarrollo areal de los procesos espinosos anteriores (especialmente en los cuatro primeros elementos) es marcadamente menor al observado en los especímenes de Lo. provocax, en relación a que están menos expandidos cráneocaudalmente. A partir de la vértebra anticlinal, las fóveas costales de los procesos transversos se ubican exclusivamente sobre el cuerpo vertebral correspondiente (sin incidir además en el precedente). Los procesos mamilares son robustos y alcanzan una posición más dorsal y verticalizada que lo observado en Lo. provocax. Estos se reducen, aunque se mantienen diferenciados, en los elementos lumbares (más desarrollados en estos que Lo. provocax). Los procesos accesorios se esbozan tempranamente. En el décimo segundo elemento se encuentra presente un proceso netamente independiente, a modo de un proceso accesorio definido, aunque reducido y dorsalizado. A partir de la vértebra anticlinal se encuentran netamente desarrollados y en su 
posición habitual. A partir de la séptima u octava vértebra torácica, y hasta la décimo primera, el extremo caudal de los procesos transversos presenta una proyección caudal robusta, que pueden entenderse como una continuación craneal a los procesos accesorios descriptos.

En el esternón, la primera de las esternebras es algo mayor a dos veces la longitud que las posteriores (algo menos extendida cráneocaudalmente respecto a Lo. provocax); la región articular con el primer par de costillas se encuentra al final del primer tercio de su extensión. El manubrio es generalmente similar en forma al de Lo. provocax, aunque más ensanchado lateromedialmente y menos proyectado cranealmente. Por otro lado, la quilla ventral se encuentra relativamente menos desarrollada.

\section{Vértebras lumbares (Lámina 3.5F)}

$\mathrm{Al}$ igual que en Lo. provocax, la serie lumbar está compuesta por 5 vértebras. Pese a que la altura de los procesos espinosos es importante, sus desarrollos areales son relativamente bajos, en relación a su breve desarrollo cráneocaudal en comparación con Lo. provocax. En vista lateral, los procesos espinosos lumbares poseen formas cuadrangulares (especialmente en la zona media y caudal), inclinan cranealmente, y son similares a los descriptos en el último sector torácico, aunque son progresivamente más altos, menos expandidos cráneocaudalmente y menos robustos; todos los márgenes de estos son mayormente rectos. En la zona articular entre la décimo segunda y décimo tercera vértebras torácicas (última vértebra preanticlinal y la anticlinal), así como en todos los elementos posteriores a estos, incluyendo las lumbares, se observan facetas articulares con su eje principal de dirección cráneocaudal y que inclinan medialmente y apartan respecto al plano longitudinal (distinto a lo observado entre las vértebras anteriores) en un ángulo entre 50 y $60^{\circ}$. En el sector anticlinal y postanticlinal torácico, los procesos articulares craneales son cóncavos dorsoventralmente, mientras que en el sector lumbar, los contactos son mayormente planos, y ubicados lejos del plano perpendicular. Los procesos mamilares muestran un similar o menor desarrollo que el observado en los elementos postanticlinales torácicos, y son más delgados y proyectados lateralmente en comparación con Lo. provocax. Los procesos transversos inclinan por debajo del plano horizontal (en el caso de los primeros elementos, en mayor medida que Lo. provocax). En el primer elemento lumbar el margen craneal es cóncavo y breve, superando cranealmente al margen craneal del cuerpo vertebral, y el caudal es mayormente recto y amplio. El extremo laterocaudal del último par de procesos transversos se encuentra aplanado y ampliamente sobresaliente.

\section{Sacro (Lámina 3.6C)}

El hueso sacro está compuesto, como es típico, por tres elementos fusionados entre sí. Posee una forma triangular a cuadrangular debido a que el último elemento es apenas más 
angosto que el primero, y mayor que lo observado en Lo. provocax. Los procesos espinosos no se fusionan en una única cresta sacra media. Estos decrecen en altura caudalmente, siendo el último aproximadamente la mitad de alto que el primero. Los tubérculos de origen del $\mathrm{m}$. intertransversarii dorsalis caudae son robustos y se encuentran en una posición algo más caudal que Lo. provocax, claramente separadas de la articulación sacro-ilíaca.

Vértebras caudales (Lámina 3.7D)

El espécimen MLP 1959 presenta la serie de vértebras caudales mayormente completa, compuesta por 20 elementos, posiblemente faltando dos o tres elementos distales, resultando en un número similar o idéntico al de Lo. provocax. Los primeras vértebras son relativamente robustas, desarrolladas lateromedialmente. Los procesos sobre ellas son amplios hasta el quinto o sexto elemento, reducidos tempranamente en comparación con Lo. provocax. Las primeras ocho o nueve vértebras caudales, poseen procesos espinosos diferenciables. Los últimos procesos espinosos son delgados y elongados cráneocaudalmente. La mayoría de las estructuras se atrofian un elemento antes en comparación con Lo. provocax. En vista lateral, las escotaduras caudales de las vértebras caudales se encuentran bien diferenciadas hasta el quinto elemento y en extremo reducidas o ausentes a partir del siguiente. La vértebra transicional corresponde al sexto elemento (posiciones adelantadas respecto a Lo. provocax). A partir en el sexto y séptimo elemento, el arco neural se encuentra atrofiado a un pequeño y breve conducto, y en los posteriores es indiferenciable del cuerpo vertebral. A partir del sexto elemento, las carillas articulares caudales no se distinguen, encontrándose en su lugar un par de crestas redondeadas poco diferenciada que corona el extremo caudal del margen dorsal de cada elemento, y que a partir del elemento número once se fusionan en una única (nuevamente, posiciones adelantadas en un elemento respecto a Lo. provocax). Los procesos mamilares se muestran presente bien diferenciables hasta tardíamente en la serie, incluyendo al elemento número 15 , mientras que a partir de allí están representados por tubérculos poco diferenciables.

Los procesos transversos parten de casi todo el margen lateral del cuerpo vertebral en el caso de las dos primeras vértebras caudales. Los procesos transversos se proyectan y posicionan progresivamente caudalmente, y se dividen en procesos transversos caudal y craneal más tempranamente, bien definidos ya sobre el sexto elemento caudal (un elemento antes que en Lo. provocax). A partir del séptimo elemento (dos elementos más temprano que Lo. provocax), el proceso transverso craneal supera al caudal en su extensión, manteniéndose esto hasta el final de la serie. A partir de la tercer vértebra caudal (dos elementos antes en comparación con Lo. provocax), se desarrollan procesos hemales a modo de protuberancias cráneoventrales muy marcadas y extendidas cranealmente). 


\section{Escápula (Lámina 3.8F)}

La forma general de la escápula de Lo. longicaudis es algo más estilizada que Lo. provocax. El límite ventral del margen craneal presenta un ángulo claramente mayor a los $90^{\circ}$. La espina es moderadamente delgada y elevada (en mayor medida que lo observado en Lo. provocax). Delimita una fosa supraespinosa con un área algo menor a una vez y media la presente en la fosa infraespinosa. Detrás del ángulo caudal, el área de origen del m. teres major y m. triceps brachii caput angulare es amplia pero no se encuentra engrosada en su extremo caudomedial a modo de un tubérculo, ni se continúa con la cara caudal de la espina caudal (contrario a lo observado en Lo. provocax). El margen caudal de la escápula es elevado y reflecto lateralmente en menor medida que Lo. provocax. El proceso hamatus es moderadamente robusto, quillado en el extremo caudal de su margen caudal y se proyecta cranealmente respecto a la espina en vista lateral, siendo paralelo al plano de la escápula en vista craneal, apenas no alcanzando el nivel de la cavidad glenoidea. El proceso subhamatus es triangular, amplio caudalmente, pero poco proyectado en sentido caudodorsal, delimitado en este sector por un margen continuo y levemente convexo. En la base del cuello, sobre la superficie medial, justo craneal a la zona deprimida correspondiente a la contracara de la espina, se observa un grupo de estrías elongadas dorsoventralmente craneales a la espina (correspondiente al grupo intermedio en los tres de Lo. provocax), mientras que inmediatamente caudal a este área se observa un segundo grupo de estrías (correspondiente en posición al cuarto de Lo. provocax).

\section{Húmero (Lámina 3.9F)}

La diáfisis del húmero es sigmoidea a convexa en vista craneal; la curvatura y extensión cráneocaudal del sector proximal de la diáfisis son algo menos marcadas que en Lo. provocax. En la vista craneal, la cabeza humeral es superada en altura por el tubérculo mayor, el cual es muy robusto y marcadamente elevado en toda su extensión (incluso en mayor medida que lo observado en Lo. provocax). En el sector caudal de este tubérculo, el área de inserción del m. teres minor se encuentra poco diferenciada.

La tuberosidad deltoidea es robusta, pero no se encuentra expandida lateralmente como fue descripto para Lo. provocax. La cresta del tubérculo mayor está poco diferenciada, sin elevarse por sobre la diáfisis. La zona delimitada por esta cresta y la deltoidea es amplia y levemente convexa. El tubérculo menor se encuentra hipertrofiado, presenta forma cuadrangular, y está marcadamente diferenciado y elevado en sus márgenes craneal y ventral, y algo menos diferenciado y poco elevado en su sector caudal. Los epicóndilos lateral y el medial poseen un desarrollo lateromedial importante, pero levemente menor que el observado en Lo. provocax. El epicóndilo medial es relativamente amplio proximodistalmente, alcanzando la 
altura de la tróclea distal. La presencia de un foramen supracondiloideo amplio fue constante en los especímenes analizados. La tróclea posee un bajo desarrollo lateromedial, relativamente menor y más profunda que Lo. provocax. En vista caudal, la zona articular posee un margen medial moderadamente marcado. La fosa olecraneana es amplia y profunda, y sus márgenes proximolateral y proximomedial no se contactan formando un ángulo. La fosa para el tendón del olécranon es profunda, elongada proximodistalmente (especialmente en sentido proximal), y posee sus márgenes lateral y medial agudos y elevados, mientras que en su sector proximal se separa en su sector profundo de la fosa olecraneana (de similar profundidad) gracias a un tabique delgado. Su margen distal está moderadamente definido.

Ulna (Lámina 3.10F)

La ulna es principalmente recta. El sector caudomedial de la tuberosidad del olécranon se encuentra desarrollado y fuertemente proyectado en sentido caudomedial. La incisura radial posee un margen lateral agudo. Inmediatamente caudal a ésta, la articulación con el cóndilo del húmero se proyecta a modo de una plataforma cuadrangular. Su superficie articular es ovalada y se encuentra expandida distalmente, pobremente desarrollada en sentido caudoproximal, sin definirse la clara forma de "C" presente en Lo. provocax (y Pt. brasiliensis, ver más adelante). La superficie diartrodial está elevada respecto a la diáfisis ulnar.

\section{Radio (Lámina 3.11D)}

La carilla articular proximal del radio posee una forma cuadrangular de esquinas redondeadas a ovaladas, sin presentarse una escotadura en su sector cráneolateral, ni un tubérculo lateral a éste. La zona de contacto con la ulna es levemente convexa. Las crestas correspondiente a los orígenes del $\mathrm{m}$. pronator teres y $\mathrm{m}$. abductor digiti I longus están poco marcadas en comparación con Lo. provocax y son más bien paralelas. Los surcos para el pasaje del $\mathrm{m}$. abductor pollicis longus y el $\mathrm{m}$. flexor carpi radialis son amplios y mejor definidos que en Lo. provocax. El tubérculo de inserción del m. brachioradialis es amplio, agudo y muy prominente. El tubérculo craneal a la zona de pasaje del $\mathrm{m}$. extensor digiti I et II es agudo y moderadamente saliente. Justo medial a la escotadura ulnar, se presenta (como en otras nutrias) una superficie articular circular breve, que al parecer contacta al carpal accesorio en posiciones flexionadas.

Autopodio anterior (Lámina 3.12D)

En vista craneal, el radial presenta un desarrollo lateromedial menor al doble que el ulnar. Su extensión lateral termina con un margen abrupto, justo antes del nivel de la zona articular entre el metacarpal III y IV, mientras que su margen medial es relativamente suave. 
Sobre la superficie mediodorsal del accesorio no se presenta una quilla definida. El margen lateral del carpal III se eleva, alcanzando aproximadamente tres cuartos de la altura del carpal IV, aumentando el área de contacto con el carpal IV, siendo este área de contacto semicircular y aplanada. En vista craneal, la mitad proximal de este contacto está cubierto por el radial. En vista caudal, el tubérculo plantar del carpal III se encuentra bien desarrollado como un área ovoide y proyectada medialmente en forma aguda. En vista craneal, la articulación entre el radial y el carpal IV posee un ángulo mayor a $45^{\circ}$ respecto al plano transverso.

\section{Hueso coxal (Lámina 3.13F)}

La superficie sinfisiaria sólo se encuentra engrosada en su sector craneal. El ala del ilion posee una forma rectangular. La espina ventro-craneal se proyecta marcadamente en sentido craneal, en mayor medida que la dorso-craneal (y en mayor medida que lo observado en Lo. provocax), resultando en una cresta ilíaca inclinada dorsalmente. La espina ventro-caudal es prácticamente indistinguible. En la cara lateral del cuello del ilion, se diferencia sutílmente la línea glútea caudal. El cuerpo del isquion forma un ángulo agudo pero cercano a los $85^{\circ}$ respecto a la rama del isquion, la cual es aplanada, amplia (especialmente en su sector dorsal) y cuadrangular, aunque más breve que lo observado en Lo. provocax. La arcada isquiática se diferencia del resto del margen caudal del isquion aunque es moderada a breve y somera. El contacto entre la rama del isquion y la del pubis no se encuentra marcado por un tubérculo. La tuberosidad isquiática se encuentra marcadamente elevada, incluso más que en comparación con Lo. provocax. El pubis es aplanado a levemente convexo en vista lateral y delgado lateromedialmente, dando origen a una rama caudal en un ángulo más abrupto (cercano a los $70^{\circ}$ ) que lo observado en Lo. provocax (en relación a la inclinación de la sínfisis). La rama caudal del pubis es alta y poco engrosada, y tiene un moderado a breve desarrollo cráneocaudal.

\section{Fémur y patela (Lámina 3.14F)}

El margen cráneoventral de la cabeza del fémur se proyecta mínimamente (en menor medida que lo observado en Lo. provocax), apenas sobresaliendo respecto al cuello femoral. Este último es relativamente robusto. El margen lateral de la fosa trocantérica se encuentra engrosado. El margen dorsal del cuello femoral está moderadamente deprimido. Sobre éste, la escotadura dorsal entre la cabeza femoral y el trocánter mayor es somera. La tuberosidad glútea es amplia, aunque distalmente apenas alcanza el nivel del trocánter menor. La región craneal de la misma se encuentra hipertrofiada y sobresaliente, aunque en menor medida que Lo. provocax, a modo de un área plana y rugosa incidida por una muesca o depresión somera.

En el extremo distal, la tróclea femoral se encuentra poco desplazada en sentido medial. Existe una cresta rugosa que cubre el sector cráneomedial de último quinto de la diáfisis femoral 
que no se continúa distalmente con la cresta medial de la tróclea, la cual es relativamente breve y poco marcada. En vista distal, el cóndilo medial se proyecta en mayor medida en sentido caudal que el lateral. La carilla medial para el sesamoideo supracondiloideo es la mayor, pero sin sobresalir marcadamente del epicóndilo.

Tibia (Láminas 3.15F, 3.16D)

El cóndilo lateral es aplanado a levemente convexo (distinto al cóndilo medial y a lo observado en Lo. provocax). Este cóndilo, en conjunto con el área articular cercana para la fíbula, se proyectan de forma aguda en sentido laterocaudal. Todo el sector cráneolateral al cóndilo lateral está marcadamente desarrollado, aunque en menor grado que lo observado en $L o$. provocax. La eminencia intercondiloidea se muestra moderadamente desarrollada. La inserción del ligamento colateral medial se encuentra marcadamente desarrollada (aunque en menor medida que Lo. provocax). La superficie articular para la cabeza de la fíbula, en posición ventral respecto al cóndilo lateral en vista caudal, se encuentra separada por una amplia superficie, que en vista lateral posee una forma de banda, que se reduce su espesor abruptamente en el sector más caudal.

Sobre el extremo distal de la cóclea tibial, ambos surcos para el astrágalo poseen un desarrollo moderado. En vista craneal, ambos surcos de la cóclea están separados por una proyección somera (menos abrupta que lo observado en Lo. provocax). En vista caudal, el margen caudal de la superficie articular distal es mayormente recto, sin que los surcos articulares incidan en el mismo.

Fíbula (Láminas 3.16D, 3.17D)

En el sector proximal y mediocaudal dela fíbula, el tubérculo correspondiente el origen del $\mathrm{m}$. soleus es marcadamente menos robusto que lo descripto para Lo. provocax. En el extremo distal de la fíbula, se diferencia una cresta medial, posiblemente zona de origen de la membrana interósea que cruza en diagonal hacia la zona lateral, dando paso gradualmente a una cresta lateral marcadamente elevada (posiblemente zona de origen de retinacula, mucho más desarrollada que en Lo. provocax) que finalmente contacta la cresta craneal que delimita la zona del pasaje del $\mathrm{m}$. fibularis longus.

Pes (Láminas 3.18D, 3.19D)

La tróclea del astrágalo (Lámina 3.18D) tiene una longitud moderada a breve en dirección cráneocaudal. La separación entre las crestas es aproximadamente constante a lo largo de toda la tróclea. 
En vista lateral, la carilla maleolar lateral presenta un desarrollo cráneomedial moderado.

En vista ventral, tanto la superficie articular proximal para el calcáneo como el tubérculo del talus sobresalen caudalmente (en menor grado que lo observado en Lo. provocax), brevemente separadas entre sí, debido al amplio desarrollo lateromedial del extremo caudal de la faceta articular proximal. La superficie articular proximal es amplia, especialmente en su sector caudal, y poseen márgenes redondeados. En vista distal, la superficie articular para el tarsal central es fuertemente convexa, continuándose con el cuello sin sobresalir respecto a éste. Esta configuración hace que, en vista dorsal, el cuello astragalar se muestre amplio y la cabeza semiesférica, continuándose sin mayores quiebres con éste. Sobre la superficie laterodistal, la carilla articular para el tarsal IV está reducida y es poco diferenciable. En vista ventral, entre las superficies articulares un foramen amplio representa la abertura ventral del canal astragalar. La apertura caudal de este canal está ausente.

El tubérculo del calcáneo (Lámina 3.18D) presenta un desarrollo próximodistal relativamente breve. El surco del tubérculo es profundo, definido y simétrico. La superficie articular proximal para el talus es extremadamente alargada proximalmente. El proceso troclear, zona de origen del $\mathrm{m}$. quadratus plantae, posee forma de una plataforma expandida lateral y distalmente pero no proximalmente. En el tarsal central (Lámina 3.19D), en vista medial, la cara articular que contacta al astrágalo se encuentra elevada en su margen craneal en mayor medida que en Lo. provocax. En el tarsal I, la carilla articular para el metatarsal I inclina lateralmente en menor medida que Lo. provocax. El sector proximomedial es redondeado y robusto, sin proyectarse a modo de un tubérculo agudo, y contacta un sesamoideo tibial aplanado y reducido, en vez de fusionarse al mismo como fue descripto para Lo. provocax. En el tarsal IV, sobre el extremo proximomedial, se encuentra una faceta articular para el astrágalo relativamente breve (en comparación con Lo. provocax). En la serie metatarsal el foramen en el sector proximal de la articulación entre el metatarsal III y IV es profundo, aunque en menor medida que lo observado en Lo. provocax. En los restantes elementos del autopodio posterior no hay mayores diferencias respecto a Lo. provocax. 


\subsubsection{Pteronura brasiliensis}

Complejo atlas-axis (Láminas 3.1H, 3.2G)

El atlas (Lámina 3.1H) está comprimido en dirección cráneocaudal. En vista caudal posee una forma más bien circular algo alargada lateromedialmente, no constreñida en su zona media. En vista dorsal, el arco neural posee un margen craneal cóncavo. El tubérculo dorsal tiene una forma simple y está poco desarrollado.

Las alas del atlas son cuadrangulares, amplias, con márgenes rectos a poco curvos, sobresaliendo en su extremo caudolateral ampliamente por detrás y ventral a los procesos articulares caudales, y en similar o mayor medida en su extremo caudomedial. La incisura alar es amplia y no se encontró obliterada en ningún caso, aunque en MNHN A1918 se encontró limitada caudalmente por una tuberosidad aguda en el extremo cráneolateral de los procesos transversos. Los forámenes transversos se muestran marcadamente amplios y redondeados; se ubican en el centro de la base del proceso alar en vista ventral (caudal respecto a lo observado en Lontra spp.).

El axis (Lámina 3.2G) posee un proceso espinoso moderado a bajo, sólo elevado en su extremo caudal (excepto en espécimen AMNH 30190). En su extremo más craneal se encuentra engrosado, en un grado intermedio entre Lo. provocax y Lo. longicaudis. El extremo caudal es marcadamente robusto y achatado cráneocaudalmente. En vista lateral, el margen dorsal es recto en su sector medio. El proceso odontoides es romo, corto y robusto. Los procesos articulares caudales presentan tubérculos dorsales marcadamente robustos. En vista craneal, las carillas articulares craneales se continúan en un angosto sector ventral con proceso odontoides.

Los procesos transversos son delgados. En vista lateral el extremo más craneal de los forámenes transversos no está obliterado por el límite caudal de las carillas articulares craneales. En vista caudal, los límites dorsales de los forámenes transversos superan el margen dorsal del cuerpo vertebral.

\section{Tercera a séptima vértebra cervical}

A diferencia de Lontra spp., la cuarta y quinta vértebra poseen una forma general y procesos espinosos muy similares entre sí, y el proceso espinoso de la sexta vértebra es claramente más alto que los anteriores. El proceso espinoso de la séptima vértebra cervical es superior en altura al de la sexta vértebra cervical, superando en altura al triple de su base. Los extremos dorsales de los procesos espinosos son particularmente gruesos. Los procesos que portan las carillas articulares craneales de la tercera vértebra se encuentran mínimamente robustecidos. Los procesos que portan las carillas articulares caudales están hipertrofiados desde el axis hasta la cuarta vértebra cervical, están reducidos en las posteriores, y mínimamente representados en la séptima vértebra. Los procesos transversos cervicales son marcadamente 
amplios. Los tubérculos dorsales de los procesos transversos de la séptima vértebra cervical se encuentran subdivididos distalmente en un proceso dorsal y otro ventral, conectados por una zona delgada.

\section{Vértebras torácicas y caja torácica (Lámina 3.4E)}

La serie torácica del espécimen MNHN A1918, el más completo de los descriptos, está incompleta, poseyendo 13 elementos, pero un número de 15 elementos torácicos (igual a Lontra spp.) pudo confirmarse en otros especímenes (e.g., espécimen del Museum Victoria MV C30422). La vértebra diafragmática corresponde al décimo segundo elemento (coincidiendo con lo típico de Lontra spp.). Las escotaduras craneal y caudal no se encuentran obliteradas entre la última preanticlinal y anticlinal, ni en la región postanticlinal. Los primeros procesos espinosos poseen una altura claramente superior a la de los cuerpos respectivos (mayor al triple), mientras que muestran una mínima expresión en la décimo segunda y décimo tercera vértebra torácica, correspondiendo esta última con la vértebra anticlinal. En las primeras vértebras torácicas los procesos espinosos poseen un margen craneal recto y el caudal levemente convexo; caudalmente se solapan progresivamente, con márgenes craneales y caudales mayormente rectos. El desarrollo en área de los procesos espinosos es relativamente bajo en todos los elementos. El sector caudal de la base de los procesos espinosos, especialmente entre el segundo y el sexto elemento, se encuentra moderadamente expandido en sentido caudal, en menor medida que Lo. provocax. En vista lateral, el proceso espinoso de la vértebra anticlinal está posicionado caudalmente, es cuadrangular y relativamente alto (en comparación con Lontra spp.); a su vez, presenta un margen craneal cóncavo, una breve extensión cráneocaudal, siendo más ancho en su zona caudal que craneal. A partir de éste, y hasta el último elemento de la serie, los procesos espinosos poseen forma cuadrangular, son levemente más elevados y poco inclinados en sentido craneal, y marcadamente engrosados en su margen dorsal.

A partir de la primera vértebra postanticlinal, las fóveas costales se ubican exclusivamente sobre el cuerpo vertebral correspondiente (sin incidir además en el precedente). Los procesos mamilares se presentan por primera vez y definidos en la vértebra anticlinal, siendo relativamente delgados y breves (mucho menores que los observados en Lontra spp.), y alcanzando algo menos de la mitad de la altura de los procesos espinosos en todos los elementos de la serie, y reducidos, aunque aún presentes, en los últimos elementos lumbares. Los procesos accesorios se presentan definidos a partir de la vértebra anticlinal, aunque se evidencian esbozos en la última preanticlinal. En los procesos transversos de las vértebras preanticlinales se diferencian tubérculos dorsales, en todos los casos menos importantes que los observados en Lo. provocax. En vista dorsal, los procesos accesorios inclinan 20 a $30^{\circ}$ en sentido caudal. 
La configuración de la caja costal y esternón el similar a la de otras nutrias, con 15 elementos algo más robustos que en Lo. provocax, los diez primeros contactando directamente el esternón, los siguientes dos indirectamente vía el décimo, y los últimos tres flotantes. La morfología del manubrio no pudo ser descripta en los materiales analizados.

Vértebras lumbares (Lámina 3.5H)

La serie lumbar está compuesta, como es típico para otras nutrias descriptas, por 5 vértebras. Se observa una breve elongación cráneocaudal de los cuerpos lumbares posteriores. El desarrollo de la superficie de los procesos espinosos es marcado, mientras que los transversos son relativamente reducidos, exceptuando los últimos. En vista lateral, los procesos espinosos lumbares son cuadrangulares y altos, especialmente los posteriores, y poco inclinados cranealmente. Las escotaduras caudales y dorsales son reducidas, exceptuando la última. El desarrollo de los procesos mamilares es mayor que el observado en Lontra spp., y en el sector lumbar anterior son agudos e hipertrofiados. Los procesos transversos inclinan por debajo del plano horizontal aunque manteniéndose cercano a éste. En el primer elemento lumbar, los procesos transversos se encuentran reducidos a una proyección perpendicular redondeada, sin alcanzar el margen craneal del cuerpo vertebral. El último elemento de la serie, y secundariamente el penúltimo, posee procesos transversos marcadamente desarrollados lateralmente, con sus extremos más engrosados y ensanchados cráneocaudalmente, mientras que el ángulo caudal es más agudo que redondeado. Sólo el último de los elementos posee procesos transversos que apenas superan ventralmente el margen ventral del cuerpo vertebral. El extremo laterocaudal del último par de procesos transversos es aplanado y ampliamente sobresaliente.

\section{Sacro (Lámina 3.5E)}

El hueso sacro está compuesto, como es típico, por tres elementos fusionados entre sí. En vista dorsal posee una forma cuadrangular, con el sector craneal de la cresta sacra lateral y la articulación sacra menos desarrollados lateromedialmente respecto al sector caudal de la cresta sacra lateral, la cual es similar en desarrollo a los procesos transversos de las primeras caudales. Los procesos espinosos no se fusionan en una única cresta sacra media. El primer proceso espinoso es similar en tamaño (USNMMa 304663) o menor (SNMS 1300) respecto a los otros dos. La cresta lateral sacra se proyecta marcadamente en sentido lateral en su sector caudal (en mayor medida que otros mustélidos comparados). Inmediatamente lateral al primer par de forámenes sacros, se observa un par de tubérculos robustos de origen del $\mathrm{m}$. intertransversarii dorsalis caudae, de desarrollo intermedio entre lo observado en Lontra spp. y otros mustélidos descriptos). 
Vértebras caudales (Lámina 3.7H)

El espécimen SNMS 1300 presenta la serie de vértebras caudales aparentemente completa, compuesta por 22 elementos. Los primeras vértebras (en especial la primera y la segunda) son relativamente robustas, similar a Lontra spp., aunque apenas alcanzan el desarrollo lateromedial observado en el sector caudal del sacro (hipertrofiado en esta especie). Los procesos sobre ellas son muy amplios hasta el sexto elemento, y se mantienen también relativamente amplios y robustos en los elementos posteriores a éste (en mayor medida que Lo. provocax). Los primeros ocho elementos caudales poseen un proceso espinoso diferenciable, estando el último representado por un tubérculo rugoso. Los procesos y las carillas articulares craneales y caudales poseen moderado a importante desarrollo hasta el quinto elemento (uno menos que en Lo. provocax). En vista dorsal, la escotadura craneal y dorsal de las cuatro primeras vértebras caudales están presentes pero relativamente reducidas. La vértebra transicional corresponde al sexto elemento. Las carillas articulares caudales se encuentran presentes hasta el quinto elemento (uno antes que Lo. provocax), y a partir del sexto, estas carillas dan lugar a un par de crestas redondeadas poco diferenciadas que coronan el extremo caudal del margen dorsal de cada elemento; a partir del décimo elemento estas crestas se fusionan en una única (tempranamente respecto a Lontra spp.). A partir del sexto y séptimo elemento (uno antes que Lo. provocax) el arco neural se encuentra atrofiado, como un pequeño puente que cubre un breve conducto.

Los tres primeros elementos caudales poseen en general los procesos transversos muy desarrollados lateromedialmente y son mayormente perpendiculares. A partir del cuarto se proyectan y posicionan gradualmente en sentido caudal, aunque en menor grado que lo observado en Lontra spp., manteniéndose mayormente perpendiculares. A partir del décimo elemento (mucho más tardíamente que en otros mustélidos) los procesos transversos se dividen en dos protuberancias: proceso transverso caudal y proceso transverso craneal, ambos de similar tamaño; presentes aunque reducidos hasta el elemento 19, distanciados en extremo por una zona deprimida, profunda y semicircular.

\section{Escápula (Lámina 3.8H)}

En la región del ángulo caudal de la escápula, al contrario de lo observado en los demás mustélidos descriptos, el margen dorsal de la escápula se continúa sin un quiebre de pendiente $\left(=180^{\circ}\right)$ con el margen dorsal y caudal del área de origen del m. teres major y m. triceps brachii caput angulare. El ángulo craneal es abierto, con una apertura de 120 a $130^{\circ}$ (en espécimen USNMMa304663) o mayor (demás especímenes). El final ventral del margen craneal conforma un ángulo amplio respecto a la cara ventral de la fosa supraespinosa, cercano a los $120^{\circ}$. El margen craneal se muestra totalmente quebrado en uno a dos sectores (en parte similar a Lo. 
provocax), siendo su sector más ventral prácticamente recto y vertical. La espina es robusta y elevada en su sector proximal, delimitando una fosa supraespinosa con un área algo mayor a dos veces la presente en la fosa infraespinosa. El área de origen del $\mathrm{m}$. teres major y $\mathrm{m}$. triceps brachii caput angulare se encuentra ampliamente desarrollada (duplicando la observada en Lontra spp.), sin continuarse como una cresta sobre cara caudal. La espina caudal está presente y es más bien lisa. La base del acromion se desarrolla gradualmente a partir de la espina, y presenta rugosidades marcadas. El proceso hamatus es robusto, guillado e inclina cranealmente, superando ventralmente el nivel de la cavidad glenoidea y, en algunos casos, alcanzando la altura del tubérculo supraglenoideo (mayor que en otros mustélidos descriptos); en vista craneal, no converge al plano de la escápula. El proceso subhamatus está expandido proximodistalmente, aunque reducido en su extensión cráneocaudal, especialmente en su sector proximal, donde no supera el margen caudal de la escápula en vista lateral. Su margen ventral es cóncavo, y el caudodorsal recto, delimitando un área triangular delgada.

\section{Húmero (Lámina 3.9H)}

La diáfisis del húmero es fuertemente sigmoidea. En vista proximal, la superficie articular es amplia y redondeada, sin destacarse su desarrollo en sentido cráneocaudal. El tubérculo mayor es muy robusto, agudo y proyectado cráneodorsalmente en mayor medida que Lontra spp. La tuberosidad deltoidea se diferencia moderadamente respecto a la diáfisis formando una cresta (excepto en el espécimen NMVB3271) poco expandida lateralmente, a veces con una proyección aguda en su región media. La cresta del tubérculo mayor se diferencia como una zona rugosa proximalmente, que se convierte distalmente en una zona elevada a modo de una cresta prominente pero poco diferenciada, sin sobresalir medialmente. En la mayoría de los especímenes (e.g., SNMS1300) alcanza distalmente al principio del tercer tercio del húmero, y no confluye con la cresta deltoidea (i.e., no se diferencia una cresta deltopectoral), la cual pierde diferenciación tempranamente. El tubérculo menor se orienta principalmente en dirección medial. Sobre la cara medial de la diáfisis humeral, al principio del tercer tercio de la misma, suele presentarse (e.g., MNHN A1918) un foramen nutricio marcado, en una posición distal respecto a lo observado en Lo. provocax. Medial y caudal a la cresta del tubérculo mayor, se observan una superficie oval y rugosa, delimitada por una cresta marcada en su sector caudal, posiblemente en relación a la inserción del m. teres major.

El epicóndilo medial representa una proyección robusta (aunque mucho más delgada cráneocaudalmente que Lontra spp.), amplia, destacándose su extensión proximodistal, dirección en la cual alcanza o supera al margen distal de la tróclea. En vista craneal, el sector proximal del margen medial del epicóndilo se encuentra incidido por un surco. La presencia del foramen supracondiloideo es constante; es amplio, aunque relativamente reducido en extensión 
próximodistal en vista craneal. La cresta epicondiloidea posee una extensión lateromedial amplia y aún más acentuada en la zona mediodistal, y abarca el último tercio de la diáfisis del húmero. La tróclea posee bajo desarrollo próximodistal (incluso menor que el observado en Lontra spp.) y moderado desarrollo lateromedial en relación al capítulo. Su margen medial está desarrollado principalmente en dirección mediodistal y se encuentra inclinado. El capítulo es marcadamente amplio en vista craneal, posee forma esférica y voluminosa, con márgenes proximal y distal marcadamente convexos, y con un margen lateral breve y poco engrosado (más esférico que Lo. provocax y otros mustélidos descriptos). La fosa para el tendón del olécranon se encuentra bien definida, es profunda, y elongada proximodistalmente (especialmente en sentido proximal), y posee sus márgenes lateral y medial agudos y elevados, mientras que en su sector proximal se separa en su sector profundo de la fosa olecraneana (de similar profundidad) gracias a un tabique delgado. Su margen distal está moderadamente definido.

\section{Ulna (Lámina 3.10H)}

La ulna es mayormente recta en vista lateral. El olécranon se encuentra marcadamente desarrollado en dirección cráneocaudal y próximodistal (en un grado no alcanzado por otros mustélidos descriptos). El sector caudomedial de la tuberosidad del olécranon se encuentra hipertrofiado, fuertemente proyectado en sentido caudomedial y engrosado. El margen proximal del olécranon es mayormente recto. La incisura troclear es somera (en mayor medida que lo observado en otros mustélidos descriptos). La incisura radial posee un margen lateral agudo. La muesca correspondiente al ligamento interóseo se encuentra muy desarrollada. Su superficie articular posee forma de $\mathrm{C}$, y es angosta en su sector distal y proyectada caudoproximalmente. La superficie diartrodial para el radio está moderadamente elevada respecto a la diáfisis ulnar (similar a Lo. longicaudis, intermedio a lo observado en Lo. provocax y otros mustélidos descriptos).

\section{Radio}

Es de un largo mayor a dos tercios del largo del húmero. Es un elemento marcadamente robusto. La carilla articular proximal del radio es ovalada, con una escotadura suave en su sector cráneolateralcráneolateral. La zona de contacto con la ulna es levemente convexa. El tubérculo lateral a dicha escotadura se encuentra presente pero reducido. La inserción del ligamento interóseo es robusta y saliente, y se extiende un poco más allá de la mitad de la diáfisis (en mayor grado que lo observado en las otras especies descriptas). Las crestas correspondientes a los orígenes del $\mathrm{m}$. pronator teres y $\mathrm{m}$. abductor digiti I longus presentan un desarrollo variable en los distintos especímenes y convergen abruptamente en el sector distal. El tubérculo de 
inserción del $\mathrm{m}$. brachioradialis es algo aplanado y redondeado, extenso pero poco sobresaliente. La morfología de la escotadura ulnar y su ubicación son similares a lo descripto en Lo. provocax, aunque tiene una forma más bien redondeada en vez de triangular. El tubérculo craneal a la zona de pasaje del $\mathrm{m}$. extensor digiti I et II es marcadamente robusto y saliente.

\section{Autopodio anterior}

En vista craneal el carpal radial se encuentra representado en gran medida por la extensión en este plano de su superficie articular proximal. Esta carilla articular posee márgenes lateral y medial con cambios de pendiente suaves. El carpal ulnar se encuentra bien desarrollado en sentido próximodistal (en mayor grado que otras nutrias), especialmente en vista craneal. El sesamoideo radial no se encontró presente en ninguno de los especímenes observados, aunque en función del área articular plana sobre la cara lateral del tubérculo del radial, debió estar presente. El carpal ulnar es un hueso cuadrangular y no se encuentra aplanado en sentido proximodistal, siendo relativamente extenso en este sentido comparado con otros mustélidos descriptos). El carpal accesorio, aunque no es descripto en gran detalle debido a la ausencia de materiales adecuados en los especímenes revisados, su morfología general es similar a la de Lontra spp., diferenciándose principalmente por poseer un cuello menos adelgazado, manteniéndose robusto a lo largo de toda su extensión.

Los carpales distales se encuentran poco reducidos en sentido próximodistal (contrario a otras nutrias descriptas). El carpal II, presenta un desarrollo importante, y en vista craneal posee un contacto anguloso con el metacarpal II. Los contactos articulares del carpal III y IV no son descriptos por falta de materiales adecuados en los especímenes revisados. El tubérculo del carpal IV está bien definido.

Los dígitos laterales se encuentran bien desarrollados y el dígito I está reducido. Tanto metacarpales como falanges (especialmente las proximales y laterales) se muestran robustas.

Como ocurrió en otras nutrias descriptas, el metacarpo I es el de menor longitud, pero en esta especie la diferencia de proporciones es mayor, siendo su longitud cercana a la mitad de la longitud del mayor (IV), mientras que el metacarpal V y II son subiguales en longitud y mayores a 3/4 partes de la longitud del mayor metacarpal. La longitud de la falange proximal del dígitos I es apenas aproximadamente dos tercios de la longitud observada en los restantes dígitos. Los especímenes revisados no conservaron un sesamoideo metacarpal articulando con el proceso plantar del metacarpal $\mathrm{V}$, ni unguis en las falanges ungueales. Los sesamoideos metacarpales son moderadamente elongados, proximalmente agudos. Las falanges ungueales son breves, poseen cresta ungueales delgadas, y procesos ungueales reducidos. El margen ventral de estos es principalmente recto, y un margen dorsal convexo. 


\section{Hueso coxal (Lámina 3.13H)}

El acetábulo, de tamaño pequeño respecto al total del hueso coxal (menor incluso en comparación con otros lutrinos descriptos); es semicircular y abierto; inclina caudalmente (en mayor grado que lo observado en Lontra spp.) acercándose al plano del isquion-pubis. El foramen obturado es amplio, aguzado cranealmente, pero sin formarse una constricción. La superficie sinfisiaria posee un breve desarrollo. Presenta una inclinación caudal en mayor grado incluso que lo observado en Lontra spp.

El ala del ilion está expandida craneal y caudalmente. El cuerpo del ilion es robusto. La espina ventro-caudal (mínimamente definida) y la dorso-caudal se encuentran posicionadas caudalmente. El tubérculo del $\mathrm{m}$. rectus femoris es particularmente amplio y triangular. El cuerpo del isquion forma un ángulo cercano a los $90^{\circ}$ respecto a la rama del isquion, la cual es aplanada y amplia (e.g. MNHN A1918) a muy amplia (e.g. SNMS 1300). La espina isquiática está ausente, reemplazada por una zona rugosa. La arcada isquiática no presenta un tubérculo diferenciado. La tuberosidad isquiática se muestra como una zona engrosada, especialmente en su sector craneal, claramente diferenciada y sobresaliente del resto del isquion en este sector, aunque continuándose con la tabla isquiática en el sector caudal. Al contrario de Lontra spp., no se diferencia una quilla sobre su cara lateral.

El pubis es marcadamente alargado. El ángulo formado entre el cuerpo pubis y el isquion es mayor a $45^{\circ}$. La cara lateral del mismo, zona de orígenes de músculos aductores, está estriada y su margen dorsal es liso a poco rugosos. El ángulo formado entre el cuerpo y la rama caudal del pubis es cercano a los $70^{\circ}$ (más abrupto que lo observado en Lo. provocax, en relación a la también mayor inclinación de la sínfisis). La rama caudal del pubis es delgada y relativamente breve, sólo engrosada en su sector ventral.

\section{Fémur y patela (Lámina 3.14H)}

El fémur es marcadamente robusto (incluso en comparación con Lontra spp.) y levemente curvado en sentido lateral. La forma y orientación de la cabeza del fémur es similar a la observada en Lo. provocax, aunque posee una mayor inclinación medial y una forma semicircular mejor definida. El trocánter mayor posee un bajo desarrollo proximodistal, con su sector proximal proyectando en forma roma, posicionado lateralmente, robusto y en general alcanzando la máxima altura de la cabeza femoral. La fosa trocantérica es similar en forma a otros lutrinos descriptos, pero se encuentra marcadamente expandida lateral y distalmente. La escotadura dorsal es amplia y somera. El trocánter menor está hipertrofiado, proyectado en sentido caudomedial, sobresaliendo medialmente en vista caudal. La tuberosidad glútea es una superficie rugosa. La región craneal de la misma se encuentra hipertrofiada y sobresaliente 
(aunque en menor medida que Lo. provocax), a modo de un área plana y rugosa incidida por una muesca o depresión somera.

La tróclea femoral se encuentra claramente desplazada en sentido medial (en mayor grado que lo observado en Lo. provocax). Es ancha, extendida cráneocaudalmente pero breve en sentido proximodistal. Su margen medial se continúa proximalmente con una zona elevada breve. En vista distal, ambos epicóndilos se desarrollan marcadamente hacia los lados, especialmente el lateral (incluso en mayor medida que Lontra spp.). Los cóndilos son proporcionalmente grandes y se encuentran marcadamente desplazados en sentido caudal. Debido a estas características, en vista distal el fémur posee un mayor desarrollo cráneocaudal que lateromedial. La fosa intercondiloidea es amplia en sentido lateromedial. La zona de inserción del ligamento colateral medial se encuentra en la zona centrocaudal del epicóndilo medial (caudalmente respecto a lo observado en Lo. provocax). En vista caudal se encuentran presente la tuberosidad supracondiloidea lateral, a modo de una zona muy rugosa y expandida lateralmente, muchas veces con una región central y proximal deprimida diferenciada, sobresaliendo sobre la diáfisis distal y epicóndilo lateral y extendiéndose proximalmente alcanzando al tercer cuarto de la diáfisis (mucho más desarrollada que en otros mustélidos descriptos). Ambas carillas para los sesamoideos supracondiloideos se encuentran ubicadas a los laterales, siendo la carilla medial menos sobresaliente que lo observado en Lo. provocax. La patela es un elemento de proporciones similares a otras nutrias descriptas, aunque más robusto.

\section{Tibia (Lámina 3.15H)}

En vista proximal, el cóndilo lateral es de contorno irregular, con su margen caudolateral redondeado; su desarrollo lateromedial es similar al desarrollo cráneocaudal, y cercano a una vez y media el desarrollo lateromedial del cóndilo medial. En vista proximal, el área intercondiloidea es relativamente ancha. La zona cráneolateral (craneal al cóndilo lateral) presenta un tubérculo amplio y rugoso. La eminencia intercondiloidea se muestra reducida. La superficie articular para la cabeza de la fíbula se encuentra distanciada del cóndilo lateral por una superficie amplia (algo menor que la observada en Lo. provocax). La cresta medial de la diáfisis, relacionada al origen del $\mathrm{m}$. caudalis tibialis o el $\mathrm{m}$. flexor digitorum medialis, es breve y marcada (y se encuentra representada por dos pequeñas crestas independientes en el espécimen NMVB3271).

La depresión correspondiente a la zona de articulación con la cresta medial de la tróclea del astrágalo es somera. En vista craneal, ambos surcos trocleares están separados por una proyección aguda, aunque menor que la observada en Lo. provocax. En vista caudal, el margen caudal de la superficie articular distal es sinuoso a plano, y marcadamente inclinado en sentido 
lateral. La faceta fibular se encuentra algo expandida en dirección proximodistal. El maléolo medial es muy robusto y poco proyectado distalmente.

\section{Fíbula}

El elemento es similar al de Lontra spp., aunque más robusto y recto. El tubérculo del m. fibularis longus es angosto en toda su extensión. En el sector mediocaudal de la fíbula, la inserción del m. soleus no se diferencia como tubérculo. El margen craneal del maléolo lateral posee un desarrollo distal levemente mayor que el caudal, siendo robusto y proyectado en menor magnitud que el maléolo medial, y más breve que lo observado en otros lutrinos descriptos.

La faceta tibial es convexa, y se encuentra expandida proximalmente. El tubérculo del maléolo lateral, que delimita cranealmente el surco del maléolo lateral, se encuentra relativamente bien desarrollado proximodistalmente, pero poco proyectado, y posicionado más proximalmente respecto a lo observado en Lontra spp.

Pes

El astrágalo (o talus) tiene un cuello y cabeza aplanados dorsoventralmente, extremadamente reducidos en comparación con la tróclea. La tróclea es somera, moderada a breve en dirección cráneocaudal, y robusta lateromedialmente. La separación entre las crestas de la tróclea es aproximadamente constante a lo largo de toda la tróclea. En vista dorsal, la superficie troclear invade cranealmente al sector lateral de la base del cuello, en donde se presenta una depresión astrágalotibial moderadamente desarrollada. En vista lateral, la carilla maleolar lateral presenta un desarrollo cráneomedial moderado. En vista ventral, tanto la superficie articular proximal para el calcáneo como el tubérculo del talus sobresalen caudalmente ampliamente, brevemente separadas entre sí. La superficie articular medial alcanza a contactar el extremo medial de la cabeza del astrágalo (mientras que este contacto no se forma en otros mustélidos descriptos), en relación al acortamiento relativo del cuello. En vista distal, la superficie articular para el tarsal central es fuertemente convexa, se continúa en sus márgenes con el cuello, y apenas sobresale proximomedialmente en su sector medial. Sobre la superficie laterodistal, la carilla articular para el tarsal IV es prácticamente indiferenciable. Inmediatamente ventral y lateral al sector caudal de la tróclea se observa el foramen correspondiente a la abertura proximal del canal astragalar, observándose su apertura ventral justo entre las zonas articulares.

El surco del tubérculo del calcáneo (zona de inserción y de pasaje del $\mathrm{m}$. flexor digitorum superficialis) está definido y es asimétrico. La zona de origen del $\mathrm{m}$. abductor digiti $\mathrm{V}$ se encuentra definida por una cresta proximodorsal. El área sustentaculum tali diverge a unos 
$80^{\circ}$ respecto a la cara medial del tubérculo, pero en la mayoría de los especímenes (e.g. NMV B3271) se encuentra poco expandida medialmente (distinto a USNMMa304663). La articulación medial, es pequeña y posicionada proximalmente en comparación con Lontra spp. El proceso troclear posee forma de una plataforma extendida lateral y distalmente pero no proximalmente, con una base angosta y elongada, y una posición distalizada.

La superficie articular para el tarsal IV es marcadamente cóncava e inclina marcadamente en sentido medial (distinto a todos las especies descriptas), y el tubérculo ventral a ésta es breve. El sesamoideo tibial es aplanado dorsoventralmente y redondeado. Los contactos articulares entre el central y los tarsales distales, así como la mayoría de los contactos entre los tarsales distales, no pudieron ser descripta debido a que estos elementos se encontraron articulados en los especímenes analizados. El tarsal IV posee un desarrollo próximodistal marcadamente menor al del tarsal III y central juntos (incluso menor que lo observado en Lontra spp.). Su cara articular proximal inclina marcadamente en sentido lateral, en relación a lo descripto en la cara articular distal del calcáneo. La cara medial del tarsal IV contacta en su primer tercio al central, y en su tercio medio con el tarsal III. En vista lateral, el tarsal IV es más alto que largo (distinto a los demás mustélidos descriptos). El surco del $\mathrm{m}$. fibularis longus está delimitado en su margen laterodistal por un tubérculo robusto (no presente en Lontra spp.). En vista ventral tubérculo plantar de este tarsal es marcadamente robusto. La cara articular distal se proyecta ventromedialmente en forma aguda.

En la serie metatarsal, el foramen ubicado en el sector proximal de la articulación entre el metatarsal III y IV es algo menos profundo que lo observado en Lo. provocax. Los cinco metatarsales son robusto, y los tres centrales marcadamente robustos (en mayor medida que Lontra spp.). Todos los metatarsales son cilíndricos y en mayor o menor grado aplanados. El metatarsal V es claramente mayor al II. El proceso plantar del metatarsal IV es relativamente breve. El metatarsal IV recibe al V mediante una superficie irregular y plana, y recibe al III mediante una superficie plana. Esta última se encuentra dividida en dos: una porción, siendo la distolateral menos elevada respecto a Lo. provocax. El metatarso V posee un proceso plantar relativamente poco desarrollado proximodistalmente. En vista lateral, este proceso se proyecta en forma moderadamente aguda en sentido ventral en su sector medio a proximal (algo distinto a Lo. provocax y muy distinto a lo observado en Lo. longicaudis). Los sesamoideos metatarsales se encuentran reducidos, especialmente en sentido proximodistal, siendo prácticamente vestigiales en los dígitos I y V. Todas las falanges son relativamente elongadas y delgadas, exceptuando el sector basal de las falanges proximales, el cual posee una similar robustez a la observada en los metatarsales. Las falanges medias poseen aproximadamente dos tercios de la longitud observada en las proximales. Los elementos ungueales son marcadamente reducidos. 
Las unguis no fueron preservadas en los materiales revisados. En vista lateral, el proceso ungueal es delgado y posee una superficie dorsal suavemente convexa. 


\section{Tabla de descripciones osteológicas de del postcráneo de mustélidos de América del Sur}

Tabla 3.3. Resumen de los principales rasgos de la anatomía caudal observados en los especímenes de mustélidos de América del Sur descriptos. Las tres primeras columnas indican posiciones en la serie caudal (e.g., $0=$ ausente, 1 = primera vértebra caudal, etc.). $*$ = considerando al tercer elemento sacrocaudal como parte del sacro en el conteo de caudales, ${ }^{* *}=$ considerándolo como el primer elemento caudal (ver descripción de la especie), $\pm=$ estimación de presencia de últimos pocos elementos caudales, $+=$ valor registrado de una serie incompleta.

\begin{tabular}{lllll}
\hline & $\begin{array}{l}\text { Elemento } \\
\text { transicional }\end{array}$ & $\begin{array}{l}\text { Último proceso } \\
\text { espinoso }\end{array}$ & $\begin{array}{l}\text { Último proceso } \\
\text { mamilar bien } \\
\text { diferenciado }\end{array}$ & $\begin{array}{l}\text { Número total de } \\
\text { caudales }\end{array}$ \\
\hline Lyncodon patagonicus & $2^{*}-3^{* *} / 3^{*}-4^{* *}$ & $0^{*}-1^{* *}$ & $6^{*}-7^{* *}$ & $+13^{*}-+14^{* *}$ \\
Galictis cuja & 3 & 5 & $11 / 12$ & 21 \\
Galictis vittata & 4 & 0 & $?$ & $?$ \\
Eira barbara & 4 & $0^{*-1} 1^{* *}$ & 15 & 21 \\
Lontra longicaudis & 6 & $8-9$ & 15 & \pm 23 \\
Lontra provocax & 7 & 9 & $17 / 18$ & 23 \\
Pteronura brasiliensis & 6 & 8 & 18 & 22 \\
\hline
\end{tabular}




\subsection{Descripciones de especímenes fósiles}

A continuación se describen los principales restos fósiles de mustélidos de América de Sur estudiados (ver también información complementaria en Apéndice 2.2), y comparaciones con los representantes vivientes. En el tomo II (Láminas 4) se ilustran los principales elementos.

\subsubsection{Lyncodon patagonicus MLP 96-V-1-1 y MLP 96-V-2-2/3}

Los restos con certeza correspondientes al espécimen MLP 96-V-1-1 son un cráneo y mandíbula en muy buen estado de conservación, el atlas, axis y C3? que presentan sus procesos transversos dañados en sus márgenes laterales (Lámina 4.1A-D).

La morfología del atlas es muy similar a la presente en especímenes actuales, destacándose todas las características típicas de la especie, e.g., procesos articulares craneales continuados sin quiebre de pendiente con el margen craneal del arco ventral, breve extensión cráneocaudal del arco neural. El tubérculo ventral es levemente más desarrollado que en los especímenes MACN 21892 y especialmente MLP 29.XII.00.17, y algo proyectado caudalmente. Las incisuras alares son amplias y abiertas, como es típico aunque algo variable en $L y$. patagonicus, algo menos encerradas caudalmente por el proceso transverso que lo observado en el ejemplar MACN 21892 y MNHN1897.422, y más similar a MNHN CG 1897-423, MNHN CG 1897-570 y al lado izquierdo de MLP 29.XII.00.17. El arco neural es algo más delgado, liso y amplio lateromedialmente que lo observado en especímenes actuales. Aunque la morfología del axis presentan muchos rasgos en común con especímenes actuales de Ly. patagonicus, también es interesante destacar algunos rasgos presentes en el espécimen MLP 96-V-1-1, no registrados en ningún representante actual de la especie. Como característica sobresaliente, el proceso espinoso del axis es relativamente amplio en sentido cráneocaudal, superando a la base del proceso odontoides hacia craneal (alcanzando una posición aproximadamente similar a la mitad del proceso odontoides) y superando ampliamente hacia caudal al cuerpo vertebral y el nivel alcanzado por las carillas articulares caudales. Esta configuración no es alcanzada por ningún representante actual de la especie, y es más similar a otros hurones como Ga. cuja. En relación a la marcada proyección caudal del proceso espinoso, el margen caudal del mismo inclina marcadamente respecto al plano transversal y la incisura caudal dorsal es profunda. Las carillas articulares craneales del axis de MLP 96-V-1-1 se encuentran algo más distanciadas del proceso odontoides de lo observado en especímenes actuales, formándose una región levemente deprimida entre estas estructuras.

La vértebra $\mathrm{C} 3$ ?, comparte todos los rasgos observados en el mismo elemento de los especímenes actuales de Ly. patagonicus, incluyendo el proceso espinoso bajo y simétrico y la morfología de los procesos transversos, aunque la pérdida del extremo caudoventral de este último, sector más diagnóstico de la posición en la serie cervical, se encuentra dañado. 
En lo que respecta a los dos especímenes juveniles de Ly. patagonicus que acompañaban al anterior (MLP 96-V-2-2/3, referenciados como $\mathrm{n}^{\circ} 2$ y $\mathrm{n}^{\circ} 3$ en función de la pérdida de sus identificaciones originales; Apéndice 2.2; ver también Lámina 4.1E-H y Lámina 4.1I-L, respectivamente), además de la pérdida o desprendimiento de la gran mayoría de las epífisis, presentan algunos otros rasgos morfológicos que los diferencias del otro espécimen fósil y otros representantes adultos actuales. Los atlas de ambos se encuentran preservados, uno de los cuales está prácticamente completo. Ambos presentan un arco neural incluso más delgado y elongado lateromedialmente que el espécimen fósil adulto. Los forámenes vertebrales laterales se encuentra aun abiertos cranealmente (rasgo no encontrado en mustélidos adultos), excepto por el lado izquierdo del espécimen $\mathrm{n}^{\circ} 3$. Las alas de los atlas son evidentemente menos amplias que en Ly. patagonicus adultos, apenas alcanzando la altura de los márgenes caudales de los procesos articulares caudales. Tanto el tubérculo dorsal como el ventral se encuentran mejor diferenciados en el espécimen $n^{\circ} 3$. En los axis de ambos ejemplares, el proceso espinoso y el proceso articular caudal se encuentran menos desarrollados que en el ejemplar fósil adulto, dándole a estos elementos una apariencia comprimida cráneocaudalmente. La vértebra C6 de ambos especímenes presenta láminas ventrales de los procesos transversos de márgenes redondeados y relativamente reducidas, sin presentar la típica forma asimétrica y proyectada caudoventralmente típica de adultos. Los elementos torácicos y lumbares no merecen mayores comentarios, excepto que el proceso espinoso de la vértebra lumbar posee márgenes más redondeado que lo observado en vértebras lumbares de especímenes actuales de la especie.

El fragmento distal de la escápula y los fragmentos de ulna y radio preservados en el espécimen $\mathrm{n}^{\circ} 3$, más allá de la falta o daño de las regiones de epífisis, presenta las características típicas de la especie. Los húmeros del espécimen $n^{\circ} 3$, preservados en sus dos tercios y mitad proximal (derecho e izquierdo respectivamente), presentan las epífisis proximales en posición, pero se evidencian las líneas de sutura aun abiertas y ausencia de cresta deltopectoral (esto último similar a MACN 21982, distinto a MLP 29.XII.00.17); mientras que en el $\mathrm{n}^{\circ} 2$ las epífisis izquierda está preservada como un elemento suelto y la mitad distal de la diáfisis, y se encuentra ausente el elemento derecho. La morfología de este sector (i.e., cabeza articular proximal, tubérculos y crestas) en estos especímenes es muy similar a lo observado en los especímenes adultos. El fragmento distal de húmero, no preserva la región articular, indicando ausencia de fusión de la epífisis distal, pero si presenta un foramen supracondiloideo con un margen medial delgado y ubicado mayormente proximal a la región articular, aunque es relativamente más pequeño y posicionado menos proximalmente respecto al grado observado en especímenes adultos de Ly. patagonicus. Los fragmentos de diáfisis y epífisis (todas ellas sueltas) de elementos del miembro posterior no implican mayores comentarios. 
Uno de los pocos elementos en que se pudieron tomar medidas comparables entre todos los especímenes fósiles y actuales fue el axis (ver Tabla 3.4). El ancho entre cóndilos articulares craneales del espécimen fósil adulto $\left(8,211 \mathrm{~mm}\right.$.), y los juveniles $\mathrm{n}^{\circ} 2$ y $\mathrm{n}^{\circ} 3(8,280$ y 8,268 mm., respectivamente) son muy similares entre sí, e incluso levemente mayor en el caso de los juveniles, y todos estos valores caen dentro del rango de valores de los especímenes de Lyncodon actuales (media = 7,915; MLP 29.XII.00.17: 8,72 mm., MACN 21982: 7,11 mm.). Por otro lado, el largo del proceso espinoso del axis sobre el eje cráneocaudal presenta diferencias mayores, siendo el ejemplar fósil adulto $(9,441 \mathrm{~mm}$.) similar a adultos actuales (media = 9,340 mm.; MLP 29.XII.00.17: 9,46 mm., MACN 21982: 9,22 mm.), pero claramente mayor que ambos especímenes juveniles fósiles (n²: 7,433 mm.; ${ }^{\circ} 3: 8,027 \mathrm{~mm}$.)

\subsubsection{Lontra sp. CADIC s/n y 1021330}

El material no numerado corresponde a un fémur aislado completo izquierdo proveniente de un sitio arqueológico de una antigüedad de 6000 AP del Canal de Beagle, Tierra del Fuego (ver Apéndice 2.2; Lámina 4.2B, C). El elemento presenta características similares a las descriptas para la especie Lo. provocax, y se diferencia de Lo. longicaudis y Pt. brasiliensis por las mismas características que fueron señaladas ya en la descripción de Lo. provocax, incluyendo la cabeza femoral marcadamente proyectada por debajo de límite con el cuello femoral, la escotadura dorsal entre la cabeza femoral y el trocánter mayor aguda y profunda, y la región craneal de la tuberosidad glútea hipertrofiada e incidida por un surco de dirección lateromedial. El material CADIC 1021330, proviene de un sitio arqueológico cercano pero más moderno (2000-400 AP; ver Apéndice 2.2; Lámina 4.2D), y corresponde a una mitad distal de fémur aislado también izquierdo. Este fragmento presenta todas las características observadas en el extremo distal del material anterior, y observadas en Lo. provocax.

\subsubsection{Lontra sp. MCNyA s/n}

El material corresponde a un calcáneo aislado (Lámina 4.2A) proveniente de un sitio arqueológico sobre el margen del Arroyo Barrancas, Entre Ríos, y fue asignado por Bonomo et al. (2010) como Lontra sp. El elemento presenta características similares a las descriptas para la especie Lo. longicaudis, y por ende se diferencia de Lo. provocax y Pt. brasiliensis por las mismas características que fueron señaladas ya en la descripción de Lo. longicaudis, i.e., gran extensión proximal de la carilla articular proximal para el talus, tubérculo del calcáneo relativamente breve, surco simétrico, proceso troclear amplio pero de margen proximal poco proyectado, ausencia de inclinación medial marcada de la carilla articular para el tarsal IV.

\subsubsection{Pteronura brasiliensis CICyTTP-Pv-1-21}


El espécimen presenta casi el total de los elementos postcraneales (Apéndice 2.2, Lámina 4.3). De manera general, todos los elementos presentan los rasgos típicos destacados para la especie, pero en este apartado se mencionan algunas características destacables. Los elementos más completo presentan proporciones similares a las presentes en especímenes actuales de la especie (e.g., Tabla 3.5).

Los sectores preservados del atlas, axis y otras vértebras (mayormente fragmentadas) no revisten mayores comentarios. El proceso espinoso del axis se encuentra elevado en su sector caudal, como es típico para las nutrias y Pt. brasiliensis (excepto por espécimen AMNH 30190).

La escápula se encuentra en parte bien preservada, pero falta la mitad dorsal de la fosa supraespinosa, y presenta daños y pérdidas de parte del acromion. En el espécimen fósil, la región articular es proporcionalmente mayor que el resto de la escápula en comparación con otros Pt. brasiliensis, aunque dentro de los especímenes actuales se evidencia un gran rango de variantes en este aspecto. En el ángulo caudal, el margen dorsal de la escápula se continúa sin quiebre de pendiente con el correspondiente al área de origen del $\mathrm{m}$. teres major y $\mathrm{m}$. triceps brachii caput angulare, rasgo exclusivo de Pt. brasiliensis dentro de las especies sudamericanas. El área de origen de estos músculos se encuentra menos desarrollada que la mayoría de los especímenes actuales, pero en similar grado a USNM 304663.

El húmero derecho es el mejor preservado. Este elemento presenta un gran número de rasgos típicos de la especie, incluyendo la forma del epicóndilo medial y del foramen supracondiloideo, y una foramina en la cara laterocraneal de la base del tubérculo mayor; aunque no se pudo comparar con precisión la morfología de la región articular distal, debido a la mala preservación del sector en ambos húmeros fósiles. La cresta deltoidea es marcada, con un quiebre sobresaliente a la altura del final del primer tercio de la diáfisis, característica observada únicamente en el espécimen NMV B3271. La morfología de los tubérculos mayor y menor se encuentra dentro del rango de formas observada en los representantes actuales. Llamativamente, la cresta del epicóndilo lateral es algo más alta y amplia respecto a todos los representantes actuales, ocupando mucho más que el último tercio de la diáfisis humeral. La curvatura y extensión cráneocaudal de la diáfisis humeral es variable dentro de Pt. brasiliensis, registrándose estos rasgos exacerbados en el espécimen fósiles, pero también en algunos especímenes actuales como USNM 304663. La presencia de una fosa olecraneana profunda pudo constatarse con más claridad en el elemento izquierdo. La morfología de los fragmentos proximal y distal de la ulna y el radio, así como la proporciones y formas de los elementos del autopodio anterior son prácticamente idénticas a las presentes en los especímenes actuales.

El fragmento más completo de la pelvis preservado en el espécimen fósil corresponde al ilion completo, el cual presenta algunos daños en la región más craneal del mismo (espina ventro-craneal y cresta ilíaca). Aunque la forma del ala ilíaca es un poco más breve 
cráneocaudalmente y amplia dorsoventralmente respecto al espécimen AMNH 30190, las proporciones son muy similares a las de SNMS 1300, pudiéndose considerar a estas variantes intraespecíficas.

El fragmento proximal de fémur y su epífisis distal, así como la tibia y fíbula, son similares a los representantes actuales, más allá de algunos caracteres de los sectores articulares de los últimos dos elementos y gran parte del primero, que no pudieron ser comparados debido a daños en el espécimen fósil. Las proporciones y formas de los elementos del autopodio posterior son muy similares a las presentes en los especímenes actuales; aunque el metatarsal I parece ser sutílmente más robustos que lo observado en MNHN A1918 y SNMS 1300. La pieza asignada con dudas al sesamoideo tibial también es sutílmente más robusta. 


\section{Tablas de descripciones de especímenes fósiles}

Tabla 3.4. Tabla de valores de medidas básicas del axis: largo cráneocaudal del proceso espinoso y ancho máximo entre procesos articulares craneales (en milímetros), en especímenes de Lyncodon patagonicus fósiles juveniles (MLP 96-V-2-2 y MLP 96-V-2-3) y adulto (MLP 96-V-1-1), en comparación con el valor promedio de especímenes actuales.

\begin{tabular}{lllll}
\hline & MLP 96-V-2-2 & MLP 96-V-2-3 & MLP 96-V-1-1 & $\begin{array}{l}\text { Lyncodon } \\
\text { (actuales) }\end{array}$ \\
\hline Largo p. espinoso & 7,433 & 8,027 & 9,441 & 9,340 \\
Ancho art. craneales & 8,280 & 8,268 & 8,211 & 7,915 \\
\hline
\end{tabular}

Tabla 3.5. Tabla de valores de largo máximo (en milímetros) medidos entre regiones articulares proximal y distal del húmero y tibia del espécimen fósil de Pteronura brasiliensis (CICyTTP-Pv-1-21) y varios representantes actuales de la especie.

\begin{tabular}{lc}
\hline Húmero & \multicolumn{1}{l}{ LaHu } \\
\hline MNHN s/n & 100,764 \\
AMNH 30190 & 106,211 \\
SNMS 1300 & 107,569 \\
USNM 304663 & 113,414 \\
CICyTTP-Pv-1-21 & $\mathbf{1 1 9 , 4 6 2}$ \\
NMV B3271 & 124,904 \\
& \\
\hline Tibia & LaTi \\
\hline SNMS 1300 & 126,759 \\
CICyTTP-Pv-1-21 & $\mathbf{1 3 3 , 5 1 6}$ \\
MNHN s/n & 133,849 \\
USNM 304663 & 138,857 \\
NMV B3271 & 150,407 \\
AMNH 30190 & - \\
\hline
\end{tabular}




\subsection{Resultados de análisis lineales}

En la Tabla 3.6 se resumen los resultados obtenidos en los análisis realizados, mientras que en los Apéndices 3.6 y 3.7 figuran en detalle los resultados de análisis realizados.

\subsubsection{Largo de la región tóraco-lumbar sobre largo promedio de los miembros (LaTL/PrLaM)}

En el ANOVA de dos factores, los supuestos de homocedasticidad (test de Levene, $\mathrm{F}=$ 0,$362 ; \mathrm{p}=0,892$ ) y distribución normal de los residuos (test de Shapiro-Wilk, $\mathrm{W}=0,967 ; \mathrm{p}=$ $0,612)$ no fueron rechazados. El ANOVA indicó una relación significativa entre las proporciones tóraco-lumbares y apendiculares y las clases locomotoras exclusivamente $(\mathrm{F}=$ 5,420; $\mathrm{p}<0,001$; Apéndice 3.6A1). Al realizar nuevamente el ANOVA para el factor locomoción exclusivamente, el resultado fue similar $(\mathrm{F}=9,238 ; \mathrm{p}<0,001$; Apéndice 3.6A2). El test de comparaciones cruzadas a posteriori permitió reconocer diferencias significativas entre nadadores y trepadores, cavadores y half-bounders, trepadores y half-bounders (Apéndice 3.6A2). Al repetirse los análisis incluyendo a Bassariscus astutus como trepador, los resultados fueron similares, aunque en el test a posteriori se sumó una diferencia significativa entre cavadores y nadadores (resultado no mostrado).

Los grupos nadador $($ media $=1,809 ; \mathrm{DE}=1,189)$ y half-bounder $($ media $=1,953 ; \mathrm{DE}=$ $0,121)$ considerando a Bassariscus como trepador) segregaron en conjunto hacia valores positivos diferenciándose totalmente de trepadores (media $=1,285 ; \mathrm{DE}=0,210$ ) y cavadores (media $=1,449 ; \mathrm{DE}=0,143)$ hacia valores inferiores. Excepciones a este patrón son el caso comentado de Bassariscus astutus (cuando éste es asignado a la clase half-bounder), y la ubicación de Aonyx sp. y Arctonyx collaris en un rango de valores transicionales estrecho (Fig. 3.1A, Tabla 3.7).

Galictis cuja se ubicó dentro de los valores de LaTL/PrLaM $(1,850)$ más bajos para las especies half-bounders analizadas, similar en proporciones a Lontra longicaudis, mientras que Lyncodon patagonicus presentó los valores más altos $(2,18)$, con la región tóraco-lumbar más elongada en relación a los miembros de los musteloideos analizados. Eira barbara presentó el valor de LaTL/PrLaM $(1,530)$ más alto dentro del grupo trepador, aunque presentó la máxima longitud relativa de miembros en comparación con otros mustélidos sudamericanos (Fig. 3.1A, Tabla 3.7).

Al realizar un ANOVA de un factor para la categoría dietaria, los supuestos de homocedasticidad (test de Levene, $\mathrm{F}=0,354 ; \mathrm{p}=0,558$ ) y distribución normal de los residuos (test de Shapiro-Wilk, $\mathrm{W}=0,959 ; \mathrm{p}=0,442$ ) no fueron rechazados. El ANOVA fue significativo $(F=6,380 ; p=0,020)$, pero explicando una porción menor de la varianza (Apéndice 3.6A3). 
La separación de especies en función de dietas fue gradual y con múltiples y marcadas excepciones, encontrándose en general los omnívoros en valores bajos de LaTL/PrLaM (media $=1,416 ; \mathrm{DE}=0,2550)$ y los carnívoros en valores altos (media $=1,695 ; \mathrm{DE}=0,274)$. Enhydra lutris fue un outlier del primer grupo, con proporciones corporales afines a los carnívoros más especializados (LaTL/PrLaM = 1,976). Dentro de los carnívoros, Bassariscus astutus y guloninos presentaron valores transicionales o relativamente bajos, mientras que lutrinos (incluyendo Lo. longicaudis), lincodontininos (incluyendo a Ga. cuja y Ly. patagonicus) valores altos, iguales o mayores a 1,60 (Fig. 3.2A, Tabla 3.8).

Al realizarse el ANCOVA de dos factores con control filogenético y el tamaño como covariable, ésta última no tuvo una relación significativa con la longitud relativa de los miembros respecto al cuerpo $(\mathrm{F}=6,219 ; \mathrm{p}=0,836$; Apéndice 3.7A1). Al realizarse ANOVAs de un factor (Apéndice 3.7A2, 3), sólo el ANOVA con control filogenético que incluyó al factor locomoción indicó una relación marginalmente significativa con la proporción tóracolumbar/miembros $(\mathrm{F}=36,71 ; \mathrm{p}=0,025 ;$ Apéndice 3.7A2) .

\subsubsection{Largo de región cervical sobre largo de región tóraco-lumbar (LaCe-LaTL)}

En el ANOVA de dos factores, los supuestos de homocedasticidad (test de Levene, $\mathrm{F}=$ $2,508 ; \mathrm{p}=0,126)$ y distribución normal de los residuos (test de Shapiro-Wilk, $\mathrm{W}=0,936 ; \mathrm{p}=$ $0,108)$ no fueron rechazados. Este ANOVA indicó una relación significativa entre la longitud relativa del cuello y la dieta exclusivamente $(\mathrm{F}=12,344 ; \mathrm{p}=0,002$; Apéndice 3.6B1). Al realizar nuevamente el ANOVA para el factor dieta exclusivamente, el resultado fue similar (F $=10,870 ; \mathrm{p}<0,003 ;$ Apéndice 3.6B2).

Los carnívoros presentaron cuellos significativamente más largos (media $=0,308 ; \mathrm{DE}$ $=0,022)$ que los omnívoros (media $=0,26 ; \mathrm{DE}=0,045$ ), aunque existen outliers en ambos grupos: Mellivora capensis fue un omnívoro outlier (seguido de cerca por melinos) con el cuello más largo de su clase. Enhydra lutris y Potos flavus juntos son outliers de la muestra, con los cuellos en extremo breves $(18,1 \%$ del largo tóraco-lumbar), mientras que Lutra lutra también fue un outlier, pero con su cuello relativamente más largo que el resto de los musteloideos analizados (36,0\%) (Fig. 3.2B, Tabla 3.8).

Dentro de los hurones incluidos, Galictis cuja presentó el cuello más largo $(33,0 \%)$. Dentro de las especies de América del Sur, esta especie fue seguida por Ly. patagonicus $(31,1 \%)$, mientras que Lo. longicaudis $(30,5 \%)$ tuvo un cuello de mayor longitud que Lo. provocax (28,5\%) (Fig. 3.2B, Tabla 3.8).

Al realizarse un ANOVA incluyendo exclusivamente el factor locomoción, los supuestos de homocedasticidad (test de Levene, $\mathrm{F}=1,929 ; \mathrm{p}=0,154$ ) y distribución normal de los residuos (test de Shapiro-Wilk, $\mathrm{W}=0,962 ; \mathrm{p}=0,436$ ) no fueron rechazados, pero el 
resultado, al igual que en el ANOVA, fue no significativo $(\mathrm{F}=1,408 ; \mathrm{p}<0,267$; Apéndice 3.6B3).

La superposición de rangos de grupos locomotores fue amplia, sólo diferenciándose (aunque en forma no significativa) a half-bounders con cuellos relativamente largos (media = 0,314; $\mathrm{DE}=0,009)$ pero dentro del rango de valores de especies cavadoras y trepadoras (máximos: 0,354 y 0,360 respectivamente; Fig. 3.1B).

Al realizarse el ANCOVA de dos factores con control filogenético y el tamaño como covariable, la covariable no tuvo una relación significativa con la longitud relativa de cuello ( $\mathrm{F}$ $=0,230 ; \mathrm{p}=0,760$; Apéndice 3.7B1). Luego de retirar la covariable, el ANOVA de dos factores con control filogenético indicó una relación significativa entre la longitud del cuello y exclusivamente la dieta $(\mathrm{F}=76,60 ; \mathrm{p}=0,027$; Apéndice $3.7 \mathrm{~B} 2)$; mientras que al dejar únicamente este factor, la relación significativa fue reafirmada $(\mathrm{F}=88,33, \mathrm{p}<0,001$; Apéndice 3.7B3).

\subsubsection{Largo de región lumbar sobre largo de región tóraco-lumbar (LaLu/LaTL)}

En el ANOVA del factor locomoción, los supuestos de homocedasticidad (test de Levene, $\mathrm{F}=1,406 ; \mathrm{p}=0,267$ ) y distribución normal de los residuos (test de Shapiro-Wilk, $\mathrm{W}=$ $0,972 ; \mathrm{p}=0,672)$ no fueron rechazados. Sin embargo, el ANOVA no fue significativo $(\mathrm{F}=$ 2,422; p= 0,093; Apéndice 3.6C1). En este análisis Ly. patagonicus fue un outlier, y éste en conjunto con Ga. cuja (cavador y half-bounder) se ubicaron en una posición alejada de los restantes half-bounders.

Al realizarse el mismo análisis eliminándose a $L y$. patagonicus e incluyéndose a $G a$. cuja como cavador (i.e., circunscribiendo el grupo de los half-bounders específicamente a halfbounder ágiles, ver Discusión, sección 4.5.2), el ANOVA se volvió significativo ( $\mathrm{F}=6,062 ; \mathrm{p}=$ 0,004). El test de comparaciones cruzadas a posteriori permitió reconocer en este caso que los cavadores difirieron en la longitud relativa de la región lumbar respecto de trepadores y de halfbounders (Apéndice 3.6C2).

En el análisis excluyendo a Ly. patagonicus y catalogando a Ga. cuja como cavador, los cavadores (media $=0,320 ; \mathrm{DE}=0,038)$ y nadadores (media $=0,338 ; \mathrm{DE}=0,040)$ segregaron hacia valores negativos de longitudes relativas de región lumbar (pero sólo los primeros en forma significativa). Los half-bounders ágiles (media $=0,415 ; \mathrm{DE}=0,001$ ) y secundariamente trepadores $($ media $=0,395 ; \mathrm{DE}=0,003)$ presentaron por otro lado una región lumbar relativamente alargada. Por otro lado existe amplias regiones de superposición para los grupos locomotores (Fig. 3.6C, Tabla 3.7).

Lyncodon patagonicus fue el taxón musteloideo analizado con la longitud de región lumbar relativamente más corta (representando sólo el 23\% de la región tóraco-lumbar). La 
condición de Ga. cuja (31\% de la región tóraco-lumbar) también fue breve aunque menos extrema, en este caso muy similar a lo observado en cavadores y nadadores. Las especies de América del Sur de Lontra, presentaron una región lumbar similar a la de Ga. cuja, y breve respecto a otras especies acuáticas. Eira barbara $(36,7 \%)$ tuvo un valor de LaLu/LaTL alto en relación a otros mustélidos sudamericanos, pero bajo respecto a otros trepadores, similar a otros guloninos grandes (Gu. gulo) (Fig. 3.6C, Tabla 3.7).

Al realizarse el ANCOVA del factor locomoción con control filogenético y el tamaño como covariable, la covariable no tuvo una relación significativa con la longitud relativa del sector lumbar $(\mathrm{F}=1,539 ; \mathrm{p}=0,378$; Apéndice 3.7C1). Luego de retirar la covariable, el ANOVA con control filogenético indicó una relación significativa entre la longitud lumbar relativa y la locomoción $(\mathrm{F}=17,95 ; \mathrm{p}=0,034$; Apéndice $3.7 \mathrm{C} 2)$.

\subsubsection{Largo de la región sacro-caudal sobre largo de región tóraco-lumbar (LaSC/LaTL)}

En el análisis de categorías locomotoras, los supuestos de homocedasticidad (test de Levene, $\mathrm{F}=1,139 ; \mathrm{p}=0,360$ ) y distribución normal de los residuos (test de Shapiro-Wilk, $\mathrm{W}=$ $0,956 ; \mathrm{p}=0,418)$ no fueron rechazados. Sin embargo, el ANOVA no fue significativo $(\mathrm{F}=$ 2,483; $\mathrm{p}=$ 0,094; Apéndice 3.6D1). Al retirar al taxón Gulo gulo, outlier del análisis comentado, el resultado de éste nuevo análisis fue significativo $(F=4,373 ; p=0,018$; Apéndice 3.6D2). El test a posteriori permitió reconocer diferencias significativas exclusivamente entre los grupos half-bounder y trepador, y marginalmente no significativas entre cavador y trepador (Apéndice 3.6D2).

El rango y la superposición de valores del índice sacro-caudal fue muy amplio para los grupos cavador (media $=1,026 ; \mathrm{DE}=0,304) \mathrm{y}$ trepador, incluso luego de eliminar al outlier Gulo gulo (media $=1,484 ; \mathrm{DE}=0,297$ ). El grupo half-bounder fue el que mostró la menor dispersión y los valores medios relativamente más bajos (media $=0,816$; $\mathrm{DE}=0,200$ ), en donde la longitud de la cola en ningún caso analizado superó la del cuerpo. El grupo de los nadadores (media $=1,265 ; \mathrm{DE}=0,277)$ presentó un rango de variantes de longitudes de cola de entre $1 \mathrm{y}$ 1,5 veces la longitud tóraco-lumbar excepto por En. lutris, con una cola de menor longitud $(\mathrm{LaSC} / \mathrm{LaTL}=0,861)$ (Fig. 3.6D, Tabla 3.7).

Galictis cuja presentó una longitud de cola equivalente a 88,3\% la longitud de la región tóraco-lumbar, claramente mayor que $M u$. putorius $(\mathrm{LaSC} / \mathrm{LaTL}=0,591)$ y Ly. patagonicus (no incluido por falta de apéndices caudales completos; ver medidas externas de Koslowsky 1904), pero menor que $M u$. vison $(\mathrm{LaSC} / \mathrm{LaTL}=0,974)$. Las especies de Lontra de América del Sur presentaron una longitud caudal destacable (entre 1,4 y 1,5 veces la longitud tóraco-lumbar), valores similares a muchos trepadores y algunos cavadores (Fig. 3.6D, Tabla 3.7). 
Al realizarse el ANCOVA del factor locomoción con control filogenético, incluyendo al tamaño como covariable, la covariable no tuvo una relación significativa con la longitud relativa de la región caudal $(\mathrm{F}=31,65 ; \mathrm{p}=0,238$; Apéndice 3.7D1). Luego de retirar la covariable, el ANOVA con control filogenético indicó una relación marginalmente no significativa entre la longitud caudal relativa y la locomoción ( $\mathrm{F}=31,26 ; \mathrm{p}=0,056$; Apéndice 3.7D2).

\subsubsection{Largo de miembro anterior sobre largo de miembro posterior (LaMA/LaMP)}

En el análisis de dos factores, aunque el supuesto homocedasticidad (test de Levene, $\mathrm{F}=$ 1,086; $p=0,397$ ) no fue rechazado, si lo fue el de normalidad (test de Shapiro-Wilk, $W=0,862$; $\mathrm{p}=0,002$ ); por lo cual el resultado del ANOVA no es confiable. Por otro lado, ninguno de los factores ni la interacción resultaron significativos (Apéndice 3.6E1). En este análisis, Mydaus sp. resultó un outlier. Al retirar a este taxón y realizar nuevamente el análisis, los supuestos no son rechazados, y el ANOVA se vuelve significativo para ambos factores (locomoción: $\mathrm{F}=$ 4,495; $p=0,014 ;$ dieta: $F=6,494 ; p=0,019)$ y la interacción entre los mismos fue marginalmente significativa $(F=5,1599 ; p=0,034)$. La locomoción fue el factor más importante, pero ninguno de estos explica una porción importante de la varianza, siendo las sumas de cuadrados menores que los residuos (Apéndice 3.6E2). Al realizar una prueba $a$ posteriori comparando todos los pares posibles, el único par significativo resultó la comparación half-bounder + carnívoro vs. cavador + carnívoro (diferencia $=-0.157 ; \mathrm{p}=0,012$ ); mientras que el par cavador:omnívoro vs. cavador:carnívoro resultó marginalmente no significativo (diferencia $=-0.130 ; \mathrm{p}=0,051$ ). Al analizar cada factor $\mathrm{y}$ la interacción en ANOVAs independientes, no existe significancia en ningún caso, pero tampoco se cumplieron los supuestos en estos análisis (resultados no mostrados).

Muchos grupos se superpusieron en valores medios. Los cavadores mostraron un muy amplio rango de valores de este índice intermembral, incluso luego de retirar al outlier Mydaus sp. de la muestra (media $=0,837 ; \mathrm{DE}=0,064$ ), siendo la longitud del miembro anterior mayor al $80 \%$ del miembro posterior (105\% en el caso de Mydaus sp.). El grupo nadador (media = 0,767; $\mathrm{DE}=0,068)$ mostró una distribución partida, con especies de miembros anteriores reducidos al máximo respecto a los posteriores en el caso de En. lutris y Lo. canadensis (LaMA/LaMP < 0,7); y formas de proporciones generalizadas (Aonyx sp., Lo. longicaudis, Lo. provocax; LaMA/LaMP $>0,8)$. Los trepadores (media $=0,843 ; \mathrm{DE}=0,031)$ y half-bounders (media $=0,790 ; \mathrm{DE}=0,027)$ presentaron distribuciones de rangos restringidos, comprendidas por los valores de los otros dos grupos locomotores (Fig. 3.1., Tabla 3.7).

Eira barbara se ubicó cerca del centro de la distribución de los trepadores. Dentro de los half-bounders, Ly. patagonicus fue la especie con el mayor desarrollo relativo de los miembros anteriores (83,0\%), seguido de cerca por Bassariscus astutus $(82,4 \%)$ y luego por $G a$. 
cuja $(79,7 \%)$ y algunos mustelinos no sudamericanos, y luego por $M$. frenata (76,9\%) (Fig. 3.1., Tabla 3.7).

Al realizarse el ANCOVA de dos factores con control filogenético y el tamaño como covariable, la covariable no tuvo una relación significativa con la longitud relativa de cuello ( $\mathrm{F}$ $=1,439 ; \mathrm{p}=0,518$; Apéndice 3.7E1). Luego de retirar la covariable, el ANOVA de dos factores con control filogenético indicó una relación marginalmente significativa entre las proporciones intermembrales y la locomoción $(\mathrm{F}=32,21 ; \mathrm{p}=0,050$; Apéndice 3.7E2); mientras que al dejar únicamente este factor, la relación se mantuvo marginalmente significativa $(\mathrm{F}=13,57, \mathrm{p}=$ 0,040; Apéndice 3.7E3).

\subsubsection{Largo del radio sobre largo del húmero (LaRa/LaHu)}

En el análisis de dos factores del total de los datos, aunque el supuesto de homocedasticidad (test de Levene, $F=0,638 ; p=0,720$ ) no fue rechazado, si lo fue el de normalidad de los residuos (test de Shapiro-Wilk, $\mathrm{W}=0,900, \mathrm{p}=0,006$ ), siendo el resultado del ANOVA no significativo aunque no confiable debido a ser rechazado uno de sus supuestos (Apéndice 3.6F1). Mydaus sp. resultó un taxón outlier. Al realizar un nuevo análisis excluyendo a este taxón, aunque el supuesto de homocedasticidad (test de Levene, $F=2,338 ; \mathrm{p}=0,059$; resultado marginal), y de normalidad de los residuos (test de Shapiro-Wilk, $\mathrm{W}=0,957 ; \mathrm{p}=$ 0,251) no fueron rechazados; el ANOVA indicó nuevamente una relación no significativa con cada factor y la interacción entre estos (Apéndice 3.6F2). Al repetir el análisis eliminando la interacción (A:B), los resultados fueron similares (resultados no mostrados). Luego de eliminar del análisis al primer outlier de este nuevo análisis: Procyon lotor (y a otros outliers emergentes de subsiguientes análisis, e.g., Procyon cancrivorus), los resultados tampoco se modifican significativamente (resultados no mostrados). Al realizar ANOVAs de un factor contemplando el efecto de cada uno de ellos independientemente, la influencia del factor locomoción fue marginalmente no significativa al excluir a Mydaus sp. (Apéndice 3.6F3), pero fue significativa al eliminar sucesivos outliers, mientras que la influencia del factor dieta se volvió significativa con sólo la exclusión de Mydaus sp. (Apéndice 3.6F4).

Pese a que no existe ninguna separación estadísticamente significativa (excepto al eliminar un gran número de outliers), los nadadores (media $=0,749 ; \mathrm{DE}=0,056$ ) y halfbounders (media $=0,737 ; \mathrm{DE}=0,050$ ) tendieron a presentar radios (antebrazos) relativamente breves, con la excepción de Aonyx sp. $(0,839)$. Cavadores (media $=0,826 ; \mathrm{DE}=0,029 ;$ luego de retirar a Mydaus sp.) y trepadores (media $=0,841 ; \mathrm{DE}=0,097$ ) presentaron por lo general antebrazos relativamente largos, aunque Mydaus sp. fue una notable excepción $(\mathrm{LaRa} / \mathrm{LaHu}=$ 0,518) (Fig. 3.1E, Tabla 3.7). 
Más allá de Mydaus sp., Ly. patagonicus $(0,665)$ fue el musteloideo con antebrazos relativamente más breves, seguido por algunos mustelinos (incluido Mu. frenata), Galictis cuja, y Lontra spp., todos ellos con valores LaRa/LaHu entre 0,69 y 0,73. Eira barbara presentó un antebrazo relativamente alargado $(0,774)$, mayor a cualquier otro mustélido sudamericano, y similar a los valores de otros linajes trepadores, exceptuando los valores extremos de Nasua sp. $(0,856)$ y especialmente de Procyon sp. (de relación radio-húmero aproximadamente igual a 1) (Fig. 3.1E, Tabla 3.7).

En lo que respecta a los grupos dietarios, los carnívoros (media $=0,753 ; \mathrm{DE}=0,075$ ) tendieron a poseer valores del índice braquial más bajos que los omnívoros (media $=0,814$; $\mathrm{DE}$ $=0,126)$, pero solapados ampliamente en sus distribuciones y encontrándose en segundo grupo un gran número de taxones con valores mucho menores (e.g., Mydaus sp.) o mucho mayores (e.g., Procyon lotor, Pr. cancrivorus) a la media (Fig. 3.2D, Tabla 3.8).

Al realizarse el ANCOVA de dos factores con control filogenético y el tamaño como covariable, la covariable no tuvo una relación significativa con los valores del índice braquial ( $\mathrm{F}$ $=3,418 ; \mathrm{p}=0,240 ;$ Apéndice 3.7F1). Luego de retirar la covariable, el ANOVA de dos factores con control filogenético indicó una relación significativa exclusivamente entre la proporción braquial y la locomoción ( $\mathrm{F}=19.97 ; \mathrm{p}=0,027$; Apéndice $3.7 \mathrm{~F} 2$ ); mientras que al dejar únicamente este factor, la relación continuó significativa $(\mathrm{F}=19,68, \mathrm{p}=0,011$; Apéndice 3.7F3).

\subsubsection{Largo del metacarpal III sobre largo de la falange proximal de dígito III (LaMcIII/LaFIII)}

En el ANOVA de dos factores, los supuestos de homocedasticidad (test de Levene, $\mathrm{F}=$ $0,566 ; \mathrm{p}=0,724)$ y distribución normal de los residuos (test de Shapiro-Wilk, $\mathrm{W}=0,970 ; \mathrm{p}=$ $0,639)$ no fueron rechazados. Sin embargo, el ANOVA no fue significativo para la dieta, locomoción, o la interacción entre ambos (Apéndice 3.6G1). Al repetir el análisis eliminando la interacción (A:B), los resultados fueron similares (resultados no mostrados). Al realizar análisis de varianza para cada factor, únicamente la dieta resultó significativa, y sólo explicando una porción minoritaria de la varianza $(\mathrm{F}=8,6303 ; \mathrm{p}=0,007$; Apéndice $3.6 \mathrm{G} 2,3)$.

La superposición entre grupos y rango de valores de todos los grupos locomotores fue importante, especialmente para el caso de cavadores (media $=1,937 ; \mathrm{DE}=0,381$ ), con taxones con falanges relativamente largas (Taxidea taxus: LaMcIII/LaFIII $=1,409$ ) a taxones con máxima reducción de falanges (mefítidos-Spilogale gracilis y melinos; valores mayores a 2,00). Nadadores (media $=1,593 ; \mathrm{DE}=0,282)$ y half-bounders (media $=1,590 ; \mathrm{DE}=0,233$ ) segregaron con similares medias hacia valores bajos de LaMcIII/LaFIII, indicando mayores 
longitudes relativas de falanges; mientras que trepadores (media $=1,769 ; \mathrm{DE}=0,248$ ) mantienen más bien una condición intermedia (Fig. 3.1G, Tabla 3.7).

La superposición entre grupos dietarios también fue importante. Los carnívoros (media $=1,601 ; \mathrm{DE}=0,236)$ se ubicaron en valores LaMcIII/LaFIII algo más bajos $\mathrm{y}$, por lo tanto, presentaron falanges relativamente largas en comparación con los omnívoros (media $=1,924$; $\mathrm{DE}=0,313)$. Todos los taxones con LaMcIII/LaFIII menores que 1,8 fueron carnívoros (específicamente hurones, nutrias, Ei. barbara, Ta. taxus y Bassariscus astutus), excepto por Potos flavus, Mellivora capensis y Spilogale gracilis; mientras que todos los taxones que tienen valores mayores a este umbral, fueron omnívoros excepto por Martes spp. y Gu. gulo (Fig. 3.2E, Tabla 3.8).

Los valores de LaMcIII/LaFIII de Ga. cuja y Ga. vittata (ambos entre 1,6 y 1,7) fueron relativamente altos en comparación con otras especies de su grupo dietario. Por el contrario, $L y$. patagonicus mostró el menor valor para este índice del total de la muestra de musteloideos $(1,254)$. Eira barbara $(1,445)$ y $M u$. frenata $(1,512)$, tienen valores relativamente bajos, un poco menores que la media su grupo dietario (Fig. 3.2E, Tabla 3.8).

Al realizarse el ANCOVA de dos factores con control filogenético y el tamaño como covariable, la covariable no tuvo una relación significativa con la proporción metacarpo-falange $(\mathrm{F}=4,562 ; \mathrm{p}=0,234 ;$ Apéndice 3.7G1). Luego de retirar la covariable, el ANOVA de dos factores indicó una relación no significativa con ambos factores (Apéndice 3.7G2); y lo mismo ocurrió al construir ANOVAs de un factor con control filogenético para ambas variables explicatorias (aunque en forma marginal en el caso de la dieta; Apéndice 3.7G3, G4).

\subsubsection{Largo de la tibia sobre largo del fémur (LaTi-LaFe)}

En el análisis de categorías locomotoras, tanto el supuesto de normalidad (test de Shapiro-Wilk, $\mathrm{W}=0,954 ; \mathrm{p}=0,178$ ) como el de homocedasticidad (test de Levene, $\mathrm{F}=3,176$; $\mathrm{p}=0,177)$ no fueron rechazados. El resultado del ANOVA fue significativo $(\mathrm{F}=9,616 ; \mathrm{p}<$ 0,001; Apéndice 3.6 H). El test a posteriori permitió reconocer diferencias significativas entre los pares: cavadores y half-bounders, cavadores y nadadores, y nadadores y trepadores.

Los grupos trepador (media $=0,974 ; \mathrm{DE}=0,044)$ y cavador $($ media $=0,936 ; \mathrm{DE}=$ $0,101)$ mostraron rangos de valores $\mathrm{LaTi} / \mathrm{LaFe}$ ampliamente superpuestos. Los cavadores específicamente mostraron un amplio rango de valores y mayormente partida en dos grandes subgrupos, con tibias mucho más breves que el fémur en el caso de tejones y Mellivora capensis $(0,78$ a 0,86$)$, y elementos de similares proporciones en el caso de mefítidos $(0,98$ a 1,07). Eira barbara $(\mathrm{LaTi} / \mathrm{LaFe}=0,920)$ presentó la tibia más breve en proporción al fémur de las especies trepadoras, seguido por Gu. gulo $(0,943)$ y Na. nasua $(0,949)$ (Fig. 3.1H, Tabla 3.7). Excepto por los saltadores Bassariscus astutus $(\mathrm{LaTi} / \mathrm{LaFe}=0,964)$, Ga. cuja $(0,971)$ у Mu. putorius 
$(1,00)$, todos los half-bounders (media $=1,038 ; \mathrm{DE}=0,052)$ y nadadores (media $=1,131 ; \mathrm{DE}=$ $0,056)$ poseyeron tibias de mayor longitud que los fémures. Todas las especies acuáticas (incluyendo Lontra sp. y En. lutris) presentaron valores máximos de longitudes relativas de tibias (i.e., LaTi/LaFe > 1,1; excepto por Aonyx sp., $\mathrm{LaTi} / \mathrm{LaFe}=1,045$ ), seguidos de cerca por mustelinos (y específicamente $M u$. vison y $M u$. frenata, $\mathrm{LaTi} / \mathrm{LaFe}=1,098$ y 1,092 respectivamente), Ma. americana $(1,089)$ y Ly. patagonicus $(1,070)$ (Fig. 3.1H, Tabla 3.7).

Al realizarse el ANCOVA del factor locomoción con control filogenético, incluyendo al tamaño como covariable, la variable locomoción tuvo una relación significativa con el índice crural $(\mathrm{F}=38,46 ; \mathrm{p}=0,007)$, mientras que la covariable obtuvo una relación marginalmente significativa con esta proporción $(\mathrm{F}=11,47 ; \mathrm{p}=0,043$; Apéndice $3.7 \mathrm{H1})$. 
Tablas de resultados de análisis lineales

(ver a continuación) 
Tabla 3.6. Resumen de los principales resultados de los análisis de ANOVAs de 1 o 2 factores (dependiendo el índice, ver Materiales y Métodos, sección 2.2.3.2) y ANCOVAs (considerando a la masa como covariable; (a) de los índices de elementos postcraneales, contemplando o no la filogenia. Para los ANCOVAs en que la covariable no tuvo una influencia significativa), se procedió a realizar un análisis de varianza similar pero excluyendo a la misma (b). En el caso del índice LaTL/PrLaM no se pudo obtener un $p$-value por falta de grados de libertad, por lo que se realizaron e informaron ANCOVAs de 1 factor. $0=$ considerando a Bassariscus astutus como trepador, $1=$ excluyendo a outliers Lyncodon patagonicus y poniendo a Galictis cuja como cavador, 2 = excluyendo a outlier Gulo gulo, 3 = excluyendo a outlier Mydaus sp. (ver sección 3.4). Ver más detalles en Apéndices 3.6 y 3.7.

\begin{tabular}{|c|c|c|c|c|c|c|c|c|c|c|}
\hline Análisis & Efecto/Covariable & Dato & LaTL/PrLaM $^{0}$ & LaCe/LaTL & LaLu/LaTL $^{1}$ & LaSC/LaTL $^{2}$ & LaMA/LaMP ${ }^{3}$ & LaRa/LaHu ${ }^{3}$ & LaMcIII/LaFIII & LaTi/LaFe \\
\hline \multirow{6}{*}{ ANOVA, 2 factores } & \multirow{2}{*}{ Dieta:Locomoción } & $\mathbf{F}$ & 1,029 & 2,433 & & & 5,1599 & 0,107 & 2,542 & \\
\hline & & $\mathbf{p}$ & 0,380 & 0,115 & & & 0,034 & 0,955 & 0,127 & \\
\hline & \multirow{2}{*}{ Dieta } & $\mathbf{F}$ & 0,141 & 12,344 & & & 6,495 & 1,345 & 1,800 & \\
\hline & & $\mathbf{p}$ & 0,712 & 0,002 & & & 0,019 & 0,258 & 0,196 & \\
\hline & \multirow{2}{*}{ Locomoción } & $\mathbf{F}$ & 5,420 & 1,132 & & & 4,496 & 1,500 & 0,230 & \\
\hline & & $\mathbf{p}$ & 0,009 & 0,361 & & & 0,014 & 0,241 & 0,874 & \\
\hline \multirow{4}{*}{ ANOVA, 1 factor } & \multirow{2}{*}{ Dieta } & $\mathbf{F}$ & & 10,870 & & & & 5,686 & 8,630 & \\
\hline & & $\mathbf{p}$ & & 0,003 & & & & 0,024 & 0,007 & \\
\hline & \multirow{2}{*}{ Locomoción } & $\mathbf{F}$ & 9,238 & & 6,062 & 4,373 & & 2,831 & 2,169 & 9,616 \\
\hline & & $\mathbf{p}$ & 0,001 & & 0,004 & 0,019 & & 0,057 & 0,122 & 0,000 \\
\hline \multirow{6}{*}{$\begin{array}{l}\text { ANCOVA(a)/ANOVA(b) } \\
\text { filogenético, } 2 \text { factores }\end{array}$} & \multirow{2}{*}{ Masa } & $\mathbf{F}$ & 6,219 (a) & $0,230(a)$ & & & 1,439 (a) & $3,418(a)$ & $4,562(a)$ & \\
\hline & & $\mathbf{p}$ & 0,836 & 0,760 & & & 0,518 & 0,240 & 0,234 & \\
\hline & \multirow{2}{*}{ Dieta } & $\mathbf{F}$ & $5,542(a)$ & $76,60(b)$ & & & $17,77(b)$ & $7,341(b)$ & 4,129 (b) & \\
\hline & & $\mathbf{p}$ & 0,839 & 0,027 & & & 0,073 & 0,089 & 0,164 & \\
\hline & \multirow{2}{*}{ Locomoción } & $\mathbf{F}$ & $22,318(a)$ & $11,89(b)$ & & & $32,21(b)$ & $19,97(b)$ & 0,774 & \\
\hline & & $\mathbf{p}$ & 0,825 & 0,120 & & & 0,050 & 0,027 & 0,597 & \\
\hline \multirow{6}{*}{$\begin{array}{l}\text { ANCOVA(a)/ANOVA(b) } \\
\text { filogenético, } 1 \text { factor }\end{array}$} & \multirow{2}{*}{ Masa } & $\mathbf{F}$ & & & 1,539 (a) & $31,65(a)$ & & & & $11,47(a)$ \\
\hline & & $\mathbf{p}$ & & & 0,378 & 0,238 & & & & 0,043 \\
\hline & \multirow{2}{*}{ Dieta } & $\mathbf{F}$ & $3,218(b)$ & 88,33 (b) & & & & & $5,777(b)$ & \\
\hline & & $\mathbf{p}$ & 0,1462 & 0,000 & & & & & 0,059 & \\
\hline & \multirow{2}{*}{ Locomoción } & $\mathbf{F}$ & $36,71(b)$ & & 17,95 (b) & $31,26(b)$ & $13,57(b)$ & $19,68(b)$ & $1,201(b)$ & 38,46 (a) \\
\hline & & $\mathbf{p}$ & 0,025 & & 0,034 & 0,056 & 0,040 & 0,011 & 0,434 & 0,007 \\
\hline
\end{tabular}



Tabla 3.7. Estadística descriptiva de cada índice para cada categoría locomotora. *Bassariscus astutus considerado como trepador, **excluyendo a Lyncodon patagonicus y considerando a Galictis cuja como cavador, *** excluyendo a Gulo gulo, **** excluyendo a Mydaus sp. (ver comentarios de estas en Resultados, sección 3.4).

\begin{tabular}{|c|c|c|c|c|c|}
\hline Índice & Variable & Nadador & Cavador & $\begin{array}{c}\text { Half- } \\
\text { bounder }\end{array}$ & Trepador \\
\hline \multirow[t]{8}{*}{ LaTL/PrLaM* } & Mínimo & 1,604 & 1,249 & 1,850 & 1,010 \\
\hline & 1er cuartil & 1,604 & 1,278 & 1,861 & 1,152 \\
\hline & Mediana & 1,847 & 1,497 & 1,923 & 1,295 \\
\hline & 3er cuartil & 1,976 & 1,543 & 2,045 & 1,528 \\
\hline & Máximo & 1,976 & 1,644 & 2,117 & 1,530 \\
\hline & Media & 1,809 & 1,449 & 1,953 & 1,298 \\
\hline & $\mathrm{CV}$ & 0,105 & 0,099 & 0,062 & 0,150 \\
\hline & $\mathrm{DE}$ & 0,189 & 0,143 & 0,121 & 0,195 \\
\hline \multirow[t]{8}{*}{$\mathrm{LaCe} / \mathrm{LaTL}$} & Mínimo & 0,181 & 0,227 & 0,307 & 0,181 \\
\hline & 1er cuartil & 0,209 & 0,255 & 0,308 & 0,261 \\
\hline & Mediana & 0,285 & 0,267 & 0,311 & 0,274 \\
\hline & 3er cuartil & 0,334 & 0,305 & 0,322 & 0,294 \\
\hline & Máximo & 0,360 & 0,351 & 0,330 & 0,295 \\
\hline & Media & 0,274 & 0,277 & 0,314 & 0,263 \\
\hline & $\mathrm{CV}$ & 0,250 & 0,132 & 0,029 & 0,160 \\
\hline & $\mathrm{DE}$ & 0,068 & 0,037 & 0,009 & 0,042 \\
\hline \multirow[t]{8}{*}{$\mathrm{LaLu} / \mathrm{LaTL}^{* *}$} & Mínimo & 0,298 & 0,267 & 0,375 & 0,320 \\
\hline & 1er cuartil & 0,304 & 0,293 & 0,375 & 0,367 \\
\hline & Mediana & 0,320 & 0,311 & 0,431 & 0,392 \\
\hline & 3er cuartil & 0,380 & 0,341 & 0,440 & 0,431 \\
\hline & Máximo & 0,382 & 0,382 & 0,440 & 0,470 \\
\hline & Media & 0,338 & 0,320 & 0,415 & 0,395 \\
\hline & $\mathrm{CV}$ & 0,118 & 0,120 & 0,085 & 0,131 \\
\hline & $\mathrm{DE}$ & 0,040 & 0,038 & 0,035 & 0,052 \\
\hline \multirow{8}{*}{$\mathrm{LaSC} / \mathrm{LaTL}^{* * *}$} & Mínimo & 0,861 & 0,611 & 0,591 & 1,098 \\
\hline & 1er cuartil & 1,090 & 0,751 & 0,591 & 1,169 \\
\hline & Mediana & 1,359 & 1,103 & 0,883 & 1,610 \\
\hline & 3er cuartil & 1,440 & 1,270 & 0,974 & 1,736 \\
\hline & Máximo & 1,481 & 1,498 & 0,974 & 1,761 \\
\hline & Media & 1,265 & 1,026 & 0,816 & 1,484 \\
\hline & $\mathrm{CV}$ & 0,219 & 0,296 & 0,245 & 0,200 \\
\hline & $\mathrm{DE}$ & 0,277 & 0,304 & 0,200 & 0,297 \\
\hline \multirow[t]{8}{*}{ LaMA/LaMP***** } & Mínimo & 0,687 & 0,774 & 0,751 & 0,811 \\
\hline & 1er cuartil & 0,693 & 0,783 & 0,771 & 0,812 \\
\hline & Mediana & 0,805 & 0,800 & 0,790 & 0,837 \\
\hline & 3er cuartil & 0,821 & 0,887 & 0,810 & 0,874 \\
\hline & Máximo & 0,831 & 0,953 & 0,830 & 0,894 \\
\hline & Media & 0,767 & 0,837 & 0,790 & 0,843 \\
\hline & $\mathrm{CV}$ & 0,089 & 0,076 & 0,034 & 0,037 \\
\hline & $\mathrm{DE}$ & 0,068 & 0,064 & 0,027 & 0,031 \\
\hline \multirow[t]{8}{*}{$\mathrm{LaRa} / \mathrm{LaHu}^{* * * *}$} & Mínimo & 0,704 & 0,796 & 0,665 & 0,745 \\
\hline & 1er cuartil & 0,706 & 0,812 & 0,693 & 0,761 \\
\hline & Mediana & 0,727 & 0,817 & 0,744 & 0,818 \\
\hline & 3er cuartil & 0,804 & 0,832 & 0,791 & 0,908 \\
\hline & Máximo & 0,840 & 0,895 & 0,800 & 1,009 \\
\hline & Media & 0,749 & 0,826 & 0,737 & 0,841 \\
\hline & $\mathrm{CV}$ & 0,075 & 0,035 & 0,068 & 0,115 \\
\hline & $\mathrm{DE}$ & 0,056 & 0,029 & 0,050 & 0,097 \\
\hline \multirow[t]{3}{*}{ LaMcIII/LaFIII } & Mínimo & 1,393 & 1,409 & 1,254 & 1,409 \\
\hline & 1er cuartil & 1,393 & 1,575 & 1,445 & 1,513 \\
\hline & Mediana & 1,593 & 2,008 & 1,584 & 1,861 \\
\hline
\end{tabular}


Resultados

\begin{tabular}{llllll}
\hline & 3er cuartil & 1,792 & 2,339 & 1,670 & 1,959 \\
Máximo & 1,792 & 2,428 & 2,012 & 2,009 \\
Media & 1,593 & 1,937 & 1,590 & 1,769 \\
CV & 0,177 & 0,197 & 0,147 & 0,140 \\
& DE & 0,282 & 0,381 & 0,233 & 0,248 \\
\hline LaTi/LaFe & Mínimo & 1,045 & 0,787 & 0,964 & 0,920 \\
& 1er cuartil & 1,074 & 0,826 & 0,985 & 0,946 \\
& Mediana & 1,159 & 0,980 & 1,028 & 0,950 \\
& 3er cuartil & 1,174 & 1,016 & 1,091 & 1,022 \\
& Máximo & 1,177 & 1,063 & 1,098 & 1,033 \\
& Media & 1,131 & 0,936 & 1,038 & 0,974 \\
& CV & 0,050 & 0,108 & 0,050 & 0,045 \\
DE & 0,056 & 0,101 & 0,052 & 0,044 \\
\hline
\end{tabular}


Tabla 3.8. Estadística descriptiva de cada índice para cada categoría dietaria.

\begin{tabular}{|c|c|c|c|}
\hline Índice & Variable & Carnívoro & Omnívoro \\
\hline \multirow[t]{8}{*}{ LaTL/PrLaM } & Mínimo & 1,295 & 1,010 \\
\hline & 1er cuartil & 1,492 & 1,222 \\
\hline & Mediana & 1,725 & 1,497 \\
\hline & 3er cuartil & 1,873 & 1,543 \\
\hline & Máximo & 2,117 & 1,976 \\
\hline & Media & 1,695 & 1,416 \\
\hline & $\mathrm{CV}$ & 0,161 & 0,180 \\
\hline & DE & 0,274 & 0,255 \\
\hline \multirow[t]{8}{*}{$\mathrm{LaCe} / \mathrm{LaTL}$} & Mínimo & 0,281 & 0,181 \\
\hline & 1er cuartil & 0,294 & 0,236 \\
\hline & Mediana & 0,308 & 0,263 \\
\hline & 3er cuartil & 0,314 & 0,275 \\
\hline & Máximo & 0,360 & 0,351 \\
\hline & Media & 0,308 & 0,260 \\
\hline & $\mathrm{CV}$ & 0,071 & 0,172 \\
\hline & DE & 0,022 & 0,045 \\
\hline \multirow[t]{7}{*}{$\mathrm{LaRa} / \mathrm{LaHu}$} & Mínimo & 0,665 & 0,518 \\
\hline & 1er cuartil & 0,706 & 0,779 \\
\hline & Mediana & 0,745 & 0,813 \\
\hline & 3er cuartil & 0,796 & 0,856 \\
\hline & Máximo & 0,845 & 1,009 \\
\hline & Media & 0,753 & 0,814 \\
\hline & $\mathrm{CV}$ & 0,075 & 0,126 \\
\hline \multirow{9}{*}{ LaMcIII/LaFIII } & $\mathrm{DE}$ & 0,056 & 0,102 \\
\hline & Mínimo & 1,254 & 1,409 \\
\hline & ler cuartil & 1,409 & 1,742 \\
\hline & Mediana & 1,570 & 1,923 \\
\hline & 3er cuartil & 1,792 & 2,057 \\
\hline & Máximo & 2,012 & 2,428 \\
\hline & Media & 1,601 & 1,924 \\
\hline & $\mathrm{CV}$ & 0,148 & 0,163 \\
\hline & DE & 0,236 & 0,313 \\
\hline \multirow{8}{*}{ LaMA/LaMP } & Mínimo & 0,687 & 0,698 \\
\hline & 1er cuartil & 0,773 & 0,792 \\
\hline & Mediana & 0,801 & 0,821 \\
\hline & 3er cuartil & 0,830 & 0,871 \\
\hline & Máximo & 0,953 & 1,023 \\
\hline & Media & 0,807 & 0,833 \\
\hline & $\mathrm{CV}$ & 0,076 & 0,086 \\
\hline & DE & 0,061 & 0,072 \\
\hline
\end{tabular}


Figuras de resultados de análisis lineales

A
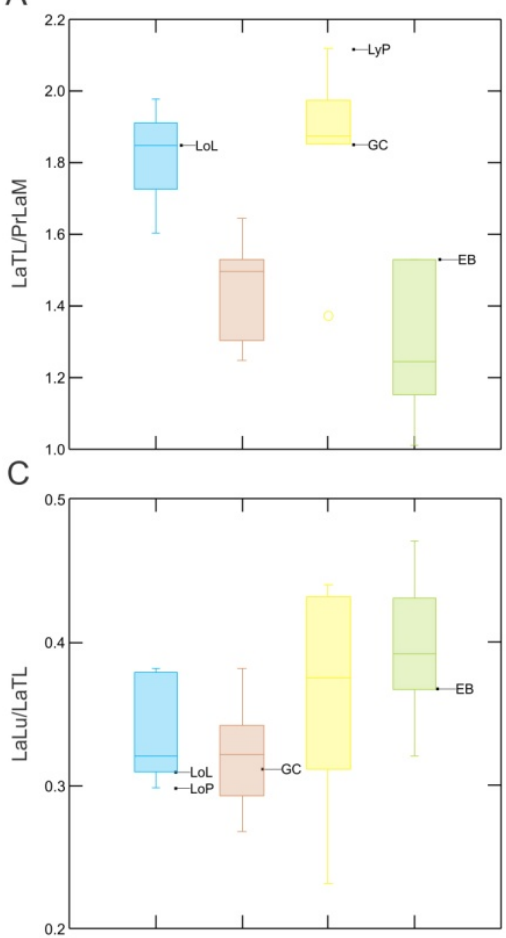

$\mathrm{E}$

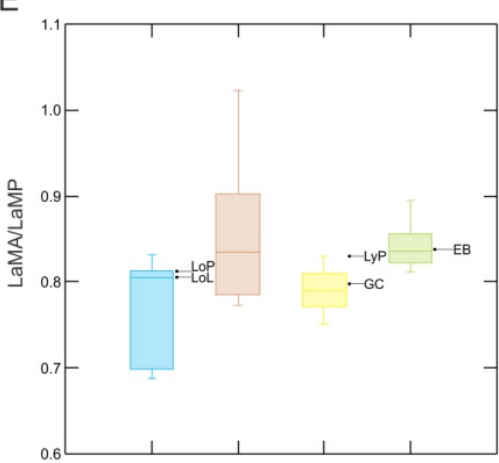

$\mathrm{G}$

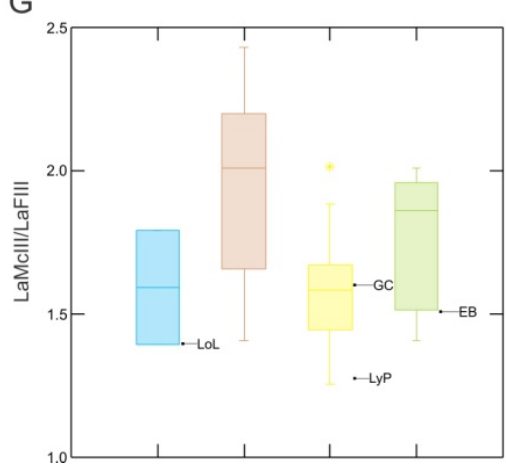

B
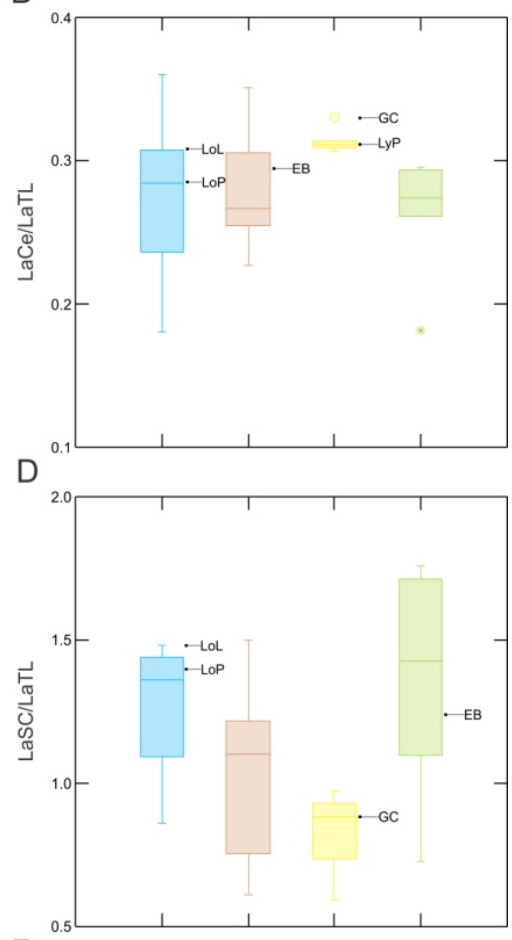

$\mathrm{F}$

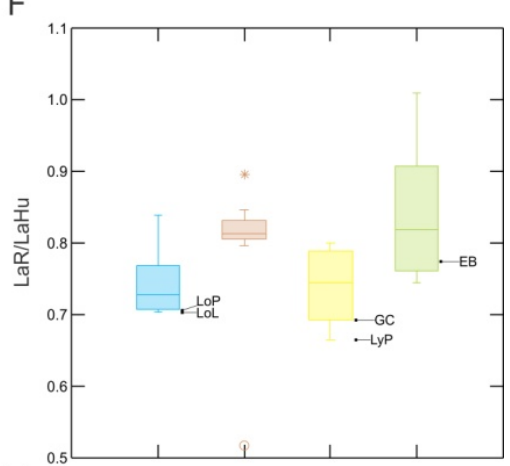

$\mathrm{H}$

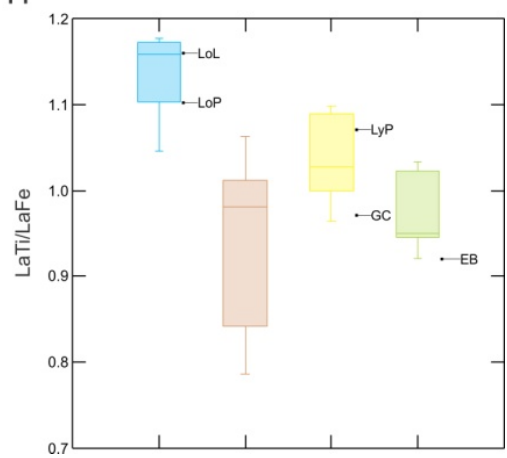

Figura 3.1. Esquemas de boxplots de cada índice morfométrico por grupos locomotores. Las especies analizadas son agrupadas en: nadador (celeste), cavador (marrón), half-bounder (amarillo) y trepador (verde). Especies analizadas de América del Sur: $\mathrm{EB}=$ Eira barbara, $\mathrm{GC}=$ Galictis cuja, $\mathrm{LoL}=$ Lontra longicaudis, LoP = Lontra provocax y LyP = Lyncodon patagonicus. 
A

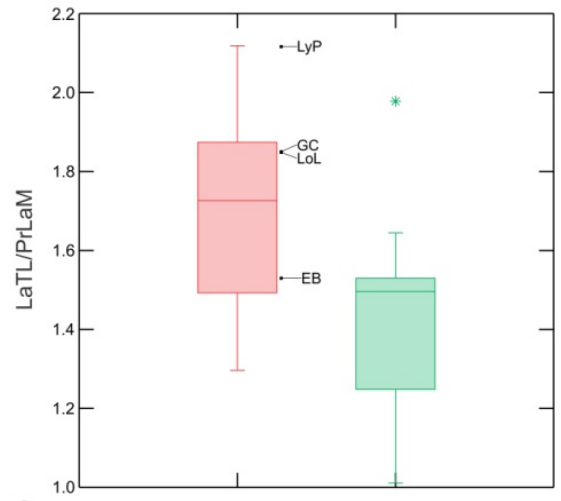

C

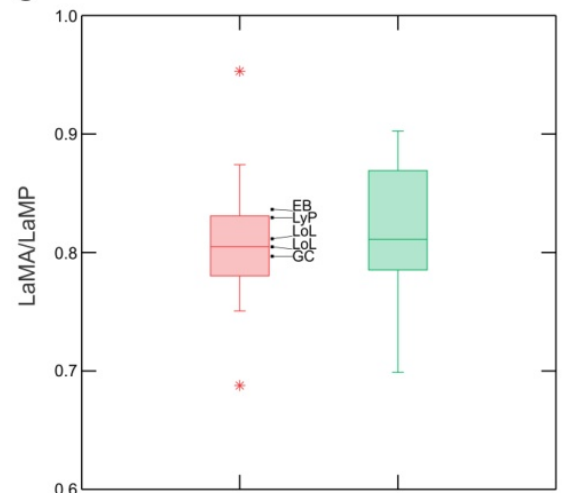

E

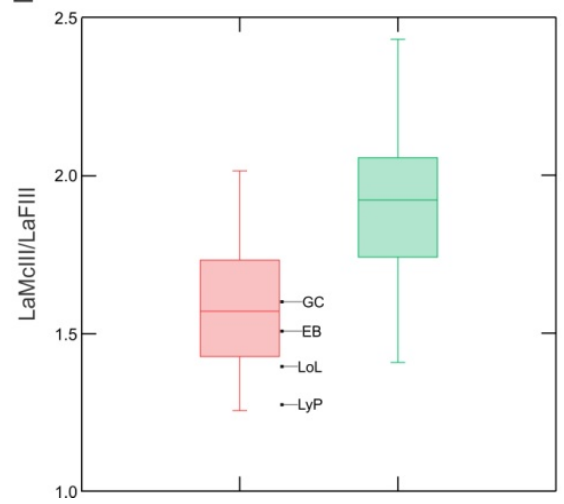

B

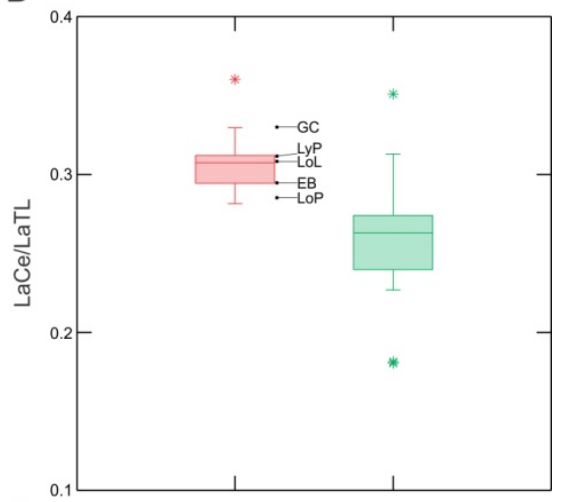

D

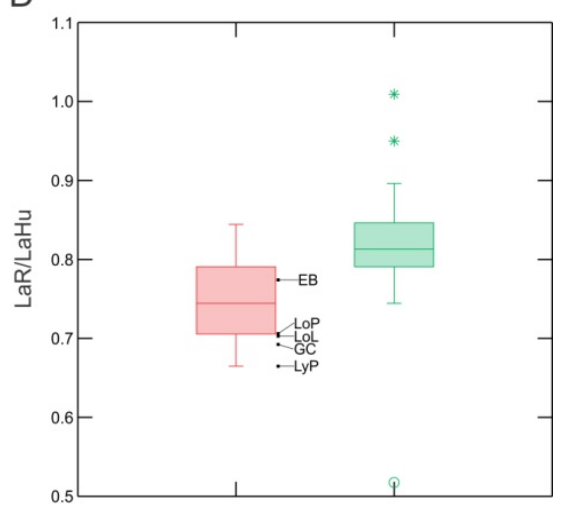

Figura 3.2. Esquemas de boxplots de cada índice morfométrico por grupos dietarios. Las especies analizadas son agrupadas en: carnívoro (rojo), y omnívoro (verde). Especies analizadas de América del Sur: $\mathrm{EB}=$ Eira barbara, $\mathrm{GC}=$ Galictis cuja, $\mathrm{LoL}=$ Lontra longicaudis, $\mathrm{LoP}=$ Lontra provocax y LyP $=$ Lyncodon patagonicus 


\subsection{Resultados de análisis de morfometría geométrica}

En los Apéndices 3.8 y 3.9 figuran en detalle los resultados de análisis realizados para este apartado.

\subsubsection{Vista lateral del axis (LAx)}

En el análisis de dieta, el primer eje de componentes principales (PC1) explicó el $54,71 \%$ de la varianza de forma de la muestra y el $100 \%$ de la separación entre carnívoros y omnívoros-no carnívoros. En valores positivos del PC1 se ubicaron las formas con axis más extendidos en dirección cráneocaudal, con procesos articulares craneales redondeados y ampliamente distanciados de los procesos articulares caudales, y procesos transversos alargados, y escotaduras craneales profundas y marcadamente encerradas, correspondiendo la morfología contraria en valores negativos del eje (Fig. 3.3, Apéndice 3.10).

$\mathrm{Al}$ analizar estadísticamente la influencia del factor dieta sobre la forma, ni el supuesto de homocedasticidad (estadístico de del test de Levene $=2,846 ; \mathrm{p}=0,102$ ), ni el de distribución normal de los residuos (estadístico de test de Shapiro-Wilk $=0,962 ; \mathrm{p}=0,320$ ) fueron rechazados. El ANOVA indicó que los cambios de forma del extremo distal del axis resumidos en el PC1 se encontraron significativamente afectados por el factor dieta $(F=8,302 ; p=0,007$; Apéndice 3.8A1).

Sobre el PC1, las especies carnívoras tendieron a posicionarse sobre valores positivos, siendo Mustela spp. y algunos guloninos los casos extremos, y las especies omnívoras sobre valores negativos, siendo Enhydra lutris y los mefítidos (Conepatus chinga, Spilogale gracilis) los casos extremos; pero existe una zona de superposición entre los dos grupos en cercanía al cero donde se solaparon algunos lutrinos e ictoniquinos carnívoros (pero poco especializados en este aspecto) con algunos prociónidos omnívoros. A su vez, los omnívoros melinos (Meles anakuma, Me. meles) se ubicaron en valores positivos típicos de especies carnívoras, y el tejón carnívoro Taxidea taxus se ubica en valores negativos típicos de especies omnívoras. A excepción de los lutrinos y prociónidos, la distribución de los grupos filogenéticos mejor representados evidenció una fuerte estructura filogenética: los mefítidos obtuvieron valores extremos negativos, los ictoniquinos valores positivos y cercanos a cero, mientras que guloninos, mustelinos y melinos se ubicaron en todos los casos en valores positivos elevados.

Lyncodon patagonicus, Lontra felina, Lo. provocax y Lo. longicaudis se ubicaron cercanos y superiores al cero, dentro de la zona de transición entre formas carnívoras y omnívoras, con formas de axis generalizadas, similares a las presentes en otros lutrinos, ictoniquininos, y algunos prociónidos, incluyendo al frugívoro Potos flavus. Las especies de Galictis, Pteronura brasiliensis, Eira barbara y $M u$. frenata se ubicaron en valores progresivamente crecientes del $\mathrm{PC} 1$, en una zona ocupada por la mayoría de las especies 
carnívoras (incluyendo guloninos, mustelinos, otros lutrinos), y también por los melinos (Fig. $3.3)$.

Al realizarse el ANCOVA del factor dieta con control filogenético, incluyendo al tamaño como covariable, la variable dieta tuvo una relación significativa con la forma del axis $(\mathrm{F}=16,92 ; \mathrm{p}=0,010)$, mientras que esto no ocurrió para la covariable $(\mathrm{F}=2,80 ; \mathrm{p}=0,156$; Apéndice 3.9A1). Un resultado similar se obtuvo al retirar la covariable y re-analizar los datos axis $(\mathrm{F}=18,19 ; \mathrm{p}=0,006$; Apéndice 3.9A2).

En el análisis de locomoción, el PC1 explicó el 54,66\% de la varianza de forma del total de la muestra y el $84,09 \%$ de la separación entre grupos locomotores, mientras que el PC2 explicó el $16,82 \%$ de la varianza de la forma del total de la muestra y el $11,38 \%$ de la separación entre grupos locomotores. Los cambios de formas observados en el PC1 son los mismos que los presentes en PC1 del análisis de categorías dietarias, mientras que en valores positivos del PC2 se ubicaron las formas con axis elongado cráneocaudalmente, extremo caudal del proceso espinoso, robusto y expandido caudodorsalmente, transverso elongado y proceso dorsal de la articulación caudal expandido caudalmente, correspondiendo la morfología contraria en valores negativos del eje (Fig. 3.4).

Al analizar estadísticamente la influencia del factor locomoción sobre la forma, el supuesto de homocedasticidad (test de Levene; PC1: F = 2,165; $\mathrm{p}=0,115 ; \mathrm{PC} 2: \mathrm{F}=0,624 ; \mathrm{p}=$ $0,605)$ no fue rechazado, pero si el supuesto de distribución normal de los residuos (estadístico de test de Shapiro-Wilk $=0,897 ; \mathrm{p}<0,001)$, por lo cual el resultado no es confiable. El MANOVA indicó que los cambios de forma del axis en el PC1 y PC2 se encontraron significativamente afectados por el factor locomoción $(F=7,570 ; p<0,001$; Apéndice 3.8A2).

La separación en el morfo-espacio del grupo locomotor nadador respecto a los restantes fue total, ubicándose sus representantes en valores positivos del PC2. Trepadores y cavadores mostraron una superposición prácticamente total de sus rangos de distribución, dada mayormente sobre valores centrales y negativos del PC2, aunque los mefítidos se diferenciaron por presentar valores extremos negativos para ambos ejes. Todos los representantes del grupo half-bounder mostraron una diferenciación gradual de estos últimos y segregando hacia valores positivos del PC1 y negativos del PC2, encontrándose Lyncodon patagonicus en la región de transición (Fig. 3.4). Los test a posteriori permitieron reconocer diferencias significativas entre los pares: cavadores y half-bounders se diferenciaron significativamente sobre el PC1, mientras que nadadores y half-bounders que se diferenciaron en forma marginalmente no significativa sobre este eje. Sobre el PC2, los nadadores se diferenciaron de los half-bounders, trepadores y de los cavadores. Trepadores y cavadores, y trepadores y half-bounders no se diferenciaron significativamente en ninguno de los ejes (Apéndice 3.8A2). 
Al igual que ocurrió para el análisis de dieta, la distribución de las especies en el morfoespacio se encontró estructurada por filogenia: la mayoría de los grupos filogenéticos bien representados presentaron una distribución de valores acotada (excepto prociónidos), generalmente a áreas relativamente pequeñas (pero ver lutrinos). Lutrinos y mefítidos presentaron áreas de distribución exclusivas (i.e., no invadidas por representantes de otros grupos), los prociónidos mostraron una distribución amplia, principalmente extendida sobre valores negativos del PC2, cuyo centro de distribución se ubicó en una posición intermedia entre mefítidos (y el taxidino) y la mayoría de los mustélidos. Melinos, guloninos y mustelinos se solaparon en valores positivos del PC1 y centrales y negativos del PC2, mientras que los ictoniquinos tuvieron una distribución disyunta entre este sector (Galictis sp., Vormela peregusna) y la región ocupada por prociónidos (Ly. patagonicus, Ictonyx striatus, Poecilictis libyca) (Fig. 3.4).

Eira barbara se ubicó en valores positivos del PC1 y cercanos a cero del PC2, próximo a otros guloninos y $\mathrm{Ba}$. astutus, y alejado de otras especies trepadoras no mustélidas (i.e., prociónidos). Las especies de Lontra se ubicaron en la región media de la zona de distribución de las nutrias, en cercanías a Aonyx cinerea, mientras que Pteronura brasiliensis se ubicó en conjunto con Lutra lutra el extremo positivo del PC1 de la distribución del grupo. Galictis spp. y $M u$. frenata se ubicaron en cercanía del otros half-bounders en valores positivos del PC1, mientras que Ly. patagonicus se encontró en una posición alejada de esta posición, en cercanías a prociónidos, e ictoniquininos pequeños (Poecilictis libyca) u omnívoros (I. striatus) (Fig. 3.4).

Al realizarse el MANCOVA del factor locomoción con control filogenético, incluyendo al tamaño como covariable, tanto la variable locomoción $(\mathrm{F}=3,14 ; \mathrm{p}=0,192)$, como la covariable $(\mathrm{F}=0,62 ; \mathrm{p}=0,192)$, tuvieron una relación no significativa con la forma del axis (Apéndice 3.9A3); y un resultado similar se obtuvo al retirar a la covariable del análisis $(\mathrm{F}=$ 4,09; $\mathrm{p}=0,107$; Apéndice 3.9A4).

\subsubsection{Vista dorsal de penúltima vértebra lumbar (DPLu)}

En el análisis de locomoción, el PC1 explicó el 46,11\% de la varianza de forma del total de la muestra y el $70,43 \%$ de la separación entre grupos locomotores, mientras que el PC2 explicó el 22,82\% de la varianza de la forma del total de la muestra y el 22,28\% de la separación entre grupos locomotores. En valores positivos del PC1 se ubicaron las formas con vértebras lumbares relativamente comprimidas en sentido cráneocaudal, regiones articulares relativamente expandidas, y procesos espinosos y transversos perpendiculares al eje vertebral (o incluso retrasados para el caso de los procesos espinosos), correspondiendo la morfología contraria en valores negativos del eje. En valores positivos del PC2 se ubicaron las formas con vértebras lumbares relativamente comprimidas en sentido cráneocaudal, procesos espinosos 
adelantados y robustos, procesos accesorios proyectados caudalmente, y procesos transversos relativamente amplios y perpendiculares, correspondiendo la morfología contraria en valores negativos del eje (Fig. 3.5, Apéndice 3.11).

Al analizar estadísticamente la influencia del factor locomoción sobre la forma, los supuestos de homocedasticidad (test de Levene; PC1: $F=0,903 ; p=0,460 ; P C 2: F=1,354 ; p=$ 0,290) y de distribución normal de los residuos (estadístico de test de Shapiro-Wilk $=0,986 ; \mathrm{p}$ $=0,874)$ no fueron rechazados. El MANOVA indicó que los cambios de forma de la penúltima vértebra lumbar en el PC1 y PC2 se encontraron significativamente afectados por el factor locomoción $(\mathrm{F}=5,164 ; \mathrm{p}<0,001 ;$ Apéndice 3.8B1).

La separación de los grupos locomotores fue prácticamente total, excepto por la ubicación del trepador Eira barbara, encontrándose esta especie alejada de los restantes trepadores (i.e., prociónidos), ubicada en una región transicional entre cavadores y halfbounder; y por una región de solapamiento entre trepadores y nadadores (Pteronura brasiliensis). Los half-bounders se ubicaron exclusivamente en el tercer cuadrante, excepto por Bassariscus astutus y Martes pennanti (half-bounders con habilidades de trepado), los cavadores exclusivamente en valores positivos del PC1, y los nadadores y trepadores (excepto Ei. barbara) en valores centrales o positivos del PC2, siendo más extremos los valores del segundo grupo para todos los casos (Fig. 3.5). Los test a posteriori permitieron reconocer diferencias significativas entre los pares: cavadores y half-bounders, nadadores y cavadores, así como trepadores y cavadores sobre el PC1. Sobre el PC2, ningún grupo locomotor se diferenció significativamente de otro (Apéndice 3.8B1).

La distribución de las especies en el morfoespacio se encontró fuertemente estructurada por filogenia, incluso en mayor grado que en el análisis del axis: la mayoría de los clados presentaron una distribución de valores acotada generalmente a áreas relativamente pequeñas y sin superposición con otros grupos (aunque la escasa representación de los grupos en este análisis favorece esto último, ver discusión), excepto por los guloninos, que presentan una distribución disyunta. Los lutrinos se ubicaron en valores centrales y positivos del PC2, mientras que los prociónidos se ubicaron en valores extremos positivos del PC2, destacándose estos últimos en mayor grado que los primeros por la marcada extensión y posición más perpendicular de los procesos transversos, robustecimiento y adelantamiento del proceso espinoso, y gran desarrollo de procesos accesorios. Mustelinos e ictoniquinos se ubicaron exclusivamente sobre el tercer cuadrante, siendo más extremos los valores para los primeros y Ly. patagonicus, poseyendo estas especies vértebras lumbares marcadamente alargadas cráneocaudalmente y procesos espinosos y transversos inclinando y extendidos en dirección craneal. Eira barbara (gulonino) y Meles meles (melino), se ubicaron en cercanías al centro de distribución, pero sobre valores negativos del PC2, mientras que Martes pennanti, el restante 
gulonino incluido, se ubicó en valores extremos negativos del PC1. Los mefítidos y Taxidea taxus (taxidino) se ubicaron exclusivamente sobre valores extremo positivos del PC1, con regiones articulares muy desarrolladas y procesos de inserciones musculares moderados a reducidos y perpendiculares (Fig. 3.5).

Los lutrinos sudamericanos representaron la mayor parte de los lutrinos de la muestra y se ubicaron entre los prociónidos y mustélidos, con procesos espinosos robustos y procesos transversos amplios respecto a otros mustélidos. Lyncodon patagonicus se ubicó en valores extremos negativos de ambos ejes similar a mustelinos, especialmente similar a Mustela cf. nivalis, con vértebras lumbares marcadamente elongadas cráneocaudalmente y angostas, y procesos espinosos y transversos delgados e inclinados cranealmente, alejándose de las especies half-bounders más generalizadas y similares a la forma consenso como Galictis spp. Mustela frenata, se ubicó en cercanías a otros mustelinos grandes en valores extremos negativos del PC1 y del PC2. Eira barbara, se ubicó más cercanamente de Galictis spp. y Meles meles que de otros guloninos o trepadores (prociónidos), con una morfología vertebral mucho más alargada cráneocaudalmente, proceso espinoso más vertical y grácil, y con procesos transversos marcadamente inclinados cranealmente y procesos accesorios reducidos en comparación con estos últimos (Fig. 3.5).

Al realizarse el MANCOVA del factor locomoción con control filogenético, incluyendo al tamaño como covariable, tanto la variable locomoción $(F=1,35 ; p=0,535)$ como la covariable $(\mathrm{F}=0,99 ; \mathrm{p}=0,491)$ tuvieron una relación no significativa con la forma del la penúltima vértebra lumbar (Apéndice 3.9B1), y un resultado similar se obtuvo al eliminar a la covariable y repetir el análisis $(\mathrm{F}=1,28 ; \mathrm{p}=0,461$; Apéndice 3.9B2).

\subsubsection{Vista craneal del extremo distal del húmero (AHu)}

En el análisis de dieta, el primer eje de componentes principales (PC1) explicó el $49,79 \%$ de la varianza de forma de la muestra y el 100\% de la separación entre carnívoros y omnívoros-no carnívoros. En valores positivos del PC1 se ubicaron las formas de cresta del epicóndilo lateral más amplias (especialmente extensas en sentido proximodistal), regiones articulares breves en sentido próximodistal y extensas en sentido lateromedial, correspondiendo la morfología contraria en valores negativos del eje (Fig. 3.6, Apéndice 3.12).

Al analizar estadísticamente la influencia del factor dieta sobre la forma, el supuesto de homocedasticidad (estadístico de test de Levene $=0,944 ; \mathrm{p}=0,337$ ) no fue rechazado, pero si el supuesto de distribución normal de los residuos (estadístico de test de Shapiro-Wilk $=0$, 9427; $\mathrm{p}=0,030$ ), por lo cual el resultado no es confiable. El ANOVA indicó que los cambios de forma del extremo distal del húmero resumidos en el PC1 se encontraron significativamente afectados por el factor dieta $(\mathrm{F}=29,06 ; \mathrm{p}<0,001$; Apéndice 3.8C1). 
Sobre el PC1, las especies carnívoras tendieron a posicionarse sobre valores negativos, y las especies omnívoras valores positivos. Todas las especies con valores inferiores a 0,0025 fueron carnívoras excepto por Mellivora capensis y Melogale orientalis, mientras que todas las especies de valores mayores a este umbral son omnívoras excepto por los guloninos Eira barbara y Gulo gulo (Fig. 3.6). La mayoría de los grupos filogenéticos bien representados se distribuyeron en un rango extenso de valores a lo largo del eje, aunque los mustélidos tienden a posicionarse en valores centrales (e.g., lutrinos) y negativos (e.g., mustelinos e ictoniquinos), y los musteloideos no mustélidos sobre valores positivos. Más allá de esta tendencia general, el prociónido Bassariscus astutus se ubicó sobre valores negativos, mientras que los helictidinos, melinos y algunos ictoniquinos y guloninos se ubicaron sobre valores positivos.

Lyncodon patagonicus se ubicó en valores extremos negativos, en cercanía a Mustela cf. nivalis, y Lontra felina. Lo. provocax, Pteronura brasiliensis y Lo. longicaudis, también se ubicaron en valores negativos pero más cercanos al centroide de la distribución, y con valores muy similares a los de Lo. canadensis y Lu. lutra. Mustela frenata presentó una posición en el morfoespacio cercana a estos lutrinos y similar a $M u$. nigripes, los cuales en conjunto con $M u$. putorius son las especies con crestas del epicóndilo medial más desarrolladas. Las especies de Galictis se ubicaron en conjunto, con una morfología muy similar a la de Vormela peregusna, y algunos lutrinos y guloninos, presentando los valores de PC1 más elevados respecto a otros ictoniquinos excepto por Ictonyx striatus (Fig. 3.6).

Al realizarse el ANCOVA del factor dieta con control filogenético, incluyendo al tamaño como covariable, tanto el factor $(F=0,054 ; p=0,824)$ como la covariable $(F=0,562 ; p$ $=0,484)$ tuvieron una relación no significativa con la forma del extremo distal del húmero (Apéndice 3.9C1). Al re-analizar los resultados retirando la covariable el resultado fue similar $(\mathrm{F}=0,27 ; \mathrm{p}=0,618 ;$ Apéndice 3.9C2).

En el análisis de locomoción, el PC1 explicó el 49,79\% de la varianza de forma del total de la muestra y el $73,51 \%$ de la separación entre grupos locomotores, mientras que el PC2 explicó el $14,42 \%$ de la varianza de la forma del total de la muestra y el $21,86 \%$ de la separación entre grupos locomotores. Los cambios de formas observados en el PC1 son los mismos que los presentes en PC1 del análisis de categorías dietarias, mientras que en valores positivos del PC2 se ubicaron las formas con crestas del epicóndilo lateral marcadamente comprimidas lateromedialmente, tróclea amplia lateromedial y proximodistalmente, y epicóndilo medial más extendido en dirección distal que medialmente, correspondiendo la morfología contraria en valores negativos del eje (Fig. 3.7).

Al evaluar estadísticamente la influencia del factor locomoción sobre la forma, el supuesto de homocedasticidad (test de Levene; PC1: F = 0,937; $\mathrm{p}=0,432 ; \mathrm{PC} 2: \mathrm{F}=0,405 ; \mathrm{p}=$ 0,750 ) no fue rechazado, pero sí el supuesto de distribución normal de los residuos (estadístico 
de test de Shapiro-Wilk $=0,936 ; \mathrm{p}<0,001)$, por lo cual el resultado no es confiable. El MANOVA indicó que los cambios de forma del extremo distal del húmero resumidos en el PC1 y PC2 se encontraron significativamente afectados por el factor locomoción $(\mathrm{F}=22,015$; $\mathrm{p}<$ 0,001; Apéndice 3.8C2).

La separación en el morfoespacio de los grupos locomotores nadador, half-bounder y trepador fue total, mientras que los representantes del grupo cavador se ubicaron principalmente en la región central del morfoespacio, superponiendo su distribución a la del grupo half-bounder y principalmente trepador (Fig. 3.7). Los test a posteriori permitieron reconocer diferencias significativas entre los pares: nadadores y cavadores, nadadores y trepadores, trepadores y halfbounders, y cavadores y half-bounders para ambos PCs. Por otro lado, en el PC2, se encontraron diferencias significativas entre half-bounders y nadadores. Trepadores y cavadores no se diferenciaron significativamente en ninguno de los dos ejes (Apéndice 3.8C2).

La mayoría de los grupos filogenéticos bien representados presentaron una distribución de valores relativamente amplia, aunque la distribución del total de los lutrinos puede circunscribirse a un sector del morfoespacio exclusivo para el grupo, en el tercer cuadrante e inmediaciones. El área de distribución de los half-bounders sólo fue invadida por Poecilictis libyca y Melogale orientalis. Por otro lado, el total de la distribución de los musteloideos no mustélidos (i.e., mefítidos, prociónidos y ailúridos), exceptuando el half-bounder Bassariscus astutus, se restringieron a un área ubicada sobre valores positivos del PC1 y cercanos a cero del PC2, aunque esta región es invadida marginalmente por algunos de los mustélidos cavadores y trepadores más especializados.

Los lutrinos sudamericanos presentaron una morfología del extremo distal del húmero similar a la de otros lutrinos, aunque tendieron a poseer crestas del epicóndilo lateral más breves y regiones articulares más desarrolladas, siendo Lo. felina el caso más extremo.

La posición de Lyncodon patagonicus nuevamente indicó una morfología extrema, con rasgos half-bounders exacerbados (e.g., máxima reducción de la cresta del epicóndilo lateral), similares a los presentes en Mustela cf. nivalis. Las especies de Galictis y Mu. frenata se ubicaron sobre valores positivos del PC2 y cercanos a cero del PC1, en la zona típica de distribución de los half-bounders. Eira barbara fue el mustélido con mayores valores del PC1, y por ende, el máximo desarrollo próximodistal de la cresta del epicóndilo lateral, en conjunto con una marcada elongación en sentido lateromedial del extremo distal del húmero. En conjunto con Gulo gulo y algunos mustélidos cavadores (e.g., melinos) se ubicaron en la región transicional entre mustélidos-no mustélidos mencionada (Fig. 3.7).

Al realizarse el MANCOVA del factor locomoción con control filogenético, incluyendo al tamaño como covariable, tanto el factor $(F=0,81 ; p=0,556)$, como la covariable $(F=2,25 ; p$ $=0,216)$, tuvieron una relación no significativa con la forma del extremo distal del húmero 
(Apéndice 3.9C3), y el resultado fue similar luego de retirar la covariable $(\mathrm{F}=0,61 ; \mathrm{p}=0,916$; Apéndice 3.9C4).

\subsubsection{Vista caudal del extremo proximal del fémur (PFe)}

En el análisis de locomoción, el PC1 explicó el 27,82\% de la varianza de forma del total de la muestra y el 57,40\% de la separación entre grupos locomotores, mientras que el PC2 explicó el 18,52\% de la varianza de la forma del total de la muestra y el 35,78\% de la separación entre grupos locomotores. En dirección a los valores positivos del PC1 se ubicaron las formas de fémures con procesos de inserciones musculares más delgados y reducidos respecto a la región articular, el trocánter mayor delgado e inclinado medialmente, fosa trocantérica reducida, el trocánter menor reducido e inclinado caudalmente, cuello femoral alargado y la cabeza articular globosa, correspondiendo la morfología contraria en valores negativos del eje, incluyendo una morfología hemi-esférica de la región articular y procesos de inserción muscular amplios, superando el trocánter mayor la altura de la región articular. En valores positivos del PC2 se ubicaron las formas de fémures con trocánter mayor expandido e inclinado en dirección lateral, distanciándose su extremo dorsal de la región articular, base del trocánter mayor (o tercer trocánter) reducido en su proyección lateral y con la apertura de la fosa trocantérica orientada en sentido caudal, adelgazándose la extensión lateromedial de su margen lateral (Fig. 3.8, Apéndice 3.13).

Al analizar estadísticamente la influencia del factor locomoción sobre la forma, el supuesto de homocedasticidad (test de Levene, PC1: $\mathrm{F}=1,881 ; \mathrm{p}=0,152 ; \mathrm{PC} 2: \mathrm{F}=1,396 ; \mathrm{p}=$ 0,261 ) y de distribución normal de los residuos (estadístico de test de Shapiro-Wilk = 0, 980; $\mathrm{p}$ = 0,276), no fueron rechazados. El MANOVA indicó que los cambios de forma del extremo proximal del fémur resumidos en el PC1 y PC2 se encontraron significativamente afectados por el factor locomoción ( $\mathrm{F}=24,491 ; \mathrm{p}<0,001$; Apéndice 3.8D1).

La separación de los grupos locomotores fue prácticamente total, radiando cada nube desde el centro de la distribución hacia regiones exclusivas de cada grupo en cada uno de los extremos de cada eje (i.e., half-bounder en valores positivos del PC1, nadadores en valores positivos del PC2, trepadores en valores negativos del PC1, y cavadores en valores negativos del PC2), con una región transicional central. La excepción más marcada a este patrón fue una región de solapamiento o transición entre cavadores y trepadores, debido mayormente a la ubicación del cavador Conepatus chinga en valores negativos medios del PC1. Los test $a$ posteriori permitieron reconocer diferencias significativas entre half-bounders y cada uno de los demás grupos locomotores, para ambos ejes (excepto entre half-bounders y trepadores en el PC2), y entre trepadores y cavadores en el PC1. Por otro lado, se registraron diferencias 
significativas entre nadadores y cada uno de los demás grupos locomotores en el PC2 (Apéndice $3.8 \mathrm{D} 2)$.

La distribución de las especies en el morfoespacio se encontró estructurada por filogenia: la mayoría de los grupos filogenéticos presentaron una distribución de valores acotada generalmente a áreas relativamente pequeñas. Los lutrinos se ubicaron en valores positivos del PC2 y centrales o negativos del PC1, los mefítidos y prociónidos en valores negativos del PC1 y centrales o negativos del PC2. Ictoniquinos y mustelinos se ubicaron en valores centrales y positivos del PC1 (más extremos en el segundo grupo) y centrales del PC2 con procesos de agarre muscular reducidos y cabeza articular amplia, excepto por el caso de ictoniquininos y especialmente Ictonyx striatus (con valores marcadamente negativos del PC2), más similar a melinos y otros musteloideos. Melivorinos, taxidinos y helictidinos (representados por una especie cada uno), así como guloninos y melinos se ubicaron en valores centrales e intermedios entre musteloideos no mustélidos y otros mustélidos, posicionándose los guloninos más pequeños y half-bounders en valores típicos de mustelinos y lincodontininos (Fig. 3.8).

Las especies de Lontra sudamericanas se ubicaron en la región media de la distribución de los lutrinos, mientras que Pteronura brasiliensis presentó una posición extrema con un valor elevado del PC2 y desplazado hacia valores negativos respecto al PC1 (en relación a rasgos lutrinos exacerbados y un trocánter menor amplio y proyectado medialmente). Eira barbara, con valores negativos para ambos ejes pero cercanos a cero, se ubicó en la zona transicional entre trepadores y cavadores, y entre mustélidos y musteloideos no mustélidos. Los lincodontininos (distinto a lo observado para ictoniquininos) se ubicaron en valores positivos del PC1 y cercanos a cero del PC2, dentro de la región exclusivamente ocupada por halfbounders, compartida con guloninos y mustelinos, con una morfología menos extrema que estos últimos (incluyendo a Mu. frenata) (Fig. 3.8).

Al realizarse el MANCOVA del factor locomoción con control filogenético, incluyendo al tamaño como covariable, tanto la variable locomoción $(F=2,08 ; p=0,272)$, como la covariable $(\mathrm{F}=0,53 ; \mathrm{p}=0,517)$, tuvieron una relación no significativa con la forma del extremo proximal del fémur (Apéndice 3.9D1); un resultado similar se obtuvo al analizar nuevamente los datos sin incluir a la covariable $(\mathrm{F}=1,793 ; \mathrm{p}=0,282$; Apéndice 3.9D2). 


\section{Figuras de resultados de análisis de morfometría geométrica}

A
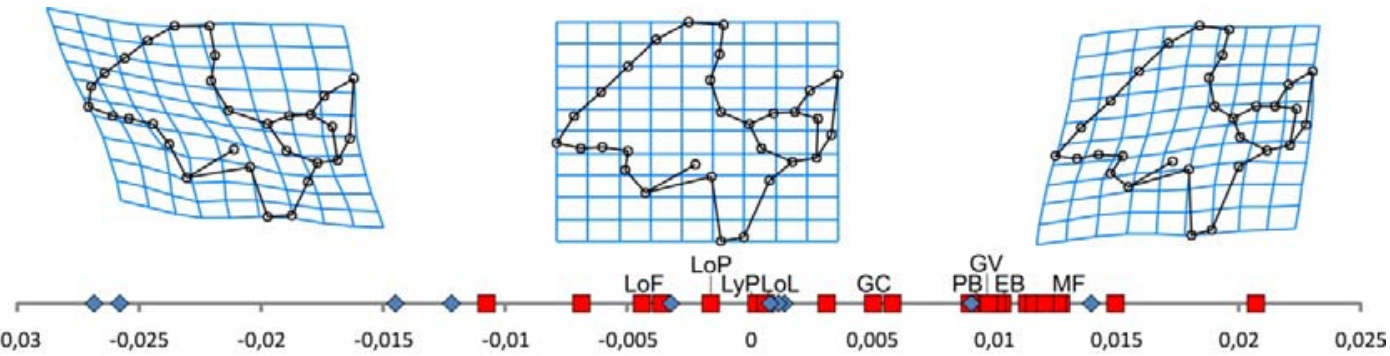

EJE 1

B

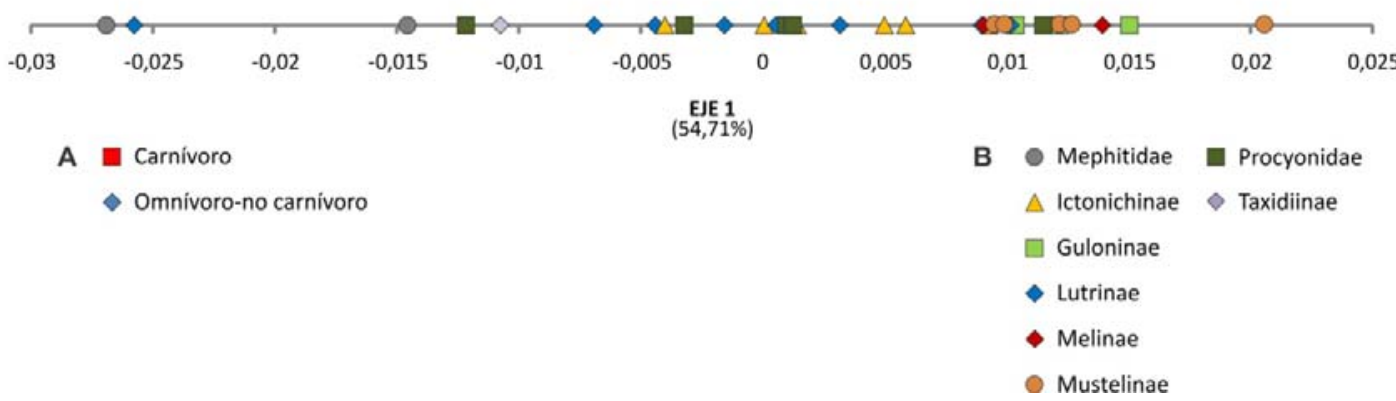

Figura 3.3. Análisis de morfometría geométrica de la vista lateral del axis. Primer componente principal de un PCA-group (análisis de componentes principales por grupo) utilizando a la dieta como variable clasificatoria. A- principales grupos dietarios, B- principales grupos filogenéticos (i.e., subfamilias mustélidas, familias no mustélidas; ver Koepfli et al. 2008, Sato et al. 2012). Las grillas de deformación indican la forma consenso y los extremos positivo y negativo del eje. Se indica la posición de las especies de mustélidos de América del Sur: $\mathrm{EB}=$ Eira barbara, $\mathrm{GC}=$ Galictis cuja, $\mathrm{GV}=$ Galictis vittata, $\mathrm{LoF}=$ Lontra felina, $\mathrm{LoL}=$ Lontra longicaudis, $\mathrm{LoP}=$ Lontra provocax, $\mathrm{LyP}=$ Lyncodon patagonicus, $\mathrm{MF}=$ Mustela frenata, $\mathrm{PB}=$ Pteronura brasiliensis. 

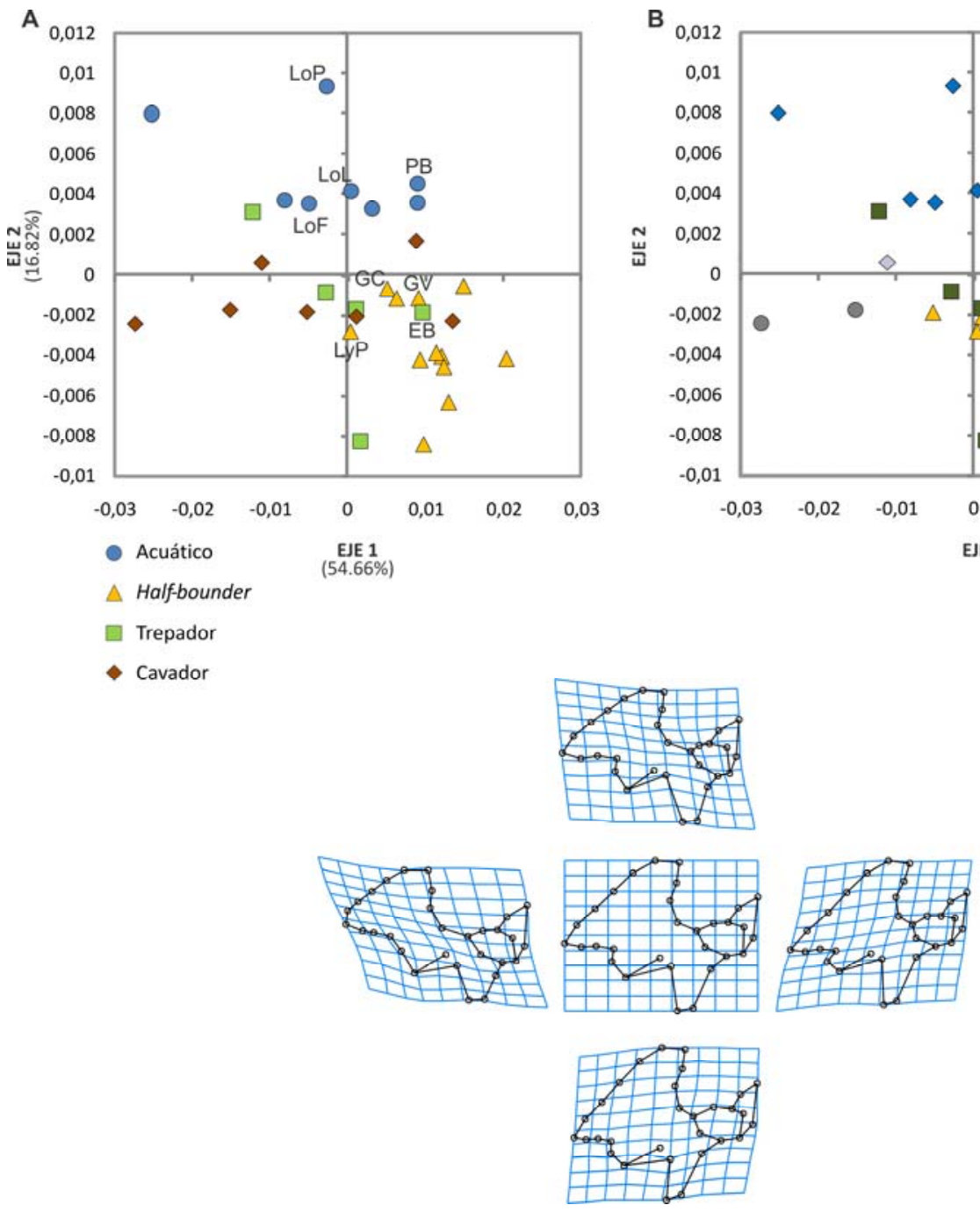

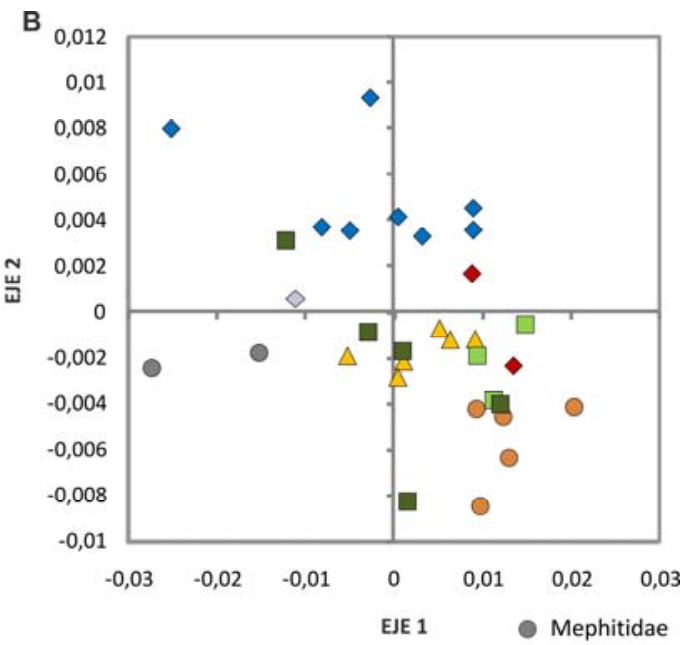

$\triangle$ Ictonichinae

- Guloninae

- Lutrinae

- Melinae

- Mustelinae

- Procyonidae

- Taxidiinae

Figura 3.4. Análisis de morfometría geométrica de la vista lateral del axis. Primer y segundo componentes principales de un PCA-group (análisis de componentes principales por grupo) utilizando a la locomoción como variable clasificatoria. A- principales grupos locomotores, B- principales grupos filogenéticos (i.e., subfamilias mustélidas, familias no mustélidas; ver Koepfli et al. 2008, Sato et al. 2012). Las grillas de deformación indican la forma consenso y los extremos positivo y negativo de cada eje. Se indica la posición de las especies de mustélidos de América del Sur: EB = Eira barbara, GC = Galictis cuja, $\mathrm{GV}=$ Galictis vittata, $\mathrm{LoF}=$ Lontra felina, $\mathrm{LoL}=$ Lontra longicaudis, $\mathrm{LoP}=$ Lontra provocax, $\mathrm{LyP}=$ Lyncodon patagonicus, $\mathrm{MF}=$ Mustela frenata, $\mathrm{PB}=$ Pteronura brasiliensis. 

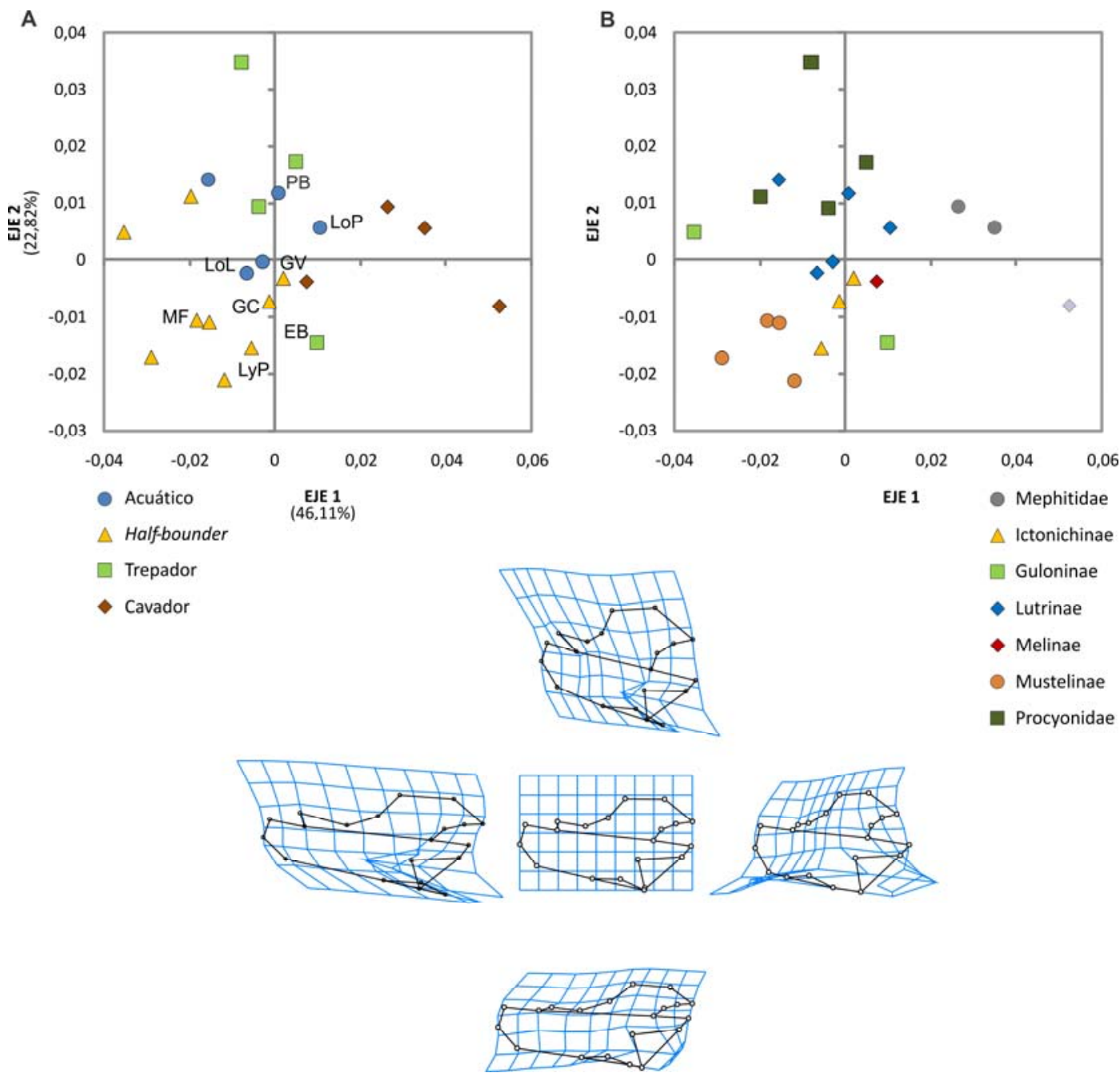

Figura 3.5. Análisis de morfometría geométrica de la vista dorsal de la penúltima vértebra lumbar. Primer y segundo componentes principales de un PCA-group (análisis de componentes principales por grupo) utilizando a la locomoción como variable clasificatoria. A- principales grupos locomotores, Bprincipales grupos filogenéticos (i.e., subfamilias mustélidas, familias no mustélidas; ver Koepfli et al. 2008, Sato et al. 2012). Las grillas de deformación indican la forma consenso y los extremos positivo y negativo de cada eje. Se indica la posición de las especies de mustélidos de América del Sur: EB = Eira barbara, $\mathrm{GC}=$ Galictis cuja, $\mathrm{GV}=$ Galictis vittata, $\mathrm{LoL}=$ Lontra longicaudis, $\mathrm{LoP}=$ Lontra provocax, $\mathrm{LyP}=$ Lyncodon patagonicus, $\mathrm{MF}=$ Mustela frenata, $\mathrm{PB}=$ Pteronura brasiliensis. 
A
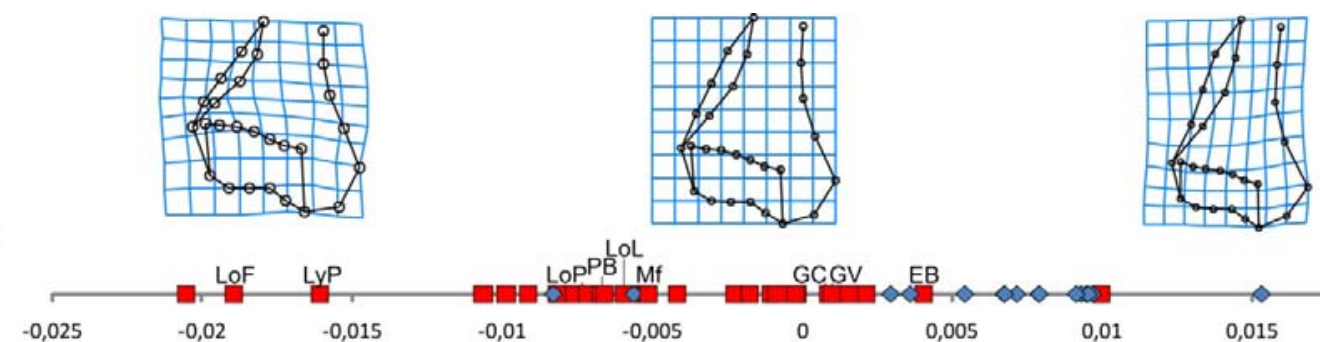

$-0,015$

$-0,01$
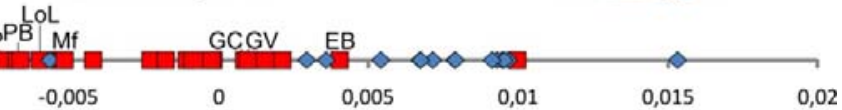

B

EJE 1

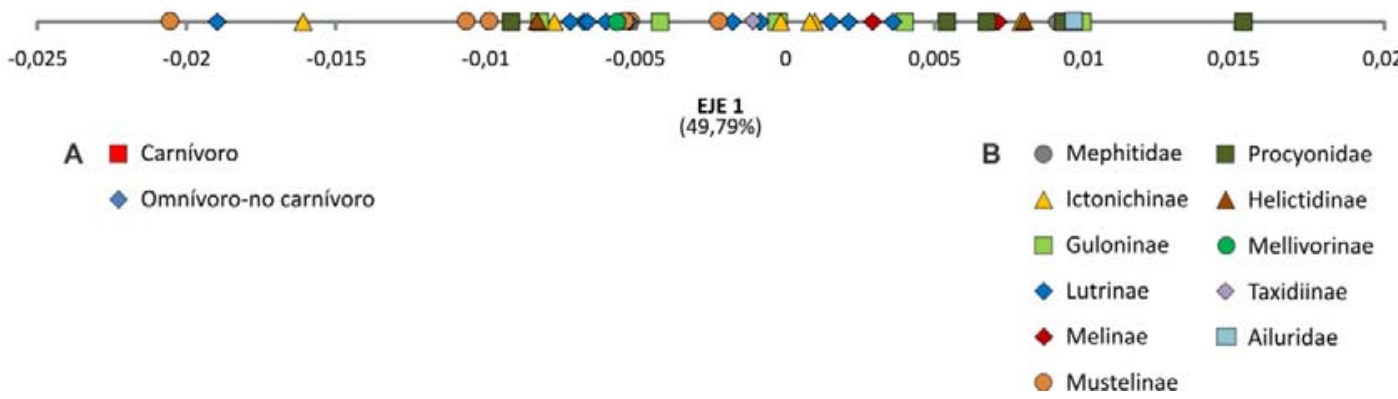

Figura 3.6. Análisis de morfometría geométrica de la vista craneal del extremo distal del húmero. Primer componente principal de un PCA-group (análisis de componentes principales por grupo) utilizando a la dieta como variable clasificatoria. A- principales grupos dietarios, B- principales grupos filogenéticos (i.e., subfamilias mustélidas, familias no mustélidas; ver Koepfli et al. 2008, Sato et al. 2012). Las grillas de deformación indican la forma consenso y los extremos positivo y negativo del eje. Se indica la posición de las especies de mustélidos de América del Sur: EB = Eira barbara, GC = Galictis cuja, GV = Galictis vittata, $\mathrm{LoF}=$ Lontra felina, $\mathrm{LoL}=$ Lontra longicaudis, $\mathrm{LoP}=$ Lontra provocax, $\mathrm{LyP}=$ Lyncodon patagonicus, $\mathrm{MF}=$ Mustela frenata, $\mathrm{PB}=$ Pteronura brasiliensis. 

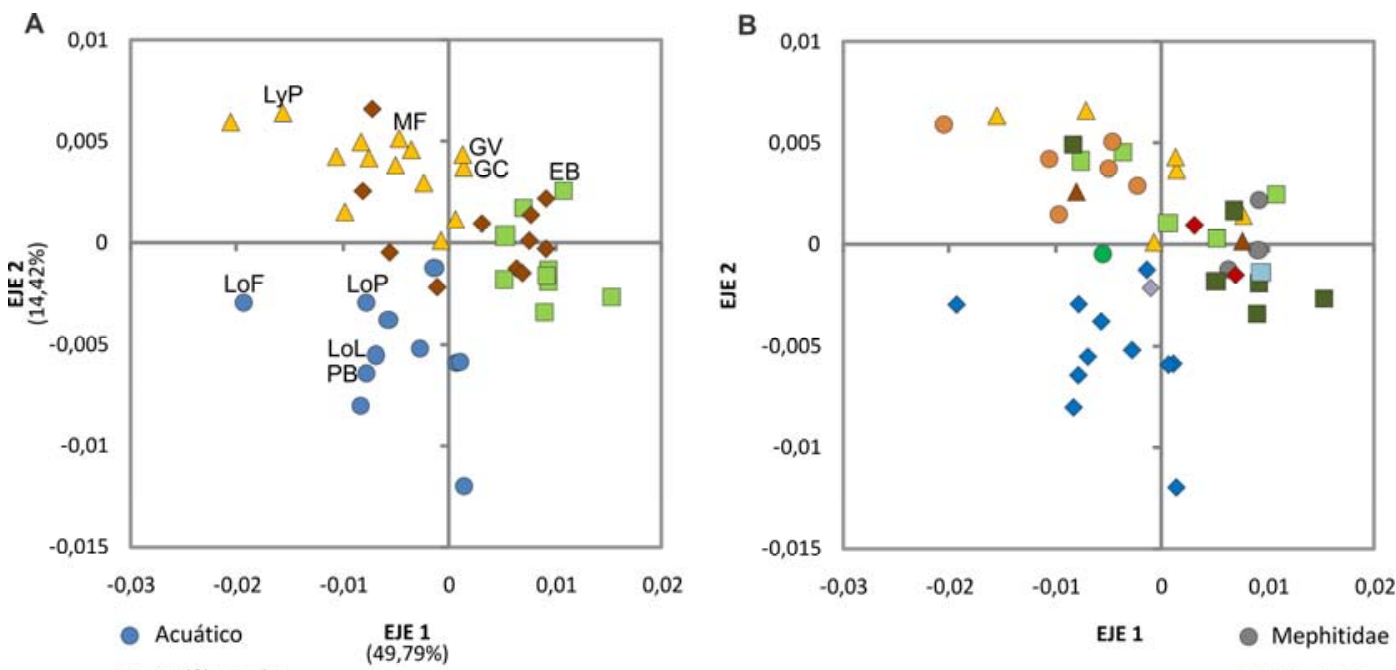
$\triangle$ Half-bounder
$\square$ Trepador

- Cavador

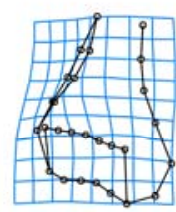

$\triangle$ Ictonichinae

Guloninae

- Lutrinae

- Melinae

- Mustelinae

Procyonidae
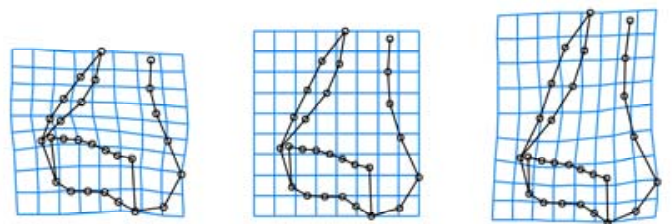

A Helictidinae

- Mellivorinae

$\diamond$ Taxidiinae

$\square$ Ailuridae

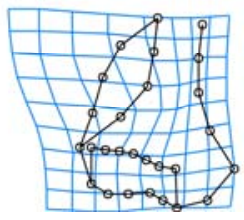

Figura 3.7. Análisis de morfometría geométrica de la vista craneal del extremo distal del húmero. Primer y segundo componentes principales de un PCA-group (análisis de componentes principales por grupo) utilizando a la locomoción como variable clasificatoria. A- principales grupos locomotores, B- principales grupos filogenéticos (i.e., subfamilias mustélidas, familias no mustélidas; ver Koepfli et al. 2008, Sato et al. 2012). Las grillas de deformación indican la forma consenso y los extremos positivo y negativo de cada eje. Se indica la posición de las especies de mustélidos de América del Sur: EB = Eira barbara, GC $=$ Galictis cuja, $\mathrm{GV}=$ Galictis vittata, $\mathrm{LoF}=$ Lontra felina, $\mathrm{LoL}=$ Lontra longicaudis, LoP $=$ Lontra provocax, $\mathrm{LyP}=$ Lyncodon patagonicus, $\mathrm{MF}=$ Mustela frenata, $\mathrm{PB}=$ Pteronura brasiliensis. 


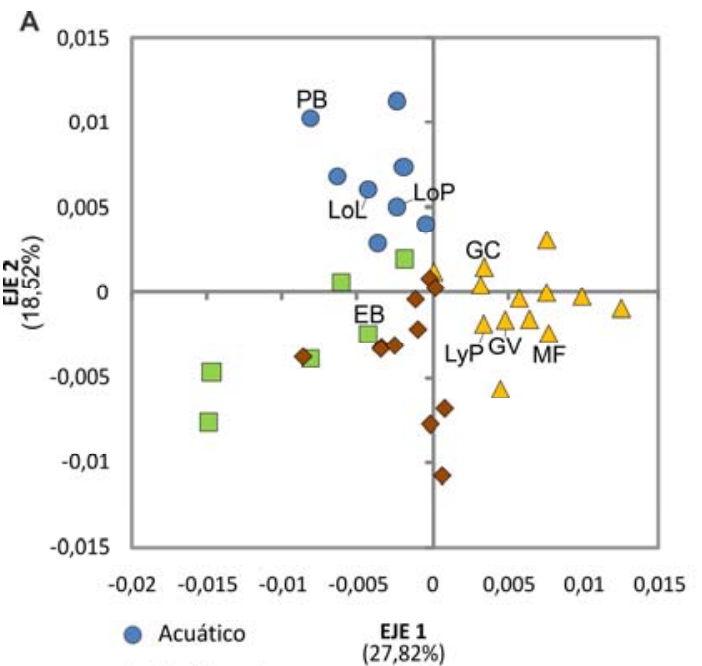

$\triangle$ Half-bounder

口 Trepador

- Cavador
B
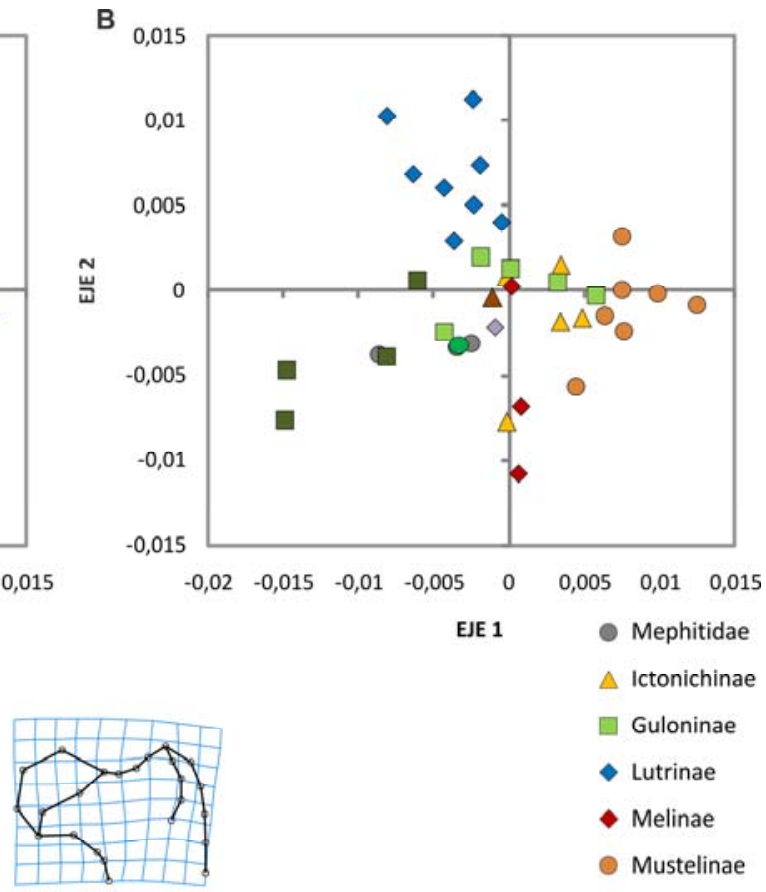

$\triangle$ Ictonichinae

$\square$ Guloninae

- Lutrinae

- Melinae

- Mustelinae

- Procyonidae

$\Delta$ Helictidinae

- Mellivorinae

$\diamond$ Taxidiinae

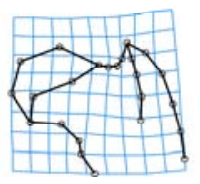

Figura 3.8. Análisis de morfometría geométrica de la vista caudal del extremo proximal del fémur. Primer y segundo componentes principales de un PCA-group (análisis de componentes principales por grupo) utilizando a la locomoción como variable clasificatoria. A- principales grupos locomotores, Bprincipales grupos filogenéticos (i.e., subfamilias mustélidas, familias no mustélidas; ver Koepfli et al. 2008, Sato et al. 2012). Las grillas de deformación indican la forma consenso y los extremos positivo y negativo de cada eje. Se indica la posición de las especies de mustélidos de América del Sur: EB = Eira barbara, $\mathrm{GC}=$ Galictis cuja, $\mathrm{GV}=$ Galictis vittata, $\mathrm{LoL}=$ Lontra longicaudis, $\mathrm{LoP}=$ Lontra provocax, $\mathrm{Ly} \mathrm{P}=$ Lyncodon patagonicus, $\mathrm{MF}=$ Mustela frenata, $\mathrm{PB}=$ Pteronura brasiliensis. 


\subsection{Resultados de optimizaciones}

\subsubsection{Optimizaciones de caracteres musculares}

En el Apéndice 3.14 se esquematizan las optimizaciones obtenidas para cada uno de los 47 caracteres miológicos analizados.

Los distintos caracteres musculares mostraron patrones de optimizaciones muy diferentes y muchas veces informativos a distintos niveles de la estructura filogenética considerada, los cuales son discutidos posteriormente (ver sección 4.1). Como ejemplo de estos casos, se reconstruyeron sinapomorfías para Arctoidea (cambios de estados de caracteres 12, 36), Ursidae (0, 15), Musteloidea (7, 10), Mephitidae (4, 12, 14, 34), Procyonidae (40), Procyonidae + Mustelidae + Ailurus (32), Procyonidae + Mustelidae (30, 33), Procyon (31), Mustelidae (0, 4, 12, 18), Mustelidae - Taxidea (6), Mustelidae - Taxidea - Meles (40), Guloninae $(14,15,17,19,40)$, Ictonychinae + Mustelinae + Lutrinae $(1,18,28)$, Ictonychinae + Lutrinae (12), Ictonychinae (31), Lutrinae $(9,11,13,27)$ y Lutrinae - Lontra (10, 27). Por otro lado, otros caracteres no mostraron una relación clara con la estructura filogenética, sino más bien variaciones recurrentes o autopomorfías propias de algunas terminales (caracteres 3, 8, 16, 20-25, 29, 35, 46).

Entre los rasgos más destacables reconstruidos para el nodo Mustelidae, se denota la adquisición de sistemas epiaxiales laterales parcial o totalmente independientes (c. 0 , estados 0 y 1), convergiendo con Canidae. Otra sinapomorfía de la familia, a su vez reconstruida como convergente a Mephitidae, es la presencia de un m. triceps brachii caput angulare (de origen óseo, c. 12, estados 2 y 3). Mustelidae - Taxidea comparten un m. rhomboideus capitis diferenciado y distanciado del m. rhomboideus cervicis (c. 6, estado 3), evidenciándose como una reversión a la condición plesiomórfica de Caniformia, mientras que una condición diferenciada pero continuada entre mm. rhomboideus (i.e., en contacto a lo largo de sus recorridos) se registra en prociónidos y mustélidos basales.

Para Guloninae se reconstruye la presencia de un $\mathrm{m}$. articularis humeri (c. 14, estado 1) como sinapomorfía del grupo y una reversión a la condición ancestral de Caniformia. Otra sinapomorfía de la subfamilia es la fusión de los orígenes del $\mathrm{m}$. pronator teres y el $\mathrm{m}$. flexor carpi radialis (c.19, estado 1; convergente a algunos arctoideos basales). Para el nodo Ictonychinae + Mustelinae + Lutrinae se destaca la adquisición de un rasgo único para Carnivora que es la presencia de un $\mathrm{m}$. iliocostalis dominante, o único componente de los sistemas epiaxiales (c. 1, estado 2); condición únicamente revertida en Enhydra lutris dentro del grupo. Dentro de este grupo Ictonychinae + Lutrinae presentan un $\mathrm{m}$. triceps brachii caput angulare como único extensor extrínseco del codo (c. 12, estado 3), siendo esta un sinapomorfía del grupo y un rasgo no presente en otros carnívoros. Lutrinae presenta un gran número de sinapomorfías en la musculatura de los miembros anteriores: los mm. pectorales revierten su 
configuración a la condición "cruzada" (ver c. 9, estado 3) y la presencia de un "pectoantebrachialis" (ver c. 11, estado 1), condiciones homólogas a las presentes en representantes de la base de Caniformia y algunos feliformes respectivamente. También existen modificaciones en los orígenes del $\mathrm{m}$. triceps brachii caput angulare (extendido sobre el $\mathrm{m}$. latissimus dorsi, c. 13, estado 1) y el m. brachioradialis (en una posición relativamente proximal; c. 27, estados 1 y 2) extienden sus orígenes; rasgos únicamente presentes en lutrinos dentro de Caniformia. Por último, la pérdida del m. gluteofemoralis (c. 31, estado 0) es una sinapomorfía de Ictonychinae y un rasgo observado en forma recurrente y convergente en múltiples linajes dentro de Carnivora (e.g., caniformes basales, Procyon, Taxidea, Melogale).

\subsubsection{Optimizaciones de caracteres óseos}

En el Apéndice 3.15 se esquematizan las optimizaciones obtenidas para cada uno de los 83 caracteres osteológicos analizados.

Así como ocurrió para los caracteres musculares, los distintos caracteres osteológicos mostraron patrones de optimizaciones muy diferentes y muchas veces informativos a distintos niveles de la estructura filogenética considerada, los cuales son discutidos posteriormente (ver sección 4.5). Como ejemplo de estos casos, se reconstruyeron sinapomorfías para Canidae (cambios de estados de caracteres 0, 27, 39, 70, 73, 76), Arctoidea (3, 4, 5, 15, 20, 21, 24, 35, 44, 66, 67, 72, 75, 79, 82), Musteloidea (33, 42, 64), Mephitidae (0, 9, 12, 13, 18, 30, 39, 51, 53, 55, 58?, 60, 62, 73?), Mephitidae - Mydaus (2, 4, 14), Procyonidae + Mustelidae + Ailurus (50), Procyonidae (19, 24, 43?, 59, 79?), Procyonidae - Potos (40, 75), Procyon (3, 4, 38, 44, 53, 72, 82), Mustelidae (4, 6?, 24?, 27, 63, 66), Mustelidae - Taxidea $(0,11,21)$, Mustelidae - Taxidea Meles (18, 22, 38, 49, 56, 57, 62?, 64?, 74?, 75), Guloninae (20?, 24, 42), Melogale + Ictonychinae + Mustelinae + Lutrinae (31, 47?, 61), Ictonychinae + Mustelinae + Lutrinae (3, 4, 50?, 55?, 73, 77?), Mustelinae (34, 65, 68, 72), Ictonychinae + Lutrinae (6?, 15, 27?), Ictonychinae (1, 10, 24?), Ictonychininae (11, 14?, 17, 19?, 20, 30, 58, 60, 73?, 74), Lyncodontininae (6?, 28, 65, 68, 72), Galictis (23, 26), Lutrinae (4, 12, 18, 20, 22?, 23, 24?, 26, 29, 32, 38, 44, 45?, 49, 58, 59, 60, 61, 66, 67, 69, 79), Lontra $(36,63,80)$ у Enhydra + Aonyx $(30,43,70)$. Por otro lado, otros caracteres no mostraron una relación clara con la estructura filogenética, sino más bien variaciones recurrentes o autopomorfías propias de algunas terminales (caracteres 25, 41, 46, 48, 76, 81).

Entre los cambios más destacables observados en los caracteres continuos, se optimizaron dos eventos de adquisición de un cuello marcadamente elongado, uno en la base de Canidae (c. 0, estado 0,406) y otro en Mustelidae-Taxidea (estado 0,293-0,305), condición revertida en algunos taxones mustélidos como Enhydra lutris, "Ictonyx" sp., y Aonyx sp. Tanto para el índice braquial (c. 3) como el crural (c. 4), la optimización sugirió una condición 
reducida de los zeugopodios en Arctoidea, y un gran número de variantes dentro del clado (e.g., exacerbada reducción del radio en Ictonychinae + Mustelinae + Lutrinae, exacerbada reducción de la tibia en Mustelidae, adquisición de un radio alargado convergentemente en Conepatus y Procyon, y una tibia alargada convergentemente en Mephitidae - Mydaus, Guloninae - Eira, Ictonychinae + Mustelinae + Lutrinae, Bassaricyon y Procyon).

Entre los principales cambios de estado obtenidos a partir de las optimizaciones de los caracteres osteológicos discretos del esqueleto axial, se destaca la reducción del ángulo caudomedial del ala del atlas la cual fue reconstruida como una adquisición en la base de Arctoidea (c. 5, estado 1; condición revertida en múltiples linajes musteloideos). La presencia de un foramen alar lateral fue reconstruida como una condición presente ya en el nodo Mustelidae y quizás incluso en el nodo Arctoidea (reconstrucción ambigua, c. 6, estado 1), y revertida en Lyncodontininae y Lutrinae (estado 0). La presencia de escotaduras dorsales caudales profundas en los arcos de las vértebras cervicales fue optimizada como una sinapomorfía de los lutrinos (c. 12, estado 0), convergentemente con mefítidos y algunos pocos taxones musteloideos (i.e., Meles meles, Nasua nasua). La presencia de un foramen transverso en la C7 fue optimizado como un rasgo sinapomórfico de Mephitidae (c. 13, estado 0). Una sinapomorfía de Mephitidae - Mydaus (c. 14, estado 2; ver también Mivart 1885, Slijper 1946, Narita y Kuratani 2005) fue una fórmula tóraco-lumbar de 21 elementos y un sacro compuesto de dos, mientras que algunos ictoniquinos alcanzan una configuración similar (19 o 20 tóracolumbares y dos sacros) de forma independiente (c. 14, estado 1). La posición de la vértebra diafragmática fue optimizada como progresivamente adelantada en los nodos más profundos de la topología, siendo la posición en la T12 una sinapomorfía de Lutrinae + Ictonychinae (c. 15, estado 2), la posición en la T11 una sinapomorfía de Arctoidea (c. 15, estado 1), y una posición en la T10 la condición plesiomórfica reconstruida para Caniformia (c. 15, estado 0). En el nodo Mustelidae - Taxidea - Meles se reconstruyó una reducción de los procesos mamilares y transversos preanticlinales (c. 18, estado 1), condición convergente a Mephitidae, y revertida sólo en Lutrinae dentro de los mustélidos. La adquisición de procesos accesorios bien desarrollados en las últimas lumbares (c. 19, estado 1) es una sinapomorfía de Procyonidae, desarrollada en forma convergente por ictoniquininos. La morfología de los procesos transversos lumbares y cuerpo de las vértebras lumbares presentaron un gran número de cambios asociados a la estructura filogenética, definiéndose sinapomorfías para Lutrinae (c. 20, estado 1), Ictonychininae (c. 20, estado 0), Mustelidae - Taxidea (c. 21, estado 0), Arctoidea (c. 20, estado 0 y c. 21, estado 1), y en forma ambigua para Guloninae y su grupo hermano (c. 20). Para Mustelidae excluyendo a las subfamilias Taxidiinae y Melinae (i.e., Mustelidae - Taxidea Meles), se reconstruyó presencia de un manubrio comprimido lateromedialmente y alargado como una sinapomorfía del grupo (c. 22, estado 1; contrastando con la condición plesiomórfica 
de Arctoidea, estado 0), posteriormente modificada en lutrinos (estado 2). La participación total de la segunda vértebra sacra en la articulación sacro-ilíaca fue reconstruida como una condición plesiomórfica de Arctoidea y Musteloidea, modificada a su vez en múltiples eventos dentro de estos clados (c. 24). La presencia de un gran número de vértebras caudales con procesos espinosos desarrollados sólo fue registrado como una autopomorfía de Potos flavus, una sinapomorfía del nodo Galictis (en 4 o 5 elementos caudales), y en un grado extremo (presente en más de 5 elementos) como una sinapomorfía de lutrinos (c. 26, estados 2 y 3 respectivamente). Procesos articulares de vértebras caudales bien desarrollados y cercanos al plano sagital (c. 27, estados 0), fueron reconstruidos como una plesiomorfía de Arctoidea, modificada en Canidae y Mustelidae en forma convergente (c. 27, estado 1), y revertida en algunos mustélidos derivados (posiblemente en el nodo Ictonychinae + Lutrinae; reconstrucción ambigua). Por otro lado, una sinapomorfía recuperada para Lyncodontini, y únicamente presente en representantes de esta tribu, fue la presencia arcos neurales socavados (c. 28, estado 1 y 2 ) en las primeras vértebras del sector transicional caudal. La morfología de procesos transversos en forma de "H" (c. 29, estado 1), obtenida como una sinapomorfía de lutrinos, se recuperó convergentemente en $\mathrm{Mu}$. vison, y en un grado menos definido está presente en otros mustélidos derivados (ver discusión).

Entre los cambios principales observados en los caracteres osteológicos discretos del miembro anterior, se destaca en la escápula la adquisición de una fosa supraespinosa mayor que la infraespinosa para el ancestro común de Melogale, hurones y nutrias, desarrollada convergentemente en algunos guloninos (e.g., Martes americana; c. 31, estado 2). Una sinapomorfía de Musteloidea fue la presencia de un proceso subhamatus bien desarrollado (c. 33, estados 1,2 y 3 ), de forma triangular en la base del grupo (estado 1) y modificado a un tipo flabeliforme en varios linajes independientemente (estados 2 y 3). Según la optimización, el ancestro común de los mustelinos adquirió, convergentemente a algunos ictoniquinos, un proceso supraglenoideo proyectado ventralmente (c. 34, estado 0). Los miembros del clado Lontra comparten un tubérculo menor del húmero inclinado proximalmente, siendo esta una sinapomorfía del grupo. Para Arctoidea se reconstruyó la presencia de una cresta del epicóndilo lateral expandida en sentido lateromedial (c. 38, estado 1), condición revertida en Mustelidae Taxidea - Meles y convergentemente en Spilogale y Procyon (c. 38, estado 0), y nuevamente recuperada la condición amplia en la base de Lutrinae. La ausencia de un foramen supracondiloideo fue reconstruida como una sinapomorfía de los clados Mephitidae y Canidae, siendo también observada esta condición en forma variable en algunos mustélidos derivados (e.g., Mustela frenata, Eira barbara; c. 39, estado 0). En la ulna, la simetría del proceso ancóneo fue variable en varios niveles jerárquicos dentro de Arctoidea: la condición asimétrica y plesiomórfica del grupo fue reconstruida como modificada a simétrica en la base de 
Musteloidea (c. 42, estado 0), para luego revertirse en el ancestro común de Guloninae (c. 42, estado 1). Los arctoideos presentaron una muesca del ligamento interóseo ubicada en el sector distal del tercio medio de la diáfisis ulnar (c. 44, estado 1), desplazada a una posición más proximal en Procyon y algunos especímenes de otras especies (en convergencia con carnívoros no arctoideos; c. 44, estado 0), y desplazada a una posición más distal en lutrinos (siendo una sinapomorfía del grupo; c. 44, estado 2). En el autopodio anterior, una extensión lateromedial del radial igual o mayor al doble del ulnar fue reconstruida como una sinapomorfía de Mustelidae - Taxidea - Meles (c.49, estado 0), revertida en Lutrinae (c. 49, estado 1). Un sesamoideo radial robusto (c.50, estado 1), fue optimizado como una sinapomorfía de Mustelidae + Procyonidae (Mustelidae + Procyonidae + Ailurus con la inclusión de Ailurus, resultado no mostrado), mientras que una morfología aplanada y alargada fue reconstruida como una posible sinapomorfía de Lutrinae + Ictonychinae + Mustelinae (reconstrucción ambigua, c. 50, estado 3). En lo que respecta al tubérculo radial, su hipertrofia (c. 51, estado 1) ocurrió múltiples veces en forma independiente en distintos linajes de carnívoros, mientras que la modificación a una morfología aplanada medialmente y con el surco para el $\mathrm{m}$. flexor carpi radialis fue reconstruida como una característica única y una sinapomorfía de mefítidos (c. 51, estado 2). Por último, un metacarpal III dominante fue adquirido de manera independiente múltiples veces dentro de Arctoidea (i.e., nodo Mephitidae, nodo Procyon, y terminales Taxidea, Melogale, Lyncodon; c. 53, estado 0), mientras que la condición plesiomórfica para el suborden fue un metacarpal IV similar o superior en longitud al III (c. 53, estado 1).

En lo que respecta al miembro posterior, dentro de los principales cambios observados en los caracteres osteológicos discretos se observó la presencia de un ilion alargado (c. 55, estado 0), desarrollado en forma convergente en mefítidos, algunos prociónidos, guloninos pequeños y aparentemente más de una vez dentro del clado Ictonychinae + Lutrinae + Mustelinae; mientras que un ilion aplanado (c. 56, estado 1) fue obtenido en forma convergente en algunos prociónidos (incluido Bassariscus astutus, ver discusión) y en Mustelidae - Taxidea - Meles (i.e., mustélidos excluyendo taxidinos y melinos) dentro de Arctoidea. Un perfil angosto de la superficie ventral del ilion (c. 57, estado 1), fue optimizado como adquirido una única vez dentro de Arctoidea, en el nodo Mustelidae - Taxidea - Meles. En lo que respecta a las proporciones del hueso coxal, una longitud del ilion mayor o igual al doble del cuerpo del isquion, presente en algunos arctoideos basales incluyendo los mefítidos, fue optimizada como una sinapomorfía desarrollada de manera convergente en ictoniquininos (c. 58, estado 0); mientras que la presencia de un cuerpo del isquion de longitud igual o prácticamente igual a la longitud del ilion (c. 58, estado 2), se recuperó como una sinapomorfía de Lutrinae. Un tubérculo isquiático reducido (c. 59, estado 0) resultó optimizado como una sinapomorfía de Procyonidae, convergentemente desarrollada en algunos mustélidos basales; mientras que por 
oposición, un tubérculo isquiático marcadamente sobresaliente y definido (acompañado de una tabla isquiática ampliamente ensanchada) resultó una sinapomorfía de Lutrinae (convergente a lo observado en Canis familiaris). Una sínfisis pélvica reducida sólo se encontró presente como una sinapomorfía convergente de grupos fosoriales como Mephitidae e Ictonychininae y una autopomorfía de Taxidea taxus (c. 60, estado 0), mientras que una sínfisis amplia, pero retrasada, fue una característica adquirida en la base de Lutrinae y no presente en otros carnívoros analizados, siendo una sinapomorfía no ambigua (c. 60, estado 2). La morfología de una cabeza femoral esférica, grande y de márgenes marcados es una adquisición de lutrinos, optimizada como convergente a la configuración de Meles (c. 61, estado 2), mientras que una cabeza femoral de similar morfología en conjunto con un cuello alargado medialmente ya habría estado presente desde el ancestro común de Melogale y hurones (c. 61, estado 1) y convergentemente en Spilogale gracilis y Martes americana. La inclinación medial del trocánter mayor fue obtenida dos veces en forma independiente dentro del clado Musteloidea, una en la base de Mephitidae y otra en el ancestro común de Melogale y hurones, o de martas y estos últimos (reconstrucción ambigua; c. 62, estado 0). Un trocánter mayor reducido, menor que la altura alcanzada por la cabeza articular (c. 63, estado 1) fue una sinapomorfía de Mustelidae, condición revertida en varios linajes mustélidos (c. 63, estado 0). La presencia de un tercer trocánter definido fue obtenida como una sinapomorfía de Musteloidea y retenida incluso en los mustélidos basales (Taxidea taxus y variable en Meles meles; c. 64, estado 2), mientras que en mustélidos más derivados se registró típicamente al mismo reemplazado por un cambio de pendiente (posible sinapomorfía de Mustelidae - Taxidea - Meles; reconstrucción ambigua, c. 64, estado 1; pero ver lutrinos y Ei. barbara). Un trocánter menor proyectado caudalmente fue optimizado como adquirido en forma independiente por el ancestro común de Lyncodontininae, Mustelinae y guloninos pequeños, como únicos eventos dentro de Arctoidea (c. 65, estado 0). El análisis de la morfología de la tróclea femoral evidenció cambios a distintos niveles: una tróclea somera y centrada (c. 66, estado 0) fue reconstruida como una sinapomorfía de Arctoidea, mientras que en la base de Mustelidae se estableció una tróclea profunda (c. 66, estado 1; condición revertida en algunos linajes); en el ancestro común de Lutrinae se registró una nueva modificación, desplazándose la tróclea a una posición medial en el ancestro común de Lutrinae (c. 66, estado 2). Un rasgo sinapomórfico de lutrinos, y únicamente presente en este grupo dentro de Arctoidea, es la presencia de una muesca de origen de la cabeza lateral del $\mathrm{m}$. gastrocnemius extendida a modo de una región rugosa y elevada sobre la diáfisis femoral, dorsal y lateral al epicóndilo lateral (c. 67, estado 1 y 2). En la tibia, la reducción del área intercondiloidea craneal fue una sinapomorfía de lutrinos, desarrollada independientemente en algunos taxones musteloideos como Potos flavus (c. 69, estado 0). Una sinuosidad marcada del margen caudal de la cóclea, fue reconstruida como convergentemente desarrollada en varios 
linajes de musteloideos (e.g., mustelinos, lincodontininos, Meles, Procyon; c. 72, estado 1), mientras que una sinuosidad suave fue la condición ancestral reconstruida para Arctoidea (c. 72, estado 0). La configuración particular del zeugopodio posterior de miembros del grupo Ictonychinae + Lutrinae + Mustelinae (sindesmosis reducida y curvatura de la diáfisis fibular divergente respecto a la curvatura de la tibia) fue reconstruida como una sinapomorfía del grupo (c. 73, estado 3), mientras que en cánidos, mefítidos e ictoniquininos, se desarrollan independientemente distintos estados de una unión distal extendida entre la fíbula y tibia (c. 73, estados 0 y 1). En el autopodio posterior, la morfología de la tróclea presenta una gran cantidad de variantes y casos de reversiones y convergencias. Una tróclea cuadrangular o extensa lateromedialmente y somera fue reconstruida como una sinapomorfía de Arctoidea (c. 75, estados 2 y 3), una tróclea profunda y extensa cráneocaudalmente fue optimizada como una adquisición de Procyonidae - Potos (c. 75, estado 0) y una tróclea similar pero menos profunda fue optimizada como una adquisición independiente en la base de Mustelidae - Taxidea - Meles (c. 75, estado 1; condición revertida en algunos linajes derivados). Es interesante destacar que en todos los especímenes analizados la faceta articular medial del astrágalo para el calcáneo se extiende proximalmente hasta una región deprimida o valle, excepto en variantes intraespecíficas observadas en cada una de las especies de mefítidos analizadas (c. 78, estados 0 y 1), aunque esta condición no fue recuperada como una sinapomorfía del grupo debido a su naturaleza variable. Por otro lado, la faceta articular medial se dirige netamente en dirección ventral en lutrinos, siendo optimizada como una sinapomorfía del grupo convergente a Taxidea taxus y carnívoros no arctoideos (c. 79, estado 0), mientras que una faceta medial globosa y marcadamente inclinada medialmente fue reconstruida como una potencial sinapomorfía de Procyonidae (reconstrucción ambigua, c. 79, estado 2).

Resumiendo los principales cambios en ambas matrices de caracteres anatómicos en los principales clados de Mustelidae (ver Fig. 3.4), para el ancestro común de Mustelidae - Taxidea se reconstruye la adquisición de rasgos musculares y esqueletarios de la región cervical cuyo interés funcional será discutido más adelante (ver Sección 4.3.2). Entre ellos se destaca una complejización de la musculatura cervical (e.g., configuración de los mm. rhomboideus; Apéndice 3.14, c. 6, estado 3) y una mayor longitud cervical (Apéndice 3.15, c.0, estado 0,293$0,305)$; ambos rasgos optimizados como una reversión a una condición ya presente en grupos de carnívoros depredadores más basales (e.g., cánidos). En nodos internos a este grupo se adquieren, progresivamente, otros rasgos relacionados a una región cervical más desarrollada (e.g., elongación del manubrio en Mustelidae - Taxidea - Meles; Apéndice 3.14, c. 22, estado 1, ver más adelante), y algunas reducciones en las principales áreas de origen de algunos grupos flexores intrínsecos del miembro anterior (e.g., fosa infraespinosa, cresta del epicóndilo lateral; Apéndice 3.15, c.31, estado 2 y c.38, estado 0; Fig. 3.4). 
A estas adquisiciones, en el nodo Ictonychinae + Mustelinae + Lutrinae se suman un gran número de modificaciones que abarcan las principales regiones postcraneales implicadas en la locomoción. En la región axial, la musculatura epiaxial domina sobre la sublumbar, cambios ilustrados por la adquisición de un m. iliocostalis lumborum dominante (Apéndice 3.14 , c. 1, estado 2) y la reducción del m. psoas minor (c. 28, estado 0), entre otros rasgos. En lo que respecta a los miembros, existen modificaciones en las proporciones generales de los mismos, el zeugopodio anterior se reduce en longitud (Apéndice 3.15, c. 3), en oposición a lo ocurrido en el zeugopodio posterior, el cual incrementa tanto su longitud (Apéndice 3.15, c. 4) como ancho, mediante la divergencia de la fíbula y tibia (c. 73, estado 3; Fig. 3.4).

En el ancestro común de Guloninae, se registran múltiples rasgos en los miembros y región axial convergentes (e.g., proporciones membrales, ver Apéndice 3.15; c. 3 y 4) o heredados en común con los miembros del clado Ictonychinae + Mustelinae + Lutrinae (ver más arriba), sumado a un conjunto de rasgos que afectan específicamente la configuración mioesqueletaria del miembro anterior, que incluyen la presencia de múltiples músculos aductores del brazo (e.g., m. articularis humeri, m. coracobrachialis; Apéndice 3.14, c. 14, estado 1 y c. 15 , estados $0 \mathrm{y} 1)$, y modificaciones en la articulación del codo (e.g., proceso ancóneo asimétrico; Apéndice 3.15, c. 42, estado 1).

En la subfamilia Lutrinae se registra el mayor número de sinapomorfías, evidenciando una reconfiguración dramática del aparato mio-esqueletario postcraneal, muchos de los cuales serán relacionados a la especialización al nado propia del linaje (Sección 4.3). En el miembro anterior, se registran modificaciones en el desarrollo y las posiciones de las regiones de inserción de los principales músculos braquiales (e.g., Apéndice 3.14, c.9, 11, 13, 27). También se registran cambios a lo largo de toda la región axial, incluyendo cambios en la morfología de los procesos transversos cervicales, torácicos, lumbares y mamilares (e.g., Apéndice 3.15, c.18, estado 0; c.20, estado 1), y un mayor desarrollo y una morfología particular de los procesos espinos y transversos caudales (Apéndice 3.15, c. 26, estado 3, y c.29, estado 1), evidenciando modificaciones sustanciales en el desarrollo de los principales sistemas musculares axiales y en el grado de libertad de los movimientos intervertebrales. Un gran número de rasgos adquiridos en el ancestro común de los lutrinos también sugieren una reconfiguración postural y de los principales músculos del miembro posterior, incluyendo el gran desarrollo de las áreas de orígenes de los principales extensores poderosos de la cadera (e.g., del plano isquio-púbico, Apéndice 3.15 , c.58, estado 2; del tubérculo isquiático, c.59, estado 2; sínfisis amplia y retrasada, c. 60, estado 2), y extensores del tobillo (e.g., c. 67, estado 1); modificaciones específicas de la articulación de la rodilla (e.g., posición de la tróclea del fémur, c. 66, estado 2; reducción del área intercondiloidea craneal de la tibia, c.69, estado 0), y articulaciones del 
autopodio (e.g., faceta astragalar medial orientada netamente ventralmente, c. 79, estado 0; Fig. $3.4)$.

\subsubsection{Optimizaciones de caracteres ecológicos y tamaño corporal}

En el Apéndice 3.16 se esquematizan las optimizaciones obtenidas para cada uno de los 3 caracteres analizados.

Para el caso de los hábitos locomotores (c. 0), se reconstruye una condición ancestral para Caniformia, Arctoidea, Musteloidea y Procyonidae relacionada a hábitos trepadores (Apéndice 3.16, c.0, estado 2). Tanto en el ancestro común de los mefítidos como de los mustélidos se adquiere convergentemente una condición de cavador (c. 0, estado 0). Para el ancestro común a los grupos Mustelidae - Taxidea - Melinae - Mellivora, se reconstruye ambiguamente una condición de cavador y half-bounder, estableciéndose una condición halfbounder sin ambigüedad en el ancestro común de Ictonychinae + Lutrinae + Mustelinae (c. 0, estado 3). Dados los hábitos acuáticos de todas las nutrias, el ancestro común de los lutrinos es recuperado como nadador (c. 9, estado 1).

Para el caso de los hábitos dietarios (c. 1), se reconstruye la adquisición de una dieta omnívora para los ancestros de todos los grandes grupos arctoideos (e.g., Arctoidea, Musteloidea, Mephitidae, Ailuridae; Procyonidae; Mustelidae; Apéndice 3.16, c. 1, estado 0). Para el caso del ancestro común de Helictidinae + Ictonychinae + Mustelinae + Lutrinae, así como el ancestro común de este grupo y Guloninae, no se resuelve la condición, mientras que se reconstruye una condición carnívora (c. 1, estado 1) sin ambigüedad para el ancestro común de Ictonychinae + Mustelinae + Lutrinae y para el ancestro de Guloninae.

En lo que respecta al tamaño corporal (c. 2), se recupera la adquisición de tamaños corporales relativamente reducidos (3,74 kg.; Apéndice 3.16, c. 2, estado 3,74) para el ancestro común de los representantes de Musteloidea y esta condición se mantiene hasta el nodo Procyonidae + Mustelidae. Mayores tamaños corporales se adquieren en el ancestro común de los mustélidos, mientras que una reversión a tamaños relativamente menores ocurre en el nodo Mustelidae - Taxidea - Melinae - Mellivora (c. 2, estado 3,38-4,72). Tamaños corporales similares o progresivamente inferiores se registran en los nodos internos de este clado, a excepción de la condición sinapomórfica reconstruida para Lutrinae, en donde se adquieren nuevamente grandes tamaños corporales (c.2., 7,10-8,19). 



\section{Figura de resultados de optimizaciones}

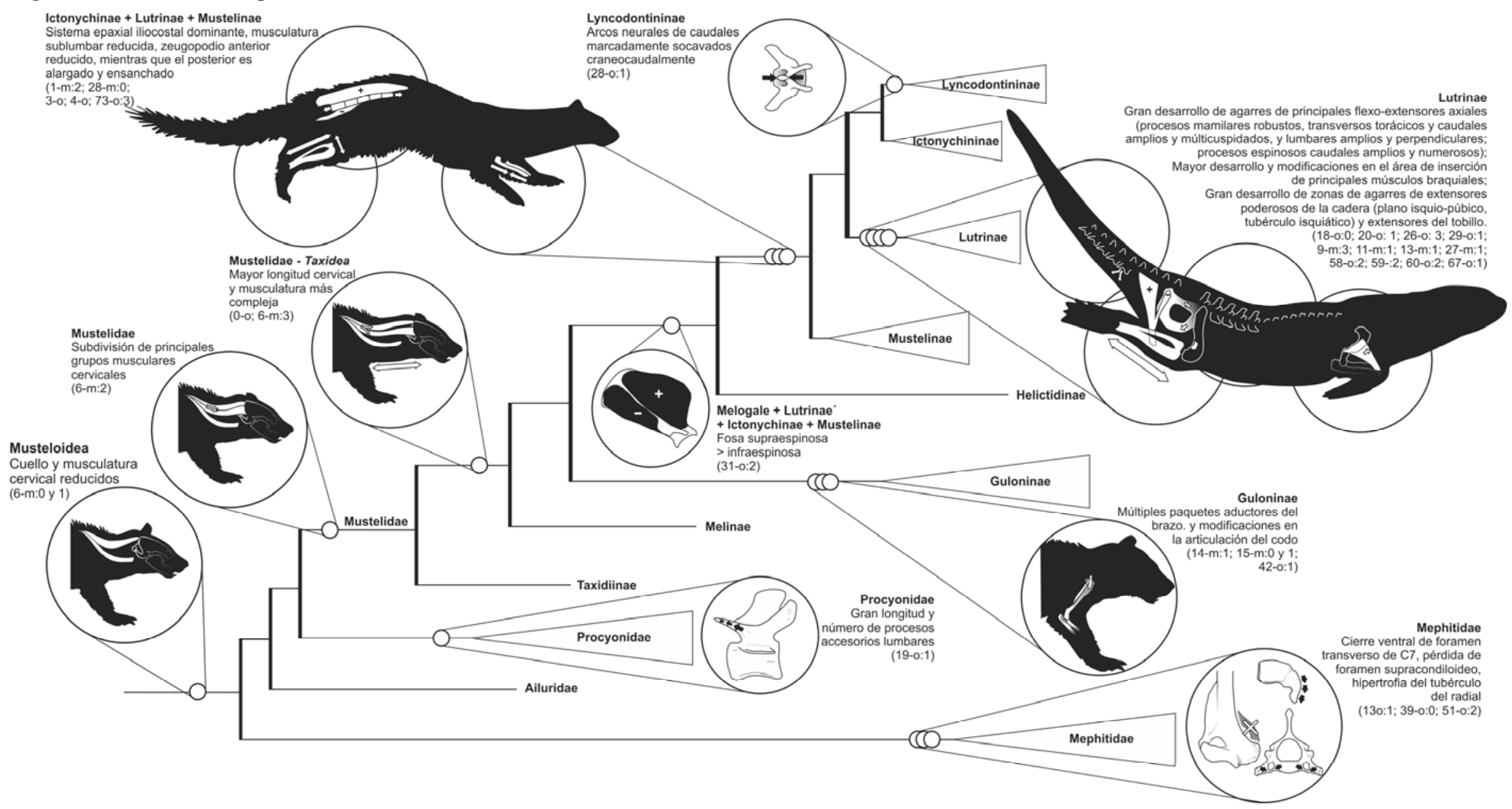

Figura 3.4. Esquema que resume los principales resultados de las optimizaciones miológicas y osteológicas (relaciones filogenéticas de Sato et al. 2012). 

Capítulo 4 DISCUSIÓN

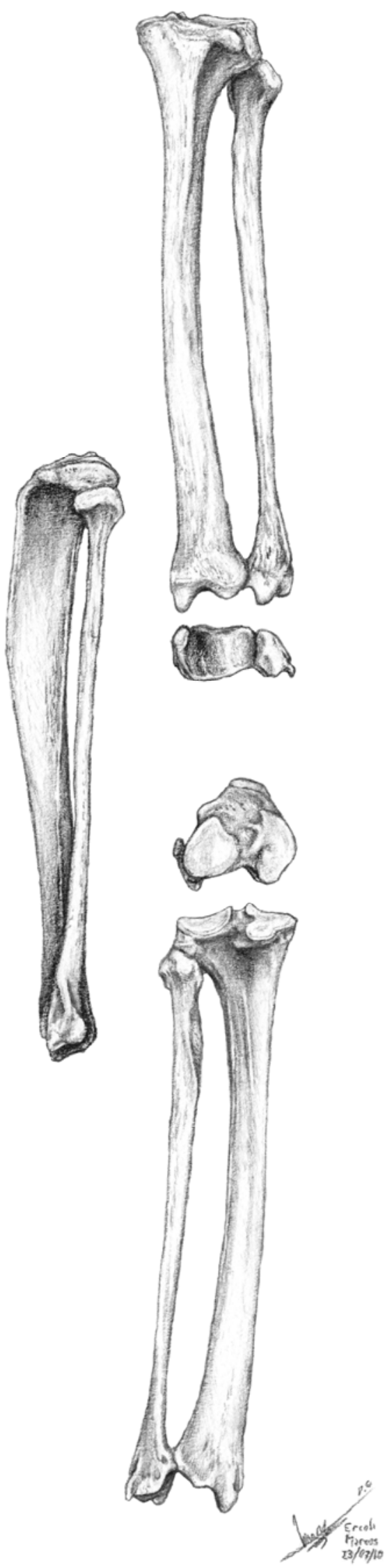





\section{Discusión}

\subsection{Análisis morfo-funcional comparativo con consideraciones filogenéticas de la miología de Galictis cuja}

Los hurones realizan carreras de tipo bound o half-bound (en general presentando una fase de vuelo extendido) que pueden relacionarse a su morfología característica de miembros breves y esqueleto axial largo y flexible. En estos pasos la función de propulsión es mayormente cedida a la región lumbar y los miembros posteriores, mientras que los miembros anteriores colaboran pobremente en la propulsión pero se especializan en resistir las fuerzas de reacción del sustrato durante el primer contacto al principio de la fase de soporte (Davis 1949, Gambaryan 1974, Leach 1977b, Seckel y Janis 2008, Ercoli et al. 2013). La locomoción en

túneles y el transporte de presas pesadas son también denominadores comunes en el comportamiento de los hurones (Cabrera y Yepes 1940, Kaufmann y Kaufmann 1965, Dücker 1968, Ben-david et al. 1991, Vargas and Anderson 1998, King y Powell 2007). Desde los trabajos pioneros de Windle y Parsons $(1897,1898)$, y Hall $(1926,1927)$ hasta las revisiones más recientes (Fisher et al. 2008, 2009), la musculatura ha sido valorada cualitativamente como informativa de las relaciones de parentesco en Carnivora. En esta Tesis y los trabajos relacionados (Ercoli et al. 2013, 2014, en preparación), los principales cambios musculares dentro de Caniformia, y en Mustelidae en particular, fueron cuantificados y revalorados. A continuación se describen las principales interpretaciones morfo-funcionales, nomenclaturales y filogenéticas de los principales grupos musculares.

\subsubsection{Región axial}

\section{Musculatura oblicua y recta capital}

La musculatura cervical se encuentra marcadamente desarrollada en carnívoros depredadores en general, en comparación con aquellos linajes más omnívoros o especializados en ítems vegetales particulares (Savage 1957, Jouffroy y Lessertisseur 1971, Bisaillon et al. 1976, ver sección 4.5.2). En hurones en general, y en Galictis cuja en particular, presentan un cuello robusto, elongado y poderoso, útil en la captura, dominación, killing bite y el transporte de presas (Kaufmann y Kaufmann 1965, Ewer 1973, Radinsky 1981a, b, Zielinski 2000, King y Powell 2007). Tanto para los mm. obliquus capitis, rectus capitis, y otros músculos cervicales de inserción capital, un gran número de aspectos morfo-funcionales son desarrollados en mayor detalle en el apartado dedicado a ${ }^{\dagger}$ Stipanicia pettorutii (ver sección 6, Anexo).

En lo que respecta a los $\mathrm{mm}$. obliquus capitis, estos tienden a encontrarse más profusamente subdivididos en las especies más carnívoras, incluyendo cánidos, hiénidos, félidos y los mustélidos más especializados a la carnivoría como las nutrias y hurones (Cuvier y 
Laurillard 1849, Alix 1876, Fisher 1942, Barone 1967, Spoor y Badoux 1986b, Evans y De Lahunta 2013; pero ver Reighard y Jennings 1901, Williams 1955). Esto puede relacionarse al incremento de los movimientos precisos de rotación de la cabeza, necesarios durante la caza (Jouffroy y Lessertisseur 1971). Los mm. rectus capitis son típicamente descriptos como extensores y estabilizadores de la cabeza (Jouffroy y Lessertisseur 1971, Evans y De Lahunta 2013), debido a que sus orígenes e inserciones se encuentran por sobre las articulaciones entre vértebras. En particular en hurones, y en un menor grado en otros carnívoros como nutrias y cánidos (Fisher 1942, Barone 1976, Evans y De Lahunta 2013), algunas subdivisiones de los $\mathrm{mm}$. rectus capitis (i.e., m. rectus capitis dorsalis "intermedius", vientre lateral del m. rectus capitis dorsalis minor; Alix 1876, Williams 1955; ver Láminas 2) presentan una marcada extensión y posicionamiento lateral de sus inserciones. Esta característica, junto con otros rasgos cervicales discutidos más adelante (e.g., mm. multifidi cervicis, m. biventer cervicis), favorecería un mayor rango y control de los movimientos de rotación de la cabeza en comparación con otros linajes depredadores. La posición de inserción del m. rectus capitis dorsalis minor, ubicada llamativamente en la periferia del plano occipital en los hurones mustelinos y en Galictis cuja (en vez de cerca al foramen magnum; ver Davis 1964, Barone 1976), podría sumarse al complejo de caracteres afectados por esta reconfiguración muscular.

\section{M. longissimus cervicis, $\mathbf{m}$. longissimus capitis y m. sternocephalicus}

$\mathrm{El} \mathrm{m}$. longissimus cervicis presenta dos configuraciones diferentes en los arctoideos. En muchos de los representantes vivientes de los arctoideos basales, los cuales son mayormente omnívoros, insectívoros y herbívoros (e.g., algunos úrsidos, mefítidos, prociónidos, Ailurus fulgens, mustélidos basales), este músculo se encuentra indiferenciado respecto al $\mathrm{m}$. longissimus thoracis (Hall 1926, 1927, Davis 1964, Julik et al. 2009). Por otro lado, en arctoideos principalmente depredadores, como cánidos y la mayoría de los úrsidos y mustélidos derivados, el m. longissimus cervicis se encuentra totalmente diferenciado de la porción torácica (Cuvier y Laurillard 1849, Alix 1876, Hall 1926, Fisher 1942, Williams 1955, Barone 1976, Evans y De Lahunta 2013). En el caso de mustélidos derivados este músculo presenta un mayor número de metámeros caudales (Alix 1876, "transversalis cervicis" de Kelley 1888, Hall 1926, Fisher 1942, Williams 1955, esta tesis, ver Lámina 2.1). Como fue propuesto para los rectos y oblicuos capitales, un mayor número e independencia de los paquetes musculares del cuello permiten una mayor movilidad y fuerza en especies depredadoras, que requieren movimientos cervicales poderosos durante la caza. En especies que incluyen otros items dietarios, la ausencia de esfuerzos cervicales mayores, sumado en algunos casos al uso más intensivo de los miembros anteriores en la manipulación del alimento (e.g., en herbívoros y frugívoros especializados; Davis 1964, McClearn 1992, Antón et al. 2006, Abella et al. enviado; ver 
también Bisaillon et al. 1976 comparando depredadores acuáticos de presas sésiles vs. móviles), reducen la necesidad de una musculatura cervical voluminosa y subdividida. Es interesante destacar que varios félidos, contrariamente a otros feliformes depredadores (e.g., Hyaena hyaena, Panthera leo; Cuvier y Laurillard 1849), no presentan un m. obliquus capitis cranialis subdividido, y en el caso de Felis catus, tampoco presenta un $\mathrm{m}$. longissimus cervicis independiente (ver Reighard y Jennings 1901, Antón et al. 2004, Salesa et al. 2005). Esta llamativa excepción podría deberse a la gran capacidad de manipulación y participación de los miembros anteriores durante la caza, así como a la preferencia por presas menores en el caso de los félidos más pequeños (Ewer 1973, Radinsky 1981a, Anyonge 1996, Karanth y Sunquist 2000).

En lo que respecta al m. longissimus capitis, para la mayoría de los carnívoros, incluyendo a Ga. cuja (ver Láminas 2.1-3), se registra una configuración similar que involucra una inserción tendinosa sobre el proceso mastoideo (e.g., Evans y De Lahunta 2013). Las únicas variantes en la posición de inserción son las correspondientes a las descripciones de Aonyx cinerea, Eira barbara, y Civettictis civetta, para quienes se ha indicado una inserción paraoccipital (Macalister 1873a, b). Dado que las únicas tres especies en las que se registró esta variante fueron a su vez las únicas tres especies descriptas por Macalister dentro de las analizadas, sería posible plantear la posibilidad de error terminológico más que una variación real en la posición de inserción del músculo. Por otro lado, en su estudio comparativo, Hall (1926) describió la ausencia compartida del m. longissimus capitis en los dos mefítidos que analizó, lo que podría considerarse como una sinapomorfía de la familia, y una diferencia notable respecto a lo observado en los restantes carnívoros conocidos (ver Windle y Parsons 1898). Desde un punto de vista funcional y evolutivo, es probable que la pérdida de este músculo se haya establecido en un ancestro común de hábitos no predadores (hoy en día comunes a todos los mefítidos), dado que implica una reducción significativa de la fuerza y movilidad de la cabeza requerida durante la caza activa (ver más arriba). A su vez, la pérdida de este músculo podría ser una restricción funcional al grado de carnivoría que puedan alcanzar los representantes de la familia.

Así como fue descripto para el sistema longissimus y para los músculos rectos y oblicuos de la cabeza, la configuración del m. sternocephalicus puede relacionarse cercanamente con la diversidad de dietas de los distintos carnívoros. En los linajes primariamente depredadores activos, las dos contrapartes del $\mathrm{m}$. sternocephalicus pars mastoidea están fusionadas en la linea media del sector ventral del cuello (Lámina 2.9B). Esto incrementa la superficie de origen y favorece una dirección más oblicua de las fibras, características vinculadas a la realización de grandes esfuerzos de flexión ventral y lateral de la cabeza. Esta condición se encuentra presente en Galictis cuja, así como todos los mustélidos 
(Cuvier y Laurillard 1849, Mackintosh 1875, Alix 1876, Windle y Parsons 1897, 1898, Hall 1926, 1927, Williams 1955, Quaife 1978; pero no mencionado por Fisher 1942; excepto Ictonyx libyca; Windle y Parsons 1897); así como también en cánidos (Windle y Parsons 1897, Barone 1976, Evans y De Lahunta 2013), félidos (Windle y Parsons 1897, Reighard y Jennings 1901, Barone 1967) y hiénidos (Spoor y Badoux 1986b, Windle y Parsons 1897). Dentro de los linajes mayormente omnívoros o herbívoros, esta fusión es inexistente en mefítidos (Hall 1926) y Ailurus fulgens (Fisher et al. 2009), mientras que en úrsidos, prociónidos y feliformes generalizados la presencia o ausencia de esta fusión es variable pero aun así en estrecha relación con los hábitos dietarios de cada especie en particular, encontrándose ausente en Potos flavus, Nasua spp., Ailuropoda melanoleuca, y presente en Ursus maritimus y Procyon lotor, y variable en otras especies como Civettictis civetta y Ursus americanus (Cuvier y Laurillard 1849, Beswick-Perrin 1871, Macalister 1873b, Mackintosh 1875, Kelley 1888, Windle y Parsons 1897, Davis 1964).

Un patrón similar puede observarse al examinar la presencia y desarrollo del $\mathrm{m}$. sternocephalicus pars occipitalis. En los linajes insectívoros, herbívoros u omnívoros, este vientre se encuentra totalmente ausente. Este es el caso de Ailuropoda melanoleuca (Davis 1964), Mephitis mephitis (Hall 1926), variantes intraespecíficas de algunos tejones (ver Hall 1927 contra Quaife 1978), y muchos prociónidos (Cuvier y Laurillard 1849, Mackintosh 1875). Por otro lado, los linajes de hábitos más carnívoros, como cánidos (Barone 1976), hiénidos (Windle y Parsons 1897, Spoor y Badoux 1986b), félidos (Reighard y Jennings 1901, Barone 1967), mustélidos guloninos (Cuvier y Laurillard 1849, Hall 1926, pero ver Mackintosh 1875) y especialmente mustelinos (Alix 1876, Williams 1955, Evans y Quoc An 1989) y Galictis cuja (Láminas 2.5 y 2.9A), suelen presentar un gran desarrollo de este vientre, el cual se extiende ampliamente sobre la cresta lambdoidea en su inserción, permitiendo poderosos y amplios movimientos de la cabeza y cuello. Taxones con dietas omnívoras intermedias evidencian configuraciones musculares intermedias a las descriptas previamente, presentando vientres occipitales reducidos, en general de menor desarrollo que los mastoideos y restringidos en área de inserción, e.g., Spilogale gracilis, Taxidea taxus (Hall 1927, pero ver Quaife 1978), Melogale personata, Ursus spp. (Cuvier y Laurillard 1849, Shepherd 1883, Kelley 1888, Beddard 1905, Hall 1926, 1927, pero ver Quaife 1978).

En Meles meles, taxón considerado omnívoro (Heptner y Naumov 1967, Wilson y Mittermeier 2009), la porción occipital del m. sternocephalicus se encuentra bien desarrollada (Cuvier y Laurillard 1849), mientras que en Ailurus fulgens y Potos flavus (herbívoro y frugívoro; Wilson y Mittermeier 2009) está presente en forma reducida (Beswick-Perrin 1971, Fisher et al. 2009); revelando para estas especies un inusualmente mayor desarrollo de la musculatura esternomastoidea respecto a otras especies de similares hábitos. Esto podría ser 
resultado de la retención de una condición ancestral depredadora activa, más que un reflejo de los hábitos de estos taxones, coincidiendo con propuestas previas (Salesa et al. 2008) y otros rasgos osteológicos discutidos más adelante (ver secciones 4.3.2-4). Por último, es necesario destacar que los lutrinos se alejan de este patrón, presentando m. sternocephalicus pars occipitalis relativamente reducido (Fisher 1942, ver también Macalister 1873a), sin haberse encontrado una explicación clara a esto.

\section{Sistema transversoespinal en la región cervical y torácica}

El m. multifidus cervicis es usualmente descripto como un músculo metamérico, con orígenes sobre procesos articulares caudales e inserciones en procesos espinosos precedentes, siendo el sitio principal de inserción el margen caudal del proceso espinoso del axis. Este es el caso de la mayoría de los carnívoros descriptos en suficiente detalle (e.g., úrsidos, félidos, cánidos; Reighard y Jennings 1901, Davis 1964, Sharir et al. 2006, Evans y De Lahunta 2013). Sin embargo, en los únicos tres mustélidos para los que se cuenta con descripciones detalladas (i.e., Mustela putorius, Lontra canadensis; Alix 1876, Fisher 1942; y Galictis cuja aquí presentado) la configuración es diferente: a los sitios de orígenes típicos se suman orígenes en procesos espinosos, y las regiones de inserción se dan en los procesos articulares caudales precedentes en vez de espinosos, poseyendo las fibras una dirección más horizontal y lateralizada (Láminas 2.1 y 2.4). A diferencia de la configuración típica de carnívoros, que favorece la extensión del cuello, la disposición registrada en mustélidos, favorecería movimientos complejos fuera del plano sagital (e.g., rotación) y estabilización (de forma similar a los rectos capitales).

En lo que respecta al sistema transversoespinal torácico, los $\mathrm{mm}$. rotatores se encuentran marcadamente desarrollados, diferenciados, y se encuentran en mayor número en Galictis cuja que en otros carnívoros descriptos (Canis familiaris, Felis catus, Ailuropoda melanoleuca; Reighard y Jennings 1901, Davis 1964, Evans y De Lahunta 2013; ver Lámina 2.1). El gran desarrollo de los músculos transversoespinales más profundos del tórax del hurón menor se encuentra asociado a una gran extensión de la superficie de los procesos espinosos en donde se insertan estos metámeros, y una reducción de los ligamentos interespinosos. Estas características otorgan una mayor flexibilidad al cuerpo, útil en incursiones en galerías y durante la dominación de presas de gran tamaño corporal (ver sección 6, Anexo). Aunque no existen datos suficientemente detallados en otros mustélidos, a partir del análisis de la morfología vertebral (ver sección 4.3.2) podría inferirse una configuración similar a la descripta para el hurón menor.

\section{Musculatura epiaxial lumbar}


El grado de diferenciación y desarrollo de los sistemas musculares epiaxiales es variable dentro de Carnivora (Slijper 1946, Gambaryan y Karapetyan 1961, Davis 1964, Jouffroy y Lessertisseur 1971, Evans y De Lahunta 1993, Julik et al. 2009) y tiene importantes consecuencias para las capacidades de movimientos de la región lumbar (Gambaryan y Karapetyan 1961, Jouffroy y Lessertisseur 1971, Gambaryan 1974, Spoor y Belterman 1986, Spoor y Badoux 1988, Feeney 1999, Wroe et al. 2008).

La musculatura epiaxial lumbar de Ga. cuja está representada por una serie de paquetes laterales voluminosos que corresponden al m. iliocostalis lumborum, y una serie media, correspondiente al sistema transversoespinal, mientras que el $\mathrm{mm}$. sacrocaudalis dorsalis lateralis se ubica entre estos dos sistemas lumbares. Por otro lado, las fibras musculares más caudales del $\mathrm{m}$. longissimus thoracis alcanzan a cubrir parcialmente al $\mathrm{m}$. iliocostalis lumborum a la altura de las primeras dos vértebras lumbares, mientras que caudalmente el sistema longissimus se pierde, confundiéndose como una fascia superficial, la cual alcanza el ilion (Lámina 2.18A). Dentro de Mustelidae, un arreglo similar fue descripto para mustelinos y lutrinos, aunque con importantes variantes terminológicas. Aunque la ausencia de datos para la mayoría de los mustélidos derivados impide una reconstrucción confiable, existe la posibilidad de que esta condición se haya encontrado previamente a la radiación d el clado Ictonychinae + Lutrinae + Mustelinae (Apéndice 3.14, c.1, estado 1). Sin embargo, algunos de estos músculos se encuentran modificados en algunos lutrinos que están altamente especializados al nado (e.g., reducción de la independencia y desarrollo relativo de el $\mathrm{m}$. iliocostalis lumborum, e.g., Enhydra lutris; ver Gambaryan y Karapetyan 1961, Jouffroy y Lessertisseur 1971, Tarasoff 1972). En trabajos previos, el sistema lateral ha sido descripto como el m. sacrospinalis (e.g., Moritz et al. 2007, ver también Alix 1876, Gambaryan y Karapetyan 1961, Jouffroy y Lessertisseur 1971), y como parte del m. longissimus dorsi (parte III, descripta como una"heavy roll muscle" lateral al resto del m. longissimus; Fisher 1942: 35). Aunque la información disponible en bibliografía es escasa, al parecer ésta es una condición a la típica y posiblemente ancestral de la superfamilia Musteloidea y grupos más inclusivos evaluados (Apéndice 3.14, c.1, estado 2), en donde el m. longissimus lumborum es el músculo epiaxial lateral más desarrollado o el único (ver Ailurus fulgens, mefítidos, prociónidos y mustélidos más basales; Cuvier y Laurillard 1849, Hall 1926, 1927, Julik et al. 2009). Como sugirieron autores previos (Slijper 1946, Gambaryan 1974, Williemsen 1980b, Ercoli et al. 2013), y se detalla en la sección de discusión osteológica tóraco-lumbar (sección 4.3.2), el desarrollo relativo de los procesos espinosos y transversos lumbares se encuentran correlacionados a estos arreglos musculares.

El mayor desarrollo y diferenciación del $\mathrm{m}$. iliocostalis lumborum en hurones mustelinos y ictoniquinos (Tabla 3.3, Apéndice 3.14, c. 0 y.1; Lámina 2.18; Gambaryan 1974) parece estar relacionada a la importancia de la musculatura axial para la ejecución de pasos 
simétricos (contracción unilateral o asimétrica) y asimétricos (contracción bilateral o simétrica; Schilling y Carrier 2010), lo que genera una región axial muy móvil y permite el desplazamiento en galerías subterráneas estrechas, en donde son requeridas marchas simétricas agazapadas y gran flexibilidad (Gambaryan 1974, King y Powell 2007, Moritz et al. 2007, Horner y Biknevicius 2010). Durante las carreras epigeas, la máxima velocidad de corrida de estas especies de miembros cortos (short-legged) depende mayormente de la fuerza y grado de extensión de la columna justo antes del comienzo de la fase flotante de vuelo extendido (i.e., etapa de propulsión previa a cada salto; Gambaryan 1974). De manera diferente, en otros linajes carnívoros la musculatura epiaxial se encuentra estrechamente fusionada y la movilidad está reducida por la presencia de ligamentos y fascias extensas, e interferencias entre procesos vertebrales (Apéndice 3.14, c.0, estado 2 y 3; c.1, estado 1; Murie 1974, Davis 1964, Gambaryan 1974, Spoor y Badoux 1988). Esto se debe a que en estas especies (e.g., úrsidos, tejones), galopantes lentas o pesadas, se maximiza la fase de vuelo cruzado y la participación de los miembros anteriores durante la propulsión (Gambaryan 1974, Spoor y Belterman 1986, Hildebrand 1988).

Moritz et al. (2007) y Horner y Biknevicius (2010) destacaron la importancia de los cambios posturales requeridos para la locomoción subterránea en el mustelino Mu. putorius (ver también King y Powell 2007). El estudio de la composición de las fibras musculares de la musculatura epiaxial de esta especie llevó a estos autores a destacar la importancia del $\mathrm{m}$. iliocostalis (m. sacrospinalis) como un estabilizador de la columna vertebral en posiciones extendidas, postura típicamente alcanzada en mustelinos bajo tierra, y en ictoniquinos como Ga. cuja también frecuentemente sobre tierra (ver Cabrera y Yepes 1940, Schutz y Guralnick 2007; pero ver también Larivière 2002a). Moritz et al. (2007) sugirieron que la porción más superficial y craneal del $\mathrm{m}$. sacrospinalis es la única en la cual dominan las fibras musculares de contracción rápida (fibras glicolíticas), pero presenta un bajo porcentaje de fibras aptas para resistir y estabilizar posiciones extendidas de la columna durante largos períodos (fibras oxidativas), mientras que el resto de la masa epiaxial posee fibras de los dos tipos, en relación a que contracciones rápidas y estabilización de posiciones extendidas son requeridas en las marchas epigeas y subterráneas, respectivamente. Es probable que este primer sector corresponda al representante más caudal del sistema longissimus (Lámina 2.18A), a simple vista compuesto por un gran número de fibras tendinosa a modo de fascias, útiles en almacenan energía cinética durante marchas ágiles (e.g., Gambaryan 1974, Argot 2003a). Aunque estudios específicos son requeridos, es probable que este último módulo muscular se encuentre especializado en almacenar energía durante la flexión axial luego de cada salto, y sea desactivado durante la marcha en túneles, en donde la sobre-extensión axial sería contraproducente y se requieren fibras de resistencia. 


\section{Musculatura caudal}

Aunque las descripciones miológicas que incluyen al apéndice caudal son escasas, una gran diversidad de arreglos puede ser reconocida de todas formas.

La configuración del $\mathrm{m}$. intertransversarii dorsales caudale y el m. intertrasnversarii ventrales caudae de Ga. cuja (Láminas 2.18-19) es muy similar a la de otros musteloideos (e.g., Lo. canadensis, Potos flavus; Julitz 1909, Fisher 1942, Jouffroy y Lessertisseur 1971). Como bien señalaron Jouffroy y Lessertisseur (1971), para muchas especies de carnívoros, el m. intertransversarii ventrales caudae no es descripto como independiente del $\mathrm{m}$. intertransversarii dorsales caudae (Reighard y Jennings 1901, Hall 1926, Williams 1955). Esto deja abierta la posibilidad de que el primero se encuentre ausente o fusionado con este último. En Ga. cuja, como en muchos otros carnivoros, el $\mathrm{m}$. intertransversarii dorsales caudae se origina directamente de la cara medial de la espina dorso-caudal del ala del ilion (Lámina 2.20), aunque esto no ocurre en algunos carnívoros (e.g., Ailuropoda melanoleuca, Canis familiaris; Davis 1964, Jouffroy y Lessertisseur 1971, Evans y De Lahunta 2013).

Respecto a la inserción del m. pubocaudalis, $\mathrm{m}$. iliocaudalis y m. coccygeus, músculos flexores ventrales caudales, la configuración de Ga. cuja es muy similar a lo previamente descripto para otros mustélidos y mefítidos (Macalister 1873a, Hall 1926, 1927, Fisher 1942, Williams 1955). En estos taxones, la inserción de los músculos mencionados nunca supera a la quinta vértebra caudal, contrario a lo observado en canidos, félidos, prociónidos y úrsidos, en donde frecuentemente superan esta posición (Reighard y Jennings 1901, Julitz 1909, Davis 1964, Jouffroy y Lessertisseur 1971, Evans y De Lahunta 2013). Al menos en mefítidos y algunos mustélidos como los ictoniquinos, estos rasgos pueden ser relacionados a un amplio rango de extensión de la cola, e indirectamente al comportamiento aposemático "battle flag", típico de mefítidos e ictoniquinos (Doering 1881, Koslowsky 1904, Hall 1926, Kaufmann y Kaufmann 1965, Dücker 1968, Larivière y Messier 1996, Caro 2009), en donde la cola es levantada ante la amenaza de un predador o anticipando la descarga de las glándulas anales (Larivière y Messier 1996, Caro 2009). Al menos ictoniquinos, mustelinos, lutrinos y Potos flavus comparten la presencia de un $\mathrm{m}$. sacrocaudalis dorsalis lateralis de origen adelantado, alcanzando la última vértebra torácica (Julitz 1909, Fisher 1942, Williams 1955; Apéndice 3.14, c.2, estado 0), contrario a lo observado en otros caniformes descriptos (e.g., Hall 1926, 1927, Davis 1964, Evans y De Lahunta 2013). Esta configuración puede relacionarse a una mayor fuerza y control de la extensión de la región lumbar y caudal en los primeros linajes, en relación a distintas necesidades funcionales (estrategias battle flag, nado carangiforme, balance y prensión caudal; Tarasoff 1972, Youlatos 2003, Ercoli et al. 2013). 


\section{Musculatura hipoaxial lumbar}

En Ga. cuja, los orígenes e inserciones del m. quadratus lumborum (muchas veces descriptos en conjunto con el m. psoas major y a veces con el m. iliopsoas; e.g., Alix 1876, Fisher 1942, Williams 1955) son similares a los descriptos típicamente para los arctoideos (Alix 1876, Hall 1926, 1927, Davis 1964, Scherling 1989, Moritz et al. 2007; Láminas 2.18-19). A diferencia de la condición observada en hiénidos y algunos cánidos (Spoor y Badoux 1988, Feneey 1999, Evans y De Lahunta 2013), los paquetes más craneales no se insertan directamente en el ilion, y al menos para Mu. putorius (Moritz et al. 2007) y Ga. cuja, los paquetes del m. quadratus lumborum abarcan 3 a 5 elementos vertebrales. Los musteloideos, incluyendo a Ga. cuja, no presentan inserciones costales del m. quadratus lumborum (excepto quizás Lo. canadensis; ver "m. iliopsoas, part medial" en Fisher 1942).

El m. psoas minor de Ga. cuja se origina de un area reducida del cuerpo de dos vértebras lumbares (L2 y L3 en especímenes con cinco lumbares, y L1 y L2 en el espécimen con cuatro lumbares). Una condición de origen también reducido se encontró en $M u$. putorius y Ao. cinerea (Macalister 1873a, Mortiz et al. 2007). La optimización de caracteres indica que una condición de origen moderado a reducido del m. psoas minor habría sido una condición ancestral del clado Ictonychinae + Lutrinae + Mustelinae (Apéndice 3.14, c.28, estados 0, 1 y ambigüedad 01), mientras que un origen más amplio es reconstruido para los nodos Mustelidae y Musteloidea. Un origen extendido también ocurre en la mayoría de los otros carnívoros comparados, incluyendo otros arctoideos (Beswick-Perrin 1871, Macalister 1873b, Mackintosh 1875, Allen 1882, Hall 1926, 1927, Fisher 1942, Williams 1955, Davis 1964, Scherling 1989, Feeney 1999, Fisher et al. 2008), cánidos (Evans 1993, Evans y De Lahunta 2013), y feliformes (Mackintosh 1875, Reighard y Jennings 1901, Jouffroy 1971, Spoor y Badoux 1988), en donde el origen de este músculo ocupa al menos tres lumbares, tipicamente cuatro, y hasta siete vertebras toracolumbares (Apéndice 3.14, c.28, estados 1, 2 y 3). Dentro de los musteloideos, el origen del m. psoas major puede incluir las últimas dos lumbares (e.g., Ao. cinerea, Macalister 1873a), o las últimas tres (e.g., En. lutris, Mu. putorius, Martes foina, Ma. pennanti, Meles meles, Po. flavus, Procyon lotor, y probablemente Lo. canadensis; Beswick-Perrin 1871; Mackintosh 1875, Allen 1882, Fisher 1942, Howard 1975, Alexander y Jayes 1981, Scherling 1989, Feeney 1999, Moritz et al. 2007). En Ga. cuja, el origen óseo cubre las últimas dos lumbares, pero indirectamente se origina desde una tercera vértebra lumbar. En otros carnívoros, como cánidos, hiénidos y úrsidos, el $\mathrm{m}$. psoas major se origina directa o indirectamente de cuatro o más elementos lumbares (Shepherd 1883, Davis 1964, Spoor y Badoux 1986b, Feeney 1999, Evans y De Lahunta 2013, parcialmente documentado por Jouffroy 1971: 258), aunque incluso en estos debe considerarse una condición relativamente reducida respecto en comparación con otros mamíferos (e.g., primates; Jouffroy 1971). 
La reducción de la amplitud del origen del m. psoas major (Apéndice 3.14, c.30, estados 0 y 1) y m. psoas minor (Apéndice 3.14, c.28, estados 0 y 1; Láminas 2.18-19) parece haberse establecido tempranamente en la historia de los Musteloidea (Ercoli et al. 2013), y haberse acentuado en mustélidos derivados (principalmente lutrinos, mustelinos e ictoniquinos). Cambios observados en estos clados pueden ser asociados a un conjunto de cambios que incluyen: adaptaciones a la locomoción en galerias subterráneas y la adquisición de cuerpos largos y de miembros cortos, la alta movilidad lumbar requerida durante marchas half-bound, cambios en las demandas respiratorias, reducción del grado de explotación del sustrato arbóreo, e incursiones acuáticas más frecuentes, esto último especialmente en el caso de lutrinos (ver interpretaciones diversas: Alix 1876, Gambaryan 1974, Alexander y Jayers 1980, Moritz et al. 2007, Horner y Biknevicius 2010). Paquetes hipoaxiales múltiples y breves, con un gran número de orígenes e inserciones en vértebras postanticlinales, y la ausencia de paquetes largos alcanzando a la pelvis y miembro posterior (características presentes en Ga. cuja y también típicas de hurones mustelinos, ver Moritz et al. 2007), sugieren una alta movilidad de la espalda y una mayor capacidad de control de los movimientos de la región lumbar más que una especialización a adelantar los miembros.

\subsubsection{Miembro anterior}

\section{Mm. trapezius}

Una intersección tendinosa entre los mm. trapezius (fibrous interval; Windle y Parsons 1897) que une la porción cervical y torácica, ha sido registrada en mustélidos, Ailurus fulgens (Fisher et al. 2009), un espécimen de Procyon lotor (Windle y Parsons 1897), y algunos zorros (Vulpes y probablemente Chrysocyon; Langguth 1969, Fenney 1999, pero ver Windle y Parsons 1897). Windle y Parsons (1897) desestimaron este carácter como informativo en lo que respecta a relaciones de parentesco, entre otras cosas, por su variación dentro del género Procyon, y mencionan su presencia sólo para algunos ictoniquinos y nutrias dentro de Mustelidae. Sin embargo, incluyendo la información recabada en estudios posteriores se ha constatado su presencia en los mustélidos descriptos en detalle (e.g., Ga. vittata, Ictonyx spp., Martes spp., Mustela spp., Lontra canadensis, Lutra lutra, y aparentemente en Meles meles; Lucae 1875, Windle y Parsons 1897, Hall 1926, 1927, Fisher 1942, Williams 1955, Leach 1977b, Evans y Quoc An 1980, Scherling 1989), así como también en Ga. cuja (esta tesis, Láminas 2.6 y 2.9; Ercoli et al. 2014). La única excepción dentro de la familia es Enhydra lutris, una nutria altamente modificada, especializada en el consumo de bivalvos y erizos y a la vida en el mar (Howard 1973; Wilson \& Mittermeier 2009). Una intersección tendinosa ha sido una condición reconstruida como derivada dentro de Caniformia, y una sinapomorfía de Mustelidae, o quizás ya estaba presente en el ancestro de los musteloideos (reconstrucción ambigua; (Apéndice 3.14, 
c.4, estado 2; ver también Ercoli et al. 2014), pero la presencia de la misma estructura en zorros abre la posibilidad de una convergencia o un origen más basal aún. Por otro lado, Hall (1926) registra para mefítidos (Spilogale gracilis y Mephitis mephitis) la ausencia de contacto entre estos dos músculos, en relación a un corrimiento en dirección caudal de su origen torácico, una condición única dentro de Carnivora y que ha sido reconstruida como una sinapomorfía para la familia (Apéndice 3.14, c.4, estado 0). Estas evidencias reflotan la eventual importancia filogenética de este carácter. La interpretación funcional no es clara, pero es posible plantear como una hipótesis funcional que este tipo de estructura esté asociada a la capacidad de deformación mecánica de los paquetes musculares necesaria durante la contracción, permitiendo que los fascículos se deslicen unos sobre otros, especialmente en músculos con forma de abanico, como los mm. trapezius (Purslow 2010). Por otro lado, un origen tan caudal del m. trapezius pars thoracica en mefítidos (T11/12), similar a lo observado en el m. rhomboideus thoracis (hasta la T6), podría relacionarse a una mayor ventaja mecánica y masa de estos músculos retractores del brazo.

\section{Mm. rhomboideus, $\mathbf{m}$. cleidocephalicus y m. omotransversarius}

El grupo de músculos romboideos parece ser informativo tanto en aspectos funcionales como filogenéticos. La presencia del $\mathrm{m}$. rhomboideus profundus ha sido considerada previamente como una característica exclusiva de mustélidos y el prociónido basal Potos flavus dentro de Carnivora (decripto como "m. levator scapulae"; Beswick-Perrin 1871, Windle y Parsons 1897, Fisher et al. 2009; pero ver presencia en algunos marsupiales e insectivoros; Jouffroy 1971). Sin embargo, su presencia en Mep. mephitis y S. gracilis (Hall 1926), considerados actualmente mefítidos pero antiguamente considerados mustélidos, sugiere que este carácter pudo aparecer antes, posiblemente en la base de Musteloidea, perdiéndose secundariamente en Ai. fulgens, y los prociónidos más derivados (reconstrucción ambigua; Apéndice 3.14, c.7).

El m. rhomboideus capitis de la mayoría de los mustélidos descriptos en detalle posee una morfología peculiar (e.g., Windle y Parsons 1897: Fig. 5, Lucae 1875, Mackintosh 1875, Hall 1926, 1927, Fisher 1942, Jouffroy 1971, Howard 1973). Éste se encuentra desarrollado a modo de una banda independiente y no continuada medialmente con el $\mathrm{m}$. rhomboideus cervicis (Windle y Parsons 1897, Jouffroy 1971). Sin embargo, en el mustélido más basal, Taxidea taxus, estos dos músculos son independientes pero se contactan (Hall 1927: Fig. 1, Quaife 1978); por lo tanto la presencia de un vientre capital separado constituye una sinapomorfía (y una reversión, ver más adelante) de Mustelidae menos Taxidiinae, modificándose ligeramente la propuesta de Windle y Parsons (1897) (Apéndice 3.14, c.6, estado 3, ver también Ercoli et al. 2014). 
Una morfología similar a la descripta en mustélidos (excluyendo Taxidea) del m. rhomboideus capitis ha sido descripta en cánidos (excepto Otocyon megalotis) y algunos feliformes (Reighard y Jennings 1901, Carlsson 1905, Langguth 1969, Feeney 1999, Evans y De Lahunta 2013; Apéndice 3.14, c.6, estado 3). En otros grupos de Caniformia en que se encuentra presente una porción capital, pueden hallarse diversas condiciones: las fibras de los $\mathrm{mm}$. rhomboideus que alcanzan la cabeza se encuentran fusionadas con la porción cervical (la mayoría de los prociónidos, úrsidos, y condición ancestral reconstruida para Arctoidea; Apéndice 3.14, c.6, estado 1; ver también Jouffroy 1971), a veces acompañada de una porción lateral independiente y accesoria al vientre capital (descripto como m. "occipitoscapularis" para Ailuropoda melanoleuca; Davis 1964), o formando un vientre único e independiente pero continuado con la porción cervical (Potos flavus y Taxidea taxus), una posible condición ancestral para Procyonidae + Mustelidae (Cuvier y Laurillard 1849, Beswick-Perrin 1871, Mackintosh 1875, Allen 1882, Windle y Parsons 1897, Beddard 1900, Hall 1927, Davis 1964, Quaife 1978, Evans y De Lahunta 2013, reconstrucción ambigua, Apéndice 3.14, c.6, estado 2). Dado que la presencia de un vientre profundo del $\mathrm{m}$. rhomboideus y una porción capital independiente puede ser relacionada a hábitos predatorios (ver más abajo), el registro de uno o ambos vientres en las especies vivientes más basales de los principales clados arctoideos, predominantemente omnívoros y herbívoros, parece ser una retención de un estado primitivo relacionado a un ancestro depredador, como también lo sugiere el registro fósil de estos clados (Peigné et al. 2005, Wang et al. 2013, Figueirido et al. 2010). La ausencia del m. rhomboideus capitis es un carácter derivado y compartido por Ailurus y los mefítidos (Apéndice 3.14, c.6, estado 0), lo que potencialmente apoyaría la afinidad entre mefítidos y ailúridos; aunque también ocurre en variantes intraespecíficas de Ursus americanus (Windle y Parsons 1897, Hall 1926, Fisher et al. 2009, así como también en Viverridae y en general en Hyaenidae dentro de Feliformia; Windle y Parsons 1897, Macalister 1873b, Spoor y Badoux 1986b).

Galictis cuja, y otros hurones (Alix 1876, Williams 1955, Evans y Quoc An 1980), comparten tener una gran masa (Lámina 2.27) y un gran número de vientres protractores del miembro anterior (y extrínsecos en general; e.g., mm. rhomboideus capitis, cervicis y profundus, m. omotransvesarius; e.g., Lámina 2.10), y la reducción de la masa que retrae o eleva el miembro (e.g., m. rhomboideus thoracis vestigial en Ga. cuja, Mustela vison y Mu. putorius). Estas características se relacionan a una mayor importancia relativa de los movimientos de la cintura escapular, especialmente los de protracción, dada la reducción de los miembros (y la musculatura intrínseca) en los hurones. Otras características, como la dirección de las fibras de los mm. rhomboideus, protractores del brazo (ver también Feeney 1999), y la forma, desarrollo y posición del área de inserción del m. omotransversarius (ver sección 4.3.4, Escápula) respecto a la articulación del hombro en Ga. cuja y otros hurones, brindarían una mayor ventaja 
mecánica para rotar la escápula sobre el húmero en el plano sagital. Estas características, así como algunas otras observadas en otros extensores extrínsecos e intrínsecos del miembro anterior (ver más adelante), podrían relacionarse también a la amortiguación del impacto al comienzo de la fase de apoyo durante la carrera a saltos, manteniendo adelantado y extendido al miembro, y evitando el colapso del mismo durante el aterrizaje (Gambaryan 1974, Leach 1977b).

La brevedad de los miembros de los hurones les permite introducirse a túneles estrechos, en donde estos se mueven mediante una marcha agazapada (crouched), limitados en lo que respecta a la extensión total de los miembros en ciertos momentos (Moritz et al. 2007, Horner y Biknevicius 2010). Esto resulta en una menor distancia entre pisadas de cada par de miembros, y una menor velocidad de persecución. El gran desarrollo de la musculatura extrínseca, y específicamente de los protractores y rotadores del miembro anterior, permite incrementar la precisión de movimientos y longitud de la zancada mediante un desplazamiento y rotación acentuados de la cintura escapular durante el adelantamiento y retroceso del miembro en las marchas simétricas (e.g., caminatas, trotes; ver Gambaryan 1974) en galerías, o durante la búsqueda de presas en la superficie (Kaufmann y Kaufmann 1965, Hildebrand 1988, Feeney 1999, Yensen y Tarifa 2003a, Moritz et al. 2007, Seckel y Janis 2008, Horner y Biknevicius 2010).

En los Caniformia basales, la condición típica es poseer una porción torácica del $\mathrm{m}$. rhomboideus relativamente extendida caudalmente en su origen (Apéndice 3.14, c.5, estado 1, 2). Una porción vestigial (alcanzando caudalmente hasta la T2, Apéndice 3.14, c.5, estado 0; Láminas 2.6 y 2.10), frecuentemente descripta como parte de la porción cervical, es la observada únicamente en las especies más terrestres del clado Ictonychinae + Lutrinae + Mustelinae y algunos Guloninae en forma aparentemente convergente (variantes intraespecíficas de Martes americana y Ma. foina; Apéndice 3.14, c.5; Macalister 1873a, Mackintosh 1875, Alix 1876, Hall 1926, Williams 1955, Howard 1973). Por ejemplo, en Ga. cuja se registró que la porción torácica representa menos del 13\% del total de la masa de los mm. rhomboideus (Tabla 3.1). La reducción de éste y otros músculos retractores en estos linajes half-bounders, se asocia a que los miembros anteriores no son propulsores activos dominantes durante la fase de apoyo en las carreras, sino reclutados y posicionados para amortiguar el impacto, durante la fase de descanso y al principio de la fase de apoyo (Gambaryan 1974, ver también Seckel y Janis 2008). Por otro lado, la mayoría de los restantes Caniformia utilizan pasos y realizan actividades que requieren gran retracción (e.g., galope, trepado, cavado) o aducción poderosa del miembro hacia el cuerpo (e.g., trepadores), y presentan un moderado a gran desarrollo de la porción torácica del m. rhomboideus, alcanzando típicamente hasta la T4 o T5 (e.g., tejones, úrsidos, prociónidos, zorros, Ailurus fulgens), y hasta la T6 en algunos casos 
(algunos cánidos, mefítidos) (Cuvier y Laurillard 1849, Beswick-Perrin 1871, Mackintosh 1875, Allen 1882, Hall 1926, 1927, Davis 1949, 1964, Langguth 1969, Quaife 1978, Scherling 1989, Feeney 1999, Fisher et al. 2009, Evans y De Lahunta 2013).

La presencia, desarrollo y posiciones de inserción tanto de los $\mathrm{mm}$. rhomboideus capitis y profundus como del $\mathrm{m}$. omotransversarius en mustélidos y específicamente en hurones, así como la masa y multiplicidad de vientres del m. sternocephalicus (Láminas 2.5 y 2.9-10; Ercoli et al. en preparación) y m. cleidocephalicus en Ga. cuja, indican importantes capacidades de rango, fuerza y precisión de movimientos de flexión lateral y ventral de la cabeza cuando los miembros anteriores están fijados (ver también Evans y Quoc An 1980); estos movimientos son necesarios durante la ubicación de las mordidas precisas y fuertes, especialmente al luchar con presas grandes. La activación de estos músculos en forma bilateral permitiría el transporte de presas pesadas. Estas actividades han sido destacadas como propias del comportamiento de caza tanto de hurones mustelinos como ictoniquinos (Cabrera y Yepes 1940, Kaufmann y Kaufmann 1965, Dücker 1968, Ben-david et al. 1991, Vargas y Anderson 1998, King y Powell 2007). De manera llamativa, y salvando las distancias, muchas de las características de los hurones son convergentes a lo descripto en hiénidos (e.g., subdivisión del m. cleidocephalicus pars mastoidea, gran masa de los mm. rhomboideus, cuello largo y robusto, m. triceps brachii alcanzando el ángulo escapular; Spoor y Badoux 1986b), linaje que, al igual que los mustélidos weasel-like, transportan presas de gran tamaño corporal.

\section{Mm. pectorales}

Las descripciones de los $\mathrm{mm}$. pectorales son en general confusas en lo que respecta a nomenclatura (problemas de sinonimia y homonimia), y por lo tanto es difícil en algunos casos interpretar las homologías entre distintas especies descriptas por distintos autores. Sin embargo, existen reorganizaciones importantes a nivel familiar o subfamiliar de los $\mathrm{mm}$. pectorales dentro de Carnivora que escapan de la subjetividad de los autores.

Existen tres tipos básicos de organización de los $\mathrm{mm}$. pectorales superficiales ("simplificado", "normal", y "cruzado"; ver Ercoli et al. 2014). Los úrsidos y pinnípedos (e.g., Ailuropoda melanoleuca, Callorhinus ursinus, Ursus americanus; Shepherd 1883, Davis 1964, English 1977) presentan un único vientre, representando el tipo "simplificado", contrario a lo típicamente observado en la mayoría de los restantes Caniformia. La configuración "normal", registrada en Ga. cuja (Láminas 2.6, 2.9, 2.11), se encuentra presente en la mayoría de los musteloideos (mefítidos, mustélidos no lutrinos, prociónidos y Ailurus fulgens). Esta organización involucra al menos un vientre craneal y otro caudal (eventualmente subdividido), y que los vientres de origen más craneal en el esternón se insertan siempre en una posición más proximal en el húmero (Ai. fulgens, E. barbara, Martes spp., Mel. meles, Mep. mephitis, 
Mustela spp., T. taxus; Cuvier y Laurillard 1849, Macalister 1873b, Alix 1876, Hall 1926, 1927, Williams 1955, Leach 1977b, Quaife 1978, Scherling 1989, Feeney 1999, Fisher et al. 2009, Evans y De Lahunta 2013). Esta configuración, reconstruida como una potencial condición plesiomórfica dentro de Musteloidea (reconstrucción ambigua, Apéndice 3.14, c.9, estado 1; pero observaciones de este estado también en Feliformia; Macalister 1873b, Spoor y Badoux 1986b) sólo es transgredida por las llamativas excepciones de Martes foina, Potos flavus, un espécimen de Lutra lutra, y Bassaricyon alleni, en donde se registra el tipo "simplificado" (Apéndice 3.14, c.9, estado 0) quizás en algunos casos en relación a una descripción simplificada o debido a especializaciones locomotoras (Cuvier y Laurillard 1849, BeswickPerrin 1871, Mackintosh 1875, Beddard 1900). Dentro de la configuración normal, los "Procyoninae" (Procyon spp., Nasua spp.; Cuvier y Laurillard 1849, Mackintosh 1875, Windle y Parsons 1897) suelen presentar una subdivisión laminar extra del vientre caudal de los mm. pectorales superficiales. Por último, los lutrinos descriptos (Enhydra lutris, Lontra canadensis, Lutra lutra; Lucae 1875, Fisher 1942, Howard 1973) presentan un re-arreglo único dentro de Arctoidea (i.e., tipo "cruzado"; Apéndice 3.14, c.9, estado 3), aunque también presente en algunos Feliformia (e.g., félidos; Reighard y Jennings 1901, Julik et al. 2012; ver Felis catus en Apéndice 3.14, c.9) y Canidae (Carlsson 1905, Langguth 1969, Feeney 1999, Evans y De Lahunta 2013 ver Canis familiaris en Apéndice 3.14, c.9), reconstruyéndose como basal para Caniformia (contra Ercoli et al. 2014, presentando este trabajo un error en la codificación de Canis). En los lutrinos se registra un vientre craneal de los $\mathrm{mm}$. pectorales superficiales modificado (m. "pectoantebrachialis") que alcanza el sector más distal del húmero e incluso la ulna (como ocurre en otros músculos del brazo, e.g., m. cleidobrachialis; Apéndice 3.14, c.11, estado 1; ver también Felis catus), y el vientre caudal se inserta ampliamente sobre el húmero. Esta sinapomorfía de nutrias (Apéndice 3.14, c.9, estado 3) está probablemente relacionada a adaptaciones a la vida acuática y es convergente con pinnípedos, en conjunto con un incremento de la masa muscular pectoral; asistiendo a la aducción, rotación medial y retracción del miembro durante las brazadas en un medio denso, así como el mantenimiento de un perfil hidrodinámico (Savage 1957, Gambaryan y Karapetyan 1961, Howard 1973, English 1977, Williams 1983a, b, Fish 1994).

El m. pectoralis profundus se encuentra generalmente subdividido en un vientre craneal y otro caudal en musteloideos (coincidiendo con la reconstrucción del estado ancestral del grupo; Apéndice 3.14, c.10, estado 1), pero se revierte a un único vientre en nutrias derivadas, convergiendo con caniformes basales (cánidos excepto Otocyon megalotis, úrsidos; Cuvier y Laurillard 1849, Lucae 1875, Shepherd 1883, Carlsson 1905, Davis 1964, Howard 1973, Apéndice 3.14, c.10, estado 0). En tejones, se registran variantes de fusiones, en donde la porción caudal del m. pectoralis profundus se fusiona con la porción craneal (Me. meles; Cuvier 
y Laurillard 1849, aunque se mantiene parcialmente reconocible según Scherling 1989) o aparentemente con la porción caudal de los mm. pectorales superficiales (T. taxus; Hall 1927, Quaife 1978).

El mayor número de vientres de los $\mathrm{mm}$. pectorales en la mayoría de los musteloideos y algunos otros carnívoros (e.g., O. megalotis; Carlsson 1905), podría relacionarse a la especialización de cada vientre a distintas funciones y mayor precisión y repertorio de movimientos; mientras que la preponderancia de una única masa muscular por cada pectoral en nutrias y animales galopantes de gran tamaño (e.g., osos), así como en cavadores o trepadores más especializados (e.g., Me. meles, T. taxus, Po. flavus) podría relacionarse a una mayor fuerza de aducción (fusión y mayor masa de los mm. pectorales superficiales) o propulsión (fusión o extensión de origen de $\mathrm{m}$. pectoralis profundus) en detrimento de la precisión en los movimientos.

\section{Otros músculos extrínsecos (m. serratus ventralis thoracis, m. latissimus dorsi)}

En musteloideos no mustélidos galopantes trepadores o cavadores como prociónidos y mefítidos respectivamente, se presentan músculos retractores con numerosos paquetes y que alcanzan posiciones de orígenes más caudales: el m. serratus ventralis thoracis típicamente alcanza o supera la T8 (excepto en Bassaricyon alleni, Procyon spp.), los mm. rhomboideus thoracis y latissimus dorsi siempre alcanzan o superan a la T4 y T14 respectivamente (Cuvier y Laurillard 1849, Beswick-Perrin 1871, Mackintosh 1875, Allen 1882, Windle y Parsons 1897, Beddard 1900, Hall 1926). Linajes de mustélidos galopantes y cavadores como los tejones (e.g., Mel. meles, Ta. taxus; Cuvier y Laurillard 1849, Windle y Parsons 1897, Hall 1927, Quaife 1978, Scherling 1989), y secundariamente galopantes y trepadores como los mayores guloninos y Ai. fulgens (Cuvier y Laurillard 1849, Macalister 1873b, Mackintosh 1875, Windle y Parsons 1897, Hall 1926, Leach 1977b, Fisher et al. 2009), presentan los orígenes más caudales de estos músculos dentro de la familia, asemejándose en mayor grado a prociónidos y mefítidos, algo ya notado por Quaife (1978) para Ta. taxus, pero dándose una configuración de grado no tan extremo como ocurre en otras familias musteloideas, abriendo la posibilidad de una restricción (constraint) funcional o filogenética a la extensión caudal de los músculos retractores en mustélidos, el cual podría haber sido "superado" gracias a la reconfiguración de la fórmula tóraco-lumbar en mefítidos (ver sección 4.3.2, Tóraco-lumbar). Más datos de semifosoriales poco estudiados como melivorinos o el mefítido Mydaus, podrían soportar o rechazar estas ideas.

Asociado a su particular tipo de carrera half-bound, los mustélidos weasel-like y nutrias presentan una reducción caudal de los principales músculos extrínsecos retractores del brazo y flexores del hombro, como el m. latissimus dorsi (sin superar la T13; Cuvier y Laurillard 1849, 
Macalister 1873a, Lucae 1875, Alix 1876, Hall 1926, 1927, Fisher 1942, Williams 1955. Howard 1973, Scherling 1989), m. serratus ventralis thoracis (alcanzando la T6/7; Alix 1876, Williams 1955), y m. rhomboideus thoracis (ver más arriba), y por lo tanto menor ventaja mecánica resultante en la retracción comparado con otros musteloideos o arctoideos. Dentro de la condición reducida en hurones, Ga. cuja se destaca por presentar un desarrollo relativamente importante de algunos de estos músculos. La masa relativa al miembro anterior del $\mathrm{m}$. latissimus dorsi (así como del $\mathrm{m}$. pectoralis profundus, otro retractor) es claramente mayor que la observada en hurones mustelinos (i.e., Mustela) e incluso similar a lo observado en cursoriales (Lámina 2.27C; Gambaryan 1974). Además, variantes intraespecíficas de Ga. cuja (Apéndice 3.1) suelen presentar paquetes extra del $\mathrm{m}$. serratus ventralis y $\mathrm{m}$. latissimus dorsi respecto a lo típicamente observado en hurones mustelinos. Los datos de masa muscular disponibles de $V$. peregusna, y de la descripción de Ictonyx libyca, ictoniquinos cercanos a Ga. cuja, indican también un desarrollo importante de estos músculos en comparación con hurones mustelinos (Windle y Parsons 1897, Gambaryan 1974). Al ponderar la masa de estos músculos respecto a la de los extrínsecos (ver más arriba), el m. latissimus dorsi y $\mathrm{m}$. pectoralis profundus en los hurones ictoniquinos caen dentro del rango de otros arctoideos (30 y 40\%) pero por debajo de las cursoriales (45\%), mientras que se destaca el escaso valor de Mustela, con sólo el 25\% de la masa extrínseca representada por estos músculos. Aunque la diferencia entre mustelinos y hurones ictoniquinos es baja, existe una tendencia a separarse estos grupos en relación a sus habilidades cavadoras (Evans y Quoc An 1980, Wilson y Mittermeier 2009). Algo similar puede

observarse al comparar a Mellivora capensis (eventual cavador) contra otros galopantes no cavadores (Lámina 2.27C).

\section{Musculatura flexora y extensora del hombro}

La musculatura intrínseca de los hurones representa sólo entre el 35 y $40 \%$ de la musculatura del miembro anterior (Lámina 2.27A). A diferencia de especies cursoriales y otros arctoideos generalizados, la musculatura del hombro de los hurones se encuentra poco desarrollada tanto en relación a la masa del miembro anterior (Lámina 2.27D), como respecto a la musculatura intrínseca, representando menos del 30\% de la misma. Esto queda reflejado en una escápula relativamente reducida en mustelinos e ictoniquinos, lo que permitiría un mayor desplazamiento de la cintura $\mathrm{y}$, en consecuencia, mayor largo de zancada, aunque menor capacidad de control muscular sobre los movimientos complejos del hombro (ver "rotator cuff" en Leach 1977b, Feeney 1999).

Galictis cuja presenta marcadas subdivisiones del m. supraspinatus (Láminas 2.8 y 2.13), característica pocas veces descripta o ilustrada en otros Caniformia terrestres (e.g., Allen 1882, Fisher 1942, Feeney 1999, Evans y De Lahunta 2013). Una configuración similar ha sido 
descripta en Lo. canadensis (Fisher 1942), e ilustrada pero no descripta en Mu. putorius (Barone y Deustch 1953: 447, y Jouffroy 1971: Fig. 14). Funcionalmente, el vientre anterior del m. supraspinatus colaboraría en la extensión del hombro en posiciones agazapadas (crouched; Feeney 1999), y un mayor número de vientres permitiría una acción eficaz sobre un gran rango de posiciones durante la extensión del hombro, esperable en la locomoción de animales de miembros cortos. Galictis cuja, así como otros taxones que utilizan half-bound o bound durante las carreras (e.g., Mustela spp., Martes spp., V. peregusna; Gambaryan 1974, Leach 1977b), se destaca por presentar un desarrollo marcado de los extensores del hombro con respecto a los flexores (Lámina 2.27E-F), lo que se refleja en el mayor desarrollo relativo de las fosa supraespinal respecto a la infraespinal (Argot 2001, Salesa et al. 2008). Esto, al igual que lo observado en la relación protractores-retractores (ver discusión de musculatura extrínseca), estaría asociado a la mayor relevancia de la amortiguación del impacto luego de saltos, en vez de una propulsión activa con los miembros anteriores (Gambaryan 1974, Leach 1977b, Seckel y Janis 2008). Algo similar ocurre en las nutrias, las cuales realizan marchas terrestres de tipo bound o half-bound frecuentemente. En las nutrias más especializadas, convergentemente con lo que ocurre en muchos pinnípedos (Gambaryan y Karapetyan 1961, English 1977) estos rasgos suelen encontrarse exacerbados en relación a la necesidad de vencer la inercia del agua al adelantar y rotar los miembros durante nado (Savage 1957, Gambaryan y Karapetyan 1961, English 1977, Williams 1983a, Fish 1994; Lámina 2.27D-E). Contrariamente, los cursoriales y generalizados galopantes (algunos de ellos cavadores) requieren una gran masa muscular proximal que imprima la fuerza de propulsión y estabilización requeridas en estas actividades (e.g., Gu. gulo; Gambaryan 1974, Leach 1977b, Moore et al. 2013, Rose et al.2014). En estas especies, se observa un mayor desarrollo relativo de la musculatura del hombro, y específicamente de los flexores, lo que se encuentra acentuado en las especies de mayor tamaño corporal (Davis 1949, Jouffroy 1971, Hildebrand 1988; Lámina 2.27D-F).

\section{M. coracobrachialis y m. articularis humeri}

La presencia del $\mathrm{m}$. coracobrachialis es un carácter interesante desde el punto de vista filogenético, a nivel familiar y subfamiliar, más que funcional para especies vivientes, algo ya notado dentro de Feliformia por Taylor (1974). Este músculo es un extensor y aductor débil del hombro, pudiendo colaborar a la sujeción al sustrato (Taylor 1974, Fisher et al. 2009), aunque su aporte ha sido relativizado por Taylor (1974). Sin embargo, es destacable que este músculo se encuentre presente, dentro de Caniformia, sólo en algunos representantes de linajes trepadores (o cavadores en el caso único de melinos), pero siempre esté ausente en linajes acuáticos, terrestres (galopantes o half-bounders) y cursoriales. Dentro de Mustelidae, este músculo se encuentra ausente en todos los lutrinos, ictoniquinos, mustelinos y taxidinos (Cuvier 
y Laurillard 1849, Macalister 1873a, Lucae 1875, Alix 1876, Windle y Parsons 1897, Hall 1927, Barone y Deustch 1953, Fisher 1942, Williams 1955, Jouffroy 1971, Howard 1973, Quaife 1978, Moore et al. 2013) y presente en todos los melinos y guloninos (Cuvier y Laurillard 1849, Macalister 1873b, Mackintosh 1875, Windle y Parsons 1897, Hall 1926, Jouffroy 1971, English 1977, Leach 1977b, Scherling 1989, Feeney 1999; Apéndice 3.14, c.15, estados 1 y 2), mostrando una estrecha relación con la división subfamiliar planteada en los últimos trabajos moleculares (Koepfli et al. 2008, Sato et al. 2012). Dentro de Caniformia también se condice estrechamente con la estructura filogenética, y se encuentra ausente en cánidos (Haughton 1867c, Cuvier y Laurillard 1849, Windle y Parsons 1897, Langguth 1969,Evans y De Lahunta 2013), mefítidos (Hall 1926, Jouffroy 1971) y prociónidos derivados (Cuvier y Laurillard 1849, Mackintosh 1875, Allen 1882, Windle 1888, Windle y Parsons 1897, Beddard 1900, Feeney 1999), y presente en úrsidos (Haughton 1867d, Cuvier y Laurillard 1849, Windle y Parsons 1897, Shepherd 1883, Davis 1949, 1964), ailúridos (Fisher et al. 2009) y es variable en Po. flavus (Beswick-Perrin 1871, Windle y Parsons 1897, Julitz 1909; Apéndice 3.14, c.15). La presencia del m. coracobrachialis es considerada una condición plesiomórfica para Carnivora (ver Windle y Parsons 1897, Fisher et al. 2009); sin embargo, en las optimizaciones realizadas no se rescató esto, ni para Musteloidea, Arctoidea ni Caniformia (Apéndice 3.14, c.15), sino como una convergencia entre los grupos mencionados. Por otro lado, no puede descartarse que un muestreo más amplio pueda modificar estas reconstrucciones, especialmente en los nodos más basales.

El m. articularis humeri se encuentra presente en todos los linajes feliformes y caniformes exceptuando a mefítidos y varios linajes mustélidos (Windle y Parsons 1897, Hall 1926, Jouffroy 1971, Taylor 1974, Fisher et al. 2009; Apéndice 3.14, c.14, estado 0). Dentro de Mustelidae, su presencia es variable e informativa respecto al arreglo subfamiliar, dado que se encuentra (casi) exclusivamente presente en guloninos (Macalister 1873b, Mackintosh 1875, Windle y Parsons 1897, Hall 1926, Leach 1977b, Feeney 1999). Rompiendo este patrón, Macalister (1873a) registró la presencia del músculo en el brazo izquierdo de una nutria de la especie Ao. cinerea. Por otro lado, aquí (ver también Ercoli et al. 2014) se registra su presencia en todos los miembros analizados de Ga. cuja (Láminas 2.8 y 2.11), siendo esto una condición única dentro de hurones y de mustélidos no guloninos en general (además de la variante descrita por Macalister (1873a); Apéndice 3.14, c.14, estado 1). La presencia de un m. articularis humeri ha sido considerada tradicionalmente un carácter plesiomórfico para Carnivora (Fisher et al. 2009; Apéndice 3.14, c.10, estado 1), lo que indica una retención de un estado primitivo en Ga. cuja y guloninos, o una convergencia más que llamativa con linajes más basales (ver Ercoli et al. 2014). 


\section{Extensores del codo}

El desarrollo de los extensores del codo, relativo al brazo, así como en relación a los flexores del codo, es muy variable en Carnivora (Lámina 2.27G). El mayor desarrollo relativo de extensores sobre flexores del codo en mustélidos terrestres, nuevamente se relaciona al tipo de marcha (i.e., half-bound vs. galope) y la ausencia de especializaciones al trepado o manipulación de presas (e.g., félidos; Lámina 2.27G). En mustélidos cavadores, en quienes es necesaria una extensión aún más poderosa durante el cavado (Hildebrand 1988, Moore et al. 2013, , Rose et al. 2014), esta proporción es aún mayor. En Ga. cuja, los extensores del codo presentan una mayor masa relativa a los flexores y un mayor número de cabezas comparado con lo típicamente descripto en otros carnívoros. La relación entre extensores y flexores del codo en hurones, aunque sólo varía sutílmente, se encuentra, al parecer, directamente relacionada al grado de especialización al cavado, siendo mayor en ictoniquinos como Ga. cuja y $V$. peregusna, que en las especies de Mustela (Lámina 2.27G).

Como ocurre en todos los mustélidos, Ga. cuja posee un m. triceps brachii caput angulare (Láminas 2.8-9A), lo que ha sido descripto como una característica única de Mustelidae dentro de Carnivora. Sin embargo, también se encuentra presente en mefítidos (Mep. mephitis y S. gracilis; Hall 1926; así como Conepatus chinga; observación personal de M.D.E. y Mariano A. Ramírez), grupo actualmente considerado como musteloideo basal (Apéndice 3.14 , c.12, estados 2 y 3 ). Esto ha sido pasado por alto por otros investigadores y pone en tela de juicio cuántas veces o en qué momento de la historia evolutiva de los arctoideos surge este carácter. Por otro lado, no puede descartarse a priori que una cabeza angular incipiente, modificada o atrofiada, se encuentre como una subdivisión del $\mathrm{m}$. triceps brachii caput longum o como un origen extra del m. tensor fascia antebrachii en caniformes basales (e.g., cánidos, úrsidos; Davis 1964, Shepherd 1883, Windle y Parsons 1897, Evans y De Lahunta 2013). En prociónidos, resulta interesante la existencia de un segundo fascículo muscular delgado o slip caudal del $\mathrm{m}$. tensor fascia antebrachii que, en general, se desprende del $\mathrm{m}$. teres major (en cercanías del ángulo escapular), con inserción común con aquel originado en el m. latissimus dorsi (Cuvier y Laurillard 1849, Mackintosh 1875, Windle 1888, Beddard 1900, Julitz 1909, Feeney 1999). Más interesante es el caso de Bassaricyon alleni, donde el slip caudal es totalmente independiente, con una inserción más proximal, en la región del codo, coincidiendo totalmente con la descripción de un m. triceps brachii caput angulare, excepto por la ausencia de un origen óseo. En función de esto, es probable que la presencia de un "prototipo" de m. triceps brachii caput angulare sea una innovación originada más profundamente en la historia evolutiva de los carnívoros, como una especialización de un vientre del $\mathrm{m}$. tensor fascia antebrachii (ver reconstrucción de mapeo musculares, c.12, estado 1 para Arctoidea y sus nodos internos, ver también Ercoli et al. 2014), más que una sinapomorfía de Mustelidae. Por otro lado, un origen 
óseo de este músculo sería un carácter compartido, sea como una retención (indicativo de cercanía filogenética) o una convergencia (como indica la optimización), entre mustélidos y mefítidos (Apéndice 3.14, c.12, estados 2 y 3).

Dado que la hipótesis más robusta indica que el $\mathrm{m}$. tensor fascia antebrachii pudo haberse originado desde el m. triceps brachii (Diogo y Abdala 2010) y la presencia de un origen escapular del primero en algunos mamíferos (e.g., ardillas arborícolas; Jouffrouy 1971: Fig. 62B), la pérdida, adquisición o intercambio de vientres entre estos músculos parece haber sido común a través de la evolución de la musculatura de la cintura escapular en mamíferos.

La presencia de una cabeza angular independiente del $\mathrm{m}$. triceps brachii tiene implicancias funcionales durante la locomoción agazapada en galerías. Este vientre es el flexor del hombro y extensor del codo en posición flexionada de mayor ventaja mecánica. En conjunto con los flexores extrínsecos del hombro y las demás cabezas de m. triceps brachii permitiría actuar sobre estas articulaciones en un mayor rango de posiciones (similar a lo inferido por Alix (1876: 174) en $M u$. putorius). Esta característica, en conjunto con lo descripto en los apartados anteriores (e.g., protractores del brazo), permitiría una mayor longitud de zancada en relación a la locomoción agazapada y en el aterrizaje en la locomoción a saltos epigea. Spoor y Badoux (1986b) relacionaron de manera similar la presencia de fibras de la cabeza larga del m. triceps brachii alcanzando la cercanía del ángulo escapular con una mayor ventaja mecánica para la extensión del codo en posiciones flexionadas, y en este caso, lo asociaron a la actividad de levantar del suelo y transportar presas pesadas. Tanto Ga. cuja como otros hurones ictoniquinos y mustelinos transportan frecuentemente presas de gran tamaño relativo (Cabrera y Yepes 1940, Rowe-rowe 1978, Zielinski 2000), por lo cual es probable que el m. triceps brachii caput angulare tenga la misma función en estos linajes. Moore et al. (2013) realizó una interpretación funcional distinta pero válida sobre el mismo grupo muscular en Ta. taxus. Asoció el incremento de masa y la presencia de dos cabezas biarticulares del m. triceps brachii (caput longum y caput angulare) con el incremento del torque aplicado sobre el hombro y la fuerza de retracción del brazo en el cavado; aunque identificó incorrectamente a las cabezas del m. triceps brachii (Moore et al. 2013, Tabla 2, Fig. 2M; arrastrando un error desde Quaife 1978): como caput longum al caput angulare, caput mediale al caput longum y al parecer como caput laterale a los restantes. Además, la presencia de dos cabezas biarticulares, no es una característica única de tejones (contra Moore et al. 2013), sino una característica compartida al menos por todos los mustélidos y mefítidos.

La presencia y quizás el origen evolutivo de una cabeza angular independiente del $\mathrm{m}$. triceps brachii parece relacionarse a marchas bound y posiciones agazapadas. Futuros estudios de mustélidos y prociónidos half-bounders como Bassariscus astutus podrían dar más luz sobre la evolución de este rasgo. 
En la mayoría de los mustélidos existen tanto la cabeza angular del m. triceps brachii como el m. tensor fascia antebrachii. Las similitudes entre ambos músculos (e.g., inserción, posición e inervación; Evans y De Lahunta 2013) pueden llevar a errores nomenclaturales o de identificación, e.g., Leach (1977b: 37). Tanto en Ga. cuja como en nutrias no existe un m. tensor fascia antebrachii independiente y con origen sobre el $\mathrm{m}$. latissimus dorsi, lo cual puede considerarse una sinapomorfía del grupo Ictonychinae + Lutrinae (Ercoli et al. 2014, Apéndice 3.14, c.12, estado 3). En las nutrias, éste es considerado tradicionalmente ausente (Cuvier y Laurillard 1849) o confundido con el m. triceps brachii caput angulare (Haughton 1867a, Macalister 1873a, Lucae 1875, Fisher 1942, Howard 1973; Apéndice 3.14, c.13, estado 1) como también ocurre en el trabajo de Leach (1977b) para Martes spp. Scherling (1989) no menciona la presencia de un $\mathrm{m}$. tensor fascia antebrachii para Me. meles, pero sí lo hacen Cuvier y Laurillard (1849) para otros especímenes de la misma especie, pudiendo tratarse de una variante intraespecífica u omisión.

En Ga. cuja se encontró un paquete medial ("intermedio") al m. triceps brachii caput mediale principal (Láminas 2.11-12), que podría tentativamente representar a un m. tensor fascia antebrachii modificado con origen humeral. Lo mismo podría proponerse para la cabeza intermedia de En. lutris (Howard 1973). En ninguna otra nutria se registra una subdivisión asignable a un $\mathrm{m}$. tensor fascia antebrachii modificado (Ao. cinerea, Lo. canadensis y Lu. lutra; Cuvier y Laurillard 1849, Macalister 1873a, Lucae 1875, Fisher 1942). Por otro lado, en las nutrias se registra un $\mathrm{m}$. triceps brachii caput angulare amplio, con un origen hipertrofiado y extendido sobre el m. latissimus dorsi (Lo. canadensis y Ao. cinerea, y al parecer en mucho menor medida en Lu. lutra; Cuvier y Laurillard 1849, Haughton 1867a, Macalister 1873a, Lucae 1875, Fisher 1942), excepto en En. lutris (Howard 1973).

Aquí se propone tentativamente que al menos en los miembros del grupo Ictonychinae + Lutrinae el origen del $\mathrm{m}$. tensor fascia antebrachii habría migrado al húmero, o más probablemente, se habría perdido. En cualquiera de las dos circunstancias, el arreglo actual de estos músculos prioriza la extensión poderosa y precisa del codo (o flexión del hombro) por sobre la función de tensión de la fascia antebraquial, en relación a las adaptaciones locomotoras y comportamentales comentadas al menos para nutrias. Por otro lado, la ausencia del tensor en Ga. cuja, no puede ser relacionado claramente a este comportamiento, y puede indicar potencialmente una retención de un grado de adaptación al medio acuático ancestral más marcado (ver discusión del m. brachioradialis). Sea cual sea el camino evolutivo seguido, en las nutrias que utilizan los miembros anteriores más activamente durante el nado (e.g., Ao. cinerea; ver Macalister 1873a, Holmes 1980, Peigné et al. 2008) se registra el máximo desarrollo del m. triceps brachii caput angulare. En función de todo lo descripto, se hace evidente la necesidad de 
más y mejores descripciones de estos músculos, informativos desde el punto de vista filogenético y funcional.

El m. anconeus colabora principalmente en la extensión del codo. Sin embargo, se han sugerido otras diversas funciones, como la estabilización de la articulación del codo, evitando la flexión del mismo en posiciones estáticas, así como también la propriocepción (Fisher et al. 2009, Evans y De Lahunta 2013) y la pronación (Morales y Giannini 2013 y citas allí). Este músculo se encuentra bien desarrollado en cavadores y trepadores pequeños a medianos relativamente especializados (T. taxus, mefítidos, E. barbara, Martes spp., Leopardus wiedii; Macalister 1873b, Hall 1926, 1927, Leach 1977b, Scherling 1989, Morales y Giannini 2013), en carnívoros terrestres de gran tamaño (e.g., cánidos, hiénidos y algunos úrsidos y félidos; Shepherd 1883, Spoor y Badoux 1986b, Evans 1993, Evans y De Lahunta 2013; Morales y Giannini 2013), y presenta un desarrollo máximo en trepadores especializados de mediano a gran tamaño (Ailuropoda melanoleuca, Ailurus fulgens; Davis 1964, Fisher et al. 2009). Esto refleja la influencia tanto de los hábitos locomotores como el tamaño corporal en la morfología de este músculo (ver Peigné et al. 2008). Debido al pequeño tamaño y la ausencia de tales especializaciones, el m. anconeus está reducido en ictoniquinos, incluyendo Ga. cuja, y especialmente en los mustelinos (Alix 1876, Barone y Deustch 1953, Williams 1955).

\section{M. biceps brachii, $\mathbf{m}$. brachialis y $\mathbf{m}$. brachioradialis}

Galictis cuja, así como otros Caniformia estricta- o mayormente terrestres, presenta una versión simplificada de los flexores principales del codo (e.g., Taylor 1974, Feeney 1999; Láminas 2.12-14). Tanto cánidos, la mayoría de los mustélidos (excepto Ta. taxus) como mefítidos y algunos prociónidos, presentan $\mathrm{m}$. biceps brachii y $\mathrm{m}$. brachialis con un único vientre (Cuvier y Laurillard 1849, Macalister 1873a, b, Allen 1882, Windle y Parsons 1897, Lucae 1875, Mackintosh 1875, Alix 1876, Beddard 1900, 1905, Hall 1926, 1927, Fisher 1942, Barone y Deustch 1953, Williams 1955, Langguth 1969, Jouffroy 1971, Howard 1973, English 1977, Leach 1977b, Quaife 1978, Evans y Quoc An 1980, Scherling 1989, Feeney 1999, Evans y De Lahunta 2013). En los cánidos, hurones (e.g., ictoniquinos, mustelinos) y secundariamente algunas nutrias y mustélidos terrestres (e.g., Mellivora capensis) estos músculos presentan poca masa (Lucae 1875, Gambaryan 1974; Lámina 2.27H). Contrariamente, en muchas especies de arctoideos con hábitos locomotores trepadores (e.g., Ai. fulgens, guloninos, algunos prociónidos,

úrsidos; y también en los félidos; e.g., Ac. jubatus y Le. pardalis), o cavadores especializados (Ta. taxus), uno o ambos músculos presentan vientres extras y una mayor masa muscular relativa (Cuvier y Laurillard 1849, Beswick-Perrin 1871, Ross 1876, Shepherd 1883, Windle y Parsons 1897, Julitz 1909, Hall 1927, Davis 1949, 1964, Gambaryan 1974, Quaife 1978, Feeney 1999, Fisher et al. 2009, Julik et al. 2012; Lámina 2.27G-H). En estas especies trepadoras, una 
flexión poderosa del codo es necesaria para desplazarse manteniendo el cuerpo cerca del sustrato, aumentando la estabilidad y el control de movimientos, lo que es requerido especialmente durante trepado en ascenso o descenso en animales de gran tamaño (e.g., úrsidos), en donde la flexión del codo se opone a la fuerza de gravedad y controla la fuerza de extensión ejercida por los m. triceps brachii (Davis 1964, Taylor 1974, Leach 1977b, Hildebrand 1988, Van Valkenburgh 1987, Argot 2001). Por otro lado, los músculos extensores del carpo más proximales originados en el húmero (e.g., m. brachioradialis, m. extensor carpi radialis; Láminas $2.11,2.13$ ) también son importantes flexores del codo, y se encuentran claramente más desarrollados en estos linajes trepadores, lo cual puede verse tanto en la masa de estos músculos como en la extensión proximal de la cresta ectepicondilar, su región de origen (Láminas 2.11, 2.27H). De manera opuesta, los cánidos y mustélidos preponderantemente terrestres como Ga. cuja y otros hurones presentan tanto masa, número de vientres y áreas de origen de los flexores del codo reducidas (Láminas 2.11, 2.27H, ver más adelante). En los linajes más cursoriales dentro de Carnivora, como cánidos, hiénidos y Ac. jubatus, el m. brachioradialis se encuentra ausente o es vestigial (Cuvier y Laurillard 1849, Windle y Parsons 1897, Carlsson 1905, Feeney 1999, Evans y De Lahunta 2013).

En el caso de las nutrias, la masa y cantidad de vientres de flexores del codo (e.g., m. biceps brachii, $\mathrm{m}$. brachialis, $\mathrm{m}$. brachioradialis y $\mathrm{m}$. extensor carpi radialis) son similares o levemente mayor a lo observado en mustélidos trepadores y terrestres (Lámina 2.27H), contraponiéndose a lo esperado en función de los grandes esfuerzos requeridos durante el nado. Sin embargo, las nutrias presentan una característica particular y única dentro de Caniformia (aunque similar a lo observado en algunos feliformes; Reighard y Jennings 1901, Carlsson 1920, Julik et al. 2012). Tanto en Ao. cinerea, En. lutris y Lu. lutra (Cuvier y Laurillard 1849, Macalister 1873a, Lucae 1875, Windle y Parsons 1897, Howard 1973), el m. brachioradialis se origina en un sector proximal del húmero, en vez de originarse de la cresta ectepicondilar, siendo esta una sinapomorfía de nutrias derivadas (Enhydra + Lutra + Aonyx; Apéndice 3.14, c.27, estado 2). En el caso de feliformes como los félidos y vivérridos, el tipo de fibras, morfología acintada y posición de origen en la zona media de la diáfisis humeral del $\mathrm{m}$. brachioradialis se ha relacionado a la rápida contracción del miembro y movimientos necesarios durante la captura de presas con los miembros anteriores (Reighard y Jennings 1901, Hudson et al. 2011, Julik et al. 2012). En el caso de nutrias, la gran masa del músculo y su posición extrema de origen proximal incrementan al máximo la ventaja mecánica del músculo, convirtiéndose en el flexor más poderoso del codo. Esta configuración es concordante con la obtención de una silueta hidrodinámica, con los miembros próximos al cuerpo, y a los esfuerzos de adelantamiento de los mismos y los cambios de dirección en un medio denso (Savage 1957, Tarasoff et al. 1972, Williams 1983a, Hildebrand 1988, Fish 1994). Es también interesante 
destacar que para Lo. canadensis, el representante del linaje más basal de las nutrias (Lontra en Sato et al. 2012), Fisher (1942) describió un origen del m. brachioradialis extendido hasta el sector proximal del húmero, pero a la vez alcanzando la cresta ectepicondilar. Aunque los datos son escasos, esta condición quizás represente, desde una perspectiva evolutiva, una situación temprana e intermedia entre hurones y los linajes lutrinos más derivados (Apéndice 3.14, c.27; reconstrucción del nodo Lutrinae).

En Ga. cuja se han registrado variantes intraespecíficas con idéntica disposición a Lo. canadensis del origen del m. brachiorarialis (i.e., desde la cresta ectepicondilar hasta la región proximal del húmero; ver Fisher 1942, Ercoli et al. 2014; Apéndice 3.1). La presencia de este carácter miológico único compartido entre este ictoniquino y lutrinos basales es relevante debido a que estos grupos han sido recientemente propuestos como grupos hermanos (Sato et al. 2012), y podría representar una sinapomorfía de Ictonychinae + Lutrinae (Ercoli et al. 2014, reconstrucción ambigua, Apéndice 3.14, c.27). Por otro lado, más allá de que Galictis es un buen nadador eventual (Dalquest y Harvey 1951, Yensen y Tarifa 2003b; ver comentarios en sección 4.3), se han propuesto hábitos acuáticos más pronunciados para ictoniquinos fósiles (e.g., ${ }^{\dagger}$ Enhydrictis-Pannonictis group, ${ }^{\dagger}$ Trigonictis cookii, ${ }^{\dagger} T r$. "idahoensis" macrodon; Ficarelli y Torre 1967, Björk 1970, Kurtén y Anderson 1980, Schutz y Guralnick 2007, Grohé et al. 2010, Colombero et al. 2012). Como ha sido destacado en Ercoli et al. (2013, 2014), un gran número de características morfológicas compartidas en el clado Ictonychinae + Lutrinae + Mustelinae, pueden ser interpretadas como beneficiosas tanto para hábitos acuáticos como la locomoción en túneles. La peculiar condición de un m. brachioradialis poderoso y de origen extendido proximalmente en un ictoniquino lincodontinino, refuerza la posibilidad de un estado ancestral de hábitos más acuáticos de lo observado en los representantes actuales de esta subfamilia.

\section{Musculatura del antebrazo}

En todos los carnívoros, la cantidad de paquetes, y posiciones relativas de los pronadores y supinadores del antebrazo, y flexores y extensores carpales y digitales son muy similares, aunque existen diferencias funcionalmente significativas en el desarrollo relativo de la masa (Lámina 2.27I-K) y algunos cambios puntuales en la configuración de los mismos (e.g., Davis 1964, Feeney 1999, Antón et al. 2006, Fisher et al. 2009).

Muy pocas variantes en el antebrazo (Apéndice 3.14, desde c.17 en adelante) son prometedoras como indicativas de relaciones de parentesco. Sin embargo, es interesante destacar que para Mustelidae se obtuvo como ancestral para el grupo una condición reducida del origen del $\mathrm{m}$. extensor digiti I et II (Apéndice 3.14, c.18, estado 0; descripto como el vientre profundo del "extenseurs externes" en Alix 1876), distinto a lo observado en otros Caniformia. 
Esta condición se encuentra presente en tres subfamilias más basales (Taxidiinae, Melinae y Guloninae), pero se revierte en los mustélidos más derivados (Ictonychinae + Mustelinae + Lutrinae; Apéndice 3.14, c.18, estado 1), destacándose su interés al menos como carácter filogenéticamente informativo dentro de esta familia. También se reconocen como caracteres sinapomórficos de Guloninae la presencia de un origen ulnar del m. extensor carpi ulnaris y la fusión en origen de los mm. pronator teres y extensor carpi radialis (Ercoli et al. 2014; Apéndice 3.14, c.17, c. 19).

El desarrollo de las áreas de origen así como las masas de estos grupos musculares (Láminas 2.14, 2.27I-K) en Ga. cuja y en otros half-bounders especialistas en presas fosoriales (ictoniquinos y mustelinos), es intermedio a lo observado en cursoriales (e.g., Canis lupus, Hyaena hyaena; Spoor y Badoux 1986b, Evans 1993, Feeney 1999) y en generalizados galopantes, fosoriales especializados (e.g., Meles meles, Taxidea taxus; Hall 1927, Quaife 1978, Scherling 1989, Moore et al. 2013) o trepadores especializados (e.g., Ailurus fulgens, prociónidos, vivérridos y herpéstidos; Taylor 1974, McClearn 1985, Fisher et al. 2009). El menor desarrollo de estos grupos musculares en hurones respecto a otros mustélidos terrestres puede relacionarse directamente a capacidades reducidas de manipulación y menor importancia de movimientos complejos poderosos del antebrazo durante la locomoción a saltos (Dücker 1968, Gambaryan 1974, Ben-david et al. 1991, Wilson y Mittermeier 2009). Una situación extrema de reducción de masa es la que se da en especies cursoriales, especialmente en aquéllas que no utilizan los miembros anteriores para dominar a sus presas (i.e., hiénidos y cánidos; e.g., Hildebrand 1988, Feeney 1999). Especies cursoriales presentan a su vez, entre otras modificaciones, reducción en número de tendones de inserción del $\mathrm{m}$. flexor digitorum profundus, reducción o ausencia del origen radial de la cabeza radial del último flexor, y la mencionada ausencia o presencia vestigial del m. brachioradialis (Watson 1882, Windle y Parsons 1897, Spoor and Badoux 1986b, Evans 1993, Feeney 1999, Evans y De Lahunta 2013).

En las nutrias, la masa relativa de los supinadores y pronadores es, en general, similar al de arctoideos fosoriales o trepadores de gran tamaño corporal, mientras que el desarrollo de flexores y extensores es más similar al de los hurones (Lámina 2.27I-K). Es interesante destacar que estos cuatro grupos musculares son progresivamente mayores en los linajes que utilizan más frecuentemente sus miembros anteriores para el nado o mayores habilidades de manipulación, desde una baja proporción en En. lutris, media en Lu. lutra, y alta en Ao. cinerea (Willemsen 1980a, b, Kruuk 2006, Wilson y Mittermeier 2009, ver también Gambaryan y Karapetyan 1961).

La extensión proximal de la muesca de origen del $\mathrm{m}$. flexor digitorum profundus caput ulnare, así como el desarrollo del margen distal del entepicóndilo del húmero (área de origen de las cabezas humerales del $\mathrm{m}$. flexor digitorum profundus), son excelentes indicadores 
osteológicos de estos cambios de masa muscular: con máximo desarrollo en especies trepadoras y cavadoras, intermedio en half-bounders, y mínima en especies cursoriales (e.g., Argot 2001, Rose et al. 2014; ver sección 4.3.4, Húmero).

Muchas de las descripciones conocidas del $\mathrm{m}$. palmaris longus y $\mathrm{m}$. flexor digitorum superficialis en carnívoros presentan claros problemas nomenclaturales (ver Spoor y Badoux 1986a, Julik et al. 2012) o errores de identificación, lo que sumado al gran número de variantes en las regiones de orígenes e inserciones de estos músculos dificultan en gran medida una comparación precisa (Windle y Parsons 1897). El origen del m. flexor digitorum superficialis se da frecuentemente sobre el m. palmaris longus y/o cabezas humerales del m. flexor digitorum profundus (e.g., Fisher 1942, Williams 1955, Davis 1964). Sin embargo, para algunos clados dentro de Carnivora (e.g., hiénidos, cánidos, algunos musteloideos y úrsidos) se ha descripto tradicionalmente como alcanzando directamente el entepicóndilo humeral (Windle y Parsons 1897, Fisher et al. 2009). Esto es cierto para hiénidos y algunos otros Feliformia (Spoor y Badoux 1986a, b). Sin embargo, las descripciones de especies caniformes que presentan orígenes humerales del $\mathrm{m}$. flexor digitorum superficialis son breves, antiguas y parecen contener errores de identificación o nomenclaturales. Como ejemplo de posibles errores de identificación, Shepherd (1883) consideró ausente al m. palmaris longus en Ursus americanus, pero es muy factible que el autor no lo haya diferenciado (por omisión o fusión real) del m. flexor digitorum superficialis, describiendo en consecuencia erróneamente el origen de este último desde el húmero. Algo similar ha ocurrido para Procyon lotor en Allen (1882), Potos flavus en BeswickPerrin (1871; error corregido posteriormente por Julitz 1909, aunque utilizando otra nomenclatura) y Nasua nasua en el trabajo de Cuvier y Laurillard (1849). Estos autores describen un "flexor sublimis digitorum" que correspondería al $\mathrm{m}$. flexor digitorum superficialis más una cabeza humeral del $\mathrm{m}$. flexor digitorum profundus, lo que queda en evidencia cuando describen uno de los tendones de inserción fusionándose al tendón flexor profundo común (Cuvier y Laurillard 1849; placa 96: fig. 3; Beswick-Perrin 1871, Allen 1882). En conclusión, teniendo en cuenta esta reinterpretación, no existen evidencias de un $\mathrm{m}$. flexor digitorum superficialis de origen humeral en todo Caniformia, contrario a lo previamente sugerido (e.g., Fisher et al. 2009), y oponiéndose a la hipótesis de que éste sería un rasgo plesiomórfico al menos en Caniformia (ver también Fisher et al. 2009).

\section{Musculatura del autopodio}

Dentro de Carnivora, los músculos de la mano han sido descriptos por distintos autores con nomenclaturas muy diversas, dificultando los análisis comparativos. La literatura está plagada de casos de sinónimos y homónimos. Windle y Parsons (1897), Spoor y Badoux (1986a) y recientemente Fisher et al. (2009) y Julik et al. (2012) han hecho importantes 
esfuerzos para solucionar estos problemas (ver Jouffroy 1971, y Diogo y Abdala 2010 para similares enfoques a un nivel taxonómico más amplio).

La musculatura de la mano de Ga. cuja (Láminas 2.15-17) se corresponde directamente con el plan general de Carnivora, sin presentar mayores variaciones. Sin embargo, en los especímenes analizados hemos detectado la presencia del $\mathrm{m}$. abductor digiti II y $\mathrm{m}$. abductor digiti IV (este último no presente en la Nómina Anatómica Veterinaria), ambos prácticamente nunca descriptos como tales en especies de Caniformia, muy probablemente por omisión más que por una ausencia real, debido a que estos paquetes quedan ocultos entre las falanges y son fácilmente confundibles con los $\mathrm{m}$. flexores breves digitorum. Excepciones a esto son los registros de uno o ambos paquetes en un prociónido (Mackintosh 1875), un mefítido (vientre "a" del "m. adductor digiti secundi"; Hall 1926), mustélidos (una marta, un tejón; Hall 1926, 1927, y dos nutrias; Howard 1973 y músculos nominados como "lateral interosseous of digiti I" y "medial interosseous of digiti V" en Fisher 1942), y un úrsido (descriptos dentro de los mm. interossei por Davis 1964). En Ga. cuja se registra la presencia de ambos paquetes por primera vez en un hurón, indicando que la presencia de estos vientres sería más común en especies Musteloidea que lo descripto en bibliografía.

El $\mathrm{m}$. flexor digitorum brevis manus es un músculo superficial al $\mathrm{m}$. flexor digitorum superficialis, con forma de pera (pear-shaped), que se origina desde los tejidos conectivos que cubren al hueso accesorio y se inserta, en general, sobre la segunda falange del dígito $\mathrm{V}$ (Beswick-Perrin 1871, Jouffroy 1971, McClearn 1985, Fisher et al. 2009, Diogo y Abdala 2010). Dentro de Caniformia, la presencia de este músculo se ha registrado en todos los prociónidos (" $\varphi$ " partiendo de " $\alpha$ " de Cuvier y Laurillard 1849:pl. 96, m. "flexor minimi digiti longus" de Beswick-Perrin 1871, músculo innominado en Windle 1888, m. "flexor minimi digiti" de Allen 1882, Windle y Parsons 1897, m. "flexor digiti brevis manus" McClearn 1985; $\mathrm{y}$ tentativamente incluido en el "m. flexor digitorum sublimis" o m. "adductor minimi digiti" por Mackintosh 1875, Julitz 1909, ver también Jouffroy 1971), y ailúridos (Antón et al. 2006, Fisher et al. 2009). En úrsidos, parece estar presente (ver descripciones de m. "flexor sublimis" en Kelley 1888, m. "flexor digiti quinti brevis" y m. "flexor brevis digitorum manus" en Davis 1964, contra Fisher et al. 2009). En función del único registro conocido, puede considerarse ausente en mefítidos (Hall 1926, correspondiendo el m. "flexor digiti quinti brevis" al $\mathrm{m}$. adductor digiti V) así como en cánidos (Windle y Parsons 1897, Feeney 1999, Evans y De Lahunta 2013) y muchos mustélidos (Macalister 1873b, Mackintosh 1875, Windle y Parsons 1897, Hall 1926, 1927, Scherling 1989), incluido Ga. cuja (Apéndice 3.14, c.26).

El único mustélido en donde tradicionalmente se ha considerado presente el $\mathrm{m}$. flexor digitorum brevis manus es en el espécimen de Mustela putorius de Alix (1876) (ver Windle y Parsons 1897, Fisher et al. 2009), aunque en su revisión, Jouffroy (1971) sugiere que el músculo 
está ausente en mustélidos. Lo que puede considerarse como un m. flexor digitorum brevis manus en esta especie, parece encontrarse en otros mustelinos y lutrinos para los que se cuenta con descripciones lo suficientemente claras (Mustela vison, En. lutris y probablemente en Lo. canadensis; Fisher 1942, Williams 1955, Howard 1973), aunque no es clara la situación en otros lutrinos (Macalister 1873a, Lucae 1875). En estas especies se describe a este músculo como un vientre del $\mathrm{m}$. flexor digitorum superficialis originándose parcialmente desde la superficie ventral o lateral del m. palmaris longus (Apéndice 3.14, c.26, estado 2), evidenciándose en este origen una diferencia clara respecto al $\mathrm{m}$. flexor digitorum brevis manus de otros arctoideos (Alix 1876, Fisher 1942, Williams 1955, Howard 1973; Apéndice 3.14, c.26, estado 1). En particular para Lo. canadensis (Fisher 1942), llamativamente el total del m. flexor digitorum superficialis (incluyendo al vientre para el dígito $\mathrm{V}$ ) se origina desde el $\mathrm{m}$. palmaris longus.

Esta situación de naturaleza de origen y posición relativa diferentes, permiten al menos establecer la posibilidad de que el músculo considerado como $\mathrm{m}$. flexor digitorum brevis manus en $M u$. putorius, y por extensión en mustelinos y lutrinos, sea en realidad un músculo diferente, originado como una nueva variante del $\mathrm{m}$. flexor digitorum superficialis, no necesariamente homólogo al $\mathrm{m}$. flexor digitorum brevis manus de arctoideos basales y feliformes. Sin embargo, para Taxidea taxus, la continuación palmar innominada del m. palmaris longus "B" de Hall (1927) y el "flexor digiti quinti brevis" de Quaife (1978) son muy similares al m. flexor digitorum brevis manos arctoideo (algo similar ocurre con las pocas fibras originadas desde el ligamento transverso en Ma. americana; Hall 1926). Aunque considerando la presencia potencial de este músculo en el mustélido más basal y su subsecuente pérdida en clados más derivados sería razonable, es primordial asegurar su presencia mediante nuevas disecciones para confirmar este escenario.

\subsubsection{Miembro posterior}

\section{M. biceps femoris y $\mathbf{m}$. abductor cruris caudalis}

Ambos músculos tienen una configuración mayormente constante dentro de Carnivora. Animales que requieren una poderosa extensión de sus miembros posteriores (e.g., half-bound, padding) o mantener los miembros dirigidos caudalmente en forma sostenida (e.g., buceo) muestran inserciones de estos músculos alcanzando la mitad distal de la tibia (Macalister 1873a, Lucae 1875, Windle y Parsons 1898, Fisher 1942, Savage 1957, Gambaryan y Karapetyan 1961, Tarasoff 1972, Tarasoff et al. 1972, Howard 1975; ver Lámina 2.21). Por el contrario, en depredadores ambulatorios o cursoriales, así como muchos trepadores, que usualmente presentan pasos energéticamente menos costosos para los miembros posteriores (e.g., Nasua, Gulo, Canis, Vulpes, Hyaena), el m. biceps femoris y el m. abductor cruris caudalis, así como otros flexores de la rodilla (e.g., m. gracilis), se insertan más proximalmente (Mackintosh 1875, 
Savage 1957, Gambaryan 1974, Spoor y Badoux 1988, McClearn 1992, Evans y De Lahunta 2013), reduciendo de esta manera la masa muscular distal de miembro y la inercia del mismo, y favoreciéndose los movimientos rápidos (Hildebrand 1988).

El $\mathrm{m}$. abductor cruris caudalis presenta variantes en su origen de interés filogenético (Apéndice 3.14, c.39). Un origen restringido al ligamento sacrotuberoso o tuberosidad isquiática, optimizado en forma ambigua para Arctoidea y Caniformia, está solamente presente en Ursidae, Canidae y Meles meles (Apéndice 3.14, c.39, estado 1), quizás en relación a una cola reducida en muchos casos. En muchos de los musteloideos (y es la condición ancestral reconstruida para el grupo), incluyendo a Ga. cuja, el origen del $\mathrm{m}$. abductor cruris caudalis es más caudal (Apéndice 3.14, c.39, estados 3 y 4). Una reversión a una posición relativamente más cranial del músculo se observa en lutrinos y mustelinos, así como en los tejones (Hall 1927, Fisher 1942, Williams 1955, Bisaillon 1976, Scherling 1989), o incluso en el nodo Mustelidae (reconstrucción ambigua; Fig. S1G).

\section{Gluteofemoralis}

El m. gluteofemoralis está ausente o reducido y fusionado al $\mathrm{m}$. gluteus superficialis en Ga. cuja, Poecilictis libyca, Melogale personata, Taxidea taxus y algunos especímenes de Lutra lutra y Meles meles, cánidos y úrsidos, así como en algunos herpéstidos (Haughton 1867a, Parsons 1898, Windle y Parsons 1898, Beddard 1905, Hall 1927, Williams 1955, Scherling 1989, Feeney 1999, Fisher et al. 2008, Hudson et al. 2010). Por el contrario, se encuentra presente y bien diferenciado en guloninos, mustelinos, la mayoría de los lutrinos, mefítidos (pero a veces muy reducido), prociónidos (con la posible excepción de Procyon; Allen 1882, Windle 1888, Gowell 1897, Jouffroy 1971, Feeney 1999), y la mayoría de los feliformes (Macalister 1873b, Lucae 1875, Mackintosh 1875, Alix 1876, Parsons 1898, Beddard 1900, Hall 1926, Fisher 1942, Ray 1949, Williams 1955, Davis 1964, Howard 1975, Bisaillon 1976, Evans y Quoc An 1980, Spoor y Badoux 1988, Fisher et al. 2008, Carlon y Hubbard 2012). La ausencia o fusión con el $\mathrm{m}$. gluteus superficialis del $\mathrm{m}$. gluteofemoralis ha sido considerada tradicionalmente como una condición derivada dentro de Carnivora (Fisher et al. 2008), y la condición presente en familias basales de Canoidea (Apéndice 3.14, c.31, estado 0). Por otro lado, la condición ancestral de Musteloidea corresponde a la presencia del m. gluteofemoralis, revertida en el nodo de Procyon, y en algunos taxones mustélidos, incluyendo al nodo Ictonychinae (Apéndice 3.14, c.31).

Es notable la ausencia o reducción compartida de un vientre $\mathrm{m}$. gluteofemoralis independiente en muchos carnívoros ambulatorios o cursoriales que no realizan rápidos cambios de dirección cuando corren y donde la cola no es usada como un órgano de balance (Taylor 1970, Tarasoff et al. 1972, McClearn 1992, Walker et al. 1998). Sin embargo, la misma 
característica es observada en muchos ictoniquinos y algunos mustelinos, aunque estos linajes sí realizan importantes cambios de dirección durante carreras rápidas de tipo half-bound (Cabrera y Yepes 1940, Yensen y Tarifa 2003a, b, King y Powell 2007), y es probable que estos estén más relacionados a una región tóraco-lumbar móvil que a la presencia de una cola poderosa y larga (e.g., hurones en general y específicamente Mu. erminea y Ly. patagonicus, ver más adelante), lo que también se desprende del análisis de la proporción sacro-caudal (ver comentarios de región sacro-caudal en secciones 3.4 y 4.3.2). Esto también puede estar relacionado a la reducción de la musculatura aductora-abductora de los miembros (ver más abajo).

Por último, es necesario destacar que en algunos miembros de Ga. cuja, el m. gluteus superficialis se encuentra subdividido, y presenta una porción caudal que recuerda en posición al m. gluteofemoralis. Es posible que estas fibras correspondan a un remanente de este último.

\section{Grupo gluteus, m. piriformis y $\mathbf{m}$. articularis coxae}

En Ga. cuja y otros mustélidos no cursoriales pero relativamente ágiles, los extensores rápidos de la cadera (grupo gluteus) se encuentran sutílmente desarrollados en comparación con la masa muscular total del miembro y en relación a otros grupos extensores (e.g., grupo hamstring; Apéndice 2.28C-D, Tabla 3.2). Esto se asociaría a la capacidad de realizar poderosos saltos y a la ausencia de especializaciones cursoriales (Maynard Smith y Savage 1956, Gambaryan 1974).

El grado de fusión observado entre el $\mathrm{m}$. piriformis y el $\mathrm{m}$. gluteus medius es variable en Ga. cuja y es una condición frecuente dentro de Musteloidea (Fisher et al. 2008, pero ver Lucae 1875, Mackintosh 1875, Alix 1876, Hall 1926; Ercoli et al. 2013; Apéndice 3.14, c.32). Por el contrario, estos músculos se encuentran totalmente separados en otros grupos de carnívoros, como feliformes, cánidos y úrsidos (Watson 1882, Davis 1964, Feeney 1999, Fisher et al. 2008, Carlon y Hubbard 2012; Apéndice 3.14, c.31, estado 0). Dada la gran variabilidad intraespecífica y el bajo número de especímenes analizado para cada taxón más datos son requeridos para una comprensión más acabada de este rasgo.

El m. articularis coxae está ausente en Ga. cuja, como también fue reportado para la mayoría de las especies arctoideas (excepto algunos especímenes de Me. meles, Mu. putorius y algunos úrsidos; Haughton 1867b, Windle y Parsons 1898, Davis 1964, Souteyrand-Boulenger 1969, Bisaillon 1976, Scherling 1989; Apéndice 3.14, c.36, estado 0). Cuando está presente, este músculo se ha relacionado a la propriocepción y el control motor en la locomoción en especies cursoriales, y a un amplio rango de movimientos de flexo-extensión de la cadera (Souteyrand-Boulenger 1969, Fisher et al. 2008). 


\section{M. sartorius}

En Ga. cuja, como en otros arctoideos (excepto en algunos especímenes de Nasua; Mackintosh 1875, Apéndice 3.14, c.35, estado 0), el m. sartorius presenta un único vientre (Láminas 2.20-21 y 2.24), y la misma condición fue descripta para la mayoría de los feliformes no cursoriales (Lucae 1875, Watson 1882, Windle y Parsons 1898, Hall 1926, Davis 1964, Scherling 1989, Feeney 1999, Fisher et al. 2008, Carlon y Hubbard 2012, pero ver Jouffroy 1971). En cánidos y hiénidos es siempre doble (Haughton 1867c, Watson 1882, Windle y Parsons 1898, Spoor y Badoux 1988, Feeney 1999, Evans y De Lahunta 2013). La presencia de dos vientres independientes estos últimos linajes, compuestos por especies mayormente cursoriales, en donde el vientre caudal extiende y el caudal flexiona la rodilla, puede ser entendido como un sistema estabilizador de movimientos de la articulación durante carreras (Gambaryan 1974, Evans 1993). Un único vientre, por otro lado, no puede ser asignado a una condición primitiva o derivada en carnívoros (Fisher et al. 2008).

\section{Aductores y abductores de la cadera}

Debido a las dificultades de establecer homologías dentro de las variantes terminológicas de las distintas fuentes bibliográficas, Fisher et al. (2008) sugirieron comparar a la musculatura aductora como un todo (ver también Jouffroy 1971). Estos autores encontraron un número de vientres aductores aproximadamente constante por familia, exceptuando los prociónidos. Sin embargo, la recopilación de una mayor cantidad de datos y la optimización de caracteres aquí presentada (ver también Ercoli et al. 2013), sugieren que ésta es una condición altamente variable dentro de Arctoidea, incluso a nivel familiar (Apéndice 3.14, c.37). Por ejemplo, en Mustelidae puede considerarse como condición ancestral la presencia de cuatro vientres (ver Fisher et al. 2008), pero en Ga. cuja, así como en algunos otros mustélidos (e.g., Martes foina, Mu. putorius; Cuvier y Laurillard 1849; Mackintosh 1875, Alix 1876), existen cinco vientres. Estas diferencias, sumado a las diferencias interpretativas propias de la subjetividad de cada investigador a la hora de subdividir el complejo grupo aductor, indican un pobre potencial de información filogenética para este carácter (ver Apéndice 3.14, c.37). Fisher et al. (2008) sugirieron que un mayor número de paquetes de la masa aductora puede relacionarse a movimientos más precisos en prociónidos y Ailurus fulgens, vinculado al balance y movimientos en el sustrato arbóreo, pero esto último no coincide con los numerosos vientres registrados en mustélidos mayormente terrestres como Ga. cuja (Láminas 2.20-21 y 2.23, tomo II) y $M u$. putorius (Alix 1876), ni el número moderado presente en los carnívoros arborícolas Potos flavus (cuatro vientres; Beswick-Perrin 1871) o Bassaricyon alleni (tres vientres; Beddard 1900). 
La masa relativa de los músculos aductores y abductores ha sido directamente relacionada a la habilidad de realizar cambios rápidos de dirección durante movimientos de alta velocidad en algunos mamíferos (e.g., Lagomorpha; Williams et al. 2007). Esta función es asistida por la cola en aquellos animales con colas largas (e.g., muchos felidos, prociónidos y vivérridos; Taylor 1970, McClearn 1992, Walker et al. 1998, Youlatos 2003). Aunque los mustélidos weasel-like han sido descriptos como capaces de realizar abruptos cambios de dirección durante carreras (Cabrera y Yepes 1940, Yensen y Tarifa 2003a, b, King y Powell 2007), estos tienen miembros y colas de longitud moderada a breve relativa al tronco (ver sección 4.3.2), y muy bajos valores de masa relativa aductora y abductora de los miembros en comparación con otros predadores ágiles (e.g., zorros, félidos, algunos prociónidos; ver también Feeney 1999; Lámina 2.28A). En estas especies, así como la propulsión es llevada a cabo en gran parte por la musculatura epiaxial (Gambaryan 1974), es posible que los cambios abruptos en la dirección sean logrados mediante la contracción asimétrica de la musculatura axial (e.g., sistema iliocostalis), particularmente bien desarrollada en mustélidos, y que sólo secundariamente existan movimientos rápidos caudales.

\section{M. semimembranosus}

Dentro de Carnivora, el número de vientres de este músculo varía entre uno y tres en diferentes familias, aunque con importantes variantes intra- e interespecíficas descriptas (e.g., Ailurus fulgens, Procyonidae; ver Fisher et al. 2008). Dentro de los mustélidos compilados por Fisher et al. (2008), el m. semimembranosus posee únicamente un vientre. Sin embargo, muchos mustélidos presentan un m. semimembranosus compuesto por dos vientres, como Ga. cuja (Láminas 2.20, 2.21B, 2.23-24), Gulo gulo, Martes spp., Meles meles, Mellivora capensis, Melogale personata, Mustela spp., Taxidea taxus (separación parcial en dos vientres), Vormela peregusna y muchas nutrias (Enhydra lutris, Lontra canadensis, algunos especímenes de Lutra lutra) (Beddard 1905, Hall 1926, 1927, Fisher 1942, Jouffroy 1971, Gambaryan 1974, Bisaillon 1976, Scherling 1989, Feeney 1999). Mephitidae y Procyonidae (excepto Nasua; Mackintosh 1875) también presentan dos vientres (e.g., Allen 1882, Windle 1888, Gowell 1897, Hall 1926, Feeney 1999). La separación en dos vientres puede deberse a una subdivisión de funciones: extensión de la cadera y flexión de la rodilla, lo que aseguraría un amplio rango y precisión de movimiento. La subdivisión de este músculo habría sido la condición plesiomórfica para Arctoidea, así como en los nodos Mephitidae, Mustelidae; Procyonidae y Ursidae. Por otro lado, un vientre simple del $\mathrm{m}$. semimembranoso es una condición derivada adquirida en el nodo Bassaricyon + Nasua y adquirida convergentemente y en forma variable intraespecíficamente en múltiples especies musteloideas (Apéndice 3.14, c.42, Ercoli et al. 2013). 
Es preciso mencionar que algunos autores usan el término "pre-semimembranosus" para referirse al vientre más craneal del m. semimembranosus (e.g., Windle y Parsons 1898, Jouffroy 1971), mientras que otros autores usan el término al parecer para subdivisiones del $\mathrm{m}$. gluteofemoralis (e.g., Fisher 1942, Scherling 1989). Por otro lado, algunos incluyen al vientre craneal del m. semimembranosus dentro de la masa aductora (e.g., Alix 1876).

\section{M. semitendinosus}

En Ga. cuja, como es típico para mamíferos (Jouffroy 1971), el m. semitendinosus tiene dos vientres, uno de origen en la tuberosidad isquial (vientre isquial) y otro originado en la $\mathrm{Ca} 2$ (vientre caudal; Láminas 2.19-2.21B). El vientre isquial está generalmente presente y bien desarrollado dentro de Carnivora, aunque en algunas nutrias y en Mustela vison está reducido (Cuvier y Laurillard 1849, Macalister 1873a, Lucae 1875, Windle y Parsons 1898, Williams 1955; obtenido en ambos linajes convergentemente; Apéndice 3.14, c.41, estado 1) y en otras nutrias está ausente (algunos especímenes de Lontra canadensis y Enhydra lutris; Fisher 1942, Howard 1975). El vientre caudal se encuentra presente en algunos Feliformia (vivérridos y herpéstidos), prociónidos (excepto en Bassaricyon alleni; Beddard 1900), y la mayoría de los mustélidos (Windley Parsons 1898, Jouffroy 1971: 294, Taylor 1976, Fisher et al. 2008). La reconstrucción de estados sugiere la adquisición convergente del paquete caudal en prociónidos y mustélidos derivados (Apéndice 3.14, c.40, estado 1); aunque un escenario de adquisición más temprana y pérdida en linajes especializados como los tejones también sería posible. Dentro de lutrinos y mustelinos, el paquete caudal se origina desde la primera o algunas de las primeras vértebras caudales (Aonyx cinerea, En. lutris, Lutra lutra, Mu. nigripes, Mu. putorius, Mu. vison; Macalister 1873a, Alix 1876, Windle y Parsons 1898, Williams 1955, Bisaillon 1976), y es relativamente amplio en el primer clado y reducido en el segundo (Apéndice 3.14, c.40). En muchos ictoniquinos y todos los guloninos el vientre caudal está también presente (e.g., Ga. vittata, Poecilictis libyca; Windle y Parsons 1898), pero su origen se restringe mayormente a la Ca2 al menos en Ga. cuja, Eira barbara y Martes americana (Macalister 1873b, Windle y Parsons 1898, Hall 1926, este estudio; Apéndice 3.14, c.40, estado 2). Este vientre también está presente en Melogale personata (Beddard 1905), aunque sin haberse descripto la posición de origen. Al mismo tiempo, este vientre del m. semitendinosus se encuentra ausente en Ailurus fulgens, cánidos, félidos, hiénidos, mefítidos, úrsidos (Beswick-Perrin 1871, Macalister 1873a, Allen 1882, Watson 1882, Windle 1888, Hall 1926, 1927, Ray 1949, Davis 1964, Jouffroy 1971, Bisaillon 1976, Fisher et al. 2008, Carlon y Hubbard 2012, Evans y De Lahunta 2013), y algunos mustelinos, incluyendo al skunk-like ictoniquino Ictonyx striatus (Windle y Parsons 1898), los tejones Meles meles y Taxidea taxus (Windle y Parsons 1898, Hall 1927, Scherling 
1989) y algunos especímenes de Martes spp. (e.g., Mackintosh 1875) y Mustela putorius (Macalister 1873b, Windle y Parsons 1898, Bisaillon 1976; Apéndice 3.14, c.40, estado 0).

Estas variantes indican que la configuración de origen del $\mathrm{m}$. semitendinosus parece ser filogenéticamente informativo tanto a nivel familiar como subfamiliar (Jouffroy 1971, Ercoli et al. 2013). Desde un punto de vista funcional, la presencia de dos vientres del $\mathrm{m}$. semitendinosus en grupos con hábitos locomotores relativamente generalizados (incluyendo marchas bound y half-bound; Gambaryan 1974) implica un incremento del número de fascículos (y en algunos casos, de masa muscular) de la musculatura hamstring, que podría vincularse con una mayor precisión y rango de movimientos, y quizás un incremento del largo de zancada (Hildebrand 1988). Por otro lado, en grupos de estilos locomotores más especializados, como semiacuáticos, cursoriales, ambulatorios estrictamente terrestres, se registra la presencia de uno u otro vientre, reflejando capacidades y posiciones específicas diferentes. En particular, dentro de la subfamilia Lutrinae, un origen amplio y exclusivamente o casi exclusivamente caudal maximiza la ventaja mecánica del $\mathrm{m}$. semitendinosus en una posición extendida de la cadera y flexionada de la rodilla, en relación a mantener los miembros posteriores en dirección caudal durante el buceo (Maynard Smith y Savage 1956, Savage 1957, Gambaryan y Karapetyan 1961, Tarasoff 1972). Un origen restringido al isquion parece ser la condición ancestral de Arctoidea (Ercoli et al. 2013), y puede estar relacionado a una posición de la cadera típicamente más flexionada, la rodilla más extendida y una posición del miembro posterior extendida bajo el cuerpo (depredadores de gran tamaño, cursoriales y ambulatorios).

\section{M. fibularis brevis y $\mathbf{m}$. extensor digitorum lateralis}

En Ga. cuja, la arquitectura del $\mathrm{m}$. fibularis brevis y el $\mathrm{m}$. extensor digitorum lateralis es inusual y diferente de la mayoría de los carnívoros, pero similar a lo observado en algunos lutrinos, guloninos y mustelinos. El m. extensor digitorum lateralis tienen muchos puntos de interacción con el $\mathrm{m}$. fibularis brevis en el aspecto lateral del pie. El $\mathrm{m}$. fibularis brevis es complejo y está dividido en dos vientres que se originan desde la mitad distal de la fíbula, formando uno de sus tendones de inserción un anillo para el pasaje del segundo (Láminas 2.22, 2.24). Dentro de Mustelidae, relaciones similares y complejas de estos dos músculos se han descripto para Enhydra lutris (Howard 1975), Mustela nigripes (Bisaillon 1976), Mu. putorius (Alix 1876), un espécimen de Martes pennanti (Feeney 1999), e ilustrado pero no descripto para Ma. foina (Cuvier y Laurillard 1849). Bisaillon (1976) relacionó esta configuración compleja a la reducción de la capacidad de flexión y rotación del tobillo, aunque esta interpretación no se encuentra sustentadas por observaciones comportamentales. La optimización de caracteres (Ercoli et al. 2013) sugiere que esta condición se desarrolló al menos cuatro veces dentro de Mustelidae (Apéndice 3.14, c.43, estados 1 y 2). Sin embargo, dado que esta característica es un 
detalle difícil de registrar y complejo, es probable que se hayan codificado falsos "ausentes" en algunas de las especies mustélidas que fueron descriptas con menor detalle por previos investigadores (e.g., Taxidea taxus; Hall 1927). De esta manera, se pone en duda si la presencia de esta interacción compleja corresponde a múltiples convergencias (como indica la optimización; Apéndice 3.14, c.43) o es un carácter heredado compartido, obviado en algunas descripciones previas.

\section{Musculatura del tobillo y los dígitos}

En Ga. cuja, la mayoría de los extensores del tobillo originados en el zeugopodio, i.e., fibularis brevis, m. extensor digitorum lateralis, m. flexor digitorum medialis, m. tibialis caudalis y en especial el m. flexor digitorum lateralis, se encuentran bien desarrollados (Lámina 2.28E-G) y presentan origen extendidos distalmente, con moderada a marcada pinnación y tendones relativamente cortos. Los mayores extensores del pie, incluyendo al $\mathrm{m}$. gastrocnemius y m. flexor digitorum superficialis, se encuentran muy desarrollados, alcanzando una masa total aproximadamente similar a la de los extensores de la rodilla (e.g., m. quadriceps femoris; Tabla 3.2). Estos rasgos, en conjunto con aquellos descriptos para el grupo gluteus, el mm. biceps femoris, y abductor cruris caudalis, también son observados en lutrinos, guloninos, mustelinos y otros ictoniquinos (Williams 1955, Savage 1957, Gambaryan 1974, Bisaillon 1976). Esta configuración puede ser relacionada a la demanda de extensión poderosa del tobillo en relación a una rápida aceleración durante los saltos y el nado, donde el poder muscular predomina sobre la economía (Gambaryan 1974, Walmsley et al. 1978, Hildebrand 1988, Payne et al. 2005) y a la capacidad de realizar movimientos no parasagitales (Barnett y Napier 1953). En el caso de hurones ictoniquinos y mustelinos, otro posible factor sería la necesidad de alcanzar y mantener marchas en posiciones agazapadas dentro de galerías, y estabilizar el tobillo durante otras actividades como el cavado y el arrastre de presas (Van de Graaff et al. 1982, Spoor y Badoux 1988, Gorsuch y Larivière 2005, King y Powell 2007). Dado que la mayoría de los mustélidos tienen miembros proporcionalmente cortos, la pinnación, en conjunto con modificaciones osteológicas específicas (ver sección 4.3.5, Tibia y fíbula), podrían actuar como factores compensatorios de la menor superficie disponible de origen muscular. Respecto a los extensores del tobillo, en úrsidos, prociónidos y mustélidos ambulatorios como Gulo gulo y Mellivora capensis tienen características intermedias a las presentes a otros mustélidos y carnívoros cursoriales (Lámina 2.28E-G; Haughton 1867d, Mackintosh 1875, Windle y Parsons 1898, Ray 1949, Gambaryan 1974, Fisher et al. 2008, Hudson et al. 2010, Evans y De Lahunta 2013).

En Ga. cuja se identificaron típicamente tres tendones del m. extensor digitorum brevis (dígitos II a IV; Lámina 2.25). La misma configuración se encuentra presente en muchos cánidos, félidos y hiénidos. En un espécimen de Ga. cuja se registró un cuarto tendón 
correspondiente al primer dígito, como también fue descripto para $G a$. vittata y condición típica de Arctoidea (Alix 1876, Allen 1882, Watson 1882, Gowell 1897, Windle y Parsons 1898, Howard 1975, Bisaillon 1976, Scherling 1989, Feeney 1999, Fisher et al. 2008). La pérdida del tendón para el dígito I del m. extensor digitorum brevis parece haber ocurrido varias veces dentro de Carnivora (Apéndice 3.14, c.45), pero no siempre esto está relacionado a adaptaciones cursoriales.

\subsubsection{Cooperación y correspondencias entre miembro anterior y posterior}

Es interesante comparar las principales características de la musculatura del miembro anterior con lo observado en el miembro posterior (Ercoli et al. 2013, 2014) de Ga. cuja y en otros hurones weasel-like. A continuación se destacan cómo los principales grupos musculares postcraneales pueden cooperar en funciones locomotoras comunes.

En linajes weasel-like, tienden a perderse o reducirse los músculos ligeros y breves que se asocian a las articulaciones de ambos miembros (m. anconeus, m. articularis humeri, $\mathrm{m}$. articularis coxae). Estos músculos son frecuentemente interpretados como proprioceptores o estabilizadores de las articulaciones (Fisher et al. 2008, 2009, Evans y De Lahunta 2013), y es esperable su reducción en linajes no cursoriales que no realizan importantes esfuerzos nocompresivos.

Los aductores fuertes de ambos miembros ( $\mathrm{mm}$. pectorales superficiales del miembro anterior y $\mathrm{mm}$. aductores del miembro posterior) se encuentran relativamente reducidos en masa pero multiplicados en vientres, siendo más precisos que fuertes (ver más adelante). Como se mencionó en Ercoli et al. (2013, 2014), esto es esperable en animales con miembros cortos y de gran movilidad del esqueleto axial, en donde esta última es la principal responsable de los cambios de dirección y de la propulsión en los hurones.

Los flexores débiles y rápidos del hombro $(\mathrm{m}$. infraspinatus, $\mathrm{m}$. teres major, $\mathrm{m}$. teres minor), así como los extensores débiles y rápidos de la pelvis ( $\mathrm{mm}$. gluteus, m. gluteofemoralis, m. piriformis) se encuentran relativamente reducidos en masa. Esto se debe a que la propulsión ha sido cedida principalmente a los extensores de la columna y algunos extensores fuertes de la cadera (e.g., m. biceps brachii, m. abductor cruris caudae, grupo hamstrings) y secundariamente el tobillo (Ercoli et al. 2013). Justamente estos últimos músculos, así como los principales protractores y extensores del miembro anterior, que amortiguan el aterrizaje luego de los saltos, se encuentran marcadamente desarrollados y extendidos distalmente en hurones en comparación con otros grupos locomotores. En oposición, estos músculos (i.e., los retractores de ambos miembros) se encuentran muy desarrollados y son cruciales en la propulsión en especies generalizadas, y especialmente en cursoriales y trepadores (Maynard Smith and Savage 1956; Gambaryan 1974, Hildebrand 1988, Feeney 1999). 
Es destacable también el gran número de fascículos largos (strap-like) que abarcan múltiples articulaciones y comprenden un porcentaje importante de la masa muscular en ambos miembros de especies generalizadas y especialmente en los hurones. Muchas de estas especies comparten, para el miembro anterior, la presencia de cabezas extras de los $\mathrm{m}$. triceps brachii (e.g., caput angulare), m. tensor fascia antebrachii, m. pectoralis profundus subdivididos, e importante desarrollo relativo de estos. A su vez, comparten una gran masa, múltiples vientres y amplia separación entre orígenes e inserciones de los hamstrings del miembro posterior (e.g., m. semimembranosus, m. semitendinosus; Gambaryan 1974, Ercoli et al. 2013). Todas estas características apuntan a una gran precisión y mayor rango de movimientos de ambos miembros, aumentando la longitud de zancada (Hildebrand 1988), una función crucial para los hurones, que poseen miembros cortos y se desplazan en posiciones agazapadas en galerías. 


\subsection{Comentarios sobre la morfología de Lyncodon patagonicus y el espécimen CML 0655}

De la descripción de los especímenes de Lyncodon patagonicus, se destacan importantes diferencias entre el espécimen CML 0655 y los restantes comparados, de las cuales aquí se mencionan las principales (descriptas en más detalle en la sección 3.2.3). En el espécimen CML 0655, la morfología general de todos los huesos largos es más estilizada, son por regla general más elongados y menos robustos, y lo mismo puede aplicarse a las vértebras lumbares. El atlas presenta una de las diferencias discretas más evidentes: en el espécimen CML 0655 se presentan escotaduras alares obliteradas por un puente externo (i.e., forámenes alares), lo que no ocurre en ningún espécimen lincodontino observado, y sí es propio de mustelinos y martinos (e.g., Ei. barbara). Por otro lado, el tubérculo ventral de CML 0655 se proyecta marcadamente, y los procesos alares son aguzados caudalmente y se separan ampliamente de las carillas articulares caudales. Otras características que diferencian al espécimen CML 0655 son: la región lumbar compuesta por 5 elementos (mientras que son 3 o 4 en otros especímenes de Ly. patagonicus, pero ver Koslowsky 1904), el ángulo caudal de la escápula presenta un margen robusto sin proyectarse como una lámina aplanada caudalmente, y el extremo distal del fémur es relativamente grácil. Pese a que el cráneo y piel del espécimen CML 0655 son claramente pertenecientes a un espécimen de Ly. patagonicus, todos estos rasgos osteológicos postcraneanos, hacen que este espécimen sea mucho más similar a especímenes observados de Mustela spp. que a aquélla especie. El registro del ingreso de este material a la Colección Miguel Lillo indica la existencia de material craneal y piel, pero no se indica material postcraneal (Dra. Mónica Díaz, comentario personal). Por lo tanto se sugiere aquí la reasignación del material postcraneal en cuestión a Mustela spp. La gran cantidad de rasgos del postcráneo convergentes entre Lyncodon y Mustela, en relación seguramente a convergencias funcionales relativas a estilos de caza y locomotores, pueden considerarse como un factor clave para esta asignación errónea. 


\subsection{Análisis morfo-funcional comparativo de la osteología de los mustélidos}

\subsubsection{Proporciones generales}

De los datos de Mivart (1885) y Holmes (1980) se desprende que los hurones y nutrias presentan regiones tóraco-lumbares elongadas respecto a los miembros, mientras que en muchos linajes musteloideos cavadores, trepadores o arborícolas (e.g., mefítidos, prociónidos, guloninos) ocurre lo contrario. En el análisis de la longitud tóraco-lumbar relativa a la longitud promedio de los miembros (LaTL/LaPrM) se encontraron diferencias significativas entre los musteloideos (Fig. 3.1A, Apéndice 3.6A), en relación a los hábitos locomotores, las cuales se mantuvieron luego de controlar la estructura filogenética de los datos (Tabla 3.6, Apéndice 3.7A). Las especies half-bounders y acuáticas se segregan conjuntamente en forma significativa presentando cuerpos elongados, mientras que las trepadoras y cavadoras tienden a poseer miembros proporcionalmente más elongados (Fig. 3.1A, Apéndice 3.6A1, 2); resultados que concuerdan con los análisis previos (Mivart 1885, Holmes 1980). La elongación relativa de los miembros en cavadores respecto a nadadores y half-bounders (Fig. 3.1A, Apéndice 3.6A1, 2) podría estar relacionada a la combinación de la presencia de miembros anteriores robustos y largos (en comparación con hurones y nutrias, aunque considerablemente más cortos que aquellos presentes en linajes ambulatorios o cursoriales; ver Samuels et al. 2013, ver más adelante) que permiten aplicar gran cantidad de fuerza al sustrato (Tabla 2.3, Fig. 3.1E; ver más adelante) y una región lumbar breve y estabilizada, que permite resistir y transmitir a los miembros posteriores los esfuerzos generados en los miembros anteriores (Davis 1964, Quaife 1978, Holmes 1980, Moore et al. 2013). La elongación de los miembros es favorable en especies trepadoras que se desplazan sobre sustratos complejos y con múltiples puntos de apoyo aislados, así como para rodear a troncos o ramas grandes al trepar verticalmente (clamber; Taylor 1974, Holmes 1980, Van Valkenburgh 1987, Argot 2001). Sin embargo, el arborícola más especializado de la muestra, Potos flavus, presenta una longitud relativa promedio de los miembros similar a la de Ei. barbara (LaTL/LaPrM =1,53), mucho menor a la de Ai. fulgens y algunos otros prociónidos trepadores ( $\mathrm{LaTL} / \mathrm{LaPrM}<1,20$ ), lo que indica que diferentes estrategias de trepado (e.g., cola prensil vs. cola no prensil, trepadores lentos vs. trepadores ágiles, patrón de pasos) y otros factores (e.g., grado de cursorialidad, filogenia) influencian estas proporciones (ver Holmes 1980, Hildebrand 1988, Taylor 1989, Argot 2003a, Youlatos 2003; ver más adelante). Lo mismo puede proponerse para cavadores, en donde miembros relativamente cortos respecto a la región tóraco-lumbar se registran en tejones e Ictonyx sp., mientras que lo contrario ocurre en mefítidos y Mellivora capensis.

Por otro lado, la presencia de miembros cortos respecto a una columna larga puede tener distintas lecturas funcionales en distintos ecomorfos: en especies subterráneas y cazadoras de roedores, miembros cortos permiten mantener un perfil bajo, cambiar rápidamente la dirección 
de marcha y realizar movimientos complejos en túneles estrechos (Ondrias 1960, King y Powell 2007, Moritz et al. 2007, Horner y Biknevicius 2010, Ercoli et al. 2013, pero ver comentarios de Holmes 1980). Estas proporciones son llevadas a un extremo en Ly. patagonicus en quien la longitud de la columna es más de dos veces el largo promedio de sus miembros (i.e., $\mathrm{LaTL} / \mathrm{LaPrM}=2,12$ ), proporción no alcanzada por las especies de Mustela analizadas (LaTL/LaPrM entre 1,85 y 2,00) ni por ningún otro musteloideo, indicando una morfología tubular y un máximo de especialización al desplazamiento en galerías estrechas en este taxón (Tabla 2.3, Fig. 3.1A). Especies cazadoras de roedores en galerías con hábitos trepadores o cavadores se encuentran ante un compromiso funcional entre la maximización de esfuerzos braquiales durante estas actividades y mantener un perfil bajo. Las especies de Galictis (Mivart 1885, Tabla 2.3, Fig. 3.1A) presentan una proporción LaTL/LaPrM más baja, con miembros algo más robustos y elongados, seguramente en relación a una mayor importancia de las incursiones epigeas y la participación de los miembros anteriores en otras actividades motoras eventuales (nado, cavado; Azara 1802, Dalquest y Harvey 1951, Yensen y Tarifa 2003a, Wilson y Mittermeier 2009, Aldo Vassallo conversación personal). Por otro lado, Bassariscus astutus es un half-bounder outlier en el análisis de varianza (Apéndice 3.6A1) debido a que sus miembros son relativamente elongados (Tabla 2.3), seguramente en relación a hábitos trepadores propios del taxón y de los prociónidos en general. La presencia de miembros relativamente cortos en relación a la región axial observada en nutrias (Tabla 2.3, Fig. 3.1A, Apéndice 3.6A1, 2) ha sido frecuentemente relacionada a mantener un perfil hidrodinámico, y la mayor importancia de los movimientos ondulatorios axiales durante el buceo (Tarasoff 1972, Tarasoff et al. 1972, Taylor 1989, Fish 1994, Williams et al. 2002). Las proporciones intermembrales y intramembrales de lutrinos presentan variantes propias de distintos linajes en relación a diversos estilos de nado (ver más adelante).

Al analizar en forma aislada la influencia de la dieta sobre la proporción LaTL/LaPrM, también se encontró una relación significativa, aunque mucho más débil (Apéndice 3.6A3, Fig. 3.2A), la cual se perdió luego del control filogenético (Apéndice 3.7A5). Las especies de hábitos más carnívoros tienden a presentar cuerpos más elongados y miembros más breves que las especies más omnívoras. Sin embargo, el detalle de los valores de los índices de las distintas especies revela un gran número de excepciones. Dentro de los taxones carnívoros, los trepadores y cavadores son los únicos que presentan miembros relativamente largos ( Ta. taxus, guloninos y Bassariscus astutus; LaTL/LaPrM < 1,7; Tabla 2.3, Fig. 3.2A). El resto de los taxones musteloideos carnívoros, (incluyendo los hipercarnívoros) son hurones y nutrias, cazadores de roedores en galerías o piscívoros, y presentan cuerpos marcadamente elongados (LaTL/LaPrM > 1,8; Tabla 2.3, Fig. 3.2A). La elongación del cuerpo en estos grupos no permite una ventaja específica para dominar, matar o ingerir a la presa (excepto quizás en estrategias 
rolling and curl, ver Anexo), pero sí posibilita el ingreso y los movimientos en el medio donde cada especie se mueve (i.e., túneles y cuerpos de agua). Una excepción a esto (i.e., asociación entre dietas carnívoras y miembros breves en musteloideos) es Enhydra lutris, taxón de cuerpo alargado, hábitos acuáticos y especialista en una dieta no carnívora (Heptner y Naumov 1967, Estes 1980, Wilson y Mittermeier 2009), el cual justamente resulta un outlier en el análisis de hábito dietario (Fig. 3.2A).

Es muy probable que la débil relación entre dieta y proporción LaTL/LaPrM sea mayormente un reflejo de que los principales linajes musteloideos carnívoros o hipercarnívoros son mustélidos especialistas en la caza de roedores en galerías y peces, y por ende, con adaptaciones locomotoras específicas tubícolas y acuáticas, y ausencia o reducción de habilidades cavadoras o trepadoras. Los guloninos representan el principal grupo de mustélidos carnívoros en que algunos de sus miembros se apartaron de estos sustratos de caza y poseen hábitos más ambulatorios y trepadores (e.g., Ei. barbara, Gu. gulo), modificándose las proporciones corporales respecto al plan weasel-like (ver también Gambaryan 1974, Holmes 1980).

\subsubsection{Región axial}

4.3.2.1. Región cervicalLa región cervical soporta y posiciona la cabeza, por lo que ha sido considerada significativa funcionalmente en lo que respecta a posturas, algunos hábitos locomotores y estrategias de caza (Slijper 1946, Savage 1957, Bisaillon et al. 1976, Spoor y Badoux 1986b, Argot 2003a, 2004, Gambaryan et al. 2005, Flores y Díaz 2009). La interpretación funcional de esta región es muy compleja, dado que presenta áreas de origen e inserción de un gran número de sistemas musculares con funciones muy diversas (Argot 2004, ver sección 4.1). Específicamente el atlas y el axis han sido valorados como importantes fuentes de caracteres filogenéticos en Carnivoromorpha en general (Spaulding y Flynn 2012), otros grupos de mamíferos (e.g., Sargis 2001, Flores 2009, Carrizo y Díaz 2013), y también parece ser el caso para los musteloideos.

\section{Complejo atlas-axis}

En cuanto a la morfología del atlas, se puede observar un aumento progresivo en el desarrollo y la proyección del ángulo caudomedial del proceso alar desde mustelinos, lincodontininos y hasta lutrinos de América del Sur; a su vez inclinado ventralmente de manera marcada en estos últimos. Esta zona representa el sitio de inserción del m. omotransversarius, $\mathrm{m}$. rhomboideus profundus y parte del $\mathrm{mm}$. intertransversarii medii cervicis, músculos vinculados a la rotación de la escápula, protracción del miembro, y flexión lateral del cuello (Jouffroy y Lessertisseur 1971, Fisher et al. 2009, Deban et al. 2012, Evans y De Lahunta 2013). En función de las optimizaciones, este rasgo, además de funcionalmente significativo, 
parece ser filogenéticamente informativo; se habría adquirido en la base de Ictonichinae + Lutrinae + Mustelinae o incluso en el ancestro común entre este grupo y guloninos (Apéndice 3.15, optimización ambigua, c. 5, estado 2), convergente con otros linajes carnívoros no arctoideos, y modificado en algunos casos puntuales (ver ictoniquininos). Tanto las nutrias de América del Sur como los hurones son predadores activos que poseen miembros breves, por lo cual los movimientos poderosos del cuello son requeridos para dominar, matar y transportar a la presa (Ewer 1973, Radinsky 1981a, Spoor y Badoux 1986b, Zielinski 2000, King y Powell 2007, ver Anexo). Específicamente en hurones, y secundariamente en nutrias, modificaciones en estos músculos protractores pueden también vincularse a la locomoción bound o half-bound, así como rangos de movimientos en la locomoción subterránea (ver desarrollo de estas ideas secciones 4.1 y 4.3.4, Escápula; ver también Taylor 1974, Feeney 1999, Gambaryan et al. 2005, Seckel y Janis 2008, Horner y Biknevicius 2010, Ercoli et al. 2014). Como contra-ejemplo, Ei. barbara presenta miembros largos y realiza prioritariamente otras estrategias locomotoras (e.g., trote, galope; ver Kaufmann y Kaufmann 1965, Kavanau 1971, Dagg 1973, Dionisios Youlatos comunicación personal), siendo el ángulo caudomedial menos sobresaliente y más redondeado.

En lo que respecta a las especies de mustélidos de otros continentes, el ángulo caudomedial del proceso alar está más desarrollado para las mismas subfamilias. Al igual que ocurre en Ei. barbara, en melinos y guloninos grandes de otros continentes, como Gulo gulo (ver también Riggs 1945), se registra un ángulo caudomedial redondeado y muchas veces poco definido, mientras que éste se encuentra presente pero sólo con un moderado desarrollo en Martes spp. (Leach y de Kleer 1978, Barraquand 2010 Apéndice 3.15, c. 5, estado 1 y 2). Dentro de los ictoniquininos, el ángulo caudomedial es prácticamente inexistente en Ictonyx striatus y algunos especímenes de Poecilictis libyca, pero es comparativamente importante en Vormela peregusna. Por otro lado, en musteloideos no mustélidos, el ángulo caudomedial del proceso alar es moderadamente marcado (e.g., Spilogale gracilis) o mayormente indefinido (e.g., Nasua nasua, Procyon spp., Conepatus chinga. Dentro de los musteloideos de otros continentes, vale la pena destacar que las especies que desarrollan carreras de tipo bound o halfbound o caza de roedores en galerías (e.g., Martes spp., Vormela peregusna, Spilogale gracilis; Heptner y Naumov 1967, Gambaryan 1974, Leach 1977b, Whitaker y Hamilton 1998, Elbroch 2003) son aquellas que tienden a presentar un ángulo caudomedial mejor definido, coincidiendo con el patrón observado para las especies de América del Sur.

El desarrollo total relativo de la superficie de los procesos alares, ha sido relacionado mayormente a la ventaja mecánica y volumen de los $\mathrm{m}$. obliquus capitis cranialis y m. obliquus capitis caudalis, que forman parte de la musculatura flexora y rotadora de la cabeza (Argot 2004, Salesa et al. 2005). Por esto, presenta mayor desarrollo en especies predadoras (e.g., la mayoría de los mustélidos) respecto a omnívoros (e.g., mefítidos). Por otro lado, dentro de las 
especies musteloideas depredadores, el desarrollo de los procesos alares del atlas parece relacionarse directamente con el tamaño corporal, siendo mayor en guloninos grandes (e.g., Gu. gulo, y secundariamente Ei. barbara, Ma. pennanti), tejones (e.g., Meles spp.), y también en los lutrinos de mayor tamaño (e.g., En. lutris, Pt. brasiliensis) (ver también Riggs 1945:Fig. 25, Leach y de Kleer 1978: Fig. 5). Como ocurre con otras áreas de fijación muscular (e.g., procesos espinosos, ver más adelante), la fuerza de los músculos que soportan una parte del cuerpo aumentan en un exponente menor que la masa misma, por lo cual es esperable una compensación de este efecto mediante una mayor ventaja mecánica y/o área de fijación muscular en las especies de mayor tamaño (Slijper 1946, Hildebrand 1988).

En nutrias en general (ver Fisher 1942, Savage 1957, Willemsen 1980a: placa 1, Yilmaz et al. 2000), y especialmente en Lo. provocax y Pt. brasiliensis dentro de las especies de América del Sur, las alas del atlas además de ser amplias lateromedialmente, presentan márgenes laterales robustos en relación al mayor desarrollo del área de origen de la porción dorsal del m. obliquus capitis cranialis (Fisher 1942). A su vez, el tubérculo dorsal es en general rugoso, en relación a un poderoso $\mathrm{m}$. rectus capitis dorsalis minor. Estos rasgos son indicadores de importantes esfuerzos de extensión de la cabeza y, secundariamente, de rotación (Savage 1957, Argot 2003a, 2004, Salesa et al. 2005, Carrizo y Díaz 2013; ver Anexo), y han sido también observados en especies fósiles asignadas a hábitos predadores acuáticos (e.g., ${ }_{\dagger}^{\dagger}$ Potamotherium; Savage 1957). Savage (1957, ver también Bisaillon et al. 1976), ha relacionado esta capacidad de extensión con una posición más dorsal de los ojos dada la necesidad de cazar presas sorprendiéndolas desde abajo, y a maniobras durante el buceo. Dentro de las especies de América del Sur, el tubérculo dorsal del atlas es particularmente importante en Lo. provocax, siendo típicamente multicuspidado y robusto (en menor grado también observado en varios especímenes de Lo. longicaudis, e.g., MLP 1959); también se registra en este taxón la máxima robustez (dentro de nutrias) del extremo craneal del proceso espinoso del axis, típicamente multicuspidado, sitio de origen del m. rectus capitis dorsalis intermedius, indicando para esta especie el máximo grado de fuerza de extensión del cuello para Lutrinae. Estas variantes, además de informativas para diferenciar taxones a nivel especie (como lo hicieron Leach y de Kleer 1978 dentro de Guloninae), son indicios de variantes en las estrategias de caza de las nutrias de América del Sur, aunque no existen registros de alimentación de Lo. provocax (Reyes-Küppers 2007).

Dentro de las especies de América del Sur, en la Ei. barbara (y el espécimen AMNH 267055 de Galictis vittata), el proceso alar y específicamente el ángulo caudolateral se muestran muy proyectados caudalmente, lo que podría aumentar el área disponible y la ventaja mecánica de la porción ventral del m. obliquus capitis cranialis. La extensión caudal del origen de este músculo, así como la extensión cráneoventral del proceso mastoideo, área de inserción del 
mismo (Antón et al. 2004, Salesa et al. 2005; ver Anexo) otorgan una flexión poderosa de la articulación atlanto-occipital, aumentando el número de fibras largas que se ubican ventralmente a la articulación. Esta configuración podría permitir una depresión poderosa de la cabeza durante el killing bite, como fue descripto para félidos (shear-bite model; Antón et al. 2004, Salesa et al. 2005), en relación a estrategias bite down (ver Anexo) y a la capacidad de aplastar (crushing) estructuras óseas como el cráneo, zona cervical, o torácica de las presas. Poglayenneuwall (1978) describió para Ei. barbara un comportamiento de caza tipo bite down, con colaboración de los miembros anteriores para sostener la presa contra el suelo, y técnicas parcialmente coincidentes con estrategias rolling and curl en el caso de presas mayores. Esta descripción, y las de Cabrera y Yepes (1940) y Kaufmann y Kaufmann (1965) indican que la especie mata a sus presas con una mordida única en la cabeza, y hacen a Ei. barbara más afín a estrategias bite down, pero a su vez indican variantes relativas al tipo de presa, como puede corroborarse en otros mustélidos (e.g., Rowe-rowe 1978, Ben-david et al. 1991, Michener y Iwaniuk 2001; ver Anexo).

A partir de las descripciones realizadas, se determinó que la presencia de una incisura o un foramen alar lateral (i.e., incisura cerrada externamente por un puente) representa un carácter discreto de gran valor filogenético (ver también Spaulding y Flynn 2012: carácter 207 a nivel Carnivoromorpha; Apéndice 3.15, c. 6). La incisura alar se encuentra presente en todos los lutrinos (i.e., Aonyx cinerea, Enhydra lutris, Hydrictis macullicolis, Lontra spp., Lutra lutra, Lutrogale perspicillata, Pt. brasiliensis, aunque variable en Lo. longicaudis Lutra lutra, ver más adelante; ver también Fisher 1942, Howard 1973:Fig. 59, Willemsen 1980a, Yilmaz et al. 2000), lincodontininos (Lyncodon patagonicus y Galictis spp.), ailúridos (i.e., Ailurus fulgens; Spaulding y Flynn 2012), prociónidos derivados (Nasua nasua, Procyon spp.; contra codificación de Spaulding y Flynn 2012 para Pr. lotor) y mefítidos (Conepatus chinga, Mephitis mephitis, Spilogale putorius; ver también Spaulding y Flynn 2012). Por otro lado, se presenta un foramen alar en todos los guloninos (i.e., Gulo gulo, Martes spp., a veces unilateralmente en Ei. barbara; ver también Leach y de Kleer 1978, Barraquand 2010, Spaulding y Flynn 2012), melinos y taxidinos (e.g., Meles meles, pero marginalmente incompleto en Meles anakuma; ver también Wagner 1976), mustelinos (i.e., Mustela spp.; ver también Evans y Quoc An 1980), melivorinos (i.e., Mellivora capensis), e ictoniquininos (e.g., Ictonyx striatus, Poecilictis libyca, Vormela peregusna) y únicamente en Potos flavus dentro de los musteloideos no mustélidos. La presencia de una incisura en vez de foramen lateral en lincodontininos, hace de este rasgo un carácter valioso que permite diferenciarlos de otros hurones ictoniquininos (e.g., Vormela, Ictonyx, Poecilictis) y mustelinos, y es uno de los rasgos que permitió reasignar el postcráneo del especímen CML 0655 (ver sección 4.2). También es interesante destacar que la ausencia de foramen alar es un rasgo únicamente presente en lutrinos y lincodontininos dentro de 
mustélidos, clados filogenéticamente cercanos según la última filogenia molecular del grupo (Sato et al. 2012), siendo esta condición optimizada ambiguamente como convergente o heredada entre estos grupos (Apéndice 3.15, c. 6, estado 0). En la optimización se reconstruye en forma ambigua el estado ancestral de Arctoidea, y la condición de foramen alar lateral el ancestro común de Mustelidae, indicando que la incisura de los lincodontininos y lutrinos habría sido obtenida en forma independiente a lo ocurrido en grupos de musteloideos basales $\mathrm{u}$ otros carnívoros (Apéndice 3.15, c. 6). Vale la pena destacar que Lontra longicaudis presenta variantes, desde una incisura encerrada a un foramen alar definido. En Ei. barbara, y en muy pocas especies de otros continentes (i.e., Lutra lutra, Meles anakuma), se registraron variantes a nivel intraespécimen (e.g., MLP 1013 lado izquierdo vs. derecho).

La forma y tamaño del proceso espinoso del axis y de las alas del atlas son variables tanto intra como interespecíficamente. Los cambios de forma se encuentran asociados a fijaciones musculares comunes (Argot 2003a, Antón et al. 2004; ver sección 4.1). Los mustélidos presentan, en general, axis y procesos espinosos más desarrollados que otros musteloideos, en relación a sus hábitos depredadores más especializados. Esto se hace evidente en el análisis de morfometría geométrica de la vista lateral del axis (ver también Apéndice 3.15, c. 9), en donde la gran mayoría de los mustélidos, exceptuando especies como En. lutris (forma acuática no piscívora especializada en el consumo de molúscos y equinodermos; Fig. 3.3; ver más adelante), se separan de los prociónidos y mefítidos en relación al mayor desarrollo cráneocaudal del axis en general y el proceso espinoso en particular. Además de la dieta, llamativamente la locomoción fue considerada también un factor significativamente influyente sobre la forma del axis a través de los análisis de varianza (Figs. 3.3, 3.4, Apéndice 3.8A1, A2), distinto a lo esperado en función de los resultados del estudio de la proporción cervical (ver más arriba). Sin embargo, al analizar los análisis post-hoc es evidente que la relación significativa con los hábitos locomotores se debió principalmente a la segregación de los acuáticos, con procesos transversos robustos y marcadamente proyectados y procesos espinosos proyectados dorsalmente en su sector caudal y en general (exceptuando En. lutris y secundariamente Ao. cinerea) amplios. Al contrario de especies terrestres, el cuello poderoso y móvil de las especies acuáticas permite colaborar en la conformación de un perfil hidrodinámico y la generación de cambios de dirección durante el nado (Savage 1957, Bisaillon 1976, ver más arriba), lo cual podría explicar la mayor ventaja mecánica y área disponible para la musculatura del axis. Más allá de esto, en algunos linajes como los mustelinos e ictoniquinos, las especies y especímenes más pequeños presentan procesos espinosos del axis menos extensos, especialmente en sentido cráneocaudal (Apéndice 3.15, c. 9). Un patrón alométrico también fue sugerido por Carrizo y Díaz (2013) para roedores filotinos, y también fue destacado al comparar los especímenes juveniles y adulto de Ly. patagonicus fósiles analizados (ver sección 4.4.1). 
El extremo caudodorsal del proceso espinoso del axis es robusto y elevado en las nutrias observadas, así como también se fue descripto para otras nutrias fósiles (e.g., †Sardolutra ("Nesolutra") ichnusae, ${ }^{\dagger}$ Lutrogale ("Isolalutra ") cretensis; Malatesta 1977, Willemsen 1980a, 1992) y vivientes (Lutra lutra; Fisher 1942, Malatesta 1977, Willemsen 1980a; Fig. 3.4). En función de la información miológica disponible (Lucae 1875, Fisher 1942, Hall 1926, ver sección 3.1), este cambio morfológico en nutrias parece vincularse al incremento de la superficie de origen y la ventaja mecánica del $\mathrm{m}$. rectus capitis dorsalis major superficialis para la extensión del la cabeza (y eventualmente a un ligamento medio cervical robusto, ver Fisher 1942), lo que sumado a lo descripto para el atlas y el resto de la región cervical (ver más adelante), concuerda con la capacidad de grande esfuerzos de extensión de la cabeza, y las interpretaciones funcionales relativas al buceo y caza ya mencionadas para nutrias (Savage 1957, Bisaillon et al. 1976; ver más arriba).

En lo que respecta a la región articular atlanto-axial, un rasgo diagnóstico de la pertenencia al género Lontra (corroborado en Lo. longicaudis y Lo. provocax), no presente en Pt. brasiliensis, es la presencia de carillas articulares caudales del atlas proyectadas medialmente, dándole al foramen vertebral, en vista caudal, una apariencia de "reloj de arena". Este rasgo quizás se relacione a un mayor rango de movimientos lateromediales de la articulación en las especies de Lontra. Aunque no fue observado en otras especies aquí descriptas, una morfología similar fue registrada por Willemsen (1980a, b, 1992) en el taxón †Lutrogale ("Isolalutra") cretensis.

\section{Longitud cervical relativa}

Los mustélidos y Bassariscus astutus en general se destacan dentro de los musteloideos por tener cuellos relativamente largos ( $\mathrm{LaCe} / \mathrm{LaTL}>28 \%$; Tabla 2.3, Fig. 3.2B) y musculosos, con el proceso espinoso del axis extendido cráneocaudalmente y procesos transversos amplios; características opuestas a las presentes en linajes musteloideos como Ailurus fulgens, mefítidos y otros prociónidos (ver Davis 1964, Salesa et al. 2008; LaCe/LaTL < 28\%; ver Tabla 2.3, Fig. 3.2B). El análisis del índice LaCe/LaTL indica algunas excepciones a este patrón (i.e., Ictonyx sp. y Melogale sp.), y una relación significativa entre la longitud del cuello y los hábitos dietarios, tanto antes (Apéndice 3.6B), como luego (Apéndice 3.7B) de considerar la estructura filogenética de los datos (Tabla 3.6). La optimización de la longitud relativa del cuello (Apéndice 3.15) sugiere que un cuello elongado (c. 0, estado 0,293-0,310) fue una adquisición temprana dentro de la familia (nodo Mustelidae - Taxidea), y es recuperada como una convergencia con Canidae (aunque estos presentan una condición más extrema; estado 0,406, Apéndice 3.15), y Bassariscus astutus (estado 0,309); que son, justamente, los linajes más carnívoros dentro de Caniformia. Algunos taxones mustélidos secundariamente especializados en dietas menos carnívoras revierten esta condición (ver más adelante). Más allá de la 
importante componente filogenética de los dato, al retirar el efecto filogenético, la separación de grupos dietarios incluso es mejor que sin contemplarlo (Tabla 3.6, Apéndice 3.6 B vs. 3.7B), destacándose el valor informativo de la proporción desde el punto de vista filogenético (ver más adelante). Tanto para Carnivora como Marsupialia, otros investigadores como Davis (1964), Bisaillon et al. (1976), Antón y Galobart (1999), Muizon (1998), Muizon y Argot (2003), Argot (2003a, 2004) Salesa et al. (2005, 2006) y Flores (2009) relacionaron estos rasgos cervicales con hábitos depredadores y el tipo de presa, en relación a movimientos precisos o poderosos del cuello durante el killing bite. Otros investigadores ya han resaltado la importancia de poseer un cuello largo y robusto para mustélidos y específicamente para mustélidos weasel-like, tanto para la caza como el transporte de las presas en la boca (Ewer 1973, Evans y Quoc An 1980, Radinsky 1981a, Zielinski 2000, King y Powell 2007, ver Anexo). Dentro de los taxones carnívoros no acuáticos, los cuellos relativamente más largos están presentes típicamente en cazadores especialistas en roedores: Bassariscus astutus en comparación con otros prociónidos, Spilogale gracilis en comparación con otros mefítidos, hurones en comparación con otros mustélidos (ver Tabla 3.6). Por otro lado, la longitud del cuello de las especies de mustélidos acuáticos también varia en función de los hábitos dietarios y características propias de diferentes estrategias de nado (Bisaillon et al. 1976, ver también Savage 1957; Tabla 3.6, Figs. 31B, 3.2B; ver más adelante).

Salesa et al. (2005) reconocieron la posibilidad de que la presencia de cuellos elongados sea a su vez un rasgo plesiomórfico para carnívoros. Al analizar las proporciones LaCe/LaTL, la longitud del cuello de Ai. fulgens, melinos y Mellivora capensis es mayor que la de otros musteloideos de hábitos similares y más derivados. Un patrón similar es parcialmente soportado por el análisis de forma del axis (Fig. 3.1B), en donde los melinos se ubican en el centro de distribución de las especies carnívoras, alejados de otras especies omnívoras, con formas de axis elongadas cráneocaudalmente y procesos de inserción muscular hipertrofiados. Estos rasgos posiblemente indiquen para estos linajes características ancestrales más afines a especies carnívoras, algo ya planteado para análisis osteológicos de ailúridos fósiles (Salesa et al. 2008) y coincidente con el análisis miológico cervical aquí presentado (ver sección 4.1.1). La condición ancestral reconstruida aquí para los nodos más basales de Musteloidea y Caniformia involucra un cuello moderadamente largo (entre 27 y $28 \%$ de la longitud tóraco-lumbar), similar al de Ailurus fulgens, confirmando la propuesta de Salesa et al. (2006). Para el caso de los nodos basales de Mustelidae, se reconstruye una longitud de cuello (c. 0, estado 0,293-0,305) muy similar a levemente menor con respecto a la presente en melinos y melivorinos $(0,305-0,350$; ver Apéndice 3.15), no pudiendo respaldarse totalmente la hipótesis de que un cuello desarrollado es un rasgo plesiomórfico para estos linajes. Taxones que se alimentan de presas inmóviles o poco móviles como los zorrinos más insectívoros, mustélidos skunk-like (e.g., 
Ictonyx sp.), Aonyx sp. y en especial En. lutris y Po. flavus presentan cuellos breves; condición que es optimizada como sinapomorfías y autopomorfías, obtenidas a partir de una condición ancestral de cuello más elongado. Dentro de los musteloideos no acuáticos, Potos flavus, presenta un cuello reducido en extremo (aproximadamente 18\% de la longitud tóraco-lumbar; Tabla 2.3). Este taxón es un frugívoro especializado que manipula con gran habilidad el alimento en sus manos (McClearn 1992, Wilson y Mittermeier 2009), y por lo tanto no requiere un cuello poderoso típico de depredadores.

\section{Tercera a séptima vértebra cervical}

Un rasgo compartido por los hurones, que los diferencia de los demás musteloideos en general (e.g., melinos, melivorinos, lutrinos, mefítidos, la mayoría de los prociónidos), involucra un bajo grado de proyección lateral de los tubérculos dorsales y los procesos transversos cervicales en general. Este rasgo limita el área disponible para músculos intertransversales breves relacionados a movimientos lateromediales (Wood et al. 2011). Por otro lado, los hurones presentan una marcada exageración tanto en masa relativa como en número de vientres de la musculatura extrínseca y torácica flexora lateral del cuello (e.g., m. sternocephalicus, m. cleidocephalicus, mm. scalenus; Hall 1926, Radinsky 1981a, Ercoli et al. 2014, ver más arriba, sección 4.1.1), relativa a la subyugación, el killing bite y transporte de presas (Ewer 1973, King y Powell 2007, Ercoli et al. 2014; ver sección 4.1.1, Anexo). Sobre la base de esto, es posible sugerir que la compresión lateromedial de las vértebras cervicales de los hurones incrementa el lugar disponible para acomodar estos músculos, más largos, voluminosos y de mayor ventaja mecánica. Estos músculos actuarían como una unidad para generar movimientos poderosos del cuello, antes que generando movimientos intervertebrales débiles y complejos. La morfología de los procesos articulares, que indican movimientos intervertebrales cervicales fuera del plano sagital relativamente escasos, apoyan esta posibilidad. Una morfología cervical (así como en la morfología del esternón) muy similar a la de los hurones se encuentra presente en $B a$. astutus, nuevamente en relación a similitudes funcionales relativas a los hábitos depredadores de esta especie.

En particular, Lyncodon patagonicus presenta diferencias sutiles pero destacables respecto a los restantes hurones de América del Sur en relación a la forma los procesos transversos de las vértebras cervicales. Los rasgos morfológicos que diferencian al huroncito patagónico, como por ejemplo los tubérculos dorsales diferenciados tan anteriormente como los elementos medios de la serie cervical (i.e., C3 o C4) y posicionados más dorsalmente, y las láminas ventrales con bases anchas, indican un mayor desarrollo de músculos breves, flexores laterales, rotadores y fijadores intervertebrales cervicales (e.g., intertransversarii dorsales et medii cervicis), en relación a estrategias rolling and curl en las que el predador debe dominar a una presa de gran tamaño o fuerza (ver explicación detallada en Apéndice 4.1A, ver también 
Anexo). Por el contrario, la morfología cervical de Mustela frenata y Galictis, que incluye, por ejemplo, un mayor desarrollo de las láminas ventrales y tubérculos ventrales, indican una mayor importancia de los flexores ventrales cervicales (e.g., longus colli, mm. scalenus), función exagerada en estrategias bite down, en las que una presa generalmente menor es atacada desde arriba y presionada contra el sustrato (Ewer 1973, Rowe-rowe 1978, Ben-david et al. 1991, Apéndice 4.1A, ver también Anexo). Eira barbara presenta una configuración intermedia, con láminas ventrales muy similares a los observadas en Galictis spp. y tubérculos dorsales desarrollados como Ly. Patagonicus; esta configuración permite una gran gama de movimientos fuertes de flexión lateral y ventral (Sargis 2001, Argot 2004, Salesa et al. 2005), posiblemente en relación a la diversidad de presas y de estilos de caza algo parcialmente soportado por los estudios realizados sobre el taxón (Poglayen-neuwall 1978, Presley 2000, Wilson y Mittermeier 2009).

Lyncodon patagonicus se diferencia también de Galictis por presentar procesos espinosos cervicales (área de origen de extensores cervicales) de los elementos más craneales marcadamente reducidos en relación a los de los elementos más caudales. En otros contextos esta morfología ha sido vinculado a una gran musculatura epiaxial de fascículos largos (e.g., m. splenius, m. biventer) en combinación con un alto grado de capacidad de extensión cervical (ver Gambaryan et al. 2005, Carrizo y Díaz 2013). Sin embargo, en hurones en general (y como condición ancestral de Mustelidae y Caniformia, Apéndice 3.15, c. 12, estado 1), las vértebras cervicales presentan escotaduras dorsales caudales y craneales relativamente someras, lo que impide amplios rangos de extensión intervertebral (Sargis 2001). La elevación del cuello para observar por sobre la vegetación, frecuentemente descripta en hurones (Bisbal 1986, Yensen y Tarifa 2003a, b, King y Powell 2007), involucraría movimientos de la base del cuello y comienzo del tórax llevados a cabo por la musculatura extrínseca y superficial. Más allá de algunas excepciones, carnívoros pequeños tienden a presentar procesos espinosos bajos (ver Apéndice 3.15, c. 10, estado 1). Este cambio de proporciones de procesos espinosos puede adjudicarse sin mayores implicancias a un efecto alométrico y extrapolable a la muestra en general. Como explican Slijper (1946; citando ejemplos en Carnivora) para los procesos espinosos de la región cervical, y Hildebrand (1988) en una visión más amplia: dado que el tamaño corporal aumenta al cubo, y la fuerza al cuadrado, la desproporción de estas magnitudes es compensada por el aumento de la ventaja mecánica o área disponible para masa muscular.

En las nutrias, los procesos articulares cervicales están lateralizados, son relativamente breves cráneocaudalmente, y extensos y curvos lateromedialmente, mientras que las escotaduras dorsales, especialmente las caudales, son más profundas. Estos rasgos han sido asociados a una gran movilidad cervical relacionada a sus los hábitos acuáticos (Savage 1957, Bisaillon et al. 1976), y son optimizados como sinapomorfías de Lutrinae (Apéndice 3.15, c. 12, estado 0). 
Más allá de estas características comunes, existen diferencias destacables entre las nutrias. La compresión cráneocaudal del cuello es mínima a inexistente en los lutrinos de América del Sur y algunos otros lutrinos (e.g., Lu. lutra; pero ver comparaciones de Bisaillon et al. 1976; Tabla 2.3, Fig. 3.1), contrario a lo que ha sido típicamente descripto para muchas especies de hábitos acuáticos (Gervais 1875, Savage 1957, Bisaillon et al. 1976, Taylor 1989). La optimización de caracteres respalda una condición de cuello relativamente elongada para el nodo Lutrinae y la mayoría de los nodos internos del grupo (c. 0, estado 0,284-0,295), confirmando que la compresión cervical debe ser considerada una autopomorfía de algunos taxones con hábitos particulares, más que una adaptación al nado en sentido amplio. Una compresión significativa del cuello se encuentra presente en algunos taxones acuáticos fósiles (e.g., †'Sardolutra ("Nesolutra") ichnusae, ${ }^{\dagger}$ Lutrogale ("Isolalutra") cretensis; Malatesta 1977, Willemsen 1980a, 1992) o vivientes (e.g., Lutrogale perspicillata, Enhydra lutris, algunos pinípedos y secundariamente Ao. cinerea; ver Gervais 1875, Savage 1957, Bisaillon et al. 1976, Willemsen 1980a; Tabla 2.3, Fig. 3.1). En En. lutris y seguramente también en Lutrogale perspicillata (en función de la hipertrofia del miembro posterior; Willemsen 1980b), la reducción del cuello favorece un perfil hidrodinámico dado que la propulsión en estos taxones está centrada en el sector caudal del cuerpo. Otro factor potencialmente explicativo para la presencia de cuellos breves es la especialización a depredar sobre animales bentónicos o lentos (Bisaillon et al. 1976), lo cual es directamente aplicable a En. lutris que es un especialista en moluscos y equinodermos (Heptner y Naumov 1967, Tarasoff 1972, Howard 1973, Taylor 1989, Fish 1994) y Ao. cinerea (Hwang y Larivière 2005, Peigné et al. 2008, Kruuk 2006), sin ser requeridos movimientos cervicales complejos o fuertes (Savage 1957, Bisaillon et al. 1976; ver Apéndice 3.15 , c. 11) y participando los miembros anteriores. Aunque Lutrogale perspicillata es principalmente un depredador de peces, los moluscos forman parte de la dieta y, según el estudio de la dentición de ${ }^{\dagger}$ Lutrogale cretensis de Willemsen (1986, 1992; ver también Hwang y Lariviére 2005), la especie proviene de un linaje especializado en depredación de animales bentónicos. Las nutrias de América del Sur (Lontra spp., Pt. brasiliensis) y las demás nutrias de otros continentes (e.g., Lutra spp., Hydrictis maculicollis) poseen características cervicales que las diferencian de las anteriores nutrias y hurones, y resultan en mayor grado semejantes a mustélidos más basales (e.g., tejones, y secundariamente con Gu. gulo; Apéndice 3.15, c. 11; ver más adelante). Los procesos espinosos (áreas de origen e inserción de los m. spinalis cervicis, m. interspinalis, m. multifidus cervicis), tubérculos dorsales de los procesos articulares caudales ( $\mathrm{m}$. multifidus cervicis) y tubérculos ventrales (m. longus colli) están, en general, marcadamente desarrollados, y los procesos transversos (e.g., m. longus colli, m. intertransversarii cervicis) son amplios dorsoventralmente y con sus tubérculos dorsales robustos y proyectados dorsocaudalmente $(\mathrm{m}$. serratus ventralis cervicis, m. longissimus 
cervicis, m. intertransversarii dorsalis cervicis; Slijper 1946, Argot 2003a, Flores y Díaz 2009, Carrizo y Díaz 2013, Evans y De Lahunta 2013, ver sección 3.1). Concordando con lo descripto por Savage (1957), estas características, sumado a lo descripto para el atlas y axis, indican que las nutrias presentan un cuello muy musculoso (con una gran masa muscular, ventaja mecánica, y áreas de agarre disponibles), capaz de realizar grandes esfuerzos musculares sumado a un amplio rango de movimientos intervertebrales dorsoventrales y lateromediales (Slijper 1946, Sargis 2001, Argot 2003a, Flores y Díaz 2009, Wood et al. 2011, Carrizo y Díaz 2013). Estos poderosos movimientos podrían ser claves para controlar la dirección del cuerpo durante la caza activa de peces, muchas veces atrapados directamente con la boca (Larivière 2002b, Wilson y Mittermeier 2009), así como durante el nado con colaboración braquial usando el cuello y cabeza como timón (Savage 1957, Bisaillon et al. 1976), algo concordante con los hábitos de estos lutrinos (Savage 1957, Tarassoff et al. 1972, Bisaillon et al. 1976, Willemsen 1980b, 1992, Fish 1994, Carter y Rosas 1997, Pardini 1998, Lewis 2008), aunque en Lontra spp. el consumo oportunista de invertebrados es importante (Pardini 1998, Reyes-Küppers 2007, Wilson y Mittermeier 2009). En estos linajes lutrinos, al contrario de En. lutris y Lutrogale perspicillata, la morfología de los cuerpos vertebrales cervicales (ver Savage 1957, Willemsen 1980a, b) y la inclinación craneal de los procesos espinosos (ver Slijper 1946:91-92, Gambaryan et al. 2005, Salesa et al. 2008), indican una posición del cuello habitualmente extendida (Savage 1957: Fig. 18, Willemsen 1980b), lo que podría colaborar en el posicionamiento de la cabeza por sobre la interface agua-aire durante el nado lento (Savage 1957). Dentro de las especies de América del Sur, Lo. provocax presenta un cuello algo menor que Lo. longicaudis (ver Tabla 2.3, Fig. 3.2B), lo que podría indicar potencialmente hábitos predadores menos activos o presas más lentas para el primer taxón. Aunque en ambos taxones se ha propuesto la ingesta de múltiples items además de peces, la presencia de invertebrados y específicamente crustáceos parece ser más importante en Lo. provocax que en Lo. longicaudis (Larivière 1999, Kruuk 2006, Wilson y Mittermeier 2009), posiblemente en relación a las proporciones cervicales comentadas.

Por otro lado, es necesario reconocer un gran número de similitudes entre los rasgos de estas nutrias cazadoras activas y mustélidos basales como los melinos (e.g., morfología de procesos transversos, longitud relativa cervical; Apéndice 3.15, c. 0, 11), linaje de animales terrestres, cavadores y omnívoros. Esto parece relacionarse más claramente a ancestría común que similitud de hábitos de las especies vivientes, poseyendo los representantes actuales melinos, una morfología más afín a formas predadoras de lo que sería esperable por su dieta (e.g., Apéndice 3.15 , c. 0, 11), indicando un ancestro común posiblemente de hábitos depredadores y cuello musculoso ya presente al menos en el nodo Mustelidae - Taxidea. 
Tanto los mefítidos (aunque menos marcadamente en Spilogale gracilis) como los prociónidos (Nasua nasua, Potos flavus, Procyon spp.; excluyendo Bassariscus astutus) comparten un cuello breve (Tabla 2.3; Apéndice 3.15, c. 0) y ancho, con un muy escaso desarrollo dorsoventral de los procesos espinosos (aunque no en el caso de N. nasua) y transversos de las cervicales caudales. Los tubérculos asociados a las zonas articulares presentan un desarrollo mínimo. Estos rasgos indican una baja fuerza en los movimientos de flexoextensión y fijación cervical (pero en algunos casos mayor rango de movimientos) en comparación con los mustélidos, seguramente en relación a hábitos predadores menos activos y una dieta más generalizada típicos para estos linajes (Cabrera y Yepes 1940, Bisaillon et al. 1976, McClearn 1992, Johnson et al. 2000, Argot 2003a, 2004, Wood et al. 2011). Dentro de los mustélidos terrestres se destacan procesos transversos reducidos específicamente en los ictoniquininos (Apéndice 3.15, c. 11), sumándose a otros rasgos cervicales (Apéndice 3.15, c. 0 , 9, ver más arriba) y de otras regiones postcraneales (ver más adelante) convergentes con los mefítidos, también en relación a convergencias ecológicas. El estudio de la forma del axis respalda esta interpretación al indicar una marcada compresión cráneocaudal del elemento y un escaso espacio para los principales grupos musculares en estos linajes (Fig. 3.3B). Conepatus, al contrario de otros musteloideos (incluido $S$. gracilis), presenta una reconfiguración cervical que involucra procesos espinosos cervicales marcadamente robustos e imbricados y los arcos neurales son elevados; rasgos que limitan la movilidad, y potencialmente entendibles como una estrategia de defensa anti-predadora (ver desarrollo de esta idea en Apéndice 4.1B).

Un carácter filogenéticamente informativo, único de mefítidos (e.g., Conepatus, Spilogale, y es necesario confirmar su presencia en Mydaus) dentro de Musteloidea y los outgroups considerados, es la presencia de un foramen transverso en la séptima vértebra cervical (sinapomorfía de Mephitidae; Apéndice 3.15, c. 13, estado 0), mientras que en otros taxones este no se encuentra cerrado ventralmente y se presenta a modo de un surco. En el espécimen MLP 19.XII.02.2 de Conepatus chinga, el lado izquierdo de la C7 presentó un foramen transverso con su cierre ventral presente pero inconcluso o roto. Vale la pena destacar que un foramen transverso fue registrado también en el lado izquierdo de un especimen de Pr. cancrivorus (CML 06243), aunque esto no fue considerado debido a la presencia de sobrecrecimientos anómalos seguramente patológicos presentes el elemento.

\subsubsection{Región tóraco-lumbar}

\section{Fórmula y proporciones de sectores torácico y lumbar}

Tanto en musteloideos como en Carnivora (Davis 1964:74, Narita y Kuratani 2005, Filler 2007: Fig. 2), el número típico de elementos tóraco-lumbares es 20 (ver también Mivart 1885, Slijper 1946, Davis 1964, Leach y de Kleer 1978, Yilmaz et al. 2000, Narita y Kuratani 
2005, Filler 2007; Tabla 4.1). Para Lyncodon patagonicus, además de especímenes con el número típico, se registró el caso excepcional del espécimen MLP 29.XII.00.17, que posee 19 elementos tóraco-lumbares, con sólo 3 elementos lumbares, sin evidencia de elementos faltantes en el material. Previos investigadores ya han detectado especímenes de arctoideos con 19 o menos elementos lumbares: e.g., Mivart (1885, Mustela, Meles y Mellivora y Gulo), Slijper (1946, Mellivora capensis), Davis (1964, Ailuropoda, Bassariscus y Procyon), y Narita y Kuratani (2005, Nasua sp., Mellivora capensis) (Tabla 4.1). Como excepción a este patrón, la mayoría de los mefítidos presentan 21 o más elementos tóraco-lumbares, mientras que en Mydaus javanensis, la fórmula parece ser siempre 20 elementos (Mivart 1885, Slijper 1946, Narita y Kuratani 2005, pero ver Slijper 1946: tabla 1 contra Slijper 1946: tabla 7). La presencia de más de 20 elementos tóraco-lumbares es una sinapomorfía y un rasgo diagnóstico del grupo (Apéndice 3.15, c. 14, estado 2), que se aparta del patrón típico y ancestral de Arctoidea y Carnivora en general, aunque también ocurre en algunos canoideos basales (e.g., Otocyon, Lycaon; ver Filler 2007), y excepcionalmente en variantes inusuales de algunos arctoideos. Dentro de los aproximadamente 300 especímenes de arctoideos observados (en bibliografía u observaciones propias; Tabla 4.1), las únicas excepciones registradas son cinco: 20 elementos en un espécimen de Conepatus (Mivart 1885); y 21 elementos para un Galictis sp. (Mivart 1885), un Bassaricyon alleni (Davis 1964), un Ursus maritimus (Narita y Kuratani 2005) y un Ei. barbara (MLP 1013) (Tabla 4.1). Un dato interesante es una anomalía registrada en el espécimen de Conepatus chinga MLP 1015, en donde se registró una hemi-vértebra izquierda con desarrollo de costilla, cuerpo, arco, proceso transverso y proceso espinoso entre las vértebras ordinarias $\mathrm{T} 7 \mathrm{y}$ T8.

Por otro lado, la proporción de elementos de los sectores torácico y lumbar de la fórmula vertebral así como las longitudes relativas de ambas regiones son muy variables entre especies. Esto queda sustentado parcialmente con los análisis de las proporciones tóracolumbares ( $\mathrm{LaLu} / \mathrm{LaTL}$; Apéndice 3.7C1, C2, ver más adelante) que indicaron diferencias significativas entre algunos grupos locomotores (pero ver consideraciones comentadas en la sección 3.4, LaLu/LaTL). Dentro de las especies de mustélidos de América del Sur, se registraron típicamente 5 lumbares en Galictis spp. (con variantes de 4 y 4/5), Lontra spp., y Pt. brasiliensis, mientras que en Ei. barbara fueron 6 (con variante de 7), y en Ly. patagonicus 4 (con variante de 3 y 5, Tabla 4.1). Seis elementos lumbares fueron registrados por Izor y de la Torre (1978) en el holotipo de Mustela felipei, y variantes entre 5 y 6 elementos fueron observadas en $M u$. frenata (ver también Hall 1951). Cambios en la fórmula vertebral tóracolumbar presentan algunos correlatos con la estructura filogenética de Musteloidea. Una configuración con 5 lumbares es típica para las subfamilias Taxidiinae e Ictonichinae (ver Mivart 1885, Narita y Kuratani 2005; Tabla 4.1). Por otro lado, el número típico de vértebras 
lumbares varía entre 5 y 6 elementos en lutrinos, mustelinos y guloninos, y entre 4 y 5 elementos en melivorinos y melinos; ver Tabla 4.1, King y Powell 2007). Llamativamente, en Ly. patagonicus se registra típicamente 16 elementos torácicos y 4 lumbares, un número de costillas excepcionalmente alto dentro de Musteloidea, sólo igualado por algunos tejones (e.g., Arctonyx sp. de Mivart 1885, ver también Quaife 1978), mefítidos (ver también Mivart 1885), y un espécimen de fórmula vertebral anómala de Galictis ("Grisonia") registrado por Mivart (1885). La fórmula vertebral típica de las martas que incluye 6 vértebras lumbares es un carácter compartido con Ei. barbara, siendo Gu. gulo el único gulonino en donde existen únicamente 5 lumbares. Seis elementos lumbares están típicamente presente también en Ailurus fulgens y muchos prociónidos (e.g., algunos Nasua nasua, Potos flavus, Procyon spp.; Mivart 1885, Narita y Kuratani 2005, Salesa et al. 2008; pero ver especímenes de Nasua spp. y Procyon lotor de Davis 1964), alcanzando incluso siete elementos lumbares en la mayoría de los especímenes de Bassariscus astutus y Bassaricyon alleni (Mivart 1885, Davis 1964; Tabla 4.1).

Estos cambios también pueden relacionarse a diferencias en los hábitos de vida. Musteloideos arborícolas (e.g., Ailurus fulgens, Bassariscus astutus, Bassaricyon alleni, Potos flavus), trepadores frecuentes (e.g., Eira barbara, Martes spp., frecuentemente en Procyon spp., Nasua spp.) y algunos trepadores eventuales (e.g., Mustela spp.), así como formas basales en general (ver Mivart 1885, Davis 1964, Izor y de la Torre 1978, Narita y Kuratani 2005, King y Powell 2007, Tabla 4.1), muestran generalmente un gran número, entre 6 y 7, de vértebras lumbares (y típicamente mayor longitud lumbar; Tabla 2.3, Fig. 3.1C). Davis (1964) concluyó que una fórmula vertebral numerosa en la región lumbar es ancestral de Arctoidea, siendo similar a lo observado en cánidos, y que el límite tóraco-lumbar tuvo, evolutivamente, un corrimiento hacia atrás en úrsidos y prociónidos derivados, pudiendo agregarse a los mustélidos (especialmente los tejones y $L y$. patagonicus) y mefítidos. Un número elevado de vértebras lumbares no parece dar ventaja decisiva o excluyente para la vida en sustratos arbóreos (e.g., ver úrsidos y Gu. gulo; Davis 1964), pero sí con estilos específicos de locomoción (Sargis 2001, Argot 2003a, b, ver más adelante). Para otras variantes, no existe ninguna explicación funcional clara. Por ejemplo, el número de vértebras lumbares de las nutrias de América del Sur es siempre de 5 elementos mientras que en las nutrias de otros continentes es típicamente 6 (pero ver algunos especímenes de Ao. cinerea e H. maculicollis; Tabla 4.1). Esto también es evidente a partir del análisis de la longitud relativa de la región lumbar, siendo cercana a 30\% en las especies de Lontra sudamericanas, algo mayor en Lu. lutra (32\%), mientras que es aproximadamente $38 \%$ en otras nutrias (e.g., Aonyx sp. y En. lutris; Tabla 2.3, Fig. 3.1C). El menor desarrollo del sector lumbar de Lontra provocax podría explicarse por sus actividades cavadoras eventuales, pero para Lo. longicaudis sería difícil apelar a este factor, al menos sin tener en cuenta adaptaciones pasadas o inercia filogenética (Bastida et al. 2007). 
El caso de los mefítidos merece un tratamiento particular. Como se mencionó antes, Mydaus, el más basal de sus miembros, presenta 20 elementos tóraco-lumbares (y 3 sacrales), condición típica de Carnivora y ancestral para Arctoidea (Davis 1964; Apéndice 3.15, c. 14 estado 0), con un número de lumbares moderado a bajo (5 o 6 elementos), esperable para especies con capacidades fosoriales. Por otro lado, los restantes representantes de la familia (Conepatus, Mephitis, Spilogale; excepto un espécimen de Conepatus sp. observado por Mivart 1885) presentan una configuración de 21 o más elementos tóraco-lumbares y sólo 2 elementos sacrales (Apéndice 3.15, c. 14 estado 2). Esto podría ser resultado de al menos un evento de migración de vértebras sacras a la región lumbar, aumentando el número tóraco-lumbar y reduciéndose el número de elementos que componen al sacro a dos. A su vez, el número de vértebras lumbares indica eventos de migración entre el sector torácico y lumbar, siendo más reducido el número de vértebras lumbares en las especies mefítidas más fosoriales (6 o 5 elementos lumbares), y elevado en la menos fosorial, Spilogale gracilis (con 7 elementos lumbares; Tabla 4.1). La reducción del sacro en mefítidos (excepto Mydaus) sería un carácter derivado y convergente con algunos ictoniquinos como Ictonyx, Poecilictis y Lyncodon (Apéndice 3.15, c. 14 estado 1); estos rasgos, sumados a otras características postcraneales apendiculares y axiales, se encuentran relacionados a estrategias de defensa y advertencia como el battle flag y descarga de glándulas anales (ver sección 4.3.2, Región sacro-caudal, sección 4.3.5, Hueso coxal).

De manera similar a lo descripto para los cambios de fórmula lumbar, las longitudes relativas de los sectores torácico y lumbar presentan algunas variantes de interés funcional destacables (Mivart 1885: tabla 1, Slijper 1946, Davis 1964: tabla 9 y 10). Dentro de los musteloideos no acuáticos, Conepatus sp., taxidinos, melinos, melivorinos, ictoniquinos y Gulo gulo poseen un sector torácico relativamente largo que duplica al sector lumbar. Un sector lumbar algo a marcadamente más largo se registra en Ei. barbara, Melogale sp., Ai. fulgens, muchos mefítidos y prociónidos, mustelinos, Martes spp., Bassariscus astutus y Nasua sp. (con longitudes máximas del sector lumbar prácticamente iguales al sector torácico; ver Tabla 2.3, Fig. 3.1C). Muchas de las especies musteloideas con sectores lumbares más elongados corresponden a especies ágiles, tanto half-bounders y/o trepadoras.

Al contrario de las especies con comportamiento aposemático (e.g., ictoniquinos, zorrinos), los half-bounders más ágiles (e.g., guloninos, mustelinos, Bassariscus astutus) presentan un sector lumbar largo (en conjunto con morfologías vertebrales acordes, ver más adelante), lo que genera un sector postdiafragmático más móvil, un arco tóraco-lumbar más marcado durante la flexión ventral y un gran espacio para la musculatura lumbar, posibilitando una mayor longitud de zancada en los saltos y fase aérea de vuelo extendido durante las carreras. Estas características, en conjunto con el adelantamiento del sector diafragmático y 
anticlinal (ver más adelante) y, en algunos casos (e.g., guloninos), la elongación de los miembros (ver sección 4.3.3-5), favorecen una mayor velocidad y agilidad durante el desplazamiento a saltos, modo de desplazamiento útil en sustratos arbóreos discontinuos e inestables (Gambaryan 1974, Leach y de Kleer 1978, Hildebrand 1988, Shapiro 1995, Sargis 2001, Schilling y Hackert 2006, Schutz y Guralnick 2007, Ercoli et al. 2013) o técnicas de ascenso y descenso específicas como el vertical looping (ver Taylor 1989, Salesa et al. 2008, ver más adelante), permitiendo cubrir una amplia distancia, rápidamente, utilizando relativamente pocos puntos de apoyo. Justamente, los half-bounders ágiles suelen ser buenos trepadores, y dependen de su velocidad sobre tierra o árboles para huir de predadores y atrapar a sus presas (Dagg 1973, Taylor 1989, Schutz y Guralnick 2007). Trepadores más lentos presentan también algunas de estas características, aunque la movilidad intervertebral en algunos sectores se encuentra restringida, en relación a la estabilización de posiciones extendidas (Argot 2003a, ver más adelante).

Contrario a los half-bounder ágiles, las longitudes relativas del sector lumbar de los hurones ictoniquinos como Galictis spp. son cortas, alcanzando un mínimo en Ly. patagonicus (23\% del total toracolumbar; ver Tabla 2.3, Fig. 3.1C). Las optimizaciones indican una región lumbar relativamente corta como una condición ancestral para el nodo Ictonichinae (c. 1, estado 0,311; Apéndice 3.15), en comparación con lo obtenido para Mustelidae $(0,375)$ y otros linajes de mustélidos derivados. Más allá de que los hurones ictoniquinos son capaces de realizar pasos half-bound, la influencia de otros factores sobre la morfología de la región lumbar es evidente al considerar estas especies. En el análisis de proporciones tóraco-lumbares de esta Tesis (ver sección 3.4, Apéndice 3.6C1,2), cuando se eliminan o trasladan a la categoría "cavador" a los lincodontininos, se recupera una separación significativa de las clases locomotoras (entre cavadores y half-bounders ágiles y entre cavadores y trepadores; Fig. 3.1C, Apéndice 3.6 C1, 2), y esta significancia persiste al controlar el efecto filogenético (Tabla 3.6, Apéndice 3.7C). Aunque cada elemento lumbar es relativamente elongado (ver también Fig. 3.5), el menor número de elementos lumbares indica que una mayor proporción de elementos postdiafragmáticos presentan costillas flotantes, lo que reduce, en algún grado, el rango de movimientos y de la velocidad de las carreras (Gambaryan 1974, Schilling y Hackert 2006, Ercoli et al. 2013), coincidiendo con las observaciones de velocidades menores que la del hombre registradas en Galictis y Lyncodon (observaciones de Azara 1802 y Koslowsky 1904, respectivamente). Sin embargo, el mayor número de costillas aumenta la superficie ósea de inserción del. m. iliocostalis lumborum, principal propulsor axial en las marchas half-bound (ver Elftman 1929, Gambaryan 1974, Taylor 1989, Schilling y Hackert 2006, Ercoli et al. 2013, ver sección 4.1) y de la musculatura intercostal y abdominal. En los ictoniquinos, la menor velocidad de carrera (e.g., huidas) parece estar compensada por estrategias de defensa anti- 
predatoria más evidentes, incluyendo coloración y comportamiento aposemático y glándulas anales más desarrolladas y potentes (Azara 1802, Mivart 1885, Doering 1881, Koslowsky 1904, Kaufmann y Kaufmann 1965, Dücker 1968, Larivière 2002a, Schutz y Guralnick 2007, Caro 2009). Como un caso aparte, algunos ictoniquinos (e.g., Ictonyx striatus) demuestran marcadas convergencias comportamentales, dietarias y morfológicas con los zorrinos (Johnson et. al. 2000, Larivière 2002a; Tabla 2.3; ver también sección 4.3.5, Hueso coxal). Éstas incluyen una baja movilidad axial (ver más adelante) que, al parecer, limitan sus habilidades de realizar marchas half-bounders y locomoción en galerías estrechas (Larivière 2002a, Wilson y Mittermeier 2009). Además, un mayor número de costillas flotantes otorga más rigidez y control muscular al sector postdiafragmático, disminuyendo los esfuerzos de la musculatura iliocostal, hipoaxial y abdominal (Moritz et al. 2007). Esta configuración disminuye el gasto energético necesario para mantener la espalda recta durante marchas simétricas (e.g., trote). La preferencia por este tipo de marcha, con una postura de la espalda recta, es otra característica típica de ictoniquinos, y les permite a los ictoniquinos weasel-like en particular, moverse furtivamente por debajo de la línea de la vegetación sin ser detectados (Cabrera y Yepes 1940, Kaufmann y Kaufmann 1965, Kingdon 1977, Larivière 2001b, Larivière 2002a, Yensen y Tarifa 2003a, b, Schutz and Guralnick 2007). Por otro lado, el mayor número de elementos lumbares en mustelinos, guloninos pequeños y muchos lutrinos ocurre en concordancia con una postura arqueada más frecuente (Heptner y Naumov 1967, Tarasoff 1972, Dagg 1973, Gambaryan 1974, Willemsen 1980b, Williams 1983b, Williams et al. 2002, Moritz et al. 2007, Horner y Biknevicius 2010), lo que disminuye el estrés muscular durante las marchas epigeas (Mortiz et al. 2007, Horner y Biknevicius 2010), pero haciendo más evidente su presencia a las potenciales presas y siendo las incursiones en galerías estrechas energéticamente más costosas.

Con respecto a las especies de mustélidos cavadores, investigadores previos (Mivart 1885, Slijper 1946, Davis 1964: 75, Quaife 1978) notaron que éstas presentan series lumbares más cortas en relación a la región torácica, y muchas veces menos numerosas (i.e., con 5 o 4 elementos lumbares; e.g., Arctonyx, Mellivora, Meles, Taxidea). Esta configuración de la región lumbar favorece la transmisión de los esfuerzos braquiales generados durante el cavado a las miembros posteriores (Davis 1964, Quaife 1978). El mayor número de costillas, permite a su vez una mayor masa y multiplicidad de vientres caudalesde los retractores extrínsecos del brazo (ver sección 4.1; ver también Quaife 1978, Moore et al. 2013, Ercoli et al. 2014). Una situación similar se registra en mefítidos, en los cuales la serie serie torácica alcanza el máximo número de elementos de 16 (alcanzando el índice LaLu/LaTL un mínimo de 0,292; Tabla 2.3, Apéndice 2.3), aunque en algunos linajes el sector lumbar no se encuentra reducido debido a la incorporación de un elemento proveniente del sacro. En el análisis morfo-geométrico de la penúltima vértebra lumbar, los musteloideos cavadores se diferenciaron de otros grupos 
locomotores (e.g., half-bounders, trepadores) por presentar vértebras compactas en sentido cráneocaudal, procesos espinosos y transversos perpendiculares (o incluso retrasados en el caso de Taxidea taxus) y amplios, y articulaciones amplias (Fig. 3.5, Apéndice 3.8B1). En el mismo sentido, los análisis lineales muestran una reducción significativa de la longitud del sector lumbar de los musteloideos cavadores respecto a otros grupos locomotores, excepto por los nadadores (sección 3.4, Apéndice 3.6C2), concordando con la interpretación de previos autores de que una región lumbar breve rígida y resistente a esfuerzos de torsión está presente en cavadores. De esta manera, los cambios morfologicos relacionados al cavado pueden ser otro factor explicativo del mayor número de costillas de ictoniquinos respecto a mustelinos, en concordancia con los mayores volúmenes de masa muscular retractora del miembro anterior (Ercoli et al. 2014) y las mayores aptitudes de cavado que presentan los primeros respecto a los segundos registradas por naturalistas y estudios ecológicos (Azara 1802, Dücker 1968, Larivière 2002a, Wilson y Mittermeier 2009). La optimización de la longitud relativa de la región lumbar (Apéndice 3.15; c. 1) indica para la base de Mustelidae y los nodos internos más basales, una región lumbar relativamente breve, seguramente en relación a que las tres subfamilias más basales del grupo son especialistas o frecuentes cavadores (i.e., Taxidiinae, Melinae y Mellivorinae).

\section{Sector prediafragmático y preanticlinal}

Las posiciones de las vértebras tanto diafragmática así como la anticlinal, ofrecen información valiosa desde un punto de vista funcional. La vértebra diafragmática ("heterostrophic vertebra"; Willemsen 1980a, b) indica el principal cambio de orientación del contacto entre facetas articulares craneales y caudales desde una disposición tangencial en el sector torácico anterior y medio, que es favorable para movimientos de rotación y ladeo, a una disposición radial, típica del sector torácico posterior y lumbar, favorable para movimientos de flexo-extensión (Slijper 1946, Willemsen 1980b, Argot 2003a, b, Schilling y Hackert 2006, Flores y Díaz 2009, pero ver también Boszczyk et al. 2001). Por otro lado, la vértebra anticlinal representa el elemento en el que la inclinación del proceso espinoso se vuelve perpendicular al eje de la columna (Slijper 1946; aunque existen variantes en la definición de su posición; ver Flores 2009). La inclinación de los procesos espinosos y la posición de la vértebra anticlinal se relacionan con la ventaja mecánica y la dirección de las líneas de acción de los sistemas epiaxiales que actúan sobre la columna (Slijper 1946, Davis 1964, Shapiro 1995, Argot 2003a). En mamíferos en general, la inclinación caudal de los procesos espinosos del sector preanticlinal genera una mayor ventaja mecánica del sistema epiaxial transversoespinal (e.g., m. multifidus, $\mathrm{mm}$. rotatores), mientras que una inclinación craneal en el sector caudal de la serie toracolumbar favorece una mayor ventaja mecánica del $\mathrm{m}$. longissimus thoracis (y en algunos casos del $\mathrm{m}$. iliocostalis), originado en los ápices de los procesos espinosos (Slijper 1946: 94). Más allá de 
estas generalizaciones, distintos investigadores plantean varias interpretaciones en lo que respecta a la posición relativa del sector de máxima flexión sagital (Leach y de Kleer 1978, Schilling y Hackert 2006; ver Apéndice 4.1C).

La condición presente en la mayoría de los mustélidos no acuáticos de América del Sur, incluyendo Ei. barbara (excepto un espécimen de Fisher 2007), Mu. frenata y Galictis spp. (excepto el espécimen MLP 2020), involucra al último elemento preanticlinal (vértabra torácica 11) como la vértebra diafragmática (i.e., posición adelantada respecto a la vértebra anticlinal). Esta misma situación se registra en otras en especies musteloideas de hábitos generalizados, como muchos especímenes de Gu. gulo y Meles spp., la gran mayoría de los ictoniquinos, y muchos prociónidos (e.g., Potos flavus, la mayoría de los Nasua y Procyon). Esta condición puede considerarse como ancestral para Arctoidea (Apéndice 3.15, c. 15, estado 1), y es intermedia entre la configuración evidenciada en algunas especies trepadoras o arborícolas (e.g., Martes sp., Bassariscus astutus; c.15, estado 0; Tabla 4.1), con una región postdiafragmática y/o postanticlinal relativamente más extendida y la presente en algunas especies cavadoras y lutrinos (sinapomorfía de Ictonichinae + Lutrinae; c. 15, estado 2), en la que la región prediafragmática y/o preanticlinal es extendida (Mivart 1885, Sliper 1946: tabla 7, Davis 1964, Leach y de Kleer 1978, Willemsen 1980b: tabla 8, Argot 2003b; Tabla 4.1).

Una posición adelantada de la vértebra anticlinal y/o diafragmática, sumado a un elevado número de vértebras lumbares, es común en especies musteloideas trepadoras o arborícolas (e.g., Ai. fulgens, Bassaricyon alleni, y algunos especímenes de Procyon spp.) y especialmente en aquellas de marchas más ágiles (e.g., Martes spp., Bassariscus astutus; al igual que se observa en algunos félidos y vivérridos; Slijper 1946, Argot 2003b). Estos rasgos se relacionan con un posicionamiento en la mitad de la región tóraco-lumbar del sector de máxima movilidad axial (i.e., cercanías de la región diafragmática; Leach y de Kleer 1978). Esto permite un gran arco durante la flexión/extensión, beneficioso para moverse en sustratos arbóreos discontinuos e inestables, realizar saltos (Taylor 1970, 1989, Trapp 1972, Gambaryan 1974, Youlatos 2003, Hildebrand 1988, Szalay y Sargis 2001, Argot 2003a, b; ver más arriba), y ascenso y descenso sobre troncos tipo vertical looping en donde se ejecutan combinaciones de movimientos de flexo-extensión precisos y amplios de la columna entre puntos de apoyo (Taylor 1970, 1989, Trapp 1972, Salesa et al. 2008, Dionisios Youlatos comunicación personal). Por otro lado, en su estudio sobre marsupiales, Argot (2003a, ver también Flores y Díaz 2009) sugirió que el adelantamiento de la vértebra diafragmática (i.e., reducción del sector prediafragmático), limita la rotación y ladeo axial en trepadores lentos, como lo son los estrategas bridging, lo que confiere la estabilidad requerida al pasar de una rama a otra. La ausencia de musteloideos especialistas en trepado lento tipo bridging, como ocurre en tupaidos, 
lorisidos, xenartros y marsupiales (Gebo 1989, Sargis 2001, Argot 2003a) limita mayores comparaciones.

En las nutrias sudamericanas (i.e., Lontra spp., Pteronura brasiliensis) tanto la vértebra diafragmática como la anticlinal se encuentran retrasadas, siendo representadas por los elementos 12 y 13 respectivamente. Esta situación fue descripta para nutrias de otros continentes vivientes y fósiles (e.g., Ao. cinerea, En. lutris, Lu. lutra, Lutro. perspicillata, ${ }^{\dagger}$ Lutro. "isolalutra" cretensis, ${ }^{\dagger}$ Sardolutra "Nesolutra" ichnusae; Slijper 1946: tabla 7, Malatesta 1977, Willemsen 1980a, b, 1992; Tabla 4.1). Excepción a esto son un espécimen de Ao. cinerea y dos especímenes de Lu. lutra (Willemsen 1980a, b, Yilmaz 2000). En un especímen de Lo. longicaudis (MACN 47.218) y otro de Pt. brasiliensis (MNHN s/n) el corrimiento de la diafragmática es de dos elementos. Al contrario de Ga. cuja (excepto espécimen MLP 2020) y la mayoría de los mustelinos, en Ly. patagonicus e ictoniquininos se registra un corrimiento caudal de la vértebra diafragmática similar a nutrias, coincidiendo con la vértebra anticlinal, aunque en el elemento 12 (Apéndice 3.15, c. 15, estado 2). La optimización indica que la posición retrasada de la vértebra diafragmática es una sinapomorfía Lutrinae + Ictonichinae, nodo recuperado en la filogenia molecular de Sato et al. (2012). El corrimiento caudal de la vértebra anticlinal en las nutrias permite incrementar el número de vértebras prediafragmáticas que poseen mayor libertad articular para movimientos de rotación y ladeo (Willemsen 1980b; ver también Williams et al. 2002). Esto permite mayores rangos de movimientos axiales complejos y poderosos necesarios durante maniobras de buceo. En estas especies cobra importancia la musculatura transversospinal que se vincula a esfuerzos de fijación, ladeo y rotación de la columna en el sector torácico caudal. Es interestante destacar que las posiciones más retrasadas de la vértebra transicional se da en especies con el mayor grado de especialización al nado, Lutrogale, En. lutris y, llamativamente, de los linajes basales (e.g., Koepfli et al. 2008, Sato et al. 2012) y americanos Pteronura y Lontra. Justamente, la posición relativamente caudal de la vértebra diafragmática (T11), fue el argumento de Willemsen (1980b) para proponer que Ao. cinerea (y algo similar en Lutrogale spp.), proviene de un linaje ancestral especializado al nado. Sin embargo, dado que el autor basó sus observaciones considerando a Ma. martes como único modelo mustélidos no lutrino (Willemsen 1980b: tabla 8), asumió erróneamente que una vértebra diafragmática en T10 es la condición típica de mustélidos no acuáticos. La muestra más amplia de esta tesis, así como la presentada por Slijper (1946: tabla 7), permite modificar esta propuesta, indicando que la posición diafragmática de Ao. cinerea (y Lu. lutra sensu Willemsen 1980a y Yilmaz et al. 2000 contra Slijper 1946), es también la típica para musteloideos terrestres (T11; ver Apéndice 3.15, c. 15, estado 1) coincidiendo con su condición de lutrino poco especializado al buceo. 
Bajo este nuevo panorama, el grado de movilidad lateromedial y rotacional del esqueleto axial, evidenciado por la posición de la vértebra diafragmática en Ly. patagonicus, algunos especimenes de Galictis, e ictoniquinos, podría deberse a una ancestría vinculada a hábitos de vida semiacuáticos (siguiendo la hipótesis de Willemsen 1980b; Apéndice 3.15, c. 15, estado 2), o cavadores (ver más adelante). Como otra alternativa, la gran movilidad axial podría ser un indicio más para vincular estrechamente a Ly. patagonicus con estrategias de caza de tipo rolling and curl, y por otro lado, estrategias de tipo bite down para especies como Ga. cuja y Vo. peregusna (Dücker 1968, Rood 1970, Ben-David et al. 1991, Kays 1996, Wilson y Mittermeier 2009; ver sección 4.3.2, Región Cervical, Anexo), aunque esto último no explicaría la posición diafragmática retrasada de otros ictoniquinos. Dada la reducción y gracilidad de los miembros anteriores requerida para incursiones en galerías de roedores fosoriales (Ondrias 1961, Gambaryan 1974), una gran fuerza y alta movilidad axial son requeridas durante la lucha con una presa con el fin de someterla antes del killing bite, especialmente si las presas son grandes y poderosas (Kaufmann y Kaufmann 1965, Ewer 1973, Rowe-rowe 1978, Radinsky 1981a, Zielinski 2000, King y Powell 2007).

Una posición relativamente caudal de la vértebra diafragmática, y especialmente de la anticlinal, se observa en taxones cavadores tales como mefítidos y tejones, rasgos alcanzados aparentemente de forna convergente en estos linajes (Apéndice 3.15, c. 15, 16). Como Slijper (1946) reconoció para los zorrinos Mydaus javanensis y Conepatus sp. (confirmándose en esta Tesis para Co. chinga), y posteriormente Davis (1964) y Quaife (1978) para Ta. taxus, en estos taxones existen vértebras postdiafragmáticas, con procesos espinosos de inclinación caudal (preanticlinales), que incluso pueden involucrar lumbares, mientras que en otros mustélidos menos especializados al cavado, la región anticlinal está compuesta por múltiples elementos posteriores (e.g., Meles, Mellivora, Arctonyx; Tabla 4.1; Apéndice 3.15, c. 15). La configuración presente en cavadores puede relacionarse a una gran importancia relativa del sistema transversoespinal en el sector tóraco-lumbar (Slijper 1946, Jouffroy y Lessertisseur 1971, Argot 2003a). Esto permite resistir (y generar) esfuerzos de torsión axiales en relación a la mecánica de la excavación (Davis 1964, Quaife 1978). Por otro lado, los animales cavadores (así como trepadores de gran tamaño, ver Davis 1964) tienen cuerpos vertebrales cortos (ver más adelante), lo que impediría una inclinación craneal de los procesos espinosos debido a que generaría una brazo de palanca negativo para la acción extensora del m. multifidus (Slijper 1946: 101-102, Argot 2003b). Esta condición favorecería el desarrollo de sectores anticlinales amplios. La única variante importante dentro de los mefítidos es Spilogale, en donde la vértebra anticlinal está en una posición craneal a (algo sólo observado en el MACN 34.551), o a nivel de, la vértebra diafragmática, y ambas se encuentran más adelantadas, como en los prociónidos y algunos mustélidos weasel-like. Particularmente, este es el único taxón mefítido ágil, 
eventualmente trepador y menos especializado al cavado (Kinlaw 1995, Long 2008, Elbroch 2003).

La altura de los procesos espinosos, área de origen e inserción de músculos epiaxiales medios, puede relacionarse, con buena correspondencia, al tamaño corporal (incluso a nivel intraespecífico, ver Leach y de Kleer 1978), dado que a mayor tamaño es necesario una musculatura epiaxial de mayor masa y ventaja mecánica para el soporte del peso corporal (ver relación alométrica explicada en el sección 4.3.2, Región cervical; ver también Slijper 1946, Leach y de Kleer 1978, Hildebrand 1988). El repertorio de movimientos y estilos locomotores posibles de cada especie es también un factor de influencia importante en la morfología de los procesos espinosos (Slijper 1946, Leach y de Kleer 1978, Shapiro 1995, Sargis 2001, Pierce et al. 2011; ver también Herán̆ 1962). En relación a esto, las especies de gran tamaño corporal se encuentran limitadas en sus estilos locomotores debido al factor alométrico, dado que procesos espinales más altos, limitan el rango de movimientos intervertebrales dorsoventrales por interferencia entre estos y tejidos circundantes (Leach y de Kleer 1978, Hildebrand 1988, Sargis 2001, Pierce et al. 2011).

En las nutrias de América del Sur, así como en todas las nutrias del resto del mundo (e.g., Ao. cinerea, H. macullicolis, Lutrogale spp., Lutra lutra; ver también Fisher 1942, Willemsen 1980a, b, Yilmaz et al. 2000), la presencia de los primeros 3 o 4 procesos espinosos torácicos muy elevados y perpendiculares, en combinación con los procesos espinosos cervicales ampliamente desarrollados ya descriptos (ver sección 4.3.2, Región cervical), permiten aumentar la ventaja mecánica para los principales músculos extensores del cuello (principalmente m. spinalis cervicis, m. splenius; Slijper 1946: 91-92, 95-97, Gambaryan et al. 2005, Argot 2003a, b, 2004, Flores y Díaz 2009, Carrizo y Díaz 2013; ver sección 4.1.1). Por otro lado, el total de los restantes procesos espinosos torácicos preanticlinales, aunque inclinados, son también relativamente largos y de ápice robustos, aumentado el área de agarre muscular y la ventaja mecánica para el sistema transversoespinal y el lugar de tránsito de los músculos extensores epiaxiales torácicos en general (e.g., m. spinalis et semispinalis thoracis, mm. interspinalis, mm. rotatores, m. longissimus thoracis; Slijper 1946, Savage 1957, Willemsen 1980b, Pierce et al. 2011, ver sección 4.1.1). Sin embargo, estas condiciones limitan, en algún grado, la flexibilidad dorsoventral de la región por interferencia de los procesos (pero ver Gambaryan 1974, Sargis 2001). La gran fuerza de extensión tóraco-lumbar, y secundariamente torsión, en los lutrinos, también destacada en el sector cervical, posibilitaría movimientos ondulatorios más poderosos durante el buceo y maniobras en un medio denso, así como durante la caza de animales en superficie (Savage 1957, Gambaryan y Karapetyan 1961, Gambaryan 1974, Bisaillon et al. 1976, Willemsen 1980b, Williams et al. 2002). Más allá de importantes variantes intraespecíficas, el mayor desarrollo cráneocaudal de los procesos 
espinosos de Lo. provocax, en comparación con otras nutrias sudamericanas, podría relacionarse a una mayor área disponible para los $\mathrm{mm}$. rotatores, quizás relacionado a las frecuentes actividades de cavado registradas para el taxón (Bastida et al. 2007, Wilson y Mittermeier 2009) o variantes en la estrategia de nado no conocidas.

En los lincodontininos y mustelinos de América del Sur, así como en Vormela peregusna (pero no en ictoniquininos más generalizados como Po. libyca), mustelinos de otros continentes y secundariamente en guloninos pequeños a medianos (ver Leach y de Kleer 1978), los procesos espinosos preanticlinales presentan márgenes caudales sinuosos y son poco elevados (especialmente en las especies más pequeñas, como Ly. patagonicus), marcadamente distanciados y amplios. La morfología de estas especies implica una menor fuerza de extensión de la columna, que puede estar relacionado con el bajo tamaño corporal (Slijper 1946, Savage 1957), y un aumento del rango de movimientos posibles y el área de inserción disponible para los mm. rotatores, y secundariamente m. multifidus (Slijper 1946, Savage 1957, Sargis 2001, Pierce et al. 2011), en relación a una gran gama de movimientos poderosos intervertebrales fuera del plano parasagital (e.g., ladeo, rotación). La mayor flexibilidad y rango de movimientos en lincodontininos, como ya fue sugerido para otros hurones, podría estar relacionado al requerimiento de amplios y complejos movimientos requeridos para moverse en túneles estrechos (Gambaryan 1974, King y Powell 2007, Moritz et al. 2007, Horner y Biknevicius 2010, Ercoli et al. 2014), así como durante la caza de tipo rolling and curl, nuevamente destacándose como caso potencialmente extremo a Ly. patagonicus. Es probable también que la columna larga, móvil y musculosa de los hurones contribuya en los cambios de dirección durante marchas epigeas rápidas, reemplazando a la musculatura aductora de los miembros en esta función (Ercoli et al. 2013, 2014, ver sección 4.1.1).

En particular, Eira barbara presenta una morfología algo distinta a la observada en hurones, con procesos espinosos amplios y cuadrangulares, altos y menos distanciados, indicando importantes esfuerzos musculares parasagitales y no parasagitales (Slijper 1946, Sargis 2001), y posiblemente un menor rango de extensión de la espalda que en hurones, debido a posibles interferencias entre los mismos. La columna de Ei. barbara es más móvil que la de Gu. gulo pero menos que Martes spp., posiblemente en relación a las restricciones impuestas por el tamaño corporal.

La morfología de los procesos espinosos del sector preanticlinal torácico de otros musteloideos también revela combinaciones de rasgos asociados a sus variados hábitos de vida. En melinos y melivorinos (así como en taxidinos según Quaife 1978), la altura e inclinación de los procesos espinales es similar al observado en lutrinos y guloninos grandes, pero estos son más amplios y cuadrangulares (Apéndice 3.15, c. 17, estado 2), limitando en mayor grado la movilidad y el tamaño de los mm. interespinales, pero permitiendo amplias áreas de otras 
inserciones musculares y poderosos movimientos tanto de extensión como fuera del plano sagital (Savage 1957, Willemsen 1980b, Sargis 2001, pero ver también Shapiro 1995; ver sección 4.1). Esto se relaciona a los esfuerzos de torsión y al soporte de la reacción del terreno generado durante el cavado con los miembros anteriores (Davis 1964, Quaife 1978, Sargis 2001). Algo diferente ocurre en los prociónidos y mefítidos, como Po. flavus, Pr. lotor, N. nasua y Conepatus chinga, en los cuales los procesos espinosos son altos y triangulares a pedunculados (i.e., robustecidos en sus extremos; morfologías optimizadas como plesiomórfica para mustélidos; Apéndice 3.15, c. 17, estados 0 y 3), indicando importantes uniones tendinosas y ligamentosas dorsales, y menores áreas de agarre para el sistema transversoespinal, limitando el rango y fuerza de los movimientos fuera del plano sagital (Gambaryan 1974, Sargis 2001). Dada la gran extensión del sector preanticlinal en mefítidos (contrario de prociónidos), gran parte de la región toracolumbar muestra estas cualidades diferentes del modelo cavador melino (desarrolladas también convergentemente mediante una reversión en Ictonychininae; Apéndice 3.15, c. 17, estados 3; ver también sección 4.3.4). En el mefítido Conepatus (Mivart 1885, Slijper 1946; ver Tabla 4.1), los procesos espinosos de los elementos preanticlinales caudales se vuelven progresivamente más perpendiculares (distinto a otros musteloideos) y anchos, y con espacios intervertebrales progresivamente menores, dando paso a un sector anticlinal rígido (Slijper 1946, Gambaryan 1974, Sargis 2001, Argot 2003a, Carrizo y Díaz 2013). Estos rasgos se suman a otros indicadores de gran estabilización axial y baja agilidad, en relación a las marchas lentas desarrolladas por los mefítidos y estrategias de defensa anti-predadoras alternativas a la huida (Azara 1802, Cabrera y Yepes 1940, Hildebrand 1977, Van de graaff et al. 1982, Elbroch 2003, Álvarez et al. 2013; ver Apéndice 4.1B). Por otro lado, en S. gracilis se presenta una morfología diferente a la de Co. chinga y más similar a la de los hurones, indicando el desarrollo de movimientos ágiles y rápidos, e.g., carreras half-bound (Kinlaw 1995, Whitaker y Hamilton 1998, Elbroch 2003, Long 2008).

\section{Sector postdriafragmático y postanticlinal}

En lo que respecta al sector postdiafragmático tóraco-lumbar, la morfología de los cuerpos vertebrales y los procesos también muestran cambios entre los distintos grupos musteloideos de interés funcional. Como regla general para Carnivora, los procesos mamilares y accesorios del sector anticlinal y postanticlinal, son sitios de agarre de los mm. multifidus y sistema longissimus (reemplazado caudalmente por el $\mathrm{m}$. sacrocaudalis dorsalis lateralis), respectivamente (Davis 1964, Evans y De Lahunta 2013, Ercoli et al. 2013, 2014, ver sección 4.1.1). El desarrollo y diferenciación de estos procesos es siempre importante en el sector postdiafragmático medio y anterior, mientras que se reducen en las últimas vértebras lumbares caudalmente, y se confunden en los procesos transversos prediafragmáticos cranealmente (ver también Leach y de Kleer 1978). El desarrollo de los procesos mamilares amplios, así como la 
tendencia a la diferenciación de sub-procesos en los procesos transversos de las vértebras preanticlinales (i.e., procesos transversos multicuspidados y amplios), es una característica reconstruida como plesiomórfica para Arctoidea (Apéndice 3.15, c. 18, estado 1), y presente en la mayoría de los musteloideos no mustélidos, tejones y nutrias (c. 18, estado 0 como sinapomorfía de Mustelidae - Taxidea - Meles). Este rasgo se vincula a la preponderancia de la fijación y/o extensión del esqueleto axial por sobre la flexibilidad y los esfuerzos lateromediales en los primeros (Argot 2003a y citas allí, Flores y Díaz 2009). Dentro de los hurones, características similares se esbozan en $\mathrm{Mu}$. vison (aunque sin llegar a considerarse estado 1 en codificación), que es el mustelino más basal (Koepfli et al. 2008, Sato et al. 2012) y presenta hábitos semi-acuáticos (Williams 1983a, b, Fish 1994, Peigné et al. 2008). Procesos accesorios amplios y robustos en inmediaciones del sector anticlinal también limitan la movilidad axial (Argot 2003a, Flores y Díaz 2009, Carrizo y Díaz 2013) y son amplios en estos grupos, especialmente en grupos trepadores como los prociónidos.

En la mayoría de los mustélidos y mefítidos (ver también Leach y de Kleer 1978, Willemsen 1980a), los procesos mamilares, y en especial los procesos accesorios (zonas de orígenes del m. sacrocaudalis dorsalis lateralis; Hall 1926, 1927, Ercoli et al. 2013; pero ver Davis 1964), se encuentran reducidos a indiferenciados en las últimas vertébras lumbares. Mientras esta condición se reconstruye como plesiomórfica para arctoideos y caniformes en general (Apéndice 3.15, c. 19, estado 0), los prociónidos ( $N$. nasua, Procyon spp. y especialmente en Po. flavus) presentan procesos muy bien definidos y amplios (estado 1), lo que constituye una sinapomorfia de la familia. Estas diferencias se observan al analizar los cambios de forma registrados en la penúltima vértebra lumbar, donde los prociónidos segregan hacia un área del morfoespacio en parte exclusiva (valores positivos del PC2), con procesos accesorios amplios, y procesos espinosos robustos e inclinados cranealmente (Fig. 3.5, Apéndice 3.8B1). Esta morfología implica una mayor área de origen de los paquetes caudales de los músculos que fijan la región lumbar y mueven lateralmente la cola. Estas funciones están remarcadas en estas especies con colas largas, musculosas y de movimientos laterales precisos, dado que este apéndice es utilizado como un órgano de balance, e incluso es prensil (Po. flavus; McClearn 1992, Youlatos 2003). En mustélidos trepadores y nadadores de colas largas y musculosas como los guloninos medianos y pequeños (Leach y de Kleer 1978) y lutrinos, se presenta una condición intermedia a otros mustélidos y prociónidos en estas estructuras. Llamativamente, los ictoniquininos son el único grupo de mustélidos con procesos accesorios en las últimas lumbares de un desarrollo comparable al de los prociónidos (Apéndice 3.15, c. 19, estado 1). Es interesante destacar que dentro de lincodontininos, los procesos accesorios de las últimas lumbares se encuentran más reducidos en Ly. patagonicus que en Galictis spp., posiblemente en relación a la mayor reducción de la cola en el primer taxón (y algo similar ocurre al comparar 
distintas especies de mustelinos). Aunque las nutrias presentan colas largas y musculosas, es probable que los movimientos laterales de la misma no sean importantes durante la natación (Savage 1957, Tarasoff 1972, Willemsen 1980b, Fish 1994) explicando la ausencia de procesos accesorios hipertrofiados en el sector axial posterior para el grupo (ver tambien Fig. 3.5).

En el sector postdiafragmático, los procesos espinosos son la zona de agarre del $\mathrm{m}$. multifidus lumborum y mm. intespinalis, que son músculos principalmente estabilizadores, y su desarrollo determina el espacio de tránsito del $\mathrm{m}$. longissimus thoracis y lumborum. Por otro lado, los procesos transversos lumbares son la zona de agarre del $\mathrm{m}$. iliocostalis lumborum y $\mathrm{m}$. quadratus lumborum que son, entre otras funciones, flexores laterales (Willemsen 1980a, b, Shapiro 1995, Argot 2003a, Fisher et al. 2008, Pierce et al. 2011, Evans y De Lahunta 2013; ver sección 4.1.1). La morfología de estos procesos y los cuerpos vertebrales se encuentran relacionadas entre sí, y son informativos en lo que respecta a hábitos locomotores, tamaño corporal (al igual que fue comentado para el sector preanticlinal; Slijper 1946: pag 94) y otras variables. Willemsen (1980b) sugirió, como una primera aproximación, que el mayor desarrollo de los sistemas epiaxiales mediales se produce a expensas de los epiaxiales laterales, y que esto queda registrado en el desarrollo relativo de los procesos espinosos y transversos respectivamente. La morfología de los cuerpos vertebrales a su vez son determinantes parciales de la morfología de estos procesos, afectándose la ventaja mecánica de los músculos y la movilidad del sector (Slijper 1946, Davis 1964, Argot 2003b, Pierce et al. 2011). En particular para lincodontininos, las marcadas diferencias en el desarrollo de los procesos espinosos postanticlinales entre las distintas especies pueden ser directamente relacionadas al factor tamaño corporal (como ocurre en los preanticlinales, ver más arriba), siendo máximo el desarrollo en Ga. vittata (1800-3380 gr.; Johnson et. al. 2000, Yensen y Tarifa 2003b), intermedio en Ga. cuja (1000-2500 gr.; Yensen y Tarifa 2003a, Wilson y Mittermeier 2009) y mínimo en Ly. patagonicus (200-250 gr.; Wilson y Mittermeier 2009). Estas diferencias se reflejan en el análisis de morfo-espacio del penúltimo elemento lumbar (Fig. 3.5), que muestra una distribución hacia valores positivos del PC2 y especialmente el PC1 desde los lincodontininos más pequeños a los de mayor tamaño. Lo mismo puede proponerse, con algunas excepciones (e.g., mefítidos), entre miembros funcionalmente similares de otros linajes (e.g., prociónidos, guloninos, lutrinos).

En cuanto a los procesos espinosos y transversos postanticlinales, la condición general en Musteloidea es que se mantengan elevados y que progresivamente se distancien e incrementen su altura. En musteloideos no mustélidos (e.g., Co. chinga, Nasua spp., Po. flavus, Procyon spp.; pero vero $\mathrm{Ba}$. astutus) y Taxidea taxus, los cuerpos vertebrales lumbares son breves cráneocaudalmente (ver Fig. 3.5) y las crestas ventrales de los cuerpos (zona de inserción de la musculatura hipoaxial flexora; Hall 1926, 1927, Argot 2003a, b, Fisher et al. 2008, Ercoli 
et al. 2013; ver sección 4.1.1) no se encuentran bien definidas. Los procesos transversos lumbares se encuentran proyectados mayormente perpendiculares y cercanos al plano horizontal, reducidos respecto a los procesos espinosos; en muchos casos en extremo (i.e., Taxidea, algunos prociónidos, mefítidos, ver también úrsidos; Mivart 1885, Davis 1964, Argot 2003b, Álvarez et al. 2013; condición que es reconstruida en los optimizaciones como una sinapomorfía de Arctoidea (Apéndice 3.15, c. 20, estado 0). La configuración de todos estos musteloideos (llevada a un extremo en mefítidos como Co. chinga y en el taxidino Taxidea taxus) sugiere un gran desarrollo de los sistemas musculares epiaxiales mediales (e.g., m. longissimus, m. multifidus), en detrimento de los laterales (i.e., m. iliocostalis, $\mathrm{m}$. intertransversales; Savage 1957, Willemsen 1980b, Ercoli et al. 2013). La posición aproximadamente horizontal de los procesos transversos sugiere que las líneas de acción de los sistemas longissimus, iliocostalis y el m. quadratus lumborum favorecen el desempeño de estos músculos como estabilizadores más que como extensores poderosos de la columna (Shapiro y Jungers 1994, Shapiro 1995, Sargis 2001, Argot 2003a, b). La forma y proximidad entre los extremos amplios de los procesos espinosos, y transversos en muchos casos, sugieren la presencia de ligamentos intervertebrales relativamente importantes e interferencia mecánica, limitando la movilidad del sector (Gambaryan 1974, Taylor 1989: Fig. 14.7, Argot 2003b, Álvarez et al). La brevedad y altura de los cuerpos de la región lumbar de los estos musteloideos (similar a la presente en úsidos y lutrinos, y mustelidos no weasel-like en general, Apéndice 3.15 , c. 21 , estado 1), también indica una importante estabilización y baja amplitud total de movimientos de la región lumbar de estos linajes (Gambaryan 1974, Argot 2003b, Pierce et al. 2011). Algunas de estas características fueron registradas para otros mamíferos trepadores lentos (que no requieren gran flexibilidad axial fuera del plano sagital y si requieren estabilización de una posición axial extendida al moverse entre múltiples soportes aislados; clamber, bridging; Shapiro y Jungers 1994, Sargis 2001, Argot 2003a, b) y frecuentemente destacada para especies cavadoras (Davis 1964, Quaife 1978). La marcada diferenciación morfológica de las vértebras lumbares entre prociónidos y el gulonino Ei. barbara (Fig. 3.5; así como de trepadores half-bounders como otros guloninos y Bassariscus astutus), causante de la distribución disyunta del grupo trepador en el análisis de morfometría geométrica y de la ausencia de significancia en la separación de algunos pares de grupos locomotores (ver sección 3.5, Apéndice 3.8B1), es evidencia a su vez de estrategias de trepado diferentes en estos linajes, además de una importante influencia de la estructura filogenética en la morfología axial (Fig. 3.5B; Apéndice 3.15, e.g., c. 20, 21). Por un lado, la morfología lumbar de la mayoría de los prociónidos (exceptuando por Bassariscus astutus, especies trepadoras lentas o sigilosas) fue reconstruida como establecida en la base de Arctoidea (pero ver adquisición de estado 1 de $\mathrm{c}$. 19), mientras que la región lumbar del linaje de los guloninos sería consecuencia de un gran 
número de modificaciones posteriores, ocurridas luego de la primer radiación de los mustélidos (Apéndice 3.15, e.g., c. 18, 20, 21; aunque la inclusión de Ba. astutus en las optimizaciones podría modificar el resultado para algunos de estos caracteres). En el caso de especies cavadoras, como fue comentado más arriba, la mayor estabilidad y rigidez lumbar se relaciona a que miembros anteriores y la musculatura extrínseca originada en las vértebras y la caja torácica se encargan de remover el terreno, mientras que la región axial posterior debe transferir la fuerza peso y los esfuerzos realizados a los miembros posteriores, encargados principalmente del soporte total (Quaife 1978, Hildebrand 1988, Moore et al. 2013). En el caso de Co. chinga y algunos otros mefítidos, la mínima movilidad en beneficio de rigidez y resistencia de la región anticlinal y la región lumbar craneal, en conjunto con otros rasgos axiales ya comentados, pueden vincularse a marchas lentas y tácticas anti-depredadores particulares (coloración aposemática, comportamiento aposemático, secreciones anales, fingir muerte, resistencia a ataques, contra-ataques ; Ewer 1973, Larivière y Messier 1996, Giannini et al. 2011, Álvarez et al. 2013; ver Apéndice 4.1B). Sin embargo, como en los musteloideos de comportamiento battle flag (= tail up, i.e., levantar la cola en señal de advertencia; ver Hall 1926, Dücker 1968, Larivière y Messier 1996; ver sección 4.3.2, Región sacro-caudal) se registra un sector lumbar posterior con cuerpos vertebrales algo más aplanados, y procesos espinosos más delgados y distanciados, en relación a la mayor movilidad de la base de la cola y sacra requerida.

Estos linajes (y musteloideos no weasel-like en general), así como también hiénidos y úrsidos, realizan carreras de tipo galopes lentos (Dagg 1973, Gambaryan 1974, Spoor y Badoux 1988, 1989, Taylor 1989, McClearn 1992, Álvarez et al. 2013). Los miembros anteriores tienen una participación más activa durante la propulsión, y no existe una fase de vuelo extendido amplia, por lo que los movimientos sagitales axiales no son tan marcados. Justamente, la región lumbar corta, poco móvil y estrechamente unida por ligamentos de estos galopantes (Murie 1871, Davis 1964, Gambaryan 1974, Spoor y Badoux 1988, 1989, Taylor 1989), implica un impedimento a la ejecución de carreras ágiles y a saltos (Slijper 1946: 102, Gambaryan 1974, Spoor y Belterman 1986, Hildebrand 1988, Shapiro 1995, Boszczyk et al. 2001, Argot 2003b, Wroe et al. 2008, Álvarez et al. 2013).

Como ocurre en otros rasgos axiales, el desarrollo y la morfología de los procesos transversos en mustélidos basales como Gulo gulo, melinos, melivorinos, mayormente galopantes (Heptner y Naumov 1967, Dagg 1973, Gambaryan 1974), y la mayoría de las nutrias, es intermedio respecto a musteloideos basales (i.e., prociónidos, mefítidos y Taxidea taxus) y mustélidos weasel-like (ver más adelante; ver Taylor 1989, Álvarez et al. 2013; ver fig. 3.5), indicando una fuerte influencia de la filogenia en la morfología lumbar (ver Apéndice 3.15, Fig. 3.5). Esto es también evidente en el análisis especifico de la vista dorsal de la penúltima vértebra lumbar, en donde trepadores mustélidos como los guloninos grandes y cavadores 
mustélidos como los melinos, presentan morfologías intermedias entre formas otros musteloideos de similares hábitos y hurones, sin alcanzar morfologías especializadas como prociónidos y mefítidos y Taxidea taxus (Fig. 3.5). La presencia de una región axial más móvil en mustélidos no weasel-like (exceptuando Ta. taxus) en comparación con musteloideos no mustélidos, puede ser explicada en función de la historia evolutiva particular de mustélidos más cercanamente relacionada a la caza de roedores en galerías y un diseño corporal de patas cortas en relación al cuerpo (Gambaryan 1974; ver más adelante) y la capacidad de realizar marchas asimétricas similares al half-bound eventualmente en muchos de estos linajes (Heptner y Naumov 1967, Tarasoff et al. 1972, Gambaryan 1974, Taylor 1989, Pasitschniak-Arts y Larivière 1995; ver optimizaciones del nodo Mustelidae - Taxidea; c. 17 y 20, reconstrucciones ambiguas, c. 21, estado 0; Apéndice 3.15, e.g., c. 18, 20, 21).

En particular en las nutrias, como fue descripto previamente en otros sectores axiales, los procesos espinosos lumbares son importantes en relación a la preponderancia del $\mathrm{m}$. longissimus, que está involucrado, junto a los flexores hipoaxiales, en el nado por ondulación carangiforme (Gambaryan y Karapetyan 1961, Tarasoff 1972, Tarasoff et al. 1972, Gambaryan 1974, Taylor 1989, Williams et al. 2002). Estas características están exageradas en las especies más especializadas al buceo (aunque con diferencias de estilos propios de cada taxón; ver Savage 1957, Gambaryan y Karapetyan 1961, Gambaryan 1974: tabla 21, Willemsen 1980a, b, Lewis 2008). En el análisis de forma de la penúltima vértebra lumbar, el gran desarrollo en superficie y la moderada inclinación craneal de los procesos espinosos y transversos, en conjunto con procesos accesorios reducidos, permite diferenciar a los lutrinos de la mayoría de los restantes musteloideos (PC3, resultado no mostrado). En el caso de En. lutris, los procesos transversos lumbares presentan la menor proyección lateral dentro del clado (ver también carnivoros nadadores extintos ${ }^{\dagger}$ Potamotherium valletoni, ${ }^{\dagger}$ Sardolutra "Nesolutra" ichnusae; Savage 1957, Malatesta 1977), y las facetas articulares (pre- y postzigapófisis) se encuentran marcadamente separadas y son curvas con una amplia extensión tanto en su componente vertical como horizontal. Estas últimas modificaciones se relacionan con la reducción de la masa muscular iliocostal, en detrimento de la capacidad de flexión lateral y restringiéndose marcadamente el grado de torsión y ladeo intervertebral posible en este sector (siendo los movimientos de maniobras del nado carangiforme llevados a cabo por otros sectores; Gambaryan y Karapetyan 1961, Tarasoff et al. 1972, Gambaryan 1974, Willemsen 1980b, Taylor 1989, Lewis 2008, Pierce et al. 2011). Por otro lado, en Pt. brasiliensis así como en Lutro. perspicillata, los procesos transversos tienen mayor importancia relativa al proceso espinoso, intermedia entre En. lutris y especies más generalizadas como Ao. cinerea, Lontra spp. y Lutra spp. (ver también Willemsen 1980b), indicando variantes en el desarrollo del sistema iliocostal lumbar. Las nutrias más generalizadas frecuentan el medio terrestre y pueden 
realizar eventualmente marchas tipo half-bound (Tarasoff 1972, Tarasoff et al. 1972, Willemsen 1980b, Taylor 1989, Williams et al. 2002, Moritz et al. 2007). Además de la ancestría común esta es una razón más por la cual los lutrinos más generalizados presentan vértebras más similares a un plan de tipo weasel-like.

En comparación con musteloideos basales y Taxidea taxus, en los demás mustélidos, especialmente en mustélidos weasel-like (lincodontininos, mustelinos, muchos guloninos), la distancia entre los procesos espinosos postanticlinales es, en general, mayor (ver también Leach y de Kleer 1978, Taylor 1989); en parte debido a la marcada elongación de los cuerpos vertebrales y, por otra parte, por la reducción dorsoventral, y la forma más aguda e inclinación marcada de los procesos espinosos, lo que ha sido vinculado a la preponderancia de los músculos por sobre los ligamentos intervertebrales (Gambaryan 1974, Leach y de Kleer 1978, Taylor 1989, Ercoli et al. 2013, Álvarez et al. 2013, ver sección 4.1.1, ver Fig. 3.5). Entre las especies de mustélidos de América del Sur, estos rasgos están exagerados en Ly. patagonicus, que converge con mustelinos pequeños, mientras que en especies de mayor tamaño como el grisón mayor $G a$. vittata, la región lumbar es más similar a mustélidos basales y de mayor tamaño. Esto también es evidente en el análisis de forma del penúltimo elemento lumbar, en donde Ga. vittata, y secundariamente Ga. cuja, se posicionan cercanos a la forma consenso, intermedia entre half-bounder mustelinos y Ly. patagonicus, y otros linajes mustélidos no especializados en este estilo locomotor (Fig. 3.5). En estas especies, las articulaciones craneales y caudales se encuentran en planos cercanos al sagital, y las crestas ventrales de los cuerpos vertebrales (zona de origen del m. quadratus lumborum; sección 3.1) estan bien definidas en el sector de transición torácico-lumbar. En lo que respecta a los procesos transversos lumbares de los mustélidos weasel-like, estos inclinan marcadamente por debajo del plano horizontal, y presentan extremos laterocraneales agudos y extendidos en sentido cráneoventral (ver también Leach y de Kleer 1978, Álvarez et al. 2013; Fig. 3.5; Apéndice 3.15, c. 20, estado 2 y 3). Esta configuración conlleva a una menor interferencia entre cuerpos vertebrales, procesos vertebrales y carillas articulares durante la flexión ventral en una amplia gama de posiciones (Slijper 1946, Boszczyk et al. 2001, Argot 2003b, Salesa et al. 2008, Pierce et al. 2011, Álvarez et al. 2013, Ercoli et al. 2013). A su vez, las uniones ligamentarias son reducidas y los músculos intervertebrales más laterales disponen de amplios espacios de inserción y tránsito, gran ventaja mecánica para la flexión ventral y lateral (Gambaryan 1974, Leach y de Kleer 1978, Shapiro 1995, Argot 2003a, b, Sorkin 2006, Salesa et al. 2008, Flores 2009, Pierce et al. 2011, Álvarez et al. 2013, Ercoli et al. 2013, ver secciones 4.1.1 y 4.3.5, Hueso coxal). En consecuencia, la movilidad del sector postanticlinal de los weasel-like es mayor a la de otros musteloideos. Por otro lado, la reducción de los procesos espinosos implica una reducción de la superficie de agarre para los sistemas transversospinalis y longissimus y ligamentos interespinales. En los 
mustélidos weasel-like, la preponderancia inferida del sistema epiaxial lateral (i.e., $\mathrm{m}$. iliocostalis, ver más adelante) por sobre los mediales (e.g., multifidus, m. longissimus), concuerda con lo que ya ha sido reconocido en estudios miológicos de carnívoros (ver Gambaryan y Karapetyan 1961, Gambaryan 1974, Willemsen 1980b, Ercoli et al. 2013, ver sección 3.1). En otros linajes mamíferos saltadores (e.g., tupainos, marsupiales; Sargis 2001: 479-480, Argot 2003a: 286-287), el rol extensor preponderante suele ser tomado por un sistema longissimus desarrollado que a su vez estabiliza y limita la flexión lateral. Es interesante notar que en los weasel-like de hábitos más terrestres (i.e., ictoniquinos $>$ mustelinos $>$ guloninos), el desarrollo de los procesos transversos no es tan marcado como en otros linajes saltadores o cursoriales (e.g., ver lagomorfos, carnívoros cursoriales, macroscelideos, roedores, marsupiales y tupainos saltadores; Davis 1964, Gambaryan 1974, Alexander y Jayes 1981, Sargis 2001, Argot 2003a, b, Álvarez et al. 2013; Apéndice 3.15, c. 20, estado 2 vs. 3), seguramente en relación a una componente de flexión ventral lumbar pasiva, durante el comienzo de la fase de apoyo de las carreras epigeas de estos mustélidos (Gambaryan 1974). Por otro lado, en trepadores weasel-like, especialmente en los trepadores ágiles de gran mayor tamaño (e.g., guloninos medianos a grandes como Ei. barbara, y ailúridos extintos sensu Salesa et al. 2008) los procesos transversos presentan formas similares pero claramente mayores que weasel-like terrestres (e.g., ver posición de Ei. barbara respecto a half-bounders y a otros trepadores en análisis de forma de la penúltima vértebra lumbar; Fig. 3.5; Apéndice 3.15, c. 20, estado 3), seguramente en relación a los mayores esfuerzos de flexión lumbar relativos al trepado vertical ágil y rápido, como se comenta más adelante.

Un sector lumbar móvil con elementos largos y con un gran desarrollo e independencia del m. iliocostalis especialmente en mustelinos y ictoniquinos (Gambaryan 1974, Ercoli et al. 2013; ver sección 4.1.1) es acorde con una gran importancia de los movimientos de flexoextensión (dependiendo el rango del número de elemento lumbares, ver más arriba) y secundariamente lateromediales de estos linajes (Gambaryan 1974, Schilling y Hackert 2006, Álvarez et al. 2013, Ercoli et al. 2013). Esto puede ser relacionado a la importancia del sistema músculo-esqueletario axial en la ejecución de pasos simétricos y movimientos complejos en galerías estrechas durante la caza (mediante la contracción unilateral del m. iliocostalis lumborum). Los hurones presentan cuerpos alargados y flexibles en relación a la necesidad de ingresar y moverse en galerías estrechas pero y a la vez deben poseer una masa corporal suficientemente importante como para poder subyugar a estas últimas (King y Powell 2007, Moritz et al. 2007). Por otro lado, la anatomía lumbar de los mustelinos e ictoniquinos permite realizar saltos poderosos durante los pasos asimétricos en la carrera epigea (mediante contracción bilateral de estos sistemas durante la fase de apoyo de los miembros posteriores; Gambaryan 1974, Leach y de Kleer 1978, Shapiro 1995, Sargis 2001, King y Powell 2007, 
Moritz et al. 2007, Schilling y Carrier 2010). La velocidad máxima de estas marchas bound o half-bound depende directamente del poder y grado de extensión de la columna durante la fase de vuelo extendido (Hildebrand 1961, 1988, Gambaryan 1974, Taylor 1989, Sargis 2001, Schilling y Hackert 2006); encontrándose algunos rasgos lumbares estrechamente relacionados a la máxima velocidad en carrera (Álvarez et al. 2013). En consecuencia, y como se comentó previamente, debido al mayor número de elementos y longitud lumbar relativa (ver Tabla 2.3, Apéndice 3.7C2), a la morfología de elementos lumbares más especializada (ver Fig. 3.5), y las proporciones indicadas por el índice crural (ver sección 4.3.5, Tibia y fíbula), es probable que los mustelinos desarrollen marchas más rápidas que los lincodontininos.

Es interesante destacar que además de en Martes spp., una morfología lumbar en muchos aspectos muy similar a la recién descripta (exceptuando por el desarrollo de los procesos espinosos) se registra también en guloninos mayores como Ei. barbara (ver también Fig. 3.5) y secundariamente Gu. gulo. Estos taxones realizan sólo eventualmente marchas halfbound y no persiguen presas dentro de sus galerías (Galbreath 1955, Heptner y Naumov 1967, Gambaryan 1974, Taylor 1989, Pasitschniak-Arts y Larivière 1995, Wilson y Mittermeier 2009, Dionisios Youlatos comunicación personal). Debido a que los representantes de esta subfamilia son trepadores, la diferenciación morfológica del sector tóraco-lumbar respecto a otros musteloideos trepadores como los prociónidos es llamativa (e.g., Fig. 3.5). Siguiendo a Hildebrand (1988) y Taylor (1989), las especies de carnívoros trepadores pueden dividirse morfo-funcionalmente en dos grupos: aquellos trepadores ágiles (con marchas half-bound o similares) que persiguen a sus presas (e.g., Bassariscus astutus, Martes spp.), y aquellos que prefieren una aproximación lenta y sigilosa (e.g., Procyon spp.) o incluso son vegetarianos (e.g., Potos flavus). Justamente sobre la base de esta clasificación y sus implicancias morfofuncionales (flexibilidad axial vs. rigidez) pueden entenderse las principales diferencias entre ambos grupos trepadores, dado que los guloninos y Bassariscus astutus se corresponden más cercanamente con la primer categoría (Heptner y Naumov 1967, Trapp 1972, Leach 1977a, Hildebrand 1988, Taylor 1989), y los restantes prociónidos y Ai. fulgens con la segunda (Cabrera y Yepes 1940, Hildebrand 1988, Taylor 1989, McClearn 1992). Es probable también que una región lumbar marcadamente móvil y de movimientos poderosos en guloninos y Bassariscus astutus (también presente en el ailúrido fósil †Simocyon batalleri; Salesa et al. 2008) sea útil durante los movimientos acrobáticos y el ascenso y descenso vertical tipo vertical looping (Taylor 1989) descripto para estas especies, en donde la coordinación del agarre al sustrato, adelantamiento del tren posterior y liberación de los miembros es coordinado con movimientos poderosos de flexión y extensión de la columna (Sokolov y Sokolov 1971, Trapp 1972, Taylor 1989, Argot 2003a, Salesa et al. 2008). 
Gambaryan (1974, ver también Leach y de Kleer 1978, Hildebrand 1988, Taylor 1989) reconoció que una característica típica en mustélidos es la gran flexibilidad axial y la presencia de marcados movimientos dorsoventrales del esqueleto axial. Este autor (Gambaryan 1974: 206, 254-255) propuso que un plan tipo weasel-like, útil para maniobrar y depredar roedores en galerías, es ancestral para el grupo y que distintos linajes (e.g., mustélidos terrestres grandes, nutrias) retuvieron en mayor o menor medida la movilidad axial. Es interesante destacar que Spilogale gracilis y Bassariscus astutus presentan una morfología de los procesos y cuerpos lumbares (salvando las distancias) tipo weasel-like, diferenciándose de otros mefítidos y prociónidos respectivamente. En el caso de Bassariscus astutus, esta convergencia morfofuncional queda reflejada en la ubicación cercana en el morfoespacio de esta especie y el gulonino half-bounder Martes pennanti (Fig. 3.5). En el caso de S. gracilis, esta configuración fue optimizada como convergente a mustélidos derivados (Apéndice 3.15, c. 20, estado 2, c. 21 estado 0), aunque sin quedar registrado esto en el análisis de la vista dorsal de la penúltima vértebra lumbar (en donde esta especie y Conepatus chinga se ubican en la misma región del morfoespacio; Fig. 3.5). Tanto S. gracilis como el prociónido Bassariscus astutus, son reconocidos como taxones ágiles y frecuentemente half-bounders (Trapp 1972, Hildebrand 1988, Taylor 1989, Kinlaw 1995, Elbroch 2003, Long 2008) y lo mismo se ha propuesto para el ailúrido extinto †Simocyon batalleri (Salesa et al. 2008). Extendiendo la propuesta de Gambaryan (1974), la existencia de taxones musteloideos no mustélidos de morfologías weasellike y marchas ágiles, sumado a evidencia miológica y la reconstrucción muscular de ancestros hipotéticos (Ercoli et al. 2014, ver sección 4.1), sugiere un ancestro weasel-like más profundamente arraigado, quizás en la base de Musteloidea. Aunque esto no es sustentado por los mapeos osteológicos (i.e., modificaciones en c. 20 y 21 consideradas convergencias), la inclusión de Ba. astutus y especies fósiles podría potencialmente modificar esto último.

\section{Costillas y esternón}

Aunque las comparaciones posibles están limitadas en función de la preservación de los especímenes, la caja torácica presenta algunos cambios de formas relativos a los hábitos particulares de los principales grupos locomotores. El primer par de costillas esta siempre compuesto por elementos breves y robustos, y en otros mamíferos ha sido relacionado a un gran desarrollo de los mm. scalenus o mm. pectorales (Argot 2003a, 2004), y a una conexión resistente entre el complejo esternal y el resto del esqueleto (Flores y Díaz 2009). Dentro de las especies aquí comparadas, la robustez es mayor en Procyon, Spilogale y secundariamente en Meles y Lontra que en musteloideos comparados (e.g., Conepatus, Nasua, hurones), sin una patrón morfo-funcional ni filogenético claro. Respecto al resto de las características de la caja torácica y esternón, pueden distinguirse tres morfotipos básicos dentro de Musteloidea, siendo la 
forma del manubrio particularmente diagnóstica e informativa por estar vinculada a rasgos musculares y hábitos dietarios y locomotores de cada grupo (Fig. 4.1).

La mayoría de los musteloideos presentan costillas robustas y largas. Las esternebras son cortas cráneocaudalmente, aplanadas dorsoventralmente y extensas lateromedialmente (incluyendo al manubrio), conformando un esternón breve y robusto y una caja torácica voluminosa y maciza. Esta condición es típica de prociónidos (excepto Ba. astutus) y mefítidos, y secundariamente de mustélidos basales (e.g., melinos). El manubrio, reteniendo la morfología plesiomórfica para Arctoidea (Apéndice 3.15, c. 22, estado 0), es robusto, breve, aplanado dorsoventralmente, mientras que el xifoides tiene una terminación amplia y espatulada. Todos estos rasgos se relacionan a un gran desarrollo de los músculos pectorales y otros músculos extrínsecos de origen costal (e.g., serratus ventralis thoracis, m. latissimus dorsi), y a poderosos movimientos braquiales de aducción y retracción típicos de trepadores y cavadores (Gambaryan 1974, Quaife 1978, Hildebrand 1988, Argot 2003a, Moore et al. 2013, Ercoli et al. 2014), y a la estabilidad axial requerida durante el trepado de tipo clamber o bridging (Sargis 2001, Argot 2003a). En el caso de los mefítidos y melinos, la caja torácica es extensa cráneocaudalmente, con un gran número de costillas (ver más arriba), en relación a un mayor número de paquetes y ventaja mecánica para los retractores del brazo más caudales (e.g., latissimus dorsi) lo que confiere mayor poder de remoción del sustrato durante el cavado (Gambaryan 1974, Quaife 1978, Moore et al. 2013, Ercoli et al. 2014). En trepadores la extensión caudal de la caja torácica es breve en relación al sector lumbar, y postdiafragmático en general, amplio y móvil, y las implicancias son comentadas más arriba (ver más arriba).

Respecto a los mustélidos weasel-like (ictoniquinos, mustelinos y guloninos pequeños; ver también Leach y de Kleer 1978, Barraquand 2010) y otros guloninos (e.g., Ei. barbara), estos presentan esternebras delgadas y alargadas, manubrio marcadamente proyectado, quillado, aplanado lateromedialmente, frecuentemente con un extremo craneal extendido, y las costillas tienen uniones más lábiles. Esta configuración les conferiere a estas especies una caja torácica alargada, angosta y flexible, en relación a menores esfuerzos braquiales (menos necesarios durante las marchas a saltos y terrestres; Taylor 1970, Gambaryan 1974, Argot 2003a, Ercoli et al. 2014), y una mayor flexibilidad del torso (Azara 1802, Cabrera y Yepes 1940, Zielinski 2000, Wilson y Mittermeier 2009), útil durante maniobras complejas en túneles estrechos (Heptner y Naumov 1967, Gambaryan 1974, King 1989, Zielinski 2000). En hurones (pero ver también Martes; Barraquand 2010), el xifoides reducido y aguzado es un indicador de la menor importancia de los orígenes de los paquetes caudales del $\mathrm{m}$. pectoralis profundus y la ausencia de movimientos de retracción poderosos, como también fue sugerido a partir de estudios de pesado de músculos (Gambaryan 1974, Ercoli et al. 2014). Específicamente, la morfología alargada del manubrio permitiría un abanico más amplio del $\mathrm{mm}$. pectorales superficiales, 
permitiendo un mayor rango de movimientos de protracción del miembro anterior, función relevante en marchas simétricas rápidas de mustélidos de miembros breves (Ercoli et al. 2014, ver sección 4.1). Esta morfología es reconstruida como una adquisición del ancestro común de estos linajes (ver optimización del nodo Mustelidae - Taxidea - Meles; Apéndice 3.15, c. 22, estado 1). Por otro lado, la extensión del manubrio podría proporcionar una mayor superficie de origen del m. sternocephalicus pars occipitalis et mastoidea (ver sección 4.1.1), en relación a una mayor masa muscular disponible para movimientos poderosos de rotación, flexión ventral y lateral de la cabeza y cuello, movimientos útiles para subyugar y despedazar presas (Kaufmann y Kaufmann 1965, Ewer 1973, Radinsky 1981a, Zielinski 2000, King y Powell 2007, Ercoli et al. 2013, ver Anexo), reforzando la propuesta de un ancestro común depredador weasel-like al menos tan antiguo como la radiación de estos grupos (o incluso más basal, ver sección 4.3.2, Región cervical, ver más adelante). Dentro de las especies sudamericanas, Ly. patagonicus muestra la máxima expresión de este rasgo, con un manubrio mucho más largo que el presente en Galictis spp. y Ei. barbara, similar (e.g., Mu. frenata) o incluso mayor que muchas especies de Mustela (e.g., Mu. vison), siendo este proceso tan largo como el resto de la primer esternebra y llamativamente levemente reflecto en sentido ventral (característica única del huroncito patagónico), permitiendo más lugar a la musculatura esterno-cefálica. Estos rasgos, en conjunto con otras características cervicales y craneales ya destacadas para Ly. patagonicus, (ver sección 4.1.1, Anexo) se encuentran tentativamente relacionadas a un grado máximo de especialización a la caza de roedores mediante movimientos poderosos del cuello. Aunque Ei. barbara comparte la mayor parte de los rasgos descriptos, en estas especies la caja torácica es más voluminosa y menos extendida caudalmente y el xifoides se encuentra ensanchado, asemejándose en mayor grado en estos rasgos a musteloideos más basales, y en relación a la combinación de un estilo de vida trepador sin excursiones subterráneas, y estrategias predatorias similares a weasel-like especies (Dagg 1973, Emmons 1990, Presley 2000, Wilson y Mittermeier 2009). Es necesario destacar que $B a$. astutus presenta una manubrio particular, alargado cráneocaudalmente como en mustelidos weasel-like, aunque es de una sección más cilíndrica en vez de quillado, difiriendo de otros prociónidos y mustélidos.

Las nutrias, aunque muy similares a especies weasel-like en muchos sentidos, presentan rasgos propios o intermedios a otras formas. La caja torácica es alargada pero más voluminosa y rígida que en otros mustélidos derivados, mientras que el esternón tiene elementos alargados pero robustos y en algunos casos quillados ventralmente. Una característica distintiva de este grupo, optimizada como una posible sinapomorfía (Apéndice 3.15, c. 22, estado 2), es la forma peculiar del manubrio: extenso cranealmente y quillado en su cara ventral como en mustélidos weasel-like, aplanado en su cara dorsal, y prolongado lateromedialmente mediante superficies progresivamente más amplias en cercanías a la primer unión costal, adquiriendo una forma de 
"hoja" o "lanza". Esta sinapomorfía de lutrinos parece indicar un buen desarrollo de músculos pectorales y cervicales de origen esternal, y podría relacionarse directamente a rasgos miológicos también sinapomórficos: 1- la presencia de un m. "pectoantebrachialis" (subdivisión del $\mathrm{mm}$. pectorales superficiales que alcanza el sector distal del húmero o incluso la ulna; descripto en Enhydra lutris, Lontra canadensis, Lutra lutra; Lucae 1875, Fisher 1942, Howard 1973); 2- la presencia de un $\mathrm{m}$. rectus thoracis con un vientre de origen extra e independiente que alcanza al manubrio; descripto en las únicas dos nutrias en que se cuenta con datos, Lontra canadensis y Lutra lutra; Lucae 1875, Fisher 1942. Todos estos rasgos son únicos de nutrias dentro de Arctoidea, informativos desde el punto de vista filogenético (ver optimización de crossed type configuration; Ercoli et al. 2014; ver también sección 4.1.1). Funcionalmente, esta condición posiblemente se encuentre en relación a los movimientos complejos y poderosos de aducción, retracción y rotación necesarios durante el buceo con propulsión braquial (Savage 1957, Gambaryan and Karapetyan 1961, Howard 1973, English 1977, Williams 1983a, b, Fish 1994, Ercoli et al. 2014).

\subsubsection{Región sacro-caudal}

El sacro es el área de origen de un gran número de músculos controladores de los movimientos de la cola (Hall 1926, Savage 1957, Mahoney y Rosenberg 1981, Ercoli et al. 2013). En los mustélidos de América de Sur este elemento es generalmente alargado y amplio,

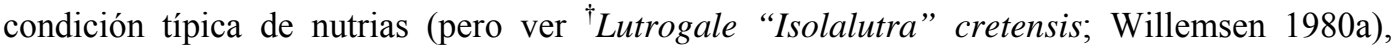
guloninos pequeños a medianos (ver también Leach y de Kleer 1978, Barraquand 2010) y hurones en general (mustelinos e ictoniquinos). Estos rasgos se relacionan con colas moderadas a largas y musculosas (Riggs 1945, Savage 1957, Mahoney y Rosenberg 1981), y con diferentes especializaciones locomotoras en estos linajes (ver más adelante). Por otro lado, en mustélidos de colas atrofiadas, el sacro tiene un desarrollo cráneocaudal relativamente breve y el último elemento está reducido (e.g., melinos, Gu. gulo, y melivorinos, excepto cuando participan más de 3 elementos; ver Tabla 4.1).

Además de la influencia alométrica que afecta directamente el desarrollo de la altura de los espinosos (ver sección 4.3.2, Región cervical y Región tóraco-lumbar) y las mayores similitudes entre grupos filogenéticamente cercanos (e.g., lutrinos y hurones comparten procesos de la cresta intermedia sacra amplios y elevados), la locomoción es otro determinante principal de la morfología del sacro.

En las nutrias, los procesos espinosos sacros (en muchos casos fusionados, ver Malatesta 1977) y de la cresta intermedia sacra (como sus correspondientes en la región caudal, ver más adelante) se encuentran muy desarrollados (en forma extrema en En. lutris) y son mayores que lo observado en otros musteloideos, indicando un gran desarrollo del área de 
origen, ventaja mecánica y espacio de tránsito del $\mathrm{m}$. sacrocaudalis dorsalis medialis (Argot 2003a, Ercoli et al. 2013; ver sección 3.1.10). Este músculo es un extensor poderoso de la cola, movimiento requerido durante el nado carangiforme de las nutrias, en donde las ondulaciones del sector posterior axial, en coordinación o no con los miembros posteriores, son la fuente principal de propulsión durante el nado rápido (Savage 1957, Tarasoff 1972, Tarasoff et al. 1972, Fish 1994). Los procesos transversos sacros, fusionados en una cresta lateral sacra amplia, permiten un gran desarrollo de los sistemas sacrocaudales laterales dorsal y ventral (Savage 1957, Organ 2010; ver sección 3.1.10). Las expansión caudal y roma de la cresta lateral sacra inclina ventralmente (no observado en otros musteloideos), quizás en relación a un amplio volumen del $\mathrm{m}$. intertransversarii dorsales caudales, lo que también indica el tubérculo hipertrofiado inmediatamente caudal a la región articular sacro-ilíaca (Ercoli et al. 2013) y el ángulo caudo-dorsal del ala del ilion (ver sección 4.3.5, Hueso coxal), regiones de origen de paquetes de este sistema. Este músculo, en conjunto con el $\mathrm{m}$. intertransversarii ventrales caudales, son frecuentemente descriptos como flexores laterales de la cola (Savage 1957, Organ 2010, Evans y De Lahunta 2013). Sin embargo, aunque estos movimientos posiblemente colaboren en los cambios de dirección, y se encuentran claramente presente en el caso específico del nado de espalda de En. lutris (Tarasoff 1972: 50, Tarasoff et al. 1972), el rango de los mismos es seguramente mucho menor que aquellos movimientos en el plano sagital (Tarasoff 1972, Tarasoff et al. 1972, Taylor 1989, Fish 1994), lo cual es evidente también en el análisis de la morfología caudal (ver más adelante). Es probable que la acción bilateral o diagonal de estos sistemas permita la fijación, rotación, extensión o flexión de la cola, colaborando con las ondulaciones dorsoventrales durante la propulsión y el posicionamiento de la cola durante el buceo en nutrias (Tarasoff 1972, Willemsen 1980b, Williams 1989, Fish 1994, 2001). Los procesos transversos amplios, tanto sacros como caudales, también colaboran en soportar una cola amplia y aplanada (en mayor o menor grado; ver Tarasoff 1972, Willemsen 1992), aumentando el área de empuje durante la propulsión (Tarasoff 1972, Tarasoff et al. 1972, Taylor 1989; ver más adelante). Justamente, una característica distintiva de nutrias es que último elemento sacro posee un gran desarrollo, indicativo de una base caudal amplia y poderosa en nutrias en general (Savage 1957, Taylor 1989). En el caso único de Pt. brasiliensis, el último elemento sacro es el mayor, vinculado a que esta nutria presenta el apéndice caudal más especializado al buceo con velocidad (ver comentarios de Fish 1994, Kruuk 2006, Lewis 2008). En esta especie, el gran desarrollo de la cola se registra en conjunto con autopodios posteriores también amplios (ver sección 4.3.5, Pes), no cumpliéndose la relación inversa entre ambos sectores propulsores de especies semi-acuáticas planteada por previos autores (Savage 1957, Tarasoff 1972: 10-11, Tarasoff et al. 1972), al igual que también fue destacado por Malatesta (1977) para el lutrino fósil `Sardolutra "Nesolutra" ichnusae. 
En los hurones, el desarrollo de los procesos espinosos, crestas intermedia y lateral sacras son claramente menores que lo observado en nutrias, pero aun así importantes, indicando un moderado desarrollo de las zona de orígenes de los sistemas musculares sacrocaudales dorsales y ventrales, principales flexo-extensores caudales. En half-bounders la longitud sacrocaudal es breve en relación al largo tóraco-lumbar (Tabla 2.3, Fig. 3.1D). Al excluir a Gu. gulo de los análisis de varianza de este índice, diferencias significativas pero débiles son encontradas entre half-bounders y trepadores (Apéndice 3.6D2), aunque estas son desestimadas luego del control filogenético (Tabla 3.6, Apéndice 3.7D2). Las falencias del muestreo del índice LaSC/LaTL (datos faltantes de trepadores half-bounders: Bassariscus astutus, Martes spp., y Mu. frenata, y grupos muchos funcionales representados por sólo 1 o 2 clados monofiléticos; Tabla 3.6), deben ser consideradas, y ponen en duda ambos resultados estadísticos. Un mayor número de muestras posiblemente modifique la significancia de este factor.

Dentro de los trepadores, existen especies que utilizan la cola como un órgano prensil, otros como balance, y otros trepadores ursid-like, como Gulo gulo, que no utilizan en forma activa dicho apéndice (Davis 1964, Taylor 1989, Youlatos 2003). Dentro de los cavadores, aquellos que tienen comportamiento aposemático (e.g., mefítidos y skunk-like mustélidos) presentan una mayor longitud caudal relativa a exhibiciones battle-flag (Larivière y Messier 1996, Caro 2009). Por último, dentro de las nutrias, los distintos estilos de nado implican variantes en el desarrollo de la superficie de propulsión caudal y pedal (Tarasoff 1972, Tarasoff et al. 1972, Taylor 1989). Todas estas y otras variantes intragrupales, no contempladas en los análisis estadísticos, revelan que la sobresimplificación de la diversidad locomotora de los musteloideos en cuatro categorías subestima y limita las interpretaciones morfo-funcionales de la región caudal. El problema de la sobre-simplificación inherente a la subdivisión de una muestra de estudio en categorías discreta ha sido planteado por previos autores, los cuales han encarado el problema planteando sistemas de categorías más complejos (e.g., Miljutin 2009) o directamente utilizar múltiples variables continuas en vez de discretas (e.g., Carrano 1999). A lo largo de este apartado, en donde este problema es notorio, se plantea evaluar cualitativamente la importancia de estos factores no contemplados en las categorías planteadas (ver más adelante).

Aunque en hurones la longitud sacro-caudal en relación a la longitud tóraco-lumbar es, en general, baja, el desarrollo de la musculatura y longitud del apéndice caudal debe considerarse importante en relación a los miembros cortos y la masa aductora y abductora relativamente reducida de estos últimos (Ercoli et al. 2013; ver sección 4.1). Se ha propuesto que colas relativamente largas y musculosas son útiles durante los cambios rápidos de dirección en carreras epigeas y balance durante la locomoción a saltos (Ewer 1973, Hildebrand 1988, King y Powell 2007, Ercoli et al. 2013) dado que llevan el centro de gravedad a una posición más cercana a los miembros posteriores, principales propulsores durante el bound o half-bound 
(Argot 2003a). En el caso de los mustelinos, muchas especies realizan incursiones al sustrato arbóreo (Heptner y Naumov 1967, King y Powell 2007, Wilson y Mittermeier 2009), por lo cual movimientos rápidos dorsoventrales y lateromediales de la cola permiten el balance necesario para controlar la dirección de la marcha y posición del cuerpo, evitando caídas, especialmente durante el ascenso o descenso vertical (Taylor 1970, Walker et al. 1998, McClearn 1992, Youlatos 2003), o en las incursiones en sustratos discontinuos o angostos (Walker et al. 1998, Argot 2003a, King y Powell 2007). Esta función podría ser de gran importancia en la comadreja de cola larga, Mustela frenata, el hurón sudamericano con cola más larga y trepador eventual (no incluido en análisis LaSC/LaTL; Sheffield y Thomas 1997). Para el caso de hurones como Mustela frenata, una cola larga y móvil con el pelaje de su extremo negro, se ha intepretado como un elemento de distracción y confusión para potenciales depredadores, como aves raptoras (King 1989). Por otro lado, en algunos hurones y los grisones, colas poderosas colaborarían durante eventuales incursiones acuáticas (Dalquest y Harvey 1951, Yensen y Tarifa 2003a, b, Wilson y Mittermeier 2009, pero ver más adelante). Sin embargo, en un plan corporal de patas cortas y tronco largo y flexible, la región tóraco-lumbar asume una gran importancia en el control de los cambios de dirección, posiciones relativas del centro de gravedad y balance, lo que puede explicar parcialmente la tendencia a un menor desarrollo de la cola respecto al tronco en hurones en general (Tabla 2.3, Fig. 3.1D). Dentro de los hurones, las procesos sacros son más importantes en Galictis spp. que en Ly. patagonicus, y en Mustela frenata que en especies de Mustela menores. Con excepciones, se ha propuesto una relación entre el desarrollo sacro-caudal y el tamaño corporal de especies de hurones, en relación a múltiples factores, incluyendo la reducción de la pérdida de calor corporal en climas fríos, la mayor especialización a la marcha en galerías y adaptaciones anti-predadoras (King 1989, King y Powell 2007, ver más adelante).

En los hurones, se destaca un gran desarrollo de la proyección caudal de la cresta lateral sacra, mayor incluso que la presente en nutrias (aunque más aguda e inclinando dorsalmente), en relación a un mayor desarrollo de los primeros paquetes del $\mathrm{m}$. intertransversarii dorsales caudales, y movimientos de acomodo de la cola no parasagitales (Organ 2010) relativos a cambios de dirección y equilibrio durante carreras ágiles (Ewer 1973, Argot 2003a). Por otro lado, en Martes spp. (ver Leach y de Kleer 1978, Barraquand 2010), aunque la proyección caudal de la cresta lateral sacra es aguda y bien definida (indicando un m. intertransversarii dorsales caudales desarrollado), la superficie de esta cresta se encuentra moderada (e.g., Ma. pennanti) a marcadamente reducida (e.g., Ma. martes; ver también procesos transversos caudales más adelante), en relación a la reducción del área de origen de los principales flexoextensores caudales. La menor importancia de los sistemas flexo-extensores caudales en guloninos pequeños respecto a mustelinos e ictoniquinos podría deberse a múltiples factores. La 
mayor longitud (Holmes 1980, ver secciones 3.4 y 4.3.1) y musculatura de los miembros (Gambaryan 1974, Ercoli et al. 2013) en guloninos, podría indicar una mayor importancia de los mismos en generar la propulsión durante saltos y cambios de dirección, en detrimento del sistema axial (Shapiro 1995). Una cola más ligera a su vez permite movimientos laterales más rápidos, indispensables en sustratos inestables y angostos (Walker et al. 1998). Los prociónidos también poseen sacros relativamente breves en comparación con otros linajes de colas largas, pero progresivamente más grandes y alargados desde Pr. lotor, N. nasua a Po. flavus, evidenciando la mayor importancia relativa de la musculatura caudal, y el progresivo uso de la cola como soporte en las distintas especies (McClearn 1992, Youlatos 2003).

Mientras que en la mayoría mustélidos y prociónidos el sacro está compuesto por tres elementos, en los mefítidos derivados (Mephitidae - Mydaus) y algunos ictoniquinos, incluyendo a Ly. patagonicus, el sacro está compuesto sólo por dos vértebras fusionadas (Apéndice 3.15, c. 14, estados 1 y 2), siendo en consecuencia relativamente breve, mientras que la cola es de una longitud destacable (Tabla 2.3). A su vez, una compresión cráneocaudal de las vértebras que componen al sacro es evidente en algunos zorrinos (e.g., Co. chinga contra S. gracilis). En los mefítidos, y secundariamente en los ictoniquinos skunk-like, esto se suma a un cuerpo del ilion marcadamente elongado (ver sección 4.3.5, Hueso coxal). Estas características permiten a estas especies una gran movilidad en la región sacra y de la base de la cola, la cual comienza en una posición adelantada respecto a la posición de los miembros posteriores y la articulación de la cadera. Esta reconfiguración posiblemente se vincule a la elevación de la cola durante la advertencia anti-predadora battle flag, comportamiento observado en estas especies (Doering 1881, Koslowsky 1904, Hall 1926, Larivière y Messier 1996, Caro 2009, ver también Kaufmann y Kaufmann 1965, Dücker 1968). La defensa se realiza mediante la descarga de glándulas anales (Mivart 1885, Hall 1926, Larivière y Messier 1996, Caro 2009), ejecutada con precisión hacia blancos elevados y relativamente lejanos (e.g., Larivière y Messier 1996), y evitando interferencias con la cola en la trayectoria. Ercoli et al. (2013) destacaron también un origen del m. coccygeus adelantado en miembros de estos linajes, lo que permitiría un amplio rango de elevación de la cola. En Mydaus, la reducción de la cola haría innecesaria esta reconfiguración, y quizás es explique el sacro amplio del taxón (Mivart 1885; Tabla 4.1). El sacro breve de ictoniquinos como Ictonyx, Poecilictis y Ly. patagonicus debe ser considerado una convergencia más con mefítidos (Apéndice 3.15, c. 14, estados 1 y 2; sumada a otras tantas destacadas a lo largo de toda la discusión). Considerando los cambios de fórmula tóracolumbares (ver sección 4.3.2, Región tóraco-lumbar), es probable que los mefítidos hayan alcanzado esta configuración cediendo el primer elemento sacro al sector lumbar, mientras que los ictoniquinos hayan cedido, por el contrario, el último elemento sacro al sector caudal. Las convergencias a estrategias aposemáticas battle flag y marchas lentas a su vez seguramente se 
encuentren facilitadas por una batería de otros rasgos en parte heredados y en parte convergentes, incluyendo la presencia de glándulas anales fétidas y coloración aposemática, aunque esto debe ser respaldado por análisis más específicos.

En el caso de Galictis spp., taxón en el que se ha registrado la estrategia tipo battle flag (Kaufmann y Kauffman 1965: 153, Dücker 1968, Yensen y Tarifa 2003b), pese a que existe un gran número de características osteológicas y miológicas concordantes con especializaciones para esta estrategia (ver Ercoli et al. 2013, ver sección 4.3.2, Región tóraco-lumbar, ver más abajo), el sacro está compuesto usualmente de 3 elementos (Apéndice 3.15, c. 14, estados 0). La base de la cola amplia (Apéndice 3.15, c. 23, estados 1) y poco móvil es seguramente determinante de una elevación de la cola con un perfil tipo "S" (i.e., con la base de la cola horizontal), como fue descripto por Kaufmann y Kaufmann (1965: 153), condición aparentemente menos especializada a estrategias aposemáticas y quizás ancestral respecto a $L y$. patagonicus. Es posible que en Galictis spp., como se comentó para las nutrias, un sacro amplio permita un mejor anclaje y mayor musculatura flexo-extensora caudal respecto a otros ictoniquinos como Ly. patagonicus. Esto podría estar relacionado a las incursiones acuáticas registradas en los grisones (incluyendo inmersiones, buceo y giros cerrados; Dalquest y Harvey 1951, Yensen y Tarifa 2003b; Aldo Vassallo y Juan Manuel Moreno comunicaciones personales, y observaciones personales) y la retención de una condición ancestral hidrofílica para el linaje (Björk 1970, Grohé et al. 2010, Colombrero et al. 2012, ver también Ercoli et al. 2014). Sin embargo, esto sólo es parcialmente soportado por las optimizaciones (e.g., Apéndice 3.15 , c. 14 y caracteres caudales contra c. 23 ), dado que algunos de estos rasgos sacros y la mayoría de otros rasgos caudales comunes a grisones y nutrias son recuperados como convergencias, aunque la inclusión de ictoniquinos fósiles, frecuentemente asociados a hábitos más generalizados y grison-like (e.g., Björk 1970, Schutz y Guralnick 2007, Grohé et al. 2010, Colombrero et al. 2012), podría modificar estos resultados.

Como ya ha sido destacado por previos investigadores (e.g., Youlatos 2003), el grado de participación de la vértebra sacra S2 en la articulación sacro-ilíaca es variable. En las especies cavadoras (Conepatus spp., Meles spp., Mell. capensis, T. taxus) participa el total (o casi) de los márgenes laterales de los procesos transversos de S2. Esta condición parece ser plesiomórfica para Mustelidae y Musteloidea (Apéndice 3.15, c. 24, estados 0). En la mayoría de los prociónidos (e.g., N. nasua, Po. flavus, Pr. lotor; ver también Youlatos 2003), S. gracilis, en ictoniquinos y lincodontininos, participa de la articualción la mitad de la S2 (o un poco menos en lincodontininos). Esta condición se habría alcanzado convergentemente en los distintos linajes en al menos 3 eventos dentro de Musteloidea. Por otro lado, en las nutrias (e.g., Ao. cinerea, Hy. maculicollis, Lontra spp., Lutro. perspicillata, Pt. brasiliensis, exceptuando a En. lutris y Lu. lutra; ver también Willemsen 1980a, Yilmaz et al. 2000), mustelinos (Mustela spp.), 
guloninos (Ei. barbara, Gu. gulo, Martes spp., ver también Leach y de Kleer 1978, Barraquand 2010) y Ba. astutus (Youlatos 2003) este elemento está excluido o prácticamente excluido de la articulación sacro-ilíaca (ver Apéndice 3.15, c. 24, estados 1 y 2 respectivamente). En el caso de las nutrias la faceta articular se encuentra a su vez marcadamente extendida en sentido ventral. Una articulación sacro-ilíaca más extensa ha sido relacionada con la presencia de reaseguros articulares en la cadera en animales que sufren esfuerzos pronunciados en los miembros posteriores (e.g., roedores saltadores bípedos, primates suspensorios; Hildebrand 1988, Youlatos 2003). Es posible que el mayor desarrollo de esta articulación en musteloideos cavadores respecto a otros musteloideos en general (Apéndice 3.15, c. 24, estado 2 vs. 1) y cavadores eventuales como los ictoniquinos respecto a los mustelinos y guloninos en particular (Apéndice 3.15 , c. 24 , estado 1 vs. 0 ), se deba en parte a los mayores esfuerzos aplicados a la cadera durante el cavado, donde los miembros posteriores soportan el peso corporal y el esfuerzo realizado por los miembros anteriores contra el sustrato (Quaife 1978, Vizcaíno y Milne 2002, Moore et al. 2013). Las modificaciones de forma del ala del ilion vinculadas al desarrollo diferencial de algunos grupos musculares (e.g., mm. gluteus, m. iliocostalis lumborum) y funciones locomotoras específicas (ver sección 4.3.5, Hueso coxal), también pueden tentativamente relacionarse a la forma y extensión del contacto sacro-ilíaco.

Pese a que el análisis de la longitud total relativa de la región sacro-caudal (LaSC/LaTL) no permitió encontrar diferencias significativas y claras entre los principales grupos locomotores (sección 3.4), análisis más detallados de la región caudal han valorado rasgos de interés funcional (e.g., Ewer 1973, Argot 2003a, 2010, Schilling y Hackert 2006, Flores y Díaz 2009, Organ 2010) y a su vez pobremente estudiados en carnívoros (Youlatos 2003). Youlatos (2003, ver también Organ 2010 y citas allí mencionadas) subdividió la región caudal, mediante dos vértebras específicas, en tres regiones con propiedades mecánicas y funciones diferenciables. La región proximal, con articulaciones funcionales, está separada de la región transicional por la vértebra transicional, la cual presenta procesos articulares craneales aún funcionales pero no los caudales. La región transicional presenta procesos de agarre muscular progresivamente reducidos. La vértebra más larga separa esta región de la distal, con elementos cilíndricos y movilidad multidireccional (Argot 2003a, Youlatos 2003, Flores y Díaz 2009, Organ 2010; ver explicación más detallada en Apéndice 4.1D).

Ninguno mustélido viviente presenta una cola prensil, i.e., capaz de soportar el total del peso corporal pendiendo de la misma (Youlatos 2003, Organ 2010 y citas allí). En su estudio de la morfología caudal de los carnívoros de cola prensil (i.e., Arctictis biturong y Potos flavus) y especies afines, Youlatos (2003) reconoció que un apéndice prensil posee características comunes, convergentes en diferentes linajes mamíferos: una cola larga, una región proximal compuesta por múltiples elementos, la vértebra transicional y la vértebra más larga retrasadas y 
una región distal de vértebras robustas (ver también Argot 2003b; Tabla 2.3). Esta configuración permite una gran fuerza y movilidad del sector proximal de la cola en el plano parasagital (colaborando también en el balance), y resistencia a los esfuerzos compresivos y de doblado inherentes al contacto con el sustrato y los esfuerzos musculares resultantes de la prensión (Youlatos 2003, Organ 2010). Un sector distal de elementos cortos y robustos permite rodear el sustrato y mayor superficie de inserción de la musculatura sacrocaudal (Flores y Díaz 2009).

Al analizar las especies de América del Sur, existen marcadas diferencias en la estructura del sector caudal. Lycondon patagonicus se destaca por presentar una cola reducida en longitud, con unos 17 elementos (Koslowsky 1904), mientras que todas las estructuras articulares y de fijación muscular se reducen tempranamente en comparación con otros mustélidos sudamericanos: e.g., los procesos espinosos están ausentes o sólo presente en el primer elemento (cuando éste corresponde a un tercer elemento sacro-caudal independiente; Apéndice 3.15 , c. 26 , estado 0), y los procesos transversos y mamilares se encuentran muy reducidos a partir del sexto elemento (ver Tabla 3.3). Los procesos transversos en ningún caso están inclinados marcadamente en dirección caudal (Apéndice 3.15, c. 30, estado 0), y tampoco se presentan procesos transversos craneales amplios (Apéndice 3.15, c. 29, estado 0). De esta forma, las vértebras caudales se vuelven rápidamente elementos cilíndricos breves y cortos. En este taxón, así como en otras especies con colas reducidas (e.g., melivorinos, melinos, taxidinos, mustelinos pequeños; ver Tabla 2.3), la presencia de múltiples elementos cilíndricos cortos y robustos en el sector distal es consecuencia de la reducción de la musculatura de la región transicional y distal, y el menor largo total caudal, más que una adaptación a resistir esfuerzos específicos (ver Youlatos 2003, Organ 2010; Apéndice 3.15, c. 25, estado 0). Una cola breve a primera vista es contraproducente en lo que respecta al balance y la modulación de la longitud de los saltos (Hildebrand 1961, 1988, Walker et al. 1998, Argot 2003a, King y Powell 2007), pero a su vez permite un mayor ángulo de inclinación de la pelvis en el momento del contacto de los miembros posteriores con el suelo (touch-down) aumentando la longitud zancada (Schilling y Hackert 2006). La cola breve entonces no es necesariamente prohibitiva de marchas half-bound o bound, lo que es evidente al ver los mínimos valores relativos alcanzados por halfbounders en general, e.g., Mu. putorius (Tabla 2.3, Fig. 3.1D). Los procesos transversos más perpendiculares en Ly. patagonicus que en grisones (Apéndice 3.15, c. 30, estado 0 vs. 1), indican mayor importancia de la estabilización que flexión lateral de la cola.

En su estudio sobre mustelinos, King y Powell (2007, ver también King 1989) identificaron varios factores que pueden explicar la reducción de la cola, importante especialmente en hurones pequeños, directamente extrapolables a Ly. patagonicus. El bajo tamaño corporal de hurones como $M u$. nivalis, sumado a los ambientes fríos que habita, implica 
que una cola larga causaría pérdidas excesivas de calor. A su vez, estos hurones pequeños tienden a pasar más tiempo en túneles, siendo menos importante la función de balance de la cola en las marchas simétricas realizadas en los mismos (ver también Moritz et al. 2007, Horner y Biknevicius 2010; pero ver tail-less half-bounders en Schilling y Hackert 2006). Por otro lado, la reducción de la longitud de la cola en especies pequeñas podría reducir las chances de ser depredadas (King y Powell 2007). Lyncodon patagonicus es una especie pequeña, mayormente subterránea y nocturna (Cabrera y Yepes 1940, Prevosti et al. 2009), típica de ambientes fríos (al menos estacionalmente; Prevosti y Pardiñas 2001, Schiaffini et al. 2013), y frecuentemente depredada por aves (Doering 1881, Trejo et al. 2006, Teta et al. 2008); todos estos factores pueden potencialmente explicar la reducción de su región caudal, convergente con mustelinos pequeños.

Los grisones ( $G a$. cuja y $G a$. vittata) tienen una morfología caudal muy similar entre sí aunque marcadamente diferente de la presente en el huroncito patagónico, aunque varios rasgos retienen estados plesiomórficos para los ictoniquinos, e.g., posición de vértebra transicional en sexto elemento sacrolumbar, procesos transversos progresivamente ubicados e inclinados caudalmente (Apéndice 3.15, c. 25, estado 1, c. 27, estado 1 (aunque sin descartarse una reversión por optimización ambigua), c. 29, estado 0, c. 30 estado 2). Como ocurrió para el sacro, la cola de los grisones es mucho más larga y robusta que en Ly. patagonicus (ver Tabla 2.3 y medidas externas de Koslowsky 1904) y en comparación con otras especies half-bound (excepto $M u$. vison; Tabla 2.3); está compuesta por un mayor número de vértebras (aproximadamente 21, Tabla 3.3), siendo muchas de ellas alargadas y con procesos ampliamente desarrollados hasta más allá de la mitad del apéndice. Los procesos transversos son amplios y robustos, $\mathrm{y}$ se encuentran progresivamente inclinados $\mathrm{y}$ posicionados caudalmente (mucho más que en Ly. patagonicus), patrón marcado en los primeros seis elementos. Esto último es bastante usual en musteloideos, y es la condición típicamente registrada en hurones (excepto $M u$. vison), guloninos medianos a pequeños (i.e., Ei. barbara, Martes spp.), y Po. flavus (pero pobremente definida en prociónidos como Na. nasua y Pr. lotor), siendo una condición recuperada como una plesiomorfía de Arctoidea (Apéndice 3.15, c. 29 , estado 0 , c. 30 , estado 1 . La inclinación progresiva de los procesos transversos proporciona al final del sector proximal y el principio del sector transicional una gran ventaja mecánica y un mayor espacio intervertebral para los mm. intertransversarii caudales (Argot 2003a, Youlatos 2003, Organ 2010, Ercoli et al. 2013), flexores laterales y rotadores (Youlatos 2003, Organ 2010), minimizándose la interferencia entre los procesos en un amplio rango de movimientos. Estos movimientos caudales son útiles durante el balance y cambios rápidos de dirección, en carreras o incursiones arborícolas (Ewer 1973, McClearn 1992, Sargis 2001, Argot 2003a, 
Youlatos 2003, Organ 2010). En el caso de hurones son esperables en relación a maniobrar en recodos durante incursiones en galerías.

Llamativamente, en los grisones, las cinco primeras vértebras caudales poseen procesos espinosos claramente diferenciados, lo cual es un número inusualmente alto para musteloideos no acuáticos (y otros carnívoros; e.g., Argot 2010). Esto se rescata como una sinapomorfía del género Galictis (Apéndice 3.15, c. 26, estado 2) y un rasgo intermedio entre lo observado en nutrias (típicamente con procesos espinosos hasta Ca8-9, Tabla 3.3; Apéndice 3.15, c. 26, estado 3) y otros musteloideos no acuáticos (Apéndice 3.15, c. 26, estados 0 y 1, condición plesiomórfica de Mustelidae). La configuración de los grisones sólo se asemeja al arborícola especializado Po. flavus (ver también marsupiales arborícolas; Argot 2003a), y son seguidos en importancia por Poecilictis libyca y algunas especies de Mustela, que cuentan con 3 procesos espinosos sutílmente definidos. Los procesos espinosos caudales (así como del sacro y del último elemento lumbar) son el origen del m. sacrocaudalis dorsalis medialis (Hall 1926, Mahoney y Rosenberg 1981, Argot 2003a, Flores 2009, Evans y De Lahunta 2013, Ercoli et al. 2013; ver sección 3.1.10); la presencia y desarrollo de los primeros ha sido relacionada a una extensión poderosa de la cola (Argot 2003a, Flores y Díaz 2009). Esto, sumado a una marcada extensión lateromedial de los primeros procesos transversos caudales y una morfología aplanada de las vértebras, indicaría una cola musculosa y amplia sobre el plano longitudinal en los grisones, recordando rasgos presentes y marcados en lutrinos; aunque las optimizaciones comentadas no respaldan un origen por ancestría común de estos rasgos. Mas allá de esto, Las especies de Galictis han sido descriptas como buenas nadadores ocasionales (Dalquest y Harvey 1951, Yensen y Tarifa 2003a, b). Hábitos acuáticos aun más pronunciados han sido propuestos para taxones fósiles cercanos (e.g., ${ }^{\dagger}$ Enhydrictis-Pannonictis, ${ }^{\dagger}$ Trigonictis cookii, ${ }^{\dagger} T r$. “idahoensis" macrodon; Ficcarelli y Torre 1967, Björk 1970, Kurtén y Anderson 1980, Schutz y Guralnick 2007, Grohé et al. 2010, Colombrero et al. 2012). De esta forma, estos rasgos pueden ser postulados como indicios de la antigua vinculación a hábitos acuáticos del grupo; y posiblemente puedan ser recuperados como sinapomorfías de Ictonychinae + Lutrinae al incluir estos taxones fósiles. A estas evidencias deben sumarse las provenientes del análisis miológico de grisones (Ercoli et al. 2013, 2014, ver sección 4.1) e, indirectamente, la propuesta de ictoniquinos como grupo hermano de las nutrias según Sato et al. (2012).

En vista dorsal, la morfología del sector caudal de todos los representantes de la tribu Lyncodontini (i.e., Ly. patagonicus, Ga. cuja y Ga. vittata) evidencia una característica sinapomórfica y única dentro de Musteloidea (Apéndice 3.15, c. 28, estado 1). Los arcos neurales de la vértebra transicional y de las primeras vértebras del sector transicional (e.g., Ca3Ca5 en Galictis spp., Ca2-Ca4 en Lyncodon, Tabla 3.3) se encuentran marcadamente socavados por escotaduras craneales y caudales profundas y amplias, siendo estas más importantes en 
desarrollo que el mismo arco neural. En el caso de Ly. patagonicus, esto es llevado al extremo en la cuarta o quinta vértebra sacro-caudal (Ca2 en MNHN 1897.423 y MACN 21982, Ca3 y aparentemente Ca2 en MLP 29.XII.00.17), en la que las escotaduras craneal y caudal se contactan, separando el arco neural en dos láminas laterales que sólo se vinculan dorsalmente por una unión ligamentaria, condición autopomórfica de Ly. patagonicus (Apéndice 3.15, c. 28, estado 2), no presente en ningún otro carnívoro estudiado. En varios de los especímenes osteológicos de Ly. patagonicus, fibras del extensor $\mathrm{m}$. sacrocaudalis dorsalis medialis se encuentran aún presentes uniendo fuertemente las regiones dorsales de los arcos neurales y procesos espinosos sacrales y caudales con los procesos mamilares caudales (arreglo similar al descripto para Ga. cuja; Ercoli et al. 2013). La extensión de las escotaduras en las vértebras del sector transicional (de por sí carentes de contactos articulares entre zigapófisis) en lincodontininos reduce al máximo la interferencia entre estructuras dorsales durante la extensión. Esta morfología les permite un muy amplio rango de extensión, al parecer crucial durante la elevación de la cola en el comportamiento battle flag realizado por los lincodontininos.

Los otros linajes que presentan comportamiento battle flag son los mefítidos e ictoniquininos. Como se comentó previamente, el sacro de estos linajes se encuentra compuesto por dos elementos (algo sólo igualado por Ly. patagonicus en lincodontininos) y el ilion es alargado. Las colas de estos son gráciles y largas, las de mayor longitud dentro del grupo de linajes cavadores, representando un 115 a $150 \%$ de la longitud tóraco-lumbar (Tabla 2.3, Fig. 3.1D). Los procesos transversos son mayormente perpendiculares (sinapomorfía del grupo convergente a ictoniquininos y algunos otros linajes; Apéndice 3.15, c. 30, estado 1) y desaparecen tempranamente, recordando nuevamente a Ly. patagonicus. Por otro lado, mefítidos e ictoniquininos comparten características no presentes en ningún lincodontinino: las regiones articulares craneales y caudales se encuentran bien desarrolladas, elevadas, extendidas cráneocaudalmente y verticales (características plesiomórficas de Arctoidea y reconstruida como una reversión sólo presente en ictoniquininos y lutrinos dentro de Mustelidae; Apéndice 3.15 , c. 27 , estado 0 ), en algunos casos las craneales rodeando ligeramente a las caudales. La vértebra transicional se encuentra retrasada hasta el quinto o sexto elemento caudal en ictoniquininos y S. gracilis, y supera al séptimo en el caso de otros mefítidos como Conepatus, siendo el sector proximal compuesto por el doble o más elementos que lo descripto para lincodontininos (Tabla 3.3; Apéndice 3.15, c. 25, estados 3, 4 y 5). Esta configuración permite un origen de la cola adelantado, justo encima de la articulación de la cadera. Las articulaciones caudales permiten un gran rango de extensión, y a su vez limitan los movimientos fuera del plano parasagital (Youlatos 2003, Organ 2010). El pobre desarrollo de los procesos de agarre 
muscular indica un bajo desarrollo de la musculatura en general, y una mayor ventaja para la estabilización que la flexión lateral (Youlatos 2003).

En resumen, las estrategias battle flag, aparentemente convergentes en estos linajes (mefítidos, ictoniquininos y lincodontininos), son alcanzadas al menos por dos formas o planes caudales distintos, en relación a otros rasgos de la historia de vida: por un lado, el modelo de mefítidos-ictoniquininos permite que la postura battle flag sea energéticamente económica, quizás en relación a que los miembros de estos linajes realizan este comportamiento con gran frecuencia y ubican la cola sobre el lomo de manera sostenida (Larivière y Messier 1996, Larivière 2001b, Larivière 2002a, Gorsuch y Larivière 2005, Dragoo y Sheffield 2009), y sumándose a otros rasgos convergentes entre estos linajes (e.g., dietas omnívoras, coloración aposemática más marcada, y en algunos caso tipo locomotor; Larivière y Messier 1996, Larivière 2002a, ver sección 4.3.2, Región tóraco-lumbar y sección 4.3.5, Hueso coxal). Esta configuración limita la capacidad de movimientos fuera del plano sagital de buena parte del sector caudal, impidiendo que se utilice la cola como balance durante cambios rápidos de dirección en marchas ágiles. Por otro lado, la configuración de lincodontininos permite alcanzar una postura battle flag pero de una manera diferente (e.g., Apéndice 3.15, 25, 27, 28), sin restricciones articulares marcadas y posiblemente energéticamente más costosa, en relación a la menor frecuencia con que recurren a esta estrategia, y a la utilización de la cola como un elemento activo durante la locomoción rápida o, como podría inferirse a partir en estudios comportamentales en el caso de Galictis spp., en las eventuales incursiones acuáticas realizadas por el taxón (Dasquest y Harvey 1951, Kaufmann y Kaufmann 1965, Dücker 1968, Yensen y Tarifa 2003b; Aldo Vassallo y M.D.E observaciones personales en Ga. cuja). Llamativamente, en Ly. patagonicus pueden encontrarse rasgos de ambos planes, como la reducción de arcos neurales vs. sacro compuesto por dos elementos. Observaciones osteológicas en Vormela peregusna y Poecilogale albinucha, taxones ictoniquininos con hábitos más similares a los lincodontininos (Rowe-rowe 1978, Gorsuch y Larivière 2005), podría ser de mucha utilidad para una mayor compresión desde el punto de vista evolutivo de la adquisición de estos rasgos.

Eira barbara presenta una morfología caudal generalizada en muchos aspectos, aunque se destaca por poseer una cola compuesta de muchos elementos alargados $(\mathrm{LaSC} / \mathrm{LaTL}=1,24$; ver Tabla 2.3), especialmente en su sector transicional y distal, y procesos moderadamente desarrollados hasta muy caudalmente y distanciados (Tabla 3.3), resultando en una cola larga, relativamente ligera y móvil. Previos autores (e.g., Kaufmann y Kaufmann 1965, Kavanau 1971, Presley 2000, Dionisios Youlatos comunicación personal) han destacado las capacidades acrobáticas, variedad de posturas, pasos y sustratos utilizados por Ei. barbara, siendo la cola de la tayra propicia para realizar movimientos rápidos durante el balance en marchas ágiles y sobre sustratos el arbóreos inestables, complejos y de diámetros variables (McClearn 1992, Walker et 
al. 1998, Sargis 2001, Argot 2003a, Youlatos 2003, Dionisios Youlatos comunicación personal). Los últimos elementos caudales son elongados y gráciles, opuesto a lo esperado en especies de cola prensil (Youlatos 2003, Organ 2010). En este sentido, la morfología caudal de Ei. barbara (así como en guloninos pequeños) presenta rasgos intermedios entre los observados en especies de Mustela y en prociónidos como Na. Nasua. En estos últimos el número de elementos caudales es mayor, los elementos son tubulares y robustos y la zona proximal es elongada; todos rasgos que implican mayor fuerza y resistencia a los esfuerzos torsionales, vinculado a la utilización de la cola como soporte en un sustrato arborícola (McClearn 1992, Youlatos 2003). Estos rasgos se encuentran aún más marcados en Po. flavus, que presenta el máximo número de elementos caudales, un sector proximal capaz de realizar poderosos movimientos dorsoventrales, y un sector distal muy móvil y robusto, en relación a la función de prensión (ver McClearn 1992, Youlatos 2003). Gulo gulo, al contrario de estas y otras especies musteloideas trepadoras, presenta por una cola reducida en número de elementos y longitud, y de limitada movilidad (ver Tabla 2.3, Fig. 3.1D), en relación a su estilo de trepado ursid-like.

Las nutrias presentan un gran número de vértebras caudales (Fisher 1942, Malatesta 1977, Baitchmand y Kollias 2000), excepto En. lutris y secundariamente Lu. Lutra (ver Tarasoff 1972, Malatesta 1977, Yilmaz et al. 2000; Tabla 4.1), las cuales son particularmente anchas y robustas. Las longitudes sacro-caudales relativas varían desde el mínimo valor representado por En. lutris (86\%) a valores elevados en Lontra provocax (139\%), mayores en Lo. longicaudis (148\%; Tabla 2.3, Fig. 3.1D). Seguramente valores mayores correspondan a otros lutrinos no incluidos en los análisis (e.g., Pt. brasiliensis). Los procesos hemales, arcos hemales y forámenes vertebrales de las vértebras caudales, así como los forámenes sacros, están desarrollados y presentes hasta elementos muy caudales, indicando una importante inervación y vascularización del apéndice caudal (Argot 2003a, Taylor 1989, Evans 1993; pero ver En. lutris; Tarasoff et al. 1972, Taylor 1989). La reducción del apéndice caudal de En. lutris relativa a otras nutrias se ha vinculado a una mayor importancia relativa de la superficie de propulsión de los autopodios posteriores, así como a la minimización de la pérdida de calor (Tarasoff 1972, Holmes 1980, Lewis 2008, Peigné et al. 2008). En las nutrias en general, la vértebra transicional se posiciona en el sexto o séptimo elemento (en relación a un sector proximal extenso), los procesos espinosos están presentes hasta el octavo o noveno elemento caudal, siendo ambos rasgos sinapomórficos del grupo (Apéndice 3.15, c. 25, 26); y los procesos mamilares y articulares se encuentran bien desarrollados (Savage 1957, Malatesta 1977; ver Tabla 3.3; Apéndice 3.15 , c. 27 , posible sinapomorfía del grupo). Estos rasgos indican una gran musculatura y rangos de movimientos dorsoventrales (Argot 2003a, Flores y Díaz 2009), esperable en el buceo carangiforme (Tarasoff 1972, Taylor 1989, Willemsen 1992, Fish 1994). Aunque el desarrollo de estas estructuras es también importante en especies arborícolas (ver 
Argot 2003a, Youlatos 2003, Organ 2010; y otros linajes semi-acuáticos, e.g., roedores; Mahoney y Rosenberg 1981), diferencias importantes pueden encontrarse en la morfología de los procesos transversos entre especies semi-acuáticas y arborícolas. En el caso de las nutrias los procesos transversos del sector proximal son muy amplios, mientras que a partir del sector transicional, se encuentran compuestos por una proyección craneal tan o más amplia que la caudal y los cuerpos vertebrales son cráneocaudalmente breves, resultando en forma de " $\mathrm{H}$ " en vista dorsal. Estos rasgos, no presentes en arborícolas ni mustélidos terrestres en general, sólo se encuentran bien definidos en lutrinos (e.g., Apéndice 3.15, c. 29, estado 1), incluyendo lutrinos fósiles (e.g., 'Sardolutra "Nesolutra" ichnusae; Malatesta 1977), pero también están presente en otros grupos semi-acuáticos (e.g., †Potamotherium valletoni; Savage 1957; pero ver también Apéndice 4.1E). Esta morfología y desarrollo de los procesos transversos de las vértebras caudales favorece un mayor área de origen y número de paquetes del $\mathrm{m}$. sacrocaudalis ventralis lateralis y m. sacrocaudalis dorsalis lateralis específicamente (Fisher 1942, Mahoney y Rosenberg 1981, Ercoli et al. 2013: 314-317, Organ 2010), permitiendo mayor precisión y masa a la musculatura caudal flexo-extensora. A su vez, permite un mayor soporte estructural a lo largo de toda la serie caudal, aumentando el área de empuje durante el nado (Tarasoff 1972, Tarasoff et al. 1972, Willemsen 1992), y limitando los movimientos de flexión lateral posibles. El máximo aprovechamiento de esta organización osteo-muscular, y la mayor robustez de los procesos transversos (ver también Savage 1957: 191) se registra en Pt. brasiliensis, en donde aproximadamente una decena de elementos poseen forma de "H" desde la mitad de la cola hasta prácticamente el último elemento caudal (i.e., elemento 19 de 22 totales). Esto concuerda con la posibilidad de que la nutria gigante sea el lutrino viviente más veloz en el nado, con un grado de especialización de propulsión caudal único (Willemsen 1992, Kruuk 2006, Lewis 2008).

Por otro lado, en algunos musteloideos no mustélidos (e.g., Procyon spp., Na. nasua, S. gracilis, ver otros) y menos frecuentemente en mustélidos, los procesos transversos del sector transicional están predominantemente representado por el proceso craneal (parcialmente representado por Apéndice 3.15, c. 29, estado 2). Aunque las razones no son del todo claras, es posible que en estos linajes se favorezca el espacio de inserción de músculos flexo-extensores caudales por sobre los flexores laterales, aunque sin limitar ningún tipo de movimiento (contrario a la morfología tipo "H").

La forma y desarrollo de los primeros procesos transversos caudales también se encuentra relacionado al desarrollo de los orígenes de músculos extrínsecos del miembro posterior y de la cintura pélvica (e.g., m. semitendinosus, m. abductor cruris caudalis, $\mathrm{m}$. coccygeus; Hall 1926, Argot 2003a, Flores y Díaz 2009, Ercoli et al. 2013, ver secciones 3.1,10-13). Como ya fue descripto (Ercoli et al. 2013, ver sección 4.1.3), las posiciones y desarrollo de estos músculos varía entre los distintos musteloideos en función de distintos tipos 
locomotores y comportamentales, así como grupos filogenéticos, y estos afectan la morfología vertebral. En el caso de las nutrias, el máximo desarrollo en superficie de los procesos transversos caudales proximales (extremo en Pt. brasiliensis, ver también Savage 1957) permite una mayor superficie de origen de la musculatura caudal de inserción pélvica, favoreciéndose una poderosa flexión ventral y acomodo lateral de la cola (Savage 1957) aunque esto último limitado en rango por interferencias entre procesos. La mayor musculatura extrínseca caudal también permite mantener a los miembros posteriores en una posición extendida y dirigidos caudalmente, cercanos y mayormente paralelos a la cola. Esta es la postura típica durante el nado en nutrias, especialmente durante la propulsión carangiforme (Maynard Smith y Savage 1956, Savage 1957, Gambaryan y Karapetyan 1961, Tarasoff 1972, Taylor 1989).

\subsubsection{Proporciones intermembrales}

Mediante el índice LaMA/LaMP se contempló la razón entre la suma de las longitudes de los principales elementos del miembro anterior (húmero, radio y metacarpal III) y la suma de las longitudes de los principales elementos del miembro posterior (fémur, tibia y metatarsal III). La distribución de valores de las proporciones intermembrales de la muestra analizada evidencia algunas variantes intergrupales, esto es, entre grupos ecológicos, y variantes intragrupales de interés funcional (Figs. 3.1E, 3.2C). Por otro lado, todos los grupos locomotores y dietarios se superponen a otros en parte de sus rangos, y la mayoría de las especies musteloideas se ubican en un estrecho rango de valores del cociente LaMA/LaMP (17 especies entre 0,78 y 0,84; Tabla 2.3, 3.1E, 3.2C). Los análisis estadísticos sin control filogenético muestran una relación significativa pero pobre entre este índice y cada uno de los factores (dieta y locomoción), así como con la interacción entre estos (dieta*locomoción; ver sección 3.4, Apéndice 3.6E1, 2). ANOVAs de cada factor no cumplen con los supuestos, por lo cual estos resultados, aunque no significativos en ningún caso, no son confiables. Por otro lado, la locomoción es el único factor que mantiene una relación significativa pero marginal con la proporción intermembral luego de contemplarse la estructura filogenética (Tabla 3.6, Apéndice 3.7E). Más allá de las dificultades estadísticas, el de los estadísticos descriptivos (Tabla 3.7) indica que los trepadores y cavadores tienden a presentar valores sutílmente más elevados que los nadadores y half-bounders. Tanto el trepado (excluyendo a los trepadores half-bounders) como el cavado implican grandes esfuerzos braquiales. Movimientos seguros en el sustrato arbóreo requieren gran fuerza de retracción, aducción y estabilización muscular de las articulaciones de los miembros (Davis 1949, Taylor 1989, Argot 2001). Los miembros anteriores se ven particularmente exigidos durante el ascenso vertical, en donde estos deben elevar todo el peso del cuerpo en contra de la fuerza de gravedad aferrándose y rodeando al sustrato (Davis 1949, Ewer 1973, Hildebrand 1988, Taylor 1989). Aunque los miembros posteriores son también elongados respecto a la región axial (Tabla 2.3, 
Apéndice 2.3, Fig. 3.1E, ver más arriba), el grado de elongación de los mismos es algo menos marcado que el de los miembros anteriores, contrario a lo que se observa en las especies que se desplazan a salto (ver más adelante).

Por otro lado, los cavadores tipo scratch-diggers requieren de miembros anteriores poderosos capaces de romper y remover el sustrato (Quaife 1978, Hildebrand 1988, Taylor 1989, Moore et al. 2013, Samuels et al. 2013). Samuels et al. (2013: 14) han sugerido que los miembros anteriores de los cavadores son breves en relación a los posteriores en relación a mayores ventajas mecánicas y resistencia. La revisión de los resultados estadísticos del índice intermembral suministrados por estos autores (Samuels et al. 2013: tabla 5) revela que el único grupo que se diferencia significativamente de los restantes es el grupo cursorial, mientras que los cavadores presentan valores muy similares a los trepadores, y mayores que los nadadores, coincidiendo con los resultados de esta Tesis (Tabla 2.3, Fig. 3.1A, E, sección 4.3.1) y los datos suministrados por Mivart (1885) y Holmes (1980). Tanto la reducción relativa y mayor robustez de la región lumbar como de los miembros posteriores en linajes cavadores puede relacionarse a la capacidad de resistir y transmitir los esfuerzos del cavado y el peso corporal durante esta actividad (Davis 1964, Quaife 1978). Es necesario destacar que existe una enorme variedad de proporciones intermembrales para especies cavadoras, encontrándose dentro de este grupo las especies musteloideas con mayores valores para este índice (Mellivora capensis, Taxidea taxus y Mydaus sp.; reconstruidas como autopomorfías de estos taxones; ver Apéndice 3.15, c. 2) y otras con proporciones moderadas (Melogale sp. y otros mefítidos; Tabla 2.3). Esta diversidad de formas indica la presencia de diferentes estrategias de cavado y grado de especialización en diferentes linajes (ver más adelante), y en concordancia con la ausencia de una relación fuerte entre las variables analizadas.

Los bajos valores del indice LaMA/LaMP en los half-bounders (Fig. 3.1E) se vincula a una mayor longitud de los miembros posteriores que es esperable dado que permite una mayor fuerza y longitud de la zancada durante los saltos y, en consecuencia, un incremento de la velocidad de desplazamiento (Gambaryan 1974, Hildebrand 1988, Argot 2001, 2004). Los menores valores del índice LaMA/LaMP en guloninos pequeños y mustelinos implica una maximización de la velocidad en estos grupos (Gambaryan 1974, Taylor 1989, King y Powell 2007), mientras que los mayores valores relativos de ictoniquinos como Ly. patagonicus y Ga. cuja y prociónidos como Bassariscus astutus, son variantes interesante dentro del grupo, e indican una menor velocidad en carrera (coincidiendo con datos anecdóticos de lincodontininos de Azara 1802, Doering 1881 y Koslowsky 1904) o la participación de los miembros en otras actividades (desconocidos en Ly. patagonicus, cavado o nado en Galictis, trepado en Bassariscus, manipulación de alimentos; Trapp 1972, Taylor 1989, Dalquest y Harvey 1951, Dücker 1968, Yensen y Tarifa 2003a, Wilson y Mittermeier 2009). 
En el caso de los nadadores, que también presentan un bajo índice intermembral, la mayor longitud de los miembros posteriores sólo se encuentra exagerada en las especies que los utilizan como uno de los principales propulsores durante el nado (e.g., En. lutris, Lo. canadensis; Tarasoff 1972, Tarasoff et al. 1972, Howard 1973, 1975, Fish 1994), resultando optimizadas como autopomorfías de estos taxones (Apéndice 3.15 ; c. 2). El cociente LaMA/LaMP es mayor, y con valores más cercanos a la media, en aquellas especies menos especializadas al buceo y con mayores capacidades de manipulación (e.g., Aonyx sp., Kruuk 2006, Wilson y Mittermeier 2009; Tabla 2.3, Fig. 3.1E). Es interesante destacar la gran diferencia entre los valores de Lo. canadensis (LaMA/LaMP = 0,687) y Lo. longicaudis y Lo. provocax $(0,81$ a 0,82$)$. Estas características, en conjunto con otras mencionadas más adelante, parecen indicar que las especies de Lontra sudamericanas presentan un menor grado de especialización al buceo propulsado por los miembros posteriores, o una mayor participación de los miembros anteriores tanto en el nado como en otras actividades (e.g., manipulación y tipo de presas, cavado; Kruuk 2006, Bastida et al. 2007, Wilson y Mittermeier 2009; ver también sección 4.3.4, Manus).

\subsubsection{Miembro anterior}

\subsubsection{Escápula}

\section{Ala y cuello escapular}

Un gran número de características anatómicas de la escápula descriptas pueden relacionarse directamente a las diferentes estrategias locomotoras en las especies analizadas.

Dentro de mustélidos de América del Sur, la espina, cuello y ala de la escápula en general son estructuras relativamente gráciles en lincodontininos, especialmente en $L y$. patagonicus, y $\mathrm{Mu}$. frenata, respecto a Ei. barbara y Lontra spp. En estos últimos, la robustez evidencia la necesidad de resistencia a esfuerzos de tensión no compresivos (Oxnard 1968, Argot 2003a, Morgan 2009) y un mayor desarrollo de músculos estabilizadores, elevadores (mm. trapezius) y retractores del miembro anterior (m. trapezius pars thoracis; Davis 1949, Fisher et al. 2009, Deban et al. 2012), en relación con la mayor participación de los miembros anteriores en la propulsión durante el nado o eventual excavación en Lontra (Larivière 1998, 1999, Moore et al. 2013), y durante el trepado, trote o galope terrestre en Ei. barbara (Kaufmann y Kaufmann 1965, Dagg 1973, Taylor 1974, Presley 2000). En lincodontininos y mustelinos, que realizan carreras de tipo bounding, los miembros anteriores tienen una participación menos activa en la propulsión (Gambaryan 1974). La gracilidad extrema de $L y$. patagonicus y $\mathrm{Mu}$. frenata en comparación con Galictis, podría deberse a la ausencia o reducción de actividades de trote o galope, nado y excavación, sí registradas para Galictis (Dagg 1973, Dalquest y Harvey 1951, Yensen y Tarifa 2003a, b, Wilson y Mittermeier 2009, Rose et 
al. 2014), coincidiendo con el análisis del índice intermembral. La menor proyección craneal del margen vertebral de la escápula, en relación a una menor área de inserción del sector craneal del $\mathrm{mm}$. serratus ventralis (depresor del miembro activo durante la fase de propulsión; Maynard Smith y Savage 1956, Argot 2003a, Deban et al. 2012), así como una fosa infraespinal reducida (correspondiente al m. infraspinatus, flexor y abductor del hombro, ver más abajo) apuntan a la misma interpretación funcional. El mismo patrón puede observarse en otros musteloideos, en donde las especies más especializadas a nadar, cavar o trepar presentan escápulas, y en particular sus espinas, más robustas (e.g., Rose et al. 2014). Una excepción a esto son los mefítidos, ambulatorios cavadores, que presentan escápulas con espinas moderadas, proceso acromial reducido, y alas escapulares gráciles y alargadas. Es probable que la penetración y remoción del sustrato, en donde tradicionalmente se encuentran involucrados músculos de inserción en la espina escapular como los mm. trapezius y los mm. deltoideus, haya sido cedida en parte a otros grupos que presentan áreas de origen o inserción mejor desarrolladas (e.g., m. infraspinatus, m. rhomboideus thoracis, $\mathrm{mm}$. serratus ventralis, y otros músculos extrínsecos, pero ver también importante desarrollo $\mathrm{m}$. trapezius pars thoracica y cresta deltoidea en el húmero en mefitidos; Hall 1926, ver también Ercoli et al. 2014).

El desarrollo relativo del área supraspinal respecto a la infraspinal es elevado en todas las especies de mustélidos sudamericanos, excepto en Ei. barbara, en el que son subiguales o la primera apenas supera a la segunda. En el caso de Pt. brasiliensis, la fosa supraspinal se encuentra marcadamente hipertrofiada. Esta proporción refleja el desarrollo relativo de los músculos que allí se originan (m. supraspinatus y m. infraspinatus respectivamente; Hall 1926, Argot 2001, Salesa et al. 2008, Fisher et al. 2009). La optimización de este rasgo (Apéndice 3.15 , c. 31) reveló que una fosa supraespinosa de mayor desarrollo relativo (estado 2) fue un estado adquirido en el ancestro común entre Melogale, hurones y nutrias; y al parecer desarrollado en forma convergente en algunos guloninos pequeños. Para el caso de las nutrias, ictoniquinos y mustelinos, esta proporción indica un mayor desarrollo de la masa muscular extensora del hombro en relación a la flexora. La mayor longitud del margen ventral de la fosa supraspinal y el amplio espacio resultante formado entre el ángulo cráneoventral y el cuello escapular se vinculan a una mayor área de origen y a un incremento de fibras reclutadas con gran ventaja mecánica para la extensión (alejadas cranealmente del centro de rotación). Las fibras originadas en este sector conforman un vientre independiente para el caso de algunos representantes de estos linajes (Ga. cuja, Lo. canadensis, posiblemente Mustela putorius; ver sección 4.1.2, Fisher 1942, Barone y Deustch 1953). Todos estos rasgos sugieren una gran fuerza de extensión del hombro, necesaria para resistir las fuerzas de reacción del sustrato por parte del miembro anterior durante el contacto al principio de la fase de soporte en la locomoción a saltos (Gambaryan 1974, Seckel y Janis 2008), así como durante toda la fase de 
soporte en posturas agazapadas (Moritz et al. 2007, Horner y Biknevicius 2010). La inclinación del margen ventral de la fosa supraespinal, que se hace más vertical a medida que se reduce el tamaño de los animales, parece encontrarse influenciada también por cuestiones alométricas, lo cual es esperable dado que el $\mathrm{m}$. supraspinatus evita el colapso del hombro durante el soporte del peso.

En las nutrias, convergentemente con pinnípedos, el tamaño de la fosa supraespinal se encuentra exacerbado probablemente en relación a la necesidad de vencer la inercia del agua al adelantar o rotar los miembros durante nado, partiendo desde una posición retraída del miembro luego de una brazada (Savage 1957, Gambaryan y Karapetyan 1961, English 1977, Williams 1983a, Fish 1994), y posiblemente también a efectos alométricos, dado su gran tamaño, durante la locomoción terrestre. La reducción relativa de la fosa infraespinosa de estos linajes acuáticos debe ser ponderada con un incremento general del tamaño relativo de la escápula y la musculatura del hombro en general (Gambaryan y Karapetyan 1961, Ercoli et al. 2014; incluyendo la hipertrofia de otros flexores del hombro más poderosos, ver más adelante). Por otro lado, en todas las nutrias, el sector de inserción del m. infraspinatus es robusto (ver sección 4.3.4, Húmero), por lo cual el músculo parece ser voluminoso más allá de lo observado en la extensión sagital de su origen. Una mejor comprensión de la morfología aberrante de Pt. brasiliensis podría alcanzarse mediante disecciones, pero la gran amplitud de escápula en sentido lateromedial y cráneocaudal podría relacionarse a una gran cantidad de masa y ventaja mecánica de la musculatura del hombro y con la capacidad de realizar poderosos movimientos de rotación durante el nado (Maynard Smith y Savage 1956, Savage 1957, English 1977, Holmes 1980).

La mayor importancia relativa del m. infraspinatus en Ei. barbara se condice con los esfuerzos necesarios para el trepado vertical (Argot 2001; ver más abajo) y con el estilo locomotor del taxón. A su vez, esta especie, al contrario de los demás mustélidos sudamericanos, posee miembros largos (Presley 2000; ver sección 4.3.1) y en tierra se desplaza con estos mayormente extendidos, mediante trotes o marchas de tipo galope (Kavanau 1971, Presley 2000), las cuales demandan mayores esfuerzos de propulsión del miembro anterior (en relación a flexión del hombro) y menores fuerzas de reacción del sustrato en el comienzo de la fase de apoyo (en relación a la extensión del hombro) en comparación a pasos bound o halfbound estrictos (Gambaryan 1974, Hildebrand 1977, 1980, Ruina et al. 2005). La condición de Ei. barbara se reconstruye en las optimizaciones como una retención de una condición ancestral para Mustelidae e incluso quizás más antigua (ver Apéndice 3.15, c. 31, estado 0 y 1), observándose similares o mayores desarrollos relativos de la fosa infraespinal en la mayoría de los guloninos de otros continentes, prociónidos, tejones y mefítidos (Apéndice 3.15, c. 31, 
estado 0 y 1), todos ellos taxones trepadores o cavadores frecuentes y mayormente de marchas tipo trote y galope.

El área de origen del $\mathrm{m}$. teres major, flexor fuerte del hombro, está relativamente reducida en todos los mustélidos no acuáticos analizados respecto las nutrias, en las que este área es amplia en conjunto con una fosa postescapular típicamente bien delimitada, en donde se origina parte del $\mathrm{m}$. subscapularis (ver distinción entre proceso del teres major y fosa postescapular (postscapular fossa) en Davis 1949). El m. teres major (y también el m. subscapularis) interviene en los marcados esfuerzos de adducción, rotación y flexión del miembro durante la propulsión en un medio denso y la retención del miembro junto al cuerpo (Savage 1957, Holmes 1980, Williams 1983a, Hildebrand 1988, Fish 1994, Salesa et al. 2008). Dentro de las especies de Amèrica del Sur, el caso extremo se observa en Pt. brasiliensis, en la cual este área se encuentra hipertrofiada y proyectada caudalmente, y una condición similar se registra también en lutrinos (e.g., Hydrictis maculicollis) de otros continentes, siendo una sinapomorfía de la subfamilia (Apéndice 3.15, c. 32, estado 2). Una fosa postescapular y proceso del teres major amplios también están presentes en algunos trepadores y cavadores (e.g., Gulo gulo, Potos flavus, y en menor grado en Nasua nasua, ver también Davis 1949, 1964, Holmes 1980, Salesa et al. 2008), aunque con múltiples excepciones que incluyen a algunos mefítidos, melinos, guloninos medianos a pequeños, incluyendo Ei. barbara. En estos linajes es probable que dicha función sea realizada en gran parte por el más rápido y débil m. infraspinatus (opuesto a nutrias) $\mathrm{y} / \mathrm{u}$ otros flexores y retractores. Dentro de las nutrias sudamericanas, presentan de menor a mayor desarrollo: Lo. longicaudis y Lo. felina, Lo. provocax y Pt. brasiliensis, posiblemente en relación a cuestiones alométricas, o a distinto grado en la capacidad de cavar o buceo de estos taxones (Davis 1949, 1964, Ewer 1973, Holmes 1980, Argot 2001, Kruuk 2006, Wilson y Mittermeier 2009). En el caso de Lo. provocax, además del origen del m. teres major, se destacan otros rasgos que señalan el incremento de áreas de origen de otros flexores poderosos del hombro respecto a Lo. longicaudis y Lo. felina (e.g., m. serratus ventralis, $\mathrm{m}$. triceps brachii caput longus, $\mathrm{mm}$. deltoideus), lo que es probable que se relacione a una mayor capacidad de excavación en Lo. provocax, aunque no existen datos comportamentales suficientes para sustentarlo (ver Larivière 1998, 1999).

Tanto en Ei. barbara como en las nutrias, el ala de la escápula es cóncava a fuertemente cóncava en relación al alojamiento de un gran m. subscapularis y, en el caso de las nutrias, está surcada por fuertes estrías que marcan los límites entre los paquetes del mismo. Este músculo aduce, rota y estabiliza al hombro (Davis 1949, Salesa et al. 2008, Fisher et al. 2009), y su mayor desarrollo en estas especies es esperable debido a la necesidad de aferrarse a ramas y troncos en el caso de Ei. barbara (Davis 1949, Salesa et al. 2008), y a los movimientos de 
brazada necesarios durante el nado y eventual excavación en nutrias (Savage 1957, Hildebrand 1988, Argot 2001).

\section{Proceso hamatus y subhamatus}

En cuanto al proceso hamatus, Ei. barbara y las nutrias comparten como característica su inclinación en sentido craneal (alejándose del plano de la escápula en Ei. barbara, y acercándose a este en el caso de nutrias). En estas especies el proceso es robusto (Ei. barbara y Pt. brasiliensis) o quillado (Lontra spp.). A su vez, el proceso subhamatus está engrosado y ubicado en posición ventral. En Lontra spp., durante el padding, los miembros anteriores son llevados cranealmente por debajo del cuerpo, en una posición aducida para reducir la fricción con el medio liquido circundante (Hildebrand 1988, Fish 1994), separándose de la línea media al alcanzar una posición extendida para comenzar la fase de propulsión. La inclinación craneal y medial del proceso hamatus, en conjunto con el adelantamiento de la zona de inserción de los $\mathrm{mm}$. deltoideus debido al perfil sigmoidal del húmero, indicaría un incremento de la capacidad de abducir el miembro desde posiciones relativamente extendidas y aducidas de la articulación del hombro, al comienzo de la fase de propulsión, colaborando en la flexión posteriormente (Gambaryan y Karapetyan 1961). La menor inclinación de Pt. brasiliensis respecto a Lontra spp. podría deberse a una posición más caudal durante el padding para los miembros anteriores, en relación a una postura habitualmente más flexionada del húmero (conclusión similar a la alcanzada en el análisis de la ulna; ver también comentarios de variantes de estilo de nado de Pt. brasiliensis en Fish 1994 y Kruuk 2006). En el caso de Ei. barbara, la morfología y dirección del proceso (similar a otros guloninos, ver Leach 1977a) indica un esfuerzo de flexión y abducción poderosos (así como fue observado para otros flexores del hombro, e.g., m. infraspinatus), actuando los mm. deltoideus en una posición relativamente más abducida del miembro respecto a lo observado en nutrias. Ambas características coinciden directamente con lo esperable durante el trepado vertical, en donde los miembros deben ubicarse rodeando al sustrato al final de la fase de descanso y durante la propulsión donde la musculatura flexora del hombro resiste y adelanta el peso del cuerpo (Taylor 1974, Leach 1977a, b, Hildebrand 1988).

En lincodontininos y $\mathrm{Mu}$. frenata, al contrario de lo que ocurre en Ei. barbara y las nutrias, el proceso hamatus no está inclinado cranealmente, lo que se vincula con la acción de los mm. deltoideus en una posición relativamente más flexionada del hombro, en relación a una postura casi exclusivamente agazapada (especialmente durante el desplazamiento en túneles, Moritz et al. 2007, Horner y Biknevicius 2010). Esto (en conjunto con una escápula relativamente reducida en tamaño) se relacionaría a que durante el adelantamiento del miembro anterior se favorece el adelantamiento de la cintura escapular (ver más adelante interpretación del proceso subhamatus) más que extendiendo ampliamente el brazo. De esta forma se mantiene una baja altura a nivel de la cruz al desplazarse en galerías (ver estudios de cinemática y 
posturales de Gambaryan 1974, Moritz et al. 2007, Horner y Biknevicius 2010). La comparación dentro de musteloideos permite extender estas afirmaciones dado que las especies de mustelinos e ictoniquinos, y secundariamente Bassaricus astutus y mefítidos (linajes que también se desplazan en túneles), presentan un proceso hamatus alargado y paralelo a la espina escapular, contrario a lo observado en otros musteloideos (ver también Riggs 1945, Leach 1977b) que no se desplazan en túneles estrechos, y poseen una mayor capacidad de abducción o flexión del hombro (e.g., guloninos, melivorinos, melinos, taxidinos, y restantes prociónidos, ailúridos)

El proceso subhamatus corresponde a la zona de inserción del $\mathrm{m}$. omotransversarius, músculo protractor que colabora con el adelantamiento del miembro durante la fase de descanso (Fisher et al. 2009, Deban et al. 2012). Este proceso es amplio en Ei. barbara, Lo. provocax y hurones, especialmente Ly. patagonicus y $M u$. frenata; siendo esta condición reconstruida como ancestral para Musteloidea (Apéndice 3.15, c. 33, estados 1, 2 y 3 vs. 0. La amplitud del proceso subhamatus fue destacada previamente para vivérridos y herpéstidos trotadores por Taylor (1974), quien lo relacionó al incremento del largo de zancada. En lutrinos y Ei. barbara este proceso presenta una morfología triangular, usual para Musteloidea. Por otro lado, en los ictoniquinos analizados (especialmente en Ly. patagonicus) así como en $M u$. frenata (y otros mustelinos), este proceso es amplio, flabeliforme, y se proyecta dorsocaudalmente por sobre su base. Esta modificación podría interpretarse como una convergencia funcional con otros linajes de mamíferos que realizan marchas bound o half-bound (scapular sling en lagomorfos; Seckel y Janis 2008), permitiendo el posicionamiento y desarrollo de este proceso ubicar la línea de acción del m. omotransversarius por sobre y detrás la articulación del hombro, lo que resulta en la rotación craneal de la escápula por sobre el húmero al contrarse el m. omotransversarius. Este músculo colaboraría junto con el vientre craneal del m. supraspinatus (ver más arriba y Feeney 1999), y el m. trapezius pars cervicalis (el cual alcanza el proceso subhamatus en lagomorfos pero no en hurones; Alix 1876, Williams 1955, Seckel y Janis 2008), en resistir la fuerza de reacción del sustrato sobre la articulación durante el aterrizaje posterior a cada salto. Una morfología similar a la descripta para hurones de América del Sur está también presente en mustelinos e ictoniquinos de otros continentes; y podría ser considerada ya presente en la base de ambos grupos (Apéndice 3.15, c. 33, estados 2 y 3), siendo incierto si esta condición fue alcanzada entre estos dos grupos de hurones por convergencia o herencia común (ver optimización ambigua de nodo Lutrinae + Ictonichinae + Mustelinae). Una condición flabeliforme convergente pero menos marcada se observa en Martes spp., guloninos en los cuales se han reportado marchas tanto bound como half-bound en alta velocidad (Dagg 1973, Gambaryan 1974, Hildebrand 1977). Por otro lado, esta morfología no se encontró en las nutrias (excepto en forma incipiente en Aonyx), lo que es esperable dado que la marcha de tipo half- 
bound de éstas presenta una fase área de vuelo extendido reducida o directamente ausente (Williemsen 1980b, Williams et al. 2002), reduciendo el esfuerzo del impacto de los miembros anteriores. Por otro lado, como se comentó en la sección 4.1, el mayor desarrollo del m. omotransversarius y otros protractores del miembro (e.g., m. rhomboideus profundus, $\mathrm{m}$. trapezius cervicis) en los hurones permitiría un mayor rango de desplazamiento de la cintura y mayor zancada durante la locomoción agazapada en galerías (Moritz et al. 2007, Horner y Biknevicius 2010, Ercoli et al. 2014).

\section{Región articular}

En cuanto a la zona articular, ésta se encuentra fuertemente proyectada ventralmente en su zona craneal tanto en Ly. patagonicus como Mu. frenata entre las especies de América del

Sur, y fue reconstruida como una condición sinapomórfica de Mustelinae y convergentemente adquirida en algunos ictoniquinos (Apéndice 3.15, c. 34, estado 0). Esta característica limita la capacidad de extensión de la articulación del hombro lo que se vincula a la especialización a desplazarse en galerías estrechas (i.e., imposibilidad de extensión total de la articulación, ver más arriba). Esto ocurre en forma menos marcada en nutrias y Galictis spp., condición plesiomórfica para Musteloidea y Arctoidea (Apéndice 3.15, c. 34, estado 1). En Ei. barbara se registra el caso opuesto en relación a amplias libertades de movimientos en el hombro, esperable para el desplazamiento en un sustrato tridimensional e inestable (Hildebrand 1988, Szalay y Sargis 2001, Argot 2003b); esta especie también presenta la mayor robustez del tubérculo supraglenoideo (Apéndice 3.15, c. 34, estado 2) y proceso coronoides, en relación a una importante masa flexora del codo, y extensora y estabilizadora del hombro (Maynard Smith y Savage 1956, Salesa et al. 2008, Fisher et al. 2009), incluyendo la presencia del m. coracobrachialis (ausente en las otras especies sudamericanas diseccionadas) y $\mathrm{m}$. articularis coxae (reducido o ausente en las demás especies sudamericanas; Macalister 1873b, Windle y Parsons 1897, Ercoli et al. 2014; sección 4.1). Estas características, presentes también en otros guloninos, melinos, Ai. fulgens y prociónidos, fueron tradicionalmente relacionadas con los esfuerzos de flexión y aducción típicos de la locomoción arbórea y un posicionamiento del centro de gravedad cercano al sustrato con el fin de evitar caídas (Taylor 1974, Van Valkenburg 1987, Heinrich y Houde 2006, Salesa et al. 2008).

\subsubsection{Clavícula}

La clavícula se encuentra reducida (e.g., Mustela vison) o ausente (e.g., Enhydra lutris, Lontra canadensis, Taxidea taxus) en todos los mustélidos (Fisher 1942, Ondrias 1961, Klingener 1972, Howard 1973, Taylor 1989, Holmes 1980). Hall (1926) tampoco registró presencia de clavícula en mefítidos. Por otro lado, Blainville (1841-1864) mencionó la presencia de clavículas reducidas para "Lutra" y "Mephitis", y la ausencia de la misma en Mellivora, 
mientras que Windle y Parsons (1897) reconocieron la presencia de este elemento en Lutra lutra, pero su aparente ausencia en Aonyx cinerea, y algunos casos de posibles variaciones intraespecíficas. Un resumen de todo esto se encuentra en Holmes (1980: 46-47). La clavícula no fue identificada en ninguno de los mustélidos analizados, aunque su ausencia real no puede ser asegurada excepto en los especímenes diseccionados. En el caso de los especímenes de Galictis cuja diseccionados, sólo se encontró un rudimento vestigial de clavícula en el lado derecho del espécimen hembra, embebido en la intersección tendinosa entre el $\mathrm{m}$. cleidocephalicus y el m. cleidobrachialis (similar a lo descripto para Mustela vison; Klingener 1972). El mustélido con la clavícula más desarrollada (algo menor a $10 \mathrm{~mm}$.) sería Martes spp. (Leach y Dagg 1976, Leach 1977a, b, Holmes 1980; contra Barraquand 2010), que incluso presenta un extremo libre, aunque aun así sin llegar a contactar a la escápula. El mayor desarrollo de la clavícula puede relacionarse a los hábitos arbóreos del mismo (ver también Taylor 1989). En musteloideos de hábitos similares, se registró la presencia de una pequeña clavicula en muchos prociónidos (e.g., Nasua spp., Potos flavus y Procyon spp.; Mackintosh 1875, Allen 1882, Mivart 1885, Windle 1888, Windle y Parsons 1897), aunque ni Macalister (1873b) en Eira barbara, ni Fisher et al. (2009) en Ailurus fulgens, mencionaron la presencia de este elemento.

\subsubsection{Húmero}

\section{Morfología general}

La robustez del húmero es muy variable en los mustélidos sudamericanos. Lyncodon patagonicus y Mustela frenata presentan diáfisis gráciles y rectas a levemente curvas, en relación a áreas de orígenes e inserciones musculares reducidas y ausencia de esfuerzos no compresivos sobre el elemento. Estas características se relacionan a pocas demandas de propulsión en los miembros anteriores y a la ausencia de especializaciones a cavar, trepar o nadar (Oxnard 1968, Holmes 1980, Willemsen 1992, Argot 2003b, Morgan 2009, Rose et al. 2014), así como a cuestiones alométricas (Heinrich y Biknevicius 1998, Fabre et al. 2013a y sus referencias). Galictis vittata y especialmente Ga. cuja, más frecuente cavador que el anterior (Kaufmann y Kaufmann 1965, Yensen y Tarifa 2003a, b, Wilson y Mittermeier 2009), presentan una mayor robustez y curvatura del sector proximal de la diáfisis en relación a los mayores esfuerzos de los músculos que se insertan sobre el sector ( $\mathrm{mm}$. pectorales, $\mathrm{mm}$. deltoideus; Hildebrand 1988, Willemsen 1992). En el análisis de forma de la vista craneal del extremo distal del húmero, Ly. patagonicus presenta, en conjunto con algunos especímenes de Mustela, la máxima reducción de las estructuras de agarre muscular y el mayor desarrollo relativo de la articulación distal (ver más adelante; Fig. 3.7), respaldando lo mencionado. 
Las diáfisis de Ei. barbara es recta y moderadamente robusta a lo largo de todo su recorrido, lo cual podría estar relacionado a los moderados esfuerzos de tensión adicionales en múltiples direcciones soportados durante el trepado (Oxnard 1968, Hildebrand 1988, Argot 2003b). Las nutrias presentan una morfología extrema (especialmente en el caso de Pt. brasiliensis) entre los musteloideos tanto en la robustez como en la curvatura sigmoidal de la diáfisis humeral. Esta morfología se ha relacionado tradicionalmente con el nado, en relación a los esfuerzos de tensión soportados al vencer la resistencia del agua durante la flexión del brazo (Willemsen 1992, Fish 1994, Peigné et al. 2008), el aumento de la densidad de los huesos para el control de la flotabilidad (Tarasoff et al. 1972, Fish y Stein 1991, Fish 1996), y el posicionamiento en dirección caudal de los miembros durante el buceo (Fish 1994). El gran grado de curvatura de la diáfisis humeral fue recuperado como una sinapomorfía de Lutrinae (Apéndice 3.15, c. 37, estado 2), sólo revertida en el taxón poco especializado al nado Aonyx. Autores como Colombero et al. (2012) han discutido acerca de la posibilidad de que la curvatura moderada de húmero de algunos ictoniquinos fósiles (e.g., ${ }^{\dagger}$ Pannonictis nestii) y la presencia de este rasgo en grisones vivientes, sea un indicador de hábitos semiacuáticos, sin una conclusión definitiva. Las optimizaciones aquí realizadas indican que una diáfisis humeral mayormente recta es la condición ancestral de Arctoidea, modificada a una morfología levemente curva en múltiples eventos en distintos linajes (e.g., Mephitidae, Procyon, Taxidea, Melogale + Ictonychinae + Mustelinae + Lutrinae; Apéndice 3.15, c. 37, estado 1), evidenciando la posibilidad de una gran gama de factores (e.g., uso de sustrato, tipo locomotor, alometrías, proporciones membrales) que podrían relacionarse a esta modificación, más que una única explicación simple.

Así como ocurre en los demás elementos principales apendiculares (Apéndice 2.3, sección 4.3.1), Ei. barbara y otros trepadores (otros guloninos, prociónidos, Ai. fulgens) se destacan por el alargamiento de estos huesos, en relación a miembros alargados que permitan rodear troncos al trepar y alcanzar puntos de apoyo distanciados (Hildebrand 1988); opuesto a lo observado en especies que se desplazan en galerías, algunos fosoriales y nadadores (e.g., Ondrias 1961, Holmes 1980). En lo que respecta a musteloideos en general, los grupos de mayor robustez de la diáfisis son en general animales de gran porte y frecuentes nadadores o cavadores, destacándose los Taxidiinae, Melinae, Mephitidae y Lutrinae (exceptuando Aonyx), seguidos por Ai. fulgens, Procyonidae, Guloninae (grupos trepadores) y muchos Ictonichinae (cavadores menos especializados). Por otro lado, las diáfisis más gráciles se registran dentro de la Subfamilia Mustelinae y algunos Guloninae pequeños (e.g., Ma. americana), animales que se desplazan frecuentemente a saltos y realizan con relativa menor frecuencia las actividades mencionadas. Estos resultados también coinciden con los de Rose et al. (2014), quienes 
concluyeron que la robustez del húmero es uno de los mejores indicadores del grado de especialización al cavado en tejones.

\section{Sector proximal y medio}

La cabeza humeral presenta variaciones en relación a las diferentes estrategias lomocotoras de los musteloideos. En lo que respecta a las especies de América del Sur, en la tayra y los grisones es elongada cráneocaudalmente y está separada ampliamente de los tubérculos (e.g., surco intertubercular amplio), en relación a libertades de movimientos relativamente amplias dentro del plano parasagital (pero ver también Holmes 1980). En Ei. barbara, y secundariamente Ga. vittata, la cabeza articular se encuentra elevada por sobre los tubérculos, permitiendo quizás un mayor grado de extensión del hombro respecto a las otras especies de América del Sur (como ha sido observado en especies trepadoras de otros linajes; e.g. Szalay y Sargis 2001). En las nutrias, la cabeza humeral también es elongada y está separada de los tubérculos, además presenta una ubicación muy caudal del centro de la cabeza articular que a su vez es ancha en su sector caudal, lo cual estaría relacionado a mayores libertades de movimiento fuera del plano parasagital en una posición flexionada del hombro (Fish 1994, Argot 2010, ver también Argot y Babot 2011). Pteronura brasiliensis presenta este patrón más acentuado, con una morfología de la cabeza articular mucho más globosa y una orientación más caudal de la cabeza articular. Lyncodon patagonicus se diferencia de la morfología observada en los grisones y es similar a $M u$. frenata y otros mustelinos y guloninos pequeños de otros continentes: la cabeza humeral se extiende caudoventralmente más que caudalmente, es delgada en su sector caudal, y se encuentra poco separada de los tubérculos. Esta morfología indica claras restricciones a movimientos dentro del plano parasagital (Szalay y Sargis 2001, Argot 2004, 2010, Argot y Babot 2011) y la ausencia de una marcada extensión del hombro (como fue también observado en la cavidad glenoidea de la escápula, ver arriba; ver también Feeney 1999). Los mefítidos presentan también una cabeza articular estrecha lateromedialmente, pero elevada respecto a los tubérculos, en relación a movimientos relativamente más amplios pero aun así restringidos al plano parasagital. Tanto en los hurones como las nutrias, el tubérculo mayor es robusto, está separado de la zona articular y elevado por sobre la cabeza articular, en concordancia con las modificaciones y mayor desarrollo de la musculatura supraespinal en especies bounders y/o acuática, como ya fue comentado en el apartado de la escápula (Feeney 1999, ver arriba sección 4.3.4, Escápula). El área de inserción del $\mathrm{m}$. infraspinatus es relativamente amplia en la mayoría de los taxones, aunque está relativamente reducida en Ly. patagonicus y $M u$. frenata (como también es observado en otros Mustela), coincidiendo con lo descripto para su origen en la escápula. Por otro lado, el desarrollo de esta área en nutrias es relativamente amplio respecto a esperable en relación al origen descripto previamente, indicando un volumen importante para el m. infraspinatus. 
Entre las especies sudamericanas, el desarrollo y sobresaliencia de la cresta deltoidea y la cresta deltopectoral, la cresta del tubérculo mayor, y el tubérculo menor es marcado en las nutrias; son seguidas en importancia por los grisones (especialmente Ga. cuja) y la tayra, y se encuentran reducidas en $M u$. frenata y Ly. patagonicus. En lo que respecta a otros musteloideos, el desarrollo de estas estructuras es muy importante en las especies nadadoras y cavadoras, incluyendo a la mayoría de las nutrias (similar a lutrinos sudamericanos, pero con excepciones que incluyen a Aonyx y Lutrogale y algunos especímenes de Lutra), mefítidos (aunque con una morfología anómala de la cresta deltoidea y tubérculos no tan hipertrofiados), Mellivora, Meles y Taxidea (pero ver comentarios de Rose et al. 2014). Estas crestas y áreas entre crestas son moderadamente amplias y marcadamente rugosas en trepadores como prociónidos (en mayor desarrollo en Potos y Nasua que Procyon), y muchos de los grandes guloninos, aunque con diferencias morfológicas propias de cada linaje (ver Apéndice 4.1F). Esto se vincula directamente el desarrollo de los mm. deltoideus (abductor y flexor del hombro) y $\mathrm{mm}$. pectorales superficiales (adductores y flexores del brazo), m. pectoralis profundus (adductor y retractor del brazo) y $\mathrm{m}$. subscapularis (adductor y estabilizador del hombro), y las diferencias en el grado de participación de los miembros anteriores en el nado, cavado, trepado o propulsión activa en estos taxones (Davis 1949, Taylor 1974, Lambert 1997, Argot 2004, 2010, Peigné et al. 2008, Fisher et al. 2009, Deban et al. 2012, Moore et al. 2013, Rose et al. 2014; ver sección 4.3.4, Escápula).

La cresta deltopectoral se encuentra presente en el sector distal del húmero de Ei. barbara (como un área rugosa), grisones y Lontra (a modo de una cresta delgada), y desarrollada en extremo en Pt. brasiliensis (a modo de una cresta robusta y rugosa; como ya fue destacado por Peigné et al. 2008). Los pectorales, y específicamente los mm. pectorales superficiales, permiten la aducción del miembro necesaria para aferrarse a ramas y troncos (Taylor 1974, Hildebrand 1988, Argot 2003b, Toledo et al. 2012), y para llevar los miembros contra el cuerpo y realizar movimientos complejos durante el nado (incluyendo aducción y retracción; Maynard Smith y Savage 1956, Savage 1957, Holmes 1980, Williams 1983a, Fish 1994, Lambert 1997). Por otro lado, estos músculos asisten en la rutina de movimientos del cavado, especialmente al comienzo de la remoción del sustrato, en donde las garras son clavadas en el terreno, y el miembro es retraído hacia el cuerpo (Schutz y Guralnick 2007, Candela y Picasso 2008, Toledo et al. 2012, Moore et al. 2013). El mayor desarrollo de estas estructuras, así como de otras zonas de agarre muscular en el sector proximal del húmero, en Lo. provocax y Ga. cuja respecto a las especies cogenéricas concuerda con hábitos cavadores más frecuentes para estas especies. El mínimo desarrollo de la cresta del tubérculo mayor y el área delimitada entre esta y la cresta deltoidea se da en Ly. patagonicus, infiriéndose un bajo desarrollo de la musculatura pectoral para esta especie. En el caso de Pt. brasiliensis, el desarrollo de esta cresta 
puede relacionarse adicionalmente a cuestiones alométricas, dado que estos músculos colaboran en el soporte del peso corporal (ver Argot 2003b, Fisher et al. 2009). Algo similar se puede observar al comparar los miembros mayores dentro de cada clado (e.g., Gulo comparado con otros guloninos; Mephitis respecto a otros mefítidos).

El tubérculo menor, zona de inserción del m. subscapularis (aductor, rotador y estabilizador del hombro), se encuentra hipertrofiado y proyectado medialmente en nutrias, especialmente en Pt. brasiliensis, lo que se condice con una mayor importancia de las funciones que desempeña este músculo durante el nado (Savage 1957, ver apartado de escápula). La marcada inclinación proximal de este tubérculo, compartida por las especies de Lontra y optimizada como una sinapomorfía de los integrantes del género (Apéndice 3.15, c. 36, estado 1), por lo que podría ser informativo desde el punto de vista filogenético o similitudes en estilos de nado, aunque también debe ser considerada una condición muy similar en el lutrino no sudamericano Lutra lutra (taxón no incluido en esta optimización). En linajes fosoriales (e.g., melinos, taxidinos, mefítidos) el tubérculo menor es amplio pero no proyectado, posiblemente potenciando en mayor medida la función estabilizadora del músculo más que aductora o rotadora.

Las áreas de orígenes humerales de los mm. triceps brachii, en el sector caudal de la diáfisis proximal del húmero, son rugosas y profundas en las nutrias, especialmente en Lontra, y moderadamente excavadas en Galictis, Ei. barbara y $M$. frenata. Algo similar puede observarse para el área de origen del $\mathrm{m}$. triceps brachii caput longum y caput angulare sobre el margen y ángulo caudal de la escápula. En el caso de musteloideos en general, el mayor desarrollo se presenta en nutrias y tejones. Estos músculos son los principales extensores del codo. Su gran desarrollo en nutrias habla nuevamente de los poderosos esfuerzos de propulsión que realizan al extender los miembros anteriores en un medio denso (Willemsen 1992, Fish 1994, 2001, Peigné et al. 2008). La misma función (aunque al parecer en forma menos marcada) es necesaria durante el trepado vertical en la locomoción arbórea en Ei. barbara, en donde es necesario una extensión del brazo controlada durante la fase de apoyo en posturas agazapadas al ascender o descender de los árboles (Taylor 1974, Van Valkenburgh 1987, McClearn 1992); también es necesaria durante el cavado en Galictis cuja, contraponiéndose a la resistencia del terreno (Quaife 1978, Moore et al. 2013). Es interesante notar que los orígenes humerales del $\mathrm{mm}$. triceps brachii no se encuentran tan desarrolladas en Ly. patagonicus como en otros halfbounders de galerías (e.g., Galictis, muchas especies de Mustela), pese a que este grupo muscular es activo en estar marchas, colaborando en la absorción del impacto luego de cada salto. Junto a este rasgo, como ya se comentó en la sección 4.3.4, Escápula, se registra, en función de la menor proyección craneal de la fosa supraspinal, un menor esfuerzo de extensión del m. supraspinatus sobre la articulación del hombro. Es probable que el menor peso de $L y$. 
patagonicus (ver Hildebrand 1988, Heinrich y Biknevicius 1998) y/o la menor frecuencia de otras actividades que requieren una extensión poderosa (cavar, trepar, propulsión durante galope) estén influenciando esta variante.

\section{Sector distal}

En lo que respecta al sector distal del húmero, las nutrias se destacan por poseer el epicóndilo medial marcadamente desarrollado en dirección medial y distal (ver Fig. 3.7), lo que extiende el área de origen y aumenta la ventaja mecánica de músculos flexores digitales y flexores y pronadores del carpo (e.g., m. flexor digitorum profundus, cabezas humerales; Jenkins 1973, Argot 2003b, Peigné et al. 2008). Esto se condice con los esfuerzos de propulsión necesarios durante el desplazamiento en el agua (Savage 1957, Willemsen 1992, Peigné et al. 2008). Los demás mustélidos sudamericanos presentan un desarrollo moderado de esta estructura, algo más importante en el trepador Ei. barbara que en los hurones (ver Fig. 3.7). Por otro lado, el desarrollo del sector proximal del epicóndilo medial es relativamente importante en Lontra spp., y extremo en Pt. brasiliensis, resultando en un área de origen sobredesarrollada del m. pronator teres (Peigné et al. 2008; ver sección 3.1.8). Este es el principal músculo pronador del brazo, y permite, en conjunto con el bajo desarrollo de la tróclea y la redondez del capitulo, poderosos y amplios movimientos fuera del plano parasagital (Taylor 1974, Holmes 1980, Argot 2003b). En lo que respecta a otros mustélidos sudamericanos, Ei. barbara presenta la tróclea más baja y la zona de inserción del $\mathrm{m}$. pronator teres más robusta, pero estos cambios son sutiles con respecto a lo esperable a priori según lo descripto para animales trepadores de otros grupos (e.g. Szalay y Sargis 2001, Argot 2003b), siendo el capítulo más bien cilíndrico (aunque ligeramente expandido en su sector central; Apéndice 3.15, c. 40). Esta morfología es clásicamente interpretada como indicadora de una poca importancia de las libertades de movimientos fuera del plano parasagital, e.g., supinación (Argot 2003b, Peigné et al. 2008). En prociónidos derivados (Procyonidae - Potos), la morfología del capítulo es incluso más aproximada a un cílindro (Apéndice 3.15, c. 40, estado 0), alejandose de un perfil globoso, destacándose entonces una morfología considerada típicamente como no compatible con movimientos de pronación y supinación amplios en grupos en los cuales otros rasgos osteológicos (morfología de la cabeza del radio, ver más adelante) y estudios comportamentales (e.g., McClearn 1992) sugieren lo contrario. El relativamente bajo grado de integración entre la morfología del radio proximal y del capítulo del húmero en musteloideos sugerido por Fabre et al. (2014), y una mayor correlación entre la pronación-supinación y el desarrollo lateromedial del capitulo más que otros rasgos en musteloideos (Fabre et al. 2013a), puede explicar estos puntos. Pteronura brasiliensis por un lado y muchos guloninos incluyendo a Ei. Barbara por otro, comparten un surco sobre el sector proximal del margen medial del epicóndilo, posiblemente de valor filogenético. Al comparar Galictis spp. y Ly. patagonicus con Mu. 
frenata, los lincodontininos presentan zonas articulares y específicamente trócleas más altas, impidiendo la rotación de la ulna sobre su eje y sugiriendo restricciones a los movimientos fuera del plano parasagital del codo (Taylor 1974, Holmes 1980, Szalay y Sargis 2001, Andersson 2003), aunque esto no queda sintetizado en los primeros dos ejes del análisis de forma del extremo distal del húmero (Fig. 3.7, pero ver Lámina 3.9). Por otro lado, los lincodontininos también presentan epicóndilos más robustos y capítulos más redondeados (parcialmente sintetizado en optimizaciones, Apéndice 3.15, c. 40, estado 1 vs. 0), indicando mayores fuerzas y libertades de movimientos de supinación/pronación (Argot 2003b, Peigné et al. 2008). El mayor rango de supinación/pronación y desarrollo del área de origen de los m. flexores digitorum profundus en Galictis y especialmente $L y$. patagonicus respecto a Mu. frenata, posiblemente se relacione a mayores capacidades de grasping, variantes en el estilo de caza, o excavación eventual en el caso de Galictis (ver sección 4.3.4, Autopodio anterior). La exacerbación relativa de estos rasgos en Ly. patagonicus, en conjunto con el valor llamativamente elevado obtenido para el índice LMcIII/LFIII y otros rasgos del autopodio anterior (ver sección 4.3.4, Autopodio anterior), podrían ser indicativo de grandes capacidades de manipulación o grasping.

En musteloideos en general, se observa que los representantes de linajes fosoriales, nadadores y trepadores presentan un gran desarrollo del epicóndilo medial, claramente mayor que el observado en half-bounders (Fig. 3.7), indicando mayores esfuerzos de pronación del codo, y mayores áreas de orígenes para muchos flexores carpales y digitales (Jenkins 1973, Argot 2003b, Peigné et al. 2008, Argot y Babot 2011, Ercoli y Schutz 2012, Samuels et al. 2013, Rose et al. 2014). Potos flavus, y otros trepadores como Nasua spp. y Ai. fulgens, muestra un amplio desarrollo medio-distal del epicóndilo medial, obteniendo una posición en el morfoespacio del análisis del húmero cercana a la de los cavadores más especializados (e.g., Taxidea taxus) y nadadores (desplazados hacia valores negativos del PC2; Fig. 3.7), indicando libertades de pronación y movimientos complejos del carpo más similares a cavadores y nadadores que a otros trepadores como Procyon spp. y guloninos, seguramente en relación a estrategias de trepado mucho más especializadas (incluyendo la prensión, para el caso de Potos y Ailurus) o mayores habilidades fosoriales (para el caso de Nasua) en comparación con otros linajes de musteloideos (McClearn 1992, Lemelin 1999, Antón et al. 2006, ver mas arriba). La rugosidad y extensión distal del epicóndilo medial, es particularmente destacable en especies cavadoras, permite un origen extenso de los flexores digitales profundos humerales, rasgo destacable para Ta. taxus (ver también Quaife 1978, Moore et al. 2013) y, en conjunto con el ancho relativo del extremo distal del húmero, rasgos diagnósticos del grado de especialización al cavado (Samuels et al. 2013, Rose et al. 2014). 
Una cresta del epicóndilo lateral amplia lateromedialmente se reconstruye como plesiomórfica para Arctoidea (Apéndice 3.15, c. 38, estado 1), mientras que una cresta reducida se observa en Mustelidae - Taxidea - Meles y, convergentemente, en algunos géneros de mefítidos (Spilogale) y prociónidos (Bassariscus, no incluido en optimizaciones). En Lutrinae existe una reversión a una cresta amplia. A su vez, en las nutrias, a diferencia de arctoideos basales, el epicóndilo lateral, junto con el sector medio y distal de la cresta lateral, se encuentran ampliamente desarrollados; en Pt. brasiliensis presenta estos rasgos más marcados y el epicóndilo se encuentra elevado. Estos rasgos de forma se reflejan en la segregación de los lutrinos hacia valores negativos del PC2, diferenciándose significativamente de los restantes musteloideos (Fig. 3.7, Apéndice 3.8C2). La hipertrofia de estas estructuras permite incrementar el área de origen de los principales extensores carpales y digitales, abductores del carpo (e.g., m. extensor carpi ulnaris, $\mathrm{m}$. extensor carpi radialis, $\mathrm{m}$. extensor digitorum communis y $\mathrm{m}$. extensor digitorum lateralis), supinadores ( $\mathrm{m}$. supinator, $\mathrm{m}$. brachioradialis) y flexores del codo (e.g., $\mathrm{m}$. brachioradialis, pero ver más abajo) que permiten extender las membranas interdigitales al comienzo y durante la brazada y posicionar las manos durante el padding en la propulsión y cambios de dirección (Savage 1957, Tarasoff et al. 1972, Schutz y Guralnick 2007). En el sector caudal de esta cresta se origina el $\mathrm{m}$. anconeus, extensor y estabilizador de la articulación del codo (especialmente entre húmero y ulna; Fisher et al. 2009), el cual es esperable que se encuentre desarrollado en nutrias, dados los amplios movimientos del codo permitidos por la zona articular relativamente poco restrictiva y los enormes esfuerzos necesarios al desplazarse en el agua (Savage 1957; ver arriba). Eira barbara presenta una cresta menos amplia lateromedialmente en comparación con las nutrias, reteniendo la morfología adquirida en el nodo Mustelidae - Taxidea - Meles (Apéndice 3.15, c. 38, estado 0), pero más elevada en comparación con otros mustélidos sudamericanos. La extensión proximal de la cresta en esta especie es muy similar a lo observado en otro guloninos medianos o grandes, prociónidos, y Ai. fulgens, y podría relacionarse tentativamente a una mayor ventaja mecánica del $\mathrm{m}$. brachioradialis (flexor del codo originado en el sector proximal de la cresta), como ha sido descripto en otros linajes trepadores, lo cual es necesario para subir o descender con el cuerpo próximo al sustrato durante el trepado, aumentando la estabilidad y el control de movimientos (e.g., Taylor 1974, Van Valkenburgh 1987, Argot 2001, Szalay y Sargis 2001). En estudios miológicos de nutrias de otros continentes (incluyendo a Lo. canadensis; Cuvier y Laurillard 1849, Macalister 1873a, Fisher 1942, Howard 1973) se ha demostrado una modificación importante del $\mathrm{m}$. brachioradialis, el cual se origina exclusiva o mayormente desde el sector proximal del húmero en vez de (o además de, en el caso de Lontra) la cresta del epicóndilo lateral, al parecer maximizando su ventaja mecánica y longitud, y por ende, fuerza y rango de supinación y flexión durante el nado. Por lo tanto, la extensión proximal de la cresta de las 
nutrias, menor a la de guloninos y muchos otros grupos trepadores y cavadores (ver Fig. 3.7), debe ser entendida como respuesta a la migración proximal del área de origen del $\mathrm{m}$. brachioradialis (ver sección 4.1.2), y no necesariamente como una reducción de la ventaja mecánica o desarrollo de este músculo.

Por otro lado, muchas especies fosoriales (e.g., la mayoría de los mefítidos, tejones, Nasua), retienen una morfología probablemente establecida en la base de Arctoidea (ver Apéndice 3.15, c. 38, estado 1), y presentan crestas epicondilares similar o aun más expandidas proximalmente y ensanchadas especialmente en su sector proximal, permitiendo una flexión incluso más poderosa que la descripta para trepadores derivados, sin existir una diferencia morfológica significativa entre ambos grupos locomotores para los dos primeros ejes del análisis morfogeométrico del extremo distal del húmero (Fig. 3.7, Apéndice 3.8C2). Por otro lado, sobre el PC3 de este análisis (resultado no mostrado) existe una segregación entre ambos grupos locomotores vinculado a la mayor expansión del sector proximal de la cresta del epicóndilo lateral y del epicóndilo medial en los cavadores (ver también Rose et al. 2014). En Galictis spp. (ver apartado de disección de Galictis cuja), y secundariamente en Mustela frenata, la morfología de la cresta es la típicamente presente en mustélidos no tejones, i.e. moderadamente amplia y alargada, forma que se habría establecido en el ancestro común entre guloninos y hurones (Apéndice 3.15, c. 38, estado 0); de esta manera, ambas especies se ubican cercanas al consenso en análisis de forma, ver Fig. 3.7). En estas especies, la extensión de esta cresta parece relacionarse al desarrollo del área de origen del $\mathrm{m}$. anconeus, y no tanto con los extensores y supinadores del carpo y dígitos, dado que sólo ocupan el sector marginal de la cresta en vista craneal (e.g., Lámina 2.11A). Una cresta similar o un poco más breve se observa en otros mustelinos e ictoniquinos, exceptuando el ictoniquino cavador skunk-like Ictonyx striatus, que presenta una cresta de epicóndilo lateral aun más amplia (Fig. 3.7; aunque sin embargo codificada como estado 0 en el c. 38; ver Apéndice 2.10). Es destacable el grado extremo de reducción que presenta la cresta de Ly. patagonicus, así como otras estructuras de inserción muscular de húmero distal, característica única dentro de Musteloidea, y sólo semejante a especímenes de algunas de las especies de Mustela más pequeñas, las cuales convergen en valores extremos negativos del PC1 y positivos del PC2 en el análisis de forma del húmero (Fig. 3.7). Estas características pueden nuevamente ser relacionadas en forma tentativa a la reducción o ausencia de actividades como el cavado o trepado (y por lo tanto de estabilizadores, y extensores del carpo; Szalay y Sargis 2001, Argot 2003b, Ercoli et al. 2012, pero ver más arriba desarrollo de epicóndilo lateral y supinadores), un máximo grado de especialización a estrategias half-bound (Fig. 3.7) y/o cuestiones alometrías.

Todos los mustélidos sudamericanos presentan el margen lateral del capítulo moderadamente elevado, excepto Pt. brasiliensis, en la cual éste es claramente más bajo que el 
resto del capítulo. En un marco comparativo más amplio, grupos fosoriales como los Mephitidae, Taxidiinae y Melinae, presentan un margen lateral del capítulo elevado, mientras que suele ser algo menor en algunos trepadores (e.g., algunos Procyonidae) y aun menor en nadadores (i.e., Lutrinae), lo cual queda parcialmente sintetizado en el PC2 del análisis de forma del húmero (Fig. 3.7). La elevación del margen lateral de la zona articular (denominado capitular tail o capitular flange) hace las veces de "tope", aumentando el área de contacto y limitando el rango de movimientos laterales del radio sobre el húmero (Szalay y Sargis 2001, Argot 2003b, Argot y Babot 2011). La presencia de un capitular tail elevado, en conjunto con un capítulo redondeado, en tejones y mefítidos indica movimientos de pronación y supinación poderosos (Quaife 1978, Moore et al. 2013) pero restringidos, evitando la desarticulación del codo durante el cavado. Por otro lado, un capitular tail reducido o ausente, sumado a un margen medial de la tróclea breve y un capítulo redondeado en nutrias (extremo en Pt. brasiliensis) y Po. flavus indica movimientos fuera del plano parasagital poderosos y amplios (como también fue sugerido por la morfología de los epicóndilos, pero ver restricciones en el radio de lutrinos más adelante), útiles durante el trepado en sustratos inestable o movimientos complejos durante el nado (Taylor 1989, Argot 2003b, Egi et al. 2007, Peigné et al. 2008, Argot y Babot 2011). En trepadores menos especializados y especialmente en terrestres, esta estructura se encuentra en general moderadamente desarrollada, y el capítulo es más bien cuadrangular, ubicándose en valores positivos del PCA2 (Fig. 3.7), siendo relativamente menos importantes los movimientos de supinación en estas especies. Por otro lado, es necesario reconocer que tanto la morfología del capítulo en la región articular del húmero como la cabeza proximal del radio son informativas respecto a los movimientos de pronación y supinación del codo, la morfología de estas estructuras no están tan estrechamente integradas (ver Fabre et al. 2014), y en algunos linajes, el análisis morfo-funcional de una de ellas indica libertades de movimientos diferentes al sugeridos por la otra estructura (e.g., Lutrinae). Este punto es retomado en el análisis de la morfología del radio (sección 4.3.4, Ulna y radio).

Las variantes en el foramen supracondiloideo son pocas. Dentro de las especies descriptas, Pt. brasiliensis se destacó por la breve extensión próximodistal del mismo. Mustela frenata presentó un foramen supracondiloideo relativamente pequeño y distal, similar a otras especies del género. La delimitación medial del mismo se encontró en algunos casos de Lontra (para algunos elementos de Lo. provocax y Lo. felina), un caso para Ei. barbara, y Mu. frenata, sin revestir ninguna implicancia funcional aparente (ver Apéndice 3.15, c. 39). En musteloideos en general, la ausencia de la delimitación medial se da exclusiva y constantemente en mefítidos, siendo reconstruido como una sinapomorfía del grupo (Apéndice 3.15, c. 39, estado 0; convergente con Canidae), y resultando informativo desde el punto de vista filogenético (Mivart 1885, Bryant et al. 1993). La ausencia del foramen en los únicos tres húmeros de Lo. felina 
analizados, y en el 33\% de los elementos de Lo. provocax también podría resultar de interés para la determinación de restos fragmentarios.

Una fosa olecraneana bien delimitada, profunda y poco extendida proximalmente tiende a estar presente en lincodontininos y $\mathrm{Mu}$. frenata (así como otros mustelinos). Morfologías similares han sido interpretadas como ventajosas para la estabilización del codo y evitar el colapso o desvíos del plano parasagital durante los momentos de máxima extensión (Szalay y Sargis 2001), funciones seguramente requeridas durante el desplazamiento en galerías (Horner y Biknevicius 2010). Ambas especies de Galictis y Ta. taxus son los mustélidos comparados que presentan más frecuentemente una fosa radial (indiferenciada de la coronoides) perforada y comunicada con la fosa olecraneana, o apenas separadas por una lámina translucida de hueso. Esto también fue observado en algunos especímenes de Martes, Meles, Ictonyx, y Poecilictis, así como en algunos ictoniquinos fósiles (e.g., ${ }^{\dagger}$ Trigonictis macrodon UM 53556). Muchas de estas especies se desplazan mediante posturas agazapadas en túneles de estrechos y realizan importante esfuerzos braquiales (cavado y/o trepado; Long 1973, Yensen y Tarifa 2003a, b, Wilson y Mittermeier 2009, Moore et al. 2013), requiriendo un amplio rango de flexo-extensión en el codo, y resultando esta demanda en la conexión de las fosas radial y olecraneana (Taylor 1974, Argot 2003b, Heinrich y Houde 2006, Moore et al. 2013; ver explicación detallada en Apéndice 4.1G).

La fosa para el ligamento del olécranon (fosa postcondilar de Riggs 1945) es profunda y está separada de la fosa olecraneana mediante un tabique divisor en Ei. barbara, la mayoría de los especimenes de Lontra spp. (no tan profunda en Lo. provocax) y Pt. brasiliensis. Es somera y está separada de la fosa olecraneana por un cambio de pendiente en las otras especies de América del Sur analizadas. Una fosa para el tendón del olécranon profunda y definida también fue observado en especies de otros continentes como nutrias (e.g. Ao. cinerea, Lutrogale perspicillata, excepto Enhydra lutris; ver Peigné et al. 2008), Mustela vison, guloninos (e.g. Martes), Meles spp., y Mellivora capensis, y menos diferenciada en otras Mustela, Melogale, y mefítidos. Dada la función del ligamento, que limita la flexión total evitando el colapso de la articulación del codo, un mayor desarrollo del mismo es esperable en especies de mayor tamaño o que realizan grandes esfuerzos en una posición flexionada del codo, como los realizados durante el nado, el cavado y el trepado vertical y el descenso de cabeza (Engelke et al. 2005, Peigné et al. 2008). También existen muchas excepciones a este argumento, posiblemente relacionadas a cuestiones de valor filogenético, como destacó Riggs (1945), aunque la optimización no sustenta un origen por ancestría común de este rasgo (Apéndice 3.15, c. 41, estado 1), excepto en forma ambigua para Lutrinae y un nodo interno del clado Mustelinae).

En el análisis de forma del húmero, además de evidenciarse una relación significativa entre los hábitos locomotores y la forma del elemento, existió una relación significativa con los 
hábitos dietarios (Fig. 3.6, Apéndice 3.8C1). Las especies menos especializadas en la carnivoría presentan regiones de inserción muscular más desarrolladas y un cóndilo articular más bajo y amplio lateromedialmente. Comportamentalmente, el grado de manipulación de las presas no parece ser un factor que diferencie a "carnívoros" de "omnívoros", dado que en ambos grupos dietarios existen especies con alta capacidad de manipulación (e.g., lutrinos y Potos flavus respectivamente; McClearn 1992, Kruuk 2006, Wilson y Mittermeier 2009). Es probable que esta relación sea consecuencia, por un lado, de una fuerte estructura filogenética a nivel familiar de la forma y los hábitos dietarios, y por otro lado, una correlación entre los hábitos locomotores y la dieta, dado que la mayoría de las especies trepadoras y fosoriales tienden a explotar más frecuentemente items vegetales e insectos, y la mayoría de las especies acuáticas, y todas las half-bounders son fundamentalmente carnívoras.

\subsubsection{Ulna y radio}

La curvatura del sector proximal de la diáfisis ulnar (incluyendo al olécranon) ha sido relacionado en muchos grupos de Carnivora con la ventaja mecánica del $\mathrm{m}$. triceps brachii y con la posición habitual del codo (e.g., Taylor 1974, Van Valkenburgh 1987, Ercoli et al. 2012). La ulna tiende a presentarse levemente curvada en dirección craneal en musteloideos trepadores y más bien recta en terrestres, mientras que sólo se registran cambios de curvatura destacables en las especies con mayor especialización a un sustrato particular (e.g., Ailurus fulgens, Potos flavus, Pt. brasiliensis, ver a continuación). No sólo la relación morfo-funcional es poco clara para la mayor parte de la muestra analizada, sino que incluso la curvatura es variable a nivel intraespecífico (e.g., distintos especímenes de Lyncodon patagonicus) e incluso intraespécimen (e.g., Martes martes MU 3). Otros autores han relacionado la forma y curvatura de la ulna a cuestiones alométricas (e.g., Fabre et al. 2013b; Martín-Serra et al. 2014). Por todo esto, la importancia de la relación de la forma de la ulna con los hábitos locomotores debe ser relativizada en este nivel de análisis.

\section{Olécranon y sector proximal del antebrazo}

En todos los lincodontininos y mustelinos, el olécranon es moderadamente robusto y desarrollado cráneocaudalmente. Debido a sus especializaciones relativas a cazar en galerías, los hurones presentan miembros cortos y específicamente antebrazos reducidos $(\mathrm{LaRa} / \mathrm{LaHu}<$ 0,75; Fig. 3.1F, Tabla 2.3). En relación a esto, una marcada reducción del antebrazo es optimizada como una adquisición del ancestro común del clado Ictonychinae + Mustelinae + Lutrinae (Apéndice 3.15, c. 3, estado 0,744-0,767), y una condición reducida menos extrema puede rastrearse incluso en nodos más basales. Las nutrias presentan una morfología similar aunque poseen un olécranon algo (Lo. longicaudis) a marcadamente mayor (Lo. felina, Lo. provocax y Pt. brasiliensis) en sentido proximodistal, tanto en relación al área articular, como al 
largo total del elemento. El gran desarrollo y longitud relativa del olécranon en las nutrias (ver también Fisher 1942, Van Valkenburgh 1987, Peigné et al. 2008), similar o mayor a especies semifosoriales como Meles meles (Schutz y Guralnick 2007, Peigné et al. 2008), se relaciona a un incremento de la ventaja mecánica de los músculos que se insertan en su extremo, las cabezas del m. triceps brachii, i.e., los principales extensores del codo (Argot 2001, Salesa et al. 2008). En las nutrias, y secundariamente en los hurones, el potencial de fuerza que pueden ejercer estos músculos es incrementado a su vez por la reducción del brazo de palanca de salida: la reducción de la longitud del antebrazo (largo funcional de la ulna y radio; $\mathrm{LaRa} / \mathrm{LaHu}<0,75$; Fig. 3.1F, Tabla 2.3; Maynard Smith y Savage 1956, Peigné et al. 2008). En el caso de las nutrias, esta configuración se debe a los enormes esfuerzos de extensión de los brazos durante el nado al desplazar un medio denso durante las brazadas (Willemsen 1992, Fish 1994, 2001). En el caso de los hurones, la ventaja mecánica de estos extensores del codo permitiría la propulsión adecuada durante caminatas y trotes de zancadas amplias (Horner y Biknevicius 2010), así como resistir los impactos durante la locomoción a saltos (Taylor 1974, Gambaryan 1974; sección 4.1.2), aunque también podría entenderse simplemente como una consecuencia de la reducción de los miembros en relación al ingreso en galerías estrechas. En concordancia con esto, el grado de robustecimiento y proyección medial de la esquina caudomedial del olécranon es mayor en nutrias (extremo en Pt. brasiliensis) que en hurones y más aun comparado con Ei. barbara. El olécranon inclinado marcadamente en sentido caudal en Pt. brasiliensis, indica una posición habitual extendida de la articulación (Van Valkenburgh 1987, Argot 2001, Salesa et al. 2008, Ercoli et al. 2012) en comparación con Lontra spp. y otros mustélidos comparados, relacionado con su estilo y grado especialización al buceo veloz (Fish 1994, Kruuk 2006, Lewis 2008).

El desarrollo areal de la superficie proximal del olécranon, especialmente en su esquina caudomedial, permite una mayor área de inserción de las cabezas largas del m. triceps brachii, especialmente de la cabeza medial, larga y angular (Salesa et al. 2008, Peigné et al. 2008, sección 3.1.8). Esta configuración permite una mayor fuerza de extensión del codo mientras los miembros apuntan hacia atrás durante el nado. La superficie proximal del olécranon está más desarrollada en nutrias especializadas al nado (e.g., Fisher 1942, Samuels et al. 2013) que en Aonyx cinerea. Enhydra lutris es una excepción debido a la ausencia de la utilización de los miembros anteriores como principales propulsores durante su estilo de nado (Tarasoff et al. 1972, Holmes 1980). Una morfología del olécranon elongada y curvada en sentido medial también ocurre en musteloideos especializados o frecuentes cavadores (mefítidos, Nasua nasua, Meles meles, Taxidea taxus), lo que estaría relacionado a los enormes esfuerzos de extensión del codo durante la excavación (Holmes 1980, Van Valkenburgh 1987, Hildebrand 1988, Salesa et al. 2008, Moore et al. 2013). 
Eira barbara, contrariamente a otros mustélidos sudamericanos, presenta una morfología similar a otros guloninos (especialmente los de mayor tamaño) y prociónidos (e.g., Procyon spp., Potos flavus), con el olécranon relativamente breve y la diáfisis alargada. En estas especies trepadoras o arborícolas no son requeridos grandes esfuerzos de extensión en posición semi-extendida del codo como en otras actividades (e.g., excavación, natación). Durante el ascenso o descenso, los trepadores mantienen una posición agazapada, los codos no son extendidos en gran medida durante la fase de apoyo, y la flexión del codo toma importancia. En consecuencia, se priorizan los movimientos rápidos y la longitud de los miembros para el soporte sobre un sustrato irregular y tridimensional por sobre una poderosa extensión (Taylor 1974, Van Valkenburgh 1987, McClearn 1992, Fabre et al. 2013a). La ausencia de un olécranon curvado cranealmente indica que Ei. barbara no adopta posiciones agazapadas tan marcadas como trepadores más especializados (e.g., Ailurus fulgens, Potos flavus; Taylor 1974, Van Valkenburgh 1987, Argot 2003b, Ercoli et al. 2012).

\section{Regiones articulares proximales del radio y la ulna}

La región articular de Ei. barbara se destaca, entre los mustélidos sudamericanos, por presentar un proceso ancóneo altamente asimétrico, con su margen lateral proyectado en mayor grado en sentido proximal. Esta característica, plesiomórfica para Arctoidea y modificada a un proceso ancóneo simétrico en la base de Musteloidea (Apéndice 3.15, c. 42, estado 0), se encuentra presente y reconstruida como una reversión en Guloninae (ver Gulo gulo en Argot 2003b), y convergentemente en el único espécimen de Poecilictis libyca en que se pudo constatar (Apéndice 3.15, c. 42, estado 1), mientras que algun grado de asimetría puede sugerirse en otros en otros mustélidos basales (e.g., Meles meles, Mellivora capensis, Taxidea taxus), siendo potencialmente de valor filogenético. En otros musteloideos, este proceso es simétrico o sólo ligeramente asimétrico (esto último en algunos mustelinos e ictoniquinos). Funcionalmente, esta característica permite aumentar el contacto con la cara lateral y caudal del cóndilo humeral, actuando como un límite a la excursión medial de la ulna durante rotación sobre su eje y la supinación (Taylor 1974, Argot 2003b). La ausencia de esta característica en otros musteloideos trepadores o cavadores (e.g. prociónidos, mefítidos), y la presencia de una morfología similar pero exagerada en Ursus americanus (Argot 2003b), relativiza su importancia adaptativa a otras variables (filogenia, estilo de trepado o cavado, tamaño corporal).

En hurones el proceso ancóneo es estrecho y con un quiebre de pendiente amplio, imponiendo limitaciones mayores a los movimientos de rolido de la ulna sobre el húmero. En las nutrias, la superficie articular del proceso ancóneo es amplia pero sin cambios de pendientes tan abruptos como en los hurones, indicando un mayor grado de movilidad de la ulna sobre el húmero (Argot 2003b), coincidiendo con lo observado en el húmero (ver más arriba). En Pt. brasiliensis se registran un gran número de cambios particulares en la región de la articulación 
del codo (como también fue descripto en el húmero para el caso de la articulación del hombro y codo; sección 4.3.4, Húmero): la incisura troclear es somera, el proceso ancóneo y coronoides son más bien aplanados y reducidos, imponiendo pocas limitaciones a los movimientos potenciales del codo (Taylor 1974, Argot 2003b), como también fue observado en el hombro (ver más arriba).

La articulación proximal del radio presenta una forma subcuadrangular a arriñonada en lutrinos, mustelinos e ictoniquinos comparados de América del Sur, con una pronunciada escotadura sobre el sector cráneolateral de su margen (capitular eminesence; Heinrich y Rose 1997), así como una elevación craneal (la cual encaja en el margen medial del cóndilo humeral; Taylor 1974, Heinrich y Rose 1997, Salesa et al. 2008). El plano de contacto entre la ulna y el radio (incisura radial de la ulna) es sólo ligeramente cóncavo y tiene una posición cercana a los $45^{\circ}$ respecto al plano sagital. Estas características, sin afectar el rango de flexión y extensión de la articulación, estabilizan y reducen el rango de rotación del radio sobre el húmero y ulna (ver más adelante, Taylor 1974, MacLeod y Rose 1993, Heinrich y Rose 1997, Argot 2003b, Fabre et al. 2013a). En Lo. provocax y Pt. brasiliensis, el tubérculo cráneolateral contiguo a dicha escotadura se encuentra marcadamente pronunciado, posiblemente indicando un mayor desarrollo del ligamento colateral del radio, que mantiene unida la articulación del codo. Es interesante destacar que en los taxones con mayores habilidades fosoriales ( $G a$. cuja respecto a los demás hurones y potencialmente Lo. provocax respecto a Lo. longicaudis) la elevación craneal de la articulación proximal del radio es mayor, en relación a una mayor estabilización de la articulación y restringiendo el grado de rotación (Taylor 1974, Fabre et al. 2013a), permitiendo resistir fuerzas no compresivas durante el cavado. Contrario a los otros mustélidos sudamericanos, Ei. barbara muestra una superficie articular proximal del radio mayormente redondeada, y un contacto entre ésta y la ulna mucho más lateralizado y cóncavo, indicando mayores de libertades de rotación del radio sobre la ulna, y menor participación del radio en el soporte del peso corporal, algo típico de animales trepadores que requieren importantes movimientos de supinación y pronación y un mayor control muscular y ligamentario (e.g., m. anconeus, ligamentos) al desplazarse por un substrato complejo e inestable (Taylor 1974, McLeod y Rose 1993, Argot 2003b, Antón et al. 2006, Peigné et al. 2008).

Con respecto a la posición relativa del radio con respecto a la ulna, los musteloideos presentan gran variación, aunque esta no alcanza los extremos de otros carnívoros (e.g., cánidos cursoriales y vivérridos y herpéstidos arborícolas; Taylor 1974, Argot 2003b). Las especies trepadoras (y algunas nadadoras) presentan un contacto con el radio más bien lateralizado y cóncavo. La optimización de este rasgo (Apéndice 3.15, c. 43, estado 1) sugiere que esta articulación adquirió una inclinación de $45^{\circ}$ respecto al plano de la diáfisis ulnar en el ancestro común de Procyonidae (siendo un ejemplo extremo es Procyon spp.) o incluso se corresponde a 
un rasgo plesiomórfico de Arctoidea (reconstrucción ambigua) y convergentemente adquirida en algunos lutrinos (Enhydra + Aonyx). Por otro lado, los linajes terrestres y fosoriales especializados presentan un radio predominantemente craneal a la ulna y un contacto plano, siendo Meles meles el extremo opuesto de esta variación.

\section{Longitud relativa del antebrazo y morfología del sector medio de la ulna y el radio}

El índice braquial ( $\mathrm{LaRa} / \mathrm{LaHu})$ no permite separa los principales grupos dietarios o locomotores, aunque esto sí ocurre (aunque sutílmente), cuando se tiene en cuenta la estructura filogenética en el caso de estos últimos (Tabla 3.6; Apéndices 3.8F, 3.9F). Este último resultado se contrapone a los resultados de Iwaniuk et al. (2000; obtenidos en un contexto comparativo más amplio, a nivel Carnivora) y revela una señal funcional oculta en el análisis sin control filogenético consecuencia de similitudes debidas a ancestría común (ver sección 4.5). Los box plots a su vez indican tendencias y casos específicos de interés. A simple vista, tanto la ulna como el radio son huesos relativamente gráciles y pequeños en ictoniquinos half-bounders y mustelinos, especialmente en el caso de Ly. patagonicus, moderadamente robustecidos y elongados en Ei. barbara, y en extremo robustos y breves en nutrias.

En los hurones las diáfisis son mayormente aplanadas y la ulna, en particular, es progresivamente más delgada distalmente (en extremo en el caso de Ly. patagonicus). La diáfisis ulnar y radial son regiones de origen de muchos de los principales músculos que mueven la muñeca y los dígitos (sección 3.1.8). Entre los hurones sudamericanos, Ga. cuja presenta la diáfisis ulnar y radial más robustas y las áreas de orígenes más marcadas. Sobre la ulna, las áreas de origen del $\mathrm{m}$. abductor digiti I longus y $\mathrm{m}$. pronator quadratus se encuentran bien delimitadas y moderadamente extendidas en Ga. cuja. Sobre el radio, las regiones de inserción del $\mathrm{m}$. pronator quadratus, del $\mathrm{m}$. pronator teres y $\mathrm{m}$. supinador, son áreas marcadas y relativamente extendidas. Esta especie es seguida en importancia de estos rasgos por $M u$. frenata. y finalmente por Ly. patagonicus, que presenta el menor desarrollo de estas áreas, especialmente la del $\mathrm{m}$. pronator quadratus, que está restringida al sector distal de las diáfisis, y la del m. supinator, debido al marcado angostamiento lateromedial del radio. En el hurón menor, el mayor desarrollo de la musculatura originada en el zeugopodio indica una mayor producción de movimientos complejos de la muñeca y los dígitos respecto a otros hurones, posiblemente en relación a la excavación o grasping, y una participación comparativamente más importante de la ulna en el soporte del peso corporal (Argot 2003b, Heinrich y Houde 2006). Una cresta de origen del $\mathrm{m}$. pronator quadratus breve y sólo amplia distalmente, morfología presente en los ictoniquinos pequeños como Ly. patagonicus y Poecilictis libyca, se relaciona más con una mayor estabilización de la articulación que a una pronación marcada. El desarrollo del área origen del m. pronator quadratus en Ei. barbara es extensa. En esta especie se destaca también una posición proximal del ligamento interóseo, como ocurre en en Martes spp. (posición 
codificada como variable entre estado 0 y 1 del c. 44 para todos los guloninos; ver Apéndice 3.15) y en algunos prociónidos (e.g., Procyon spp., variable en Nasua nasua). Estos rasgos indican un importante rango y fuerza de movimientos de pronación, así como un reaseguro proximal para evitar la dislocación del radio proximal durante estos amplios movimientos (Taylor 1974, Heinrich y Houde 2006, Peigné et al. 2008, Argot y Babot 2011). Como una explicación alternativa (y más simple) para comprender la ubicación del ligamento interóseo, la elongación del sector distal del antebrazo propia de los trepadores podría entenderse como principal causa de la posición relativamente proximal del ligamento, pudiendo aplicarse la misma deducción a especies cursoriales (ver Apéndice 3.15, c. 44, estado 0). Esta configuración es permisiva de los movimientos requeridos para acomodar la posición de los autopodios en un sustrato desnivelado y el grasping, coincidente con lo observado en otros rasgos ya mencionados (redondez del radio proximal, posición lateralizada de la incisura radial en la ulna, área de origen del $\mathrm{m}$. pronator teres en el húmero, pero ver también restricciones articulares indicadas en apartado del húmero). El caso extremo de desarrollo máximo del área de origen del m. pronator quadratus dentro de Musteloidea está representado por Potos flavus que presenta con un origen amplio que alcanza su máximo desarrollo más proximalmente (Argot 2003b, Antón et al. 2006, Argot y Babot 2011), seguramente en relación a sus marcadas habilidades de manipulación y trepado de ramas terminales por prensión (McClearn 1992).

Las nutrias (tanto las sudamericanas como las de otros continentes), por el contrario, presentan en general un importante desarrollo de la superficie de origen para el m. pronator quadratus, que se extiende tanto proximal como distalmente, en conjunto con muescas para el ligamento interóseo distales y robustas, indicando una mayor fuerza de pronación, aunque con un límite estricto al rango de movimientos de rotación (Taylor 1974, Salesa et al. 2008). Estos rasgos representan una sinapomorfía de la subfamilia (sólo revertida en Aonyx; Apéndice 3.15, c. 44, estado 2). Peigné et al. (2008) sugirieron una menor importancia de la pronación de Pt. brasiliensis respecto a otras nutrias debido a la presencia de un $\mathrm{m}$. pronator quadratus de inserción más reducida, lo cual es corroborado en este estudio. Sin embargo, el desarrollo de este origen aun así es importante y no es muy diferente al de algunos especímenes de Enhydra, Lutra y Aonyx, haciendo evidente la necesidad de datos miológicos. El gran desarrollo de una superficie diartroidal plana en este taxón (ver más adelante), también apoya un menor rango de movimientos del radio sobre la ulna. Por otro lado, las amplias libertades de movimiento en la articulación del codo, sumado a las importantes zonas de inserción de pronadores y supinadores en el radio, demuestran la existencia de importantes movimientos fuera del plano parasagital en esta región para Pt. brasiliensis.

En lo que respecta a musteloideos de otros continentes, el mismo patrón es corroborado, más allá de la afinidad filogenética: los trepadores (guloninos, prociónidos, Ailurus fulgens) 
presentan antebrazos moderada a marcadamente elongados ( $\mathrm{LaRa} / \mathrm{LaHu}>0,74$; Tabla 2.3, Fig. $3.1 \mathrm{~F}$ ) y regiones musculares moderadamente marcadas, adaptados a movimientos ágiles y el desplazamiento en sustratos inestables (Taylor 1974, Heinrich y Houde 2006, Argot y Babot 2011). Los cavadores (tejones, la mayoría de los mefítidos, y secundariamente Melogale moschata) requieren grandes superficies de agarre muscular en el húmero, amplias ventajas mecánicas y el refuerzo de la estructura esqueletaria debido al gran estrés al que se somete esta estructura durante el cavado (Quaife 1978, Taylor 1989, Rose et al. 2014). En este grupo, las proporciones braquiales son similares a las de los trepadores (aunque siendo el húmero algo más breve; i.e., $\mathrm{LaRa} / \mathrm{LaHu}>0,79$ Tabla 2.3, Fig. 3.1F), aunque los elementos son más bien robustos y las áreas de orígenes musculares son importantes, similares en este sentido a especies nadadoras, características que les permiten la remoción poderosa del sustrato durante el cavado (ver también Rose et al. 2014). Maynard Smith y Savage (1956) propusieron que elementos distales breves favorecen la ventaja mecánica para la remoción del sustrato en especies cavadoras. Excepto en el caso atípico de Mydaus sp. (longitud del radio igual a un 51\% de la longitud del húmero; Mivart 1885), las proporciones braquiales de los musteloideos cavadores no parece concordar con esto último, sin diferenciarse significativamente de otros grupos funcionales (concordando con los resultados de Rose et al. 2014), y presentando valores de índice braquial incluso típicamente mayores que half-bounders y nadadores. Las optimizaciones (Apéndice 3.15, c. 3) refuerzan este punto, sugiriendo que estos linajes cavadores musteloideos retienen una proporción braquial cercana a la ancestral para Arctoidea (estado 0,771-0,800), más que evidenciar especializaciones fosoriales marcadas. Las enormes variantes en las proporciones intermembrales y morfológicas en general (Tabla 2.3; ver más arriba, sección 4.3.4, Escápula), indican variantes propias de distintos linajes. Sin embargo, la reducción extrema del antebrazo del mefítido Mydaus sp. (Fig. 3.1F, Tabla 2.3; Apéndice 3.15, c. 3) no puede ser explicada ni por hábitos ni por filogenia, y la proporción braquial de la especie debe ser corroborada con más fuentes que Mivart (1885).

Los elevados valores del índice braquial para Co. chinga y Procyon spp. (así como el índice crural, ver sección 4.3.5, Tibia y fíbula), reconstruidas como autopomorfías de estos linajes (ver Apéndice 3.15, c. 3), no pueden ser claramente explicados ni por sus grados de especialización al cavado y trepado (respectivamente), especialización dietaria, ni filogenia (e.g., ver taxones hermanos Co. leuconotus y Bassariscus astutus, respectivamente; Tabla 2.3). Estas proporciones llevan a estos taxones a ser outliers en los análisis de ANOVA (Apéndice 3.6F2, 3), alejándolos del patrón generalizado típico de carnívoros (ver Ewer 1973: 30). Otros factores más específicos de la historia de vida de estos taxones, podrían potencialmente dar luz a estas proporciones, e.g., adaptaciones sub-cursoriales y marchas energéticamente más económicas, o vigilancia por sobre la vegetación (ver propuestas de Hildebrand 1952 para 
Chrysocyon brachiurus; Holmes 1980 para mefítidos y Rose et al. 2014 para tejones; ver también Ewer 1973 e índices de Samuels et al. 2013).

En lo que respecta al índice braquial, Aonyx spp. se escapa del patrón típico acuático, con una ulna y radio de formas y proporciones más generalizadas (ver Tabla 2.3). Esta autopomorfía (ver Apéndice 3.15, c. 3, estado 0,839) puede relacionarse a su estilo de nado poco especializado y, eventual o excepcionalmente, capacidad de trepado (Peigné et al. 2007, Wright 2005). Como ya se comentó, los hurones (mustelinos e ictoniquinos) presentan ulnas y radios breves, en relación a la reducción de los miembros y la caza de roedores en galerías (King 1989, King y Powell 2007), en conjunto con un menor desarrollo de las áreas de orígenes musculares. Teniendo en cuenta la relación significativa entre la proporción braquial y la locomoción luego del control filogenético (Tabla 3.6, Apéndice 3.7), la máxima reducción del valor de este índice en Ly. patagonicus $(0,665)$ posiciona a la especie en cercanías a halfbounders, pero al parecer en valores no compatibles con especies trepadoras eventuales o frecuentes (Tabla 3.6, Fig. 3.1F), lo que respalda potencialmente un elevado grado de especialización a la caza de roedores en galerías.

\section{Región distal del antebrazo}

Dentro de Musteloidea, las variantes de orientaciones, formas, y desarrollos de la superficie diartroidal son muchas, sin reconocerse una interpretación sencilla de esta diversidad de formas. Una morfología sobre-elevada a modo de meseta de esta articulación habría sido la condición ancestral para Arctoidea y Musteloidea (Apéndice 3.15, c. 46, estado 1). En particular para las nutrias, la articulación diartroidal se ubica en una posición más lateral respecto a otros mustélidos, lo que sumado a la morfología del proceso estiloides, sugieren una posición habitual supinada del antebrazo (Argot 2003b). En particular, las nutrias sudamericanas presentan la articulación del proceso estiloides particularmente extendida en forma de "C", claramente definida en Lo. provocax, Lo. felina y Pt. brasiliensis, aunque no en tal grado en Lo. longicaudis. Esto indica una extensión del contacto articular a lo largo de un gran rango de movimientos de flexión y abducción de la muñeca, reasegurando estos movimientos, aunque al parecer restringiendo las libertades de rotación sobre el eje próximodistal (Argot 2003b, Salton y Sargis 2008, similar a lo inferido a partir de la superficie articular proximal del radio, ver más arriba, y en el carpo, ver más abajo, sección 4.3.4, Autopodio anterior). Esta configuración, reconstruida como una sinapomorfía de la subfamilia o alternativamente como alcanzada independientemente por los dos linajes sudamericanos (reconstrucción ambigua, Apéndice 3.15, c. 45), permitiría a las nutrias sudamericanas los movimientos de muñeca necesarios durante el padding en una posición semi-supinada (como fue registrado en nutrias de otros continentes; Savage 1957, Tarasoff 1972), en conjunto con un mayor grado de estabilización de la muñeca mediante contactos articulares amplios, evitando la dislocación de la articulación durante estos 
esfuerzos (Salton y Sargis 2008), realzando la importancia relativa de los miembros anteriores durante el nado en estas especies.

La forma del extremo distal del radio, en lo que respecta a los surcos de pasaje de tendones y la articulación con el radial, es bastante conservadora dentro de los mustélidos terrestres comparados, aunque algunas diferencias puntuales pueden destacarse, relacionados a variantes en el grado de movilidad de la muñeca. La robustez del extremo distal del radio en general es algo más importante en taxones fosoriales, y especies de gran tamaño en general, pudiendo influenciar en esta característica cuestiones alométricas y la utilización del radio como principal soporte del peso corporal, especialmente en taxones de gran tamaño y escasos movimientos fuera del plano parasagital (Salton y Sargis 2008, Fabre et al. 2013a). Al comparar a Ei. barbara con los hurones sudamericanos, se destaca la presencia de los surcos para el pasaje del $\mathrm{m}$. abductor digiti I longus, m. extensor digiti I et II más profundos en la primera, indicando la necesidad de un incremento de la sujeción de los tendones de los mismos, coincidente con los movimientos más amplios o rápidos de flexión de la articulación (Yalden 1970, Salton y Sargis 2008). El surco para el m. abductor digiti I longus se extiende caudalmente posiblemente continuándose con la zona de tránsito del $\mathrm{m}$. flexor carpi radialis, indicativo de gran rango de flexión y extensión de la muñeca. El gran desarrollo del tubérculo de inserción del m. brachioradialis indica mayor masa muscular flexora del codo y supinadora del antebrazo (Salesa et al. 2008). En las nutrias se observan un gran número de rasgos anatómicos propios (observados en Lontra spp. y Pt. brasiliensis). El extremo distal del radio es marcadamente robusto, los surcos para el pasaje de los tendones se encuentran hipertrofiados en tamaño y profundidad, el surco para el $\mathrm{m}$. abductor digiti I longus y $\mathrm{m}$. flexor carpi radialis conforman una "C" que rodea distalmente al tubérculo de inserción del $\mathrm{m}$. brachioradialis y éste último presenta el máximo desarrollo. Estas características indican amplios rangos de movimientos de flexión de la muñeca y reaseguros en la retención de los tendones en sus posiciones (ver también Yalden 1970, Argot 2003b). La morfología articular del extremo distal del radio es más irregular en nutrias que en mustélidos terrestres sudamericanos, y presenta un proceso estiloides más desarrollado, siendo más similar a lo observado en tejones como Meles meles, o Mellivora capensis que a otros musteloideos. Por otro lado, las nutrias presentan una superficie de articulación extra en el sector caudodistal del radio, que contacta al carpal accesorio en posiciones flexionadas y rotadas (supinadas) de la muñeca (características presentes en las tres especies de nutrias sudamericanas comparadas), diferenciándose de otros musteloideos (Fig. 4.2). Todas estas características, así como fue observado a lo largo del todo el antebrazo, y la región articular del codo para Lontra spp., sugieren rangos de movimientos de flexión y extensión importantes pero también trabas articulares en ciertos niveles, evitando la sobre-extensión o sobre-flexión, y restringiendo los movimientos de rotación de la muñeca, en 
relación a un máximo grado de estabilización de una posición semi-supinada durante el nado (ver Savage 1957).

La robustez del tubérculo para el $\mathrm{m}$. brachioradialis es variable, siendo marcada frecuentemente en especies cavadoras, nadadoras y especialmente en Gulo gulo, taxones en los cuales tiende a expandirse a modo de una cresta robusta. Al analizar estas características en los Musteloidea en general, se destaca que las especies terrestres plantígradas, y especialmente las fosoriales (e.g., Mellivora capensis, Meles spp.), presentan un surco para el m. abductor digiti I longus que no rodea en sentido caudodistal al tubérculo para el $\mathrm{m}$. brachioradialis ( visualizarse en vista caudal, ni comunicarse con la zona de pasaje del $\mathrm{m}$. flexor carpi radialis), en relación posiblemente a un menor rango de flexión del autopodio. Por otro lado, lo contrario ocurre en especies trepadoras o nadadoras (e.g., Gulo gulo, Martes spp., Procyon spp., lutrinae), en donde el surco rodea distalmente al tubérculo del $\mathrm{m}$. brachoradialis, permitiendo acomodar al tendón del m. abductor digiti I longus en posiciones de gran flexión de la articulación. Las zonas de pasaje de tendones y tubérculo para el $\mathrm{m}$. brachioradialis son menos amplias en general para mustelinos e ictoniquinos.

\subsubsection{Autopodio anterior}

\section{Morfología general}

En lo que respecta al autopodio en general, en los hurones es alargado (especialmente la serie metacarpal; Apéndice 2.3) en proporción al resto miembro anterior, algo ya notado por Holmes (1980). Por otro lado, en Ei. barbara el autopodio es robusto y amplio, pero más corto respecto al brazo, aunque Holmes (1980: 58) destacó que sí es elongado en relación al cuerpo. La falta de correspondencia entre las proporciones registradas en los análisis de esta Tesis y lo esperable a partir de la comparación tradicional de adaptaciones "terrestre vs. trepador" (i.e., autopodio amplio respecto al brazo; e.g., Hildebrand 1988, Taylor 1989, Argot 2003), se podría relacionar con otros factores no contemplados por estas categorías: e.g., la reducción de los huesos largos de los miembros en los hurones en relación a la locomoción en galerías (Gambaryan 1974, Moritz et al. 2007, Horner y Biknevicius 2010), y el agarre mediante garras en vez de prensión digital en mustélidos trepadores (Taylor 1989, Iwaniuk et al. 2001, ver más adelante). Además, en Ei. barbara, la elongación marcada del brazo y antebrazo le permite rodear ramas al trepar y desplazarse rápidamente mediante trotes o marchas principalmente tipo galope por un sustrato irregular (Kavanau 1971, Hildebrand 1988, Presley 2000). En las nutrias, el autopodio presenta una longitud relativa al brazo similar (en Lontra spp.) o mucho mayor (Pt. brasiliensis) a hurones, aunque es claramente más robusto, algo que también fue destacado por Holmes (1980) para lutrinos norteamericanos y musteloideos cavadores. En el caso extremo de Pt. brasiliensis, el autopodio es mayor al antebrazo. En estos, el tamaño relativo del autopodio 
refleja el aumento de la superficie de propulsión para el nado, sumado a la reducción de los elementos proximales en relación a mantener un perfil hidrodinámico y aumentar las ventajas mecánicas de los músculos que mueven el antebrazo y carpo (Tarasoff 1972, English 1977, Holmes 1980: 58, Taylor 1989, Fish 1994), como también ocurre en otros mamíferos acuáticos (e.g., pinípedos; English 1976, 1977).

\section{Serie carpal proximal}

En Ly. patagonicus, Ga. cuja y Mu. frenata, la serie carpal proximal está compuesta de elementos gráciles y bien imbricados, dándole una apariencia más bien compacta (ver también Holmes 1980). En hurones, el radial posee, en vista craneal, una extensión lateromedial que duplica aproximadamente a la del ulnar (rasgo sinapomórfico de Mustelidae - Taxidea - Meles; Apéndice 3.15, c. 49, estado 0), y un límite articular medial moderadamente bien definido. La superficie articular para el radio es más aplanada que en otros mustélidos sudamericanos. El bajo grado de convexidad de esta articulación evidencia una baja capacidad de flexo-extensión de la articulación (Yalden 1970, Peigné et al. 2008, Salton y Sargis 2008), movimientos menos importantes durante la locomoción terrestre en animales con miembros cortos (Yalden 1970, Salton y Sargis 2008) y en particular para especies con marchas de tipo half-bound, debido a que los miembros anteriores se especializan en amortiguar los impactos luegos de los saltos sobre un sustrato estable (Horner y Biknevicius 2010), sin que la flexión activa del carpo sea parte crucial de la propulsión durante esta marcha (distinto a cursoriales, Yalden 1970). Por otro lado, la expansión lateromedial de la superficie articular proximal y del radial, en general, evidencia un rango de movimientos mediales de la muñeca relativamente importante (aunque menor que otras especies, ver más adelante).

En las nutrias y Ei. barbara, la serie carpal proximal es más robusta y expandida lateromedialmente, y el radial posee una articulación para el radio marcadamente convexa en sentido cráneocaudal. La gran convexidad cráneocaudal de la región articular en ambos linajes favorece un gran rango de flexión y extensión de la muñeca (Yalden 1970, Peigné et al. 2008, Salton y Sargis 2008). En Ei. barbara el desarrollo lateromedial del radial es extenso (más del doble que el ancho del ulnar) y su superficie articular para el radio se encuentra expandida medialmente, y presenta un límite medial que pierde definición de manera transicional. Esta morfología se relaciona directamente a una mayor amplitud y menores restricciones a los movimientos lateromediales de la articulación de la muñeca, así como el traspaso alternado de la fuerza peso de la ulna al radio (Yalden 1970, Salton y Sargis 2008). Yalden (1970) utilizó a Ei. barbara, Mel. meles, y En. lutris como modelos mustélidos para analizar las morfología funcional del carpo. En el caso de Ei. barbara, Yalden (1970) detectó un rango de desviación lateromedial total de $40^{\circ}$, el doble que lo observado en otros mustélidos terrestres y cánidos, y un grado máximo de hiper-extensión de $30^{\circ}$, el triple que estos otros. Esto soporta la inferencia 
de una marcada movilidad para la articulación proximal del carpo del taxón. Estos datos sugieren a esta especie como el mustélido sudamericano con mayor movilidad carpal. Esta movilidad se relacionaría con la adaptación a sustratos diversos e irregulares durante el trepado (Yalden 1970, Argot 2003b, Antón et al. 2006). Aunque según Yalden (1970, estudio de laboratorio en sustrato horizontal) este grado de hiper-extensión no permite una postura plantígrada, una postura plantígrada ha sido registrada por otros autores (e.g., tracks de Murie 1974, Dionisios Youlatos comunicación personal). Dado que los principales rasgos morfológicos de la muñeca de Ei. barbara es optimizada como la heredada de un ancestro común previo a la radiación de Mustelidae - Taxidea - Meles o incluso anterior a este punto (Apéndice 3.15, c. 48, estado 0, c. 49, estado 0, c. 50, estado 1, c. 51, estado 0), es probable que el ancestro común de este clado haya tenido similares libertades articulares.

Por otro lado, en el caso de las nutrias, se registran un incremento de la longitud lateromedial de los carpales proximales, en conjunto con una menor importancia relativa del desarrollo lateromedial del sector articular radial (sinapomorfía de Lutrinae; Apéndice 3.15, c. 49, estado 1), y un límite medial neto a la extensión de la misma. En el caso de Lo. provocax la zona articular radial presenta un sector caudomedial levemente cóncavo, lo que resulta en mayores restricciones a los movimientos lateromediales y de flexión extrema en esta especie. Esta configuración permitiría a estas nutrias una expansión de la superficie palmar, que es el área efectiva de propulsión, a la vez restringiendo el grado de movilidad lateromedial (Yalden 1970, Peigné et al. 2008). La presencia de un tubérculo caudomedial marcado indica también un límite a los valores máximos de flexión e imprime una componente de rotación y desviación lateral a la flexión (Yalden 1970). Peigné et al. (2008), en su revisión de la morfología de nutrias, así como Yalden (1970) en su análisis especifico de En. lutris, sugirieron articulaciones proximales del carpo más móviles (especialmente en sentido lateromedial) que en estas nutrias sudamericanas (más similares a Meles meles). Para el caso especifico de Lo. felina, Peigné et al. (2008) destacaron la presencia de un área cóncava caudomedial, coincidiendo con lo observado en Lo. provocax, interpretándolo como una mayor restricción a los movimientos fuera del plano parasagital y una mayor desviación lateral durante la flexión (Yalden 1970; ver también Morgan y Verzi 2011), pudiendo tratarse también de un carácter filogenéticamente informativo. Lo. felina y Lo. provocax, son las nutrias más australes, y habitan (al contrario que su pariente Lo. longicaudis) en costas pedregosas en donde se mueven y construyen sus madrigueras (Bastida et al. 2007), pudiendo estas actividades relacionarse con los rasgos estabilizadores de la muñeca comentados (así como ocurre en el autopodio posterior; ver sección 4.3.5, Pes).

En lo que respecta a otros musteloideos, sólo se presentan en este trabajo comparaciones puntuales debido a la incompletitud en el material osteológico, fotográfico y bibliográfico disponible. Tanto en los prociónidos (Nasua y Procyon) como los mefítidos (Conepatus y 
Spilogale), la articulación proximal del radial se trunca en forma abrupta medialmente, indicando bajas capacidades relativas de excursión de la muñeca en este sentido. En prociónidos, la articulación proximal del radial es marcadamente convexa, similar o más curva que la presente en Ei. barbara, y extendida cráneocaudalmente lo que, sumado a una articulación de la muñeca inclinada cranealmente, indica mayores capacidades de flexoextensión, desarrollando una marcada hiper-extensión, en relación a apoyos más plantígrados y sustratos arbóreos (Yalden 1970, Holmes 1980, McClearn 1992, Argot 2001, 2003b). Por otro lado, existen diferencias en las configuraciones de la articulación del sector proximal del carpo de Procyon y Nasua (e.g., desarrollo lateromedial del radial y de la articulación proximal del radial, desarrollo del tubérculo del carpo), que indican una postura más digitigrada (aunque no estricta) en Procyon y una postura más plantigrada en Nasua, con una componente de supinación del autopodio durante el adelantamiento del miembro en la marcha de este último, coincidiendo con las observaciones comportamentales de McClearn (1992; ver explicación detallada en Apéndice 4.1H). Davis (1964) registró un máximo desarrollo lateromedial del radial en Ailurus fulgens, Potos flavus y Ailuropoda melanoleuca, linajes de amplias excursiones fuera del plano parasagital de la muñeca y diestros manipuladores. En los mefítidos (especialmente en Conepatus chinga), la articulación es aplanada, orientada en sentido proximal y con el límite craneal marcado, evitaándose la hiper-extensión (Yalden 1970), en relación quizás con una postura más digitígrada (coincidiendo con tracks sin rastros de almohadilla carpiana de Conepatus leuconotus de Murie 1974, pero ver Mivart 1885). La morfología de Mel. meles es similar a la de otros musteloideos fosoriales (e.g., mefítidos, Nasua), aunque presenta una extensión medial de la articulación proximal del radial mayor, la cual es cóncava en el sector contiguo al robusto tubérculo caudomedial, similar a lo observado en Lontra provocax, limitando la movilidad en esta dirección (Yalden 1970, Peigné et al. 2008, Morgan y Verzi 2011). Los guloninos (e.g., Martes spp.; ver Heráň 1962, Barraquand 2010) y mustelinos de otros continentes poseen una morfología carpal proximal similar a la descripta para sus parientes sudamericanos, lo que sugiere la herencia a partir de un ancestro común previo a la radiación de estas subfamilias (e.g., Apéndice 3.15, c. 48, 49). Mustela vison, de hábitos semiacuáticos, presenta una leve mayor amplitud lateromedial del carpo, convergiendo con lutrinos en este aspecto morfo-funcional.

El sesamoideo radial, así como los músculos y ligamentos relacionados a éste, han sido estudiados intensamente en algunos linajes arctoideos (ailúridos y algunos úrsidos), en relación a su hipertrofia y al rol de esta estructura en la sujeción y manipulación del alimento o sustrato de estos linajes (Davis 1964, Antón et al. 2006, Salesa et al. 2006, 2008, Fisher et al. 2009, Abella et al. enviado). Salton y Sargis (2008) sugirieron que especies terrestres o cavadores de Tenrecoidea presentan un sesamoideo radial ("prepollex", como limite medial del retinaculum 
flexor) grande en relación a la contención de flexores carpales desarrollados. Sin embargo, esto no se ha propuesto en estudios de carnívoros (e.g., Davis 1964, Antón et al. 2006, Salesa et al. 2006) ni tampoco existe una relación clara entre el desarrollo de los flexores carpales (Lámina 2.27) y el tamaño del sesamoideo radial en carnívoros. En Ei. barbara, este elemento es robusto y relativamente voluminoso, y está fuertemente articulado al carpo. Estos ragos, junto con un accesorio lateralmente proyectado, permitirían movimientos de desviación de la muñeca, así como aumentar la superficie palmar de la mano (Taylor 1989, Antón et al. 2006, Abella et al. enviado). El mayor contacto entre la zona carpal de la palma con el sustrato es especialmente útil al moverse sobre ramas delgadas en las cuales los dígitos se ubican de lado, rodeando el sustrato más que ubicándose sobre éste, sin participar del soporte del peso corporal. También permite un aumento del área medial de contacto proximal del metacarpal I, permitiendo un mayor rango de movimientos de este dígito. Por otro lado, no se presenta en la tayra la morfología hipertrofiada necesaria para habilidades de grasping de tipo "pulgar falso", desarrolladas convergentemente en otros arcoideos (Antón et al. 2006, Salesa et al. 2006, 2008, Abella et al. enviado). En Ga. cuja, Ly. patagonicus, Mu. frenata, Mu. vison, y otros hurones, el sesamoideo radial es aplanado, de forma alargada y proyectado ventralmente, curvado sobre el proceso caudomedial del radial. La delgadez del elemento indica un $\mathrm{m}$. abductor digiti I longus moderdo a débil (insertado proximalmente) y una superficie relativamente amplia para el $\mathrm{m}$. abductor et opponens digiti I (distoventralmente; sección 3.1.8, Lámina 2.16), además de colaborar en el soporte medial de la almohadilla plantar. Estas características, opuestas a las observadas en Ei. barbara, se vinculan a una reducción del área palmar (Iwaniuk et al. 2000, Argot 2003b, Antón et al. 2006, Abella et al. enviado). El metacarpal I y dígito I son los elementos relativamente más móviles en mustélidos, especialmente en el grado de flexoextensión (ver más adelante). La presencia de un área de origen del m. abductor et opponens digiti I amplia y móvil (dado que la forma del elemento favorece un deslizamiento del sesamoideo radial sobre el radial; Salesa et al. 2006), puede ser beneficiosa tanto para generar, acompañar y maximizar estos movimientos durante la manipulación de presas en hurones, aunque esto debe ser entendido sólo como una probable lectura funcional que debe ser puesta a prueba en futuros estudios específicos (ver más adelante). La morfología descripta para hurones fue optimizada como un rasgo establecido previamente a la radiación de ictoniquinos y mustelinos, y convergente con Spilogale, aunque existe un gran número de datos faltantes para el caracter (Apéndice 3.15, c. 50, estado 3). En las nutrias la configuración es muy similar a los hurones, aunque destacándose por ser el sesamoideo algo más breve y robusto proximalmente (c. 50, estado 3), evidenciando una mayor importancia de la abducción del dígito I y la expansión de la superficie de la palma necesaria durante la propulsión. 
Los sesamoideos radiales de los prociónidos (Bassariscus astutus, Nasua nasua y Procyon lotor; ver también Davis 1964) y Ailurus fulgens (Davis 1964, Fisher et al. 2009) se asemejan en algún grado al de Ei. barbara, y esta condición fue reconstruida como ancestral a la radiación Mustelidae + Procyonidae (Apéndice 3.15, c. 50, estado 1), aunque es evidente que la inclusión de Ailurus u otros taxones conllevaría a la reconstrucción de una adquisición de esta condición incluso más tempranamente. Sin embargo, en musteloideos no mustélidos, el sesamoideo radial es más robusto (exceptuando a Procyon) y de contorno redondeado en su extremo ventral, proyectándose fuertemente ventralmente en Nasua; quizás colaborando en mayor grado en la manipulación del sustrato o alimentos, incrementando la almohadilla correspondiente (Davis 1964, Iwaniuk et al. 2000, Antón et al. 2006, Salesa et al. 2006). Por otro lado, en zorrinos, el sesamoideo radial se encuentra reducido a una pequeña esfera o nódulo distalizado (caso único dentro de arctoideos, y condición plesiomórfica del suborden; Apéndice 3.15 , c. 50, estado 4), evidenciando la ausencia de movimientos complejos de abducción o de prensión del dígito I. A su vez, el proceso caudomedial del radial se proyecta a modo de una plataforma aplanada en dirección caudal. Esta proyección habilita una importante superficie lateral para la contención del pasaje (y quizás también origen) de flexores carpales y digitales, y específicamente al tendón del m. flexor carpi radialis (observación personal de un espécimen con algunos tendones preservados), siendo esta una sinapomorfía de la familia (Apéndice 3.15, c. 51, estado 2) relacionada a importantes esfuerzos de flexión ejercidos durante el cavado y la ausencia de movimientos complejos (Salton y Sargis 2008, Morgan y Verzi 2011).

En mustélidos así como en otros arctoideos (ver descripción de úrsidos y prociónidos en Davis 1964: 99, y mustélidos en Yalden 1970; pero ver mefítidos más adelante), el ulnar contacta a la ulna proximalmente, en vez de lateralmente como es observado en linajes carnívoros cursoriales. Un contacto proximal indica que el ulnar no colabora mayormente en los movimientos de desviación lateromediales de la articulación de la muñeca (debido a que es el carpal IV es quien se desliza junto con el radial ver Yalden 1970), sino más bien en el soporte (la transmisión de la fuerza peso) y rotación axial. En Ei. barbara y Pt. brasiliensis el ulnar es menos plano y la carilla articular proximal para el proceso estiloides es más cóncava que otros mustélidos como Ga. cuja, Ly. patagonicus y Lontra spp. Esto podría indicar una mayor participación de este elemento y la ulna en la transmisión del soporte del peso corporal en ambas especies, esperable para animales trepadores y posiciones flexionadas durante el trepado, como en Ei. barbara (Argot 2001, Andersson 2004) y para las incursiones en tierra de Pt. brasiliensis (en relación a su mayor peso; Yalden 1970). En Meles meles, se registró un una superficie de contacto con la ulna fuertemente cóncava y elevada cranealmente, mientras que dentro de prociónidos, ésta es más concava y elevada en Nasua que en Procyon, evidenciandose diferentes grados de restricciones a los movimientos de rotación de la articulación. En los 
mefítidos, esta región articular también es elevada proximalmente (más marcadamente en Co. chinga que $S$. gracilis), haciendo de tope a la excursión lateral y los movimientos de rotación de la muñeca. Por otro lado, en los mefítidos, las carillas de contacto con la ulna del ulnar y del accesorio conforman una superficie relativamente reducida, lateralizada y profunda en comparación con otros musteloideos (en donde es más somera e se inclina más proximalmente, ver también Davis 1964), nuevamente sugiriendo restricciones a los movimientos fuera del plano articular de la muñeca en el linaje.

El carpal accesorio y específicamente su tubérculo, son sitio de inserción de ligamentos, ambos vientres del m. flexor carpi ulnaris y otros músculos digitales (Evans y De Lahunta 2013, sección 3.1.8), y se han dado diversas interpretaciones funcionales a los cambios de su morfología (Davis 1964, Salton y Sargis 2008). El tubérculo se encuentra moderadamente desarrollado en lincodontininos, mientras que es más robusto y extendido proximodistalmente en nutrias (tanto sudamericanas como de otros continentes; e.g., Fisher 1942), indicando en estas últimas, un incremento de los esfuerzos de flexión de la muñeca durante las brazadas (en movimientos thrust-recovery durante nados lentos o cambios de dirección; Tarasoff 1972, Taylor 1989, Salton y Sargis 2008). En ambos grupos, este tubérculo inclina principalmente en dirección caudal, indicando movimientos concentrados en el plano parasagital (Antón et al. 2006). Por otro lado, en Ei. barbara la estructura es también robusta, pero se encuentra menos proyectada, y está inclinada lateralmente, algo registrado en otros animales arborícolas o trepadores (ver Davis 1964, Antón et al. 2006, Salton y Sargis 2008). Esta configuración puede estar relacionada a una baja estabilización articular, mayores habilidades de agarre (grasping), y a la producción de poderosos movimientos complejos de la muñeca, requeridos durante el trepado (en correlación con lo observado en la articulación proximal del carpo; Taylor 1974, Antón et al. 2006, Heinrich y Houde 2006, Salesa et al. 2008, Salton y Sargis 2008). En los mefítidos, el carpal accesorio, como ocurrió con el tubérculo del radial, se proyecta marcadamente en sentido caudal y es llamativamente agudo y aplanado lateromedialmente, haciendo las veces de límites de la región de tránsito de poderosos flexores entre ambas estructuras, permitiendo una gran ventaja mecánica y ángulo de acción a los mismos (Taylor 1989, Salton y Sargis 2008, Morgan y Verzi 2011), y dando anclaje a ligamentos y el retinaculum flexor (Salton y Sargis 2008). En Meles meles, la situación es similar, pero a su vez, la robustez del accesorio es marcada (similar o mayor que en las nutrias), indicando un sitio de inserción mayor para flexores carpales y mayores esfuerzos de flexión en este cavador especializado (Taylor 1989, Salton y Sargis 2008, similar a lo observado en Taxidea taxus por Moore et al. 2013). En prociónidos trepadores, el tubérculo es robusto y corto, similar a Ei. barbara, pero llamativamente inclina directamente en dirección caudal, indicando desviaciones laterales de la muñeca de menor rango y mayor ventaja mecánica para la flexión (Taylor 1974, 
1989, Antón et al. 2006, Morgan y Verzi 2011). Entre los hurones, la diferencia de robustez del tubérculo probablemente indique variaciones en la habilidad de cavado, mayor en los ictoniquinos que presentan un tubérculo más robusto que el de los mustelinos, que cavan menos.

\section{Serie carpal distal}

En lo que respecta a la serie carpal distal, ésta es muy similar entre los mustélidos sudamericanos. Sin embargo, Ei. barbara presenta variantes interesantes. Esta especie posee un carpal IV alargado proximodistalmente, con una faceta de contacto para el radial verticalizada y una faceta de contacto con el ulnar notablemente amplia y también verticalizada. La primera de estas características genera un reaseguro (interlocking, trabas a modo de "engranajes" entre elementos carpales; Yalden 1970: 493-494) del contacto entre el radial y carpal IV en posiciones parcialmente flexionadas de la muñeca (similar al carpal III, ver más adelante). En animales trepadores, en la fase de propulsión al marchar sobre ramas se registran posturas parcialmente flexionadas de la muñeca (Yalden 1970, Van Valkenburgh 1987, Argot 2001, Heinrich y Houde 2006). Los contactos articulares extendidos en el plano sagital evitan la dislocación del carpo durante estos esfuerzos (ver discusión de contactos distales de radial en Yalden 1970, Argot y Babot 2011). Por otro lado, en la tayra, el incremento de la superficie articular del carpal IV para el ulnar es mayor que la recíproca, evidenciando una mayor capacidad de desviación lateral de la muñeca (mayor distancia de recorrido antes de que el ulnar contacte al metacarpal V), permitiendo un gran rango de movimientos lateromediales (ver Yalden 1970). Relaciones similares entre la morfología y el sobre-desarrollo del carpal IV y la locomoción arborícola se ha descripto también para primates, marsupiales y afroterios (Argot 2001, 2003b, 2010, Salton y Sargis 2008, Argot y Babot 2011). En lo que respecta a los restantes carpales distales, en Ei. barbara se registra nuevamente una configuración singular: el contacto entre el radial y los carpales distales es más irregular, mientras que los carpales distales son relativamente pequeños, redondeados (e.g., carpal III sin forma de "L") y menos imbricados entre sí en comparación con hurones y nutrias. Así como fue descripto para el carpal IV, esta configuración implica una mayor seguridad en la articulación media del carpo, en relación a la locomoción arbórea y posiciones semi-flexionada del carpo (Yalden 1970, Argot 2001). Por otro lado, la morfología de los contactos entre carpales distales indica mayores habilidades de manipulación y menor soporte del peso sobre los dígitos mediales, permitiéndoles mayor libertad de movimientos (Yalden 1970, Argot 2010). En Martes spp. se registran configuraciones muy similares a la observada Ei. barbara (Herán̆ 1962, Barraquand 2010), aunque presentan una hilera de carpales distales menos irregular y un carpal IV no tan elongado proximodistalmente (similar a otros mustélidos).

Las configuraciones del carpo de las nutrias y los hurones sudamericanos son similares en vista craneal, aunque el mayor tamaño relativo del carpal IV y de la superficie articular 
proximal cubierta del carpal III y IV de nutrias las asemejan más a mustélidos basales (e.g., Mel. meles), e indican que poseen un mayor grado de movilidad lateral y reaseguros articulares mayores durante la flexo-extensión intracarpal (Yalden 1970, Peigné et al. 2008). Aproximadamente la misma configuración es descripta en trabajos previos en mustelinos, ictoniquinos y lutrinos de otros continentes (e.g., Mustela vison, Lontra canadensis, Lutra lutra; ver Heráň 1962, Baitchman y Kollias 2008). En los prociónidos, el contacto entre el radial y los elementos distales es una superficie irregular, y los carpales distales no se imbrican marcadamente, ragos similares a los observados en guloninos, y con las mismas implicancias funcionales. En esta familia (al igual que en úrsidos; Davis 1964), el carpal IV se proyecta en forma aguda proximalmente entre el radial y el ulnar, rasgo no presente en mefítidos ni mustélidos, y por lo tanto potencialmente filogenéticamente informativo (Apéndice 3.15, c. 52, estado 2).

\section{Proporciones y morfología de los metacarpales y falanges}

La relación entre el largo del metacarpal III y la falange proximal de dígito III (LaMcIII/LaFIII; manus shape index; Iwaniuk et al. 1999) es frecuentemente utilizada para estimar habilidades de manipulación relacionadas a estrategias de caza y locomoción arborícola (permitiendo los mayores valores un agarre firme y gran movilidad; Van Valkenburgh 1987, Argot 2001, 2004, Samuels et al. 2013), aunque su utilidad ha sido cuestionada (Iwaniuk et al. 1999, 2000). En su análisis de los carnívoros de América del Norte, Iwaniuk et al. (1999) no encontraron una relación significativa entre este índice y categorías simplificadas de locomoción o el grado de carnivoría. El análisis aquí presentado revela que la relación entre LaMcIII/LaFIII y los factores locomoción (Fig. 3.1G) y los hábitos dietarios (Fig. 3.2E) no fue significativa, exceptuando por una débil relación con la dieta que se pierde luego de aplicar el control filogenético (Tabla 3.6, Apéndice 3.6G, 3.7G), coincidiendo con Iwaniuk et al. (1999, 2000). Pese a esto, algunas variantes intra- e intergrupales específicas pueden interpretarse como especializaciones morfo-funcionales a estrategias de caza particulares, manipulación de alimentos, o sustratos específicos (McClearn 1992, Lemelin 1999, Iwaniuk et al. 2000, Argot 2001, 2004; ver más adelante).

La ausencia de relación significativa entre el índice LaMcIII/LaFIII y la locomoción, puede ser en parte explicada analizando cualitativamente las variantes en este índice para cada grupo locomotor. Por ejemplo, un gran número de taxones trepadores de falanges proximales relativamente breves (e.g., Gu. gulo, Martes sp., Nasua sp., Procyon sp.; Tabla 2.3, Fig. 3.1G), y un gran número de taxones terrestres con falanges proporcionalmente largas, contrariamente a lo esperado sobre la base de interpretaciones clásicas (ver Van Valkenburgh 1987, Argot 2003b). Iwaniuk et al. $(1999,2000)$ destacaron que en especies trepadoras de mediano a bajo tamaño, garras con morfologías adecuadas puede dar un agarre firme sin necesidad de dígitos 
extremadamente largos (ver también Hildebrand 1988), y este es el caso de guloninos y muchos prociónidos. En consecuencia, la ausencia de correlación entre este índice y la locomoción podria deberse a la presencia de distintas estrategias de sujeción al sustrato arbóreo existentes en carnívoros (e.g., grasping vs. clawing; ver también Taylor 1989). Por otro lado, el grosor del sustrato arbóreo utilizado es otra variable de interés que podría explicar en parte las grandes variantes dentro del grupo trepador (ver Lemelin 1999) al vincular los bajos valores LaMcIII/LaFIII con la utilización frecuente de ramas relativamente delgadas en Po. flavus (McClearn 1992) y en Ei. barbara (Dionisios Youlatos comunicación personal). Lamentablemente, para la gran mayoría de los carnívoros, no se cuenta con datos de este nivel de detalle sobre el tipo de sustrato arbóreo utilizado.

Los hurones presentan metacarpales elongados, como es esperable en especies terrestres en general (Hildebrand 1988, Salton y Sargis 2008). Sin embargo, Lyncodon patagonicus se diferencia grandemente en varios rasgos de la región metacarpal y falangeal con respecto a Galictis spp. En ambos géneros el dígito III es el mayor, pero en Galictis los metacarpales se alejan del patrón relativamente simétrico y marcadamente mesoaxónico de Ly. patagonicus, siendo en los grisones proporcionalmente más largos los dígitos laterales (la longitud del IV se acerca a la del III). En Mu. frenata se da un patrón intermedio. La optimización de las proporciones del metacarpal III y IV sugieren que la condición plesiomórfica de Arctoidea, mantenida en la mayoría de los representantes del suborden, es la presencia de un metacarpal IV de longitud similar al III, mientras que la dominancia del III fue obtenida independientemente en varios linajes (Apéndice 3.15, c. 53, estado 0). En el análisis del índice LaMcIII/LaFIII se registra el mismo ordenamiento: Galictis posee el valor más alto de los hurones sudamericanos (Ga. vittata: 1,67; Ga. cuja: 1,60), seguido por Mu. frenata $(1,45)$, y finalmente Ly. patagonicus $(1,25$, el mínimo valor de la muestra de musteloideos analizada; Tabla 2.3). Menores valores en este índice implican una mayor longitud relativa de las falanges proximales, y han sido relacionados, entre otros factores, con un mayor potencial de capacidades de manipulación de alimentos, presas o uso de sustratos delgados (Iwaniuk et al. 1999, Lemelin 1999, Argot 2001).

Aunque en todos los mustélidos los cinco dígitos contactan al suelo durante la marcha (Mivart 1885, Murie 1974, Holmes 1980), el grado de participación de los distintos dígitos y modo de soporte del peso es variable (ver también Salton y Sargis 2008). La reducción de la longitud y robustez del dígito I, marcada en hurones, y presente en algún grado en la mayoría de los mustélidos y carnívoros en general, implica un menor grado de participación de éste en el soporte del peso. La configuración mesoaxónica del autopodio grácil y elongado de Ly. patagonicus podría relacionarse a una marcha terrestre y una digitigradía más estricta que en Galictis (y más similar a Mustela, como fue sugerido por Mivart 1885, Yensen y Tarifa 2003a, b, ver también Salton y Sargis 2008), en detrimento de capacidades de cavado (pero ver más 
adelante Ta. taxus), trepado o nado, que demandan una mayor robustez o longitud de los dígitos periféricos (Yalden 1970, Argot 2001, 2003, Salton y Sargis 2008, Morgan y Verzi 2011). Sin embargo, esta configuración, sumado a falanges particularmente elongadas (Tabla 2.3, Fig. 3.2E), podría permitir una gran capacidad de manipulación (Van Valkenburgh 1987, Iwaniuk et al. 1999, 2000), aunque se desconocen datos ecológicos al respecto. Otras características destacadas para el taxón en la discusión del húmero (e.g., desarrollo del epicóndilo medial en comparación con otros hurones; sección 4.3.4, Húmero) y proporciones intermembrales (e.g., alto valor para LaMA/LaMP; sección 4.3.3), también coinciden con esta posibilidad. Por otro lado, la configuración autopodial de Ga. cuja y Ga. vittata es ventajosa para la realización de mayores esfuerzos contra el sustrato, en relación a la capacidad de cavado en esta especie (Kaufmann y Kaufmann 1965, Yensen y Tarifa 2003a, Salton y Sargis 2008, Wilson y Mittermeier 2009). En su análisis de caracteres externos, Pocock (1926) propuso a Ly. patagonicus como una especie que combina características gráciles de los mustelinos con rasgos de cavador, incluyendo garras de los miembros anteriores alargadas y almohadillas que recuerdan a aquellas de especies cavadoras. Aunque es cierto que las garras del miembro anterior son marcadamente alargadas (en proporción a las del miembro posterior; rasgo típico de cavadores; Ewer 1973, Van Valkenburgh 1987), éstas son muy delgadas, y las proporciones de carpo y gracilidad de los elementos del miembro anterior (i.e., no alcanzadas por ninguna especie Musteloidea del grupo) son incompatibles con un modelo cavador. La ausencia de rasgos exclusivos de cavadores en el esqueleto postcraneal pone en duda esta propuesta, aunque no explica la enigmática morfología del carpo del taxón. Partiendo de que no existe información sobre la estrategia de caza de Ly. patagonicus y considerando la hipótesis de estrategias de caza similares a las rolling and curl propuestas para el taxón en este trabajo (ver Anexo), no se puede descartar la posibilidad de que los miembros anteriores tengan una función importante durante la sujeción de la presa durante la lucha cuerpo a cuerpo con roedores fosoriales, y la mayor longitud relativa de las falanges proximales y ungueales se relacione a la estrategia de caza del taxón.

Eira barbara presenta metacarpales con proporciones más similares entre sí, con los dígitos periféricos proporcionados y menos reducidos, y con falanges por lo general robustas, y un metacarpal y dígito IV de mayor longitud relativa a los hurones, equiparando al III, lo que resulta en una configuración más bien paraaxónica (ver también Presley 2000). Esta configuración sugiere una mayor área de contacto con el sustrato durante el trepado, y un mayor traspaso del peso a la periferia, y específicamente al sector lateral del autopodio, características esperables en la locomoción arbórea y apoyo plantígrado (Hildebrand 1988, Taylor 1989, Salton y Sargis 2008, Dionisios Youlatos comunicación personal). La elongación del metacarpal y digito I (contrario a lo observado en hurones), ha sido relacionada directamente a mayores 
capacidades de agarre a ramas relativamente delgadas en muchos mamíferos (Argot 2001, 2003b, Salton y Sargis 2008), aunque la ausencia de oposición real del pulgar en carnívoros relativiza su importancia funcional. El valor del cociente LaMcIII/LaFIII de Ei. barbara es llamativamente bajo $(1,51)$, siendo el menor entre los estimados para los taxones musteloideos trepadores, excepto por Po. flavus $(1,41)$, el cual es el musteloideo con mayores capacidades de manipulación documentadas (McClearn 1992). Este índice sugiere que la tayra podría ser el gulonino con mayores capacidades de manipulación (Tabla 2.3), lo que resulta llamativo dado que, pese a que el taxón frecuentemente manipula el alimento y las presas durante la caza, no se ha registrado gran destreza en estas maniobras (Kaufmann y Kaufmann 1965, Poglayen-neuwall 1978). Por último, en Ei. barbara, las crestas de las falanges ungueales son robustas, con procesos ungueales marcadamente altos, y las unguis elongadas distalmente y curvadas, aunque delgadas lateromedialmente, coincidiendo con una forma óptima para clavar las garras en troncos y ramas durante el trepado, así como útiles para la caza (Van Valkneburgh 1985, 1987, Hildebrand 1988, Taylor 1989, Argot 2003b). Por otro lado, la delgadez relativa de las ungueales, la robustez y brevedad de las falanges más proximales y la proporcionalidad de los dígitos (MacLeod y Rose 1993, Salton y Sargis 2008, Morgan y Verzi 2011), permiten la actividad de cavado eventual (aunque no óptima) en la especie (Pocock 1921, Presley 2000).

En los hurones sudamericanos y Ei. barbara, la falange proximal del dígito I es más grácil, suele estar curvada levemente en sentido lateral, y es relativamente larga (siendo más similar en longitud a su metacarpo que lo observado en otros dígitos). Por otro lado, la articulación carpo I-metacarpo I está inclinada medialmente y es marcadamente cóncavaconvexa. En mayor o menor medida, esta morfología se registra en general en los mustélidos, y difiere (especialmente en el sector articular) de mefítidos y prociónidos. Esta configuración, en combinación con otras características como un sesamoideo radial elongado y aplanado y móvil (ver más arriba) podría relacionarse a la participación del dígito I durante sujeción (sin manipulación compleja necesariamente) de presas entre las manos o contra el sustrato (Kaufmann y Kaufmann 1965, Ducker 1968, Gossow 1970, Rowe-rowe 1978, Ben-david et al. 1991, Yensen y Tarifa 2003a, b, Bastida et al. 2007), pero estudios más detallados son requeridos. Por otro lado, muchas nutrias, prociónidos y ailúridos vivientes presentan mayores capacidades de manipulación, incluyendo convergencia de dígitos, o prensión con una mano, involucrando otras modificaciones óseas y musculares, y lo mismo ha sido inferido para representantes fósiles de estos grupos (Taylor 1989, Larivière 2001a, McClearn 1992, Antón et al. 2006, Salesa et al. 2006, Fisher et al. 2009, Fabre et al. 2013a). La morfología de las falanges ungueales de los hurones es relativamente generalizada, siendo más elongadas y menos curvadas las de los Ictonychinae que las de los Mustelinae, en relación a mayores capacidades 
de cavado en los primeros (Larivière 2001b, Gorsuch y Larivière 2005, Yensen y Tarifa 2003a, b).

En las nutrias, las proporciones de los metacarpales son muy diferentes de las observadas en los mustélidos terrestres sudamericanos. El metacarpal y dígito IV son claramente mayores al III, y el metacarpal V es mayor que el II (pero no la longitud del dígito), modificándose la posición del eje principal de la mano (similar a lo observado en los pies, ver Tarasoff et al. 1972). En el caso de las especies sudamericanas de Lontra (e.g., Lo. longicaudis; Tabla 2.3), las falanges proximales (y secundariamente las mediales) son largas, aplanadas y robustas, asemejándose en longitud a las de sus respectivos metacarpales (LaMcIII/LaFIII = 1,39). Esta configuración indica una gran relevancia de los miembros anteriores en el padding, aumentando al máximo la superficie de contacto con el medio líquido y la fuerza de propulsión durante el nado (Tarasoff 1972, Taylor 1989). Una condición llamativamente distinta es la de la especie cogenérica norteamericana Lontra canadensis que presenta un bajo valor del índice $\mathrm{LaMcIII} / \mathrm{LaFIII}=1,79)$, en relación a una escasa utilización de miembros anteriores en el nado (Fish 1994, como también fue destacado en el análisis del índice intermembral, sección 4.3.3, ver más arriba). La especialización de los autopodios anteriores al padding es llevada a un extremo por Pt. brasiliensis, especie, que posee una marcada elongación de las falanges medias (incluso más que en Lontra longicaudis), y los metacarpales y dígitos laterales son proporcionalmente más robustos que los mediales. Más allá de estas variantes, la morfología registrada en nutrias, sumado a la membrana interdigital que une los dígitos, les permite aumentar al máximo la superficie de contacto con el medio líquido y la fuerza de propulsión durante el nado (Taylor 1989, Tarasoff 1972). Como fue mencionado para las especies trepadoras (e.g., Ei. barbara, Po. flavus), estas proporciones autopodiales también permiten potencialmente amplias capacidades de manipulación (Taylor 1989, Iwaniuk et al. 2000, 2001), característica típica de lutrinos en general (e.g., Kruuk 2006, Wilson y Mittermeier 2009). En Lontra spp. los procesos ungueales son altos, y las unguis se extienden poco en dirección distal pero se encuentran engrosadas en dirección lateromedial, indicando una condición más generalizada que en Pt. brasiliensis.

Más allá de las diferencias comentadas, una configuración muy similar a la descripta en las especies sudamericanas (especialmente Lontra) se observa en Lu. lutra, Lutro. perspicillata y Lo. canadensis (Heráň 1962, Baitchman y Kollias 2000). Enhydra lutris presenta una combinación de características llamativas. Como otras nutrias, presenta los metacarpales y falanges robustos y las ungueales relativamente breves; sin embargo, las falanges proximales y medias son muy breves (Holmes 1980), lo que impide una gran superficie de contacto con el agua, posiblemente en relación al rol minoritario de los miembros anteriores en la locomoción y su impericia para tomar objetos de determinados tamaños con una sola mano (Tarasoff 1972, 
Howard 1973, Holmes 1980, Taylor 1989). Es interesante notar que en $M u$. vison, al contrario de otras especies del género Mustela, el metacarpal IV supera al III, y las falanges son ligeramente más planas, lo que recuerda lejanamente la configuración de las nutrias, pudiendo ser relacionad esto con las importantes incursiones acuáticas que realiza taxón (Heptner y Naumov 1967, Williams 1983a, Fish 1994).

En lo que respecta a otros musteloideos, los tejones y mefítidos presentan una serie metacarpal robusta y falanges proximales robustas y en general breves (con una longitud similar o menor a la mitad de los metacarpales correspondientes; Tabla 2.3, Fig. 3.1G), y falanges ungueales marcadamente elongadas, agudas y poco curvadas. Estas características indican una gran ventaja mecánica y resistencia durante el cavado en estas especies scratch-diggers, transmitiéndose más eficientemente los esfuerzos de flexión generados en el antebrazo a las garras (Taylor 1989, Salton y Sargis 2008, Morgan y Verzi 2011, Moore et al. 2013, Samuels et al. 2013), y mínimas aptitudes para manipular o sujetar objetos (Taylor 1989, Iwaniuk et al. 2001). Sin embargo, como notó previamente Van Valkenburgh (1987), en Ta. taxus (y secundariamente en Mell. capensis, ver Tabla 2.3) se registra una longitud de falange proximal III equivalente al 71\% de la longitud del metacarpal III (i.e., LaMcIII/LaFIII = 1,41). Aunque este valor del índice LaMcIII/LaFIII podría relacionarse en una primera instancia a manipulación de presas en esta especie de tejón (más carnívoras que otros cavadores), estudios sobre la estrategia de caza del taxón no revelan participación activa de los miembros anteriores en dicha actividad (e.g., Sullivan 1996, Michener y Iwaniuk 2001). En el caso de Co. chinga, los metacarpales y dígitos tienen una disposición simétrica y mesoaxónica, siendo progresivamente menores los dígitos periféricos respecto al central, característica típicamente presente en cavadores especializados (Hildebrand 1988, Salton y Sargis 2008, Morgan y Verzi 2011) y desarrollada de forma convergente en Ta. taxus (Apéndice 3.15, c. 53, estado 0). En Mel. meles, los metacarpales y dígitos III y IV son prácticamente iguales, similar a muchos otros mustélidos (ver también Heráň 1962). Al parecer, esto reflejaría la retención de una morfología ancestral para arctoideos (Apéndice 3.15, c. 53, estado 1) más que una adaptación al hábitos fosoriales. Así como ocurrió en otras regiones del postcráneo (e.g., morfología y longitud relativa del sector cervical, proporciones generales del cuerpo, ver secciones 4.3.1, 4.3.2, Región cervical), nuevamente los melinos presentan rasgos atípicos para sus hábitos actuales, posiblemente informativos desde el punto de vista filogenético y evolutivo.

En prociónidos como Procyon y guloninos pequeños o medianos (e.g., Martes spp., Heráň 1962, Iwaniuk et al. 1999, Barraquand 2010), los metacarpales y falanges son elongados y gráciles, y las falanges ungueales presentan unguis recurvadas y comprimidas lateromedialmente, características que indican especialización al sustrato arbóreo y ausencia de capacidades de cavado (Taylor 1989, Salton y Sargis 2008, Morgan y Verzi 2011), así como 
capacidades de manipulación en muchos de estos taxones (e.g., McClearn 1992). En Na. nasua se registra metacarpales y falanges robustas, y falanges ungueales hipertrofiadas, engrosadas lateromedialmente y curvadas distalmente, similar a Ei. barbara, compatibles con capacidades de scratching y trepado (Van Valkenburgh 1987, Taylor 1989, Argot 2003b).

\subsubsection{Miembro posterior}

\subsubsection{Hueso coxal}

\section{Morfología general}

Entre los musteloideos analizados existen dos configuraciones principales del hueso coxal: un grupo presenta un ángulo agudo entre el plano isquio-púbico y el plano del ilion (típicamente entre $45 \mathrm{y} 70^{\circ}$ ), siendo este último elemento relativamente aplanado; y otro grupo presenta un ángulo aproximadamente recto entre estos planos, siendo la cara externa del ilion marcadamente cóncava (Fig. 4.3). El ángulo formado entre el plano isquio-púbico y el plano del ilion es cercano a los $60-70^{\circ}$ en todos los mustélidos sudamericanos, con un valor máximo en Ei. barbara y un valor mínimo en Ly. patagonicus y Mu. frenata. En Ly. patagonicus, el ángulo entre ambos planos es cercano a los $45^{\circ}$. La concavidad de la cara externa del ilion es baja en todos los mustélidos sudamericanos, aunque es más pronunciada en Ei. barbara que en los demás taxones. El ángulo entre los planos isquio-púbicos es cerrado en todos estos casos. Una configuración similar puede encontrarse en otros mustélidos no sudamericanos incluyendo a la mayoría de los lutrinos, todos los mustelinos e ictoniquinos, los guloninos pequeños a medianos y helictidinos. Dentro de los musteloideos esta configuración está claramente definida en Bassariscus astutus, mientras que se registra también, aunque menos claramente en el mefítido Spilogale gracilis.

De manera diferente, en Enhydra lutris (y menor medida Lutra maculicollis), Gulo gulo, melinos, taxidinos, melivorinos y muchos prociónidos y mefítidos, el ángulo formado entre el plano isquio-púbico y el plano del ilion es mayor (e.g., cercano o superando a los $90^{\circ}$ en Meles meles, Conepatus chinga, y entre 80 y $90^{\circ}$ en Procyon lotor), siendo esta potencialmente la condición ancestral de Arctoidea (reconstrucción ambigua, Apéndice 3.15, c. 54, estado 0), desarrollada convergentemente en en Enhydra lutris (y menor medida Lutra maculicollis). Es estas especies, la espina ventro-craneal se encuentra lateralmente proyectada y la cara externa es marcadamente cóncava y amplia. Por otro lado, los ángulos de confluencia entre los planos isquio-púbicos tienden a ser mayores (aproximadamente $90^{\circ}$ en todas estas especies).

Estos dos grandes grupos morfológicos presentan una clara correspondencia funcional con los estilos locomotores de las respectivas especies que lo conforman. Holmes (1980, y bibliografía citada), relacionó la morfología de iliones aplanados y orientados mayormente en el plano parasagital con adaptaciones a la locomoción rápida mientras que la configuración 
opuesta fue asociada a adaptaciones fosoriales (Holmes 1980 y bibliografía allí citada), o regiones lumbares cortas (Argot 2010), dejando un gran número de casos sin interpretación funcional. El análisis de Elftman (1929) en marsupiales fue mucho más completo, proponiendo una relación entre la morfología del hueso coxal y el desarrollo relativo de los principales grupos musculares que allí se originan y sus funciones relativas.

En el ilion, sobre la cara interna de su extremo craneal se insertan el m. iliocostalis, músculos abdominales, y eventualmente el m. longissimus (Hall 1926, 1927, Elfman 1929, Savage 1957, Gambaryan y Karapetyan 1961, Gambaryan 1974, Evans y De Lahunta 2013; secciones 3.1.6, 3.1.9). La expansión lateral de las áreas de orígenes de estos sistemas axiales resulta en un mayor espacio para estos músculos, y una mayor ventaja mecánica para la flexión lateral a los paquetes más laterales (Savage 1957). Por otro lado, esta expansión lateral, también implica una mayor concavidad de la cara externa del ilion y permite un mayor volumen y área de origen de los mm. gluteus, extensores débiles, abductores y rotadores de los miembros posteriores (Elftman 1929, Savage 1957, Argot 2002, Fisher et al. 2008). Un último grupo muscular relacionado al sector corresponde al $\mathrm{m}$. iliacus, porción ilíaca del $\mathrm{m}$. iliopsoas que se origina sobre el sector ventral del ala del ilion, flexor y rotador de los miembros posteriores (Elftman 1929, Davis 1964, Fisher et al. 2008). Todos los taxones con morfologías de iliones cóncavos y alejandos del plano isquio-púbico (Fig. 4.3B), se destacan por realizar pasos simétricos a baja y media velocidad, y usar exclusivamente galope, en vez de bound o halfbound, en carrera. En estas marchas, los miembros se mueven ampliamente fuera del plano parasagital (Davis 1964, Gambaryan 1974, Jenkins y Camazine 1977, Van de Graaff et al. 1982, Berdnikovs 2005). A su vez, la activación alternada de los sistemas axiales más laterales permite una importante componente de flexión lateral y rotación de la zona pélvica, acompañando el adelantamiento de cada miembro, para extender la longitud de la zancada (Gregory 1912, Gambaryan 1974, Jenkins y Camazine 1977, Van de Graaff et al. 1982, Hildebrand 1988). Estas marchas son más seguras y estables que el half-bound o bound debido al mayor número de puntos de apoyo en la secuencia de pasos, y es por ello que son típicas de especies cavadoras y trepadoras, especialmente las de mayor tamaño (Hildebrand 1976, 1988, Holmes 1980, Van de Graaff et al. 1982, McClearn 1992, Berdnikovs 2005), así como también en especies lentas (Van de Graaff et al. 1982, Berdnikovs 2005, Álvarez et al. 2013). Un mayor ángulo de contacto entre los planos isquio-púbicos, en combinación con un fémur orientado más perpendicularmente a la cadera, se asocia con amplias libertades de aducción y abducción y otros movimientos fuera del plano parasagital de los miembros, otorgando mayor ventaja mecánica de la musculatura aductora para la aducción (Jenkins y Camazine 1977, Van de Graaff et al. 1982, Berdnikovs 2005: 200-201). 
Por el contrario, las especies que realizan locomoción a saltos requieren de poderosos movimientos de flexión y extensión de la región lumbar. A partir de lo descripto por Gambaryan (1974) y lo desprendido de las disecciones de Ga. cuja, en estos linajes los paquetes laterales epiaxiales tienden a estar representados por una única gran masa (el m. iliocostalis, o éste fusionado al $\mathrm{m}$. longissimus dorsi). Tanto los mustélidos weasel-like como muchas nutrias (Heptner y Naumov 1967, Gambaryan 1974, Willemsen 1980a, b) comparten una morfología similar del ala de ilion que es aplanada y proyectada por sobre los procesos espinosos lumbares (Fig. 4.3A). Un morfología similar fue registrada para Perameles, un marsupial saltador (Elftman 1929). Según las optimizaciones, esta morfología ya habría estado presente en el ancestro común del clado Mustelidae - Taxidea - Melinae (Apéndice 3.15, c. 56, estado 1). Estos rasgos permiten una ubicación relativamente medial del $\mathrm{m}$. iliocostalis, ventralmente al origen del $\mathrm{m}$. longissimus dorsi (en caso de estar presente). De esta manera, el m. iliocostalis toma el rol de extensor principal de la columna al principio de generación del salto (Gambaryan 1974, Ercoli et al. 2013). La superficie externa y ventral del ala del ilion aplanada y relativamente reducida de estas especies se habría desarrollado convergentemente en guloninos pequeños y hurones (Apéndice 3.15, c. 55, estado 0), e indica un bajo desarrollo del los mm. gluteus, extensores débiles, abductores y rotadores, y el m. iliacus, flexor y rotador de la cadera del miembro posterior, siendo la variedad de movimientos de esta articulación menos importantes en la locomoción a saltos que en otras marchas (en donde se prioriza, en el sector proximal de los miembros, una extensión poderosa en una posición aducida del miembro, Elftman 1929, Maynard Smith y Savage 1956, Gambaryan 1974, Van de Graaff et al. 1982, Álvarez et al. 2013). Convergentemente a lo observado en estos mustélidos, aunque sólo parcialmente registrado por la codificación de caracteres (ver Apéndice 3.15, c. 55 y 56), morfologías similares se registran en Po. flavus, Ba. astutus y S. gracilis, los prociónidos y el mefítido más ágiles, capaces de realizar marchas half-bound o similares (Trapp 1972, PoglayenNeuwall y Toweill 1988, Whitaker y Hamilton 1998), corroborando la relación morfofuncional. Respecto al ángulo agudo entre los planos isquio-púbicos, el menor ángulo favorecería la extensión en el plano parasagital de los miembros en vez de los movimientos fuera del plano parasagital.

En Ei. barbara y algunas especies de Martes spp. se registran formas intermedias de estos rasgos, en relación a sus tamaños moderados, y a la capacidad de realizar tanto galopes como eventualmente half-bound, o pasos intermedios (Kaufmann y Kaufmann 1965, Heptner y Naumov 1967, Dagg 1973, Leach 1977a, Presley 2000, Dionisios Youlatos comunicación personal). En nutrias, los movimientos poderosos de flexo-extensión de la zona lumbar (tanto propulsores, como estabilizadores durante el la retracción de los miembros posteriores) también son importantes durante el buceo (Gambaryan y Karapetyan 1961, Willemsen 1980b, Bebej 
2011). Sin embargo, en el caso de extrema especialización de En. lutris, esta función es cedida en gran medida al m. longissimus dorsi mientras que el $\mathrm{m}$. iliocostalis se encuentra relativamente más reducido (ver análisis osteológico de sección 4.3.2, Región tóraco-lumbar, y miológico en Gambaryan y Karapetyan 1961). Para En. lutris es detacable la lateralización del extremo craneal del ilion. Posiblemente esta modificación ósea se encuentre vinculada a la configuración miológica de la región lumbar y cadera paticular de Enhydra (ver por Gambaryan y Karapetyan 1961, Lewis 2008), y en relación a algunas estrategias de nado también propias de este taxón dentro de Lutrinae (Tarassoff 1972, Taylor 1989; ver Apéndice 4.1I). Como Holmes (1980) destacó, En. lutris no es necesariamente un extremo de especialización en comparación con otras nutrias, sino que presenta un estilo aparte, implicando otros movimientos y grupos musculares (ver Tarasoff 1972, Williams 1989, Lewis 2008, Peigné et al. 2008). Es necesario destacar que una configuración similar a la de la nutria marina se registra también en pinnípedos, secundariamente en algunas otras nutrias vivientes, y en algunos carnívoros otterlike extintos (e.g., el lutrino †Sardolutra ("Nesolutra") icnusae, y el carnívoro de afinidades inciertas ${ }^{\dagger}$ Potamotherium valletoni; Savage 1957, Malatesta 1977), seguramente con similares implicancias miológicas y funcionales.

\section{Ala y cuerpo del ilion}

En nutrias, el ala del ilion es alargada cranealmente (marcadamente en el caso de En. lutris) pero su superficie externa es poco cóncava, con una línea glútea moderadamente marcada (excepto en Lo. felina y Lo. longicaudis dentro de las especies de América del Sur) y espinas robustecidas y proyectadas en sus ángulos. Esta morfología parece indicar un moderado desarrollo de los mm. gluteus, intermedio al de saltadores y ambulatorios. Sin embargo, el análisis del sitio de inserción de este grupo muscular (ver sección 4.3.5, Fémur y patela) y de la masa muscular de representantes de estos grupos (Gambaryan 1974, Ercoli et al. 2013) indican un mayor desarrollo de los mm. gluteus, seguramente en relación a un gran desarrollo de paquetes superficiales sin origen óseo, e importantes movimientos de rotación y abducción de los miembros, necesarios durante la propulsión y cambios de dirección durante el nado.

El gran desarrollo de las espinas dorso-craneal, dorso-caudal y ventro-craneal implica una gran importancia relativa de la porción lumbar del m. longissimus dorsi en nutrias (principal extensor de la región lumbar en las nutrias especializadas, Gambaryan y Karapetyan 1961), m. intertransversarii dorsales caudae (extensor y estabilizador poderoso de la cola) y musculatura abdominal (flexores de la región lumbar, Ercoli et al. 2013, ver secciones 4.1.1, 4.3.2, Región caudal, Láminas 2.18-20) respectivamente. Esto, sumado a lo comentado para el m. iliocostalis, es concordante con los movimientos requeridos durante el buceo, en donde las ondulaciones dorsoventrales del esqueleto axial juegan un rol preponderante en la propulsión y los miembros posteriores acompañan este movimiento (Willemsen 1980b, Williams 1989, Fish 1994, 2001). 
Pteronura brasiliensis ha sido destacada como la nutria sudamericana más especializada en el buceo, en la que la participación de la cola, que es aplanada y amplia, es mayor que en otras nutrias (Fish 1994, 2001, Kruuk 2006). El mayor desarrollo del área de origen del m. intertransversarii dorsales caudae evidencia un mayor control muscular de este apéndice en esta especie.

En Ei. barbara, así como en muchos musteloideos trepadores, las espinas dorsales presentan un desarrollo relativamente menor que en nutrias, disminuyendo la importancia de las zonas de agarre de los músculos extensores lumbares y caudales, mientras que la proyección ventral de las espinas ventrales parece vincularse más una expansión del área para los mm. gluteus y abdominales que a un incremento del área de inserción del m. quadratus lumborum. El mayor desarrollo de los mm. gluteus y menor de los extensores sobre los flexores axiales en Ei. barbara es coincidente con la capacidad de realizar galope y trepado vertical en esta especie, actividades que requieren un adelantamiento activo poderoso de la cintura pélvica, y movimientos más rápidos de extensión de la cadera son requeridos (Taylor 1989, Berdnikovs 2005). En los hurones sudamericanos, la espina dorso-craneal está reducida, indicando la reducción del sector lumbar del m. longissimus dorsi (extensor y estabilizador), reemplazado por la expansión del m. iliocostalis (extensor y flexor lateral axial), como fue observado en las disecciones (sección 3.1.9), en relación a la locomoción half-bound y la incursión en galerías estrechas (Gambaryan 1974, King y Powell 2007, Ercoli et al. 2013).

En la mayoría de los linajes terrestres, el desarrollo de las espinas ventrales del ala del ilion y del tubérculo para el $\mathrm{m}$. psoas minor (zonas de inserción de flexores axiales) es moderado (e.g., melinos, muchos ictoniquinos y Gulo gulo) a bajo (Ly. patagonicus, mustelinos, la mayoría de los guloninos, prociónidos y mefítidos), mientras que siempre es importante en nutrias. Esto se debe a que durante el buceo la flexión debe ser promovida por la contracción de la musculatura abdominal e hipoaxial, mientras que en el galope, y especialmente durante la locomoción a saltos, parte de la flexión de la espina es pasiva, causada por la inercia del cuarto posterior al comenzar la fase de apoyo de los miembros anteriores (Gambaryan 1974, Fish 1994, Berdnikovs 2005). Un caso extremo se da en Ly. patagonicus, en el que el área disponible para el origen de los mm. gluteus, m. iliocostalis, y musculatura flexora axial es mínima, posiblemente en relación a su alto grado de especialización a marchas half-bound y bajo tamaño corporal (ver más abajo). En el caso de mefítidos y la mayoría de los prociónidos, la región lumbar relativamente rígida (ver sección 4.3.2, Región tóraco-lumbar) impide un galope sinuoso como en mustélidos, y hace innecesario el desarrollo de los músculos flexores lumbares que actúan en este plano (Hildebrand 1977, van de Graaff et al. 1982, McClearn 1992).

Más allá de las cuestiones funcionales discutidas, la proyección craneal del ala del ilion, superando ampliamente la altura de la articulación con el sacro, se encuentra fuertemente 
influenciada por el tamaño corporal. En las especies sudamericanas, el desarrollo es máximo en Pt. brasiliensis, seguido en orden por Lontra spp., Ei. barbara, Galictis vittata, Ga. cuja, Mu. frenata, y Ly. patagonicus. En algunos especímenes del huroncito patagónico (e.g., MACN 21982) el ala del ilion ni siquiera alcanza en nivel de las superficies articulares craneales del sacro. Entre los musteloideos en general, las nutrias presentan el mayor desarrollo de esta superficie, seguidas por Mellivora capensis, tejones, mefítidos, prociónidos. Este marcado patrón alométrico no es inesperado si se considera la importancia del $\mathrm{m}$. iliocostalis como principal propulsor tanto en el galope como el half-bound en mustélidos, y la relación no lineal entre el desarrollo de la musculatura y el tamaño corporal de los animales (Hildebrand 1988). Esta lectura, permite comprender también las variaciones intraespecíficas registrada en el pesado de Ga. cuja (Apéndice 3.3), en donde en el espécimen de menor tamaño (i.e., hembra) se registró una drástica reducción relativa de la masa iliocostal lumbar.

La longitud relativa del cuerpo del ilion y del ilion en general tiene un desarrollo relativo máximo en mefítidos y convergentemente en ictoniquinos como I. striatus (Apéndice 3.15 , c. 58, estado 0), y secundariamente mustelinos pequeños y Ly. patagonicus. Aunque no se descarta que esta condición se encuentre relacionada a factores alométricos en las especies más pequeñas y otras cuestiones (ver morfología similar en úrsidos, Davis 1964), también puede relacionarse a estrategias battle-flag, presente en muchos ictoniquinos y mefítidos (Doering 1881, Koslowsky 1904, Hall 1926, Cabrera y Yepes 1940, Dücker 1968, Lariviere y Messier 1996, Larivière 2002a, Caro 2009), en correspondencia a un origen adelantado de la cola respecto a los miembros posteriores (ver secciones 4.3.2, Región tóraco-lumbar y Región sacrocaudal).

\section{Morfología del acetábulo}

El tamaño de la incisura acetabular y la morfología de los márgenes del acetábulo indican el grado de apertura relativo de éste último y, por ende, el nivel de estabilización y restricciones impuestas a los movimientos en la cadera (Savage 1957, Jenkins y Camazine 1977, Álvarez et al. 2013). Entre los mustélidos sudamericanos, los hurones ictoniquinos y mustelinos comparten una incisura acetabular que ocupa aproximadamente un cuarto de la circunferencia, de márgenes con pendientes abruptas y un margen dorsal del acetábulo moderadamente elevado y aplanado. El aumento del área de contacto y encierro de la cabeza del fémur evidencia una articulación reforzada, capaz de resistir el estrés generado por los saltos durante la propulsión y la absorción del impacto durante el aterrizaje (Gambaryan 1974, Jenkins y Camazine 1977). El margen dorsal recto y sobresaliente implica también una restricción al rango de abducción de los miembros, movimiento no necesario, e incluso contraproducente, durante la locomoción a saltos y en túneles estrechos, en la que los miembros son llevados lo más próximo al cuerpo posible y la propulsión se da sobre el plano parasagital (ver Gambaryan 1974, Jenkins y 
Camazine 1977, Horner y Biknevicius 2010, Álvarez et al. 2013). Por el contrario, tanto Ei. barbara como las nutrias comparten un foramen acetabular más somero y abierto (especialmente el margen dorsal) y una incisura acetabular que ocupa una mayor proporción de la circunferencia. Esta configuración le permite a estas especies adoptar un mayor rango de posiciones de los miembros posteriores mediante un amplio rango de abducción y rotación (Elftman 1929, Savage 1957, Jenkins y Camazine 1977), necesario para aferrarse o rodear un sustrato amplio durante el trepado en la tayra (Elftman 1929, Jenkins y Camazine 1977, Taylor 1989, Berdnikovs 2005), y para ubicar los miembros en posición adelantada en tierra, y en una posición más caudal y algo abducida durante el nado superficial o buceo en nutrias que frecuentan ambos ámbitos (Savage 1957, Tarasoff 1972). En Ei. barbara, a su vez, la pared craneal del foramen acetabular es menos profunda y desarrollada que en nutrias, evidenciando una posición habitual más flexionada de la cadera. En líneas generales, las mismas tendencias pueden observarse a nivel Musteloidea (e.g., Procyon lotor en Jenkins y Camazine 1977), en donde las especies acuáticas y arborícolas (en grado extremo Potos flavus) tienden a poseer un acetábulo más abierto y somero, mientras que las especies terrestres generalizadas y cavadoras (tejones y Mellivora capensis) presentan restricciones algo mayores, con un acetábulo más profundo, y las especies saltadoras (e.g., ictoniquinos y mustelinos) muestran los acetábulos más cerrados.

\section{Plano isquio-púbico}

Dentro de los mustélidos de América del Sur, los hurones (aunque no tan marcadamente en Ly. patagonicus) presentan un cuerpo del isquion elongado y un buen desarrollo de la tabla isquiática y el tubérculo isquiático (amplio y distanciado del acetábulo), zona de origen de los extensores poderosos de la cadera y flexores de la rodillas (e.g., m. biceps femoris, m. semimembranosus y m. semitendinosus; Alix 1876, Elftman 1929, Fisher 1942, Ercoli et al. 2013). Lo mismo ocurre en la mayoría de los Musteloidea, y es reconstruida como la condición plesiomórfica del grupo (Apéndice 3.15, c. 59, estado 1). Por otro lado, Ai. fulgens (Fisher et al. 2008), Po. flavus, mefítidos, Procyon spp., ictoniquininos (especialmente en Poecilictis libyca) y secundariamente melinos y taxidinos, presentan el cuerpo del isquion más breve y un tubérculo y rama isquiática cercanos al centro de giro de la articulación. Aunque en hurones y guloninos pequeños el desarrollo de las áreas de origen de los músculos extensores poderosos de la cadera es similar o incluso menor a la de estos otros grupos de musteloideos (Apéndice 3.15, c. 58), la reducción relativa de los miembros, les permite una mayor ventaja mecánica a la extensión de los miembros posteriores, requerida durante la fase de apoyo en la propulsión a saltos (Gambaryan 1974, Ercoli et al. 2013). En resumen, los linajes que realizan saltos poderosos y marchas ágiles (y energéticamente costosas) presentan una gran ventaja mecánica de la musculatura extensora de la cadera y flexora de la rodilla de origen isquio-pubial (sumado 
a la presencia de un vientre del m. semitendinosus caudal; Elftman 1929, Maynard Smith y Savage 1956, Argot 2002, Ercoli et al. 2013). Por otro lado, en arborícolas no saltadores y especies terrestres ambulatorias (especialmente en las que se desplazan largas distancias, e.g., Gulo gulo, Janis y Wilhelm 1993) estos músculos presentan orígenes cercanos al centro de giro (en el caso de prociónidos y algunos guloninos incluso están reducidos; Apéndice 3.15, c. 59, estado 0) y las posiciones de inserción son más proximales (en conjunto con un mayor desarrollo de los extensores rápidos, ver arriba; Maynard Smith y Savage 1956, Ercoli et al. 2013; sección 4.1.3), configuración que les permite imprimir mayor rapidez a los movimientos con un menor costo energético (Hildebrand 1988).

Por otro lado, la mayoría de las nutrias (incluyendo todas las sudamericanas), presentan estas áreas hipertrofiadas, con un tubérculo isquiático sobre-elevado, un cuerpo isquiático alargado, y una plano isquio-púbico marcadamente expandido en sentido caudal y ventral (en caso extremo en Pt. brasiliensis; ver también Maynard Smith y Savage 1956, Savage 1957, Willemsen 1980a, b; ver sinapomorfías de Lutrinae; Apéndice 3.15, c. 58, estado 2 y 59, estado 2). Por otro lado, todas las partes que conforman el plano isquio-púbico se encuentran modificadas en sus posiciones relativas: el cuerpo del isquion se proyecta más dorsalmente (especialmente en Pt. brasiliensis), el ángulo conformado entre la rama caudal del isquion y su cuerpo es abierto (Pt. brasiliensis y Lo. provocax) o cercano a los $90^{\circ}$ (Lo. longicaudis), y el ángulo entre el cuerpo del isquion y pubis es muy bajo, cercano a los $50^{\circ}$ (en directa relación con un ángulo sacro-pélvico también bajo, ver Maynard Smith y Savage 1956, Savage 1957, Willemsen 1980a, b), posicionando al isquion alejado y dorsal con respecto al centro de rotación de la cadera (ver sinapomorfías de Lutrinae; Apéndice 3.15, c. 60, estado 2). Esta reconfiguración total del sector caudal de la cintura, que en su conjunto sólo se encuentra presente en lutrinos dentro de Musteloidea, se asemeja a la condición observada en Pinnipedia, y permite que los principales músculos originados en el sector, los extensores fuertes de la cadera (m. semitendinosus, m. semimembranosus, m. biceps), dispongan de un amplia área de origen y la máxima ventaja mecánica, tanto para la extensión como aducción, cuando los miembros posteriores se encuentran en posiciones extendidas que es cuando los miembros actúan durante el buceo (Maynard Smith y Savage 1956, Savage 1957, Gambaryan y Karapetyan 1961, Tarasoff 1972, Malatesta 1977, Willemsen 1980b). En algunas nutrias (e.g., En. lutris; Fisher 1942, Howard 1975), la desaparición del vientre isquial y el sobre-desarrollo del caudal implica una mayor ventaja mecánica del grupo hamstring para la extensión de la cadera, y la facilitación de una posición netamente caudal de los miembros posteriores (Williams 1989, Ercoli et al. 2013). La brevedad del fémur en nutrias (ver más adelante) exacerba aun más la ventaja mecánica de estos músculos (reduciendo el brazo de salida; 
Maynard Smith y Savage 1956). Huesos coxales alargados y delgados también colaboran en mantener un perfil hidrodinámico (Tarasoff et al. 1972, Berdnikovs 2005).

Tanto el cuerpo como la rama caudal del pubis corresponden a las áreas de orígenes de los principales aductores de los miembros posteriores, mientras que la cara interna de la rama caudal del pubis aloja a la sínfisis pélvica entre cada hemipelvis (Savage 1957). La longitud de la sínfisis pélvica se encuentra directamente vinculada al sexo en relación a la presencia del canal de parto en las hembras, aunque la intensidad de esta variante intraespecífica es mucho menor a las registradas en función del tamaño o hábito locomotor (e.g., Berdnikovs 2005, Álvarez et al. 2013). En mustélidos sudamericanos, así como en mustelinos y guloninos de otros continentes (mustélidos weasel-like en general; ver también Holmes 1980), el desarrollo moderado a amplio de estas estructuras, además de permitir amplias áreas de orígenes y ventaja mecánica para la extensión de la cadera a los músculos aductores (Hildebrand 1988, Berdnikovs 2005), permite el desarrollo de una sínfisis pélvica relativamente amplia, como ya lo destacó Holmes (1980). El incremento del área de fusión entre las dos hemipelvis permitiría a estas especies saltadoras resistir con mayor seguridad el impacto del aterrizaje en la locomoción a los saltos (Álvarez et al. 2013, pero ver Elftman 1929). Por otro lado, las especies de Mustela más pequeñas y Ly. patagonicus presentan pubis menos desarrollados que sus parientes de mayor tamaño, posiblemente en relación a cuestiones alométricas (Hildebrand 1988, Álvarez et al. 2013). En las nutrias, que no usan tan frecuentemente estrategias half-bound, o no presentan una fase aérea extendida en la locomoción (Williams et al. 2002), las sínfisis son más breves que en los hurones. Holmes (1980) realizó una observación similar, aunque relacionó la configuración lutrina con adaptaciones a la vida acuática. La reconfiguración del plano isqui-púbico de las nutrias, como ocurre para los extensores fuertes de la cadera, implica una mayor ventaja mecánica para la aducción en posiciones extendidas de los miembros (Savage 1957). Por otro lado, en Lo. longicaudis y Pt. brasiliensis se registra una mayor inclinación caudal de la sínfisis, seguramente en relación a la posición habitualmente extendida de los miembros posteriores, aunque la ausencia de este rasgo en Lo. provocax no puede ser explicada de esta manera, y quizás tenga que ver con variantes es sus hábitos de vida.

En Gulo gulo, Ei. barbara, Meles spp., Mellivora capensis, Melogale moschata, y muchos prociónidos, se registra una reducción cráneocaudal de la rama caudal del pubis, mientras que el cuerpo del pubis es relativamente largo. Esto implica una reducción del área de origen disponible para muchos de los principales músculos aductores del miembro posterior (Holmes 1980, Berdnikovs 2005), pero también una mayor separación entre la línea de acción de los aductores respecto a la articulación de la cadera y un incremento de la ventaja mecánica para los mismos, especialmente en aquellas especies con fémures alargados (ver también Spoor y Badoux 1988). En ictoniquininos, convergente a lo observado en mefítidos y Taxidea taxus 
(Apéndice 3.15, c. 60, estado 0), esta configuración se lleva al extremo, con una reducción máxima de la rama caudal del pubis y sínfisis (Holmes 1980, Berdnikovs 2005, Álvarez et al. 2013), en relación a la ausencia de carreras ágiles, en relación a un menor estrés al cual se encuentra sometida esta región, e indirectamente, posiblemente también en relación a sus hábitos fosoriales. Aunque muy poco se sabe sobre la locomoción de ictoniquininos, al menos para Ictonyx striatus se ha descripto tipo de pasos, hábitos y comportamientos muy similares a zorrinos (razón por la cual su nombre vulgar es mofeta común; Larivière 2002a).

\subsubsection{Fémur}

\section{Morfología del sector proximal y proporciones generales del fémur}

La longitud relativa y robustez del fémur se encuentran afectadas por variantes en los estilos y sustratos locomotores, así como el tamaño corporal. El fémur de las nutrias sudamericanas es marcadamente robusto (Lámina 3.14), especialmente en su sector distal, breve en sentido proximodistal, aplanado cráneocaudalmente y expandido lateralmente (similar a pinípedos y otras nutrias; Savage 1957, Samuels et al. 2013), rasgos marcados en Pt. brasiliensis (ver también Lewis 2008, Peigné et al. 2008). Estas características, así como el posicionamiento de un trocánter mayor lateralizado, han sido interpretadas como adaptaciones a la vida acuática, en relación a la reducción del arrastre en un medio denso y la resistencia a los esfuerzos generados sobre el sector distal de los miembros posteriores durante el nado (Savage 1957, Holmes 1980, Willemsen 1980a, b, Lewis 2008, Peigné et al. 2008, Samuels et al. 2013). La expansión lateral y rugosa que se observa a lo largo de la diáfisis femoral se relaciona a un m. gluteofemoralis que alcanza el sector próximo al epicóndilo lateral, permitiendo una poderosa abducción y rotación de la pierna (Howard 1975, Peigné et al. 2008). Estas características también se reconocen en todas las nutrias de otros continentes, excepto en Aonyx spp., en las que se muestran apenas esbozadas (ver Holmes 1980, Peigné et al. 2008). Enhydra lutris, especializada en el nado con los miembros posteriores y ondulaciones axiales (Gambaryan y Karapetyan 1961, Fish 1994, Lewis 2008), presenta la morfología más similar a Pt. brasiliensis entre los lutrinos y el máximo desarrollo de esto rasgos (Malatesta 1977, Holmes 1980, Lewis 2008). Por otro lado, un ensanchamiento de la diáfisis femoral algo menor se encuentra presente en la mayoría de los musteloideos terrestres, especialmente en linajes de mayor tamaño y cavadores (e.g., tejones y mefítidos; Holmes 1980, Peigné et al. 2008), pudiendo favorecer un transporte seguro de la fuerza peso del cuerpo durante el cavado (Heptner y Naumov 1967, Van de Graaff et al. 1982, Heinrich y Biknevicius 1998, Peigné et al. 2008).

Entre los mustélidos terrestres sudamericanos, Ei. barbara presenta un fémur elongado y estilizado de sección mayormente circular. La misma condición fue registrada en otros 
guloninos, como lo son las especies de Martes. La elongación del fémur, como fue destacado para los huesos largos del miembro anterior, se relaciona directamente al estilo de vida trepador del taxón, permitiéndole posicionar los miembros en un estrato discontinuo y rodearlo cuando es necesario (Dagg 1973, Holmes 1980, Van Valkenburgh 1987, Argot 2002). Pese a la presencia registrada del m. gluteofemoralis en Ei. barbara así como en todos los guloninos (Macalister 1873b, Ercoli et al. 2013), éste no produce una modificación sustancial de la morfología del fémur. El gran tamaño corporal de Gu. gulo, así como su mayor grado de uso del sustrato terrestre (Ondrias 1961), son factores seguramente importantes en el robustecimiento relativo de la diáfisis femoral observado en esta especie (Hildebrand 1988, Biewener 1989). En prociónidos, pese a muchas similitudes en los hábitos locomotores, la diáfisis femoral es notablemente más robusta que en guloninos pequeños y medianos, especialmente en sus extremos, y la presencia de la inserción lateral del m. gluteofemoralis en Nasua spp. y Po. flavus queda claramente evidenciada por una cresta rugosa visible.

Más allá de muchas similitudes, los hurones sudamericanos ictoniquinos presentan algunas diferencias respecto a $\mathrm{Mu}$. frenata y otros mustelinos en general. En los lincodontininos e ictoniquinos en general (e.g., Poecilictis libyca), el fémur es breve, mientras que en $M u$. frenata, y más marcadamente en otras especies del género (Holmes 1980), la diáfisis femoral es más larga y grácil, con proporciones internas (aunque no respecto a otras partes del cuerpo; ver sección 3.4, LaTL/LaPrM, Tabla 2.3) más similares a las de Ei. barbara que a los lincodontininos o ictoniquininos (ver también Holmes 1980). Esta diferencia destacable, podría ser un indicador de una mayor capacidad de trepado y menor capacidad de cavado en Mustela respecto a ictoniquinos (Heptner y Naumov 1967, Holmes 1980, Yensen y Tarifa 2003a, b, Wilson y Mittermeier 2009). Esta y otras características de ictoniquinos (e.g., la limitada capacidad de abducción de la cadera y región lumbar reducida; ver más arriba) serían potenciales limitantes para rodear ramas durante el trepado vertical en la mayoría de los casos, excepto en ramas de pendiente bajas o sustratos irregulares al cual pueda aferrarse por prensión del autopodio (Azara 1802, Cabrera y Yepes 1940, Sunquist et al. 1989, Yensen y Tarifa 2003a, b, observaciones personales; ver Fig. 4.4).

La morfología de la región proximal del fémur se encuentra altamente influenciada por la estructura filogenética y los hábitos locomotores (Fig. 3.8, Apéndice 3.8D1). Los dos primeros ejes del análisis de la forma de la vista caudal del sector proximal del fémur permite diferenciar en forma significativa a todos los grupos locomotores entre sí (Apéndice 3.8D1). En todos los mustélidos sudamericanos, especialmente los no acuáticos, la cabeza femoral se posiciona moderada a marcadamente alejada medialmente respecto a la diáfisis femoral, se orienta dorsal y medialmente y posee una fóvea de posición caudocentral en vista medial. Del análisis comparativo de Jenkins y Camazine (1977) se desprende que esta configuración indica 
que la diáfisis del fémur se encuentra habitualmente en una posición lateralizada, y relativamente aducida, respecto a la cadera, permitiendo amplios movimientos de flexoextensión de la articulación aunque con limitaciones moderadas de las excursiones a posiciones abducidas (mayores que Procyon lotor y menores que en cursoriales, ver Jenkins y Camazine 1977, Heinrich y Houde 2006). La cabeza femoral de los especímenes de Ei. barbara posee un aspecto en general más redondeado, en relación a la mayor movilidad de la cadera comentada en el apartado de pelvis (ver arriba), aunque la muesca de la fóvea no está dorsalizada, más similar a otros guloninos y félidos (trepadores y cazadores sigilosos; Gambaryan 1974, Jenkins y Camazine 1977, Heinrich y Houde 2006) que a lo observado en prociónidos (trepadores ambulatorios; Jenkins y Camazine 1977). En Ei. barbara, el cuello femoral está menos definido y la cabeza articular se proyecta menos medialmente, lo que queda resumido como un desplazamiento hacia valores negativos de los primeros dos $\mathrm{PC}$ en el análisis de forma de fémur (Fig. 3.8). Estos rasgos se asocian a un reaseguro articular menos marcado que en hurones y nutrias. En estos últimos linajes, la cabeza femoral es grande y de márgenes y cuello femoral bien delimitados, lo que se refleja en un posicionamiento sobre valores positivos de ambos ejes de forma (Fig. 3.8), y lo que presenta una lectura funcional opuesta (i.e., mayor reaseguro de la articulación; Holmes 1980, Schutz y Guralnick 2007). Por otro lado, las nutrias sudamericanas comparten una marcada proyección cráneoventral de la superficie articular (aunque menos definido en Lo. longicaudis y Lo. felina que en Lo. provocax y Pt. brasiliensis), al parecer en relación con un reaseguro en posiciones parcialmente extendidas y rotadas externamente de la articulación, resistiendo los esfuerzos distales durante el comienzo de la fase de propulsión en el padding.

El mismos patrón morfológico se constata en otros musteloideos, en donde algunos guloninos, mustelinos, lutrinos, ictonictininos (excepto Ictonyx striatus), y Melogale moschata, presentan cabezas femorales alejadas medialmente de la diáfisis (posicionándose en valores centrales o positivos de ambos ejes; Fig. 3.8B), característica optimizada como adquirida en el ancestro común de hurones y Melogale y convergentemente en Spilogale (Apéndice 3.15, c. 61, estado 0), y permisiva de amplias libertades de movimientos flexo-extensores, pero no tan amplias en los otros sentidos. La mayoría de los guloninos y prociónidos, linajes musteloideos trepadores, tienden a presentar cabezas femorales hemi-esféricas, y tienden a posicionarse sobre valores negativos de ambos ejes en el análisis de forma (Fig. 3.8B). Musteloideos basales como los tejones, Mellivora capensis, y la mayoría de los mefítidos (especialmente Conepatus chinga) tienden a presentar una morfología similar a los anteriores, con un cuello femoral más vertical o reducido, con una cabeza femoral inclinada dorsalmente (expandida sobre el plano longitudinal y alcanzando a ubicarse parcialmente sobre la diáfisis femoral) y, en general, una fóvea de posición dorsalizada, posicionándose en valores centrales o negativos de ambos ejes del análisis 
de forma (Fig. 3.8B). Esta configuración, reconstruida como un rasgo plesiomórfico para Arctoidea (Apéndice 3.15, c. 61, estado 0), es más acorde con un eje del fémur en línea con la articulación de la cadera (y una transmisión más directa de la fuerza peso), y una posición habitual algo abducida del miembro, en relación a marchas generalizadas (Ewer 1973, Jenkins y Camazine 1977, Heinrich y Houde 2006).

Por otro lado, en especies nadadoras (e.g., lutrinos, especialmente en las de mayor tamaño: En. lutris, Pt. brasiliensis), y secundariamente en hurones y algunos linajes cavadores (e.g., tejones), la cabeza femoral es proporcionalmente grande (Apéndice 3.15, c. 61, estado 2 y 1, respectivamente), indicando mayor seguridad y restricciones articulares en la cadera, en relación al soporte del estrés de los miembros posteriores tanto durante impactos entre saltos, cavado, nado, acentuándose en algunas especies relación a los requerimientos impuestos debido al gran tamaño corporal (Holmes 1980, Hildebrand 1988, Biewener 1989, Schutz y Guralnick 2007, Ercoli y Schutz 2012). La depresión aguda y marcada que separa la cabeza articular del trocánter mayor en Lo. provocax (ver Lámina 3.14G) y Lo. felina, es una característica prácticamente única dentro de las nutrias (que se caracterizan típicamente por una separación más transicional entre ambas estructuras; Fig. 3.8; ver también Björk 1970), únicamente reconocida también en En. lutris (ver Lewis 2008), y le permitiría a esta especie alcanzar un mayor grado de flexión de la cadera en posiciones abducidas, quizás en relación a actividades específicas no realizadas por otras nutrias.

El trocánter mayor de los hurones sudamericanos es delgado, inclinado medial (convergente a mefítidos; Apéndice 3.15, c. 62, estado 1) y cranealmente y poco proyectado proximalmente (sinapomorfía de Mustelidae; Apéndice 3.15, c. 63, estado 0; ver Fig. 3.8). Esta configuración se asocia a la reducción de los mm. gluteus en relación a la locomoción a saltos, como fue destacado en el apartado de la pelvis (contra Schutz y Guralnick 2007, ver Ercoli et al. 2013). El trocánter mayor y la fosa contigua están relativamente reducidos y próximos al centro de rotación, reduciéndose la ventaja mecánica de los músculos rotadores y abductores que allí se insertan. Estas características indican una posición habitualmente flexionada y aducida de los miembros posteriores, y más precisión y rapidez que fuerza en los movimientos de extensión del mm. gluteus (Maynard Smith y Savage 1956), quizás colaborando en el posicionamiento preciso de los miembros durante locomoción en galerías estrechas y los saltos. Como queda sintetizado en el desplazamiento hacia valores positivos del PC1 del análisis de forma del fémur, y en la optimización de los caracteres osteológicos 62 y 63 (Apéndice 3.15, c. 62 y 63), la misma configuración se habría establecido en el ancestro común de martas y hurones (o de Melogale y hurones; reconstrucción ambigua; Apéndice 3.15, c. 63), y se encuentra presente en otros mustelinos, guloninos pequeños (e.g., Martes americana; Heptner y Naumov 1967), y el ictoniquino fósil ${ }^{\dagger}$ Trigonictis (ver Björk 1970). Una configuración similar 
también se registra en ictoniquininos, aunque en forma menos definida dado que el trocánter mayor tiende a ser levemente más elevado (Apéndice 3.15, c. 62, estado 0) y más robusto en su base en comparación con lincodontininos y otros half-bounders (Apéndice 3.15, c. 64, estados 1 y 2), asemejándose en mayor grado a la morfología típica de musteloideos basales y convergente al tipo mefítido (ver más adelante).

En Ei. barbara el trocánter mayor es robusto, mayormente paralelo a la diáfisis, distanciado lateralmente y superando proximalmente al centro de la cabeza femoral. Esta configuración indica una mayor importancia relativa de los $\mathrm{mm}$. gluteus como extensores y especialmente como abductores (Maynard Smith y Savage 1956). La fosa trocantérica es algo más amplia que en hurones y guloninos más pequeños, especialmente en sentido lateromedial, indicando un amplia área de inserción para los mm. gemelli, m. obturator internus, m. obturator externus, en relación a complejos movimientos fuera del plano sagital (e.g., Ewer 1973). Características similares están también presentes en $G u$. gulo, Mellivora capensis, tejones, y prociónidos (ver Fig. 3.8), en relación a los grandes esfuerzos de abducción y estabilización durante el cavado y trepado, y a la participación de los extensores rápidos durante el galope, actividades comunes a estas especies (Maynard Smith y Savage 1956, Ewer 1973, Gambaryan 1974, Hildebrand 1988). Los zorrinos presentan una morfología similar a la descripta para estos últimos, aunque el trocánter mayor es más delgado en su ápice, asemejándose a ictoniquininos cavadores. Sumado a las convergencias descriptas en la pelvis y esqueleto axial (ver secciones 4.3.2, Región tóraco-lumbar y Región sacro-caudal, 4.3.5, Hueso coxal), la forma del fémur indica un moderado desarrollo de los extensores rápidos de la cadera, y un bajo desarrollo de los extensores fuertes en estos linajes. Esto concuerda con la preferencia de pasos lentos o simétricos (Van de Graaff et al. 1982, Larivière 2002a), una dieta generalizada y la ausencia de persecuciones rápidas de presas (Larivière 2002a), y la presencia de otras estrategias de defensa además del escape en estas especies (coloración y comportamiento aposemático, secreciones de glándulas de almizcle; Larivière y Messier 1996, Caro 2009, Wilson y Mittermeier 2009, Álvarez et al. 2013).

En las nutrias, la pared caudal del trocánter mayor rodea pobremente a la fosa trocantérica, la cual es amplia (Fig. 3.8). En vista craneal, el trocánter mayor se encuentra fuertemente robustecido y remarcado (especialmente en Lo. provocax), indicando un importante desarrollo de los mm. gluteus superficialis (coincidiendo con Schutz y Guralnick 2007, Lewis 2008), mayor que el esperable en función de su origen óseo ilíaco (pero ver orígenes no oseos de m. gluteus superficialis; Fisher 1942, Howard 1975, Ercoli et al. 2013). La robustez de ambas estructuras, y la ausencia de inclinación medial del trocánter mayor (reversión y sinapomorfía optimizada para el ancestro común de Lutrinae; Apéndice 3.15, c. 62, estado 1), indican importantes esfuerzos de movimientos dentro y especialmente fuera del plano 
parasagital en la articulación (Schutz y Guralnick 2007, Lewis 2008), como también fue sugerido en el análisis de la pelvis. En vista dorsal, es evidente una reconfiguración del trocánter mayor y la fosa, observándose una rotación interna respecto a mustélidos no acuáticos. Este rearreglo de la articulación de la cadera se puede relacionar una posición habitual rotada exteriormente del fémur (coincidiendo con lo inferido a partir de zonas articulares), y a la reconfiguración en la pelvis de las áreas de orígenes de muchos de los músculos que alanzan estas estructuras (ver secciones 4.1.3, 4.3.5, Hueso coxal). La misma morfología es común a las nutrias de otros continentes, aunque Lutra spp. (ubicada en cercanías a la forma consenso del análisis de forma del fémur; Fig. 3.8) presentan un trocánter mayor más breve, mientras que Lutro. perspicillata, En. lutris y Pt. brasiliensis uno más robusto (Fig. 3.8). Esta variación indicaría cambios en el grado de participación del $\mathrm{mm}$. gluteus en la propulsión y maniobrabilidad en las diferentes estrategias de buceo (Lewis 2008, ver sección 4.3.5, Hueso coxal).

El tercer trocánter es parte de la región de inserción del m. gluteus superficialis (abductor y secundariamente extensor de la cadera) y, eventualmente, el sector proximal del $\mathrm{m}$. gluteofemoralis. Llamativamente, Wozencraft (1989) consideró ausente a esta estructura en carnívoros vivientes, aunque se encuentra típicamente presente en musteloideos actuales (e.g., Spaulding y Flynn 2012). La presencia de un tercer trocánter definido fue reconstruida como una sinapomorfía de Musteloidea (Apéndice 3.15, c. 64, estado 2), y se encuentra presente en Mellivora capensis y guloninos de gran tamaño; está hipertrofiado en muchos mefítidos (en mayor medida en Mephitis y Spilogale que Conepatus), prociónidos (excepto Potos flavus), tejones, y En. lutris (ver Lewis 2008). La presencia de esta estructura en muchas nutrias y variantes intraespecíficas de especies ictoniquinas es reconstruida como obtenida convergentemente. Por otro lado, se muestra sólo insinuado a modo de un quiebre de pendiente en hurones, otros ictoniquininos, guloninos pequeños y Melogale moschata (posible sinapomorfía del ancestro común de guloninos y hurones; reconstrucción ambigua, Apéndice 3.15, c. 64, estado 1). Estas dos morfologías (tercer trocanter definido vs. a modo de quiebre de pendiente), coinciden cercanamente con dos tipos de estrategías locomotoras, aunque sin descartarse una importancia filogenética del carácter, siendo los primeros principalmente galopantes ambulatorios o trepadores (con amplios movimientos de abducción; Jenkins y Camazine 1977, Argot 2002, 2003b), y los segundos, half-bounders.

Es interesante destacar que en musteloideos, incluyendo a los half-bounders, el trocánter mayor se encuentra a nivel o apenas supera el centro de la cabeza articular, contrario a lo observado en saltadores de otros linajes mamíferos medianos a pequeños. Por ejemplo, en lagomorfos y roedores saltadores, el trocánter mayor sobre-elevado les permite maximizar la ventaja mecánica de los mm. gluteus, encontrándose estos dentro de los principales propulsores 
durante el salto (e.g., Elissamburu y Vizcaíno 2005, Croft y Anderson 2007, Osbahr et al. 2009, García-Esponda y Candela 2010). En cambio, en los musteloideos la propulsión del salto es cedida en gran medida a los sistemas epiaxiales y los extensores fuertes intrínsecos (e.g., hamstrings; Gambaryan 1974, Ercoli y Schutz 2012, Ercoli et al. 2013, Álvarez et al. 2013, ver también Elftman 1929).

El trocánter menor, es la región de inserción del m. iliopsoas, músculo flexor lumbar y rotador externo y flexor de la pierna (Fisher et al. 2009, Evans y De Lahunta 2013, sección 3.1.12). En particular para Ei. barbara, este músculo es amplio, está posicionado proximalmente y proyectado medialmente (ver Fig. 3.8), confiriéndole una mayor eficiencia a la rotación rápida de la cadera desde una posición estática de la pelvis, movimiento relacionado al agarre del sustrato durante el trepado (Ewer 1973, Taylor 1976, Argot 2002, Heinrich y Houde 2006, Schutz y Guralnick 2007, Álvarez et al. 2013). Por otro lado, en nutrias y especialmente en hurones, el trocánter menor presenta una posición más distanciada de la región articular favoreciéndose la función de flexor de la cadera (Taylor 1976). En los hurones de América del Sur, el trocánter menor está típicamente menos definido y se proyecta caudalmente en vez de medialmente, limitando el potencial de rotación del m. iliopsoas (ver Fig. 3.8). Esto está en relación a la mayor importancia relativa de la flexión pasiva de la cadera y zona lumbar por sobre el adelantamiento activo e individual de cada miembro durante la locomoción half-bound (Gambaryan 1974, Fisher et al. 2002, Elissamburu y Vizcaíno 2005, Heinrich y Houde 2006, Schutz y Guralnick 2007). Respecto a otros mustélidos sudamericanos, el trocánter menor tiene su máximo desarrollo y proyección medial en nutrias, seguramente en relación al nado, en donde los movimientos complejos en la cadera y región lumbar son poderosos dada la densidad del medio (Fish 1994, 2001). Por otro lado, esta configuración permite a las nutrias adelantar los miembros y ubicarlos bajo el cuerpo durante la locomoción terrestre (Savage 1957, ver más adelante).

En lo que respecta a otros musteloideos, tanto en mustelinos como en guloninos pequeños, se encuentra la misma disposición que en hurones sudamericanos. Las optimizaciones sugieren que esta morfología fue obtenida independientemente en el ancestro común de Lyncodontininae (aunque la inclusión de otros hurones ictoniquininos podría indicar una adquisición más temprana) y Mustelinae, y en forma menos definida en guloninos pequeños (Apéndice 3.15, c. 65, estado 0). Por otro lado, en Gulo gulo, Poecilictis libyca, Ictonyx striatus, prociónidos, mefítidos, Ailurus fulgens y tejones, la configuración es más similar a nutrias y Ei. barbara: el trocánter menor es robusto, distal y proyectado medialmente (Fig. 3.8), condición reconstruida como plesiomórfica para Arctoidea y todas las familias arctoideas (Apéndice 3.15, c. 65, estado 1; contra Spaulding y Flynn 2012), evidenciando la importancia de poderosos movimientos independientes de cada miembro, dentro y fuera del plano parasagital en estas 
especies ambulatorias galopantes (Davis 1964, Taylor 1976, Jenkins y Camazine 1977, Heinrich y Houde 2006, ver también discusión de área de origen del m. iliacus en sección 4.3.5, Hueso coxal). Estos rasgos están más marcados en los mustélidos de mayor tamaño y cavadores, que requieren mantener posiciones específicas e imprimir grandes esfuerzos propios de dicha actividad (e.g., Meles meles, Mell. capensis, T. taxus; Schutz y Guralnick 2007, Moore et al. 2013).

En relación con lo comentado en la sección 4.3.5, Hueso coxal, las nutrias (incluidas las especies sudamericanas) presentan las marcas de inserción de los aductores y del m. semimembranosus muy bien definidas, colaborando estos músculos en la ubicación y retención de los miembros caudalmente durante el buceo (Fish 1994, Lewis 2008).

\section{Sector distal del fémur}

La tróclea femoral presenta algunas modificaciones entre los mustélidos sudamericanos. Eira barbara presenta una tróclea más somera y breve proximodistalmente en comparación con otras especies; la patela es ancha; los cóndilos presentan un relativamente amplio desarrollo lateromedial y están separados por una fosa intercondiloidea también amplia, mientras que en sentido cráneocaudal son más alargados que la tróclea. Todas estas características indican una baja ventaja mecánica para la extensión ejercida por los mm. quadriceps femoris, bajos esfuerzos de tensión en la rodilla (aunque sin limitar la capacidad para alcanzar posiciones totalmente extendidas), en conjunto con amplias libertades de movimiento fuera del plano parasagital y reaseguros ligamentarios (e.g., ligamentos crucianos, Savage 1957, Tarasoff 1972, Candela y Picasso 2008, Peigné et al. 2008). Esto es acorde con el desplazamiento en sustratos desnivelados durante el trepado y marchas relativamente lentas (Ewer 1973, Taylor 1976, Argot 2002, 2003b). Estas mismas características son observadas también en otros guloninos. Por otro lado, rasgos muy similares se presentan en linajes ambulatorios lentos como mefítidos y, de forma exagerada, en prociónidos (así como en otros predadores trepadores; Taylor 1976, Argot y Babot 2011), siendo optimizados como una reversión de guloninos al estado ancestral y típico de arctoideos basales (Apéndice 3.15, c. 66, estado 0). En mefítidos, Procyon spp., y Po. flavus en extremo, los cóndilos presentan un grado de proyección caudal moderada a baja y una tróclea aplanada y breve, confiriéndole a la vista distal del fémur una apariencia ancha, e indicando menores esfuerzos de extensión del $\mathrm{mm}$. quadriceps femoris y menores restricciones a movimientos fuera del plano parasagital que en guloninos (Ewer 1973, Taylor 1976, Hildebrand 1988). Nasua spp. presentan una condición intermedia entre tejones (ver más adelante; Apéndice 3.15 , c. 66 , estado 1) y otros prociónidos, en relación a la estabilización requerida durante el cavado.

Como se comentó más arriba, todas las nutrias comparten una gran robustez del extremo distal del fémur, característica tradicionalmente considerada como indicadora de hábitos semi- 
acuáticos o acuáticos (Savage 1957, Björk 1970, Samuels et al. 2013). Las nutrias (ver Savage 1957) presentan trócleas profundas, de posición algo medial respecto al eje de la diáfisis (ver sinapomorfía de lutrinos, Apéndice 3.15, c. 66, estado 2), márgenes marcados y anchas (especialmente en Pt. brasiliensis) y patelas voluminosas. El desarrollo cráneocaudal tanto de la tróclea como de los cóndilos es moderado. Estos rasgos indican un rango moderado de extensión y restricciones a los movimientos fuera del plano de acción del m. quadriceps femoris (Savage 1957, Taylor 1976, Argot 2002, 2003b), quizás en relación a la preservación de la capacidad de adelantar los miembros posteriores y ubicarlos bajo el cuerpo al moverse en tierra (como fue inferido también a partir del trocánter menor, Savage 1957). En Pt. brasiliensis la tróclea es más amplia y breve, y el extremo distal del fémur es más robusto y está muy expandido lateralmente, con la fosa intercondiloidea amplia, indicando movimientos no parasagitales aun más importantes con respecto a otras nutrias y un incremento de los reaseguros ligamentarios y la superficie de contacto entre las partes de la rodilla (Savage 1957, Peigné et al. 2008). Esto se vincula a una mayor especialización al nado y una menor importancia de las excursiones terrestres, en las cuales son priorizadas mayores restricciones a movimientos sagitales, y se evidencian indicadores de posturas habitualmente más extendidas y una mayor ventaja mecánica para la extensión de la rodilla (Savage 1957, Holmes 1980). Los movimientos fuera del plano parasagital podrían colaborar con las maniobras de cambios de dirección descriptas para el estilo de nado de esta especie (Taylor 1989, Nowak 2005, Kruuk 2006). Como fue observado en otros linajes fósiles y vivientes acuáticos, la ubicación medial de la tróclea en nutrias sugiere una posición del fémur habitualmente rotada externamente (teniendo en m. rectus femoris una dirección más oblicua), en relación al posicionamiento del miembro más paralelo y cercano a la cola durante el nado (Savage 1957, Taylor 1989, Lewis 2008).

Los hurones, tanto lincodontininos como mustelinos, presentan un marcado angostamiento lateromedial y extensión próximodistal de la tróclea y patela. En vista distal, en hurones en general, aunque menos marcadamente en ictoniquininos, el desarrollo cráneocaudal de la tróclea es también importante, y los cóndilos articulares se encuentran moderadamente proyectados caudalmente. Esto indica una mayor ventaja mecánica y esfuerzos de tensión para el m. quadriceps en posiciones semi-extendidas (Taylor 1976), en relación a la mayor importancia de los movimientos parasagitales en comparación con otros mustoideos generalizados no half-bounders (e.g., Savage 1957, Gambaryan 1974, Hildebrand 1988, Argot 2002, 2003b, Schutz y Guralnick 2007). Esto es crucial durante la aceleración ocurrida en la fase de propulsión, en cercanías al momento del lift-off (despegue) del salto. Por otro lado, la morfología de los cóndilos sugiere que el grado de extensión máximo podría ser menos extremo que en nutrias, con una posición agazapada más marcada. En de Ly. patagonicus, el desarrollo 
cráneocaudal de la tróclea es menor que en Galictis spp. y varias especies de Mustela, indicando menor ventaja mecánica sobre la extensión, posiblemente en relación a los menores esfuerzos propios de especies de bajo tamaño corporal (Hildebrand 1988, Biewener 1989), como fue comentado también para los principales extensores de la cadera (ver sección 4.3.5, Hueso coxal). De manera similar a los hurones, los tejones presentan una tróclea robusta, algo menos angosta y elongada, evidenciando una poderosa extensión del $\mathrm{m}$. quadriceps femoris en relación al soporte y adelantamiento el cuerpo durante el cavado (Schutz y Guralnick 2007, Moore et al. 2013) en conjunto con restricciones algo menores a los movimientos no parasagitales.

Las facetas para los sesamoideos supracondilares, la muesca de origen del $\mathrm{m}$. popliteus y las zonas de orígenes de ligamentos de la rodilla, son amplios en todos los mustélidos sudamericanos, especialmente en Ei. barbara y lutrinos, y en musteloideos en general, aunque en prociónidos los sesamoideos son rudimentarios. Justo sobre el sector dorsal y caudal al cóndilo lateral del fémur se conforma una muesca rugosa distintiva en las nutrias sudamericanas, así como en muchas otras de otros continentes (Fisher 1942: Fig. 12, Peigné et al. 2008), indicando un aumento del área de origen de la cabeza lateral del m. gastrocnemius, y m. flexor digitorum superficialis (Fisher 1942, Howard 1975). Dicho rasgo se encuentra marcado en linajes acuáticos y nutrias más especializadas al nado, como Pt. brasiliensis (ver también Savage 1957, Kruuk 2006, Peigné et al. 2008), indicando un mayor desarrollo y ventaja mecánica de estos músculos, en relación a los grandes esfuerzos de flexión de la rodilla y extensión del autopodio durante la fase de propulsión en el buceo (Savage 1957).

\subsubsection{Tibia y fíbula}

\section{Morfología general}

Todos los mustélidos, y la mayoría de los musteloideos, presentan la diáfisis tibial curvada, convexa en vista medial, y el grado de curvatura parece estar estrechamente relacionado a la longitud del elemento (pero ver también Savage 1957).

La robustez de la tibia y la fíbula, y las longitudes de estos elementos respecto al fémur, son altamente variables en los musteloideos (Tabla 2.3, Fig. 3.1H), e informativos respecto a las estrategias locomotoras (Maynard Smith y Savage 1956, Davis 1964, Jouffroy 1971, Peigné et al. 2008, Argot 2010). Los resultados estadísticos indicaron que la proporción crural está influenciada de forma significativa por las distintas estrategias locomotoras (Apéndice 3.8H) y esta significancia se mantuvo incluso luego de contemplar la estructura filogenética de los datos y al tamaño corporal, indicando que el resultado es robusto y no sesgado por estos factores (Tabla 2.3, Apéndice 3.9H). Por ejemplo, los dos linajes mustélidos weasel-like principales, Guloninae - Eira e Ictonychinae + Mustelinae + Lutrinae, presentan sinapomorfías convergentes, como lo es un índice crural alto (Apéndice 3.15, c. 4), diferenciándose de la 
condición ancestral para la familia, y convergiendo a su vez con las proporciones presentes en otros linajes carnívoros cursoriales o ambulatorios (e.g., félidos, cánidos, mefítidos), posiblemente en relación con un importante desarrollo de la musculatura del tobillo en weasellike (ver más adelante) y a la extensión de la zancada en los linajes cursoriales.

\section{Región proximal de la tibia}

En los hurones de América del Sur, los cóndilos articulares de la tibia están escasamente separados por un breve sector intercondiloideo no articular y son asimétricos en forma: el medial es arriñonado, angosto y plano, mientras que el lateral es redondeado, menos extendido cranealmente y plano a convexo. Lo mismo ocurre en hurones ictoniquinos y mustelinos de otros continentes (e.g., Mustela spp., pero no en ictoniquinos skunk-like, e.g., Poecilictis libyca; Apéndice 3.15, c. 68, estado 0 vs. 1). Esta morfología, en correspondencia con lo observado en el sector distal del fémur (ver sección 4.3.5, Fémur y patela), ha sido relacionada a importantes restricciones de los movimientos fuera del plano parasagital (Argot 2002, Ercoli et al. 2012, Álvarez et al. 2013). En Eira barbara y los guloninos pequeños se registra una morfología similar a los hurones, aunque los cóndilos están separados por un espacio intercondiloideo algo mayor, siendo el cóndilo lateral mayor, y ambos presentan similar curvatura. Esto podría indicar excursiones del miembro posterior fuera del plano parasagital más importantes que en los hurones, lo cual estaría relacionado a la utilización más frecuente de sustratos desnivelados y complejos (i.e., medio arbóreo; Ewer 1973, Taylor 1976, Argot 2002, Dionisios Youlatos com. pers.).

Las nutrias sudamericanas y de otros continentes (aunque menos definidamente en Ao. cinerea) presentan cóndilos comparativamente más amplios y simétricos (con formas más semicirculares y cóncavas; ver Apéndice 3.15, c. 68, estado 1), que están separados por un área intercondiloidea amplia. Por otro lado, el cóndilo lateral es marcadamente mayor que el medial en el caso de Pt. brasiliensis, así como ocurre en otros carnívoros altamente especializados al medio acuático (Savage 1957). Estas morfologías podrían ser más permisivas de mayores movimientos fuera del plano parasagital (Savage 1957, Taylor 1989, Nowak 2005) y asegurar la rodilla durante los poderosos movimientos realizados por la región distal del miembro posterior (Savage 1957, Peigné et al. 2008).

En otros linajes musteloideos (e.g., tejones, prociónidos, mefítidos) se registra un gran rango de formas, pero, como regla general, tienden a poseer cóndilos moderadamente simétricos, distanciados entre sí y de contornos más redondeados (Apéndice 3.15, c. 68, estado 2). El desarrollo de sus superficies respecto al total de la vista proximal de la tibia, redondez y distanciamiento de los cóndilos es progresivamente mayor desde los melinos, Conepatus chinga y Nasua nasua, Procyon spp hasta Ailurus fulgens y Potos flavus. Esta progresión se relaciona a 
mayores libertades de movimientos y posiciones habituales agazapadas (crouched) más marcadas (Argot 2002, Ercoli et al. 2012).

En los hurones, el área intercondiloidea craneal es relativamente extensa en sentido cráneocaudal, con una tuberosidad tibial proyectada, de base adelantada y relativamente angosta. Una configuración muy similar se registra en guloninos, aunque en Ei. barbara, aunque el desarrollo de esta superficie es algo menor. Estos rasgos favorecen una gran ventaja mecánica del m. quadriceps femoris para la extensión de la rodilla en posiciones extendidas (contraponiéndose parcialmente a lo inferido a partir de la morfología femoral distal de Ei. barbara), y mayor resistencia a esfuerzos de tensión (Taylor 1976, Szalay y Sargis 2001, Argot 2002, Sargis 2002, Candela y Picasso 2008, Ercoli et al. 2012, Álvarez et al. 2013). En correlación con la morfología de la tróclea femoral (Taylor 1976, Argot 2002, 2010), la restricción del desarrollo lateromedial de la base de la tuberosidad tibial en estas especies (especialmente en hurones) puede relacionarse a un relativo bajo grado de movimientos fuera del plano parasagital (Álvarez et al. 2013, ver sección 4.3.5, Fémur y patela). Movimientos principalmente parasagitales y ventaja mecánica a extensores de la rodilla son esperables en linajes capaces de realizar marchas ágiles y rápidas, especialmente en la locomoción a saltos, y que alcanzan posiciones extendidas de la rodilla (Argot 2002, Sargis 2002, Álvarez et al. 2013).

Por otro lado, los tejones (e.g., Meles meles), Mellivora capensis, Gulo gulo y Nasua nasua, especies cavadoras y/o galopantes, presentan una tuberosidad tibial marcadamente adelantada, pero con una base relativamente amplia (ver Ercoli et al. 2012), indicando poderosos esfuerzos de extensión y estabilización, y una postura habitualmente extendida de la rodilla, así como movimientos sólo parcialmente restringidos al plano parasagital (Szalay y Sargis 2001, Sargis 2002, Ercoli et al. 2012). Álvarez et al. (2013) relacionaron estos rasgos a marchas de tipo galope lentas, rasgos especialmente exagerados en especies fosoriales, en las que la rodilla se encuentra especializada en resistir el peso corporal durante el cavado y los esfuerzos generados por la acción de los miembros anteriores contra el sustrato.

Muchos arborícolas presentan una región intercondiloidea craneal breve y tuberosidades tibiales retrasadas (ver Heinrich y Houde 2006), lo que se relacionaría con una postura habitualmente agazapada, sin alcanzar posiciones extendidas de los miembros posteriores, y con el uso de marchas lentas sobre ramas delgadas (Argot 2002). Dentro de Musteloidea, los casos extremos son Potos flavus (ver Apéndice 3.15, c. 69., estado 0) y Ailurus fulgens, especialistas del sustrato arbóreo. Debido al frecuente uso del sustrato arbóreo en Ei. barbara, podría esperarse una gran correspondencia con esta morfología. Sin embargo, para este rasgo, el modo de uso del sustrato arbóreo es más importante que el sustrato en sí (Argot 2002): la tayra se desplaza en los árboles caminando o corriendo sobre ramas medianas la mayor parte del tiempo, y sin movimientos de rotación tan marcados en esta articulación (Dionisios Youlatos, 
comunicación personal); y seguramente debido a esto la mayor similitud del sector proximal de la tibia con formas weasel-like.

En las nutrias sudamericanas y de otros continentes (e.g., En. lutris, Lu. lutra; ver también Savage 1957, Ercoli et al. 2012) el desarrollo cráneocaudal del área intercondiloidea craneal es claramente menor a la de otros musteloideos (aunque más extensa en Pt. brasiliensis que Lontra spp.), indicando posiciones agazapadas, y menores ventajas mecánicas para la extensión de la rodilla en posiciones extendidas (Candela y Picasso 2008, Ercoli et al. 2012). Esta morfología fue reconstruida como condición sinapomórfica del grupo (Apéndice 3.15, c. 69., estado 0), revertida en Aonyx cinerea, que presenta una morfología generalizada. En el buceo de las nutrias, los miembros son mantenidos en dirección caudal durante la propulsión, en muchos casos moviéndose en sincronía con movimientos ondulatorios axiales (Savage 1957, Gambaryan y Karapetyan 1961, Tarasoff 1972, Fish 1994, Hildebrand 1988, Taylor 1989, Lewis 2008, Peigné et al. 2008). Esta postura implica mantener la rodilla semi-flexionada, concordando con la interpretación morfo-funcional sugerida.

Más allá de estas relaciones morfo-funcionales, existe una influencia marcada del tamaño corporal (al menos para las especies no-acuáticas), en la proyección craneal de la tuberosidad tibial y la cresta tibial (y, por lo tanto, la masa muscular que allí se inserta). Las especies más pequeñas dentro de cada grupo funcional (e.g. Spilogale y Conepatus dentro de los cavadores, las especies de Mustela más pequeñas y Lyncodon dentro de los hurones) tienden a presentar un menor desarrollo de estas estructuras que sus análogos funcionales de mayor tamaño. Esto se relaciona a que las especies pequeñas presentan bajos costos energéticos de soporte y locomoción y pueden adquirir posturas agazapadas habitualmente más marcadas en los miembros posteriores lo cual les permitiría moverse en sustratos irregulares (Hildebrand 1988, Bienwener 1989, Heinrich y Biknevicius 1998, Candela y Picasso 2008, Schilling y Hackert 2006, Schmidt y Fischer 2009).

La región cráneolateral del área intercondiloidea craneal, representa el límite medial del pasaje del tendón del m. extensor digitorum longus (sulcus muscularis, en sentido estricto, de algunos félidos y cánidos; Hunt 2009), y se encuentra moderadamente desarrollada en todos los musteloideos, siendo mucho menos marcada que en especies cursoriales (e.g. cánidos, Acinonyx; ver Hildebrand 1954, Hunt 2009, Ercoli et al. 2012, Álvarez et al. 2013; Apéndice 3.15 , c. 70, estado 2). En algunas nutrias, aunque el lugar de pasaje del tendón del m. extensor digitorum longus está mal definido, y la región cráneolateral tiende a estar más desarrollada que en las especies terrestres, tomando la forma de una plataforma extendida distalmente, que correspondería a una extensión de la inserción del m. biceps femoris (Ercoli et al. 2012 contra Heinrich y Houde 2006, ver secciones 3.1.13-14, Lámina 2.24). Esta inserción hiper-extendida típica de lutrinos (Cuvier y Laurillard 1849, Fisher 1942, Howard 1975) permite que el músculo 
colabore en mayor grado en la rotación externa de tibia y la flexión de la rodilla, funciones importantes para posicionar caudalmente el miembro posterior durante el nado (Savage 1957, Gambaryan y Karapetyan 1961, Taylor 1989, Lewis 2008).

Más allá de lo descripto para la inserción del ligamento patelar (i.e., tuberosidad tibial), las demás inserciones ligamentosas de la rodilla (e.g., ligamentos colaterales, crucianos y meniscos) son muy marcadas en nutrias en general, seguidas en menor importancia por los tejones (e.g., Meles meles), algunos guloninos (incluyendo a Ei. barbara) y secundariamente en zorrinos (e.g., Spilogale gracilis, Conepatus chinga). El desarrollo de los ligamentos de la rodilla es mayor en especies más trepadoras, destacándose Potos flavus, que presenta el mayor desarrollo entre los prociónidos, y Ei. barbara. El mayor desarrollo de los ligamentos se relaciona con mayores esfuerzos de la rodilla soportados fuera del plano parasagital (e.g., torsión; ver Argot 2002). Melinos, Ei. barbara (y en menor grado otros guloninos), muchos prociónidos, melivorinos, mustelinos y lutrinos (desarrollada en extremo en este grupo) comparten la presencia de una cresta de inserción del ligamento colateral medial en el sector medial y proximal de la tibia (rasgo sinapomórfico de Musteloidea; ver Apéndice 3.15, c. 71, estado 1). Este ligamento suele encontrarse muy desarrollado en otros mamíferos trepadores (e.g., Sciuridae, Primates, Marsupialia; ver Haines 1942, Argot 2002 y citas allí), condición que ha sido vinculada con soportar esfuerzos de propulsión mientras la tibia se encuentra rotada y desviada del plano parasagital (Argot 2002). En tejones, algunos ejemplares de Ei. barbara (e.g., MLP 1013) y Conepatus chinga (e.g., MLP 19-XII-02-2), se suma una constricción medial al cóndilo medial, en relación al pasaje restringido de este ligamento, limitante de la rotación en posiciones extendidas de la articulación (Evans y De Lahunta 2013). En nutrias, el pasaje de dicho ligamento no genera una constricción, pero un desarrollo del ligamento colateral medial claramente marcado puede inferirse en función de las marcas dejadas tanto en su origen (área aplanada por debajo de la región del sesamoideo medial en el fémur) como su inserción (cresta rugosa sobre la cara medial del sector proximal de la diáfisis tibial). Este rasgo favorece la resistencia de la abducción de la tibia y el alejamiento del miembro mientras éste se encuentra en una posición rotada (Argot 2002, Evans y De Lahunta 2013). Es interesante destacar la ausencia de una cresta marcada de inserción de este ligamento en ictoniquinos en general, quizás reducido en este linaje, y siendo un rasgo de interés desde el punto de vista filogenético.

\section{Extensión relativa del zeugopodio, espacio interóseo y contactos entre fíbula y tibia}

En los hurones, así como también en nutrias (e.g., Lontra spp., y secundariamente algunos guloninos, e.g., Martes americana, ver Leach 1977a), el sector contiguo caudolateral al cóndilo lateral de la tibia se proyecta en forma marcada en relación a un posicionamiento y orientación caudal de la articulación proximal con la fíbula, permitiendo un posicionamiento de la diáfisis de esta última retrasada y distanciada respecto a la diáfisis tibial (Fig. 4.5A). A su 
vez, la diáfisis de la fíbula presenta una curvatura opuesta a la de la tibia (convexa caudolateralmente vs. convexa craneocranealmente, respectivamente) de manera que ambos elementos se distancian (Fig. 4.5A). Esta configuración, reconstruida como adquirida en la base de la radiación del clado Ictonychinae + Lutrinae + Mustelinae (Apéndice 3.15, c. 73, estado 3), parece indicar una menor importancia de la fíbula en el soporte del peso (i.e., menos eficiente para resistir la compresión axial; Bertram y Biewener 1988, Argot 2002), presencia de movilidad entre estos elementos (Barnett y Napier 1953, Argot 2002, ver más adelante), y una mayor extensión de la membrana interósea. Una morfología similar se presenta en algunos plantigrados de gran tamaño (e.g., úrsidos, Taxidea), pero en estos casos, la fíbula es un elemento robusto y sólo diverge de la tibia en el plano transverso (codificados como dato faltante; Apéndice 3.15, c. 73), con lo que ambos elementos participan del soporte del peso y la membrana interósea está extendida.

Algunos ictoniquininos (Poecilictis libyca e Ictonyx striatus), como fue comentado ya para otros rasgos e índices postcraneales, convergen en gran medida con mefítidos. En el miembro posterior, ambos grupos poseen la tibia y la fíbula de longitudes similares o algo mayores que el fémur (Tabla 2.3; adquisición convergente de c. 73, estado 1 y c. 4; ver Apéndice 3.15), y una fíbula estrechamente cercana a la tibia en su sector medio y especialmente distal (Fig. 4.5B), colaborando en gran medida en el soporte del peso y reduciendo la movilidad (Barnett y Napier 1953, Argot 2002).

Con respecto a la lectura funcional de la extensión de la membrana interósea, la mayor extensión lateromedial en hurones (distinto en ictoniquininos skunk-like; Apéndice 3.15, c. 73) permite aumentar la superficie de origen del $\mathrm{m}$. flexor digitorum medialis y lateralis, flexores digitales y extensores del tobillo, músculos que se han descripto como hipertrofiados en especies de mustélidos de marchas half-bound (Ercoli et al. 2013; sección 4.1.3). Esto posibilita la existencia de un gran desarrollo de los extensores poderosos del tobillo que, sumados a los de origen femoral, son necesarios durante el final de la fase de propulsión del salto para lograr la aceleración necesaria antes del despegue de los miembros (Maynard Smith y Savage 1956, Gambaryan 1974) sin una elongación excesiva del miembro posterior en general o el zeugopodio en particular (ver sección 4.3.1, Fig. 3.1H; ver Smith y Savage 1956: tabla 2). Como una variante, en Galictis la longitud del fémur es levemente mayor a la de la tibia $(\mathrm{LaTi} / \mathrm{LaFe}=0,97$; Tabla 2.3, ver también Mivart 1885), y la fíbula es más robusta y próxima a la tibia en comparación con guloninos weasel-like (e.g., Martes americana: 1,09), Mustela spp. (e.g., Mu. putorius: 1,00; Mu. nivalis: 1,03, Mu. frenata: 1,09, Mu. vison: 1,10) у Ly. patagonicus (1,07; ver también Lámina 3.17 B vs. C), indicando posiblemente una condición más generalizada y en consecuencia una menor especialización a la locomoción rápida y a saltos en Ga. cuja (Maynard Smith y Savage 1956). Llamativamente, este índice aleja a Galictis de 
especies eventualmente nadadoras (e.g., Mu. vison) y nutrias (ver más adelante), contrariamente a muchos otros rasgos destacados a lo largo de la discusión.

La presencia de una fíbula de similar longitud al fémur, curvada y con algún grado de libertad de movimientos, son rasgos usualmente considerados contraproducentes para la locomoción por medio de saltos en otros grupos de mamíferos (Maynard Smith y Savage 1956, Barnett y Napier 1953, Bertram y Biewener 1988, Argot 2002). Sin embargo y contrario a estos otros grupos saltadores, en los hurones, la presencia de una fíbula desarrollada, curvada y grácil permitiría soportar y expandir lateralmente la membrana interósea, sitio de origen de los principales músculos extensores del tobillo; bajo las restricciones impuestas a la longitud máxima de los miembros por la necesidad de incursiones en galerías estrechas.

En lutrinos (Peigné et al. 2008) se registra un patrón similar al de los hurones pero en algunos sentidos más acentuado (e.g., Apéndice 3.15, c. 4, ver también c. 73). Como tiende a ocurrir en los hurones de mayor tamaño, las caras caudales de las diáfisis tibiales y fibulares se encuentran marcadas por estrías proximodistales que señalan las divisiones principales de las masas extensoras del tobillo y autopodio. Sin embargo, la tibia es mucho mayor que el fémur (y que otros huesos largos, ver Maynard Smith y Savage 1956, Jouffroy 1971: 397, Peigné et al. 2008). En los análisis de varianza (Fig. 3.1H; Apéndices 3.6H, 3.15, c. 4), la tibia de las especies acuáticas fue mayor al $110 \%$ de lo longitud del fémur y hasta un máximo de casi $118 \%$ (En lutris y Lo. canadensis; Tabla 2.3), proporción significativamente mayor a la observada en trepadores y cavadores (Apéndices 3.6H). Este índice permitió una diferenciación total de las especies de hábitos acuáticos de los restantes musteloideos, exceptuando por el lutrino generalista Aonyx sp. $(\mathrm{LaTi} / \mathrm{LaFe}=1,05$; Tabla 2.3). Estos rasgos osteológicos se relacionan a la necesidad de conservar un perfil hidrodinámico, manteniendo el miembro cercano al cuerpo (i.e., reducción de la longitud del fémur, Tarasoff 1972, Taylor 1989), y a un gran desarrollo de la masa muscular extensora y flexora del tobillo y dígitos (similar o mayor incluso a la de hurones, ver Jouffroy 1971, Tarasoff 1972, Ercoli et al. 2013; sección 4.1.3), necesaria para el desplazamiento en un medio acuático mediante esfuerzos de propulsión concentrados en el autopodio, que en nutrias está hipertrofiado y embebido en membranas interdigitales extensas (Savage 1957, Tarasoff 1972, Taylor 1989, Schutz y Guralnick 2007, Peigné et al. 2008). En particular, Lontra provocax presenta una proporción crural intermedia entre Aonyx sp. y otros lutrinos, con un valor de LaTi/LaFe mucho menor que los restantes Lontra spp. analizados (Lo. canadensis y Lo. longicaudis). Como también fue descripto en otros apartados de discusión apendiculares (e.g., ver secciones 4.3.4, Escápula, Húmero, y 4.3.5, Fémur), muchos rasgos apendiculares de esta especie, especialmente del miembro posterior, indican tentativamente un menor grado de especialización al nado y aptitudes para el cavado eventual. 
Los guloninos pequeños presentan morfologías y proporciones de tibia y fíbula similares a hurones (e.g., Leach 1977a; Tabla 2.3; Apéndice 3.15, c. 4, 73), asociados a similares patrones de pasos, aunque todos los elementos de los miembros son más elongados y gráciles, lo que está relacionado con la explotación frecuente del sustrato arbóreo (Taylor 1989, Schutz y Guralnick 2007; Tabla 2.3, ver secciones 4.3.1, 4.3.4). De manera similar, en la mayoría de los prociónidos todos los huesos son largos y moderadamente delgados, pero en este caso, la diáfisis fibular colabora en gran medida en el transporte del peso, en relación a la utilización del sustrato arbóreo y la ausencia de estrategias half-bound. Por otro lado, la longitud relativa de la tibia varía marcadamente en las distintas especies: menor que el fémur en Potos flavus y Nasua nasua $(\mathrm{LaTi} / \mathrm{LaFe} \approx 0,95)$, y mayor en Bassaricyon sp. $(1,02)$ y Procyon spp. $(\approx$ 1,03; Tabla 2.3), similar a lo observado en el cociente braquial (ver sección 4.3.4, Ulna y radio), sin una clara relación con la estructura filogenética (Apéndice 3.15, c. 4). Como ocurrió en el antebrazo, Procyon spp. y zorrinos, especialmente Conepatus spp., presentan miembros elongados en relación al cuerpo y elementos distales elongados y gráciles (ver secciones 4.3.1, 4.3.4, Ulna y radio), al parecer sin una relación directa a las variantes locomotoras analizadas estadísticamente, y quizás indicativo de hábitos ambulatorios a sub-cursoriales y marchas energéticamente más económicas (ver Hildebrand 1952, Holmes 1980), u otros rasgos ecológicos más específicos.

En los mustélidos de gran porte y galopantes, incluyendo tejones, guloninos grandes (Gulo gulo y Ei. barbara), y melivorinos, en oposición a los otros grupos descriptos, la tibia es claramente menor que el fémur (Tabla 2.3), condición reconstruida como ancestral a Mustelidae (Apéndice 3.15, c. 4, estado 0,826-0,870), y característica típica de carnívoros no cursoriales (Maynard Smith y Savage 1956, Davis 1964, Argot 2002, 2010, ver también Vizcaíno y Milne 2002). Todos los elementos son robustos, y la fíbula se curva acercándose a la diáfisis tibial en su región central. Estos rasgos indican marchas relativamente lentas o energéticamente costosas y mayor participación de la fíbula en el soporte del peso corporal en las especies de gran tamaño (Bertram y Biewener 1988, Argot 2002, 2010), especialmente en fosoriales, que durante el cavado soportan en los miembros posteriores el peso corporal y los esfuerzos generados durante el cavado con los miembros anteriores (Vizcaíno y Milne 2002). En particular, los cavadores son el grupo más claramente diferenciado en lo que respecta a la proporción crural, pese a las grandes variantes intragrupales, presentándose para este índice valores significativamente menores respecto a nadadores y trepadores (Fig. 3.1H, Apéndice 3.6H).

En los hurones, y especialmente en lutrinos, tanto el tubérculo de origen del m. fibularis longus, las crestas de origen del $\mathrm{m}$. fibularis brevis, así como de sus zonas de tránsito de estos sobre el maléolo fibular están bien definidas (especialmente circunscriptas en Lo. provocax). Estos músculos fibulares, son evertores y rotadores del pie y extensores del tobillo. Aunque 
todos movimientos podrían formar parte del repertorio de movimientos complejos durante el nado en algunas nutrias (e.g., En. lutris, ver Tarasoff 1972), las restricciones articulares del tobillo (especialmente en lutrinos sudamericanos, ver más adelante; sección 4.3.5, Pes) parecen indicar la preponderancia de la función extensora de este sistema.

El contacto distal entre fíbula y tibia es muy variable y complejo, posiblemente relacionado tanto a cuestiones funcionales como afinidad filogenética (Apéndice 3.15, c. 73). En ningún musteloideo existe fusión en la articulación distal entre fíbula y tibia, posibilitando, en mayor o menor grado, movimientos fuera del plano parasagital (Barnett y Napier 1953, Ewer 1973). En lincodontininos y Lontra spp., el contacto articular entre la fíbula y la tibia es poco saliente, extenso cráneocaudalmente (aproximadamente semilunar) y cóncavo-convexo. En función de las muescas dejadas por los ligamentos contiguos (ver Heinrich y Rose 1997), la continuación del contacto articular (sinovial) por tejido ligamentoso (sindesmosis) es mínima en hurones y algo mayor en nutrias, siendo máximo en Pt. brasiliensis. Esta configuración sugiere la potencialidad de realizar movimiento entre la fíbula y tibia más amplios (aunque sutiles) en los hurones, algo que tradicionalmente fue relacionado con la capacidad de acomodar el autopodio a sustratos desnivelados, la eventual capacidad de marchas o descansos plantígrados, y una condición previamente sugerida como primitiva en carnívoros (Barnett y Napier 1953, Savage 1957, Ewer 1973, Taylor 1976, Yensen y Tarifa 2003a, b, Argot 2010), lo que es respaldado por las optimizaciones (Apéndice 3.15, c. 73, estados 2 y 3). Las uniones ligamentosas más extensas o incluso fusiones de este contacto en las especies acuáticas o semiacuáticas es una tendencia reconocida en otros linajes de mamíferos, lo que se entiende como propicio para un anclamiento seguro a muchos de los músculos motores del autopodio (Maynard Smith y Savage 1956). La retención de un componente de movilidad relativamente importante en Lontra spp. (así como en otras nutrias, e.g., Lutra lutra, Barnett y Napier 1953) podría indicar una mayor capacidad de adaptar el paso a sustratos desnivelados, algo esperable en función de sus excursiones en sustratos rocosos (Bastida et al. 2007; Apéndice 3.15, c. 73, estado 3).

El contacto distal entre fíbula y tibia es plano, amplio y extendido proximalmente y continuado por tejidos ligamentosos en mefítidos e ictoniquininos skunk-like (Ictonyx striatus y Poecilictis libyca; contrario de otros ictoniquinos; Apéndice 3.15, c. 73, estado 1), y secundariamente en Procyon, al parecer indicando similares, o incluso mayores, restricciones a los movimientos (contactos de movilidad intermedia, ver Barnett y Napier 1953), intermedio a lo descripto para Meles meles o nutrias y los cánidos y hiénidos, estos últimos presentando sindesmosis muy amplia (Apéndice 3.15, c. 73, estado 0). En función de las optimizaciones (Apéndice 3.15, c. 73, estados 0 y 1), la extensión proximal de la unión tendinosa del sector distal de la fíbula y tibia se habría desarrollado al menos tres veces independientemente dentro 
de Caniformia (i.e., mefítidos, ictoniquininos y cánidos), a partir de un condición ancestral de un contacto restringido y acompañado de pocas fibras tendinosas (Apéndice 3.15, c. 73, estado 2). Esta última condición es la retenida en la gran mayoría de los mustélidos (Apéndice 3.15, c. 73, estados 2 y 3). En muchos de estos linajes (e.g., guloninos, mustelinos y la mayoría de las nutrias), el contacto tiende a ser más plano, proximal, de contorno redondeado en vez de desarrollado cráneocaudalmente, y sobresaliente, acompañado de pocas fibras ligamentosas, indicando libertades de movimientos algo más complejos que los inferidos en hurones sudamericanos. Para Potos flavus, especie que registra una movilidad máxima en la región del tobillo (Jenkins y McClearn 1984, Taylor 1989), Heinrich y Rose (1997) indicaron la ausencia total de marcas de inserciones ligamentosas en la región. No hay una única explicación a esta diferencia, pero en muchas de estas especies podría relacionarse a una mayor explotación eventual o frecuente de sustratos arbóreos, marcadamente desnivelados, o diferentes grados de digitigradía (Barnett y Napier 1953, Ewer 1973, Taylor 1976, Argot 2010). Como fue destacado por Barnett y Napier (1953) y Ewer (1973), Nasua nasua es un caso especial, en donde la articulación proximal entre fíbula y tibia se encuentra fusionada, en relación a la estabilidad necesaria para el cavado (sensu Barnett y Napier 1953, pero puesto en duda por Ewer 1973), mientras que la articulación distal es relativamente móvil, en relación a la explotación del sustrato arbóreo y plantigradía (ver también Taylor 1976).

Sobre la cara medial del maléolo medial de la tibia de Ei. barbara, se encuentra un tubérculo hipertrofiado y sobresaliente, diferenciándose de otros mustélidos sudamericanos. Ésta es la región de origen de la porción larga del ligamento colateral medial del tobillo (Evans y De Lahunta 2013) y el límite craneal a la amplia zona de tránsito del m. tibialis caudalis y m. flexor digitorum medialis (Fisher et al. 2009, Ercoli et al. 2013; sección 3.1.14). La exacerbación de estas estructuras podría colaborar en evitar la dislocación del tobillo durante importantes movimientos fuera del plano parasagital (e.g., rotación, inversión; Jenkins y McClearn 1984, Taylor 1989, Heinrich y Rose 1997). Un tubérculo de dimensiones similares o algo menores se encuentra en Melogale moschata, Martes pennanti y Gu. gulo (guloninos basales y de tamaño similar o mayor a Ei. barbara) pero no en Martes americana (Leach 1977a), posiblemente en relación a variantes del tamaño corporal, estilos de trepado, o informativo de relaciones de parentesco.

\section{Configuración de la cóclea astragalar}

La superficie articular distal de la tibia, en conjunto con la correspondiente a la fíbula, conforman la cóclea astragalar, distinguiéndose en esta los surcos medial y lateral correspondientes a las crestas del astrágalo, y la cresta o guía central de los movimientos parasagitales (central anteroposterior ridge, Taylor 1976). Tanto en hurones como nutrias sudamericanas, la cóclea se encuentra fuertemente incidida, con un tubérculo craneal más o 
menos agudo, correspondiente al final craneal de la cresta central. Este es más marcado en Lo. provocax que Lo. longicaudis, y en Mu. frenata, y secundariamente en Ly. patagonicus, es similar o más marcado que Galictis spp. La condición de los primeros indica restricciones mayores a movimientos fuera del plano parasagital (Taylor 1976). Este rasgo, además, presenta potencial para diferenciar estas especies cercanas. En la vista caudal de la tibia, ambos surcos se encuentran diferenciados aunque menos profundos, separados por un tubérculo caudal más sobresaliente en hurones que en lutrinos (Apéndice 3.15, c. 72, estado 1 y 0 respectivamente). En Ei. barbara, aunque en vista craneal la cóclea posee un contorno apenas menos abrupto que en hurones y nutrias, la tayra se diferencia grandemente de estos últimos en la vista caudal, en donde apenas se insinúan suaves cambios de curvatura en el contorno coclear de la superficie astragalar tibial. Esta configuración podría permitirle a esta especie un mayor grado de libertad a movimientos fuera del plano parasagital en el tobillo, permitiendo una mayor gama de posiciones del astrágalo y el autopodio en su conjunto respecto a otros taxones mustélidos sudamericanos (aunque lejano al extremo alcanzado por especialistas como Nandinia binotata, Potos flavus; Taylor 1976, Dionisios Youlatos comunicación personal). Sumado esto a las características observadas en el autopodio posterior (ver sección 4.3.5, Pes), estos ragos colaboraría con la capacidad de eversión del autopodio observado en esta especie durante el descenso o colgado de ramas, así como fue descripto para otros taxones trepadores (Jenkins y McClearn 1984, Taylor 1976, Heinrich y Rose 1997).

En lo que respecta a taxones de otros continentes, en guloninos, helictidinos, melivorinos, melinos y prociónidos basales, se registran configuraciones similares a las presentes en Ei. barbara, con surcos de la cóclea abriendo ampliamente en vista craneal, y prácticamente sin diferenciarse en vista caudal, con similares implicancias funcionales (ver estudios funcionales y morfo-funcionales, e.g., Trapp 1972, McClearn 1992, Heinrich y Rose 1997). Por otro lado, mustelinos, ictoniquinos y lutrinos de otros continentes, así como también en mefítidos, se registran restricciones similares a las presentes en los representantes sudamericanos.

\subsubsection{Autopodio posterior}

Como fue comentado para el autopodio anterior, esta sección se encuentra limitada debido a la escasez de materiales depositados en las colecciones estudiadas y la bibliografía publicada.

\section{Astrágalo y calcáneo}

Siguiendo las propuestas morfo-funcionales de Jenkins y McClearn (1984), la mayoría de los mustélidos de América del Sur comparten un gran número de rasgos en el astrágalo y calcáneo que pueden relacionarse a un grado moderado de libertad de movimientos fuera del 
plano sagital, incluyendo la inversión, mediante la cual la planta se orienta medialmente debido a la rotación y el desplazamiento del calcáneo sobre la cara medial del astrágalo. Aunque sin llegar a la reversión del autopodio, los movimientos que presentan los mustélidos sudamericanos son claramente mayores a lo observado en algunos linajes carnívoros cursoriales (e.g., cánidos; Polly 2008, Hunt 2009), lo que es esperable dada la condición relativamente generalizada de los autopodios de los primeros. Entre los rasgos que sustentan la condición relativamente móvil del autopodio de mustélidos se destaca el breve desarrollo cráneocaudal de la tróclea astragalar y que las crestas de la misma están relativamente poco marcadas y no son totalmente paralelas, en relación a restricciones parasagitales de la articulación del tobillo no tan marcadas; así como la disposición y curvatura de las superficies articulares subtalares (articulación entre astrágalo y calcáneo; pero ver nutrias más adelante) y una articulación transversa (articulación entre astrágalo + calcáneo y central + tarsal IV) extendida lateromedialmente (Davis 1964, Jenkins y McClearn 1984, Heinrich y Houde 2006, Polly 2008, Hunt 2009, Argot 2010). Más allá de esto, el grado de libertad de estas articulaciones varía ampliamente entre los distintos mustélidos de América del Sur y entre otros musteloideos.

La profundización de la tróclea astragalar y la cóclea tibio-fibular, y aparentemente el desarrollo del tubérculo del talus, son estructuras que cambian en relación a restricciones articulares. El tubérculo del talus, además de restringir el pasaje del m. flexor digitorum lateralis (ver más adelante), potencialmente interfiere con la cóclea en posiciones extendidas. Entre los hurones sudamericanos, Ly. patagonicus presenta la tróclea con crestas más marcadas y elongadas proximodistalmente que Ga. cuja y Ga. vittata, en correlación con lo observado en la profundización y sinuosidad de la cóclea (sección 4.3.5, Tibia y fíbula) y un tubérculo del talus agudo y proyectado caudalmente. Una condición similar a la registrada en el huroncito patagónico se observa en mustelinos en general, y se relacionaría al mayor rango y estabilización de los movimientos del tobillo dentro del plano parasagital, algo esperable en digitígrados especialistas en marchas terrestres (Ewer 1973, Jenkins y McClearn 1984, Van Valkenburgh 1987, Candela y Picasso 2008, Argot 2010). Como destacó Taylor (1976, 1989) para los vivérridos y herpéstidos, estos rasgos pueden relacionarse directamente a marchas a saltos, y son registrados en half-bounders que incursionan o no en los árboles, dado que el modo de propulsión básico no varía en gran medida al cambiar de sustratos (aunque sí el agarre al sustrato en sí). Quizás esto explique en parte por qué la tróclea de los guloninos es muy similar o incluso más profunda en comparación con mustélidos terrestres saltadores (los hurones, e.g., Galictis spp.; ver también Van Valkenburgh 1987; ver Apéndice 3.15, c. 75, estado 1), mientras que el tubérculo del talus es redondeado y menos proyectado. Por otro lado, Van Valkenburgh (1987) señaló que, aunque la profundización de la tróclea es informativa respecto al uso de sustrato, éste es un rasgo marcadamente influenciado por ancestría común. Por ejemplo, en los 
guloninos, como Eira barbara y Gulo gulo, especies trepadoras galopantes (Kavanau 1971, Presley 2000, Kaufmann y Kaufmann 1965, Dagg 1973, Hildebrand 1977), la tróclea es relativamente profunda, distinto a lo esperado en función de sus hábitos (ver también Van Valkenburgh 1987). En prociónidos (e.g, Nasua nasua, Procyon lotor, excepto Potos flavus), se registran crestas de la tróclea aun más marcadas y de gran curvatura, y tubérculos proyectados (rasgos en algun grado convergentes con linajes de carnívoros cursoriales y establecidas en la base del clado Procyonidae - Potos), indicando llamativamente máximas restricciones a movimientos fuera del plano parasagital en el tobillo, en combinación con amplios rangos de flexo-extensión y libertades en articulaciones intratarsales (Apéndice 3.15, c. 75, estado 0). Por otro lado, en tejones (e.g., Arctonyx, Meles) y en mefítidos (e.g., Conepatus), se retiene la condición plesiomórfica para Musteloidea, i.e., una escasa extensión cráneocaudal de la tróclea (Apéndice 3.15, c. 75, reconstrucción ambigua de estados 2 y 3), evidenciando un rango bajo de flexo-extensión del tobillo, aunque sólo en los zorrinos (al igual que úrsidos) el tubérculo del talus está reducido y se registran bajas restricciones a otros movimientos en el tobillo. Esta configuración es esperable, pero no necesariamente obligatoria, en especies de marchas plantígradas o semiplantígradas y lentas (Ewer 1973, Taylor 1976).

Las nutrias en general presentan trócleas someras y breves cráneocaudalmente (Apéndice 3.15, c. 75, estados 2). Esto indica movimientos menos limitados, coincidiendo con lo observado en otras articulaciones (e.g., autopodio anterior), lo que se encuentra posiblemente relacionado a las diferentes estrategias de nado (Tarasoff 1972, Lewis 2008). Lontra provocax presenta una condición distinta, aparentemente autopomórfica (Apéndice 3.15, c. 75, estados 0), poseyendo una tróclea extensa cráneocaudalmente y relativamente profunda (sensu Van Valkenburgh 1897; posición basal del clado Lontra, Sato et al. 2012).

A partir de la diversidad de morfologías dentro de cada grupo de hábito locomotor puede concluirse que no existe una relación directa entre las libertades de movimientos del tobillo y la explotación de sustratos arbóreos o acuáticos, existiendo grandes variantes en los distintos linajes involucrados. Como destacaron Davis (1964) y Taylor (1989), el tarso es más conservativo que el carpo, y las adaptaciones al uso de sustrato terrestre vs. arbóreo no son tan evidentes. En contra de lo esperable (e.g., Davis 1964, Van Valkenburgh 1987, Taylor 1989), las mayores restricciones a los movimientos del tobillo se registran en los prociónidos (aunque no tan marcadas en Po. flavus; Apéndice 3.15, c. 75; ver Heinrich y Houde 2006, Salesa et al. 2008), el grupo más especializado al trepado, con representantes capaces de gran inversión del autopodio al descender head-first de los árboles y colgar de ramas (Trapp 1972, Jenkins y McClearn 1984, McClearn 1992). Como también destacaron Trapp (1972), Taylor (1976), Jenkins y McClearn (1984), diferentes linajes arborícolas presentan estas habilidades mediante la exageración de los movimientos no parasagitales de diferentes articulaciones, y las mismas no 
pueden comprenderse sin incluir el análisis de la morfología de otras articulaciones (ver más adelante). Por otro lado, la ubicación espacial del complejo astrágalo-calcáneo y el eje de rotación del astrágalo, y la inclinación y convergencia de las crestas de la tróclea varía grandemente entre arctoideos en general (ver estudio detallado de Davis 1964), haciendo muy compleja la lectura precisa de los rangos y libertades de movimientos del tobillo.

La longitud y robustez del tubérculo del calcáneo ha sido relacionado a la ventaja mecánica y área de inserción disponible para los principales extensores del tobillo, incluyendo los m. gastrocnemius, m. flexor digitorum superficialis y m. soleus (Savage 1957, Heinrich y Rose 1997, Candela y Picasso 2008), y zona de orígenes de flexores y abductores digitales (Fisher et al. 2008, Peigné et al. 2008, Ercoli et al. 2013; sección 3.1.15). Un importante rango de variación intra e interespecíficas de estos rasgos parece relacionarse al tamaño corporal (siendo el tubérculo más pequeño y grácil en especies de menor tamaño, y mayor en prociónidos, tejones y nutrias; pero ver Polly 2008), pero no existe una relación clara con el grado de digitigradía (coincidiendo con Polly 2008, pero ver Heinrich y Rose 1997, Candela y Picasso 2008). Coincidiendo con lo que describió Polly (2008) para Lutra lutra, y Holmes (1980) para Lontra canadensis y Enhydra lutris, dentro de las especies de América del Sur, el desarrollo del tubérculo del calcáneo es mayor en las nutrias (especialmente en Lo. provocax y Pt. brasiliensis), debido al gran desarrollo del autopodio posterior en general (a su vez embebido en membranas interdigitales amplias), región donde se producen grandes esfuerzos de propulsión durante el padding (Savage 1957, Tarasoff 1972, Peigné et al. 2008). En las nutrias en general, el área de origen e inserción de los principales ligamentos plantares (sector distoventral del calcáneo, tubérculo ventral del central; ver Heinrich y Rose 1997, Evans y De Lahunta 2013) presentan un máximo desarrollo, seguramente en relación a resistir los esfuerzos de extensión durante la propulsión.

El proceso troclear (coracoid process, peroneal process; Davis 1964, Polly 2008 respectivamente), sitio de origen del $\mathrm{m}$. quadratus plantae y ligamentos (Tarasoff 1972, Peigné et al. 2008), se encuentra marcadamente desarrollado como una plataforma amplia en las nutrias (Apéndice 3.15, c. 80, estados 0 y 1; ver también Willemsen 1980a, Peigné et al. 2008). El m. quadratus plantae, además de colaborar en la flexión de las articulaciones metacarpofalangeales, retiene en posición al m. flexor digitorum profundus y colabora en la eversión del autopodio (Sooriakumaran y Sivananthan 2005, Fisher et al. 2008). La cara ventral del proceso troclear corresponde a la zona de tránsito del $\mathrm{m}$. peroneus longus, relacionado a la capacidad de abducción y eversión del autopodio y la flexión digital (Heinrich y Rose 1997, Polly 2008, Fisher et al. 2008, Ercoli et al. 2013; sección 3.1.15). Dentro de Carnivora, Ginsburg (1961) relacionó el desarrollo marcado de esta estructura y los músculos asociados a una posición plantígrada, mientras que Heinrich y Rose (1997, ver también estudio de roedores de Candela y 
Picasso 2008) lo asociaron al uso de sustrato arbóreo. Por otro lado, Polly (2008) relacionó el desarrollo y posición de esta estructura a ambos factores, pero a la vez indicando que las especies cavadoras y especialmente las nadadoras presentan los mayores procesos trocleares. El análisis comparativo de los musteloideos estudiados coincide con lo descripto por Polly (2008), dado que se observó que la estructura presenta el máximo desarrollo en especies acuáticas, las cuales no son estrictamente plantígradas en tierra (ver Murie 1974, Canevari y Fernández Balboa 2007, Canevari y Vaccaro 2007; serían semidigitigrados sensu Polly 2008). Esta condición, exacerbada en los linajes más especializados como En. lutris y pinnipedos (Savage 1957, Tarasoff 1972), permite posicionar correctamente al autopodio y resistir el empuje del agua y los cambios de inclinación del mismo, mediante restricciones articulares (ver más adelante), refuerzos ligamentarios y esfuerzos musculares, durante la propulsión en el nado (Savage 1957, Tarasoff 1972:99-108 y 129, Fish 1994), coincidiendo con el desarrollo de la masa relativa del grupo fibular en nutrias (Ercoli et al. 2013, sección 3.1.16). Por otro lado, la ausencia o reducción de la estructura en muchas especies cavadoras (e.g., Taxidea taxus, mefítidos) se contrapone a la interpretación de Polly (2008) y otros autores, y nuevamente revela dificultades a la hora de interpretar funcional o filogenéticamente al caracter (ver Apéndice 3.15, c. 80).

El foramen o canal astragalar, que representa la zona de pasaje de una rama de la arteria peroneal posterior, ha sido reconocido como un carácter de interés funcional y evolutivo desde muy tempranamente (e.g., Ameghino 1906, Matthew 1909, Kraglievich 1917). En todos los especímenes de mustélidos sudamericanos se detectó la apertura ventral (o de salida), entre las articulaciones para el calcáneo. Cuando este canal está presente y es funcional, abre caudalmente en un área no articular inmediatamente ventral a la tróclea del astrágalo, dorsal al surco para el pasaje del tendón del m. flexor digitorum lateralis (plantar tendinal groove; Wang 1993). Ameghino (1906) relacionó el desarrollo de esta región de tránsito del tendón y la presencia de la apertura caudal del canal astragalar con la presencia de un dígito I desarrollado, e indirectamente con plantigradía, y lo opuesto para la atrofia de estas estructuras. Wang (1993) relacionó la presencia de la apertura caudal del canal y el área no articular circundante con un escaso rango de extensión del tobillo, y posturas plantígradas (pero ver Heinrich y Rose 1997). Estas propuestas coinciden con la presencia (i.e., retención, ver más adelante) de un canal astragalar funcional en muchos linajes musteloideos (e.g., melinos, muchas nutrias, mefítidos, ver más adelante, ver también Kraglievich 1917, Wang y Carranza-Castañeda 2008).

Entre los mustélidos sudamericanos, en hurones se registra la mayor restricción del pasaje del tendón y obliteración del canal astragalar, especialmente en Ly. patagonicus dentro de los lincodontininos, especie mayormente digitígrada (ver Mivart 1885). En las nutrias Lo. provocax y Pt. brasiliensis la apertura caudal del canal astragalar está presente y desarrollada, 
posiblemente indicando rangos de extensión del tobillo no tan amplios (y seguramente posturas alejadas de una condición digitígrada estricta). Es interesante destacar que esto no ocurre en Lo. longicaudis (sumándose a otras importantes diferencias entre las especies de Lontra) ni Ei. barbara, posiblemente en relación a la capacidad de alcanzar posturas más extendidas del tobillo (Murie 1974, Wang 1993), aunque más datos sobre Lo. longicaudis son requeridos. Aunque no se observó la abertura caudal del canal astragalar en ningún especímenes analizados de Lo. longicaudis, una abertura atrofiada para un espécimen del taxón fue descripta por Kraglievich (1917).

Desde un punto de vista filogenético, la presencia de un canal astragalar funcional es considerada una condición primitiva para Carnivora, ya presente en los Creodonta (Davis 1964, Malatesta 1977). Esta interpretación es respaldada por las optimizaciones realizadas (Apéndice 3.15 , c. 76 , estado 1), las cuales a su vez sugieren que la presencia de la apertura caudal de este forámen es una condición plesiomórfica para el ancestro común de Musteloidea y los ancestros de cada una de las familias musteloideas. Dentro de los Carnivora vivientes se retiene en taxiidinos (T. taxus), melinos (Mel. anakuma, Mel. meles), melivorinos (Mell. capensis), muchos lutrinos (incluyendo especies de Lutra, Lontra, Pteronura, Enhydra), algunos guloninos (Gulo gulo y algunos Martes), otros carnívoros no mustélidos (Ailuropoda, Genetta, Viverra, Viverricula, Potos, Bassariscus, Ailurus, Conepatus, Mephitis, variable en Ursus y Procyon). También se encuentra en muchas especies extintas, muchas de ellas carnívoros basales: ${ }^{\dagger}$ Hesperocyon, ${ }^{\dagger}$ Megalictis, ${ }^{\dagger}$ Paroligobunis, ${ }^{\dagger}$ Brachypsalis, ${ }^{\dagger}$ Didymictis, ${ }^{\dagger}$ Vulpavus, ${ }^{\dagger}$ Sivaonyx, ${ }^{\dagger}$ Gallardina, variable en ${ }^{\dagger}$ Potamotherium (Ameghino 1906, Matthew 1909, Kraglievich 1917, Galbreath 1955, Savage 1957, Davis 1964, Malatesta 1977, Wang 1993, Heinrich y Houde 2006, Peigné et al. 2008, Wang y Carranza-Castañeda 2008). Su pérdida (Apéndice 3.15, c. 76, estado 0) parece haber ocurrido múltiples veces de manera convergente y quizás por múltiples causas.

La superficie articular subtalar, región de contacto entre el astrágalo y calcáneo, está conformada principalmente por dos carillas principales: la proximal (ectal/posterior calcaneal, en astrágalo y calcáneo respectivamente; e.g., Heinrich y Rose 1997) y la medial (sustentacular/sustentaculum). Cambios morfológicos de las mismas son muy informativos en lo que respecta a la movilidad del tarso y específicamente la capacidad de inversión. Esto ha sido evaluado en carnívoros (e.g., Trapp 1972, Taylor 1976, Jenkins y McClearn 1984, Polly 2008, Polly y MacLeod 2008, Hunt 2009), así como otros grupos de mamíferos (e.g., roedores, marsupiales, primates; Jenkins y McClearn 1984, Argot 2002, Sargis 2002, Candela y Picasso 2008 y bibliografía allí citada).

En los lutrinos, lincodontininos y mustelinos (ver Willemsen 1980a, Polly 2008) las articulaciones proximales presentan formas similares, posiblemente indicativo de cercanía 
filogenética (estado reconstruido como ya presente en un ancestro común en la base del nodo Ictonychinae + Lutrinae + Mustelinae; Apéndice 3.15, c. 77, estado 0). Esta articulación es elongada y angosta (excepto En. lutris) en el astrágalo, y moderadamente curva y expandida medioproximalmente en el calcáneo, permitiendo sólo moderadas libertades de inversión en estos taxones. Por otro lado, la carilla articular medial del astrágalo revela mayores diferencias morfo-funcionales entre estos linajes (Fig. 4.6). En todos los representantes vivientes de lutrinos, esta faceta es redondeada a triangular, aplanada y no inclina medialmente, ocupando toda la base del cuello astragalar (Fig. 4.6C), siendo reconstruido este rasgo como una sinapomorfía de nutrias (Apéndice 3.15, c. 79, estado 0). En las nutrias, y más claramente en Lontra, esta faceta articular termina proximalmente en una región marcadamente deprimida en el astrágalo, correspondiéndose en la faceta medial del calcáneo con un repliegue proximal marcadamente convexo (también registrado por Davis 1964:119 para otros arctoideos). Estos rasgos, registrados en este grado únicamente en lutrinos dentro de Musteloidea (aunque ver Taxidea taxus), indican importantes restricciones a la capacidad de excursión del calcáneo hacia el sector cráneomedial del astrágalo, limitando el grado de rotación axial y deslizamiento del calcáneo sobre el astrágalo (Davis 1964, Jenkins y McClearn 1984, Candela y Picasso 2008; coincidiendo también parcialmente con Heinrich y Rose 1997, Heinrich y Houde 2006), siendo prácticamente prohibitivo de movimientos de inversión. Es probable que estas características permitan mantener la planta del pie perpendicular al plano sagital, evitando que rote al ceder a la presión del agua y disminuya el área de propulsión efectiva (paddle area; Savage 1957; Tarasoff 1972:99-108 y 129). Tarasoff (1972, y referencias allí citadas) llegó a una conclusión similar en su revisión sobre la articulación tarsal de Enhydra lutris y Lontra canadensis y otros pinnipedos (128-129): "The tarsal joint of Lutra -actualmente Lontra-, Enhydra and Zalophus resemble those of terrestrial carnivores and are adapted for movement in a horizontal plane with no lateral rotation". Por otro lado, dentro de los lutrinos, existen variaciones en la morfología de esta articulación que sugieren un mayor grado relativo de movilidad en especies como Lutra lutra (ver Williemsen 1980a, Polly 2008).

En los hurones lincodontininos la articulación medial del astrágalo es más elongada cráneomedialmente y de una posición más medial e inclinada (Fig. 4.6B), reteniendo una morfología similar a la ya presente en el ancestro común musteloideo (Apéndice 3.15, c. 78 y 79), permisiva de algún grado de inversión (Jenkins y McClearn 1984, Candela y Picasso 2008). Por otro lado, en mustelinos (e.g., Mu. frenata) se da una condición intermedia a la de lutrinos y lincodontinos, usualmente más similar a estos últimos (ver también Heinrich y Rose 1997, Heinrich y Houde 2006, Polly 2008). En ningún grupo musteloideo bounder o half-bounder que utilice el sustrato terrestre o arbóreo (i.e., no acuático) (e.g., guloninos pequeños, mustelinos, lincodontininos, Bassariscus astutus) se registra una configuración de articulación subtalar que 
impida ampliamente movimientos de inversión, como si ocurre en carnívoros cursoriales (Jenkins y McClearn 1984, Polly 2008, Hunt 2009; Apéndice 3.15, c. 79) u otros grupos de mamíferos cursoriales y saltadores (Candela y Picasso 2008). La retención de una morfología tarsal más bien generalizada en mustélidos weasel-like se relaciona seguramente a múltiples factores, entre ellos: la retención de un autopodio posterior pentadáctilo y generalizado (Mivart 1885), la utilización eventual o frecuente de otros sustratos y pasos (e.g., apoyando eventualmente el talón, Heptner y Naumov 1967, Gambaryan 1974, Polly 2008, Wilson y Mittermeier 2009) y la menor importancia relativa, y menor especialización, del miembro posterior respecto a la región lumbar durante la propulsión en el salto (Gambaryan 1974). Por otro lado, la movilidad cruro-astragalar y subtalar podría colaborar en la adquisición de posturas sentadas sobre los miembros posteriores, como ha sido registrado durante la vigilancia o búsqueda de presas (Dagg 1973, Emmons 1990, King y Powell 2007).

En Ei. barbara se registra una configuración diferente a la de estos los hurones. Aunque la articulación proximal del calcáneo es similar a la de los hurones, la faceta correspondiente del astrágalo retiene una morfología optimizada como plesiomórfica para arctoideos en general y perdida en la mayoría de los mustélidos (Apéndice 3.15, c. 77, estado 1), siendo breve cráneocaudalmente y marcadamente ancha; mientras que la carilla articular medial se encuentra posicionada sobre el sector medial del cuello del astrágalo y más inclinada medialmente. Estos rasgos le permiten a Ei. barbara (y seguramente a Martes spp. ver Trapp 1972, Holmes 1980) un mayor rango de giro y desplazamiento del calcáneo sobre el astrágalo, indicando un gran rango de inversión del autopodio (Jenkins y McClearn 1984, Sargis 2002, Candela y Picasso 2008). En esta especie trepadora, estos movimientos aseguran un contacto adecuado del autopodio con un sustrato irregular (Taylor 1976, Jenkins y McClearn 1984, Taylor 1989, Heinrich y Rose 1997, Sargis 2002, Heinrich y Houde 2006, Dionisios Youlatos comunicación personal).

En lo que respecta a otros musteloideos (ver también Davis 1964, Polly 2008), la configuración de las facetas articulares subtalares de los melinos (Arctonyx collaris, Meles spp.), Gulo gulo, Martes spp. y los mefítidos es intermedia pero más similar a la de la tayra que a otros mustélidos sudamericanos. En el astrágalo de prociónidos y ailúridos (Ailurus fulgens, Procyon spp., Bassariscyon gabbii, y menos claramente en Na. nasua) se registra una faceta proximal marcadamente ensanchada y una faceta medial globosa y marcadamente inclinada medialmente (Apéndice 3.15, c. 79, estado 2; Fig. 4.6A), mientras que la faceta articular proximal del calcáneo se encuentra ampliamente expandida proximalmente sobre el plano medial, permitiendo un rango de inversión mayor que el de Ei. barbara o Martes spp. (McClearn 1992, Dionisios Youlatos comunicación personal). Esta configuración, posiblemente presente ya en el ancestro común de los prociónidos (Apéndice 3.15, c. 79, estado 2), es llevada 
al extremo por Po. flavus y Bassariscus astutus, taxones capaces desplazarse por ramas delgadas, y de revertir totalmente y colgar de sus miembros posteriores (Trapp 1972, Jenkins y McClearn 1984, Taylor 1989, McClearn 1992).

\section{Articulación tranversa tarsal}

La articulación transversa tarsal es compleja produciéndose entre sus partes movimientos de aducción-abducción, supinación-pronación, como flexión-extensión (Taylor 1976, Jenkins y McClearn 1984). A grandes rasgos, en musteloideos, los extremos de máxima y mínima movilidad corresponden a prociónidos y mefítidos respectivamente, mientras que los mustélidos presentan variantes dentro de este espectro. En los prociónidos (e.g., Procyon lotor y Nasua nasua), la cabeza del astrágalo es convexa y marcadamente curva, extendida sobre el cuello astragalar tanto dorsoventralmente como lateromedialmente, mientras que la articulación correspondiente en el tarsal central es amplia, somera y marcadamente extendida en ambas direcciones y elevada cranealmente (en $\mathrm{Pr}$. lotor), o irregular y elevada craneal y medialmente (en Na. nasua). La superficie proximal del carpal IV (articulación con el calcáneo), es comprimida dorsoventralmente, pero expandida y convexa en sentido lateromedial. Esta configuración permite un gran movilidad multidireccional para la articulación, colaborando en la inversión durante la locomoción arbórea (Taylor 1976, Jenkins y McClearn 1984, Heinrich y Rose 1997, Argot 2002, Sargis 2002, Candela y Picasso 2008), y es compatible (pero no excluyente) con marchas plantígradas (Ewer 1973, Taylor 1976). Por otro lado, en mefítidos como Conepatus chinga o Mephitis mephitis, la cabeza del astrágalo es plana en sentido dorsoventral, y la marcada convexidad lateromedial de Co. chinga se corresponde con una articulación proximal del central en igual grado cóncava (con una pared medial verticalizada, similar a Na. nasua), mientras que la articulación proximal del tarsal IV es apenas más ancha que alta, dejando escaso margen de movimiento para la articulación transversa (Jenkins y McClearn 1984, Heinrich y Rose 1997, Candela y Picasso 2008), mayormente de abducción y aducción. Esto probablemente se relacione a los hábitos estrictamente terrestres (ver Taylor 1976) del taxón (Azara 1802, Cabrera y Yepes 1940, Elbroch 2003), registrándose una morfología diferente y mucho más móvil en Spilogale gracilis, taxón eventualmente trepador, más ágil y capaz de realizar marchas half-bound y huidas rápidas (Kinlaw 1995, Long 2008, Elbroch 2003). Es interesante destacar que Conepatus y Mephitis presentarían una escasa movilidad de la articulación transversa en conjunto con una condición plantígrada.

En cuanto a los mustélidos sudamericanos, Ei. barbara presenta el mayor rango de movimientos la articulación tranversa tarsal, seguida por las nutrias (siendo Lo. longicaudis más móvil que en Lo. provocax) y luego por los hurones lincodontininos. Esta disminución progresiva de la movilidad en estos linajes se evidencia por la también progresiva reducción de la curvatura y extensión de la cabeza astragalar, el cambio de forma de la superficie proximal 
del carpal IV (de semilunar a cuadrangular, disminuyendo su extensión lateroventral) (Jenkins y McClearn 1984, Heinrich y Rose 1997), características desarrolladas en grados intermedios respecto a prociónidos y Co. chinga. La gran movilidad de Ei. barbara, como en prociónidos (aunque en mucho menor grado), se relaciona a los movimientos complejos del autopodio necesarios para colgar y descender por ramas y troncos. Por oposición, la reducción de estos movimientos en hurones se relaciona a la explotación mayoritaria de un sustrato terrestre y marchas half-bound más digitígradas, en donde se prioriza la estabilización articular del tarso (Taylor 1976, Jenkins y McClearn 1984, Heinrich y Rose 1997, Polly y MacLeod 2008). Dado que la propulsión en el sustrato arbóreo implica grandes esfuerzos no compresivos y en posiciones flexionadas de la articulación, la elevación del sector anterior del central en Ei. barbara (similar a prociónidos y también presente en grado menor en guloninos pequeños y mustelinos; ver también Barraquand 2010), permitiría un contacto extendido en posiciones flexionadas y el re-aseguro de la articulación tarsal transversa durante el trepado, análogo a lo propuesto por Yalden (1970) para articulaciones intracarpales. El grado moderado de movilidad lateromedial de la articulación transversa tarsal en nutrias, en combinación con la reducción de capacidad de inversión (en mayor o menor grado, ver articulación subtalar), sugeriría capacidad de direccionar y acomodar la planta del pie, sin disminuir la superficie de propulsión efectiva (Tarasoff 1972). En Lo. provocax y Lo. felina (contrario a Lo. longicaudis, Lo. canadensis, Pt. brasiliensis, En. lutris y Lu. lutra; ver también Willemsen 1980a, b, Peigné et al. 2008, y similar a algunas nutrias fósiles, e.g., 'Sivaonyx beyi; Peigné et al. 2008) se registra una carilla para el tarsal IV en la cabeza del astrágalo bien desarrollada y definida, limitando la movilidad de la articulación transversa tarsal (Heinrich y Rose 1997), relacionado a un cuello del astrágalo largo (sensu Peigné et al. 2008), y posiblemente un rasgo primitivo para nutrias. Esta y otras características de Lo. provocax y Lo. felina comentadas en esta sección (e.g., reducción de la movilidad y re-aseguro de la articulación subtalar y tobillo en comparación con otras nutrias) y para otras regiones del postcráneo (e.g., ver sección 4.3.4, Escápula), sugieren restricciones articulares importantes, quizás en relación a distintos estilos de nado, o a que estas especies se mueven y construyen sus madrigueras en costas pedregosas (Bastida et al. 2007). En muchos mustélidos de otros continentes, como el tejón Meles meles, se registra un grado de movilidad similar al de nutrias, pero la capacidad de abducción de la articulación transversa se encuentra más limitada por una articulación proximal del tarsal IV mínimamente expandida lateralmente.

Por razones no del todo claras, la morfología de la articulación entre el calcáneo y tarsal IV es muy variable. La inclinación medial de la misma respecto al plano transverso es marcada en Spilogale, Nasua, Pteronura y secundariamente en otras nutrias (e.g., Willemsen 1980a) y otros arctoideos (Davis 1964), taxones diferentes tanto en hábitos, tamaños y afinidades filogenéticas (pero ver Heinrich y Rose 1997). En vista distal, el ángulo entre el eje principal de 
la faceta articular del calcáneo para el tarsal IV y la articulación medial para el astrágalo es cercano a $0^{\circ}$ en nutrias, y cercano a $45^{\circ}$ en otros mustélidos sudamericanos. Este rasgo compuesto ha sido relacionado a múltiples factores: e.g., la habilidad de inversión en marsupiales (Argot 2002), restricciones a los movimientos laterales en roedores (Candela y Picasso 2008), y a la reducción de los dígitos periféricos (Polly 2008) o la rotación de la articulación transversa en carnívoros (Taylor 1976); requiriéndose estudios específicos para su mayor comprensión (Candela y Picasso 2008).

\section{Elementos tarsales distales, metatarsales y falanges}

El sesamoideo tibial, sitio de inserción del $\mathrm{m}$. tibialis caudalis, no demanda mayores comentarios, excepto para Lo. provocax, especie en la que, al contrario de otros musteloideos (incluso Lo. longicaudis), un proceso proximomedial del tarsal I parece corresponder al sesamoideo tibial fusionado y reducido, quizás en relación a la marcada reducción de los movimientos de inversión (función en la que participa el m. tibialis caudalis; Fisher et al. 2008) inferidos por las regiones articulares.

Los tarsales distales son elementos pequeños e imbricados. La posibilidad de movimientos entre estos se encuentra a su vez limitada por estar fuertemente rodeados por ligamentos (Davis 1964, Taylor 1976, Sargis 2002, Hunt 2009). Tanto en Ei. barbara como en nutrias en general, los tarsales distales están relativamente poco imbricados, a la vez que la cara medial del tarsal IV y las áreas de contactos con el central y tarsal III están relativamente reducidas. Estos rasgos indican cierta movilidad entre estos elementos en estos linajes (Davis 1964, Heinrich y Rose 1997). Distalmente, el área de contacto del tarsal IV con los metatarsales IV y $\mathrm{V}$ es amplia, netamente cóncava y continuada, sin formarse un contacto de tipo cócleatróclea como en lincodontininos, permitiendo potencialmente mayores movimientos de abducción del dígito $\mathrm{V}$ respectos a estos los últimos. Similares comparaciones pueden hacerse a nivel Musteloidea, en donde las especies más terrestres (e.g., mustelinos, melinos) presentan contactos intratarsales y tarso-metatarsales menos móviles que las especies acuáticas o trepadoras (e.g., prociónidos), posiblemente en relación a la importancia de una mayor área de contacto plantar en estas últimas (Tarasoff 1972, Sargis 2002, ver también Davis 1964).

La morfología de los metatarsales y falanges varía entre los distintos musteloideos estudiados, y muchas de las inferencias funcionales que se pueden realizar son concordantes con las ya descriptas para el autopodio anterior. Una característica sinapomórfica de Arctoidea, y presente en la mayoría de los representantes vivientes (pero ver hurones y otros linajes más adelante), es la presencia de un metatarsal IV dominante en longitud (Apéndice 3.15, c. 82, estado 1), rasgo posiblemente relacionado a la ausencia de posturas digitígradas o hábitos cursoriales acentuados en el grupo. En los hurones, los tres metatarsales y dígitos centrales, y especialmente el III (cercanamente seguido en longitud por el IV) son significativamente más 
largos (Apéndice 3.15, c. 82, estado 0). Tanto Ly. patagonicus como Mu. frenata, así como mustelinos de otros continentes, comparten series metatarsales y de falanges proximales de elementos gráciles y elongados, encontrándose los metatarsales fuertemente empaquetados y los sesamoideos metatarsales bien desarrollados. El primer metatarsal es aplanado, y su dígito reducido, colaborando pobremente en el soporte y propulsión. Esta configuración indica una máxima elongación del autopodio, concordante con marchas terrestres de apoyo digitígrado (postura típicamente utilizada por estos linajes; Mivart 1885, Polly 2008), zancadas largas y rápidas (y fase aérea de vuelo extendido extensas; Gambaryan 1974) y el apoyo del peso corporal en la articulación metatarso-falange, esfuerzo importante durante el aterrizaje al principio de la fase de apoyo (Maynard Smith y Savage 1956, Ewer 1973, Taylor 1976, Hildebrand 1988, Candela y Picasso 2008, Hunt 2009, Argot 2010). Esta condición, esperable en especies saltadoras, es a su vez limitante de movimientos intrínsecos del pie (Maynard Smith y Savage 1956, Taylor 1976). Por otro lado, Galictis spp., presenta una autopodio más generalizado, con series metatarsales y falanges más robustas y menos compactadas, asociado con una postura digitígrada menos frecuente o estricta y una mayor superficie palmar (Ewer 1973, Argot 2010); rasgos beneficiosos para otras actividades eventualmente registradas para el taxón, como padding y cavado (Azara, 1802, Dalquest y Harvey 1951, Yensen y Tarifa 2003a, b, Wilson y Mittermeier 2009).

En las especies trepadoras plantígradas o semiplantígradas, los dígitos son más similares entre sí, siendo relativamente importantes las longitudes de los periféricos y los metatarsales están más laxamente empaquetados (i.e., con amplios espacios interóseos; Ewer 1973, Taylor 1976). Esta configuración permite un área palmar robusta, amplia y flexible, útil en establecer un contacto seguro con el sustrato durante la locomoción plantígrada arborícola (Taylor 1976, Hildebrand 1988). El dígito I, desarrollado en los carnívoros trepadores, colabora ampliamente en la propulsión y sujeción (aunque no por oposición a los restantes dígitos, como en otros mamíferos, ver Argot 2002, Sargis 2002). Eira barbara, así como el prociónido Nasua nasua, comparten una serie metatarsal y falangeal robustas y moderadamente elongadas, capaces de resistir los esfuerzos impuestos al colaborar durante actividades de cavado que desarrollan estas especies (Hildebrand 1988, Taylor 1989). Especies cercanas a estas pero que no cavan frecuentemente (e.g., Procyon spp., Martes spp.), presentan una morfología similar pero con elementos más elongados y gráciles, especialmente las falanges, en relación a un aumento de la superficie de contacto y la capacidad de grasping de los autopodios posteriores (Van Valkenburgh 1987, Argot 2002), sin las restricciones impuestas por la resistencia a los esfuerzos de cavado. Como ocurre en el autopodio del miembro anterior, el gran desarrollo del metatarsal medio de Procyon spp. (Apéndice 3.15, c. 82, estado 0) no puede ser fácilmente explicado desde el punto de vista funcional considerando los hábitos de la especie, pero resultan 
filogenéticamente informativos a nivel genérico dentro de Procyonidae. En Ei. barbara, el sector medial y lateral de los tubérculos plantares del metatarsal I y $\mathrm{V}$ respectivamente, se encuentran marcadamente proyectados y robustecidos, en mayor medida que lincodontininos, y mucho mayor grado que mustelinos y lutrinos de América del sur y otros continentes. Esto habilita una mayor área de origen para el $\mathrm{m}$. flexor breves profundi del dígito I, y el m. abductor digiti $\mathrm{V}$, en relación a la mayor movilidad (e.g., abducción), soporte del peso y fuerza de los dígitos periféricos, necesarias durante el trepado (Taylor 1976, Sargis 2002). Por otro lado, sobre el sector proximolateral del metatarsal I, la inserción del m. fibularis longus (McClearn 1985, Fisher et al. 2008) es relativamente aguda y proyectada medialmente en lutrinos, ictoniquinos y mustelinos, mientras que es amplio proximodistalmente y menos proyectado medialmente en Ei. barbara, quizás informativo en lo que respecta a ancestría común.

Las especies cavadoras terrestres, como mefítidos y tejones (e.g., Meles meles), presentan metatarsos y falanges robustos y cortos, y calcáneos alargados y robustos. Esta configuración puede entenderse como una reducción de brazo de palanca de salida y un incremento del brazo de palanca de entrada respectivamente para los músculos extensores (flexores ventrales) del tobillo, aumentando la producción de fuerza y la resistencia de estos esfuerzos (Maynard Smith y Savage 1956, Hildebrand 1988, Taylor 1989, Candela y Picasso 2008) durante la colaboración de los miembros en el cavado (Hildebrand 1988, Taylor 1989, Moore et al. 2013). Estas adaptaciones al cavado (i.e., fuerza y estabilización contra rapidez; Hildebrand 1988, Taylor 1989, Candela y Picasso 2008) son a su vez contraproducentes con marchas terrestres ágiles y veloces (Taylor 1989, Álvarez et al. 2013). En otro contexto aunque también en relación a esto, Carrano (1999) encontró una relación inversa entre el incremento en el soporte de la fuerza peso y la reducción de rasgos cursoriales.

En las nutrias, los elementos distales del pie (falanges y especialmente metatarsales) se encuentran elongados respecto a los elementos proximales del miembro posterior, son robustos y aplanados (Apéndice 3.15, c. 82), y los elementos del dígito I están reducidos (incluso en mayor medida que en hurones), lo cual está en relación a un estilo de vida acuático (Savage 1957, Jouffroy 1971, Tarasoff 1972, Peigné et al. 2008). La elongación relativa de estos elementos es particularmente importante en Pteronura brasiliensis (Peigné et al. 2008) y Enhydra lutris (Holmes 1980), justamente las especies más especializadas al nado (Holmes 1980, Lewis 2008, Peigné et al. 2008). En el caso especifico de Pt. brasiliensis, en comparación con otros lutrinos menos especializados (e.g., Lontra spp.), presenta una mayor diferenciación de robustez y longitud de los dígitos más laterales (ver también Peigné et al. 2008), las falanges proximales y medias son más elongadas y aplanadas, y las falanges distales se encuentran reducidas en mayor grado. De esta manera, el área de propulsión efectiva de autopodio resulta expandida especialmente en su sector lateral, tendiendo a un aspecto similar a "media luna" el 
contorno de ambos miembros posteriores al actuar juntos en posición caudal, colaborando junto al sector axial durante el nado de tipo carangiform (i.e., ondulaciones axiales posteriores; ver Tarasoff 1972, Tarasoff et al. 1972, Taylor 1989). Por otro lado, la reducción de las falanges distales comentada para la nutria gigante imposibilita a su vez la colaboración de los miembros posteriores en actividades de tipo scratching-dig (Hildebrand 1988, Taylor 1989; ver más arriba). Una morfología de "media luna" aun más especializada es la presente en En. lutris. En esta especie, el metatarsal y dígito $\mathrm{V}$ son los más largos y robustos, lo cual ha sido clásicamente interpretado como una adaptación a un modo de vida acuático en donde los miembros posteriores son particularmente importantes en la propulsión en velocidad (Jouffroy 1971, Tarasoff 1972, Tarasoff et al. 1972, Holmes 1980, Taylor 1989, Peigné et al. 2008). El quinto dedo lidera durante la propulsión, adoptando el pie una forma de copa (cup-shaped foot; Tarasoff et al. 1972) y evitando fugas laterales del líquido desplazado. Contrariamente, en otras nutrias incluyendo a la especializada Pt. brasiliensis, el desarrollo y los movimientos de la cola son más relevantes en velocidad (Taylor 1989, Fish 1994, Nowak 2005, Kruuk 2006, Peigné et al. 2008). Las escasas excursiones terrestres de En. lutris (Heptner y Naumov 1967, Tarasoff et al. 1972, Taylor 1989), se relacionan al grado de especialización del taxón (Tarasoff et al. 1972, Holmes 1980, Williams 1989).

En lutrinos menos especializados al buceo como Lontra spp., se registra una morfología más generalizada (e.g., dígitos laterales con una elongación menos exagerada que en Pt. brasiliensis o En. lutris), lo que se relaciona seguramente a una explotación más exhaustiva del sustrato terrestre en las inmediaciones de los cuerpos de agua que utilizan (Bastida et al. 2007, Peigné et al. 2008), como también concluyeron Holmes (1980) y Tarasoff (1972) para Lu. lutra y Lo. canadensis respectivamente.

En lo que respecta a la morfología de las falanges ungueales, la relación entre forma y uso de sustrato, es similar a lo descripto para el carpo (Holmes 1980, Taylor 1989). En las especies musteloideas fosoriales, como ya fue indicado por Holmes (1980) y Taylor (1989) entre otros, las falanges ungueales de los miembros posteriores son claramente menores en longitud que la de los miembros anteriores, lo cual se encuentra relacionado a la menor importancia de los primeros en el cavado, circunscribiéndose principalmente a retirar las acumulaciones del sedimento ya removido por los miembros anteriores (Taylor 1989, Moore et al. 2013). 


\subsection{Comentarios sobre los elementos postcraneales de especímenes de mustélidos fósiles}

\subsubsection{Lyncodon patagonicus MLP 96-V-1-1 y MLP 96-V-2-2/3}

El gran número de epífisis sueltas o con suturas no totalmente fusionadas a las diáfisis en los especímenes de Lyncodon patagonicus $\mathrm{n}^{\circ} 2$ y n³ (MLP 96-V-2-2/3) es evidencia de que estos dos especímenes son juveniles de similar desarrollo, aunque la morfología de algunos procesos de agarre muscular y el grado de fusión de algunas epífisis indican un estado de desarrollo algo más avanzado en el espécimen n³; algo sustentando también por el grado más avanzado de erupción de la dentición. Únicamente en el espécimen $n^{\circ} 3$ se presentó el foramen lateral transverso del atlas cerrado como ocurre en todos los adultos, mientras que el largo cráneocaudal y morfología del proceso espinoso del espécimen $\mathrm{n}^{\circ} 3$ fue más similar a especímenes adultos que lo observado en $\mathrm{n}^{\circ} 2$. Por último, las epífisis proximales del húmero se encontraron parcialmente fusionadas a las diáfisis en el $n^{\circ} 3$, mientras que en el $n^{\circ} 2$ la única preservada no está fusionada.

En función del desarrollo de los procesos mastoideos y la cresta occipital del cráneo, es muy probable que el espécimen adulto sea una hembra, y en consecuencia, que los restos asociados correspondan a una hembra y sus dos crías. Aunque no se conoce el tamaño de camada de Ly. patagonicus, otros lincodontininos tienen de 1 a 5 crías (Yensen y Tarifa 2003a, b).

La presencia de estos especímenes y otros restos de Ly. patagonicus en el Holoceno Temprano del norte y este de la provincia de Buenos Aires, región en la cual la especie no hábita en el presente, ha sido vinculada a pulsos climáticos fríos y áridos correspondiente al último máximo glaciar (Prevosti y Pardiñas 2001). Posteriormente, la especie habría sufrido un proceso de vicarianza que habría dado origen a las subespecies actuales, una con su núcleo de distribución en el noroeste de Argentina (Ly. patagonicus thomasi) y otra en la Patagonia (Ly. patagonicus patagonicus; Cabrera 1929, Schiaffini et al. 2013).

Más allá de que el análisis de los restos craneales de Prevosti y Pardiñas (2001) no reveló diferencias significativas con especímenes actuales de Lyncodon patagonicus, algunos rasgos en el postcráneo del ejemplar fósil adulto son llamativamente diferentes a los presentes en los representantes actuales de esta especie, y deben ser tenidos en cuenta, e.g., arco neural del atlas marcadamente amplio y liso, marcada extensión de proceso espinoso del axis y la escotadura dorsal caudal y la morfología de región articular de axis (ver también Tabla 3.4). Un análisis más detallado de los rasgos postcraneales destacados, en conjunto con ciertos rasgos reconocibles en el material craneal, e.g., reducción máxima de procesos mastoideos y cresta temporal, rostro extremadamente corto y arcadas zigomaticas débiles (más bien similar a especímenes juveniles actuales), dientes yugales (especialmente P3 y P4) imbricados, paladar sin prominencia central media entre procesos pterigoides; podrían revelar si estas características 
de estos materiales únicos son de interés funcional, taxonómico o de otro tipo. Las características osteológicas comentadas concuerdan con hábitos carnívoros y especialización a la caza de roedores en galerías, como es el caso de los representantes vivientes de la especie.

\subsubsection{Lontra sp. CADIC s/n y y 1021330}

Las comparaciones del material fósil CADIC s/n "Lontra sp." colectado en el canal de Beagle, Tierra del Fuego, con respecto a materiales de Lo. provocax, Lo. longicaudis y material fotográfico y bibliográfico de Lo. felina, permiten su asignación a la especie Lo. provocax. La longitud del fémur $(81,122 \mathrm{~mm}$.) representa un valor intermedio entre Lo. provocax (media = 88,706 mm.; DE = 7,718), y Lo. felina (media = 68,2 mm), ubicándose únicamente dentro del rango de valores de Lontra provocax (valor mínimo $=80,172$ ), y lejano a los valores de la especie Lo. longicaudis (media $=66,022 \mathrm{~mm}$.; $\mathrm{DE}=7,666$ ). Por otro lado, el fémur del espécimen fósil presenta rasgos observados solamente en especímenes de Lo. provocax: la cabeza femoral está marcadamente proyectada por debajo de límite con el cuello femoral; y la región craneal de la tuberosidad glútea se encuentra hipertrofiada e incidida por un surco de dirección lateromedial. Por otro lado, al igual que en especímenes actuales de Lo. felina y Lo. provocax, existe una profunda escotadura dorsal entre la cabeza femoral y el trocánter mayor, la cual en vista caudal tiene un aspecto simétrico, más similar a Lo. provocax que Lo. felina. En función de todas estas comparaciones, se propone la asignación del mismo a Lontra provocax. Las características del fragmento distal de fémur del material CADIC 1021330, permiten confirmar, por su notable similitud respecto al anterior, la misma asignación taxonómica. Por otro lado, es necesario destacar que los sitios en donde fueron encontrados los restos se encuentran dentro del área de distribución actual de de Lo. provocax. Las características de estos fémures evidencian una gran potencia en los movimientos de la cadera dentro y fuera del plano parasagital, y son compatibles con hábitos acuáticos, como es el caso de los representantes vivientes de la especie.

\subsubsection{Lontra sp. MCNyA s/n}

El calcáneo de Lontra sp. MCNyA s/n colectado en Arroyo Barrancas, Entre Ríos, tiene un longitud máxima de 24,668 $\mathrm{mm}$. Este valor coincide cercanamente con el observado en Lontra longicaudis $($ media $=22,34 \mathrm{~mm}, \mathrm{DE}=1,97$; difiriendo del espécimen MACN 47.218 sólo por 0,1 mm), y es mayor al presentado por Lo. provocax (e.g., espécimen MACN 29821; $30,56 \mathrm{~mm}$ ). Esta medida, en conjunto con la morfología de las articulaciones para el astrágalo y tarsal IV, y la ausencia de un proceso troclear marcadamente distalizado, permiten eliminar la posibilidad de una asignación a Pt. brasiliensis. La morfología del elemento también tiene una correspondencia total con la especie Lo. longicaudis, con un tubérculo breve, un surco 
simétrico, la superficie articular proximal para el talus relativamente extendida proximalmente, $\mathrm{y}$ un proceso troclear expandido distalmente pero no proximalmente (característica que distingue a Lo. longicaudis de Lo. provocax). Aunque no se pudieron obtener datos de calcáneos de Lo. felina, considerando la distribución actual de la especie (i.e., alcanzando el extremo sur de su distribución el norte de la provincia de Buenos Aires; Larivière 1999) y la extracción del material fósil de depósitos relativamente modernos, es muy probable desestimar a esta especie como una posibilidad. La asignación de este material a Lo. longicaudis es esperable dado que los restos provienen de un asentamiento del Holoceno _Tardío (sitio Cerro Barrancas), y esta nutria es la única especie que actualmente vive en la región y sus restos fueron hallados junto a elementos de Myocastor (Bonomo et al. 2010), especie también típica de la región en la actualidad.

\subsubsection{Pteronura brasiliensis CICyTTP-Pv-1-21}

Este material fue hallado en depósitos pleistocénicos de los márgenes del Arroyo Ensenada, Entre Ríos (Noriega et al. 2004, Prevosti y Ferrero 2008). Noriega et al. (2004; ver también Carlini et al. 2002) señalaron diferencias en la composición faunística del Cuaternario del sudoeste de la provincia de Entre Ríos respecto a las faunas centro-pampeanas, y una condición de tipo insular para la región mesopotámica, incluyendo una mayor importancia de componentes de distribución brasílica, incluyendo a Tapirus sp. y el espécimen CICyTTP-Pv-121 de Pteronura brasiliensis aquí estudiado, y la reducción/incremento del tamaño corporal de distintas especies de herbívoros. Los autores relacionaron estos cambios a modificaciones en los ríos Paraná y Uruguay en relación al último momento interglaciar. Prevosti y Ferrero (2008) analizaron los restos craneales de este espécimen fósil, confirmando su asignación a la especie Pt. brasiliensis, y destacando también variantes menores en rasgos específicos craneanos que lo diferencian de representantes actuales de la especie, incluyendo medidas lineales ligeramente superiores (ver también Noriega et al. 2004); pero asignaron esto a variantes intraespecíficas (contra Carlini et al. 2002). Este estudio coincide con Prevosti y Ferrero (2008: 1175) en que los elementos postcraneales son muy similares a los de representantes vivientes de la especie. Los escasos rasgos que se reconocen en el espécimen CICyTTP-Pv-1-21 se apartan del rango de los actuales, y están restringidos mayormente al desarrollo de la cresta ectepicondilar del húmero y al desarrollo de la cavidad glenoidea de la escápula, entendibles como variantes intraespecíficas de Pt. brasiliensis. Carlini et al. (2002) y Prevosti y Ferrero (2008: 1175) señalaron que las epífisis de algunos elementos postcraneales no se encontraron totalmente fusionadas, lo que en conjunto con la dentición totalmente erupcionada, indica que el ejemplar es un adulto joven. Aunque la fusión de epífisis es avanzada en la mayoría de los casos, se corroboró que algunas regiones de sutura aun no están completas, a lo cual puede sumarse que 
la mayoría de los daños o partes faltantes se encuentran en las epífisis, potencialmente indicando la falta de osificación total de las mismas. Contrario a lo obtenido por Prevosti y Ferrero (2008) en su estudio de variantes craneales, en el postcráneo, los valores de longitud de húmero y tibia (los elementos apendiculares más completos del material) se encontraron dentro del rango de valores observados para la especie actual (Tabla 3.5), aunque este análisis debe ser considerado preliminar, en relación al bajo número de especímenes actuales contemplados. Muchos de los rasgos presentes en los elementos postcraneales son propios de hábitos de vida acuáticos (e.g., hipertrofia del área de origen los músculos extensores del hombro y los aductores del brazo, curvatura sigmoidal del húmero marcada, proporciones del miembro posterior), relacionados a la la obtención de una silueta hidrodinámica y una propulsión efectiva durante el nado, concordando con los representantes actuales de la especie. 


\subsection{Comentarios generales sobre los análisis lineales y de morfometría geométrica}

En este apartado se realiza una evaluación general del comportamiento de las variables lineales y datos de forma en los distintos análisis, y sobre cómo la estructura filogenética afecta la relación entre la morfología y las variables ecológicas. Por otro lado, relaciones morfofuncionales específicas para cada región u elemento fueron comentadas a lo largo de la sección 4.3 .

Los análisis de medidas lineales mostraron resultados diversos respecto a la significancia de los efectos de los factores locomoción y dieta sobre cada índice. Sin embargo, por regla general, todas las proporciones postcraneales de los musteloideos analizados fueron significativamente afectadas en grado variable por alguna de estas variables ecológicas y en la mayoría de los casos específicamente por la locomoción. En las regiones apendiculares y tóraco-lumbar, la locomoción fue el principal o único factor ecológico significativo (ver sección 3.4). El análisis del cambio de forma de los elementos postcraneales analizados mediante morfometría geométrica (i.e., vista lateral de axis, vista dorsal de penúltima vértebra lumbar, vista craneal del extremo distal de húmero y vista caudal del extremo distal del fémur), reveló también una influencia significativa de la locomoción en todos estos elementos (ver sección 3.5). Dado que la estructura osteo-muscular postcraneal permite, o limita, movimientos y posiciones específicas, útiles durante la propulsión y el soporte, es esperable una relación estrecha entre los valores de los índices o cambios de forma y los estilos locomotores (Ewer 1973, Hildebrand 1988, Taylor 1989, pero ver Martín-Serra et al. 2014).

Dentro de la estructura apendicular, la dieta ha sido tradicionalmente considerada un factor significativo únicamente en el miembro anterior, lo cual puede relacionarse a la relativamente importante participación de los miembros anteriores durante la caza y alimentación (Ewer 1973, Iwaniuk et al. 2000, Argot 2003b, 2004). En esta tesis, la proporción braquial y del autopodio anterior, así como la forma el húmero distal, resultaron influenciados significativamente por la dieta (secciones 3.4, 3.5). Sin embargo, la influencia de este factor sobre los índices del miembro anterior y forma del húmero distal (ver también distribución de principales clados en morfoespacio; e.g., Fig. 3.7B) se volvió no significativa luego de analizar la influencia de la filogenia (mediante el método comparativo filogenético GEE), y por lo tanto siendo considerada como un potencial artefacto o estructurada por las relaciones filogenéticas. En relación a esto, Iwaniuk et al. (2000), en un contexto comparativo más amplio, encontraron una relación negativa entre el grado de depredación y el grado de manipulación de los miembros anteriores. Iwaniuk et al. (2000) plantearon que la reducción del grado de manipulación en depredadores se debía a las adaptaciones cursoriales necesarias en persecusiones de presas, y la existencia de especies omnívoras especializadas en manipular alimentos con gran habilidad (e.g., Potos flavus, Ailuropoda melanoleuca). 
Por otro lado, la longitud relativa de la región cervical se encontró exclusivamente y marcadamente influenciada por la dieta, lo cual estaría relacionado a la de la importancia de un cuello largo en la realización de movimientos rápidos y poderosos durante la caza y el transporte de presas ágiles o pesadas (Ewer 1973, Bisaillon et al. 1976, Spoor y Badoux 1986b, King 1989, Antón y Galobart 1999, Salesa 2005, 2006; ver sección 4.3.2, Región cervical). El análisis de forma del axis también indicó una importante influencia de los hábitos dietarios; en este elemento, aunque la locomoción también fue considerada (antes de contemplar la estructura filogenética) como un factor de influencia significativa, siendo la diferenciación morfológica del grupo locomotor nadador la principal causa de esta relación significativa. En el caso de las nutrias, una correlación entre la locomoción y la forma de elementos cervicales no es inesperada dado que en este grupo los movimientos de la región cervical se encuentra involucrados en los distintos estilos de nado y maniobras de cambio de dirección. Por otro lado, la influencia de otros factores como la filogenia y la tendencia a la carnivoría en los grupos musteloideos nadadores y half-bounders también pueden influenciar esta relación. Ciertamente, luego de contemplar la filogenia, la locomoción se volvió un factor no significativo y sólo la dieta resultó un factor significativo sobre la forma del axis, similar a lo observado en el análisis de la longitud relativa cervical.

Estudios previos han planteado que el tamaño corporal tiene una influencia significativa en la morfología del postcráneo, en función del incremento de las fuerzas desproporcionalmente mayores transferidas sobre los miembros en las especies de mayor tamaño corporal (Jenkins 1973, Biewener 1983, Hildebrand 1988, Heinrich y Biknevicius 1998, Fabre et al. 2013b), y esta es la hipótesis H2 de esta tesis. Heinrich y Biknevicius (1998), en un análisis en el que incluyeron cuatro guloninos, reconocieron una marcada relación alométrica, registrando una disminución de la longitud e incremento de la robustez del fémur y principalmente del húmero al incrementarse el tamaño corporal. Esto se debería a los cambios posturales del fémur y mayores fuerzas de reacción a la cual está sometido el miembro anterior durante la marcha en las especies más grandes. Fabre et al. (2013b), en sus análisis con control filogenético de una muestra de musteloideos, detectaron un efecto directo y significativo aunque débil de la masa sobre la robustez de las diáfisis humeral y el tamaño de las regiones articulares del húmero y radio (y un efecto inverso sobre la ulna), sugiriendo que otros factores, como la estrategia locomotora y caza, tendrían una mayor importancia relativa. Martín-Serra et al. (2014) también encontraron un efecto significativo pero más fuerte del tamaño sobre la robustez de la mayoría de los elementos del miembro anterior luego de contemplar la filogenia, pero sólo incluyendo nueve especies de musteloideos en la muestra. Por otro lado, Iwaniuk et al. (2000) no encontraron una relación significativa entre la masa corporal y la morfología del miembro anterior para una muestra amplia de carnívoros. En función de los coeficientes parciales de los 
ANCOVAs de los análisis lineales y de los MANCOVAs de morfometría geométrica, la influencia del tamaño corporal tampoco fue en ningún caso significativa en este estudio (exceptuando una influencia maginalmente significativa en algunos análisis del índice LaTi/LaFe; ver filas de masa en Tabla 3.6, Apéndices 3.7, 3.9), sin afectar de manera drástica la inclusión o no de este factor en los análisis. Es necesario considerar que la ausencia de alometría en los índices y analisis de forma aquí realizados (en donde sólo se analizaron extremos de elementos apendiculares) se encuentra probablemente relacionado, al menos en parte, a que en ninguno de los mismos cuantificó la robustez de ningún elemento apendicular.

El efecto de la estructura filogenética sobre la variación de los elementos postcraneales fue significativo en la gran mayoría de los estudios publicados en que esto fue evaluado (e.g., Iwaniuk et al. 2000, Ercoli et al. 2012, Álvarez et al. 2013, Fabre et al. 2013a, b, Morales y Giannini 2013, Samuels et al. 2013, Martín-Serra et al. 2014). En esta tesis, la consideración de la estructura filogenética (ver comparación de resultados sin vs. con control filogenético; Tabla 3.6) tuvo distintos comportamientos en distintos análisis lineales: no modificó mayormente los principales resultados e interpretaciones en el caso de los índices cervico-tóraco-lumbares, desarrollo de los miembros respecto al tronco y del miembro posterior (LaTL/PrLaM, $\mathrm{LaCe} / \mathrm{LaTL}, \mathrm{LaLu} / \mathrm{LaTL}$ y LaTi/LaFe), mientras que sí existieron modificaciones destacables para el índice sacro-caudal, la proporción intermembral y aquellos que involucraron al miembro anterior (LaSC/LaTL, LaMA/LaMP, LaRa/LaHu y LaMcIII/LaFIII). En todos los análisis morfogeométricos, los principales resultados fueron modificados al contemplar la filogenia (Apéndice 3.9). Como sugirieron Martins et al. (2002), el desempeño (performance estadística) de un método comparativo varía en función de las propiedades de los datos analizados y la hipótesis filogenética considerada. En el caso de la longitud caudal relativa, el cociente intermembral y las proporciones del autopodio anterior, la contemplación de la filogenia desestimó la significancia otorgada en previos análisis a uno o más factores específicos (locomoción, dieta y dieta, respectivamente), considerando a los resultados sin control filogenético como falsos positivos (i.e., cuando rasgos heredados exacerban las diferencias entre grupos funcionales). Lo mismo ocurrió para el factor locomoción en el caso de todos los análisis de forma, y además la dieta en el caso del análisis de forma del húmero. En estos casos, se puede plantear la posibilidad de que rasgos comunes a los miembros de un grupo ecológico específico que a su vez los diferencian de miembros de otros grupos, corresponden a características heredadas, sean o no características informativas desde el punto de vista funcional. En el caso del índice braquial, la implementación del método comparativo filogenético, permitió desestimar la relación con la dieta obtenida previamente a su aplicación, pero a su vez reveló una relación significativa entre este índice y la locomoción (considerada marginalmente no significativa en el análisis sin control filogenético), pudiendo considerarse a 
estos casos un falso positivo y un falso negativo (i.e., cuando rasgos heredados oscurecen, y actúan a modo de "ruido", una relación morfo-funcional significativa), respectivamente (Tabla 3.6).

En el caso de que cada clado tenga representantes en varios grupos funcionales y cada grupo funcional representantes de varios clados, la implementación de este tipo de métodos comparativos permite reconocer con mayor facilidad falsos positivos y falsos negativos. Cuando el total o la mayoría de los miembros de cada grupo ecológico conforman a su vez un grupo monofilético (sea por sesgos de muestreo o naturaleza del grupo analizado; e.g., nutrias), la implementación de métodos comparativos como el aquí aplicado tienden a subvalorar la relación entre la variable explicatoria y la explicada. Esto se debe a que una porción de la información, valiosa desde el punto de vista funcional, pero a su vez estructurada en la filogenia, es considerada "ruido" filogenético (ver Ercoli et al. 2012). Por otro lado, el procedimiento de eliminación de taxones outliers funcionales puede sobrevalorar la significancia funcional aun luego de la aplicación de métodos comparativos filogenéticos, en caso de que los valores alcanzados por estos outliers sean similares a los de especies cercanas (y por ende informativo de rasgos heredados sin interés funcional).

Es por todo esto que, luego de aplicar métodos comparativos filogenéticos, la pérdida o ganancia de significancia en la relación entre una o más variables y un índice o set de variables morfogeométricas en particular no debe en todos los casos considerarse ligeramente. El conocimiento previo sobre el grupo de estudio, la estadística descriptiva, así como las optimizaciones, puede arrojar luz a esta cuestión. A lo largo de la discusión morfo-funcional, no sólo se discuten los valores de significancia, sino también se analizan los valores de taxones outliers y sus relativos, formación de subgrupos monofiléticos dentro de categorías específicas, principales cambios de estados en optimizaciones de rasgos específicos, etc.

Distintos métodos filogenéticos comparativos presentan diferentes supuestos y sesgos (Rohlf 2001, Martins et al. 2002). Uno de los supuestos de la familia de métodos filogenéticos basados en regresiones (e.g., Felsestein's Independent Contrast, Phylogenetic Generalized Least Squares, Felsenstein 1985, Martins y Hansen 1997), incluyendo al GEE, es que los rasgos bajo estudio se desarrollaron en procesos de tipo estocásticos, como el movimiento browniano (Martins y Hansen 1997, Rohlf 2001). Otros métodos filogenéticos comparativos (e.g., métodos comparativos de partición de varianza, e.g., Phylogenetic Autoregression, Phylogenetic Eigenvector Regression; Cheverud et al. 1985, Diniz-Filho et al. 1998) no poseen modelos evolutivos entre sus supuestos, pero también adolecen de otros tipos de sesgos (e.g., simplificación de las relaciones filogenéticas, aproximaciones iterativas; Cheverud et al. 1985, Diniz-Filho et al. 1998, Rohlf 2001, Martins et al. 2002). Más allá de esto, estudios de simulación (Diniz- Filho y Torres 2002, Martins et al. 2002, Diniz-Filho et al. 2011) han 
revelado que en la gran mayoría de los casos, la aplicación de uno u otro método filogenético comparativo otorgan resultados similares (e.g., resultados de diferentes métodos comparativos obtuvieron correlaciones siempre mayores al $80 \%$ en una amplia gama de escenarios evolutivos hipotéticos; Martins et al. 2002), y mejoran notablemente la performance estadística respecto a análisis realizados sin contemplar el efecto de la filogenia, incluso cuando son violados algunos de sus principales supuestos.

Más allá del debate teórico respecto al modo de implementación y tipo de métodos filogenéticos comparativos aplicado a matrices de datos morfológicas (Martins y Hansen 1997, Diniz-Filho y Torres 2002, Rohlf 2001, 2006), muchos autores han destacado la importancia de la aplicación de los mismos al analizar conjuntos de datos provenientes de distintos taxones. Estos permiten lidiar con la falta de independencia causada por la estructura filogenética de los datos, un supuesto típico de la mayoría de los métodos estadísticos (incluyendo los análisis de varianza aquí aplicados), y evitar interpretaciones incorrectas (Martins y Hansen 1997, DinizFilho 2000, Desdevises et al. 2003). 


\section{Tablas de Discusión}

Tabla 4.1. Características principales del esqueleto axial de representantes de Arctoidea (i.e., Ailuridae, Mephitidae, Mustelidae, Procyonidae y Ursidae) compilados a partir de datos propios ("Esta Tesis") y bibliografía disponible: "M" = Mivart (1885), "K" = Koslowsky (1904), "Fish" = Fisher (1942), "S" = Slijper (1946), "D" = Davis (1964), "L y K" = Leach y de Kleer (1978), "W" = Willemsen 1980a, b, "B y K" = Baitchmand y Kollias (2000), "Y et al." = Yilmaz et al. (2000), "A" = Argot (2003b), "N y K" = Narita y Kuratani (2005), "Fil" = Filler (2007), "M et al." = Moritz et al. (2007). Se indica $\mathrm{n}^{\circ}$ de individuos observados $/ \mathrm{n}^{\circ}$ de colección de espécimen, $\mathrm{n}^{\circ}$ de elementos torácicos, lumbares, tóraco-lumbares, sacrales, caudales, posición de vértebra anticlinal y diafragmática. Paréntesis indican variantes secundarias de la muestra analizada para una especie, guiones indican variantes sin aclaraciones de frecuencia de ocurrencia, barras indican elementos asimétricos en la transición tóraco-lumbar. Asteriscos indican que el dato proviene de una submuestra del $\mathrm{n}^{\circ}$ de individuos total analizados por un autor dado. "?" indican datos faltantes o dudosos, i.e., en el caso de los zorrinos el número de vértebras anticlinales es difícil de establecer debido a los sutiles y variantes cambios de pendientes de los procesos espinosos, por lo cual se presenta el rango total de posibilidades.

(ver a continuación) 



\begin{tabular}{|c|c|c|c|c|c|c|c|c|c|}
\hline Especie & 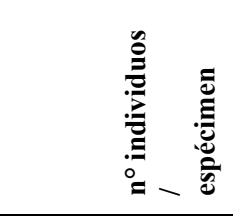 & 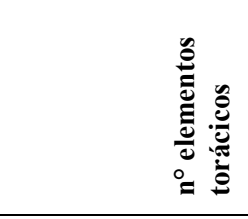 & 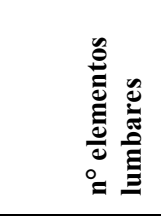 & 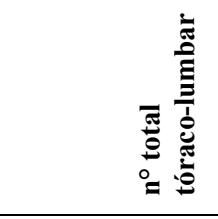 & 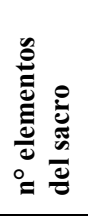 & 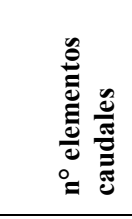 & 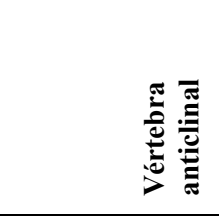 & 吾 & Fuente \\
\hline Ailuropoda melanoleuca & $3(2,1,2,1)$ & $14 / 13(14,14,13,13)$ & $4 / 5(4,5,5,4)$ & $18(18,19,18,17)$ & $?$ & $?$ & Ausente & $11-12$ & $\mathrm{D}$ \\
\hline Ailurus fulgens & 5 & 14 & 6 & 20 & ? & ? & $?$ & 11 & $\mathrm{D}$ \\
\hline Ailurus fulgens & ? & 14 & 6 & 20 & ? & ? & Ausente? & 11 & Fil \\
\hline Ailurus fulgens & ? & 14 & 6 & 20 & 3 & 18 & 11 & $?$ & M \\
\hline Aonyx cinerea & SMNS 13741 & 15 & 5 & 20 & 3 & ? & 13 & $12 ?$ & Esta Tesis \\
\hline Aonyx cinerea & 2 & 14 & 6 & 20 & 3 & ? & ? & $11^{*}$ & $\mathrm{~W}$ \\
\hline Aonyx sp. & ? & 14 & 6 & 20 & 3 & 20 & ? & $?$ & $\mathrm{M}$ \\
\hline Aonyx capensis & $i$ & 14 & 6 & 20 & 3 & ? & ? & $?$ & W \\
\hline Arctonyx sp. & ? & 16 & 4 & 20 & 4 & $15-20$ & ? & $?$ & M \\
\hline Bassaricyon alleni & $5(1,1,1)$ & $13(14,14,14 / 13)$ & $7(7,6,6 / 7)$ & $20(21,20,20)$ & ? & ? & ? & 10 & $\mathrm{D}$ \\
\hline Bassariscus astutus & USNM 051864 & 13 & 7 & 20 & 3 & ? & $10 ?$ & 10 & Esta Tesis \\
\hline Bassariscus astutus & $5(1,1)$ & 13 & $7(6,5)$ & $20(19,18)$ & ? & ? & ? & 10 & $\mathrm{D}$ \\
\hline Bassariscus astutus & ? & 13 & 7 & 20 & 3 & $23 ?$ & 11 & $?$ & M \\
\hline Conepatus chinga & MACN 28.20 & 16 & 5 & 21 & 2 & \pm 20 & 13 a 14 o sacro? & 14 & Esta Tesis \\
\hline Conepatus chinga & MLP 1015 & $16 / 17$ & 5 & $21 / 22$ & 2 & $+16, \pm 21$ & 13 a 14 sacro? & $13 / 14$ & Esta Tesis \\
\hline Conepatus chinga & MLP 19-VII-02-2 & 16 & 5 & 21 & 2 & ? & 13 a 15 o sacro? & 14 & Esta Tesis \\
\hline Conepatus chinga & MACN 28.75 & 16 & 5 & 21 & 2 & ? & 12 a sacro? & $13 ?$ & Esta Tesis \\
\hline Conepatus sp. & $?$ & 16 & 4 & 20 & 3 & 18 & $?$ & $?$ & M \\
\hline Conepatus sp. & ? & 16 & 5 & $?$ & ? & $?$ & ? & 14 & $\mathrm{~S}$ \\
\hline Conepatus chinga & MACN 28.74 & 15 & 6 & 21 & 2 & $+22 \pm 23$ & 13 a 15 o sacro? & 13 & Esta Tesis \\
\hline Eira barbara & ? & 14 & 6 & 20 & ? & ? & 11 & 11 & Fil \\
\hline Eira barbara & ? & 14 & 6 & 20 & 3 & 23 & ? & $?$ & $\mathrm{M}$ \\
\hline Eira barbara & MLP 1013 & 14 & 7 & 21 & 3 ? & $+21, \pm 23$ & 12 & 11 & Esta Tesis \\
\hline Eira barbara & SMNS 480 & 14 & 6 & 20 & 2 & ? & 12 & $11 ?$ & Esta Tesis \\
\hline Enhydra lutris & $?$ & 14 & 6 & 20 & 4 & 21 & $?$ & $?$ & $\mathrm{M}$ \\
\hline Enhydra lutris & ? & 14 & 6 & 20 & ? & $?$ & ? & 12 & $\mathrm{~S}$ \\
\hline Galictis cuja & CML 7260 & ? & 5 & ? & 2 & ? & 12 & 11 & Esta Tesis \\
\hline Galictis cuja & MACN 23519 & 15 & 5 & 20 & 3 & ? & 12 & 11 & Esta Tesis \\
\hline Galictis cuja & MLP 15-V-97-42 & 15 & 5 & 20 & 3 & ? & 12 & 11 & Esta Tesis \\
\hline Galictis cuja & MLP 2020 & 15 & 5 & 20 & 3 & $+18, \pm 19$ & 12 & 12 & Esta Tesis \\
\hline Galictis cuja & MLP 2034 & $15 / 16$ & $5 / 4$ & 20 & 3 & ? & $12 ?$ & 11 & Esta Tesis \\
\hline Galictis cuja & MLP 23.X.98.3 & 15 & 5 & 20 & 3 & ? & 12 & 11 & Esta Tesis \\
\hline Galictis cuja & MLP 25-IV-01-1 & 15 & 5 & 20 & 3 & 20 & 12 & 11 & Esta Tesis \\
\hline
\end{tabular}




\begin{tabular}{|c|c|c|c|c|c|c|c|c|c|}
\hline Especie & 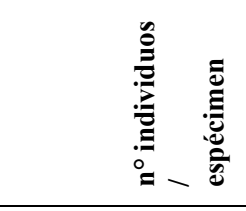 & 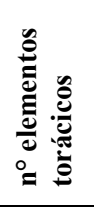 & 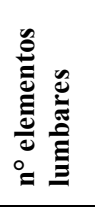 & 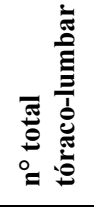 & 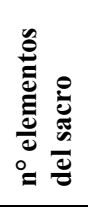 & 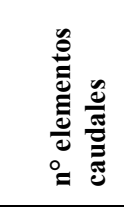 & 苟 & & Fuente \\
\hline Galictis sp. & $?$ & 16 & 5 & 21 & 3 & 21 & $?$ & $?$ & $\mathrm{M}$ \\
\hline Galictis vittata & AMNH 35514 & $?$ & 6 & $?$ & 3 & $?$ & $?$ & $?$ & Esta Tesis \\
\hline Galictis vittata & USNM 395077 & 15 & 5 & 20 & 3 & $?$ & 12 & 11 & Esta Tesis \\
\hline Galictis cuja & MLP 1014 & 15 & 5 & 20 & 3 & $?$ & 12 & 11 & Esta Tesis \\
\hline Gulo gulo & 1 & 15 & 5 & 20 & ? & $?$ & 12 & 12 & A \\
\hline Gulo gulo & $?$ & $14-15$ & 5 & $20-19$ & 3 & 15 & ? & $?$ & M \\
\hline Gulo gulo & NMV 22772 & 15 & 5 & 20 & 3 & \pm 13 & 12 & 11 & Esta Tesis \\
\hline Helarctos malayanus & 1 & 15 & 4 & 19 & $?$ & $?$ & Ausente & 12 & A \\
\hline Helarctos malayanus & 1 & 15 & 4 & 19 & 5 & $?$ & Ausente & 11 & $\mathrm{~S}$ \\
\hline Hydrictis maculicollis & NMV 3011 & 15 & 5 & 20 & 3 & $?$ & 12 & $?$ & Esta Tesis \\
\hline Hydrictis maculicollis & 1 & 14 & 6 & 20 & 4 & $?$ & $?$ & $?$ & $\mathrm{~W}$ \\
\hline Ictonychininae indet. & $?$ & 15 & 5 & 20 & 2 & 23 & $?$ & $?$ & M \\
\hline Lontra canadensis & $?$ & 14 & 6 & 20 & 3 & 22 & $?$ & $?$ & B y K \\
\hline Lontra canadensis & $?$ & 14 & 6 & 20 & 3 & $24-25$ & ? & $?$ & Fish \\
\hline Lontra longicaudis & MACN 47.218 & 15 & 5 & 20 & 3 & \pm 23 & 13 & 13 & Esta Tesis \\
\hline Lontra longicaudis & MLP 1959 & 15 & 5 & 20 & 3 & $+20, \pm 23$ & 13 & 12 & Esta Tesis \\
\hline Lontra longicaudis & MLP 1964 & $15 ?$ & 5 & $20 ?$ & 3 & ? & ? & $?$ & Esta Tesis \\
\hline Lontra provocax & MACN 20821 & 15 & 5 & 20 & 3 & 23 & 13 & 12 & Esta Tesis \\
\hline Lutra lutra & 1 & 14 & 6 & 20 & 2 & $?$ & 12 & 12 & $\mathrm{~S}$ \\
\hline Lutra lutra & 8 & 14 & 6 & 20 & 3 & $?$ & $?$ & $11^{*}$ & W \\
\hline Lutra lutra & 3 & 14 & 6 & 20 & 3 & \pm 18 & 11 & $?$ & Y et al. \\
\hline Lutra sp. & 2 & 14 & 6 & 20 & 3 & $?$ & $?$ & $?$ & N y K \\
\hline Lutrinae indet. & $?$ & $14-15$ & $6-5$ & 20 & 3 & $20-26$ & $?$ & $?$ & $\mathrm{M}$ \\
\hline Lutrogale perspicillata & NSMMa 4590 & 14 & 6 & 20 & 3 & $?$ & 13 & 12 & Esta Tesis \\
\hline Lutrogale perspicillata & 2 & 14 & 6 & 20 & 3 & $?$ & $?$ & $12 *$ & $\mathrm{~W}$ \\
\hline Lyncodon patagonicus & 1 & 15 & 5 & 20 & 2 & 17 & $?$ & $?$ & K \\
\hline Lyncodon patagonicus & MACN 21982 & 16 & 4 & 20 & 3 & $?$ & 12 & 12 & Esta Tesis \\
\hline Lyncodon patagonicus & MLP 29.XII.00.17 & 16 & 3 & 19 & 2 & $+15, \pm 16$ & 12 & 12 & Esta Tesis \\
\hline Lyncodon patagonicus & MNHN 1897.422 & 16 & 4 & 20 & 2 & 17 & 12 & $?$ & Esta Tesis \\
\hline Lyncodon patagonicus & MNHN 1897.423 & 16 & 4 & 20 & 2 & \pm 16 & $12 ?$ & 12 & Esta Tesis \\
\hline Martes americana & 25 & 14 & 6 & 20 & 3 & \pm 18 & 11 & $?$ & L y K \\
\hline Martes foina & $?$ & $?$ & $?$ & $?$ & $?$ & $?$ & $?$ & 10 & $\mathrm{~S}$ \\
\hline Martes martes & 1 & 14 & 6 & 20 & 3 & $?$ & $?$ & $10^{*}$ & W \\
\hline
\end{tabular}




\begin{tabular}{|c|c|c|c|c|c|c|c|c|c|}
\hline Especie & 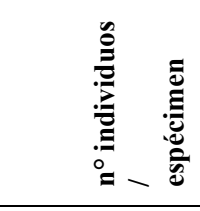 & 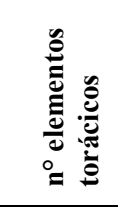 & 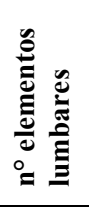 & 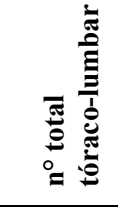 & 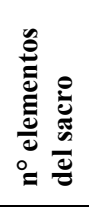 & 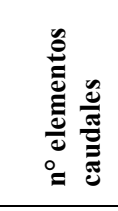 & 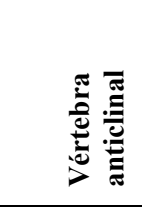 & 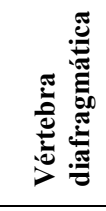 & Fuente \\
\hline Martes pennanti & 23 & 14 & 6 & 20 & 3 & \pm 20 & 11 & $?$ & L y K \\
\hline Martes sp. & ? & 14 & 6 & 20 & 3 & $18-23$ & ? & ? & M \\
\hline Martes zibellina & 1 & 14 & 6 & 20 & 3 & 18 & $?$ & $?$ & $\mathrm{~N}$ y K \\
\hline Meles anakuma & UMUT 08361 & 15 & 5 & 20 & 3 & ? & 12 & 11 & Esta Tesis \\
\hline Meles meles & MACN 5.36 & 15 & 5 & 20 & 3 & 19 & 12 a 13 & 12 & Esta Tesis \\
\hline Meles meles & ? & $?$ & $?$ & $?$ & $?$ & $?$ & $?$ & 12 & $\mathrm{~S}$ \\
\hline Meles sp. & $?$ & $15(14)$ & 5 & $20(19)$ & 3 & 18 & 13 & $?$ & $\mathrm{M}$ \\
\hline Mellivora capensis & $?$ & 14 & $5-4$ & $19-18$ & $3-4$ & $15-16$ & 15 a sacro & $?$ & M \\
\hline Mellivora capensis & 1 & 14 & 4 & 18 & 4 & 15 & ? & ? & N y K \\
\hline Mellivora capensis & $?$ & 15 & 4 & $?$ & $?$ & $?$ & $?$ & $?$ & $\mathrm{~S}$ \\
\hline Melogale orientalis & NMV 2407 & $?$ & $?$ & $?$ & 3 & \pm 15 & $?$ & $?$ & Esta Tesis \\
\hline Melogale sp. & ? & 14 & 6 & 20 & 3 & 18 & $?$ & $?$ & M \\
\hline Melursus sp. & $?$ & 15 & 5 & 20 & 5 & 11 & $?$ & $?$ & M \\
\hline Mephitis sp. & ? & 16 & 6 & 22 & 2 & 21 & ? & ? & M \\
\hline Mustela erminea & 2 & 14 & 6 & 20 & 2 & 18 & ? & ? & N y K \\
\hline Mustela Frenata & AMNH 60508 & $?$ & 5 & $?$ & $?$ & $?$ & 12 & $11 ?$ & Esta Tesis \\
\hline Mustela Frenata & AMNH 61406 & $?$ & $?$ & $?$ & 3 & $?$ & 12 & 11 & Esta Tesis \\
\hline Mustela Frenata & MN 5525 & 14 & 6 & 20 & 3 & $?$ & 12 & $?$ & Esta Tesis \\
\hline Mustela nivalis & 1 & 14 & 6 & 20 & 2 & 18 & $?$ & $?$ & N y K \\
\hline Mustela putorius & $?$ & $14-15$ & $5-6$ & 20 & 3 & \pm 18 & 11 & 11 & M et al. \\
\hline Mustela putorius & 1 & 14 & 6 & 20 & 2 & $?$ & 11 & 10 & $\mathrm{~S}$ \\
\hline Mustela sp. & $?$ & $15-13$ & $5-6$ & $20-19$ & 3 & 16 & $?$ & $?$ & M \\
\hline Mustela sp. & MMPMa 327 & 14 & 6 & 20 & 2 & ? & ? & ? & Esta Tesis \\
\hline Mustela vison & CML 55724 & 14 & 6 & 20 & 3 & \pm 18 & 12 & 11 a 12 & Esta Tesis \\
\hline Mydaus javanensis & 1 & 14 & 6 & 20 & 3 & $?$ & $?$ & $?$ & N y K \\
\hline Mydaus javanensis & 1 & $15(16 ?)$ & 5 & $20(21 ?)$ & 3 & $?$ & Ausente & 14 & $\mathrm{~S}$ \\
\hline Mydaus sp. & $?$ & $14(15)$ & $6(5)$ & 20 & 3 & 12 & 12 & $?$ & M \\
\hline Nasua narica & 1 & 15 & 5 & 20 & $?$ & $?$ & $?$ & 12 & $\mathrm{D}$ \\
\hline Nasua nasua & 5 & 15 & 5 & 20 & $?$ & $?$ & $?$ & 12 & $\mathrm{D}$ \\
\hline Nasua nasua & MACN 25859 & 14 & 6 & 20 & 3 & $+22 \pm 24$ & 12 & 11 & Esta Tesis \\
\hline Nasua nasua & MACN 33.269 & $15 / 14$ & $5 / 6$ & 20 & 3 & $?$ & 12 & 11 & Esta Tesis \\
\hline Nasua nasua & MACN 5.12 & 14 & 6 & 20 & 3 & 24 & 12 & 11 & Esta Tesis \\
\hline Nasua nasua & $?$ & 14 & 6 & 20 & $?$ & $?$ & $?$ & 11 & $\mathrm{~S}$ \\
\hline
\end{tabular}




\begin{tabular}{|c|c|c|c|c|c|c|c|c|c|}
\hline Especie & 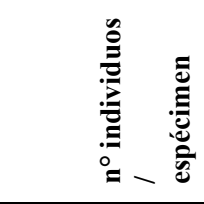 & 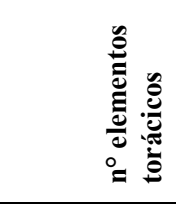 & 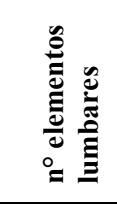 & 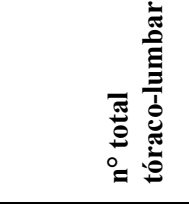 & 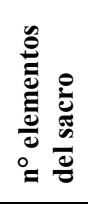 & 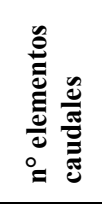 & 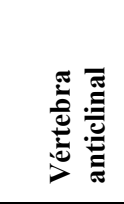 & 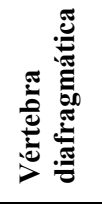 & Fuente \\
\hline Nasua sp. & $?$ & 14 & 6 & 20 & $?$ & $?$ & 12 & 11 & Fil \\
\hline Nasua sp. & ? & 14 & 6 & 20 & 3 & $19-23$ & ? & $?$ & $\mathrm{M}$ \\
\hline Nasua sp. & 1 & 13 & 6 & 19 & 2 & ? & ? & $?$ & N y K \\
\hline Poecilictis libyca & NMV 1544 & 15 & 5 & 20 & 2 & 21 & ? & $?$ & Esta Tesis \\
\hline Poecilictis libyca & NMV 1546 & 15 & 5 & 20 & 2 & $?$ & 12 & 11 & Esta Tesis \\
\hline Poecilictis libyca & NSMMa 35842 & 15 & 5 & 20 & 2 & $?$ & ? & $?$ & Esta Tesis \\
\hline Potos flavus & ? & 14 & 6 & 20 & $?$ & $?$ & 11 & 11 & Fil \\
\hline Potos flavus & ? & 14 & 6 & 20 & 3 & 26 & 12 & $?$ & $\mathrm{M}$ \\
\hline Potos flavus & MLP 1740 & $?$ & 6 & $?$ & 3 & ? & $11 ?$ & $11 ?$ & Esta Tesis \\
\hline Potos flavus & 1 & 14 & 6 & 20 & 2 & 31 & $?$ & $?$ & $\mathrm{~N}$ y K \\
\hline Procyon cancrivorus & MLP 2110 & 14 & 6 & 20 & 3 & 21 & 12 & 11 & Esta Tesis \\
\hline Procyon lotor & $11(2,1,1)$ & $14(15,14,13)$ & $6(5,5,6)$ & $20(20,19,19)$ & ? & ? & $?$ & 12 & D \\
\hline Procyon lotor & MACN 23573 & 14 & 6 & 20 & 3 & ? & 11 & 11 & Esta Tesis \\
\hline Procyon lotor & 2 & 14 & 6 & 20 & 3 & $?$ & ? & $?$ & Ny K \\
\hline Procyon sp. & ? & 14 & 6 & 20 & ? & ? & 12 & 11 & Fil \\
\hline Procyon sp. & ? & 14 & 6 & 20 & 3 & $16-20$ & 12 & $?$ & $\mathrm{M}$ \\
\hline Pteronura brasiliensis & MNHN s/n & 15 & 5 & 20 & 3 & $?$ & 13 & 13 & Esta Tesis \\
\hline Pteronura brasiliensis & SNMS 1300 & ? & 5 & $?$ & 3 & 22 & ? & $?$ & Esta Tesis \\
\hline Spilogale gracilis & MACN 34.551 & 14 & 7 & 21 & 2 & 20 & 10 & 11 & Esta Tesis \\
\hline Spilogale gracilis & MACN 34.552 & 14 & 7 & 21 & 2 & 23 & 11 & 11 & Esta Tesis \\
\hline Taxidea taxus & ? & 15 & 5 & 20 & 3 & $14 ?$ & ? & $?$ & M \\
\hline Taxidea taxus & 2 & 15 & 5 & 20 & 3 & 18 & ? & $?$ & Ny K \\
\hline Ursus americanus & 1 & 14 & 6 & 20 & ? & ? & ? & $?$ & Ny K \\
\hline Ursus americanus & 1 & 15 & 5 & 20 & 5 & ? & 14 & 11 & $\mathrm{~S}$ \\
\hline Ursus arctos & ? & 14 & 6 & 20 & 6 & 9 & ? & $?$ & $\mathrm{M}$ \\
\hline Ursus arctos & ? & 14 & 6 & 20 & ? & $?$ & ? & 11 & $\mathrm{~s}$ \\
\hline Ursus maritimus & 1 & 15 & 6 & 21 & 5 & $?$ & ? & $?$ & $\mathrm{NyK}$ \\
\hline Ursus maritimus & ? & 14 & 6 & 20 & ? & ? & ? & 11 & $\mathrm{~S}$ \\
\hline Ursus sp. & $7(2,1)$ & $14(15,14 / 15)$ & $6(5,6 / 5)$ & 20 & ? & $?$ & Ausente & 11 & $\mathrm{D}$ \\
\hline Ursus sp. & $?$ & 15 & 5 & 20 & ? & ? & 16 & 11 & Fil \\
\hline Vormela peregusna & AMNH 60103 & $?$ & ? & $?$ & $?$ & $?$ & 12 & 11 & Esta Tesis \\
\hline
\end{tabular}




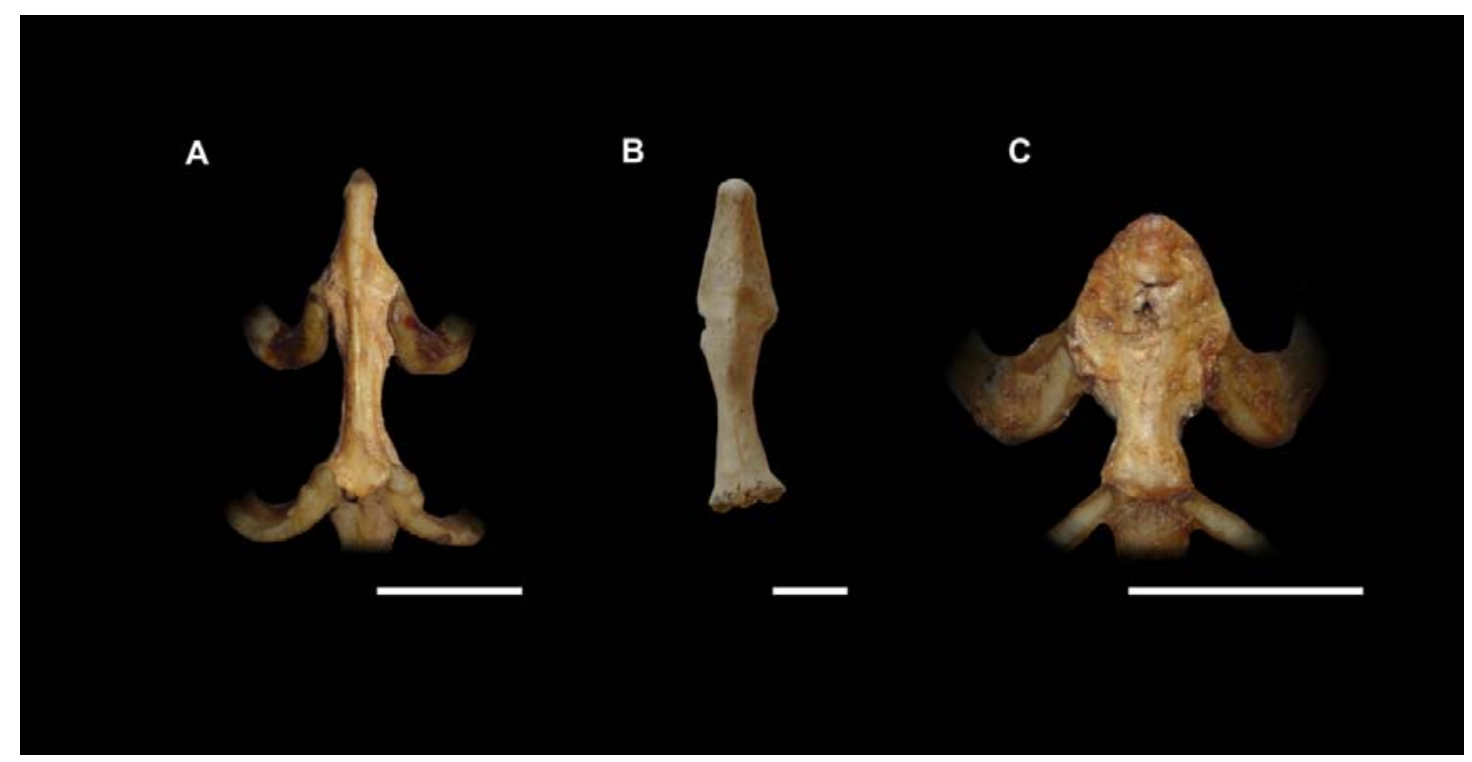

Fig. 4.1. Vista ventral de la primera esternebra de Galictis cuja (A), Lontra provocax (B) y Conepatus chinga $(\mathrm{C})$, en donde se ejemplifica la diversidad de formas del manubrio. Escala $=10 \mathrm{~mm}$.

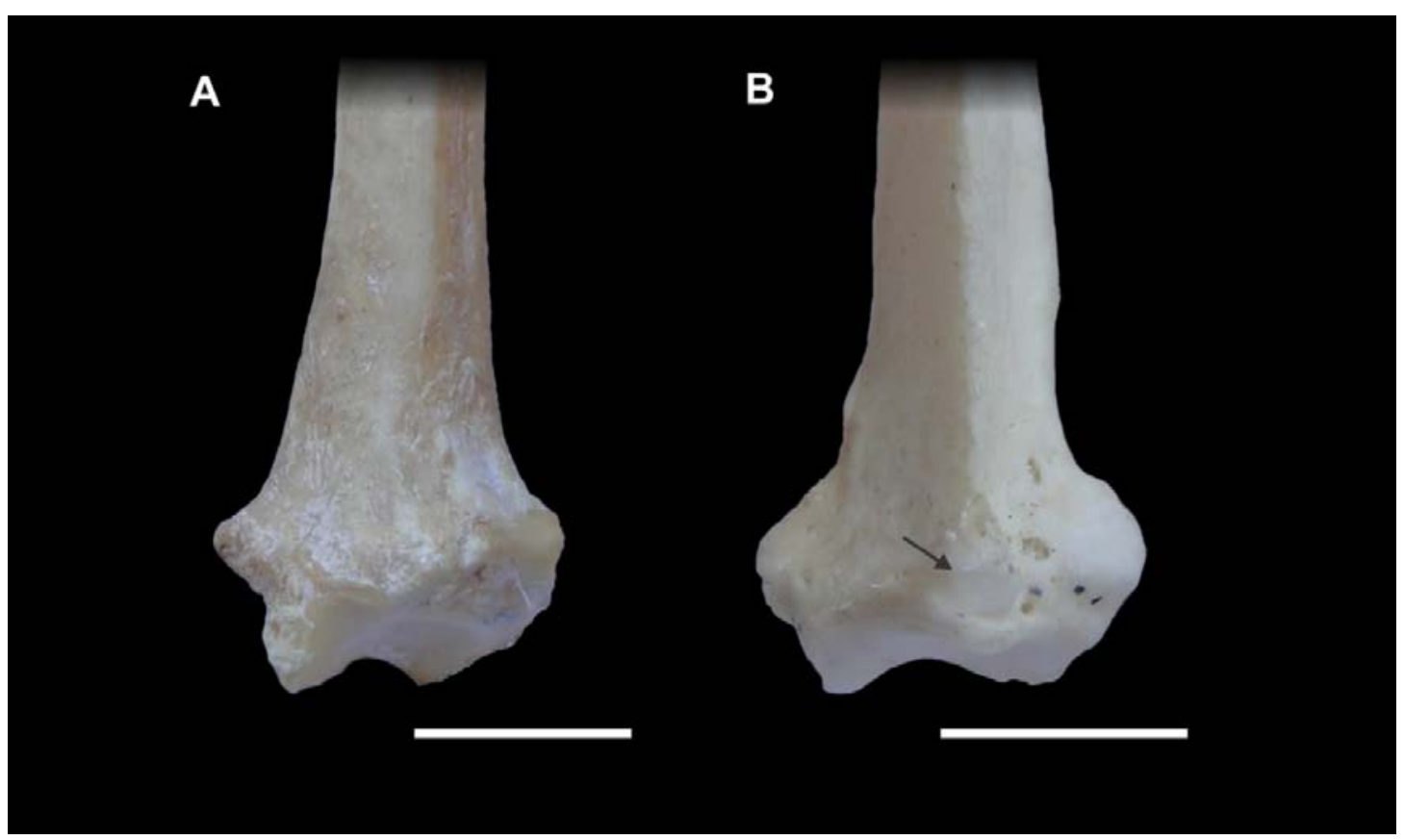

Fig. 4.2. Vista caudal de extremo distal del radio derecho de Procyon lotor (A) y Lontra provocax (B). En este último, se ilustra (ver flecha) la presencia de la faceta articular extra para el carpal accesorio, bien definida en Lontra. Escala $=10 \mathrm{~mm}$. 



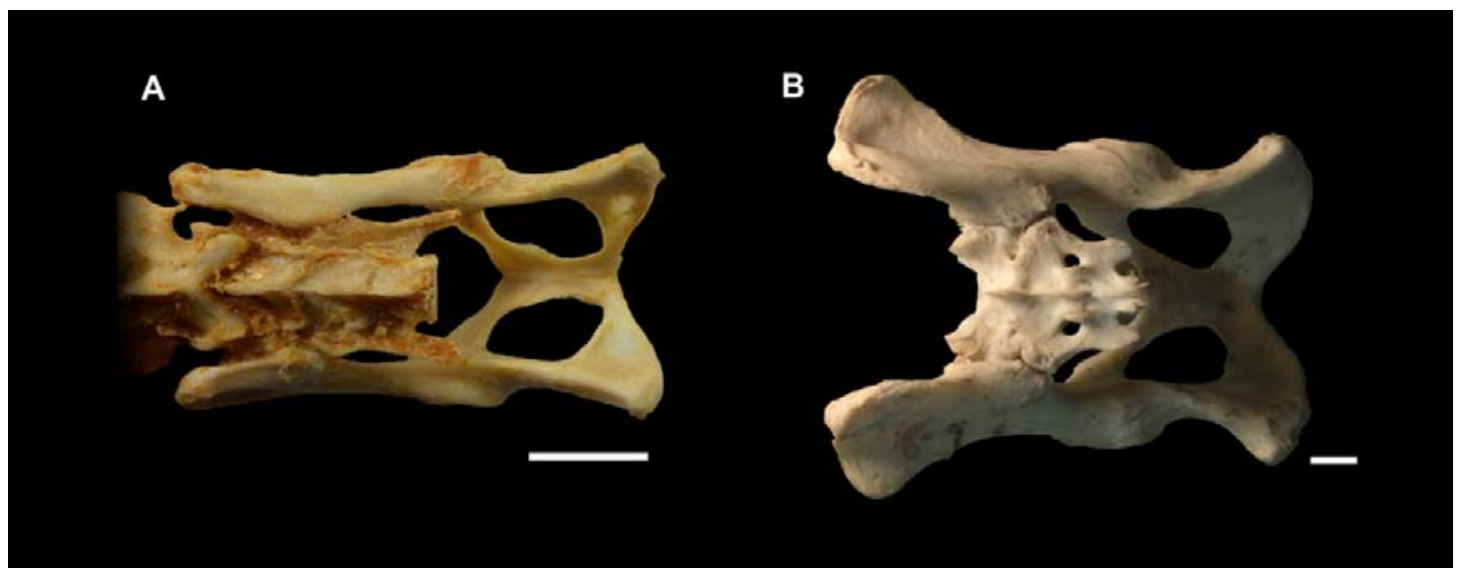

Fig. 4.3. Vista dorsal de pelvis y sacro de Galictis cuja (A) y Procyon cancrivorus (B). Se ilustran de esta forma diferentes grados de expansión lateral del ala del ilion. Escala $=10 \mathrm{~mm}$. 


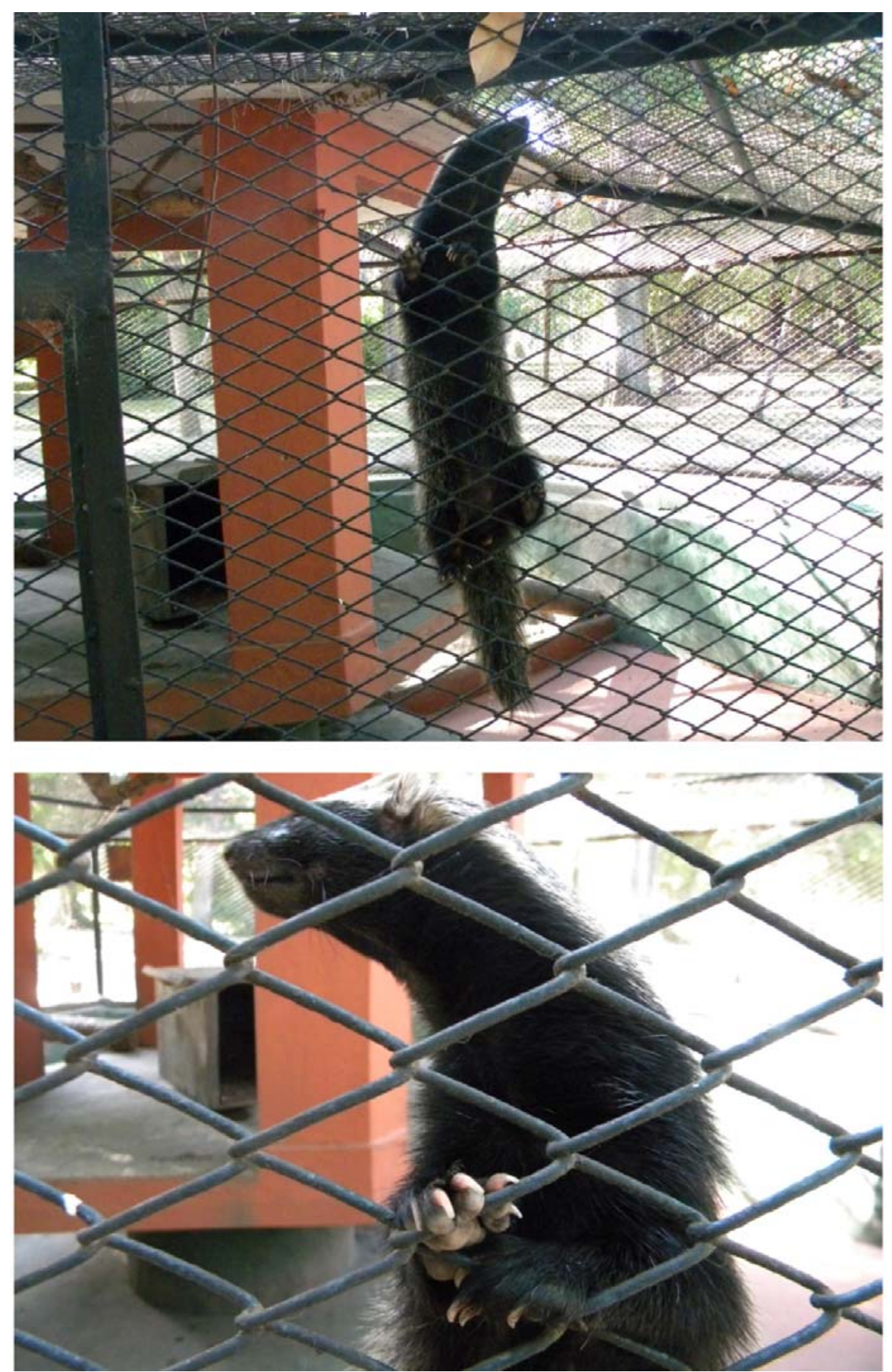

Fig. 4.4. Imágenes de un espécimen de Galictis cuja trepando un enrejado en cautiverio (enero de 2012, Zoológico de La Plata). Notar que aunque la brevedad de los miembros y dígitos impide una sujeción total al sustrato (e.g., rodeando totalmente al mismo por convergencia de dígitos), el trepado puede ser realizado rodeado las irregularidades del mismo entre almohadillas plantares. 



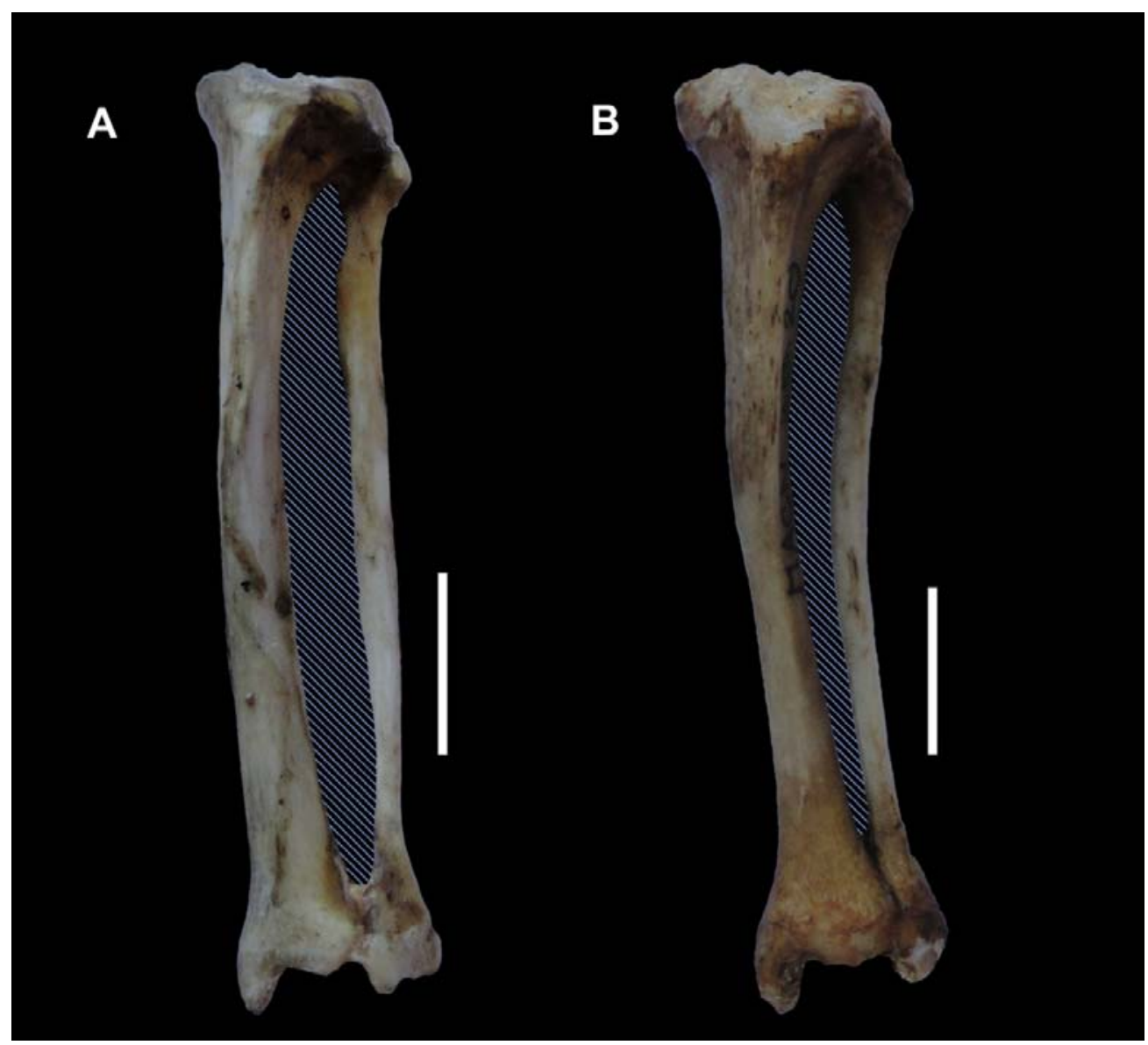

Fig. 4.5. Vista craneal de zeugopodio posterior izquierdo de Galictis cuja (A) y Conepatus chinga (B). Se ilustran (área rayada) la extensión diferencial de la región interósea. Escala = $10 \mathrm{~mm}$.

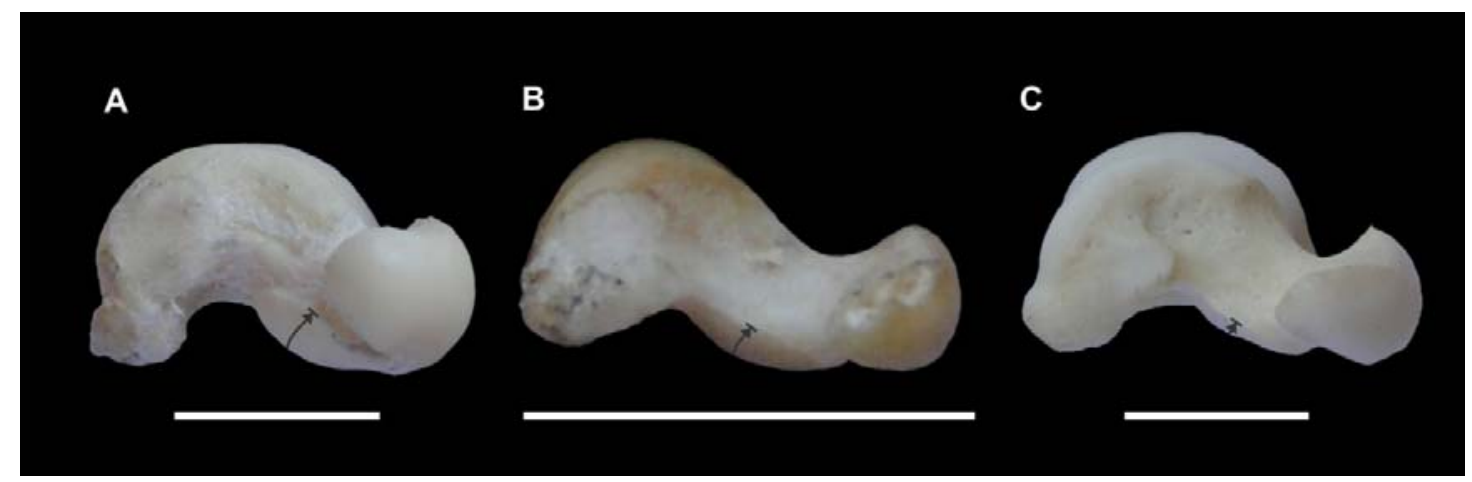

Fig. 4.6. Vista medial de astrágalo izquierdo de Procyon lotor (A), Galictis cuja (B) y Lontra provocax (C). Se ilustran (ver flechas) los distintos grados de inclinación de la faceta articular medial para el calcáneo. Escala $=10 \mathrm{~mm}$. 
Comentarios finales y Conclusiones 


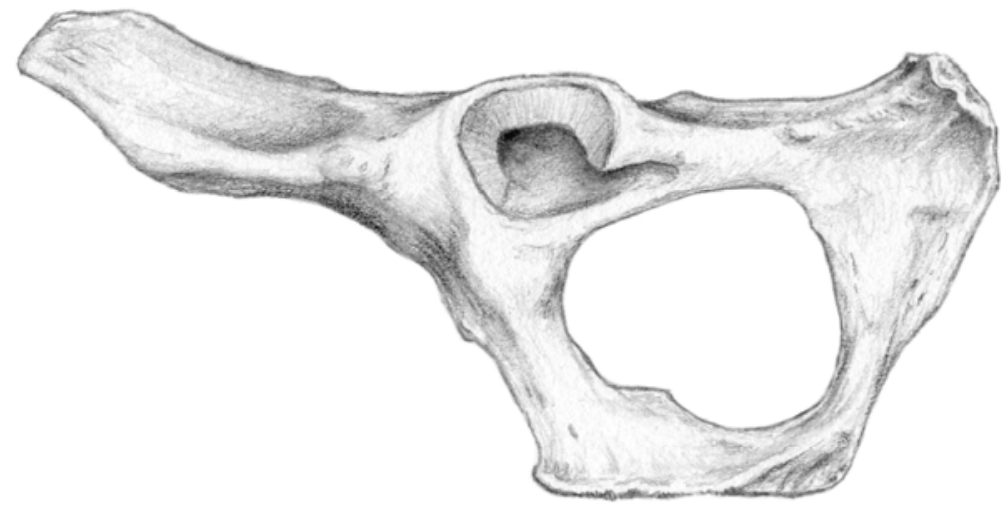

\section{Capítulo 5}

\section{COMENTARIOS FINALES Y CONCLUSIONES}

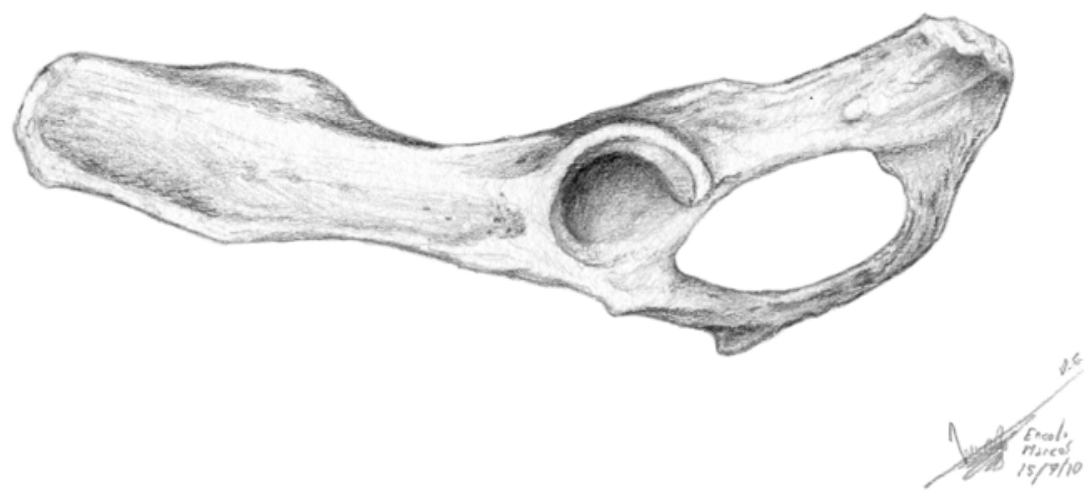





\section{Comentarios finales y conclusiones}

El análisis detallado de la anatomía músculo-esqueletaria postcraneal de los mustélidos de América del Sur en un marco comparativo cualitativo y cuantitativo, permitió una mayor comprensión de cómo las distintas especies se encuentran especializadas en realizar funciones motoras específicas en relación a sus modos de vida. Para esto, no sólo se contempló cómo la morfología se encuentra influenciada por los hábitos de vida (e.g., estilo locomotor, sustrato de locomoción, estrategia de caza) y tamaño corporal de los representantes actuales, sino también por la historia evolutiva de las especies, mediante métodos filogenéticos comparativos. El diseño de mapas musculares aportó una valiosa contribución al estado actual del conocimiento de la miología de los mustélidos, siendo este trabajo el primero en presentar mapas musculares del esqueleto axial de un carnívoro silvestre, información que puede ser utilizada en futuros estudios morfo-funcionales de especies vivientes o extintas. Este estudio también aportó una de las pocas fuentes de información respecto pesado muscular para el grupo y también es el primer análisis detallado de la anatomía músculo-espueletaría de mustélidos de América del Sur.

En lo que respecta a los diversos estilos locomotores, las propuestas metodológicas seguidas en esta Tesis implicaron una sobre-simplificación y subdivisión en cuatro categorías discretas y excluyentes a un universo de variables motoras de la naturaleza continua, compleja y no excluyente (variables de estilos locomotores, sustratos de locomoción de forrajeo, sustrato de descanso, habilidades fosoriales; ver Carrano 1999, Miljutin 2009). Miljutin (2009) sugiere que no deben ser confundidos los medios o sustratos de locomoción (e.g., acuático, subterráneo, terrestre, arbóreo, aéreo) con las principales especializaciones al usos de estos sustratos (e.g., nadador, cavador, cursorial, trepador, volador). Más allá de esto, esta simplificación permitió reconocer patrones morfo-funcionales postcraneales principales en los mustélidos analizados, mientras que el análisis cualitativo exhaustivo y comparativo permitió confirmarlos y una mayor comprensión de variantes motoras más específicas. Confirmando la hipótesis H1, a partir del estudio morfo-funcional de esta Tesis fue posible distinguir numerosos rasgos morfofuncionales para cada uno de los principales grupos locomotores, destacándose a continuación los principales:

- Half-bounders: Los musteloideos que presentan este estilo locomotor son principalmente hurones, caracterizados como cazadores de roedores dentro de sus galerías. Esta estrategia de caza implica que el depredador debe ingresar a ellas, moverse rápidamente y cazar en estos túneles estrechos, lo cual repercute en múltiples características postcraneales. A partir de los resultados obtenidos en esta tesis, fue posible confirmar que un gran número de rasgos propuestos previamente como especializaciones a la locomoción half-bounder en hurones mustelinos, se encuentran presentes también en hurones lincodontininos (confirmando la 
hipótesis H1a). El cráneo es bajo (ver también nadadores, más adelante) y los miembros son particularmente breves, lo que les permite obtener un bajo perfil; la columna es larga y flexible, permitiéndoles mantener un tamaño corporal apropiado para hacer frente a la presa y a la vez moverse en los recodos estrechos de las galerías (Gambaryan 1974, King 1989, King y Powell 2007). Estas modificaciones propias del plan corporal de los hurones, necesarias en las incursiones subterráneas, derivan en modificaciones en el estilo locomotor epigeo. En las marchas simétricas (caminatas, trotes), una mayor longitud de zancada es alcanzada mediante amplios desplazamientos antero-posteriores de la cintura pectoral y amplios rangos de flexoextensión de muchas de las principales articulaciones apendiculares. En relación a estas funciones, la escápula es relativamente breve, los músculos protractores del brazo se encuentran marcadamente desarrollados, y existen un gran número de fascículos extrínsecos o biarticulares en ambos miembros (ver también Ercoli et al. 2014). Las marchas, bound y half-bound son utilizadas por los hurones cuando se desplazan con rapidez; los saltos consecutivos son propulsados por la activación progresiva de la musculatura epiaxial, extensora de la cadera y extensora del tobillo, lo cual permite una aceleración adecuada al final de la fase de apoyo y una amplia fase aérea de vuelo extendido, permitiendo un desplazamiento relativamente veloz más allá de la brevedad de los miembros (Gambaryan 1974, Moritz et al. 2007, Horner y Biknevicius 2010, Ercoli et al. 2013). En la región axial, los esfuerzos de propulsión son realizados por la extensión de los m. iliocostalis lumborum, marcadamente desarrollados en estos linajes. En relación a esto, las vértebras lumbares presentan cuerpos aplanados y elongados, y sus procesos transversos, así como la superficie interna del ilion, son elongados, permitiendo una importante superficie de origen a este sistema, así como también libertades de movimientos. El miembro posterior, pese a su acortamiento relativo a la región axial, presenta un gran número de rasgos que favorecen su extensión poderosa al final de la fase de apoyo: tanto los extensores poderosos de la cadera (e.g., grupo hamstring), como los del tobillo (e.g., m. gastrocnemius, m. flexor digitorum medialis, m. flexor digitorum lateralis, grupo fibular) presentan un gran desarrollo relativo. Sus áreas de orígenes, e.g., el plano isquio-púbico, y el zeugopodio posterior, se encuentran marcadamente extendidas. En relación a esto último, se observa en los hurones un zeugopodio de gran longitud relativa respecto al fémur y una marcada divergencia de las curvaturas de las diáfisis tibial y fibular con la consecuente extensión de la membrana interósea y área de origen de los extensores del tobillo, así como también una marcada pinnación de los músculos allí originados (ver también Ercoli et al. 2013). Por otro lado, contrariamente a lo que ocurre en especies que utilizan otro tipo de marchas, en los halfbounders los miembros anteriores no tienen una participación activa en la propulsión sino que su rol principal es amortiguar el impacto al principio de la fase de apoyo (Leach 1977, Seckel y Janis 2007, Ercoli et al. 2014). Estos no sólo están más reducidos en longitud, sino que 
presentan una reducción relativa de los musculatura retractora del brazo, y flexora del hombro y codo (Ercoli et al. 2014). Esta reducción se evidencia en, por ejemplo, la menor importancia relativa del desarrollo de la superficie infraespinosa, así como en la gracilidad del proceso hamatus. Los principales grupos musculares especializados en resistir el impacto luego de los saltos son los protractores, y los extensores del hombro y codo, los cuales se encuentran marcadamente desarrollados y subdivididos en los hurones. El proceso subhamatus presenta un aspecto flabeliforme, y se encuentra en posición relativamente proximal respecto a la articulación del hombro, favoreciendo la ventaja mecánica del $\mathrm{m}$. omotransversarius para la rotación sobre el plano sagital de la escápula, lo que en conjunto con la activación del $\mathrm{m}$. supraspinatus (que está marcadamente desarrollado), permite evitar el colapso de la articulación del hombro durante el aterrizaje. El amplio abanico de vientres del m. triceps brachii, originados desde el extremo de la escápula hasta regiones próximas al codo, lograría un efecto similar sobre el codo.

Existe un amplio consenso respecto a que una morfología de tipo marten-like o viverridlike (depredadores ágiles de ambientes arbolados) fue ancestral para Carnivora (e.g., Martin 1989, Heinrich y Houde 2006). Gambaryan (1974) propuso que una morfología weasel-like fue ancestral para Mustelidae, y que en los distintos linajes vivientes (melinos, guloninos, mustelinos, lutrinos) se evidencian rasgos que corroboran la posibilidad de un ancestro común adaptado a cazar roedores dentro de sus galerías; aunque no incluyó taxidinos en su análisis. Por otro lado, King (1989) propuso que el ancestro común de los guloninos y mustelinos (que correspondería en las últimas filogenias al nodo Guloninae + Helictidinae + Mustelinae + Ictonychinae + Lutrinae; Sato et al. 2012), sería una forma marten-like. Koepfli et al. (2008) relacionaron directamente el momento de radiación de las principales subfamilias mustélidas vivientes con un momento de aridización global durante el Mioceno Medio y Tardío, exceptuando por los taxidinos, preexistentes a este evento. En este período temporal las áreas boscosas tropicales se redujeron y los paisajes abiertos se extendieron, produciéndose una fragmentación más marcada de los biomas y nuevos nichos ecológicos vacantes, situación compatible con la propuesta de Gambaryan (1974). En estos ambientes predominaron presas herbívoras y granívoras relativamente pequeñas, cuyos hábitos subterráneos les permitieron conseguir refugio de las inclemencias ambientales y de los depredadores, exceptuando justamente a aquellos adaptados a incursionar en sus estrechas galerías. Las optimizaciones de rasgos ecológicos sugieren que el ancestro del clado Guloninae + Helictidinae + Mustelinae + Ictonychinae + Lutrinae podría haber sido una forma carnívora y half-bounder (reconstrucción ambigua para ambos caracteres, ver sección 3.6), coindiciendo más cercanamente con la propuesta de King (1989) que con la propuesta de Gambaryan (1974) y de lo inferido a partir de las optimizaciones miológicas y osteológicas (ver sección 3.6, ver más abajo). Sin embargo, las 
optimizaciones de estos rasgos ecológicos sufren múltiples limitantes que podrían ocultar un origen más antiguo de una morfología weasel-like. A las limitantes relacionadas al diseño de categorías dietarias y locomotoras simplificadas, discretas y excluyentes (ver más arriba), y la clasificación de formas que eventualmente realizan marchas half-bound en otras categorías (e.g., muchos mustélidos, Bassariscus astutus, Spilogale gracilis), se suman la exclusión de formas fósiles en los análisis. Este último factor es destacable en su importancia dada la existencia de múltiples linajes mustélidos basales especializados a hábitos cavadores y omnívoros (e.g., taxidinos, melinos y melivorinos), y la existencia en el registro fósil de especies de linajes musteloideos totalmente extintos, o ancestrales a los tejones vivientes, en los cuales se han inferido hábitos depredadores activos y marchas ágiles. Tanto en carnívoros insertae sedis (e.g., ${ }^{\dagger}$ Palaeogale), como en mustélidos de subfamilias extintas (e.g., ${ }^{\dagger}$ Zodiolestes, ${ }^{\dagger}$ Miomustela, registrados a partir del Mioceno) fue reconocido el ecomorfo weasel-like (Martin 1989), evidenciado por la presencia de cráneos alargados, miembros breves e incluso algunos de ellos fueron encontrados en paleocuevas de roedores (e.g., 'Zodiolestes; Martin 1989, Baskin 1998). El análisis de las configuraciones miológicas y esqueletarias de los mustélidos analizados, permite el reconocimiento de características esperables en formas weasel-like en diversos linajes de mustélidostóraco-, y muchas de ellas fueron optimizadas como heredadas a partir de ancestros comunes de las principales subfamilias (ver sección 3.6). Entre los rasgos reconocidos como adquisiciones en el ancestro común del clado Mustelidae - Taxidea, se destacan la complejización de la musculatura cervical, una región tóraco-lumbar flexible y elongada, y un cuello proporcionalmente más elongado y miembros relativamente cortos y generalizados (ver sección 3.6; Fig. 3.4; Apéndices 3.14, 3.15). Todos estos rasgos indican que ya en el ancestro común del clado posiblemente se habrían establecido rasgos indicativos de hábitos depredadores activos y también son sugerentes de estrategias de locomoción y caza similares a las presentes en los hurones vivientes o formas similares. Este resultado coincide cercanamente con la propuesta de Gambaryan (1974; hipótesis H4 de esta tesis), y respalda la posibilidad de que el ancestro común entre los melinos y mustélidos más derivados (nodo Mustelidae - Taxidea) haya sido una forma weasel-like. Más aun, el estudio de la anatomía postcraneal de otros linajes musteloideos soportan la posibilidad de que marchas ágil de tipo half- bound y de hábitos depredadores (esperables tanto en formas weasel-like como marten-like), habrían estado ya presentes en el ancestro común de los musteloideos (Ercoli et al. 2014). Por otro lado, en diferentes clados de mustélidos, incluyendo al ancestro común de ictoniquinos, mustelinos y lutrinos, y a los guloninos más derivados, se registra la adquisición convergente (y en algunos casos progresiva) de condiciones exageradas de estos rasgos, así como el agregado de otras características novedosas. Estos cambios pueden resumirse en la adquisición de un máximo grado de especialización de los miembros anteriores a la amortiguación de los impactos (e.g., 
máximo desarrollo de protractores y extensores braquiales) en conjunto con la reducción de un gran número de estructuras relacionadas a otras funciones (e.g., reducción del zeugopodio anterior y cresta del epicóndilo lateral), e indicadores de un mayor desarrollo de las regiones postcraneales encargadas de la propulsión en los saltos, incluyendo a los principales extensores de la región lumbar y los miembros posteriores (ver sección 3.6; Fig. 3.4). Todos estos rasgos son indicativos de la aparición recurrente de formas mustélidas con un alto grado de especialización a la caza de roedores en galerías y locomoción a saltos a partir de ancestros más generalizados de tipo marten-like.

- Nadadores: Entre los musteloideos, la categoría de nadadores es tradicionalmente aplicada al grupo natural de las nutrias, aunque algunos hurones también frecuentan el medio acuático de una manera menos especializada. Las nutrias son los únicos musteloideos que pueden bucear con movimientos ondulatorios, y distintos linajes evidencian diferentes grado de participación activa de la cola, miembros anteriores y posteriores durante el proceso (e.g., Tarasoff 1972, Taylor 1989, Fish 1994). El análisis comparativo realizado reveló un gran número de rasgos en la anatomía postcraneal únicos de lutrinos, muchos de los cuales pueden ser considerados adaptaciones al medio acuático. El plan corporal de las nutrias combina características similares en muchos aspectos a mustélidos basales, y muchos otros similares o incluso exagerados respecto al plan hurón, estos últimos relacionados a la obtención de una silueta hidrodinámica y realizar nados sigilosos en superficie. Esto se debe a que muchas de las funciones requeridas para desplazarse en galerías estrechas también son necesarias durante el buceo, por ejemplo, mantener un perfil alargado y estrecho les permite entrar en túneles a los hurones y reducir el arrastre (drag) en un medio denso a las nutrias; la movilidad axial les permite doblar en recodos estrechos y moverse rápidamente en carreras a hurones, y propulsarse mediante ondulaciones y realizar giros durante el buceo a las nutrias. En relación a esto, las nutrias poseen una cabeza aplanada, un cuerpo elongado, miembros breves (aunque variando las proporciones intermembrales en función de diversas estrategias de nado), así como una gran movilidad axial y capacidad de realizar movimientos de flexo-extensión, presente desde la región cervical hasta la cola (Fig. 3.4). Las demandas funcionales comunes a ambos ecomorfos hacen realista la reconstrucción de una forma ancestral lutrina derivada de un ecomorfo similar a los hurones modernos, lo cual también es respaldado por las optimizaciones de caracteres ecológicos y tamaño corporal (ver sección 3.6.3). Por otro lado, esta situación permite comprender la existencia de múltiples especies de hurones con afinidad por las incursiones en el medio acuático, incluyendo a los grisones, y a Mustela vison y Mu. lutreola; aunque tampoco es posible descartar a priori algun grado de afinidad con hábitos semi-acuáticos ya establecidos en el ancestro hipotético de los hurones y nutrias. Las nutrias poseen otros rasgos que las diferencian de hurones y otros linajes cercanos, entre ellos, un mayor tamaño corporal, los 
procesos espinosos cervicales y tóraco-lumbares elevados y presentes incluso en múltiples elementos caudales evidenciando la importancia de los sistemas epiaxiales mediales (especialmente el $\mathrm{m}$. longissimus) en la extensión activa de la columna, y el desarrollo de los tubérculos ventrales de las vértebras cervicales y lumbares evidencia la importancia de la función antagonista, mientras que la morfología de las articulaciones intervertebrales permiten amplios movimientos flexo-extensores de todas estas regiones. La cola es musculosa, ancha y, en la mayoría de los casos, es larga; la misma es utilizada como un eficaz propulsor durante el buceo. En esta región, así como la región post-diafragmática, las libertades para la realización de movimientos en el plano sagital se encuentran acompañadas por restricciones a los movimientos en otros planos, lo que se encuentra evidenciado por la morfología de las articulaciones y el gran desarrollo lateromedial de procesos transversos, poseyendo los caudales una forma de "H" diagnóstica. La morfología de las vértebras cervicales y torácicas (e.g., desarrollo de tubérculos dorsales de procesos transversos, posición retrasada de la vértebra transicional; e.g., Bisaillon et al. 1976, Willemsen 1980a, b) indican también un importante componente de movimientos de rotación y ladeo en estas regiones, los cuales podrían colaborar en maniobras de cambios de dirección.

El miembro anterior presenta una poderosa musculatura extrínseca del brazo e intrínseca del hombro, evidenciada por el gran desarrollo relativo del ala de la escápula, y un gran desarrollo de las principales regiones de agarres musculares del brazo y antebrazo (e.g., tubérculos, crestas y epicóndilos del húmero, olécranon y tuberosidad del m. biceps brachii). Muchos músculos presentan amplios brazos de palanca; entre estos, la musculatura pectoral es particularmente voluminosa y presenta un vientre pectoantebraquial que se extiende hasta el codo o antebrazo, el $\mathrm{m}$. triceps brachii caput angulare se fusiona al $\mathrm{m}$. latissimus dorsi, y el $\mathrm{m}$. brachioradialis extiende su origen hasta el sector proximal del húmero, rasgos que evidencian una reconfiguración única dentro de mustélidos, relacionada a los poderosos movimientos del sector distal del miembro anterior. El miembro posterior suele ser mucho más largo que el anterior en las especies más especializadas al buceo. La cadera y miembros posteriores sufren una reconfiguración de sus partes en la cual los miembros posteriores adquieren una postura habitual posicionada caudalmente, y algo similar puede plantearse para el miembro anterior (e.g., curvatura sigmoidal del húmero). Entre estos cambios se destacan un plano isquio-púbico rotado en dirección dorsal, un fémur breve, una morfología de la rodilla que indica una posición habitualmente flexionada, mientras que muchos de los principales músculos largos del miembro posterior presentan un gran desarrollo e inserciones distalizadas (e.g., m. biceps femoris, $\mathrm{m}$. semimembranosus, m. semitendinosus), similar a lo planteado para el miembro anterior, evidenciando la ejecución de poderosos movimientos en el sector distal de las extremidades. Tanto el plano isquio-púbico, como el ilion, el fémur, y el zeugopodio presentan amplias 
superficies permitiendo un gran desarrollo de los principales grupos musculares que controlan el miembro posterior. El autopodio posterior, compuesto de dígitos alargados y membranas interdigitales, presenta una enorme superficie de propulsión, mientras que el tobillo impide los movimientos de inversión/eversión, evitándose el ladeo del autopodio en la propulsión. En los lutrinos que más utilizan los miembros anteriores como propulsores, funciones similares son evidenciadas en la muñeca y antebrazo, presentándose restricciones articulares y ligamentosas a los movimientos de pronación, supinación y rotación de la muñeca. En resumen, una porción mayoritaria del gran número de rasgos reconstruidos como sinapomorfías (muchas de ellas no ambiguas) del clado Lutrinae, son a su vez sugerentes de una reconfiguración de las principales regiones del postcráneo (ver sección 3.6; Fig. 3.4) vinculadas a la especialización a la locomoción y caza en el medio acuático ya presentes en el ancestro común de los lutrinos.

- Trepadores: Como indicaron Hildebrand (1988) y Taylor (1989; ver también Davis 1964, Iwaniuk et al. 1999, 2000), dentro de Carnivora, existen diversas maneras de trepar. Algunos trepadores, como los guloninos pequeños y el prociónido Bassariscus astutus realizan persecuciones rápidas sobre el sustrato arbóreo; mientras que otros prefieren desplazarse con sigilo, sea para emboscar a sus presas o por la ausencia de necesidad de perseguir presas, como es el caso del frugívoro especializado en ramas terminales Potos flavus. Otras variantes en las estrategias de trepado se encuentran en el modo de aferrarse al sustrato (e.g., clavando las garras vs. aferrándose por convergencia de dígitos), modo de uso del apéndice caudal (e.g., balance, soporte, agarre por prensión), etc. Debido a esta diversidad de modos de trepado, es posible encontrar rasgos comunes a los trepadores, y otros propios de cada estilo de trepado. En lo que respecta al esqueleto axial, la mayoría de los trepadores, especialmente los más ágiles, tienden a poseer regiones postanticlinales, postdiafragmáticas y lumbares más numerosas y largas. Estos rasgos sumado a la elongación craneal de los procesos transversos lumbares en los trepadores ágiles, permiten un mayor desarrollo de la musculatura sublumbar y un arco tóraco-lumbar más marcado durante la flexión ventral, y desplazarse utilizando pocos puntos de apoyo distantes y aislados, realizar saltos, así como ascensos o descensos de tipo vertical looping. Por otro lado, Gulo gulo, así como los úrsidos, poseen una morfología diferente, con sectores lumbares breves y rígidos, sin ser capaces de este estilo de trepado ni de moverse en ramas delgadas. Aunque dentro de los musteloideos no existen especialistas en estrategias bridging (ver Argot 2003a), el adelantamiento de la vértebra diafragmática en la mayoría de los trepadores, y el incremento del desarrollo de los procesos accesorios, especialmente en los trepadores sigilosos como los prociónidos, evidencian cierto grado de restricción a movimientos de la columna fuera del plano sagital, estabilidad requerida al pasar de una rama a otra. En la mayoría de los trepadores se registran colas largas y livianas, con un moderado desarrollo de la musculatura, procesos transversos largos pero angostos y procesos espinosos reducidos. Estas morfologías les permiten 
amplios y rápidos movimientos, especialmente lateromediales, útiles durante el balance en la marcha sobre ramas delgadas o inestables. El grado de especialización del apéndice caudal es claramente mayor en prociónidos que en otros musteloideos trepadores. Únicamente en Potos flavus, dentro de los musteloideos, se registra una cola prensil. La capacidad de prensión caudal es alcanzada mediante un mayor desarrollo de la musculatura caudal proximal, evidenciado por el gran desarrollo de los procesos espinosos y transversos del sector proximal; y la presencia de elementos caudales distales más numerosos y breves resistentes a los esfuerzos propios de esta actividad. Por otro lado, Gulo gulo posee un apéndice caudal reducido en relación a un estilo de trepado tipo úrsido, siendo sólo capaz de desplazarse en ramas principales.

Dentro de los rasgos comunes a todos los trepadores, estos presentan miembros relativamente largos en comparación con sus troncos, y con amplias libertades de movimientos fuera del plano sagital, permitiéndoles rodear parcialmente troncos y ramas, y acceder a puntos de apoyo en el sustrato arbóreo, de naturaleza tridimensional, inestable y discontinua. La redondez y ubicación lateral de la carilla articular proximal del radio, es uno de los rasgos osteológicos tradicionalmente asignados a estas facultades. También en relación a esta función, la musculatura que se encarga de mover los miembros fuera del plano sagital y estabilizar las articulaciones (e.g., mm. pectorales, grupo rotator cuff, m. anconeus, mm. gluteus), así como las áreas de agarre de estos grupos musculares (cresta pectoral, acromion, cresta epicondilar, ala del ilion, respectivamente) se encuentran particularmente bien desarrolladas, y todas las articulaciones de los miembros presentan típicamente amplias libertades de movimientos. Las articulaciones intracarpales e intratarsales presentan contactos reasegurados o imbricados (interlocking; Yalden 1970), evitando desarticulación del autopodio durante el trepado vertical en posiciones semi-flexionadas. Las modificaciones en las principales articulaciones del pie (tobillo, subtalar y transversa) son particularmente complejas e informativas y, más allá de variantes de cada linaje, las especies trepadoras tienden a evidenciar una marcada capacidad de inversión o reversión total de los miembros posteriores. Más allá de estas generalizaciones, en los trepadores más rápidos, que realizan frecuentemente marchas half-bound (e.g., Martes spp.), se registra algún grado de restricción a los movimientos fuera del plano parasagital en el hombro, codo, cadera y rodilla, e indicadores de posturas de los miembros relativamente extendidas (e.g., olécranon recto en vez de curvado cranealmente, tuberosidad tibial posicionada cranealmente), diferenciándose de representantes de otros estilos de trepado (e.g., la mayoría de los prociónidos). Algunas de las características que diferencian al estilo de trepado y locomoción en los árboles de muchos guloninos de otros linajes trepadores (e.g., gran flexibilidad y agilidad, marchas half-bound eventuales o frecuentes, miembros comparativamente más breves y con menores rangos de movimiento fuera del plano parasagital), podrían estar condicionadas y reflejar una historia evolutiva de los mustélidos 
cercanamente relacionada a la caza activa de roedores en galerías y carreras half-bound. Sumado a esto, existe una aparente reversión a estos hábitos especializados en algunos guloninos derivados.

Dado que los trepadores deben elevar su propio peso mientras se aferran con los miembros anteriores durante el ascenso vertical, y moverse en posiciones agazapadas con el fin de aumentar la estabilidad, la musculatura retractora del brazo y flexora del hombro y codo se encuentran marcadamente desarrolladas, similar en algún grado a lo observado en cavadores ante la necesidad de remover sustrato, y en nadadores mediante padding braquial en relación a vencer la resistencia del medio denso. Los trepadores se distinguen claramente de los cavadores por presentar falanges ungueales recurvadas y angostas, con sus ápices agudos, permitiéndoles clavarlas en la corteza durante el trepado. En el caso de los trepadores más ágiles y pequeños, los cuales no cuentan con dígitos particularmente elongados ni son plantígrados estrictos, este es el principal medio implementado para asegurar un agarre firme al sustrato (ver Iwaniuk et al. 1999, 2000). A diferencia de ellos, en trepadores especialistas con capacidades de manipulación o agarre por convergencia de dígitos, como lo son la mayoría de los prociónidos y Ailurus, la musculatura flexora de los dígitos y autopodios, así como la musculatura del antebrazo en general, es más compleja y se encuentra más desarrollada; algo también evidenciado a partir del desarrollo de las estructuras óseas asociadas (e.g., desarrollo del epicóndilo medial, cresta del epicóndilo lateral, sesamoideo radial, procesos ungueales).

- Cavadores: En los carnívoros cavadores la remoción del sustrato es realizada principalmente por los miembros anteriores, actividad que involucra poderosos y complejos movimientos de éstos (Quaife 1978, Hildebrand 1988, Moore et al. 2013). Es por esto que en algunos aspectos, la anatomía músculo-esqueletaria de los braquio-excavadores es similar a la de otros grupos locomotores que también realizan grandes esfuerzos braquiales, como lo son los trepadores y nadadores. Entre estos rasgos compartidos se puede incluir al gran desarrollo de los músculos retractores, aductores y abductores del miembro anterior (e.g., m. latissimus dorsi, mm. pectorales, m. deltoideus), flexores del hombro (e.g., m. infraspinatus, m. teres major) y carpo (e.g., m. flexores digitorum profundus), así como amplias áreas de agarre de estos músculos (e.g., ala de la escápula, crestas, tubérculos y epicóndilos del húmero, olécranon, tubérculo del carpal accesorio). En los cavadores, una mayor importancia de la retracción poderosa de los miembros anteriores también se encuentra evidenciada por el mayor número de paquetes caudales de los principales retractores del brazo $(\mathrm{m}$. serratus ventralis thoracis, $\mathrm{mm}$. rhomboideus thoracis y m. latissimus dorsi), en general acompañado de un mayor número de costillas, sitios de origen de varios de estos músculos. Los cavadores presentan un gran desarrollo de la musculatura extensora del codo, y el olécranon es alargado en proporción al resto del antebrazo (ocurriendo algo similar en el carpal accesorio), rasgos que los asemejan a 
nadadores y diferencian de trepadores, y que les permiten una poderosa extensión de la articulación durante la remoción del sustrato. En comparación con los nadadores, el miembro anterior y específicamente el antebrazo es generalmente más elongado tanto respecto al cuerpo como al miembro posterior en los musteloideos fosoriales. Otra diferencia importante entre cavadores y muchos trepadores (y secundariamente nadadores), es que en los primeros se registran restricciones articulares más marcadas tanto en la articulación del codo (e.g., capitular tail desarrollado, tróclea profunda, articulación proximal del radio de aspecto cuadrangular e irregular y de ubicación craneal), como del carpo (menor amplitud de movimientos en la muñeca). En el autopodio anterior, los metacarpos y falanges proximales son robustos, y en general estas últimas son relativamente breves, mientras que las falanges ungueales son grandes y aplanas, en relación a la capacidad de penetrar en el sustrato y resistir los esfuerzos inherentes a su remoción. Modificaciones similares aunque menos exageradas se observan en el miembro posterior, debido su menor participación durante el cavado, mayormente restringida a apartar el terreno ya removido por los miembros anteriores.

Durante el cavado, los miembros posteriores y la región lumbar deben transmitir y resistir las fuerzas generadas en la región anterior del cuerpo así como el total del peso corporal (Hildebrand 1988, Vizcaíno y Milne 2002). Es por ello que en los linajes cavadores, la región tóraco-lumbar, y específicamente la lumbar se encuentra marcadamente reducida en longitud y es rígida, lo que se encuentra evidenciado por la presencia de cuerpos vertebrales lumbares breves y de mayor sección, procesos transversos y espinosos principalmente perpendiculares, gran desarrollo de los sistemas epiaxiales fijadores (sistema transversospinalis y longissimus) así como sus áreas de orígenes (e.g., procesos espinosos y mamilares), entre otros rasgos. El área articular entre el sacro y la cintura pélvica se encuentra reforzada con la participación total de los dos primeros pares de procesos transversos sacros. Por otro lado, los miembros posteriores presentan elementos robustos, un zeugopodio proporcionalmente breve, y una configuración de la cadera, rodilla y tobillo que facilita una transmisión segura del peso corporal (e.g., contactos articulares amplios, gran desarrollo de ligamentos, así como de los extensores de la rodilla y el tobillo, y sus áreas de inserción).

Más allá de estas generalidades, es necesario destacar que existen diferencias importantes en la morfología de los miembros de los distintos grupos cavadores: en los tejones e ictoniquinos, la proporción entre el largo de la región tóraco-lumbar y el promedio de los miembros es mucho mayor que en Mellivora y los mefítidos. También se registran importantes variantes entre mefítidos y otros cavadores en los valores de los índices braquial y crural, y la forma de la escápula, evidenciando la influencia de otros factores, e.g., filogenia, grado de cursorialidad, diferentes grupos reclutados durante el cavado. Diferencias cruciales entre distintos linajes cavadores pueden registrarse también en el sector preanticlinal: mientras que en 
melinos y mellivorinos los procesos espinosos son amplios y cuadrangulares, en relación a una gran masa transversoespinal y capacidad de generación de movimientos de torsión, en mefítidos como Conepatus, así como en otros muchos musteloideos no mustélidos y taxidinos, los procesos espinosos son pedunculados, permitiendo una gran desarrollo del $\mathrm{m}$. longissimus e inserciones ligamentosas, pero reduciendo el área de inserción del sistema transversoespinal, indicando rigidez. Coincidiendo con la propuesta de Gambaryan (1974; y vinculado a lo comentado para mustélidos trepadores), los movimientos más poderosos y complejos, y la región axial más móvil de los mustélidos cavadores en comparación con musteloideos no mustélidos, puede vincularse a su mayor participación en los esfuerzos de cavado y otras actividades, y a la historia evolutiva particular de mustélidos más cercanamente relacionada a la caza de roedores en galerías y carreras half-bound.

Además de las variantes músculo-esqueletarias relacionadas a distintos estilos y sustratos de locomoción comentadas, fueron reconocidas otras relacionadas a otras variables ecológicas:

- Comportamiento aposemático: Tanto los zorrinos, como algunos ictoniquinos, grupos lejanamente emparentados dentro de Musteloidea, presentan un gran número de características externas y comportamentales vinculadas a tácticas anti-predatorias (Larivière y Messier 1996, Caro 2009). Estas especies, denominadas aquí skunk-like, poseen coloración contrastante, y recurren a movimientos y sonidos que buscan advertir y disuadir de potenciales ataques a depredadores. Dentro de estos comportamientos se encuentra la estrategia battle-flag o tail-up, que implica elevar la cola (de color contrastante y voluminosa) por sobre el dorso, en señal de advertencia y como preludio a la descarga de las glándulas anales. El estudio aquí presentado plantea que las estrategias battle-flag implican modificaciones morfo-funcionales que afectan principalmente la región lumbar, sacra, caudal y pelvis. En ambos linajes, el sacro breve y la elongación relativa del ilion posibilitan un origen de la cola relativamente adelantado respecto a la cadera. En el caso de mefítidos (exceptuando el taxón basal Mydaus), la reducción del sacro a dos elementos parece haber sido obtenida cediendo el elemento craneal (de tres elementos ancestrales) a la serie tóraco-lumbar (adquiriendo una fórmula de 21 elementos tóracolumbares), mientras que en ictoniquinos el último elemento habría sido cedido a la región caudal (manteniéndose la fórmula tóraco-lumbar de 20 elementos), quedando en evidencia los diferentes caminos evolutivos tomados por cada uno de estos linajes monofiléticos hasta alcanzar convergentemente similares planes corporales generales skunk-like y comportamientos aposemáticos. Aunque en todos estos linajes la gran movilidad sagital intervertebral de los últimos elementos lumbares y caudales es marcada, maximizando la extensión de la cola, esta es alcanzada mediante dos técnicas o mecánicas diferentes: Tanto en mefítidos como en 
ictoniquininos los cuerpos vertebrales son relativamente planos, las articulaciones craneales y caudales están elevadas cercanas al plano parasagital, la vértebra transicional está retrasada y los procesos transversos caudales son principalmente perpendiculares. Esta morfología, alcanzada convergentemente en ambos linajes, permite estabilizar posiciones habitualmente extendidas de la cola, en detrimento de otros movimientos. Por otro lado en lincodontininos, el mayor grado de extensión de la cola se obtiene mediante la reducción del sector dorsal de las vértebras caudales, y en el caso de Galictis spp., reteniéndose una amplia movilidad y musculatura caudal (i.e., procesos transversos amplios e inclinados). Mientras que en Lyncodon patagonicus se detectan características intermedias entre ambas técnicas y tribus ictoniquinas (e.g., la disposición de los procesos transversos es más bien similar a ictoniquininos), la configuración sacro-caudal de Galictis spp. podría representar eventualmente un estado primitivo de implementación de estrategias battle-flag (energéticamente más costoso, elevación de cola en forma de "S", y posibilitando una gran gama de otros movimientos caudales y actividades, e.g., balance, cambios de dirección en carreras e incursiones acuáticas), conservando un sacro de tres elementos, procesos transversos caudales amplios e inclinados, y sin restricciones articulares caudales que favorezcan la estabilización de posiciones extendidas, aunque no es posible descartar tampoco que estos rasgos sean alcanzados mediante reversiones ocurridas dentro de Lyncodontininae.

Dentro de los rasgos miológicos, tanto ictoniquinos como mefítidos convergen en la presencia de flexores caudales reducidos en el grado de extensión caudal de su origen. Por otro lado, Hall (1926) detectó que los mefítidos tienen una modificación miológica aparentemente única, en donde el vientre caudal del $\mathrm{m}$. semitendinosus se origina del sector lateral del ano en vez de las vértebras caudales, y convirtiéndose en el $\mathrm{m}$. director ani superiori, colaborando en el control de la dirección de la descarga de las glándulas anales, rasgo no presente en Galictis cuja, pero aún no estudiado en ictoniquininos, y que su análisis futuro podría ayudar a aclarar el panorama de la evolución convergente de los rasgos relacionados al comportamiento aposemático en estos linajes. En conclusión, la estrategia battle-flag fue alcanzada mediante dos técnicas o mecánicas diferentes (extensión estabilizada de la cola con marcadas restricciones articulares en mefítidos e ictoniquinos vs. extensión controlada por musculatura y reducción de restricciones articulares en lincodontininos) y por dos caminos evolutivos diferentes (cediendo primer sacra a zona tóraco-lumbar en mefítidos vs. cediendo última sacra a zona caudal en ictoniquinos), existiendo una convergencia tanto en el comportamiento como en la técnica entre ictoniquinos y mefítidos, pero difiriendo la técnica de elevación de la cola en lincodontininos y mefítidos. Por último, la convergencia entre estos dos linajes musteloideos a estrategias aposemáticas battle flag y marchas lentas a su vez seguramente se encuentren facilitadas por una batería de rasgos heredados, modificados posteriormente en grado de expresión, incluyendo 
a las glándulas anales fétidas y la tendencia a la coloración contrastante, aunque esto debe ser respaldado por análisis más específicos.

- Omnivoría vs. carnivoría: Coincidiendo con estudios previos (Savage 1957, Jouffroy y Lessertisseur 1971, Bisaillon et al. 1976, Spoor y Badoux 1986; y en relación a la confirmación de la hipótesis H1), la mayoría de los rasgos postcraneales que permitieron diferenciar a los linajes omnívoros o herbívoros de los carnívoros fueron reconocidos en la región cervical. Más allá del medio de locomoción, los linajes más carnívoros analizados poseen cuellos relativamente más largos y robustos. La gran mayoría de los principales sistemas musculares cervicales (e.g., mm. rectus capitis, mm. obliquus capitis, m. sternocephalicus, m. cleidocephalicus, mm. scalenus, $\mathrm{mm}$. longissimus, mm. rhomboideus) poseen una mayor masa, cantidad de paquetes, áreas de agarre y brazos de palanca, indicando una mayor amplitud, fuerza y precisión de los movimientos cervicales, útiles durante la captura, dominación y transporte de presa. Esto queda reflejado también en la anatomía ósea, dado que en los linajes carnívoros se registran vértebras cervicales más elongadas, procesos transversos y procesos articulares más amplios, y procesos espinosos del axis más amplios. También se reconocieron rasgos del miembro anterior (e.g., proporciones LaTL/PrLaM, LaRa/LaHu, LaMcIII/LaFIII) relacionados al grado de carnivoría. Sin embargo, estas asociaciones son mayormente un reflejo de que los principales linajes musteloideos carnívoros o hipercarnívoros son mustélidos especialistas en la caza de roedores en galerías y peces, y por ende, con adaptaciones locomotoras específicas (y similares, ver más arriba) tubícolas y acuáticas, algo corroborado en las regresiones con control filogenético y en el análisis de los outliers. Dentro de las diferencias en la morfología de los principales grupos de mustélidos depredadores (i.e., hurones y nutrias), en las nutrias se destaca una mayor movilidad y fuerza de extensión del cuello, tradicionalmente relacionadas a la utilización del cuello como timón, e.g., durante la emersión, sorprendiendo presas desde abajo (ver Savage 1957, ver también Bisaillon et al. 1976). Es interesante notar que Meles spp. presenta un gran número de rasgos indicativos de dietas carnívoras y marchas ágiles, lo cual diferiere a lo esperado para un cavador omnívoro (cuello relativamente largo, procesos de inserción muscular cervicales amplios, musculatura cervical voluminosa y subdividida, región tóraco-lumbar elongada y procesos espinosos preanticlinales amplios, miembros relativamente breves, configuración paraxónica de miembro anterior), y sugerentes de la posibilidad de un ancestro más afín a hábitos depredadores activos, como lo son actualmente los mustélidos weasel-like o lutrinos.

- Estrategias de caza de los hurones: Como se comentó la caza de roedores dentro de sus galerías implica que el depredador debe ingresar, moverse rápidamente y cazar en túneles estrechos. Los hurones deben ser lo suficientemente angostos para entrar en los túneles estrechos de los roedores, pero lo suficientemente grandes y hábiles como para dominar y matar 
a su presa. Por otro lado, al contrario de otras estrategias predatorias, los especialistas en la caza de roedores subterráneos no requieren una alta velocidad, ni gran destreza de manipulación, cavado o trepado (aunque no son necesariamente contraproducentes en algunos casos). Todo esto repercute en múltiples características postcraneales. Los miembros son particularmente breves lo que les permite obtener un bajo perfil, y la columna es larga y flexible, permitiéndoles mantener un tamaño corporal apropiado para hacer frente a la presa y moverse en los recodos estrechos de las galerías (Gambaryan 1974, King 1989, King y Powell 2007). Todos los hurones presentan cuellos alargados y robustos, con sus principales sistemas musculares desarrollados y subdivididos en similar o mayor grado que otros linajes carnívoros. Los sistemas profundos cervicales presentan inserciones "lateralizadas", lo que sumado a la morfología y posicionamiento lateral del proceso mastoideo y procesos transversos cervicales, indican poderosos movimientos de rotación y ladeo, útiles durante la subyugación de las presas y el killing bite. Aunque estos rasgos son en mayor o menor grado comunes a todos los hurones, y comparaciones más específicas deben ser consideradas preliminares, existen algunas variantes dentro de los hurones (ver sección 4.3.2, región cervical; Anexo) que deben ser corroboradas en futuros estudios. Tanto Lyncodon patagonicus, como las especies más especializadas a la caza de roedores grandes o agresivos en sus galerías suelen presentar muchos de estos rasgos particularmente exacerbados. Estas especies requieren de grandes y complejos esfuerzos para desestabilizar y posicionar a la presa antes de realizar un killing bite preciso y ubicado en regiones vulnerables de la víctima (e.g., tráquea). Por otro lado, otros hurones como Galictis cuja, se diferencian de los anteriores por presentar procesos mastoideos más adelantados y ubicados ventralmente, y un mayor desarrollo de las láminas ventrales de los procesos transversos cervicales, en detrimento de los tubérculos dorsales, en relación a una mayor musculatura flexora del cuello, y estrategias de caza más similares a las observadas en otros mustélidos.

En comparación con los mustélidos de otros continentes, se conoce relativamente poco sobre los hábitos de vida de las especies de América del Sur, y se han publicado muy pocos estudios descriptivos y morfo-funcionales que incluyan a sus elementos postcraneales, siendo nulos los antecedentes para el caso de Lyncodon patagonicus. Este es el primer estudio que tuvo como meta central un análisis integrador de la anatomía postcraneal de los mustélidos de América del Sur, y posibilitó establecer las principales características morfo-funcionales de cada linaje:

- Lincodontininos: Se conocen registros de los hurones lincodontininos en América del Sur desde el Plioceno Tardío (Subedad Vorohuense; Reig 1957, Soibelzon y Prevosti 2007). Estos fueron los primeros hurones que arribaron al subcontinente, y los únicos hurones hasta el 
ingreso de Mustela en América del Sur (reconocida en el registro fósil en el Holoceno Medio de Ecuador, pero muy probablemente ya presentes en el Pleistoceno Temprano; ver Izor y de la Torre 1978, Soibelzon y Prevosti 2007, Eizirik 2012). En función de las especies fósiles reconocidas en América del Norte (e.g., ${ }^{\dagger}$ Trigonictis spp.; Björk 1970), es probable que el ancestro de los lincodontininos haya sido similar a un grisón. En función del registro paleontológico conocido, en el momento en que ingresaron los lincodontininos, no existian en América del Sur formas depredadoras weasel-like ni marsupiales ni carnívoros (Analía M. Forasiepi, conversación personal; ver también Ercoli et al. 2012). La ausencia de linajes depredadores weasel-like previo al ingreso de estos lincodontininos, e incluso la ausencia de hurones mustelinos en el cono sur de América del Sur hasta la actualidad, sumado a la presencia de roedores fosoriales nativos (e.g., cuises, tuco-tucos, vizcachas), posibilitó un escenario ecológico de nicho vacante que fue llenado por los lincodontininos. El plan corporal de los grisones puede considerarse como generalizado en muchos aspectos en comparación con otros hurones. La dentición mesocarnívora, y el cuello alargado, musculoso y con amplias libertades de movimientos, les permiten depredar sobre un gran número de ítems (incluyendo lagomorfos mayores que ellos mismos, mamíferos pequeños, reptiles y aves), los miembros son cortos pero no al extremo de otros hurones, y son relativamente robustos; la región axial es muy móvil y la cola robusta; características que les permiten moverse con facilidad sobre la superficie, en túneles subterráneos, en ciertas ocasiones en agua, y más raramente en el sustrato arbóreo. Esta plasticidad les permite a los grisones vivientes habitar desde selvas hasta estepas, y posiblemente permitió que el linaje se establezca en diferentes ambientes de América del Sur.

Un número importantes de evidencias de diferentes fuentes sugieren la posibilidad de una estrecha relación con hábitos acuáticos para el linaje de los grisones: A- Las últimas filogenias moleculares indican que los ictoniquinos son el grupo hermano de los lutrinos; B- El estudio miológico de Galictis cuja, reveló algunos arreglos musculares únicamente descriptos previamente para lutrinos, y que a su vez pueden ser considerados como adaptaciones al nado (e.g., posición de origen del m. braquioradialis); C- El análisis osteológico de Galictis spp., sugiere la retención de rasgos osteológicos comunes a lutrinos y que, nuevamente, pueden ser considerados adaptaciones al nado, siendo especialmente destacadas características caudales (e.g., presencia de procesos espinosos definidos en más de cuatro elementos caudales y procesos transversos amplios y aplanados); D- La presencia de membranas interdigitales, y otros rasgos propios de los hurones en general, también presentes en lutrinos (e.g., cuerpos elongados y flexibles, miembros breves, extensores lumbares, y del miembro posterior, poderosos). EAunque Galictis cuja es capaz de vivir en ambientes semi-desérticos, algunos estudios comportamentales y observaciones (tanto en vida silvestre como cautiverio) sugieren una gran afinidad por los cuerpos de agua, habiéndose descripto incursiones acuáticas para ambas 
especies, inmersiones frecuentes y prolongadas (reteniendo la respiración por más de 30 segundos), y natación con notable habilidad. F- Un gran número de grisones fósiles han sido descriptos como especies de hábitos acuáticos, posiblemente más marcados que los presentes en grisones actuales (e.g., †Enhydrictis-Pannonictis, 'Trigonictis cookii, †Tr. "idahoensis" macrodon; Ficcarelli y Torre 1967, Björk 1970, Kurtén y Anderson 1980, Schutz y Guralnick 2007, Grohé et al. 2010, Colombrero et al. 2012), algunos de ellos considerados parientes cercanos de los lincodontininos sudamericanos (e.g., Björk 1970, aunque son necesarios análisis filogenéticos que propongan una hipótesis de relaciones entre estas especies). Todas estas evidencias, aunque no concluyentes, son indicios de la antigua vinculación a hábitos acuáticos del grupo, y posiblemente, del ancestro común de los hurones lincodontininos de América de Sur.

El estudio de la anatomía postcraneal del huroncito patagónico permite proponer que el taxón se encuentra altamente especializado en la caza de roedores fosoriales, confirmando la hipótesis $\mathrm{H} 1 \mathrm{~b}$, algo esperable en función de los pocos datos anecdóticos conocidos del comportamiento del taxón y los estudios anatómicos previos (Prevosti et al. 2009 y citas allí), mayormente centrados en la anatomía craneal y caracteres externos. Entre los rasgos postcraneales encontrados que respaldan un alto grado de especialización al ingreso y caza dentro de galerías de roedores se puede reconocer un tamaño corporal pequeño, un cuello musculoso y con libertades de movimiento de ladeo y rotación exacerbadas, miembros y cola breves y gráciles, y una región axial con movilidad y longitud exacerbadas (aun mayor que la presente en otros hurones). Tanto la gracilidad y brevedad general de los miembros, las mayores restricciones a movimientos fuera del plano parasagital, la reducción de los sistemas musculares que flexionan el hombro y generan poderosos y complejos movimientos en el antebrazo, la elongación de las falanges del autopodio anterior y la reducción de la cola, entre otras características, sugieren a su vez la ausencia de especializaciones trepadoras, cavadoras (contra Pocock 1921) y nadadoras. Este grado de especialización a la caza de roedores en galerías, claramente mayor que el presente en los grisones vivientes y fósiles conocidos en suficiente detalle, evidencia un caso de convergencia adaptativa con los mustelinos más especializados en la caza de roedores dentro de galerías.

Durante el enfriamiento del Hemisferio Norte en el Plioceno Tardío, la progresiva extensión de los paisajes abiertos resultó en que varios linajes de herbívoros pequeños adquirieran hábitos fosoriales (King 1989, Koepfli et al. 2008 y citas allí). Esto habría habilitado un nuevo nicho ecológico para los depredadores que pudiesen acceder a estas presas, el cual habría sido aprovechado por los ancestros de Mustela (similares a martas), los cuales progresivamente se volvieron más carnívoros y de tamaños menores (contrario a la regla de Cope; ver King 1989). En lo que respecta al linaje de Lyncodon, ${ }^{\dagger}$ Lyncodon bosei (Ensenadense, 
Pleistoceno Temprano a Medio; Pascual 1958) presenta características dentarias intermedias entre Lyncodon patagonicus y los grisones, incluyendo la presencia de varios elementos dentarios ausentes en la especie actual, evidenciando un menor grado de especialización hipercarnívora. Los registros certeros más antiguos de la especie actual de Lyncodon provienen del Pleistoceno Tardío, coincidentes con el último máximo glacial (Prevosti y Pardiñas 2001, Schiaffini et al. 2013). En función de la correlación entre ésta y posteriores variaciones paleoclimáticas, y la primera aparición y modificaciones en la distribución de la especie (Prevosti y Pardiñas 2001, Schiaffini et al. 2013), una situación de aprovechamiento de nicho vacante similar a la propuesta para Mustela puede proponerse para el caso de Lyncodon en América del Sur (y eventualmente Poecilogale en África), volviéndose más especializado en una dieta hipercarnívora y hábitos subterráneos, adaptado a lugares abiertos y áridos, y partiendo de ancestros de mayor tamaño corporal.

Dado que las especies fósiles de ictoniquinos de América del Sur son sólo conocidas a partir de restos dentarios, craneales y mandibulares, análisis sobre sus estilos y sustratos de locomoción serían insostenibles. Aunque algunas variantes en lo que respecta al grado de carnivoría han sido sugeridas por Berman (1994), la anatomía general de las especies de Galictis y Lyncodon fósiles recuerdan cercanamente a los representantes vivientes de estos géneros, y lo mismo fue observado en la anatomía mastoidea (ver Anexo). Una situación distinta es la de ${ }^{\dagger}$ Stipanicicia pettorutii, única especie fósil de un género de mustélido sudamericano sin representantes vivientes (Reig 1956), para la cual en esta Tesis se presenta el primer estudio funcional. Confirmando la hipótesis H1e, el estudio de la anatomía mastoidea de †Stipanicicia (Anexo) sugirió que este taxón habría poseído una musculatura mastoidea marcadamente desarrollada y subdividida, incluso en mayor grado que Galictis y lo típicamente observado en otros hurones vivientes. Aunque la posición del proceso mastoideo recuerda a la de Lyncodon, su desarrollo lateromedial es notablemente más exacerbado, indicando una gran ventaja mecánica para realizar movimientos incluso más poderosos de flexión lateral, rotación y fijación. Estas características, en conjunto con otros rasgos craneales (arcadas zigomáticas altas, marcado desarrollo de las crestas temporal y lambdoidea, paladar ancho, modificaciones dentarias relacionadas a la hipercarnivoría), son similares a las observadas en las especies de Mustela de similar tamaño más especializadas a la caza de roedores grandes dentro galerías, e indicarían que ${ }^{\dagger}$ Stipanicicia fue capaz de dominar, matar y transportar presas de gran tamaño relativo.

-Eira barbara: Esta es la única especie de gulonino de América del Sur. El registro fósil con antigüedad confiable se remonta al Pleistoceno de Brasil (Cartelle 1999), pero Eizirik (2012) propone que la especie se habría diferenciado tempranamente de los otros representantes de la subfamilia, quizás durante el Mioceno Tardío, siendo debatido cual habría sido el 
subcontinente en donde esto habría ocurrido. La tayra presenta un gran número de rasgos osteológicos plesiomórficos para mustélidos que lo diferencian (al menos en grado) de las martas, y que a su vez pueden considerarse evidencias de un mayor grado de especialización al sustrato arbóreo (confirmando la hipótesis H1c) y diferentes estilos locomotores respecto a estos últimos. La cola es notablemente elongada y móvil. Los miembros son marcadamente elongados (en grado intermedio entre prociónidos y otros mustélidos). Existen reaseguros articulares (e.g., interlocking entre series carpales) y ligamentosos vinculados a evitar la desarticulación pero permitiendo una amplia gama de posturas. La morfología de la escápula, la pelvis y sector proximal del fémur indican un importante desarrollo de los músculos abductores y flexores del hombro, y abductores, rotadores y extensores débiles de la cadera. En el autopodio anterior y muñeca, las libertades de movimientos son particularmente amplias, el sesamoideo radial voluminoso, mientras que las falanges son particularmente elongadas otorgando una gran capacidad de agarre al sustrato. La región axial es móvil, pero el desarrollo de los procesos espinosos tóraco-lumbares indican un gran desarrollo de los sistemas epiaxiales longissimus y transversospinalis, mientras que la forma de los procesos transversos lumbares indican un gran desarrollo de la musculatura hipoaxial. Esta configuración mio-esqueletaria intermedia a la presente en algunos musteloideos galopantes y mustélidos weasel-like, indica una gran versatilidad en el uso del sustrato arbóreo (coincidiendo con observaciones comportamentales previas; Kavanau 1971, Presley 2000, Dionisios Youlatos comunicación personal), y habilidades de trepado vertical ágil, indicando que la tayra posiblemente sea el mustélido viviente con mayores habilidades de trepado, aunque menos especializado que los prociónidos. Por otro lado, los zeugopodios relativamente breves y la región axial elongada y flexible, en conjunto con un cuello elongado y de procesos de agarre muscular desarrollados son características no esperables para un especialista trepador de dieta generalizada, y vinculadas más cercanamente a un plan weasel-like, ancestral para la mayoría de los mustélidos vivientes (Mustelidae - Taxidea, Gambaryan 1974, ver más arriba).

-Lutrinos sudamericanos: Los lutrinos de América del Sur no conforman un grupo monofilético, y habrían ingresado al menos en dos oleadas independientes (i.e., ancestros del género Pteronura y Lontra, respectivamente; Eizirik 2012, Prevosti y Soibelzon 2012). Los restos más antiguos de lutrinos del subcontinente se registran en el Pleistoceno Temprano (Rusconi 1932, Berman 1994, Prevosti y Ferrero 2008), y estos, así como los más modernos, fueron asignados a especies vivientes, existiendo un importante gap en el registro del linaje. Además de muchos rasgos presentes en nutrias de otros continentes, muchos de ellos vinculados también a adaptaciones acuáticas (confirmando la hipótesis H1d), los linajes de lutrinos de América del Sur poseen otras características destacables. Los representantes sudamericanos de Lontra poseen morfologías y proporciones de los miembros relativamente generalizadas, con 
miembros anteriores relativamente bien desarrollados y dígitos largos, difiriendo notablemente de la especie cogenérica norteamericana (Lontra canadensis). Estas y otras características descriptas evidencian una mayor importancia del miembro anterior en los hábitos de vida, sea en manipulación de objetos y/o propulsión braquial. Junto a estas características apendiculares que pueden considerarse eventualmente propias de un estilo de nado "generalizado", los dos géneros de América del Sur comparten regiones axiales, y específicamente apéndices caudales, altamente especializados al nado (e.g., gran número de vértebras, amplitud de procesos de inserción muscular, retraso de vértebra transicional, procesos transversos con forma de "H"), siendo Pteronura posiblemente el lutrino viviente más especializado en el nado por propulsión caudal; como ha sido sugerido en estudios previos (Fish 1994, Kruuk 2006, Lewis 2008). Las nutrias de América del sur también se destacan por la brevedad relativa de la región lumbar (con 5 vértebras en vez de las 6 típicas) y, en el caso específico de especies de Lontra sudamericanas, por la brevedad de los miembros posteriores, reforzando la importancia que tienen los miembros anteriores y la cola durante el nado en estos linajes.

Es interesante también destacar, un gran número de rasgos que diferencian a Lontra provocax (en conjunto con Lontra felina en algunos casos) de Lontra longicaudis, entre ellos: el mayor desarrollo en superficie de los procesos espinosos preanticlinales, mayor desarrollo del proceso subhamatus de la escápula, la cresta deltopectoral del húmero y de la musculatura braquial en general, mayores restricciones articulares a ciertos grados de movimientos del antebrazo y la muñeca (e.g., concavidad medial de la articulación proximal del radial), gran capacidad de abducción de la cadera, tróclea femoral profunda y tibia proporcionalmente corta. Estos rasgos son compatibles con mayores esfuerzos braquiales y modificaciones mioesqueletarias vinculadas a transmitir y resitir mayores esfuerzos, via la región axial, a los miembros posteriores. Aunque muy poco se sabe del comportamiento del huillín, todas estas características pueden vincularse tentativamente a mayores aptitudes cavadoras para la especie, posiblemente en relación a que este último taxón habita costas con rocas y arenosas, y construye en este terreno sus madrigueras (Batisda et al. 2007), aunque son necesarios estudios comportamentales específicos del taxón para confirmar esta posibilidad.

El estudio comparativo de la anatomía postcraneal de especies de Mustelidae en particular, y Musteloidea en general, reveló también un gran número de rasgos filogenéticamente informativos a diferentes niveles jerárquicos tanto osteológicos (e.g., presencia de foramen alar en atlas, abertura de foramen transverso de C7, morfología de arcos neurales de vértebras caudales, inclinación del tubérculo menor del húmero, tipo de contactos entre carpales) como miológicos (e.g., configuración de los mm. rhomboideus, configuración de musculatura epiaxial, posición de origen del m. brachioradialis, cantidad y posición de origen de 
los vientres del m. semitendinosus), previamente no explorados; resultados que permiten confirmar la hipótesis H3. Estas fuentes de caracteres, y específicamente el diseño de caracteres propuestos para esta tesis, podrán ser utilizados en estudios futuros como fuentes de caracteres filogenéticos. 


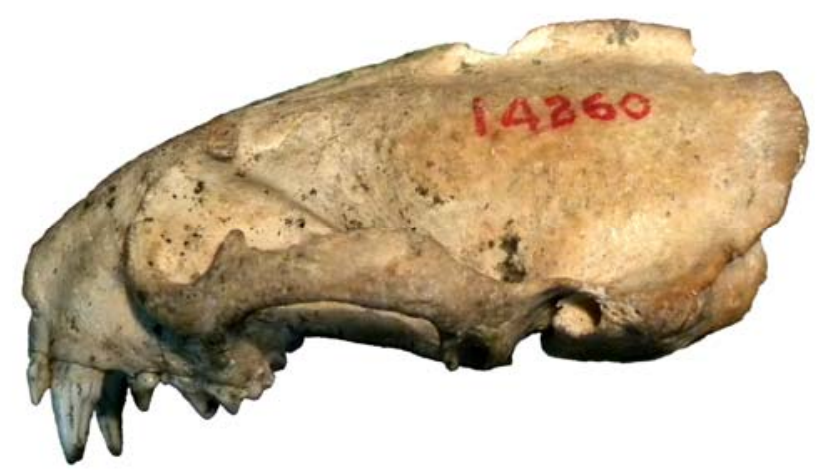

ANEXO: ANÁLISIS MORFO-FUNCIONAL DE LA ANATOMÍA MASTOIDEA DE STIPANICICIA PETTORUTII

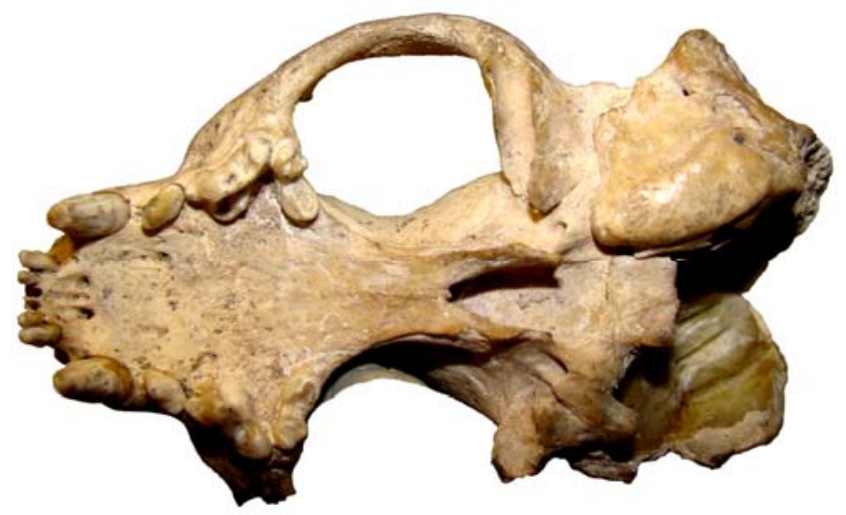





\section{Anexo: Análisis morfo-funcional de la anatomía mastoidea de Stipanicicia pettorutii}

\subsection{Introducción}

\subsubsection{Introducción a Stipanicicia pettorutii, Reig 1956}

${ }^{\dagger}$ Stipanicicia, Reig 1956, es el único género de mustélidos sudamericano sin representantes vivientes, y que presenta rasgos que indican que habría poseído una morfología músculo-esqueletaria cervical inusual para hurones lincodontininos. ${ }^{\dagger}$ Stipanicicia pettorutii, Reig 1956 es un hurón extinto registrado exclusivamente por restos craneanos y mandibulares, con dudas en depósitos marplatenses (Plioceno Tardío-Pleistoceno Temprano) y confirmados en ensenadenses (Pleistoceno Temprano-Medio) de los partidos General Alvarado, Pueyrredón y Necochea de la provincia de Buenos Aires (Reig 1956, Berman 1994, Prevosti 2000, Prevosti y Soibelzon 2012). Este taxón fue descripto por Reig (1956) y asignado a Galictinae (= Lyncodontinae, excluyéndose a Eira; Baskin 1998, Soibelzon y Prevosti 2007, Sato et al. 2012), afín a formas de hurones vivientes de América del Sur (Lyncodon y Galictis) y a especies fósiles del Viejo Mundo (e.g., linaje ${ }^{\dagger}$ Enhydrictis-Pannonictis) y América del Norte (e.g., ${ }^{\dagger}$ Trigonictis, ${ }^{\dagger}$ Lutravus) (Furlong 1932, Gazin 1934, Reig 1956, Björk 1970).

En su diagnosis original de ${ }^{\dagger} S$. pettorutii (Reig 1956), y la diagnosis modificada brindada por Berman (1994), se destaca un cráneo corto y alto, con cresta sagital elevada, y arcada zigomática robusta (rasgos más similares a Lyncodon que a Galictis) y procesos mastoides conspicuos, constricción postorbitaria marcada, paladar ancho y largo (incluso más que Lyncodon), reducción de la fórmula dentaria (ausencia de P2, como en Lyncodon) y similitudes en la morfología del carnicero superior con Galictis. Aunque la zona occipital del ejemplar holotipo (MACN-Pv 14260) se encuentra en parte dañada (y está totalmente ausente en el hipodigma MLP 53-III-19-6), la totalidad del proceso mastoideo y cresta lambdoidea (excepto detalles de su aspecto más profundo) se encuentra en excelente estado de preservación, diferenciándose con relativa claridad las principales regiones de inserción de la musculatura cervical.

En esta tesis, mediante comparaciones con carnívoros en general y hurones lincodontininos vivientes en particular, se describe en forma comparativa, la peculiar morfología del proceso mastoideo, y estructuras próximas, de ${ }^{\dagger} S$. pettorutii, en un intento de reconstruir parcialmente la musculatura cervical e indagar sobre los hábitos de caza del taxón.

\subsubsection{Introducción a las estrategias de caza en mustélidos}

Los mustélidos son un grupo muy diverso y el comportamiento de caza varía en los distintos clados. Más allá de los diferentes tipos de especializaciones presentes en los distintos 
linajes mustélidos, existe un patrón o modo de estrategia de caza común, típicamente registrado para mustélidos terrestres en general en el cual, una vez la presa se encuentra a la distancia adecuada, el depredador se ubica sobre ella, la sujeta con sus miembros anteriores y muerde su región occipital, generalmente matándola destruyendo la región posterior del cráneo (Ewer 1973, Rowe-rowe 1978 y citas allí). Este patrón típico de caza mustélida puede reconocerse en representantes de la mayoría de los linajes mustélidos, partiendo por los, hurones ictoniquinos y mustelinos (ver más abajo), guloninos (e.g., Eira, Martes, Gulo; Ewer 1973, Riley 1985) durante la caza de una gran variedad de presas, hasta linajes tan distantes como es el caso del tejón-turón Melogale personata durante la caza de pequeños mamíferos, y del tejón Taxidea taxus durante la caza de ardillas terrestres (Ewer 1973, Michener e Iwaniuk 2001, y citas allí); y quizás incluso esta generalización pueda extenderse a musteloideos en función de observaciones similares en otros taxones (e.g., Mephitis; ver Stebler 1938, Ewer 1973). Los lutrinos requieren consideraciones especiales debido a la especialización del grupo a la vida acuática (e.g., dieta piscívora, caza cooperativa, persecuciones acuáticas) y aquellas propias de algunos linajes particulares (e.g., dieta malacófaga de Enhydra lutris). Sin embargo, los lutrinos depredadores más activos recurren a la estrategia de caza típica mustélida en los casos de incursiones de caza terrestres, como las destacadas para Lutra lutra en galerías de lagomorfos (Ewer 1973).

Los representantes de la Subfamilia Ictonychinae como Mustelinae denominados "hurones" (en sentido amplio) comparten un gran número de rasgos ecológicos, comportamentales y morfológicos relacionados a especializaciones a la caza de roedores (y en algunos casos lagomorfos, topos) mediante la persecución en las galerías de sus presas (Ewer 1973, King y Powell 2007, Schutz y Guralnick 2007, Wilson y Mittermeier 2009). La dieta de la mayoría de los hurones es hipercarnívora (Ewer 1973, King y Powell 2007, Wilson y Mittermeier 2009), lo que se encuentra reflejado en el grado de la especialización dentaria. El cráneo es bajo, el cuerpo alargado y flexible, y los miembros cortos, en relación a mantener un perfil de altura bajo y poder así ingresar a las galerías de los roedores rápidamente (Gambaryan 1974, Moritz et al. 2007, Horner y Viknevicius 2010, ver también Ercoli et al. 2013, 2014). La visión de los hurones suelen estar reducida en las especies más especializadas, siendo más importantes las vibrisas, el olfato y la audición para la captura de presas (Ewer 1973, Sunquist et al. 1989, Vargas and Anderson 1998, Yensen y Tarifa 2003a, b, King y Powell 2007). El hocico es breve, el cuello y la musculatura masticatoria poderosas para dominar, matar y transportar a las presas (Kaufmann y Kaufmann 1965, Ewer 1973, Radinsky 1981a, b, King 1989, Zielinski 2000, King y Powell 2007).

Estudios de comportamiento de caza de los hurones son relativamente abundantes, conociéndose trabajos detallados de comportamiento de caza y preferencia de presas para los ictoniquininos (ictoniquinos del Viejo Mundo; e.g., Rowe-rowe 1978, Ben-David et al. 1991) y 
mustelinos del Nuevo y Viejo Mundo (e.g., Goethe 1964, Gossow 1970, Heidt 1972, Ewer 1973, Derting 1989, King 1989, Vargas and Anderson 1998, King y Powell 2007), aunque mucho menos se conoce de los lincodontininos (ictoniquinos del nuevo mundo: Lyncodon patagonicus, Galictis cuja y Ga. vittata), en donde los reportes son pocos y menos específicos (e.g., Azara 1802, Cabrera y Yepes 1940, Dalquest y Harvey 1951, Kaufmann y Kaufmann 1965, Dücker 1968, Kays 1996, Gregg 2013; ver más adelante).

Muchos investigadores (Goethe 1964, Gossow 1970, Ewer 1973, Powell 1978, Rowerowe 1978, Ben-David et al. 1991) han trazado un patrón básico en el comportamiento de caza de los mustélidos. En mustélidos, el método por el cual se da muerte a la presa puede ocurrir de dos formas básicas, dependiendo del tamaño y la agresividad de la presa y la especialización del depredador: a- presionándo a la víctima contra el suelo mientras que es mordida desde arriba en el cuello y nuca (y eventualmente región posterior del cuello, tórax y cabeza), a veces colaborando con los miembros anteriores (denominada a partir de aquí como "bite down"); o bluchando, enrollándose y desestabilizando a la presa, muchas veces incluyendo giros, propiciando mordidas en la zona del cuello y frecuentemente más precisas en la zona de la tráquea (estrategia “rolling and curl”; Goethe 1964, Ewer 1973, Rowe-rowe 1978, Ben-David et al. 1991, Wilson y Mittermeier 2009).

La estrategia bite down trasciende a los hurones y es considerada la estrategia típica o generalizada mustélida, registrada en muchos linajes mustélidos (Ewer 1973; ver más arriba), mientras que la estrategia rolling and curl se restringe a solamente algunos linajes de hurones especializados. En los estrategas bite down, es utilizada para cazar presas relativamente chicas y fáciles de dominar, y muchas veces se ayudan con los miembros anteriores para sujetar a la victima contra el suelo. Taxones que al parecer realizan típicamente esta estrategia son, Galictis, Ictonyx y Vormela (Dücker 1968, Rood 1970, Rowe-rowe 1978, Ben-David et al. 1991, Kays 1996, Wilson y Mittermeier 2009, ver más adelante). Muchas veces la primera mordida es imprecisa, ocurriendo en casi cualquier zona del cuerpo, y su fin es atrapar a la presa, corrigiendo la posición posteriormente (Dücker 1968, Gossow 1970, Heidt 1972, Ewer 1973). La estrategia rolling and curl permite evitar las actitudes de defensa de las presas (e.g. patadas), aunque demandan un mayor gasto de energía, muchas veces dejando exhausto al depredador. Es utilizada frecuentemente en casos en que la presa es un adversario de mayor tamaño y fiereza, y al enroscarse sobre ella les permite posicionar mejor sus mordidas. Este comportamiento también les permite a los hurones evitar sufrir daños durante las actitudes de defensa (e.g., patadas). Mordidas presionando a la presa hacia abajo, en general, sólo son realizadas secundariamente o cuando la víctima se encuentra moribunda al final de la caza (Rowe-rowe 1978, Vargas y Anderson 1998). Taxones que realizan esta estrategia más especializada son, en mayor o menor grado, algunas especies de Mustela (siendo el caso extremo Mustela nigripes), y 
Poecilogale, especies en general hipercarnívoras (Rowe-rowe 1978, Vargas y Anderson 1998, King y Powell 2007, Wilson y Mittermeier 2009).

Variantes de disponibilidad de presas en distintos lugares o momentos del año, así como variantes intra-específicas en el tamaño corporal (e.g., dimorfismo marcado en las especies de hurones más pequeñas), implican que la mayoría de los hurones pueden, eventualmente, realizar una u otra estrategias en mayor o menor grado (ver Ewer 1973, Wilson y Mittermeier 2009, y citas allí). Esto es especialmente válido para hurones de una dieta más bien amplia y oportunista (e.g., Mustela vison; Ewer 1973, Wilson y Mittermeier 2009), por lo cual la asignación de una especie a una de las dos categorías debe ser considerada una primera aproximación de "grano grueso" por la complejidad real del comportamiento. Por ejemplo, Vormela e Ictonyx, que típicamente depredan con estrategias bite down, recurren a estrategias rolling and curl en caso de enfrentarse a presas mayores o agresivas (Rowe-rowe 1978, Ben-David et al. 1991); y se ha reportado a Mustela nigripes (típico rolling and curl), recurriendo a estrategias bite down en caso de presas pequeñas o dóciles como hamsters, o depredando en superficie (Vargas y Andersson 1998).

A grandes rasgos, el comportamiento de caza, y específicamente el killing bite (i.e., mordida que causa la muerte a la presa) de los mustélidos es más similar al de los félidos que al de los cánidos o hiénidos, aunque los félidos tienen una participación más activa de la visión y los miembros anteriores, y las mordidas suelen ser en la región cervical en presas pequeñas, o entre la zona occipital y principalmente garganta y zona nasal (sofocándolas) en el caso de presas más grandes o con actitudes de defensa (Ewer 1973, Anyonge 1996, Karanth y Sunquist 2000). Contrariamente, en cánidos y hiénidos la presa es mordida repetidas veces, o sujetada y sacudida con las mandíbulas, muriendo por desangrado o múltiples lesiones más que por una mordida específica (Ewer 1973, Radinsky 1981a, Ben-David et al. 1991, Anyonge 1996, Karanth y Sunquist 2000). En el caso de algunos mustélidos, sacudidas laterales de la cabeza suelen colaborar en la fractura y dislocación de las presas, especialmente en las de mayor tamaño, aunque esto no suele ocurrir en todos los hurones (Poole 1970, Rowe-rowe 1978, BenDavid et al. 1991, Vargas y Andersson 1998), ni aparenta ser tan importante en el repertorio de caza como en los cánidos (Ewer 1973, Radinsky 1981a, b).

La muerte de la presa puede ocurrir por asfixia en el caso de mordidas en la tráquea, perforación de órganos vitales, dislocación de la espina o destrucción de la zona occipital (Rowe-rowe 1978, Vargas y Andersson 1998, Ben-David et al. 1991). Luego de la captura y muerte de la presa, los hurones, así como hiénidos y félidos grandes en general (Spoor y Badoux 1986b, Karanth y Sunquist 2000) suelen transportar a sus presas a lugares seguros, demandando grandes esfuerzos fisiológicos y músculo-esqueletarios (Cabrera y Yepes 1940, King 1989, Zielinski 2000, King y Powell 2007). 
Es poco lo que se conoce sobre el comportamiento de caza de los lincodontininos sudamericanos. Para el caso de Lyncodon patagonicus, lo único registrado es anecdótico y se lo describe como un animal agresivo, ágil, y que ingresa a galerías de roedores (posiblemente especies de Ctenomys y Microcavia) (Koslowsky 1904, Cabrera y Yepes 1940, Eisenberg 1989, Prevosti y Pardiñas 2001, Prevosti et al. 2009, Schiaffini y Prevosti 2013), y seguramente hipercarnívoro sobre la base de su dentición (Ewer 1973, Prevosti y Pardiñas 2001, Schiaffini y Prevosti 2013). Respecto a las especies de Galictis, ambas se alimentan principalmente de pequeños vertebrados, incluyendo ratones, cuises, anuros y una gran variedad de otros ítems menores. En algunos casos, se ha descripto la inclusión de una gran proporción de lagomorfos y eventualmente caviomorfos de gran tamaño relativo en su dieta (Cabrera y Yepes 1947, Dalquest y Harvey 1951, Eisenberg 1989, Sunquist et al. 1989, Kays 1996, Yensen y Tarifa 2003a, b). En ambas especies, las pocas descripciones existentes sugieren la utilización frecuente de mordidas en la nuca, o cabeza, o también en la espalda o cuello de sus presas, incluso aplicadas sobre caviomorfos de gran tamaño (Dücker 1968, Rood 1970, Kays 1996, Gregg 2013). Galictis vittata ha sido descripto cazando ratones mordiendo mientras presiona contra el suelo el cuello, espalda u hombros de la víctima, y luego pasando a morder la cabeza (Dalquest y Harvey 1951, Gregg 2013), mientras que en Ga. cuja, la primer mordida puede empezar en la zona lumbar (Dücker 1968). Dücker (1968) comentó que Ga. cuja no utiliza los miembros anteriores al principio de la caza, pero sí posteriormente, cuando la presa es sujetada por ambos miembros anteriores. Así como ocurrió con los ictoniquinos de mayor tamaño del viejo continente, los grisones parecen ser más afines a estrategias bite down.

Dado que las diferentes rutinas de caza involucran diferentes esfuerzos y movimientos, especialmente en la región cervical, es esperable encontrar diferencias músculo-esqueletarias tanto en el cráneo como en el postcráneo. Es esperable que la región cervical de las especies típicamente estrategas bite down presenten rasgos que favorezcan los poderosos movimientos de flexión ventral del cuello, mientras que las especies más especializadas a cazas rolling and curl, presenten rasgos que favorezcan los enormes esfuerzos de torsión y ladeo registrados en su comportamiento. Sobre la base de esto, se desprende como un primer objetivo la búsqueda de rasgos morfo-funcionales que permitan diferenciar a los hurones de otros carnívoros, y reconocer las variantes de estrategias de caza dentro del grupo.

\subsection{Materiales y Métodos}

\subsubsection{Materiales osteológicos craneales}

Para la reconstrucción muscular y análisis morfo-funcional de la región mastoidea de

${ }^{\dagger}$ Stipanicicia pettorutii se utilizó, como principal objeto de estudio, al holotipo (MACN-Pv 14260), único espécimen fósil conocido de la especie que preserva dicha región. Como 
comparativos osteológicos se utilizaron materiales en mano craneales de las especies ictoniquinas Galictis cuja, Galictis vittata, Ictonyx libyca, Lyncodon patagonicus y un gran número de especimenes de Mustela spp. como representantes de la Familia Mustelidae. Se utilizó a Galictis cuja y Mustela putorius (especies cuya anatomía miológica es bien conocida) como principales modelos mustélidos, y Crocuta crocuta, Canis familiaris y Felis catus, como modelos no mustélidos. Se incluyeron en la muestra también a especímenes fósiles de ictoniquinos de las especies Galictis sp., Ly. bosei, y Ly. patagonicus (Tabla 6.1). Todos estos materiales se encuentran depositados en las colecciones mastozoológicas y paleontológicas del MACN y MLP. También se utilizó el material fotográfico previamente comentado de especímenes mustelinos e ictoniquinos, así como modelos 3D (tomografías computadas de rayos x de alta resolución) de especímenes de Mustela frenata de Digital Morphology (http://www.digimorph.org) y material fotográfico de un gran número de especies de Mustela en ADW (http://animaldiversity.org; Myers et al. 2014).

Los materiales estudiados correspondieron a especímenes adultos (o eventualmente adultos jóvenes), reconocidos en función de la dentición completa y grado de fusión de suturas del cráneo y huesos largos.

\subsubsection{Análisis morfo-funcional de la región mastoidea de Stipanicicia pettorutii}

Para la reconstrucción muscular de ${ }^{\dagger} S$. pettorutii, se utilizó como recurso primario los datos recabados en las disecciones de Galictis cuja (ver apartado de disecciones, Ercoli et al. 2014, en preparación), y secundariamente datos de disecciones de otros mustélidos weasel-like (Cuvier y Laurillard 1849, Alix 1876, Hall 1926, Williams 1955, Scapino 1968, 1974, 1987). Se realizaron comparaciones detalladas de las muescas y marcas de inserciones musculares entre los materiales osteológicos de estas especies, el caso de estudio, y otros lincodontininos fósiles (Tabla 6.1). Por otro lado, se utilizaron a las especies de carnívoros predadores más estudiadas (tanto en miología como comportamiento) como modelos comparativos, sobre la base de las descripciones y mapas musculares detallados publicados de cánidos (Cuvier y Laurillard 1849, Barone 1976, Evans 1993, Evans y De Lahunta 2013), hiénidos (Cuvier y Laurillard 1849, Spoor y Badoux 1986b) y félidos (Cuvier y Laurillard 1849, Reighard y Jennings 1901, Antón et al. 2004), comparándolas con los materiales osteológicos con el fin de reconocer rasgos que permitan delimitar las principales áreas de inserción.

Se revisaron las principales fuentes bibliográficas general y especializada en el estudio del comportamiento de caza de carnívoros en general (Ewer 1973, Radinsky 1981a, b, Sunquist et al. 1989, Anyonge 1996, Karanth y Sunquist 2000, Antón et al. 2004), y mustélidos ictoniquinos (Azara 1802, Cabrera y Yepes 1940, Dalquest y Harvey 1951, Kaufmann y Kaufmann 1965, Dücker 1968, Rood 1970, Rowe-rowe 1978, Ben-David et al. 1991, Kays 
1996, Gregg 2013) y mustelinos (Hall 1951, Gossow 1970, Heidt 1972, Ewer 1973, Derting 1989, Vargas and Anderson 1998, Zielinski 2000, King y Powell 2007), en particular.

A partir de toda esta información, se construyeron mapas musculares sobre las especies modelo, y finalmente, sobre el material osteológico de ${ }^{\dagger} S$. pettorutii, realizándose inferencias morfo-funcionales.

\subsection{Resultados}

\subsubsection{Análisis comparativo de la región mastoidea de Stipanicicia pettorutii}

La figura 6.1 ilustra las comparaciones entre las principales especies mencionadas en este apartado. En hurones y mustélidos en general, el extremo ventral del proceso se proyecta por debajo de los cóndilos articulares en mayor grado que los cánidos, siendo similar en los hiénidos y félidos. Por otro lado, partiendo desde cánidos y hiénidos, y seguidos por félidos y luego mustélidos, el proceso mastoideo se aleja progresivamente en sentido cráneoventral del centro de rotación de la articulación atlas-cráneo, aumentando la separación entre el proceso paraoccipital y la zona articular en general. Más allá de esta primera apreciación general, dentro de los hurones, existen importantes variantes en el grado de adelantamiento del proceso mastoideo. En vista lateral, en ${ }^{\dagger} S$. pettorutii se ubica principalmente caudal y algo distanciado del meato auditivo y dorsal al nivel de la articulación cráneo-mandibular. Dentro de los hurones vivientes, una inclinación similar se registra en especímenes de Lyncodon y de muchas especies del género Mustela (e.g., ejemplares macho de Mustela nigripes). Por otro lado, un adelantamiento marcado se registra en otros hurones como Galictis y Vormela, así como también en otros linajes mustélidos (e.g., nutrias).

En mustélidos en general, es típica la presencia de un proceso mastoideo amplio y robusto (ver también Riley 1985), mayor en comparación con la mayoría de los carnívoros analizados (e.g., Felis, Canis) y similar o algo mayor en comparación con hiénidos (pero ver también úrsidos, prociónidos; Davis 1964, Radinsky 1981a). 'Stipanicicia pettorutii se destaca en estos rasgos incluso en comparación con otros hurones, estando el proceso mastoideo fuertemente desarrollado y proyectado lateralmente, alejándose de la bóveda craneana. El marcado grado de proyección lateral del proceso mastoideo fue destacado en la descripción original de Reig (1956), quien comparó este grado con el observado en el ictoniquino fósil ${ }^{\dagger}$ Enhydrictis. En Galictis, la proyección lateral del proceso mastoideo (respecto a los cóndilos articulares) es tan importante como en hiénidos, mientras que en algunas especies de Mustela (ver también Radinsky 1981a, b) y en `S. pettorutii, la proyección lateral es aún mayor. En ${ }^{\dagger} S$. pettorutii, la cresta lamboidea es elevada, rugosa y engrosada, especialmente en su sector más ventral, en mayor medida que lincodontininos vivientes, mientras que dicha cresta se encuentra reducida en otros ictonichinos como Ictonyx libyca. 
En la vista occipital, la proyección dorsal del proceso mastoideo es baja en los hurones y lutrinos en general, intermedia en félidos pequeños, y relativamente mayor en hiénidos, cánidos, otros mustélidos y félidos de mayor tamaño corporal (e.g., Antón et al. 2006, Valenciano et al. 2013). El mismo patrón se observa al comparar la región dorsal occipital, marcadamente elevada en hiénidos y cánidos. En hurones (aunque lamentablemente esta estructura no se encuentra preservada en ${ }^{\dagger} S$. pettorutii) el proceso paraoccipital se encuentra reducido en su proyección ventral (similar a félidos pequeños), contrario a lo que ocurre en hiénidos y cánidos.

\subsubsection{Reconstrucción muscular $d^{\dagger}{ }^{\dagger}$ Stipanicicia pettorutii}

La figura 6.2 ilustra el mapa muscular reconstruido para ${ }^{\dagger}$ Stipanicicia pettorutii en comparación con los correspondiente a Galictis cuja. En `Stipanicicia pettorutii se reconocen las inserciones de todos los músculos descriptos para los Mustelidae y posee una gran correspondencia topológica con respecto a $G a$. cuja, siendo los márgenes de delimitación visibles en similar medida que en los especímenes machos adultos de Galictis. Todas las áreas de inserción en el proceso mastoideo de ${ }^{\dagger} S$. pettorutii poseen un desarrollo similar o mayor que sus homólogas en hurones en general, y en Galictis cuja en particular.

El área de inserción del m. cleidocephalicus pars mastoidea (m. cleidomastoideus) usual es el sector ventral del proceso mastoideo (ver sección 3.1.8). En ${ }^{\dagger} S$. pettorutii, este área es marcadamente rugosa. Como en Galictis, el m. cleidocephalicus pars mastoidea de la especie fósil parece haber sido representado por múltiples paquetes en su inserción (una condición relativamente atípica dentro de Carnivora; pero ver Spoor y Badoux 1986b, Evans y De Lahunta 2013), al menos uno craneal cuyo límite craneal se encuentra definido por una cresta robusta, y otro caudal correspondiente en su inserción a un área marcadamente robusta en el espécimen fósil. El paquete caudal presenta dos posibles límites caudales (lindantes con el m. obliquus capitis cranialis), sin poderse definir si el área circunscripta entre ambos limites (área en duda: rallado), corresponde al paquete caudal, o un nuevo vientre del $\mathrm{m}$. cleidocephalicus pars mastoidea, $\mathrm{o}$, menos probablemente, una diferenciación craneal del $\mathrm{m}$. obliquus capitis cranialis ventral (ver más adelante). Más allá de esta ambigüedad, existe una hipertrofia de la superficie de inserción, especialmente en sentido lateromedial, en ${ }^{\dagger}$ S. pettorutii es marcado.

En Galictis el m. sternocephalicus se diferencia en un vientre que se inserta en la parte dorsal de la cresta lambdoidea (pars occipitalis) y dos que se insertan a lo largo de la cresta mastoidea (pars mastoidea dorsal) y en su extremo ventral (pars mastoidea ventral; ver sección 3.1.2). Algo similar también fue descripto para otros mustélidos como Ta. taxus (Quaife 1978). En función de las marcas observadas a lo largo de la superficie lateral mastoidea y cresta lambdoidea, una configuración similar a la de Galictis parece haber ocurrido en ``S. pettorutii, 
pero con ambos paquetes mastoideos, y especialmente el ventral, hipertrofiados, en función de la robustez y rugosidad del sector mastoideo de la cresta lambdoidea.

El m. splenius es un músculo laminar que se inserta sobre la cresta lambdoidea, por debajo de los m. sternocephalicus y en continuación con el m. longissimus capitis (ver sección 3.1.2). Aunque las marcas dejadas por este músculo son sólo evidentes en breves sectores de la región mastoidea, haciendo difícil entender su extensión total, su desarrollo parece usual en ${ }^{\dagger} S$. pettorutii. En ${ }^{\dagger} S$. pettorutii el m. longissimus capitis presenta la región de inserción bien delimitada y sobresaliente, sobre el extremo caudolateral del proceso mastoideo. Se diferencia de Galictis y hurones en general (pero no de otros carnívoros, ver más adelante) por una posición relativa elevada de la zona de inserción, y una orientación laterocaudal en vez de ventral.

El m. obliquus capitis cranialis presenta un vientre ventral independiente de gran desarrollo en Ga. cuja, que se inserta en la cara caudal del proceso mastoideo, y sector ventral a la porción mastoidea de la cresta lambdoidea (lateral al m. rectus capitis lateralis, con el cual se encuentra en estrecho contacto; ver sección 3.1.2). En ``S. pettorutii el área de este músculo se encuentra marcadamente extendida, siendo la posición exacta del límite con vientre caudal del m. cleidocephalicus pars mastoidea discutible, pudiendo representar el área entre los dos limites posibles (área rallada, ver más arriba). En función de un área sobresaliente caudalmente a modo de cresta sobre el sector profundo de la máxima curvatura de la cresta lamboidea, es muy posible estimar la presencia de un $\mathrm{m}$. obliquus capitis cranialis dorsal en ${ }^{\dagger} S$. pettorutii, o al menos la presencia de fibras del $\mathrm{m}$. obliquus capitis cranialis extendiéndose ampliamente bajo la cresta lambdoidea, como fue descripto para Galictis cuja (así como parece ser el caso de otros caniformes, pero con variantes en su diferenciación y posición de inserción, Cuvier y Laurillard 1849, Fisher 1942, Williams 1955, Quaife 1978, Evans y De Lahunta 2013, ver sección 3.1.2; pero ver también Hall 1926, 1927).

El área de origen del $\mathrm{m}$. digastricus se extiende desde el proceso paraoccipital hasta el sector ventro-medial del proceso mastoideo en Ga. cuja (y mustélidos en general; Hall 1926, 1927, Scapino 1987). Aunque las marcas son tenues y el proceso paraoccipital está roto, es muy probable que una configuración de origen similar haya sido la de ${ }^{\dagger} S$. pettorutii.

Debido a la marcada extensión lateral del proceso mastoideo y posición relativamente caudal de su ápice en ${ }^{\dagger}$ Stipanicicia pettorutii respecto a Galictis cuja (ver más adelante), tanto el $\mathrm{m}$. cleidocephalicus pars mastoidea, $\mathrm{m}$. sternocephalicus pars mastoidea, y el vientre ventral del m. obliquus capitis cranialis presentan inserciones marcadamente extendidas en sentido lateromedial. Todos estos músculos y el $\mathrm{m}$. longissimus capitis, presentan sus centros de inserción relativamente laterales, dorsales y caudales respecto a $G a$. cuja. Aunque las zonas de inserción de otros músculos extensores de la articulación atlas-cráneo se encuentran dañadas o 
ausentes en el espécimen (e.g., otros músculos rectus capitis u obliquus capitis), el área total disponible (en función de la altura de la cresta lamboidea) en el plano occipital para ellos parece haber sido pobre, similar a Ga. cuja y otros hurones vivientes.

\subsection{Discusión}

\subsubsection{Análisis morfo-funcional de la anatomía mastoidea de Stipanicicia pettorutii}

Dentro de los hurones fósiles de América del Sur, todos los especímenes conocidos son asignables a los géneros vivientes (Berman 1994, Soibelzon y Prevosti 2007, Prevosti y Soibelzon 2012, ver Introducción) y presentan morfologías afines a estas, sin esperarse mayores variantes en lo que respecta a estrategias de caza. Por ejemplo, el holotipo de ${ }^{\dagger}$ Lyncodon bosei (MLP 54.III.5.1), así como el espécimen fósil de Lyncodon patagonicus (MLP 96.V.1.1), presentan una morfología mastoidea y occipital muy similar a los especímenes hembra de los representantes actuales del genero, con procesos mastoideos posicionados caudalmente respecto al meato, relativamente elevados y con crestas lambdoideas reducidas especialmente en su sector medio. Como única excepción a esto se encuentra ‘'Stipanicicia pettorutii, taxón representante de un género sin representantes actuales y con una morfología mastoidea inusual en comparación con otros lincodontininos.

Antes de analizar las implicancias funcionales de la reconstrucción miológica de ${ }^{\dagger}$ Stipanicicia pettorutii, es necesario evaluar cómo las distintas configuraciones musculares registradas en la región cervical de cada una de las especies comparadas se relacionan, o no, con las funciones motoras requeridas en sus estrategias de caza particulares. La figura 6.3 ilustra las comparaciones entre las principales especies mencionadas en este apartado.

Al comparar los carnívoros analizados, una de las características más destacables es el adelantamiento progresivo del proceso mastoideo, partiendo desde una posición retrasada en cánidos y hiénidos, seguidos por félidos pequeños y luego mustélidos, incluyendo ${ }^{\dagger} S$. pettorutii, y llega a un máximo adelantamiento en algunos ictoniquinos, como Galictis y Vormela, y lutrinos. Esta configuración lleva a los centros de las inserciones de los principales músculos mastoideos (e.g., m. sternocephalicus pars mastoidea, m. cleidocephalicus pars mastoidea y sector ventral del $\mathrm{m}$. obliquus capitis cranialis) a una posición relativamente ventral y craneal, alejándolos del centro de rotación atlanto-occipital. Estos músculos intervienen en la flexión ventral, ladeo, fijación y retracción del cuello (Reighard y Jennings 1901; Fisher et al. 2009; Evans y de Lahunta 2013). Esta configuración da una mayor ventaja mecánica y rango a movimientos de flexión de la cabeza y cuello, especialmente en posiciones flexionadas o ladeadas de la cabeza. Dichos movimientos son cruciales en estilos de caza bite down de félidos pequeños y muchos mustélidos, en los que debe aplicarse una gran fuerza para penetrar y aplastar la región dorsal de pequeñas presas. A una conclusión similar llegaron Antón et al. 
(2004 y citas allí), al analizar en forma comparativa pantherinos vivientes y tigres dientes de sable machairodontinos. Los autores registraron un adelantamiento relativo del proceso mastoideo en machairodontinos, asociándolo a una mayor importancia de la flexión del cuello y especialmente de la articulación atlanto-occipital (dada por el m. obliquus capitis cranialis), en relación a una mayor importancia de estos movimientos en la estrategia de killing bite de este linaje. El menor adelantamiento cráneoventral del proceso mastoideo en ${ }^{\dagger} S$. pettorutii, algunas especies de Mustela y Ly. patagonicus respecto a Galictis spp. y Vormela peregusna, podría relacionarse con la menor importancia de la estrategia bite down en los primeros.

El mínimo adelantamiento del proceso mastoideo en hiénidos y cánidos favorece la fijación y movimientos rápidos antes que flexión ventral poderosa, posiblemente en relación a estabilizar y ubicar la cabeza durante las reiteradas mordidas y tironeos requeridos durante sus estrategias de caza (Ewer 1973, Anyonge 1996, Karanth y Sunquist 2000).

Mas allá de que las nutrias más carnívoras pueden potencialmente recurrir a estrategias bite down en tierra (e.g., caza de lagomorfos en galerías por parte de Lutra lutra; Kruuk 2006). El adelantamiento del proceso mastoideo de los lutrinos merece una consideración particular en relación al estilo de vida acuático del grupo. Debido a la naturaleza densa del medio acuático, y la posibilidad de desplazamiento en múltiples direcciones, las nutrias requieren una gran fuerza del cuello para cambiar de dirección durante el nado y persecuciones, así como para posicionar la cabeza durante la caza (Savage 1957, Bisaillon et al. 1976; ver sección 4.3.2, Región cervical), lo cual podría relacionarse al adelantamiento del proceso mastoideo, mientras que no son necesariamente esperables grandes esfuerzos de lucha y transporte de la presa, dada la incapacidad de la presa de aferrarse o "traccionar" contra un sustrato sólido, la sustentación proporcionada por el agua y a la mayor participación de los miembros anteriores. En relación a esto, la anatomía ósteo-muscular de las nutrias se encuentra modificada en relación a múltiples adaptaciones a la vida acuática, incluyendo modificaciones en el aparato masticatorio (Savage 1957, Scapino 1968, Riley 1985). Por ejemplo, el m. temporalis extiende su origen a modo de una superficie marcadamente deprimida sobre la cara laterodorsal del proceso mastoideo (ver Fisher 1942, Scapino 1968, Riley 1985), obteniendo este músculo una línea de acción más horizontal que lo observado en mustélidos terrestres (Riley 1985). Esta reconfiguración de la musculatura masticatoria de los lutrinos puede ser un factor influyente en la morfología y posición del proceso mastoideo, independientemente de los movimientos cervicales requeridos durante estrategias de caza.

En lo que respecta al desarrollo del m. cleidocephalicus pars mastoidea, en hiénidos (Spoor y Badoux 1986b) y mustélidos (Hall 1926, 1927, Williams 1955, Quaife 1978, Ercoli et al. 2014, sección 3.1.8), se registra una amplia zona de inserción, alcanzando un máximo en ${ }^{\dagger} S$. pettorutii. En cánidos y muchos félidos (Barone 1976, Reighard y Jennings 1901, Antón et al. 
2004), este músculo presenta una inserción menos importante y, en general, no llega hasta el sector ventral del proceso mastoideo sino hasta la cresta mastoidea (Antón et al. 2004, Barone 1976, Evans y de Lahunta 2013), dándole mucho menor ventaja mecánica para la flexión a este músculo. Felis catus parece presentar una condición intermedia entre estos dos grupos (Reighard y Jennings 1901), alcanzando éste músculo el extremo del proceso mastoideo en forma reducida. La menor importancia del músculo en la flexión ventral es una de las mayores diferencias en la región mastoidea entre hurones y félidos fósiles y vivientes (ver esquemas de Quaife 1978, Antón et al. 2004). La presencia de múltiples vientres y el adelantamiento de la inserción, máximo en Galictis, sugiere una gran importancia y precisión de los movimientos de flexión ventral en estos mustélidos, especialmente en posiciones ya flexionadas del cuello.

Sobre el sector lateral del proceso mastoideo, se inserta el $\mathrm{m}$. sternocephalicus pars mastoidea (flexor y ladeador del cuello), ampliamente desarrollado en hiénidos, hurones y algunos otros mustélidos (e.g., Taxidea), así como también el m. longissimus capitis y sector ventral del m. splenius (extensores y ladeadores del cuello; Reighard y Jennings 1901; Quaife 1978, Spoor y Badoux 1986b; Antón et al. 2004; Evans y de Lahunta 2013, Valenciano et al. 2013). Debido a la expansión lateral del proceso mastoideo y robustecimiento del sector distal de la cresta lambdoidea en hiénidos, mustélidos y específicamente ${ }^{\dagger} S$. pettorutii, estos músculos cervicales presentan una gran ventaja mecánica y área disponible de inserción, expuestas en vista occipital (Quaife 1978, Radinsky 1981a). En cánidos, hiénidos, félidos y mustélidos, los m. sternocephalicus pars mastoidea suelen extender sus orígenes, sobre su contraparte en la línea media (Cuvier y Laurillard 1849, Mackintosh 1875, Reighard y Jennings 1901, Hall 1926, 1927, Quaife 1978, Evans y De Lahunta 2013, Ercoli et al. 2014), reclutándose nuevas fibras con mayor ventaja mecánica para el ladeo y rotación, reducidas o no presentes en otros linajes.

La morfología del proceso, posiciones y desarrollo de todos estos músculos mastoideos permiten inferir una gran capacidad de retracción de la cabeza hacia el cuerpo (al actuar en forma bilateral), así como también de movimientos laterales y de rotación sobre el eje cráneocaudal poderosos (al actuar en forma unilateral), progresivamente más importantes en cánidos, félidos pequeños, hiénidos y mustélidos, y específicamente ${ }^{\dagger} S$. pettorutii, como un caso extremo dentro de los comparados. Estas características coinciden con lo esperable para un incremento progresivo de la importancia de los esfuerzos de arrastre de presas (especialmente para hiénidos y mustélidos), y a la dominación y resistencia a los movimientos de presas de gran tamaño relativo, mientras estas son sujetadas en las fauces. En el caso del hurón fósil, esto parece ser concordante con estrategias de tipo rolling and curl aplicadas a presas grandes o poderosas. Las garras retráctiles y miembros anteriores más móviles y poderosos de los félidos les permiten un mayor control de las presas durante la sujeción, explicando en parte la menor 
importancia relativa de la musculatura cervical (Gorniak y Gans 1980, Spoor y Badoux 1986b, King y Powell 2007).

En hiénidos, cánidos y félidos grandes (Antón et al. 2006), se registra una elevación marcada de la cresta lambdoidea, lo que permite un incremento de la ventaja mecánica y del lugar de inserción para los sistemas rectos y oblicuos capitales en general. También se registra una mayor extensión dorsal del proceso mastoideo, alejándose dorsalmente del nivel de los cóndilos articulares (especialmente en cánidos), área principalmente ocupada por el $\mathrm{m}$. longissimus capitis y parte del $\mathrm{m}$. sternocephalicus pars mastoidea, lo que también se observa en mustélidos grandes como Taxidea taxus (Quaife 1978, ver también Valenciano et al. 2013). A su vez, la extensión de la inserción del m. longissimus capitis es relativamente más amplia en estos linajes. Todas estas características indican una masa extensora de la cabeza hipertrofiada, posiblemente en relación a cuestiones alométricas debido al gran tamaño relativo de la cabeza en hiénidos, cánidos y félidos grandes (Hildebrand 1988), así como también a la capacidad de levantar presas de gran tamaño para el caso de los linajes feliformes (Spoor y Badoux 1986b, Karanth y Sunquist 2000). En hurones en general, la extensión de la zona de inserción del m. longissimus capitis es menor, más similar a félidos pequeños, en donde la función de este músculo ha sido descripta como flexor lateral, más que extensor del cuello (Reighard y Jennings 1901). Sin embargo, el adelantamiento del proceso mastoideo en félidos y mustélidos, especialmente en Galictis, parece explicar en parte la ausencia de una posición elevada de la inserción del m. longissimus capitis en estos linajes, dándose aproximadamente la misma distancia al centro de rotación atlanto-occipital de las fibras musculares. Dado que el proceso mastoideo se encuentra relativamente retrasado en ${ }^{\dagger} S$. pettorutii respecto al de Ga. cuja, esto explicaría la posición de inserción relativamente dorsal de la inserción de este músculo en el taxón fósil, sin más que esta consideración biomecánica.

El m. obliquus capitis cranialis se inserta generalmente en la región entre el proceso paraoccipital y el mastoideo. La acción de este músculo ha sido interpretada de forma muy variable en los distintos trabajos anatómicos, reflejando variantes funcionales marcadas en los distintos linajes (e.g., extensión, flexión, rotación axial, ladeo, fijación; Davis 1964, Quaife 1978, Antón et al. 2004, Evans y De Lahunta 2013). En hiénidos, félidos y hurones, se ubica en parte por debajo del nivel de los cóndilos articulares. Por otro lado, en cánidos y mustélidos grandes (e.g., Taxidea taxus), este músculo se ubica mayormente por sobre el nivel articular. En algunos mustélidos y cánidos al menos, la porción más ventral se diferencia de una porción dorsal (m. obliquus capitis cranialis dorsal o "accesorio"; Evans y De Lahunta 2013; ver también Cuvier y Laurillard 1849: pl. 107, Fisher 1942, Ercoli et al. 2014). Sobre la base de la reconstrucción realizada en ${ }^{\dagger} S$. pettorutii, es muy probable que el taxón haya poseído una condición para este rasgo muy similar a hurones vivientes, aunque con el área disponible para la 
porción ventral del $\mathrm{m}$. obliquus capitis cranialis hipertrofiada. Esta configuración indica para hurones, félidos y hiénidos, que la porción ventral del $\mathrm{m}$. obliquus capitis cranialis (independiente en el caso de hurones y algunos otros linajes weasel-like) se encuentra reclutado en conjunto con el $\mathrm{m}$. rectus capitis lateralis principalmente para la fijación de la articulación atlanto-occipital, flexión ventral y en menor grado movimientos de ladeo (restringidos por la articulación atlanto-occipital; Evans y De Lahunta 2013). Por otro lado, como fue observado en machairodontinos por Antón et al. (2004), el adelantamiento de proceso mastoideo convergentemente marcado en hurones permite aumentar la participación del músculo en la flexión ventral poderosa de la articulación, dado que una gran porción ventral se aleja ventralmente del centro de rotación. Por otro lado, la porción dorsal del m. obliquus capitis cranialis (bien desarrollada en algunos caniformes; Hall 1926, 1927, Fisher 1942, Williams 1955, Quaife 1978, Evans y De Lahunta 2013) actúa en la función extensora antagonista. En el caso especifico de mustélidos, el sector dorsal de este músculo posiblemente actúe eficientemente como un rotador, en relación a la independencia y posición lateralizada de ambos, su origen y su inserción, respecto al centro de rotación. De manera opuesta en cánidos, el total del $\mathrm{m}$. obliquus capitis cranialis actúa casi exclusivamente como extensor debido a su posición elevada de inserción (Evans y de Lahunta 2013) en antagonismo con el m. rectus capitis lateralis, y secundariamente como fijador o rotador de la articulación (Barone 1976, Antón et al. 2004); nuevamente indicando un mayor importancia de la extensión poderosa en este linaje. En función de todo lo expuesto, ${ }^{\dagger}$ S. pettorutii, habría tenido un m. obliquus capitis cranialis dorsal similar a la de Ga. cuja y otros hurones. Por otro lado, el vientre ventral de este músculo habría presentado en el espécimen fósil un mayor desarrollo lateromedial, y posicionamiento lateral (pero no ventral) en comparación con Ga. cuja, exacerbándose la importancia del músculo en movimientos de fijación, retracción y ladeo, incluso en mayor grado que en hiénidos. Sin embargo, la extensión ventral del área de inserción de este músculo habría sido similar en ambos taxones, sin exacerbarse la participación en función de flexión ventral (ya de por si importante en mustélidos) en el taxón fósil, o incluso siendo menos importante en este último, debido a la posición relativamente retrasada del músculo respecto a Ga. cuja.

La reducción del proceso paraoccipital en mustélidos y félidos pequeños en general, sector de inserción del $\mathrm{m}$. digastricus, podría relacionarse a variaciones en el rango y fuerza de apertura de la mandíbula (Scapino 1987, Antón et al. 2004). Más allá de una componente alométrica en el desarrollo del proceso paraoccipital (Scapino 1987), un proceso paraoccipital breve y un basicráneo cráneocaudalmente amplio en los mustélidos favorece un gran número de fibras largas del m. digastricus y un amplio rango de apertura de las mandíbulas, compensando la brevedad de la extensión de las mismas para atrapar presas (esto también ocurre en félidos, 
aunque esto es principalmente compensado en este linaje por el adelantamiento de la inserción; Scapino 1987).

\subsubsection{Comentarios sobre la influencia del tamaño y el dimorfismo}

Los carnívoros en general (ver comentarios más arriba), y los hurones en particular, presentan evidentes diferencias alométricas y dimórficas que afectan las zonas de inserciones musculares (crestas sagital y parasagital, y secundariamente al proceso mastoideo). Aunque un estudio estadístico del efecto alométrico se aleja de los objetivos de esta Tesis y de la factibilidad de la muestra con que se cuenta, a continuación se plantean algunas observaciones al respecto. Los hurones más pequeños (especialmente en el caso de algunas especies de Mustela) se diferencian de los mayores por la robustez relativa de las zonas de inserción muscular, algo esperable debido a la relación alométrica entre el trabajo mecánico y el volumen muscular (Slijper 1946, Hildebrand 1988). Esto fue evidente tanto para los especímenes fósiles como actuales analizados. El dimorfismo sexual, además de involucrar a la componente alométrica relacionada al tamaño corporal mencionada, dado que las hembras suelen ser de menor tamaño que los machos (y crestas y procesos relativamente menores), implica variantes intraespecíficas que han sido relacionadas directamente con el rango y tipo de presas potenciales y en consecuencia con la explotación de recursos de cada sexo o especie (Moors 1980, Lynch y Hayden 1995, pero ver Wiig 1986). Al observar las diferencias en la zona mastoidea entre machos y hembras de una misma especie, las hembras tienden a poseer procesos mastoideos de una dirección relativamente más lateral y una posición más caudal, mientras que los machos poseen procesos más adelantados, alejados de la articulación atlanto-occipital. La morfología de las hembras (más allá de la gracilidad de los procesos en relación a su menor tamaño), parece vincularse morfo-funcionalmente a esfuerzos y estrategias de caza de presas de mayor tamaño relativo. Aunque no existen suficientes datos como para validar esto, el estudio de Rowe-rowe (1978) y Gossow (1970) demuestra que las hembras cambiaron de estrategia de caza pasado cierto umbral de tamaño de presa (pasando de dominar y "aplastar" a la presa, a pelear y "enroscarse" por posiciones específicas cuerpo a cuerpo, ver más adelante), mientras que los machos siguen con el mismo comportamiento de caza. Esto implica una componente morfológica alométrica consecuencia indirecta del menor tamaño relativo de la hembra, y relacionada directamente a los cambios morfo-funcionales necesarios para depredar sobre presas relativamente mayores. De todas formas, un gran número de otros factores etológicos y fisiológicos pueden influir en el tamaño, estrategia y eficiencia de caza de machos y hembras (e.g., las hembras con crías deben conseguir presas más rápida y eficientemente, los machos compiten por las hembras en función del tamaño corporal), factores aun no comprendidos en su totalidad (King 1989 y citas allí dentro). Coincidentemente, en el espécimen hembra 
diseccionado, el desarrollo relativo del $\mathrm{m}$. obliquus capitis cranialis, músculo crucial en estrategias de caza de presas grandes de tipo rolling and curl (ver más adelante), es aproximadamente tres veces mayor que el del espécimen macho, mientras que el macho presenta algunos sistemas flexores ventrales del cuello, función crucial en técnicas de caza de presas pequeñas (tipo bite down, ver más adelante), e.g., mm. scalenus, que prácticamente duplican el desarrollo relativo observado en la hembra, respaldando las diferencias funcionales y comportamentales comentadas. Por último, sistemas involucrados de diferente modo en ambas estrategias como los $\mathrm{m}$. sternocephalicus pars mastoidea y $\mathrm{m}$. cleidocephalicus pars mastoidea no presentan diferencias en sus desarrollos relativos.

En caso de que esto sea correcto, el dimorfismo sexual en hurones no favorecería necesariamente una disminución de la competencia intraespecífica, dado que las hembras presentan modificaciones estructurales y comportamentales que les permitiría cazar presas de similar tamaño que los machos. Esta hipótesis debe ser puesta a prueba con estudios detallados involucrando tanto el tamaño de presa, estrategia de caza, como la morfología asociada a cada sexo (ver King 1989).

\subsubsection{Estrategias de caza en hurones}

Entre las especies modelo comparadas, los hurones son más similares a los félidos que a otros carnívoros por la presencia un proceso mastoideo adelantado y en mayor o menor grado ventral, en relación a la capacidad de cazar presas pequeñas ubicándose por sobre estas, y flexionando el cuello y cráneo durante la mordida, y matándola mediante aplastamiento de la región cervical u occipital (bite down). Por otro lado, se asemejan en mayor medida a hiénidos que otros carnívoros por poseer una región mastoidea amplia, especialmente en sentido lateromedial, implicando un desarrollo amplio de la musculatura cervical y poderosos movimientos de ladeo, rotación y retracción del cuello, importantes para el arrastre de presas en ambos linajes, sumándose en el caso específico de hurones la capacidad de cazar presas de gran tamaño relativo mediante estrategias rolling and curl (ver a continuación).

La reducción de la extensión dorsal de la zona mastoidea de los hurones, así como de toda la zona occipital, es una de las principales diferencias respecto a grandes predadores. Como se comentó más arriba esto se debe a múltiples factores, incluyendo un hocico relativamente corto, la ausencia de poderosos movimientos de extensión durante la depredación o transporte de presas, y principalmente a cuestiones alométricas relativas al bajo tamaño corporal.

De las comparaciones realizadas, pueden reconocerse características osteológicas relativas a reconfiguraciones musculares que permiten caracterizar los extremos comportamentales de estrategia de caza de los hurones: las especies que más frecuentemente utilizan la estrategia bite down presentan procesos mastoideos ventrocranealmente proyectados, 
ubicándose sus extremos por debajo y apenas detrás del nivel del meato auditivo. Otras características que se pueden proponer como frecuentemente asociadas a este grupo son arcadas zigomáticas débiles, paladares angostos y hocicos relativamente alargados y dentición menos especializada a la hipercarnivoría. Otras características comentadas para el esqueleto axial postcraneal (e.g., la morfología de las láminas ventrales de los procesos transversos cervicales, y menos claramente la posición de la vértebra diafragmática y modificaciones en el autopodio anterior; ver secciones 4.3.2 y 4.3.4) podrían también sumarse a estas diferencias. La morfología mastoidea le permite a estas especies deprimir al principio rápidamente y luego fuertemente la cabeza y el cuello, mediante la activación bilateral de músculos como el m. sternocephalicus pars mastoidea y el m. cleidocephalicus pars mastoidea, los cuales ven incrementada su ventaja mecánica con el progreso de la flexión ventral de la cabeza y cuello (función para la cual el m. obliquus capitis cranialis ventral seguramente también es reclutado tardíamente en posiciones ya flexionadas). Las demás características mencionadas pueden vincularse a una dieta más amplia, en general compuesta por presas relativamente pequeñas, y a la eventual participación de los miembros anteriores durante la captura de la presa (e.g., Dücker 1968, Heidt 1972, Rowe-rowe 1978, Ben-David et al. 1991).

Las especies correspondientes al grupo rolling and curl se caracterizan por tener procesos mastoideos proyectados lateralmente, típicamente con sus extremos ubicados por detrás y relativamente separados del meato auditivo (acercándose a la región articular atlantooccipital). Otras características afines a este grupo son la presencia de arcadas zigomáticas poderosas, paladares anchos y hocicos relativamente cortos, dentición más especializada a la hipercarnivoría y miembros anteriores relativamente gráciles y pequeños en comparación con la longitud de un cuerpo marcadamente elongado y flexible. La modificación en la dirección y posición del extremo del proceso mastoideo habla de una modificación en la función de los músculos que allí se insertan. En este grupo, la función de flexión lateral, rotación y retracción de la cabeza y cuello se encuentra exacerbada (e.g., m. obliquus capitis cranialis, siendo menos exacerbada la flexión ventral) y le permitiría a estas especies sujetarse y resistir los movimientos durante la lucha, desestabilizar a la presa y posicionarse para ubicar con precisión las mordidas. Las demás características mencionadas pueden vincularse a una dieta más especializada, a la aplicación y resistencia de poderosos esfuerzos en el cráneo, mientras los miembros aseguran el agarre a la presa, pero no son utilizados para detener a la presa en una captura inicial. Respecto a Lyncodon patagonicus, aunque prácticamente nada se sabe respecto a su comportamiento (Cabrera y Yepes 1940, Ewer 1973, Prevosti et al. 2009), presenta la morfología craneal y postcraneal típica de taxones rolling and curl pequeños (i.e., considerando la menor importancia de los procesos debido a la influencia alométrica). 
Una vez muerta la presa, y muchas veces luego de un descanso en los estrategas rolling and curl, los hurones arrastran al cadáver hasta un lugar seguro (dentro del sistema de galería de la presa o a sus propias madrigueras o escondites) previo a comenzar a alimentarse (Dalquest y Harvey 1951, Vargas y Anderson 1998, King y Powell 2007). El cuello alargado permite transportar a las presas hacia delante evitando que esta interfiera con el movimiento de los miembros anteriores sólo hasta cierto tamaño de presas (King y Powell 2007), y requiriendo esfuerzos de extensión del cuello y cabeza, involucrando la espinas neurales y zona dorsal de la cresta parasagital. Pasado cierto límite, los hurones arrastran presas mayores caminando hacia atrás (Rowe-rowe 1978, Vargas y Anderson 1998), evitando interferencia con los miembros anteriores. En este último caso, los esfuerzos del traslado recaen sobre la musculatura que retrae, fija y ladea el cuello y cabeza, mayormente insertada en la zona mastoidea y sector lateral de la cresta parasagital. Las especies de hurones que depredan sobre animales de gran tamaño relativo y recurren frecuentemente al arrastre hacia atrás (e.g., Poecilogale albinucha, Mustela nigripes), requieren también para esto procesos mastoideos más amplios y lateralmente proyectados, en relación a un incremento de la ventaja mecánica para movimientos fuera del plano sagital y áreas de inserción de los m. obliquus capitis cranialis m. sternocephalicus pars mastoidea, m. cleidocephalicus pars mastoidea (entre otros), en comparación con especies que depredan sobre animales pequeños.

Es interesante destacar que en la región cervical, y específicamente en los procesos transversos, también se detectaron cambios morfológicos (e.g., posición de tubérculos dorsales, extensión cráneoventral de láminas ventrales) relativos a maximizar movimientos específicos del cuello que pueden ser relacionados a diferentes estrategias de caza (ver sección 4.3.2, Región axial, Apéndice 4.1A), reforzando la interpretación funcional de la anatomía mastoidea.

\subsubsection{Estrategia de caza de Stipanicicia pettorutii}

La capacidad de ${ }^{\dagger}$ Stipanicicia pettorutii de realizar poderosos movimientos de flexión ventral, y la reducción la relativa la importancia de la fuerza de los movimientos extensión de la cabeza parecen haber sido similares a lo observado en hurones vivientes en comparación con otros grupos de carnívoros. 'Stipanicicia pettorutii presenta una morfología craneana más afín al tipo rolling and curl que al bite down, dado que habría poseído la capacidad de realizar poderosos movimientos laterales, de rotación y de retracción de la cabeza y el cuello. La mayoría de las características que distinguen a ${ }^{\dagger} S$. pettorutii del resto de los hurones (especialmente en comparación con los grisones) a su vez pueden considerarse como un caso extremo de las modificaciones requeridas para estrategas rolling and curl, con un proceso mastoideo exageradamente proyectado lateralmente, y una robustez del mismo sólo comparable a la de los especímenes macho de los rolling and curl que depredan sobre presas relativamente 
más grandes (e.g., Mustela nigripes; Ben-David et al. 1991, Vargas y Anderson 1998). Por otro lado, la gran ventaja mecánica y cantidad de vientres de músculos mastoideos laterales, habrían permitido eventualmente al taxón movimientos de sacudida de cabeza poderosos ("shaking"). En ${ }^{\dagger}$ S. pettorutii se reconocen también otras características craneales frecuentemente asociadas a este morfotipo (robustez de la arcada zigomática, proporciones del hocico y paladar, modificaciones dentarias en relación a la hipercarnivoría).

En resumen, ${ }^{\dagger}$ S. pettorutii habría sido un cazador de tipo rolling and curl, especializado en subyugar y transportar presas de gran tamaño relativo, incluso en comparación con los hurones vivientes más especializados en este sentido. Existe la posibilidad de que este taxón haya sido un depredador especialista en roedores en galerías, como ocurre en los estrategas rolling and curl actuales, pero esto deberá ser puesto a prueba con hallazgos de materiales postcraneales del taxón. Salvando las diferencias alométricas, ${ }^{\dagger}$ S. pettorutii presentaría mayores similitudes morfológicas y en consecuencia comportamentales con L. patagonicus que respecto a las especies de Galictis. 


\section{Tablas de Anexo de ${ }^{\dagger}$ Stipanicicia pettorutii}

Tabla 6.1. Especímenes en mano utilizados para el análisis osteológico comparativo y reconstrucción de la musculatura mastoidea de ${ }^{\dagger}$ Stipanicicia pettorutii. Para el caso de los especímenes fósiles, se señala la bibliografía de referencia entre paréntesis. Para los especímenes actuales, se indica el sexo, si este es conocido, entre paréntesis.

\begin{tabular}{ll}
\hline Especie & Espécimen \\
\hline $\begin{array}{l}\text { Ictoniquinos fósiles } \\
\text { Stipanicicia pettorutii }\end{array}$ & MACN-Pv 14260 (Reig 1956) \\
$\begin{array}{l}\text { Galictis sp. } \\
\text { Lyncodon patagonicus } \\
\text { Lyncodon bosei } \\
\text { Ictoniquinos actuales } \\
\text { Galictis cuja }\end{array}$ & MLP(Pv) 95-III-V-1 \\
& MAC-V-1-1 (Prevosti y Pardiñas 2001) \\
& 257-III-5-1 (Pascual 1958) \\
Galictis vittata & MLP 8-V-596-6(?), MLP 6-III-36-5(M) \\
Ictonyx libyca & MACN-Ma 948(H) \\
Lyncodon patagonicus & MACN-Ma 24.12(?) \\
& 6.III.36.32(?), MLP(Pv), MACN-Ma 31.214(M), MLP 27-III-96-1(?), MLP \\
Mustelinos actuales & \\
Mustela erminea & MACN-Ma 35.205(M) \\
$\begin{array}{l}\text { Mustela eversmanni } \\
\text { Mustela putorius }\end{array}$ & MACN-Ma 35.206(?) \\
Mustela vison & MACN-Ma 20645(?), MACN-Ma 25.148(?) \\
& \\
Otros carnivoros & \\
actuales & \\
Crocuta crocuta & MACN-Ma 19.188(H), MACN-Ma 19.185(M), MACN-Ma 19.186(M) \\
Canis familiaris & MACN-Ma 24.4(?),MACN-Ma 4310(?), MACN-Ma 24.29(?), MACN-Ma \\
Felis catus & 26.23(?) \\
\hline
\end{tabular}




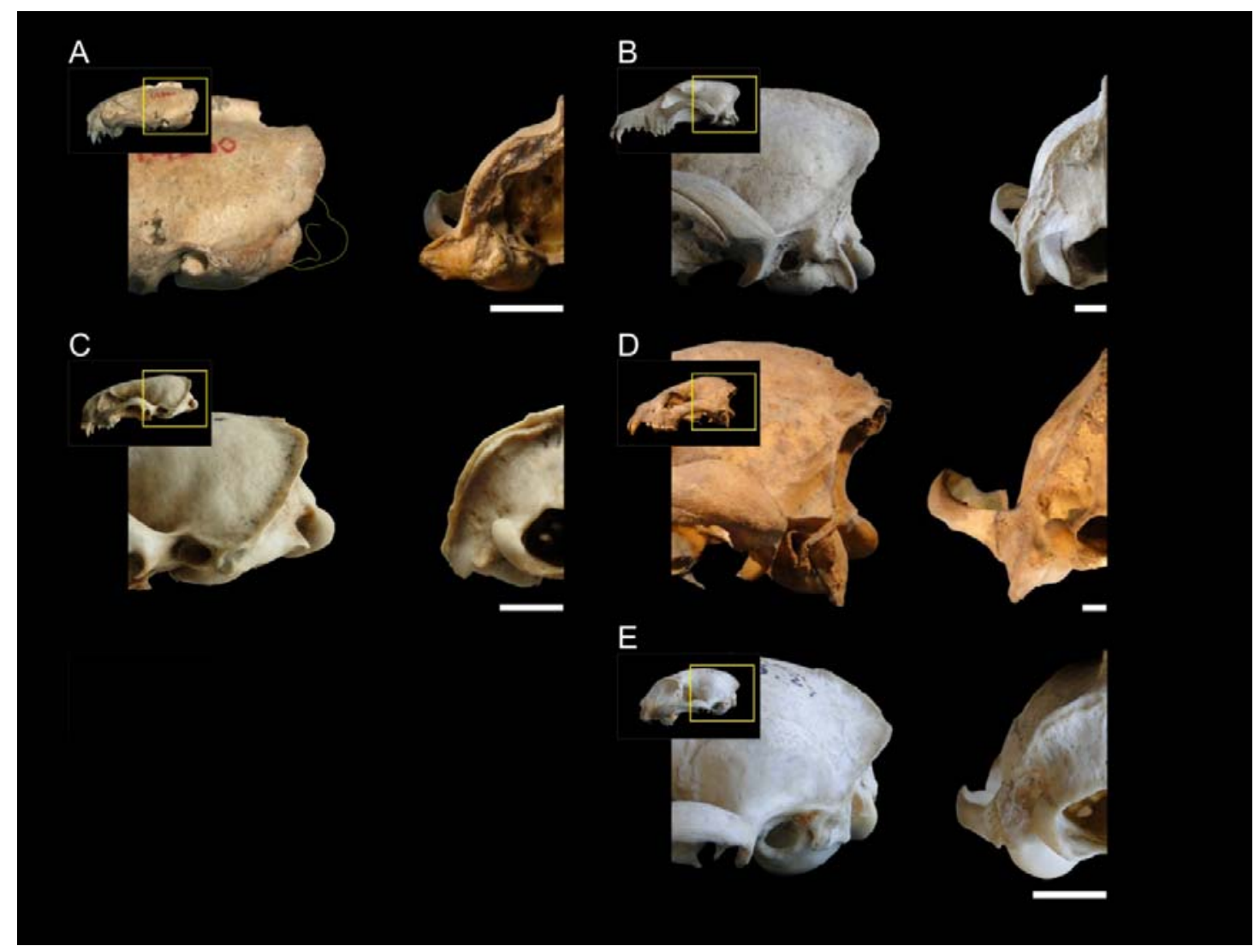

Figura 6.1. Comparación de vista lateral (izquierda) y occipital (derecha) del sector posterior del cráneo de ${ }^{\dagger}$ Stipanicicia pettorutii (A), y representantes de los principales grupos de carnívoros comparados: Canis lupus (Canidae, B), Galictis cuja (Mustelidae, C), Crocuta crocuta (Hyaenidae, D) y Felis catus (Felidae, E). Escala $=10 \mathrm{~mm}$. 


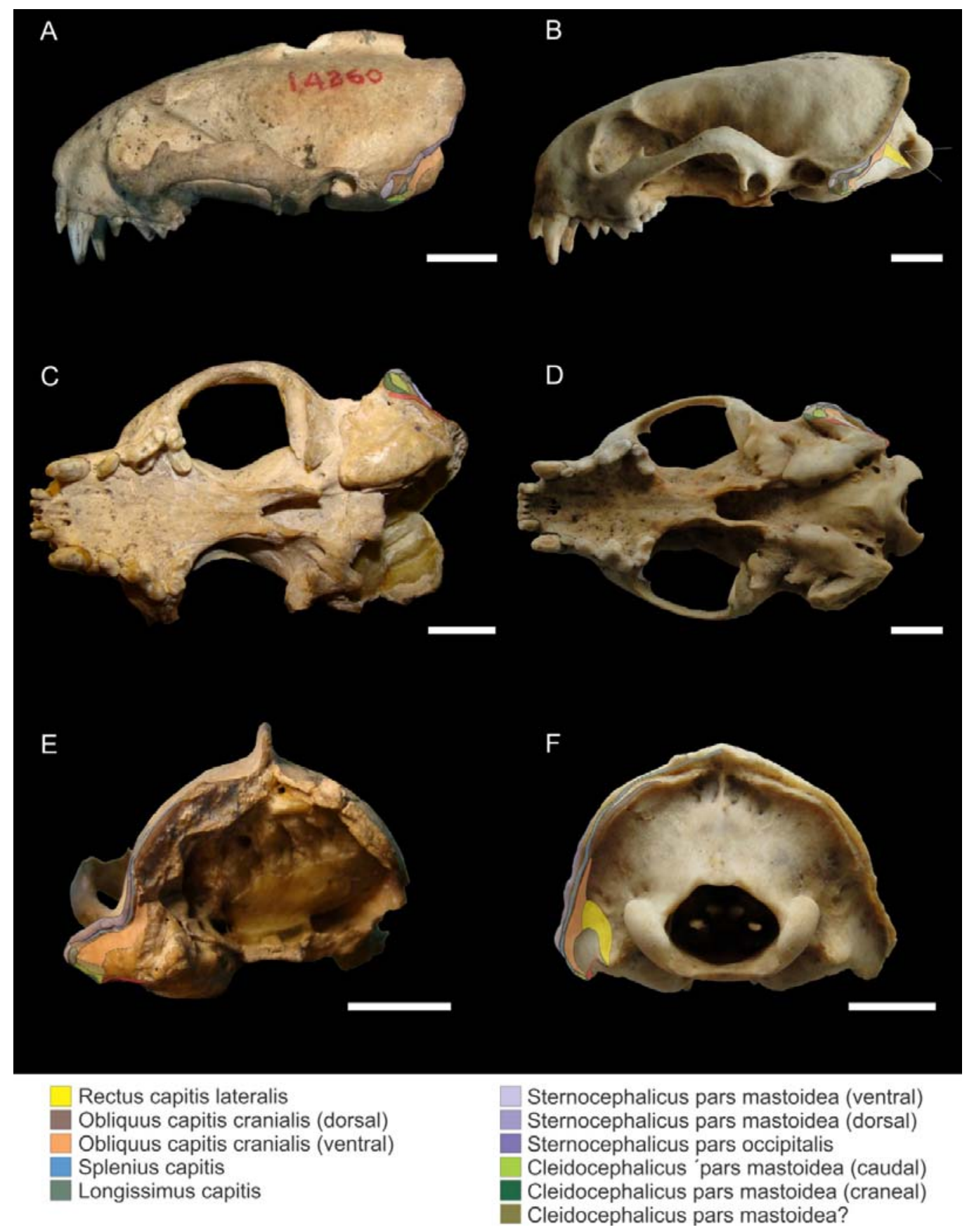

Figura 6.2. Reconstrucción de la musculatura mastoidea ${ }^{\dagger}$ Stipanicicia pettorutii (A, C y E), comparada con Galictis cuja (B, D y F). Vista lateral (A, B), ventral (C, D) y occipital (E, F) del cráneo. El grosor de las líneas indica la confianza en las reconstrucciones de los contornos, mientras que las líneas de guiones indican contornos pobremente definidos o dudosos, y las líneas punteadas indican regiones rotas del material. Sobre la articulación atlanto-occipital de Ga. cuja se indica el rango de flexión-extensión estimado. Escala $=10 \mathrm{~mm}$. 



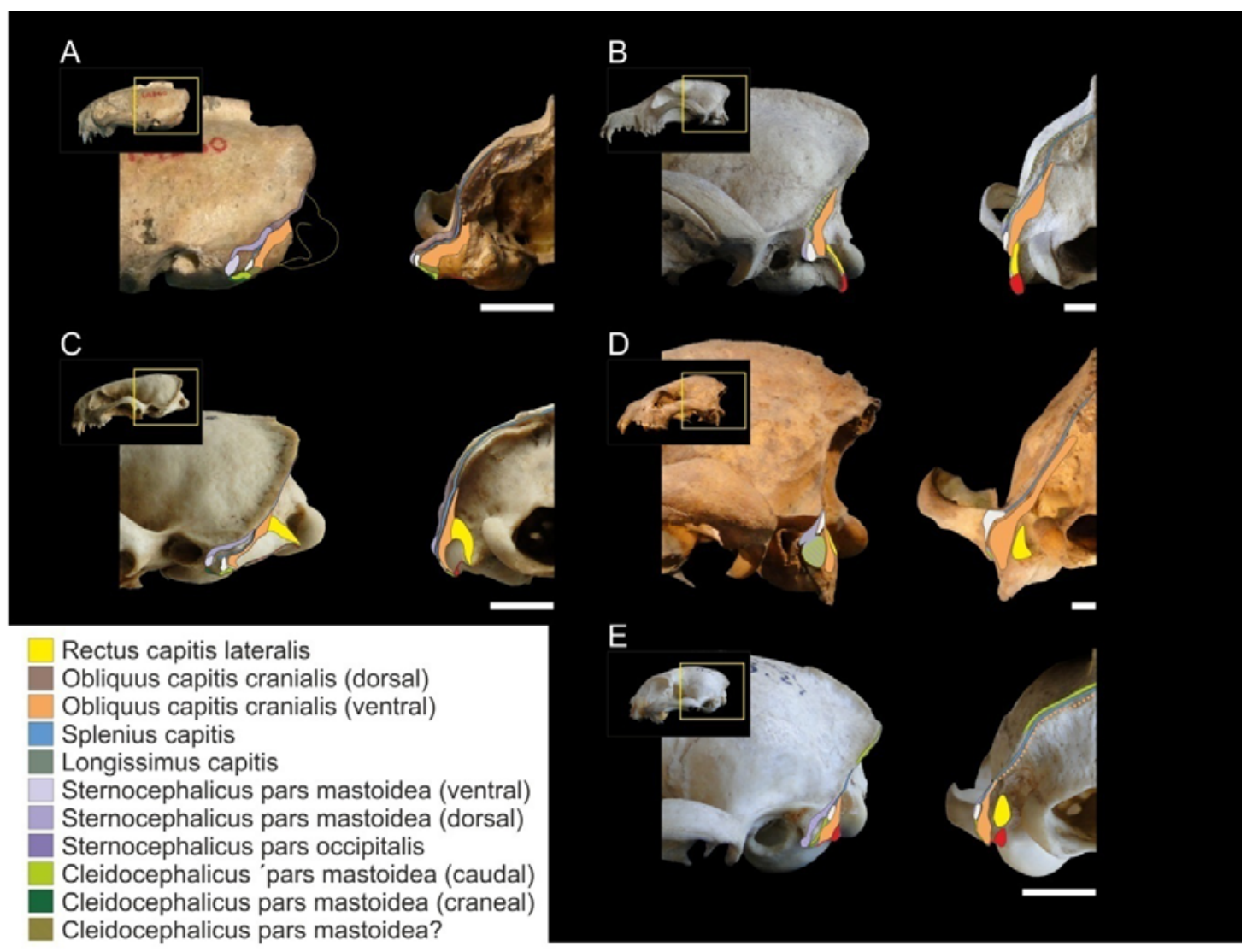

Figura 6.3. Mapas musculares de la región mastoidea en vista lateral y occipital de †'Stipanicicia pettorutii (A), y representantes de los grupos de carnívoros comparados: Canis familiaris, Canidae (B), Galictis cuja, Mustelidae (C), Crocuta crocuta, Hyaenidae (D), Felis catus, Felidae (E). Escala =10mm. 



\section{BIBLIOGRAFÍA}





\section{Bibliografía}

\section{Abella J, Pérez-Ramos A, Valenciano A, Alba DM, Ercoli MD, Hontecillas D, Montoya P,} Morales J. The giant panda's false thumb and the significance of exaptive convergence in evolution. Enviado. Scientific Reports.

Abramov A, Wozencraft C. 2012. "Mustela itatsi", [Online]. IUCN Red List of Threatened Species. Disponible en: http://www.iucnredlist.org/details/41656/0.

Agnarsson I, Matjaz K, May-collado LJ. 2010. Dogs, cats, and kin: A molecular species-level phylogeny of Carnivora. Molecular Phylogenetics and Evolution 54: 726-745.

Alexander RM, Jayes AS. 1981. Estimates of the bending moments exerted by the lumbar and abdominal muscles of some mammals. Journal of Zoology, London 194: 291-303.

Alix ME. 1876. Memoire sur la myologie du putois (Putorius communis, Cuv.). Journal de Zoologie, Paris 5: 153-188.

Allen H. 1882. The muscles of the limbs of the raccoon (Procyon lotor). Proceedings of the Academy Natural Sciences of Philadelphia 34: 115-144.

Álvarez A, Ercoli MD, Prevosti FJ. 2013. Locomotion in some small to medium-sized mammals: a geometric morphometric analysis of the penultimate lumbar vertebra, pelvis and hindlimbs. Zoology 116: 356-371.

Ameghino F. 1888. Rápidas diagnósis de algunos mamíferos fósiles nuevos de la República Argentina. P. E. Coni é hijos, Buenos Aires.

Ameghino F. 1889. Contribución al conocimiento de los mamíferos fósiles de la República Argentina. Actas de la Academia Nacional de Ciencias de Córdoba 6: 1-1027.

Ameghino F. 1906. Sur quelques mammiféres du Miocéne Moyen de France. Anales del Museo Nacional de Buenos Aires 3: 41-58.

Anderson E, Forrest SC, Tim WC, Richardson L. 1974. Paleobiology, biogreography, and systematics of the black-footed ferret, Mustela nigripes (Audubon and Bachman), 1851. Great Basin Naturalist Memoirs 8: 11-62.

Andersson K. 2003. Locomotor evolution in the Carnivora (Mammalia): evidence from the elbow joint. Thesis for the degree of Filosofie Licentiat, Uppsala University, Uppsala.

Andersson K. 2004. Elbow-joint morphology as a guide to forearm function and foraging behaviour in mammalian carnivores. Zoological Journal of the Linnean Society 142: 91104.

Antón M, Galobart A. 1999. Neck function and predatory behaviour in the scimitar toothed cat Homotherium latidens. Journal of Vertebrate Paleontology 19: 771-784. 
Antón M, Salesa MJ, Pastor JF, Peigné S, Morales J. 2006. Implications of the functional anatomy of the hand and forearm of Ailurus fulgens (Carnivora, Ailuridae) for the evolution of the "false-thumb" in pandas. Journal of anatomy 209: 757-64.

Antón M, Salesa MJ, Pastor JF, Sanchez IM, Fraile S, Morales J. 2004. Implications of the mastoid anatomy of larger extant felids for the evolution and predatory behaviour of sabretoothed cats (Mammalia, Carnivora, Felidae). Zoological Journal of the Linnean Society 140: 207-221.

Anyonge W. 1996. Microwear on canines and killing behavior in large carnivores: saber function in Smilodon fatalis. Journal of Mammalogy 77: 1059-1067.

Argot C. 2001. Functional-adaptive anatomy of the forelimb in the Didelphidae, and the paleobiology of the Paleocene marsupials Mayulestes ferox and Pucadelphys andinus. Journal of Morphology 247: 51-79.

Argot C. 2002. Functional-adaptive analysis of the hindlimb anatomy of extant marsupials and the paleobiology of the Paleocene marsupials Mayulestes ferox and Pucadelphys andinus. Journal of Morphology 108: 76-108.

Argot C. 2003a. Functional-adaptive anatomy of the axial skeleton of some extant marsupials and the paleobiology of the Paleocene marsupials Mayulestes ferox and Pucadelphys andinus. Journal of morphology 255: 279-300.

Argot C. 2003b. Functional adaptations of the postcranial skeleton of two miocene borhyaenoids (Mammalia, Metatheria), Borhyaena and Prothylacinus, from South America. Palaeontology 46: 1213-1267.

Argot C. 2004. Functional-adaptive features and palaeobiologic implications of the postcranial skeleton of the late Miocene sabretooth borhyaenoid Thylacosmilus atrox (Metatheria). Alcheringa 28: 37-41.

Argot C. 2010. Morphofunctional analysis of the postcranium of Amphicyon major (Mammalia, Carnivora, Amphicyonidae) from the Miocene of Sansan (Gers, France) compared to three extant carnivores: Ursus arctos, Panthera leo, and Canis lupus. Geodiversitas 32: 65-106.

Argot C, Babot J. 2011. Postcranial morphology, functional adaptations and palaeobiology of Callistoe vincei, a predaceous metatherian from the Eocene of Salta, north-western Argentina. Palaeontology 54: 447-480.

Azara FD. 1802. Apuntalamientos para la historia natural de los quadrúpedos del Paraguay y Río de la Plata. La viuda de Ibarra, Madrid.

Baitchmand EJ, Kollias G V. 2000. Clinical anatomy of the North American river otter (Lontra canadensis). Journal of Zoo and Wildlife Medicine 31: 473-483.

Barcinová L. 2009. Advances in insectivore and rodent systematics due to geometric morphometrics. Mammal Review 39: 80-91. 
Barnett CH, Napier JR. 1953. The rotatory mobility of the fibula in eutherian mammals. Journal of Anatomy 87: 11-21.

Barone R. 1967. La myologie du lion (Panthera leo). Mammalia 31:459-514.

Barone R. 1976. Anatomie, comparee des mammíteres domestiques, 12ma edición. Vigot Freres Editeurs, Paris.

Barone R, Deutsch H. 1953. Myologie des members du furet (Putorius furo). Bulletin de la Société des sciences vétérinaires et de médecine comparée de Lyon 55: 445-454.

Barraquand C. 2010. Atlas radiographique et ostéologique de la martre (Martes martes) et de la fouine (Martes foina). Thèse d' exercice, Médecine véterinaire, Toulouse.

Baskin JA. 1998. Mustelidae. En: Janis CM, Scott KM, Jacobs LL (Eds.) Evolution of Tertiary mammals of North America: terrestrial carnivores, ungulates, and ungulate-like mammals, vol.1. Cambridge University Press, Cambridge, pp. 152-173.

Bastida R, Rodriguez D, Secchi E, Da Silva V. 2007. Mamíferos marinos sudamericanos. Vazquez Mazzini Editores, Buenos Aires.

Bebej RM. 2011. Functional morphology of the vertebral column in Remingtonocetus (Mammalia, Cetacea) and the evolution of aquatic locomotion in early archaeocetes. Thesis Doctoral, University of Michigan, Michigan.

Beddard MA. 1900. On the anatomy of Bassarircyon alleni. Proceedings of the Zoological Society of London 69: 661-675.

Beddard FE. 1905. On the anatomy of the ferret-badger, Helictis personata. Proceedings of the Zoological Society of London 75: 21-29.

Ben-David M, Pellis SM, Pellis VC. 1991. Feeding habits and predatory bejaviour in the marbled polecat (Vormela peregusna syriaca): and prey behaviour. Behaviour 118: $127-$ 143.

Berdnikovs S. 2005. Evolution of sexual dimorphism in mustelids. Tesis Doctoral, University of Latvia, Riga.

Berman WD. 1994. Los carnívoros continentales (Mammalia, Carnivora) del Cenozoico en la provincia de Buenos Aires. Tesis Doctoral, Facultad de Ciencias Naturales y Museo, Universidad Nacional de La Plata, La Plata.

Berta A, Marshall LG. 1978. South American Carnivora. En: Westphal F (Ed.) Fossilium catalogus I: Animalia. Dr. W. Junk Publishers, La Haya, pp. 1-48.

Bertram JE, Biewener AA. 1988. Bone curvature: sacrificing strength for load predictability? Journal of Theoretical Biology 131: 75-92.

Beswick-Perrin J. 1871. On the myology of the limbs of the kinkajou (Cercoleptes caudivolvulus). Proceeding of the Zoological Society of London 1871: 547-559. 
Biewener AA. 1983. Allometry of quadrupedal locomotion: the scaling of duty factor, bone curvature and limb orientation to body size. Journal of Experimental Biology 105: 147-71.

Biewener AA. 1989. Scaling body support in mammals: limb posture and muscle mechanics. Science 245: 45-48.

Bisaillon A. 1976. La musculature du membre pelvien du putois d'Amérique (Mustela nigripes, Audubon et Bachman). Anatomischer Anzeiger 139: 486-504.

Bisaillon A, Piérard J, Larivière N. 1976. Le segment cervical de carnivores (Mammalia: Carnivora) adaptés à la vie aquatique. Canadian Journal of Zoology 54: 431-436.

Bisbal EFJ. 1986. Food habits of some Neotropical carnivores in Venezuela (Mammalia, Carnivora). Mammalia 50: 329-339.

Björk PR. 1970. The Carnivora of the Hagerman local fauna (late Pliocene) of southwestern Idaho. Transactions of the American Philosophical Society 60: 1-54

Blainville HMD De. 1841-1864. Ostéographie ou description iconographique comparée du squelette et du système dentaire des mammifères récents et fossiles pour servir de base à la zoologie et à la géologie, Tome 2: Carnassiers. J. B. Baillère, Paris.

Bonomo M, Capdepont I, Matarrese A. 2009. Alcances en el estudio de colecciones. Los materiales arquelógicos del Delta del Río Paraná depositados en el Museo de La Plata (Argentina). Arquelogía Suramericana 5: 68-101.

Bonomo M, Politis G, Castro C. 2010. Primeros resultados de las investigaciones arqueológicas en el Delta superior del Paraná y su contribución al atlas arqueológico de la Provincia de Entre Ríos. Folia Histórica del Nordeste 18: 33-58.

Bornholdt R, Helgen K, Koepfli KP, Oliveira L, Lucherini M, Eizirik E. 2013. Taxonomic revision of the genus Galictis (Carnivora: Mustelidae): species delimitation, morphological diagnosis, and refined mapping of geographical distribution. Zoological Journal of the Linnean Society 167: 449-472.

Boszczyk BM, Boszczyk AA, Putz R. 2001. Comparative and functional anatomy of the mammalian lumbar spine. The Anatomical Record 264: 157-168.

Brockhaus FA, Efron IA. 1890. Brockhaus and Efron Encyclopedic Dictionary (Texto original en ruso).

Bryant HN, Russell AP, Fitch WD. 1993. Phylogenetic relationships within the extant Mustelidae (Carnivora): appraisal of the cladistic status of the Simpsonian subfamilies. Zoological Journal of the Linnean Society 108: 301-334.

Cabrera A. 1929. Sobre Lyncodon patagonicus con descripción de una nueva sub-especie. Revista Chilena de Historia Natural Pura y Aplicada 32: 259-263.

Cabrera A, Yepes J. 1940. Mamíferos Sud-Americanos (vida, costumbres y descripción). Compañía Argentina de Editores, Buenos Aires. 
Candela AM, Picasso MBJ. 2008. Functional anatomy of the limbs of Erethizontidae (Rodentia, Caviomorpha): Indicators of locomotor behavior in Miocene porcupines. Journal of Morphology 593: 552-593.

Canevari M, Fernández Balboa C. 2007. 100 mamíferos argentinos. Editorial Albratros, Buenos Aires.

Canevari M, Vaccaro O. 2007. Guía de Mamíferos del sur de América del Sur. L.O.L.A., Buenos Aires.

Carlini AA, Tonni EP, Noriega JI. 2002. El primer registro paleontológico del lutrino gigante Pteronura (Carnivora, Mustelidae) en la Argentina. Su importancia paleobiogeográfica. I Congreso Latinoamericano de Paleontología de Vertebrados, Santiago, Chile, Resúmenes 25-26A.

Carlon B, Hubbard C. 2012. Hip and thigh anatomy of the clouded leopard (Neofelis nebulosa) with comparisons to the domestic cat (Felis catus). The Anatomical Record 295: $577-589$.

Carlsson A. 1905. Ist Otocyon caffer die ausgangsform des hundegeschlechts oder nicht? Zoologische Jahrbücher 22: 717-754.

Carlsson A. 1920 Über Arctictis binturong. Acta Zoologica 1: 337-380.

Caro T. 2009. Contrasting coloration in terrestrial mammals. Philosophical Transactions of the Royal Society of London, Series B, Biological Sciences 364: 537-548.

Carrano MT. 1999. What, if anything, is a cursor? Categories versus continua for determining locomotor habit in mammals and dinosaurs. Journal of Zoology 247: 29-42.

Carrizo LV, Díaz MM. 2013. Descripción morfológica del esqueleto axial de filotinos (Rodentia: Sigmodontinae): aspectos morfofuncionales y filogenéticos. Mastozoología Neotropical 20: 7-29.

Cartelle C. 1999. Pleistocene mammals of the Cerrado and Caatinga of Brazil. En: Eisenberg J, Redford KH (Eds.) Mammals of the Neotropics, vol. 3. The University of Chicago Press, Chicago, pp. 27-46.

Cartelle C, Hirooka S. 2005. Primeiro registro pleistocênico de Pteronura brasiliensis (Gmelin, 1788) (Carnivora, Mustelidae). Arquivos do Museu Nacional, Río de Janeiro 63: 595-598.

Carter SK, Rosas FCW. 1997. Biology and conservation of the giant otter Pteronura brasiliensis. Mammal Review 27: 1-26.

Cassini GH. 2013. Skull geometric morphometrics and paleoecology of santacrucian (late Early Miocene; Patagonia) native ungulates (Astrapotheria, Litopterna, and Notoungulata). Ameghiniana 50: 193-216. 
Cheverud JM, Dow MM, Leutenegger W. 1985. The quantitative assessment of phylogenetic constraints in com- parative analyses: sexual dimorphism in body weight among primates. Evolution 39: 1335-1351.

Cicchino AC, Castro D del C. 1998. Phtheiropoios mendocinus sp. nov y estado del conocimiento de las demas especies del género Phtheiropoios Eichler, 1940 (Phthiraptera: Gyropidae) en la provincia de Mendoza, Argentina. Gayana Zoología 62: 183-190.

Cione AL, Tonni EP. 2005. Bioestratigrafía basada en mamíferos del Cenozoico superior de la provincia de Buenos Aires, Argentina. Relatorio del XVI Congreso Geológico Argentino, Resúmenes 183-200.

Cione AL, Tonni EP, Bargo S, Bond M, Candela AM, Carlini AA, Deschamps CM, Dozo MT, Goin FJ, Montalvo CI, et al. 2007. Mamíferos continentales del Mioceno tardío a la actualidad en la Argentina: cincuenta años de estudios. Ameghiniana, Publicación especial 11: $257-278$.

Colombero S, Pavia M, Rook L. 2012. Pannonictis nestii (Galictinae, Mustelidae) a new element in the vertebrate association of the human site of Pirro Nord (Italy, Early Pleistocene). Geodiversitas 34: 665-681.

Coues E. 1877. Fur-bearing Animals: A Monograph of North American Mustelidae. Government Printing Office, Washington.

Croft DA, Anderson LC. 2007. Locomotion in the Extinct Notoungulate Protypotherium. Palaeontologia Electronica 11: 1-20.

Cuvier G, Laurillard M. 1849. Recueil de Planches de Myologie. Dusacq, Paris.

Dagg AI. 1973. Gaits in mammals. Mammal Review 3: 135-154.

Dalquest WW, Harvey JR. 1951. Behavior of young grisons in capitivity. American Midland Naturalist 46: 359-366.

Davis DD. 1949. The shoulder architecture of bears and other carnivores. Fieldiana, Zoology 31: $285-305$.

Davis DD. 1964. The giant panda: a morphological study of evolutionary mechanisms. Fieldiana: Zoology 3: 1-339.

Deban SM, Schilling N, Carrier DR. 2012. Activity of extrinsic limb muscles in dogs at walk, trot and gallop. The Journal of Experimental Biology 215: 287-300.

Derting TL. 1989. Prey selection and foraging characteristics of least weasels (Mustela nivalis) in the laboratory. American Midland Naturalist 122: 394-400.

Desdevises Y, Legendre PI, Azouzi LA, Morand SE. 2003. Quantifying phylogenetically structure environmental variation. Evolution 57: 2647-2652. 
Diniz-Filho JAF, Torres NM. 2002. Phylogenetic comparative methods and the geographic range size - body size relationship in new world terrestrial carnivora. Evolutionary Ecology 16: $351-367$.

Diniz-Filho JAF, Sant' Ana CER, Bini LM. 1998. An eigenvector method for estimating phylogenetic inertia. Evolution 52: 1247-1262

Diniz Filho JAF, Rangel TF, Santos T, Mauricio Bini L. 2011. Exploring patterns of interspecific variation in quantitative traits using sequential phylogenetic eigenvector regressions. Evolution 66: 1079-1090.

Diogo R, Abdala V. 2010. Muscles of vertebrates - comparative anatomy, evolution, homologies and development. Taylor \& Francis, Oxford.

Doering, A. O. 1881. Enumeración sistemática de las especies observadas durante la expedición. Vertebrados. Informe Oficial de la Comisión Científica Agregada a la Expedición al Río Negro de 1879, Entrega 1, Zoología, Buenos Aires.

Dragoo JW, Honeycutt RL. 1997. Systematics of mustelid-like carnivores. Journal of Mammalogy 78: 426-443.

Dragoo JW, Sheffield SR. 2009. Conepatus leuconotus. Mammalian Species 827: 1-8.

Dücker VG. 1968. Beobachtungen am kleinen grison, Galictis (Grisonella) cuja (Molina). Zeitschrift fur Saugetierkunde 33: 288-297.

Egi N. 2001. Body mass estimates in extinct mammals from limb bone dimensions: the case of North American hyaenodontids. Palaeontology 44: 497-528.

Egi N, Nakatsukasa M, Kalmykov NP, Maschenko EN, Takai M. 2007. Distal humerus and ulna of Parapresbytis (Colobinae) from the Pliocene of Russia and Mongolia: phylogenetic and ecological implications based on elbow morphology. Anthropological Science 115: $107-117$.

Eisenberg J. 1989. Mammals of the Neotropics, vol. 1. University of Chicago Press, Chicago.

Eizirik E. 2012. A molecular view on the evolutionary history and biogeography of Neotropical carnivores (Mammalia: Carnivora). En: Patterson BD, Costa LP (Eds.) Bones, clones, and biomes: an extended history of recent Neotropical mammals. The University of Chicago Press, Chicago, pp. 123-142.

Eizirik E, Murphy WJ, Koepfli K-P, Johnson WE, Dragoo JW, Wayne RK, O'Brien SJ. 2010. Pattern and timing of diversification of the mammalian order Carnivora inferred from multiple nuclear gene sequences. Molecular Phylogenetics and Evolution 56: 49-63.

Elbroch M. 2003. Mammal tracks \& sign: A guide to North American species. Stackpole Books, Pennsylvania.

Elftman HO. 1929. Functional adaptations of the pelvis in marsupials. Bulletin of the American Museum of Natural History 58: 189-232. 
Elissamburu A, Vizcaíno SF. 2005. Diferenciación morfométrica del húmero y fémur de las especies de Paedotherium (Mammalia, Notoungulata) del Plioceno y Pleistoceno temprano. Ameghiniana 42: 1-9.

Emmons LH. 1990. Neotropical rainforest mammals. The University of Chicago Press, Chicago.

English AW. 1975. Functional anatomy of the forelimb in pinnipeds. Tesis Doctoral, University of Illinois at Chicago, Health Sciences Center, Chicago.

English AW. 1976. Functional anatomy of the hands of fur seals and sea lions. The American Journal of Anatomy 147: 1-18.

English AW. 1977. Structural correlates of forelimb function in fur seals and sea lions. Journal of Morphology 151: 325-352.

Ercoli MD, Schutz H. 2012. Análisis de la morfología del extremo distal del húmero y del extremo proximal del fémur en mustélidos fósiles y vivientes en relación al sustrato y estilos locomotores. XVI Jornadas Argentinas de Paleontología de Vertebrados, Resúmenes.

Ercoli MD, Prevosti FJ, Álvarez A. 2012. Form and function within a phylogenetic framework: locomotory habits of extant predators and some Miocene Sparassodonta (Metatheria). Zoological Journal of the Linnean Society 165: 224-251.

Ercoli MD, Álvarez A, Stefanini MI, Busker F, Morales MM. 2014. Muscular Anatomy of the Forelimbs of the Lesser Grison (Galictis cuja), and a Functional and Phylogenetic Overview of Mustelidae and Other Caniformia. Journal of Mammalian Evolution, en prensa.

Ercoli MD, Echarri S, Busker F, Álvarez A, Morales MM, Turazzini GF. 2013. The Functional and Phylogenetic Implications of the Myology of the Lumbar Region, Tail, and Hind Limbs of the Lesser Grison (Galictis cuja). Journal of Mammalian Evolution 20: 309-336.

Estes JA. 1980. Enhydra lutris. Mammalian Species 133: 1-8.

Evans HE. 1993. Miller's anatomy of the dog. W. B. Saunders Company, Philadelphia.

Evans HE, de Lahunta A. 2013. Miller's guide to the dissection of the dog. W. B. Saunders Company, Philadelphia.

Evans HE, Quoc An N. 1980. Anatomy of the ferret. En: Fox JG (Ed.) Biology and diseases of the ferret.Williams \&Wilkins, Baltimore, pp. 19-69.

Ewer RF. 1973. The carnivores. Cornell University Press, Nueva York.

Fabre A-C, Cornette R, Peigné S, Goswami A. 2013b. Influence of body mass on the shape of forelimb in musteloid carnivorans. Biological Journal of the Linnean Society 110: 91-103. 
Fabre A-C, Cornette R, Slater G, Argot C, Peigné S, Goswami A, Pouydebat E. 2013a. Getting a grip on the evolution of grasping in musteloid carnivorans: a three-dimensional analysis of forelimb shape. Journal of Evolutionary Biology 26: 1521-1535.

Fabre A-C, Goswami A, Peigné S, Cornette R. 2014. Morphological integration in the forelimb of musteloid carnivorans. Journal of Anatomy, en prensa.

Feeney S. 1999. Comparative osteology, myology, and locomotor specializations of the fore and hind limbs of the North American foxes Vulpes vulpes and Urocyon cinereoargenteus. Tesis Doctoral, University of Massachusetts, Amherst.

Felsenstein J. 1985. Phylogenies and the comparative method. American Naturalist 125: 1-15.

Ficcarelli G, Torre D. 1967. Il mustelide Enhydrictis galictoides del Pleistocene della Sardegna. Palaeontographia Italica 33: 139-160.

Figueirido B, Serrano-Alarcón FJ, Slater GJ, Palmqvist P. 2010. Shape at the cross-roads: homoplasy and history in the evolution of the carnivoran skull towards herbivory. Journal of Evolutionary Biology 23: 2579-2594.

Filler AG. 2007. Homeotic evolution in the mammalia: diversification of therian axial seriation and the morphogenetic basis of human origins. PloS one 2: e1019.

Finarelli JA. 2008. A total evidence phylogeny of the Arctoidea (Carnivora: Mammalia): relationships among basal taxa. Journal of Mammalian Evolution 15: 231-259.

Fischer G. 1817. Adversaria zoological fasciculus primus. Mémoires de la Sociéte Impériale des Naturalistes de Moscou 5: 357-428.

Fish FE. 1994. Association of propulsive swimming mode with behavior in river otters (Lutra canadensis). Journal of Mammalogy 75: 989-997.

Fish FE. 1996. Transitions from drag-based to lift-based propulsion in mammalian swimming. Integrative and Comparative Biology 36: 628-641.

Fish FE. 2000. Biomechanics and energetics in aquatic and semiaquatic mammals: platypus to whale. Physiological and Biochemical Zoology 73: 683-698.

Fish FE. 2001. A mechanism for evolutionary transition in swimming mode by mammals. En: Walter JMM, Buffrénil V de (Eds.) Secondary adaptation of tetrapods to life. Verlag Dr. Friedrich Pfeil, Munchen, pp. 261-287.

Fish FE, Stein BR. 1991. Functional correlates of differences in bone density among terrestrial and aquatic genera in the family Mustelidae (Mammalia). Zoomorphology 110: 339-345.

Fisher EM. 1942. The osteology and myology of the California river otter. Stanford University Press, Stanford.

Fisher RE, Adrian B, Elrod C, Hicks M. 2008. The phylogeny of the red panda (Ailurus fulgens): evidence from the hindlimb. Journal of Anatomy 213: 607-628. 
Fisher RE, Adrian B, Barton M, Holmgren J, Tang SY. 2009. The phylogeny of the red panda (Ailurus fulgens): evidence from the forelimb. Journal of Anatomy 215: 611-635.

Flaherty EA, Ben-David M, Pauli JN. 2014. A comparison of locomotor performance of the semiarboreal Pacific marten (Martes caurina) and semiaquatic mustelids. Canadian Journal of Zoology 92: 259-266.

Flores DA. 2009. Phylogenetic analyses of postcranial skeletal morphology in didelphid marsupials. Bulletin of the American Museum of Natural History 320: 1-81.

Flores DA, Díaz MM. 2009. Postcranial skeleton of Glironia venusta (Didelphimorphia, Didelphidae, Caluromyinae): description and functional morphology. Zoosystematics and Evolution 85: 311-339.

Flynn JJ, Wesley-Hunt GD. 2005. Carnivora. En: Archibald D, Rose K (Eds.) The rise of placental mammals: origins and relationships of the major extant clades. Johns Hopkins University Press, Baltimore, pp. 175- 198.

Flynn JJ, Finarelli JA, Zehr S, Hsu J, Nedbal MA. 2005. Molecular phylogeny of the Carnivora (Mammalia): assessing the impact of increased sampling on resolving enigmatic relationships. Systematic Biology 54: 317-337.

Fox J, Weisberg S. 2011. An $\{R\}$ companion to applied regression, 2da edición. Thousand Oaks, Sage.

Furlong EL. 1932. A new genus of otter from the Pliocene of the Northern Grait Basin Province. Contributions to palaeontology from Carnegie Institution of Washington 418: 93-103.

Galbreath EC. 1955. Skull and skeleton of a mustelid, Brachypsalis, from the Miocene of northeastern Colorado. University of Kansas Paleontological Contributions Vertebrata 5: $1-15$.

Gambaryan PP. 1974. How mammals run. Anatomical adaptations. John Wiley \& Sons, Nueva York.

Gambaryan PP, Karapetyan WS. 1961. Besonderheiten im bau des seelöwen (Eumetopias californianus), der baikalrobbe (Phoca sibirica) und des seeotters (Enhydra lutris) in anpassung an die fortbewegung im wasser. Zoologische Jahrbuecher 79: 123-148.

Gambaryan PP, Zherebtsova O V, Platonov V V. 2005. Morphofunctional analysis of the cervical-thoracic region in some burrowing mammals. Russian Journal of Theriology 4: $13-41$.

Gao X, Sun S. 2005. Effects of the small forest carnivores on the recruitment and survival of Liaodong oak (Quercus wutaishanica) seedlings. Forest Ecology and Management 206: 283-292. 
García-Esponda CM, Candela AM. 2010. Anatomy of the hindlimb musculature in the cursorial caviomorph. Mammalia 74: 407-422.

Gazin CL. 1934. Upper Pliocene mustelids from the Snake River Basin of Idaho. Journal of Mammalogy 15: 137-149.

Gebo DL. 1989. Locomotor and phylogenetic consideration in anthropoid evolution. Journal of Human Evolution 18: 201-233.

Gervais P. 1875. Remarques ostéologiques sur la loutre de mer (Enhydris marina). En: Pinart AL, Jannettaz É, de Cessac JL, Gaudry A, Fischer P (Eds.) Voyage a la côte nord-ouest de l'Amérique exécutés durant les années 1870-72. A.L. Bancroft and Co., San Francisco.

Giannini NP, Gaudioso P, Flores DA, Gaudin TJ. 2011. A possible function for an enigmatic synapomorphy of Didelphis. Mammalian Biology 76: 512-514.

Ginsburg L. 1961. Plantigradie et digitigradie chez les carnivores fissipedes. Mammalia 25: 121.

Goethe F. 1964. Das verhalten der musteliden. Handbook of Zoology Berlin 8:1-80.

Goloboff PA, Farris JS, Nixon KC. 2008. TNT, a free program for phylogenetic analysis. Cladistics. 24:774-786.

Goodall CR. 1991. Procrustes Methods in the Statistical Analysis of Shape. Journal of the Royal Statistical Society. Series B 53: 285-339.

Goodrich JM, Burskirk S. 1998. Spacing and ecology of North American badgers (Taxidea taxus) in a prairie-dog (Cynomys leucurus) complex. Journal of Mammalogy 7: 171-179.

Gorniak GC, Gans C. 1980. Quantitative assay of electromyograms during mastication in domestic cats (Felis catus). Journal of Morphology 163: 253-281.

Gorsuch WA, Larivière S. 2005. Vormela peregusna. Mammalian Species 779: 1-5.

Gossow VH. 1970. Vergleichende verhaltensstudien an marderartigen I. Über lautauBerungen und zum beuteurhalten. Zeitschrift fur Tierpsychologie 27: 405-480.

Gowell RC. 1897. Myology of the hind limb of the raccoon (Procyon lotor). Kansas University Quarterly 6: 121-126.

Gregg M. 2013. Galictis vittata (On-line). Animal Diversity Web. Accessed May 23, 2014 at http://animaldiversity.ummz.umich.edu/accounts/Galictis_vittata/

Gregory WK. 1912. Notes on the principles of quadrupedal locomotion and on the mechanism of limbs in hoofed animals. Annals of the New York Academy of Sciences 22: 267-294.

Griffin KA, Gilbert FF. 1993. Heart rate of fishers (Martes pennanti) during exercise. Journal of Mammalogy 74: 285-290.

Grohé C, Chaimanee Y, de Bonis L, Yamee C, Blondel C, Jaeger JJ. 2010. New data on Mustelidae (Carnivora) from Southeast Asia: Siamogale thailandica, a peculiar otter-like 
mustelid from the late middle Miocene Mae Moh Basin, northern Thailand. Die Naturwissenschaften 97: 1003-1015.

Haines RW. 1942. The tetrapod knee joint. Journal of anatomy 76: 270-301.

Hall ER. 1926. The muscular anatomy of three mustelid mammals, Mephitis, Spilogale, and Martes. University of California Publications in Zoology 30: 7-39.

Hall ER. 1927. The muscular anatomy of the American badger (Taxidea taxus). University of California Publications in Zoology 30: 205-219.

Hall ER. 1951. American weasels, vol. 4. University of Kansas Publication, Museum of Natural History, Kansas.

Harding LE, Smith FA. 2009. Mustela or Vison? Evidence for the taxonomic status of the American mink and a distinct biogeographic radiation of American weasels. Molecular Phylogenetics and Evolution 52: 632-642.

Haughton S. 1867a. On the anatomy of the otter (Lutra vulgaris). Proceedings of the Royal Irish Academy, Series 2 xi: 511-515.

Haughton S. 1867b. On the anatomy of the badger. Proceedings of the Royal Irish Academy, Series 2 xi: 507-508.

Haughton S. 1867c. On the muscular anatomy of the Irish terrier, as compared with that of the Australian dingo. Proceedings of the Royal Irish Academy, Series 2 ix: 504-507.

Haughton S. 1867d. On the muscles of the Virginian bear. Proceedings of the Royal Irish Academy, Series 2 ix: 508-511.

Heidt GA. 1972. Anatomical and behavioral aspects of killing and feeding by the least weasel, Mustela nivalis L. Arkansas Academy of Science Proceedings 26: 53-54.

Heinrich RE, Biknevicius AR. 1998. Skeletal allometry and interlimb scaling patterns in mustelid carnivorans. Journal of Morphology 235: 121-134.

Heinrich RE, Houde P. 2006. Postcranial anatomy of Viverravus (Mammalia, Carnivora) and implications for substrate use in basal Carnivora. Journal of Vertebrate Paleontology 26: $422-435$.

Heinrich RE, Rose KD. 1997. Postcranial morphology and locomotor behaviour of two early Eocene miacoid carnivorans, Vulpavus and Didymictis. Paleontology 40: 279-305.

Helgen KM, Lim NT 1, Helgen LE. 2008. The hog-badger is not an edentate: systematics and evolution of the genus Arctonyx (Mammalia: Mustelidae). Zoological Journal of the Linnean Society 154: 353-385.

Heptner VG, Naumov NP. 1967. Mammals of the Sovietic Union, vol. II, Part 1. Vysshaya Shkola Publishers, Moscú.

Heráň I. 1962. Adaptive merkmle an dem skelett der Marderartigen (Mustelidae). Acta Musei Nationalis Pragae 18B: 145-203. 
Hildebrand M. 1952. An analysis of body proportions in the Canidae. American Journal of Anatomy 90: 217-256.

Hildebrand M. 1954. Comparative morphology of the body skeleton of the recent Canidae. University of California Publications in Zoology 52: 399-470.

Hildebrand M. 1961. Further studies on locomotion of the cheetah. Journal of Mammalogy 42: 84-91.

Hildebrand M. 1976. Analysis of tetrapod gaits: general considerations and symmetrical gaits. En: Herman RM, Grillner S, Stein PSG, Stuart DG (Eds.) Neural control of locomotion. PlenumPress, Nueva York, pp. 203-236.

Hildebrand M. 1977. Analysis of asymmetrical gaits. Journal of Mammalogy 58: 131-156.

Hildebrand M. 1988. Analysis of vertebrate structure. John Wiley \& Sons, Nueva York.

Hoffstetter R. 1963. La faune Pléistocène de Tarija (Bolivie), Note préliminaire. Bulletin du Muséum National d'Histoire naturelle, Paris 35: 194-203.

Holmes T. 1980. Locomotor adaptations in the limb skeletons of North American mustelids. Tesis Master, Humboldt State University, California.

Horner AM, Biknevicius AR. 2010. A comparison of epigean and subterranean locomotion in the domestic ferret (Mustela putorius furo: Mustelidae: Carnivora). Zoology 113: 189-197.

Howard LD. 1973. Muscular anatomy of the fore-limb of the sea otter (Enhydra lutris). Proceedings of the California Academy of Sciences 39: 411-500.

Howard LD. 1975. Muscular anatomy of the hind limb of the sea otter (Enhydra lutris). Proceedings of the California Academy of Sciences 40: 335-416.

Hudson PE, Corr SA, Payne-Davis RC, Clancy SN, Lane E, Wilson AM. 2011. Functional anatomy of the cheetah (Acinonyx jubatus) forelimb. Journal of Anatomy 218: 375-85.

Hunt RM Jr. 1996. Biogeography of the Order Carnivora. En: Gittleman JL (Ed.) Carnivore behavior, ecology and evolution, vol. 2. Cornell University Press, Nueva York, pp. 485541.

Hunt- RM Jr. 2009. Long-legged pursuit carnivorans (Amphicyonidae, Daphoeninae) from the early Miocene of North America. Bulletin of the American Museum of Natural History 318: $1-95$.

Hutchins M. 2003. Grzimek's animal life encyclopedia, 2da edición. Gale Group, Nueva York.

Hwang YT, Lariviere S. 2001. Mephitis macroura. Mammalian Species 686: 1-3.

Iwaniuk AN, Pellis SM, Wishaw IQ. 1999. The relationship between the forelimb morphology and behaviour in North American carnivores (Carnivora). Canadian Journal of Zoology 77: 1064-1074. 
Iwaniuk AN, Pellis SM, Whishaw IQ. 2000. The relative importance of body size, phylogeny, locomotion, and diet in the evolution of forelimb dexterity in fissiped carnivores (Carnivora). Canadian Journal of Zoology 78: 1110-1125.

Iwaniuk AN, Pellis SM, Whishaw IQ. 2001. Are long digits correlated with high forepaw dexterity? A comparative test in terrestrial carnivores (Carnivora). Canadian Journal of Zoology 79: 900-906.

Izor RJ, de la Torre L. 1978. A new species of weasel (Mustela) from the highlands of Colombia, with comments on the evolution and distribution of South American weasels. Society 59: 92-102.

Izor RJ, Peterson NE. 1985. Notes on South American weasels. Journal of Mammalogy 66: 788-790.

Janis CM, Wilhelm PB. 1993. Were there mammalian pursuit predators in the Tertiary? dances with wolf avatars. Ecology 1: 103-125.

Jarek S. 2009. Shapiro-Wilk multivariate normality test. Package mvnormtest. Disponible en http://cran.r-project.org/web/packages/mvnormtest/

Jenkins FA Jr. 1973. The functional anatomy and evolution of the mammalian humero-ulnar articulation. American Journal of Anatomy 137: 281-298.

Jenkins FA Jr, Camazine SM. 1977. Hip structure and locomotion in ambulatory and cursorial carnivores. Journal of Zoology 181: 351-370.

Jenkins FA Jr, McClearn D. 1984. Mechanisms of hind foot reversal in climbing mammals. Journal of Morphology 182: 197-219.

Johnson DDP, MacDonald DW, Dickman AJ. 2000. An analysis and review of models of the sociobiology of the Mustelidae. Mammal Review 30: 171-196.

Jones KE, Bielby J, Cardillo M, Fritz SA, Dell JO, Orme CDL, Safi K, Sechrest W, Boakes EH, Carbone C, et al. 2009. PanTHERIA: a species-level database of life history, ecology, and geography of extant and recently extinct mammals. Ecology 90: 2648.

Jouffroy FK. 1971. Musculature des members. En: Grassé P-P (Ed.) Traité de Zoologie. Anatomie, Systématique, Biologie, Tome XVI, Fascicule III: Mammifères. Musculature des Members, Musculature Peaucière, Musculature des Monotrèmes. Arthrologie. Masson et Cie. Éditeurs, Paris, pp. 1-475.

Jouffroy FK, Lessertisseur J. 1971. Musculature du tronc, généralités. En: Grassé P-P (Ed.) Traité de Zoologie. Anatomie, Systématique, Biologie, Tome XVI, Fascicule II: Mammifères. Musculature. Masson et Cie. Éditeurs, Paris, pp. 472-871.

Julik EJ, Smith HF, Adrian B, Barton M, Fisher RE. 2009. The axial musculature of the red panda. The FASEB Journal 23 (Meeting Abstract Supplement): LB10. 
Julik E, Zack S, Adrian B, Maredia S, Parsa A, Poole M, Starbuck A, Fisher RE. 2012. Functional anatomy of the forelimb muscles of the ocelot (Leopardus pardalis). Journal of Mammalian Evolution 19: 277-304.

Julitz C. 1909. Extremitäten und des Wickelschwanzes vom Wickelbären, Cercoleptes caudivolvulus, mit besonderer Berücksichtigung der Anpassungserscheinungen. Archiv für Naturgeschichte Berlin 75: 143-188.

Karanth KU, Sunquist ME. 2000. Behavioural correlates of predation by tiger (Panthera tigris), leopard (Panthera pardus) and dhole (Cuon alpinus) in Nagarahole, India. Journal of Zoology 250: 255-265.

Kaufmann JH, Kaufmann A. 1965. Observations of the behavior of tayras and grisons. Zeitschrift fur Saugetierkunde 30: 146-155.

Kavanau JL. 1971. Locomotion and activity phasing of some medium-sized mammals. Journal of Mammalogy 52: 386-403.

Kays RW. 1996. Comments on the behaviour of grison (Galictis vittata) hunting an agouti (Dasyprocta punctata). Small Carnivore Conservation 15: 5.

Kelley EA. 1888. Notes on the myology of Ursus maritimus. Proceedings of the Academy of Natural Sciences of Philadelphia 40: 141-154.

King C. 1989. The advantages and disadvantages of small size to weasels, Mustela species. En: Gittleman JL (Ed.) Carnivore behavior, ecology, and evolution, vol. 1. Cornell University Press, Nueva York, pp. 302-334.

King CM, Powell RA. 2007. The natural history of weasels and stoats. Oxford University Press, Oxford.

Kingdon J. 1977. East African mammals: an atlas of evolution in Africa. Academic Press, London.

Kinlaw A. 1995. Spilogale putorius. Mammalian Species 511: 1- 7.

Kirkpatrick CM, Stullked DE, Jones RD Jr. 1955. Notes on captive sea otters. Arctic 8: 4659.

Klingener D. 1972. Laboratory anatomy of the mink. W. C. Brown Co., Dubuque.

Koepfli K-P, Gompper ME, Eizirik E, Ho CC, Linden L, Maldonado JE, Wayne RK. 2007. Phylogeny of the Procyonidae (Mammalia: Carnivora): Molecules, morphology and the Great American Interchange. Molecular Phylogenetics and Evolution 43: 1076-1095.

Koepfli K-P, Deere KA, Slater GJ, Begg C, Begg K, Grassman L, Lucherini M, Veron G, Wayne RK. 2008. Multigene phylogeny of the Mustelidae: Resolving relationships, tempo and biogeographic history of a mammalian adaptive radiation. BMC Biology 22: 1-22.

Koslowsky J. 1904. Dos mamíferos de Patagonia cazados en el valle del Lago Blanco (territorio del Chubut). Revista del Museo de La Plata 11: 129-132. 
Kraglievich L. 1917. La perforación astragaliana en Conepatus, Lutra y Sarcophilus. Physis 3: 413-417.

Kruuk H. 2006. Otters. Ecology, behaviour and conservation. Oxford University Press, Oxford.

Kurtén B, Anderson E. 1980. Pleistocene Mammals of North America. Columbia University Press, Nueva York.

Lambert D. 1997. The osteology and paleoecology of the giant otter Enhydritherium terraenovae. Journal of Vertebrate Paleontology 17: 738-749.

Langguth A. 1969. Die südamerikanischen Canidae unter besonderer Berücksichtigung des Mähnenwolfes Chrysocyon brachyurus Illiger (Morphologische, systematische und phylogenetische Untersuchungen). Zeitschrift für Wissenschaftliche Zoologie 179: 1-188.

Larivière S. 1998. Lontra felina. Mammalian Species 575: 1-5.

Larivière S. 1999. Lontra longicaudis. Mammalian Species 609: 1-5.

Larivière S. 2001a. Aonyx congicus. Mammalian Species 650: 1-3.

Larivière S. 2001b. Poecilogale albinucha. Mammalian Species 681: 1-4.

Larivière S. 2002a. Ictonyx striatus. Mammalian Species 698: 1-5.

Larivière S. 2002b. Lutra maculicollis. Mammalian Species 712: 1-6.

Larivière S, Messier F. 1996. Aposematic behaviour in the striped skunk, Mephitis mephitis. Ethology 102: 986-992.

Larivière S, Walton LR. 1998. Lontra canadensis. Mammalian Species 587: 1-8.

Leach DH. 1977a. The descriptive and comparative postcranial osteology of marten (Martes Americana Turton) and fisher (Martes pennanti Erxleben): the appendicular skeleton. Canadian Journal of Zoology 55: 199-214.

Leach DH. 1977b. The forelimb musculature of marten (Martes americana Turton) and fisher (Martes pennanti Erxleben). Canadian Journal of Zoology 55: 31-41.

Leach DH, Dagg AI. 1976. The morphology of the femur in marten and fisher. Canadian Journal of Zoology 54: 559-565.

Leach DH, de Kleer VS. 1978. The descriptive and comparative postcranial osteology of marten (Martes americana Turton) and fisher (Martes pennanti Erxleben): the axial skeleton. Canadian Journal of Zoology 56: 1180-1191.

Lemelin P. 1999. Morphological correlates of substrate use in didelphid marsupials: implications for primate origins. Journal of Zoology, London 247: 165-175.

Lessa G, Cartelle C, Faria D, Gonçalves PR. 1998. Novos achados de mamíferos carnívoros do Pleistoceno final-Holoceno en grutas calcárias du Estado da Bahia. Acta Geologica Leopoldensia 21: 157-169.

Lewis ME. 2008. The femur of extinct bunodont otters in Africa (Carnivora, Mustelidae, Lutrinae). Systematic Palaeontology 7: 607-627. 
Lodé T. 1999. Comparative measurements of terrestrial and aquatic locomotion in Mustela lutreola and M. putorius. Zeitschrift für Saugetierkunde 64: 110-115.

Long CA. 1973. Taxidea taxus. Mammalian Species 26: 1-4.

Long CA. 2008. The wild mammals of Wisconsin. Pensoft Publishers, Sofia.

Lucae JCG. 1875. Die Robbe und die otter in ihrem knocken und muskel-skelet. Abhandlungen der Senckenbergischen Naturforschenden Gesellschaft 8: 277-378.

Lund PW. 1842. Blik paa Brasiliens Dyreverden F. Sidste Jordomvaeltning. Det Kongelige Danske Videnskabernes Selskbas Naturvidenskabelige og Mathematiske Aflandlinger, Kjöbenhavn 9: 137-208.

Lund PW. 1950. Memórias sôbre a paleontologia brasileira. Revistas e comentadas por Carlos de Paula Couto. Ministerio da Educaçâoe Salude, Instituto Nacional do Livro, Rio de Janeiro.

Lynch JM, Hayden TJ. 1995. Genetic influences on cranial form: variation among ranch and feral American mink Mustela vison (Mammalia: Mustelidae). Biological Journal of the Linnean Society 55: 293-307.

Macalister A. 1873a. On the anatomy of Aonyx. Proceedings of the Royal Irish Academy Academy Series 2 i: 539-547.

Macalister A. 1873b. The muscular anatomy of the civet and tayra. Proceedings of the Royal Irish Academy Academy Series 2 i: 506-513.

Mackintosh BA. 1875. Notes on the myology of the coati- mondi (Nasua narica and N. fusca) and common marten (Martes foina). Proceedings of the Royal lrish Academy Series 2 i: $48-55$.

Macleod N, Rose KD. 1993. Inferring locomotor behavior in paleogene mammals via eigenshape analysis. American Journal of Science 293: 300-355.

Mahoney JM, Rosenberg HI. 1981. Anatomy of the tail in the beaver (Castor canadensis). Canadian Journal of Zoology 59: 390-399.

Malatesta A. 1977. The skeleton of Nesolutra ichnusae sp. n., a quaternary otter discovered in Sardinia. Geologica Romana 14: 173-209.

Martin LD. 1989. Fossil history of the terrestrial Carnivora. En: Gittleman JL (Ed.) Carnivore behavior, ecology, and evolution. Cornell University Press, Nueva York, pp. 536-568.

Martín-Serra A, Figueirido B, Palmqvist P. 2014. A three-dimensional analysis of morphological evolution and locomotor performance of the carnivoran forelimb. PLoS ONE 9: e85574.

Martins EP, Hansen TF. 1997. Phylogenies and the comparative method: a general approach to incorporating phylogenetic information into the analysis of interspecific data. American Naturalist 149: 646-667. 
Martins EP, Diniz-Filho JAF, Housworth EA. 2002. Adaptive constraints and the phylogenetic comparative method: a computer simulation test. Evolution 56: 1-13.

Matthew WD. 1909. Carnivora and Insectivora of the Bridger Basin, Middle Eocene. Memoirs of the American Museum of natural History 9: 293-567.

Maynard Smith J, Savage RJG. 1956. Some locomotory adaptations in mammals. Journal of the Linnean Society of London, Zoology 42: 603-622.

McClearn D. 1985. Anatomy of raccoon (Procyon lotor) and coati (Nasua narica and N. nasua) forearm and leg muscles: relations between fiber length, moment-arm length, and jointangle excursion. Journal of Morphology 183: 87-115.

McClearn D. 1992. Locomotion, Posture, and feeding behavior of kinkajous, coatis, and raccoons. Society 73: 245-261.

McDonald RA. 2002. Resource partitioning among British and Irish mustelids. Journal of Animal Ecology 71: 185-200.

Meckel J-F. 1828. Traité général d'anatomie comparée. Villeret et cie, Paris.

Meloro C, O'Higgins P. 2011. Ecological adaptations of mandibular form in fissiped Carnivora. Journal of Mammalian Evolution 18: 185-200.

Michener GR, Iwaniuk AN. 2001. Killing technique of North American badgers preying on Richardson's ground squirrels. Canadian Journal of Zoology 79: 2109-2113.

Miljutin A. 2009. Substrate utilization and feeding strategies of mammals: description and classification. Estonian Journal of Ecology 58: 60-71.

Mitteroecker P, Bookstein F. 2011. Linear discrimination, ordination, and the visualization of selection gradients in modern morphometrics. Evolutionary Biology 38: 100-114.

Mitteroecker P, Gunz P. 2009. Advances in Geometric Morphometrics. Evolutionary Biology 36: $235-247$.

Mivart G. 1885. On the anatomy, classification, and distribution of the Arctoidea. Proceedings of the Zoological Society of London 53: 340-404.

Moore AL, Budny JE, Russell AP, Butcher MT. 2013. Architectural specialization of the intrinsic thoracic limb musculature of the American badger (Taxidea taxus). Journal of Morphology 274: 35-48.

Moors PJ. 1980. Sexual dimorphism in the body size of mustelids (Carnivora): the roles of food habits and breeding systems. Oikos 34: 147-158.

Morales MM, Giannini NP. 2013. Ecomorphology of the African felid ensemble: The role of the skull and postcranium in determining species segregation and assembling history. Journal of Evolutionary Biology 26: 980-992. 
Morgan CC. 2009. Geometric morphometrics of the scapula of South American caviomorph rodents (Rodentia: Hystricognathi): Form, function and phylogeny. Mammalian Biology 74: 497-506.

Morgan CC, Verzi DH. 2011. Carpal-metacarpal specializations for burrowing in South American octodontoid rodents. Journal of Anatomy 219: 167-175.

Moritz S, Fischer MS, Schilling N. 2007. Three-dimensional fibre-type distribution in the paravertebral muscles of the domestic ferret (Mustela putorius $f$. furo) with relation to functional demands during locomotion. Zoology (Jena, Germany) 110: 197-211.

Muizon C de. 1998. Mayulestes ferox, a borhyaenoid (Metatheria, Mammalia) from the early Palaeocene of Bolivia. Phylogenetic and palaeobiologic implications. Geodiversitas 20: $19-142$.

Muizon C de, Argot C. 2003. Comparative anatomy of the Tiupampa didelphimorphs; an approach to locomotory habits of early marsupials. En: Jones M, Dickman CR, Archer M, Archer M (Eds.) Predators with pouches: the biology of carnivorous marsupials. Csiro Publishing, Sydney.

Murie J. 1871. On the Female Generative Organs, Viscera, and Fleshy Parts of Hycna brunnea, Thunberg. The Transactions of the Zoological Society of London 7: 503-512.

Murie OJ. 1974. A field guide to animal tracks. Houghton Miffli Company, Boston.

Myers P, Espinosa R, Parr CS, Jones T, Hammond GS, DeweyTA. 2014. The animal diversity web (online). Disponible en http://animaldiversity.org.

Narita Y, Kuratani S. 2005. Evolution of the vertebral formulae in mammals: a perspective on developmental constraints. Journal of Experimental Zoology 304: 91-106.

Noriega JI, Carlini AA, Tonni EP. 2004. Vertebrados del Pleistoceno tardío de la cuenca del Arroyo Ensenada (Departamento Diamante, provincia de Entre Ríos). En: Aceñolaza FG (Ed.) Temas de la Biodiversidad del Litoral Fluvial Argentino. Instituto Superior de Correlación Geológica, Miscelánea 12, pp. 71-76.

Nowak RM. 2005. Walker's Carnivores of the World. The John Hopkins University Press, Baltimore.

Ondrias JC. 1960. Secondary sexual variation and body skeletal proportions in European Mustelidae. Arkiv Für Zoologi 12: 577-583.

Ondrias JC. 1961. Comparative osteological investigations on the front limbs of European Mustelidae. Arkiv Für Zoologi 13: 311-320.

Organ JM. 2010. Structure and function of platyrrhine caudal vertebrae. The Anatomical Record 293: 730-745. 
Osbahr K, Acevedo P, Villamizar A, Espinosa D. 2009. Comparación de la estructura y de la función de los miembros anterior y posterior de Cuniculus taczonowskii y Dinomys branickii. Revista U D C A Actualidad \& Divulgación Científica 12: 1-14.

Oxnard CE. 1968. The architecture of the shoulder in some mammals. Journal of Morphology 126: $249-290$.

Paradis E, Claude J. 2002. Analysis of comparative data using generalized estimating equations. Journal of Theoretical Biology 218: 175-185.

Paradis E, Claude J, Strimmer K. 2004. APE: analyses of phylogenetics and evolution in R language. Bioinformatics 20: 289-290.

Pardini R. 1998. Feeding ecology of the Neotropical river otter Lontra longicaudis in an Atlantic forest stream, south-eastern Brazil. Journal of Zoology, London 245: 385-391.

Parsons FG. 1898. The muscles of mammals, with special relation to human myology. II. The muscles of the shoulder and fore-limb. Journal of Anatomical Physiology 32: 721-752.

Pascual R. 1958. "Lyncodon bosei” nueva especie del Ensenadense. Un antecesor del huroncito patagonico. Revista del Museo de La Plata 4: 1-38.

Pasitschniak-Arts M, Larivière S. 1995. Gulo gulo. Mammalian Species 499: 1-10.

Payne RC, Hutchinson JR, Robilliard JJ, Smith NC, Wilson AM. 2005. Functional specialisation of pelvic limb anatomy in horses (Equus caballus). Journal of Anatomy 206: $557-74$.

Peigné S, Salesa MJ, Antón M, Morales J. 2005. Ailurid carnivoran mammal Simocyon from the late Miocene of Spain and the systematics of the genus. Acta Palaeontologica Polonica 50: $219-238$.

Peigné S, Bonis L De, Likius A, Mackaye HT, Vignaud P, Brunet M. 2008. Late Miocene Carnivora from Chad: Lutrinae (Mustelidae). Zoological Journal of the Linnean Society 152: 793-846.

Petter G. 1964. Deux mustélidés nouveaux du pontien d' Espagne orientale. Bulletin du Muséum National d'Histoire Naturelle, Paris 36: 270-278.

Piérard J. 1965. Note sur l'insertion du muscle fibularis (peroneus) longus chez les mammiferes et particulierement chez le chien et le chat. The Canadian Veterinary Journal 6: $282-289$.

Pierce SE, Clack JA, Hutchinson JR. 2011. Comparative axial morphology in pinnipeds and its correlation with aquatic locomotory behaviour. Journal of Anatomy 219: 502-514.

Pilgrim GE. 1932. The genera Trochictis, Enhydrictis, and Trocharion, with remarks on the taxonomy of the Mustelidae. Journal of Zoology, London 102: 845-867.

Pocock RI. 1921. On the external characters and classification of the Mustelidae. Proceedings of the Zoological Society of London 91: 803-837. 
Poglayen-Neuwall I. 1978. Breeding, rearing and notes on the behaviour of tayras (Eira barbara) in captivity. International Zoo Yearbook 18: 134-140.

Poglayen-Neuwall I, Toweill DE. 1988. Bassariscus astutus. Mammalian Species 327: 1-8.

Politis GG, Bonomo M, Castiñeira C, Blasi A. 2011. Archaeology of the Upper Delta of the Paraná River (Argentina): Mound construction and anthropic landscapes in the Los Tres Cerros locality. Quaternary International 245: 74-88.

Politis GG, Tonni EP, Fidalgo F. 1983. Cambios corológicos de algunos mamíferos en el Area Interserrana de la provincia de Buenos Aires durante el Holoceno. Ameghiniana 20: 72-80.

Polly PD. 2008. Adaptive Zones and the Pinniped Ankle: A 3D Quantitative Analysis of Carnivoran Tarsal Evolution. En: Sargis E, Dagosto M (Eds.) Mammalian Evolutionary Morphology: A Tribute to Frederick S. Szalay. Springer, Dordrecht.

Polly PD. 2010. Tiptoeing through the trophics: geographic variation in carnivoran locomotor ecomorphology in relation to environment. En: Goswami A, Friscia A (Eds.) Carnivoran evolution: New views on phylogeny, form and function. Cambridge University Press, Cambridge.

Polly PD, MacLeod N. 2008. Locomotion in fossil Carnivora: an application of eigensurface analysis for morphometric comparison of 3D surfaces. Palaeontologia Electronica 11: 10A: $13 p$.

Poole TB. 1970. Polecats. Forestry Commission Forest Record No. 76.

Powell RA, Buskirk SW, Zielinski WJ. 2003. Fisher and Marten. En: Feldhamer GA, Thompson B, Chapman JA (Eds.) Wild mammals of North America: biology, management and conservation. 2da edición. Johns Hopkins University Press, Baltimore, pp. 635-649.

Presley SJ. 2000. Eira barbara. Mammalian Species 636: 1-6.

Prevosti FJ. 2000. Un nuevo resto de $\uparrow$ Stipanicicia pettorutii (Carnivora, Mustelidae) del Cuaternario de la provincia de Buenos Aires: implicancias bioestratigráficas. XV Jornadas Argentinas de Mastozoología, Resúmenes: 95.

Prevosti FJ, Ferrero BS. 2008. A pleistocene giant river otter from Argentina: remarks on the fossil record and phylogenetic analysis. Journal of Vertebrate Paleontology 28: 11711181.

Prevosti FJ, Pardiñas UFJ. 2001. Variaciones corológicas de Lyncodon patagonicus (Carnivora, Mustelidae) durante el Cuaternario. Mastozoología Neotropical 8: 21-39.

Prevosti FJ, Pardiñas UFJ. 2009. Comment on "The oldest South American Cricetidae (Rodentia) and Mustelidae (Carnivora): Late Miocene faunal turnover in central Argentina and the Great American Biotic Interchange" by D.H. Verzi and C.I. Montalvo. Palaeogeography, Palaeoclomatology, Palaeoecology 280: 543-547. 
Prevosti FJ, Soibelzon LH. 2012. Evolution of the South American carnivores (Mammalia: Carnivora). A paleontological perspective. En: Patterson BD, Costa LP (Eds.) Bones, clones, and biomes: an extended history of recent Neotropicalmammals. The University of Chicago Press, Chicago, pp. 102-122.

Prevosti FJ, Turazzini GF, Ercoli MD, Hingst-Zaher E. 2012. Mandible shape in marsupial and placental carnivorous mammals: a morphological comparative study using geometric morphometrics. Zoological Journal of the Linnean Society 164: 836-855.

Purslow PP. 2010. Muscle fascia and force transmission. Journal of Bodywork and Movement Therapies 14: 411-417.

Quaife LR. 1978. The form and function of the North American badger (Taxidea taxus) in relation to its fossorial way of life. Tesis Doctoral, The University of Calgary, Calgary.

Quintana CA. 2001. Composición y cambios en la secuencia faunística. En: Mazzanti DL, Quintana CA (Eds.) Cueva Tixi: cazadores y recolectores de las sierras de Tandilia Oriental. Geología, Paleontología y Zooarqueología. Publicación Especial del Laboratorio de Arqueología, 1ra edición. Editorial de la Facultad de Humanidades, Universidad de Mar del Plata, pp. 37-64.

R Development Core Team. 2013. R: A language and environment for statistical computing. Foundation for Statistical Computing, Vienna. Disponible en: http://www.R-project.org

Radinsky LB. 1981a. Evolution of skull shape in carnivores: 1. Representative modern carnivores. Biological Journal of the Linnean Society 15: 369-388.

Radinsky LB. 1981b. Evolution of skull shape in carnivores: 2. Additional modern carnivores. Biological Journal of the Linnean Society 16: 337-355.

Ramírez-Chaves HE, Mantilla-Meluk H. 2009. Nuevo registro de la comadreja colombiana Mustela felipei (Carnivora: Mustelidae), con notas sobre su distribución y conservación. Mastozoología Neotropical 16: 379-388.

Ramírez-Chaves HE, Patterson BD. 2014. Mustela felipei (Carnivora:Mustelidae). Mammalian species 646: 11-15.

Ray LJ. 1949. The myology of the inferior extremity of the Malay bear, Ursus malayanus. Proceedings of the Zoological Society of London 119: 121-132.

Reig OA. 1956. Note préliminaire sor un nouveau genre de mustélidés fossiles du pléistocene de la République Argentine. Mammalia 20: 223-230.

Reig OA. 1957. Un mustélido del género Galictis del Eocuartario de la provincia de Buenos Aires. Ameghiniana 1: 33-47.

Reighard J, Jennings HS. 1901. Anatomy of the cat. Henry Holt and Company, Nueva York.

Reyes -Küppers RR. 2007. Ecology and behaviour of the Southern river otter Lontra provocax Thomas 1908 in Chile. Tesis Doctoral, Osnabrück University, Osnabrück, Alemania 
Riggs ES. 1945. Some early Miocene carnivores. Geological Series Field Museum of Natural History 9: 67-119.

Riley MA. 1985. An Analysis of Masticatory Form and Function in Three Mustelids (Martes americana, Lutra canadensis, Enhydra lutris). Journal of Mammalogy 66: 519-528

Rohlf FJ. 2001. Comparative methods for the analysis of continuous variables: geometric interpretations. Evolution 55: 2143-2160.

Rohlf FJ. 2006. A comment on phylogenetic correction. Evolution 60: 1509-1515.

Rohlf FJ. 2011. TpsRegr, ver. 1.38. Department of Ecology and Evolution, State University of New York at Stony Brook, Stony Brook.

Rohlf FJ. 2013a. TpsDig, ver. 2.10. Department of Ecology and Evolution, State University of New York at Stony Brook, Stony Brook.

Rohlf FJ. 2013b. TpsUtil, ver. 1.56. Department of Ecology and Evolution, State University of New York at Stony Brook, Stony Brook.

Rood JP. 1970. Ecology and social behavior of the desert cavy (Microcavia australis). American Midland Naturalist 83: 415-454.

Rose J, Moore A, Russell A, Butcher M. 2014. Functional osteology of the forelimb digging apparatus of badgers. Journal of Mammalogy 95: 543-558.

Ross FO. 1876. Myology of the Cheetah, or hunting leopard of India (Felis jubata). Proceedings of the Royal Irish Academy, Series 2 iii: 23-32.

Rowe-rowe DT. 1978. Comparative prey capture and food studies of South African mustelines. Mammalia 42: 175-196.

Ruina A, Bertram JEA, Srinivasan M. 2005. A collisional model of the energetic cost of support work qualitatively explains leg sequencing in walking and galloping, pseudoelastic leg behavior in running and the walk-to-run transition. Journal of Theoretical Biology 237: 170-192.

Rusconi C. 1932. Dos nuevas especies de Mustélidos del piso ensenadense. Anales de la Sociedad Científica Argentina 113: 42-45.

Salesa MJ, Antón M, Peigné S, Morales J. 2008. Functional anatomy and biomechanics of the postcranial skeleton of Simocyon batalleri (Viret, 1929) (Carnivora, Ailuridae) from the Late Miocene of Spain. Society 152: 593-621.

Salesa MJ, Antón M, Turner A, Morales J. 2005. Aspects of the functional morphology in the cranial and cervical skeleton of the sabre-toothed cat Paramachairodus ogygia (Kaup, 1832) (Felidae, Machairodontinae) from the Late Miocene of Spain: implications for the origins of the machairodont kill. Zoological Journal of the Linnean Society 144: 363-377. 
Salesa MJ, Siliceo G, Antón M, Abella J, Montoya P, Morales J. 2006. Anatomy of the "false thumb" of Tremarctos ornatus (Carnivora , Ursidae , Tremarctinae): phylogenetic and functional implications. Estudios Geológicos 62: 389-394.

Salton JA, Sargis EJ. 2008. Evolutionary morphology of the Tenrecoidea (Mammalia) carpal complex. Biological Journal of the Linnean Society 93: 267-288.

Samuels JX, Meachen JA, Sakai SA. 2013. Postcranial morphology and the locomotor habits of living and extinct carnivorans. Journal of Morphology 274: 121-146.

Sargis EJ. 2001. A preliminary qualitative analysis of the axial skeleton of tupaiids (Mammalia, Scandentia): functional morphology and phylogenetic implications. Journal of Zoology, London 253: 473-483.

Sargis EJ. 2002. Functional morphology of the hindlimb of Tupaiids (Mammalia, Scandentia) and its phylogenetic implications. Journal of Morphology 254: 149-185.

Sato JJ, Hosoda T, Wolsan M, Suzuki H. 2004. Molecular phylogeny of arctoids (Mammalia: Carnivora) with emphasis on phylogenetic and taxonomic positions of the ferret-badgers and skunks. Zoological Science 21: 111-118.

Sato JJ, Wolsan M, Prevosti FJ, D’Elía G, Begg C, Begg K, Hosoda T, Campbell KL, Suzuki H. 2012. Evolutionary and biogeographic history of weasel-like carnivorans (Musteloidea). Molecular Phylogenetics and Evolution 63: 745-757.

Savage RJG. 1957. The anatomy of Potamotherium an Oligocene lutrine. Proceedings of the Zoological Society of London 129: 151-244.

Scapino RP. 1968. Biomechanics of feeding in Carnivora. Tesis Doctoral, University of Illinois, Illionis.

Scapino RP. 1974. Function of the masseter-pterygoid raphe in carnivores. Anatomischer Anzeiger, Jena 136: 430-446.

Scapino RP. 1987. Function of the digastric muscle in carnivores. Journal of Morphology 150: $843-860$.

Scherling A. 1989. Zur anatomie des bewegungsapparates des dachses (Meles meles L.). Tesis Doctoral, Universität Gießen, Gießen.

Schiaffini MI, Prevosti FJ. 2013. Trophic segregation of small carnivorans (Carnivora: Mustelidae and Mephitidae) from the Southern Cone of South America. Journal of Mammalian Evolution, en prensa.

Schiaffini MI, Martin GM, Giménez AL, Prevosti FJ. 2013. Distribution of Lyncodon patagonicus (Carnivora, Mustelidae): changes from the Last Glacial Maximum to the present. Journal of Mammalogy 94: 339-350. 
Schilling N, Carrier DR. 2010. Function of the epiaxial muscles in walking, trotting and galloping dogs: implications for the evolution of epiaxial muscle function in tetrapods. The Journal of Experimental Biology 213: 1490-502.

Schilling N, Hackert R. 2006. Sagittal spine movements of small therian mammals during asymmetrical gaits. Journal of Experimental Biology 209: 3925-3939.

Schmidt M, Fischer MS. 2009. Morphological integration in mammalian limb proportions: dissociation between function and development. Evolution 63: 749-766.

Schutz H, Guralnick RP. 2007. Postcranial element shape and function: assessing locomotor mode in extant and extinct mustelid carnivorans. Zoological Journal of the Linnean Society 150: 895-914.

Seckel L, Janis CM. 2008. Convergences in scapula morphology among small cursorial mammals: an osteological correlate for locomotory specialization. Journal of Mammalogy 15: $261-279$.

Shapiro LJ. 1995. Functional morphology of indrid lumbar vertebrae. American Journal of Physical Anthropology 98: 323-342.

Shapiro LJ, Jungers WL. 1994. Electromyography of back muscles during quadrupedal and bipedal walking in primates. American Journal of Physical Anthropology 93: 491- 504.

Sharir A, Milgram J, Shahar R. 2006. Structural and functional anatomy of the neck musculature of the dog (Canis familiaris). Journal of Anatomy 208: 331-351.

Sheffield SR, King CM. 1994. Mustela nivalis. Mammalian Species 454: 1-10.

Sheffield SR, Thomas HH. 1997. Mustela frenata. Mammalian Species 570: 1-9.

Shepherd FJ. 1883. Short notes on the myology of the American black bear (Ursus americanus). Journal of Anatomy and Physiology 18: 103-117.

Simpson GG. 1945. The principles of classification and a classification of mammals. Bulletin of the American Museum of Natural History 85: 1-350.

Silva M, Downing JA. 1995. CRC handbook of mammalian body masses. CRC Press, Boca Raton.

Slijper EJ. 1946. Comparative biologic-anatomical investigations on the vertebral column and spinal musculature of mammals. Verhandelingen der Koninklijke Nederlandsche Akademie van Wetenschappen, afd. Natuurkunde (Tweede Sectie) 42: 1-128.

Schmidt M, Fischer MS. 2009. Morphological integration in mammalian limb proportions: dissociation between function and development. Evolution 63: 749-766.

Soibelzon L, Prevosti FJ. 2007. Los carnívoros (Carnivora, Mammalia) terrestres del Cuaternario de América del Sur. En: Pons GX, Vicens D (Eds.) Geomorfologia Litoral i Quaternari. Homenatge a D. Joan Cuerda Barceló. Monographie de la Societat d'Història Natural de les Balears 12: 5-12. 
Soibelzon L, Prevosti FJ. 2012. Fossils of South American land carnivores (Carnivora, Mammalia). En: Ruiz M, Shostell J (Eds.) Molecular population genetics, evolutionary biology and biological conservation of Neotropical carnivores. Nova Science Publisher, Nueva York, pp. 509-530.

Sokolov AS, Sokolov II. 1970. Some specific features of the locomotor organs of river- and sea otters associated with their mode of life. Byulleten Moskovskogo Obshchestva Ispytatelei Prirody. Otdel Biologicheskii 75: 40-51.

Sokolov II, Sokolov AS. 1971. Some characteristics of locomotor organs of Martes martes L. associated with its mode of life. Byulleten Moskovskogo Obshchestva Ispytatelei Prirody. Otdel Biologicheskii 76: 5-17.

Sooriakumaran P, Sivananthan S. 2005. Why does man have a quadratus plantae? A review of its comparative anatomy. Croatian Medical Journal 46: 30-35.

Sorkin B. 2006. Ecomorphology of the giant bear-dogs Amphicyon and Ischyrocyon. Historical Biology 18: 375-388.

Souteyrand-Boulenger JD. 1969. Le muscle articulaire de la hanche chez les carnivores. Mammalia 33: 276-284.

Spaulding M, Flynn JJ. 2012. Phylogeny of the Carnivoramorpha: The impact of postcranial characters. Journal of Systematic Palaeontology 10: 653-677.

Spoor CF, Badoux DM. 1986a. Nomenclatural review of long digital forelimb flexors in carnivores. The Anatomical Record 216: 471-473.

Spoor CF, Badoux DM. 1986b. Descriptive and fuctional myology of the neck and forelimb of the striped hyena (Hyaena hyaena, L. 1758). Anatomischer Anzeiger 161: 375-387.

Spoor CF, Badoux DM. 1988. Descriptive and functional myology of the back and hindlimb of the striped hyena (Hyaena hyaena, L. 1758). Anatomischer Anzeiger 167: 313-321.

Spoor CF, Badoux DM. 1989. Descriptive and functional morphology of the locomotory apparatus of the spotted hyaena (Crocuta crocuta, Erxleben, 1777). Anatomischer Anzeiger 168: $261-266$.

Spoor CF, Belterman T. 1986. Locomotion in Hyaenidae. Bijdragen tot de Dierkunde 56: 24 28.

Stains HJ. 1984. Carnivores. En: Anderson S Jones Jr JK (Eds.) Orders and families of recent mammals of the world, John Wiley \& Sons, Nueva York, pp. 491-521.

Storz JF, Wolzencraft WC. 1999. Melogale moschata. Mammalian Species 631: 1-4.

Stebler AM. 1938. Feeding behavior of a skunk. Journal of Mammalogy 19: 374.

Sullivan J. 1996. Taxidea taxus. En: Fire Effects Information System, [Online]. U.S. Department of Agriculture, Forest Service, Rocky Mountain Research Station, Fire Sciences Laboratory (Producer). Disponible en: http://www.fs.fed.us/database/feis/. 
Sunquist ME, Sunquist F, Daneke D. 1989. Ecological separation in a Venezuelan llanos carnivore community. En: Redford KH, Eisenberg JF (Eds.) Advances in Neotropical mammalogy. Sandhill Crane Press, Gainesville, pp. 197-232.

Swainson W. 1835. On the natural history and classification of quadrupeds. En: The Cabinet Encyclopaedia. London, Longman, Rees, Orme, Brown \& Longman, London.

Szalay FS, Sargis EJ. 2001. Model-based analysis of postcranial osteology of marsupials from the Palaeocene of Itaboraí (Brazil) and the phylogenetics and biogeography of Metatheria. Geodiversitas 23: 139-302.

Tarasoff FJ. 1972. Anatomical observations on the river otter, sea otter and harp seal with reference to those structures that are of known significance in thermal regulation and diving. Tesis Doctoral, McGill University, Montreal.

Tarasoff FJ, Bisaillon A, Piérard J, Whitt AP. 1972. Locomotory patterns and external morphology of the river otter, sea otter, and harp seal (Mammalia). Canadian Journal of Zoology 50: 915-929.

Taylor ME. 1970. Locomotion in some east African viverrids. Journal of Mammalogy 51: 42 51.

Taylor ME. 1974. The functional anatomy of the forelimb of some African Viverridae (Carnivora). Journal of Morphology 143: 307-336.

Taylor ME. 1976. The functional anatomy of the hindlimb of some African Viverridae (Carnivora). Journal of Morphology 148: 307-336.

Taylor ME. 1989. Locomotor adaptation by carnivores. En: Gittleman JL (Ed.) Carnivore behavior, ecology, and evolution. Cornell University Press, Nueva York, pp. 383-409.

Tedford RH. 1976. Relationship of pinnipeds to other carnivores (Mammalia). Systematic Zoology 25: 363-374.

Teta P, Prevosti FJ, Trejo A. 2008. Raptor predation and new locality records for the poorly known Patagonian weasel (Lyncodon patagonicus) (Carnivora: Mustelidae). Mammalian Biology 73: 238-240.

Toledo N, Bargo MS, Cassini GH, Vizcaíno SF. 2012. The forelimb of Early Miocene sloths (Mammalia, Xenarthra, Folivora): morphometrics and functional implications for substrate preferences. Journal of Mammalian Evolution 19: 185-198.

Trapp GR. 1972. Some anatomical and behavioral adaptations of ringtails, Bassariscus astutus. Journal of Mammalogy 53: 549-557.

Trejo A, Kun M, Seijas S. 2006. Dieta del águila mora (Geranoaetus melanoleucus) en una transecta oeste-este en el ecotono norpatagónico. El Hornero 21: 31-36. 
Ubilla M, Perea D, Goso C, Lorenzo N. 2004. Late Pleistocene vertebrates from northern Uruguay: tools for biostratigraphic, climatic and environmental reconstruction. Quaternary International 114: 129-142.

Valenciano AL, Abella J, Sanisidro O, Álvarez-Sierra MA, Morales J. 2013 Functional morphology of skull and mandibles of the Late Miocene giant mustelid Eomellivora piveteaui Ozansoy, 1965 from Cerro de los Batallones (Madrid, Spain). Anatomical Record 296 (Special Feature): 283-284.

Van de Graaff KM, Harper J, Goslow GE. 1982. Analysis of posture and gait selection during locomotion in the striped skunk (Mephitis mephitis). Journal of Mammalogy 63: $582-590$.

Van Valkenburgh B. 1985. Locomotory diversity in past and present guilds of large predatory mammals. Paleobiology 11: 406-428.

Van Valkenburgh B. 1987. Skeletal indicators of locomotor behavior in living and extinct carnivores. Journal of Vertebrate Paleontology 7: 162-182.

Vanderhaar JM, Hwang YT. 2003. Mellivora capensis. Mammalian Species 721: 1-8.

Vargas A, Anderson SH. 1998. Ontogeny of black-footed ferret predatory behavior towards prairie dogs. Canadian Journal of Zoology 76: 1696-1704.

Verzi DH, Montalvo CI. 2008. The oldest South American Cricetidae (Rodentia) and Mustelidae (Carnivora): late Miocene faunal turnover in central Argentina and the Great American Biotic Interchange. Palaeogeography, Palaeoclimatology, Palaeoecology 267: 284-291.

Vizcaíno SF, Milne N. 2002. Structure and function in armadillo limbs (Mammalia: Xenarthra: Dasypodidae). Journal of Zoology 257: 117-127.

Wagner H. 1976. A new species of Pliotaxidea (Mustelidae: Carnivora) from California. Journal of Paleontology 50: 107-127.

Waibl H, Gasse H, Hashimoto Y, Budras K-D, Constantinescu GM, Saber AS, Simoens P, Sotonyi P, Augsburger H, Bragulla H. 2005. Nomina Anatomica Veterinaria. International Committee on Veterinary Gross Anatomical Nomenclature, World Association of Veterinary Anatomists, Hannover.

Walker C, Vierck CJ, Ritz LA. 1998. Balance in the cat: role of the tail and effects of sacrocaudal transection. Behavioural Brain Research 91: 41-47.

Walmsley B, Hodgson JA, Burke RE. 1978. Forces produced by medial gastrocnemius and soleus muscles during locomotion in freely moving cats. Journal of neurophysiology 41: 1203-1216.

Wang X. 1993. Transformation from plantigrady: functional morphology of locomotion in Hesperocyon (Canidae: Carnivora). American Museum Novitates 3069: 1-23. 
Wang X, Carranza-Castañeda Ó. 2008. Earliest hog-nosed skunk, Conepatus (Mephitidae, Carnivora), from the early Pliocene of Guanajuato, Mexico and origin of South American skunks. Zoological Journal of the Linnean Society 154: 386-407.

Wang X, Carranza-Castañeda Ó, Aranda-Gómez JJ. 2013. A transitional skunk, Buisnictis metabatos sp. nov. (Mephitidae, Carnivora), from Baja California Sur and the role of southern refugia in skunk evolution. Journal of Systematic Palaeontology 12: 291-302.

Watson MD. 1882. On the muscular anatomy of Proteles as compared with that of Hyaena and Viverra. Proceedings of the Zoological Society of London 50: 579-586.

Wiig Ø. 1986. Sexual dimorphism in the skull of minks Mustela vison, badgers Meles meles and otters Lutra lutra. Zoological Journal of the Linnean Society 87: 163-179.

Willemsen GF. 1980a. Comparative study of the functional morphology of some Lutrinae, especially Lutra lutra, Lutrogale perspicillata and the Pleistocene Isolalutra cretensis. Proceedings of the Koninklijke Nederlandse Akademie van Wetenschappen B 83: 289-326.

Willemsen GF. 1980b. Comparative study of the functional morphology of some Lutrinae, especially Lutra lutra, Lutrogale perspicillata and the Pleistocene Isolalutra cretensis. Proceedings of the Koninklijke Nederlandse Akademie van Wetenschappen B 83: 289-326.

Willemsen GF. 1986. Lutrogale palaeoleptonyx (Dubois, 1908), a fossil otter from Java in the Dubois collection. Proceedings of the Koninklijke Nederlandse Akademie van Wetenschappen B 89:195-200.

Willemsen GF. 1992. A revision of the Pliocene and Quaternary Lutrinae from Europe. Scripta Geologica 101: 1-115.

Williams RC. 1955. The osteology and myology of the ranch mink (Mustela vison). Tesis Doctoral, Cornell University Press, Nueva York.

Williams SB, Payne RC, Wilson AM. 2007. Functional specialisation of the pelvic limb of the hare (Lepus europeus). Journal of Anatomy 210: 472-490.

Williams TM. 1983a. Locomotion in the North American mink, a semi-aquatic mammal. I. Swimming energetics and body drag. The Journal of Experimental Biology 103: 155-168.

Williams TM. 1983b. Locomotion in the North American mink, a semi-aquatic mammal. II. The effect of an elongate body on running energetics and gait patterns. Journal of Experimental Biology 105: 283-295.

Williams TM. 1989. Swimming by sea otters: adaptations for low energetic cost locomotion. Journal of Comparative Physiology A 164: 815-824.

Williams TM, Ben-David M, Noren S, Rutishauser M, McDonald K, Heyward W. 2002. Running energetics of the North American river otter: do short legs necessarily reduce efficiency on land? Comparative Biochemistry and Physiology, Part A, Molecular \& Integrative Physiology 133: 203-212. 
Wilson DE, Mittermeier RA. 2009. Handbook of the mammals of the world, vol. 1: Carnivores. Lynx Editions, Barcelona.

Wilson DE, Reeder DA. 2005. Mammal species of the world. A taxonomic and geographic reference. 3ra edición. Johns Hopkins University Press, Baltimore.

Windle BCA. 1888. Notes on the limb myology of Procyon cancrivorus and of the Ursidae. Journal of Anatomical Physiology 23: 81-89.

Windle BCA. 1889. The flexors of the digits of the hand. I. The muscular masses in the forearm. Journal of Anatomy and Physiology 24: 72-84.

Windle BCA, Parsons FG. 1897. On the myology of the terrestrial Carnivora. Part I. Muscles of the head, neck and fore-limb. Proceeding of the Zoological Society of London 65: 370409.

Windle BCA, Parsons FG. 1898. The Myology of the terrestrial Carnivora. Part II. Proceeding of the Zoological Society of London 66: 152-186.

Winge H. 1895. Jordfunde og nulevende Rovdyr (Carnivora) fra Lagoa Santa, Minas Geraes, Brasilien. E Museo Lundii 2: 1-103.

Whitaker JO, Hamilton WJ. 1998. Mammals of the Eastern United States. Cornell University Press, Nueva York.

Wood AR, Bebej RM, Manz CL, Begun DL, Gingerich PD. 2011. Postcranial functional morphology of Hyracotherium (Equidae, Perissodactyla) and locomotion in the earliest horses. Journal of Mammalian Evolution 18: 1-32.

Woodburne MO, Cione AL, Tonni EP. 2006. Central American provincialism and the Great American Biotic Interchange. En: Carranza-Castañeda O, Lindsay EH (Eds.) Advances in Late Tertiary Vertebrate Paleontology in Mexico and the Great American Biotic Interchange. Universidad Nacional Autónoma de México, Instituto de Geología y Centro de Geociencias, Mexico DF, pp. 73-101.

Wozencraft WC. 1989. The phylogeny of the recent carnivora. En: Gittleman JL (Ed.) Carnivore behavior, ecology and evolution. Cornell University Press, Nueva York, pp. 495-535.

Wright L. 2005. Interesting cooperative bedding gathering behaviour in captive asian smallclawed otters (Amblonyx cinerea). IUCN Otter Specialist Group Bulletin 18: 25-28

Wroe S, Lowry MB, Antón M. 2008. How to build a mammalian super-predator. Zoology 111: 196-203.

Wyss AR, Flynn JJ. 1993. A phylogenetic analysis and definition of the Carnivora. En: Szalay FS, Novacek MJ, McKenna MC (Eds.) Mammal Phylogeny. Springer Verlag, Nueva York, pp. $32-52$. 
Yalden DW. 1970. The functional morphology of the carpal bones in carnivores. Acta Anatomica 77: 481-500.

Yensen E, Tarifa T. 2003a. Galictis cuja. Mammalian Species 728: 1-8.

Yensen E, Tarifa T. 2003b. Galictis vitatta. Mammalian Species 727: 1-8.

Yilmaz S, Dinç G, Toprak B. 2000. Macro-anatomical investigations on skeletons of otter (Lutra lutra). III. Skeleton axiale. Veterinarski Arhiv 70: 191-198.

Youlatos D. 2003. Osteological correlates of tail prehensility in carnivorans. Journal of Zoology, London 259: 423-430.

Zabala J, Zuberogoitia I. 2003. Badger, Meles meles (Mustelidae, Carnivora), diet assessed through scat-analysis: a comparison and critique of different methods. Folia Zoologica 52: 23-30.

Zielinski WJ. 2000. Weasels and Martens - Carnivores in Northern Latitudes. En: Stenseth N (Ed.) Activity patterns in small mammals. Springer-Verlag, Berlin, pp. 95-118. 